\title{
ORGANIZACIÓN DE LA TECNOLOGÍA LÍTICA EN LA CUENCA DEL RÍO ATUEL (SUR DE LA PROVINCIA DE MENDOZA) DURANTE EL HOLOCENO TARDÍO
}

Lic. María de la Paz Pompei

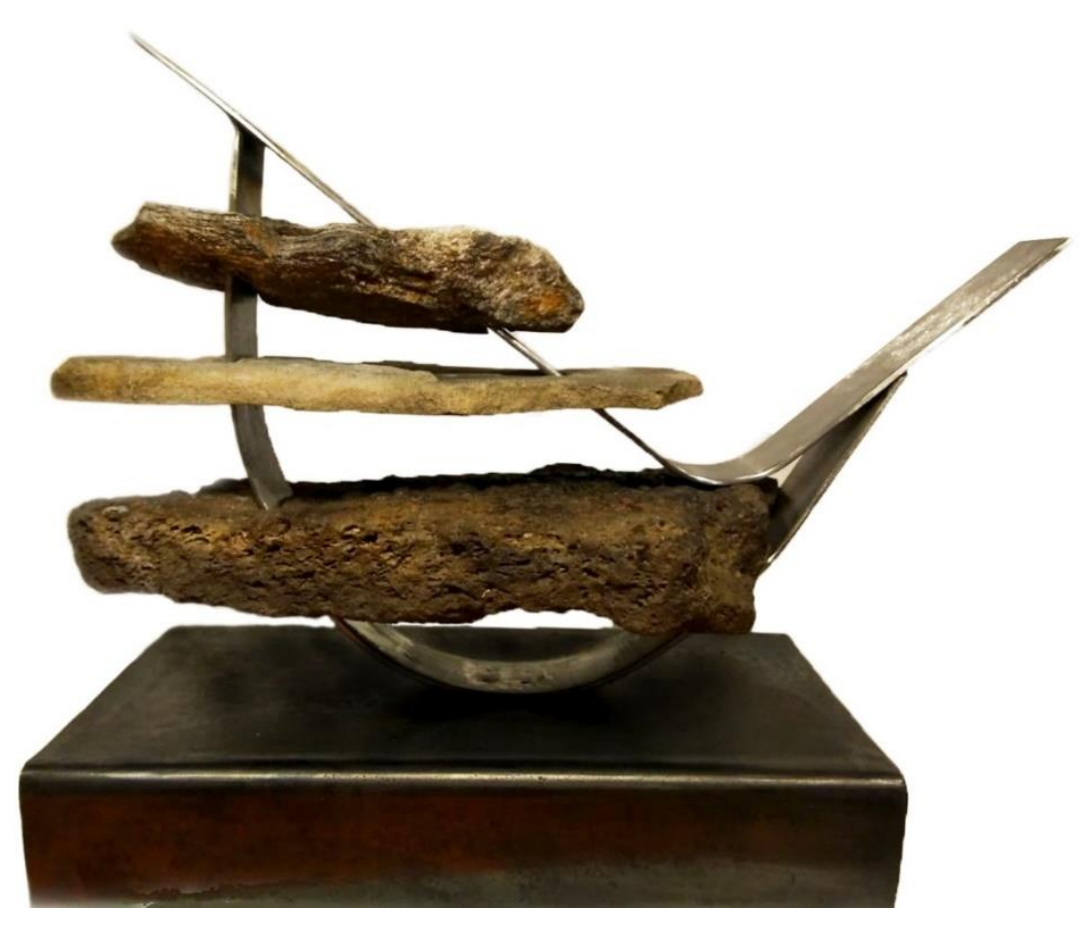

Trabajo de Tesis para optar al título de Doctora en Ciencias Naturales

Directores:

Gustavo Adolfo Neme

Luciano Raúl Prates

Facultad de Ciencias Naturales y Museo

Universidad Nacional de La Plata 
A mis padres por todo el amor y la motivación que me brindaron siempre 


\section{AGRADECIMIENTOS}

Alcanzar la meta de la "carrera" del doctorado no es sólo mérito de quien escribe la tesis. Llegar a estas "primeras" páginas luego de transitar las que vienen fue GRACIAS a distintas instituciones y a muchísimas personas que, a mi lado o a la distancia, recorrieron conmigo un proceso largo y fugaz, paciente e intenso y, sobre todo, GRATO.

En primer lugar, mi más profundo agradecimiento es para mis directores de tesis, Gustavo Neme y Luciano Prates, y para Adolfo Gil, quien fue mi director de proyecto. Sin la guía de ellos tres, este trabajo no hubiera sido posible. Hace muchos años, aún cuando estudiaba en la facultad, Fito y Gustavo generaron en mí las ganas de investigar y de realizar este trabajo. Siempre me motivaron a seguir este camino y, si bien fue "sinuoso" por cosas de la vida, volví a San Rafael con la certeza de que iba a contar con su ayuda, su experiencia y su estímulo. No sólo fue así, sino que se quintuplicó mi expectativa. Estuvieron siempre, con consejos, comentarios, opiniones constructivas, discusiones enriquecedoras y su buen humor infaltable. Con toda generosidad y desde el primer capítulo hasta el último, Gustavo me brindó su tiempo y su conocimiento, siempre atento a lo que necesitara, esperando tan sólo un mate de vuelta. En Luciano encontré una persona que, con mucha humildad y profesionalismo, aportó más de lo que yo podía esperar. Aprendí mucho de sus consejos y me ayudó tanto estos años, que las palabras no me alcanzan, así que, gracias, por la paciencia y por el tiempo.

A mi amiga y colega Laura Salgán, le agradezco infinitamente por todo lo que me enseñó en estos años. Compartió conmigo, no sólo mates y brindis, sino también su saber y su particular -y fantástica- mirada sobre el universo de la tecnología lítica. Pasó horas dedicándole tiempo a este trabajo, escuchando mis dudas, respondiendo preguntas tras fructíferas discusiones, leyendo capítulos, aportándome bibliografía y aconsejándome muy sabiamente. Siempre me alentó y confió en mí, me hizo pensar, me hizo reír para distenderme y me hizo saber cada vez un poco más. A ella, un agradecimiento enorme.

A Luis Ballarini, director del Museo de Historia Natural de San Rafael, quien me facilitó el espacio para llevar a cabo este trabajo, y a Miriam Ayala quien me recibió cada día en el museo y preparó con cariño, como hace años, los materiales para analizar, además de acudir a mi incesante búsqueda de bibliografía en el laboratorio. Al IANIGLA, a su director Fidel Roig y a su secretaria Jimena Castillo. A Felipe Genovese por abrirnos las puertas de la UTN-Facultad Regional San Rafael. A la ANPCYT/FONCYT y al 
CONICET por el otorgamiento de las becas que me permitieron solventar esta tesis. A la FCNyM-UNLP por permitirme hacer la licenciatura y esta carrera de doctorado de manera pública y gratuita.

Al geólogo Sergio Dieguez quién, con mucha predisposición, respondió a cada una de mis dudas, me asistió en la descripción de las rocas de los muestreos y me ayudó a comprender cómo se disponen las materias primas a lo largo de la cuenca del río Atuel.

A Ramiro Barberena y a Karen Borrazzo porque hace unos años pude aprender de ellos muchos temas y herramientas. Entre ellos, con Ramiro entendí cuestiones biogeográficas útiles para mis estudios posteriores, y con Karen aprehendí el gusto por el lítico.

Un agradecimiento especial es para el paleontólogo Marcelo de la Fuente y su esposa Gladys García, quienes me buscaron cada mañana por casa para llevarme al museo, me prestaron todo lo que me faltara y hasta su casa cuando me faltó agua (problemas de los desiertos... anécdotas sobran), siempre con mucho cariño y cuidándome. Agradezco también a los paleontólogos Soledad Vázquez e Ignacio Maniel del MHNSR, quienes me ayudaron con hojas geológicas, interpretaciones y edición de fotos. A Nahuel Scheifler y Elina Albarrán por facilitarme mi estadía durante cursos en Olavarría y Mendoza Capital. A Guillermo Heider, Fernando Franchetti y Gustavo Lucero por proporcionarme bibliografía muy útil.

Clara Otaola y Miguel "Mili" Giardina fueron indispensables para que esta tesis tuviera mayor solidez en estadística y en gráficos. Desinteresadamente, me ayudaron en estos y muchos otros aspectos que van más allá de la tesis. En ese sentido, desde que me mudé a San Rafael, Nuria Sugrañes estuvo presente desde el primer día, preocupándose por mi adaptación y por cebarme riquísimos mates. Pero sobre todo, brindándome mucho cariño y su amistad, que fue muy necesaria en momentos de catarsis, como así también, de festejos y alegrías. A Clara, Mili, Nuria, Laura, Chetti, Cinthia Abbona, Eva Peralta, Manuel López, Gustavo y Fito les agradezco por haber estado siempre en estos años, acompañándome en todo momento, desde una excavación hasta la materialización de esta tesis, con mucho cariño, paciencia y entusiasmo.

Eva y Manu fueron dos pilares que me sostuvieron en los momentos más complicados. Transitar estos años con ellos casi en la misma instancia de doctorado, hizo que nos comprendiéramos mucho y nos acompañáramos los tres. Siempre con palabras justas, siempre empujándonos para adelante, siempre con una sonrisa y un abrazo... siempre los querré. Otras personas que también caminaron estos pasos doctorales a la par, 
fueron los paleontólogos y biólogos Nacho, Sole, Marcos Jannello, Jessica Moreno y Verónica Vennari, quienes alegraron los almuerzos y colmaron de historias varias cenas. A los "Sinfas" por construirnos como una familia de familias de otros pagos. Gracias amigos por tantas sonrisas.

Patricia Escola fue de esas personas cuyas cualidades se admiran profundamente, no sólo por su capacidad y talento profesional, sino, sobre todo, por su calidad como ser humano. Cada vez que hablamos de lítico, se expandió más allá y, generosa en esencia, me dio consejos personales que no olvidaré jamás. ¡Muchas gracias Pato! Te llevaré conmigo siempre.

Agradezco a los jurados de tesis por sus observaciones y comentarios enriquecedores que aportaron positivamente al contenido de esta tesis.

A la distancia, pero desde muy cerca, amigos y amigas de acá y de allá, contribuyeron con su cariño para que esta tesis pueda salir a la luz (de la impresora...). Agradezco especialmente a mis amigas-hermanas platenses Mercedes Corbat, Soledad García, Agustina Martínez, Victoria Lissa, Carolina Padín, Laura Ciampagna y, desde algún lugar sonriéndome, Verónica Trola. Las experiencias e historias que compartimos desde la etapa de la licenciatura son infinitas, y la distancia jamás opacó la alegría en las buenas y la compañía en las malas; siempre, con mucho amor y comprensión, estuvieron y estarán, al igual que el "Cute” Moralejo, "Loes” del Papa y Pabito Ambrústolo. A mis amigas-hermanas patagónicas Andrea Cabrera, Laura Farina, Soledad Cardoso y Flavia Prieto porque desde el jardín y la escuela en San Martín de los Andes, comparten conmigo distintos momentos de la vida, y en esta etapa estuvieron más que presentes.

A mi familia por ser el motor que me impulsa cada día. A mis padres Roberto y Ana, y a mis hermanos Ana Clara y Joaquín, porque siempre me alentaron a seguir el camino que me hiciera feliz, y me acompañaron a cada paso y en cada tropiezo. A mis tíos, mis primos y, especialmente, a mi abuela Amelia que me demuestra que con perseverancia todo se puede lograr. A mi madre por enseñarme con amor y experiencia de lo que es capaz una mujer luchadora. A mi padre por transmitirme desde muy chica la pasión por conocer tiempos y espacios remotos; y por la escultura de la carátula a la que él llamó "Entre desiertos" y que hizo con tanto amor y dedicación. El metal que atraviesa las tres rocas refleja artísticamente la intención de esta tesis.

A Federico Bobillo, Fede, mi compañero... en el día a día, al lado mío o a la distancia, con mucha paciencia, con mucho humor y amor, resolviendo complicaciones domésticas o preguntas sobre lítico. Me ayudó en las tareas de campo (excavaciones y 
muestreos), con la edición de las fotos de los instrumentos y fue indispensable en la última instancia, previa a la entrega del manuscrito. Estuvo siempre dispuesto a debatir sobre cuestiones tecnológicas y me enseñó muchísimo de lo que aprendí en estos años sobre el registro lítico. Pero sobre todo, aprendí de él que, pese a la distancia, a las desconexiones vía Skype y otros contratiempos durante estos años, "el amor es más fuerte”. Gracias por ser mi sostén, amigo, compañero y amor.

Si por olvido omití a alguien, mis disculpas, y GRACIAS a todas y cada una de estas personas. 


\section{FLECHA}

"Una punta de flecha hallé una tarde semioculta, perdida en la maleza, clavada en una herida que ella abriera en el pecho desierto de la tierra.

Era aguda, era hermosa y cristalina astilla trabajada de la piedra; tal vez su material vino a este mundo en el raudo meteoro de una estrella. Yo alcé como flor de otros veranos su forma corazón, blanca y perfecta.

El arco que impulsaba su destino hace mucho la dejó sola e inerte con el mudo misterio de su hechura y el antiguo secreto de su suerte.

Vi en el tiempo la mano creadora que forjó su ángulo grave y reluciente y la vi como ayer, surcando el aire con el silbo de su andar frío y silente; y pensé en la trayectoria y la distancia pequeña mensajera de la muerte.

Así se me ocurrió que en algún tiempo de ese mismo lugar y por la tarde, otro ser como yo miraba el cielo, y el sol del horizonte que arde y arde.

Sentí como que hablaban los silencios, y la vaga sensación de estar con alguien, y no sé por qué razón dejé la flecha en el mismo lugar que estaba antes; mas primero la apreté fuerte en el puño y cien siglos se clavaron en mi sangre”.

Marcelo Berbel (1971). 


\section{INDICE GENERAL}

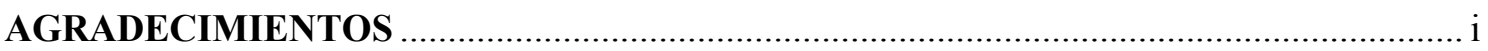

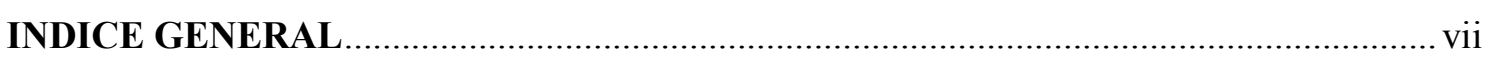

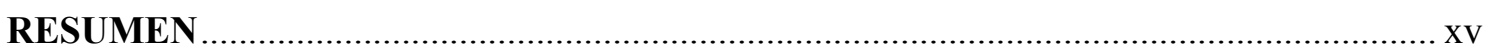

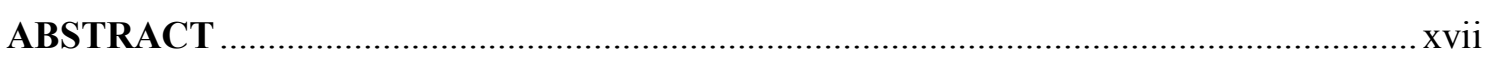

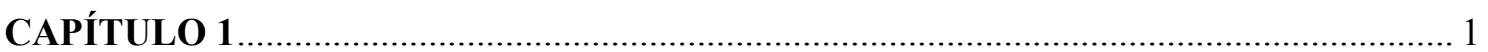

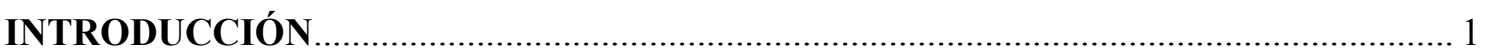

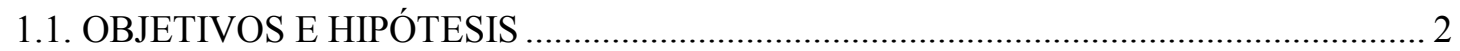

1.1.1. OBJETIVO GENERAL DE LA TESIS ……....................................................... 2

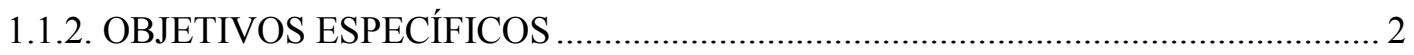

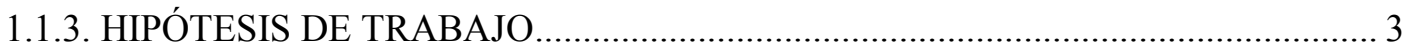

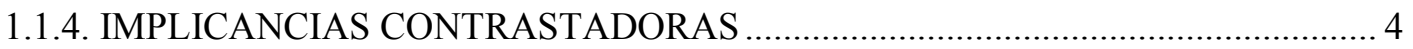

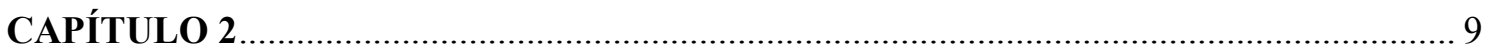

DEFINICIÓN DEL ÁREA DE ESTUDIO Y ESTRUCTURA AMBIENTAL .................... 9

2.1. ÁREA DE ESTUDIO Y ORGANIZACIÓN ESPACIAL …............................................... 9

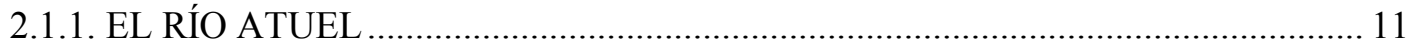

2.2. CARACTERÍSTICAS CLIMÁTICAS Y AMBIENTALES DE LA PROVINCIA DE

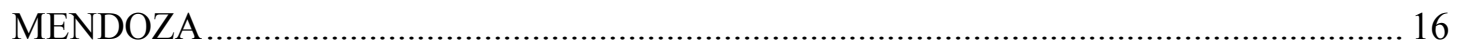

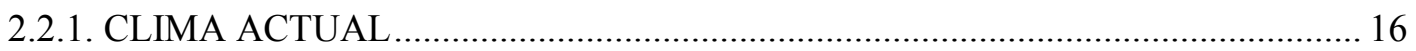

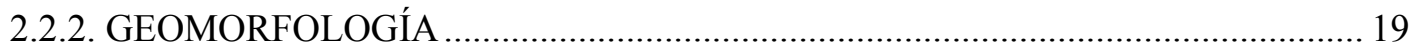

2.2.2.1. Geomorfología de la cuenca del río Atuel .................................................... 19

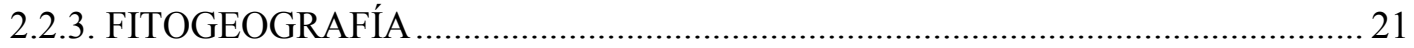

2.2.3.1. Fitogeografía de la cuenca del río Atuel ........................................................ 22

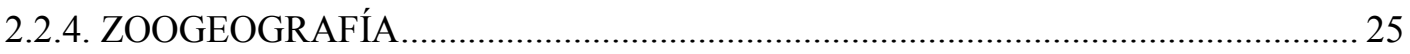

2.3. AMBIENTE ÁRIDO-SEMIÁRIDO: LOS DESIERTOS DEL SUR DE MENDOZA ... 28

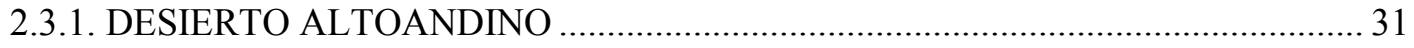

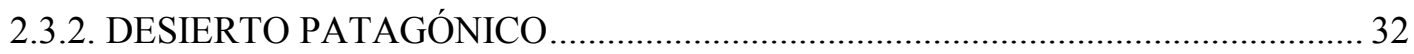

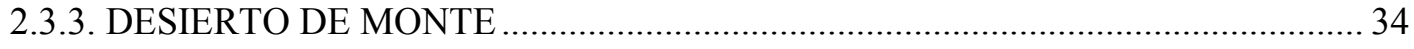

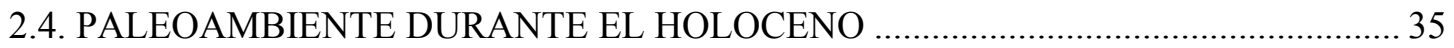

2.4.1. PLEISTOCENO FINAL-HOLOCENO TEMPRANO (14.000-8.000 años AP).......... 36

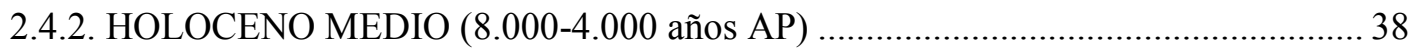

2.4.3. HOLOCENO TARDÍO (4.000-200 años AP) ........................................................ 40

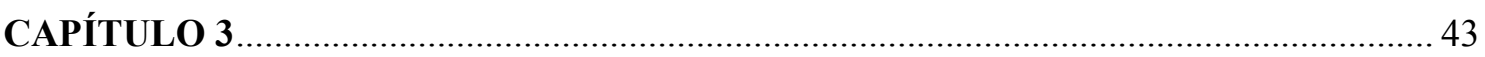

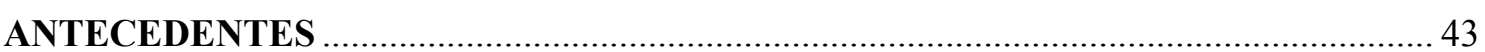


3.1. ARQUEOLOGÍA EN EL SUR DE MENDOZA.......................................................... 43

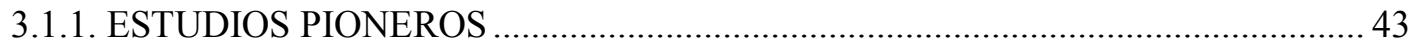

3.1.2. BIOGEOGRAFÍA Y POBLAMIENTO HUMANO ................................................ 51

3.1.2.1. El registro arqueológico del Pleistoceno final-Holoceno temprano en la

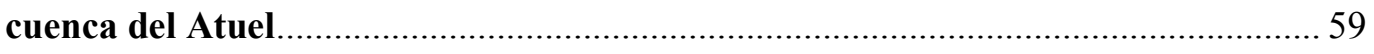

3.1.2.2. El registro arqueológico del Holoceno medio en la cuenca del Atuel .......... 60

3.1.2.3. El registro arqueológico del Holoceno tardío en la cuenca del Atuel ...........60

3.2. ESTUDIOS PRECEDENTES SOBRE LA ORGANIZACIÓN DE LA TECNOLOGÍA

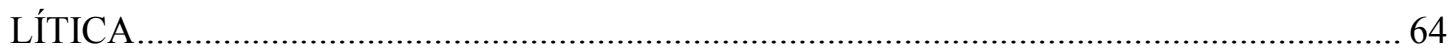

3.2.1. ORGANIZACIÓN DE LA TECNOLOGÍA LÍTICA EN ARGENTINA, EN

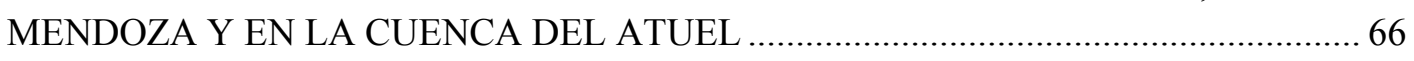

3.2.1.1. Estudios de tecnología lítica en regiones vecinas del sur de Mendoza......... 68

3.2.1.2. Estudios de tecnología lítica en el sur de Mendoza ....................................... 74

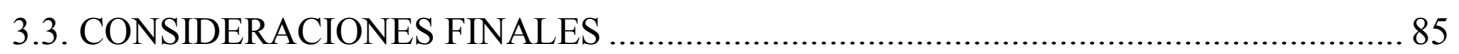

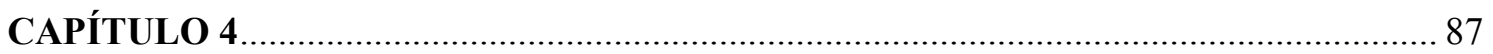

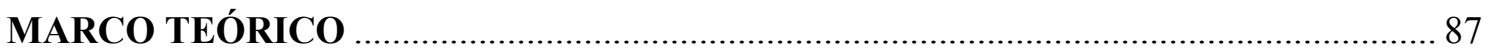

4.1. MARCO TEÓRICO GENERAL: LA ECOLOGÍA EVOLUTIVA ….............................. 87

4.1.1. ECOLOGÍA DEL COMPORTAMIENTO HUMANO …......................................... 88

4.1.1.1. Teoría de Forrajeamiento Óptimo: modelos y vinculación con las estrategias tecnológicas

4.1.1.1.1. Críticas al uso de los Modelos de Forrajeamiento Óptimo en arqueología 95

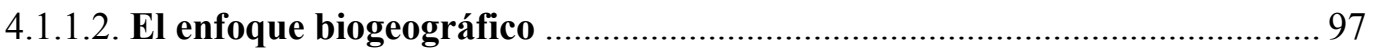

4.1.1.2.1. Expectativas biogeográficas del registro lítico ........................................... 99

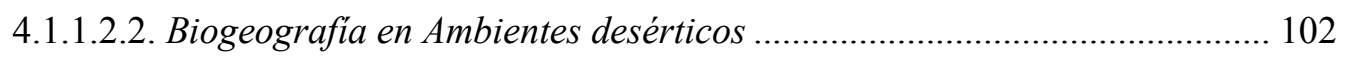

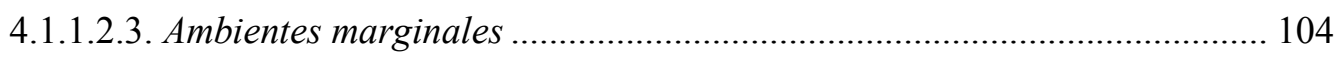

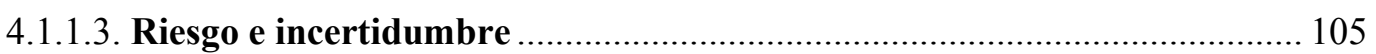

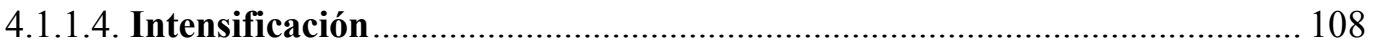

4.2. MARCO TEÓRICO ESPECÍFICO: LA ORGANIZACIÓN DE LA TECNOLOGÍA . 109

4.2.1. ORGANIZACIÓN DE LA TECNOLOGÍA LÍTICA …......................................... 110

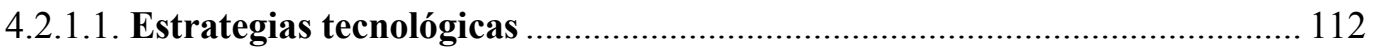

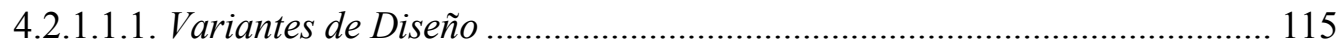

4.2.1.1.2. Estrategias tecnológicas y diseños ante el riesgo y el estrés temporal ..... 118

4.2.1.2. De la obtención de rocas al descarte de artefactos: el continuum de la

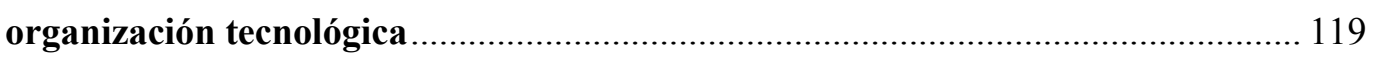

4.2.1.2.1. Estructura de la base regional de recursos líticos .................................... 121

4.2.1.2.2. Modos y estrategias de aprovisionamiento .............................................. 124

4.2.1.3. Movilidad, uso del espacio e interacción ................................................... 132

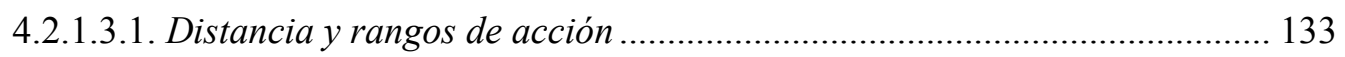


4.2.1.3.2. Modelos de circulación de materias primas y movilidad.......................... 135

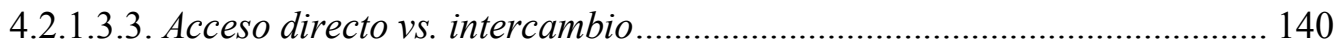

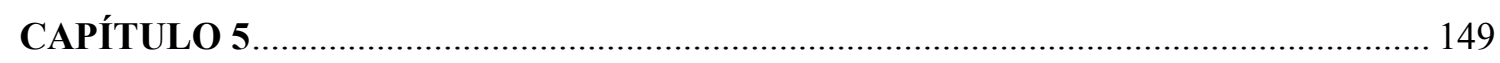

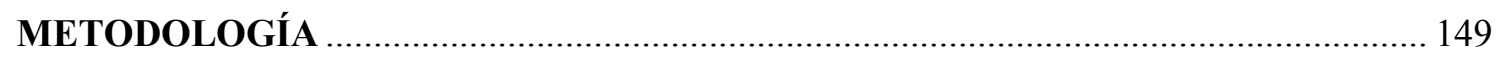

5.1. MÉTODOS Y TÉCNICAS DE MUESTREO DEL ESPACIO REGIONAL ................. 149

5.1.1. RELEVAMIENTO ARQUEOLÓGICO DEL ÁREA DE ESTUDIO ..................... 150

5.1.2. ESTUDIO DE LAS PROPIEDADES DE LAS FUENTES LÍTICAS .................... 152

5.2. ANÁLISIS DE LOS CONJUNTOS ARTEFACTUALES ............................................ 154

5.2.1. DESCRIPCIÓN DE LOS CONJUNTOS LÍTICOS ............................................... 154

5.2.2. VARIABLES CONSIDERADAS EN EL ANÁLISIS DE LOS ARTEFACTOS

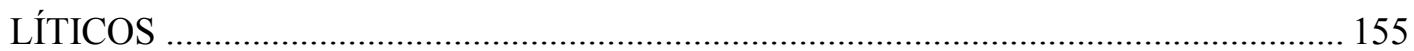

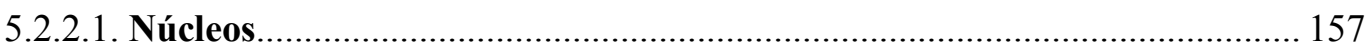

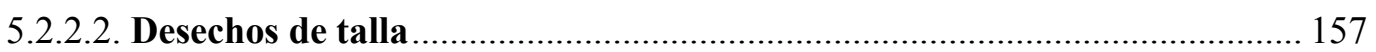

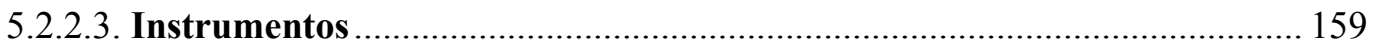

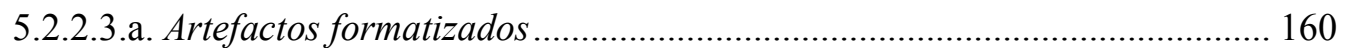

5.2.2.4. Artefactos (lascas u hojas) con filos, puntas o superficies con rastros

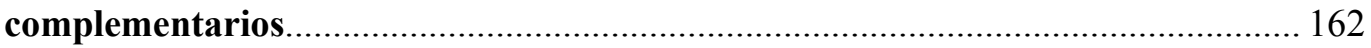

5.2.3. DETERMINACIÓN DE LAS MATERIAS PRIMAS........................................... 162

5.2.3.1. Estudios geoquímicos ………........................................................................... 163

5.3 ÍNDICES Y ESTADÍSTICOS UTILIZADOS EN EL TRATAMIENTO DE LOS

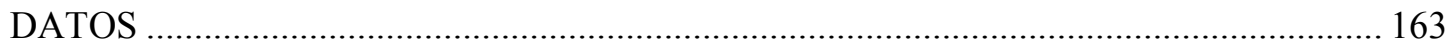

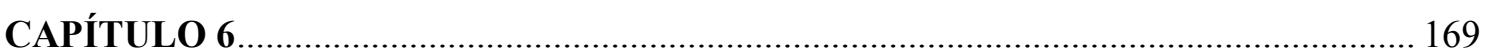

LA BASE REGIONAL DERECURSOS LÍTICOS ENLACUENCA DEL RÍO ATUEL 169

6.1. GEOLOGÍA Y LITOLOGÍA REGIONAL ............................................................ 170

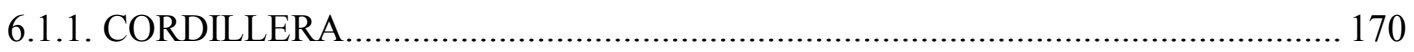

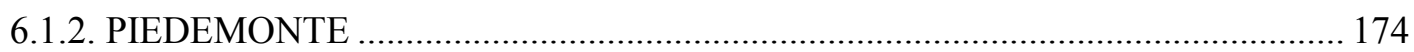

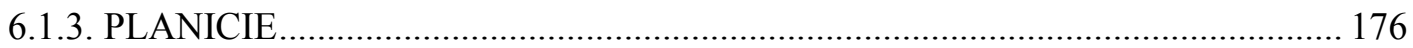

6.1.4. ALGUNAS CONSIDERACIONES ACERCA DE LA GEOMORFOLOGÍA Y

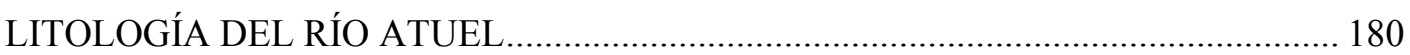

6.2. RELEVAMIENTO Y MUESTREOS DE MATERIAS PRIMAS LÍTICAS ................. 181

6.2.1. MUESTREOS EN EL RÍO ATUEL .................................................................. 183

6.2.1.1. Muestreos sistemáticos y asistemáticos en la cuenca superior ................... 183

6.2.1.2. Muestreos sistemáticos y asistemáticos en la cuenca media ....................... 185

6.2.1.2.1. Muestreos sistemáticos y asistemáticos en el río Salado ........................... 186

6.2.1.3. Muestreos sistemáticos en la cuenca inferior ............................................. 188

6.2.2. SÍNTESIS DE LOS MUESTREOS EN LA CUENCA DEL ATUEL ..................... 189

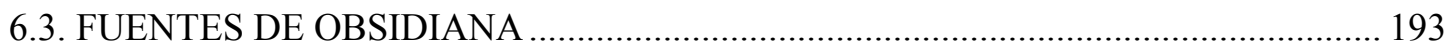


6.4. CONSIDERACIONES GENERALES DE LA BASE REGIONAL DE RECURSOS LÍTICOS EN LA CUENCA DEL ATUEL ............................................................................. 196

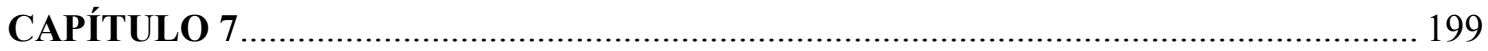

RESULTADOS DEL ANÁLISIS DEL REGISTRO LÍTICO EN EL DESIERTO

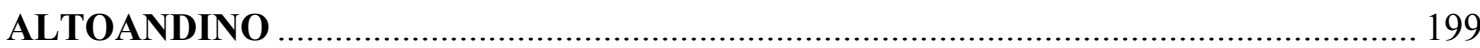

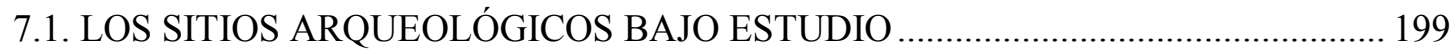

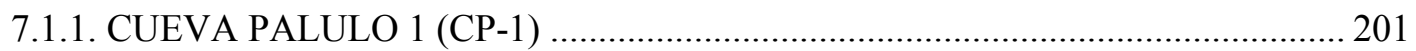

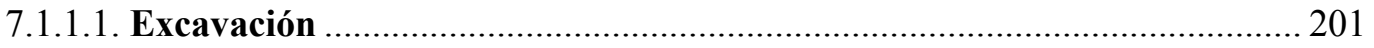

7.1.1.2. Estratigrafía, cronología y definición de las unidades de análisis.............. 203

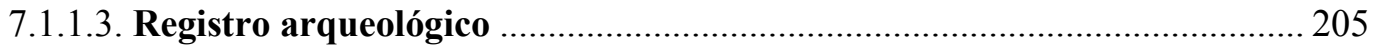

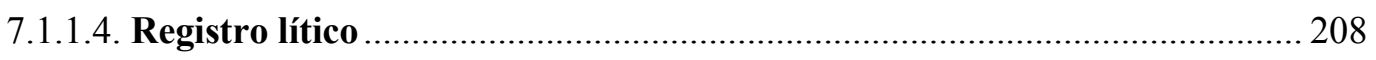

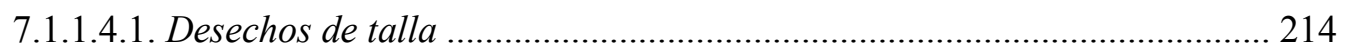

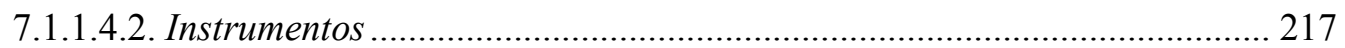

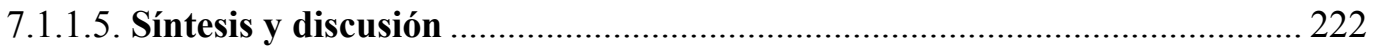

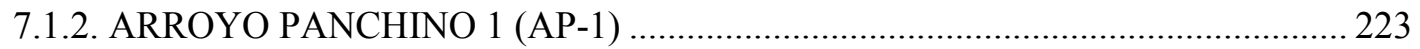

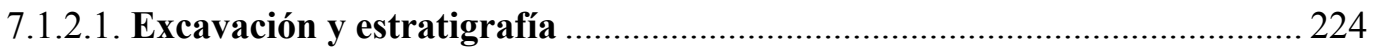

7.1.2.2. Cronología y definición de las unidades de análisis ................................... 225

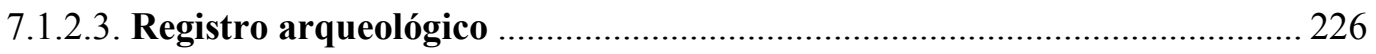

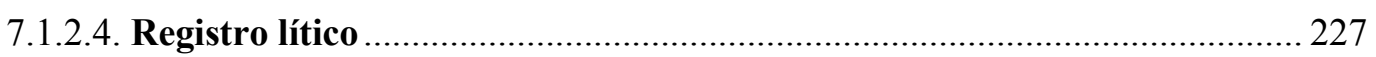

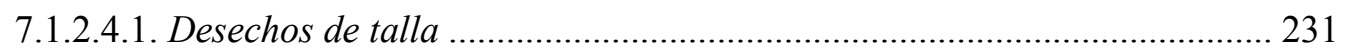

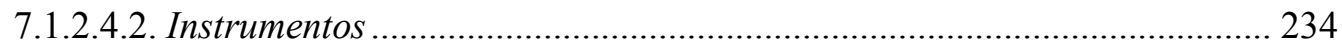

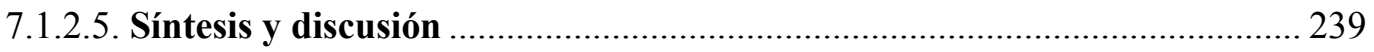

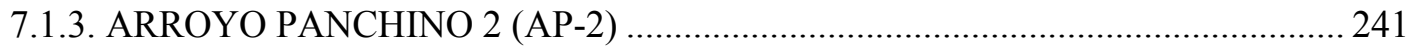

7.1.3.1. Estratigrafía y cronología .......................................................................... 242

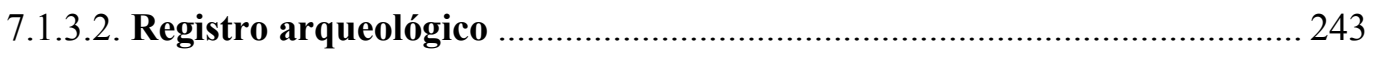

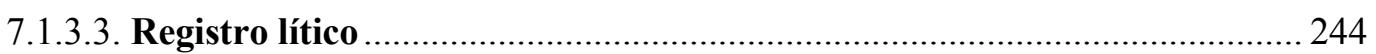

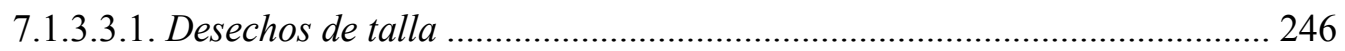

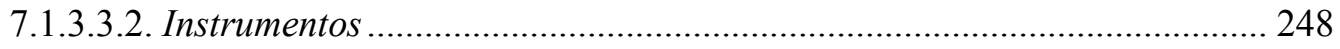

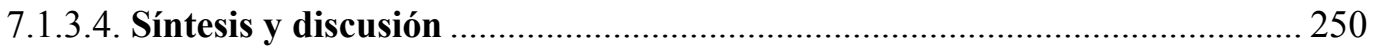

7.2. ANÁLISIS TECNO-TIPOLÓGICO DEL DESIERTO ALTOANDINO....................... 251

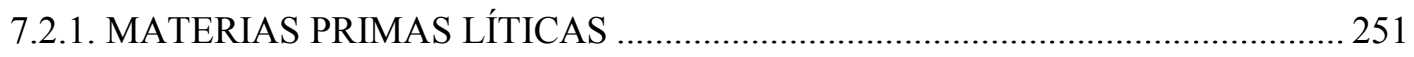

7.2.2. ESTRUCTURA TECNOLÓGICA EN EL DESIERTO ALTOANDINO............... 260

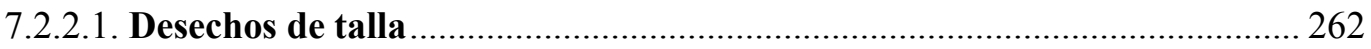

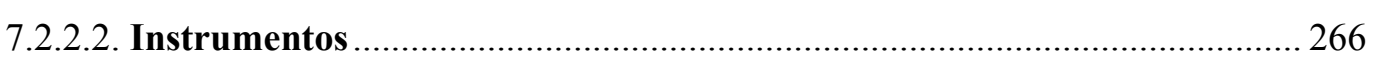

7.3. OBSIDIANAS EN EL DESIERTO PATAGÓNICO …................................................. 274

7.3.1. ANÁLISIS DE ELEMENTOS TRAZA …............................................................. 274

7.3.2. APROVISIONAMIENTO Y USO DE OBSIDIANAS …...................................... 275 


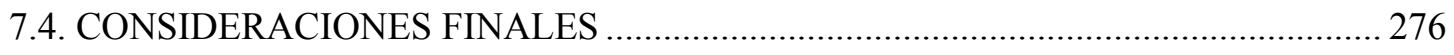

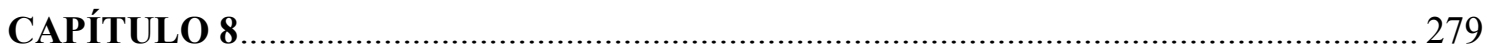

RESULTADOS DEL ANÁLISIS DEL REGISTRO LÍTICO EN EL DESIERTO

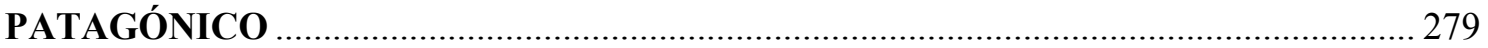

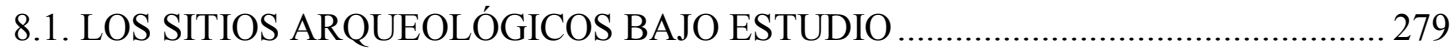

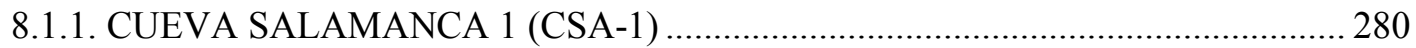

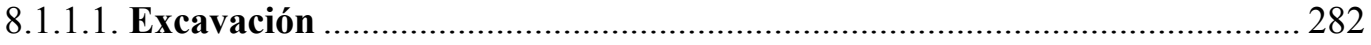

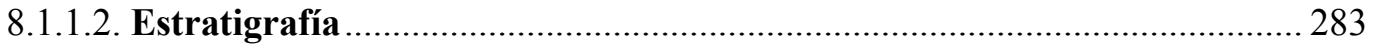

8.1.1.2.1. Caracterización sedimentológica delas unidades estratigráficas de CSA-1...284

8.1.1.3. Cronología y definición de las unidades de análisis ................................... 285

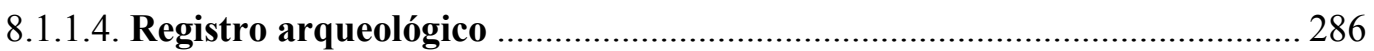

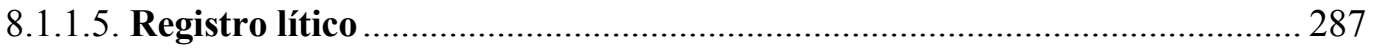

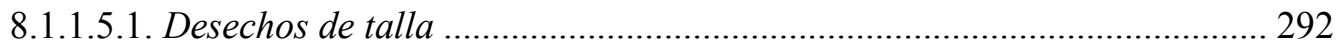

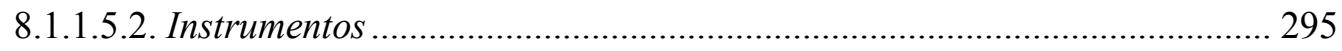

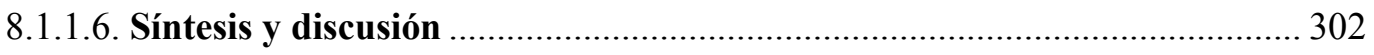

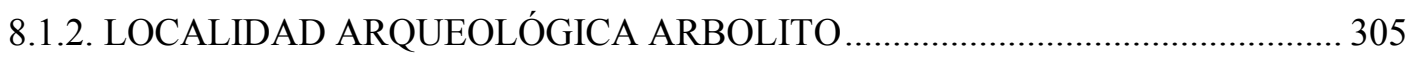

8.1.2.1. Excavaciones y estratigrafía de AR-6 y AR-7 ………………………......... 307

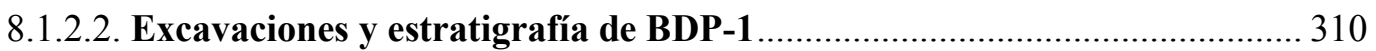

8.1.2.3. Cronología de la localidad Arbolito .......................................................... 312

8.1.2.4. Registro arqueológico de la localidad arqueológica Arbolito..................... 313

8.1.2.5. Registro lítico de los sitios AR-6 y AR-7 ………....................................... 314

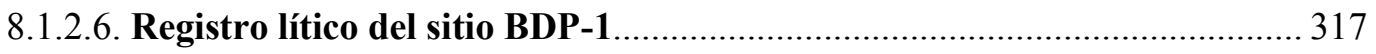

8.1.2.7. Registro lítico de la localidad Arbolito: sitios AR-6, AR-7 y BDP-1.......... 319

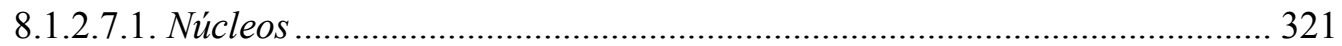

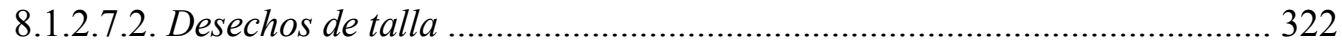

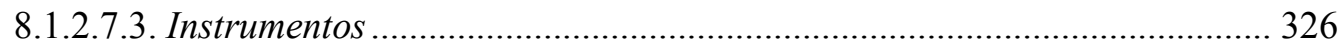

8.1.2.8. Síntesis y discusión acerca de la localidad arqueológica Arbolito .............. 330

8.2. ANÁLISIS TECNO-TIPOLÓGICO DEL DESIERTO PATAGÓNICO ........................ 332

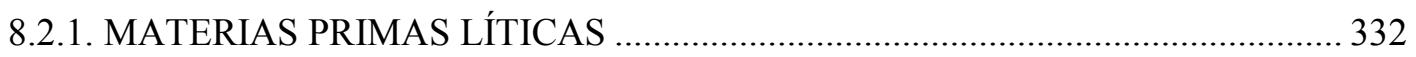

8.2.2. ESTRUCTURA TECNOLÓGICA EN EL DESIERTO PATAGÓNICO ................ 341

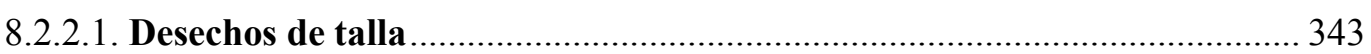

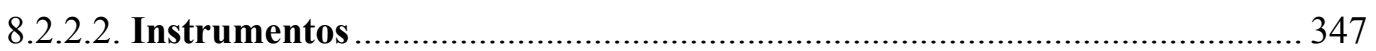

8.3. OBSIDIANAS EN EL DESIERTO PATAGÓNICO ................................................. 357

8.3.1. ANÁLISIS DE ELEMENTOS TRAZA …................................................................... 357

8.3.2. APROVISIONAMIENTO Y USO DE OBSIDIANAS ….......................................... 360

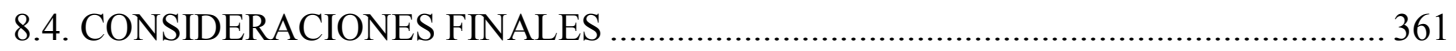

CAPÍTULO 9 


\section{RESULTADOS DEL ANÁLISIS DEL REGISTRO LÍTICO EN EL DESIERTO DE}

MONTE

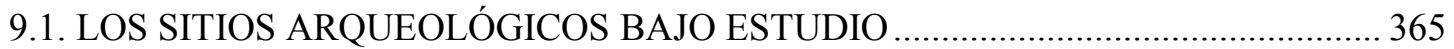

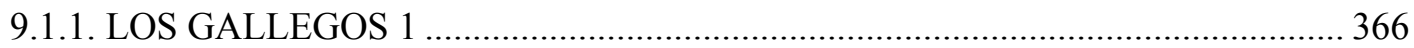

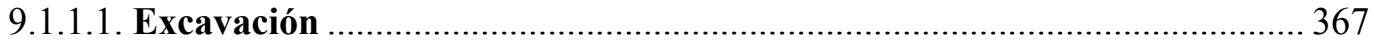

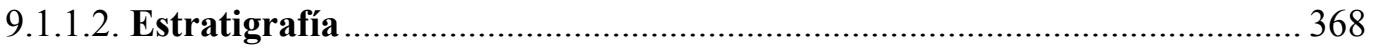

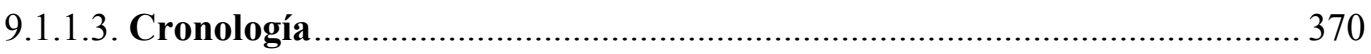

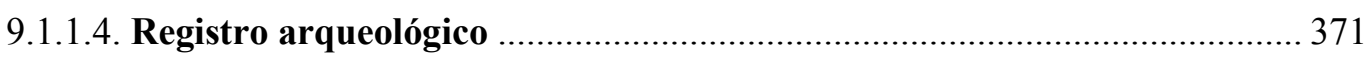

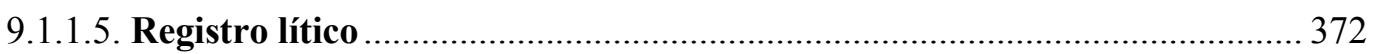

9.1.1.5.1. Desechos de talla en LG-1 (cuadrículas A1 y B1) ..................................... 376

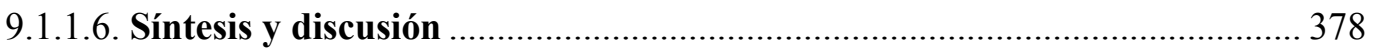

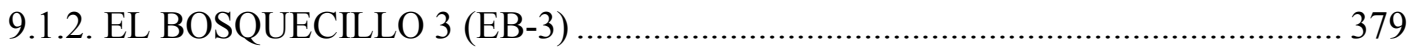

9.1.2.1. Excavación, estratigrafía y cronología ………………………………....... 380

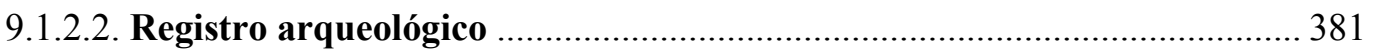

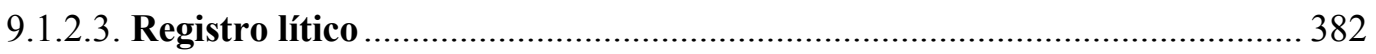

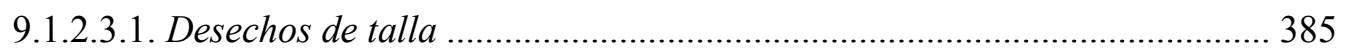

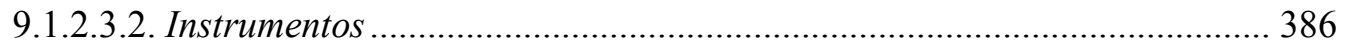

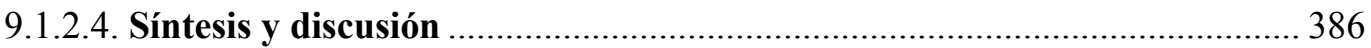

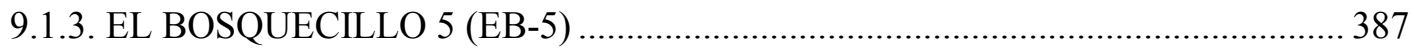

9.1.3.1. Excavación, estratigrafía y cronología ……………………………............ 387

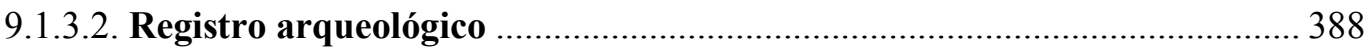

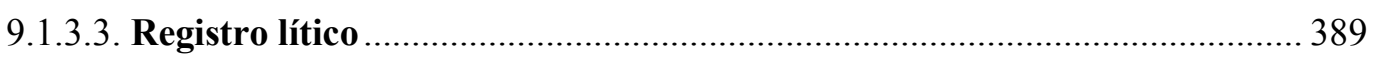

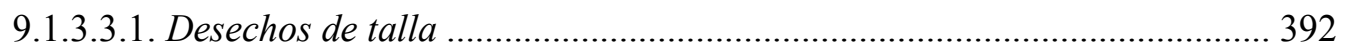

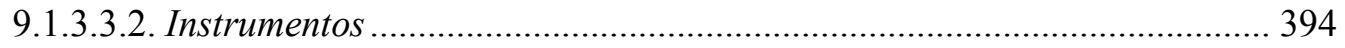

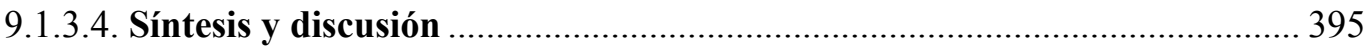

9.2. ANÁLISIS TECNO-TIPOLÓGICO DEL DESIERTO DE MONTE............................. 395

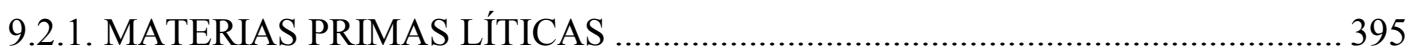

9.2.2. ESTRUCTURA TECNOLÓGICA EN EL DESIERTO DE MONTE .................... 400

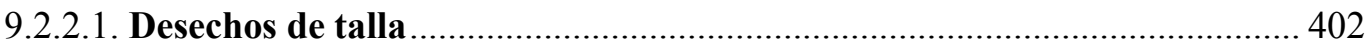

9.3. OBSIDIANAS EN EL DESIERTO DE MONTE.......................................................... 403

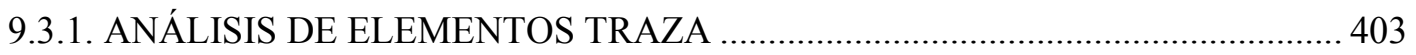

9.3.2. APROVISIONAMIENTO Y USO DE OBSIDIANAS ……................................... 404

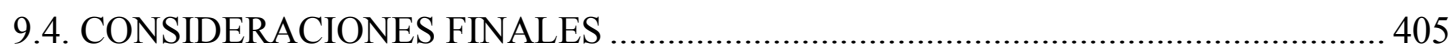

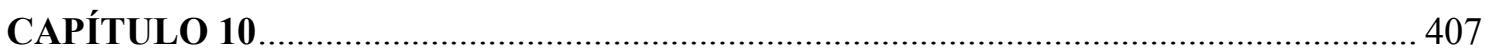

TENDENCIAS ESPACIALES Y TEMPORALES DEL REGISTRO LÍTICO EN LA

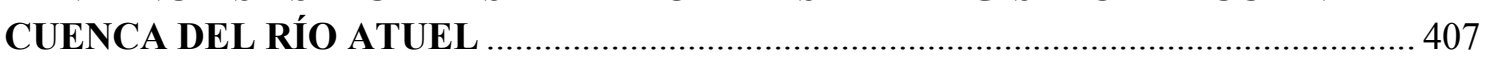

10.1. TENDENCIAS TECNOLÓGICAS EN PERSPECTIVA ESPACIAL ......................... 408 
10.1.1. APROVISIONAMIENTO Y USO DE RECURSOS LÍTICOS EN EL ESPACIO 408

10.1.2. CLASES ARTEFACTUALES EN EL ESPACIO. 414

10.1.3. CONSIDERACIONES GENERALES DE LAS TENDENCIAS TECNOLÓGICAS

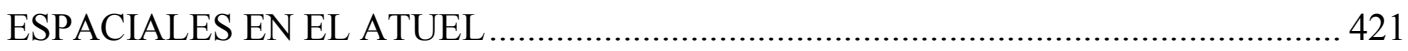

10.2. TENDENCIAS TECNOLÓGICAS EN PERSPECTIVA TEMPORAL ..................... 425

10.2.1. APROVISIONAMIENTO Y USO DE RECURSOS LÍTICOS A TRAVÉS DEL TIEMPO. 425

10.2.2. CLASES ARTEFACTUALES A TRAVÉS DEL TIEMPO. 430

10.2.3. CONSIDERACIONES GENERALES DE LAS TENDENCIAS TECNOLÓGICAS

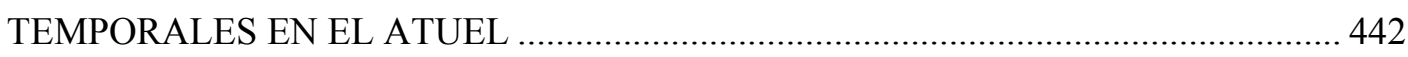

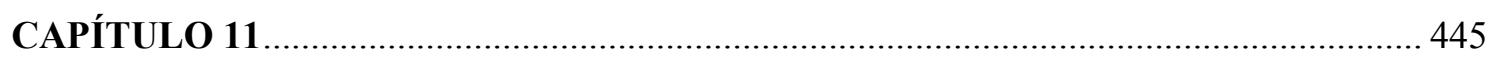

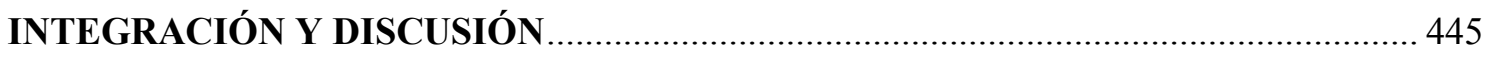

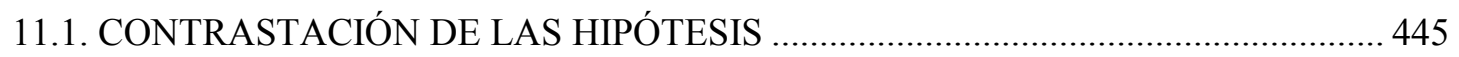

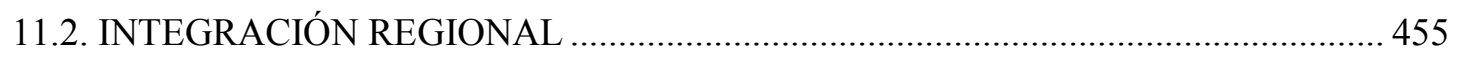

11.3. UN MODELO DE APROVISIONAMIENTO PARA EL SUR DE MENDOZA....... 462

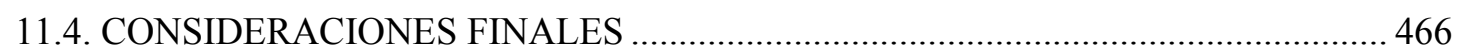

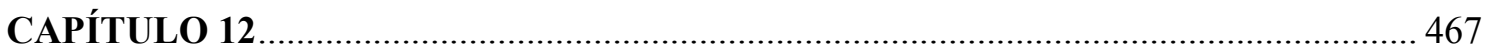

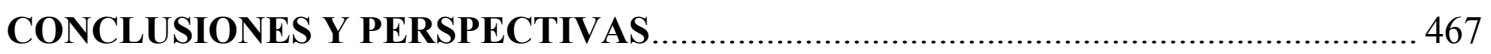

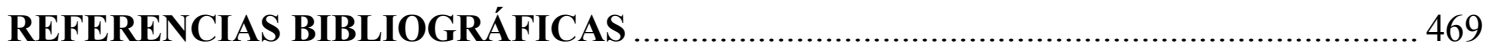

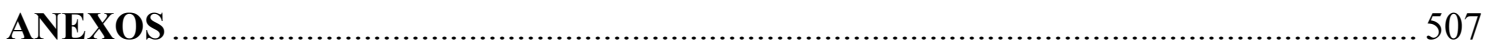

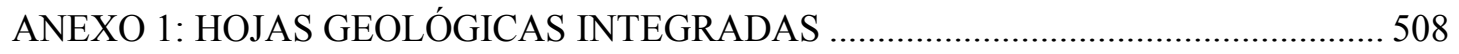

ANEXO 2: ANÁLISIS GEOQUÍMICOS ............................................................................ 513 


\section{RESUMEN}

La presente tesis está orientada a definir las distintas estrategias adaptativas humanas implementadas en la ocupación de los ambientes áridos-semiáridos del sur de Mendoza y, específicamente, evaluar los cambios en la organización de la tecnología en la cuenca del río Atuel durante el Holoceno tardío. En este sentido, el estudio de la tecnología lítica de los grupos cazadores-recolectores que habitaron la cuenca del río Atuel, estuvo dirigido al reconocimiento de los modos de aprovisionamiento lítico y a la reconstrucción de las trayectorias artefactuales, a través del tiempo y en los tres desiertos que atraviesa el río: de oeste a este, desiertos Altoandino, Patagónico y de Monte. Para ello se aplicó un enfoque biogeográfico dentro del marco de la Ecología del Comportamiento Humano, que constituye una herramienta adecuada para discutir en escalas espaciales amplias y evaluar la relación entre los cambios ambientales, la estructura del paisaje, la organización tecnológica y la demografía.

Los estudios en esta tesis incluyeron el análisis tecno-tipológico de artefactos de diez sitios arqueológicos localizados en los tres desiertos que recorre el río Atuel desde la cordillera hasta la planicie. Además, se llevaron a cabo prospecciones y muestreos sistemáticos de materias primas, y se realizaron estudios específicos sobre las propiedades de las fuentes líticas, teniendo en cuenta aspectos relacionados con la distribución de los recursos líticos, el grado de explotación e intensidad de uso, y las características y variables tradicionales en los estudios de procesos específicos de manufactura. Asimismo, se realizaron análisis geoquímicos de muestras naturales y artefactos de obsidiana, con el fin de complementar la abundante información previa disponible para el sur de Mendoza. La integración de estas líneas de evidencia y la información previa del área, permitió generar tendencias espaciales y temporales de las distintas estrategias tecnológicas adoptadas por los grupos humanos que ocuparon la cuenca del Atuel.

Una de las hipótesis propuestas plantea que la definición de las estrategias tecnológicas adoptadas en la explotación, uso y circulación de los recursos líticos -locales y no locales- está influenciada por las particularidades ambientales y de distribución de recursos líticos en los diferentes desiertos que recorre la cuenca del río Atuel. Otras dos hipótesis temporales señalan un momento de recolonización del área a principios del Holoceno tardío, y una etapa de ocupación efectiva en la segunda mitad de este periodo. 
Los resultados obtenidos permitieron delinear tendencias tecnológicas espaciales y temporales. Entre ellas, se destacan: el predominio en el uso de rocas silíceas; el incremento en el uso de la obsidiana, el aumento de la diversidad de fuentes de esta roca y en la bifacialidad a través del tiempo; el uso de rocas de menor calidad para la talla y la ocupación de los sitios en el Desierto de Monte hacia fines del Holoceno tardío; el predominio de instrumentos bifaciales sobre obsidiana y de unifaciales sobre rocas silíceas; la ausencia o escasez de núcleos como modo de transporte de rocas; la baja o nula reserva de corteza en los sitios; el incremento en la inversión de trabajo y, asimismo, del uso de obsidiana, a mayor altitud; la disminución en el tamaño de las puntas de proyectil y la homogeneidad de los tamaños de los desechos de talla a través del tiempo; la similitud en las funciones inferidas de los grupos tipológicos de los instrumentos entre los dos segmentos temporales del Holoceno tardío; el empleo de instrumentos de diseños confiables, mantenibles (versátiles y flexibles), sobre todo en ambientes estacionales como el Desierto Altoandino; el predominio en el aprovisionamiento serial incluido en rocas locales y cíclico directo en rocas no locales; la baja representación de las etapas iniciales de manufactura; las trayectorias artefactuales terminales sobre rocas silíceas (locales) y secuenciales sobre obsidiana (no local), entre otras.

La integración de estas tendencias con los datos obtenidos en estudios previos, permitió reconocer patrones similares entre los tres desiertos en relación al uso de materias primas, a sus trayectorias artefactuales y al tipo de estrategia tecnológica utilizada a lo largo del tiempo. Asimismo, cada desierto implicó estrategias particulares en el modo de aprovisionamiento, uso y circulación de los recursos líticos, y cambios en los patrones de ocupación y movilidad a través del tiempo (e.g. reducción de la movilidad e integración creciente en las redes de intercambio a nivel regional). En conjunto, esta información permite discutir y ampliar los modelos vinculados a la organización de la tecnología lítica durante el Holoceno tardío en el sur de Mendoza y, específicamente, en la cuenca del río Atuel. 


\section{ABSTRACT}

The present thesis is aimed at defining the different human adaptive strategies implemented in the occupation of the arid-semiarid environments of southern Mendoza and, specifically, to evaluate the changes in the organization of technology in the Atuel river basin during the late Holocene. In this sense, the study of the lithic technology of the hunter-gatherer groups that inhabited the Atuel river basin, was aimed at recognizing the ways of lithic supply and the reconstruction of artefactual trajectories, over time and in the three deserts that crosses the river: from west to east, Altoandino, Patagónico and Monte deserts. For this, a biogeographical approach was applied within the framework of the Ecology of Human Behavior, which is an adequate tool to discuss at broad spatial scales and evaluate the relationship between environmental changes, landscape structure, technological organization and demography.

The studies in this thesis included the techno-morphological analysis of artifacts from ten archaeological sites located in the three deserts that the Atuel River crosses from the mountain range to the plain. In addition, systematic surveys and sampling of raw materials were carried out, and specific studies were carried out on the properties of the lithic sources, taking into account aspects related to the distribution of lithic resources, the degree of exploitation and intensity of use, and the characteristics and traditional variables in the studies of specific manufacturing processes. Likewise, geochemical analyzes of natural samples and obsidian artifacts were carried out, in order to complement the abundant previous information available for southern Mendoza. The integration of these lines of evidence and the previous information of the area, allowed generating spatial and temporal trends of the different technological strategies adopted by the human groups that occupied the Atuel basin.

One of the hypotheses proposed here suggests that technological strategies adopted in the exploitation, use, and circulation of lithics resources-local and non-local-, are related to its distribution and the environmental characteristics of the different deserts of Atuel river basin. Moreover, two other hypotheses established a recolonization of the area at the beginning of the late Holocene, and an effective occupation stage in the second half of this period.

The results obtained allowed to describe spatial and temporal technological trends, as follow: the predominant use of siliceous rocks; the increase in the use of obsidian over 
time, particularly, in the bifaciality and diversity of source origins; the use of lower quality rocks for the size and occupation of the Monte Desert sites towards the end of the late Holocene; the high proportion of bifacial instruments in obsidian and, unifacials in siliceous rocks; the scarce presence of cores as transportation strategies of rocks; the lower or null percentage of cortex in the sites; the increase in investment and, use of obsidian at higher altitudes; the decrease in the size of projectile points and homogeneity of the flakes knapping, over time; the similarity in functions of the typological groups of instruments between the two temporal segments of the late Holocene; the use of instruments with reliable, maintainable (versatile and flexible) designs, especially, in seasonal environments such as the Altoandino Desert; the significance in serial procurement strategies for local rocks and direct cyclical procurement of non-local rocks; the low representation of the initial stages of manufacturing; the final artefactual circulation of siliceous rocks (local) and sequential in obsidian (non-local), among others.

The integration of these trends with the data obtained in previous studies, allow us to recognize similar patterns among the three deserts related to the use of raw materials, their artifact trajectories and the type of technological strategy used over time. Likewise, each desert implied particular strategies in procurement, use and circulation of lithic resources, and changes in patterns of occupation and mobility in the Holocene (e.g. reduction of mobility and increase integration in regional exchange networks). Together, this information lets to discuss and expand the models related to lithic technology organization, during the late Holocene in southern Mendoza and, particularly, in Atuel river basin. 


\section{CAPÍTULO 1}

\section{INTRODUCCIÓN}

"In the long run, study of variable behavioral responses within different kinds of desert may prove to be more interesting than studies contrasting deserts and nondeserts" (Yellen 1977: 266).

“...Every archaeologist has had the experience: You pick up a gleaming flake of obsidian from a site, look up at a vast dune field surrounded by low ranges of sandstone or other sedimentary rock, and wonder, how did this get here?...” (Kelly 2011: 189).

Los ambientes desérticos imponen a los seres humanos limitaciones que requieren estrategias adaptativas concretas para su ocupación sostenida. En el sur de Mendoza, las estrategias empleadas por las sociedades que lo ocuparon fueron variables a lo largo del tiempo. En la cuenca del río Atuel, se ha postulado la ocurrencia de cambios en el registro arqueológico regional durante el Holoceno tardío (últimos 4.000 años), tales como la exploración y ocupación efectiva de áreas consideradas marginales; la incorporación de la tecnología cerámica y del sistema de arco y flecha, el uso generalizado de elementos de molienda y la incorporación de especies vegetales domésticas. Sin embargo, aún no se han realizado estudios que evalúen el impacto de la variabilidad de recursos disponibles en los distintos tipos de desiertos presentes en la cuenca (Altoandino, Patagónico y de Monte) sobre la organización de las sociedades prehispánicas. Sólo una aproximación de estas características podrá aislar la variable ambiental en las diferencias intrarregionales que se observan en el registro arqueológico de cada uno de los desiertos estudiados en esta tesis. El estudio de la tecnología lítica provee la información suficiente para inferir 
las decisiones tecnológicas tomadas por los miembros de un grupo en un tiempo dado y en función de los recursos ofrecidos por el ambiente. El presente plan de investigación tiene como eje principal el estudio de la organización de la tecnología lítica en la cuenca del río Atuel durante el Holoceno tardío. Mediante su ejecución se busca evaluar las tendencias tecnológicas en los tres desiertos del sur mendocino y analizarlas en perspectiva temporal, considerando la intensidad y variabilidad de uso del recurso.

\subsection{OBJETIVOS E HIPÓTESIS}

\subsubsection{OBJETIVO GENERAL DE LA TESIS}

El objetivo general de esta tesis es definir las distintas estrategias adaptativas humanas en los tres desiertos del sur de Mendoza, a partir del estudio de la organización de la tecnología lítica de los grupos cazadores-recolectores que los ocuparon durante el Holoceno tardío.

\subsubsection{OBJETIVOS ESPECÍFICOS}

a. Definir la base regional de recursos líticos (sensu Ericson 1984):

Caracterizar las fuentes de materias primas locales de buena calidad para la talla. Esto implica ampliar los conocimientos disponibles sobre las rocas útiles para tallar en la cuenca del río Atuel y de los estudios geoquímicos de las fuentes de obsidianas, en la línea de lo ya iniciado por otros investigadores (Durán et al. 2004; De Francesco et al. 2006; Giesso et al. 2008, 2011a y b; Barberena et al. 2011; Gil et al. 2011c; Cortegoso et al. 2012; Salgán 2011, 2013; Salgán et al. 2012a).

b. Evaluar las tendencias tecnológicas en perspectiva espacial:

Caracterizar la variabilidad tecnológica y tipológica de los conjuntos líticos del área en las distintas zonas topográficas (zonas altas y zonas bajas) y ambientales (Desierto de Monte, Desierto Patagónico y Desierto Altoandino). Esto implica identificar si existe una señal tecnológica diferente en ambientes con propiedades particulares de estacionalidad.

\section{c. Evaluar las tendencias tecnológicas en perspectiva temporal:}

Examinar la intensidad de uso de los artefactos y la variabilidad tecnológica a través del tiempo, particularmente durante el Holoceno tardío, para responder preguntas generales, por ejemplo: ¿Hay tendencias en el registro lítico que puedan vincularse con 
diferentes instancias en el proceso de poblamiento? (cf. Franco 2004). ¿Se verifica la discontinuidad del Holoceno medio a nivel local? Las evidencias en el inicio del Holoceno tardío ( $c$ a. 4.000 años AP) ¿se asocian a un proceso de "recolonización” como propusieron Neme y Gil (2008)? ¿Se verifica una etapa de “Ocupación Efectiva” (Borrero 1994-1995) del territorio hacia fines del Holoceno tardío (ca. 2.000-1.500 años AP)?

\subsubsection{HIPÓTESIS DE TRABAJO}

1) Los ambientes del sur de Mendoza presentan variabilidad topográfica, ecológica, climática y estacional. Esta heterogeneidad ambiental incidió en los modos de ocupación de la región, generando una jerarquización de los diferentes sectores (Borrero 2004; Gil 2006; Neme y Gil 2008), e influyó en los rangos de movilidad y en las estrategias tecnológicas, en particular, en la tecnología lítica.

De esto se deduce que, si existieron eventos de estrés temporal (sensu Torrence 1983), los rangos de acción (Foley 1981a y b) de las poblaciones humanas tuvieron que verse condicionados, y se espera que la señal tecnológica sea distinta para ambientes ubicados a diferentes alturas, con disponibilidad estacional diferente, a lo largo de la cuenca del Atuel.

2) Luego de la discontinuidad ocupacional del Holoceno medio, se registra un momento de "recolonización" (Neme y Gil 2008) a principios del Holoceno tardio (ca. 4.000-2.000 años AP) que implicó un aumento de la movilidad de los grupos humanos del sur de Mendoza y una mayor intensidad de uso de la región con respecto a la etapa anterior.

Este aumento del uso de la región y de la movilidad tiene un correlato directo en la tasa de descarte de materiales líticos y en las estrategias tecnológicas desplegadas (Franco 2002a, b, 2004).

3) En la segunda mitad del Holoceno tardío (ca. 2.000-1.500 años AP) comienza la etapa de "Ocupación Efectiva”" (Borrero 1989-1990, 1994-1995; Franco 2002a, 2004; Borrero y Franco 1997), que implicó un aumento demográfico y una disminución de la movilidad de los grupos de cazadores-recolectores que habitaron el sur mendocino. Esto conllevó a la transición hacia una economía de agricultores de pequeña escala.

Las estrategias tecnológicas de los grupos humanos variaron a través del tiempo en función de los cambios en la movilidad, la territorialidad, la colonización de las áreas más marginales (La Payunia y tierras cordilleranas) y la disponibilidad y acceso a los 
recursos. Todas estas transformaciones se relacionan con un proceso de intensificación que tuvo correlatos concretos en las estrategias tecnológicas (Neme 2002, 2007).

\subsubsection{IMPLICANCIAS CONTRASTADORAS}

Con respecto a la Hipótesis 1 se espera:

1) a- que los conjuntos líticos de sitios arqueológicos localizados a mayor altitud (Cordillera, Valles Intermedios y Piedemonte) estén más concentrados en ciertos espacios y sean, por lo tanto, más densos en frecuencia de materiales que aquellos ubicados a una altura menor;

1) $\boldsymbol{b}$ - que la disponibilidad diferencial de las fuentes de materias primas líticas en cada uno de los desiertos analizados, tenga su correlato en el modo de uso de las rocas en estos ambientes;

1) $c$ - un predominio en el uso de fuentes de aprovisionamiento locales cercanas o de inmediata vecindad (Gould 1980; Meltzer 1989; Civalero y Franco 2003) en los espacios altos (Cordillera, Valles Intermedios y Piedemonte), y mayor variabilidad de materias primas locales y no locales, en tierras bajas (Planicie Oriental). Esto implica que: 1- las áreas de explotación, procesamiento, utilización y descarte se encuentren próximas en espacios altos, y en las tierras bajas, los lugares de abastecimiento de materias primas líticas óptimas para la talla estén más distantes; 2- los conjuntos líticos recuperados en zonas altas, presenten una gran frecuencia de rocas locales, en las que estén representadas todas las etapas de reducción, a diferencia de los conjuntos líticos de zonas más bajas donde la frecuencia de materias primas locales sea similar a la frecuencia de las materias primas no disponibles localmente (Meltzer 1989), por lo que habrá menor resolución en la identificación de las distintas etapas de reducción, aunque con mayor énfasis en los últimos estadios en el caso de materias primas no locales; 3- los núcleos de materia prima local, no estén agotados y sean poco estandarizados, y los de materia prima no local sean más estandarizados y agotados; 4- los conjuntos artefactuales de ambas zonas, posean altos porcentajes de corteza en materia prima local, y bajo o nulo porcentaje de corteza en materias primas exóticas; 5- los sitios a mayor altitud sean reocupados en el mismo locus y, por ende, los desechos estén más fragmentados en relación al pisoteo y por la meteorización mecánica postdepositacional producto del contexto ambiental; al contrario, que los desechos hallados a menor altura presenten menos fracturas;

1) $d$ - un énfasis en una estrategia conservada (que se relaciona, a su vez, con una estrategia de "equipamiento personal") en ambientes de mayor altura, en contraposición 
al empleo de una estrategia expeditiva (relacionada a un "equipamiento de sitio") en espacios bajos (Nelson 1991; Kuhn 2004). Esto implica lo mismo que se dijo para 1) c-, y además, se espera: 1- diseños confiables, mantenibles, transportables en instrumentos que sean, además, eficientes y reciclables (mayor frecuencia de lascas de reactivación y de formatización), dentro de los conjuntos líticos de los sitios de mayor altura, en comparación con los diseños esperables para los conjuntos líticos de sitios a menor altura, que responderían a una estrategia más expeditiva (Nelson 1991; Franco y Borrero 1996). En general, se espera mayor variabilidad artefactual, debido a que estarían representadas todas las etapas de reducción lítica sobre materia prima inmediatamente disponible (Meltzer 1989);

1) $\boldsymbol{e}$ - evidencias de cambios en los patrones de movilidad a lo largo del tiempo, tanto en tierras altas como bajas. Las trayectorias artefactuales a lo largo del tiempo serán diferentes de acuerdo al contexto ambiental que se esté discutiendo, dado que las estrategias de movilidad tendrán sus particularidades en cada tipo de desierto (véanse los resultados esperados para Hipótesis 2 y 3 ).

Con respecto a la Hipótesis 2, se espera:

2) a- que se incremente la tasa de descarte (mayor densidad en frecuencia de materiales líticos);

2) b- que los conjuntos líticos tengan mayor variabilidad en: 1- núcleos en materia prima local no agotados, con pocas extracciones, y núcleos sobre materia prima exótica agotados o muy explotados; 2- aumento de la frecuencia de rocas no locales; 3predominio de raederas; instrumentos enteros manufacturados de forma expeditiva sobre materia prima inmediatamente disponible; 4- presencia de percutores (en relación a la manufactura local de instrumentos; Franco 2004); 5- alto porcentaje de desechos sobre rocas disponibles localmente, de calidad inferior a la de las mejores rocas disponibles a escala regional; 6- alto porcentaje de lascas primarias, secundarias y con rastros complementarios, asociadas a los estadios iniciales de manufactura, sobre materias primas locales; 7- presencia de lascas de mayor tamaño que en momentos más tardíos, debido a una menor explotación de los núcleos, y al uso de lascas sin retocar (Franco 2004); 8- baja frecuencia de lascas de reducción bifacial, sobre materia prima exótica; 9predominio de talones lisos o corticales sobre materia prima inmediatamente disponible o local cercana, y talones preparados sobre materia prima no-local o local lejana (Franco 2004); 
2) c- que el registro arqueológico presente una alta visibilidad y buena resolución, y que los sitios se localicen en lugares más óptimos.

Con respecto a la Hipótesis 3, relacionada con la etapa de Ocupación Efectiva, se espera:

3) a- un notable incremento en la tasa de descarte de materiales líticos debido al aumento demográfico;

3) b-que aumente la variabilidad de materias primas: que se continúen utilizando aquellas disponibles localmente, y que las foráneas señalen un aumento en su utilización y mayor variabilidad en su manufactura, por el afianzamiento de las redes de interacción. Por ejemplo, se espera que aumente la variedad de fuentes de procedencia de obsidiana, como resultado de modificaciones en los sistemas de intercambio (Ericson 1984) y la ampliación de las redes de intercambio (Neme 2001; Gil y Neme 2005; Pallo y Borrero 2015). Esto implica que, aunque el énfasis esté puesto en una estrategia expeditiva, puede evidenciarse un componente conservado debido a la distancia hasta las fuentes de aprovisionamiento de obsidianas de alta calidad (Neme 2002);

3) c- que las estrategias de aprovisionamiento (Kuhn 2004) sean distintas según la procedencia de las materias primas: se espera que en el caso de las materias primas exóticas haya un aumento en la transportabilidad de formas-base, nódulos y/o núcleos con formas específicas (equipamiento personal), y que en el caso de materias primas disponibles en la inmediata vecindad se emplee la estrategia de equipamiento de sitios, debido a la disminución en la movilidad;

3) $\boldsymbol{d}$ - que haya un cambio en el tipo de estrategias tecnológicas, con énfasis en la expeditividad (Binford 1979; Parry y Kelly 1987; Nelson 1991). Esto implica: 1- en general, mayor uso de filos naturales, reacondicionamiento de filos e instrumentos informales y/o instrumentos enteros sobre materia prima local, y disminución de los productos de talla; 2- mayor aprovechamiento de la materia prima, evidenciado en la utilización de núcleos (constatado por la cantidad de extracciones) más agotados y de menor tamaño, debido a la presencia de mayor cantidad de personas (Borrero 1989-1990; Franco 2002a, b, 2004); 3- aumento en los porcentajes de lascas: sobre materias primas exóticas (de menor tamaño que las confeccionadas sobre materia prima local), de reactivación y de formatización, y más pequeñas como consecuencia del tamaño más pequeño de los núcleos (Franco 2004); 
3) $\boldsymbol{e}$ - que el registro arqueológico presente una alta visibilidad, pero una baja resolución por superposición de actividades humanas (Borrero 1989-1990); que sea mayor la diferenciación de actividades dentro de los sitios.

En síntesis, se espera que los conjuntos líticos de la cuenca del río Atuel manifiesten variaciones espaciales y temporales en los modos de aprovisionamiento y transporte de los recursos líticos, según su distancia y disponibilidad, registrándose un uso diferencial de materias primas locales y no locales (Ericson 1984). Asimismo, se esperan variaciones en las estrategias de manufactura, uso y descarte de instrumentos, y en otros elementos requeridos para su producción y mantenimiento (Nelson 1991), implementadas en los distintos desiertos que atraviesa el río Atuel en su trayecto oesteeste, y en los dos momentos del Holoceno tardío: inicial y final. Además, se espera que los rangos de movilidad disminuyan a lo largo del tiempo (observado en el comportamiento de las rocas no locales y su rango de acción mínimo), aumentando la territorialidad y las relaciones de intercambio intergrupal (Pallo y Borrero 2015), escenario compatible con la etapa de ocupación efectiva del espacio (Borrero 1989-1990). 


\section{CAPÍTULO 2}

\section{DEFINICIÓN DEL ÁREA DE ESTUDIO Y ESTRUCTURA AMBIENTAL}

\section{1. ÁREA DE ESTUDIO Y ORGANIZACIÓN ESPACIAL}

La provincia de Mendoza se localiza en el centro-oeste argentino al pie de la Cordillera de los Andes, entre los $32^{\circ}$ y $37^{\circ} 35^{\prime}$ de Latitud Sur, y los $66^{\circ} 30^{\prime}$ y $70^{\circ} 35^{\prime}$ de Longitud Oeste (IGM), con una superficie de $150.839 \mathrm{~km}^{2}$ (Dirección Provincial de Catastro). Este territorio puede dividirse en tres unidades de relieve (González Díaz y Fauqué 1993; Abraham 1996) o regiones de estructura geográfica: montañas, planicies y campo volcánico La Payunia.

El relieve es un factor ambiental relevante en Mendoza ya que condiciona fuertemente las posibilidades de uso del territorio: presenta una gran heterogeneidad y una altitud que se halla -en su mayoría-, por encima de los $1000 \mathrm{msnm}$ (incluye picos montañosos de más de 6000 metros como los del Cerro Aconcagua, el Tupungato o el Nevado del Plomo, entre otros). A esto deben sumarse las condiciones climáticas rigurosas de aridez y semiaridez que limitan la edafogénesis (Abraham 2000: 29).

La articulación en tres unidades de relieve se realiza teniendo en cuenta los grandes dominios morfoclimáticos y biogeográficos de la provincia. Cada unidad se divide en subunidades de menor jerarquía, determinadas fundamentalmente por las variaciones del relieve (Capitanelli 1972; González Díaz y Fauqué 1993; Abraham 2000). Las unidades se diferencian en las siguientes subunidades:

1) Región de las montañas en el oeste: incluye tres subunidades, la Cordillera Frontal, la Cordillera Principal y la Precordillera o Sierra de Uspallata;

2) Región de las planicies y depresiones en el centro y este de la provincia: conformada por el piedemonte, valles y depresiones -como la Gran Depresión Central o “de los Huarpes"- bad-lands (huayquerías), el macizo antiguo o "Bloque de San Rafael", y la llanura fluvio-eólica o "de la Travesía” (donde se localizan los "Bañados del Atuel”); y 
3) Región volcánica de La Payunia o ambiente de la "Patagonia mendocina": incluye mesetas, bad-lands (huayquerías), parte del Bloque de San Rafael, sierras, llanura ondulada con volcanes aislados y macizos volcánicos (estos últimos incluyen los campos volcánicos de Llancanelo-Cerro Nevado y del Payún); unidad que penetra como cuña desde el sur.

Las regiones de las montañas y La Payunia están bajo la acción del anticiclón del Pacífico y coinciden con las Provincias Fitogeográficas Andina y Patagónica. La de las planicies y depresiones centrales y orientales está bajo influencia del anticiclón del Atlántico y, desde el punto de vista fitogeográfico, corresponde a la Provincia del Monte (F. Roig 1972; Abraham 2000). Dichas estructuras geográficas están modeladas por procesos morfodinámicos y morfogenéticos de dos tipos:

-factores exógenos (climáticos): erosión hídrica, eólica, escurrimiento, geocriogénesis (acción del hielo), los cuales son relevantes en los riesgos de degradación de suelos y desertificación;

-factores endógenos (tectónica, vulcanismo): determinan riesgos naturales tan importantes como los de carácter sísmico y volcánico (Abraham 2000).

Dentro de este contexto geográfico, el área de estudio corresponde al sur de la provincia de Mendoza, extendiéndose desde el río Diamante al norte (34 Latitud Sur), hasta el límite provincial con Neuquén al sur ( $37^{\circ}$ de LS); y desde el límite argentino chileno al oeste $\left(70^{\circ}\right.$ Longitud Oeste), hasta el río Desaguadero (límite con la provincia de San Luis) al este (66 $36^{\circ}$ de LO) (Figura 2.1). Esta región del sur mendocino se caracteriza por un ambiente muy heterogéneo debido, especialmente, a la presencia de la Cordillera de los Andes, cuya influencia impacta en las diferencias altitudinales y en los sistemas de precipitación regional.

Hidrográficamente, el sur de Mendoza cuenta con cuatro sistemas fluviales principales. De norte a sur: Diamante, Atuel, Malargüe y Grande. Los dos primeros atraviesan todo el ancho provincial hasta las planicies orientales (Figura 2.1) y forman parte del sistema hidrográfico andino o del Desagüadero-Salado. El río Malargüe es una cuenca endorreica que desagua en la Laguna de Llancanelo, mientras que el río Grande tiene un curso norte-sur hasta alcanzar su desembocadura en el sistema hidrográfico del río Colorado, en el límite con Neuquén, donde se junta con el río Barrancas, y cambia su curso con dirección hacia el este. El caudal de los ríos mencionados aumenta de norte a sur coincidiendo con el distanciamiento respecto a la Diagonal Árida y con el ingreso en la Provincia Patagónica. 


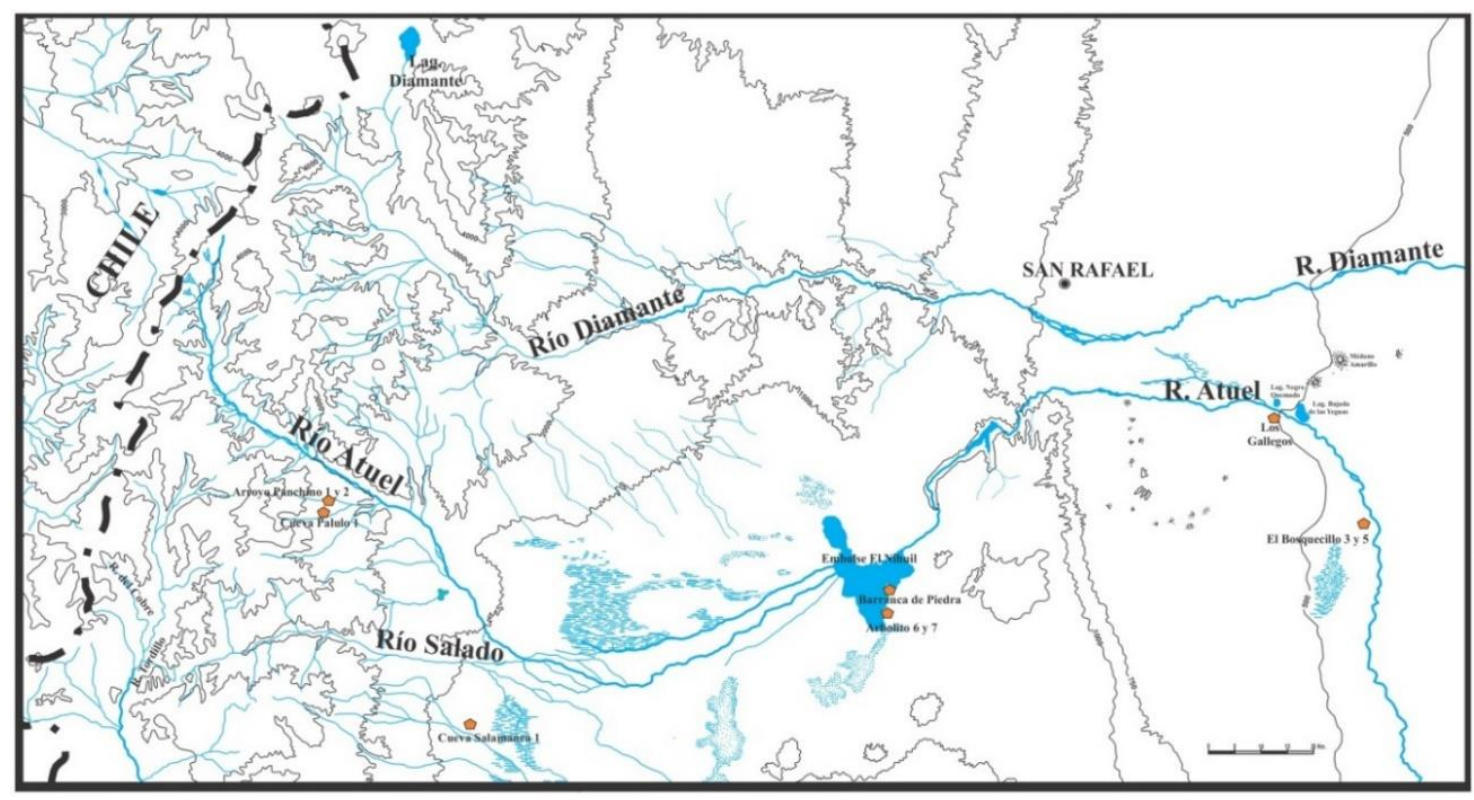

Figura 2.1. Sur de Mendoza mostrando los sistemas fluviales y los sitios arqueológicos bajo estudio. Modificado de Sugrañes (2017: 168).

En las llanuras orientales se desarrollan los grandes reservorios de agua subterránea, ya que los sistemas fluviales, al salir de la zona montañosa e ingresar a las zonas de llanuras, infiltran agua en el subsuelo, conformando la principal vía de recarga de los reservorios subterráneos (Torres y Zambrano 2000). De esta forma, es común la presencia de vertientes de caudal altamente variables, desde pequeños "lloraderos" que se infiltran a escasos metros del lugar donde afloran, hasta "ojos de agua" que dan origen a caudalosos arroyos que pueden escurrir por varios kilómetros.

\subsubsection{EL RÍO ATUEL}

El río Atuel, eje espacial del presente trabajo, recorre distintos ambientes durante su curso hacia el este. Nace en la Laguna del Atuel (Figura 2.2), en la Cordillera Andina Meridional a unos $3500 \mathrm{msnm}$. Su cuenca se divide en superior, media e inferior (Figura 2.3), variando su topografía de oeste a este (Figura 2.4). Tiene una longitud de unos 790 $\mathrm{km}$ y su cuenca una superficie de $39.904 \mathrm{~km}^{2}$. Su principal afluente es el río Salado, que se une al Atuel en su cauce medio, en las proximidades de la localidad de la Junta. Además, recibe numerosos arroyos de distinto caudal, la mayor parte en la cuenca media. Entre los afluentes principales se cuentan Las Lágrimas, El Blanco, Las Rosas, Las Chilcas, El Malo, y La Manga. 


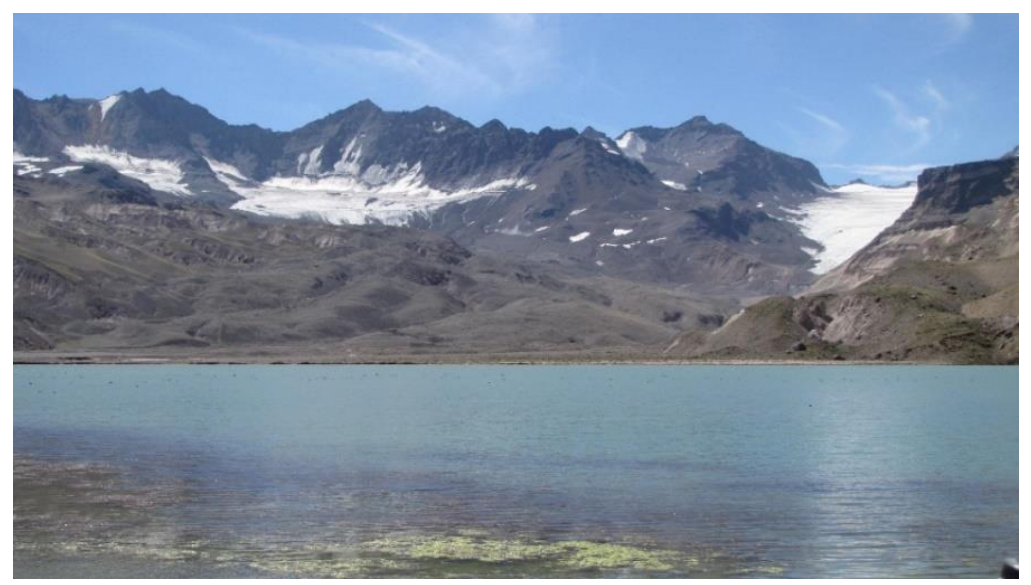

Figura 2.2. Laguna del Atuel en el verano (3500 msnm). Detrás se ven algunos de los glaciares que la alimentan.

La cuenca superior, conocida también como alto valle del río Atuel, incluye toda la cuenca cordillerana desde su nacimiento en la Laguna del Atuel (Figura 2.2) hasta el comienzo del piedemonte andino al este en las proximidades de la localidad de El

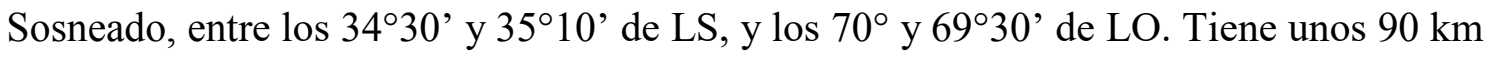
en el eje este-oeste, por $20 \mathrm{~km}$ en el eje norte-sur, encerrando un gradiente altitudinal que va desde 1500 msnm en el piedemonte, hasta más de 5000 msnm (Neme 2007: 38).

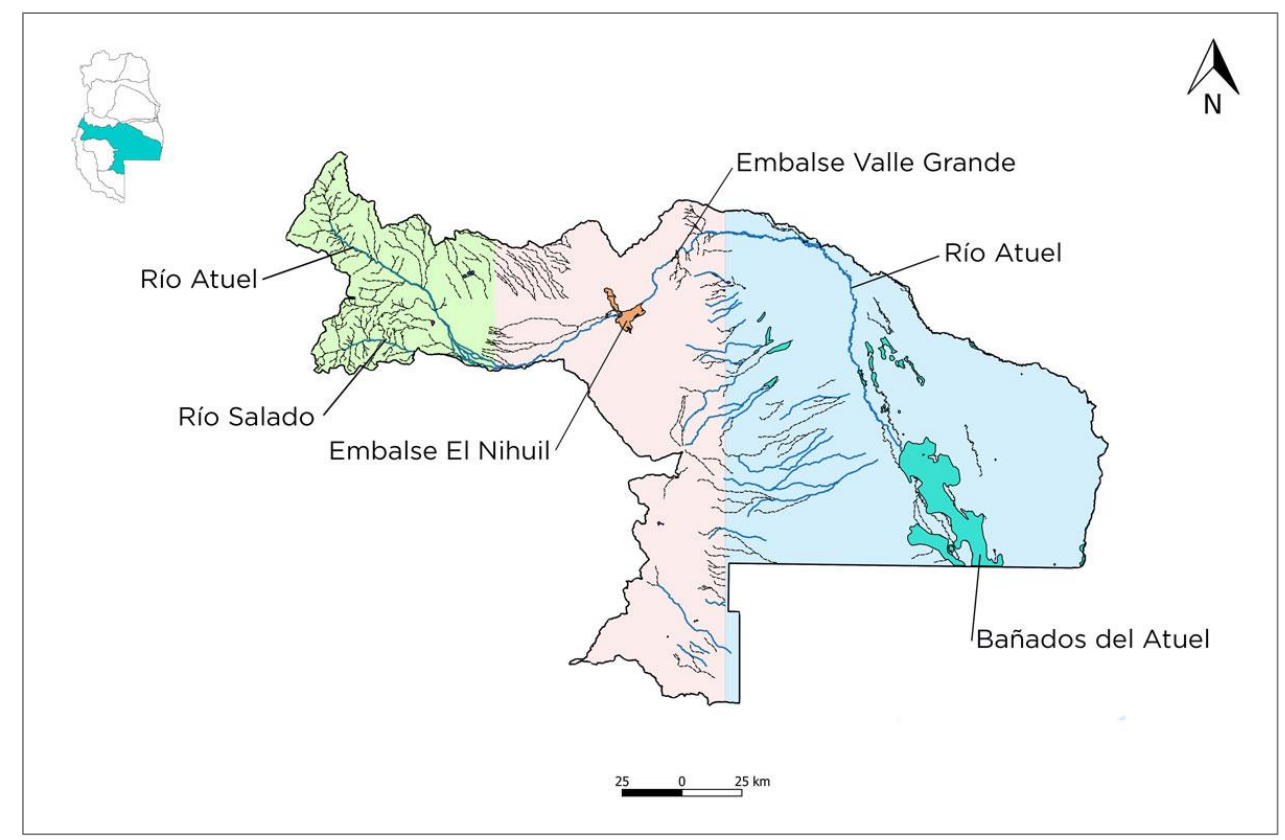

Figura 2.3. Subdivisiones de la cuenca del río Atuel: en verde cuenca alta, en rosa cuenca media y en celeste cuenca baja. Tomado del Departamento General de Irrigación (S.I.C.A.R. 2018). 
La cuenca de recolección abarca una superficie de $2545 \mathrm{~km}^{2}$ y $70 \mathrm{~km}$. El valle fluvial se encuentra encajonado entre abruptas barrancas que concentran la energía erosiva del agua y aceleran la profundización del cauce. Esta fuerza es favorecida por la fuerte pendiente.

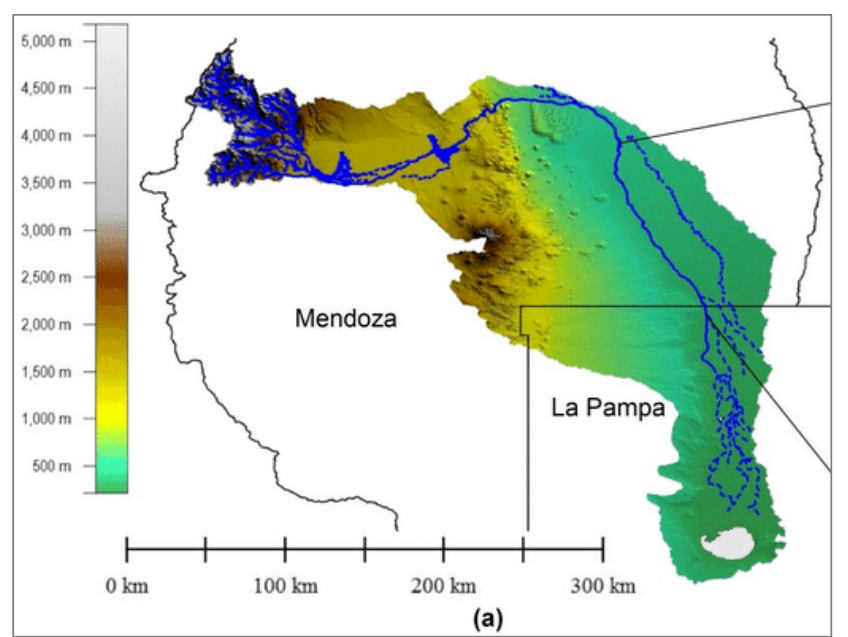

Figura 2.4. Cuenca del Atuel y relieve topográfico. Tomado de Departamento General de Irrigación (S.I.C.A.R. 2018).

La cuenca media del río Atuel (Figura 2.5) se localiza entre los $35^{\circ} 4^{\prime}$ y $35^{\circ} 16^{\prime}$ de

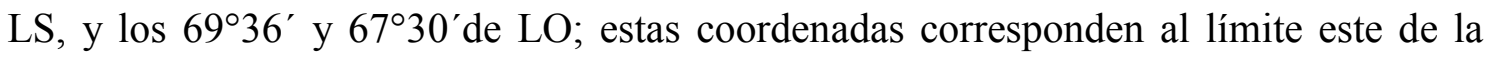
Cordillera Principal y la localidad de Carmensa, respectivamente, abarcando altitudes desde 1600 msnm hasta 500 msnm (Zárate et al. 2006; Gil y Neme 2010). El río en su cuenca media discurre a partir de El Sosneado, luego se expande en una amplia planicie de depresión (Depresión de los Huarpes) hacia La Junta, donde recibe las aguas del río Salado, su principal afluente (Figura 2.1). En esta zona gran parte de los escurrimientos superficiales se infiltran y forman bañados y esteros.

El río discurre por la mencionada Depresión de los Huarpes hasta alcanzar el Bloque de San Rafael (Sierra Pintada), donde el valle principal se encuentra encajonado debido a la erosión que ha labrado una estrecha garganta con saltos (Cañón del Atuel). Esta zona también es de gran desarrollo turístico (S.I.C.A.R. 2018). En este sector de la cuenca, a partir del embalse Valle Grande hasta Villa Atuel, la red hidrográfica tiene una densa red de cauces de régimen temporario aluvional, donde los principales elementos de recarga son las serranías del Bloque de San Rafael y los faldeos del cerro El Nevado. Aquí, la red de distribución de riego es contigua con la cuenca del río Diamante (S.I.C.A.R. 2018). 


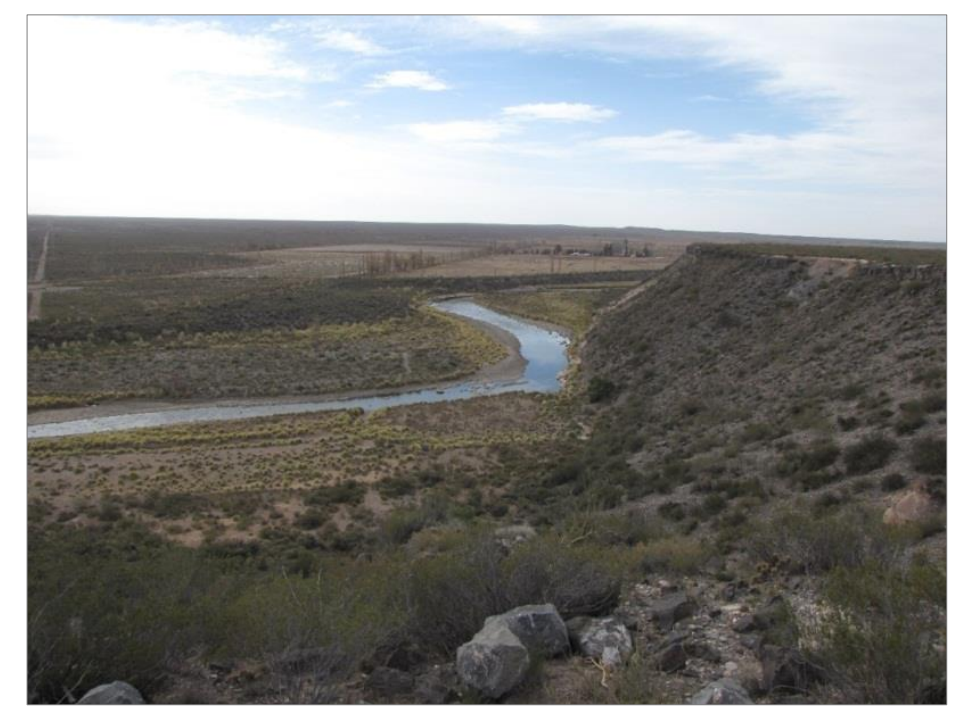

Figura 2.5. Foto del Atuel en la cuenca media.

La cuenca de agua subterránea del valle medio del Atuel y de los ríos Malargüe (cuenca de Llancanelo) y Salado se localiza en el extremo sur de la provincia de Mendoza (Figura 2.6). Superficialmente abarca unos $5200 \mathrm{~km}^{2}$ y se extiende desde las estribaciones de la cordillera de los Andes al oeste hasta los afloramientos terciarios del Bloque de San Rafael al este. Al sur, la cuenca está cerrada por las sierras de Palauco; al norte por la presencia de sedimentitas terciarias que la separan de la cuenca sur. Los principales acuíferos de esta cuenca hidrogeológica se encuentran en la cubierta sedimentaria inconsolidada formada principalmente por los productos del transporte y depositación de los ríos Atuel, Salado, Malargüe y otros arroyos. Los sedimentos aportados por los ríos originaron en sus cabeceras conos aluviales coalescentes en abanico, alineados al este de la cordillera y luego, como consecuencia del cambio de gradiente topográfico, dieron lugar a la llanura de inundación fluvial. Así, el gradiente topográfico que regula la distribución y clasificación del material, dio origen en la zona proximal a sedimentos de grano grueso en todo su desarrollo vertical, conformando acuíferos que se comportan como libres (Hernández y Martinis 2002: 12). Esta zona es el área principal de recarga de la cuenca media e inferior del río Atuel. Los bordes orientales de los conos están nítidamente marcados por el comienzo de las zonas de descarga. A partir de la culminación de los conos y disminución del gradiente, también disminuye la granulometría de los sedimentos, que se produce como consecuencia de la brusca disminución de la pendiente y pérdida de capacidad de transporte fluvial. Estos depósitos dan origen a la existencia de niveles impermeables y a la formación de acuíferos semiconfinados y confinados al este de los conos (Hernández y Martinis 2002: 12). 
La cuenca inferior (Figura 2.7) se extiende desde la localidad de Carmensa hasta el oeste de la provincia de La Pampa, donde se divide en numerosos brazos hasta desembocar en el río Desagüadero-Salado formando así una serie de humedales conocidos como los “Bañados del Atuel”, cuyo desarrollo principal tiene lugar en el oeste de la provincia de La Pampa. En esta zona es donde se desarrolla la mayor actividad agrícola de la cuenca entre las localidades de Rincón del Atuel, La Correína, Calle Larga, La Llave, Villa Atuel, Colonia López, Soitué y Jaime Prats, Real del Padre, General Alvear y, por último, San Pedro del Atuel o Carmensa. Desde esta última localidad, el río adquiere rumbo sureste (S.I.C.A.R. 2018).

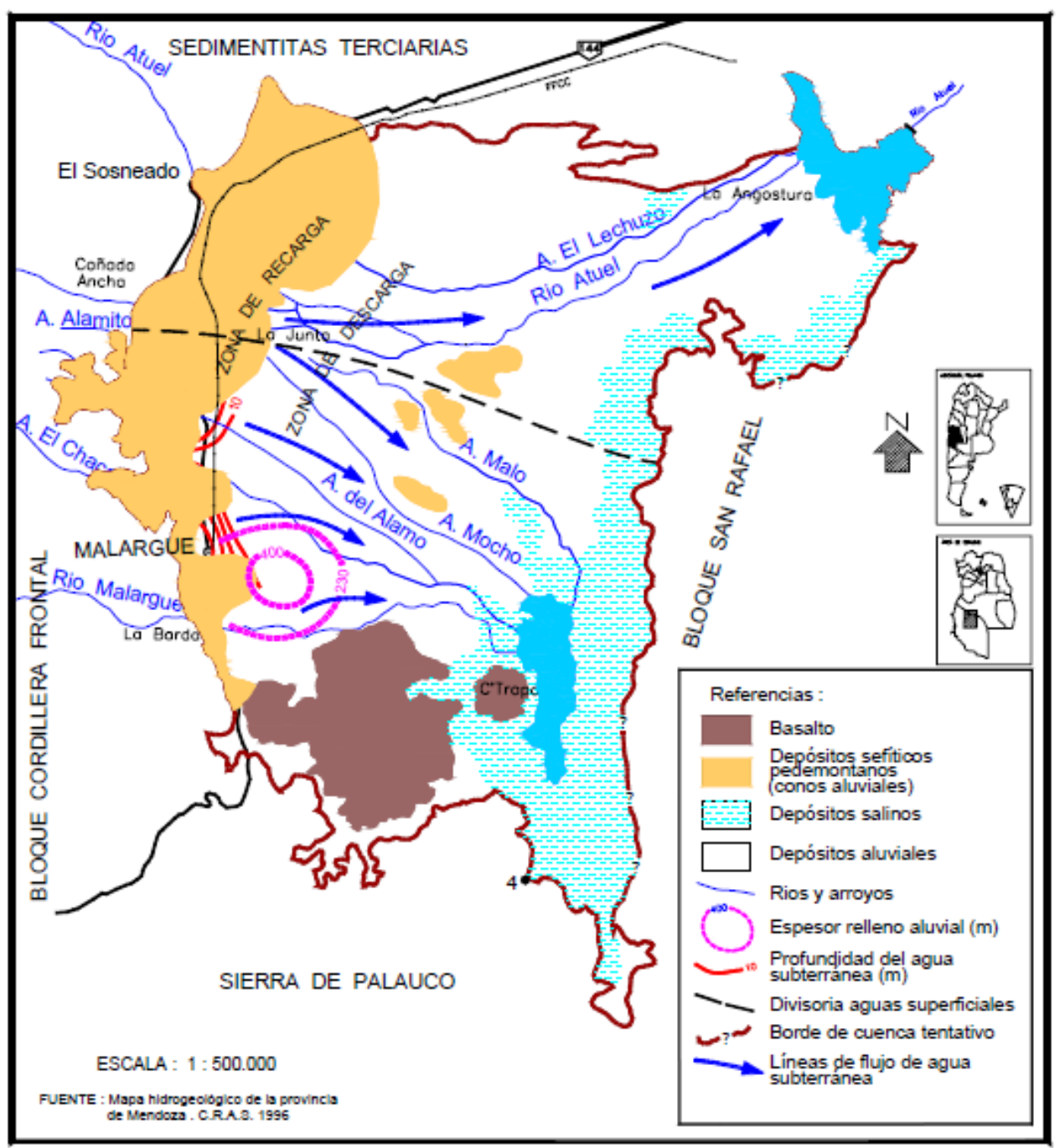

Figura 2.6. Esquema hidrogeológico de la cuenca de los ríos Atuel, Salado y Malargüe. Tomado de Hernández y Martinis (2002: 13). 


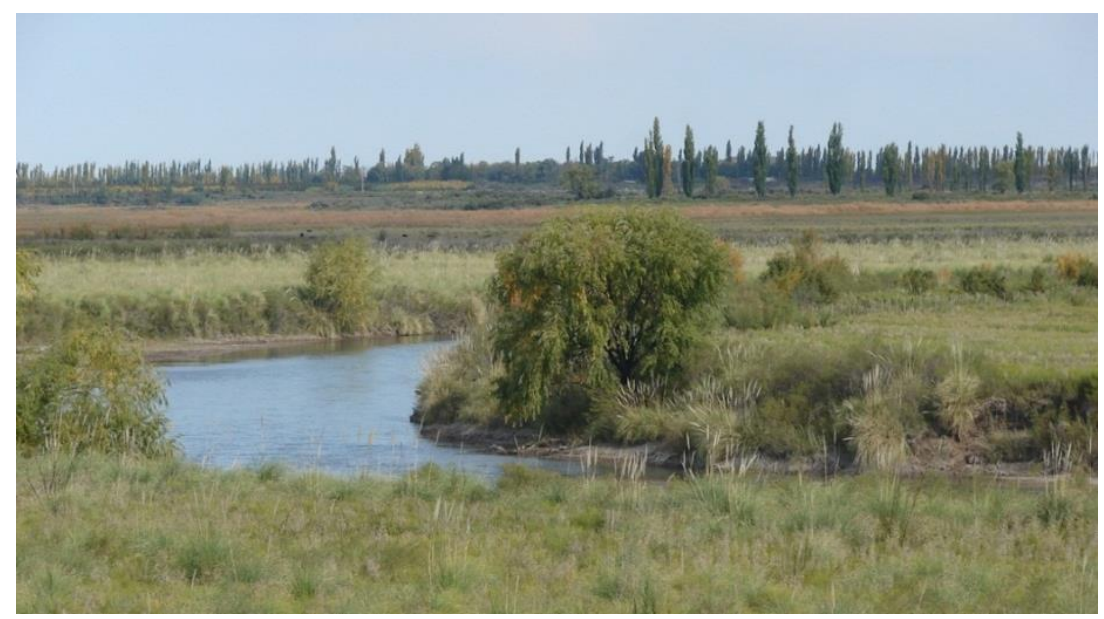

Figura 2.7. Sector de la cuenca inferior del río Atuel.

El régimen del río es principalmente estival, dado que depende del derretimiento de las nieves acumuladas durante los meses fríos. La acumulación nívea depende de las precipitaciones que tienen lugar en cordillera, acumuladas por la acción del anticiclón del Pacífico. El módulo anual del río tiene unos $35 \mathrm{~m}^{3}$ por segundo, con picos de $80 \mathrm{~m}^{3}$ en enero y mínimos de $18 \mathrm{~m}^{3} / \mathrm{seg}$. en julio (Figura 2.8).

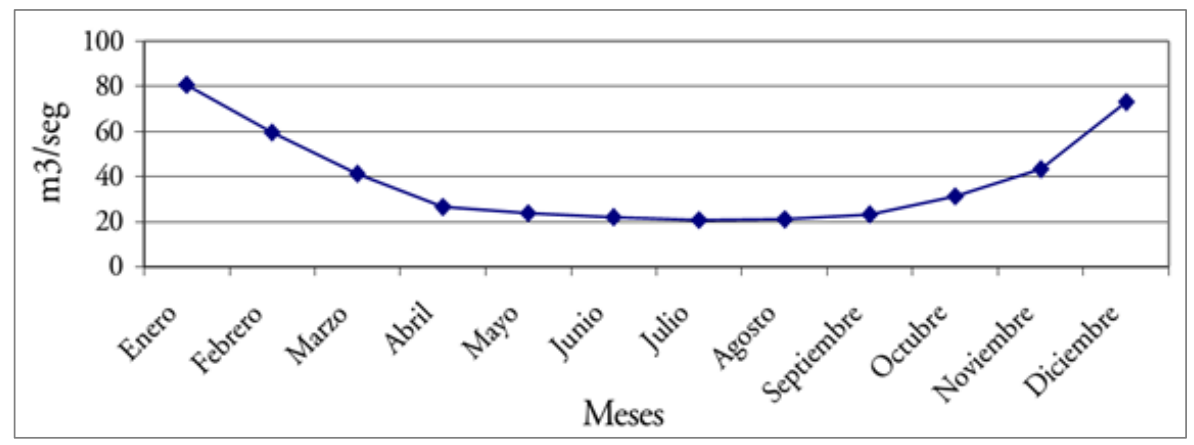

Figura 2.8. Variación mensual del módulo del río Atuel, promedio 1977-1985 (estación de aforos La Angostura). Datos extraídos de la delegación del ORSEP San Rafael; tomado de Neme (2007: 39).

\subsection{CARACTERÍSTICAS CLIMÁTICAS Y AMBIENTALES DE LA PROVINCIA DE MENDOZA}

\subsubsection{CLIMA ACTUAL}

El clima de la provincia de Mendoza resulta de la convergencia de procesos causados por la confluencia de la circulación atmosférica (masas de aire) y de factores geomorfológicos (Capitanelli 2005). Respecto a la circulación atmosférica, las masas de aire que provienen del anticiclón del Atlántico se desplazan $1000 \mathrm{~km}$ antes de llegar al 
sur de Mendoza, aportando casi la totalidad del agua que precipita en la planicie y en la falda oriental de la montaña. Los efectos del anticiclón del Pacífico sobre el clima (aunque este océano se encuentre a sólo $170 \mathrm{~km}$ de la provincia) son más complejos debido a la presencia de la cordillera (Capitanelli 1972, 2005) que provoca la descarga de agua del lado occidental, sin llegar a territorio mendocino. Así, los vientos húmedos provenientes del Atlántico, luego de su extenso recorrido desde el océano, confluyen con las masas de aire procedentes del Pacífico (que atraviesan la cordillera en forma de vientos cálidos y secos) en el centro de la región, generando un área de menores precipitaciones, también definida como una estrecha franja de máxima aridez (menos de $200 \mathrm{~mm} / \mathrm{año} \mathrm{de}$ precipitación), conocida como la Diagonal Árida Sudamericana (Bruniard 1982). Esta se extiende en dirección NO-SE desde $\operatorname{los} 27^{\circ} \mathrm{S}$ en la Cordillera de los Andes hasta aproximadamente los $44^{\circ} \mathrm{S}$ en la costa atlántica; el sur de Mendoza es incluido parcialmente allí (Abraham 2000). La Diagonal Árida constituye un límite climático o eje de agotamiento de la influencia de las zonas más húmedas colindantes determinado por la inversión de los regímenes estacionales de precipitación (Bruniard 1982). Su ubicación coincide con el límite o zona ecotonal entre el Dominio Andino al SO (Provincia Patagónica) y el Dominio Chaqueño al NE (Provincia del Monte) (Cabrera 1971; Bruniard 1982; Navarro et al. 2012). La región bajo estudio presenta un clima semiárido, de tipo seco estepario y desértico (Norte 2000).

Los rasgos geomorfológicos que definen las condiciones climáticas son las “montañas" y las "planicies" ya que, los cordones montañosos (su forma, disposición y orientación), condicionan el clima de la región. En la provincia pueden distinguirse, según Capitanelli (1972), tres regiones climáticas dominadas por diferentes centros de acción (Figura 2.9):

I) región dominada por el anticiclón del Pacífico, con precipitaciones invernales;

II) región dominada por el anticiclón del Atlántico, con precipitaciones estivales; y

III) región de superposición de la acción de los centros citados, más la depresión del noroeste.

A su vez, Capitanelli (1972) define cuatro grandes regiones morfoclimáticas:

1) la de las "grandes montañas" o región "montañosa", dominada por las masas de aire emitidas por el anticiclón del Pacífico, con precipitaciones invernales, de tipo nival;

2) la región de "Planicies", que incluye las cuencas distales de los ríos Diamante y Atuel, está dominada por las masas de aire del Atlántico, con precipitaciones de verano; 
3) la región "transicional” en el borde oriental de la cordillera y la precordillera, con clima de transición, debido a la confluencia de las masas de aire del Pacífico, Atlántico y depresión del noroeste; y

4) la región "volcánica de la Payunia", dominada, al igual que la región "montañosa", por las masas de aire del Pacífico, con precipitaciones pluviales y nivales de invierno.

Las regiones 1) y 4) coinciden con las provincias fitogeográficas Andina y Patagónica, respectivamente. La segunda región (de "Planicies") corresponde fitogeográficamente a la provincia de Monte. Como se dijo, la región "transicional" está influenciada por ambos anticiclones. La región "montañosa" posee un clima propio, de carácter glaciar o periglaciar según la altitud (Capitanelli 1972), utilizable pocos meses al año, desde noviembre a marzo, aproximadamente (Abraham 2000). Esta clasificación ha sido de gran utilidad para definir las características climático-ambientales de los tres desiertos que atraviesa el río Atuel, los cuales son presentados en este capítulo.

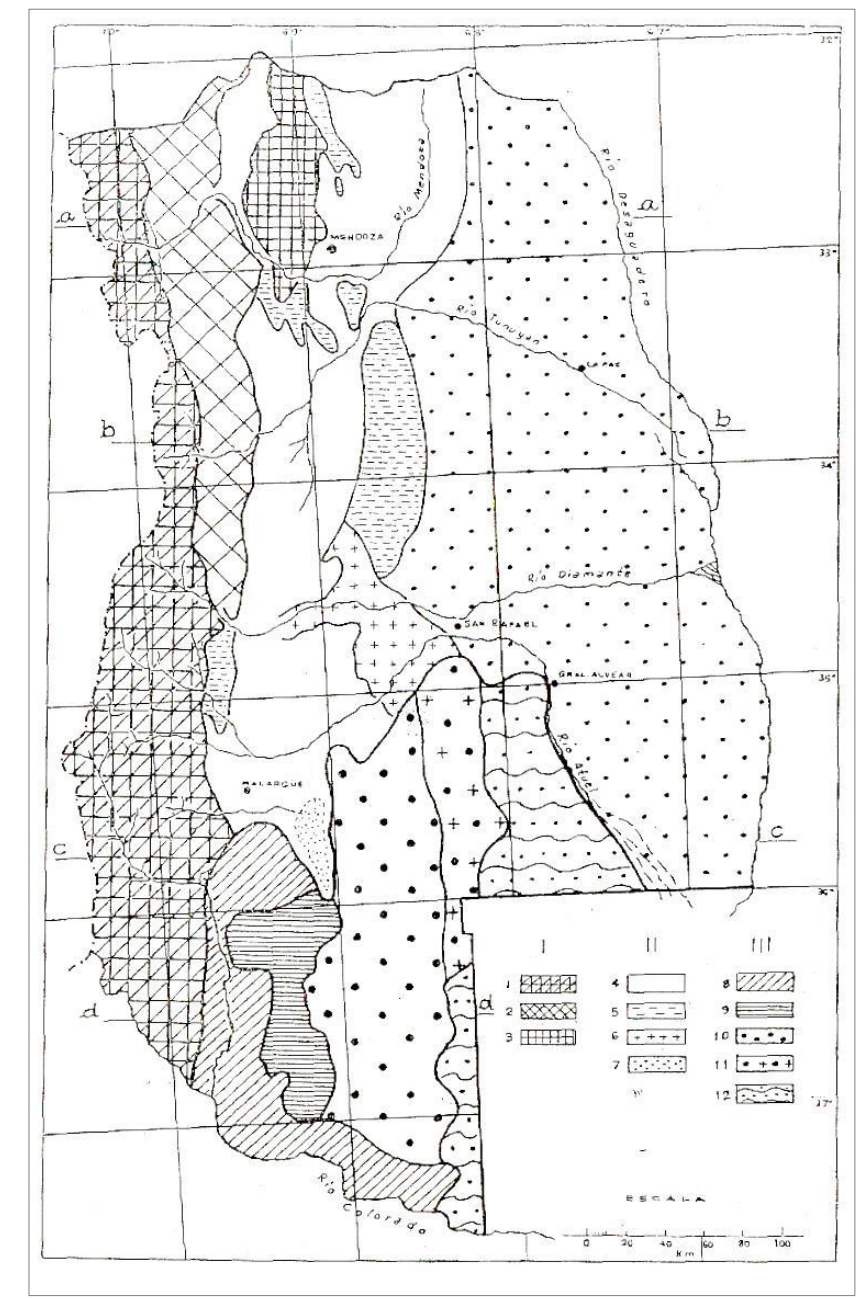

Figura 2.9. Bosquejo geomorfológico. I. REGIÓN DE LAS MONTAÑAS: 1) Cordillera Principal; 2) Cordillera Frontal; y 3) Precordillera (o cordillera de Uspallata). II. REGIÓN DE LAS 
PLANICIES: a) Piedemonte: 4) depresiones y valles; 5) bad-lands (huayquerías); 6) macizo antiguo o Bloque de San Rafael; y b), 7) llanura. III. REGIÓN VOLCÁNICA: 8) bad-lands (huayquerías);

9) meseta volcánica; 10) volcanes; 11) macizo antiguo con volcanes sobrepuestos; 12) llanura ondulada con volcanes aislados. Tomado de Capitanelli (1972: 18).

Las precipitaciones, en general, muestran un gradiente oeste-este desde la cordillera (con picos de unos $900 \mathrm{~mm}$ en los sectores más altos de cordillera) hasta el oasis de San Rafael donde alcanzan sus mínimos $(250 \mathrm{~mm})$. Luego, vuelven a incrementarse hacia el este en las proximidades del límite con San Luis (350 mm).

\subsubsection{GEOMORFOLOGÍA}

En general pueden distinguirse dos Provincias Geológicas que constituyen los "pilares" positivos de las cuencas del Diamante y del Atuel: la Cordillera y el Bloque de San Rafael. En el medio de ambos rasgos se halla la Depresión de los Huarpes (relieve negativo). Hacia el este, luego del Bloque de San Rafael, se encuentra la llanura sanrafaelina, (también considerada como relieve "negativo"), incluida dentro de la Provincia Geológica de la Planicie Cuyana.

La Cordillera de los Andes se divide en Cordillera Principal, Cordillera Frontal y Precordillera, con altitudes medias entre 5000 y 6000 msnm (Figura 2.9). La Precordillera y la Cordillera Frontal no alcanzan latitudinalmente la cuenca del río Atuel: la primera se extiende solamente hasta el centro de la provincia, y la Cordillera Frontal llega hasta la cuenca del Diamante, vinculándose estrechamente con la litología del Bloque de San Rafael (Capitanelli 1972).

\subsubsection{Geomorfología de la cuenca del río Atuel}

La Cordillera de los Andes a esta latitud está representada solamente por la Cordillera Principal. Esta es producto de un plegamiento joven, ocurrido durante el terciario sobre sedimentos marinos del Jurásico y Cretácico (Capitanelli 1972; Yrigoyen 1979). De norte a sur, hasta el río Diamante, es estrecha (20 a $25 \mathrm{~km}$ ) y de gran altitud sobre el nivel del mar (6900 a $5300 \mathrm{~m}$ ). Entre sus cumbres, la máxima altura corresponde al Aconcagua, de 6959 m. Desde el río Diamante hacia el sur es más ancha (50 a $70 \mathrm{~km}$ ) y baja (5000 a 3000 m) (Capitanelli 1972; Rodríguez y Regairaz 1972). Las alturas absolutas son imponentes, pero las relativas (desnivel local) no exceden los $2000 \mathrm{msnm}$. Los faldeos son suaves y la red de drenaje, alimentada por la fusión de los hielos y nieves, 
es densa. Los suelos son escasos, secos, con ausencia o escasez de cubierta vegetal. En todas partes dominan taludes de escombros, vertientes de reptación y corrientes de solifluxión (Capitanelli 1972: 17). La excepción la constituyen las "áreas de vegas" donde suelen formarse suelos incipientes debido a la presencia de agua y a la ausencia de pendientes abruptas, lo cual permite cierta estabilidad de los sistemas geomórficos y ecológicos (Neme 2007). A los 3700 msnm desaparece la vegetación (F. Roig 1972) aunque algunos ejemplares aislados aparecen hasta los $4400 \mathrm{msnm}$, sobre una región de congelamiento permanente del suelo (permafrost). Los suelos son entisoles pedregosos, asociados en partes con arenas de médanos y materiales aluviales (Abraham 2000).

La región que comprende la Cordillera Principal es una de las zonas de mayor actividad volcánica de los Andes Meridionales. Los volcanes activos se encuentran en la vertiente occidental de la cordillera, pero la dirección predominante de los vientos hace que sus efectos repercutan principalmente del lado oriental (Sruoga et al. 1993). Estos volcanes, del Terciario superior (Neógeno) y del Cuaternario, funcionan como condensadores de nieves y reservorios de glaciares (Abraham 2000).

Hacia el este de la cordillera, a $\operatorname{los} 35^{\circ}$ de LS aproximadamente, el paisaje cordillerano se ve interrumpido por la Depresión de los Huarpes (relieve negativo). Esta constituye una cuenca de superficie relativamente llana, rellena con depósitos pliopleistocénicos, ubicada entre la cordillera y el Bloque de San Rafael, ya en el sector medio del río Atuel.

Continuando hacia el este, se halla el Bloque de San Rafael (relieve positivo que atraviesa la planicie), el cual constituye una unidad morfoestructural pericordillerana (Figura 2.9). Tal estructura tiene un sentido noroeste-sudeste y está integrada por elevaciones acotadas, limitadas por depresiones de origen tectónico que están rellenadas por depósitos cenozoicos (Abraham 2000). Hacia el norte de este bloque se halla el relieve montañoso conocido como Sierra Pintada (Burckardt y Wherli 1900), que corresponde a elevaciones en la zona extra-cordillerana del departamento de San Rafael. Esta sierra establece, aproximadamente, el límite entre la influencia de los anticiclones del Pacífico y del Atlántico, al oeste y este, respectivamente, lo que provoca un cambio en el régimen de precipitaciones. Las alturas máximas de este sector alcanzan unos $1840 \mathrm{msnm}$ en las cercanías del río Diamante. Hacia el sur, el nivel topográfico desciende, oscilando entre los 1000 y 1500 msnm, salvo por la culminación del Cerro Nevado, que alcanza los 3800 m de altura (Rodríguez y Regairaz 1972). En este sector más austral, el río Atuel corta la Sierra Pintada de manera oblicua, formando un cañón que alcanza los 300 metros de 
desnivel relativo. Los afluentes que bajan al Atuel, a lo largo del cañón, dieron forma a un terreno quebrado que se extiende en ancho variable de algunos kilómetros a los lados del río. Aguas arriba del cañón, se encuentra el Salto del Nihuil (Abraham 2000). Actualmente, el río ha sido endicado por una central hidroeléctrica construida en la década de 1950, lo que ha dado lugar al lago El Nihuil. El Bloque de San Rafael también se ve afectado por el efecto de la actividad volcánica de retroarco de la Payunia.

En el extremo oriental de la cuenca del río Atuel, se localiza el sector de las Planicies, denominada también Llanura sanrafaelina (González Díaz 1972) o "Depresión de la Travesía" (Polanski 1954) que corresponde al último relieve negativo de la cuenca. Así, queda delimitada por los bloques montañosos del oeste y las sierras pampeanas del este (Abraham 2000; Polanski 1954). Es una geoforma extensa que se extiende desde el borde de las montañas hasta el curso del río Desaguadero (sensu Abraham 2000), con alturas de entre 1500 y $300 \mathrm{msnm}$, aunque es posible encontrar cerros aislados de mayor altura, como el volcán Diamante de 2800 msnm (Abraham 2000). En el sector sur de la provincia de Mendoza, las planicies constituyen una cuenca sedimentaria compuesta por sedimentos eólicos y aluviales, depositados por los ríos Diamante y Atuel, cubierta, asimismo, por un extensivo y complejo campo de dunas en el sector oriental (Tripaldi 2010; Zárate et al. 2005). Esta cuenca se presenta como una planicie levemente ondulada, de inclinación indeterminada. La red hidrográfica surgió en condiciones más húmedas y sobrevive en la actualidad gracias a las crecientes periódicas que limpian y mantienen los canales de drenaje (Abraham 2000).

\subsubsection{FITOGEOGRAFÍA}

Existe una gran diversidad de propuestas biogeográficas para comprender las variaciones vegetacionales de la provincia de Mendoza, dado que se basan en distintos criterios para delimitar las áreas (e.g., florísticos, fisionómicos, filogenéticos, formas biológicas, etc.). De todas formas, los diferentes autores reconocen implícitamente la variabilidad ambiental dominante en la región: fitogeográficamente la provincia se encuentra comprendida en la región Neotropical, en los Dominios Chaqueño y AndinoPatagónico (Cabrera y Willink 1973; Cabrera 1976; Morrone 2000, 2001), y se considera como parte de la zona de transición de América del Sur (Morrone 2004, 2006). Dentro del Dominio Chaqueño hay un predominio de la Provincia del Monte y, en menor escala, del Espinal. En cuanto al Dominio Andino-Patagónico, están presentes las Provincias Altoandina y Patagónica. Específicamente en el sur mendocino, están representadas todas 
estas provincias fitogeográficas, con excepción del Espinal (Cabrera 1971). Cada una de estas tres provincias (de Monte, Patagónica y Altoandina) se relaciona con alguno de los tres desiertos del sur mendocino (Véase Sección 2.3. en este capítulo).

\subsubsection{Fitogeografía de la cuenca del río Atuel}

En su Bosquejo fisionómico de la vegetación de la provincia de Mendoza, F. Roig (1972) esboza las formaciones vegetales provinciales, de las cuales aquí se mencionan las que atraviesa el río Atuel en su trayectoria de oeste a este (Figura 2.10):

-Formaciones diversas de montaña: en esta región habría una mayor proporción de elementos botánicos pertenecientes a la provincia fitogeográfica de Patagonia desde los $1500 \mathrm{msnm}$ hasta los $2300 \mathrm{msnm}$ (Böcher et al. 1972). Por otro lado, muchos elementos propios de la Provincia del Monte se encuentran distribuidos mayormente hasta los 1800 msnm (Otaola y Llano 2015). Como característica propia de la Provincia Altoandina, las comunidades arbustivas que dominan en general en la base y parte media de las montañas son paulatinamente reemplazadas por pastizales en las partes más altas, sobrepasando el límite de la vegetación (3700 msnm, altitud en la que la flora sufre una gran disminución, sensu Böcher et al. 1972; F. Roig 1972). Así, entre los 4300-4400 msnm., la vegetación sólo está representada por algunas caméfitas o hemicriptófitas en forma de ejemplares aislados o formando comunidades de muy poca cobertura, buscando protección entre las rocas (F. Roig 1972: 79).

En Mendoza, el pastizal sólo existe en la cordillera y en el piedemonte. Está representado por los coironales de diversas especies del género Stipa y Azorella sp. (única especie leñosa que habita en las alturas) y se destaca Poa holciformis que cubre la mayor parte del sector andino (Volkheimer 1978; F. Roig 1972; Roig et al. 2000). La vegetación a estas altitudes superiores también se ve limitada por otros factores como las pendientes pronunciadas, los suelos esqueléticos (litosoles), la acción de la soligelifluxión, la menor cantidad de horas de temperatura efectiva, el mal desarrollo del horizonte humínico, etc. (Volkheimer 1978; Roig et al. 2000). Las vegas interrumpen la aridez cordillerana conformando verdaderos "oasis" en el desierto. Están constituidas por comunidades densas de elevada cobertura donde dominan las juncáceas (la más importante es Andesia bisexualis) y ciperáceas, a las que se suman plantas de diversas familias (e.g., Senecio chamaecephalus, Werneria pygmaea, Gentiana prostrata, etc.) (F. Roig 1972: 78). En las lagunas o pantanos de montaña predominan distintas algas (e.g., Potamogeton pectinatus y Miriophyllum clatinoides). 


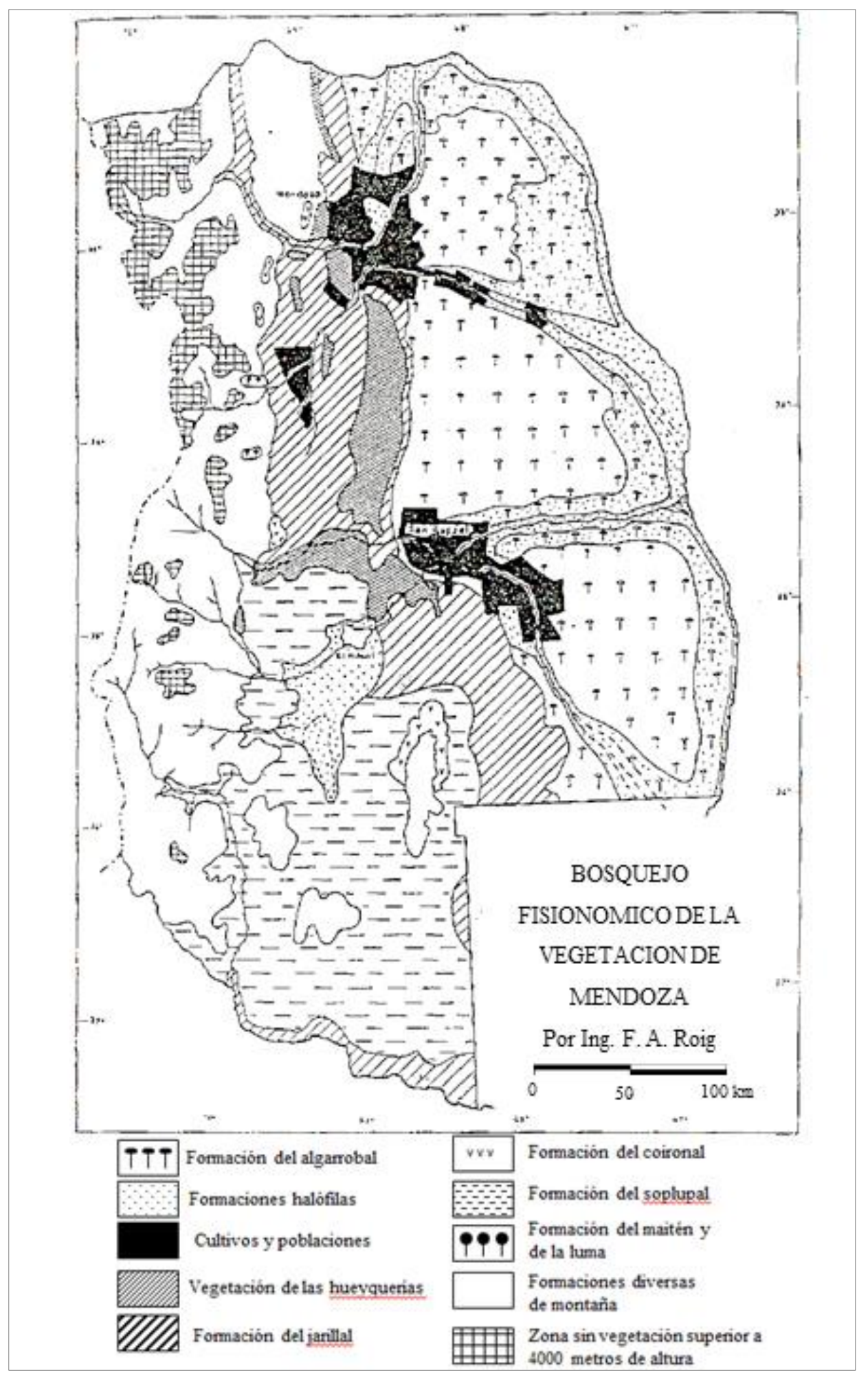

Figura 2.10. Bosquejo fisionómico de la vegetación de la provincia de Mendoza. Tomado de F. Roig (1972: 50).

-Formación del solupal: está constituida por las estepas arbustivas localizadas al sur del río Diamante. Es una estepa arbustiva de Larrea que varía bastante, espacialmente de oeste a este. Esta variación está relacionada con cambios en los suelos, sucediéndose 
comunidades de Larrea nítida, Prosopis flexuosa, Ephedra ochreata, al oeste; una estepa herbácea constituida por Panicum urvilleanum, Grindelia chiloensis, Sporobolus rigens, al este; y comunidades de halófilas dominadas por Atriplex en las proximidades de las salinas (F. Roig 1972: 63).

-Formaciones halófilas: según F. Roig (1972: 60) en la provincia de Mendoza ocupan todo el cuaternario de origen lacustre. En estos suelos, las comunidades se modifican según dos factores: la concentración de sales (en la provincia de Mendoza no hay suelos alcalinos) y la mayor o menor cantidad de agua disponible. En los lugares más salinos, en general, se acumula agua con mayor frecuencia, correspondiéndose con las partes más bajas de las cuencas. Las zonas de acumulación salina pueden clasificarse en tres tipos de suelos salinos: los de las cuencas endorreicas; los de la parte inferior de los aluviones y del margen de las planicies pedemontanas; y suelos salinos marginales a los ríos (F. Roig 1972: 61). La cuenca endorreica más notable es la de Llancanelo, cuya periferia está ocupada por vegetación halófila en la que domina Frankenia juniperoides; también está presente Limonium brasiliense. Esta formación se superpone con la Formación del algarrobal conformando una zona de ecotono, la cual corresponde a suelos de origen palustre o fluvial en donde el algarrobal se presenta con un estrato arbustivo rico en plantas halófilas (F. Roig 1972: 62).

-Formación del jarillal: constituida por estepas donde predominan Larrea divaricata (sobre todo donde los suelos son pedregosos y profundos), Prosopis flexuosa -en forma arbustiva- y Gochnatia glutinosa. Estos "jarillales" se encuentran preferentemente en suelos de aluvión en el mismo piedemonte o en suelos de origen lacustre; llegan hasta los 1300-1400 msnm, donde son sustituidos por comunidades de montaña.

En la margen izquierda del río, al norte de la Formación del jarillal, como así también en la Sierra Pintada, en la localidad de Los Chañares (San Rafael), se halla la "vegetación de las Huayquerías". Tales huayquerías o "mal país", se caracterizan por una extrema aridez, con vegetación arbustiva achaparrada y de escasa cobertura: abunda Cercidium praecox y es notable la comunidad de Chuquiraga erinacea en la que suele encontrarse Ditaxis malpighipilia (F. Roig 1972: 57). Esta vegetación, extremadamente xérica, se circunscribe a las grietas de los litosoles o a los márgenes de los cauces temporarios (Roig et al. 2000). Las huayquerías cubren grandes extensiones y en general separan los bolsones de las travesías. Son ambientes originados por el tectonismo que dejó al descubierto materiales terciarios formados por rocas en general deleznables, fuertemente erosionables, que dan como producto un paisaje intrincado (Roig et al. 2000). 
-Formación del algarrobal: se extiende desde aproximadamente $580 \mathrm{msnm}$ hasta el río Desaguadero. Se compone mayormente de un estrato arbóreo representado por Prosopis flexuosa (árboles generalmente aislados, distantes 10-20 m unos de otros), y de un estrato arbustivo de Atriplex lampa y Larrea divaricata; esta última puede alcanzar hasta $3 \mathrm{~m}$ de altura en busca de luz cuando las copas de los Prosopis tienden a juntarse. También se identifica un estrato herbáceo de pastos con elevada cobertura, representado por Pappophorum caespitosum, Aristida mendocina, A. adscencionis, Setaria, Digitaria, entre otros. En este sector oriental se forman médanos y guadales por la acción del viento y el agua que seleccionan los materiales del suelo. Además, según el contenido de arcilla de los suelos -que impide la percolación de agua- es cómo se dará el “dinamismo de las comunidades" (F. Roig 1972: 52): a mayor contenido de arcilla, mayor desarrollo del guadal o peladero, por lo que van desapareciendo algunas especies (e.g., ciertas especies del "chañaral" y el bosque de Prosopis flexuosa, aunque esta última es una especie de bastante amplitud ecológica).

En general, la característica de estos bosques es que disponen de agua en profundidad. Esta puede hallarse en capas freáticas o en suelos capaces de retener el agua de las lluvias durante una parte considerable del año, como sucede en los suelos loésicos (F. Roig: 52) (Figura 2.10).

\subsubsection{ZOOGEOGRAFÍA}

La Provincia de Mendoza se encuentra zoogeográficamente dentro de la subregión Andino-Patagónica, incluida en la Región Neotropical (Ringuelet 1961). Dos grandes elementos geográficos permiten reconocer una neta diferenciación faunística: el macizo andino y las llanuras centrales y del este. Cada uno de estos elementos geográficos, a su vez, contienen áreas ecológicamente definibles coincidentes con la vegetación, las condiciones edáficas y las climáticas (V. Roig 1972: 81). La provincia se divide de oeste a este en los distritos andino, subandino y patagónico (Figura 2.11). La diferenciación entre estos refleja las características fisiográficas de las provincias mencionadas con anterioridad (Sección 2.2.2.). Estas características influyen en la composición de la fauna de la provincia que, según el Esbozo general del poblamiento animal realizado por V. Roig (1972), está comprendida por:

1) "Fauna de las montañas", al oeste: también llamada "Provincia Andina" por los biogeógrafos, perteneciente al dominio andino y patagónico (sensu Ringuelet 1961), se registra a partir de los $2300 \mathrm{msnm}$ y llega hasta los $4500 \mathrm{msnm}$, aproximadamente, altitud 
en la que desaparece completamente la vegetación por influencia de la temperatura y la presión atmosférica. Allí se pueden encontrar dos géneros de aves paseriformes: Geossitta y Cynclodes. Distintas aves pasan la mayor parte del verano en los cuerpos lacustres, arroyos y ríos de la cordillera (Chloephaga melanoptera, Lophoneta specularioides, Merganeta armata); por su abundancia y gran tamaño corporal, pudieron haber tenido una gran importancia en la subsistencia de los grupos humanos que habitaban en las inmediaciones de los humedales (Giardina 2010). Otras aves pertenecen exclusivamente a lugares de altura, e.g., Attagis gayi presente desde los $2500 \mathrm{msnm}$. Por encima de los 3000 se hallan, entre otros micromamíferos, roedores de las especies Akodon andinus y Phyllotis darwini, y lagartos como Liolaemus fitzgeraldi. Los únicos mamíferos grandes de Mendoza, son el guanaco (Lama guanicoe), el puma (Felis concolor) y el zorro colorado (Pseudalopex culpaeus). Estos tres se encuentran principalmente en los altos Andes, aunque a los dos primeros se los encontraba usualmente en la precordillera y en la llanura, donde aún suelen encontrarse pero en menor cantidad (V. Roig 1972: 83).

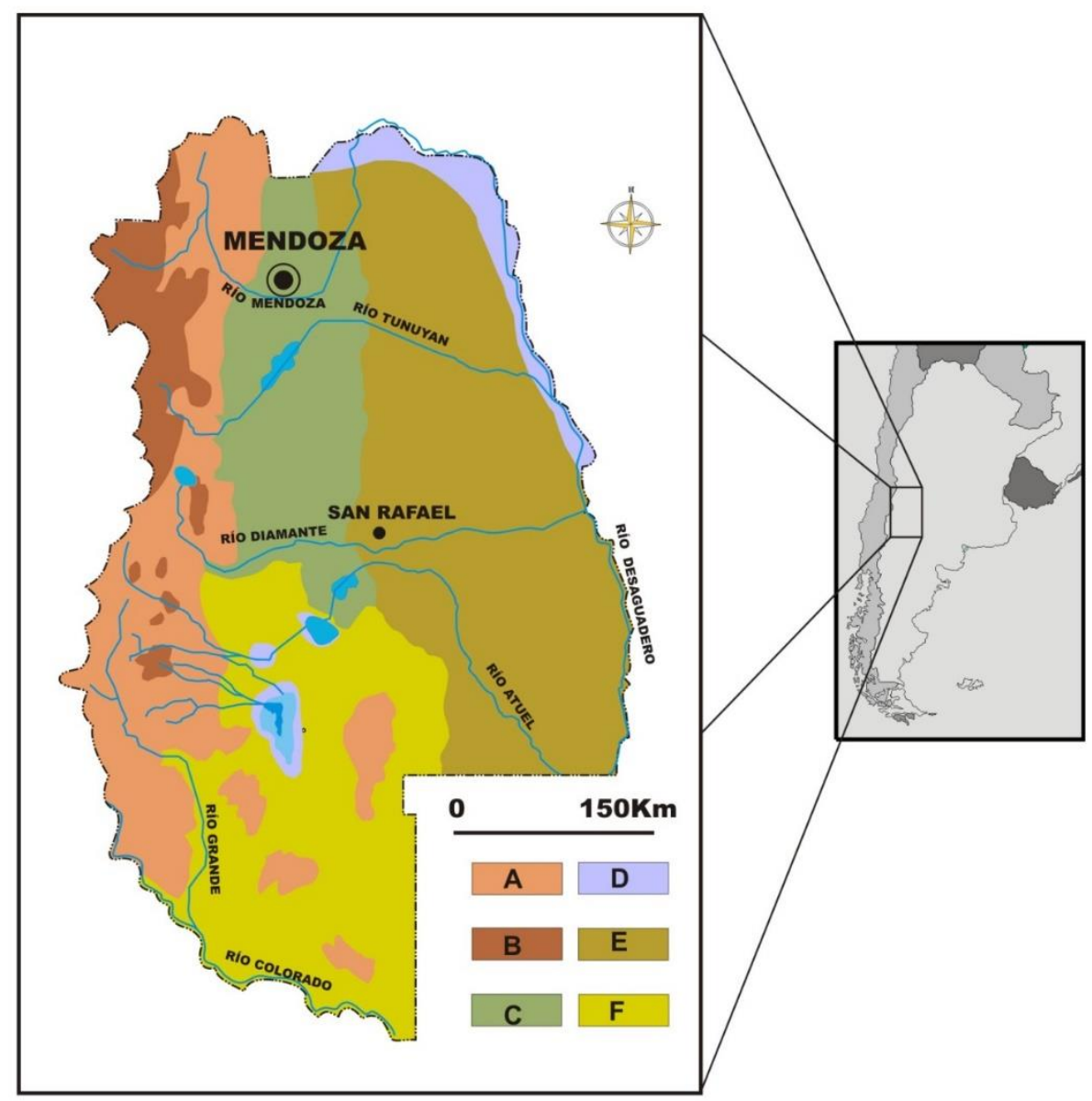

Figura 2.11. Bosquejo zoogeográfico de fauna de la provincia de Mendoza. Tomado de V. Roig (1972: 82), modificado por Giardina (2010: 89). 
2) "Fauna de las llanuras", al este (hacia el sur se ensamblan los elementos de la Patagonia y algunos otros elementos provenientes de la zona pampeana): se caracteriza, fundamentalmente, por la fauna de edentados y félidos. Entre los primeros, V. Roig (1972) menciona a Chaetophractus villosus, Chaetophractus vallerosus, Zaedius pichiy, el pichiciego (Chlamyphorus truncatus) y el mataco (Tolypeutes matacus). Por su parte, los félidos incluyen: Felis geoffroyi, F. pajeros, F. yaguarondi y F. concolor. Se hallan distribuidos en todo el territorio ocupado por el monte, siendo particularmente abundantes en el área central de la provincia mendocina (V. Roig 1972: 85). Los roedores también están muy bien representados: los de mayor porte son la mara (Dolichotis patagonum) y la vizcacha (Lagostomus maximus); y los de menor tamaño incluyen Graomys griseoflavus, Akodon varius, Microcavia australis y Galea musteloides.

Entre las aves de la llanura se registran Pterocnemia pennata, perdices como Nothura maculosa, Nothura Darwini y Eudromia elegans. También algunos falconiformes como jotes (Chatartes aura), águilas (Buteo albicaudatus) y el gavilán (Accipiter bicolor). Otras aves de menor porte son: la paloma turca y la paloma Zenaida auriculata, el loro barranquero (Cyanoliseus patagonus), el hornero (Furnarius), el cacholote pardo (Pseudoseisura gutturalis) y algunos pájaros carpinteros como el Colapteste campestoides, Lepidocolaptes angustirostris y Tricopicus cactorum. Existe una gran variedad de aves paseriformes; las más características son Rhinocrypta lanceolata y Teledromas fuscus. También se hallan marsupiales como achocaya o ratón del palo (Marmosa pusilla), y la comadreja overa (Didelphis azarae). Respecto a los anuros, se registra la presencia de Bufo arenarum y Leptodactylus ocellatus. Los ofidios presentes son Constrictor y los géneros Tomodon, Chlorosoma, Elapomorphus, Dryophylax y Pseudoboa. Alguno de los saurios presentes documentados por V. Roig (1972) son la iguana Tupinambus rufescens y otros saurios como Teius teyou y varias especies del género Liolaemus.

3) "Fauna de la estepa patagónica", al sur: la "cuña" que forma su presencia en Mendoza puede ser más evidente en su composición faunística que botánica debido a que los animales poseen mayor capacidad invasora que las plantas. "La dispersión de las especies es tan generalizada que no es factible pretender delimitar sobre un mapa la distribución de algunos animales, tal es el caso del piche, el hurón y algunos pequeños roedores" (V. Roig 1972: 87). Igualmente, V. Roig (1972) menciona la presencia de huemul (Hippocamelus bisculus) documentado más de 70 años atrás, sugiriendo que esta influencia de la fauna patagónica puede haber sido más fuerte en épocas pasadas. Otros 
taxa presentes en la provincia, característicos de la estepa patagónica son: el hurón Galictis cuja y el ratón Aconaemys fuscus. Las aves están representadas por la presencia de Zonotrichia capensis australis, Phrygilus unicolor y Asthenes modesta australis, y Geossita cunicularia. Los saurios que indican la presencia de la Patagonia en Mendoza son: Leisosaurus bellii, Liolaemus elongatus, L. kriegii; los anuros, por su parte, están representados por Pleuroderma bufonia en las cercanías de Malargüe.

\subsection{AMBIENTE ÁRIDO-SEMIÁRIDO: LOS DESIERTOS DEL SUR DE MENDOZA}

Los desiertos suelen ser definidos, principalmente, por el déficit hídrico, ya sea por el régimen y cantidad de precipitaciones o su pérdida por evapotranspiración (Yellen 1977; Pianka 1982). Las categorías "desierto", “árido" o "semi-árido", implican un amplio rango de variabilidad ecológica (Pianka 1982; Smith et al. 2005) (Figura 2.12 y 2.13). Como dice Yellen (1977: 266), cuanto más de cerca se examina el concepto de un “desierto", más difuso se vuelve. La variabilidad intrínseca a un desierto puede abarcar precipitaciones de menos de $60 \mathrm{~mm}$ de promedio anual en regiones extremadamente áridas hasta $500 \mathrm{~mm}$ en áreas llamadas "semiáridas". La variación en el régimen estacional de las precipitaciones puede tener un profundo impacto sobre los ecosistemas. Además, estas pueden ser aleatorias durante todo el año o producirse en momentos específicos, marcando aún más la estacionalidad. La variación de la precipitación tiene un gran componente aleatorio (impredecible) que se manifiesta no sólo durante el ciclo anual, sino también de año en año y de lugar en lugar. Asimismo, la lluvia puede ser irregular e impredecible desde el punto de vista espacial y temporal (Yellen 1977). Sin embargo, los desiertos exhiben una serie de características comunes, ya que todos “...tend to be relatively poor environments, both in terms of biomass and in species diversity. They are also 'water controlled'. The flow of energy from the sun through desert ecosystems is so mediated by water availability that traditional energy-flow models in ecology can be replaced by a water-flow model when discussing deserts. Since water moves in a single direction through desert ecosystems and is not locally recycled, the links in such a water model may be few and straightforward" (Yellen 1977: 266). Así, todos los desiertos pueden considerarse ecosistemas controlados por el agua con insumos infrecuentes discretos y en gran parte impredecibles (Noy-Meir1973: 26, citado en Yellen 1977). 
Poseen rasgos característicos tales como una baja productividad primaria, una alta variabilidad en la estructura de los recursos y una baja predictibilidad de dichas variaciones; condiciones a las que los seres vivos deben adaptarse para sobrevivir. Los desiertos, entre sí, muestran una diferenciación reflejada en la estructura de sus recursos y sus patrones de variación (Whitford 2002). Los ambientes desérticos constituyen un contexto en el que se asumen situaciones en las que se deberían desarrollar ciertas estrategias que hagan factible su ocupación por parte de los humanos y su continuidad en el tiempo (Yellen 1977).

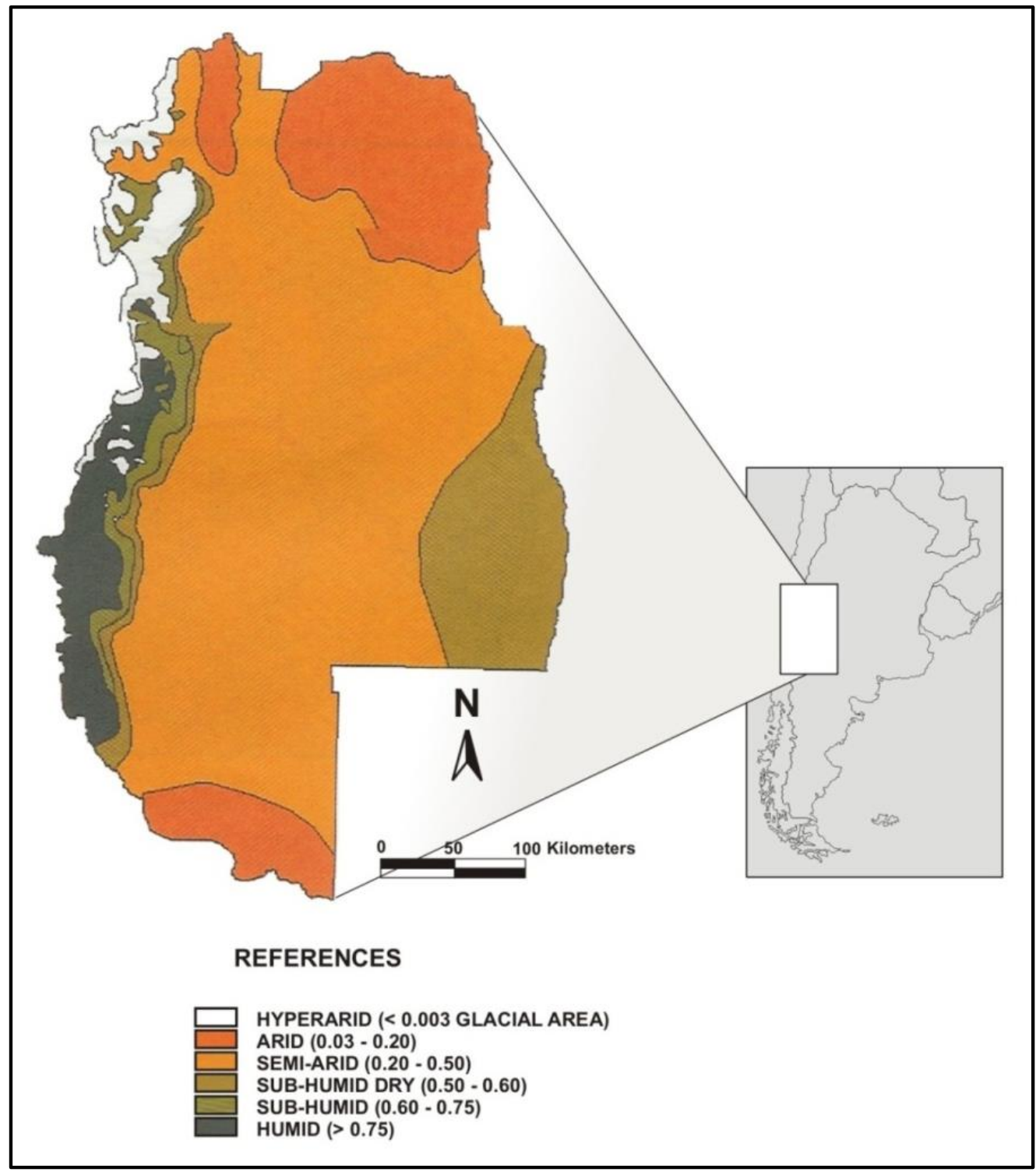

Figura 2.12. Mapa de aridez de la provincia de Mendoza. Tomado de Abraham (2000). 


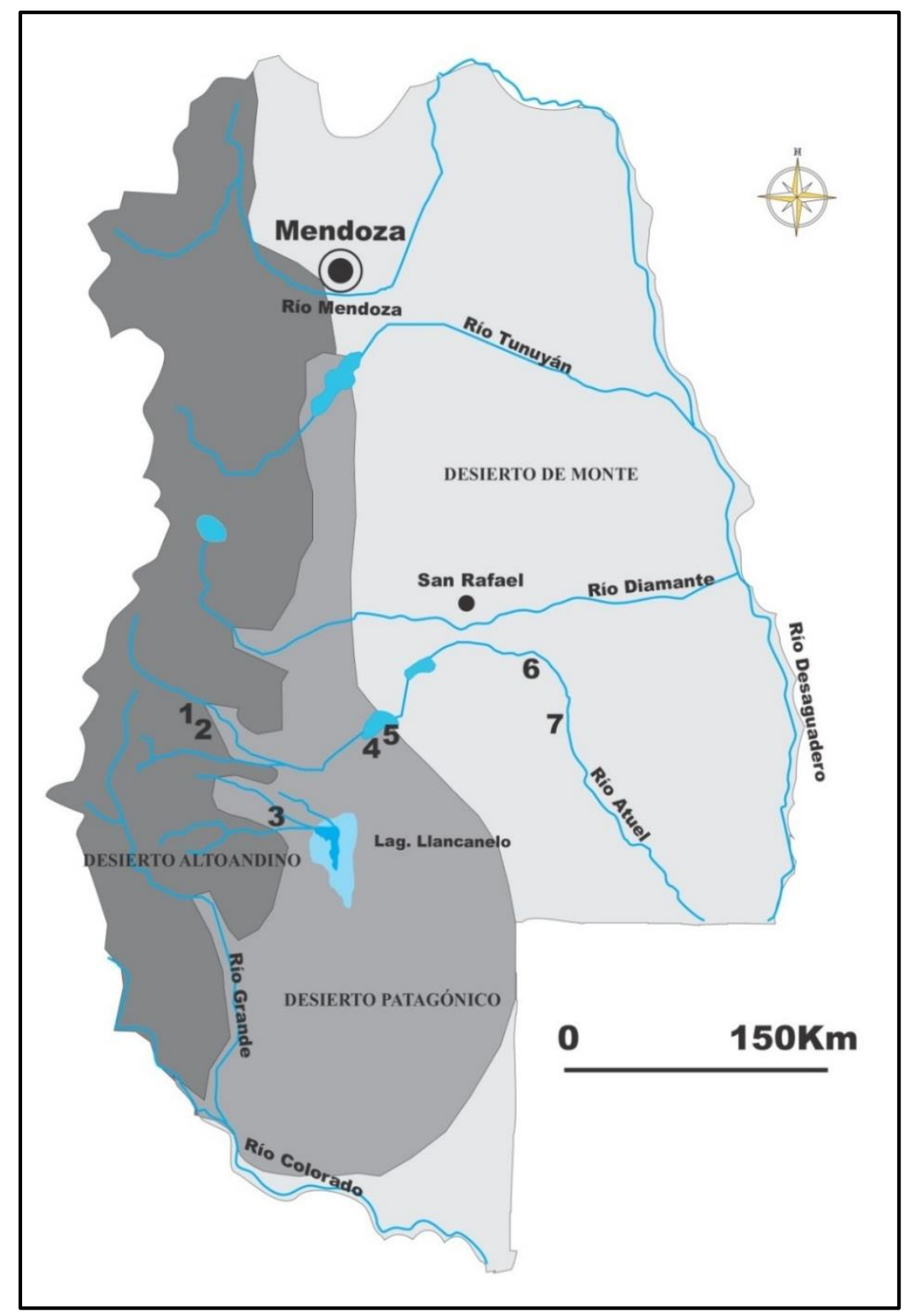

Figura 2.13. Desiertos del sur de Mendoza y localización de los sitios arqueológicos: 1) Arroyo

Panchino 1 y Arroyo Panchino 2; 2) Cueva Palulo 1; 3) Cueva Salamanca 1; 4) Arbolito 6 (cuadrículas A1 y A2) y Arbolito 7; 5) Barranca de Piedra 1; 6) Los Gallegos 1 (cuadrículas A1 y B1); 7) El Bosquecillo 3 y El Bosquecillo 5.

Como se mencionó anteriormente, tanto la presencia de la Cordillera de los Andes como de la Diagonal Árida Sudamericana generan, por un lado, un gradiente principal de precipitaciones oeste-este (Figura 2.12) y, por otro, un cambio en el régimen estacional de las precipitaciones (invernales en el oeste vs. estivales en el este) (Volkheimer 1978; Capitanelli 1972; Garreaud 2009). Ambas propiedades se conjugan para diferenciar tres tipos de desiertos, en eje longitudinal (oeste-este), definidos sobre la productividad primaria y la biogeografía vegetal: Altoandino, Patagónico y de Monte (Figura 2.13). 
Los tres implican abundancia y distribución diferencial de recursos (e.g., la distribución de guanaco según lo modelado por Politis et al. 2011) y patrones de variabilidad intra e interanual no necesariamente sincrónicos entre las mencionadas áreas (Neme y Gil 2012).

\subsubsection{DESIERTO ALTOANDINO}

En el Desierto Altoandino las precipitaciones tienen lugar durante la estación invernal, principalmente en forma de nieve, y alcanzan los $800 \mathrm{~mm}$ anuales en el cordón del límite argentino-chileno y los $400 \mathrm{~mm}$ a alturas de $2200 \mathrm{~m}$ (Capitanelli 1972; Abraham 2000). Este desierto está vinculado hidrográficamente a la cuenca superior del río Atuel. Se localiza en su totalidad dentro de la llamada Cordillera Principal (Figura 2.14), con picos que superan los $5000 \mathrm{msnm}$ dentro de la región. La fuerte topografía y la elevada porosidad del suelo hacen que el agua escurra rápidamente, por lo que sólo un porcentaje muy menor puede ser aprovechado por la vegetación. Sólo en aquellos lugares con trampas naturales de sedimento o con topografía menos pronunciada, las condiciones permiten la formación de suelos, vegas y lagunas donde se desarrolla la vida (Volkheimer 1978). La fuerte presencia de glaciares y niveles de precipitación superiores a los del resto de la región (promedio de $500 \mathrm{~mm}$ ) aseguran un suministro de agua constante y muy ubicuo, con una red de drenaje bien desarrollada y vertientes en la mayor parte de los valles andinos. Todo esto hace de los ambientes de montaña lugares espacialmente heterogéneos, con una distribución de recursos desigual y circunscripta. La corta extensión de la estación de crecimiento y la presencia de suelos libres de nieve sólo entre los meses de noviembre y marzo disminuyen aún más la productividad primaria y la diversidad biológica, la cual se restringe a especies migratorias o con capacidad de hibernación.

El Desierto Altoandino coincide, fitogeográficamente, con la denominada "vegetación de las montañas" o "Formaciones diversas de montaña" (pastizales, juncáceas, ciperáceas, etc.) (Sección 2.2.3.1.), aunque en general, las variaciones altitudinales y topográficas que presenta el valle superior del río Atuel lo hacen un territorio de confluencia de elementos propios de las provincias fitogeográficas Andina, del Monte, de la estepa Patagónica y de La Payunia. Por encima de los $2200 \mathrm{msnm}$, la leña comienza a escasear, limitándose a unas pocas especies con desarrollo aéreo, y otras con desarrollo subterráneo (Böcher et al. 1972). La fauna del desierto Altoandino corresponde a lo que se describió antes como "Fauna de las montañas" (Véase Sección 
2.2.4.), sensu V. Roig (1972). El predominio de vegas y pastizales de altura hace que sea un buen ambiente para el desarrollo de camélidos, los cuales abundan durante la mayor parte del año, al igual que sus depredadores naturales. El resto de los recursos animales disponibles está constituido por roedores y diversos tipos de aves migratorias.

Una de las mayores ventajas del Desierto Altoandino en términos de vida humana es la abundancia de materias primas de excelente calidad para la talla. Distintos tipos de rocas silíceas y obsidianas han sido localizadas en este ambiente. Aquí se localizan las fuentes de obsidiana más importantes de la región: Las Cargas, Laguna del Maule 1 y Laguna del Diamante (Véase Capítulo 6). Además, los distintos cauces de arroyos y de los ríos Atuel y Salado son lugares en los que se pueden encontrar otros tipos de rocas de muy buena calidad tales como riolitas y andesitas. Otra ventaja para el asentamiento humano es la presencia de reparos rocosos. La fuerte topografía y el rápido ascenso en altura generan una zonación biótica que permite el acceso a diversos recursos, especialmente vegetales, en distancias cortas. Sin embargo, la productividad de los mismos es baja, al igual que su densidad dentro del paisaje.

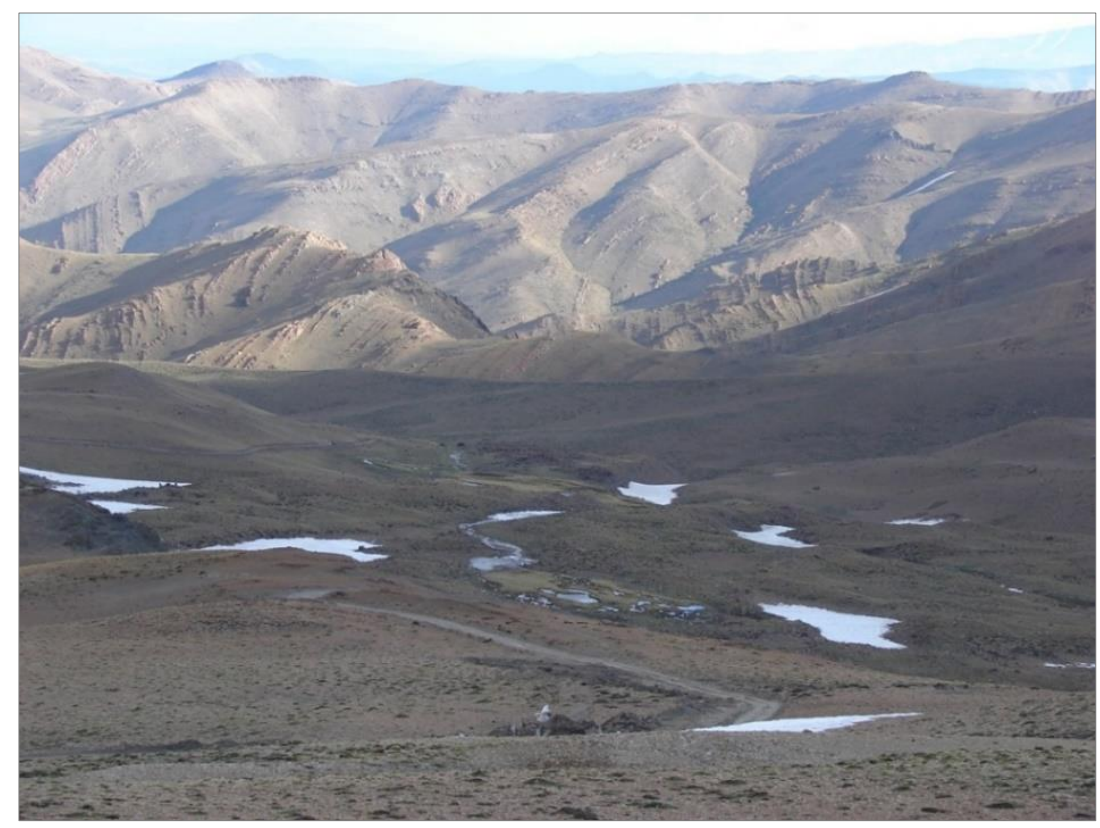

Figura 2.14. Imagen del Desierto Altoandino en el sur de Mendoza.

\subsubsection{DESIERTO PATAGÓNICO}

En el Desierto Patagónico las precipitaciones también tienen lugar durante el invierno, en el orden de los $300 \mathrm{~mm}$ anuales (Capitanelli 1972; Abraham 2000). Dentro 
de la región de estudio se corresponde hidrográficamente con la cuenca media del río Atuel, entre unos 2200 y 1600 msnm (Figuras 2.5, 2.13 y 2.15).

El sector más occidental del Desierto Patagónico coincide con el piedemonte cordillerano, el cual constituye una unidad de transición entre la región montañosa y la llanura, y su extensión se relaciona directamente con la masa rocosa a partir de la cual se ha originado (Abraham 2000). Allí, todavía están presentes en el paisaje algunos reparos rocosos, útiles para refugio. En términos ambientales, esta situación transicional conlleva numerosas ventajas para la vida humana, al posibilitar que viva una mayor diversidad de especies animales y vegetales.

Las materias primas son abundantes, especialmente en cordillera y en los cauces de agua, destacándose las rocas silíceas y distintos tipos de vulcanitas. Hacia el este, la presencia de la fuente de obsidiana El Peceño asegura la disponibilidad de esta roca de alta calidad para la talla.

Hacia el este del sector de piedemonte, este desierto limita con el Desierto de Monte (Sección 2.3.3.) Por lo tanto, constituye un ambiente ecotonal con amplia diversidad de especies.

Hacia el este se desarrolla la Formación fitogeográfica del solupal (F. Roig 1972), descrito en la Sección 2.2.3.1., que al oeste se corresponde con las Formaciones halófilas (F. Roig 1972), detalladas en la misma sección (2.2.3.1.). La fauna del desierto Patagónico corresponde a lo que V. Roig (1972) definió como Fauna de la estepa patagónica, la cual ha sido detallada en la sección 2.2.4. La provincia fitogeográfica de Patagonia es el ambiente más adecuado para el desarrollo de las poblaciones de guanacos y ñandúes (Rhea pennata), además de la presencia de roedores de diverso tamaño como mara, chinchilla, y cuises y Dasipódidos, especialmente Zaedyus. La vegetación es mucho más productiva desde el punto de vista humano, con grandes comunidades de molle, alpataco y Ephedra, entre otras. Todo esto, sumado a la presencia de vertientes y cursos de agua permanente, y la posibilidad de ser un espacio habitable durante todo el año, hace de los ambientes patagónicos pedemontanos y de los valles intermedios, los ambientes mejor ranqueados en la "jerarquía de espacios" del sur de Mendoza (Neme y Gil 2008a) (Véase Capítulo 3). 


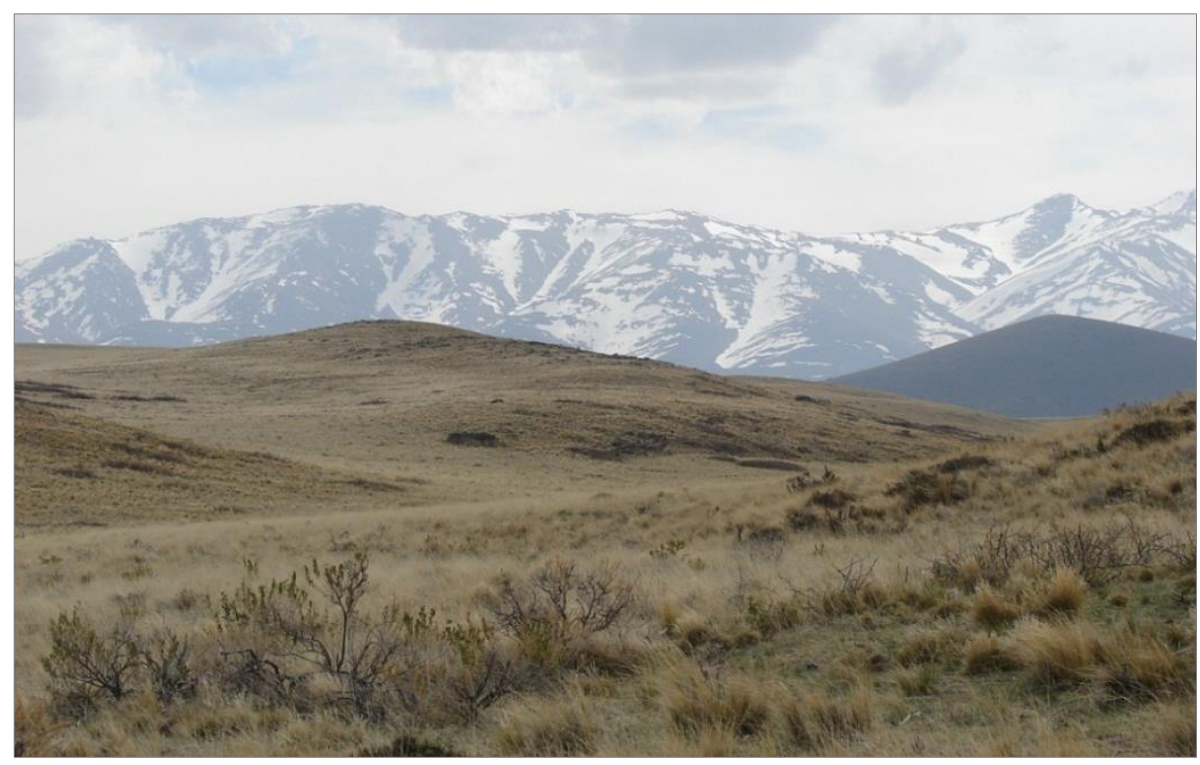

Figura 2.15. Imagen del Desierto Patagónico en el sur de Mendoza.

\subsubsection{DESIERTO DE MONTE}

El Desierto de Monte es el más oriental, se localiza en la planicie y se corresponde con la cuenca inferior del río Atuel en su discurrimiento hacia el este. Hacia el este del Bloque de San Rafael se localiza el sector de las Planicies (sección 2.2.2.1.), que coincide con el desierto de Monte. El río Atuel va perdiendo capacidad de transporte al atravesar la planicie y los médanos del sector más oriental; esto genera un diseño fluvial de tipo anastomosado (Abraham 2000). El escenario característico se da por la presencia de depósitos eólicos finos (Figura 2.16) y su modificación por la fuerte acción humana del área.

El Desierto de Monte es el que recibe la menor cantidad de precipitaciones ( $c a$. 250 milímetros anuales), disminuyendo la densidad de cursos de agua y vertientes permanentes. Una alta evapotranspiración, la mayor de la región (Capitanelli 1972; Abraham 2000; Mares et al. 1985), imprime aún más las condiciones de un ambiente árido con fuerte déficit hídrico durante todo el año. Sin embargo, la ocurrencia veraniega de las precipitaciones hacen que la productividad vegetal sea la más alta de la región, en términos de biomasa aprovechable por el ser humano.

La diversidad animal es mayor que en el resto de los desiertos, aunque en general la densidad de camélidos es más baja que en las otras áreas, especialmente por la baja frecuencia de pasturas. Los Dasipódidos son muy diversos y ubicuos, al igual que grandes roedores como la mara, la vizcacha y la chinchilla. De las dos especies de Ratites 
presentes en el sur de Mendoza se puede encontrar en este desierto Rhea americana, importante tanto por su carne como por los huevos.

El algarrobal constituye la formación más importante del desierto de Monte (Sección 2.2.3.1.). Está compuesto por especies de los géneros Prosopis y Larrea, y por especies como Atriplex lampa, entre otras (Abraham 2000; Roig et al. 2000). El bosque se mantiene gracias a la presencia de una freática cercana a la superficie. Las especies explotables por humanos son numerosas y algunas de ellas muy productivas. Entre ellas se destacan las distintas especies de Prosopis (caldenia y flexuosa), duraznillo (Ximenia americana), Piquillín (Condalia microphila) y Geofroea decorticans, entre otras. En resumen, el Monte es menos productivo en términos de grandes especies de animales, aunque más diverso; mientras que es muy productivo y estable desde el punto de vista de la vegetación. Las fuentes de agua están más localizadas y la materia prima es más escasa en comparación con el resto de los desiertos mencionados.

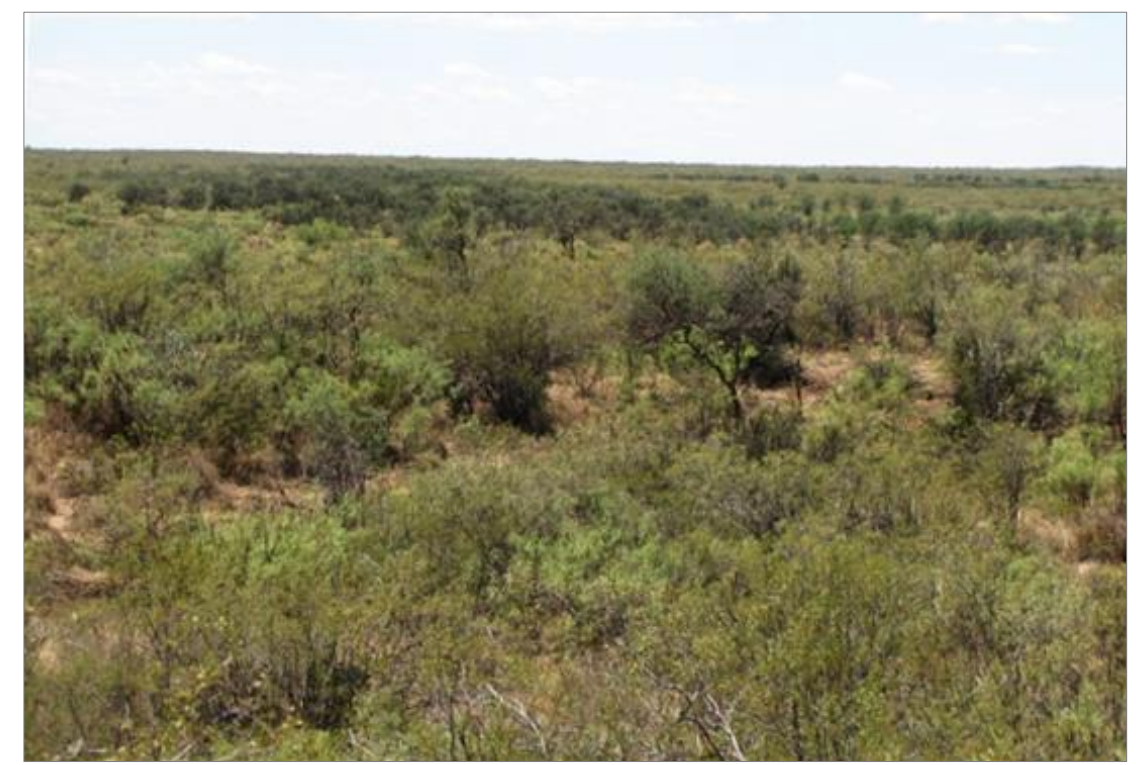

Figura 2.16. Imagen del Desierto de Monte en el sur de Mendoza.

\subsection{PALEOAMBIENTE DURANTE EL HOLOCENO}

Las reconstrucciones paleoambientales en el sur de Mendoza se basaron en distintos tipos de proxies como registros de megafauna, microfauna, polen, malacológicos, dendrocronológicos y geológicos (e.g. registros sedimentológicos y glaciarios de distintas cuencas hidrográficas del sur mendocino). Así, al ser diverso el tipo de registro ambiental utilizado, también varía el grado de resolución espacial y 
temporal obtenido (Grosjean et al. 2003; Dearing 2006). Estas investigaciones muestran cambios climáticos desde fines del Pleistoceno-principios del Holoceno (Lagiglia 1970; Markgraf 1983, 1989; D’Antoni 1983; Stingl y Garleff 1985; Villalba 1990; Espizúa 1993; Grosjean et al. 2003; De Francesco y Diéguez 2006) y registran una transición entre condiciones más frías - dominantes durante la última glaciación- a las templadas que rigen en la actualidad (Zárate 2002).

Los registros paleoambientales de la región coinciden en que las condiciones climáticas actuales comienzan $c a$. 3.000 años AP y que la principal variación climática durante este período fue el avance glaciar ocurrido $c a$. 400 años AP, posiblemente, asociado con la Pequeña Edad de Hielo (Markgraf 1983; Stingl y Garleff 1985; Espizúa 2003). El primer análisis realizado en la región corresponde a muestras de polen provenientes de un perfil del sitio arqueológico Gruta del Indio (Lagiglia 1970; D’Antoni 1983). Sobre la base de este registro, Lagiglia describe un proceso de desertización creciente desde fines del Pleistoceno hasta la actualidad (Lagiglia 1970), proponiendo que alrededor de los 3.800 años AP y hasta el presente existe un clima seco y xerofítico. Esto lo corroboran Páez y colaboradores (2010) al registrar, en el mismo sitio, la presencia de comunidades del Monte a partir de los 4.100 años AP, indicando un régimen de precipitación de verano y temperaturas altas similares a las presentes, con el desarrollo de salinas con comunidades halófitas desde los ca. 1.900 años AP (Páez et al. 2010).

\subsubsection{PLEISTOCENO FINAL-HOLOCENO TEMPRANO (14.000-8.000 años AP)}

En este momento de transición, que comenzaría hace 14.000 años AP, inicia el retroceso general de los glaciares en el área andina (Lowell et al. 1995). En dicho momento se producen los cambios ambientales más importantes de la región, los cuales tienen que ver con un rápido retroceso de las masas de hielo después del último máximo glaciar. Evidencias de este retroceso han sido registradas en las cuencas altas de los ríos Grande (Espizúa 1998) y Atuel (Stingl y Garleff 1985), y en los análisis polínicos de muestras provenientes de una turbera en el río Salado (Markgraf 1983) y de la Sierra Pintada (D'Antoni 1983). Para este lapso, ya entrando en el Holoceno temprano, en el área de Mendoza se pasaría de condiciones frías y de mayor disponibilidad de agua en los cuerpos lacustres a condiciones áridas y de mayor temperatura como lo sugieren los indicadores polínicos (D’Antoni 1983; García et al. 1999; Páez y Zárate 2000; Zárate 2002). Los modelos paleoclimáticos para este lapso evidencian un período más húmedo y frío que el actual (Lagiglia 1970) aunque con temperaturas algo más altas que en 
momentos previos, con mayor disponibilidad de agua en los ríos y tal vez más ventoso, y con una fuerte influencia de procesos eólicos indicadores de condiciones paleoclimáticas semiáridas. Asimismo, se observan cambios en los pastizales de tipo patagónico hacia los arbustos desérticos, de lluvias invernales a lluvias veraniegas (D'Antoni 1983), lo que evidencia el paso de un desierto de tipo patagónico (con mayores precipitaciones, invernales y temperaturas medias más bajas) a matorrales desérticos (con lluvias veraniegas y temperaturas similares a las actuales) (Markgraf 1983).

Más allá de la región, en la vertiente occidental de la cordillera, distintos tipos de testigos de alta resolución (lacustres y oceánicos) también muestran cambios en el mismo sentido que los mencionados, con temperaturas más bajas y mayores niveles de precipitación que los actuales hacia momentos de la transición (Lamy et al. 1999; 2002) (Figura 2.17).

Para este momento, la mayoría de los ambientes del sur de Mendoza se encontrarían disponibles para su uso por parte de los grupos humanos, aunque la exploración/colonización habría comenzado en los sectores extra-cordilleranos alrededor de 11.000 años AP (Neme y Gil 2008a; Véase Capítulo 3). El Monte se habría empobrecido bajo condiciones de mayor humedad, con el consecuente incremento en la biomasa vegetal de la Provincia Patagónica, mejores pasturas y espacios aptos para la proliferación de comunidades de camélidos. Así, las condiciones ambientales de la región para este momento, favorecerían el desarrollo de la caza por encima de la recolección. Los inicios del Holoceno se caracterizarían, además, por la presencia de grandes cuerpos lacustres de agua dulce producto de los procesos de deglaciación que estaban teniendo lugar en toda la cordillera, el más emblemático de estos fue el paleolago de Llancanelo (Groeber 1939; De Francesco y Dieguez 2006). La presencia de estos grandes cuerpos de agua, de cientos de kilómetros de extensión debieron tener fuertes implicancias en los circuitos de movilidad humana durante las primeras etapas de la colonización regional (Neme 2009). 


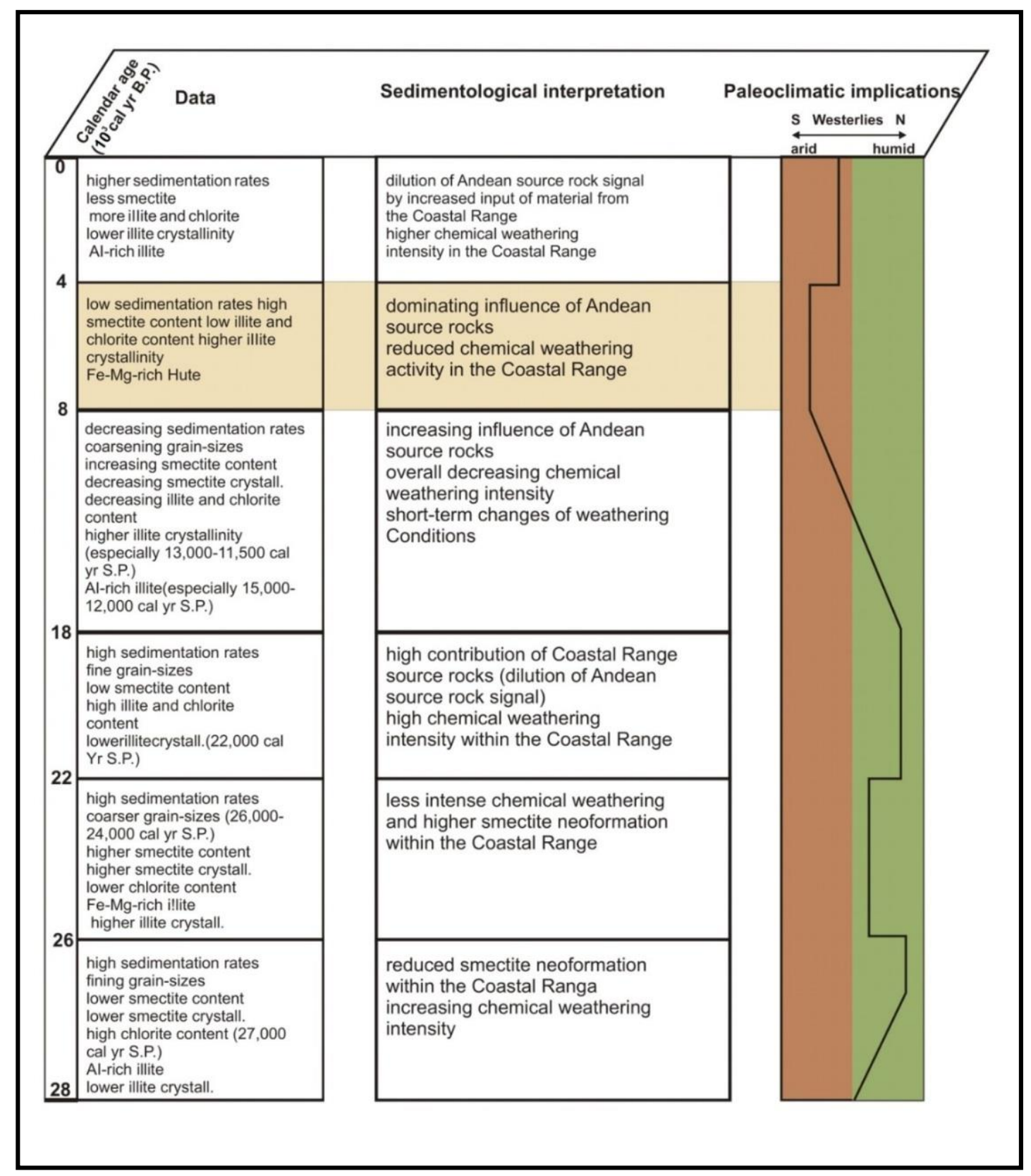

Figura 2.17. Resumen de datos, interpretaciones sedimentológicas e implicaciones paleoclimáticas durante los últimos 28.000 años, basado en el estudio de sedimentos continentales de latitudes medias de Chile. Tomado de Lamy et al. (1999: 91).

\subsubsection{HOLOCENO MEDIO (8.000-4.000 años AP)}

Durante este período, los distintos proxies analizados a escalas regional y continental, indican un aumento en la aridez y en las temperaturas, lo que evidencia el paso de condiciones húmedas (registradas para el Holoceno temprano) a condiciones más secas (Zárate 2002; Gil et al. 2005). En el sur de Mendoza, los indicadores paleoambientales provienen de registros polínicos de la cordillera (Markgraf 1983; 
Navarro et al. 2012; Navarro y Whitlock 2010), de las planicies (sitios Gruta del Indio y La Guevarina) (D’Antoni 1983; Páez et al. 2010), de la geomorfología glacial y de la estratigrafía del alto valle del río Atuel (Stingl y Garleff 1985), junto con información geomorfológica general de las Planicies del Este, entre San Rafael y General Alvear (Tripaldi et al. 2010; Zárate 2002). El proceso de aridez es propuesto para escalas tanto locales como continentales, pero en el sur de Mendoza, la heterogeneidad ambiental habría conducido a respuestas ambientales diferentes durante el Holoceno medio (Gil et al. 2005, Gil et al. 2008). Las condiciones ambientales de este período fueron cambiando la situación de aridez extrema, tanto el registro malacológico como el polínico resultaron estériles durante el Holoceno medio en las muestras de La Guevarina, quizás como consecuencia de estas condiciones áridas (De Francesco 2010). Sin embargo, no todo el período tuvo estas características de aridización: Markgraf (1983) ha propuesto una disminución de las temperaturas en las montañas acompañada de un incremento de las precipitaciones invernales, que habrían generado un aumento en el caudal del río Atuel. Pero hacia fines del Holoceno medio, este autor supone un decrecimiento en las precipitaciones y un incremento de las temperaturas estivales (Markgraf 1983). D'Antoni (1983) supone un aumento generalizado de las temperaturas tanto en el piedemonte como en la cordillera, con el consecuente derretimiento de los glaciares y el incremento del caudal en los ríos. Por su parte, Stingl y Garleff (1985) evidencian un importante avance glaciar, lo que sugiere que en las áreas de cordillera las precipitaciones pudieron aumentar, favoreciendo las condiciones en este tipo de ambientes.

Los testigos de sedimentos marinos y paleolacustres de Chile central también muestran un proceso de aridización creciente (Veit 1998; Lamy et al. 1999; Heusser 1990; Jenny et al. 2002). Jenny y colaboradores (2002) sugieren que previamente a los 5.700 años AP las llanuras orientales del sur de Mendoza habrían tenido una mayor influencia del anticiclón del Atlántico Sur, debido a la desviación de los westerlies (Jenny et al. 2002). Esto habría causado un aumento en las lluvias de verano mientras que el sistema fluvial andino estaría experimentando descargas menores durante el Holoceno medio temprano (ca. $9.500-8.000$ a $5.700{ }^{14} \mathrm{C}$ cal años AP). Luego, entre 6.000 y 4.000 años $\mathrm{AP}$, se habrían dado condiciones más áridas y probablemente temperaturas más altas en las planicies, donde se daría una menor influencia del anticiclón del Atlántico, resultando en una disminución de las lluvias de verano; mientras tanto, los Andes habrían experimentado un aumento de las nevadas y reavances neoglaciales (Zárate et al. 2005). 
Por ejemplo, Sting y Garleff (1985) observan un avance glacial significativo entre 6.000 y 4.500 años AP a 2000 msnm, cerca de la localidad de El Sosneado.

Las condiciones crecientes de aridez al transcurrir el Holoceno medio, habrían generado un decrecimiento de la productividad primaria a nivel regional. Sin embargo, esto no sucedió en los ambientes cordilleranos, los cuales habrían sufrido, en cambio, un mejoramiento en las condiciones de humedad y, como consecuencia, de la productividad.

\subsubsection{HOLOCENO TARDÍO (4.000-200 años AP)}

Es a partir de los 3.000-4.000 años AP que se darían las condiciones climáticas actuales (Navarro et al. 2012; Zárate et al. 2010). Esto no quiere decir que el Holoceno tardío haya sido un período estable y/o uniforme (Zárate 2002; Neme et al. 2005). Al contrario, fue un período de cambios climáticos que provocaron modificaciones en la abundancia y disponibilidad de recursos, tanto a escala espacial como temporal. En este período, el ENSO (El Niño Southern Oscillation) se hizo más frecuente, trayendo como consecuencia un aumento de las precipitaciones en alta cordillera y ocasionando una mayor disponibilidad de agua en las tierras bajas por una mayor recarga de los acuíferos del piedemonte. Asimismo, y como se dijo antes, la neoglaciación registrada entre los 2.500-2.000 años AP y la Pequeña Edad de Hielo ocurrida hace 400 años (Espizúa 2003) sugieren importantes cambios tendientes hacia un período cálido conocido como Medieval Warm Period (MWP) (Neme et al. 2005). La influencia de la Pequeña Edad de Hielo, particularmente, podría haber sido una de las principales responsables del inicio de la formación de las planicies de inundación actual, ya que en casi todas las regiones estudiadas del sur mendocino hay evidencias de un proceso de formación muy reciente (Zárate et al. 2010).

La evidencia malacológica, constituida por una mayor abundancia y diversidad de moluscos dulceacuícolas, señala que durante este período se habría dado un mejoramiento ambiental (De Francesco 2010). El único registro polínico continuo del Holoceno tardío corresponde a una columna sedimentaria proveniente de cordillera y analizada por Markgraf (1983). En ella se evidencia que la totalidad del registro estaba dominado por gramíneas sin modificaciones en los 4.000 años analizados, aunque en los taxa de los alrededores, sí se observan cambios entre 3.000-2.800 años AP. Luego de los 2.800 años AP, el polen característico de la vegetación Altoandina aumenta, el polen de efedra decrece y al mismo tiempo aumentan los elementos de Monte como Sollanaceae (Markgraf 1983). Estos cambios corresponderían a un aumento de la temperatura para ese 
momento. Por su parte, el registro glaciológico evidencia, al inicio del Holoceno tardío, una reducción de los glaciares que, hacia los 2.500 años AP aproximadamente, alcanzan el posicionamiento actual (Stingl y Garleff 1985). Asimismo, la vegetación regional habría tomado la configuración actual; pero la gran variabilidad climática mencionada para este período (especialmente en relación a precipitaciones y temperatura), habría repercutido en una mayor variación en la productividad de las plantas año a año, en una relación de dependencia con la frecuencia de los eventos ENSO o de los ciclos neoglaciares. Los análisis de ensambles de microvertebrados estudiados en distintos sitios y localidades del sur de Mendoza muestran también condiciones ambientales similares a las actuales (Fernández 2010; Fernández et al. 2015).

El registro de Chile central (testigos oceánicos y lacustres) sugiere también condiciones muy variables, en general, más húmedas que las del Holoceno medio. Las variaciones en las precipitaciones estarían controladas por cambios en la posición latitudinal de los westerlies. En comparación con las condiciones actuales, el cinturón de westerlies del sur se ubicó significativamente más al norte durante el último máximo glacial. Las variaciones menos importantes de la posición latitudinal del oeste meridional también se produjeron en escalas temporales más cortas (Lamy et al. 1999).

Los análisis geoquímicos, sedimentológicos y de diatomeas proporcionan evidencia de un período árido entre cal. 200 AC y 200 AD, y un posterior aumento de humedad después de cal. 200 AD. Los períodos con una mayor frecuencia de eventos de inundación indican un incremento en la intensidad de westerlies, más actividad del sistema frontal de invierno y posiblemente variabilidad relacionada con el ENSO, probablemente comparable a las condiciones modernas en el Chile central (Jenny et al. 2002). 


\section{CAPítulO 3}

\section{ANTECEDENTES}

\subsection{ARQUEOLOGÍA EN EL SUR DE MENDOZA}

\subsubsection{ESTUDIOS PIONEROS}

La historia de las investigaciones arqueológicas en el sur de Mendoza tiene sus raíces en diversos estudios realizados desde comienzos del siglo XX. Estos se inician con los trabajos de Ambrosetti (1905) y Outes (1906), quienes hacen descripciones de restos aislados encontrados en diferentes lugares de la provincia. Posteriormente, Debenedetti (1917) realiza investigaciones en los Valles Preandinos de la provincia de San Juan, que se integran a las de Reed (1918) en el cementerio de Viluco (San Carlos, Mendoza). El trabajo resultante es publicado años más tarde por Boman en 1920.

Canals Frau realiza un cuidadoso análisis de los distintos yacimientos de los departamentos Tupungato, Luján, San Rafael y otros próximos a la ciudad de Mendoza. Desarrolla el primer trabajo de conjunto sobre el Valle de Uco, y es en este estudio -no sistemático-, en el que intenta una aproximación cronológica de las culturas de Mendoza, que eran hasta entonces consideradas como sincrónicas y de escasa profundidad cronológica. Más tarde amplía sus investigaciones en el área, y a través de ellas, caracteriza a la llamada "Cultura de Agrelo" (Canals Frau 1956; Canals Frau y Semper 1956).

Por su parte, Rusconi reúne en una única obra (Rusconi 1961-1962) los estudios que venía realizando desde 1937. A comienzos de 1940 recorre parte del curso del río Salado (afluente del río Atuel), aunque no encuentra restos arqueológicos. A fines del mismo año recoge y estudia materiales arqueológicos en la localidad de El Nihuil (cuenca media del río Atuel), y excava la Gruta del Indio (Figura 3.1), pero de manera no sistemática. Terminando el año 1947 recorre las inmediaciones del Puente Chadí Leufú (río Salado), donde registra alfarería pintada. 


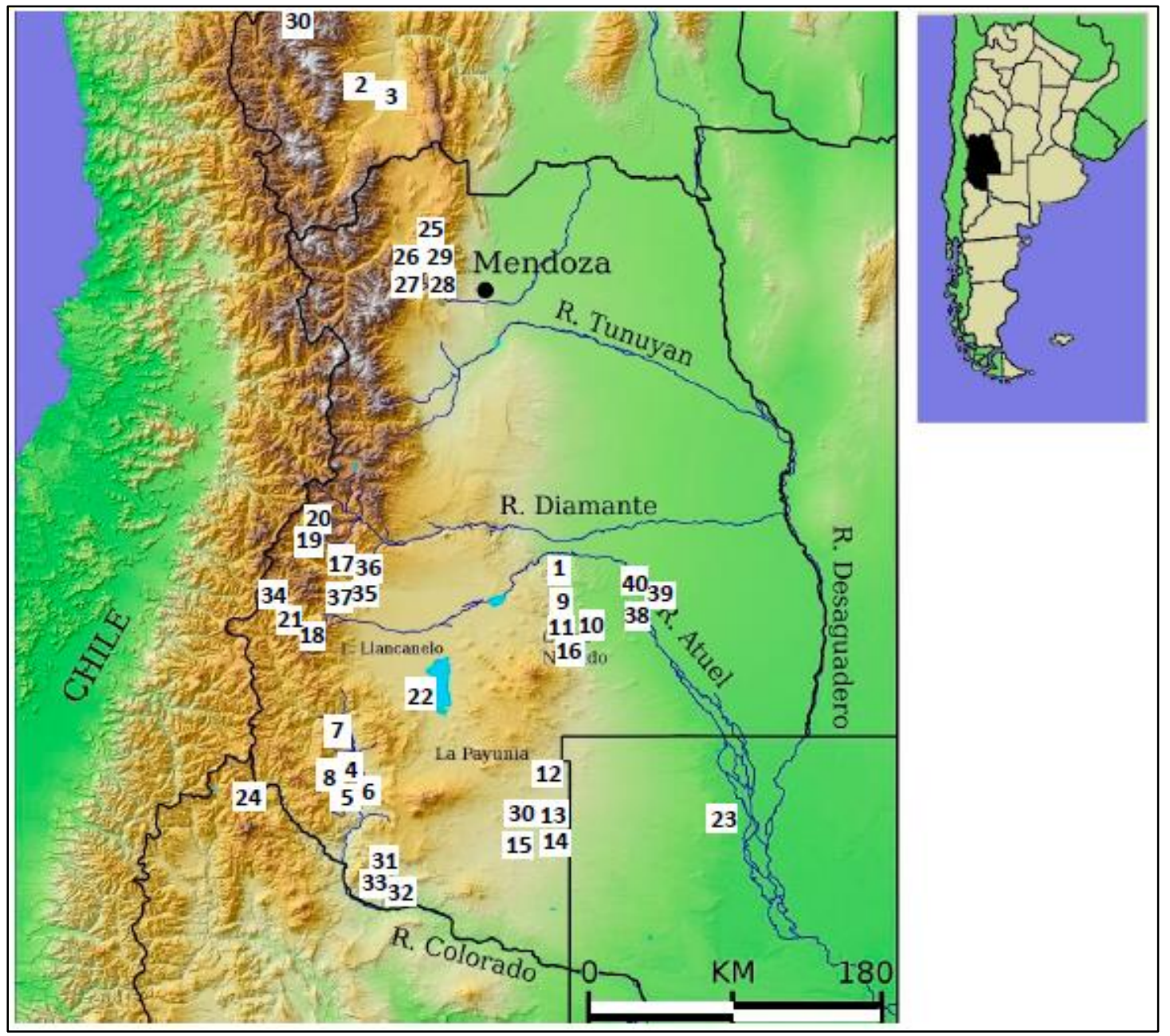

Figura 3.1. Mapa de la provincia de Mendoza y regiones aledañas, mostrando los sitios arqueológicos enumerados en el orden de su mención en este capítulo. Referencias: 1) Gruta del Indio; 2) Los Morrillos; 3) La Colorada de la Fortuna; 4) Gruta de El Manzano; 5) Cueva de Luna; 6) Alero Puesto Carrasco; 7) Cueva de los Indios-Bardas Blancas; 8) Alero 01 de Cañada de Cachi; 9) Los Leones-3 y Los Leones-5; 10) Agua de los Caballos; 11) Puesto Ortubia 1; 12) Cueva Delerma; 13) La Peligrosa-1; 14) La Corredera; 15) Piedras Bayas; 16) Cueva Zanjón del Buitre; 17) Arroyo Malo-1, Arroyo Malo-3, Arroyo Malo-4, Arroyo Malo-5 y Arroyo Malo-6; 18) Cueva Arroyo Colorado; 19) Los Peuquenes; 20) El Indígeno; 21) Arroyo El Desecho; 22) Llancanelo; 23) Vallejo; 24) Cueva Huenul 1; 25) Agua de la Cueva; 26) El Piedrón 01 y El Piedrón 02; 27) La Manga; 28) Río Blanco 01; 29) Terraza Gendarmería 4.1, Los Conitos 01, Los Conitos 02 y Los Conitos 03; 30) sitios ARQ: 3, 4, 21, 9, 20, 10, 17, 25, 16, 29, 18, 15, 5, 11, 28, 27, 14, 23, 24, 22, 26, C07, C08, C05, C06, GZ01, GZ03, C14 y C15; 31) La Leona; 32) Agua de Pérez 1 y Agua de Pérez-Cantera; 33) La

Carmonina 1 y Pista; 34) Valle Hermoso 1; 35) Ojo de Agua 1 y Ojo de Agua 2; 36) Arroyo La Manga; 37) Cerro Manteca; 38) La Olla; 39) El Bosquecillo 3 y El Bosquecillo 5; 40) Los Gallegos-1.

Los dos últimos autores establecieron las bases de las investigaciones arqueológicas posteriores, con los primeros trabajos de recopilación de información de 
carácter etnohistórico y lingüístico (Canals Frau 1937, 1953, 1955; Rusconi 1940, 1961 1962). Pese a estos avances, la excavación siguió siendo una técnica poco usual y asistemática. Contemporáneamente, Vignati (1940), realiza una revisión crítica de los estudios etnográficos de Mendoza y describe el ajuar de una momia de Angualasto (Vignati 1953), aportando también datos arqueológicos y etnográficos sobre las Lagunas de Guanacache, localizadas en el límite este de las provincias de San Juan y Mendoza (Vignati 1931, 1934, 1937, 1940, 1953).

Entre principios de la década de 1950 y la de 1980, se dan diversos avances en las investigaciones arqueológicas llevadas a cabo por arqueólogos de formación profesional, predominando la perspectiva de la escuela Histórico Cultural (Gambier 1985; Lagiglia 1968, 1974; Schobinger 1975, entre otros). Se destacan las primeras investigaciones arqueológicas sistemáticas del sur de Mendoza, iniciadas en el año 1955 por Lagiglia en el valle del río Atuel (Lagiglia 1956a y b), y por Lagiglia y Semper en la década siguiente (Semper y Lagiglia 1962-68). Ambos trabajaron con mayor énfasis en el departamento de San Rafael, y centraron sus estudios de prospección y excavación en los valles de los ríos Atuel y Diamante (Lagiglia 1968; Semper y Lagiglia 1962-68). Los análisis realizados en el sitio arqueológico Gruta del Indio, ubicado en el cauce medio del río Atuel, dieron cuenta de una estratigrafía con gran profundidad temporal, con cronologías correspondientes a la transición Pleistoceno tardío-Holoceno temprano (Lagiglia 1956a y b; Semper y Lagiglia 1962-68; Lagiglia y García 1999) y fueron fundamentales para la construcción de una secuencia de desarrollo cultural para el sur mendocino. Este sitio fue la base para la construcción del primer diagrama polínico arqueológico de Argentina (Lagiglia 1970a; D’Antoni 1983) y para el desarrollo de estudios paleoecológicos ulteriores (D’Antoni 1983; Páez et al. 2010).

Para este sitio, Lagiglia y Semper definieron cuatro etapas de ocupación, a las que denominaron, de la más reciente a la más antigua, Atuel I, II, III y IV (Lagiglia 1968, 1977a; Semper y Lagiglia 1962-68). Esta secuencia de desarrollo cultural, compuesta por "etapas crono-culturales", bien diferenciadas por los modos de vida y rasgos estilísticos específicos, estableció las bases para los trabajos arqueológicos ulteriores (Neme 2007) y fue ampliada, modificada y extendida más tarde por Lagiglia a otros valles de la región (Lagiglia 1972, 1977a, 1980, 1981, 1997a, 2002).

Semper y Lagiglia (1962-68), caracterizan a Atuel IV (11.500 años AP) como la etapa paleoindia, contexto al que se asocian cuatro instrumentos líticos y restos de megafauna (boñigas y huesecillos dérmicos de Mylodontidae) (véase discusión acerca de 
la asociación de megafauna y ocupación humana en el apartado siguiente). Atuel III (4.000-2.250 años AP) corresponde a lo que definen como cazadores-recolectores de la etapa "protoformativa" (Lagiglia 1977a; también llamado "Precerámico Final" por Semper y Lagiglia 1962-68). A Atuel II (2.250-1.800 años AP) pertenecen los agricultores iniciales e incipientes de maíz, zapallo, quinoa y poroto. La etapa más reciente, Atuel I (1.800-200 años AP), corresponde a culturas de la época histórica o etnográficas registradas por los primeros cronistas: grupos araucanizados (puelches, pehuenches, etc.), y a esta etapa también pertenecen las pictografías con escena de soldados españoles y una posible embarcación (Semper y Lagiglia 1962-68; Lagiglia 1968, 1977a, 1980, 1981, 1999, 2002; Gil y Neme 2010).

Durante sus trabajos en el Dpto. de Calingasta (San Juan), Mariano Gambier caracterizó lo que él llamó "La cultura de Los Morillos" (Gambier 1985), a la que asoció con cazadores-recolectores del sudoeste de la provincia de San Juan. Para la definición de esta cultura, Gambier se basa en los restos arqueológicos recuperados en las excavaciones de tres grutas del sitio Los Morrillos, en la gruta El Chacaycito y el alero de Los Corredores (ambos sobre el río Colorado), y en el sitio al aire libre La Colorada de la Fortuna (en el valle interandino La Colorada) (Figura 3.1). Gambier distingue cuatro ocupaciones diferentes y separadas en el tiempo. Tres en el interior de las grutas y otra en uno de los aleros superiores; la más antigua fechada en 6.500 años a.C. Este contexto fue, al principio, denominado Morrillos I, pero luego, al ser excavado el sitio La Colorada de la Fortuna (a unos $33 \mathrm{~km}$ al oeste de las tres grutas de Los Morrillos) lo denominó "Industria de La Fortuna", dado que lo considera un sitio tipo por su riqueza material. Observa que en el sitio homónimo se mezclan los restos de ambas culturas (puntas pedunculadas La Fortuna y puntas triangulares apedunculadas Morrillos). Dicha mezcla es asignada a un estadio de coexistencia o posible "unificación de ambas culturas" durante el momento final de las puntas Fortuna (Gambier 1985: 36). Se debe tener en cuenta la perspectiva histórico-cultural prevaleciente en esta época y tomada por este autor, quien asocia variedad artefactual con variedad cultural.

En un intento por establecer los límites de dispersión de ambas culturas, Gambier dirige sus trabajos a la provincia de San Luis y luego al sur de Mendoza, donde realiza excavaciones en la cuenca del río Grande. En 1978, realiza la primera excavación de dicha región en el sitio Gruta de El Manzano, sobre la margen derecha del río, en la región volcánica de La Payunia, departamento de Malargüe (Gambier 1980) (Figura 3.1). El registro lítico, detalladamente descripto e ilustrado (Gambier 1985), lo define como 
correspondiente a una "industria" de tipo Morrillos, caracterizada por puntas de proyectil apedunculadas, triangulares, medianas; microrraederas y microrraspadores enmangables y no enmangables; cuchillos; raspadores; desbastadores, manos de molino, instrumentos de hueso, entre otros artefactos (Gambier 1985; Durán 2000). Las materias primas registradas en Gruta de El Manzano son basalto, cuarcita, obsidiana y rocas silíceas diversas. Según Gambier, las láminas de basalto y obsidiana presentan filos naturales muy agudos, por lo que pudieron ser utilizadas al natural, enmangadas o no; otras presentan retoques, lo cual confiere láminas cóncavo-convexas (Gambier 1985: 137). Esta "industria" se asociaría a otra presumiblemente contemporánea de puntas lanceoladas tipo Fortuna; una asociación equiparable a la "mezcla" de materiales que el mismo autor observara en el sitio La Colorada de la Fortuna, al sur de la provincia de San Juan. Por lo tanto, según Gambier (1985), el sur de Mendoza habría sido ocupado por grupos humanos cuyas características serían asimilables a las tradiciones culturales desarrolladas en el sector norte de Cuyo. El material fechado en Gruta de El Manzano arrojó una edad de 7.200 años AP, y es la más antigua registrada hasta el momento en la cuenca del río Grande. El registro arqueológico recuperado es organizado en dos grandes conjuntos (o "tradiciones"): una etapa de cazadores-recolectores y otra etapa Agroalfarera (Gambier 1987).

Los resultados obtenidos por Gambier, tanto en el sur de San Juan como en el sur de Mendoza, ponen en evidencia, entonces, las similitudes entre el esquema y sistema de vida de los grupos Morrillos con los del río Grande de Malargüe (Gambier 1985: 141). A su vez, en su intento de insertar al ser humano en su ambiente, dice que la semejanza de los contextos culturales de estos dos grupos demuestra similitudes culturales y formas de vida en un espacio andino circunscripto, donde las condiciones climáticas de las zonas altas y bajas favorecen al desarrollo de la vida de manera alternada, produciendo una complementariedad necesaria para la supervivencia (Gambier 1985: 141), y en directa dependencia con el movimiento estacional que realizan los guanacos (Gambier 1985: 163). En el modelo de uso del espacio descripto por Gambier para el valle medio de río Grande, el registro descripto muestra la importancia de la movilidad de los grupos cazadores-recolectores que habitaron la región. Según Gambier, la Gruta de El Manzano -localizada en las tierras bajas- era ocupada durante el invierno, luego los grupos humanos se trasladaban hacia las tierras altas cordilleranas en la estación estival o momentos más cálidos (Gambier 1980, 1985). Estos trabajos le permitieron al investigador llegar a la conclusión de que ambas culturas, Morrillos y Fortuna, habrían tenido una dispersión que 
alcanzó no sólo el río Diamante (Gambier 1976), sino también la cuenca media del río Grande (Gambier 1985).

En concordancia con esto último, Durán, comienza sus investigaciones también en el valle del río Grande hacia fines de la década de los '80 (Durán 1997; Durán y Ferrari 1991; Durán et al. 1999). A partir de los datos obtenidos en las excavaciones de distintos reparos postula un uso estacional de la región, con un proceso de fisión estival en Área El Payén (AEP) y la Cordillera de los Andes, y de fusión invernal en el cauce medio del río Grande, implicando desplazamientos estacionales hacia ambas vertientes de la cordillera. Se basa en el concepto de fusión-fisión, característico de las organizaciones cazadoras-recolectoras (Gamble 1990: 45) y en la estructura de los recursos del área. En este último sentido, y dentro de su esquema de pensamiento transicional desde la mirada histórico-cultural hacia el enfoque ecológico-sistémico o procesual funcionalista de la Nueva Arqueología (Renfrew y Bahn 1993), Durán (2000) afirma que los seres humanos son considerados parte de la naturaleza, que la cultura es vista como un mecanismo de adaptación de la especie que contribuye a su éxito reproductivo, que es posible encontrar regularidades en el funcionamiento de cualquier sistema socio-cultural, y que las causas de esas regularidades pueden hallarse al analizar las relaciones que establecen esos subsistemas con el ambiente que los incluye (Durán 2000: 15). Desde su perspectiva, no define a las sociedades a partir de la variedad artefactual (como lo hacía Gambier, desde su enfoque histórico-cultural), sino que las interpreta en relación a su vínculo con el ambiente y las características de los patrones de asentamiento-subsistencia. Por lo tanto, variedad artefactual no implica variedad cultural, sino que la variabilidad del registro arqueológico sería producto de diversas actividades relacionadas a la disponibilidad estacional de los recursos y a la funcionalidad de los sitios (Duran 2000). Propone una secuencia regional constituida por ocho períodos: Período 1 de cazadores-recolectores del Holoceno temprano; Período 2 caracterizado por un hiatus en la información arqueológica, contemporáneo a un importante evento volcánico (sensu Durán y Mikkan 2009); Períodos 3 y 4 (diferenciados por los fechados radiocarbónicos) de cazadoresrecolectores del Holoceno tardío (sin cerámica); Período 5a de cazadores-recolectores portadores de cerámica (Cerámico Inicial) sobre la margen derecha del río Grande, y Período $5 \mathrm{~b}$ de cazadores-recolectores de contextos acerámicos, sobre la margen izquierda; Período 6a de cazadores-recolectores de la margen derecha del río Grande portadores de cerámica, y Período $6 \mathrm{~b}$ de cazadores-recolectores de contextos acerámicos, sobre la margen izquierda; Período 7 caracterizado por ser el momento próximo al 
contacto o de contacto inicial con el estado español; y por último, Período 8 de pastores. Así, plantea un modelo de asentamiento-subsistencia para tiempos pre y post- hispánicos (Durán 1997). Tal esquema temporal es resultado de sus excavaciones en cinco sitios arqueológicos ubicados en las tierras bajas de la región, entre 1300 y $1500 \mathrm{msnm}$ (piedemonte): Cueva de Luna, Gruta de El Manzano, Alero Puesto Carrasco, Cueva de los Indios-Bardas Blancas y Alero 01 de Cañada de Cachi, localizados en ambas márgenes del río Grande (Figura 3.1).

Sobre la base de distintos indicadores, Durán propone un uso estival -no invernaldel valle del río Grande (Durán 2002: 89), lo que habría implicado que no todos los miembros del grupo se trasladaban hacia las tierras altas, y que probablemente los cazadores de la vertiente occidental se desplazaban hacia el valle durante la estación estival. Esta última posibilidad implica ampliar el patrón costa-cordillera a otro del tipo costa-cordillera-sierra/valle del río Grande (Durán 2000, 2002) (Figura 3.2).

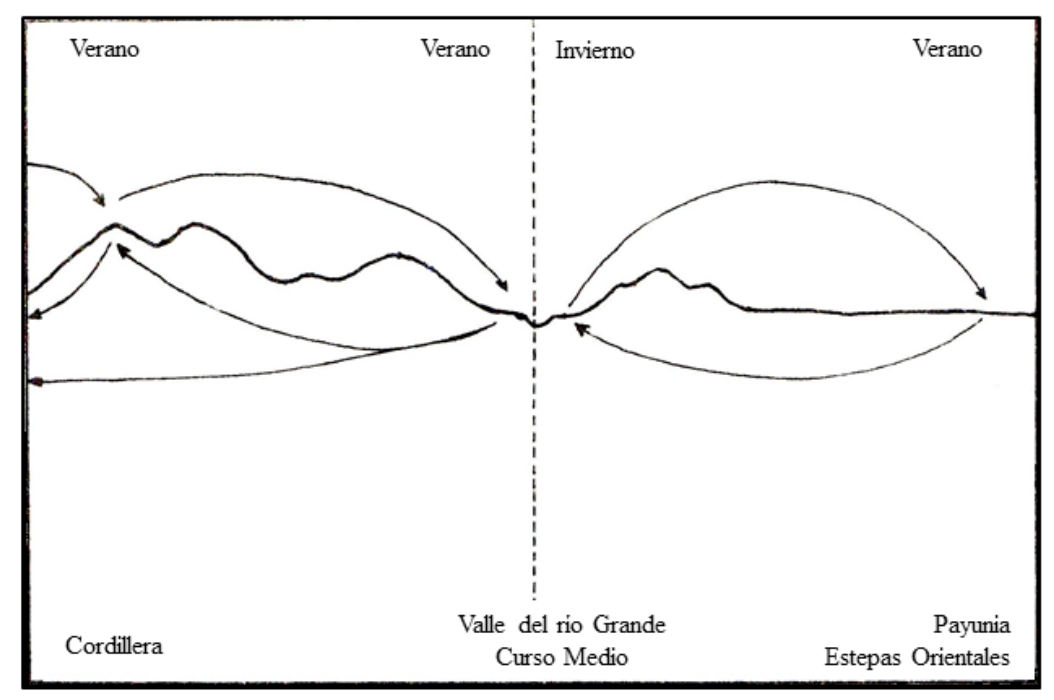

Figura 3.2. Esquema de aprovechamiento del valle del río Grande, que hace de ese río un límite inter-étnico. Tomado de Durán (2000: 183).

Asimismo, pone en duda la existencia de una "Etapa Agroalfarera" en el sudoeste de Mendoza, al afirmar que no están claros los criterios y datos para definir dicha etapa (Durán 1992). Además de estos aportes, las investigaciones de Durán plantean nuevos problemas, como por ejemplo: la posibilidad de que el hiatus del Período 2 se deba al impacto de erupciones volcánicas sobre las ocupaciones humanas (Durán 2000; Durán y Mikkan 2009); explicar por qué durante el Holoceno tardío (Períodos 5 y 6) los sitios de la margen derecha del río Grande presentan cerámica, mientras que sus contemporáneos 
de la margen izquierda son acerámicos, y si esto se debe a que el río Grande funcionó como un "límite" interétnico, no en el sentido de una barrera infranqueable, sino implicando relaciones intergrupales dentro del uso estacional de la región.

En una revisión de su modelo, Lagiglia (1997b) modificó algunos aspectos en la secuencia de desarrollo cultural que había planteado, aunque sin modificar radicalmente su propuesta (Gil 2006; Gil y Neme 2010). En esta reinterpretación presentó cuatro etapas (Paleoindia, Arcaica, Protoproductiva y Agroalfarera), que a su vez contienen distintas Tradiciones, Períodos y/o Culturas (Lagiglia 1997b; Lagiglia 2002). Lagiglia denominó a la secuencia "Desarrollo Cronológico Cultural de la Subárea Centro Oeste Argentino y de la Subárea Norpatagónica Mendocina Neuquina”, la cual constituyó una síntesis de las etapas de ocupación de la prehistoria del sur de la provincia de Mendoza (Lagiglia 1977b; 2002). Observó un desarrollo similar para ambas subáreas hasta aproximadamente 2.000 años AP, cuando habría tenido lugar una marcada divergencia que llevó al establecimiento de dos modos de vida diferentes: las sociedades agricultoras del centro oeste argentino (al norte del río Diamante) y los cazadores-recolectores de norpatagonia (al sur del río Diamante) (Figura 3.3). Sobre esta base, y siguiendo con la perspectiva histórico-cultural, Lagiglia (2002) planteó un modelo de ocupación continuo para el sur de Mendoza.

Sin embargo, tal y como indican Gil y Neme (2010), la distribución de los fechados radiocarbónicos en los que se basa la tendencia temporal del registro arqueológico no permite avalar un uso temporalmente "continuo" ni homogéneo del área como propone Lagiglia, y deben evaluarse momentos de abandono o variaciones en la intensidad de ocupación de la región (Gil y Neme 2010: 263; Borrero 2002). De hecho, existe un hiatus cronológico en las fechas radiocarbónicas de la cuenca media del Atuel entre aproximadamente 7.400 y 3.900 años AP (Gil y Neme 2010), lo cual no necesariamente conlleva a la extinción local de las poblaciones humanas, pero sí indica el problema que surge al definir un contexto desde la perspectiva histórico-cultural utilizada por Lagiglia y otros investigadores coetáneos (Gil y Neme 2010: 263). Además, Gil y Neme (2010) critican que, desde dicha propuesta teórica, se hayan construido unidades contextuales definidas a partir de las evidencias de un único sitio, Gruta del Indio (Lagiglia 1956a y b, 1968, 1997b, 2002), sin discriminar distintos aspectos dentro de la variabilidad existente intra e interconjuntos arqueológicos (muy significativa en cuanto a los modos de ocupación del valle y al tipo de dieta). Esto ha generado ciertos inconvenientes, tanto teóricos como operativos, para la integración de la diversidad 
regional (Gil y Neme 2010: 266), la cual ha sido uno de los objetivos centrales en los estudios ulteriores.

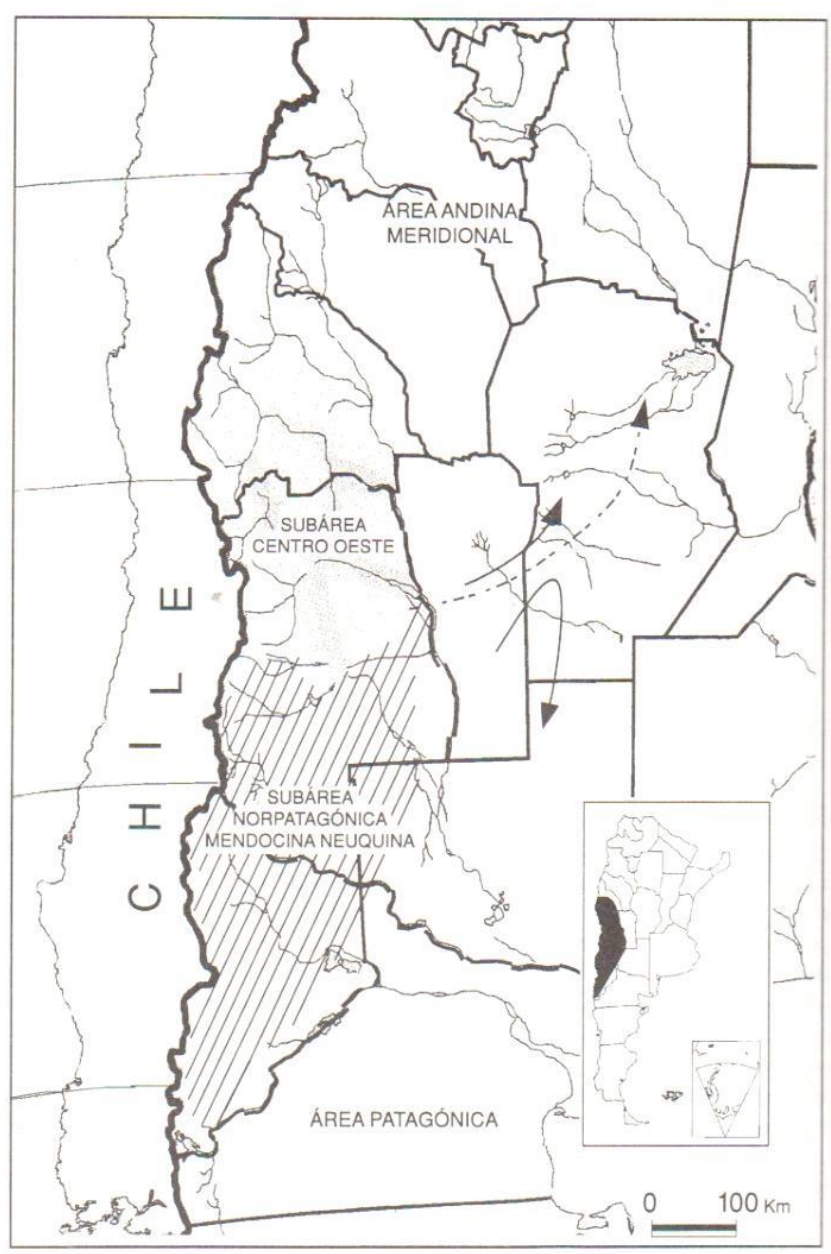

Figura. 3.3. Ubicación de las subáreas arqueológicas del Centro Oeste Argentino y

Norpatagonia Mendocina Neuquina. Tomado de Lagiglia (2002: 44).

\subsubsection{BIOGEOGRAFÍA Y POBLAMIENTO HUMANO}

En la década de los '90, aunque la visión histórico cultural que se había generado en los '60 se mantuvo vigente, sus ideas principales fueron evaluadas y discutidas desde nuevas perspectivas teóricas (Durán 1997, 2000; Gil 2002, 2006; Neme 2002, 2007; Neme y Gil 2002, 2008a; Gil et al. 2005; Neme et al. 2005; García 1995, 2003; Novellino 2002; Zárate 2002). Gil y Neme comienzan a desarrollar sus investigaciones arqueológicas en el sur de Mendoza desde una perspectiva biogeográfica (Neme y Gil 2008a; Gil 2006; Neme 2007) y bajo el marco teórico de la Ecología del Comportamiento Humano, lo que les permite realizar una aproximación innovadora al registro arqueológico de esta supra-región. 
En su tesis doctoral, Gil (2000) realiza una investigación regional sobre el campo volcánico La Payunia, al suroeste de la provincia de Mendoza, con el objetivo de conocer las estrategias humanas implementadas en el poblamiento de esta región con características ambientales de zonas áridas-semiáridas, y buscando también determinar el rol que cumplieron los cultígenos en dicho poblamiento regional. Subdivide a la región en dos amplias áreas sobre la base de rasgos geomorfológicos y ambientales: Área El Nevado (AEN) y Área El Payén (AEP). En AEN realiza tareas de relevamiento y excavación en los sitios: Los Leones-3, Los Leones-5, Agua de Los Caballos-1, Puesto Ortubia 1 (Figura 3.1). En el caso de AEP, releva y excava los sitios: Cueva Delerma, La Peligrosa-1, La Corredera y Piedras Bayas (Figura 3.1). Gil parte del supuesto de que la colonización, asentamiento y uso del espacio en zonas áridas-semiáridas como La Payunia, están regidos por el agua como factor crítico (Gil 2000, 2006). Observa que en esta región, la disponibilidad de agua es muy variable, impredecible, heterogéneamente distribuida y generalmente escasa, haciendo riesgosa la alta movilidad de los campamentos. Entonces, de manera hipotética, plantea que esta disponibilidad sería diferencial en AEN con respecto a AEP, temporal y espacialmente. También señala que habría diferencias en la permanencia de los campamentos residenciales de ambas áreas (Gil 2000, 2006). Considera que en los lugares donde el factor hídrico es crítico, las decisiones relacionadas al movimiento del campamento no dependerían tanto de la eficiencia de la explotación del recurso, sino más bien de asentarse con proximidad a las fuentes hídricas (Kelly 1995). Como consecuencia de lo expuesto, espera que en La Payunia la estructura de los recursos no sea el factor decisivo en cuanto al alcance espacial de la movilidad. Los movimientos individuales serían más comunes que los residenciales, y tales variaciones en frecuencia se correlacionarían con variables de la estructura ambiental (Gil 2000). En el caso de un ambiente desértico, el área de explotación de recursos sería más reducido ya que explotarían aquellos que se encuentran cerca del campamento localizado próximo al recurso hídrico (Tylor 1964; Kelly 1995).

Por otra parte, Gil (2000, 2002, 2006) postula cuatro "contextos": unidades de análisis que tienen significado temporal y arqueológico (también significativas en términos biogeográficos y ecológicos), construidas con el objetivo de acotar la variabilidad espacial y temporal en la organización de los sistemas. Estos contextos reflejarían las fases biogeográficas en el poblamiento de La Payunia: al Contexto A corresponde una ocupación muy efímera en los inicios del Holoceno medio (ca. 7.600 años AP), en el sitio arqueológico Cueva Delerma (AEP). Gil (2000) postula que la baja 
depositación arqueológica registrada posiblemente corresponda a la exploración de la región o a un uso efímero del sitio por "viajeros", con escasa explotación del área circundante a Cueva Delerma (Gil 2000, 2002). Luego señala un "hiatus arqueológico regional" (Gil 2000, 2002; Neme y Gil 2008a) de 5.000 años de duración que incluye parte del Holoceno medio y del Holoceno tardío, sin evidencias de ocupación humana. El registro arqueológico se reanudaría ca. 2.000 años AP, tanto en AEN con los registros de Cueva Ponontrehue, como en AEP con evidencias en el alero La Corredera, y podrían agregarse los registros de los niveles inferiores de Agua de La Mula y de Agua de Los Caballos 1. El registro arqueológico de La Corredera, es considerado como una nueva fase de exploración y/o colonización regional, lo que daría inicio al Contexto $B$ ubicado temporalmente entre los 2.000 y los 1.000-1.200 años AP. Estas ocupaciones indicarían un uso poco intenso de la región. Hacia finales del Holoceno tardío (entre 1.000-1.200 y 250 años AP), se habrían establecido los primeros sitios de actividades múltiples e instalaciones a cielo abierto, que manifestarían un depósito arqueológico significativamente más diverso y denso que los de momentos previos. Esto da lugar al Contexto $C$ caracterizado por una mayor estabilidad y frecuencia de uso que en fechas anteriores. Dicho contexto reflejaría la etapa de ocupación efectiva de La Payunia (Borrero 1989-90, 1994-95), momento en el que se incorpora nueva tecnología (uso de arco y flecha, y cerámica), el uso de plantas domésticas (e.g., el maíz) y de productos no locales (Gil 2000). Se registran en AEN elementos de molienda, restos de moluscos marinos y cerámicas no locales procedentes de la vertiente occidental de la Cordillera, elementos alóctonos que serían clave para comprender el poblamiento de La Payunia.

Para Gil los cultígenos registrados en esta región no habrían sido producidos localmente, sino obtenidos por interacción con vecinos agricultores (Gil 1997-1998, 2000). Luego, conforme comienza el Contexto D, Gil $(2000,2006)$ advierte cambios en la subsistencia, la organización tecnológica y, presumiblemente, la movilidad. Serían ocupaciones asimilables a las que Durán incluyó dentro del Período Hispano-Indígena (Períodos 7 y 8; Durán 2000). Gil (2000, 2006) observa, entre estas modificaciones, la incorporación de fauna euroasiática (Capra hircus y Ovis aries) y un notable incremento en la importancia dada a determinadas materias primas líticas como la obsidiana. Gil se plantea si este contexto corresponde a una etapa de ocupación efectiva con cambios en la organización del sistema preexistente (sensu Borrero 1994-95), o a una ocupación efectiva con saturación del espacio. En conclusión, Gil (2000, 2006) sostiene que ambas áreas de La Payunia, AEN y AEP, fueron colonizadas (AEN antes que AEP, y con 
ocupaciones más prolongadas y/o frecuentes) y ocupadas de manera efectiva hacia los últimos 1.200-1.000 años. Según este autor el registro arqueológico previo no correspondería al momento de colonización regional y sugiere que sea tomado cuidadosamente ya que su señal arqueológica es muy débil. Para el momento de colonización/ocupación efectiva, Gil $(2000,2006)$ asegura que, si bien los datos no concuerdan con las expectativas planteadas (encontrar diferencias entre AEN y AEP), las ocupaciones efectivas en AEN (generalmente asociadas a fuentes permanentes de agua) revelan mayor estabilidad e intensidad de uso de las bases residenciales que lo registrado para AEP.

Al considerar un marco espacial mayor, se comprende el porqué del reciente poblamiento de la región (Durán 2000; Gil 2000, 2006; Neme 2001, 2007): Gil parte del supuesto de la existencia de una jerarquía ambiental (vinculada con la productividad ambiental y el comportamiento de recursos críticos), que implica que los lugares con recursos hídricos estables y homogéneamente distribuidos, deberían ser colonizados y ocupados efectivamente (sensu Borrero 1989-90, 1994-95) antes que aquellos con recursos hídricos poco abundantes, inestables y heterogéneamente distribuidos (Gil 2006:34), que pueden ser evitados hasta el momento que sea necesario ampliar la base de recursos en las regiones vecinas más favorables. Como resultado, se le daría una jerarquía ambiental marginal a La Payunia (Gil 2002, 2006), en relación a las regiones vecinas (Neme y Gil 2008a).

En la región cordillerana del valle del río Atuel, Neme $(2001,2007)$ estudia principalmente los cambios en los patrones de asentamiento y modos de subsistencia de los grupos humanos, alrededor de 2.000 años AP. Estos cambios, que lo caracterizan y que lo distinguen claramente de los rasgos propios del Holoceno temprano y medio, son entre otros: el aumento en la cantidad de elementos de molienda, el incremento de materias primas no locales, la incorporación de cerámica, el aumento en el intercambio, la disminución relativa del guanaco en relación a otras especies, el registro de plantas cultivadas, la gran densidad de hallazgos superficiales y la aparición de aldeas o poblados con estructuras en las regiones por encima de los 2500-3000 msnm, ca. 1.400 años AP (Neme 2001, 2002, 2007).

El análisis de modelos arqueológicos y etnográficos sobre grupos que ocuparon ambientes de altura indican la presencia de rasgos característicos de la ocupación de estos ambientes, tales como: intercambio, movilidad y almacenamiento (Neme 2002, 2007). Por su parte, en su caracterización de los ambientes de altura, Neme (2001, 2002, 2007) 
menciona otros rasgos fundamentales de estos ambientes: la heterogeneidad ambiental, la variabilidad extrema, la baja predictibilidad, la baja productividad primaria y la alta inestabilidad y fragilidad (véase también Capítulo 4, Sección 4.1.1.2.3.); según él, los tres últimos tienen la responsabilidad del aumento de la movilidad residencial de los grupos humanos que explotan regiones de montaña (Neme 2002). Además de estas características, en estos ambientes las economías especializadas sobre un recurso, en una única zona ambiental y con crecimiento sostenido de la población, tienden a ser muy vulnerables, con alto riesgo, insuficientes niveles calóricos y bajo retorno per capita (Aldendelfer 1998).

En 1992, Neme profundiza los trabajos sistemáticos a lo largo del alto valle del río Atuel. Muestrea sitios localizados en tres grupos diferentes según el piso "ecotopográfico" correspondiente (Neme 2007): el Grupo A (entre 1500-1900 msnm), en el piedemonte, incluye a Ojo de Agua, Tierras Blancas y distribuciones superficiales en el arroyo La Manga.

El Grupo B (entre 1900-2500 msnm; zona ecotonal entre la provincia fitogeográfica Altoandina y la Patagónica), en los valles intermedios, comprende los sitios Arroyo Malo 1, Arroyo Malo 3, Arroyo Malo 4, Arroyo Malo 5, Arroyo Malo 6 y Cueva Arroyo Colorado (Figura 3.1), con fechados desde el Holoceno temprano en los niveles inferiores de Arroyo Malo 3, que constituye la ocupación más temprana de toda la región del alto valle del río Atuel, en particular, y de toda el área cordillerana del sur de Mendoza, en general. Este sitio presenta una secuencia de ocupación agrupada en cuatro conjuntos temporales: el primer conjunto corresponde a los últimos 2.200 años AP. El conjunto 2 data de 2.200-5.000 años AP. El conjunto 3 está fechado en 5.000-7.600 años AP. Por último, el conjunto 4 es el más antiguo: 7.600-8.900 años AP (Neme 2001, 2007; Pérez Winter 2008, 2010).

El Grupo $C$ (entre 2500-3600 msnm), en la cordillera, se corresponde con los sitios Los Peuquenes y El Indígeno (Neme 2002, 2007) (Figura 3.1). Las evidencias cronológicas de ambos sitios del Grupo C -los de mayor altitud- muestran ocupaciones muy recientes: inicio de la ocupación de El Indígeno en 1.470 años AP y ocupaciones tardías en Los Peuquenes de momentos pos contacto. Ambos presentan estructuras habitacionales, registran una gran cantidad de tiestos cerámicos locales y de contextos chilenos, una importante presencia de morteros, productos de talla e instrumentos como puntas de proyectil y raspadores -principalmente en obsidiana-, una gran representación de guanaco, y también una considerable cantidad de huesos de aves. Estos dos sitios se 
clasifican dentro de lo que denomina "Poblados de altura" que, además de localizarse espacialmente a $3000 \mathrm{msnm}$ y temporalmente a partir de 1.470 años AP, se caracteriza por presentar evidencias de alta reocupación.

Por otra parte, Neme destaca el incremento de materias primas no locales a través del tiempo. Entre ellas, la obsidiana aumenta hacia el Holoceno tardío, representando una mayor disponibilidad en los últimos 2.000 años. Además, este autor observa una tasa de descarte de instrumentos más alta y una disminución de los productos de talla hacia momentos más tardíos, lo cual fue interpretado como la elección de una estrategia tecnológica expeditiva, asociada a la disminución de la movilidad (sensu Binford 1979; Neme 2007). Neme (2002: 80) dice: "Para confirmar esta hipótesis es necesario corroborar si este patrón está ocurriendo a escala regional o es sólo un problema de disponibilidad o funcionalidad del sitio Arroyo Malo 3". Neme (2007) concluye en que un proceso gradual, influenciado por el incremento en la densidad de población regional, implicó una explotación más intensiva de estos ambientes de altura incorporando nuevas estrategias de aprovechamiento de los recursos y un cambio en los hábitos de consumo. Según él (Neme 2002, 2007), el desbalance entre la población y los recursos, se ve reflejado a través de un decrecimiento en la proporción de guanacos en los conjuntos posteriores a los 2.000 años AP, la incorporación de taxones animales más pequeños y el aumento en el uso de recursos vegetales. La ampliación de la dieta trajo aparejado un decrecimiento en la eficiencia forager (Broughton 1994a) debido al consumo de recursos de menor retorno energético. Todos estos cambios fueron caracterizados como parte de un proceso de intensificación en el uso de los recursos de esta región. Los indicadores arqueológicos asociados a dicho proceso fueron: un cambio en los patrones de movilidad, mayores costos de procesamiento de los alimentos, colonización de un nuevo hábitat, incremento en los sistemas de intercambio, fuerte énfasis en la recolección de vegetales, uso de estructuras habitacionales, mayor reocupación de los sitios, presencia de una estrategia tecnológica expeditiva, aumento en el número de instrumentos de molienda y la incorporación de innovaciones tecnológicas como la cerámica (Neme 2007).

En un trabajo posterior, Neme y Gil (2008a) combinaron las investigaciones realizadas en sus respectivas tesis doctorales, ya mencionadas. Utilizando el concepto de “ambientes marginales" (Borrero 2004), ambos autores establecen una "jerarquía de espacios" en la cual, la alta cordillera y los desiertos de La Payunia, ocupan los últimos lugares en el ranking de preferencia de las áreas del sur de Mendoza, mientras que el 
piedemonte y los valles intermedios serían las mejor ranqueadas. En segundo lugar se ubican los valles fluviales extra-cordilleranos (planicies orientales) (Figura 3.4).

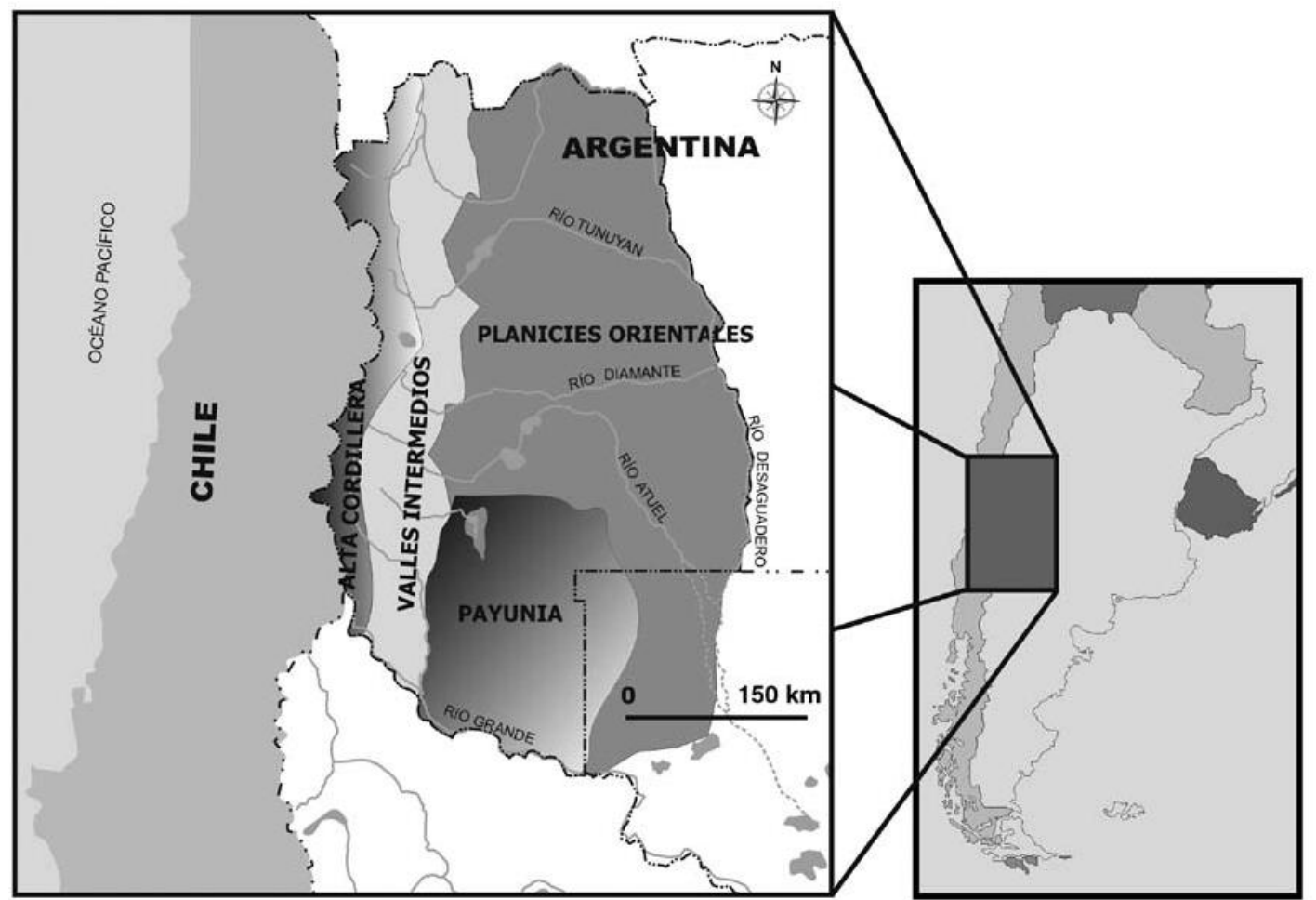

Figura 3.4. Ecorregiones del sur de Mendoza y jerarquía de espacios. Tomado de Neme y Gil (2008a: 7).

Además, Neme y Gil (2008a) propusieron abordar la cuestión del poblamiento de la región desde una perspectiva biogeográfica a partir de los conceptos propuestos por Borrero, del cual también tomaron su definición de jerarquía de espacios (Borrero 198990, 1994-95). Según el esquema de estos dos autores, el momento de exploración/colonización se habría dado primero en los sectores extra-cordilleranos $c a$. 11.000 años AP. El registro arqueológico comienza a consolidarse con un gran aumento hacia fines del Holoceno temprano y principios del Holoceno medio (hace aproximadamente, 8.000 años AP), ya no sólo en los cauces extra-cordilleranos, sino también en el piedemonte y los valles intermedios de cordillera. Sin embargo, la señal arqueológica disminuye drásticamente $c a$. 7.000-4.000 años AP, hasta desaparecer; por lo que se define a este momento de vacío en la señal arqueológica como un hiatus ocupacional (Gil et al. 2005; Neme y Gil 2008a, 2012). Esto ocurre en todos los ambientes del sur de Mendoza, a excepción de los sectores de los valles intermedios de cordillera (a unos $2000 \mathrm{msnm}$ ), que atestiguan sobre la presencia humana $c a$. 5.500 años AP en los 
sitios Arroyo El Desecho (AD-4) y Arroyo Malo 3 (AMA-3), en los valles del Salado y del Atuel, respectivamente (Neme y Gil 2008a: 12) (Figura 3.1). Las condiciones de aridez crecientes durante el Holoceno medio y la consecuente merma de la biomasa en las zonas a menor altitud habrían hecho de estos lugares altos, espacios preferibles para la ocupación humana (Neme y Gil 2008a: 15). Posteriormente, a principios del Holoceno tardío entre 3.800 y 3.200 años AP, reaparecen depósitos arqueológicos en casi todos los ambientes del sur mendocino. A esta situación de reocupación de las áreas ranqueadas más altas en el espectro ambiental de la región, Neme y Gil (2008a) la interpretan como consecuencia de un proceso de "recolonización" ocurrido en los valles fluviales extracordilleranos, el piedemonte y los valles intermedios, todos ellos paisajes con mayor y más estable disponibilidad de agua. Llaman así a este proceso ya que el registro no se corresponde con las expectativas de una "exploración" (posterior al hiatus del Holoceno medio) y debilita la posibilidad de abandono a escala espacio-temporal amplia de la región generando, asimismo, la expectativa de hallar registros de momentos previos (explorados/colonizados), que representen dicha instancia biogeográfica. Entonces, el concepto de "recolonización", implica entender que el abandono de un sitio, sector, localidad o área no necesariamente obliga a una nueva exploración (Neme y Gil 2008a: 13). A mediados del Holoceno tardío se da la etapa de ocupación efectiva de los espacios que habían sido "recolonizados" a principios del Holoceno tardío (valles fluviales extracordilleranos, el piedemonte y los valles intermedios). Un poco después, entre $2.000 \mathrm{y}$ 1.500 años AP, son colonizadas La Payunia y la alta cordillera. El hecho de que este proceso de colonización ocurra en estas áreas marginales ya avanzado el Holoceno tardío es explicado por Neme y Gil (2008a) como consecuencia de un proceso de intensificación regional dado principalmente por un desbalance entre la población y los recursos del área (Neme 2002).

De lo anterior surgen algunas consideraciones importantes: en primer lugar, es necesario hacer hincapié en el hecho de que las áreas marginales han sido utilizadas como lugares de extracción de obsidianas y otras rocas, incluso en momentos previos a su colonización. Esto posibilita plantear discusiones en torno al poblamiento de la región y uso del paisaje por los grupos humanos que la habitaron. En segundo lugar, pero no por ello menos importante, se deduce que el enfoque biogeográfico, como alternativa a la tradicional investigación histórico-cultural, implica ciertos problemas a resolver y tiene un alto potencial de refutabilidad, siendo un programa de investigación fértil y flexible (Neme y Gil 2008a: 16). En este sentido, pueden plantearse y discutirse cuestiones como 
la gradual incorporación de las fuentes de obsidiana desde el Holoceno medio, o el ingreso de las plantas domésticas y de la tecnología cerámica durante el Holoceno tardío.

\subsubsection{El registro arqueológico del Pleistoceno final-Holoceno temprano en la cuenca del Atuel}

La heterogeneidad ambiental del sur de Mendoza ha generado un contexto óptimo para formular una serie de preguntas biogeográficas (Neme y Gil 2012); algunas de estas problemáticas son: comprender las diferencias en la relación humanos-megafauna entre el Centro-Occidente argentino y las áreas adyacentes, el poblamiento humano de la región, el límite austral de la dispersión agrícola pre hispánica, las diferencias en el uso de los recursos animales y vegetales en cada área y las diferencias regionales en los patrones tafonómicos de la región, las fuertes diferencias en el uso y circulación de la obsidiana tanto a nivel espacial como temporal, y las variaciones en la frecuencia de tipos y cantidades de cerámica en relación a la estructura de los recursos regionales (Neme y Gil 2012). Estos autores señalan la importancia de considerar las variaciones que existen en términos de resolución temporal y/o espacial de las distintas líneas de evidencia y de la necesidad de abordar el registro en diferentes escalas de análisis.

Como se ha visto, un tema muy debatido desde los inicios de la arqueología del sur de Mendoza es el momento del ingreso de las primeras poblaciones humanas. En un comienzo, se propuso que habrían sido muy tempranas y que habrían explotado la megafauna que se encontraba en el lugar (Semper y Lagiglia 1962-68; Lagiglia 1977a, 2002; entre otros). Sin embargo, y si bien hubo más de mil años de coexistencia de seres humanos y megafauna, estudios posteriores no pudieron demostrar su asociación. Los restos óseos analizados no presentan señales de exposición al fuego, ni tampoco se perciben en ellos huellas de actividad humana (Lagiglia y García 1999; García 2003; García y Lagiglia 1999; Gil et al. 2011a; Gil y Neme 2010; Forasiepi et al. 2010; Long et al. 1998; Neme y Gil 2008a, 2012). Aunque la megafauna habría estado disponible en la mayoría de los ambientes del sur de Mendoza entre $c a .31 .000$ y 9.000 años ${ }^{14} \mathrm{C} \mathrm{AP}$ (García y Lagiglia 1999), no habría sido explotada por los grupos humanos (Barberena et al. 2010; Neme y Gil 2008a; Forasiepi et al. 2010; Praderio et al. 2012). 


\subsubsection{El registro arqueológico del Holoceno medio en la cuenca del Atuel}

Otro de los temas controversiales en la arqueología del sur de Mendoza se refiere a las ocupaciones humanas durante el Holoceno medio (8.000-4.000 años AP) (Durán 2000; Gil et al. 2005; Neme y Gil 2009, 2010; García 2010; Durán y Mikkan 2009), cuya señal arqueológica es muy débil o ausente desde $c a$. 7.000 años AP. Esta escasez de evidencia ha sido explicada de distintas formas, las cuales pueden resumirse en: resultado de problemas de muestreo (García 2005, 2010), de catástrofes ambientales (Durán 2000; Durán y Mikkan 2009) o de fluctuaciones ambientales y climáticas (Gil et al. 2005; Neme y Gil 2009, 2010). En este último caso, se propuso concretamente que un aumento de la aridez habría forzado cambios en los sistemas de movilidad de las poblaciones (perjudicando la visibilidad del registro arqueológico) y/o migraciones hacia espacios con mejores condiciones para la subsistencia (Gil et al. 2005).

\subsubsection{El registro arqueológico del Holoceno tardío en la cuenca del Atuel}

Con respecto a los cambios ocurridos a partir del Holoceno tardío, trabajos posteriores a la propuesta de Semper y Lagiglia (1962-68), y Lagiglia (1977a), buscaron contrastar este modelo de secuencia regional de desarrollo cultural, a través de diferentes vías de análisis. Neme (2007), considera que la característica más importante de este momento es la aparición de las Aldeas de altura y, con ellas, el comienzo de la explotación estacional de los ambientes ubicados por encima de los 2500 m.s.n.m., ca. 1.400 años AP. Esto conllevó a la formulación de nuevas preguntas que aún necesitan ser exploradas (Gil 1997-1998, 2003, 2006; Neme 2002; Gil y Neme 2010), las cuales han estado relacionadas principalmente con: la importancia de las plantas domésticas (Novellino y Guichón 1997-1998; Hernández et al. 2001; Gil 1997-1998; 2003; 2006; Gil et al. 2010, 2011b; Ugan et al. 2012; Llano 2011; Llano y Andreoni 2012); y la utilización de los recursos de un ambiente espacialmente muy variable (Gil 2002, 2006; Neme 2002; Gil et al. 2005; Corbat et al. 2009; Johnson et al. 2009; Llano 2011; Llano y Andreoni 2012; Llano et al. 2012; Giardina 2012; Otaola et al. 2012). Algunos ejemplos concretos de estos estudios son varias tesis doctorales realizadas en los últimos años, como las de Llano, Fernández, Giardina, Otaola y Corbat. Llano (2011) realiza un estudio sobre el retorno económico de los vegetales de la región, y evalúa bajo qué condiciones se incorporaron los recursos silvestres y domésticos en la dieta humana. Las otras cuatro tesis se enfocaron en estudios zooarqueológicos poco considerados hasta ese momento en el área, como la explotación de aves (Giardina 2010), micromamíferos (Fernández 2012) 
e ictiofauna (Corbat 2016), y los análisis tafonómicos de los conjuntos óseos (Otaola 2012). En los cuatro casos se ajustó y replanteó la hipótesis general sobre la “intensificación” propuesta por Neme $(2002,2007)$ para ca. 1.500-2.000 años AP, la cual habría generado cambios (e.g. reducción de la movilidad de los grupos cazadoresrecolectores), en respuesta a un desbalance entre la población y los recursos, probablemente a causa de un aumento en la presión demográfica. Estos estudios sugieren que el aumento en la explotación de recursos de menor rendimiento no ha sido homogéneo en los distintos sectores del área, ni sincrónico en la escala macro regional (Otaola et al. 2012).

El tema de la llegada de las plantas domésticas al sur de Mendoza fue abordado originalmente a través de la distribución espacial y cronológica de los macro restos vegetales (Semper y Lagiglia 1962-68; Lagiglia 1968; Gil 1997-1998; 2000; 2003; 2006; Gil et al. 2010, 2011b, 2012; Hernández et al. 2001; Llano 2011; Llano y Andreoni 2012). Las tendencias observadas mostraron una mayor ubicuidad del maíz y en menor medida de zapallo, poroto y quínoa. Además también se destacó la existencia de dos pulsos en el registro de este tipo de evidencia, uno $c a$. 2.000 años AP y el otro para los últimos 1.200 años AP (Gil et al. 2011b). La distribución espacial registró la presencia de domesticadas en el interfluvio Atuel-Diamante con un registro un poco más austral en el área del Nevado (sitios Agua de los Caballos, Puesto Ortubia, Zanjón del Buitre) (Figura 3.1). La problemática de la domesticación fue considerada posteriormente a la luz del registro faunístico (Neme y Gil 2008b) y finalmente a partir de los datos isotópicos.

En este sentido, más específicamente para los últimos 2.000 años AP, se observan tendencias en los datos de isótopos estables (Gil et al. 2012) hacia cambios en la dieta de los grupos humanos en relación a un uso creciente de plantas domésticas (simultáneamente al uso de recursos animales menores como peces, roedores medianos, aves -mencionados antes-, huevos de reídos, etc.). El uso de los isótopos estables en la arqueología del sur de Mendoza se inició en apoyo a la discusión del límite de la frontera agrícola prehispánica (Gil et al. 2012). Este debate giraba en torno a la idea del establecimiento de comunidades agrícolas al menos hasta el valle del Atuel, desde unos 2.000 años AP (Lagiglia 1980), sin plantear variaciones en las dietas humanas durante ese período. Como ya se ha dicho (Sección 3.2.1.1. y Figura 3.3; en este capítulo), Lagiglia planteó para ese momento una marcada divergencia en el modo de vida de las poblaciones al norte y al sur del río Diamante: sociedades productoras de alimentos y cazadores-recolectores, respectivamente. En tal discusión, el uso del maíz como proxy 
sirvió para monitorear isotópicamente el establecimiento y desarrollo de la agricultura (Gil 2003). Los resultados del análisis isotópico de muestras de colágeno humano, señalaron principalmente un mayor enriquecimiento en el Atuel medio respecto a cordillera, piedemonte y La Payunia. Tal tendencia indicaría el escaso aporte directo y/o indirecto de recursos $\mathrm{C}_{4} \mathrm{y}$ su alta variabilidad a lo largo de los últimos 2.000 años AP (a la par de una dieta proteica de origen animal); además, la tendencia general destacó una caída en los valores de $\delta^{13} \mathrm{C}$ durante los últimos 500 años (Gil y Neme 2010; Gil et al. 2010). Por ende, "los valores de colágeno señalaron un patrón de dieta altamente variable, donde el rol del maíz nunca fue central ni estable a lo largo de los últimos 2.000 años. La incorporación de los valores obtenidos en apatita confirmó y acentuó la escasa importancia del maíz" (Gil et al. 2012: 142). Como plantea Gil (2006), las particularidades ambientales de La Payunia pudieron generar la necesidad de establecer redes de interacción con grupos productores de alimentos de regiones vecinas, lo cual explicaría la presencia de cultígenos en el registro arqueológico de La Payunia y la ausencia de evidencias de su producción local. Propone que esto no necesariamente tiene que ver con el ingreso de dietas alternativas, sino con la existencia de redes de alianza sin implicancias en la subsistencia (Gil 2006). Otra posibilidad es que las tierras de La Payunia hayan sido incorporadas en circuitos de subsistencia debido al uso logístico dado desde otros centros, probablemente como ampliación de rangos de movilidad antes que como saturación del espacio disponible (Borrero 2002).

Complementariamente a las líneas antes descriptas, los estudios de organización tecnológica y movilidad han sido explorados recientemente desde los análisis cerámicos (Sugrañes y Franchetti 2012; Sugrañes 2017) y, principalmente, líticos, como respuestas adaptativas a las condiciones ambientales. Con respecto al perfil adaptativo de la tecnología cerámica de las poblaciones humanas del sur de Mendoza, se ha propuesto que su introducción a partir de 2.000 años AP coincide con el proceso de intensificación experimentado por los cazadores-recolectores cordilleranos, lo que provocó cambios en los patrones de asentamiento y en los modos de subsistencia, y una ampliación en las redes de intercambio en el sur de Mendoza, en respuesta a un aumento demográfico (Neme 2001, 2007, 2009; Neme y Gil 2006). Este periodo de intensificación vendría acompañado de una reducción en la movilidad, de un aumento en la territorialidad, de un proceso de regionalización en toda la zona de Cuyo y Chile central, y de una creciente diferenciación social (Neme 2002, 2007). Todo esto se reflejaría, entre otros aspectos, en una mayor cantidad y diversidad de restos cerámicos en términos tecnológicos (tamaño 
del antiplástico, espesor, tratamiento de superficie, decoración, cocción, etc.) y estilísticos (uso de pulidos, incisos, engobes, etc.) en sitios de alta cordillera del flanco oriental (El Indígeno, Valle Hermoso y Los Peuquenes), con estilos considerados de la vertiente occidental de la cordillera (e.g. cerámica Aconcagua, considerada como no local o exótica en los tres sitios mencionados); que en sitios de valles intermontanos-piedemonte y planicie oriental (Gruta El Manzano, Llancanelo y Atuel Medio) (Neme 2007; Sugrañes y Franchetti 2012) (Figura 3.1). Un motivo de esta variación puede ser que la escasez de recursos leñosos en las cercanías a los sitios localizados en ambientes más altos haya limitado la fabricación de cerámica, provocando la necesidad de transportar cerámica confeccionada en áreas vecinas a menor altitud y con mayor disponibilidad de leña (Neme y Gil 2012).

En cuanto a los análisis líticos, al aplicar el modelo biogeográfico propuesto por Borrero (1994-95) al poblamiento humano de diferentes áreas del sur de Mendoza (Gil y Neme 2002; Neme y Gil 2008a), no se priorizó en primera instancia la incorporación de la información sobre la tecnología lítica, sino que, concisamente, se utilizó aquella concerniente a las bases regionales de rocas que permitiera evaluar las interacciones a distancia con respecto al traslado de las mismas. En este sentido, los estudios geoquímicos sobre fuentes y artefactos de obsidiana del sur de Mendoza que se vienen desarrollado intensamente desde hace más de 20 años (Seelenfreud et al. 1996; Durán et al. 2004; Barberena et al. 2011; Giesso et al. 2011a; Cortegoso et al. 2012), han caracterizado a las fuentes de obsidiana detectadas y han abordado estudios de circulación y procedencia de los artefactos confeccionados en esta materia prima, señalando una direccionalidad diferencial entre los ambientes del sur de Mendoza. Sin embargo, aún queda pendiente evaluar la representatividad de las muestras caracterizadas geoquímicamente y es necesario determinar la importancia de cada cantera en cada una de las áreas estudiadas para discutir modelos biogeográficos del uso de ambientes áridos y de altura (Cortegoso et al. 2012). Además, sólo recientemente se ha puesto hincapié en los aspectos tecnológicos que hacen al abastecimiento, transporte, manufactura, uso y descarte de obsidianas (Salgán et al.2012b, 2015; Salgán y Pompei 2017).

En suma, a partir de lo expuesto, surge que, si bien varios estudios previos abordaron el tema de la organización tecnológica, lo hicieron básicamente en relación con la subsistencia (Gil 2000, 2002) y poco se ha avanzado en cuanto a las características del registro lítico, particularmente en el valle del Atuel (Pérez Winter 2008). Es necesario, 
por lo tanto, profundizar en este tipo de estudios para validar o reformular los modelos regionales planteados con anterioridad.

\subsection{ESTUDIOS PRECEDENTES SOBRE LA ORGANIZACIÓN DE LA TECNOLOGÍA LÍTICA}

Al focalizar el estudio arqueológico en la tecnología lítica, se observa que también se ha planteado una gran diversidad de enfoques teórico-metodológicos para su abordaje (Leroi-Gourhan 1964; Binford 1973, 1977, 1979, 1980; Bamforth 1986; Bleed 1986; Shott 1986; Kelly 1988; Torrence 1989a y b; Nelson 1991; Jeske 1992; Lemonnier 1992; Nami 1992; Andrefsky 1994, 2009; Böeda 1995; Bamforth y Bleed 1997; Whittaker 1997; Hiscock 2001; Kuhn 2004; Bamforth 2006, entre otros). Sin embargo, en sus inicios, los estudios del material lítico se centraban en el análisis específico de los instrumentos. Así, durante la primera mitad del siglo XX y principios de la década de 1960, estos estudios estaban orientados a la creación de "tipos" de instrumentos, tan específicos temporal y espacialmente que sirvieran como rasgo diagnóstico o "fósiles guía”, y permitieran la construcción de secuencias cronoestratigráficas. Estos tipos se utilizaban para definir "industrias", vinculadas a su vez a "culturas" definidas (Cortegoso 2005b; Civalero 2006).

Más tarde, al tomar consciencia de que la tecnología lítica es substractiva y de que los instrumentos van cambiando conforme avanza su vida útil, muchas de las tipologías diseñadas hasta ese momento fueron puestas en consideración, ya que las tipologías debían ser capaces de reflejar tales modificaciones para poder ser contempladas como indicadores útiles de tiempo, espacio y función. Esto llevó a entender a los instrumentos como elementos dinámicos de la cultura material (Civalero 2006). En este sentido, la Nueva Arqueología, entiende al pasado en un sentido dinámico y considera clave como parte de los procesos culturales, a la adaptación permanente de los seres humanos al medio ambiente (Binford 1965, 1968, en Cortegoso 2005b).

Entonces, la tecnología es considerada como el vínculo entre las sociedades y su entorno; su estudio se enfocó primero en la reconstrucción de los patrones de movilidad y sistemas de asentamiento, y en la manera en que estos determinan necesidades artefactuales y el acceso a las materias primas (Carr 1994). El análisis específico de instrumentos había requerido también hacer hincapié en el otro extremo de la secuencia. 
En las últimas décadas las propuestas teóricas se aplicaron a la interpretación de los conjuntos líticos (Cortegoso 2005b). Algunas metodologías han acompañado este desarrollo teórico en el análisis de los conjuntos líticos; entre ellas se destacan los modelos de flujo o estudios de secuencia, desarrollados desde los años '60, tanto en la escuela francesa como en la norteamericana, los cuales permiten relacionar objetos aparentemente distintos, estudiándolos en términos cognitivos o de comportamiento.

Los arqueólogos franceses han usado el concepto de chaîne opératoire o cadena operativa derivado de la etnología a partir de las iniciativas de Leroi-Gourhan (1964) en Le geste et la parole (El gesto y la palabra), y por Lemonnier (1992), quien considera que la técnica recubre tres órdenes de hechos (objetos, procesos y conocimientos) y que está conformada por cinco componentes: materia, energía, objetos, gestos y conocimientos. Estos autores ponen el acento en los aspectos cognitivos del comportamiento. Otra línea intelectual desarrollada en Francia fue la impulsada por arqueólogos como Bordes (1961) y por Tixier en los años '60. Estos autores realizaron la replicación experimental de piezas del Paleolítico europeo (Civalero 2006) y consideraron que la técnica revela la ejecución, y el método los conocimientos.

Los modelos secuenciales norteamericanos, a diferencia de los estudios franceses

que ponen énfasis en los aspectos técnicos-, se centran en el desarrollo teórico organizacional en un sentido más amplio, buscando conocer cómo fueron estructuradas las actividades tecnológicas (Cortegoso 2005b; Civalero 2006). En el marco procesual de la Nueva Arqueología de los '60, el interés estaba puesto en la comprensión de los artefactos líticos como parte de un sistema dinámico del pasado, entendiendo los procesos implicados en la adquisición, producción, intercambio y consumo del instrumental lítico (Yerkes y Kardulias 1993, en Civalero 2006). Así, Schiffer (1972, 1975, 1976) denominó al proceso de producción lítica como "cadena del comportamiento", y propuso un modelo de comportamientos secuenciales desde la producción de artefactos (contexto sistémico, dinámico) hasta su depositación en el registro arqueológico (contexto arqueológico, estático). Estos modelos secuenciales estadounidenses se centran en dos características de la tecnología lítica: la producción de instrumentos líticos y la historia de su uso. Esto ha permitido discutir diferentes problemas relacionados con los sistemas tecnológicos del pasado (Civalero 2006). En esta tesis se utilizan principalmente tres de estos modelos: la secuencia de producción lítica en el sentido de Aschero (1975, 1983; Aschero et al. 1995), el modelo de producción lítica de Nelson (1991), a partir del cual ella aborda también la 
distribución de actividades tecnológicas en diferentes sitios, y el sistema de producción lítica de Ericson (1984).

Cabe mencionar en este compendio, el estudio de Torrence (2001) quien propone dos escalas de trabajo. Por un lado, la micro-escala incluye casos particulares, un contexto social determinado, con actores y conocimientos definidos. Se abordan aspectos ideológicos, simbólicos y sociales, tomando a la tecnología como una actividad social, donde los instrumentos son socialmente producidos y tienen un significado simbólico. Las investigaciones francesas mencionadas (Leroi-Gourhan 1964; Lemonnier 1992; entre otras) pueden clasificarse dentro de esta escala de análisis. Por otro lado, a una escala más amplia, regional o macro-escala se pone énfasis en el ambiente, en el manejo de las materias primas y de los instrumentos, y por ende aborda aspectos económico-ecológicos. Esta escala incluye estudios sobre organización de la tecnología, diseños y estructuras de los conjuntos líticos (sensu Nelson 1991).

Dadas las preguntas que guían la investigación de esta tesis, la escala regional en términos de Torrence 2001- es la más adecuada para los propósitos planteados, ya que el marco de la organización de la tecnología lítica que concierne a dicha escala, considera al conjunto de decisiones y estrategias tecnológicas (conservadas, expeditivas y oportunistas) para la transformación de los recursos, en relación a la variabilidad artefactual lítica de cada conjunto, que a su vez se vincula con aspectos funcionales, adaptativos y/o simbólicos. Entonces, también es posible analizar conjuntos líticos desde este marco a una escala menor donde se puedan apreciar mecanismos ambientales que estén influyendo en la relación humano-ambiente a escala local o de sitio (sensu Dincauze 2000). Con respecto a la dimensión temporal, Cortegoso (2005b) asegura que las explicaciones alcanzadas desde la organización de la tecnología son necesariamente funcionales y aplicables a estudios sincrónicos. Por lo tanto, para abordar procesos de cambio tecnológico a través del tiempo se requieren marcos que contemplen variables diacrónicas con una perspectiva de cambio orientada teóricamente y contrastable a nivel arqueológico (Cortegoso 2005b).

\subsubsection{ORGANIZACIÓN DE LA TECNOLOGÍA LÍTICA EN ARGENTINA, EN} MENDOZA Y EN LA CUENCA DEL ATUEL

Como se vio en el apartado anterior, los estudios de tecnología lítica han tenido un desarrollo paralelo pero distinto en diferentes partes del mundo (Leroi-Gourhan 1964 y Lemonnier 1992, entre otros representantes de la escuela francesa; Binford 1973, 1977, 
Kelly 1988, Shott 1986 y Kuhn 2004, entre otros estudiosos norteamericanos). En Argentina, distintas perspectivas han aplicado metodologías semejantes, pero se han desarrollado de manera desigual en distintas regiones del país, siendo mayoritarias las investigaciones en el NOA (énfasis en sociedades productoras de alimentos) y en Patagonia (hincapié en sociedades cazadoras-recolectoras); y menores en Pampa, NE y Cuyo.

En la historia de las investigaciones argentinas sobre tecnología lítica se observa que, luego de un escaso desarrollo a comienzos del siglo $\mathrm{XX}$, estos estudios cobran mayor interés a partir de la década de 1930 con el apogeo del paradigma histórico-cultural y su concepto de "tipo" de origen europeo para la creación y aplicación de tipologías líticas, industrias, tradiciones, secuencias culturales y periodizaciones, y para la identificación de difusión de rasgos (c.f. Boschín y Llamazares 1984). Hacia los años '70, se sistematizan los análisis y se especializan y diversifican las metodologías aplicadas al análisis lítico, pero el objetivo principal continuó siendo la construcción de la historia cultural en el sentido amplio del término, aunque con cierta cautela para eludir connotaciones difusionistas. Luego, se incorporaron estudios realizados en el marco de la arqueología procesual y más tarde en el de la organización de la tecnología, lo cual implicó revisar y ajustar los modelos y categorías planteados desde la escuela histórico-cultural austroalemana.

La tipología de Aschero (1975) fue utilizada ampliamente en todo el país permitiendo utilizar un lenguaje común para el abordaje de gran parte del conjunto artefactual. A su vez, se incorporan metodologías nuevas derivadas de los estudios actualísticos como la arqueología experimental, tafonomía y etnoarqueología; y se comienzan a diseñar temas como la búsqueda de individualizar actividades en los sitios, especialmente de manufactura o de talla.

Hacia los años '80, continuaron las revisiones y críticas a la escuela históricocultural a partir del concepto clave de "actividad" (muy operativo para trabajar a escala micro-regional), aunque aún en la actualidad continúan siendo vigentes los trabajos enmarcados en esta perspectiva teórico-metodológica europea. En esta época se desarrolla plenamente la especialización en estudios líticos.

A principios de los '90, ya se nombraba a la organización tecnológica y a muchos de los modelos y conceptos derivados de este marco teórico, que siguen conformando el eje central de los trabajos actuales. Después, se desarrollan gran variedad de temas principalmente encarados desde la perspectiva de la organización tecnológica, y aparecen 
trabajos que interrelacionan la tecnología con otros aspectos de la vida social, dándose una tendencia creciente a incorporar enfoques sociales y de arqueología del paisaje. El material lítico se aplica en discusiones de temas como redes de intercambio, territorialidad, simbolismo y complejización (Nami 2001; Flegenheimer y Bellelli 2007) ${ }^{1}$.

En los últimos años, siguen confluyendo diversas temáticas abordadas a partir de variadas propuestas teóricas y metodológicas, lo que resulta en diferentes tipos de trabajos: los que siguen poniendo el foco en la construcción de secuencias temporales; los que trabajan desde el concepto de cadena operativa de la escuela francesa y buscan conocer los gestos técnicos, prácticas y hábitos de los talladores (e.g. Hocsman 2009; Bobillo y Hocsman 2015); los que se enfocan en la tecnología desde el aspecto organizacional (e.g. Escola 2000, 2004a y b; Franco 2002b, 2004; Cortegoso 2005b); los que estudian bases regionales de recursos líticos y el aprovisionamiento en canteras, se focalizan en la movilidad y circulación de tales recursos, y/o en su relación con la construcción de los paisajes arqueológicos (e.g. Bayón et al. 1999; Hermo 2008; Charlin 2009a; Colombo 2013; Salgán 2013); los que abordan estudios actualísticos como la experimentación o la tafonomía de conjuntos líticos (e.g. Borrazzo 2010; Weitzel 2010); los que realizan análisis espaciales basados en el uso de SIG (e.g. Barrientos et al. 2014; Lucero 2015); los que estudian patrones de variación artefactual desde una perspectiva fenotípica (e.g. Barrientos 2016); los que hacen análisis de morfometría geométrica (e.g. Charlin y González-José 2012); los que elaboran análisis cladísticos (e.g. Cardillo y Alberti 2015), etc.

\subsubsection{Estudios de tecnología lítica en regiones vecinas del sur de Mendoza}

En lo que respecta a las regiones aledañas al sur de la provincia de Mendoza, varios estudios referidos a conjuntos líticos (García 2003; Berón 2004; Durán et al. 2004; Cortegoso 2005a y b; Prates 2008) plantean interacciones supra-regionales que involucran a la cuenca del río Atuel como parte de un circuito macro-regional de interacción, o como región a explotar desde otros espacios.

\footnotetext{
${ }^{1}$ Para un análisis más detallado de los estudios sobre tecnología lítica en Argentina, véase: Nami (2001) quien hace una revisión general de trabajos sobre análisis lítico desarrollados 25 años antes de su publicación; y Flegenheimer y Bellelli (2007) quienes, a modo de compendio sobre esta temática, realizan una revisión de la colección completa de la revista Relaciones de la Sociedad Argentina de Antropología, desde el volumen I en el año 1937 hasta su $70^{\circ}$ aniversario.
} 
Basándose en semejanzas morfológicas y tecnológicas de las piezas halladas, Austral (1971, en Gil 2006) incluyó al sur mendocino y a la región pampeana en un modelo macro regional. Propuso integrar en una misma área arqueológica los hallazgos del sitio paradero-taller Vallejo (La Pampa) (Figura 3.1) con los de sitios del sur de Mendoza. En esa misma área también se integrarían -en un solo complejo industrial- dos industrias: la Pampeana Bonaerense y la Industria Pampeano Atuelense, esta última caracterizada según distintos criterios empleados por Austral, los cuales incluyen cerámica tosca, puntas líticas de proyectil triangulares apedunculadas, raspadores microlíticos, morteros y manos, además de la presencia/ausencia (y sus cantidades) de unifaces (Austral 1971: 68, en Gil 2006). La Industria Pampeano Bonaerense se correspondería contemporáneamente con el Período Reciente de la Etapa Ceramolítica (3.000-4.000 años AP, aproximadamente). Si bien estos planteamientos son acordes al contexto histórico de las investigaciones arqueológicas en el país, Gil critica a Austral por la falta de consideración de la variabilidad intersitio y funcionalidad ocupacional, y considera que "se trataría de un ordenamiento evolutivo cuya validez como ordenamiento cronológico cultural ha sido cuestionado en otras regiones" (Gil 2006: 17).

En la cuenca media del río Negro (provincia de Río Negro), Prates (2008) estudió el registro arqueológico de numerosos sitios superficiales y estratigráficos pertenecientes al Holoceno tardío. En estos se habrían realizado actividades múltiples, incluyendo el aprovisionamiento y reducción de materia prima lítica, y la formatización de instrumentos (Prates 2004). Se explotaron materias primas procedentes de fuentes secundarias locales para la confección de instrumentos a partir de una estrategia expeditiva (Prates 2008). Dentro del grupo tipológico de las puntas de proyectil, Prates (2008) observa que la morfología más abundante en estos conjuntos es de tipo apedunculada y de tamaño pequeño. Este autor propuso que tales puntas predominaban al norte de la cuenca del río Negro y Limay (sector más próximo al sur de Mendoza), y las puntas provistas de pedúnculo se hallaban con mayor frecuencia al sur de ambos ríos (Prates 2008).

En el norte de Neuquén, Barberena y colaboradores (2011) analizaron la distribución de la señal geoquímica de la fuente de obsidiana Cerro Huenul y plantearon diferentes hipótesis para dar cuenta de su distribución y posible traslado por medio de intercambio. En esta misma región, Rughini (2016) analizó la tecnología lítica de dos cuadrículas de excavación del sitio Cueva Huenul 1 (Figura 3.1), donde se dan dos momentos de ocupación: Holoceno temprano, entre ca. 11.000-10.000 AP; y Holoceno tardío, en los últimos 1.600 años. Estas fechas evidencian un hiatus ocupacional para el 
Holoceno medio y comienzos del Holoceno tardío. Tras su análisis, la autora concluye que en el primer momento la intensidad de uso humano del sitio fue baja, caracterizándose por estadías breves y esporádicas, y por el empleo de una estrategia de equipamiento de los individuos. Luego, durante el Holoceno tardío, sugiere la continuidad de las mismas tendencias tecnológicas, aunque con una mayor diversidad de grupos tipológicos sobre obsidiana local (fuente Cerro Huenul, explotada sistemáticamente desde el Holoceno temprano), utilizada preferentemente de manera expeditiva, una mayor presencia de rocas silíceas y una mayor frecuencia de descarte de instrumentos -tanto formales como informales-, posiblemente como consecuencia de una intensidad de ocupación mayor (Rughini 2016).

En la región de Cuyo, en la década de los '90 se realizaron las primeras investigaciones sobre tecnología lítica basadas en una perspectiva organizativa (Cortegoso 2004, 2009; Campos et al. 2006). El trabajo de García (2003) en el sitio Agua de la Cueva, al norte de Mendoza (Figura 3.1), brindó información concerniente a ocupaciones tempranas de los Andes Centrales de hace $c a$. 11.000 - 7.500 años $\mathrm{C}^{14}$ AP. Además, García (2003) indica un uso predominante de recursos líticos locales y la existencia de mecanismos de acceso a productos alóctonos como la obsidiana (e.g. encuentros sociales, intercambio, movimientos de larga distancia). Considera que las sociedades de finales del Holoceno temprano habrían modificado la elección de las especies cazadas en momentos previos, involucrando así un cambio en el diseño del conjunto de artefactos líticos, sin evidencias de cambios en el patrón de asentamiento o en la intensidad de explotación de recursos vegetales (García 2003).

En su tesis doctoral, Cortegoso (2004) realiza un estudio sobre la tecnología lítica de la cuenca del Río Blanco, localizada en el departamento de Luján de Cuyo, al noroeste de la provincia de Mendoza. Su interés de investigación está dirigido hacia la explotación de los recursos líticos, evaluando las diferencias en el asentamiento y el cambio en la subsistencia desde sociedades cazadoras-recolectoras hacia grupos humanos que incorporan productos cultivados en su dieta. El rango cronológico involucrado comprende unos 5.000 años, incluyendo momentos del Holoceno medio y del tardío (sitio El Piedrón 01, en Cordillera, fechado en 5.500 años AP; y sitio Río Blanco 01, en el valle de Potrerillos, datado en 1.200 años AP). Entre los objetivos de su tesis, Cortegoso buscó comprender las variaciones funcionales de ambos tipos de registros desde una perspectiva sincrónica y diacrónica. Además, se interesó por el estudio de la estructura de los sistemas de producción lítica (incluyendo el análisis de las estrategias y modos de 
aprovisionamiento, entre otros aspectos). La organización tecnológica y las estrategias y diseños implementados, habrían respondido a distintos modos de subsistencia, los cuales tuvieron diversos requerimientos tecnológicos (Cortegoso 2004, 2009). Así, y al igual que en el presente trabajo de tesis doctoral, ella analiza los conjuntos líticos registrados en tres ambientes distintos, representados en dicha cuenca por variaciones altitudinales. Ellos son: la Cordillera Frontal, donde analiza los conjuntos líticos de los sitios El Piedrón 01, El Piedrón 02 y La Manga; en los valles intermontanos analiza los sitios Río Blanco 01, La Canchita, y Terraza Gendarmería 4.1; por último, en la Precordillera, estudia Los Conitos 01, Los Conitos 02 y Los Conitos 03, (Cortegoso 2004, 2009) (Figura 3.1).

Cortegoso (2004), compara algunas características del registro arqueológico de la cuenca del Atuel, ocupado por cazadores, con el de los agricultores del norte de la provincia. Esta autora menciona las expectativas generadas en el modelo de Neme (2002) para distinguir al Holoceno tardío de momentos previos, donde se da un proceso gradual de intensificación producto de un aumento en la presión demográfica. Ella destaca de este modelo "el hecho de que el proceso de incorporación de ambientes altos podría estar relacionado a la fuerte influencia del intercambio trasandino" (Cortegoso 2004: 79), concomitante con la situación registrada arqueológicamente en el ambiente cordillerano de la cuenca del río Blanco.

Como resultado de las fuentes de rocas estudiadas y de los análisis petrográficos realizados, Cortegoso $(2004,2009)$ distingue cinco grandes grupos de procedencia: Cordillera, valle del río Mendoza (cantera Paleomédanos -registro superficial), Piedemonte occidental de Precordillera (cantera de Los Conitos), Precordillera (norte) y una procedencia de localización indeterminada ${ }^{2}$. También, estudia las secuencias de reducción de los sitios en estratigrafía analizados según los componentes de ocupación para reconstruir las trayectorias artefactuales que permitan entender los aspectos organizativos de la subsistencia (rango espacial de movilidad, tiempo de ocupación, actividades realizadas en los distintos ambientes), sugiriendo asociaciones entre los conjuntos y los patrones de uso y asentamiento en el espacio, es decir, proponiendo una ocupación diferencial de los ambientes (Cortegoso 2004, 2009), tanto en perspectiva sincrónica como diacrónica. Esta última, marca las diferencias en las estrategias de

\footnotetext{
${ }^{2}$ Para una presentación más detallada de la disponibilidad de recursos líticos en la cuenca del río Blanco, véase: Cortegoso (2009) donde hace una discriminación entre las materias primas líticas de Cordillera, Valle de Potrerillos, Piedemonte Occidental y Precordillera, e incluye la procedencia de materias primas de áreas localizadas fuera de la cuenca del río Blanco, haciendo hincapié en las fuentes de obsidianas suprarregionales.
} 
utilización y los cambios acontecidos a lo largo del tiempo: cazadores del Holoceno medio y agricultores del Holoceno tardío que utilizaron distintos tipos de emplazamientos en el mismo espacio, pero en diferentes momentos. La variable sincrónica, muestra que las actividades se planifican según el uso dado a distintos ambientes (Cortegoso 2004, 2009).

Otros estudios cuyanos basados en el registro lítico corresponden a las tesis doctorales de Lucero (2015) y Castro (2015), realizadas en el valle del río de Las Taguas al noroeste de la provincia de San Juan. Entre algunos de los objetivos de la primera tesis mencionada se aspiró a conocer la organización de la tecnología lítica en los ambientes de altura de la cuenca superior del río mencionado (3700 msnm), evaluar la organización espacial y el uso del espacio desde una perspectiva geográfica en relación a la explotación de recursos en un contexto geográfico particular, y dilucidar cuáles fueron las estrategias adaptativas de los grupos pastoriles que ocuparon la región durante un período correspondiente al Holoceno tardío (3.080-510 años AP). Los enfoques teóricos utilizados para tales fines son la Ecología del Comportamiento Humano, la Biogeografía y el estudio de los Paisajes Arqueológicos. Lucero (2015) hace hincapié en las estrategias desarrolladas para enfrentar el riesgo y la incertidumbre en ambientes de altura con una alta estacionalidad. La principal herramienta metodológica que aplica es la de los Sistemas de Información Geográfica (SIG), dado que se estudia la información arqueológica de los sitios de superficie desde un enfoque espacial, permitiendo combinar diversas fuentes de datos (ambientales, geográficos, geológicos) y realizar análisis de distribución, proximidad y movimientos en el paisaje arqueológico. Para testear movimientos trasandinos y las posibles vías utilizadas se realizan análisis de rutas de menor costo (Lucero 2015).

Los resultados de este trabajo muestran una explotación diferencial de los recursos según el emplazamiento de las fuentes y la disponibilidad de las materias primas, así como diferencias en la circulación humana y el contacto entre grupos de ambas vertientes de la cordillera mediados por los rasgos del paisaje (Lucero 2015). Para evaluar patrones espaciales de distribución el autor selecciona unidades analíticas en escalas macro, meso y micro. En una micro-escala de análisis espacial, Lucero (2015) analiza los sitios arqueológicos localizados en tres sectores (espacio meso-regional) del valle: 1) Sector Bajo (3600-3800 msnm): sitios ARQ- (3, 4, 21, 9, 20, 10, 17, 25, 16, 29, 18, 15, 5, 11 , 28, 27, 14, C07, 23 y 24; ordenados desde el más bajo hasta el de mayor altitud). 2) Sector Medio o franja intermedia (3800-4000 msnm): sitios ARQ- (22, C08, C05, C06 y 26; 
también desde el de menor al de mayor altitud). 3) Sector Alto (4000-5664 msnm): sitios ARQ- (GZ01, GZ03, C14 y C15; de menor a mayor altitud snm) (Figura 3.1). Cruzando la información de la disposición diferencial de recursos líticos con la de los sitios arqueológicos en la región, Lucero (2015) determina que los grupos humanos habían elegido el tipo de campamento (semitemporal o estancia) en base a esta variable. Además, observa diferencias en los tipos constructivos de acuerdo al nivel altitudinal implicado (mayor inversión tecnológica en sectores bajos y menor en sectores medios y altos). Estas diferencias implicarían tiempos de estadía más cortas en lugares altos y más largas en lugares bajos (Lucero 2015).

Los análisis de procedencia y explotación de recursos, secuencias reductivas, sistemas de producción, variabilidad artefactual y clases técnicas señalan (Lucero 2015; Lucero et al. 2017): materias primas mayoritariamente locales; tendencia geográfica hacia una mayor diversificación de las materias primas según disminuye la altitud de los sitios; énfasis en el equipamiento de lugares; evidencias de estrategias tecnológicas expeditivas y conservadas; secuencias reductivas completas que atraviesan los tres sectores; sitios del bajo presentan mayor diversidad tipológica debido a su gran y recurrente ocupación temporal, su uso (posibles campamentos residenciales estacionales) y porque los instrumentos se confeccionaron allí; diferencias en la reducción del tiempo y la energía invertida en la fabricación de artefactos a lo largo del tiempo debido a un progresivo énfasis en las prácticas de pastoralismo, menor frecuencia y reducción de tamaño de las puntas de proyectil hacia momentos más tardíos (asociados a la incorporación del arco y flecha hacia 3.000 años AP), aunque los pastores no habrían abandonado las prácticas de caza. A una escala macro, la ocupación de estos ambientes de altura puede responder a una mayor aridez de los valles bajos durante el Holoceno tardío, siendo la trashumancia la estrategia apropiada para la explotación anual de recursos de subsistencia cambiando de pisos ecológicos (Lucero 2015; Lucero et al. 2017).

Como se dijo antes, la tesis de Castro (2015) también se basó en el estudio arqueológico del valle del río de Las Taguas Superior, donde se localiza el sector arqueológico ARQ-18, con una antigüedad de entre $8.950 \pm 100$ y 1.500 años AP. El registro muestra ocupaciones tanto de cazadores-recolectores ( $c a .9 .000-6.700 \mathrm{AP}$ ), como de grupos con economías diversificadas (5.100-1.500 AP), separados por un hiatus ocupacional de unos 1.600 años (entre 6.700 y 5.100 AP), que a su vez coincide con el período de extrema aridez ( $c a 6.700-6.000 \mathrm{AP}$ ). Tal registro temporal le permite proponer 
un modelo biogeográfico de poblamiento humano del área desde la exploración y colonización inicial en el Holoceno temprano, hasta la ocupación efectiva en la transición Holoceno medio-tardío, y durante el Holoceno tardío. Uno de los principales objetivos de su tesis fue evaluar los cambios en las estrategias tecnológicas y los modos de aprovisionamiento de la materia prima a través del tiempo, y conocer la funcionalidad del valle del río de Las Taguas dentro de la macro-región. Bajo el marco teórico de la Ecología del Comportamiento Humano, los resultados indican que, en lo que respecta a cazadores-recolectores, estos implementaron estrategias conservadas y expeditivas, desarrollaron tareas vinculadas a la caza de camélidos y ocuparon el sitio durante estadías cortas; con respecto al registro lítico de los grupos con economías diversificadas (cazadores-recolectores/pastores), se evidencia la ejecución de tareas más diversas que estarían relacionadas a la caza-recolección y al pastoreo, predominan estrategias tecnológicas expeditivas, limitando el desarrollo de estrategias conservadas a las actividades de caza, y habrían permanecido en el sitio durante estadías más largas. En este sentido, Castro y colaboradores (2013) proponen el advenimiento de una posible "recolonización" del espacio, y Castro (2015: 312) observa en el C-III que "la continuidad de determinados grupos tipológicos a través del tiempo puede deberse a la existencia de 'funciones primarias' (Aschero 1976-83) de carácter básico que se desarrollan más allá de la actividad económica predominante (sensu Hocsman 2014)" (Castro 2015: 312). En este grupo más tardío se observó el inicio hacia una "simplificación de la tecnología" que correspondería con una etapa de transición de la caza al pastoreo (5.100-3.000 años AP) (Castro et al. 2013; Castro 2015).

\subsubsection{Estudios de tecnología lítica en el sur de Mendoza}

En el sur de la provincia de Mendoza, los antecedentes en estudios sobre organización tecnológica, muestran una tendencia hacia problemas de subsistencia (Gil 2000, 2006), siendo escasos los trabajos dedicados a la caracterización de la tecnología lítica de los conjuntos desde esta perspectiva teórica (Bonnat 2009, 2011; Paulides 2011; Salgán 2013), sobre todo en el valle del Atuel (Pérez Winter 2008).

En su tesis doctoral, Salgán (2013) se propuso como objetivo general profundizar el conocimiento sobre la organización de la tecnológica lítica de grupos cazadoresrecolectores que ocuparon los ambientes áridos y semiáridos del sur de Mendoza durante el Holoceno tardío. En este sentido, concuerda con el objetivo general del presente trabajo de tesis doctoral. La diferencia radica en que Salgán se abocó al estudio de los recursos 
líticos del campo volcánico La Payunia, localizado al suroeste de la provincia de Mendoza. De esta región hizo hincapié en el registro arqueológico del Área El Payén (AEP) correspondiente al Holoceno tardío. Para lograr el objetivo mencionado, Salgán (2013) se basa en el análisis de los modos de aprovisionamiento y uso de los recursos líticos, integrando y generando información referente a la base regional de recursos líticos. Asimismo, aborda y evalúa cómo fue la circulación de las materias primas en la región durante el Holoceno tardío. Lleva a cabo tanto tareas de relevamiento de las fuentes de aprovisionamiento, como análisis de los conjuntos líticos de sitios estratigráficos y de colecciones previas; y realiza estudios petrográficos y geoquímicos de rocas potencialmente útiles, y de artefactos. Esto le permite caracterizar las fuentes disponibles en la región y diferenciarlas de las extra-regionales; y dar cuenta de las distintas estrategias tecnológicas adoptadas por los grupos que ocuparon la región (Salgán 2013, 2015).

Salgán $(2013,2015)$ analiza el registro lítico superficial y estratigráfico de los tres sectores en los que se divide a La Payunia: norte, central y sur (Ramos y Folguera 2011, citado en Salgán 2013: 49). A cada sector corresponden, a su vez, distintas localidades y sitios arqueológicos. Así, en el sector norte analiza el registro artefactual de la localidad arqueológica La Peligrosa, que incluye los sitios: La Peligrosa-2 (correspondiente al bloque temporal tardío; últimos 1.000 años AP), La Corredera (bloque temporal temprano; ca. 2.000-1.000 años AP), Piedras Bayas, La Leona y La Peligrosa Transecta 2 (estos últimos tres, son sitios superficiales) (Figura 3.1). En el sector central se ubica la localidad Altiplanicie del Payén donde la autora realiza fundamentalmente relevamientos superficiales sistemáticos y recolecciones asistemáticas en distintos sectores (Salgán 2013). Por último, en el sector sur, se emplazan tres localidades: la localidad Agua de Pérez se compone por dos sitios homónimos, uno en estratigrafía y el otro en superficie: Agua de Pérez 1 (correspondiente al bloque temporal tardío) y Agua de Pérez-Cantera; la localidad La Carmonina incluye los sitios La Carmonina 1 (con una antigüedad correspondiente al bloque temprano) y Pista (sitio superficial) (Figura 3.1); la localidad Río Colorado consiste en un muestreo superficial (que corre en sentido SO-NE). A partir de los conjuntos artefactuales estratigráficos y superficiales recuperados de las cinco localidades mencionadas, Salgán (2013) realiza el análisis tecnológico, la identificación de las materias primas y la descripción de la estructura tecnológica de los conjuntos líticos de cada localidad. 
A nivel espacial, Salgán $(2013,2015)$ observa que la materia prima predominante en los tres sectores es la roca silícea que puede ser considerada de acceso local inmediato y supera el 90\% del total de artefactos en los sitios; se dispone en el paisaje de modos diferentes: nódulos, filones o bloques; es de uso expeditivo y se utiliza sobre todo para la confección de variedad de instrumentos, aunque predominan los artefactos simples (artefactos de formatización unifacial y artefactos con rastros complementarios). Es seguida en frecuencia por la obsidiana en los sectores norte y sur, y por el basalto en el sector central; también se registran riolitas pero sólo en los sectores norte y sur, y se destinó sólo a la confección de percutores. Ninguna de estas materias primas alcanza el $5 \%$ del total. La obsidiana es foránea o no local, de uso mayormente conservado y se la ha utilizado preferentemente para la confección de instrumentos bifaciales. En La Payunia se registran obsidianas de cuatro fuentes, aunque con diferencias en el registro de cada sector: "las fuentes de obsidiana mayormente representadas son El Maule (presente en todos los sectores) y Cerro Huenul (en el sector central y sur). La fuente Las Cargas, sólo en sector central; y El Peceño, en el sector norte” (Salgán 2013: 360). Algunas cuestiones ambientales (ausencia de cursos de agua permanente) o topográficas (barreras geográficas) habrían provocado el ingreso de los artefactos de obsidiana de Laguna del Maule a La Payunia por el sur (direccionalidad sur-norte) desde los ríos Barrancas, Grande y Colorado, y desde allí serían transportados a los sectores central y norte. En este último sector se observa una disminución en su frecuencia y sólo se encuentra representada como instrumentos bifaciales, con signos de reactivación. Esta fuente, a pesar de localizarse a más de $180 \mathrm{~km}$ de distancia a La Payunia, se considera de acceso directo, dada su abundancia, trayectoria de producción, diversidad de clases artefactuales, variedad de tamaños y reserva de corteza (Salgán 2013). La obsidiana habría sido transportada con una direccionalidad extra regional de oeste a este y habría circulado a escala intra regional de sur a norte. La reciente aparición de una fuente secundaria de obsidiana proveniente del Maule, podría explicar este patrón de circulación, pero ya no a través de un transporte de artefactos en sentido oeste-este, sino a través de la obtención directa de esta materia prima en el río Barrancas-Colorado, extendiendo así el área de aprovisionamiento de esta fuente hacia el este (Gil y Neme 2013). Otra apreciación espacial es la jerarquización del espacio regional en función de la disponibilidad de materias primas líticas, la disponibilidad de agua (en forma de vertientes naturales) y productividad primaria. Dado que el sector central dispone escasamente de agua y no permite la formación de suelos (localidad Altiplanicie del Payén sin registro de sitios), es 
ubicado en el tercer lugar de esta jerarquía, siendo el primer lugar ocupado por el sector norte, seguido por el sector sur. En los sectores norte y sur -con mayor abundancia de rocas-, las tareas de procesamiento primario se realizan en las fuentes; en los sitios, los tamaños más frecuentes de desechos de talla son pequeños, siendo alta la intensidad de reducción (Salgán 2013, 2015). Por su parte, en el sector central -con escasez de recursos líticos- es frecuente el traslado de núcleos y de lascas de gran tamaño. La intensidad de reducción de las rocas es baja y los recursos locales y no locales son utilizados para la formatización de herramientas tanto unifaciales como bifaciales (Salgán 2013, 2015).

Salgán (2013) observa algunas tendencias temporales obtenidas del análisis de los cuatro sitios estratigráficos, dos del sector norte: La Corredera y La Peligrosa-2, correspondientes a los bloques temporales temprano y tardío, respectivamente; y dos al sector sur: Carmonina 1 y Agua de Pérez 1, pertenecientes a los bloques temporales temprano y tardío, respectivamente (Salgán 2013). Se evidencia un aumento en la frecuencia e intensidad de uso de obsidiana en el bloque temporal tardío (BTAR) respecto al bloque temporal temprano (BTEM), que podría ser consecuencia de la disminución de la movilidad y del afianzamiento de redes de intercambio intergrupal (Salgán 2013). Además, se observa un incremento en la diversidad de clases artefactuales y se diversifican las fuentes de esta materia prima. Con respecto a las rocas silíceas -locales-, no se registran muchas variaciones en las tendencias de ambos bloques temporales, estas son: aumento en la intensidad de uso, reducción en el tamaño de los artefactos descartados y formatización de una mayor variedad de instrumental. Se observa una tendencia a maximizar los recursos líticos locales y los procedentes de distancias ubicadas en el rango de los 120-180 km durante los últimos 1.000 años AP (BTAR), lo que permite suponer un cambio en el modo de aprovisionamiento y uso de los recursos líticos, y en la forma de ocupación del espacio, este último evidenciado por la leve disminución en la tasa de descarte de artefactos del sector sur, respecto al marcado aumento en el norte, de un bloque temporal al siguiente. Estas tendencias permitieron discutir las expectativas planteadas en relación al modelo biogeográfico de poblamiento, sugiriendo una ocupación previa de la región (exploración/colonización ca. 2.000 años AP) y evidenciar un proceso de intensificación en la producción tecnológica para el bloque temporal tardío (ocupación efectiva; últimos ca. 1.000-1.200 años AP) (Gil 2006; Neme 2007; Salgán 2013).

Otro estudio enfocado en la tecnología lítica de conjuntos arqueológicos del Holoceno tardío del sur de Mendoza, es el realizado por Bonnat (2009) en el sitio 
arqueológico Valle Hermoso 1 (fechado en 1.410 y 1.950 años A.P), emplazado a unos 2200 msnm en el valle homónimo en las nacientes del río Grande (Dpto. de Malargüe) y limita al norte con la cuenca del río Atuel (Bonnat 2009, 2011). Desde la perspectiva organizativa de la tecnología lítica, este autor se propone estudiar las estrategias de abastecimiento y selección de diferentes materias primas líticas destinadas a la confección de artefactos líticos, y las distintas estrategias empleadas en su manufactura, producción y uso, desarrolladas en dicho sitio por grupos cazadores-recolectores que habitaron el área de Valle Hermoso durante los últimos 2.000 años. Los hallazgos fueron agrupados en dos conjuntos temporales: el superior datado en $c a$. 0-1.400 años AP, y el nivel inferior posee un fechado de $c a$. 1.400-2.000 años AP. Antes de ese momento no se hallan restos arqueológicos, por lo que el sitio se corresponde con las tendencias regionales de un incremento de las actividades y, por ende, del registro arqueológico, hacia fines del Holoceno tardío. Según Bonnat (2009), Valle Hermoso 1 se localiza a una altura similar a la de los sitios más altos de la región como El Indígeno, Los Peuquenes y Laguna el Diamante, ambientes que habrían sido colonizados entre 2.000 y 1.500 años AP. Para evaluar esta hipótesis, Bonnat (2009) investiga si en el sitio se representan actividades líticas vinculadas a una etapa de colonización del área, por lo que se concentra en el registro del conjunto inferior (niveles 4 a 7). Algunas de las tendencias que se observan en el sitio son: una tasa de depositación de artefactos mayor en el conjunto superior; uso diferencial de los recursos locales (toba, toba ignimbrítica, andesita, basalto y riolita) y los no locales (obsidiana y vidrio volcánico ${ }^{3}$; fuente Las Cargas localizada a $20 \mathrm{~km}$ lineales); predominio en el uso de obsidianas halladas en forma de núcleos, productos de talla e instrumentos, con predominio de reducción unifacial; ingreso de rocas no locales a través de viajes especiales o por medio de intercambio bajo la forma de instrumentos; acceso a rocas locales a partir de aprovisionamiento incluido en otras actividades; producción in situ de lascas de obsidiana y toba; implementación de estrategias expeditiva (para explotación de rocas locales) y conservada (para las no locales). Estas tendencias permitieron dar cuenta de la función del sitio como campamento base estacional de actividades diversas (Bonnat 2009, 2011), y corroborar la hipótesis de un empleo diferencial de las estrategias de aprovisionamiento y manufactura de instrumentos sobre materias primas locales y no locales (Bonnat 2009). Sin embargo, la información generada por Bonnat (2009) a partir del estudio de distintas variables (composición del

\footnotetext{
${ }^{3}$ Bonnat (2009) los define como "aquellos desechos de obsidiana que presentan impureza e irregularidades dentro de la masa vítrea" (Bonnat 2009: 73).
} 
conjunto lítico, materias primas presentes y análisis tecno-tipológico de núcleos, productos de talla e instrumentos), no le permite observar evidencias que correspondan a las expectativas planteadas para una etapa de colonización del área (sensu Franco 2002b, 2004), ya que no se registraron evidencias de estrategias tecnológicas diferentes entre ambos conjuntos temporales, superior e inferior.

En general, de las investigaciones realizadas en el sur de Mendoza se observan registros arqueológicos que manifiestan -desde diferentes líneas de evidencia-, un uso de distintas áreas que, si bien poseen registros para el Holoceno temprano y comienzos del Holoceno medio, estos se hacen más frecuentes y densos recién en el Holoceno tardío. Muchas de estas áreas del sur mendocino presentan una falta de registro arqueológico y radiocarbónico para casi todo el Holoceno medio (entre 7.000 y 4.000 años AP). Como se dijo antes, esta situación fue interpretada por Gil y colaboradores (2005) como un hiatus ocupacional que se habría generado, según ellos ${ }^{4}$, por un proceso de aridización de la región, y que pudo provocar cambios en la organización de los grupos humanos que estaban ocupando el sur de la provincia (Gil et al. 2005). Esta condición del registro arqueológico limita, entonces, la posibilidad de estudiar conjuntos líticos que pertenezcan a segmentos más antiguos del Holoceno medio, siendo una excepción los análisis realizados por Neme $(2001,2007)$ y por Pérez Winter $(2008,2010)$ en el sitio Arroyo Malo 3. Este es un alero que se emplaza a $2000 \mathrm{msnm}$ en el alto valle del río Atuel ${ }^{5}$ (Neme 2001, 2007). Es el único sitio de esta área de la cuenca que en su secuencia arqueológica está representado el Holoceno medio (Dieguez y Neme 2003) y que posee también evidencias de ocupación durante el hiatus de ocupación mencionado. En el sitio se excavaron dos cuadrículas: A1, cuyo material lítico fue estudiado por Neme $(2001,2007)$; y B1, que implica los conjuntos líticos analizados por Pérez Winter (2008, 2010).

Del estudio de Neme $(2001,2007)$ sobre la cuadrícula A1 del sitio Arroyo Malo 3, se obtuvieron resultados de distintos materiales (óseo, vegetal, lítico). La secuencia temporal de la cuadrícula fue dividida arbitrariamente en tres unidades o conjuntos, de los cuales dos pertenecen al Holoceno tardío (conjuntos 1 y 2) y el tercer conjunto está fechado entre 8.900 años AP (último nivel, 35) y 3.810 años AP (nivel 24), por lo cual, es un paquete temporal que incluye parte del Holoceno temprano y Holoceno medio, pero con una tasa de depositación mucho más baja que la de los otros dos conjuntos, y con

\footnotetext{
${ }^{4}$ Para otras explicaciones de este hiatus de ocupación véase Sección 3.2.1.2.2. en este capítulo (propuestas de García 2005, 2010; Durán 2000; Durán y Mikkan 2009; Gil et al. 2005; Neme y Gil 2009, 2010).

${ }^{5}$ En el presente trabajo de tesis es considerado dentro del Desierto Altoandino.
} 
evidencias de un rango de actividades bastante limitado. Neme observa que, de una gran diversidad de materias primas (mayor a otros sitios de la región), se da un predominio de basaltos y obsidianas en los tres conjuntos. Estas últimas y las rocas silíceas serían materias primas no locales (según el estudio del área de captación de recursos realizado en el lugar; Neme 2001, 2007), que se habrían incrementado a través del tiempo. El conjunto 2 (2.200-3.800 años AP) presenta la mayor intensidad de ocupación del sitio, y en el conjunto 1 (últimos 2.200 años AP) se observa la mayor proporción de obsidiana y un aumento en la proporción de rocas silíceas. En cuanto a los productos de talla, Neme $(2001,2007)$ dice que hay pocos cambios significativos en su comportamiento desde el conjunto más antiguo al más reciente; sólo se destaca el aumento de microdesechos ${ }^{6}$ en los conjuntos 1 y 2, más tardíos. La poca abundancia de los materiales arqueológicos, y la escasa diversidad artefactual registrada, indican una baja frecuencia de ocupación del alero, donde se habrían llevado a cabo actividades limitadas a la talla, reacondicionamiento de instrumentos y procesamiento de vertebrados. En el conjunto más tardío se incluiría el procesamiento de vegetales.

La segunda cuadrícula mencionada, B1, analizada por Pérez Winter (2008, 2010), tiene una secuencia de $2 \mathrm{~m}$ de profundidad, conformada por 40 niveles de $5 \mathrm{~cm}$ cada uno. Los niveles 0 a 12 corresponden al Conjunto 1 (últimos 2.200 años AP); los niveles 13 a 22 constituyen el Conjunto 2 (2.200-5.000 años AP); el Conjunto 3 incluye los niveles 23 a 27 (5.000-7.600 años AP); y el Conjunto 4 está compuesto por los niveles 28 a 40 (7.600-8.900 años AP) (Pérez Winter 2008, 2010). Todos los conjuntos excepto el primero, se corresponden con algún segmento temporal del Holoceno medio, sobre todo el Conjunto 3 que no está presente en la cuadrícula A1 analizada por Neme $(2001,2007)$. Pérez Winter $(2008,2010)$ se propone, entonces, estudiar el material lítico perteneciente a los conjuntos 2, 3 y 4 de la cuadrícula B-1 que abarcan un rango temporal de ca. 8.900 a 2.200 años AP. Observa que: el conjunto 4, el más antiguo, presenta la mayor tasa de depositación temporal de toda la secuencia; las materias primas no locales o foráneas aumentan del conjunto más antiguo al más reciente, con un registro de obsidiana perteneciente a la fuente Las Cargas. No existe una diferencia significativa de las actividades tecnológicas registradas en los tres conjuntos, donde todos muestran la ausencia de los primeros estadios de talla, por lo que se deduce que las materias primas ingresaron al sitio como formas-base. Esto es apoyado por el tamaño de los artefactos de

\footnotetext{
${ }^{6}$ Neme $(2001,2007)$ incluyó en esta categoría a las lascas de adelgazamiento bifacial, microlascas y ultramicrolascas.
} 
los tres conjuntos, que es principalmente pequeño, lo cual correspondería con las últimas etapas de reducción. Predominan los desechos de talla por sobre los instrumentos y se registraron estrategias de reducción unifacial y bifacial, tanto en materias primas locales como en las no locales. Por último, el conjunto 2 (más reciente), contiene la mayor cantidad de materias primas foráneas (Pérez Winter 2008, 2010). Estas tendencias indicarían que hay un aumento en la movilidad y una disminución de la actividad en el alero, aunque no cambia su funcionalidad (sitio de actividades específicas sensu Neme 2007). Esta alta movilidad de los grupos humanos durante el Holoceno medio también fue sugerida para el norte de Mendoza por Cortegoso (2005a) y Lucero et al. (2006). Como se mencionó anteriormente, en el sur de Mendoza se la ha asociado a un proceso de aridización (Gil et al. 2005). A su vez, las tendencias también indican diferencias más significativas en el conjunto 3, que abarca gran parte del Holoceno medio (Pérez Winter 2008, 2010).

En el mismo valle del Arroyo Malo, tributario del río Atuel, donde se emplaza Arroyo Malo 3, se localizan los sitios Arroyo Malo 1 (a cielo abierto), Arroyo Malo 4 (reparo), Arroyo Malo 5 (alero) y Arroyo Malo 6 (alero). El primero, Arroyo Malo 1, es el único que incluye cerámica, y tiene un fechado radiocarbónico de $560 \pm 65$ años AP (pos contacto). En él se excavaron tres cuadrículas, de las cuales Neme $(2001,2007)$ realizó el análisis exhaustivo de la cuadrícula A2, localizada en el centro de la concentración principal de materiales (lítico, óseo, cerámica, etc.) dentro del sitio. Del análisis del material lítico, este autor percibe un predominio de materias primas no locales, principalmente obsidianas, seguida por sílices. En este sitio (Arroyo Malo 1), están presentes todas las etapas de la secuencia de producción lítica (lascas primarias, secundarias, microlascas, lascas de reactivación e instrumentos). Aquí también se realizaron cuatro transectas, de las cuales la primera y la tercera presentan la mayor cantidad de hallazgos: siete instrumentos líticos (puntas, raspadores y lascas con retoque), registrándose también productos de talla, restos óseos indeterminados y algunos tiestos cerámicos. De los otros tres sitios, el único que posee registro lítico es Arroyo malo 6.

También en los valles intermedios, en el mismo piso "eco-topográfico" (véase clasificación de Neme 2007 en Sección 3.2.1.2. de este capítulo) ubicado a 1900-2500 msnm, Neme incluye, además de la localidad Arroyo Malo, a la localidad Arroyo El Desecho. En esta última localidad se encuentran cuatro sitios arqueológicos: Cueva de la India Embarazada, cuevas número 1 y 2 del Arroyo El Desecho, y Cueva Arroyo Colorado (AD-10 sensu Lagiglia 1989); estas dos últimas cuevas se localizan sobre la 
margen izquierda del Arroyo Colorado (tributario del Arroyo El Desecho) en la cuenca del río Salado. De la excavación del sitio arqueológico Cueva Arroyo Colorado (seis cuadrículas de 0,75 $\mathrm{m}$ de potencia y niveles artificiales de $5 \mathrm{~cm}$ ), se recuperaron, entre otros materiales culturales (carbón, material óseo, cerámica), restos líticos que no fueron analizados por Neme como parte de su tesis doctoral, pero que sí sirvieron a Lagiglia, Neme y Gil para elaborar una secuencia de desarrollo cultural a partir de la tipología de puntas de proyectil (Lagiglia et al. 1994). Dicha secuencia está conformada por tres componentes: en el primero, más reciente (fechado en: $1.380 \pm 70$ y $770 \pm 80$ años AP), las puntas de proyectil son alargadas con escotadura angular; en el segundo, son de base redondeada con talla no regularizada; y el tercero, más antiguo (3.190 \pm 80 años AP), registra puntas triangulares y amigdaloides espesas (Neme 2007).

En el sector más elevado del alto valle del río Atuel (2500-3600 msnm) se halla el área arqueológica El Indígeno (con 126 recintos circulares pircados) y el sitio Los Peuquenes (con nueve estructuras habitacionales), ambos con presencia de cerámica (Sugrañes 2017). En el asentamiento El Indígeno (3600 msnm), se realizaron excavaciones donde se recuperaron restos líticos, los cuales incluyen productos de talla, cinco puntas de proyectil, cuatro raspadores, dos percutores, una raedera, dos tajadores y dos instrumentos indefinidos (Neme 2001, 2007). Se obtuvieron cuatro fechados radiocarbónicos; el más antiguo data de $1.470 \pm 60$ años AP (Neme 2001, 2007). Los desechos de talla muestran la presencia de toda la secuencia de producción, desde lascas primarias hasta lascas de reactivación; y una gran diversidad de materias primas con predominio de obsidiana, la cual es considerada no local (Neme 2001, 2007).

Por su parte, las nueve estructuras registradas en el sitio Los Peuquenes fueron divididas en tres grupos (I, II y III) de tres pircas cada una. Se seleccionaron para su excavación, cuatro cuadrículas de la estructura número 1 del grupo I, y una única cuadrícula de la estructura número 6 del conjunto III (Neme 2001, 2007). La muestra para el análisis del material lítico proviene de la cuadrícula A2 de la estructura 1, sobre la cual se realizaron dos fechados radiocarbónicos, el más antiguo de los cuales arrojó una edad de $280 \pm 50$ años AP. Un tercer fechado fue realizado en la cuadrícula A1 de la estructura 6, el cual dio una antigüedad de $360 \pm 50$ años AP. Todo esto indica, por otro lado, una corta y tardía ocupación del lugar. Entre los resultados se observa: que la obsidiana (de procedencia no local) es la predominante entre una gran diversidad de materias primas, seguida por las silíceas, que también se estima que sean foráneas; y el resto sería local. Entre los artefactos líticos abundan las microlascas y ultramicrolascas, pero también se 
registran lascas de adelgazamiento bifacial, lascas angulares e instrumentos unifaciales y bifaciales (principalmente puntas de proyectil), la mayoría confeccionados sobre obsidiana (Neme 2001, 2007). Estas tendencias hacia la representación de las últimas etapas de la producción lítica sugieren que en el sitio se habrían realizado actividades de formatización y reactivación de instrumentos (Neme 2001, 2007). También se registraron manos y molinos asociados a fogones, tanto en superficie como en estratigrafía. La escasa cantidad de vegetales que crecen en el área, así como la ausencia de plantas domésticas, plantean el interrogante acerca de qué tipo de plantas se procesaron en el sitio (Neme 2001, 2007).

En el piso "eco-topográfico" más bajo del alto valle del río Atuel (1500-1900 msnm) (piedemonte) se excavó el sitio estratigráfico a cielo abierto Ojo de Agua 1 (Neme 2007). Las excavaciones se realizaron sobre dos de los afloramientos de material, uno a cada lado de las márgenes del arroyo Ojo de Agua: la cuadrícula A1, en la margen derecha del arroyo, presenta material lítico, mientras que la cuadrícula A2, en la margen izquierda, contiene material óseo histórico. Por lo tanto, aquí sólo se hace mención al registro lítico de la cuadrícula A1, la cual no posee fechados radiocarbónicos; pero dado que en ella no se recuperó material postcontacto, se le asigna la edad correspondiente a los entierros recuperados en las inmediaciones del sitio, los cuales fueron datados en $c a$. 1.200 años AP (Novellino y Neme 1999; Gil y Neme 2010). Neme $(2001,2007)$ registra: un gran número de productos de talla (sobre todo, microlascas), en contraposición con el hallazgo de dos instrumentos (un raspador de sílice y un fragmento de punta de proyectil de obsidiana). La materia prima predominante es la obsidiana (materia prima no local), seguida por rocas silíceas. En base al registro lítico descripto se infiere, que en el sitio se habrían desarrollado tareas de confección y mantenimiento de instrumentos (Neme, 2007).

También en este ambiente de piedemonte, Neme (2001, 2007) realiza prospecciones superficiales en el arroyo La Manga (Figura 3.1). En las transectas, la mayoría de los materiales (no recolectados) corresponden a productos de talla y a algunos instrumentos de obsidiana, basalto y sílice (Neme 2001, 2007). En las transectas efectuadas en el área de Cerro Manteca (Figura 3.1), Neme (2001, 2007) observa tendencias semejantes a las anteriores, aunque la densidad de materiales es muy baja y la distribución de productos de talla e instrumentos es diferencial en las tres áreas que distingue el autor. Durante estos trabajos de prospección superficial en Ojo de Agua 
aparecieron concentraciones de materiales como la del sitio Ojo de Agua 2 (Neme 2007) (Figura 3.1), compuesta por productos de talla e instrumentos.

En la cuenca media del río Atuel se localizan numerosos sitios arqueológicos, la mayoría de ellos con dataciones asignadas al Holoceno tardío. Como se mencionó anteriormente, el único sitio con evidencias de ocupaciones humanas antiguas es Gruta del Indio (Lagiglia 1956a y b; Semper y Lagiglia 1962-68; Lagiglia y García 1999). El sitio presenta registros que datan del Pleistoceno final-Holoceno temprano (12.000-8.000 años AP) y de comienzos del Holoceno medio (7.500 años AP, aproximadamente). En este sitio los únicos materiales líticos recuperados son -como se dijo arriba- tres instrumentos y un desecho (un buril, un raspador-perforador, una raedera y una lasca con retoques), pertenecientes al componente Atuel IV que data del Holoceno temprano (entre 9.500 y 13.750 años AP) (Gil 2006; Lagiglia 2001). Luego de los 1.000-1.200 años AP se observa un notable aumento en la cantidad de sitios arqueológicos de esta cuenca (Gil y Neme 2010). A continuación se presentan aquellos que poseen conjuntos líticos estudiados con anterioridad a la realización de esta tesis.

Próximo a Gruta del Indio se halla el sitio a cielo abierto, Rincón del Atuel, con registros arqueológicos de los últimos 1.700 años ${ }^{14} \mathrm{C}$ (Gil y Neme 2010). Del análisis de los materiales líticos se evidenció la presencia de núcleos y lascas con corteza, lascas internas (predominantes), de adelgazamiento y de reactivación, manos e instrumentos. Hay una gran diversidad de materias primas, de las cuales son más frecuentes las silíceas y obsidianas, esta última predomina hacia momentos más recientes (Gil et al. 2008). El análisis por activación neutrónica de tres muestras de obsidiana de este sitio, permitió relacionarlo con la fuente de obsidianas El Peceño, distante unos $50 \mathrm{~km}$ hacia el sur (Gil et al. 2008). Además, se evidencia una mayor frecuencia de especímenes líticos en obsidiana y sílice en las categorías de tamaños más pequeños, siendo las calcitas y andesitas predominantes en las categorías de tamaños más grandes. Riolitas, basaltos, vulcanitas y tobas se hallan en una situación intermedia (Gil et al. 2008). Estas tendencias muestran una correlación negativa con los resultados del análisis del registro óseo. Se destaca que la tendencia hacia un mayor uso de las obsidianas en momentos más recientes (en contraposición a una aparición efímera en momentos más tempranos) y su escasa representación fuera del sitio, son evidencias de un cambio en la organización tecnológica durante el Holoceno tardío; lo cual, sumado a otros cambios registrados a partir de 1.0001.200 años AP, son contemporáneos con la cronología propuesta para la ocupación efectiva de La Payunia (Neme et al. 2005; Gil 2006; Gil et al. 2008). 
El sitio La Olla se encuentra en el último tramo de la cuenca media del río Atuel (Figura 3.1), a cielo abierto sobre su margen izquierda. Es un campamento de actividades múltiples en el que se halló un esqueleto humano, asociado a un pan de patay (Gil y Neme 2010). En La Olla se evidencian cambios en la organización tecnológica que son interpretados en términos de movilidad y rangos de acción (Giardina et al. 2015). Su registro muestra recurrencia ocupacional para la última parte del Holoceno tardío (Gil y Neme 2010).

En el mismo tramo, pero sobre la margen derecha del río Atuel, se excavaron los sitios El Bosquecillo 3 (EB-3) y El Bosquecillo 5 (EB-5) (Figura 3.1), cuyos conjuntos líticos se analizan en el presente trabajo de tesis doctoral. Sobre la misma margen y en este sector medio-bajo del valle del Atuel, se excavó el sitio Los Gallegos-1 (LG-1) (Figura 3.1), el cual también es analizado en el marco de esta tesis (véase Capítulo 9: resultados del Desierto de Monte). En estos tres sitios (EB-3, EB-5 y LG-1) se han realizado estudios arqueofaunísticos (Corbat et al. 2009), pero hasta ahora no se han analizado los conjuntos líticos.

\subsection{CONSIDERACIONES FINALES}

En la cuenca del río Atuel se realizaron los primeros trabajos arqueológicos sistemáticos del sur de Mendoza. Los estudios pioneros en la Gruta del Indio, dieron pie a la elaboración de la primera secuencia regional y sentaron las bases para la discusión sobre el Paleoindio, la llegada de la agricultura y el arte rupestre, entre otras temáticas importantes para la región. A su vez, la cuenca alta de este río fue, posteriormente, el escenario para abordar algunas de las ideas sobre la trashumancia, la intensificación y los sistemas de intercambio transcordilleranos.

Sin embargo, y pese a lo temprano de muchas de estas investigaciones, no se habían realizado estudios transversales que abarcaran toda la cuenca del Atuel; discutiendo desde una mirada biogeográfica, el impacto que tuvieron -sobre la organización de las sociedades prehispánicas- las diferencias en la estructura de recursos que muestra la cuenca del río, desde su nacimiento a más de 3000 metros de altura, hasta su desembocadura en los bañados del Atuel en el límite entre Mendoza y La Pampa. Sólo una aproximación de estas características podrá aislar la variable ambiental en las 
diferencias intrarregionales que se observan en el registro arqueológico de cada uno de los desiertos estudiados en esta tesis (Altoandino, Patagónico y de Monte).

Los antecedentes presentados en este capítulo señalan algunas diferencias importantes desde la biogeografía: el poblamiento fue más temprano en el área de la planicie ( $c a$. 10.500 años AP) y su despoblamiento se da en el Holoceno medio (con una duración de ca. 4.000 años); en comparación con el área de cordillera, ocupada más tarde (ca. 9.000 años), pero de manera más continua, incluso durante el Holoceno medio. A principios del Holoceno tardío (entre 3.800 y 3.200 años AP) se recolonizan la mayoría de los ambientes de la región, excepto los "ambientes marginales" (La Payunia y alta cordillera), que poseen registro desde $c a$. 2.000 años AP; momento en el que se define una ocupación efectiva de los ambientes previamente colonizados.

Los antecedentes explicitados en este capítulo también evidenciaron la necesidad de profundizar las investigaciones enmarcadas dentro de la organización de la tecnología lítica, ya que permitirá contrastar los modelos regionales precedentes y generar nuevas ideas sobre la forma en que intervino la estructura regional de recursos líticos sobre la organización de las sociedades humanas. Como se verá en el Capítulo 6, la disposición de las rocas a través de la cuenca del Atuel tiene marcadas diferencias en términos de calidad, diversidad y abundancia. Los antecedentes sugieren un cambio en el uso de las fuentes de obsidiana entre las distintas unidades biogeográficas (cordillera, piedemonte y planicie), lo que podría tener un fuerte impacto en la organización de la tecnología lítica a nivel regional y en el modo de uso del resto de las materias primas de menor calidad. Entonces, como se desprende de los antecedentes discutidos en este capítulo, un análisis tecnológico comparativo entre los distintos desiertos permitirá entender mejor el funcionamiento y la adaptación humana a los ambientes árido-semiáridos del sur de Mendoza. 


\section{CAPÍTULO 4}

\section{MARCO TEÓRICO}

En este capítulo se presentan los postulados teóricos utilizados durante el desarrollo de esta investigación. Para esto, en la primera parte, se explicitan los alcances y limitaciones de la Ecología Evolutiva, y sus diversas aplicaciones en el campo de la tecnología lítica. En la segunda parte, se dan a conocer los principales conceptos teóricos de la Organización de la tecnología lítica y sus empleos en distintas regiones del mundo y del país, principalmente, en el sur de Mendoza. Todos estos lineamientos fueron utilizados en la construcción de los objetivos y de las hipótesis a ser contrastadas en esta tesis.

\subsection{MARCO TEÓRICO GENERAL: LA ECOLOGÍA EVOLUTIVA}

Para comprender el comportamiento humano pasado es importante entender cómo se vinculan los seres humanos entre sí y con su medio ambiente, en contextos espaciotemporal particulares. La Ecología Evolutiva (en lo sucesivo EE) es una de las maneras de entender la ecología humana y puede definirse como la aplicación de la teoría de la selección natural al estudio del diseño adaptativo y biológico en un marco ecológico que incluye el comportamiento, la morfología y la historia de vida (Winterhalder y Smith 1992; Bird y O’Connell 2006). En la década de 1960, obtuvo su lugar dentro de la disciplina arqueológica al tiempo que la Nueva Arqueología usaba conceptos de adaptación y procesos adaptativos, pero no explicaba los cambios sociales. La EE considera las sub-ramas originadas con la Nueva Arqueología (tafonomía, zooarqueología, etc.), pero enfatizando en la variabilidad (su unidad analítica) y en la noción de cambio que subyace a ella.

Dentro de la arqueología, la EE se ocupa de estudiar aquellos procesos que ocurren a corto plazo (i.e., fenotípicos, e.g., la conducta), utilizando modelos formales de “optimización". A través de estos modelos se intenta explicar cuáles son las características o rasgos adaptativos, generados en decisiones particulares, y expresados 
en una conducta específica. En otras palabras, las causas de una estrategia de comportamiento deben ser localizadas en la interacción entre las capacidades cognitivas $\mathrm{y}$ de resolución de problemas, por una parte, y sus condicionamientos ambientales del momento, por otra (Boone y Smith 1998). Los cambios se explican en términos de adaptación al medio natural, y el espacio cumple un rol importante como vehículo de las conductas adaptativas, que son producto de la selección natural (Smith 1983; Smith y Winterhalder 1992; Cannon y Broughton 2010). Esta favorecerá aquellas variantes del comportamiento que incrementen el fitness (ajuste adaptativo, o propensión a sobrevivir y reproducirse en un ambiente específico) para responder opcional y adaptativamente ante condiciones ambientales particulares. Asimismo, la EE suele analizar la variación de la respuesta adaptativa en términos de "estrategias adaptativas", y la explica sobre la base del desarrollo de una serie de "reglas de decisión", lo que hace que dicha variación del comportamiento no sea producto directo de la selección natural. Las pautas del comportamiento y el registro arqueológico derivan de los cambios de comportamientos que responden a la variabilidad de los ambientes naturales y sociales. Por lo tanto, el marco ecológico-evolutivo sólo tiene sentido si hay regularidades entre factores ambientales y datos arqueológicos (Boone y Smith 1998).

La EE ha sido criticada por los "seleccionistas" o arqueólogos evolutivos (Lyman y O’Brien 1998; Dunnell 1980; Rindos 1985, entre otros) por su presunta falta de importancia puesta en la historia y en las tradiciones culturales. Además ha sido criticada por su presunto reduccionismo y por no cuestionar cuál es la historia evolutiva que permite entender o acceder al estado de adaptación actual. Sin embargo, estas críticas han sido objetadas por su falta de fundamento, y el programa de la EE ha continuado su desarrollo diversificando sus aplicaciones hacia distintos campos del estudio del comportamiento humano (Boone y Smith 1998; Bird y O'Connell 2006).

\subsubsection{ECOLOGÍA DEL COMPORTAMIENTO HUMANO}

La Ecología del Comportamiento es definida como la subdisciplina de la ecología evolutiva que estudia las relaciones del comportamiento vinculadas con el fitness que los organismos enfrentan en ambientes particulares (Bird y O'Connell 2006; Pianka 1982). Dentro de esta, la Ecología del Comportamiento Humano (en adelante ECH) es la corriente que mejor se aplica al estudio del registro arqueológico (Cannon y Broughton 2010) y la que explica más apropiadamente el pasado humano (Codding y Bird 2015). La ECH es un marco adecuado para conocer y explicar la variabilidad del comportamiento 
humano a través del tiempo, y su articulación con el ambiente (Bird y O’Connell 2006). El comportamiento humano es visto como una extensión del fenotipo, producido por la interacción de factores genéticos (selección natural) y ambientales (incluyendo el ambiente natural y social), de tal manera que la toma de decisiones tienda a maximizar el éxito reproductivo (Kelly 1995); este es el principio de "optimización”. De acuerdo con esta perspectiva, y considerando la historia evolutiva de nuestra especie, la selección natural ha favorecido capacidades psicológicas y predisposiciones, que nos hacen propensos a actuar de manera que nos lleva a este fin (Shennan 2002). Es decir, que hemos heredado la tendencia a evaluar los fenotipos disponibles y optar por el comportamiento $-\mathrm{y}$ por ende, las estrategias- que realcen nuestro fitness y tiendan hacia la optimización (Bettinger 1991), concepto en el que se centra, básicamente, la metodología de la ECH. Dentro de esta línea, los cambios en las frecuencias de los artefactos -cambios en el comportamiento humano- son entendidos como formas de adaptación fenotípica a condiciones sociales y ecológicas variables (Winterhalder y Smith 1992).

Los primeros en establecer el marco para la investigación en Ecología del Comportamiento fueron los ecólogos en los años 1960 y 1970, al estudiar patrones sociales, reproductivos y de predación en animales (Mac Arthur y Pianka 1966; Pianka 1982; Bird y O'Connell 2006, y referencias citadas allí; cf. Bettinger 1991; Winterhalder y Smith 1992; Kelly 1995; Shennan 2002). Luego, hacia la década de 1980, este enfoque fue aplicado al estudio del comportamiento humano por etnógrafos y arqueólogos. Estos últimos se centraron, originalmente, en cuestiones de subsistencia (Beaton 1973; Wilmsen 1973) y luego incluyeron el abordaje de patrones en el transporte de recursos, cambios en la tecnología, origen y difusión de la agricultura, status y desarrollo de las jerarquías sociales, entre otros temas (Bird y O'Connell 2006).

Los estudios sobre cazadores-recolectores enmarcados en la $\mathrm{ECH}$, deben considerar el principio de optimización, el cual es clave para entender la estructuración del vínculo del ser humano con un medio ambiente cambiante (Bettinger 1991; Kelly 1995; Winterhalder y Smith 1992; Cannon y Broughton 2010). Utilizando modelos de optimización, la ECH ha permitido mejorar nuestra comprensión de la variedad de comportamientos responsables de la creación y uso de instrumentos líticos y sus residuos, y entender cómo y por qué la tecnología ha beneficiado a los seres humanos en el pasado (Bousman 1993). Los modelos de optimización son comúnmente utilizados dentro de la ECH como una forma de evaluar hipótesis alternativas acerca de, por ejemplo, los cambios tecnológicos y de subsistencia. Estos modelos implican considerar la existencia 
de costos y beneficios. Para el caso de la tecnología lítica, los costos estarían representados por la búsqueda, manejo y transporte de materias primas, y la preparación y producción de instrumentos. En estos modelos se asume que aquellas soluciones que minimicen los costos y maximicen los beneficios serán las opciones seleccionadas por los procesos evolutivos que median el comportamiento humano.

Tanto las herramientas proporcionadas por el estudio de la organización de la tecnología, como las procedentes de la $\mathrm{ECH}$, han servido para explicar la variación tecnológica y el cambio como consecuencia de la resolución de problemas de adaptación. Aunque se basan en fundamentos algo distintos, los dos marcos comparten varias metas fundamentales y presuposiciones: ambos tratan de comprender el comportamiento humano en términos de limitaciones económicas y recompensas, costos y beneficios; los dos suponen que las alternativas de comportamiento que están más cerca del óptimo tenderán a volverse más comunes con el tiempo, manteniendo las condiciones constantes (en igualdad de condiciones); se enfocan en la energía o el tiempo como currencies clave para comprender el comportamiento tecnológico; los dos asumen que la variación en el comportamiento tecnológico no es directamente objeto de la selección natural, pero refleja la flexibilidad en los fenotipos del comportamiento humano; y ambos han abordado cuestiones de diseño de artefactos e inversión tecnológica (Kuhn y Miller 2015). Asimismo, los investigadores que trabajan con conceptos de la $\mathrm{ECH}$ tienden a formular modelos en términos de beneficios fitness, mientras que los estudios de la organización de la tecnología tienen que ver de manera más explícita con el tiempo, la energía y el riesgo.

Para responder a preguntas arqueológicas la ECH suele usar modelos formales que en conjunto son conocidos como Teoría de Forrajeamiento Óptimo (Optimal Foraging Theory) (Smith 1983; Bettinger 1991; Kelly 1995; Bird y O'Connell 2006, y referencias citadas allí), la cual se desarrollará en la siguiente sección (4.1.1.1.). En el marco de esta tesis, se acuerda con Bamforth (1986) en cuanto a considerar a las materias primas líticas como un recurso más. En palabras de este autor: la búsqueda de una 'tecnología forager', o de alguna otra tecnología definida sólo por los hábitos alimenticios de una sociedad, es improbable que sea fructífera, porque el material para la manufactura de instrumentos es un recurso en el mismo sentido que lo son las plantas y animales: su naturaleza y distribución condicionan fundamentalmente las formas en que estas pueden ser explotadas. Para entender la organización tecnológica, debemos examinar estos aspectos de los recursos líticos en conjunción con las formas en las cuales los seres 
humanos están o estuvieron organizados para satisfacer sus otras necesidades (Bamforth 1986: 40).

\subsubsection{Teoría de Forrajeamiento Óptimo: modelos y vinculación con las estrategias tecnológicas}

La estrategia de investigación de la EE es hipotético-deductiva: usa modelos explicativos para desarrollar hipótesis contrastables y luego evaluarlas con evidencias empíricas. Así, tales modelos funcionan como herramientas heurísticas para ir desde las premisas de la teoría general a las implicancias concretas y testeables, en este caso, en el registro arqueológico (Winterhalder 2000; Winterhalder y Smith 1992). Los modelos que integran la Teoría de Forrajeamiento Óptimo (en adelante TFO) usan principios microeconómicos para comprender las diferencias en los costos y beneficios relacionados con la optimización (maximizar el éxito reproductivo), uno de sus conceptos centrales (Smith 1983; Winterhalder y Smith 1992; Kelly 1995; Bettinger 2001; Cannon y Broughton 2010). Estos modelos son: el de amplitud de dieta, de elección de parches, de tiempo de forrajeamiento, y el del lugar central (Bettinger 1991; Bird y O'Connell 2006). Este conjunto de modelos formales se basa en el supuesto de que maximizar la tasa de adquisición de nutrientes mejora el fitness, ya sea aumentando la ingesta de nutrientes o alcanzando un umbral de ingesta más rápidamente, lo que libera tiempo para llevar a cabo otras actividades relacionadas con la condición física (Bird y O'Connell 2006: 146).

De los modelos principales de la TFO arriba mencionados, dos maximizan los rendimientos (relación entre el costo de obtención y el de procesamiento) considerando los costos y beneficios de adquirir diferentes recursos:

1) modelo de amplitud de dieta (en lo sucesivo MAD; -también conocido como modelo de elección de presas): tiene en cuenta las implicancias energéticas de la caza o la recolección de presas individuales en entornos homogéneos;

2) modelo de elección de parches (en adelante MEP): considera la posibilidad de adquirir alimentos de agrupamientos de presas en entornos espacialmente heterogéneos.

Por un lado, el MAD (Figura 4.1.a-) asume que los foragers explotan primero los recursos de mayor retorno y luego van agregando los recursos de menor retorno a su dieta; la inclusión de nuevos recursos de menor retorno dependerá de la abundancia de aquellos recursos de mayor retorno. Este modelo evalúa los costos medidos en términos de tiempo dedicado a las actividades de búsqueda y de manejo (Bettinger 1991; 2009). Si el tiempo de búsqueda de los recursos ubicados más alto en el ranking disminuye (e.g., debido a un 
aumento en la densidad de los mismos), el modelo prevé dietas estrechas. En cambio, si aumenta (e.g., debido a la escasez de los mejores recursos alimenticios por fluctuaciones climáticas), las dietas deberían tornarse más diversas. Una dieta más estrecha también puede darse por un aumento en el tiempo de manejo - específico según la presa- debido al empleo de estrategias tecnológicas más costosas (e.g., un conjunto diversificado de armas especializadas). Las dietas más amplias pueden darse, asimismo, por una disminución en el tiempo de manejo debido al uso de tecnologías menos costosas, (e.g., uso de un repertorio limitado de armas generalizadas de uso múltiple o materias primas más accesibles). La "dieta óptima" se dará en situaciones de equilibrio entre ambos costos (Bousman 1993).

Por su parte, el MEP (Figura 4.1.b-) sostiene que un cazador abandonará un parche de recursos cuando los retornos de este parche sean iguales o más bajos que el retorno promedio del ambiente (Charnov 1976; Bettinger 1991, 2001). Asimismo, el forager abandonará el parche antes de que el recurso se agote por completo. Al igual que el de elección de presa, este modelo evalúa los tiempos de forrajeamiento (tiempo de búsqueda y tiempo de manejo). La diferencia entre ambos es de escala: en el MEP no se busca un recurso dentro de un parche, sino que se busca un set de recursos localizados dentro de un parche en un ambiente heterogéneo. Además, supone que las tasas de retorno de los recursos (medidas en energía obtenida de los alimentos) disminuyen a medida que aumenta el tiempo de forrajeamiento en un parche.

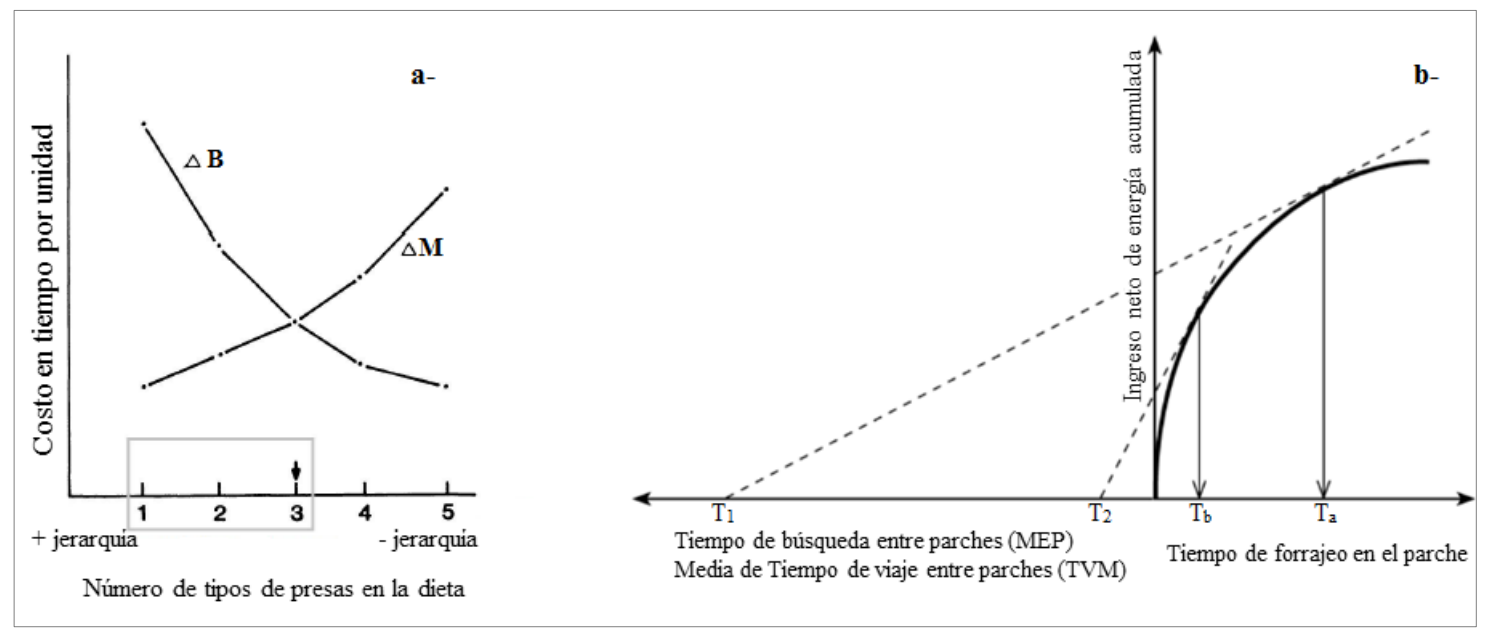

Figura 4.1. Modelos de Forrajeamiento Óptimo: a- Modelo de Amplitud de Dieta: costos de búsqueda (B) decrecientes (curva $\Delta \mathrm{B}$ ); e incrementos en el tiempo de manejo (M) a medida que más recursos son agregados a la dieta (Curva $\Delta \mathrm{M})$; recuadro en gris: dieta óptima (incluye todos los recursos a la izquierda de la intersección de las dos curvas (flecha) (modificado de 
Smith 1983). b- Modelo de Elección de Parches y Teorema del Valor Marginal: a mayor tiempo de viaje (búsqueda) entre parches $\left(>\mathrm{T}_{1}\right)$, mayor será el tiempo de forrajeo dentro del parche $\left(>T_{a}\right)$; por el contrario, a un menor $\mathrm{T}_{2}$, menor será el $\mathrm{T}_{\mathrm{b}}$.

También es importante tener en cuenta que cuando el tiempo de búsqueda entre los parches aumenta, también aumentará el tiempo invertido dentro de cada parche, compensando así el aumento del costo de búsqueda entre parches (Teorema del Valor Marginal) (Figura 4.1.b-). Algunas estrategias tecnológicas influyen directamente en las tasas de retorno de los recursos, las cuales pueden aumentar o disminuir la pendiente de la curva neta de ganancia de energía; mayores tasas de retorno energético permitirían (no requerirían) un mayor tiempo de búsqueda entre parches o proporcionarían más tiempo para actividades de no-subsistencia (Bousman 1993: 62).

Ambos modelos fueron unificados por Bettinger y Baumhoff (1982) en el modelo de viajeros y procesadores ("travelers-processors") que consiste en un continuum de estrategias de cazadores-recolectores entre los foragers "minimizadores de tiempo" ("viajeros") y los "maximizadores de energía" ("procesadores"). Dicho modelo evalúa la relación entre el aumento de la población y la disminución de los recursos, y sus consecuencias sobre los modos en que los cazadores-recolectores adjudican el tiempo, utilizan el espacio y adquieren la energía (Bettinger y Baumhoff 1982; Bettinger 1991 2001). Este modelo predice que, a medida que aumenta la densidad de población, también aumentan la amplitud de dieta, los costos de manejo y la tecnología. La estrategia "viajeros", implica situaciones de baja densidad de población y abundancia de recursos de alta calidad, por lo que los foragers pasan más tiempo "viajando" de un parche a otro, que dentro de cada uno de los parches. Si un grupo en esas condiciones aumenta su demografía, entonces reduce el beneficio de la estrategia. Además, si otros parches ya fueron explotados o están siendo ocupados por otros grupos, este modelo predice que es más rentable permanecer en el mismo parche de recursos. Cuando los recursos de alta calidad comienzan a escasear, los "procesadores" amplían la dieta con recursos de menor calidad que, como se dijo, conllevan más tiempo de manejo (Bettinger y Baumhoff 1982). De aquí que los viajeros "minimicen el tiempo" utilizando tecnologías menos costosas o "baratas", y los procesadores "maximicen la toma de energía" empleando tecnologías más “costosas" (Bousman 1993).

De acuerdo con Bousman (1993), la tecnología puede tener un rol crítico en determinar las elecciones económicas de los grupos humanos en aspectos como estrés de 
recursos, ocupación de nuevos espacios y disminución del riesgo, por lo que deberían integrarse a los análisis los costos y beneficios que conlleva la utilización de variantes tecnológicas específicas, contemplando los costos de la tecnología lítica dentro del tiempo de manejo de los recursos (Bousman 1993). De esta manera, y siguiendo a Bamforth y Bleed (1997), la tecnología lítica puede reflejar la adaptación social y económica de los grupos humanos al ambiente, y vincularse a los análisis de optimización mediante la consideración de los costos de producción de distintas alternativas tecnológicas, a partir de la estimación de la inversión de trabajo -en tiempo y energía (Jeske 1989; Jochim 1989; Ugan et al. 2003; Bettinger et al. 2006), en la elección y aprovisionamiento de materia prima (Andrefsky 1994; Bamforth 2006), y en la confección de artefactos líticos tallados (Jeske 1992). Las estrategias tecnológicas conforman un rango de opciones con costos y beneficios variables (Hayden et al. 1996; Andrefsky 1998, entre otros) que definen tasas de retorno particulares, con sus resultantes consecuencias sobre el fitness.

Una mención aparte merece el modelo de aprovisionamiento de materias primas líticas de Garvey (2015) aplicado al sur de Mendoza. Garvey, desde una perspectiva evolutiva y sobre la base del trabajo de Bettinger y colaboradores (2006), predice el "tiempo de uso crítico" dedicado a una tarea-como el invertido en el uso de instrumentos, necesario para justificar la inversión en materias primas líticas difíciles de obtener y de alta calidad, cuando las rocas locales están disponibles pero son de menor calidad. Este modelo se basa en las diferencias de calidad de las materias primas, como una forma de predecir las decisiones de su aprovisionamiento. Las diferencias existentes entre los distintos tipos de rocas, tienen implicancias tanto en los costos asociados con su adquisición y reducción, como los beneficios que ofrecen cuando son utilizadas. Parte del supuesto de que las rocas de alta calidad (sensu Andrefsky 1998, y otros citados por Garvey 2015) mejoran las tasas de retorno para las actividades en las que han de ser utilizadas.

El modelo de Garvey (2015) ha sido aplicado al registro arqueológico del valle del río Atuel, eje central de esta tesis. Garvey (2015) comparó el uso del basalto y la obsidiana a través del tiempo. Observó que el primero, más común en los conjuntos tempranos, es una roca de gran ubicuidad por lo que su costo de aprovisionamiento es bajo, pero su tasa de retorno es relativamente baja, dada su granulosidad y dureza. En cambio, la obsidiana, cuya utilización aumenta hacia el Holoceno tardío, proviene de fuentes distantes a los sitios por lo que su costo de aprovisionamiento es más alto, en comparación a su costo de manufactura simplificado por su alta calidad para la talla. La 
relación entre estos dos tipos de materias primas, sus respectivos índices de retorno en relación con el tiempo que se tarda en adquirirlos, y los instrumentos que pueden obtenerse de ellos, definen el tiempo de uso crítico, la cantidad de tiempo que debe dedicarse a una tarea para hacer viable la obsidiana en presencia de basalto de menor calidad pero más fácilmente disponible (Garvey 2015: 166). Las tendencias tecnológicas y temporales que obtuvo Garvey (2015) son de interés para las discusiones planteadas en esta tesis (e.g., aumento del uso de materias primas como la obsidiana o incremento del número de sitios arqueológicos a través del tiempo; cuántos sitios en estratigrafía pueden contrastar esto; qué usos se le da al basalto y cuáles a la obsidiana y las demás materias primas registradas; qué significa “distante” en la relación fuentes-sitios, etc.).

\subsection{Críticas al uso de los Modelos de Forrajeamiento Óptimo en arqueología}

Algunos autores han sostenido que el hecho de que las sociedades prístinas se hayan desarrollado en contextos con condicionantes ambientales y sociales muy distintos a los actuales, no favorece a que los modelos derivados de la TFO constituyan un marco interpretativo válido para explicar los comportamientos de los grupos de cazadoresrecolectores (Binford 1982, 1983a, citados en Bettinger 1991; García Moreno 2010; Jochim 1988; Durham 1981, y Jochim 1983, 1988, citados en Bousman 1993, entre otros). Nelson (1991), por ejemplo, se ha cuestionado si la gente, realmente, trata de optimizar su tiempo, su energía y sus materiales y "lograr" soluciones óptimas. Para ella esta cuestión es compleja y prefiere ver la optimización como un aspecto importante de la adaptación, donde la gente busca soluciones apropiadas para los problemas adaptativos (e.g., aprovisionándose de alimentos y otros recursos naturales). Plantea que se pueden construir modelos de condicionamientos para el aprovisionamiento de recursos y proponer tanto soluciones tecnológicas óptimas como prever sus consecuencias: si son pertinentes, se observa que la optimización de la organización tecnológica tiene gran importancia; si son poco pertinentes, la optimización, según las dimensiones del modelo, no es aplicable (Nelson 1991).

Se critica a los modelos MAD y MEP de abordar los problemas de manera netamente economicista, sin evaluar la obtención de beneficios cualitativos (materiales e inmateriales) derivados de la captación de recursos, ni tener en cuenta las implicaciones sociales, culturales e ideológico-simbólicas que las actividades cinegéticas, entre otras, tienen sobre estos grupos. Según los críticos de la TFO, estos modelos no alcanzarían a representar, por ejemplo, la gran variabilidad y complejidad de las actividades, técnicas 
y estrategias de caza, recolección y/o pesca de las sociedades prehistóricas, dado que estas están condicionadas por otros factores de índole socio-cultural, tales como la organización social, la división sexual del trabajo, la caza y recolección en grupo, las capacidades y necesidades individuales, el almacenamiento o reparto desigual de los alimentos, o la búsqueda de excedentes (García Moreno 2010: 32). Así, se considera que los modelos de forrajeamiento óptimo (MFO) son demasiado simplistas al basarse en parámetros de subsistencia mediante los que se busca establecer reglas generales de comportamiento, y reduccionistas, al tomar una teoría desarrollada en biología para explicar fenómenos de las ciencias sociales (Jochim 1998; García Moreno 2010).

Respecto a dichas consideraciones, Bettinger (1991) hace una breve compilación de las críticas a la TFO y admite que los primeros modelos dentro de esta teoría eran algo reduccionistas, por lo que los beneficios se medían sólo en retorno calórico, ignorándose la variabilidad y diversidad de circunstancias en las que se dan la obtención y explotación de recursos. Posteriormente, empero, se crearon modelos de mayor complejidad que permiten un análisis más realista, como los modelos de contingencia y el de programación lineal (Bettinger 1991). Este último, por ejemplo, permite manejar múltiples variables, a razón de satisfacer un objetivo con determinados requerimientos, añadiendo la cantidad de recursos que se consideren necesarios para calcular la dieta óptima; aunque esta predicción no está exenta de imprecisiones y la aplicación de tal modelo no alcanza como prueba de hipótesis del comportamiento (Kelly 1995: 77). Bird y O'Connell (2006), por su parte, muestran la multiplicidad de aproximaciones de la $\mathrm{ECH}$ al registro arqueológico, que intentan abordar aspectos vinculados a la división sexual, principios sociales y otros aspectos no económicos en la vida de los cazadores-recolectores. Acerca de la crítica de Binford (1982, 1983a, citados en Bettinger 1991) y otros teóricos del rango medio, Bettinger (1991) alega que la TFO es teoría de rango medio en el sentido pretendido por el propio Binford, ya que emplea unas pocas generalidades acerca de utilidad y economía, y plantea predicciones explícitas que pueden ser sometidas a prueba (Bettinger 1991).

Más allá de estas críticas, es importante remarcar que los MFO son un medio de aproximación a la compleja realidad de los cazadores-recolectores. A través de ellos no se pretende explicar la totalidad del fenómeno humano presente en este tipo de sociedades, sino generar herramientas simples y contrastables con el registro arqueológico.

Los MFO, según Bettinger (1991) están destinados a producir expectativas específicas (o predicciones) sobre el comportamiento forrajeador en caso de ser generado 
de acuerdo a una lógica particular (el algoritmo de adopción de decisiones) en presencia de determinadas condiciones externas, densidad de presas, etc. El real sometimiento a prueba consiste en que el comportamiento observado se ajuste o no a las expectativas que surgen de los modelos (Bettinger 1991).

Por otro lado, Smith (1983) sostiene que la utilidad (o no) de una simplificación depende del estado de desarrollo de la disciplina y de los objetivos del análisis. Incluye, además, la necesidad de obtener patrones generales más explicativos o descripciones y análisis más precisos y realistas a niveles particulares (Smith 1983).

En síntesis, tanto el MAD como el MEP han sido desarrollados para tomar en consideración el comportamiento de los foragers no humanos, por lo que varias de las revisiones recientes han demostrado que muchos de los aspectos particulares del forrajeamiento humano no se incorporan adecuadamente en estos modelos (Durham 1981, y Jochim 1983, 1988, citados en Bousman 1993). Sin embargo, los MFO proporcionan un marco sistemático para analizar el forrajeamiento humano y, con el fin de demostrar cómo el análisis tecnológico podría integrarse con la teoría de forrajeamiento, bastarán los modelos simples y bien conocidos (Bousman 1993: 60).

\subsubsection{El enfoque biogeográfico}

Dentro del marco de la ECH, los modelos biogeográficos permiten generar nuevas valoraciones sobre las adaptaciones pasadas y presentes de los grupos humanos en distintos tipos de ambientes. Según Barberena (2013: 368), "la biogeografía consiste en el análisis de las pautas de conducta y distribución espacial y temporal de poblaciones de organismos en relación con las propiedades del paisaje que habitan". Por lo tanto, se pone énfasis en la estructura del paisaje y su condicionamiento sobre la organización geográfica de las poblaciones humanas. Este enfoque permite integrar múltiples líneas de evidencia arqueológica, discutir en escalas espaciales amplias (Borrero 2005; Neme y Gil 2008a) y evaluar la relación entre los cambios ambientales, la organización tecnológica y la demografía (Veth 1993; Neme y Gil 2008a).

La biogeografía tiene una visión "horizontal", no "vertical" como la ecología tradicional basada en el intercambio de energía entre diferentes niveles tróficos o energéticos, ya que se centra en la distribución de las especies en el tiempo y en el espacio (Yellen 1977: 262). Su análisis se basa en la estratificación del paisaje en unidades espaciales significativas (Barberena 2008, 2013). De esta manera, el acercamiento biogeográfico, basado en un conocimiento ambiental profundo, es una buena forma de 
abordar una región con escasos antecedentes; especialmente porque permite generar ideas e hipótesis dándole sentido a los datos arqueológicos disponibles, enriqueciendo las discusiones y generando preguntas.

En este sentido, el modelo de poblamiento humano propuesto por Borrero (198990, 1994-95), se fundamenta en la jerarquización de los espacios de una región (disponibles para ser poblados). Esta jerarquización condiciona las historias de ocupación de diferentes ambientes en el sentido de que los espacios de menor jerarquía o "marginales" serían ocupados más tardíamente que aquellos de mayor jerarquía (Yellen 1977). Esto otorga al proceso de poblamiento un carácter discontinuo a nivel espacial (Borrero 2001). Las etapas de poblamiento están caracterizadas por diferentes modos de interacción entre los humanos y el ambiente que ocupan, y no se suceden necesariamente: por ejemplo, una misma región puede ser "explorada" sucesivas veces por una o más poblaciones humanas debido a las condiciones jerárquicas de cada espacio en relación con las alternativas disponibles en cierto momento. Por lo tanto, el proceso de poblamiento no es unidireccional (Neme y Gil 2008a: 6) y puede presentar un carácter discontinuo en la dimensión temporal (Barberena 2008: 26).

En el contexto de la presente investigación, "la heterogeneidad ambiental del sur de Mendoza hace de la misma un lugar óptimo para la formulación de preguntas biogeográficas" (Neme y Gil 2012: 256), donde distintos espacios son jerarquizados a partir de sus diferencias en la disponibilidad de agua, productividad primaria, riesgo y accesibilidad a los distintos recursos (Borrero 1994-95, 2002, 2004; Veth 1993; Gil 2006). Para estos segmentos espaciales se esperan diferencias cronológicas en su colonización y ocupación efectiva (Neme y Gil 2008a). Así, el sur de Mendoza fue subdividido en áreas menores, ordenadas jerárquicamente de acuerdo a la disponibilidad y accesibilidad de los recursos (Neme et al. 2005): valles intermedios y piedemonte, valles fluviales extra-cordilleranos, campo volcánico de La Payunia (Área El Nevado y Área El Payén) y alta cordillera; el primero con la jerarquía más alta y los dos últimos considerados como los espacios "marginales" (sensu Borrero 2004). Esta jerarquización ha generado expectativas diferentes acerca de las distintas etapas de ocupación del sur de Mendoza.

Las perspectivas espacial y temporal planteadas para la región, se han desarrollado en el capítulo de antecedentes (véase Capítulo 3, Sección 3.1.2.). 


\subsection{Expectativas biogeográficas del registro lítico}

Los artefactos líticos, su diseño y los lugares donde han de descartarse o depositarse, se corresponderán con la forma en que se organiza el uso del espacio, las actividades a realizar, la disponibilidad de recursos y el tiempo de ocupación (Bamforth 1986; Kuhn 1989; Bousman 1993, entre otros). Dadas estas asociaciones, es de esperar que las estrategias tecnológicas difieran, no sólo espacialmente, sino también en las distintas etapas de poblamiento (Franco y Borrero 1999; Franco 2002a, 2004). Es oportuno, entonces, hacer referencia al concepto de estructura tecnológica regional (i.e., patrones de distribución de artefactos, rasgos y/o estructuras, sensu Kornfeld 2003), ya que constituye una vía de acceso útil para entender la forma en que los grupos humanos se organizan en el espacio a través del tiempo (Salgán et al. 2012b: 160).

El modelo ecológico de poblamiento propuesto por Borrero (1989-90, 1994-95) sirvió para generar expectativas arqueológicas concretas relativas al material lítico (Franco 2004; cf. Franco 2002a; Civalero 2000; Civalero y Franco 2003). En lo particular, en el sur de Mendoza, los trabajos compilados por Gil y Neme (2002) plantearon tendencias e interrogantes que han orientado los estudios líticos durante la última década (Salgán et al. 2012b). Se han planteado expectativas biogeográficas acerca de la ocupación humana en el sur de Mendoza a partir de los conjuntos líticos de distintas áreas como la cuenca alta del río Atuel (Pérez-Winter 2008), nacientes del río Grande (Bonnat 2009), curso superior del río Salado (Paulides 2011) o el campo volcánico La Payunia (Salgán 2013). A partir de lo expuesto y, sobre la base de estas perspectivas planteadas anteriormente en la región y el trabajo de Franco (2004), se presentan aquí las expectativas específicas propuestas para el río Atuel (Tabla 4.1.), durante todo el Holoceno.

La etapa de exploración “...se refiere a la radiación inicial hacia una zona deshabitada e implica movimientos de individuos o grupos usando las rutas naturales de menor resistencia..." (Borrero 1994-95:10), por lo que se puede esperar una baja depositación de materiales, funcionalmente poco específicos, y que se acumulen en localizaciones no óptimas. Además, el mayor tiempo de exposición a los procesos postdepositacionales hace que estén cubiertos por más sedimentos, etc., contribuyendo todas estas variables a que la visibilidad sea muy baja (Borrero 1994-95). El registro lítico estaría representado por una abundancia de artefactos formatizados de manera expeditiva (para uso inmediato), baja frecuencia de artefactos conservados (fracturados o agotados), 
y la presencia de desechos de reactivación o asociados con las etapas finales de artefactos transportados (Borrero y Franco 1997).

\begin{tabular}{|c|c|c|c|c|c|c|}
\hline \multirow{3}{*}{$\begin{array}{c}\text { Variables } \\
\text { arqueológicas } \\
\text { analizadas }\end{array}$} & \multicolumn{6}{|c|}{ ETAPA DE POBLAMIENTO } \\
\hline & \multirow{2}{*}{\multicolumn{2}{|c|}{$\begin{array}{l}\text { EXPLORACIÓN/ } \\
\text { COLONIZACIÓN }\end{array}$}} & \multicolumn{4}{|c|}{ OCUPACIÓN EFECTIVA } \\
\hline & & & \multicolumn{2}{|c|}{ (propiamente dicha) } & \multicolumn{2}{|c|}{ Saturación del espacio } \\
\hline \begin{tabular}{|l|} 
Visibilidad \\
arqueológica
\end{tabular} & \multicolumn{2}{|c|}{ Baja/Alta } & \multicolumn{2}{|r|}{ Alta } & \multicolumn{2}{|c|}{ Media } \\
\hline $\begin{array}{l}\text { Resolución } \\
\text { arqueológica }\end{array}$ & \multicolumn{2}{|c|}{ Baja/Alta } & \multicolumn{2}{|r|}{ Baja } & \multicolumn{2}{|c|}{ Media } \\
\hline Tasa de descarte & \multicolumn{2}{|c|}{ Baja/Alta } & \multicolumn{2}{|c|}{ Muy alta } & \multicolumn{2}{|c|}{ Baja } \\
\hline Variab. de los conj. & \multicolumn{2}{|c|}{ Baja-Media/Media-Alta } & \multicolumn{2}{|c|}{ Alta-Muy alta } & \multicolumn{2}{|c|}{ Alta-Muy alta } \\
\hline Materia prima lítica & Local & No local & Local & No local & Local & No local \\
\hline $\begin{array}{l}\text { Estrategia } \\
\text { tecnológica }\end{array}$ & Expeditiva & Conservada & Expeditiva & Conserv/Expedit. & Conservada & Conservada \\
\hline $\begin{array}{l}\text { Frec. de MP por } \\
\text { conj. }\end{array}$ & Alta & Baja & Media & Alta & Media & Alta \\
\hline $\begin{array}{l}\text { Calidad de la MP } \\
\text { para la talla }\end{array}$ & $\begin{array}{c}\text { Inferior a } \\
\text { otras } \\
\text { disponibles } \\
\text { en la región }\end{array}$ & Excelente & $\begin{array}{c}\text { MB o } \\
\text { mejor } \\
\text { calidad } \\
\text { disponible }\end{array}$ & Excelente & $\begin{array}{c}\text { MB o } \\
\text { mejor } \\
\text { calidad } \\
\text { disponible }\end{array}$ & Excelente \\
\hline Alteración térmica & Baja & Nula & Media-Alta & Nula & Alta & Alta \\
\hline Frecuencia de AF & Alta & Baja-Nula & Baja & Alta & Baja & Alta \\
\hline Frecuencia de DT & Alta & Baja & $\begin{array}{l}\text { Baja- } \\
\text { Media }\end{array}$ & Alta & Alta & Alta \\
\hline Frecuencia de NU & Alta & Baja & Baja & Baja & Baja & Baja \\
\hline Estado de AF & Enteros & $\begin{array}{l}\text { Fracturados } \\
\text { o exhaustos }\end{array}$ & $\begin{array}{l}\text { Enteros y } \\
\text { fracturados }\end{array}$ & $\begin{array}{l}\text { Enteros y } \\
\text { fracturados }\end{array}$ & Enteros & $\begin{array}{l}\text { Enteros y } \\
\text { fracturados }\end{array}$ \\
\hline Estado de Núcleos & No agotados & Agotados & Agotados & Agotados & Agotados & Agotados \\
\hline $\begin{array}{l}\text { Otras características } \\
\text { de los conjuntos } \\
\text { líticos }\end{array}$ & $\begin{array}{l}\text {-Baja frecuenc } \\
\text { raspadores } \\
\text {-Predominio d } \\
\text {-Percutores fra } \\
\text { agotados } \leftrightarrow \text { ma } \\
\text { o> frec. de DT } \\
\text { de reducción s }\end{array}$ & $\begin{array}{l}\text { a de } \\
\text { raederas } \\
\text { cturados o } \\
\text { de } 1^{\circ} \text { estadios local } \\
\text { bre MP local }\end{array}$ & $\begin{array}{l}\text { ॰ frecuenci } \\
\text { ॰Equipam. d } \\
\text { en MP } \\
\text { local } \\
\text { ॰Equipam. p } \\
\text { en MP no lo } \\
\text {-Núcleos y } \\
\text { tamaño; recl } \\
\text { o> índice de }\end{array}$ & $\begin{array}{l}\text { a de raspadores } \\
\text { e sitios c/núcleos } \\
\text { ersonal c/núcleos } \\
\text { cal } \\
\text { AF de menor } \\
\text { amación } \\
\text { fractura, en gral. }\end{array}$ & $\begin{array}{l}\text {-Mejor calida } \\
\text { rocas } \\
\text { o> variab. de } \\
\text { obsidianas y } \\
\text { locales } \\
\text { y no } \\
\text { locales }\end{array}$ & $\begin{array}{l}\text { dd de las } \\
\text { fuentes de } \\
\text { de MP }\end{array}$ \\
\hline
\end{tabular}

Tabla 4.1. Modelo de poblamiento y expectativas líticas (tomado y modificado de Franco 2004; Pérez-Winter 2008; Salgán et al. 2012b).

Las etapas de exploración inicial y colonización no son fáciles de discernir entre una y otra dado que las expectativas -líticas en este caso- son muy semejantes (Tabla 
4.1.), distinguiéndose apenas por el aumento en las tasas de depositación y el incremento en la variabilidad aludida arriba, a través del tiempo. En consecuencia, varios autores han tomado ambas etapas en conjunto (Franco 2004; Salgán et al. 2012b, entre otros). Así, para este momento compuesto de ambas etapas se espera que el conjunto instrumental cubra las necesidades de subsistencia mínimas de un grupo, que priorice la versatilidad de los artefactos, manufacturados principalmente en materia prima no local, y que abunden los artefactos confeccionados de manera expeditiva, sobre materia prima mayormente local (Franco 2004).

La etapa de ocupación efectiva corresponde al momento en el que todo el espacio deseable está en uso (Borrero 1989-90), y se caracteriza arqueológicamente por una alta visibilidad, pero con una baja resolución, producida por la superposición de actividades y de rangos de acción (Borrero 1989-90). Su registro arqueológico implica una sucesión de ocupaciones continuas o separadas por hiatus pequeños y de amplitud comparable. Se espera la ocurrencia de equipamiento de sitios, con una amplia distribución de ítems en rol activo o de uso regular, y una distribución más puntual de ítems en rol pasivo o de uso estacional (Binford 1979; Franco 2004). Se estima registrar un incremento en la reclamación de artefactos, mayores índices de fractura de instrumentos, tamaños más pequeños de los mismos y marcadas evidencias de alteración térmica como producto de estadías más largas en los sitios y por el uso de fogones (Franco 2002b, 2004).

Dentro de esta etapa se distinguen dos estrategias diferentes, denominadas “ocupación estable" y "saturación del espacio" (Borrero 1994-95). La primera, consiste en una sucesión de ocupaciones continuas o separadas por hiatus pequeños y de amplitud comparable. La segunda estrategia se caracteriza por situaciones muy competitivas entre poblaciones. En una escala pequeña el proceso de saturación debió operar de manera frecuente; pero resulta más difícil reconocerlo que a una escala regional o suprarregional, porque en ellas se puede caracterizar este proceso por intercambio de productos esenciales para la subsistencia (Borrero 1994-95), y se lo puede vincular al proceso de intensificación (Neme 2002).

Las situaciones de estrés temporal pueden intercalarse a estas etapas de ocupación, por lo cual también se plantean aquí las expectativas vinculadas a tales contextos. Básicamente, se espera que se priorice la confiabilidad (sensu Nelson 1991; Franco 2004), a partir de la estandarización en la manufactura de instrumentos en rocas de muy buena a excelente calidad, lo que podría aumentar la frecuencia y variabilidad de fuentes de aprovisionamiento distantes, debido a la integración del área en circuitos de movilidad e 
intercambio de materias primas y otros recursos, y por la necesidad de disponer de instrumentos de manera anticipada (Franco 2002b, 2004; Salgán et al. 2012b).

Las expectativas presentadas aquí (Tabla 4.1.) dependen del manejo de la estructura regional de recursos líticos. Esta se asocia a un conocimiento variable del ambiente, de su disponibilidad y accesibilidad (Salgán et al. 2012b: 164).

\subsection{Biogeografía en Ambientes desérticos}

En el estudio de ambientes áridos-semiáridos, el propósito de usar modelos biogeográficos es integrar datos sobre los principales cambios paleoambientales, las respuestas de los recursos a esos cambios, las secuencias de ocupación conocidas dentro de las zonas áridas y las variaciones demográficas y tecnológicas, inferidas desde el registro arqueológico (Veth 1989: 81; Neme y Gil 2008a: 6). Esto es importante ya que en los desiertos la cantidad de precipitaciones no siempre es predecible de un año a otro, y su distribución espacial y temporal también puede variar mucho en un mismo año (Yellen 1977). La adaptación de las especies de plantas y animales a este tipo de ambientes hace que pequeños cambios en la cantidad de precipitaciones, tengan fuertes influencias en la productividad de la región y en la forma en que se estructuran los recursos (Pianka 1982).

De acuerdo con Yellen (1977), factores como la abundancia, la variabilidad y la predictibilidad de recursos influyen en la conducta humana, en la organización social, y también en las formas en que las sociedades cambian con el tiempo (Yellen 1977: 265). Así, los grupos que se enfrentan a este tipo de ambientes (incluso, cuando es un ambiente nuevo que están "explorando") deben enfrentar múltiples problemas: "no se trata simplemente de aprender qué animales cazar o dónde encontrar materias primas, sino de aprender los ritmos de los factores limitantes de una región" (Borrero 2011: 53). Entre otras respuestas culturales, los grupos pueden unirse ante situaciones de estrés.

Existe abundante bibliografía sobre las adaptaciones humanas en ambientes desérticos (Yellen 1977; Tanaka 1982; Veth 1989, 1993; Gould 1991; Gil 2000; Borrero 2005; Smith et al. 2005; Hiscock y O'Connor 2005, entre otros). Una de las propuestas es la hipótesis de estabilidad-tiempo ${ }^{7}$ de Yellen (1977), un cuerpo particular de teoría

\footnotetext{
${ }^{7}$ El concepto operativo en esta proposición es el estrés. Mientras que los ambientes pobres en nutrientes proporcionan condiciones más estresantes que los ricos en nutrientes, es igualmente importante que el estrés esté directamente relacionado con la fluctuación del medio ambiente (Yellen 1977: 263). Desde una perspectiva biogeográfica, un vínculo estrecho entre un individuo y un sitio en particular es ventajoso si los recursos son estables y confiables a lo largo del tiempo (Yellen 1977: 271).
} 
biogeográfica que trata de la mecánica de adaptación a ambientes desérticos que varían en su estabilidad y previsibilidad a largo plazo. Entre otros aspectos clave de su trabajo, aquí se toma una frase fundamental para el desarrollo de esta tesis: "study of variable behavioral responses within different kinds of desert may prove to be more interesting than studies contrasting deserts and non-deserts" (Yellen 1977: 266).

Con respecto a los modelos de poblamiento de ambientes áridos, cabe mencionar la investigación de Veth $(1989,1993)$ sobre la colonización de los desiertos en Australia. Este autor, hace una estratificación del desierto en: "barreras" (grandes desiertos de arena que se caracterizan por un drenaje no coordinado e interno), "refugios" (extensos sistemas de piedemontes/tierras altas y sistemas de barrancos/gargantas de Australia que proporcionaron redes confiables de agua durante las oscilaciones climáticas de los últimos 40.000 años) y "corredores" (grandes extensiones de tierras bajas y arenosas con disponibilidad de agua permanente $\mathrm{y}$ habitables durante los períodos climáticamente favorables, pero abandonadas durante el máximo glacial cuando escaseaban el agua y los recursos alimenticios). Veth $(1989,1993)$ sostiene que una combinación de presión demográfica, cambios tecnológicos y tipo de estructura social, habrían permitido la colonización y ocupación permanente de los desiertos arenosos marginales (barreras) recién hacia el Holoceno medio (hace unos 5.000 años), y no durante el Holoceno temprano, como había sugerido Smith (1988). Hasta entonces, los colonizadores del interior de Australia sólo se habrían pre-adaptado a condiciones verdaderamente áridas dentro de los refugios del máximo glacial, las “islas del interior” (Veth 1993: 114).

En este sentido, Borrero (2002) había sugerido que en el sur de Mendoza (donde pudieron ocurrir expansiones y contracciones en el rango de acción humana en función de la disponibilidad de agua), debía evaluarse "el papel de desiertos y semi-desiertos como barreras geográficas, debido a que son estos los ambientes más afectados por ciclos de sequía como los registrados en la región" (Borrero 2002: 198). Neme y Gil (2012), aseguran que los rasgos geográficos que caracterizan la heterogeneidad ambiental del sur de Mendoza (localización de sistemas serranos, campos volcánicos, valles de ríos permanentes, etc.) son los que determinan dónde se encuentran los parches de recursos, las fuentes de materias primas, las vías de circulación y los refugios asociados a la vida humana. A pesar de que algunas pudieron jugar estos roles importantes, las barreras biogeográficas de la región son, con pocas excepciones, superables, variando sólo estacionalmente en su permeabilidad (Neme y Gil 2012: 256-257). 


\subsection{Ambientes marginales}

De acuerdo con Neme y Gil (2008a: 6) el término "marginal” puede ser entendido de diferentes maneras en relación al contexto en el que es usado. He aquí algunas de sus acepciones: como ambiente económicamente "pobre" con implicancias estacionales (e.g., explotación estacional; necesidades no satisfechas en áreas adyacentes) y otras implicancias (e.g., movilidad, territorialidad, organización social, tecnología, demografía, etc. relacionadas con ambientes "pobres" en agua) (Bettinger 1991; Neme 2002; Kelly 1995; Outram 2004); como el límite exterior de la dispersión de una especie (en el sentido biogeográfico estricto: límites del rango geográfico de los humanos y de otras especies de homínidos) (Coles y Mills 1998; Mondini y Muñoz 2004); como límite tecnológico (vinculado originalmente con el concepto de difusión, e.g., los límites de la agricultura) (Gil 2003; Arnold y Greenfield 2004; Gremillion 2004); como una cualidad relativa y variable (relativa a los espacios, especies y problemáticas bajo estudio) (Veth 1993; Mondini y Muñoz 2004, entre otros).

Aquí se adopta el sentido geográfico propuesto por Borrero (2004) en el cual un área marginal implica un espacio que está discontinuamente ocupado o es explotado por núcleos poblacionales distantes que utilizan esas tierras de forma poco frecuente y/o intermitente (Neme y Gil 2008a: 6). Así, la marginalidad resulta de la distribución y el funcionamiento de las poblaciones (Borrero 2004). Los ambientes marginales son reconocidos por una mayor "resistencia" a ser ocupados debido a sus características de estacionalidad marcada y baja productividad; se espera que sean poblados tardíamente y que hayan sido explotados de modo marginal, como reservorios para explotación sin llegar a ser colonizados realmente (Borrero 1994-95; Neme 2007).

Como se dijo arriba (véase también Capítulo 3) en la subdivisión del sur de Mendoza se han definido dos áreas marginales para la región: La Payunia en el Desierto Patagónico y la alta cordillera (por encima de los 2500-3000 msnm) en el Desierto Altoandino. En el primer caso, el recurso hídrico es el factor limitante ya que controla los procesos biológicos, es decir, es un recurso crítico (Gil 2001, 2006). En el caso del ambiente de alta cordillera, se lo considera como un desierto, pero no por la escasez de precipitaciones, sino por su problema de disponibilidad para los seres vivos, ya que las precipitaciones se dan en forma de nieve y los suelos pedregosos no permiten su acumulación ni aprovechamiento (véase Capítulo 2).

La identificación de ambientes marginales dentro de una región permite generar expectativas de uso diferencial de los distintos espacios, generando además implicancias 
arqueológicas contrastables que potencian el poder explicativo del, a veces escaso, registro arqueológico. De ahí, la importancia, entonces, de identificar estos espacios y la estructura de sus limitantes para el desarrollo y explotación por parte del ser humano.

\subsubsection{Riesgo e incertidumbre}

En articulación con el enfoque biogeográfico (sección anterior, 4.1.1.2.), explorar un territorio implica un riesgo debido al desconocimiento acerca de cómo se disponen los recursos (Hiscock 1994). El riesgo suele ser definido como la variación impredecible de alguna variable ambiental (Halstead y O'Shea 1989); la incertidumbre es vista como la falta de información sobre esos riegos o variaciones ambientales (Bousman 1993). Igualmente, distinguir entre riesgo e incertidumbre en un contexto arqueológico puede ser muy difícil por lo que la utilización del término riesgo permite involucrar ambas situaciones.

Los distintos autores suelen coincidir en que, a mayor variabilidad, aumenta la incertidumbre y, si los recursos son impredecibles, el riesgo puede ser mayor. Cuán impredecible es un recurso puede conocerse a partir de la medición de la predictibilidad, propuesta por Crolwell (1974, citado en Cashdan 1992), quien distingue entre constancia y contingencia. Un recurso es constante cuando está altamente disponible en cantidades conocidas en lugares determinados a lo largo de todo el año. En cambio, un recurso es altamente contingente si está siempre disponible en determinados lugares en cantidades conocidas en una sola estación específica del año.

En la compleja interacción entre humanos y medio ambiente, los individuos -en este caso, los foragers-, deben enfrentarse a múltiples problemas ambientales; pero su supervivencia estará limitada -en cada caso, según el contexto natural y cultural, y la estructura espacial y temporal-, sólo a uno o dos recursos críticos, referidos como "factores limitantes" (Halstead y O'Shea 1989). Estos autores definen la variabilidad como el patrón actual de variación impredecible -riesgo e incertidumbre tomados en conjunto- en la adquisición de alimentos, ya que factores comunes como el clima, situaciones aisladas o esporádicas como la propagación de alguna enfermedad, o fenómenos cíclicos a escala temporal larga (muy amplia como para ser reconocida), influyen en la disponibilidad de recursos particulares. Asimismo, Halstead y O'Shea (1989) consideran que cualquier fuente de variabilidad exhibirá tres características diagnósticas, que determinan el alcance y severidad del problema con el que una sociedad debe enfrentarse: estructura temporal (cuán frecuente es, cuánto dura la fuente de 
variabilidad involucrada), estructura espacial (tamaño del área afectada y homogeneidad relativa del efecto dentro del área), e intensidad relativa (severidad y variación espacial y temporal de los efectos de la escasez).

En el caso de los ambientes áridos-semiáridos como los desiertos del sur mendocino, el "factor limitante" principal es el recurso hídrico (Gil 2001, 2006; Borrero 2005) (véase Capítulos 2 y 3, y situación particular en Sección 4.1.1.2.3). La frecuencia e intensidad de las precipitaciones, son un factor clave en la configuración de la disponibilidad de los recursos a lo largo del año. La alta variabilidad inter anual e intra regional aumenta los niveles de incertidumbre para las poblaciones humanas, condicionando la movilidad y demografía (Gil 2006).

Un aspecto importante a la hora de hacer aproximaciones biogeográficas en ambientes áridos y semiáridos es que no debemos trabajar únicamente con una visión normativa, en la cual se utilicen los promedios de precipitación anuales (estructura temporal). Por el contrario, es más importante el conocimiento de los valores extremos (máximos y mínimos) de precipitación, humedad, temperatura, etc., que serán los que impongan los límites demográficos en la región que queremos estudiar. Las respuestas adaptativas serán más variables cuando las precipitaciones sean más extremas y se vayan de la media esperada (e.g., fenómeno climático de El Niño). Además, no hay homogeneidad espacial (estructura espacial) ya que, por ejemplo, en un mismo año puede ser muy seco en el Desierto de Monte, y muy húmedo en el Desierto Patagónico. Los patrones de precipitaciones pueden ser más variables que lo esperado en tiempo, espacio e intensidad. Por ende, se debe analizar esto a distintas escalas. Esta heterogeneidad, a su vez, permite que los grupos humanos complementen los recursos de un desierto con los de otro. En este sentido, por ejemplo, las poblaciones de ambientes vecinos de aquellos con recursos variables, pero con una correlación negativa en dicha variación, tenderán a maximizar su interacción y cooperación, estructurando sus redes de intercambio y generando vínculos con las poblaciones de aquellas áreas vecinas (Neme y Gil 2005; Eerkens 2012).

Para las poblaciones humanas puede ser mejor un ambiente variable e impredecible que homogéneo y predecible, ya que este último puede sufrir cambios que modifiquen íntegramente las estrategias de los grupos humanos. Se observan dos situaciones: economías diversificadas (como las del primer escenario), que favorecen la estabilidad; y economías especializadas (como las del segundo escenario), que implican inestabilidad inherente. Así, la diversificación puede ocurrir en respuesta tanto a la 
inestabilidad de los recursos como a requerimientos de mayor producción; en cambio, la especialización sería una respuesta principalmente a estos últimos (Betts y Friesen 2004).

Entre las respuestas culturales a las variaciones existen diferentes estrategias para reducir o amortiguar la variabilidad impredecible y resolver los problemas impuestos por el ambiente (Halstead y O'Shea 1989). Estas se conocen colectivamente como mecanismos buffer o de amortiguación. Sirven para disminuir el riesgo de vivir en ambientes donde los recursos comienzan a escasear o dejan de ser predecibles. Tales mecanismos buffer son:

1) Movilidad: es la respuesta más simple; implica que los foragers se mueven para evitar la escasez.

2) Almacenamiento físico: permite disminuir la escasez de recursos y estabilizar su disponibilidad inmediata y a futuro.

3) Intercambio: también llamado "almacenamiento social" debido a que implica que la abundancia presente se convierta en obligaciones futuras en tiempo de necesidad.

4) Diversificación: implica un aumento en la base de recursos explotados o la explotación de áreas más grandes, lo cual reduce el riesgo de una escasez catastrófica.

El tipo de mecanismo a utilizar dependerá del contexto socio-ambiental y de cómo se presente la variabilidad en su estructura temporal, estructura espacial e intensidad relativa (Halstead y O'Shea 1989; Cashdan 1992; Bryson 1994, entre otros). Como señalan Halstead y O'Shea (1989) distintos tipos de respuesta se ajustan a diferentes tipos de riesgo.

A fin de examinar las respuestas humanas a la variabilidad, es razonable enfocarse en cambios que pueden ocurrir más de una vez en una vida humana (Dincauze 2000). Los factores bióticos y abióticos generan ciertas variaciones a corto plazo que pueden ser percibidas por los grupos humanos, quienes responden generando cambios en su entorno (factores socio-culturales), especialmente a través de la tecnología (Dincauze 2000). El mismo patrón de comportamiento humano puede ser costoso en un contexto y no en otro (Bamforth y Bleed 1997), y que los cambios sean concebidos como positivos o negativos dependerá de los patrones de respuesta del grupo en cuestión, resultado de sus normas y valores culturales, y no meramente de la capacidad tecnológica para afrontarlos (Dincauze 2000).

La tecnología es una herramienta estratégica para resolver los problemas que el ambiente impone, ya que permite generar respuestas para disminuir o evitar el riesgo ante la escasez o inaccesibilidad a los recursos (Torrence 1989b; Nelson 1991). El riesgo no 
es sólo la probabilidad de fallar, sino también, los costos de esa falla (Torrence 1989b; Bamforth y Bleed 1997). Así, el riesgo estructura las alternativas tecnológicas, dentro de los límites de las habilidades sociales de los grupos, para afrontar costos tecnológicos, es decir, aquellos involucrados en el aprovisionamiento de materias primas, en la manufactura y mantenimiento de instrumentos, y en el transporte de materiales e instrumentos (Bamforth y Bleed 1997; Bousman 1993).

\subsubsection{Intensificación}

La intensificación es el proceso por el cual los grupos humanos aumentan la productividad por unidad de área (Broughton 1994b; Bettinger 1983, 2001; Morgan 2015). Esto es, más energía es extraída de un determinado lugar, pero para extraerla es necesario gastar más tiempo.

Como se mencionó en el Capítulo 3 (Antecedentes), el proceso de colonización de las áreas marginales del sur de Mendoza - con efectos particulares en los ambientes de altura- hacia el Holoceno tardío final (últimos 2.000-1.500 años AP) se da como resultado de un proceso de intensificación regional desencadenado por un desbalance entre la población y los recursos del área (Neme 2002; Neme y Gil 2008a). El aumento en la presión demográfica habría provocado -en términos de optimización-, la explotación de recursos de menor jerarquía dentro del ranking regional; es decir que la respuesta adaptativa fue la ampliación de la dieta. Estos recursos (i.e., presas menores, plantas) no sólo proveen menor retorno energético -lo cual demanda mayor tiempo de procesamiento-, sino que requerirían mayor tiempo y energía invertidos en su manejo (handling time). Por ende, esta diversificación de los recursos permite una mayor extracción de energía por unidad de área o unidad de trabajo, pero a costa de una disminución promedio de la eficiencia forager (Broughton 1994b; Butler y Campbell 2004).

La especialización suele darse estacionalmente en ambientes de alta latitud y se vincula con un aumento en las prácticas de almacenamiento (Binford 2001). La diversificación es la respuesta más común en ambientes áridos caracterizados por una menor disponibilidad de recursos. Sin embargo, ambas estrategias derivadas de la intensificación no se excluyen una a otra y pueden manifestarse de modo sucesivo en el proceso de intensificación (Butler y Campbell 2004; Zangrando 2009, entre otros).

Las características del proceso de intensificación pueden incluir: diversificación en la explotación de los recursos, ocupación y explotación de áreas más pobres, 
utilización de nuevas variedades de plantas, circulación de bienes a gran escala, aumento en la dependencia de recursos almacenables, disminución de la movilidad y, cabe subrayar, aparición de nueva tecnología vinculada a un aprovechamiento más integral de los recursos, modificaciones en los sistemas de circulación de las materias primas y ampliación de las redes de intercambio (véase Neme 2007: 10; Bettinger y Baumhoff 1982; Broughton 1994b; Hiscock 1994; Morgan 2015).

En el registro arqueológico este proceso se detecta a través de la presencia de una mayor diversidad de taxas, presas de menor tamaño, cambios en los perfiles de edad, presencia de estructuras de almacenamiento, hallazgos de ocupaciones en hábitats marginales, mayor tasa de descarte de plantas, aumento de elementos tecnológicos no locales (tanto en materias primas líticas como en estilos cerámicos), presencia de tecnología cerámica e innovación en la composición artefactual respecto de periodos anteriores (e.g., arcos, redes, arpones, morteros, entre otros).

\subsection{MARCO TEÓRICO ESPECÍFICO: LA ORGANIZACIÓN DE LA TECNOLOGÍA}

El abordaje de la tecnología en arqueología implica una abundante variabilidad de propuestas y enfoques derivados del desarrollo teórico y metodológico que se viene dando en esta disciplina desde el siglo XX (Binford 1973, 1979; Jochim 1981; Schiffer y Skibo 1987; Nelson 1991; Lemonnier 1992; Bird y O'Connell 2006; Andrefsky 2009, entre otros). De aquí que existan distintas definiciones de lo que es la tecnología en arqueología. Por ejemplo, Kuhn (1995, en Cortegoso 2005b) sostiene que el modo en que se define la tecnología y se identifican los elementos claves del comportamiento tecnológico, depende en gran medida de las metas de investigación. Binford (1973) utilizó este concepto como una estrategia para comprender la variación de los conjuntos en relación a sus diferentes usos o lugares y planes diferentes, y más tardé afirmó que "technology, in both its 'tools" sense as well as the 'labor' sense, is invented and reorganized by men to solve certain problems presented by the energy-entrophy structure of the environment in which they seek to gain a livelihood" (Binford 1980: 13). Por su parte, Schiffer y Skibo (1987: 595) la definen como "a corpus of artifacts, behaviors, and knowledge for creating and using products that is transmitted intergenerationally". Dichos productos se manufacturan a partir de una diversidad de materias primas, por ejemplo, rocas para la confección de 
instrumentos de caza y arcillas para la fabricación de vasijas. Tales recursos son los hallados con más frecuencia en el registro arqueológico debido a su mayor preservación, aunque también se encuentran tecnofacturas sobre maderas, huesos, cueros, fibras vegetales, etc. Los conjuntos líticos, por lo tanto, pueden ser considerados como la categoría artefactual más importante para la comprensión del comportamiento humano del pasado, debido a que constituyen uno de los registros más completos de la evolución humana (Andrefsky 2009).

En esta tesis se optó por analizar a los artefactos líticos desde la perspectiva de una clasificación tecnológica materialista (Hiscock 2001) (véase Capítulo 5), la cual consiste en describir la variabilidad de los artefactos a partir de atributos directamente observables, estableciendo divisiones o categorías según los intereses particulares de la investigación, y sin hacer referencia a aspectos funcionales, o a las acciones, intenciones y/o conocimientos del tallador. Debido a esto último, y para considerar dichos aspectos funcionales, se complementa la propuesta de Hiscock (2001) con la perspectiva teóricometodológica de Aschero (1975, 1983), que define a los Grupos Tipológicos sobre la base de un análisis técnico-morfológico y morfológico-funcional; es decir, sí se incluye a este último aspecto. La perspectiva dada desde el marco teórico de la organización de la tecnología a los materiales líticos de sociedades a pequeña escala (Nelson 1991; Franco 2004; Kuhn 2004; Cortegoso 2005b) es la que se considera más adecuada para responder a los problemas y objetivos planteados en esta tesis, ya que permite vincular las decisiones tecnológicas con la organización geográfica de una sociedad y con la estructura del ambiente (Nelson 1991; Franco 2004; Kuhn 2004; Cortegoso 2005b). En este sentido, y en relación al marco de la Ecología Evolutiva (EE) desarrollado anteriormente, las presiones ambientales interactúan con el comportamiento humano y favorecen algunas alternativas tecnológicas por sobre otras (Bleed y Bleed 1987; Franco y Borrero 1996).

\subsubsection{ORGANIZACIÓN DE LA TECNOLOGÍA LÍTICA}

La organización de la tecnología ha sido definida como el "estudio de la selección e integración de estrategias para confeccionar, usar, transportar y descartar los utensilios y los materiales necesarios para su manufactura y mantenimiento" (Nelson 1991: 57). Este tipo de estudio organizativo contribuye a ampliar la noción acerca de la función de los utensilios al incluir variables de estrategias tecnológicas, considerando las variables económicas y sociales que influyen sobre tales estrategias y que implican inferencias 
relativas a la dinámica del comportamiento tecnológico de cada cultura (Binford 1979; Torrence 1989b; Kelly 1988; Nelson 1991; Carr 1994).

El concepto de estrategias tecnológicas ha sido extensamente desarrollado en los estudios enmarcados dentro de la organización de la tecnología lítica. En su tratamiento se han integrado datos etnográficos, etnoarqueológicos y experimentales, contribuyendo así a la construcción de modelos teóricos para explicar los comportamientos y actividades que generaron los conjuntos arqueológicos (Binford 1979, 1980; Hayden 1979; Gould 1980; Gould y Saggers 1985; Bleed 1986; Shott 1989; Nami 1992; Kuhn 2004, entre otros). Entre los primeros de estos estudios integradores, se hallan los bien difundidos y vigentes trabajos de Binford (1973, 1977, 1979, 1980) y los de Bettinger (1991, 2001, 2009; Bettinger y Baumhoff 1982), que aportan herramientas teóricas enriquecedoras al estudio de sociedades cazadoras-recolectoras y brindan concepciones teóricas útiles al estudio de la tecnología lítica.

Binford (1980) por ejemplo, distingue dos estrategias dentro del sistema de asentamiento-subsistencia que tienen correlato en la organización tecnológica: la estrategia foragers, con movilidad residencial, y la estrategia collectors, con movilidad logística (Binford 1980). Estas estrategias tienen profundas implicancias en la forma en que los recursos líticos son explotados. Por ejemplo, las sociedades que aplican la estrategia forager, explotan los recursos diariamente sobre un radio máximo desde la base residencial. Las que aplican la estrategia collector, lo hacen a través de partidas especiales por parte de algunos integrantes del grupo que salen desde el campamento base o residencia hacia campamentos temporarios operativos o estaciones, localizados en las cercanías del recurso a explotar (Binford 1980). Los forager trasladan y usan los instrumentos en sucesivos lugares; en cambio, los collectors los descartan en su lugar de uso (Binford 1979). Binford (1977) sostiene que la estrategia expeditiva es más frecuente entre los foragers, mientras que la conservada es la priorizada por los grupos con movilidad logística (collectors). Ambas estrategias de utilización de recursos líticos, expeditiva (expediency) y conservada (curation), y las estrategias de aprovisionamiento lítico directo e incluido (embedded) (Binford 1977, 1979, 1980), entre otras distinciones hechas por este mismo autor, se verán en las secciones 4.2.1.1. y 4.2.1.2., respectivamente.

Desde este marco, entonces, pueden aplicarse múltiples modelos enfocados en alguna/s de estas estrategias. Aquí se han seleccionado: estrategias de utilización de recursos líticos (conservada y expeditiva), secuencias de reducción, estrés temporal, 
estrategias de aprovisionamiento lítico, movilidad, circulación e interacción. Tales modelos han sido ampliamente desarrollados en la literatura arqueológica (Binford 1977, 1979, 1980; Torrence 1983, 1989b; Bamforth 1986, 1991, 2006; Bleed 1986; Kelly 1988, 2011; Meltzer 1989; Nelson 1991; Bousman 1993; Andrefsky 1994; Shott 1986, 1996; Escola 2000, 2004a; Janetski 2002; Odell 2003; Kuhn 2004; Franco 2004; Cortegoso 2005b; Charlin 2009a; Eerkens 2011; Hughes 2011a; Pallo y Borrero 2015, entre otros), por lo que aquí se hará una presentación sintética.

\subsubsection{Estrategias tecnológicas}

Las estrategias han sido consideradas como elecciones para la solución de problemas que responden a las condiciones creadas por la interacción entre los seres humanos y su ambiente (Nelson 1991: 58, y referencias citadas allí). Aquí, entra en juego la toma de decisiones óptimas o las elecciones tecnológicas de los individuos en la producción y uso de instrumentos líticos, donde se ejecutan aquellas estrategias que resulten más adecuadas (funcional, material y socialmente) ante una situación particular; con la expectativa de que las elecciones efectivas ante ciertas condiciones, y/o que resultaron flexibles a nuevas situaciones, tengan mayor persistencia en el tiempo (Torrence 1989b; Carr 1994).

Binford (1973, 1977, 1979) introdujo los conceptos de conservación y expeditividad, como estrategias de utilización de los recursos líticos. Luego, Nelson (1991), agregó una tercera estrategia a la que llamó comportamiento oportunista y que opone a la expeditividad dado que el carácter situacional -característico hasta entonces de la estrategia expeditiva-, se lo asigna a la estrategia oportunista (Nelson 1991: 65). Aclara que los tres conceptos no delimitan una clase de artefactos o un tipo de conjuntos, sino que identifican tipos de planes para facilitar usos humanos del ambiente que pueden ser efectuados en diversidad de formas y constituyen respuestas a condicionamientos diferentes. Bamforth (1986) sostiene que clasificar una colección de instrumentos como "conservados" o "expeditivos" es una gran simplificación y que nos dice muy poco; considera que sólo son términos útiles para describir aspectos del comportamiento tecnológico (Bamforth 1986: 49). A las estrategias tecnológicas, Nelson (1991) las coloca en el tercer nivel de análisis en las investigaciones sobre organización tecnológica, luego de las condiciones ambientales (primer nivel) y de las estrategias económicas y sociales (segundo nivel). Las formas de los artefactos y la composición de los conjuntos son las consecuencias de las diferentes maneras de implementar la conservación y la 
expeditividad (Nelson 1991: 62) ${ }^{8}$, es decir, son consecuencia de las estrategias tecnológicas.

A partir de la introducción del término "conservación" (curation) en los estudios sobre organización tecnológica (Binford 1973, 1977, 1979), este adquirió numerosas acepciones (Bamforth 1986; Kelly 1988; Nelson 1991; Bousman 1993, entre otros). Para Nelson (1991), la conservación es una estrategia de cuidado de los instrumentos y equipos que puede incluir manufactura anticipada, transporte, reformatización y ocultamiento o almacenamiento. La variable clave que la distingue de la expeditividad es la preparación de materias primas con antelación a condiciones inadecuadas (materiales, tiempo o instalaciones) para que la confección tenga lugar en el momento y el lugar de uso (Nelson 1991). Por lo tanto, esta estrategia permite enfrentar problemas relacionados con las tensiones temporales (time stress) para realizar una tarea (e.g., explotación de recursos disponibles por periodos cortos), y facilitar la disponibilidad de materiales o instrumentos en el mismo lugar de uso; se aprovecha el tiempo de "captura", antes de la captura misma. La estrategia, entonces, es invertir mayor cantidad de tiempo o energía en la manufactura, transporte, almacenaje, etc. (Binford 1979; Torrence 1983; Bamforth 1986; Kelly 1988; Nelson 1991).

La inversión en tiempo por adelantado conlleva altos costos energéticos en manufactura, compensados por el mantenimiento, reformatización y reutilización (Nelson 1991). Pero para Bamforth (1986) la disponibilidad de la materia prima puede actuar como un constreñimiento tecnológico; por ejemplo, el mantenimiento de los instrumentos líticos sólo ocurre si la materia prima no está disponible fácilmente. Así, Bamforth (1986) hace hincapié en los costos en tiempo y energía generados al invertir en el transporte. No obstante, al margen de la ubicuidad de la materia prima, aprovisionarse de recursos móviles de forma constante y no esporádica requiere continuidad en la disponibilidad del instrumental asociado. En esas circunstancias se espera una conservación a largo plazo de los utensilios (Nelson 1991).

La expeditividad, según la propuesta original de Binford (1973, 1977, 1979), implica instrumentos manufacturados con una menor inversión de trabajo y descartados en su inmediato lugar de uso (Binford 1973: 242). Así, el tiempo y el lugar de uso son

\footnotetext{
${ }^{8}$ Cabe aclarar que, debido a la ambigüedad con que se trata a estos conceptos (sobre todo al de conservación), en Argentina se acordó que ambos términos son empleados, en general, para caracterizar la manufactura o el uso de materias primas e instrumentos, más allá de su referencia a comportamientos planificados (Bayón et al. 1995, citado en Escola 2000, 2004a).
} 
predecibles, y el tiempo y las materias primas se dan en cantidades suficientes (Nelson 1991). A diferencia de la conservación, la expeditividad tecnológica aparecerá allí donde se disponga de materias primas (de buena o mala calidad) y de tiempo para confeccionar instrumentos; es distinta también del comportamiento oportunista, el cual es más común en aquellos lugares que no suelen ser reutilizados regularmente (Nelson 1991). La expeditividad depende de tres condiciones (Nelson 1991: 64):

1) Acumulación planificada o previsión de las actividades en las cercanías de las materias primas (Bamforth 1986; Parry y Kelly 1987);

2) Disponibilidad de tiempo para confeccionar instrumentos como parte de las actividades de uso, sin tensiones temporales (time stress) (Torrence 1983);

3) Ocupación prolongada o reutilización habitual del lugar con el fin de sacar provecho del acopio o del escondrijo (Parry y Kelly 1987).

Esta estrategia minimizaría el esfuerzo tecnológico, al manufacturarse los instrumentos en el lugar de uso (Carr 1994: 36). Con respecto a los costos y beneficios generados por esta estrategia en relación al abastecimiento de materia prima, hay distintas posturas: algunos consideran que los costos de transportar materias primas son altos ( $c f$. Bamforth 1986); para otros el aprovisionamiento está incluido en otras actividades sin generar costos reales (estrategia “embedded”, sensu Binford 1979; Véase Sección 4.2.1.2. en este capítulo). Disyuntiva difícil de resolver dados los pocos ejemplos etnográficos disponibles (Nelson 1991).

Acerca del comportamiento tecnológico oportunista, Nelson (1991) sostiene que no es planificado, sino que responde a condiciones inmediatas e imprevistas, y que tampoco debe considerárselo situacional (sensu Binford 1979), ya que la organización tecnológica es un sistema de estrategias para enfrentar condicionamientos o situaciones (Nelson 1991: 65). Los contextos ambientales y de comportamiento específicos, además de la falta de planificación característica de este comportamiento (peculiaridad que lo distingue del comportamiento expeditivo), producen diferencias importantes en el diseño y la distribución de las actividades, y por ende en la forma y distribución de los artefactos (Nelson 1991: 65-66).

Retomando las dos estrategias tecnológicas planificadas, conservación y expeditividad, no deben ser percibidas como sistemas (cursiva en el original) mutuamente excluyentes, sino como opciones de planes que se adecuan a condiciones diferentes dentro de una serie de estrategias adaptativas (Nelson 1991). Aunque son los extremos de un continuum y suelen ser tratadas como comportamientos dicotómicos no constituyen tipos 
fijos de comportamiento que respondan siempre a circunstancias específicas (Escola 2000: 11). Este tratamiento dual proviene de la ya clásica asociación directa entre las estrategias tecnológicas y las de asentamiento, representadas estas últimas por el continuum forager-collector, definido por Binford $(1979,1980)$ a partir de su experiencia etnográfica entre los Nunamiut. Este autor, ante la observación de que los artefactos no necesariamente son descartados en el mismo lugar donde se han utilizado, ha considerado a la organización de la tecnología desde la perspectiva de un sistema de asentamientos, para analizar los diferentes modos de aprovisionamiento, manufactura, uso y descarte de instrumentos, ya que estos modos son pistas o correlaciones con las funciones del sitio dentro de un sistema de asentamiento (Binford 1979: 255). A partir de aquí se ha vinculado a la estrategia expeditiva con los grupos forager, quienes trasladarían y usarían sus instrumentos en sucesivos lugares; y a la estrategia conservada con los collector, que descartarían sus instrumentos en el mismo lugar de uso (Binford 1973, 1977, 1979, 1980; Bamforth 1986; Torrence 1989b; Bousman 1993; Andrefsky 1994; Carr 1994; Escola 2004a; Franco 2004; Cortegoso 2005b; Salgán 2013). Sin embargo, para Andrefsky (1994), el modo en que se utilizan las materias primas líticas depende más de la abundancia y calidad de las rocas disponibles en el ambiente, que del grado de movilidad residencial de los grupos, por lo que la influencia de las estrategias de asentamiento sería sólo indirecta.

Para Nelson (1991) los diversos aspectos de las estrategias tecnológicas (incluyendo el comportamiento oportunista) tienen consecuencias sobre el diseño y la distribución espacial de utensilios e instrumentales (Nelson 1991). El diseño se refiere a variables conceptuales de utilidad que condicionan las formas de los utensilios y la composición de los instrumentales. Por su parte, las distribuciones de los artefactos son producidas por la salida de elementos del sistema a través del abandono, pérdida o descarte, y procesos post-abandono (Nelson 1991, y referencias citadas allí). Aquí se hará hincapié en las variables de diseño, las cuales constituyen respuestas a diferentes condicionamientos o estrategias para utilizar el ambiente (Nelson 1991).

\subsection{Variantes de Diseño}

Distintas variables del diseño serán más o menos adecuadas a condiciones y estrategias tecnológicas según el contexto, e importantes para optimizar la disponibilidad de cualquier sistema tecnológico. Bleed (1986) introdujo los conceptos "confiable" (reliable) -implica que el instrumento se realiza para estar disponible cuando se lo 
necesita-, y "mantenible" (maintainable) -si el instrumento se rompe o no es apropiado para la manufactura, se lo repara rápida y fácilmente para ser llevado a un estado funcional. Este último diseño es confeccionado para trabajar con facilidad en una variedad de circunstancias, por lo que incluye diseños tanto seriados (prevén el orden de diversas tareas futuras, cambiando la forma de modo secuencial) como modulares (permiten a las tareas futuras cualquier orden, empleando partes activas reemplazables) (Bleed 1986; Nelson 1991). Así, Nelson (1991) distingue entre dos estrategias de diseño que poseen diversidad de usos: flexible y versátil. La primera, cambia de modo que permita cumplir requerimientos multifuncionales. La estrategia versátil mantiene una forma generalizada para satisfacer diversidad de necesidades ${ }^{9}$. Por último, Nelson define el diseño transportable, caracterizado por el traslado del instrumental hacia la tarea, en lugar de ser confeccionado en el lugar donde se efectúa la tarea (Nelson 1991). Aquí se siguen estas definiciones propuestas por Nelson (para un desarrollo más extenso de cada variable de diseño tratada por esta autora véase Nelson 1991: 68), quien detalla también las ventajas, desventajas y las consecuencias materiales de cada una de las variables de diseño tratadas por ella (Nelson 1991).

Además de las propuestas de Bleed (1986) y Nelson (1991), otros autores también han elaborado aplicaciones de los elementos de diseño (Shott 1986; Torrence 1989b; Bousman 1993; Carr 1994, entre otros). Si bien el trabajo de Bleed (1986) abrió una nueva vía de aproximación a la tecnología mediante las variables de diseño, la utilidad de las categorías de confiabilidad y mantenibilidad estuvo restringida y ligada al modelo de foragers-collectors de Binford (1980). Así como la relación planteada entre collectors y conservación llevó a vincular foragers y expeditividad, los diseños confiables y mantenibles fueron asociados a las estrategias tecnológicas de conservación y expeditividad, respectivamente (Escola 2000). Sin embargo, este esquema dicotómico, algo simplista -y difícilmente tratado como el continuum que pretende ser-, resulta insuficiente para explicar el amplio abanico de respuestas observadas en el registro etnoarqueológico y arqueológico (Escola 2000, 2004a). Así, no sólo la confiabilidad, sino también la mantenibilidad (incluyendo flexibilidad y versatilidad) y la transportabilidad son definidas como alternativas de diseño complementarias y estrechamente vinculadas a una planificación centrada en la anticipación, optimización y extensión de la vida útil de los instrumentos, es decir, generadas a partir de una estrategia de conservación

\footnotetext{
${ }^{9}$ Nelson (1991) también hace la distinción entre diseño flexible secuencial y diseño flexible modular.
} 
(Torrence 1989b; Bousman 1993; Carr 1994). Por ende, ninguno de estos elementos de diseño podría surgir como resultado de un comportamiento expeditivo (Escola 2000, 2004a).

Para este último caso, Escola (2000, 2004a) propone hablar de “diseños utilitarios", concepto que comprende a todos aquellos diseños que tienden a facilitar la ejecución de tareas inmediatas, conocidas, muchas veces específicas, respondiendo a consideraciones de corto plazo, y con mínimo esfuerzo tecnológico. El instrumental podría caracterizarse por la utilización y/o formatización de determinados biseles, ángulos de filo y contornos de borde (instrumentos “informales”, sensu Andrefsky 1994, que representan un extremo del continuum de formatización), que permitirían enfrentar necesidades variadas con una mínima inversión de trabajo ${ }^{10}$ en su producción (Escola 2002: 20). Cabe aclarar que Escola (2000, 2004a), a raíz de su experiencia en talla lítica, considera que gran parte del repertorio instrumental considerado formal (instrumentos unifaciales de retoque marginal: como cuchillos, raederas, muescas, denticulados) no requiere de gran esfuerzo, destreza técnica e inversión de trabajo para su manufactura, por lo que no deberían caracterizarse como instrumentos formales. Así, estos conjuntos sugieren la necesidad de ampliar el espectro artefactual que se espera encontrar en el marco de una estrategia expeditiva (Escola 2000, 2004a).

No se debería confundir estrategia tecnológica con diseño de los artefactos. Esta diferencia la señala Nelson (1991) al hablar de algunas definiciones ofrecidas para la estrategia de conservación, como la que hace Bamforth (1986: 38): "technologies based on curation comprise tools that are effective for a variety of tasks [diseño versátil], are manufactured in anticipation of use, maintained through a number of uses, transported from locality to locality for these uses and recycled to other tasks when no longer useful for their primary purposes [diseño flexible]" (Bamforth 1986: 38; sin subrayado en el original). Tales diseños (versátil y flexible en este ejemplo) constituyen respuestas a diferentes condicionamientos o estrategias para utilizar el ambiente, y no necesariamente son criterios de definición del concepto conservación (Nelson 1991). Igualmente, la utilidad teórica más importante que se obtiene al considerar las características de diseño de los sistemas de armas es la capacidad de ver los sistemas tecnológicos como variables

\footnotetext{
${ }^{10}$ Entendida en términos de: a) las técnicas de reducción involucradas en la producción de determinadas formas base, b) la evidencia de cierta estandarización de los soportes, tamaño o módulo, y c) las técnicas de retoque implementadas en la formatización y regularización final de los instrumentos. Estos deben ser algunos de los criterios claves para la definición de "formalidad" e "informalidad" en instrumentos de retoque marginal o parcialmente extendido (Escola 2000, 2004a).
} 
específicas que pueden ser alteradas para alcanzar soluciones óptimas a los problemas ambientales (Bleed 1986: 745). Reconocer cuáles variables de diseño fueron implementadas en cada contexto, permite ampliar el conocimiento de las estrategias tecnológicas del pasado humano (Nelson 1991).

\subsection{Estrategias tecnológicas y diseños ante el riesgo y el estrés temporal}

La organización tecnológica es una respuesta a las condiciones ambientales, incluyendo la previsibilidad, distribución, periodicidad, productividad y movilidad de los recursos, el tamaño y la parcelación de las áreas de recursos, y los posibles azares (Nelson 1991). Esta variabilidad ambiental conlleva un "riesgo", definido por Torrence (1989b) en términos de subsistencia, como la probabilidad de no llegar a obtener los alimentos necesarios (véanse otras definiciones en la Sección 4.1.1.3. de este capítulo). A medida que aumentan las posibilidades de fracaso y los costos de adquisición, producción y aplicación, el riesgo debe desempeñar un papel cada vez más importante en la estructuración de las opciones tecnológicas, dentro de los límites establecidos por la capacidad de una sociedad para soportar costos tecnológicos (Bamforth y Bleed 1997). El tipo de inversión tecnológica dependerá de la intensidad relativa de la variación impredecible (riesgo).

Un diseño confiable surgirá, entonces, en respuesta a la severidad del riesgo, mientras que uno mantenible se manifestará en relación a la duración del riesgo (Torrence 1989b). Con respecto a su duración, el estrés temporal ("time stress") alude a la existencia de limitaciones en la cantidad de tiempo disponible para realizar una tarea (Torrence 1983: 12). Esta es una variable clave para explicar las diferencias en la estructura de los toolkits de cazadores-recolectores, así como en los patrones de aprovisionamiento, manufactura y descarte de artefactos (Torrence 1983), ya que implica seleccionar diversas estrategias tecnológicas apropiadas para disminuir las posibilidades de perder un recurso y hacer un uso eficiente del tiempo en la búsqueda, obtención y manejo de los recursos (Amick 1994; Bousman 1993; Franco y Borrero 1999).

Se esperaría que, ante estas situaciones de riesgo o estrés temporal, la estrategia implique manufactura con anterioridad al uso, es decir, lo que generalmente se ha entendido como “conservación” (Binford 1979; Nelson 1991; Torrence 1983). Sin embargo, tal respuesta (manufactura con anticipación al uso) puede responder a dos situaciones distintas: las generadas ante riesgo o estrés temporal, y las dadas por incongruencias en la distribución de recursos líticos y faunísticos (Franco 2004). Para 
dilucidar este problema de ambigüedad del concepto de conservación, Odell (1996) ha propuesto que este sea usado sólo para referirse a la estrategia relacionada con la primer situación (riesgo o estrés temporal), designando "comportamiento económico inducido por la escasez" (Odell 1996: 76) o "economía de materias primas" a aquellas estrategias que buscan mitigar la escasa disponibilidad de rocas en el paisaje. Franco (2004) relaciona a la segunda estrategia mencionada con la incongruencia de recursos que, según esta autora, no siempre implica escasez (Franco 2004: 105).

Se ha planteado que para reducir el riesgo la tecnología debe ser "eficaz" 11 (Bleed 1986; Jeske 1992; Bousman 1993) (véase también otras respuestas al riesgo como los “mecanismos buffer" en la Sección 4.1.1.3. de este capítulo). Según Bousman (1993: 69), la eficiencia puede medirse por al menos cuatro criterios:

1) producción más rápida: confeccionando instrumentos expeditivos (e.g., un cuchillo);

2) aumento de su vida útil: haciendo instrumentos mantenibles (e.g., un cuchillo más duradero);

3) mayor efectividad: confeccionando instrumentos confiables (e.g., un cuchillo más afilado);

4) mayor volumen de producción: usando instrumentos eficientes, al tener mayor cantidad de filos por unidad de materia prima (e.g., más cuchillos por unidad de materia prima).

Las estrategias tecnológicas y las variables de diseño elegidas en la toma de decisión se manifiestan en la variabilidad de los materiales líticos del registro arqueológico, por ejemplo, en la confección de artefactos líticos tallados (Jeske 1992), o en la elección y aprovisionamiento de la materia prima (Andrefsky 1994; Bamforth 2006), entre otros.

\subsubsection{De la obtención de rocas al descarte de artefactos: el continuum de la} organización tecnológica

La preservación y perdurabilidad natural de los materiales líticos en el registro arqueológico permiten desarrollar reconstrucciones completas de la organización y trayectoria artefactual o historia de vida de los artefactos líticos del pasado (Schiffer 1972, 1976; Kordehoff 1987; Beck et al. 2002; Kuhn 2004; Andrefsky 2009, entre otros), recorriendo un continuum de comportamiento pautado y secuencial posible de reproducir gracias a la naturaleza extractiva de la tecnología lítica. Esta sucesión de pasos o "cadena del comportamiento" (Schiffer 1972, 1975, 1976) abarca desde la obtención del recurso

\footnotetext{
${ }^{11}$ La tecnología incrementa la eficiencia en la obtención de energía, por lo que se la vincula directamente con la estructura costo-beneficio de los modelos de forrajeamiento óptimo (MFO) (Torrence 1989b) descritos en la Sección 4.1.1.1. de este capítulo.
} 
lítico, su manufactura, transporte, uso, mantenimiento y/o reciclado, dentro del contexto sistémico, hasta su descarte final en el contexto arqueológico (Schiffer 1972, 1975).

El proceso de modificación del material lítico aludido puede ser denominado "producción lítica" (Ericson 1984). Su estudio sistemático permite obtener un mayor conocimiento del comportamiento humano pasado, comenzando por el primer punto de modificación dentro del sistema: la cantera (Ericson 1984) o área de abastecimiento/aprovisionamiento. Este tipo de sitios ha sido señalado como el punto de inicio de los estudios de organización de la tecnología lítica (Ericson y Purdy 1984; Nelson 1991; Franco y Borrero 1999; Escola 2002; Bellelli 2004; Cattáneo 2004, entre otros). Sin embargo, ha sido poco explorado en las investigaciones arqueológicas realizadas bajo este marco (Schiffer 1972, 1976) debido, principalmente, a las dificultades metodológicas que conlleva trabajar en estos sitios: gran volumen de material, fragmentación, gran frecuencia de materiales no diagnósticos, poco atractivos y redundantes, superposición de ocupaciones a lo largo del tiempo (palimpsestos) y ausencia de estratigrafía, que los hace contextos arqueológicos poco datables (Church 1994; Ericson y Purdy 1984; Beck et al. 2002; Cattáneo 2004; Escola 2004b; Franco y Aragón 2004; Hermo 2009; Colombo 2013, entre otros).

A pesar de estas dificultades, Ericson (1984) propuso como objetivo de su investigación abrir la discusión sobre la importancia de las canteras prehistóricas y la producción lítica en los contextos de obtención, intercambio, tecnología y organización social. Este autor definió el concepto de "sistema de producción lítica" como el total de actividades sincrónicas y ubicaciones involucradas en la utilización y modificación de una fuente específica de material lítico para la manufactura y uso de artefactos líticos en un sistema social más amplio (Ericson 1984: 3). En otras palabras, se trata de un continuum de comportamiento o trayectoria artefactual que comienza cuando la roca (lito sin modificación en estado natural) entra al contexto sistémico (sensu Schiffer 1972) ante su primer modificación, convirtiéndose en artefacto (o bien cultural). Allí comienza este sistema y su designación varía a medida que todo el proceso de producción se va desarrollando dentro o fuera de un área específica. Así, Ericson (1984) denomina producción terminal a los procesos de producción que se dan en un área específica; producción secuencial a los procesos cuyas etapas están representadas en áreas diferenciales; y producción irregular a los que tienen lugar cuando las actividades se encuentran dispersas en una gran área (Ericson 1984: 4). Si se pretende comprender los patrones regionales de obtención, tecnología e intercambio, se debe conocer qué eventos 
ocurrieron en las áreas de abastecimiento o canteras, y reconstruir la totalidad de la historia de vida artefactual partiendo del registro arqueológico de este tipo de sitios.

Existen algunas variables que pueden afectar o modificar la estructura $y$ morfología de los sistemas de producción lítica. Entre ellas, Ericson (1984) menciona seis: 1) la base regional de recursos líticos; 2) los modos de obtención, procuramiento o adquisición; 3) la distancia social entre talladores y consumidores; 4) la inversión de trabajo; 5) los modos de transporte; y 6) la organización social. La determinación de estas y otras variables permite hacer una caracterización de cada sistema.

\subsection{Estructura de la base regional de recursos líticos}

La distribución o forma natural en la que se disponen las materias primas en el paisaje (e.g., exposición superficial), su disponibilidad o "estructura" en el ambiente (tipos y extensión de fuentes, tamaño de los nódulos, calidad para la talla, litologías, etc.) y su accesibilidad (facilidad relativa con la que pueden ser obtenidas) influyen sobre las estrategias tecnológicas implementadas en su obtención y explotación (Gould 1980; Kelly 1983; Ericson 1984; Gould y Saggers 1985; Kuhn 1991; Nelson 1991; Nami 1992; Bousman 1993; Andrefsky 1994; Ingbar 1994; Haury 1995; Flegenheimer y Bayón 1999; Franco y Borrero 1999; Franco 2004, entre otros); la abundancia, calidad y variabilidad de las rocas disponibles también juegan un rol fundamental en la opción de dichas estrategias, la selección misma de las rocas y el tipo de instrumentos a producir (Gould 1980; Gould y Saggers 1985; Bamforth 1986; Nami 1986, 1992; Amick 1994; Andrefsky 1994; Aragón y Franco 1997; Garvey 2015, entre otros). Todas estas variables conforman la base regional de recursos líticos y contribuyen al conocimiento de su estructura.

Los recursos líticos se encuentran en concentraciones localizadas e involucran costos de búsqueda, de aprovisionamiento y de procesamiento (Hayden 1989), como así también, de traslado según la "distancia a la fuente de aprovisionamiento" (Renfrew 1977; Torrence 1984; Meltzer 1989; Beck et al. 2002; Brantingham 2003; Kuhn 2004). Cuando los costos de aprovisionamiento de la materia prima aumentan, los cazadores-recolectores utilizan estrategias economizadoras en su obtención y uso, tales como la estandarización de formas del artefacto, la reducción en el tamaño de los instrumentos y la extensión de la vida útil (Jeske 1989), entre otros ejemplos. Para evaluar tales costos de obtención y de aprovisionamiento, y comprender cómo se utilizaron los distintos tipos de rocas según su abundancia relativa, se requiere conocer la "estructura regional de recursos líticos", 
entendida como el total de actividades desarrolladas y localidades involucradas en la modificación y utilización de los recursos líticos (Ericson 1984).

Un factor relacionado con la distribución y disponibilidad de las materias primas tiene que ver con su origen. Nami (1992) distingue entre fuentes primarias y fuentes secundarias. "Las primeras son definidas como aquellas en que la roca se presenta en su lugar de origen, ya sea en forma de filón, escoria, etc. Las segundas son aquellas en que las rocas se presentan transportadas desde fuentes primarias a otro lugar, ya sea cercano o lejano, por la acción de agentes naturales: transporte de ríos, acción glaciaria, etc." (Nami 1992: 42). Cualquier base regional de recursos líticos se constituye de la totalidad de fuentes potenciales, tanto primarias como secundarias. Church (1994) incluye fuentes terciarias (conjuntos líticos reclamados con posterioridad a su primer descarte), pero estas no se consideran aquí.

Entre los criterios de selección de las materias primas líticas, Nami (1992) también considera las características que deben poseer estos materiales para ser apropiados para la talla. Para las técnicas de percusión o presión, las rocas más aptas deben presentar fractura concoidea, y poseer otras cualidades, tales como: ser isotrópicas (tener las mismas propiedades en todas las direcciones), criptocristalinas (mínima estructura cristalina o de grano fino), homogéneas (la misma estructura en todas partes y sin impurezas o inclusiones), elásticas (retornar al estado original luego de ser reducidas por la aplicación de fuerza), duras (entre 6-7 de dureza en la escala de Mohs) y quebradizas (con mayor facilidad a la fractura) (Nami 1992: 37; cf. Aragón y Franco 1997).

Wilson (2007) sostiene que hay varios factores involucrados en la elección de una fuente sobre: 1) características geológicas o geográficas (calidad de la materia prima, abundancia de nódulos utilizables, tamaño de los nódulos disponibles, facilidad de obtención, extensión areal, accesibilidad a la fuente, etc.); 2) factores humanos (dirección de los viajes, distancia a la fuente, estrategia de movilidad, tiempo disponible, presencia de otros recursos deseados en el área, nivel de fatiga de los individuos, organización social, estrategia de aprovisionamiento e intercambio, límites territoriales, tabúes, y otras restricciones sociales, etc.). Propone un "gravity model" considerando estos factores como determinantes de la utilización de una fuente de materias primas $\mathrm{y}$, utilizado los límites geológicos y geográficos, enuncia una ecuación para calcular el valor del atractivo (atractiveness value) de cada fuente, lo que le permite establecer un ranking de las fuentes disponibles (Wilson 2007). 
Sobre la base de estudios etnográficos y etnoarqueológicos, Andrefsky (1994) asegura que la disponibilidad de la materia prima desempeña un papel primordial en la organización de la tecnología y es uno de los condicionantes más importantes en la producción de instrumentos líticos. Este autor señala que el uso de categorías tales como instrumentos formales e informales como medio para identificar aspectos del asentamiento puede ser engañoso si no se considera la disponibilidad de materias primas líticas. Plantea que esta puede ser evaluada en función de la abundancia y calidad. A partir de tres estudios arqueológicos en el oeste de EE.UU. (Pinon Canyon, Calispell Valley y Rochelle) presenta un modelo de producción artefactual basado en la importancia de la abundancia y la calidad de los recursos líticos: si las materias primas disponibles son de mala calidad, sin importar su abundancia, los conjuntos líticos estarán caracterizados por instrumentos informales elaborados sobre materia prima no local. Al contrario, si las materias primas son de buena calidad pero no están disponibles en el paisaje (poca abundancia), se priorizará la manufactura de instrumentos formales. A esto se agrega una tercera situación: si las materias primas son de buena calidad $y$ abundantes, se producirán instrumentos tanto formales como informales (Andrefsky 1994) (Figura 4.2).

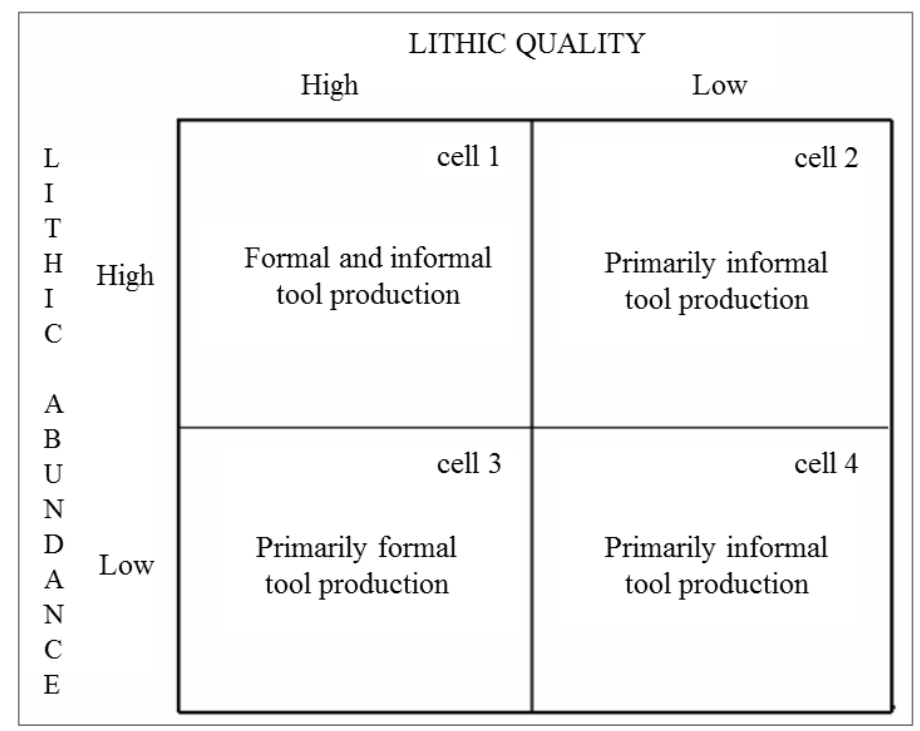

Figura 4.2. Relación entre la abundancia y calidad de las materias primas disponibles y el esfuerzo invertido en la manufactura de los artefactos (Tomado de Andrefsky 1994:30).

La accesibilidad remite a la relativa facilidad para obtener materias primas o, dicho de otro modo, a la ausencia de obstáculos o dificultades para adquirir recursos líticos, tales como estacionalidad, topografía, limitaciones por el tipo de formación de 
suelo, vasta cobertura vegetal, poca posibilidad de transitar por el espacio donde se disponen las rocas, y otros rasgos del paisaje que pueden restringir el acceso y dificultar la obtención.

Aunque las rocas puedan estar disponibles localmente, existen patrones de comportamiento humano que condicionan la forma de acceso a las materias primas. Estos factores de índole social pueden vincularse a reglas de parentesco, alianzas, jerarquización social, territorialidad, valores simbólicos e ideológicos que pueden poseer los sitios de aprovisionamiento, por ejemplo, rituales, tabúes, lazos totémicos con una región o cantera específica, entre otros (Gould et al. 1971; Gould y Saggers 1985; Nelson 1991; Bayón y Flegenheimer 2004; Heldal 2009; Colombo 2013; Bobillo y Hocsman 2015 y referencias allí citadas). Si bien los factores sociales no conforman tácitamente la base de recursos líticos, condicionan la "facilidad" de su obtención, distinguiéndose el acceso directo del indirecto, conceptos que se verán en la Sección 4.2.1.3.

Una vez en contacto con las rocas, prosigue su aprovisionamiento por medios directos o indirectos ( $c f$. Renfrew 1977; Torrence 1984; Meltzer 1989; Ingbar 1994, Brantingham 2003; Kuhn 2004, entre otros). Las variables descritas determinan qué modos de adquisición y estrategias de aprovisionamiento serán implementados por los grupos humanos. La estructura de la base regional de recursos líticos (sensu Ericson 1984), es una primera vía de aproximación a cuestiones diversas relacionadas con el rango de acción, la elección de estrategias de obtención de materias primas y otros problemas que deben encarar las poblaciones.

\subsection{Modos y estrategias de aprovisionamiento}

Las variables que estructuran la base de recursos líticos de una región, en relación a la forma y disposición de las rocas en el terreno, también pueden definir los modos de obtención que se van a implementar. Para Colombo (2013) la obtención, propiamente dicha, implica el contacto con las rocas yacentes en la superficie del terreno y su transformación en artefactos. Se diferencian dos modos distintos según la disposición de las rocas en el terreno: la extracción, que se da cuando se requiere la fragmentación de bloques, filones u otros cuerpos de piedra no transportables, a partir de técnicas como la percusión, el agrietamiento, la excavación y el shock térmico; y la recolección, que consiste en una técnica más sencilla que implica recoger rocas transportables, como bloques pequeños, nódulos y rodados (Colombo 2013). Este contexto se daría únicamente en las canteras o áreas de abastecimiento, por lo que este autor distingue "obtención" -en 
sentido estricto-, de "adquisición", este último más ambiguo ya que es un término utilizado también en casos de intercambio o de reclamación (Colombo 2013).

Los modos de obtención influyen sobre los formas y costos de transporte, ya que este implica trasladar las materias primas -obtenidas de determinada manera- hasta los sitios (distintos a las canteras o áreas de abastecimiento) donde serán utilizadas (Colombo 2013). Por ende, las estrategias implementadas varían conforme sea la distancia a recorrer entre las áreas de abastecimiento y los sitios de uso, o según la distancia entre productores (talladores) y consumidores. Si el tallador está en contacto cercano con los consumidores, responderá directamente a las necesidades de estos últimos (e.g., entregando artículos terminados); pero a medida que se alejan, el tallador producirá formas menos específicas o usará una estrategia mixta de artículos terminados y formas-base. Además de la distancia, a medida que aumenta la población de una región, cambian las pautas de movilidad (residencial o logística) y se promueve el desarrollo de sistemas de intercambio regional. Estos factores, por ende, también influyen sobre los modos y estrategias de transporte de artículos (e.g., formas-base y preformas) ( $c f$. Binford 1979, 1980; Ericson 1984; Bamforth 1986, 1991; Kelly 1988; Bousman 1993; Beck et al. 2002; Bayón y Flegenheimer 2004; en Sección 4.2.1.3. véase el concepto de transporte en el sentido de “conveyance", Hughes 2011b).

Para algunos autores, la cantidad de inversión de trabajo se da en función de la capacidad de obtención y de traslado, es decir, cuánto de lo obtenido se puede transportar y a cuánta distancia. La disminución del peso del material a acarrear, ya sea por la extracción y/o recolección de bloques, nódulos o clastos pequeños, o por la inversión en la reducción y producción de artículos acabados o por terminar en la cantera es una estrategia útil, sobre todo en casos en que las bases residenciales se encuentren a grandes distancias (Gould et al. 1971; Renfrew 1977; Ericson 1984; Kelly 1988; Bousman 1993; Beck et al. 2002, entre otros). Esto último lo indica, por ejemplo, el estudio de Beck y colaboradores (2002) en los conjuntos de dos canteras de dacita de la transición Pleistoceno-Holoceno de la Gran Cuenca: con el fin de vincular y estudiar la variabilidad de ambos conjuntos, los autores utilizaron modelos de la teoría del lugar central y evaluaron la relación entre diferentes grados de reducción de bifaces, con los costos de transporte de los productos resultantes al salir de las canteras (Beck et al. 2002). En el marco de estos modelos asumieron que, manteniendo la tecnología y las condiciones del lugar constantes, el comportamiento óptimo del forrajeamiento (en este caso, del 
“aprovisionamiento") ${ }^{12}$ cambia en función del aumento en el tiempo de viaje del lugar central (base residencial) a la cantera, ida y vuelta. Haciendo alusión al título de su artículo, "rocks are heavy", asumen que si aumenta la distancia entre ambos puntos, será más beneficioso seguir reduciendo bifaces en la cantera, lo cual también disminuye la cantidad de material inutilizable (i.e., que no es útil como formas-base, ni cumple otros roles, sensu Kelly 1988) en los sitios residenciales. Así, los conjuntos de artefactos que llegan a estos últimos sitios estarán conformados por bifaces en etapas posteriores de reducción a las de su cantera asociada (Beck et al. 2002).

Según Bamforth $(1986,1991)$, si la materia prima no está disponible fácilmente estos y otros artefactos trasladados desde las canteras, serán mayormente mantenidos y reciclados cuanto más distantes se encuentren de ellas. Conforme al concepto de conservación de Bamforth (1986: 38), mantenimiento y reciclado son componentes fundamentales. Sin embargo, también se debe considerar la distinción que hizo Odell (1996) entre "conservación” y "economía de materia prima” (véase sección 4.2.1.1.2.), ya que ambos - mantenimiento y reciclado- dan cuenta igualmente de un aprovechamiento óptimo de la materia prima misma debido a su escasez (sensu Odell 1996). Por lo tanto, no necesariamente están asociados con la organización de la movilidad; ni siempre la optimización de la energía invertida en el abastecimiento de rocas determina la forma posterior de utilización de la materia prima (Hayden 1989).

Un paralelismo entre recursos de subsistencia y recursos líticos, muestra que el forrajeamiento es tan importante en la explotación de los primeros, como el aprovisionamiento lo es sobre los recursos líticos. Considerando a las materias primas líticas como un recurso al igual que los de subsistencia (sensu Bamforth 1986), se hace necesario evaluar los costos y beneficios asociados a la producción tecnológica (Bousman 1993) ya que, como señala Franco (2004), las ventajas tecnológicas pueden, por ejemplo, disminuir el tiempo de búsqueda de los alimentos. Así, se sugiere que los costos y beneficios del aprovisionamiento, manufactura y transporte de materiales líticos sean incluidos dentro de los costos generales de obtención de recursos y en la evaluación general de una estrategia de forrajeamiento específica por parte de cazadores-recolectores (Beck et al. 2002; Franco 2004). Estos son aspectos importantes a tener en cuenta debido a que no siempre se requiere de tiempo y energía suficientes, ni suele ser el objetivo

\footnotetext{
12 Estos modelos, tradicionalmente, han sido aplicados al transporte diferencial de partes de animales (presas), pero recientemente se han comenzado a utilizar con otros tipos de recursos, incluyendo los líticos.
} 
invertir exclusivamente en el aprovisionamiento de materias primas líticas. Pero entonces, ¿en qué consiste el llamado "aprovisionamiento" lítico?

El aprovisionamiento comprende el proceso total en el que se proveen rocas a los sitios y a las personas (en forma de nódulos, núcleos, formas-base y/o instrumentos terminados), incluyendo los modos de obtención y de transporte de materias primas líticas -descritos arriba-, e incluso el intercambio (aprovisionamiento indirecto) (Colombo 2013). Aquí de nuevo, la estructura de los sistemas de producción lítica variará según las estrategias implementadas en el aprovisionamiento del material (Ericson 1984).

Como ya ha sido mencionado (Sección 4.2.1.), uno de los primeros investigadores que planteó modelos de aprovisionamiento lítico fue Binford $(1977,1979,1980)$ quien, a partir de sus estudios etnográficos entre los Nunamiut, distinguió entre dos tipos de estrategias según los costos involucrados: incluido -o incidental- (embedded) y directo (Binford 1979: 259). El primero, se refiere a la obtención de materias primas mientras transcurren otras tareas, principalmente de subsistencia, y en previsión de necesidades futuras, sin generar costos extra en el aprovisionamiento ya que está "incluido" dentro del circuito de movilidad programado de los grupos humanos. El aprovisionamiento directo, remite a los movimientos de una población en el ambiente con el propósito principal de obtener materias primas para la confección de instrumentos. Sin embargo, Binford (1979) sostiene que no hay costos "directos" en el aprovisionamiento de materias primas líticas y que, de haberlos, son muy bajos y se dan solamente cuando no se pudieron obtener recursos de otra manera, o cuando las partidas logísticas salen con el propósito exclusivo de obtener materias primas. La variabilidad en las proporciones de materias primas encontradas en un sitio dado es principalmente una función de la escala del hábitat que fue explotado (Binford 1979: 260). Tampoco hay costos de reparación y mantenimiento de los instrumentos, ya que estas tareas son ejecutadas durante el "off time" de otras actividades. Así, las materias primas son adquiridas con bajo costo y haciendo un uso eficiente del tiempo cuando la gente está explorando o recolectando otros recursos, y son transportadas cuando la gente se desplaza por otros motivos (e.g., viajes estacionales) (Binford 1979).

Binford (1979) también observó que las estrategias para el abastecimiento de rocas, manufactura, uso y descarte de instrumentos entre los Nunamiut varían según el equipo instrumental del que se trate. Ellos distinguen tres tipos básicos de equipo de campo: equipo personal (personal gear), equipo de sitio (site furniture; también se incluyen household gear, insurance gear y seasonal gear) y equipo situacional 
(situational gear). Tanto el equipo personal como el equipo de sitio se consideran de carácter anticipatorio, es decir, los instrumentos son manufacturados con anticipación al uso y previendo necesidades futuras, por lo que no son afectados por limitaciones de tiempo, y se espera que sean manufacturados en las mejores materias primas disponibles regionalmente. El equipo situacional, en cambio, responde a necesidades y contingencias no previstas, y es por tanto, manufacturado sobre materias primas disponibles en forma inmediata (Binford 1979).

Desde luego, no todos los investigadores comparten con Binford (1979) las consideraciones que hizo para ambos tipos de aprovisionamiento -incidental y directobasándose en la relación entre la organización de la tecnología y el sistema de asentamiento-subsistencia de los grupos humanos. Bamforth (2006), por ejemplo, considera que es problemático considerar que el aprovisionamiento de materias primas implique un "bajo costo" debido a su inclusión dentro de la estrategia "embedded" y que, por ende, los costos no afecten al desarrollo de la tecnología. En cambio, Bamforth (2006) observa que en el afloramiento Windy Ridge, una cantera de cuarcita situada a lo largo de la Divisoria Continental de las Montañas Rocosas al norte de Colorado, los costos de obtención de materia prima estarían dados por la distribución de las fuentes y el volumen de materia prima requerida por los grupos. Los cazadores-recolectores de la zona extrajeron rocas intensamente, aunque a menudo no las transportaron a gran distancia. Para Bamforth (2006: 522), la localización de las fuentes de materia prima influye en el patrón de asentamiento y movilidad. En el caso de Windy Ridge, se requirió invertir tiempo y energía, lo cual demuestra la importancia que esta fuente representaba para esos grupos. El autor concluye que los costos de obtención no dependen del tipo de estrategia de aprovisionamiento - "embedded" o directa-, sino de las necesidades tecnológicas de los grupos y de la distribución y naturaleza de la fuente de aprovisionamiento (Bamforth 2006).

En relación a esto último, se puede hacer referencia a la modificación que hizo Franco (2004) al concepto de "economía de materia prima" -originalmente propuesto por Odell (1996). Para ella, la escasez de materia prima no es una condición sine qua non para que se de esta estrategia de economizarla, como sí lo es la incongruencia de recursos líticos y faunísticos (o alimenticios). En tal contexto, entonces, no se podría dar la estrategia de aprovisionamiento "embedded", ya que esta requiere de la congruencia entre los recursos de subsistencia y las rocas de las que se van a proveer a su paso. Igualmente, Franco y Borrero (1999) concuerdan con las expectativas de la estrategia embedded, 
siempre y cuando los recursos líticos sean abundantes. Pero ante situaciones de escasez, sostienen que es más probable que su obtención tenga un papel más importante en la planificación de las tareas de los cazadores-recolectores; y también creen necesario conocer la disponibilidad de otros recursos, que afectarán consideraciones de diseño de artefactos y el tiempo de búsqueda y aprovisionamiento de materias primas (Franco y Borrero 1999, y referencias allí citadas).

Gould (1980) y Gould y Saggers (1985), a partir de sus estudios experimentales y etnoarqueológicos en Australia Central, observaron que los aborígenes australianos realizan excursiones planificadas con el objetivo exclusivo de abastecerse de materias primas líticas.

En su artículo titulado "Lithic procurement in Central Australia: a closer look at Binford's idea of embeddedness in archaeology”, Gould y Saggers (1985), hacen referencia a la propuesta de Binford (1979) y plantean que, aunque concuerdan con su argumento de que el aprovisionamiento de materias primas por cazadores-recolectores móviles ocurrió incidentalmente en relación con otras actividades de subsistencia, sus propios resultados indican que tal razonamiento no alcanza para explicar otras situaciones. Proponen que las propiedades técnicas superiores de ciertas materias líticas también conllevan a que estos grupos australianos realicen esfuerzos especiales para su obtención a través del aprovisionamiento de "special-purpose", dado con frecuencia y no simplemente durante emergencias o cuando las materias primas escasean (Gould y Saggers 1985: 120).

Gould (1980) había sugerido que el aprovisionamiento de recursos líticos está influenciado por la proximidad a centros ceremoniales o lugares sagrados, y aseguró que tales recursos pueden ser seleccionados por su carga ideológica (Gould 1980: 228), más allá del dominio de la subsistencia. En este sentido, Stout (2002) en un estudio etnográfíco de los fabricantes de azadas líticas ("adze") de la aldea de Langda en Irian Jaya (Indonesia), demuestra que el aprovisionamiento de recursos líticos se logra a través de la conformación de un grupo especializado en la realización de tales actividades. Estas tareas de aprovisionamiento están planificadas y se extienden por varios días, por lo que el grupo pasa la noche en viviendas localizadas cerca de los lugares de aprovisionamiento (Stout 2002). También se ha demostrado que la preferencia en la selección de algunas rocas por su color para manufacturar puntas de proyectil, se explica por cuestiones sociales, simbólicas y/o estéticas (Flegenheimer y Bayón 1999; Colombo y Flegenheimer 2013). 
Para evaluar las estrategias de aprovisionamiento y uso de materias primas líticas en la cueva Üçağızlı, en el centro-sur de Turquía, Kuhn (2004) propuso el concepto de "aprovisionamiento tecnológico" como un marco útil para tal fin, y para explorar los cambios en dichas estrategias a lo largo del tiempo. Las estrategias de aprovisionamiento son sistemas idealizados para hacer que los instrumentos acabados y/o las materias primas necesarias estén disponibles cuando y donde se necesiten. La noción de estrategias de aprovisionamiento (Kuhn 1992, 1995, 2004) abarca una variedad de vías por las que los artefactos se transfieren de la cantera al depósito arqueológico. La relación entre la distancia de transporte y su costo, varía según cómo ocurrió dicha transferencia. Se puede dar de maneras distintas, variando consigo las transformaciones y usos de los artefactos, y por ende, sus historias de vida (sus trayectorias generalizadas), entre la fuente y el punto de descarte. Para este autor esta vía es más útil e indicativa que el principio común de basarse en la distancia a la fuente como supuesta medida del costo de la materia prima (Kuhn 2004).

Sobre estos criterios, Kuhn (2004) identifica tres estrategias de aprovisionamiento, cada una de las cuales opera bajo diferentes conjuntos de restricciones, implica el trasporte de materiales e instrumentos de determinada manera y conlleva diferentes consecuencias artefactuales:

1) Aprovisionamiento de lugares: consiste en el almacenamiento de instrumentos $y / o$ materias primas en lugares del paisaje donde las actividades tienden a ocurrir. Esta estrategia de aprovisionamiento está relacionada con el equipamiento de sitio (insurance gear o household gear) mencionado arriba, que fue propuesto por Binford (1979). Los sitios se abastecen con materias primas en varios estados de manufactura, desde nódulos hasta instrumentos terminados. El transporte de materias primas puede realizarse bajo diferentes formas (nódulos, núcleos, formas-base, instrumentos terminados) y llevarse a espacios recurrentemente ocupados, que con el tiempo pueden devenir en espacio equipado y disminuir la intensidad de reducción y reactivación de los recursos líticos disponibles.

2) Aprovisionamiento de individuos: son las personas las que se encuentran abastecidas con toolkits (juegos de instrumentos y/o materias primas) que transportan con ellos. Este aprovisionamiento se vincula con el equipamiento personal (personal gear) de Binford (1979). Se espera que esté integrado por instrumentos terminados, intensamente reactivados y reformatizados, y que se seleccionen aquellas materias primas de mejor calidad (aún cuando su costo de obtención sea elevado). Todo ello para maximizar la 
utilidad potencial de los artefactos en relación al peso del toolkit, el cual debe ser transportable.

Las dos primeras estrategias implican la planificación y anticipación de las necesidades y, como tales, representan formas alternativas de "comportamiento de conservación”. El aprovisionamiento de individuos encaja más estrechamente con el entendimiento común del término (Binford, 1979; Nelson 1991), pero ambos implican abastecer individuos o lugares de acuerdo a las necesidades anticipadas (Kuhn 2004: 432).

3) Aprovisionamiento de actividades: implica poca o ninguna planificación porque surge en respuesta a una necesidad inmediata, produciendo artefactos ad hoc. Así, el mayor limitante es el tiempo disponible, por lo que se espera una mínima inversión en la manufactura y la utilización de materiales disponibles in situ. Se relaciona con la estrategia tecnológica “oportunística” de Nelson (1991) y con el equipamiento situacional (situational gear) de Binford (1979).

La implementación de una u otra de estas estrategias de aprovisionamiento o la combinación de varias para que los instrumentos estén cuando se los necesita, depende de la interacción de factores, como la distribución y calidad de las materias primas, la naturaleza y planificación de las actividades en las cuales los instrumentos van a ser utilizados, la pauta de movilidad y la predictibilidad espacio-temporal (Kuhn 1992, 2004). Así, por ejemplo, en ambientes más predecibles o con recursos específicos, donde las necesidades específicas son conocidas de antemano, estas se pueden saldar equipando el sitio. No habría restricción en los artefactos en relación a su transporte, porque estarían fijos en un sitio, y habría más cantidad de materia prima para ser utilizada según las demandas. Cuanto más se ocupe un lugar, o mientras más conocimientos tengan los grupos acerca de la localización específica de los recursos que necesitan, más práctico va a ser equipar el sitio. En cambio, en un ambiente menos predecible o con demandas más generales, la solución sería asegurar que los individuos lleven algún instrumento consigo, es decir, un toolkit o equipamiento personal (Kuhn 1992: 188). Este estaría restringido a ciertos instrumentos debido al transporte, a una tecnología conservada y a diseños transportables, que en conjunto maximicen su vida útil. Kuhn (1994), también había propuesto, desde un modelo matemático, que para grupos móviles que priorizan la transportabilidad, es eficiente llevar más volumen repartido en pequeños instrumentos.

El estudio de Martínez y Mackie (2003-04) sobre arqueología del paisaje desde una perspectiva organizacional, se basa en el análisis de material de superficie del fondo de valle del río Quequén Grande (Holoceno tardío) para dar cuenta de la construcción del 
paisaje a través de la estrategia del aprovisionamiento de lugares (sensu Kuhn 1994, 1995). Estos autores mencionan que en el área de estudio, si bien los afloramientos rocosos son extraños, hay registros -como el del sitio El Guanaco- donde se han "acumulado" ortocuarcitas transportadas hasta allí unos $125 \mathrm{~km}$ desde su fuente, e incluso hay otras materias primas cuyo origen se localiza hasta cerca de $300 \mathrm{~km}$; es decir, son exóticas o no locales (véase Sección 4.2.1.3.), lo cual permite realizar cuestionamientos sobre los patrones de aprovisionamiento. Allí, además, los conjuntos líticos se componen de artefactos pesados y voluminosos como piedras de moler, metates, manos, y núcleos de gran tamaño. El hecho de que estos elementos fueran movidos a través del paisaje refleja un aprovisionamiento planeado de los espacios. Asimismo, Martínez y Mackie (2003-04) sostienen que la presencia y distribución de las materias primas no depende exclusivamente de su distribución natural, ya que un almacenamiento antropogénico dado por acopio de materias primas, puede ser una fuente de explotación, esto es, una cantera artificial. Dicho proceso de acumulación se conoce como "litificación" (litification) (Martínez y Mackie 2003-04; cf. Webb 1993).

El último trabajo subraya otra cuestión: ¿cómo se realiza la transferencia de artefactos líticos y/o materias primas desde su fuente de origen hasta sitios muy distantes? ¿Cómo parte de los circuitos de movilidad del grupo en cuestión? ¿Por intercambio de bienes entre grupos? ¿Por otras razones? Esto alude a la idea de Meltzer (1989) de que las rocas exóticas se transfieren a través de mecanismos como el intercambio entre poblaciones (Meltzer también menciona otros modos como la migración y la conquista, pero no se tratarán aquí). En tal caso, el "aprovisionamiento" o adquisición es indirecto, estrategia que no ha sido detallada en este apartado, debido a que los modos y estrategias de aprovisionamiento presentados, parten del supuesto de un acceso directo a las fuentes de aprovisionamiento.

\subsubsection{Movilidad, uso del espacio e interacción}

La relación entre las estrategias tecnológicas, la organización geográfica de una sociedad y la estructura del ambiente, como se dijo antes, puede ser abordada y entendida desde las herramientas que provee el estudio de la organización tecnológica (Nelson 1991; Franco 2004; Kuhn 2004; Cortegoso 2005b). Asimismo, nos permite conocer la intensidad de uso humano de los ambientes de una región y qué lugares del espacio fueron seleccionados (Belardi 2005). Comprender cómo y porqué los seres humanos explotaron ciertas materias primas líticas y cómo las han hecho circular por el espacio son cuestiones 
inherentes a los estudios sobre tecnología lítica. A continuación, se presentan otros modelos y propuestas para su comprensión.

\subsection{Distancia y rangos de acción}

En su estudio sobre patrones de distribución espacial de los artefactos Renfrew (1977), considera la frecuencia y abundancia de artefactos según la distancia hasta la fuente de aprovisionamiento, para entender los mecanismos de circulación de bienes, desde una perspectiva regional. Este autor establece que cuando la disponibilidad de un recurso está circunscripta a un punto de origen en el paisaje (una fuente localizada), su distribución en el espacio es más abundante en sectores cercanos a la fuente de aprovisionamiento de materia prima (ley de decrecimiento monotónico) (Renfrew 1977). A medida que aumenta la distancia a dicho punto, la frecuencia disminuye debido a los costos de transporte involucrados, patrón que ha sido denominado curva de decaimiento o fall-off.

También sobre la base de la distancia a la fuente de recursos líticos y sobre información etnográfica y arqueológica provista por estudios previos (Binford 1980; Gould 1980; Kelly 1983; Gould y Saggers 1985), Meltzer (1989) estableció que la distinción entre disponibilidad local o no-local de las materias primas estará dada por la distancia límite de $40 \mathrm{~km}$ a la fuente (Meltzer 1989) ${ }^{13}$. Este autor también introdujo el concepto de "inmediata vecindad" para referirse a las materias primas de disponibilidad cercana al lugar de uso y/o descarte (Meltzer 1989). A estas categorías propuestas por Meltzer (1989), Civalero y Franco (2003) añaden la categoría de recursos líticos "inmediatamente disponibles", distinta a la categoría "local" (a la cual también subdividen). Entonces, a partir de las modificaciones realizadas por estas autoras quedan establecidos tres rangos de distancias que son los aplicados en esta tesis: recursos inmediatamente disponibles (distancia menor a $5 \mathrm{~km}$ ), local (distante entre 5 y $40 \mathrm{~km}$ ) incluyendo local cercanos (5-30 km) y local lejanos (30-40 km)-, y no local (distancia mayor a $40 \mathrm{~km})$.

En situaciones en que las materias primas provienen de fuentes de aprovisionamiento distantes, localizadas a más de $40 \mathrm{~km}$ (i.e., no locales o exóticas), se

\footnotetext{
${ }^{13}$ Gamble (1993) también utiliza este límite de 40 km como identificación de elementos locales y exóticos, ya que es el límite que correspondería a dos días de viaje desde el campamento, aproximadamente. Sin embargo, ambientes con rasgos topográficos marcados - e.g., pendientes pronunciadas-, obstaculizarían los desplazamientos de los grupos. Esto es más significativo en el Desierto Altoandino del sur de Mendoza.
} 
debe proyectar el trabajo a una escala suprarregional. A tal escala, muchas de las fuentes de aprovisionamiento lítico en escala regional se presentan lo suficientemente acotadas dentro del espacio de estudio como para que los escasos hallazgos que se verifiquen fuera de estas localizaciones tengan significado en términos de procedencia (Franco y Borrero 1999). En tal sentido, Gould y Saggers (1985) acuñaron el término "paisaje lítico", al que definieron como la disponibilidad y distribución física de las materias primas en una región. Estos autores consideraron a las fuentes como un espacio más de actividad humana que implicaría múltiples episodios de extracción y producción de artefactos tallados, constituyendo un paisaje lítico (Gould y Saggers 1985). Sin embargo, en tales términos, este concepto sería equivalente a "base regional de recursos líticos" (sensu Ericson 1984). Otra definición, más inclusiva, de paisaje lítico es la que propusieron Barrientos et al. (2014) que implica la ocurrencia, en un espacio geográfico dado, de diferentes unidades estructurales compuestas por dos elementos principales: una fuente de materia prima y una dispersión asociada (o área de dispersión) incluyendo, esta última, la distribución espacial tanto de las rocas naturales como de las modificadas por el ser humano, obtenidas de esa fuente ya sea directa o indirectamente (Barrientos et al. 2014: 1153). Cabe aclarar que el término de paisaje lítico no debe confundirse con el de "litificación del paisaje" (sensu Martínez y Mackie 2003-2004), visto en la Sección 4.2.1.2.2. de este capítulo.

Franco y Borrero (1999) han manifestado que "las distribuciones de materias primas transformadas en artefactos comienzan a mapear los rangos de acción de las poblaciones que ocuparon una región, y a la vez se relacionan con la movilidad y otras propiedades de las mismas (...) las rocas raras en los conjuntos arqueológicos (por ejemplo obsidiana), que provienen de fuentes de aprovisionamiento distantes, proyectan el trabajo a una escala suprarregional..." (Franco y Borrero 1999: 34). Es decir que la distribución de los artefactos líticos en el espacio actúa como un indicador frecuentemente utilizado para estudiar el rango de acción de las poblaciones (sensu Foley 1981a, b, c) y el contacto o interacción entre ellas, permitiendo discutir cómo se presentaron estas relaciones en el pasado (Renfrew 1977; Torrence 1984; Meltzer 1989; Gamble 1993; Ingbar 1994; Franco y Borrero 1999; Beck et al. 2002; Jones et al. 2003; Brantingham 2003; Kuhn 2004, entre otros). Según Meltzer (1989), las rocas de disponibilidad local suelen ser consideradas como indicadores del rango de acción y las rocas no-locales o exóticas como el resultado de la interacción entre poblaciones y, consecuentemente, del intercambio de recursos entre ellas. En situaciones de estrés, el intercambio actúa como 
mecanismo para afrontar el riesgo y la incertidumbre; puede ser medible por curvas de fall-off y outlier observados más allá de los rangos de acción (Renfrew 1977; Meltzer 1989; Janetski 2002; Franco 2004; Eerkens 2011, 2012; Pallo y Borrero 2015). En regiones áridas y semiáridas como las del sur de Mendoza, las poblaciones utilizarían amplios territorios al punto, quizás, de superponerse con otros, constituyendo alianzas sociales que permitan el intercambio o el acceso a recursos lejanos (Gamble 1990, 1993; Mandryk 1993; Yellen 1977). Los rangos de acción, la distancia a la fuente y el modo de acceso a los recursos, permiten conocer los aspectos relacionados a la territorialidad (Foley 1981a y b; Kuhn 2004). Saber esto es útil para contrastar las implicancias esperadas para el Holoceno tardío en el sur de Mendoza, momento en el cual los rangos de movilidad habrían disminuido y los vínculos intergrupales, aumentado.

\subsection{Modelos de circulación de materias primas y movilidad}

La tecnología lítica permite inferir aspectos sobre las estrategias y cambios implicados en la movilidad de los grupos (Kelly 1988, 1992; Parry y Kelly 1987). A partir de estudios etnoarqueológicos y arqueológicos sobre tecnología, se ha sugerido que la movilidad no siempre puede explicar íntegramente los patrones de producción, uso y descarte de los artefactos (Bamforth 1986, 1991; Torrence 1989b; Andrefsky 1994, entre otros), ya que otros factores también intervienen en la configuración de la tecnología adoptada ( $c f$. Gould 1980; Gould y Saggers 1985, entre otros). Pese a esto, se ha sostenido que la movilidad residencial (los consumidores se mueven hacia los recursos) o la movilidad logística (los recursos son movidos hacia los consumidores) influyen en forma variable sobre la tecnología lítica debido a que se relacionan con el tipo de estrategia tecnológica a implementar (estrategias expeditiva y conservada, respectivamente, sensu Binford 1977) y que también repercute sobre el tipo de equipamiento, como se vio en la Sección 4.2.1.2.2. (Binford 1977, 1979, 1980; Shott 1986; Parry y Kelly 1987; Carr 1994, entre otros).

Kelly (1988), examinó el cambio en el uso de bifaces a través del tiempo en Carson Sink en el oeste de Nevada para entender las pautas cambiantes en el uso de la tierra y en la movilidad. Examinó la distribución de las diversas etapas de reducción bifacial como indicio de movilidad. Así, halló poca evidencia de talla bifacial en el fondo del valle de Carson, donde predomina la producción de instrumentos de lascas simples. A estos conjuntos los vinculó con una estrategia de movilidad logística. Por el contrario, a los agrupamientos de artefactos, los identificó en las montañas, donde son comunes los 
desechos de reducción bifacial. A estos los asoció con una estrategia de movilidad residencial (Kelly 1988: 724-725). Sugirió que los bifaces pueden ser usados en tres roles diferentes: cómo núcleos (grandes bifaces transportables y versátiles de los que se pueden extraer lascas con muchos filos útiles); como útiles reactivables de larga vida útil (por su mantenibilidad -flexibilidad y versatilidad); o como instrumentos formatizados de función específica que son parte de una tecnología confiable (e.g., instrumento convertido en bifaz por causas estilísticas o cuestiones de forma). Kelly (1988) sostiene que el uso de un bifaz en cada uno de estos tres roles está relacionado con una combinación de la distribución de materias primas y de la estrategia de movilidad de un grupo. Así, en grupos con movilidad logística, se espera encontrar el uso del bifaz como núcleo; usarlo como instrumento de larga vida útil servirá en contextos donde haya escasez de materia prima o baja movilidad residencial (Kelly 1988). Cabe agregar que varios estudios etnográficos y arqueológicos han demostrado que la estrategia tecnológica de conservación puede ser adoptada tanto en grupos con movilidad logística como en grupos con una alta movilidad residencial (Bamforth 1986; Odell 1996, entre otros).

Muchas variables pueden afectar el tipo y estrategia de movilidad (Kelly 1983, 1992), pero la subsistencia es una de las más importantes (Kelly 1995). Debido a que los recursos se encuentran distribuidos en el espacio, no hay lugares puntuales que provean todos los recursos necesarios para la población. Por ende, la movilidad según Kelly (1992), es un fenómeno complejo y multidimensional. Es una propiedad inherente a los seres humanos, más específicamente a grupos cazadores-recolectores, y es definida como su desplazamiento en un ciclo anual. Se emplea como estrategia básica para prevenir el riesgo o moderar su impacto (Kelly 1992; Belardi 2005). Para Kelly no existen sociedades "sedentarias", sino individuos o grupos de personas que se mueven menos (Kelly 1992), aunque esto provoca procesos adaptativos cualitativamente distintos. Las formas en que la gente se mueve ejercen fuertes influencias sobre su cultura y sociedad, sus cambios afectan distintos aspectos de la vida de las poblaciones (Kelly 1992). Un grado alto de movilidad puede impactar en la tecnología lítica imponiendo costos de transporte y restringiendo el tiempo dedicado a la manufactura de instrumentos, por ejemplo, aunque también puede tener efectos positivos en la adquisición de la materia prima. En cambio, un bajo grado de movilidad puede restringir el acceso a las fuentes de materias primas y otros recursos (Lurie 1989: 47), pudiendo promover formas de acceso indirecto o el intercambio entre poblaciones. 
La distribución de los artefactos líticos del registro arqueológico permite rastrear los circuitos y rangos de acción de las poblaciones, y la interacción que tuvieron entre ellas en el pasado (Renfrew 1977; Foley 1981a, b, c; Torrence 1984; Meltzer 1989; Gamble 1993; Ingbar 1994; Franco y Borrero 1999; Beck et al. 2002; Jones et al. 2003; Brantingham 2003; Kuhn 2004, entre otros). Sin embargo, no es sencillo construir los patrones de movilidad de los grupos y sus vínculos, debido a que los constreñimientos resultantes de la distribución natural de la materia prima pudieron alterar las asociaciones entre tipos de instrumentos, estrategias tecnológicas, tipo de movilidad residencial, logística y rango territorial. Además, la evidencia de instrumentos líticos provenientes de largas distancias sólo provee información sobre el rango territorial dentro del cual opera una población, no el grado de movilidad de esa población (Kelly 1992). También se ha sugerido que puede haber un sesgo de representación en la frecuencia de las materias primas en el sitio/área en que se hallan - e.g., a través de muestreo de fuentes-, con respecto al territorio mínimo por el que los grupos humanos se desplazaron en el pasado (Ingbar 1994). Así, se plantea que, para conocer el territorio por el cual los grupos se movilizaron, se deben complementar los datos de las materias primas utilizadas -y su localización- junto con los datos sobre la producción de instrumentos, uso, mantenimiento y descarte (Ingbar 1994: 50; cf. Shott 1986; Bamforth 1991; MacDonald 1995, entre otros).

En este último sentido, el trabajo de Custer et al. (1983), provee un modelo alternativo de análisis sobre las estrategias de adquisición de materias primas líticas en grupos móviles. Ellos observan que los patrones de asentamiento paleo-indio y el uso de instrumentos diferenciales en la llanura costera del Atlántico Medio, pueden vincularse con los patrones de distribución de recursos líticos. Para la Península de Delmarva y la llanura costera exterior de New Jersey los autores propusieron un sistema de abastecimiento cíclico, que consiste en la utilización repetida de una misma fuente lítica por parte de la misma población, que regresa periódicamente a abastecerse en su ciclo anual/estacional de desplazamiento; las rocas disponibles en otras localidades no se explotarían o se evitarían. En cambio, para la llanura costera interior de Nueva Jersey, Custer et al. (1983) sugirieron un sistema de abastecimiento serial. Este implica condiciones en las que una población utiliza dos o más fuentes de recursos líticos situados en diferentes puntos del espacio, a lo largo de su ciclo anual. Esas fuentes serían visitadas en el transcurso de sus actividades de subsistencia (i.e., similar a la estrategia de aprovisionamiento incluido de Binford 1979). Esta propuesta ha sido empleada por otros 
autores como Carr (1994) quien evaluó el uso de canteras de chert de distinta calidad, en la manufactura de piezas bifaciales (puntas de proyectil) en Wisconsin (EE.UU.). Para este autor, la estrategia de aprovisionamiento serial es común entre rocas disponibles en el espacio local y las mismas estarían sobrerrepresentadas. Salgán (2013) aplicó el modelo de Custer et al. (1983) en La Payunia y planteó dos tipos de aprovisionamiento directo en el Holoceno tardío: uno de tipo serial para rocas disponibles en el espacio local (específicamente, rocas silíceas) y otro de tipo cíclico para rocas no locales (obsidiana). Además, en los sectores norte y sur de La Payunia, Salgán (2013) observó un aprovisionamiento serial incluido (sobre silíceas) y propuso un aprovisionamiento de tipo cíclico indirecto (para obsidianas de las fuentes Las Cargas y El Peceño). Su modelo también constituye una vía exploratoria útil en el estudio de los conjuntos líticos de la cuenca del río Atuel.

También ha de apreciarse el trabajo de Jones y colaboradores (2003) quienes, al estudiar el uso de fuentes de obsidiana y de dacita, estimaron la escala geográfica o territorio de movilidad de las poblaciones tempranas en la región de la Gran Cuenca de EE.UU. Para ello se basaron en el análisis de los estadios de producción lítica e ilustraron la secuencia de cada fuente explotada. Observaron que las materias primas mejor representadas en los conjuntos son un buen indicador del rango de acción mínimo. Así, las primeras etapas de producción lítica se localizan cerca de la fuente geológica y, los movimientos alejados de la fuente, provocan un incremento en los eventos de uso de los instrumentos. Estos patrones permiten señalar la dirección de los movimientos, la extensión total del rango de acción/territorio y la longitud de las barreras de transporte a escala espacial amplia (Jones et al. 2003) y acotada (Jones et al. 2012).

Al respecto, MacDonald y Hewlett (1999) han propuesto un modelo de organización de la movilidad basado en un esquema de tres niveles, cada uno asociado a la ejecución de determinadas tareas (Figura 4.3). El primer nivel, llamado "micromovimiento", es el más acotado -correspondería al radio de forrajeamiento del modelo de Binford (1983)- y el que implica la obtención de los recursos necesarios para la subsistencia. El "meso-movimiento", el segundo nivel, se refiere a viajes a distancias intermedias para visitar a amigos y parientes, y es la distancia de viaje característica a la que se dan los vínculos matrimoniales a largo plazo (semejante al rango anual en el modelo de Binford, 1983). El tercer y último nivel de movilidad es el "macromovimiento", el cual implica viajes exploratorios para localizar sitios exóticos con nuevos recursos potenciales o especialmente escasos. Los riesgos son mayores por lo que 
no son frecuentes, ni todos los individuos participan. Es similar al rango extendido y lifetime range del modelo de Binford (1983). Dada su dimensión, este nivel de movilidad no se incluye en los rangos de acción habituales de estos grupos.

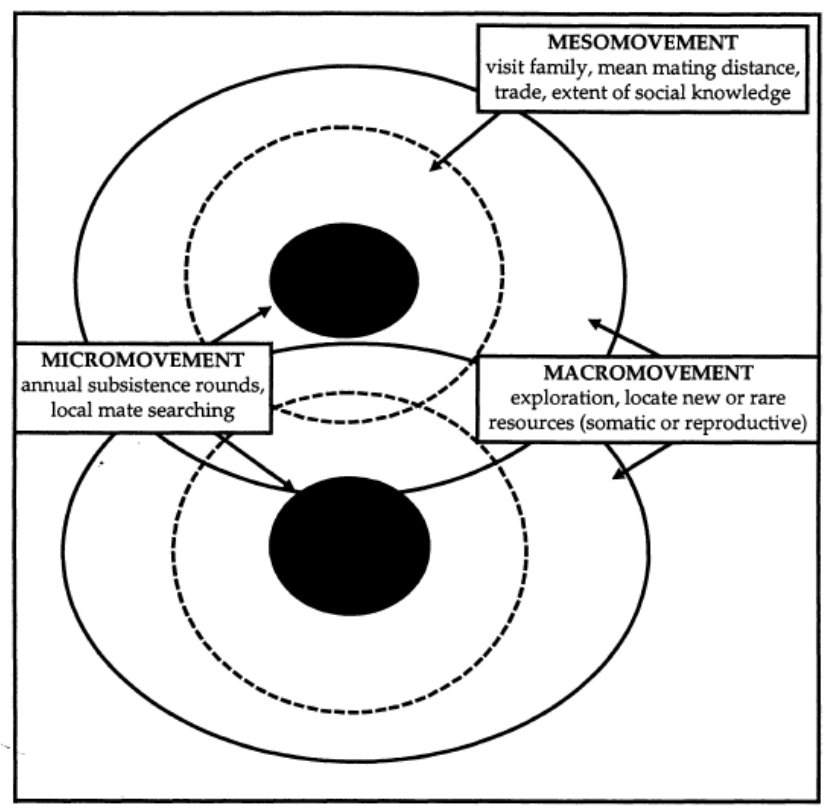

Figura 4.3. Modelos de movilidad forager. Las áreas superpuestas indican contactos hipotéticos entre dos niveles de movilidad forager (Tomado de MacDonald y Hewlett 1999: 512).

Acerca de la movilidad y su vínculo con el aprovisionamiento y circulación de bienes exóticos, también cabe mencionar el modelo propuesto por Whallon (2006). Este autor considera que la movilidad de los cazadores-recolectores no siempre se vincula con el posicionamiento de las personas para la explotación óptima de los recursos de subsistencia, sino que otra razón esencial para su movilidad es el establecimiento y mantenimiento de una red de relaciones sociales en cuyo marco se comparte información entre grupos sociales ampliamente dispersos y que funciona como una safety net en situaciones de escasez de recursos locales. Whallon (2006) propone que tanto la frecuencia como la amplitud de la escala espacial de estas redes pueden estar relacionadas con patrones espacio-temporales de variación en la disponibilidad de recursos. Así, desarrolla un modelo de la organización espacial en el que tales redes son el resultado de dos tipos de movilidad: network mobility (movilidad por razones sociales, ya que se encarga de mantener lazos entre grupos) e informational mobility (movimientos para recolectar y actualizar información sobre la disponibilidad de recursos en el ambiente) (Whallon 2006: 262-263). 
Ambos tipos de movilidad proporcionan estimaciones cuantitativas de las escalas espaciales involucradas, ya que la extensión de ambas redes de intercambio resultantes (i.e., la distribución de bienes exóticos, sensu Meltzer 1989) depende, sobre todo, de su relación con las características ambientales inter-regionales. La dirección de los movimientos producto de las redes de información, sería transversal a los patrones de movilidad residencial y logística -relacionados con las actividades de subsistencia (Whallon 2006). El modelo distingue la movilidad entre regiones adyacentes y entre regiones distantes, y entre bandas de forrajeo mínimas y máximas o regionales. Estas alternativas pueden ser identificables bajo ciertas condiciones. En cuanto a las materias primas líticas, Whallon (2006) sugiere que circulan principalmente entre los grupos locales dentro de los límites de una banda regional. Esto implica contactos y movilidad entre regiones adyacentes ( $c a . \leq 200 \mathrm{~km}$ en el caso de estudio del suroeste de Alemania). Los contactos a mayor escala $(\geq 300 \mathrm{~km})$ generan interacción y movilidad entre bandas máximas, y son insinuados por la distribución de otro tipo de bienes, como los suntuarios (en el caso de estudio, conchas y moluscos fósiles decorados), más que recursos utilitarios como las materias primas líticas. El modelo de Whallon (2006) predice que a mayor homogeneidad ambiental en una escala espacial amplia, se espera menor network mobility e informational mobility entre regiones adyacentes, y mayor entre regiones geográficamente lejanas. Ambas situaciones son los puntos extremos de un continuum, como el del modelo forager-collector, pero en este caso plantean expectativas para analizar la distribución de bienes exóticos, tema abordado en la siguiente sección.

\subsection{Acceso directo vs. intercambio}

Ericson (1984) distingue entre estrategias utilizadas en caso de acceso directo (obtención en la fuente; véase Sección 4.2.1.2.2), de las empleadas en situaciones de acceso indirecto (adquisición mediante intercambio). Los modos y estrategias de aprovisionamiento indirecto, en cualquiera de los casos, implica la presencia de intermediarios entre la fuente de materia prima y el consumidor (Ericson 1984; McAnany 1988). La transferencia involucra no sólo a las materias primas líticas y sus productos, sino también a otros recursos utilitarios y no-utilitarios (Meltzer 1989).

En el tratamiento teórico de estas transacciones se ha puesto énfasis en las relaciones sociales involucradas y no tanto en sus correlatos materiales, por lo que no se cuenta con información suficiente para comprender el registro arqueológico. Meltzer 
(1989: 20-21) realiza una compilación de los postulados de distintos autores y enumera las razones o funciones del intercambio: a) mantener lazos entre grupos; b) posibilitar la adquisición de artefactos no disponibles en el rango de acción/territorio de explotación del grupo; c) mantener la interacción entre grupos como reaseguro económico para momentos de estrés de recursos en el ambiente local; d) sostener un sistema de "mutualismo" entre grupos vecinos que necesitan del excedente de los otros para complementar sus dietas; e) iniciar o reforzar relaciones sociales. Sobre la base de información etnográfica disponible, Meltzer (1989: 21) considera que esta última es la función más generalizada del intercambio y que opera a largo plazo, aunque sus correlatos pueden ser escasos o difusos.

La distinción entre acceso directo e intercambio no es simple. Meltzer (1989: tabla 2.1: 27-29) ha analizado los productos materiales de cuatro variables que se suelen tomar para distinguir entre aprovisionamiento directo e indirecto: 1) presencia-ausencia de materias primas exóticas; 2) cantidad/número de clases de artefactos manufacturados en materias primas exóticas; 3) afinidades estilísticas de elementos dentro de las clases de artefactos; 4) estrategias de reducción de los artefactos. Al observar estos puntos, Meltzer (1989) concluye que ambos procesos, directo e indirecto, pueden producir el mismo producto, lo que lleva a un problema de equifinalidad (Meltzer 1989: 26). Esto también lo han advertido otros autores (Renfrew 1977; Ingbar 1994; Brantingham 2003).

Las propuestas y expectativas desarrolladas por Meltzer (1989) están ideadas para funcionar a una escala de sitio. En Patagonia, Franco (2002b, 2004) y Charlin (2007, 2009a), han sugerido incorporar a la propuesta de Meltzer (1989) variables e indicadores cuantitativos que permitan ampliar el tratamiento a escala regional y con las características promediadas del registro arqueológico. A partir de sus propuestas se presentan las expectativas derivadas. En cuanto a sitios con acceso directo a los recursos líticos se espera: 1- alta frecuencia de artefactos procedentes de una misma fuente en el conjunto arqueológico; 2- representación de todas las etapas de la secuencia de manufactura de los artefactos a nivel regional o micro-regional; 3- presencia de núcleos; 4- un elevado índice de corteza; y 5- utilización de la materia prima sin restricción a un tipo particular de artefacto (Franco 2007; Charlin 2009a). Por otro lado, ante situaciones de intercambio de materias primas entre grupos, proponen dos posibilidades: a- el intercambio de instrumentos terminados y, b- el intercambio de materia prima en bruto, esto es, nódulos o núcleos (Franco 2002b, 2007; Charlin 2009a). En ambos casos se espera que la materia prima tenga una escasa representación en el conjunto arqueológico 
y que sea utilizada para confeccionar sólo ciertas clases de instrumentos conservados (sensu Binford 1979; Charlin 2009a: 55). Para distinguir entre a- y b-, estas autoras suponen que en el primer caso, sólo se hallarán evidencias de las últimas etapas de reducción de los instrumentos, representadas por lascas de reactivación y mantenimiento y/o reutilización de instrumentos. En el caso b- esperan que aunque predominen las etapas finales (debido a la conservación de la materia prima), esté representada toda la secuencia de manufactura, incluyendo nódulos o núcleos y artefactos con corteza (Franco 2007; Charlin 2009a). Para el sur de Mendoza, Salgán et al. (2012a: 267) sintetizan las expectativas arqueológicas de los conjuntos artefactuales según el modo de aprovisionamiento directo o indirecto, y especifican las expectativas para los artefactos líticos (Tabla 4.2).

\begin{tabular}{|c|c|c|}
\hline EXPECTATIVAS ARQUEOLÓGICAS & ACCESO DIRECTO & ACCESO INDIRECTO \\
\hline Frecuencia de materia prima en el conjunto & Alta & Baja \\
\hline Representación de estadios de manufactura & Todas las etapas & Predominio de etapas finales \\
\hline Tamaño de los artefactos & Variable & Muy pequeños-pequeños \\
\hline Porcentaje de Corteza & Alto & Bajo \\
\hline $\begin{array}{c}\text { Diversidad estilística en diseño de } \\
\text { instrumentos }\end{array}$ & Alta & Baja \\
\hline Clases artefactuales & Amplio & Restringido \\
\hline Núcleos & Agotados, formas estandarizadas & Ausentes o muy explotados \\
\hline Desechos de talla & $\begin{array}{l}\text { Alta variabilidad y frecuencia, } \\
\text { presentes todas las etapas aunque } \\
\text { prevalecen las finales }\end{array}$ & $\begin{array}{l}\text { Baja variabilidad, prevalecen } \\
\text { etapas finales y de } \\
\text { reactivación de artefactos }\end{array}$ \\
\hline Instrumentos & $\begin{array}{l}\text { Alta variabilidad de tipos } \\
\text { artefactuales }\end{array}$ & $\begin{array}{l}\text { Alta frecuencia en relación a } \\
\text { otras clases artefactuales. } \\
\text { Baja variabilidad en tipos. } \\
\text { Artefactos con corteza }\end{array}$ \\
\hline
\end{tabular}

Tabla 4.2. Expectativas arqueológicas de los conjuntos artefactuales según el modo de aprovisionamiento (tomado y modificado de Salgán et al. 2012a: 267).

En relación a los estudios sobre distribución de artefactos y uso del espacio Renfrew (1977) ha descrito una variedad de modelos alternativos para el comercio de larga distancia y las consecuencias o expectativas arqueológicas en términos de la distribución de artículos a través del paisaje. Entre estos, se encuentran el comercio descendente ("down-the-line trade") y el comercio direccional ("directional trade") (Figura 4.4). El primero, se rige por la ley del decrecimiento monotónico (mencionada antes), que establece que la abundancia de los bienes que se negocian permanece relativamente estable dentro de la zona de suministro y luego disminuye de manera geométrica a medida que uno se aleja de la fuente de bienes (curva de fall-off). Por otro 
lado, el comercio direccional describe un patrón en el que los bienes fluyen hacia un lugar central y se distribuyen regionalmente desde allí. En lugar de un decaimiento (fall-off) en la abundancia de bienes a medida que aumenta la distancia a la fuente, el directional trade produce "salidas" (“departures") de la curva de fall-off. Es decir, se registrarían descensos en las frecuencias de los ítems exóticos desde estos lugares de congregación hacia distintos puntos de la región.

El mencionado directional trade lo observó Janetski (2002) en su estudio sobre el registro de intercambio en sitios Fremont (oeste de América del Norte) y lo interpretó como un modelo de feria (sensu Ford 1983; Renfrew 1977), el cual constituye un mecanismo o contexto importante para la distribución de especies exóticas a partir de ferias/festivales comerciales de intercambio interurbano y de larga distancia (entre las comunidades Fremont y con los Anasazi u otros vecinos en el contexto Fremont). La ubicación de estos festivales dependería de la disponibilidad de recursos y podría haber cambiado según su productividad. En relación a la propuesta de Renfrew (1977), las localidades que exhiben frecuencias más altas de bienes exóticos insinúan la posibilidad de que estos sean los lugares donde se congregó la gente con los artículos comerciales. Además, el autor agrega que la aplicación de este modelo de feria puede proporcionar información útil sobre los cambios temporales en la distribución de obsidiana en el este de la Gran Cuenca (Janetski 2002: 360-61).

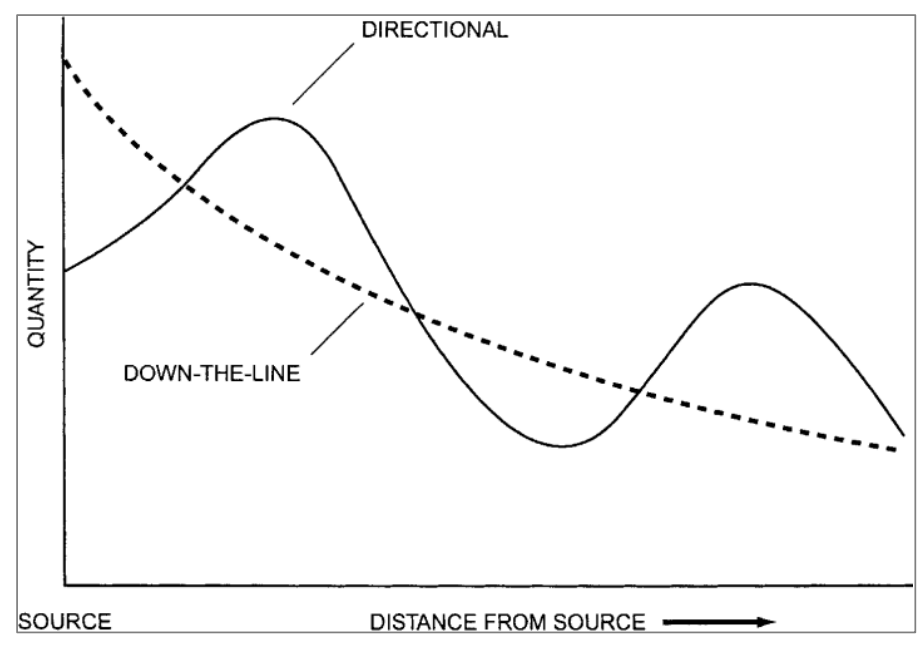

Figura 4.4. Predicciones de la distribución espacial de bienes distribuidos a través de comercio descendente $v s$. comercio direccional (tomado y modificado de Renfrew 1977: 86).

Así, se observa que el principio de decaimiento siempre se cumple ya que siempre hay alguna escala en la que hay más rocas cercanas a su fuente antes que lejos; de lo que 
se trata es de discutir cada caso y descubrir la escala en la que se manifiesta el decaimiento (Borrero 2012:282). Se necesita evaluar otros factores que también afectan al fall-off, como aquellos vinculados con los sistemas de movilidad, territorialidad, intercambio o previsión (Kelly 2011), y considerar que las curvas de decaimiento no son exclusivamente una medida de sistemas de intercambio (Pallo y Borrero 2015).

En palabras de Hughes (2011a), el papel de la distancia como indicador de comercio/intercambio versus aprovisionamiento mediante acceso directo es problemático porque, dependiendo de factores que condicionan el grado de movilidad residencial y de subsistencia (e.g., densidad de población y fluctuación estacional de recursos), los materiales provenientes de fuentes relativamente distantes podrían haber sido obtenidos directamente por un grupo durante un aspecto de su ciclo anual de asentamiento/subsistencia o incidentalmente durante la participación en festivales no locales u otras ceremonias (Hughes 2011a: 4). En la búsqueda de respuestas pertinentes al modo en que circularon/se transfirieron bienes, Hughes (2011a) plantea que las investigaciones han tendido a confundir distribución con proceso (e.g., distancia geográfica con comercio), utilizando al primero como proxy del segundo. Para discernir esta cuestión, entonces, propone emplear "convey" y "conveyance" como "behaviorally neutral terms to help emphasize the fact that the spatial disjunction of materials and mode(s) of acquiring and transporting those materials are independent variables" (Hughes 2011a: 1). Aclara que el término transmission se emplea explícitamente como sinónimo de conveyance (o transportation) (Hughes 2011a). Así, este autor también se cuestiona si el transporte ("conveyance") de bienes -hallados en lugares distintos a los de su origen- ocurrió a través de acceso directo a las fuentes (a veces, viajando largas distancias, incluyendo estrategias como el aprovisionamiento incidental) o por medios indirectos como el comercio/intercambio (trade/exchange), haciendo hincapié en abordar las causas de las distribuciones de bienes y sus vínculos conductuales (Hughes 2011a). Es decir, bajo qué condiciones y circunstancias el intercambio comercial, el acceso directo y/o la movilidad explican mejor el transporte (conveyance) de materiales a diferentes distancias en diferentes momentos del pasado.

Beck y Jones (2011) discuten esta cuestión de acceso directo (y movilidad) vs. intercambio (como así también, aspectos como reciprocidad y redistribución), a partir de su representación en el registro etnográfico y arqueológico del Paleoarcaico de la Gran Cuenca. Estos autores proponen tres hipótesis para explicar cómo se adquirieron los artefactos líticos: 1) a partir de una red de intercambio formal, especialmente para la 
obtención de los artefactos de las fuentes más distantes; y sólo ocasionalmente adquiridos directamente; 2) por medio de adquisición directa (tanto locales como no locales), siendo otros artefactos exóticos, pero no la mayoría, adquiridos por medio de intercambios recíprocos oportunísticos entre individuos; 3) a través de adquisición directa, estrategia que involucró a todos los artefactos líticos utilizados por la gente del Paleoarcaico ya sea local o no local, es decir, el intercambio no tuvo lugar (Beck y Jones 2011: 56). Los resultados revelaron que no existe un intercambio formal, por lo cual, se anula la primer hipótesis; pero sí se evidencia uno informal del tipo "intercambio recíproco oportunístico entre individuos", lo que también descarta la última hipótesis (todos los artefactos fueron adquiridos por acceso directo). Los autores concluyen que la localidad Sunshine provee un ejemplo de distancia social que reduce la distancia efectiva entre las zonas de transporte (conveyance) debido a que la gente necesitaba tener contacto con otros grupos, no sólo por viabilidad demográfica sino también por viabilidad social (Beck y Jones 2011: 79).

Para Eerkens (2011) el concepto de transporte (conveyance) es un indicador de interacción interregional. Asume que todas las sociedades humanas transportan (convey) bienes a través del paisaje, motivados por una serie de razones, principalmente, por tres fines: 1- subsistencia: por incongruencia entre la localización física de la gente y los recursos alimenticios, que impulsa a mover alimentos o personas - movilidad logística y residencial, respectivamente (sensu Binford 1980; Eerkens 2011: 136); 2- tecnológicos: por desequilibrios en la distribución de las materias primas requeridas en los sistemas tecnológicos, e.g., la obsidiana se restringe geológicamente en su distribución espacial, pero su calidad excepcional hacen que el esfuerzo dedicado a adquirirla valga la pena (ya sea directamente a través de la movilidad o indirectamente a través del comercio), en lugar de usar un material local de menor calidad (Eerkens 2011: 137); y 3-sociopolíticos: el transporte no es motivado por preocupaciones económicas (como 1- y 2-), sino para incentivar relaciones sociales, evidenciado por bienes de prestigio o riqueza (Eerkens 2011: 138). Cada uno de estos motivos implica un tipo de comportamiento diferente con respecto al transporte, observables en el registro arqueológico. En el caso de motivos tecnológicos, estos se evidencian por curvas de decaimiento abruptas con límites marcados, debido a los costos de mover los bienes sobre el terreno (para los puntos 1- y 3-, cf. Eerkens 2011).

Pallo y Borrero (2015), señalan que un abordaje sobre la distribución de las frecuencias de los ítems de procedencia conocida, requiere decidir en qué casos se trata 
de rangos de acción, en cuáles de territorialidad y en cuáles se alude a intercambio u otras formas de interacción social. Cada situación debe evaluarse para decidir hasta qué punto lo que se mide con su distribución es la participación en un sistema de intercambio o un rango de acción (como evidencia de abastecimiento directo). Para estos autores la noción de intercambio abarca bienes que cambian de mano y se corresponde con mecanismos de reciprocidad (Pallo y Borrero 2015). Consideran que la mejor medida de intercambio es la presencia de abundantes bienes fuera del área de circulación intra-poblacional y sostienen que materias primas como las obsidianas son particularmente adecuadas para tales estudios ya que, además de obtenerse en fuentes puntuales, suelen presentar un patrón de uso diferencial vinculado con propiedades como su excelente calidad para la talla (Pallo y Borrero 2015; cf. Charlin 2009a; Eerkens 2011; Kelly 2011, entre otros).

Kelly (2011) utiliza datos etnográficos para determinar la posibilidad de que la adquisición directa o comercio (trade) explique la presencia de obsidiana en el registro arqueológico del Desierto de Carson en el oeste de Nevada (EE.UU.) ( $c f$. Kelly 1988, 2001). Allí, todas las fuentes de obsidiana están muy alejadas; la más cercana está a unos $110 \mathrm{~km}$ al este del Desierto de Carson. Esta materia prima ingresa allí como bifaces completos retocados (como puntas de proyectil y bifaces), los cuales son conservados, reafilándolos y/o adelgazándolos. Los núcleos de obsidiana son casi inexistentes (Kelly 2001, 2011). Esto indica que la obsidiana fue muy apreciada en el Desierto de Carson; pero los patrones observados en los desechos no necesariamente indican "trade or direct acquisition". Si fue comercializada o adquirida directamente no cambiaría el hecho de su procedencia tan distante, por lo tanto, probablemente no cambiaría la forma en que se utilizó la obsidiana (Kelly 2011: 192). Además, advierte que la presencia de elementos no locales en el registro arqueológico no informa acerca del mecanismo por el cual llegaron hasta allí; sólo dice de dónde vienen (Kelly 2011).

En este trabajo, la localización natural de la obsidiana y su distancia al Desierto de Carson, argumentan a favor de la comercialización/intercambio como el único mecanismo posible para introducir esta materia prima. Los foragers no podrían haber adquirido la obsidiana incluyendo (embedding) su adquisición en otras actividades de asentamiento-subsistencia a larga distancia, ni siquiera si tales incursiones estuvieran dirigidas únicamente a la adquisición de obsidiana (lo que parece poco probable) (Kelly 2011: 196-97). Dada la importancia de esta posibilidad, plantea que es crucial poder diferenciar trade vs. direct acquisition (Kelly 2011: 198). 
Pallo y Borrero (2015) aclaran que tratan de no restringirse a esta polarización (intercambio o movilidad/acceso directo). Para ellos, estas son sólo dos alternativas, quizás extremas, pero existe mucha variación intermedia generable a través de visitas u otros mecanismos propios de formaciones sociales abiertas (sensu Borrero 2011; e.g., Janetski 2002; Beck y Jones 2011), que muestran su relevancia para comprender los patrones distribucionales registrados (Pallo y Borrero 2015). El mecanismo de visitas, por ejemplo, implica el movimiento de gente sin el propósito específico de realizar intercambio (participar en cacerías, controlar recursos, etc.) durante el cual puede ocurrir la depositación incidental de bienes. Asimismo, existen otros mecanismos sociales que amplían la distribución de ítems -generalmente en frecuencias muy bajas-, sin implicar mecanismos de intercambio. Esto lo sugieren, por ejemplo, las tendencias en la distribución de obsidianas provenientes de Pampa del Asador, observadas por Pallo y Borrero (2015) hacia el oriente y en el sector meridional de dicha fuente.

Estudios de esta índole ofrecen una vía a través de la cual reconocer cambios en las distancias sociales (cambios en la densidad de población, actividad económica o relaciones entre grupos vecinos) (Hughes 2011a; Beck y Jones 2011). Un trabajo concerniente a este tema y a la región estudiada aquí, es el de Berón (2007) quien hace referencia a la presencia de dos placas grabadas, confeccionadas sobre lajas de esquisto, presumiblemente procedentes del sur de Mendoza, Formación Piedras de Afilar (González Díaz 1972, citado en Berón 2007). La autora sugiere que estas rocas fueron utilizadas para confeccionar artefactos valorados como elementos de intercambio o prestigio (Berón 2007).

Finalmente, como señala Kelly (2011: 189): “...Every archaeologist has had the experience: You pick up a gleaming flake of obsidian from a site, look up at a vast dune field surrounded by low ranges of sandstone or other sedimentary rock, and wonder, how did this get here?...". Esta pregunta será una parte esencial de los aspectos que esta tesis intenta evaluar. 


\section{CAPítulo 5}

\section{METODOLOGÍA}

El presente trabajo de tesis se desarrolla siguiendo varios lineamientos metodológicos, vinculados con las distintas etapas de la investigación y adecuados para contrastar las hipótesis planteadas. En este capítulo se detallan las estrategias de muestreo implementadas para el relevamiento arqueológico del área de estudio y de los sectores del espacio con fuentes potenciales de aprovisionamiento de recursos líticos. Esto incluye el enfoque tecnológico para el abordaje de las estrategias de abastecimiento de materias primas líticas y las técnicas de análisis geoquímico para su caracterización y estudio de procedencia. Por otro lado, se desarrollan también los aspectos metodológicos considerados para los análisis técnico-morfológicos y los vinculados con el procesamiento de los datos.

\subsection{MÉtOdOS Y TÉCNICAS DE MUESTREO DEL ESPACIO REGIONAL}

La perspectiva regional implica observar el comportamiento de las variables en cada una de las escalas involucradas, en términos de densidad, diversidad y composición artefactual. Estas unidades espaciales son recortes sin significado funcional, aunque útiles como estrategia para explorar la estructura arqueológica a distinta resolución e identificar diferencias dentro del ambiente.

Esta investigación toma como eje espacial a la cuenca del río Atuel desde una perspectiva regional. Dentro de esta región se incluyen tres unidades de análisis. La micro-escala (sensu Dincauze 2000: 198-99) corresponde al sitio arqueológico y otros fenómenos muy locales, con una amplitud espacial máxima de $1 \mathrm{~km}^{2}$. La meso-escala incluye a la localidad arqueológica. Cuando abarca 1-10 $\mathrm{km}^{2}$ se habla de "mesolocalidad" (Dincauze 2000:199). Aquí se insertan un conjunto definido de sitios o de distribuciones arqueológicas y distintos rasgos geomorfológicos del paisaje como volcanes y flujos de lava, planicies de inundación y terrazas, cuencas de drenaje menores, campos de dunas, valles glaciales, etc. Cuando la meso-escala agrupa diferentes 
localidades arqueológicas y cubre espacios comprendidos entre $10 \mathrm{~km}^{2}$ y $10 \mathrm{~km}^{4}$, se considera que la escala es "meso-regional" (Dincauze 2000: 199) y responde a criterios geográficos, geológicos o geomorfológicos. La escala meso-regional correspondería aquí a cada uno de los tres sectores en que se divide al río Atuel: de oeste a este, cuencas superior, media e inferior, que en gran parte coinciden con los tres desiertos definidos en el Capítulo 2 (Ambiente), Altoandino, Patagónico y de Monte. La macro-escala implica rasgos que varían entre $10^{4}$ y $10^{7} \mathrm{~km}^{2}$, incluyendo provincias fisiográficas (Dincauze 2000: 198-99); a esta escala se dan los aspectos que tienen relevancia directa para la territorialidad humana, la circulación de bienes e individuos (e.g. artefactos confeccionados sobre obsidiana), la explotación de recursos y la comunicación, (Dincauze 2000: 198), dado que involucra a distintas regiones interrelacionadas. En este caso la macro-escala corresponde a la cuenca del río Atuel $\left(40.000 \mathrm{~km}^{2}\right)$.

Un enfoque que permite analizar y discutir el registro arqueológico desde distintas escalas espaciales es el distribucional (Belardi 2005). El enfoque distribucional permite, por un lado, situar los artefactos dentro de la transecta y dentro de un ambiente determinado o localidad; y por otro, reconocer el ambiente dentro del sector de la región, y ubicar a la región dentro del contexto macro-regional (sensu Dincauze 2000).

\subsubsection{RELEVAMIENTO ARQUEOLÓGICO DEL ÁREA DE ESTUDIO}

La presente investigación se basó en el estudio de los conjuntos líticos distribuidos superficial y estratigráficamente a lo largo del río Atuel. El registro arqueológico es un continuum, por lo que se considera tan importante el material recolectado de superficie en diferentes sectores del espacio, como el obtenido en estratigrafía a través de excavaciones específicas (Belardi et al. 1992). La obtención y análisis de los artefactos líticos comprendió métodos y técnicas específicos, y la información distribucional de los mismos fue integrada en diferentes escalas espaciales (Franco 2004; Belardi 2005).

Las tareas realizadas en el campo incluyeron numerosas técnicas de relevamiento y registro de datos, tales como sondeos, excavaciones sistemáticas amplias, transectas de recolección superficial y, en algunas oportunidades, observaciones ambientales. Los sondeos se realizaron cuando fue necesario verificar la existencia de materiales enterrados y observar algunas características del depósito. Estos sondeos constituyeron áreas pequeñas de $0,5 \times 0,5 \mathrm{~m}$ cuya excavación se realizó mediante capas artificiales de $10 \mathrm{~cm}$. Las excavaciones sistemáticas amplias (de mayores dimensiones que los sondeos) fueron diseñadas, por lo general, en unidades de $2 \mathrm{~m}$ x $1 \mathrm{~m}$. En la mayoría de 
los casos los niveles artificiales fueron de $5 \mathrm{~cm}$ de espesor y se extrajeron considerando cambios sedimentarios. Al contemplarse esto último, hubo situaciones en las que se requirió excavar por niveles artificiales de $10 \mathrm{~cm}$. Los hallazgos macroscópicos dentro de las cuadrículas fueron ubicados tridimensionalmente y el sedimento fue cernido en zarandas con mallas de $1 \mathrm{~mm}$. Durante las excavaciones, además, se separaron muestras para flotación ( ca. 10 litros por nivel), que fueron luego procesadas en laboratorio, siendo segregadas por su fracción pesada (malla de $1 \mathrm{~mm}$ ) y fracción liviana (malla de 0,5 mm). La recolección superficial se efectuó mediante transectas lineales rectas, dirigidas y al azar, siguiendo rumbos de brújula y GPS. En ellas se recolectó todo el material arqueológico. Siguiendo la propuesta de Neme (2001, 2007), además de los datos arqueológicos, se relevaron:

Pendiente: según los grados de inclinación $\left(90^{\circ}\right.$ abrupta, $70^{\circ}$ pronunciada, $50^{\circ}$ regular, $30^{\circ}$ suave, $10^{\circ}$ muy suave y $0^{\circ}$ nula);

Visibilidad: $100 \%$ óptima, $80 \%$ muy buena, $60 \%$ buena, $40 \%$ regular, $20 \%$ mala, $0 \%$ nula; la presencia o ausencia de cobertura vegetal y de rasgos importantes como alteraciones antrópicas modernas (paso de caminos o senderos, corrales, etc.) o cauces de agua.

En los sondeos y en las excavaciones amplias, todos los materiales fueron separados por categorías (líticos, huesos, carbones, semillas, cerámicas, pigmentos, etc.) y por nivel de extracción. Con respecto a las transectas, hubo casos en los que la recolección estuvo dirigida hacia los materiales líticos. En los demás casos se registró todo el material arqueológico. La cantidad de transectas se definió en el lugar según área a registrar, su accesibilidad, cantidad de personas disponibles para recolectar, tiempo, etc. Cada transecta fue subdividida en cuadrículas de observación y/o recolección de dos metros de lado (Neme 2001). En los casos de transectas de $100 \mathrm{~m}$ de longitud, la distancia entre una unidad y la siguiente se estableció en $20 \mathrm{~m}$; en transectas de $1000 \mathrm{~m}$ de longitud, se definió en 50 o 100 m, según el grado de resolución requerido y las condiciones para transitar por el terreno.

Los distintos formatos de documentación -fotográfica, filmográfica y escritafueron archivados en el Departamento de Antropología del Museo de Historia Natural de San Rafael (MHNSR) y quedaron a disposición para su consulta y/o utilización. De las numerosas colecciones que posee esta institución, algunas de ellas fueron revisadas para el presente estudio (conjuntos líticos de la localidad arqueológica Arbolito y los sitios Rincón del Atuel-1 y La Olla). 
El trabajo de laboratorio incluyó distintas tareas. Los materiales de los sitios arqueológicos estudiados aquí, en su mayoría, ya habían sido documentados e inventariados previamente al trabajo de tesis; pero en el caso de la localidad arqueológica El Nihuil, debido a que la excavación de los sitios Arbolito 6 (cuadrículas A1 y A2), Arbolito 7 (A1) y Barranca de Piedra (A1) se realizó durante el periodo de ejecución de la tesis, se requirió preparar, ordenar, documentar e inventariar el material.

Las muestras destinadas a ser fechadas por ${ }^{14} \mathrm{C}$ (AMS) fueron analizadas en el laboratorio de Arizona AMS Facilites de Tucson (Arizona) y en el Laboratorio de la Universidad de Georgia (UGA); lo mismo se realizó con las muestras de obsidiana analizadas en el Missoury Research Lab. Estas fueron caracterizadas geoquímicamente utilizando dos tipos de metodologías: Análisis de Activación Neutrónica y Fluorescencia de Rayos X; ambos se describen en la Sección 5.2.3.1. La clasificación de los materiales líticos se detalla en la Sección 5.2.

\subsubsection{ESTUDIO DE LAS PROPIEDADES DE LAS FUENTES LÍTICAS}

Para el abordaje del estudio de las fuentes de aprovisionamiento de materias primas líticas se consideraron los siguientes aspectos: distribución y disponibilidad de los recursos líticos, y su accesibilidad; potencialidad de uso de los nódulos; características y variables tradicionales en los estudios de procesos de manufactura (Ericson 1984; Gould y Saggers 1985; Nelson 1991; Nami 1986, 1992; Andrefsky 1994, 1998; Ingbar 1994; Franco y Borrero 1999; Franco 2004; Cortegoso 2005b; Charlin 2007, 2009b, entre otros).

Los muestreos de materias primas en la cuenca del río Atuel se realizaron con el fin de caracterizar la estructura regional de recursos líticos. Para ello se siguió la propuesta de Franco y Borrero (1999). El relevamiento de las fuentes de aprovisionamiento consistió, en primer lugar, en revisar las descripciones de la bibliografía geológica y geomorfológica del área, como base para la selección de los espacios con afloramientos de rocas aptas para la talla. Tales espacios fueron georreferenciados por medio de un Sistema de Información Geográfica (SIG). Dentro de cada uno de los espacios seleccionados se estableció un tiempo de trabajo (Franco y Borrero 1999: 30) en el que cada recolector (2 a 4 personas, según el caso) recorrió sectores distintos a sus compañeros, con el fin de registrar en conjunto la totalidad de dicho espacio en el tiempo estipulado. En todos los casos, el tiempo de recolección fue de 10 minutos. Estas variables fueron controladas para obtener datos comparables y evaluar así el rendimiento de cada 
depósito en términos de costos de aprovisionamiento (Ambrústolo et al. 2015). En ese tiempo se registró la presencia de las materias primas de mejor calidad para la talla; de las materias primas de calidad regular o mala se registraron las más frecuentes y/o las presentes en los conjuntos líticos de sitios en estratigrafía, localizadas en la misma zona. De cada pieza recogida se anotó el tipo de materia prima y su calidad para la talla, el tamaño (diámetro máximo según grilla de tamaños; Franco 2002b) y la forma en la que se presentaba (guijarros, bloques, etc.) (Franco y Borrero 1999).

Particularmente, las tareas realizadas en la fuente primaria de obsidiana El Peceño implicaron la utilización de dos herramientas metodológicas de muestreo espacial: transectas lineales y cuadrículas de recolección superficial. Las transectas lineales “... tienen como fin registrar las actividades tecnológicas frecuentes en la fuente, áreas de cantera taller (Callahan 1979; Elston 1992), distancia de transporte de la materia prima, variaciones macroscópicas y diferencias espaciales en cuanto a disponibilidad, calidad para la talla, tamaños y frecuencia" (Salgán y Pompei 2017: 53). De las ocho líneas de transecta, cuatro se trazaron en la ladera oeste del cerro El Peceño en dirección este-oeste y las cuatro restantes en la ladera este, en dirección oeste-este (Figura 5.1.) (Salgán y Pompei 2017). Cada transecta fue orientada con brújula y GPS, con una equidistancia aproximada entre ellas de $20 \mathrm{~m}$, y con un total de 10 unidades de recolección cada una. Las cuadrículas superficiales de muestreo realizadas en esta fuente, por su parte, incluyeron una primera etapa de identificación de los sectores de canteo y taller sobre obsidiana. Luego, se marcaron cuadrículas de 0,50 x 0,50 m en sectores donde la concentración de artefactos y nódulos naturales era mayor. Cada cuadrícula fue demarcada, fotografiada y georreferenciada, recolectándose posteriormente el total del material superficial (Salgán y Pompei 2017).

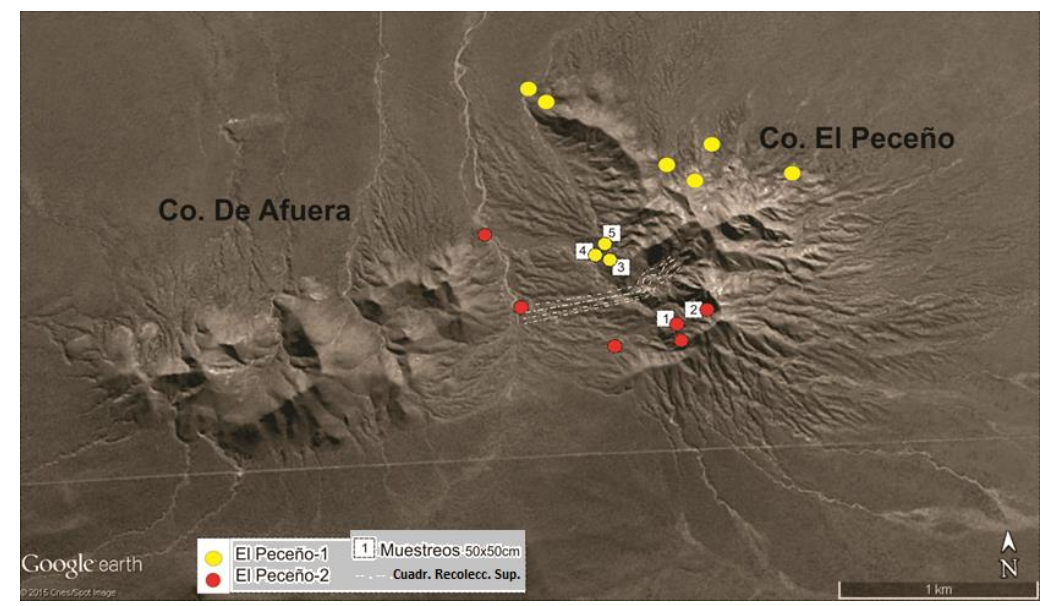

Figura 5.1. Transectas lineales y cuadrículas de recolección superficial. 


\subsection{ANÁLISIS DE LOS CONJUNTOS ARTEFACTUALES}

El análisis de los artefactos líticos estuvo orientado a la descripción de la variabilidad de los artefactos a partir de atributos directamente observables. No se han considerado los aspectos funcionales, el objetivo del artesano ni su predisposición mental de la forma (Hiscock 2001; Odell 2003). La propuesta general de Hiscock (2001) se define como un enfoque tecnológico materialista donde se establecen categorías, destacando rasgos relativos a la producción de los artefactos y a su uso, como fenómenos separados; las categorías de análisis adoptadas son mutuamente excluyentes.

La clasificación tecnológica materialista considera al artefacto como resultado de su historia de vida, "backward-looking" (Hiscock 2001), cuyo interés radica en las variaciones de atributos cuantitativos y cualitativos de los artefactos líticos, por ejemplo, los cambios observados al aumentar la distancia a la fuente de aprovisionamiento. Estos cambios se evalúan en relación a la secuencia de producción y los factores involucrados en la manufactura, uso y reactivación de los artefactos, como así también la disponibilidad y propiedades de las materias primas, el tipo de enmangue, los costos de transporte, etc. (Hiscock 2001).

El tratamiento tecnológico y tipológico de los conjuntos líticos se llevó a cabo en el laboratorio siguiendo la propuesta metodológica de Aschero $(1975,1983)$ y considerando las modificaciones realizadas por Franco (2002b) y Aschero y Hocsman (2004). Además, se han sumado las propuestas de otros autores (Ingbar et al. 1989; Shott 1989; Hayden y Hutchings 1989; Andrefsky 1998; Odell 2003; Franco 2004; Cortegoso 2005b; Charlin 2007, entre otros).

\subsubsection{DESCRIPCIÓN DE LOS CONJUNTOS LÍTICOS}

El análisis consistió en la observación y registro de atributos clasificables (sensu Civalero 2006) de todas las piezas recuperadas en los diez sitios arqueológicos en estratigrafia (doce cuadrículas) considerados: Cueva Palulo 1, Arroyo Panchino 1, Arroyo Panchino 2, Cueva Salamanca 1, Arbolito 6 (cuadrículas A1 y A2), Arbolito 7, Barranca de Piedra 1, Los Gallegos 1 (cuadrículas A1 y B1), El Bosquecillo 3 y El Bosquecillo 5.

Todos los datos tomados - cualitativos y cuantitativos- fueron volcados en una planilla de Microsoft Excel, confeccionada para describir la variabilidad artefactual, procesar y cruzar los datos, y armar los gráficos pertinentes. En el diseño de dicha planilla 
se consideraron, como eje central del análisis, las clases artefactuales definidas por Aschero $(1975,1983)$.

Las variables descriptivas y los índices de tamaños se tomaron de acuerdo a las propuestas de Aschero (1975, 1983), considerando las modificaciones realizadas por Franco (2002b) y Aschero y Hocsman (2004). Asimismo, en el análisis de los desechos de talla se consideraron también otros términos, conceptos y atributos propuestos por diversos autores (Sullivan y Rozen 1985; Bellelli et al. 1987; Ingbar et al. 1989; Shott 1994; Bradbury y Carr 1995, entre otros). Por su parte, en la descripción de los instrumentos líticos en particular, también se tuvo en cuenta la clase técnica, definida por Aschero y Hocsman (2004), que distinguen grados de trabajo invertido en la producción de artefactos. De esta manera, la clase Artefactos formatizados se subdivide en: aArtefactos de formatización bifacial, debido a que la reducción y el adelgazamiento bifacial de una forma-base implican un mayor tiempo de trabajo que producir un artefacto con el sólo retoque de sus bordes (Escola 2000; Aschero y Hocsman 2004), y bArtefactos de formatización unifacial.

La variación morfológica es entendida aquí como un continuum entre tipos morfológicamente distintos ( $c f$. Dibble 1987; Hiscock y Attenbrow 2002, 2005, entre otros). El interés está en comparar el modo en que fueron explotados los artefactos según la materia prima lítica y cómo esta se distribuye en el espacio regional. El estudio de la variabilidad artefactual desde enfoques tipológicos conlleva dificultades (Binford 1979, 1980; Gould 1980; Hayden 1979, 1998; Charlin 2007). En Argentina se han realizado diversos estudios orientados a superarlas (Charlin 2007; Hermo 2008; Sario 2011, entre otros). En ellos, la denominación de los Artefactos formatizados según la clasificación morfológico-funcional de Aschero $(1975,1983)$ se utiliza de modo descriptivo y no analítico, debido a su utilidad para la comunicación entre colegas o sintetizar la información (Charlin 2007).

\subsubsection{VARIABLES CONSIDERADAS EN EL ANÁLISIS DE LOS} ARTEFACTOS LÍTICOS

En esta sección se expone un listado de las variables consideradas en las clases artefactuales definidas por Aschero $(1975,1983)$. Estas se refieren a la identificación de la pieza, los atributos de las materias primas y las variables métricas, siguiendo con las medidas específicas que han sido descritas por clase artefactual. Cabe agregar que se ha seguido el mismo criterio que utilizó Salgán (2013) en su trabajo de tesis doctoral en el 
campo volcánico La Payunia, ya que esto facilitará el cruce de la información obtenida en ambas áreas del sur de Mendoza.

\section{Atributos de identificación de la pieza}

-Número de pieza.

-Procedencia.

-Sitio o área.

-Unidad de muestreo.

-Muestreo: -superficial;

-estratigráfico: cuadrícula; nivel; sector.

\section{Atributos de la materia prima}

-Materia prima: según determinación por petrografía macroscópica. Sólo en el caso de rocas volcánicas que no hayan podido ser identificadas dentro de alguna de las clases de roca de este grupo (basalto, riolita, andesita, etc.), se las clasificó como "vulcanitas indeterminadas".

-Color: categorías cromáticas generales según la observación macroscópica, incluyendo claros y oscuros, y tipo de coloración (uniforme o veteado).

-Translucidez: translúcido y opaco.

-Calidad para la talla: mala, regular, buena, muy buena y excelente (sensu Aragón y Franco 1997).

-Presencia de alteraciones en la superficie externa: pátina; ventificación; rodamiento; hoyuelos; craquelado; alteración del color por quemado; alteraciones térmicas múltiples; sustancias adheridas; geodas superficiales; indiferenciado.

-Presencia de alteraciones en la matriz: fracturas internas; inclusiones minerales e impurezas; geodas internas.

\section{Atributos de los artefactos}

-Reserva de corteza: 0\%: indica ausencia de reserva de corteza; 25\%: entre 0,1 y $25 \%$; 50\%: entre 26 y 50\%; 75\%: entre 51 y $75 \%$; y $100 \%$ : entre 76 y $100 \%$ de reserva de corteza en la cara dorsal) (Franco 2002b). Este indicador se considera un atributo estimado, ya que hay numerosos factores que pueden influir sobre él (Sullivan y Rozen 1985).

-Estado de fragmentación: entero o fracturado. 
-Orientación de la pieza (sensu Aschero 1975, 1983).

-Tamaño (en milímetros): largo, ancho y espesor, tanto en artefactos enteros como en los fragmentados. En los enteros, esta variable permitió estimar el volumen de las piezas y el módulo de tamaño (sensu Aschero 1975, 1983): Muy Pequeño (MPE): 0-20 mm; Pequeño (P): 21-40; Mediano Pequeño (MEP): 41-60; Mediano Grande (MEG): 61 80; Grande (G): 81-120; Muy Grande (MG): 121-160; y Grandísimo (GD): $\geq 161$.

-Peso: mediante el uso de balanza digital, registrando valores en gramo con error de 0,1 gr. Esta variable permite inferir con mayor precisión la realidad volumétrica de la producción lítica (Geneste 1990). En el caso de los desechos de talla de tamaño igual o menor a $5 \mathrm{~mm}$ de lado, se los pesó juntos por unidad de muestreo y por materia prima.

\subsubsection{Núcleos}

-Designación morfológica de los núcleos: de lascados aislados, bifacial, discoidal, piramidal cónico o regular, piramidal irregular o parcial, bipiramidal, poliédrico, globuloso, prismático unidirreccional regular/irregular, prismático bidireccional, prismático parcial, bipolar, amorfo y no diferenciado, siguiendo la propuesta de Aschero $(1975,1983)$.

-Medidas de longitud (L), ancho (A) y espesor (E) máximo: medidos en mm con calibrador vernier según el eje morfológico (sensu Aschero 1975, 1983).

-Volumen: en $\mathrm{mm}^{3}$ (L x A x E).

-Forma base: rodado o guijarro, nódulo natural, lasca secundaria, lasca secundaria de rodado, lasca no diferenciada de rodado y no diferenciado.

-Cantidad de negativos de lascado en la cara dorsal, con boca de extracción visible (Ingbar 1994).

-Cantidad de plataformas de percusión (Aschero 1975, 1983).

-Grado de explotación: agotado, no agotado (Franco 2002b).

- Longitud y ancho de la extracción máxima y mínima (Prates 2008).

\subsubsection{Desechos de talla}

-Clase de desecho: lasca primaria, lasca secundaria, lasca con dorso natural, lasca de descortezamiento; lasca de arista, lasca angular, lasca plana, lasca de adelgazamiento bifacial, lasca de reactivación indirecta de instrumentos, lasca de reactivación directa de instrumentos; lasca en cresta, lasca de flanco de núcleo o de reactivación de plataforma 
de percusión, tableta de núcleo (por reactivación del núcleo), chunk o lasca de núcleo; lasca bipolar; tipo no diferenciado con corteza, tipo no diferenciado con negativos de lascado y tipo no diferenciado posiblemente núcleo o lasca nucleiforme (sensu Aschero 1975, 1983). En la presentación de los resultados se utilizan sólo aquellas clases de desechos registradas en los conjuntos líticos.

Además del largo, ancho y espesor (medición en mm que, como se dijo, es común a la totalidad de los artefactos analizados), se estimó la superficie artefactual de cada desecho utilizando una grilla de tamaños en intervalos de $5 \mathrm{~mm}$ (sensu Franco 2002b), donde se asignó un tamaño según la superficie de la cuadrícula (Figura 5.2) que mejor se ajustara a la de cada pieza. Los desechos cuyo tamaño es igual o menor a $5 \mathrm{~mm}$ de lado (superficie: 5 por $5 \mathrm{~mm}$ ), designados como " $\leq 5 \mathrm{~mm}$ " o "5 x $5 \mathrm{~mm}$ " ("ultramicrolasca" sensu Aschero 1975, 1983), sólo se mencionan al comienzo de la respectiva sección "Registro lítico" de los capítulos 7, 8 y 9 (Resultados), y han sido excluidos de los cálculos de las tasas de depositación y del análisis tecnológico, debido a que muchos de los atributos requeridos para la definición del tipo de desecho no son discernibles con precisión a ese tamaño.

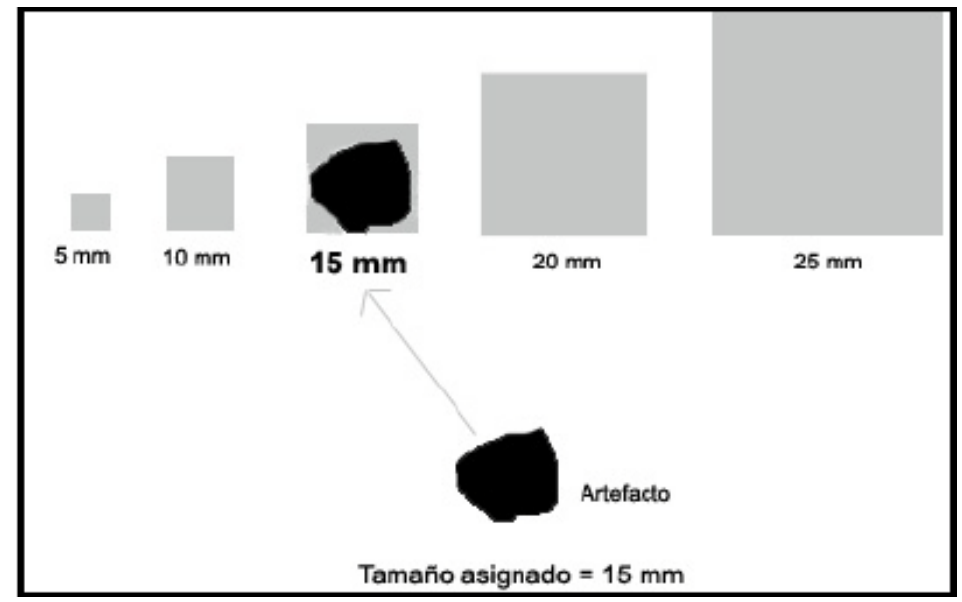

Figura 5.2. Ejemplo de utilización de la grilla de tamaños (Franco 2002b) (Tomado de Borrazzo 2010: 151).

-Estado de fragmentación: entero (o "completo") y fragmentado (Hiscock 2002). Los fragmentados se diferencian en transversales proximales, transversales distales, transversales mediales (faltan ambos, el extremo proximal y el distal), longitudinales izquierdos, longitudinales derechos, y sus combinaciones (e.g., fragmento transversal distal-longitudinal izquierdo; marginales; y fragmentos no diferenciados. 
-Longitud, ancho y espesor máximo (en mm de acuerdo al eje tecnológico, sensu Aschero1975, 1983). En lascas fragmentadas estas medidas también fueron tomadas para calcular el área y aplicar el modelo de Ingbar et al. (1989).

-Forma del talón: natural (cortical), liso, diedro, facetado, filiforme, puntiforme, no diferenciado y ausente no pertinente (Aschero 1975, 1983). También se incluye el tipo estallado (crushed platforms, sensu Bradbury y Carr 1995). El tipo de talón permite identificar el origen de la extracción y, por ende, constituye una variable de aproximación acerca del momento de la secuencia de reducción de la materia prima, desde las primeras etapas (explotación de núcleos, extracción y formatización inicial de formas-base) hasta las instancias finales de manufactura y mantenimiento de instrumentos. Distintos autores (Magne 1989; Tomka 1989; Nami 1991; Bradbury y Carr 1995; Espinosa 1995, entre otros) plantean que los talones naturales (corticales), lisos y probablemente los estallados (aunque esto último podría variar según la materia prima), podrían vincularse con los primeros estadios de la secuencia de reducción; y que los talones diedros, facetados, filiformes y puntiformes corresponderían a las etapas intermedias y/o avanzadas. Asimismo, esta variable debe ser analizada en relación a las propiedades físicas de la materia prima (Nami 1992), al tamaño (en relación a la naturaleza extractiva de la actividad de talla) y a otros atributos de los desechos como los característicos de la cara ventral (e.g., bulbo pronunciado - vinculado a percusión dura- o difuso -correspondiente a percusión blanda) (Aschero 1975, 1983; Espinosa 1995).

-Cantidad mínima de extracciones en la cara dorsal: número mínimo de formasbase extraídas previamente de una lasca (Ingbar et al. 1989).

-Atributos de la cara ventral: bulbo, bulbo difuso, cono, labio, lasca adventicia, estrías, ondas y punto de percusión (sensu Aschero 1975, 1983).

-Presencia de rastros complementarios: microlascados aislados o melladuras (1 a $2 \mathrm{~mm}$ ), muescas pequeñas, astilladuras, marcas y hoyuelos de percusión, sustancias adheridas (carbonatos, mineral, resinas, pigmentos, indeterminado) y lascados previos en cara ventral (señalando la cantidad cuando es más de un lascado) (Aschero 1975, 1983).

\subsubsection{Instrumentos}

Se utiliza la categoría "instrumentos" para incluir a artefactos formatizados de manera unifacial y bifacial, tanto simples como compuestos (que incluyen más de un filo o punta formatizado; véase siguiente sección), manufacturados por lascados; como así 
también a litos modificados por uso como los percutores, y a los artefactos manufacturados o modificados por abrasión, picado y/o pulido.

\subsubsection{3.a. Artefactos formatizados}

Esta clase artefactual comprende artefactos de filo y puntas-herramientas, discriminados en artefactos formatizados simples (poseen un filo o una punta) y artefactos formatizados compuestos (constituidos por más de un filo y/o punta). Debido a la escasa cantidad de instrumentos compuestos y con el fin de no repetir el número de piezas, se decidió distinguir, según el grado de inversión de trabajo, entre artefactos de formatización bifacial (en adelante AF Bifacial) y artefactos de formatización unifacial (en adelante AF Unifacial), sólo en los casos de los instrumentos simples. En las tablas de grupos y sub-grupos tipológicos de los instrumentos de cada sitio arqueológico, presentadas en los resultados (Capítulos 7, 8 y 9), se detallan el tipo de formartización (bifacial/unifacial), tanto de los instrumentos simples como de los compuestos.

\section{- Instrumentos simples de formatización bifacial (AF Bifacial)}

-Forma-base: según Aschero (1975, 1983).

-Clase: preforma bifacial, bifaz parcial, bifaz en sentido estricto y punta de proyectil (sensu Aschero 1975, 1983; Aschero y Hocsman 2004).

-Largo, ancho y espesor máximo: medidos en mm según eje morfológico (EM) (Aschero 1975, 1983).

-Peso en gramos: para puntas de proyectil enteras esta medida evita la redundancia en las medidas de tamaño, dado que las medidas métricas de largo y espesor de las puntas se utilizan para el cálculo del índice de reactivación (Iriarte 1995).

-Forma perimetral del limbo: triangular corta, triangular alargada, lanceoladas, cordiforme, cordiforme con ápice aguzado, con asimetría bilateral y con asimetría axial, siguiendo a Aschero $(1975,1983)$.

-Forma secundaria del borde del limbo: recta, cóncava, convexa, siguiendo a Aschero (1975, 1983).

-Tratamiento del ápice: normal, aguzado y embotado (sensu Aschero 1975, 1983).

-Otros atributos morfológicos para puntas de proyectil:

-apedunculadas: forma de la base del limbo (recta, convexa, acuminada, cóncava atenuada, cóncava profunda o "escotada"); tratamiento técnico diferencial de la 
base (normal -sin adelgazamiento-, adelgazada por retoques, adelgazada por acanaladura, embotada por retoque abrupto);

-pedunculadas: diferenciación del pedúnculo con respecto al limbo (pedúnculo diferenciado, destacado o esbozado); tratamiento técnico diferencial del pedúnculo (normal -sin adelgazamiento-, adelgazado por retoques, adelgazado por acanaladura, embotado por retoque abrupto); forma de los bordes del pedúnculo (paralelos rectos, paralelos cóncavos, convergentes rectos, convergentes cóncavos, convergentes convexos, divergentes rectos, divergentes cóncavos); forma de la base del pedúnculo (recta, convexa, cóncava atenuada, cóncava profunda o escotada, puntiforme); diferenciación de las aletas respecto al limbo y al pedúnculo (salientes, entrantes, en hombro); diferenciación de las aletas por el ángulo que forma con la base del limbo y el pedúnculo (rectas, obtusas o abiertas, agudas).

- Instrumentos simples de formatización unifacial (AF Unifacial):

-Forma-base: según Aschero (1975, 1983).

-Número de filos y/o puntas formatizados y/o con rastros complementarios.

-Número de dorsos formatizados: según Aschero (1975, 1983).

-Forma primaria del filo: normal (regular o irregular), dentado (regular o irregular), festoneado (regular o irregular), en muesca y natural (sensu Aschero 1975, 1983).

-Forma secundaria para filos frontales, laterales o convergentes: recta, cóncava, convexa atenuada, convexa extendida (en arco extendido), semicircular y semicircular extendida.

-Sección transversal de la pieza: circular, biconvexa, plano convexa, triangular, triangular redondeada, romboidal, rectangular y no diferenciado (sensu Aschero 1975, 1983).

-Atributos del filo y/o punta formatizada: extensión relativa del filo respecto del borde de la pieza (restringido, corto, largo, extendido, perimetral) (sensu Aschero 1975, 1983); largo, ancho y espesor máximo del filo o punta: medidos en mm; en el caso de filos con un grado de concavidad o convexidad alto, el largo se midió con cinta métrica flexible, para disminuir el error de medición de las curvas de los filos (Cardillo y Charlin 2007).

-Presencia-ausencia de reactivación: siguiendo lo propuesto por Aschero (1975, 1983) y Franco (1994). 
-Longitud, ancho y espesor máximo: medidos en mm según el eje tecnológico (ET) con el fin de evaluar el tamaño de la forma-base, y por el eje morfológico (EM) (Aschero 1983) en los casos que no fue posible identificar el ET, para evaluar el grado de reducción del instrumento ( $c f$. Dibble 1984, 1987; Franco 1994; Hiscock y Attenbrow 2002, 2003; Kuhn 2004; Bousman 2005).

-Peso: en gramos.

- Instrumentos compuestos (AF compuestos):

Por pieza, se caracterizan los atributos de cada filo y/o punta, según correspondan a formatización unifacial y/o bifacial, siguiendo los criterios establecidos para AF Unifaciales y AF Bifaciales, descritos arriba.

\subsubsection{Artefactos (lascas $u$ hojas) con filos, puntas o superficies con rastros} complementarios

Se emplea el término "Artefactos sin formatización con rastros complementarios" (ASF RC) para designar a los filos, superficies o puntas activas, cuyo origen "puede estar en el uso del útil, en la preparación de plataformas para el retoque o extracción, en las presiones ejercidas sobre los bordes durante la prehensión del útil o bien, en un sinnúmero de efectos producidos en procesos post-depositación" (Aschero 1983:20). Sólo se han considerado aquí aquellos casos de filos y/o puntas naturales con muescas continuas. Las variables medidas en esta clase artefactual son las mismas que las señaladas para AF Unifacial, excepto aquellas variables que corresponden a la descripción del filo (forma del filo, sección transversal, ancho y espesor del filo) y a la presencia de reactivación (Salgán 2013).

\subsubsection{DETERMINACIÓN DE LAS MATERIAS PRIMAS}

Se efectuó la identificación petrográfica a nivel macroscópico de todos los artefactos; y, en casos necesarios, se consultó con el Lic. Sergio Dieguez. Para el estudio de obsidianas se realizaron análisis geoquímicos de muestras seleccionadas, provenientes de sitios arqueológicos $\mathrm{y}$ de fuentes de aprovisionamiento. Las características macroscópicas de los artefactos proveen una aproximación a las materias primas presentes en los conjuntos arqueológicos, permiten evaluar qué rocas podrían estar disponibles en el espacio regional y definir la representatividad de cada tipo (Odell 2003). 


\subsubsection{Estudios geoquímicos}

Para el análisis geoquímico de muestras naturales y artefactos se utilizó un espectrómetro portátil de fluorescencia de Rayos X (Durán et al. 2004). Dicho análisis estuvo a cargo de Michael Glascock en las instalaciones del Missouri Research Reactor. A la información inédita obtenida de estos estudios, se sumó la información ya disponible para el sur de Mendoza (Seelenfreud et al. 1996; Durán et al. 2004; Barberena et al. 2011; Giesso et al. 2011a; Gil et al. 2011c; Cortegoso et al. 2012; Salgán et al. 2015, Salgán y Pompei 2017, entre otros). En dichos casos, los fragmentos naturales de obsidiana habían sido seleccionados con el fin de caracterizar la variabilidad macroscópica regional (Giesso et al. 2011a; Salgán et al. 2012), y para contar con muestras de referencia. En el caso de la fuente El Peceño, se contaba también con antecedentes arqueométricos (Giesso et al. 2011a; Glascock 2010). En el año 2015 se seleccionaron nueve muestras de obsidianas de dicha fuente según su variación macroscópica $\mathrm{y}$, en los casos que fue posible, su disposición en la matriz natural o afloramiento (Salgán y Pompei 2017); tales muestras se analizaron geoquímicamente a partir de la técnica no destructiva de Fluorescencia de Rayos-X (XRF).

La calibración de obsidiana para XRF se llevó a cabo usando un set de 40 muestras de fuentes de obsidiana calibradas con datos medidos previamente por ICP, XRF e INAA (Glascock y Ferguson 2012). En la calibración, cada muestra es sometida a un conteo de dos minutos donde se calculan los elementos mínimos presentes. Los elementos medidos incluyen: Mn, Fe, Zn, Rb, Sr, Y, Zr, Nb, Ba y Th. El tratamiento de la información se efectuó por medio del programa GAUSS Run-Time Module (MURR 2012), que permite generar plots bivariantes de elementos para identificar el mejor diagnóstico para XRF. En todos los casos se dibujaron elipses de un $90 \%$ de probabilidad de confianza para indicar su rango de distribución (Salgán y Pompei 2017: 54; cf. Glascock 2008, 2011).

\section{3 ÍNDICES Y ESTADÍSTICOS UTILIZADOS EN EL TRATAMIENTO DE LOS DATOS}

Los índices y estadísticos han sido calculados a partir de las variables en bruto. La media geométrica (Figura 5.3.) es el estadístico más utilizado para medidas lineales como longitud, ancho y espesor, por lo cual, constituye la medida de tamaño que se ha calculado para todas las clases artefactuales. Su ventaja radica en que el valor obtenido es el 
resultado del cálculo de un centroide que resume las distancias entre las $n$ variables (Charlin 2007).

$$
\bar{x}=\sqrt[n]{\prod_{i=1}^{n} x_{i}}=\sqrt[n]{x_{1} \cdot x_{2} \cdots x_{n}}
$$

Figura 5.3. Ecuación para calcular la media geométrica.

Se calcularon los índices de diversidad de Shannon-Wiener, de Simpson y de Dominancia a fin de caracterizar de forma más precisa las muestras comparadas. Estos fueron usados durante el análisis de las clases de roca disponibles en las fuentes potenciales de aprovisionamiento, en la comparación de clases de roca explotadas para confeccionar artefactos en los diferentes sitios arqueológicos y en las medidas de reducción de las materias primas. El concepto de diversidad permite caracterizar la estructura de una población o muestra ya que es una medida de la variabilidad (Jones y Leonard 1989). La diversidad presenta dos dimensiones: 1- la riqueza, que da cuenta del número de categorías o clases representadas en una muestra, y 2- la homogeneidad, que indica cómo se distribuyen las cantidades por categoría (Jones y Leonard 1989). Por lo tanto, se trata de una medida compuesta; esto implica que en el análisis se consideren tres tipos de índices que están correlacionados.

El índice de Shannon-Wiener estudia la correspondencia entre el número de individuos y de clases, por lo que es una medida simultánea de la riqueza y la homogeneidad (Shott 1989). Los valores superiores del índice indican que la mayoría de las clases se hallan representadas por pocos individuos o por cantidades similares de estos (i.e. tienen una distribución homogénea). Los valores inferiores, por su parte, advierten que pocas clases se encuentran representadas por muchos individuos (la distribución es asimétrica ya que se halla dominada por una o pocas clases) ( $c f$. Krebs 1989; Hammer et al. 2004; Kintigh 1989; Shott 1989; Grayson 1989; Gotelli y Graves 1996). Tal índice tiene la ventaja de ser sensible a la frecuencia de ítems en las clases menos representadas (Peet 1974, citado en Shott 1989).

Los resultados obtenidos a través del índice de Shannon-Wiener se pueden complementar con los índices de Simpson y Dominancia. Ambos varían entre 0 y 1, según la uniformidad o asimetría en la distribución de cantidades entre clases, respectivamente. Según Hammer y colaboradores (2004), comparar la diversidad entre muestras implica la 
utilización de dos procedimientos de aleatorización (o randomization): el boostrapping y la permutación, dos técnicas de remuestreo al azar, con y sin reemplazo respectivamente. La distribución muestreal interviene como si fuera la verdadera distribución poblacional $\mathrm{y}$, mediante el remuestreo de la misma, se produce la distribución teórica. Las $n$ observaciones originales tienen igual probabilidad de ser seleccionadas. Suelen seleccionarse 1000 muestras de tamaño $n$ en dicha técnica de remuestreo; a partir de cada una se estiman los parámetros y así se establece la distribución teórica comparativa.

Para el tratamiento estadístico de los datos se utilizó el software PAST 2.07 (Hammer et al. 2001). En el caso de los conjuntos líticos en estratigrafía se comparó la diversidad entre bloques temporales y se evaluó cuán significativas son las diferencias tecnológicas entre distintos momentos del Holoceno tardío. Para ello se utilizaron test estadísticos paramétricos y no paramétricos.

La necesidad de comparar y evaluar la representatividad de cada conjunto a lo largo del tiempo en sitios arqueológicos, sobre todo en estratigrafía, se hace más evidente cuando se tienen en cuenta los procesos de formación de sitio. El estado de fragmentación de los artefactos puede variar debido a diversos factores postdepositacionales y a las características de la roca (e.g., mayor fragilidad de la obsidiana respecto a otras materias primas líticas). Por este motivo, y con el fin de no sobreestimar la muestra analizada, se consideró la propuesta de Hiscock (2002) para desechos de talla, quien utiliza conteos e índices análogos a los utilizados en estudios tafonómicos para materiales óseos. Así, en lugar de trabajar con el MNI (Minimum Number of Individuals -número mínimo de individuos- en tafonomía ósea), Hiscock (2002) propone utilizar otros tres índices sobre conjuntos artefactuales:

-NAS (Number of Artefactual Specimens): número total de artefactos recuperados, ya sean enteros o fragmentados;

-NFS (Number of Flake Specimens): número de especímenes identificados como lascas, ya sean enteras o fragmentadas;

-MNF (Minimum Number of Flakes): estimación del número mínimo de lascas necesario para dar cuenta de las lascas completas y fragmentadas presentes en un conjunto. Este "número mínimo de lascas" se calcula utilizando la fórmula $\mathbf{M N F}=\mathbf{C}+\mathbf{T}+\mathbf{L}$ (Hiscock 2002: 254), donde $\mathbf{C}$ corresponde a todas las lascas completas; T es la categoría más numerosa de fragmentos transversales, sin considerar a los mediales, es decir, los proximales o los distales. L es el número de fragmentos longitudinales que a su vez se da por $\mathbf{L}=\mathbf{C} \mathbf{L}+\mathbf{B L}$, donde $\mathbf{C} \mathbf{L}$ es el número mayor de fragmentos longitudinales, 
ya sean izquierdos o derechos sin fractura transversal (con la condición de que posean inicio y terminación de la fractura); y BL es el mayor (el que más se repite) de las cuatro categorías relevantes de fragmentos longitudinales fracturados transversalmente (derecho/proximal, izquierdo/proximal, derecho/distal, izquierdo/distal) (Hiscock 2002: figura 1: 253).

El MNF se calcula para cada materia prima con el fin de aumentar su precisión, ya que un fragmento distal de una clase de roca, por ejemplo basalto, y otro proximal de otra materia prima, obsidiana, por ejemplo, se contarían como dos lascas diferentes. De lo contrario, sin dicha discriminación por materia prima, los dos fragmentos se computarían como una sola lasca (Hiscock 2002). También se requiere controlar que la fragmentación no se produzca sobre alguna materia prima en particular, ya que puede responder a las características inherentes de la roca y/o su resistencia a procesos de manufactura o tafonómicos. Para ajustar la estimación de la abundancia original de todos los artefactos que integran los conjuntos se utiliza el MNA (Minimum Number of Artefacts) (Salgán 2013). Este índice es el resultado de la sumatoria del MNF (calculado para desechos de talla) y los instrumentos y núcleos enteros (los núcleos e instrumentos fragmentados son considerados "fragmentos no diferenciados", tomados sólo en el conteo del índice NAS). El índice de fragmentación de cada localidad es la razón entre el NAS y el MNA obtenido (Hiscock 2002; Borrazzo 2010).

En el estudio de la explotación de distintas rocas, el tratamiento de los conjuntos de cada materia prima consideró los índices propuestos por Ericson (1984), que tienen la función de generar información acerca de los estadios de producción por materia prima; por ejemplo:

-índice de corteza (desechos primarios y secundarios de descortezamiento / $\mathrm{n}$ total de desechos);

-índice de producción (desechos de talla / instrumentos);

-índice de bifacialidad (instrumentos bifaciales / $\mathrm{n}$ total instrumentos).

En el análisis de la reducción de las distintas clases artefactuales, se utilizaron los índices derivados de estudios experimentales, con el fin de evaluar diferencias y similitudes entre distintas técnicas de manufactura y entre distintos estadios del proceso de reducción (Amick y Mauldin 1989). De ellos, muchos se centran en los desechos de talla, debido a que son los artefactos comúnmente más numerosos del registro arqueológico (Shott 1994, 1996; Sullivan y Rozen 1985; Ingbar et al. 1989; Bradbury y Carr 1995, entre otros). En tales estudios experimentales se observaron algunas 
constantes en la variación de determinados atributos a medida que aumenta la reducción: disminución del tamaño, incremento en la cantidad de negativos de lascado en la cara dorsal de la lasca (Ingbar et al. 1989), etc. Los resultados indican que la densidad de negativos de lascado (100 x cantidad de negativos de lascado en la cara dorsal / área de la lasca) es la medida que más se ajusta al proceso de reducción. Por lo tanto, se adopta para calcular el grado de reducción de los desechos de talla, excepto aquellos que corresponden a lascas de formatización de filo. El área o superficie de la lasca es calculada a través del largo por el ancho (en mm) según el eje tecnológico (ET). El resultado expresa la cantidad de extracciones (negativos de lascado) por $\mathrm{mm}^{2}$ (abreviado como e/ $/ \mathrm{mm}^{2}$ ). La densidad es una medida relativa al tamaño por lo que es posible calcularla sobre lascas fragmentadas (Charlin 2009a, b). Esto resulta necesario en las materias primas de representación minoritarias, como los basaltos o riolitas. Una medida similar puede aplicarse en el caso de los núcleos, pero como el tamaño de muestra de núcleos es bajo, no alcanzó para comparar la explotación de distintas clases de materias primas.

El índice de reducción también se aplica de manera exploratoria para estimar la secuencia de manufactura representada en los diferentes conjuntos, partiendo de que el tamaño de la pieza y la intensidad de los lascados disminuyen a medida que avanza el proceso de reducción. En este análisis sólo se consideran los artefactos enteros. Una manera simple de abordar las características estructurales y organizativas en los conjuntos es a través de la delineación de trayectorias de producción (véase Capítulo 4: Marco teórico). Para ello se consideran atributos tecno-morfológicos (Aschero 1975, 1983) que permiten analizar las etapas de reducción representadas en los diferentes locus. Para el análisis de las etapas de manufactura, se consideran los desechos de talla enteros. Las primeras etapas de manufactura o descortezamiento están representadas por las lascas externas, que corresponden a desechos de talla que presentan en su cara dorsal entre el $100 \%$ y $75 \%$ de reserva corteza (lascas primarias y secundarias, respectivamente), sumado a las lascas nodulares o de reactivación de núcleo (lascas de flanco de núcleo, de dorso natural y tableta de núcleo). Luego, siguen las lascas internas, es decir, desechos de talla que poseen baja o nula reserva de corteza $(50 \%, 25 \%$ o $0 \%)$ y presentan en su cara dorsal negativos de lascado previos (lascas angulares y de arista). Por último, se consideran las lascas de formatización de filo, cuya morfología, tamaño y características tecnológicas son atribuidos a las últimas etapas de manufactura (lascas de adelgazamiento bifacial, lascas planas y lascas de reactivación de filo) (Salgán 2013: 128). En el caso de 
los artefactos formatizados se analizan los modos de manufactura y su frecuencia, el estado de descarte y, en artefactos unifaciales, el grado de reducción (sensu Kuhn 1990).

En el caso de instrumentos unifaciales un indicador de reducción útil es el índice geométrico de reducción propuesto por Kuhn (1990). Este se basa en un modelo geométrico sobre la sección transversal de la forma-base; y constituye un indicador de la frecuencia o intensidad de reactivación de un filo y, por lo tanto, de la vida útil del instrumento. Dicho índice considera la razón entre el espesor máximo del filo retocado (t) y el espesor máximo de la forma-base (T). Esta medida cuenta con la ventaja de ser independiente del tipo de reducción implementada y del tamaño original de la formabase. Pese al debate sobre la confiabilidad de tal medida (por la incidencia de distintos factores asociados con la forma de la forma-base del instrumento), las experimentaciones realizadas por Hiscock y Clarkson (2005a y b) han demostrado que las variaciones en la sección transversal de la forma-base ("the flatflake problem") no ejercen una influencia significativa sobre el cálculo del índice (Salgán 2013). Originalmente, el índice geométrico fue propuesto para calcular el grado de reducción en las raederas; sin embargo, es aplicable a otras clases de instrumentos de filo unifacial (no a los filos naturales con rastros complementarios). Para una aplicación adecuada, la forma-base debe ser una lasca, ya que el modelo se basa en la forma triangular de la lasca en sección transversal. Esta forma geométrica implica que el punto de mayor espesor se localiza hacia el centro de la pieza y, por consiguiente, a medida que la reducción del artefacto avanza a través de sucesivas reactivaciones, los negativos de lascado del filo se aproximan al centro del artefacto. Esto conlleva un incremento del espesor del filo (t), hasta que alcanza el espesor máximo de la forma-base (T). Así, la tasa de $\mathrm{t} / \mathrm{T}$ adquiere valores entre 0 y 1 a medida que avanza la reducción $[(t / T) / n]$. 


\section{CAPÍTULO 6}

\section{LA BASE REGIONAL DE RECURSOS LÍTICOS EN LA CUENCA DEL RÍO ATUEL}

La base regional de recursos líticos comprende la información vinculada con la distribución, disponibilidad, accesibilidad y abundancia de las materias primas dentro de una determinada región (véase Capítulo 4). Esta información es crucial para entender los procesos que intervienen en la configuración de la estructura regional de recursos líticos, que incluye el aprovisionamiento, utilización e intercambio de materias primas líticas (Ericson 1984).

En este capítulo se caracteriza la base regional de recursos líticos de la cuenca del río Atuel mediante tres líneas diferentes. Primero, a través de la descripción de las características geológicas y litológicas propias de la cuenca, lo que permite definir de modo estimado la distribución y localización de las fuentes potenciales de aprovisionamiento de materias primas. Segundo, por medio del análisis geoquímico de nódulos y artefactos de obsidiana procedentes de fuentes y sitios arqueológicos de la región. Tercero, desde la realización de relevamientos y muestreos -sistemáticos y asistemáticos- de rocas, considerando la información geológica y arqueológica previa. A través de esto es posible establecer la disponibilidad, calidad, abundancia relativa, variabilidad, accesibilidad, previsibilidad, productividad y los modos en que entraron en circulación las materias primas aptas para la talla (Torrence 1989b; Nelson 1991). Sin esa información no es posible comprender las estrategias para la explotación y utilización de recursos líticos en el pasado (Franco y Aragón 2004; Ambrústolo 2011, entre otros).

El conjunto de datos obtenidos y su contrastación con los resultados del análisis del registro lítico de la cuenca del río Atuel (véase Capítulos 7, 8 y 9), permiten definir la estructura regional de recursos líticos (sensu Ericson 1984). 


\subsection{GEOLOGÍA Y LITOLOGÍA REGIONAL}

La construcción de la base regional de recursos líticos requiere de un conocimiento preciso de la geología y litología del área como paso necesario para localizar y determinar las fuentes potenciales de aprovisionamiento lítico en los distintos ambientes (cordillera, piedemonte y planicie).

El análisis de la bibliografía y cartografía geológica permitió dividir la cuenca del Atuel en tres sectores: cordillera, correspondiente a la Cordillera Principal (relieve positivo) y vinculada al Desierto Altoandino; piedemonte, asociado a la Depresión de los Huarpes (relieve negativo) y al Bloque de San Rafael (relieve positivo), principalmente, relacionados al Desierto Patagónico; y la Planicie oriental (relieve negativo), también llamada Llanura Sanrafaelina o Depresión Pedemontana (Sepúlveda et al. 2000), asociada al Desierto de Monte (Figura 6.1).

\subsubsection{CORDILLERA}

A partir de la información obtenida de la Hoja Geológica 27b "Cerro Sosneado" (Volkheimer 1978), correspondiente al área cordillerana y confeccionada con mayor resolución que la de Sruoga et al. 2005 (Figura 6.1.A), se determinó la localización de recursos líticos potencialmente utilizados como depósitos aluviales, coluviales y morenas de la última glaciación.

En el área cordillerana, los recursos líticos están distribuidos en distintos sectores de la cuenca superior del río Atuel (Volkheimer 1978). Al norte del río, entre los arroyos Malo y Blanco (Figura 6.2), se distinguen dos zonas con fuentes primarias y secundarias diferentes de materias primas (Pérez Winter 2008). En algunos afloramientos predominan sedimentitas de origen marino (Mesozoico), principalmente areniscas, conglomerados y lutitas. Esta litología se prolonga hacia el norte, en la zona superior de ambos arroyos. En la zona del $\mathrm{A}^{\circ}$ Malo, predominan limolitas y lutitas. Los sedimentos más gruesos (areniscas y conglomerados) se hallan hacia el este, en el sector de la desembocadura del $\mathrm{A}^{\mathrm{o}}$ Blanco. En este área también se pueden encontrar afloramientos dispersos de andesita y toba. Las "Andesitas Molle" (Oligoceno superior) se localizan en pequeños cuerpos intrusivos y diques que perforan las areniscas liásicas (Jurásico inferior) al oeste y noroeste del codo del arroyo Blanco. 


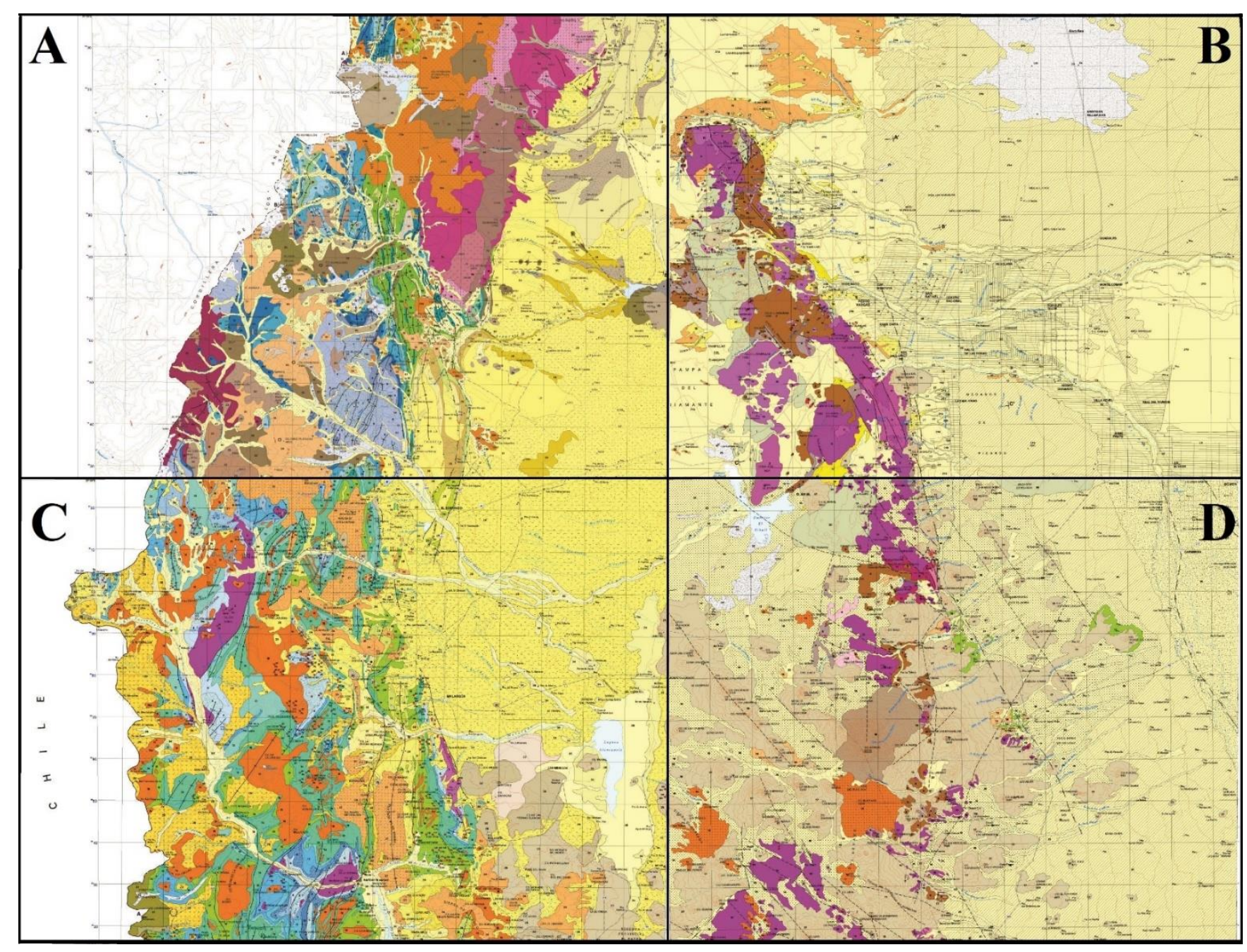

Figura 6.1. Hojas geológicas integradas de escala 1:250.000, que incluyen toda la cuenca del río Atuel. A- Hoja Geológica 3569-I, "Volcán Maipo" (Sruoga et al. 2005); B- Hoja Geológica 3569 II “San Rafael” (Sepúlveda et al. 2000); C- Hoja Geológica 3569-III/3572-IV “Malargüe” (Nullo et al. 2005); D- Hoja Geológica 3569 IV "El Nihuil” (Sepúlveda et al. 1999). Referencias en el ANEXO 1. 
Al sur del río Atuel, también se hallan Andesitas Molle en el cuerpo intrusivo del cerro Chivato (2436 m) y en los diques y filones capa ubicados al oeste y sureste del cerro. Allí también aparece un pórfiro diorítico de aspecto gris blanquecino y la Formación Tordillo (Jurásico) compuesta, entre otras rocas, por areniscas que están frecuentemente silicificadas (Volkheimer 1978: 45). El cerro Chivato se encuentra al sureste de tres de los sitios arqueológicos analizados en esta tesis: Arroyo Panchino 1 (AP-1), Arroyo Panchino 2 (AP-2) y Cueva Palulo 1 (CP-1) (Figura 6.2).

Los tres sitios arqueológicos mencionados se emplazan sobre la Formación Coyocho ("Basalto II", sensu Groeber 1946-1947) (Pleistoceno inferior) con predominio de rocas efusivas como andesita, basandesita y basalto, acompañadas por erupciones de tobas, brechas ígneas, aglomerados volcánicos y vulcanitas. Estas rocas afloran en los cerros Sosneado (al noroeste de los sitios y del río Atuel) y Risco Plateado (al oeste, fuera de la Hoja 27b).

Las cabeceras de varios de los cursos de agua permanente de esta región, poseen afloramientos de tobas y basaltos, de difícil acceso. El río Atuel y sus tributarios (e.g. arroyo Malo), aportan una gran variedad de materias primas provenientes de las áreas más alejadas e inaccesibles, conformando fuentes secundarias de potencial aprovisionamiento lítico. Los depósitos morrénicos distribuidos a lo largo del cauce del Atuel y de tributarios como los arroyos Malo (en su margen izquierda) y Las Ánimas (sobre su margen derecha) (Figura 6.2), contienen rocas de distintos tipos, que también constituyen fuentes secundarias.

Los estudios arqueológicos realizados por Pérez Winter $(2008,2010)$ sobre los recursos líticos del área de El Sosneado, permitieron caracterizar las concentraciones de materia prima en el arroyo Malo (cerca del sitio Arroyo Malo 3 -AMA 3), al noroeste de los sitios AP-1, AP-2 y CP-1. Estas concentraciones incluyen guijarros de distintos tamaños y de variadas rocas como dioritas, distintos basaltos (de grano muy fino y con presencia/ausencia de olivino) y areniscas. 


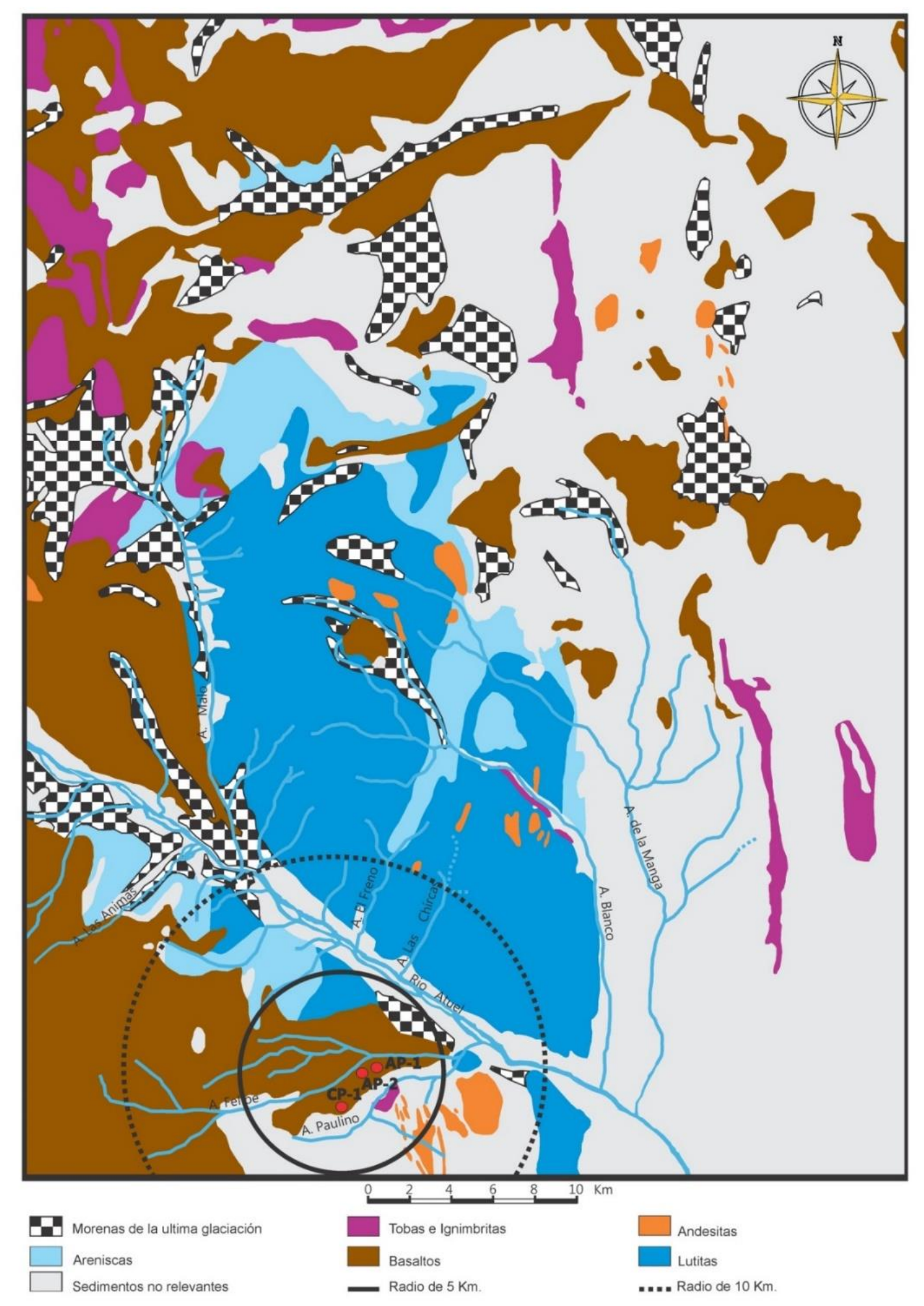

Figura 6.2. Detalle y ampliación de la Hoja Geológica 27b, Cerro Sosneado (escala 1: 200.000) modificada de Pérez Winter (2008: 85). Aquí se muestra la localización de los sitios Arroyo Panchino 1 y 2 (AP-1 y AP-2) y Cueva Palulo 1 (CP-1), correspondientes al Desierto Altoandino. 
En los alrededores del sitio AMA 3, hay abundante materia prima, con predominio de basaltos y andesitas de calidad para la talla variable aunque, en general, buena (Pérez Winter 2008). En los muestreos realizados por Pérez Winter (2008) frente a la laguna El Sosneado, se registró abundancia de rocas de buena calidad para la talla, como basaltos de grano fino, andesitas y plutonitas. A menos de $5 \mathrm{~km}$ de AMA 3 (disponibilidad inmediata, sensu Civalero y Franco 2003) se registraron tobas, ignimbritas, andesitas, basaltos, areniscas, limolitas, dioritas y dacitas. A una escala local, entre 5 y $40 \mathrm{~km}$ del sitio (Civalero y Franco 2003), se identificaron basaltos, areniscas, lutitas, andesitas, basandesitas, brechas, tobas, vulcanitas, riolitas e ignimbritas. Según Pérez Winter (2008), las únicas rocas no locales registradas en AMA 3 corresponden a obsidianas y, presumiblemente, a un basalto negro de grano fino. Este último podría provenir de las coladas basálticas del Área Laguna de la Niña Encantada (unos $25 \mathrm{~km}$ al sur de los sitios de cordillera considerados en esta tesis) donde aparece en bloques de entre 15 y más de $50 \mathrm{~cm}$, con una textura similar (Pérez Winter 2008).

\subsubsection{PIEDEMONTE}

En el área del río Salado (afluente del Atuel), confluyen varias formaciones geológicas que alcanzan los depósitos aluviales -pertenecientes al Holoceno- por donde discurre el río: Coyocho inferior-Pleistoceno- (integrada por basaltos olivínicos y, en menor cantidad, brechas basálticas); Agrio -Cretácico inferior- (comprende la porción terminal del Grupo Mendoza, la cual contiene, entre otras, clastos de rocas volcánicas de composición andesítica y basáltica (Nullo et al. 2005).

En la Hoja Geológica 3569-III/3572-IV “Malargüe” (Nullo et al. 2005) (Figura 6.1.C), se detallan formaciones con diversos tipos de rocas, aunque en el área del Atuel predominan las rocas sedimentarias y son escasas las volcánicas, más adecuadas para su explotación. Se destacan: los Depósitos de la llanura pedemontana, formados principalmente durante el Pleistoceno, que comprenden arenas, limos y arcillas; los Depósitos del Primer Nivel de Agradación (transición Mioceno-Plioceno) que incluyen conglomerados y areniscas; los Depósitos morrénicos (Holoceno), conformados por bloques, gravas, arenas; la Formación Chapúa (Pleistoceno), integrada por basaltos olivínicos, al igual que la Formación Coyocho Superior (transición PliocenoPleistoceno).

En el sector más oriental del piedemonte, en la región del Embalse El Nihuil se reconocen distintos subgrupos y depósitos de rocas, descriptos en la Hoja Geológica 
3569-IV "El Nihuil” (Sepúlveda et al. 1999) (Figura 6.1.D). Allí se observa que en el lago artificial y al oeste del mismo, el río Atuel atraviesa Depósitos aluviales pedemontanos (conformados por aglomerados, arenas y limos), sobre depósitos aluviales encausados (constituidos también por arenas y limos, además de gravas) y cerca de Depósitos salitrosos de playa (arenas finas y sedimentos pelíticos salitrosos). Luego sigue su curso al noroeste del embalse por el llamado "Cañón del Atuel”, en el Bloque de San Rafael y conformado, principalmente, por el Grupo Cochicó (volcanitas, hipabisales y sedimentitas) (volcanismo del Choiyoi) y el Grupo Chapúa (basaltos, tobas y aglomerados volcánicos de composición basáltica).

Las distintas rocas volcánicas habrían estado disponibles como recurso en afloramientos rocosos y como guijarros retransportados por el cauce del río Atuel: los nódulos y guijarros habrían sido transportados a través y depositados en terrazas fluviales y llanura de inundación, constituyendo potenciales fuentes secundarias de aprovisionamiento. A saber (Sepúlveda et al. 1999):

- Depósitos Aluviales Pedemontanos: esta unidad abarca una gran parte de la superficie de la Hoja, dividiéndose al este y al oeste de la sierra del Nevado. Al oeste se distribuye principalmente en el sector septentrional (noroeste de la Hoja 3569-IV) y, en menor medida, también está presente en el sector meridional (suroeste de la Hoja). Al este de la sierra, esta unidad se encuentra controlada por la falla del Nevado en una faja de $c a .30 \mathrm{~km}$ de ancho por $70 \mathrm{~km}$ de largo de rumbo noroeste-sureste, en la que emergen algunos conos basálticos del Grupo Chapúa (véase más adelante). En la parte proximal de los depósitos se encuentran los sedimentos más gruesos (aglomerados polimícticos con clastos provenientes de las serranías del Bloque de San Rafael y del cerro Nevado); y en las partes distales se hallan arenas y limos. El ambiente de depositación es continental aluvial; el escurrimiento superficial en manto es el principal movilizador del material. Su antigüedad no es mayor al Pleistoceno superior y se presenta cubriendo a casi todas las unidades pre-cuaternarias.

- Depósitos aluviales encausados: esta unidad está integrada por las terrazas aluviales que bordean los cauces secos del sistema de drenaje de la sierra del Nevado. Está conformada por aglomerados, gravas, arenas polimícticas y limos. El ambiente de depositación es continental aluvial. Los depósitos se apoyan en partes sobre la mayoría de las unidades anteriores, a las que disectan. Se considera que estos depósitos se han generado durante todo el Holoceno y posiblemente en el Pleistoceno superior. 
- Depósitos Salitrosos de Playas: unidad que se halla principalmente en el sector NO de la Hoja, y al noroeste, oeste y sur del embalse El Nihuil. No se describe aquí dado que no contiene información litológica relevante para la tesis.

- Grupo Cochicó: es parte del volcanismo del Choiyoi. Si bien aflora en varios lugares (véase Figura 6.1.B y D), acá se destaca su presencia a ambos lados del Cañón del Atuel, aguas abajo del Embalse El Nihuil. Su litología y edad se detallan en la Sección 6.1.3.

- Subgrupo Cerro Carrizalito: se compone de volcanitas ácidas a mesosilícicas e hipabisales. Entre las primeras existen brechas ignimbritas, lavas y tobas de composición riolítica. Entre las rocas hipabisales hay pórfidos graníticos, dioríticos y granodioríticos con secuelas aplíticas, en algunos casos con diferenciaciones pegmatoides. El ambiente de emplazamiento de estas rocas es considerado continental y en algunas zonas marcan distintos estadios de la evolución magmática de aparatos volcánicos. Este subgrupo es parte del Grupo de la Sierra Pintada y se incluye en la sección superior del magmatismo Pérmico-Triásico del Bloque de San Rafael (Llambías et al. 1993 citado en Sepúlveda et al. 1999).

- Grupo Chapúa: esta formación constituye la mayor parte del Campo Basáltico Llancanelo (Bermúdez et al. 1993). Se trata de rocas extrusivas como coladas y lapillitas, e intrusivas como brechas de conducto y diques, de composición predominantemente basáltica alcalina. Su ubicación temporal corresponde a la transición entre el Plioceno superior (Neógeno) y Pleistoceno inferior (Cuaternario).

Sobre la base de la información geológica del piedemonte fue posible localizar las principales áreas con recursos líticos potencialmente explotados. Los grupos que ocuparon las zonas geológicas de Malargüe y El Nihuil habrían aprovechado las rocas volcánicas disponibles en afloramientos, llanuras de inundación y bancos de la cuenca del río Atuel, entre otras, volcanitas, andesitas y basaltos.

\subsubsection{PLANICIE}

En la porción del río Atuel que se ubica entre, aproximadamente, los 67³0 y 68 ${ }^{\circ} 5^{\prime}$ de LO, se distinguen en la Hoja Geológica 3569-II “San Rafael” (Sepúlveda et al. 2000) (Figura 6.1.B), varios depósitos de rocas y sedimentos. A saber:

- Médanos y Mantos de arena: formados por arenas y limos que no han sido definidos formalmente como unidad litoestratigráfica, pero cubren un amplio sector 
dividido por Sepúlveda et al. (2000) en tres áreas geográficas: Médanos de la Travesía, Médanos de Nacuñán y Médanos de Picardo. Estos últimos, que se extienden al sur del río Atuel, constituyen un campo arenoso vegetado e inactivo de unos $600 \mathrm{~km}^{2}$ con alturas de hasta 40 m. Los Médanos de Picardo apoyan sobre la Formación Villa Atuel (González Díaz 1972); de acuerdo con Krömer (1996) son correlacionables con la Formación Puerta Negra (Ramonell et al. 1992) y su edad sería Holoceno tardío. "En la parte superior se han encontrado restos arqueológicos con cerámica que podrían llegar a tener una edad máxima de hasta 2.000 años AP (Lagiglia, com. pers.)" (Sepúlveda et al. 2000: 51).

- Sedimentos de planicies de derrame, playas y salinas: constituidos por sedimentos finos, salinos, de limos, arcillas y sales haloides. La zona de interés en la que aparecen estos depósitos es la de las salinas del Diamante, donde constituye el nivel de base de la red de drenaje y que no ha sido capturada por la red de avenamiento de los ríos Atuel y Diamante.

- Sedimentos fluviales encauzados: conformados por gravas, arenas y limos. Constituyen las planicies de inundación de la red de drenaje actual, principalmente de los ríos Diamante y Atuel. No se dispone de dataciones absolutas para el inicio de la formación de estas planicies, aunque es probable que corresponda a los últimos 2.000 años.

- Formación La Horqueta (marino): constituida por metacuarcitas, filitas y esquistos en facies de esquistos verdes, con participación de filonitas originadas por metamorfísmo dinámico. Se ubica temporalmente dentro del Paleozoico, aproximadamente entre el Ordovícico y el Silúrico.

- Gabro Loma Alta: alcanza la orilla norte del Embalse El Nihuil. Litológicamente, en esta unidad participan rocas de distinta composición que han sufrido fuerte metamorfismo dinámico: gabros y diabasas porfídicas, gabros cataclasados, cataclasitas, milonitas y espilitas. Su cronología correspondería al Ordovícico inferior-medio.

- Formación Río Seco de los Castaños (marino): comprende areniscas, limolitas, lutitas, grauvacas, ortocuarcitas, areniscas conglomerádicas y escasos conglomerados. Estas rocas afloran exclusivamente en el valle del río Atuel, aguas abajo del dique Valle Grande, con una extensión aproximada de $3 \mathrm{~km}$ de largo por unos $600 \mathrm{~m}$ de ancho, en una franja de rumbo aproximado noroeste-sureste. En partes se encuentran atravesados por vetas de cuarzo y calcita. El ambiente de depositación es marino, probablemente de plataforma (las rocas presentan marcas de ondulitas). Esta formación se corresponde temporalmente con el Devónico. 
- Formación El Imperial: No se describe dado que su litología no es importante para esta tesis.

- Grupo Cochicó: es parte del volcanismo del Choiyoi, conformado por el Grupo Cerro Carrizalito que, a su vez, incluye a la Formación Quebrada del Pimiento (Cingolani 2017). El Grupo Cochicó está compuesto por rocas piroclásticas, volcanitas, hipabisales de composición mesosilícica (entre ellas, ignimbritas dacíticas y riolíticas de tonos morados a violáceos) y sedimentitas de ambientes fluvial y eólico. En la zona del Bloque de San Rafael sus afloramientos alcanzan el Valle Grande al este del Cañón del Atuel. Estratigráficamente se apoya en fuerte discordancia angular sobre la Formación El Imperial y está cubierto discordantemente por las vulcanitas pérmico-triásicas del Grupo Cerro Carrizalito. La edad corresponde al Pérmico inferior (Sepúlveda et al. 1999, 2000).

- Grupo Choiyoi: incluye volcanitas e intrusivos de composición ácida y básica a mesosilíceos, y tiene amplia difusión en el Bloque de San Rafael. Se caracteriza por la acidificación hacia los términos más jóvenes que permite diferenciar una sección inferior dacítica-andesítica (Formación Agua de los Burros), de otra superior que representaría un volcanismo de tendencia bimodal: una entidad de composición predominantemente basáltica (Formación Quebrada del Pimiento) y otra de composición riolítica (Formación Choique Mahuida) (Salvarredi 1996). Predomina la facies basáltica sobre la riolítica en la base de la sección. Cronológicamente se encuentra entre el Pérmico (Paleozoico) y el Triásico inferior (Mesozoico).

- Grupo El Portillo: compuesto por intrusivos granodioríticos y riolíticos. Es un conjunto intrusivo hipabisal a plutónico, de naturaleza silícea, con estrecha relación genética con las volcanitas del Grupo Choiyoi. Su edad aproximada corresponde al Triásico inferior.

- Formación Puesto Viejo: compuesta por conglomerados, areniscas, pelitas, ignimbritas de composición ácida y coladas y diques de composición básica. Está vinculada al sector oriental del Bloque de San Rafael y compuesta por una serie de sedimentitas continentales de distinta granulometría, entre las que se intercalan filones capas, diques y mantos de rocas de composición básica y mantos de tobas e ignimbritas de composición ácida. El ambiente de depositación de la unidad es básicamente continental de abanicos aluviales. Data del Triásico inferior.

- Formación Aisol (continental): consiste en areniscas, limolitas, arcilitas y tobas. Los afloramientos atribuidos a esta unidad no son muy abundantes. En su composición mineralógica suele aparecer vidrio volcánico, restos de diatomeas y material cinerítico. 
El principal es el de la localidad tipo, al sur del cañón del Atuel, en inmediaciones del cerro El Nihuil al suroeste de la Hoja (lindando con la Hoja "El Nihuil", antes descripta), bordea al cerro Aisol, es atravesada por el río seco de La Frazada y, al este, alcanza el dique del Valle Grande. Se ubica temporalmente dentro del Mioceno (Neógeno).

- Formación Río Seco del Zapallo: está compuesta por conglomerados, areniscas, limolitas, arcilitas y tobas, con participación de rodados de rocas ígneas, metamórficas y sedimentarias de la Cordillera. Entre las areniscas se intercalan algunos lentes o bancos de arcilla muy cinerítica y yesífera o limos de colores rojizos. También, se identifican sedimentitas de granos más finos, como limolitas y arcilitas. El rasgo ambiental característico de esta formación es que se trata de depósitos continentales de planicie aluvial, en los que se ha registrado la presencia de cuerpos lagunares y la participación de sedimentos piroclásticos. Temporalmente, se ubica en el Plioceno inferior.

- Grupo Chapúa: conformado por coladas piroclásticas y aglomerados volcánicos de composición basáltica. Su área de distribución principal comprende los cerros Negro y Guadalito. También se halla al suroeste de la elevación pedemontana (o serranía) y al sur del río Atuel, asociado a los cerros Aisol y El Nihuil. Posee una edad que varía entre el Plioceno superior (Neógeno) y el Pleistoceno inferior (Cuaternario).

- Formación Villa Atuel: comprende paquetes de depósitos eólicos con bancos intercalados con depósitos fluviales de arenas y limos loesoides. Pertenecen a esta formación sucesiones de conglomerados sin base expuesta, integrados mayormente por clastos subangulosos de basaltos, procedentes del cercano cerro Negro y que se encuentran cubiertos por limos arenosos macizos de origen eólico. Esta formación corresponde temporalmente al Holoceno.

Entre las entidades que componen el Grupo Choiyoi y el Grupo El Portillo se encuentran: facies volcánicas brechosas e hipabisales; diques y coladas basálticas de la Formación Quebrada del Pimiento; coladas riolíticas, con mantos de vitrófiros y depósitos de manantiales termales silíceos; ignimbritas cristalinas de la Formación Choique Mahuida (separando a los paquetes ignimbríticos se observan intercalaciones de coladas riolíticas, brechas de borde de foso y megabloques deslizados); coladas de lavas basálticas, intercaladas entre los ciclos ignimbríticos superiores, y diques basálticos, ocupando probables fracturas de foso de la caldera, de la Formación Quebrada del Pimiento; pórfidos graníticos y riodacíticos, tal vez también dacíticos, con grandes fenocristales de feldespato potásico; pórfidos riolíticos claros y gris claros; diques basálticos de la Formación Quebrada del Pimiento; vetas de silexita que cruzan 
transversal y radialmente a la caldera y que junto a la silicificación en las proximidades del borde representarían fases hidrotermales finales del Grupo El Portillo (Sepúlveda et al. 2000: 27).

La llamada "Industria de lascas de Los Coroneles" por Lagiglia (1968, 1974, 1977a, 1981) hace referencia a "un complejo de lascas atípicas, con planos de percusión preparados, ángulos de fractura suplementarios (...) logrado a percusión. No existen en ninguna de las fases de la industria trabajos de retoques por presión..." (Lagiglia 1977a: 78). Estas lascas han sido trabajadas sobre basaltos procedentes de la Formación Colonia Los Coroneles, descripta por Sepúlveda et al. (2000) en la Hoja 3569-II (“San Rafael”). Estos autores consideran que dicha unidad está constituida por depósitos fluviales conglomerádicos con cementación calcárea, compuesta por rodados polimícticos de rocas de la Cordillera Principal y Cordillera Frontal. "La superficie exhibe bloques, particularmente de basaltos, con "barniz del desierto" y material arqueológico (núcleos y lascas) en especial elaborado a partir de estas rocas volcánicas" (Sepúlveda et al. 2000: 47). El área tipo de la Formación Colonia Los Coroneles, se ubica en las inmediaciones de la Colonia 25 de Mayo, en ambas márgenes del río Diamante. Los afloramientos conforman elevaciones mesetiformes que altimétricamente descienden hacia el este.

\subsubsection{ALGUNAS CONSIDERACIONES ACERCA DE LA GEOMORFOLOGÍA} Y LITOLOGÍA DEL RÍO ATUEL

A lo largo del Atuel existen distintos depósitos, formaciones y grupos de origen volcánico que habrían aportado recursos líticos aptos para la talla, tales como: basaltos, andesitas, vulcanitas y riolitas, entre otras. Esto condice con el registro lítico de sitios residenciales y logísticos del área en los que se habrían aprovechado rocas volcánicas (de calidad buena a excelente) para la manufactura de instrumentos. Las fuentes de obsidiana de calidad predominantemente excelente, se detallan en la última sección.

En la Figura 6.3 están representadas las principales fuentes de materias primas que, según información arqueológica previa (Lagiglia 1977a; Gil 2006; Pérez Winter 2008; Bonnat 2009; Barberena et al. 2011; Giesso et al. 2011a; Garvey 2012; Salgán 2013), han sido utilizadas en el pasado, a nivel regional y supra-regional; y en la Figura 6.4 las fuentes localizadas en la cuenca del río Atuel. 


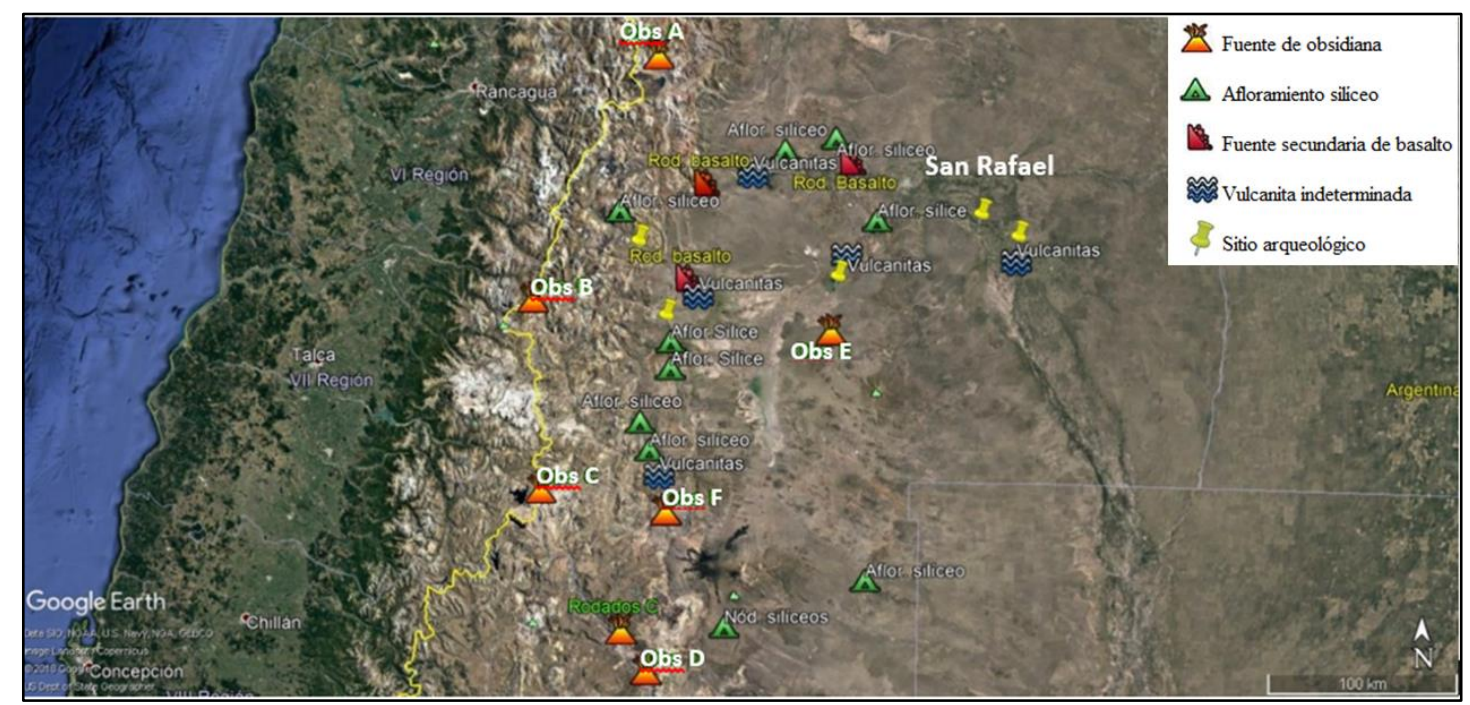

Figura 6.3. Fuentes de materias primas líticas en el sur de Mendoza y regiones aledañas. Fuentes de obsidiana: Obs A- Laguna del Diamante-Paramillos; Obs B-fuente Las Cargas; Obs CLaguna del Maule-Laguna Negra; Obs D- Cerro Huenul; Obs E- El Peceño; Obs F-Coche Quemado.

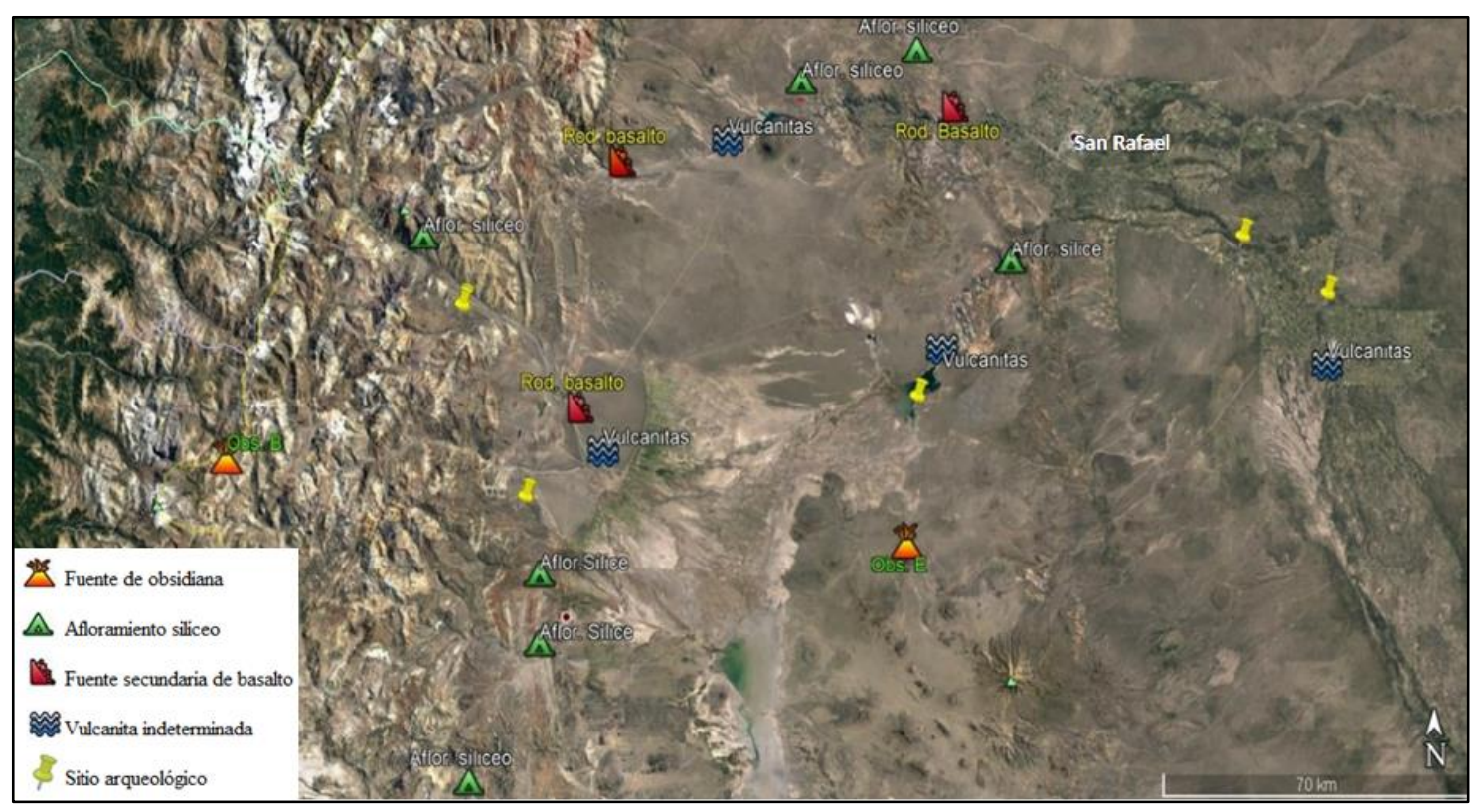

Figura 6.4. Detalle de las fuentes de materias primas localizadas en la región bajo estudio.

\subsection{RELEVAMIENTO Y MUESTREOS DE MATERIAS PRIMAS LÍTICAS}

La abundancia y variabilidad de las fuentes potenciales de materias primas, son variables necesarias para evaluar los costos de búsqueda y aprovisionamiento de rocas en 
el pasado (Haury 1995; Franco y Borrero 1999). Por ese motivo se seleccionaron distintas porciones de espacio a cubrir en los tres ambientes considerados (Figura 6.5), se realizó un reconocimiento previo -en el campo- de las rocas disponibles en cada sector a registrar, utilizando piqueta, y se realizaron relevamientos y muestreos de las fuentes de aprovisionamiento siguiendo la propuesta metodológica de Franco y Borrero (1999):

- Se seleccionaron las áreas de muestreo considerando la información geológica disponible (véase sección anterior).

- Se estableció un tiempo de búsqueda de diez minutos para el recorrido de las áreas de muestreo.

- En este tiempo se registraron las materias primas de mejor calidad para la talla y las más frecuentes entre las de calidad regular o mala, utilizando planillas específicas consignadas para este propósito. Las variables registradas fueron: tipo de materia prima, calidad para la talla, tamaño (diámetro mayor) y forma en la que se presenta (guijarros achatados, rodados, etc.) (véase Tabla 6.1).

- Se seleccionaron muestras para analizar en el laboratorio (excepto las de calidad mala o regular).

-Se tomó la posición con GPS, se registró el tipo de fuente y se efectuó un registro fotográfico.

A través de esta metodología se buscó entender la relación entre el tiempo de búsqueda de la materia prima y los resultados obtenidos, evaluando el rendimiento de las fuentes y los factores vinculados con el costo-beneficio de su búsqueda, aprovisionamiento y procesamiento (Franco y Borrero 1999; Charlin 2007). 


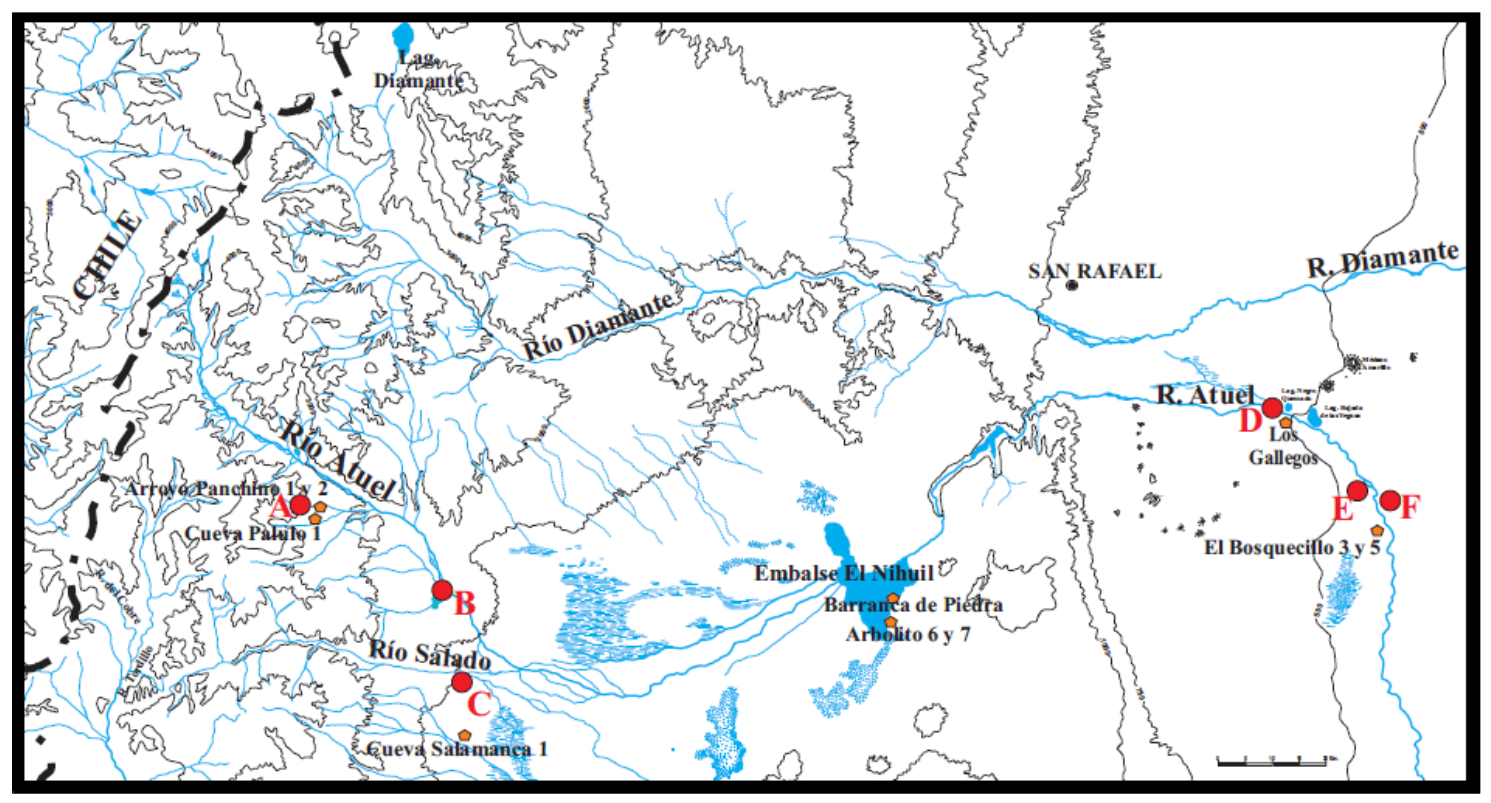

Figura 6.5. Localización de los muestreos de materias primas y de los sitios arqueológicos en la cuenca del río Atuel. Referencias: A- Muestreo asistemático en la cuenca superior; B- Muestreo sistemático en la cuenca media; C- Muestreo sistemático en el río Salado; D- Muestreo asistemático en la localidad arqueológica La Guevarina; E- Muestreo asistemático en las cercanías al sitio Jaime Prats; F- Muestreo asistemático en la localidad arqueológica La Olla.

\subsubsection{MUESTREOS EN EL RÍO ATUEL}

\subsubsection{Muestreos sistemáticos y asistemáticos en la cuenca superior}

En la cuenca superior del río Atuel se prospectó el área del puesto "Los Arroyos", donde los arroyos Felipe y Paulino desembocan en el Atuel. Aguas arriba, el arroyo Felipe corre próximo a los sitios Arroyo Panchino 1 (AP-1) y Arroyo Panchino 2 (AP-2); y el arroyo Paulino, lo hace próximo a Cueva Palulo 1 (CP-1).

A mayor altitud (2277 msnm), en las inmediaciones al sitio AP-1 (Figura 6.2), también se realizó una prospección para definir el área a muestrear. Como la superficie está mayormente cubierta por vegetación, se buscaron rocas en el lecho del arroyo Felipe. Las muestras obtenidas corresponden a andesitas y vulcanitas indeterminadas de mala a muy mala calidad para la talla, y basaltos de calidad regular a mala. Luego se prospectó un sector alto de la cuenca superior del río Atuel, a unos 2400 msnm (Figura 6.6), con las mismas clases de roca.

Pese a que en la información arqueológica previa del área se menciona la disponibilidad local de rocas de buena a muy buena calidad (Pérez Winter 2008), estas no fueron identificadas en los muestreos realizados. Debido a esto, la región cordillerana 
no se presenta en la Tabla 6.1 ya que no se tomaron muestras para analizar en el laboratorio.

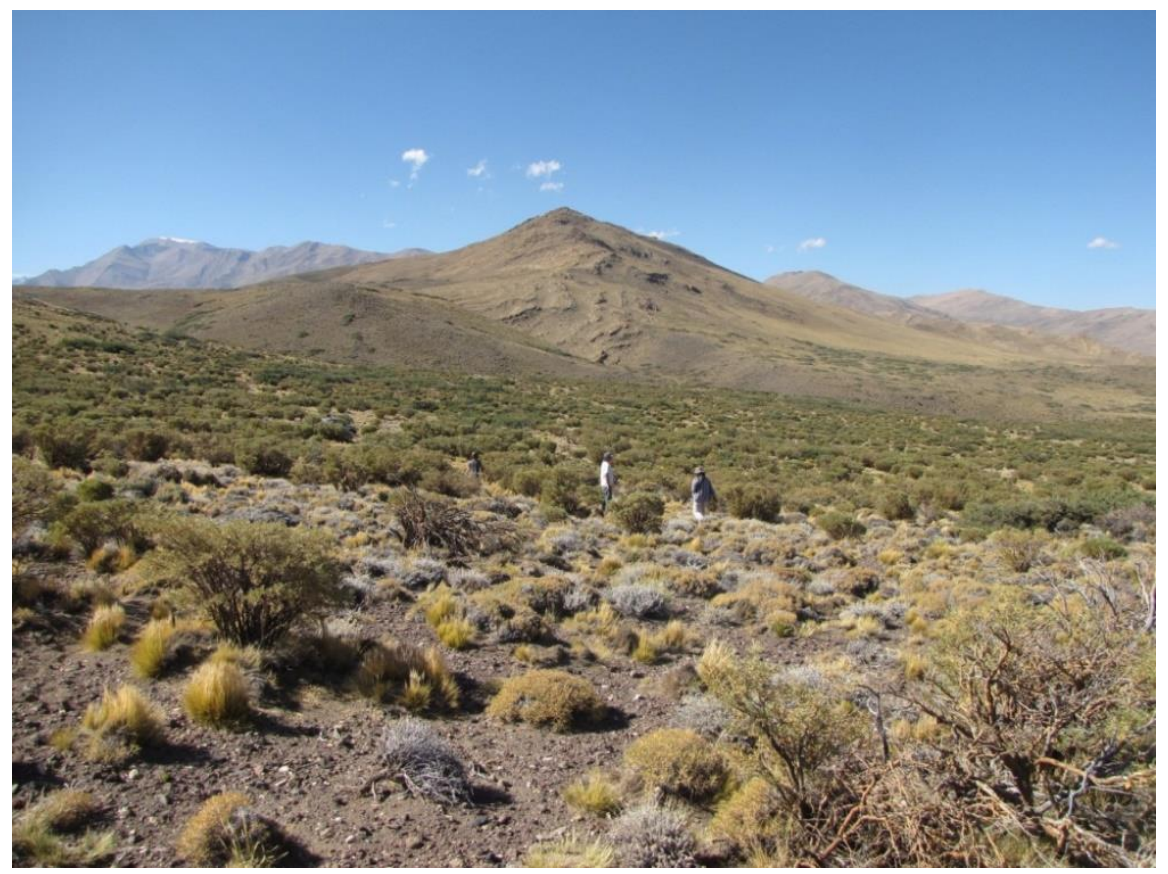

Figura 6.6. Prospección de la cuenca superior del río Atuel, próximo a los sitios AP-1, AP-2 y CP-1.

Próximo al arroyo Paulino (Figura 6.2), también se realizó una prospección previa al muestro (345 $6^{\prime} 45^{\prime \prime} \mathrm{LS}-6^{\circ} 50^{\prime} 54^{\prime \prime} \mathrm{LO}$, a $2318 \mathrm{msnm}$ ) (Figura 6.5.A) y aquí también la vegetación dificultó la identificación de rocas (Figura 6.7). Allí sí se recolectaron algunas muestras del lecho del arroyo para analizarlas en el laboratorio y comparar con las muestras arqueológicas de CP-1, AP-1 y AP-2. 


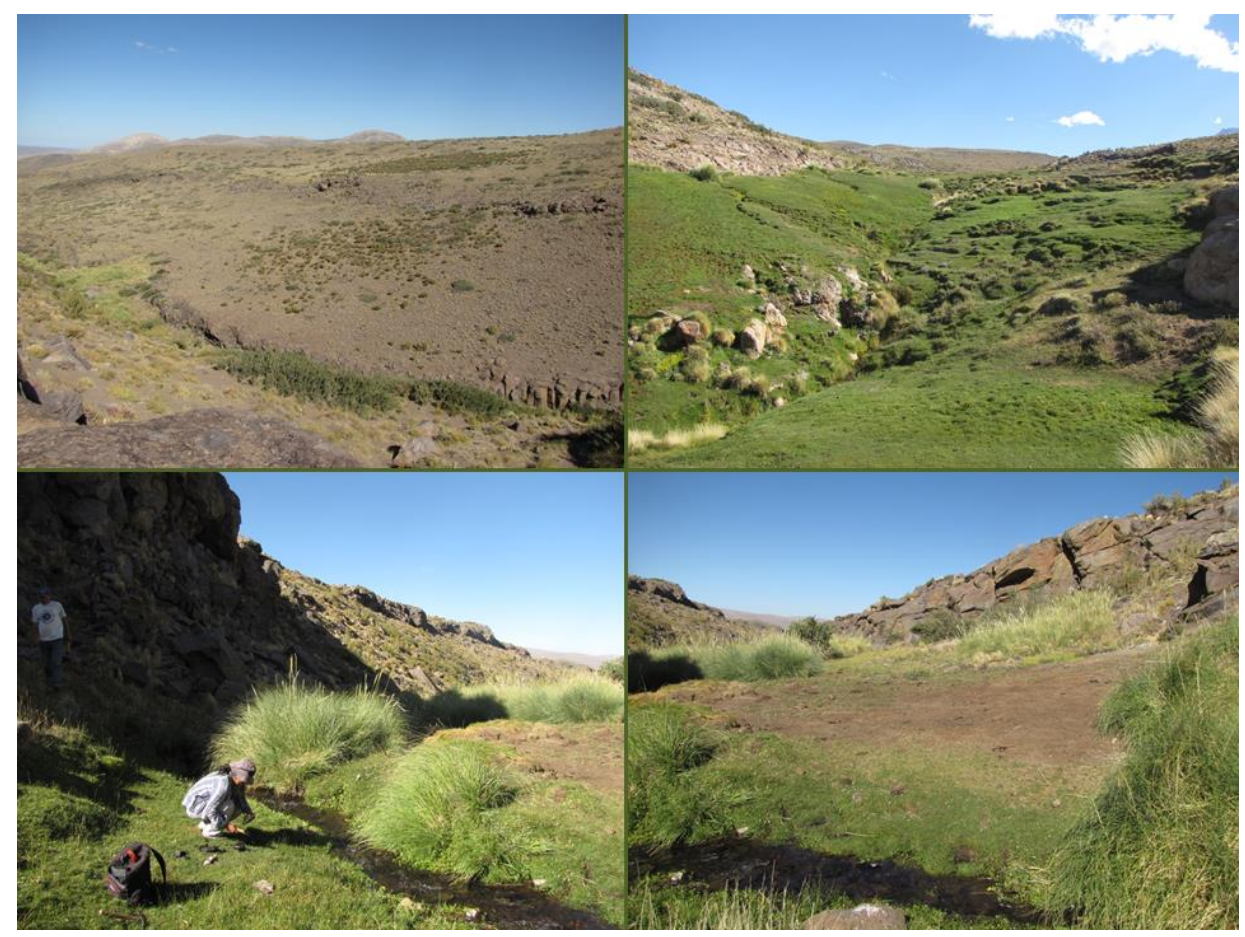

Figura 6.7. Prospección asistemática de la cuenca superior del río Atuel, a orillas del arroyo Paulino, en las inmediaciones del sitio CP-1.

\subsubsection{Muestreos sistemáticos y asistemáticos en la cuenca media}

En la cuenca media se realizaron muestreos y relevamientos en el río Atuel propiamente dicho (Figuras 6.5.B, 6.8 y 6.9) y en uno de sus tributarios, el Salado (Figuras 6.5.C, 6.10 y 6.11).

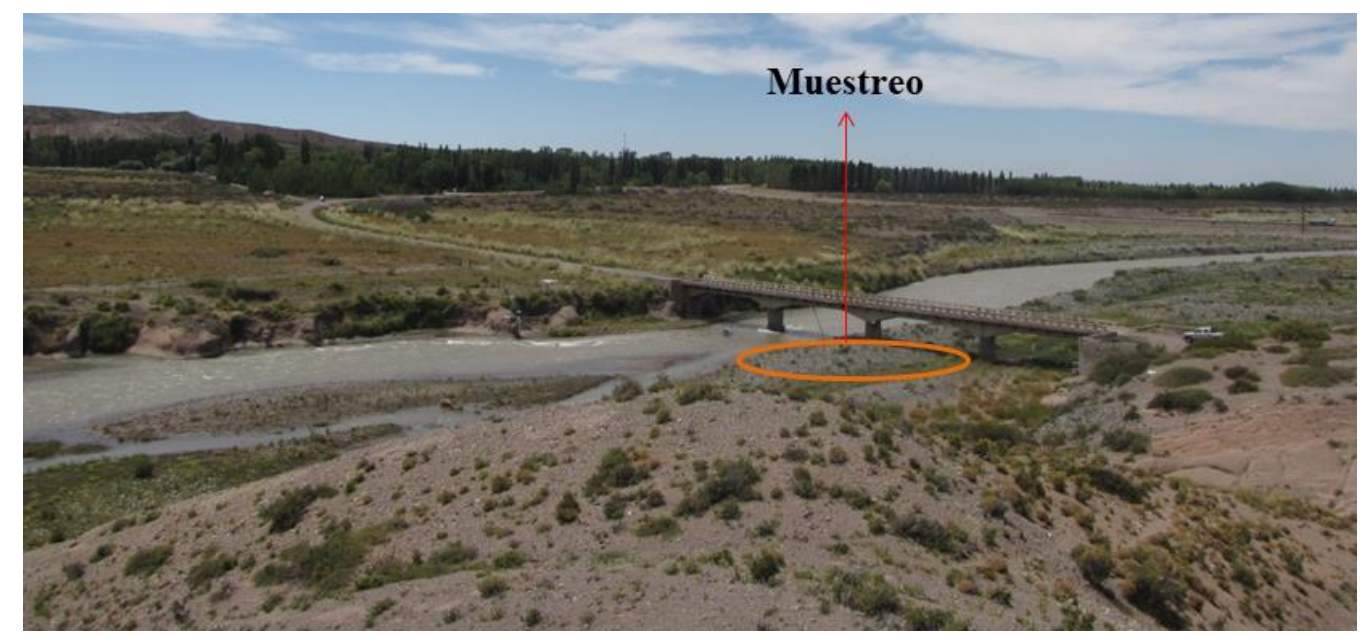

Figura 6.8. Localización del área de muestreo realizado en la cuenca media del río Atuel. Imagen tomada mirando hacia el noreste. 


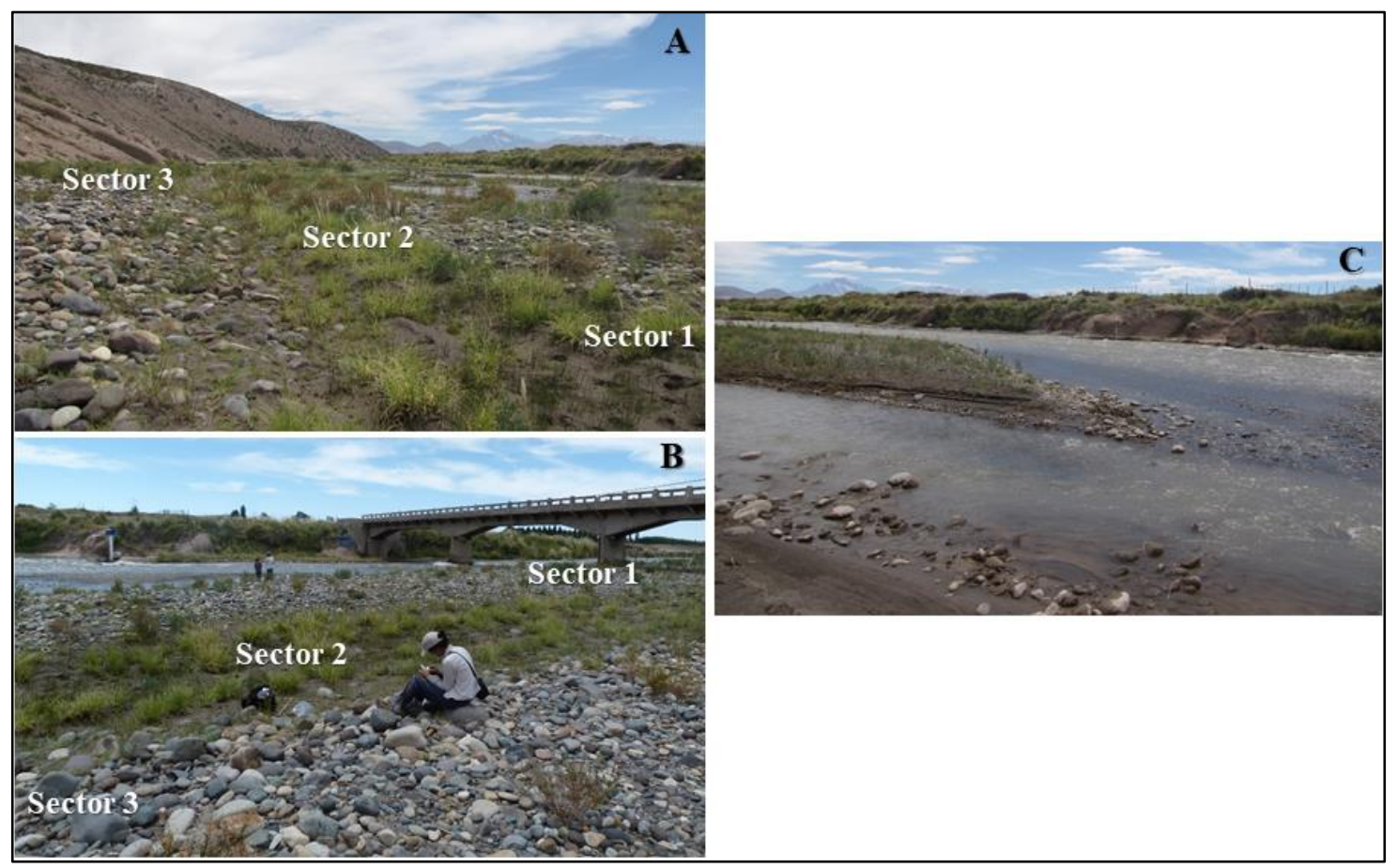

Figura 6.9. Muestreo por sectores realizado en la cuenca media del río Atuel. A- Vista del río hacia el oeste con detalle de los sectores muestreados; al fondo se observa el cerro El Sosneado; B- Vista del río hacia el norte con detalle de las rocas disponibles en el Sector 3; al fondo, dos de los recolectores probando rocas del lecho del río; C- Detalle del transporte de rocas por el río.

El área de muestreo correspondiente al Atuel se localiza a orillas del río $\left(35^{\circ} 5^{\prime} 0,67^{\prime \prime} \mathrm{LS}-69^{\circ} 36^{\prime} 14,01^{\prime \prime} \mathrm{LO}\right)$, en las inmediaciones del puente viejo El Sosneado de la Ruta 40 (Figuras 6.5.B, 6.8 y 6.9). En el muestreo asistemático se registró basalto de calidad buena a muy buena. Para el muestreo sistemático, el lugar fue dividido en tres sectores (orientados noreste-sudoeste), cada uno muestreado durante diez minutos por una persona. El Sector 1 se localizó al noreste, el Sector 2 en el medio, y el Sector 3, al suroeste (Figura 6.5.B). Los tres sectores se recorrieron en sentido este-oeste abarcando $50 \mathrm{~m}$ cada uno, aproximadamente; entre cada recolector, la separación fue de unos $15 \mathrm{~m}$. La única materia prima de calidad buena o superior, registrada en los tres sectores, fue el basalto; en el sector 2 también se registró andesita (Tabla 6.1). En los tres sectores, la cuarcita es la roca más frecuente entre las de calidad regular/mala.

\subsection{Muestreos sistemáticos y asistemáticos en el río Salado}

Los muestreos sistemáticos se realizaron siguiendo la misma metodología que la mencionada para el río Atuel. Los tres sectores muestreados (Sectores 1, 2 y 3) se realizaron al lado del río, a pocos metros del puente de la actual Ruta 40. La posición 
$\left(35^{\circ} 13^{\prime} 09,8^{\prime \prime} \mathrm{LS}-69^{\circ} 39^{\prime} 41,3^{\prime \prime} \mathrm{LO}\right)$ se tomó en el centro del área de muestreo, en el Sector 2, a 1573 msnm (Figuras 6.5.C, 6.10 y 6.11). En los tres sectores la dirección del recorrido fue suroeste-noreste, cubriendo alrededor de $50 \mathrm{~m}$; y entre cada recolector, la separación fue de unos $20 \mathrm{~m}$. En los tres muestreos sistemáticos y en el asistemático se reconocieron basaltos (de calidad predominantemente buena) y dacitas (de calidad regular-buena); algunas muestras fueron recolectadas para su análisis (Tabla 6.1). Entre las rocas de calidad regular o mala más frecuentes se reconocieron andesitas y riolitas.

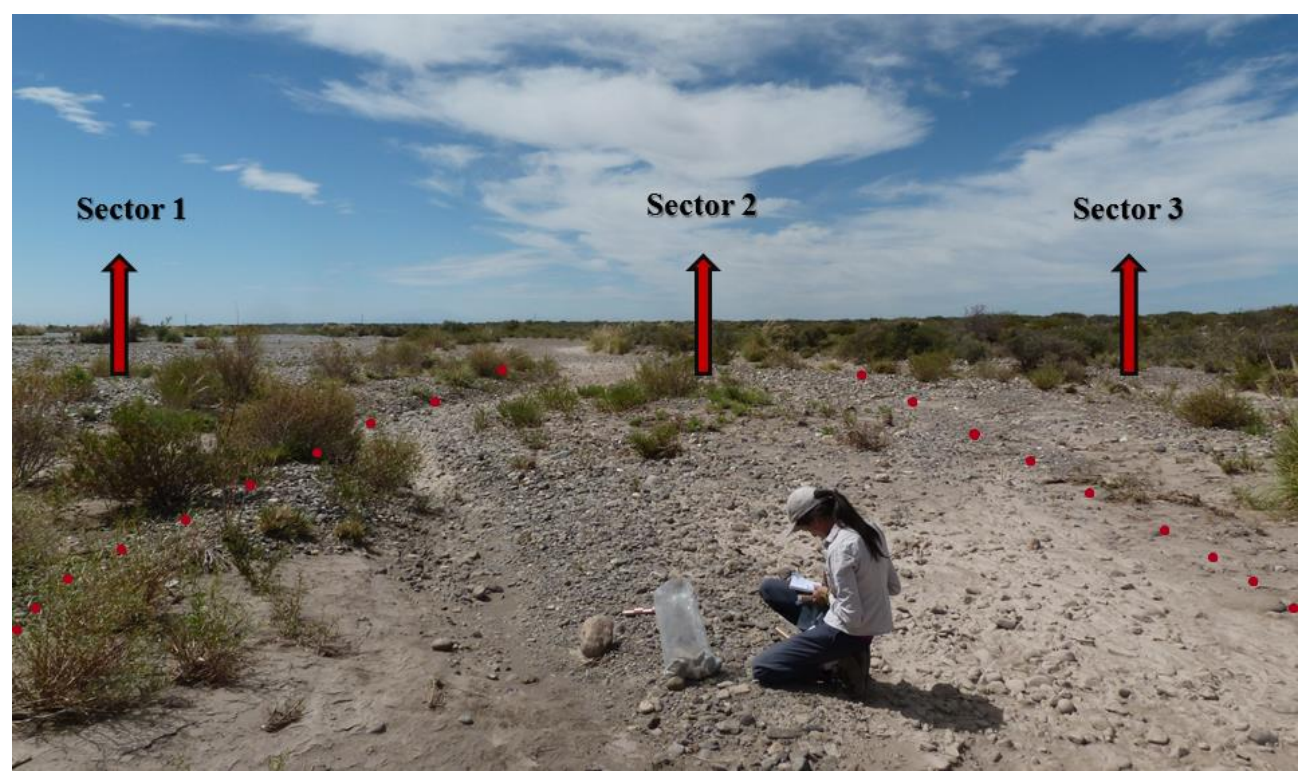

Figura 6.10. Muestreo en el río Salado mostrando los tres sectores de recolección. Imagen tomada mirando hacia el este.

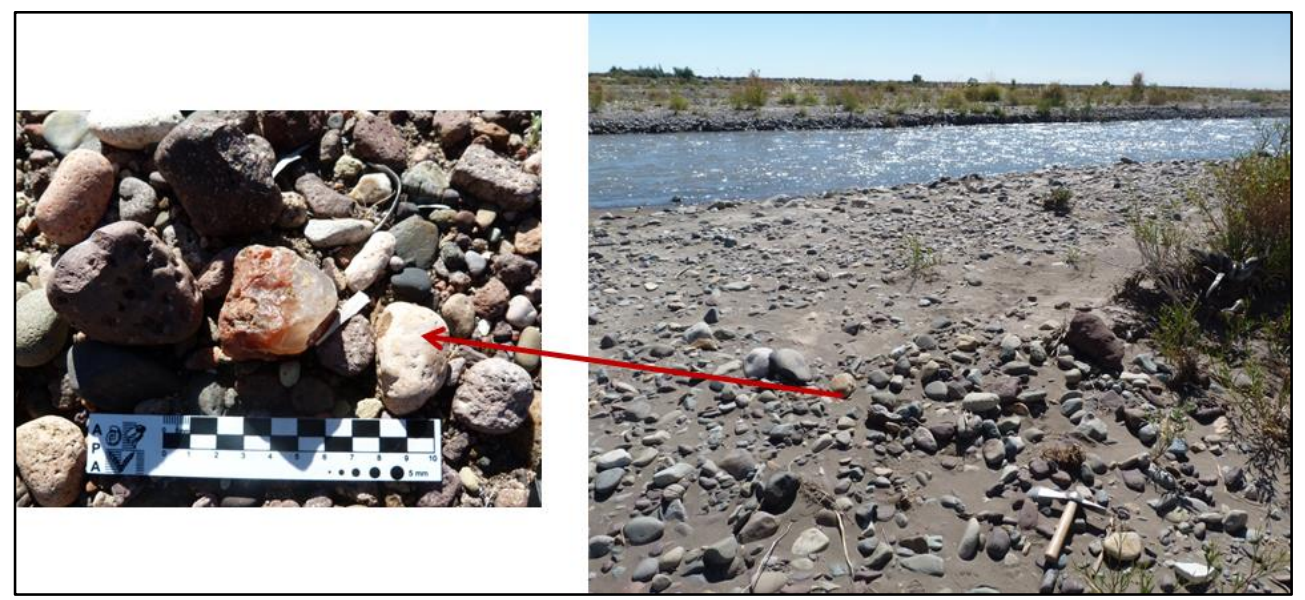

Figura 6.11. Sector 1 y detalle de las rocas registradas en el muestreo realizado en el río Salado, tributario del río Atuel. 


\subsubsection{Muestreos sistemáticos en la cuenca inferior}

En la cuenca inferior del río Atuel se realizaron muestreos asistemáticos debido al encauzamiento antrópico actual del río (Figura 6.12 y 6.13). Se tomaron muestras de tres localidades en el recorrido desde la ciudad de San Rafael hacia General Alvear por la RN 143 (Figura 6.5.D, E y F). Estos están próximos a los sitios arqueológicos del Desierto de Monte analizados en esta tesis (LG-1, EB-3 y EB-5; véase Capítulo 9). Cerca de la localidad de La Guevarina se registraron materias primas de calidad buena a muy buena, principalmente, silíceas, vulcanitas indeterminadas, basaltos, riolitas, porfídicas y cuarzos, aunque estas últimas, generalmente de calidad regular $\left(34^{\circ} 46^{\prime} 45,2^{\prime \prime} \mathrm{LS}\right.$ $\left.68^{\circ} 01^{\prime} 32,3^{\prime \prime} \mathrm{LO} ; 548 \mathrm{msnm}\right)$. En las cercanías de la localidad de Jaime Prats se reconocieron cuarzos, porfídicas y riolitas, entre otras de calidad buena y regular-buena

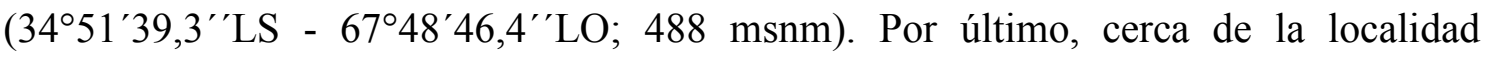

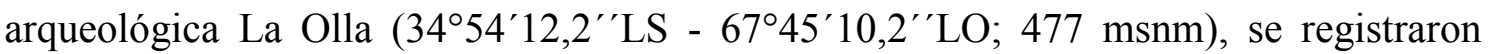
basaltos y riolitas, principalmente, de calidad buena y regular-buena; y las más frecuentes entre las de calidad regular o mala fueron los cuarzos y cuarcitas.

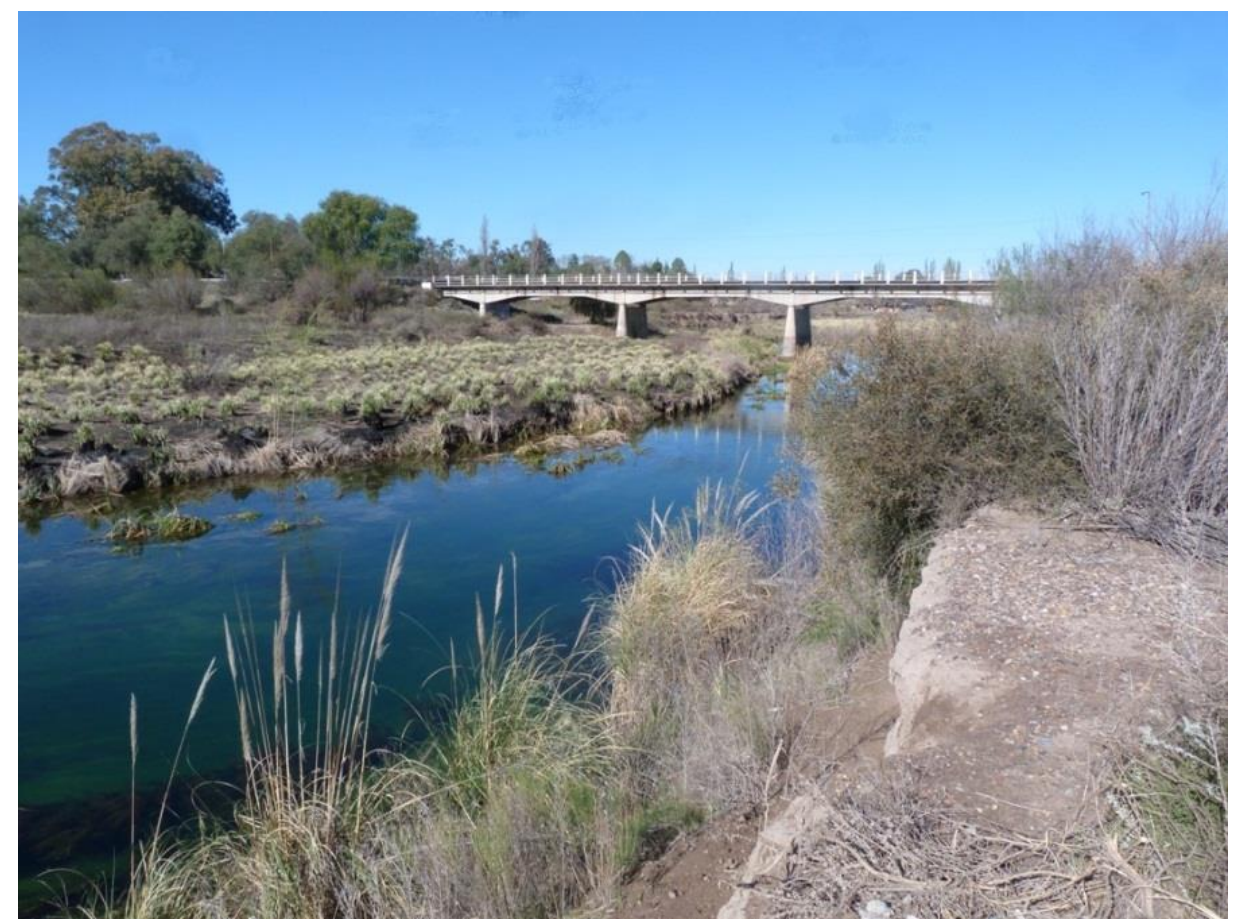

Figura 6.12. Cuenca inferior del río Atuel en el área del sitio La Guevarina. Al fondo, puente de la RN 143. 


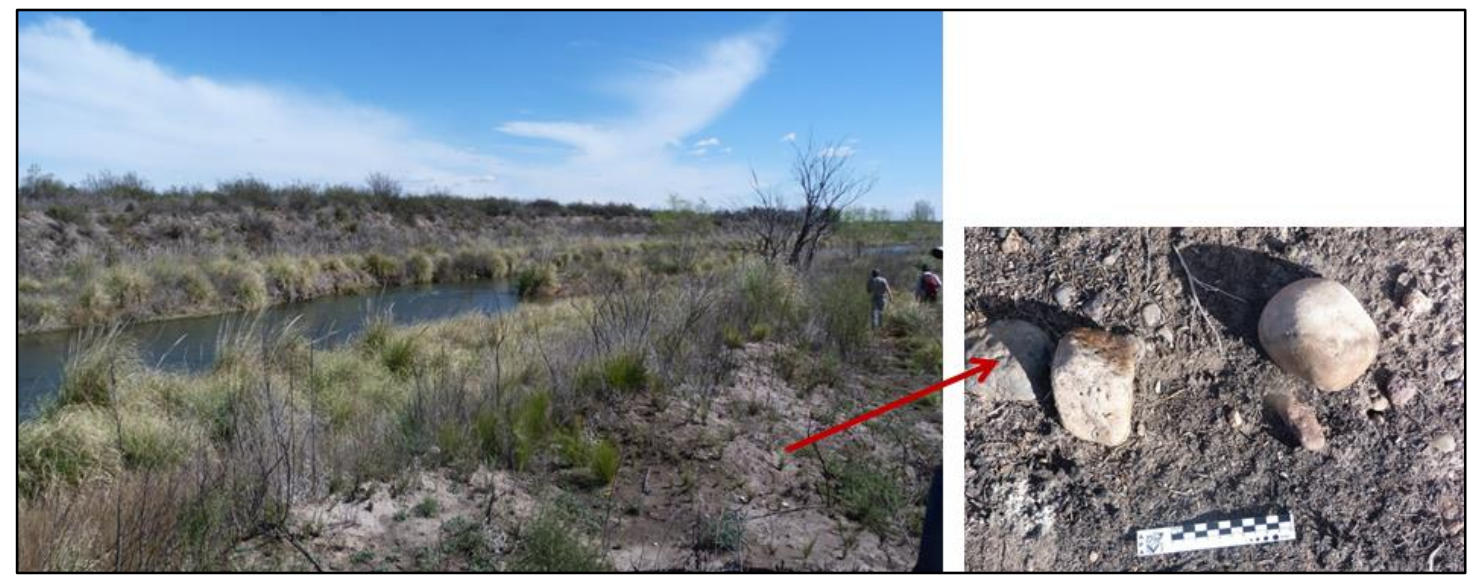

Figura 6.13. Cuenca inferior del río Atuel en el área del sitio Jaime Prats con detalle de las rocas registradas, distribuidas de manera aislada.

\subsubsection{SÍNTESIS DE LOS MUESTREOS EN LA CUENCA DEL ATUEL}

En la Tabla 6.1 se presentan las materias primas registradas en los muestreos realizados en el piedemonte y en la planicie; las rocas registradas en la región de cordillera no se incorporaron ya que, como se dijo antes, presentan calidad mala y regular, y sólo se determinó cuáles son las más frecuentes entre ellas (Sección 6.2.1.1.).El diámetro máximo de las muestras se asignó utilizando la grilla de tamaños con intervalos de $5 \mathrm{~mm}$ de lado (sensu Franco 2002b).

\begin{tabular}{|c|c|c|c|c|c|c|c|}
\hline Región & Localidad & Muestreo & $\begin{array}{c}\text { Materia } \\
\text { prima }\end{array}$ & $n$ & Calidad & $\begin{array}{c}\text { Tamaño } \\
(\mathbf{m m})\end{array}$ & Forma \\
\hline \multirow{16}{*}{ 莺 } & \multirow{16}{*}{$\begin{array}{l}\text { Cuenca } \\
\text { media del } \\
\text { río Atuel }\end{array}$} & \multirow{3}{*}{\begin{tabular}{|c} 
Atuel \\
Sistemático \\
Sector 1
\end{tabular}} & \multirow{3}{*}{ Basalto } & & Buena & 95 & Rodado achatado \\
\hline & & & & & Buena & 60 & Rodado achatado \\
\hline & & & & & Buena & 50 & Rodado achatado \\
\hline & & \multirow{4}{*}{$\begin{array}{c}\text { Atuel } \\
\text { Sistemático } \\
\text { Sector } 2\end{array}$} & Andesita & 1 & Reg.-Buena & 140 & Rodado achatado \\
\hline & & & \multirow{3}{*}{ Basalto } & \multirow{3}{*}{3} & Reg.-Buena & 270 & Rodado achatado \\
\hline & & & & & Buena & 105 & Rodado achatado \\
\hline & & & & & Reg.-Buena & 70 & Rodado achatado \\
\hline & & \multirow{3}{*}{$\begin{array}{c}\text { Atuel } \\
\text { Sistemático } \\
\text { Sector } 3\end{array}$} & \multirow{3}{*}{ Basalto } & \multirow{3}{*}{3} & Reg.-Buena & 110 & Rodado achatado \\
\hline & & & & & Buena & 120 & Rodado achatado \\
\hline & & & & & Buena & 60 & Rodado achatado \\
\hline & & \multirow{6}{*}{ 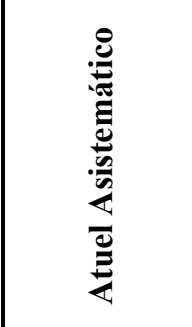 } & \multirow{6}{*}{ Basalto } & \multirow{6}{*}{9} & Buena & 115 & Rodado achatado \\
\hline & & & & & Reg.-Buena & 70 & Rodado achatado \\
\hline & & & & & Reg.-Buena & 90 & Rodado achatado \\
\hline & & & & & Buena & 95 & Rodado achatado \\
\hline & & & & & Buena & 55 & Rodado achatado \\
\hline & & & & & Buena & 50 & Rodado achatado \\
\hline
\end{tabular}




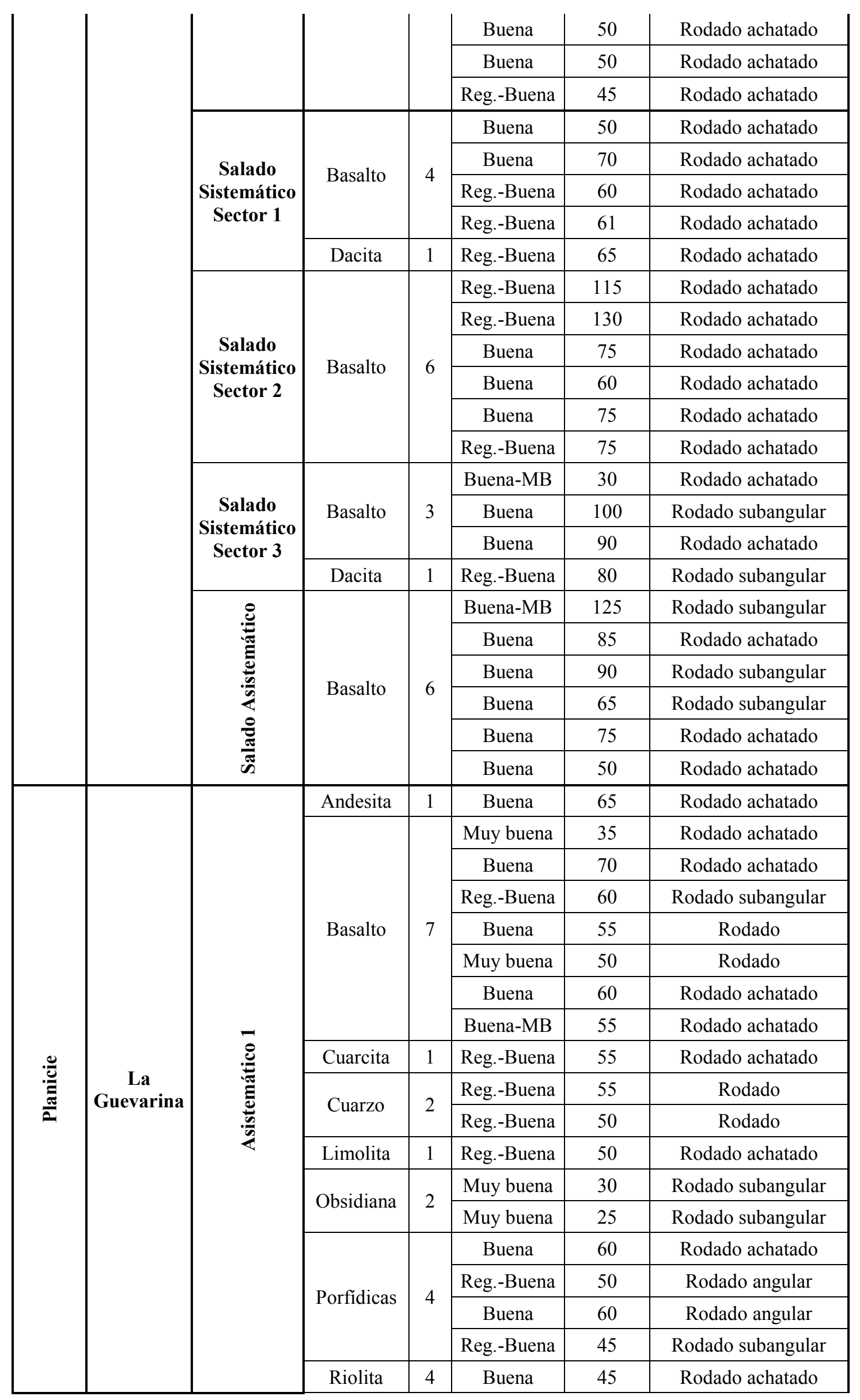




\begin{tabular}{|c|c|c|c|c|c|c|}
\hline & & & & Buena & 75 & Rodado achatado \\
\hline & & & & Buena & 60 & Rodado \\
\hline & & & & Reg.-Buena & 55 & Rodado subangular \\
\hline & & & & Buena & 60 & Rodado subangular \\
\hline & & & & Buena & 45 & Rodado achatado \\
\hline & & Silíceas & 5 & Buena-MB & 40 & Rodado subangular \\
\hline & & & & Reg.-Buena & 35 & Rodado achatado \\
\hline & & & & Buena-MB & 40 & Rodado achatado \\
\hline & & Vulcanitas & & Buena & 60 & Rodado achatado \\
\hline & & indetermi- & 3 & Buena & 45 & Rodado \\
\hline & & & & Buena & 50 & Rodado achatado \\
\hline & & Basalto & 2 & Bueno-MB & 10 & Rodado oblongo \\
\hline & & Dasarte & 2 & Muy buena & 60 & Rodado achatado \\
\hline & 8 & Cuarzo & 1 & Buena & 60 & Rodado oblongo \\
\hline & 苞 & $\begin{array}{l}\text { Pórfido } \\
\text { riolítico }\end{array}$ & 1 & Buena & 70 & Rodado achatado \\
\hline & $\frac{2}{2}$ & Vulcanitas & & Reg.-Buena & 65 & Rodado subangular \\
\hline & & indetermi- & 3 & Reg.-Buena & 60 & Rodado \\
\hline & & & & Buena & 50 & Rodado achatado \\
\hline & & Basalt & 2 & Buena & 60 & Rodado oblongo \\
\hline & 3 & Dasaltu & 2 & Buena & 150 & Rodado \\
\hline & 尖 & Cuarzo & 1 & Reg.-Buena & 50 & Rodado \\
\hline & $\bar{\Xi}$ & Porfídica & 1 & Reg.-Buena & 60 & Rodado achatado \\
\hline & $\frac{2}{4}$ & $\begin{array}{c}\begin{array}{c}\text { Vulcanita } \\
\text { indetermi- } \\
\text { nada }\end{array} \\
\end{array}$ & 1 & Buena & 25 & Rodado achatado \\
\hline & & Basalto & 2 & Muy buena & 50 & Rodado achatado \\
\hline & & & & Muy buena & 60 & Rodado achatado \\
\hline & & Riolita & 1 & Reg.-Buena & 60 & Rodado achatado \\
\hline & & Silíceas & 1 & Reg.-Buena & 50 & Rodado achatado \\
\hline & & & & Buena & 55 & Rodado angular \\
\hline & & & & Reg.-Buena & 55 & Rodado angular \\
\hline & $\stackrel{+}{8}$ & $\begin{array}{l}\text { Vulcanitas } \\
\text { indetermi- }\end{array}$ & & Buena & 60 & Rodado achatado \\
\hline & : & $\begin{array}{c}\text { nadas } \\
\text { (c/textura }\end{array}$ & 6 & Buena & 70 & Rodado achatado ang. \\
\hline & $\frac{5}{3}$ & porfídica) & & Reg.-Buena & 50 & Rodado achatado \\
\hline & & & & Buena & 55 & Rodado achatado ang. \\
\hline & & & & Buena & 55 & Rodado achatado \\
\hline & & $\begin{array}{l}\text { Vulcanitas } \\
\text { indetermi- }\end{array}$ & 4 & Reg.-Buena & 60 & Rodado achatado ang. \\
\hline & & grano fino) & & Buena & 60 & Rodado achatado \\
\hline & & & & Buena & 55 & Rodado achatado \\
\hline Jaime & $\stackrel{8}{=}$ & Curno & 2 & Reg.-Buena & 25 & Rodado achatado \\
\hline Prats & & Cuarao & 2 & Reg.-Buena & 25 & Rodado achatado \\
\hline
\end{tabular}




\begin{tabular}{|c|c|c|c|c|c|c|}
\hline & & \multirow{5}{*}{ Porfídicas } & \multirow{5}{*}{5} & Reg.-Buena & 55 & Rodado achatado \\
\hline & & & & Reg.-Buena & 45 & Rodado achatado \\
\hline & & & & Reg.-Buena & 35 & Rodado achatado \\
\hline & & & & Reg.-Buena & 35 & Rodado subangular \\
\hline & & & & Buena & 35 & Rodado achatado \\
\hline & & Vulcanitas & & Reg.-Buena & 45 & Rodado subangular \\
\hline & & $\begin{array}{l}\text { 1ndeterm1- } \\
\text { nadas }\end{array}$ & 2 & Buena & 30 & Rodado \\
\hline & \multirow{7}{*}{ 苞 } & Basalto & 1 & Buena & 55 & Rodado \\
\hline & & \multirow{3}{*}{ Cuarzo } & \multirow{3}{*}{3} & Buena & 45 & Rodado achatado \\
\hline & & & & Buena & 35 & Rodado achatado \\
\hline & & & & Reg.-Buena & 25 & Rodado subangular \\
\hline & & Porfídica & 1 & Reg.-Buena & 55 & Rodado achatado \\
\hline & & \multirow{2}{*}{ Riolita } & \multirow{2}{*}{2} & Buena & 50 & Rodado achatado \\
\hline & & & & Reg.-Buena & 55 & Rodado achatado \\
\hline \multirow{9}{*}{ La Olla } & \multirow{9}{*}{ 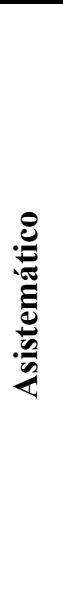 } & Arenisca & 1 & Buena & 55 & Rodado achatado \\
\hline & & \multirow{3}{*}{ Basalto } & \multirow{3}{*}{3} & Buena & 60 & Rodado achatado \\
\hline & & & & Reg.-Buena & 45 & Rodado subangular \\
\hline & & & & Buena & 45 & Rodado achatado \\
\hline & & $\begin{array}{c}\text { Plutónica } \\
\text { ultramáfica } \\
\end{array}$ & 1 & Reg.-Buena & 70 & Rodado achatado \\
\hline & & \multirow{3}{*}{ Riolita } & \multirow{3}{*}{3} & Reg.-Buena & 65 & Rodado achatado \\
\hline & & & & Reg.-Buena & 50 & Rodado achatado \\
\hline & & & & Buena & 40 & Rodado achatado \\
\hline & & $\begin{array}{c}\text { Vulcanita } \\
\text { indetermi- } \\
\text { nada }\end{array}$ & 1 & Reg.-Buena & 45 & Rodado achatado \\
\hline
\end{tabular}

Tabla 6.1. Calidades, tamaños ( $\mathrm{mm}$ de lado) y formas de las materias primas registradas durante los muestreos sistemáticos y asistemáticos realizados en la cuenca del río Atuel, por región y localidad.

En la región del piedemonte (incluye al Bloque de San Rafael; cuenca media del río Atuel) abundan los basaltos de calidades variadas entre regular-buena y muy buena (basalto de grano fino) y predomina la buena calidad. Su distribución en el área del Atuel es dispersa y más abundante que la del resto de las rocas registradas allí. Además, en los muestreos sistemáticos sobre el Atuel se detectó andesita y, sobre el Salado, dacita; aunque en este último río también se registraron andesitas; estas son de calidad mala y regular. A esta porción de la cuenca del Atuel, próxima a la desembocadura del Salado, se puede acceder en cualquier estación del año, y allí se dispone de rodados, generalmente achatados, y de tamaños diversos. 
En la región de la planicie (Planicie Oriental en la cuenca inferior del Atuel) se registró mayor variedad de materias primas que en la cuenca media, y las formas y tamaños también presentan mayores diferencias. La distribución de las rocas también varía entre dispersa y concentrada. En los muestreos asistemáticos realizados en la cuenca inferior no se registraron andesita y dacita; pero sí se reconoció gran variedad de vulcanitas indeterminadas, cuarzos, silíceas, cuarcíticas, limolitas, porfídicas y pórfiros riolíticos, plutónicas, granitoides e incluso una arenisca, todas de calidades variables, entre regular y buena. La mejor calidad se da entre el basalto de muy buena calidad para la talla, también presente en los muestreos de la cuenca media del Atuel. Esta mayor variedad de materias primas en la planicie, estaría vinculada a la localización del Bloque de San Rafael al oeste, que estaría aportando mayor variedad de materias primas hacia el este a través del río Atuel, entre ellas, rocas silíceas de buena y muy buena calidad para la talla.

En los muestreos realizados en la cuenca superior del Atuel no se registraron rocas de calidad buena o superior; pero, según la información previa tanto arqueológica (Pérez Winter 2008; Bonnat 2009) como geológica (Volkheimer 1978; Sruoga et al. 2005), se sabe que en el área donde se realizaron las prospecciones y muestreos asistemáticos (Figura 6.5.A), están disponibles materias primas útiles para la talla, entre otras: andesitas, dacitas, algunas riolitas y gran variedad de basaltos de calidad buena a muy buena, como el procedente de la Formación Coyocho (Volkheimer 1978) o el basalto negro de grano fino de la fuente primaria del Área Laguna de la Niña Encantada (Pérez Winter 2008).

\subsection{FUENTES DE OBSIDIANA}

Las características de la estructura química de la obsidiana permiten utilizarla como un indicador sensible de procedencia (Glascock 1998; Shackley 2005) y, por lo tanto, para evaluar -a partir de su distribución espacial- los rangos de acción y los procesos de interacción entre las poblaciones humanas (Renfrew 1977; Meltzer 1989; Beck et al. 2002; Jones et al. 2003, 2012). En el sur de Mendoza y centro de la provincia de Neuquén los estudios composicionales de esta roca han permitido caracterizar geoquímicamente siete fuentes de obsidiana (Seelenfreud et al. 1996; Durán et al. 2004; Bellelli et al. 2006; De Francesco et al. 2006; López et al. 2009; Giesso et al. 2011 a y b; Barberena et al. 2011; Cortegoso et al. 2012; Salgán et al. 2015; Salgán y Pompei 2017). 
En Neuquén se registraron dos fuentes de obsidiana, ambas en el área extracordillerana: Cerro Huenul, al norte, y La Bandera-Portada Covunco, en el centro de la provincia (Durán et al. 2004; Bellelli et al. 2006; López et al. 2009; Barberena et al. 2011; Giesso et al. 2011a y b). En el sur de Mendoza se detectaron cinco fuentes, tres en la cordillera andina (Laguna El Diamante, Las Cargas y Laguna del Maule) y dos en sectores extra-cordilleranos (E1 Peceño y Coche Quemado) (Seelenfreud et al. 1996; Durán et al. 2004; Barberena et al. 2011; Giesso et al. 2011a; Cortegoso et al. 2012; Salgán et al. 2015; Salgán y Pompei 2017, entre otros). Los trabajos realizados hasta el momento mostraron, en general, diferencias geoquímicas entre las distintas canteras, salvo en Las Cargas, que guarda similitudes con la fuente de Laguna del Diamante-Paramillos (De Francesco et al. 2006; Giesso et al. 2011a) y Coche Quemado (Salgán et al. 2017).

A continuación se resumen las características principales de cada fuente.

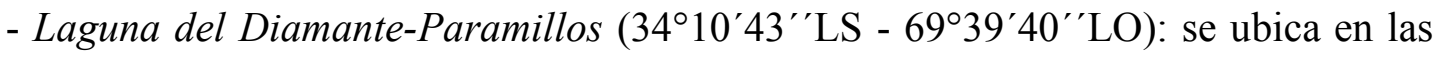
nacientes del río homónimo, en la Cordillera del Límite a 3400 msnm. Está emplazada en una enorme caldera volcánica de $20 \mathrm{~km}$ por $16 \mathrm{~km}$ y $700 \mathrm{~m}$ de profundidad. Sobre los depósitos de material piroclástico se descubrieron algunas concentraciones de bloques de obsidiana de tamaños diversos (en general, no mayores a $10 \mathrm{~cm}$ ). La dispersión de estas obsidianas es amplia, abarcando las tierras altas del cuadrante noreste del cráter, los valles de los arroyos que drenan hacia la laguna y las playas de la misma, en donde hay alta disponibilidad de rodados pequeños (Durán et al. 2004: 31).

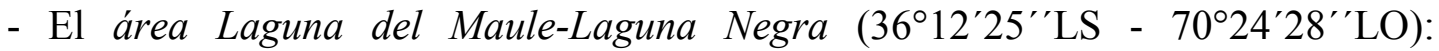
constituye un amplio complejo volcánico que se desarrolla en el límite cordillerano de Neuquén, Mendoza y Chile a $2090 \mathrm{msnm}$. Este complejo presenta distintas coladas de obsidiana de muy buena calidad para la talla a ambos flancos de la cordillera. La mayor parte han sido caracterizadas químicamente (Seelenfreud et al. 1996; Durán et al. 2004; Giesso et al. 2011a; Fernández et al. 2017), diferenciándose hasta el momento tres subfuentes, de las cuales se ha determinado la ubicación primaria de una de ellas (Cortegoso et al. 2012; Fernández et al. 2017). Los arroyos que cortan los afloramientos pertenecen a la cuenca de los ríos Barrancas y Grande, por lo que una importante cantidad de obsidiana se distribuye aguas abajo a lo largo de decenas de kilómetros en forma de rodados, formando una fuente secundaria de gran extensión (Durán et al. 2004; Fernández et al. 2017).

- Las Cargas $\left(35^{\circ} 12^{\prime} 01,8^{\prime \prime} \mathrm{LS}\right.$ - 70¹9'23,5' 'LO): se emplaza en las cabeceras del río Grande a 2350 msnm, en el límite Argentino-Chileno, próximo al complejo volcánico 
Planchón-Peteroa. La fuente prospectada hasta el momento presenta bloques de obsidiana primarios y depósitos secundarios, probablemente formados por la fuerte actividad glaciar que afectó la zona. Posee una gran extensión espacial y presenta excelente calidad y disponibilidad (Giesso et al. 2008; Salgán et al. 2015). En este caso, también pasa algo semejante a lo mencionado para Laguna del Maule-Laguna Negra: algunos de los cauces que cortan los afloramientos transportan obsidianas aguas abajo, aunque se desconoce aún la distancia de dispersión de los nódulos transportados por el río Grande. Los únicos datos disponibles muestran presencia de rodados a unos $10 \mathrm{~km}$ aguas abajo (Neme com. pers. 2018).

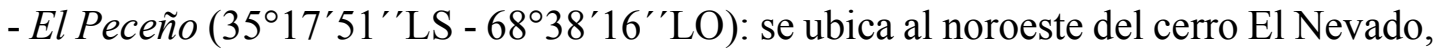
en el cerro El Peceño, en un sector extra-cordillerano. Se encuentra en la Planicie Oriental del sur mendocino, a unos $1550 \mathrm{msnm}$. La caracterización geoquímica de la fuente permitió diferenciar dos variedades geoquímicas o sub-fuentes procedentes de dos sectores diferentes del cerro (Salgán y Pompei 2017) (Figura 6.14). En la fuente predominan los vitrófilos opacos, veteados de color gris, por sobre las obsidianas negras. Los núcleos y nódulos varían desde el tamaño de un puño o menores, hasta grandes bloques de unos $30 \mathrm{~cm}$ de diámetro.

- Coche Quemado (36 $11^{\prime} 7^{\prime \prime} \mathrm{LS}$ - 6940'49' LO): se localiza a orillas del río Grande a $1270 \mathrm{msnm}$, en el piedemonte cordillerano. Aparece como un conglomerado de matriz calcárea en cuyo interior se encuentran rodados de obsidiana no mayores a $10 \mathrm{~cm}$ de muy buena y excelente calidad para la talla. Este conglomerado forma parte de la formación geológica Agua de la Piedra, correspondiente al Oligoceno (Salgán et al. 2017). El afloramiento fue cortado por el río Grande y, producto de la meteorización, libera nódulos que luego son transportados aguas abajo. Recientemente se realizaron análisis de elementos traza sobre estos nódulos naturales que permitieron diferenciar a esta fuente del resto de las del sur de Mendoza.

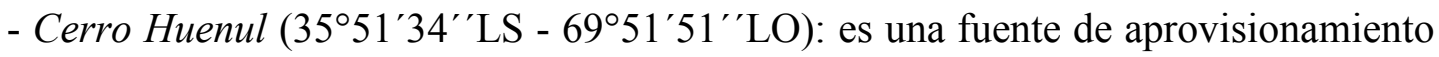
primario y secundario, localizada en el norte de la provincia de Neuquén a $1050 \mathrm{msnm}$. Se caracteriza por su fácil acceso, disponibilidad y abundancia de roca. La mayor parte de la obsidiana aparece en forma de rodados medianos y pequeños, y muestra una gran dispersión espacial (Barberena et al. 2011). 


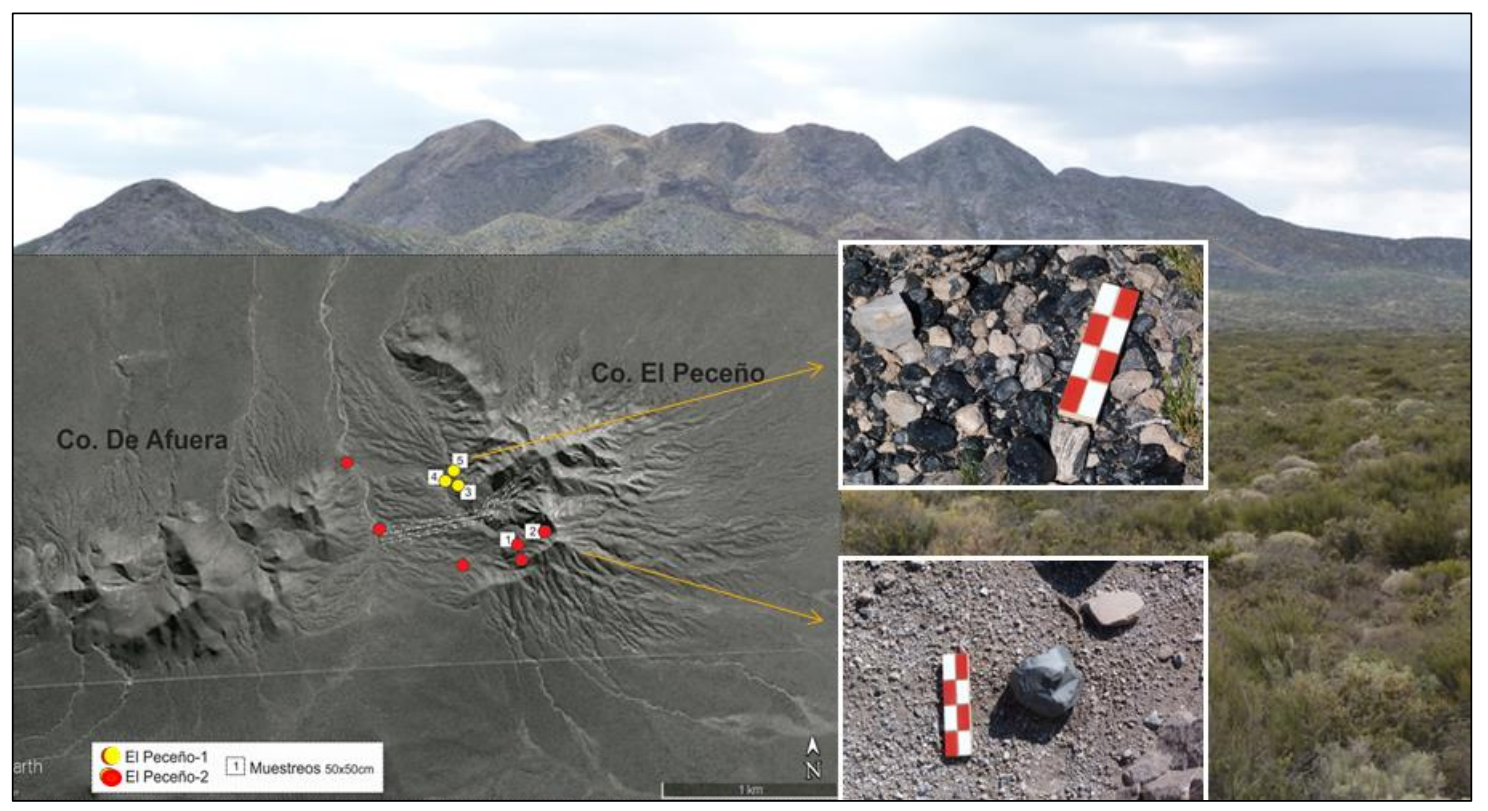

Figura 6.14. Fuente de obsidiana El Peceño y las sub-fuentes EP-1 y EP-2 diferenciadas espacial, geoquímica y tecnológicamente (Tomado y modificado de Salgán y Pompei 2017: 54).

\subsection{CONSIDERACIONES GENERALES DE LA BASE REGIONAL DE RECURSOS LÍTICOS EN LA CUENCA DEL ATUEL}

El análisis de la disponibilidad de recursos líticos en la cuenca del río Atuel muestra en su recorrido una disponibilidad diversa de recursos líticos. En la cordillera (Desierto Altoandino), se encuentran las fuentes de obsidiana más utilizadas en la región -Las Cargas, Laguna del Maule y Laguna del Diamante- de excelente calidad para la talla. En Laguna del Maule y Las Cargas, se sabe que los ríos transportan la obsidiana, ampliando la disponibilidad espacial de la roca y facilitando su acceso en distintos niveles altitudinales.

El área de la cuenca superior del río Atuel, ofrece una amplia variedad de rocas de calidad buena y muy buena, entre las que se destacan la obsidiana y el basalto, y otras de menor calidad, tales como: riolitas, andesitas y dacitas (entre otras). Una parte de las fuentes de excelente y muy buena calidad para la talla, no están disponibles todo el año $\mathrm{y}$, en algunos casos, la vegetación de los sectores de vega limita la visibilidad. Sin embargo, y al igual que la obsidiana, son transportadas por los ríos y arroyos, ampliando su dispersión y disponibilidad.

El piedemonte andino cuenta con distintas fuentes de materias primas de muy buena calidad para la talla. Una serie de afloramientos de rocas silíceas han sido 
detectados pocos kilómetros al sur de la cuenca del Atuel (Figura 6.4). Además, el piedemonte andino y la planicie cuentan con dos fuentes de obsidiana de excelente calidad, El Peceño y Coche Quemado (Figura 6.3. E y F). Coche Quemado se encuentra a unos 100 kilómetros de los sitios más próximos del piedemonte (entre ellos, Cueva Salamanca 1; véase Capítulo 8), y El Peceño a unos 20 kilómetros de Arbolito 6 y 7, y Barranca de Piedra 1 (véase Capítulo 8). Los muestreos de materias primas en el curso medio del Atuel y su tributario, el Salado, han permitido identificar rocas provenientes de toda la cuenca alta. Ambos cauces estarían transportando los mismos tipos de rocas (e.g. basalto y andesita), salvo la cuarcita -registrada únicamente en el Atuel- y la dacita y riolita, en las inmediaciones del río Salado.

En la planicie, las rocas silíceas de buena y muy buena calidad para la talla provendrían del Bloque de San Rafael. La fuente de obsidiana El Peceño, localizada al sur del Bloque, en el límite entre el piedemonte y la planicie, se encuentra a unos $100 \mathrm{~km}$ de los sitios Los Gallegos 1 y El Bosquecillo 3 y 5 (véase Capítulo 9). La obsidiana de esta fuente es de calidad muy buena a excelente, su disponibilidad es amplia y se presenta en tamaños variables según la sub-fuente (Salgán y Pompei 2017). No se registraron en el sector otras materias primas en concentraciones significativas; sólo nódulos aislados de materias primas de calidad buena a regular (riolita, cuarzo, basalto y vulcanitas indeterminadas) y de distribución dispersa a lo largo de la cuenca inferior del río Atuel. Se debe tener en cuenta que, aproximadamente a la misma longitud sobre la cuenca del río Diamante, se localiza la Formación Colonia Los Coroneles (Lagiglia1968, 1974, 1977a, 1981; Sepúlveda et al. 2000), la cual provee basaltos de muy buena y buena calidad. Las rocas que transporta el Atuel, si bien están disponibles todo el año, son de accesibilidad limitada, dado el menor tamaño de los nódulos transportados, la mayor depositación de los sedimentos y la mayor cobertura vegetal que limita la visibilidad.

En resumen, los basaltos, vulcanitas indeterminadas, riolitas y andesitas se encuentran dentro del rango de rocas inmediatamente disponibles a los sitios analizados en esta tesis; pero sus calidades para la talla varían entre regular y muy buena. Esta última categoría, sólo se registró en los basaltos del área de El Sosneado y Risco Plateado (cordillera y piedemonte andino), y serían transportados por el Atuel aguas abajo (en la localidad La Guevarina, en la planicie, se registró basalto de muy buena calidad). Las riolitas se agrupan en el área de la cuenca media del Atuel, aunque se disponen de manera secundaria en la cuenca inferior. Fuentes de rocas silíceas se hallan disponibles localmente en los tres ambientes estudiados (cordillera, piedemonte y planicie; véanse 
Figuras 6.3 y 6.4). Las principales fuentes de obsidiana se concentran al oeste, en la región cordillerana. La fuente Las Cargas se conecta con el río Grande, mientras que Laguna del Maule, se vincula con la cuenca del río Barrancas-Colorado. La fuente de obsidiana extracordillerana Coche Quemado, se localiza en la cuenca del río Grande y, por lo tanto, no es local respecto de todos los sitios comprometidos en esta tesis. Finalmente, El Peceño es la única fuente de obsidiana registrada dentro del rango local de algunos sitios del piedemonte y a unos $100 \mathrm{~km}$ de los sitios de cordillera y de planicie. 


\section{CAPÍTULO 7}

\section{RESULTADOS DEL ANÁLISIS DEL REGISTRO LÍTICO EN EL DESIERTO ALTOANDINO}

\subsection{LOS SITIOS ARQUEOLÓGICOS BAJO ESTUDIO}

El objetivo de este capítulo es presentar los resultados del análisis artefactual de los conjuntos líticos del Desierto Altoandino. En él se localizan tres de los sitios arqueológicos abordados en esta tesis: Cueva Palulo 1 (CP-1), Arroyo Panchino 1 (AP1) y Arroyo Panchino 2 (AP-2) (Figuras 7.1 y 7.2). Su emplazamiento, los procedimientos de excavación, las características estratigráficas y cronológicas, y el registro arqueológico obtenido de estos sitios, se exponen a continuación y luego se enfatiza en el registro lítico. 


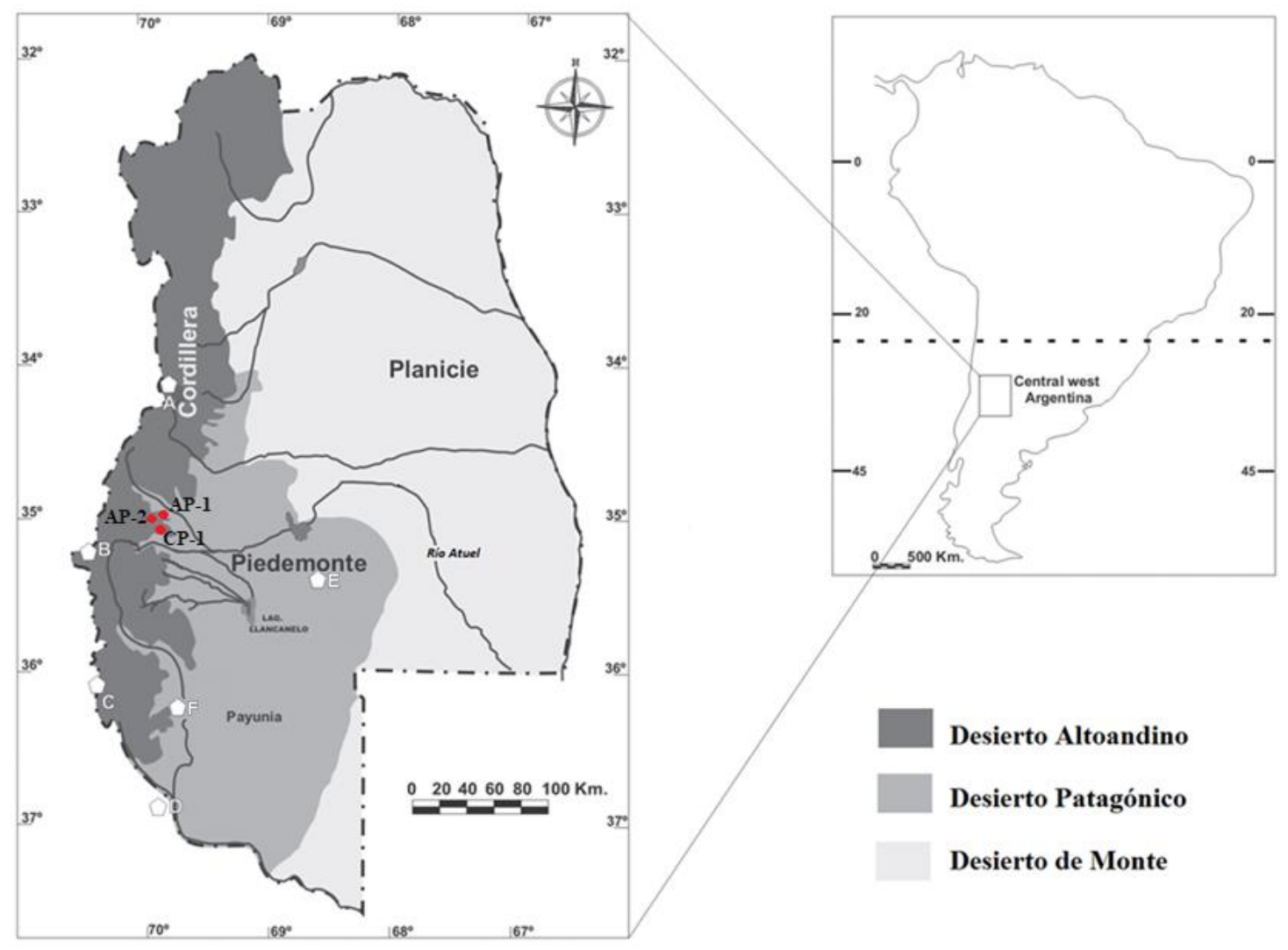

Figura 7.1. Localización de los sitios arqueológicos del Desierto Altoandino (cuenca superior del río Atuel): Arroyo Panchino 1 (AP-1), Arroyo Panchino 2 (AP-2) y Cueva Palulo 1 (CP-1); y fuentes de aprovisionamiento de obsidiana: A) Laguna El Diamante; B) Las Cargas; C) Laguna del Maule 1; D) Cueva Huenul; E) El Peceño.; F- Coche Quemado. 


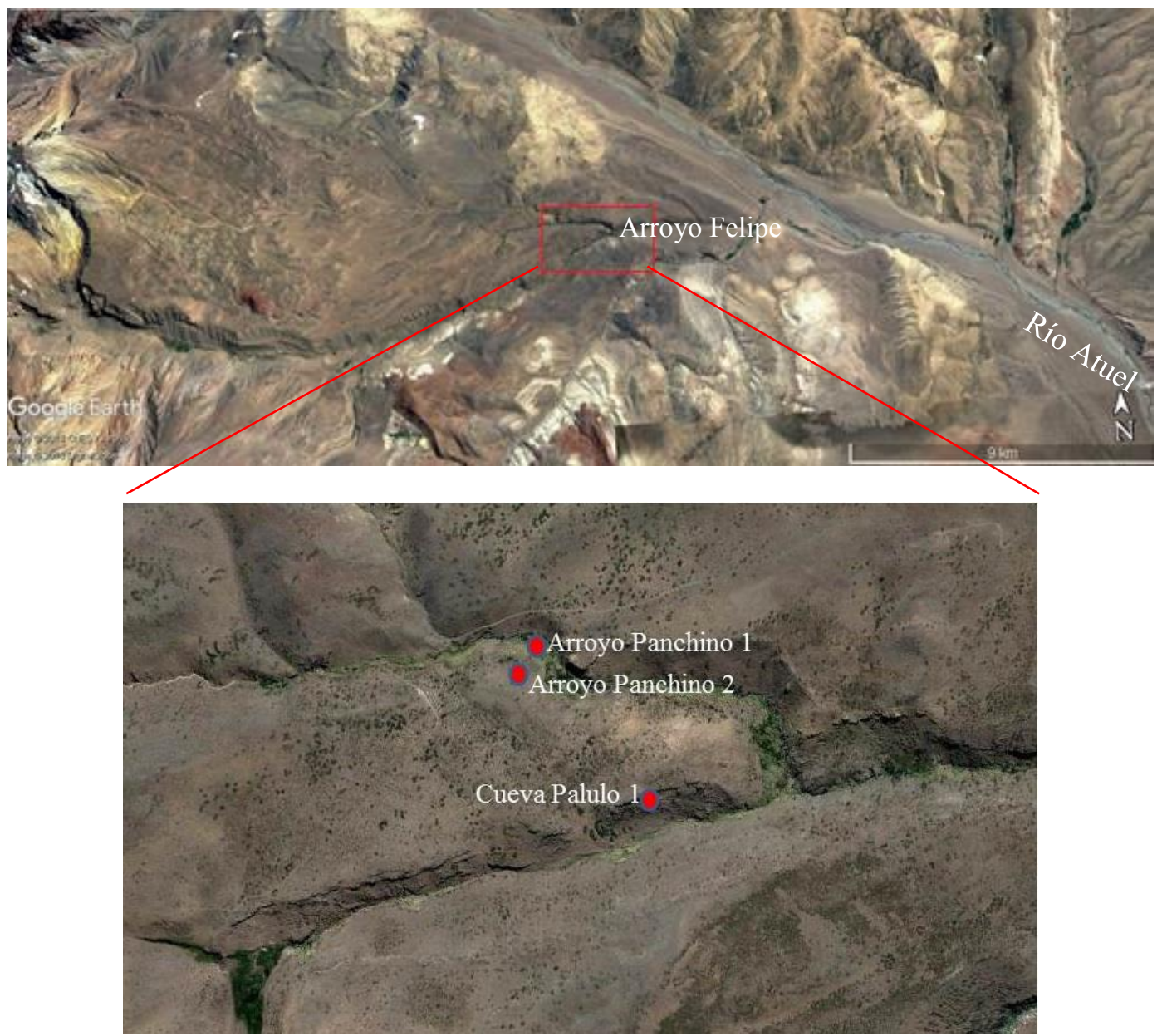

Figura 7.2. Localización de los sitios Arroyo Panchino 1 y 2, y Cueva Palulo 1.

\subsubsection{CUEVA PALULO 1 (CP-1)}

El sitio arqueológico Cueva Palulo (en adelante, CP-1) se emplaza a $2304 \mathrm{msnm}$ a los pies del arroyo Felipe (Figura 7.2), en un pequeño valle tributario del río Atuel. Se localiza a $34^{\circ} 56^{\prime} 40,40^{\prime \prime}$ de LS y a 69'50'39,64' de LO (Figuras 7.1, 7.2 y 7.3). Fue excavado en el año 2007 y allí se registró el uso de fauna y recursos vegetales en distintos momentos del Holoceno tardío.

\subsubsection{Excavación}

Para elegir el lugar donde se realizaría la cuadrícula A1 del sitio CP-1 se tomaron en cuenta, por un lado, la existencia de excavaciones asistemáticas realizadas en tiempos recientes por parte de pobladores locales y gente del Museo Regional de Malargüe y, por otro lado, la colmatación casi completa de la cueva, lo cual implicó utilizar el sector de mayor altura próximo a la entrada. El trabajo de campo consistió en la excavación de una cuadrícula de 2 x 1,5 m, abarcando una superficie de $3 \mathrm{~m}^{2}$ (Figura 7.4). 


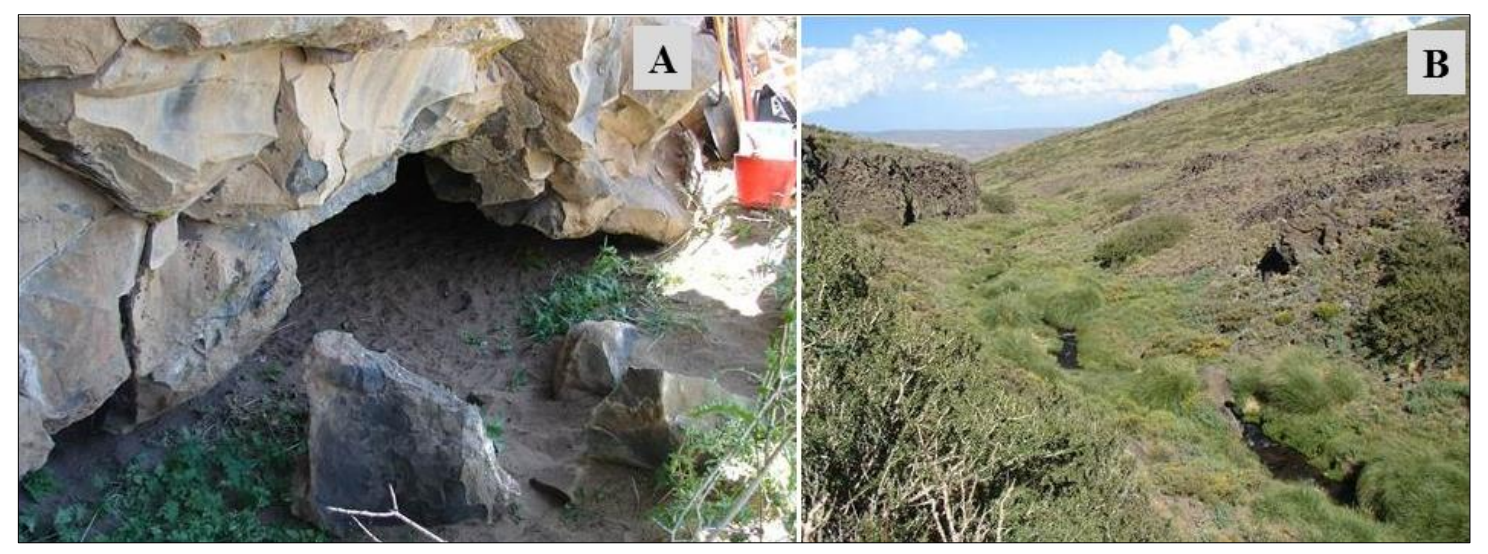

Figura 7.3. Vista de la cueva (A) y del ambiente circundante (B).

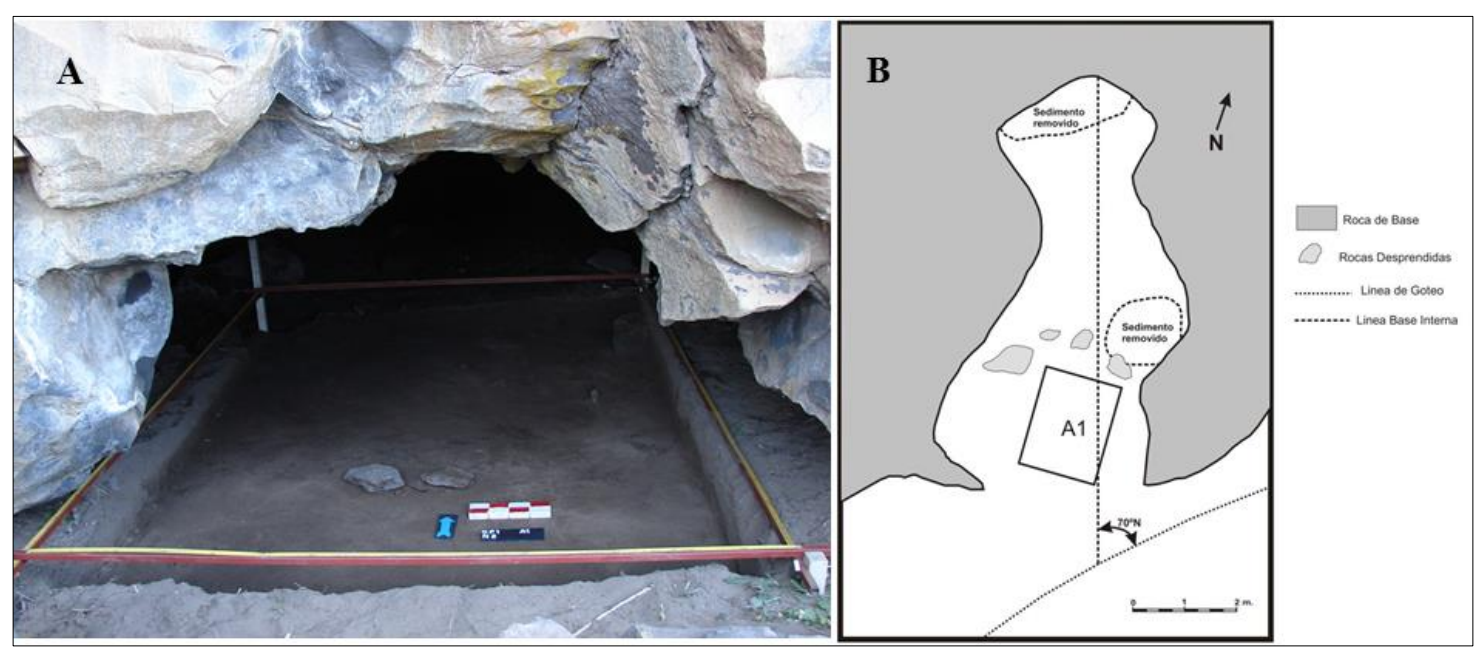

Figura 7.4. A. Planta del sitio CP-1 y localización del sector excavado; B. Planta de CP-1 y ubicación de la cuadrícula de excavación. Tomado de Otaola (2013: 241).

La cuadrícula fue dividida en dos sectores: norte y sur, y las tareas comenzaron con la nivelación de toda la superficie a $15 \mathrm{~cm}$ de profundidad respecto del nivel de referencia. Luego, se procedió a la excavación de niveles artificiales de $5 \mathrm{~cm}$ de espesor cada uno, excepto el último que midió $10 \mathrm{~cm}$. Se excavó un total de 21 niveles artificiales, alcanzando una profundidad máxima de $110 \mathrm{~cm}$ (Figura 7.5). 


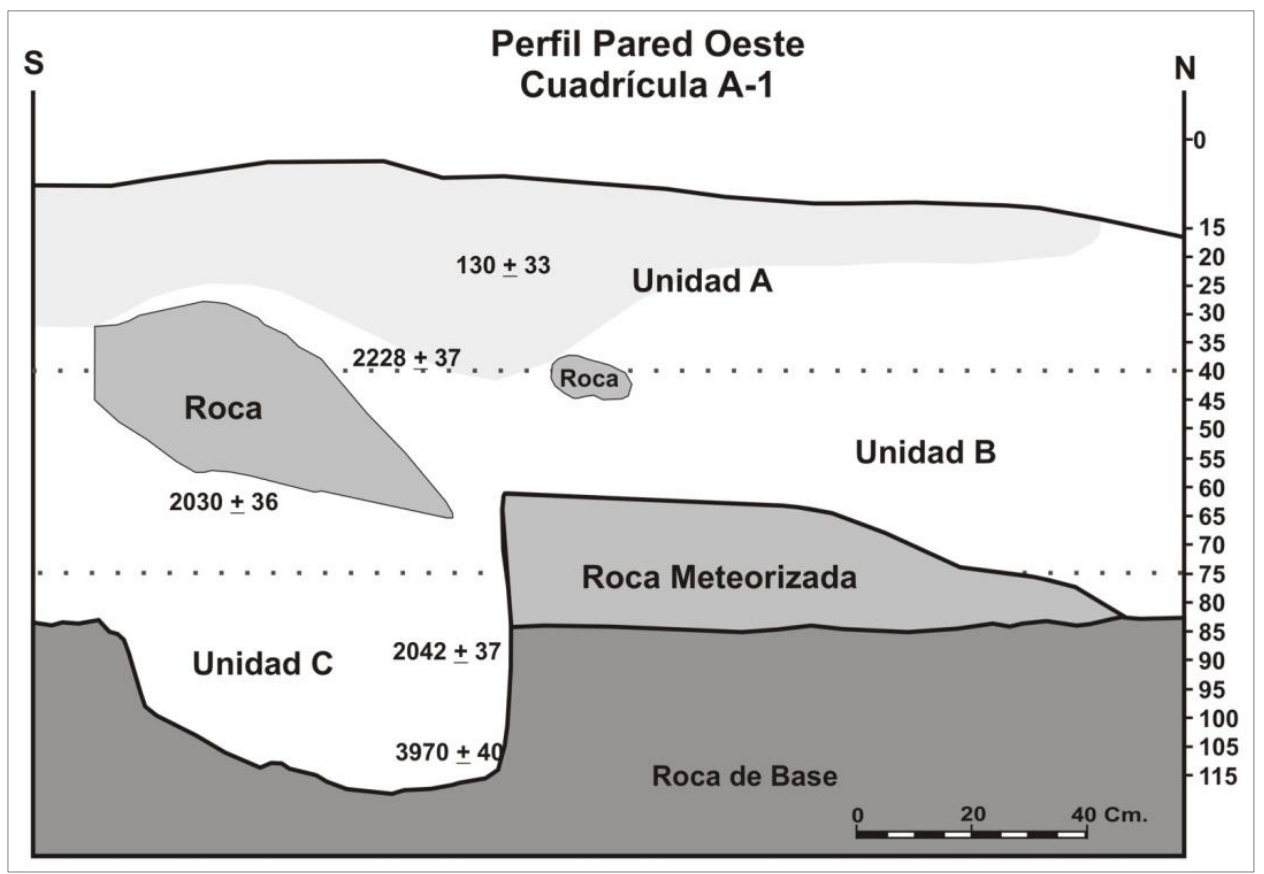

Figura 7.5. Perfil Oeste de la cuadrícula A1. Tomado de Otaola (2013: 242).

\subsubsection{Estratigrafía, cronología y definición de las unidades de análisis}

La estratigrafía de CP-1 presenta una sedimentología homogénea a lo largo de la excavación: su composición implica sedimento arenoso con limo y clastos endógenos, pertenecientes a la roca del techo de la cueva. En algunos sectores, especialmente en el norte, la presencia de humedad y el contenido de materia orgánica eran mayores, y el sedimento estaba menos compactado. Hacia la parte basal de la estratigrafía se detectó un nivel de roca meteorizada que se entremezclaba con los últimos materiales arqueológicos recuperados en el sitio.

El registro arqueológico del sitio comprende materiales óseos, líticos y cerámicos, además de carbones dispersos sobre los cuales se realizaron cinco fechados radiocarbónicos (AMS) (Tablas 7.1 y 7.2, y Figura 7.5) de los que se calculó la edad calibrada (Figura 7.6). La distribución de dichos materiales a lo largo de la secuencia estratigráfica permite no sólo comprender los eventos de depositación en relación al tiempo, sino también establecer unidades cronoestratigráficas para evaluar las tendencias tecnológicas a lo largo del tiempo y la asociación de los materiales líticos con otras líneas de evidencia (Tabla 7.2).

Los resultados muestran una secuencia que comienza hace $3.970 \pm 40$ años ${ }^{14} \mathrm{C}$ AP (nivel 20) y se continúa hasta $130 \pm 33$ años ${ }^{14} \mathrm{C}$ AP (nivel 3). La existencia de fechados cruzados sugiere una migración vertical debido a la fuerte actividad de 
bioturbación a la que están sometidos este tipo de reparos en la región (Dieguez y Neme 2003; Otaola 2013). En este sentido se detectaron cuevas de roedores y la presencia de raíces, además de la caída de bloques del techo de la cueva.

\begin{tabular}{|cccccc|} 
Cuadrícula & $\begin{array}{c}\text { Nivel } \\
\text { artificial }\end{array}$ & $\begin{array}{c}\text { Fecha } \\
{ }^{14} \mathrm{C}\end{array}$ & $\begin{array}{c}\text { Edad } \\
\text { cal AP }\end{array}$ & Material & Código Lab \\
\hline A1 & 3 & $130 \pm 33$ & 95 & Carbón disperso & AA93999 \\
\hline A1 & 6 & $2.228 \pm 37$ & 2.215 & Carbón disperso & AA85699 \\
\hline A1 & 11 & $2.030 \pm 36$ & 1.949 & Carbón disperso & AA94000 \\
\hline A1 & 16 & $2.042 \pm 37$ & 1.958 & Carbón disperso & AA85698 \\
\hline A1 & 20 & $3.970 \pm 40$ & 4.360 & Carbón disperso & AA85697 \\
\hline
\end{tabular}

Tabla 7.1. Fechados radiocarbónicos y edades calibradas obtenidos en CP-1.

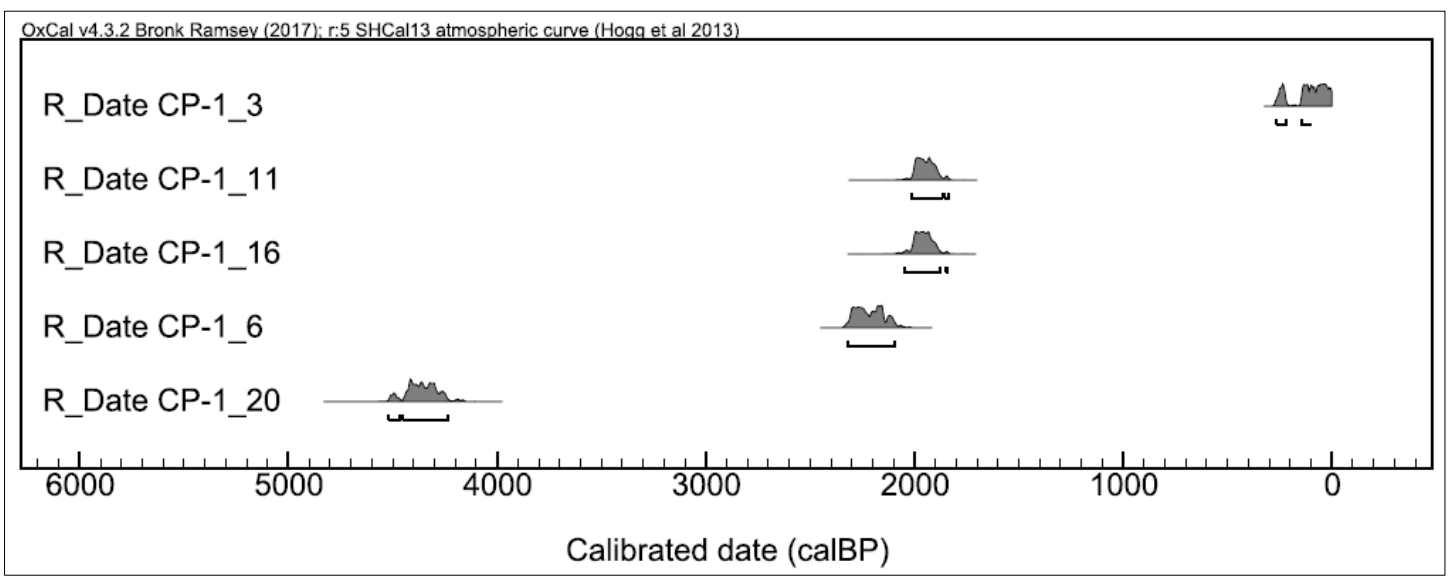

Figura 7.6. Edades calibradas para el sitio CP-1. Calibración realizada con el programa

OxCal v4.3.2 (Ramsey 2009), usando la curva atmosférica SHCal 13 para el hemisferio sur

(Hogg et al. 2013).

Sobre la base de la estratigrafía, la cronología y la distribución del material óseo, lítico y cerámico (Figura 7.7), se han definido tres unidades agregativas: C, B y A (Figura 7.5). La unidad más profunda y antigua de la secuencia, la Unidad C, abarca los niveles artificiales 13 a 21. En esta unidad se obtuvo el fechado de $c a .3 .900$ años ${ }^{14} \mathrm{C}$ AP, en momentos previos a la incorporación de la tecnología cerámica. Los tres tiestos recuperados en niveles pertenecientes a esta unidad (véase Tabla 7.2) habrían migrado verticalmente, por lo que son entendidos como pertenecientes a la unidad suprayacente. 


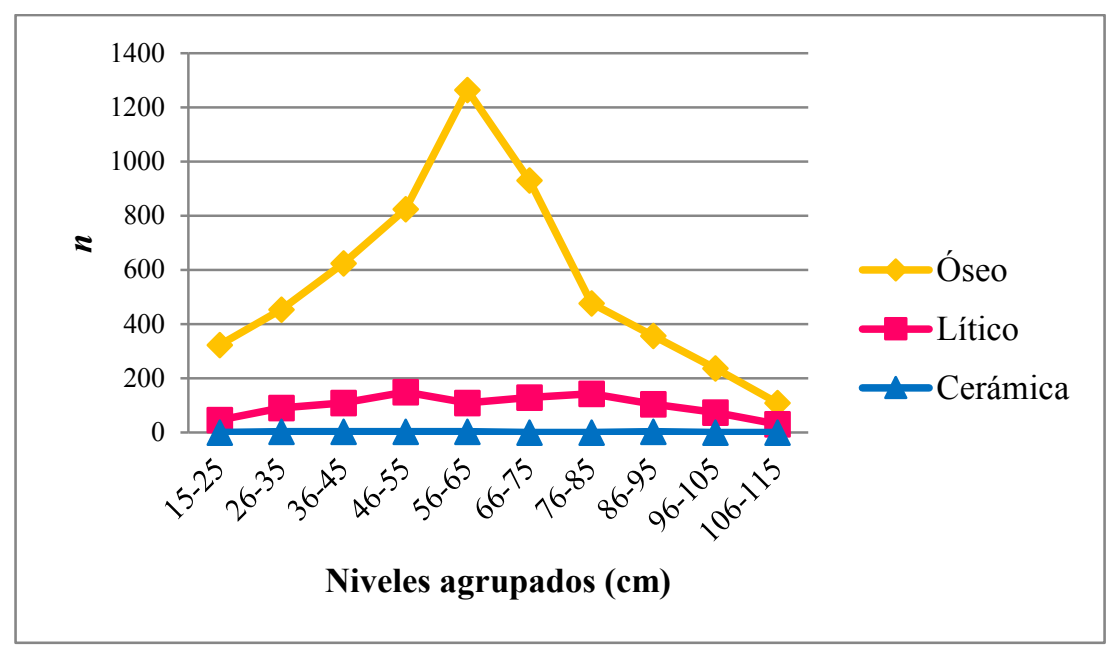

Figura 7.7. Frecuencias en la distribución de los materiales arqueológicos recuperados en CP-1.

La Unidad B comprende los niveles de excavación 6 al 12. En ella se obtuvieron fechados invertidos, por lo que se asume una cronología de ca 2.000 años AP. Para conocer la tasa de depositación de los materiales del sitio, se consideraron sólo los artefactos líticos, dado que no presentan problemas tafonómicos importantes. En esta unidad la tasa de depositación es de 1,56 /año, 0,14 artefactos depositados por año en la Unidad C y 0,93 /año en la Unidad A.

La unidad más reciente, la Unidad A, incluye los primeros $25 \mathrm{~cm}$ de la secuencia (niveles 0 al 5) y correspondería a los últimos 130 años. Es prudente señalar que en ella se registraron fauna y otros materiales modernos, y que en la superficie de esta cueva hay evidencia de perturbación antrópica reciente (Otaola 2013).

Como se observa, estas unidades agregativas están definidas cronoestratigráficamente y representan tres momentos distintos a lo largo de la secuencia: un primer momento hacia principios del Holoceno tardío, también llamado "inicial" (4.0002.000 años AP) (en adelante, HTI); un segundo momento correspondiente al Holoceno tardío "final" (2.000- presente) (en adelante, HTF), caracterizado por el ingreso de la tecnología cerámica, del arco y la flecha, y por ser el período en el cual se darían las evidencias de un proceso de intensificación; por último, un tercer momento correspondiente a momentos relativamente recientes.

\subsubsection{Registro arqueológico}

Sobre la base del registro zooarqueológico y arqueobotánico del sitio CP-1, Otaola y Llano (2015) evaluaron la ocurrencia del proceso de intensificación. Para esto hicieron 
una detallada descripción de los procesos de formación intervinientes en el sitio, así como de algunas cuestiones tafonómicas. Todo esto fue utilizado para entender el origen y representatividad de los materiales botánicos y óseos que fueron recuperados en el lugar.

\begin{tabular}{|ccccccc|}
$\begin{array}{c}\text { Fechados } \\
{ }^{14} \mathbf{C}\end{array}$ & $\begin{array}{c}\text { Nivel } \\
\text { artificial }\end{array}$ & $\begin{array}{c}\text { Unidad } \\
\text { temporal }\end{array}$ & Óseo & Vegetal & Lítico & Cerámica \\
\hline $\mathbf{1 3 0} \pm \mathbf{3 3}$ & $\mathbf{1}$ & & 134 & 15 & 27 & 0 \\
& $\mathbf{2}$ & & 189 & 18 & 18 & 0 \\
& $\mathbf{4}$ & & 254 & 34 & 53 & 1 \\
& $\mathbf{5}$ & & 200 & 11 & 38 & 1 \\
$\mathbf{2 . 2 2 8} \pm \mathbf{3 7}$ & $\mathbf{6}$ & & 423 & 1 & 55 & 0 \\
& $\mathbf{7}$ & & 219 & 11 & 49 & 2 \\
& $\mathbf{8}$ & & 605 & 9 & 100 & 0 \\
& $\mathbf{9}$ & $\mathbf{B}$ & 534 & 0 & 39 & 0 \\
$\mathbf{2 . 0 3 0} \pm \mathbf{3 6}$ & $\mathbf{1 0}$ & & 731 & 1 & 70 & 2 \\
& $\mathbf{1 1}$ & & 500 & 0 & 44 & 0 \\
\hline & $\mathbf{1 2}$ & & 431 & 0 & 85 & 0 \\
\hline $\mathbf{1 3}$ & & 213 & 0 & 61 & 0 \\
& $\mathbf{1 4}$ & & 263 & 1 & 81 & 0 \\
$\mathbf{2 . 0 4 2} \pm \mathbf{3 7}$ & $\mathbf{1 5}$ & & 184 & 0 & 55 & 2 \\
& $\mathbf{1 6}$ & & 173 & 0 & 49 & 1 \\
& $\mathbf{1 7}$ & $\mathbf{C}$ & 168 & 0 & 57 & 0 \\
& $\mathbf{1 8}$ & & 69 & 0 & 17 & 0 \\
& $\mathbf{1 9}$ & & 82 & 0 & 29 & 0 \\
\hline $\mathbf{3 . 9 7 0} \pm \mathbf{4 0}$ & $\mathbf{2 0}$ & & 27 & 0 & 2 & 0 \\
\hline & & & $\mathbf{5 6 0 1}$ & $\mathbf{1 4 4}$ & $\mathbf{9 8 2}$ & $\mathbf{1 1}$ \\
\hline
\end{tabular}

Tabla 7.2. Disposición de los materiales arqueológicos recuperados y los fechados realizados a lo largo de la secuencia, por nivel artificial de excavación y unidad temporal en CP-1.

Con respecto a la arqueobotánica del sitio, en el mismo se hallaron 189 macrorrestos en total (Otaola y Llano 2015). Entre estos se registraron cuatro familias que, en orden de frecuencia, son: Anacardiaceae (el molle, Schinus polygamus, es el macrorresto más frecuente), Cactaceae (e.g., Maihuenia patagónica), Chenopodiaceae y Fabaceae. Todos los taxa representados, excepto Chenopodiaceae, fueron interpretados como de origen antrópico, especialmente por los signos de termoalteración que mostraban (Otaola y Llano 2015). 
Desde el punto de vista zooarqueológico, el sitio CP-1 cuenta con un total de 6360 especímenes óseos, de los cuales se ha podido identificar -a algún nivel taxonómico- el $37 \%$ de la Unidad A, el 35\% de la Unidad B y el 29\% de la Unidad C. Entre los taxones identificados a nivel de especie o familia, el más representado es el guanaco (Lama guanicoe; NISP=313); le siguen en orden de importancia los camélidos (NISP=73); y los dasipódidos (NISP=11). El resto de los taxones identificados se encuentran representados en una muy baja frecuencia: Rhea pennata (NISP=1); Lycalopex culpaeus (NISP=3) y Chaetophractus sp. (NISP=1). Estos taxa poseen evidencias de procesamiento: marcas de corte; negativos de impacto y pulido (Otaola y Llano 2015).

Acerca de los instrumentos confeccionados sobre hueso, Otaola (2013) señala la presencia de un instrumento punzante sobre metapodio de guanaco y un fragmento de un instrumento indeterminado que posee una punta redondeada y con brillo, en la Unidad B; $\mathrm{y}$, en la Unidad A, un instrumento confeccionado sobre un hueso largo de mamífero grande (Otaola 2013) (Figura 7.8).

Con estos dos tipos de registro -zooarqueológico y arqueobotánico-, muy diferentes en cuanto a su manipulación, conservación y disponibilidad, Otaola y Llano (2015) llegaron a la conclusión de que en este sitio no se registran cambios como los esperados según el modelo de intensificación propuesto para la región ca. 2.000 años AP. Señalan que, si bien habría mayor intensidad en el aprovechamiento del guanaco, no se registra un aumento en la diversidad de taxones explotados ni tampoco la incorporación de taxa de bajo rendimiento, en detrimento de taxones de alto rendimiento económico (Otaola y Llano 2015).

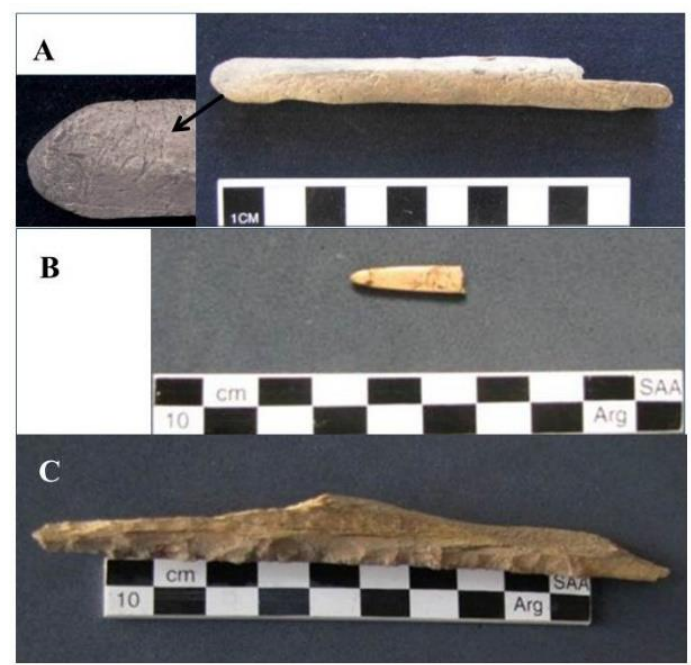

Figura 7.8. Instrumentos óseos de CP-1. A) Posible instrumento punzante sobre metapodio de guanaco en Unidad B; B) Fragmento de instrumento indeterminado en Unidad B; C) Posible 
instrumento con retoques en borde interno del elemento óseo en Unidad A. Modificado de

Otaola (2013: 265-266).

\subsubsection{Registro lítico}

Para el análisis del registro lítico de CP-1 se optó por unificar los sectores -norte y sur- en que había sido dividida la cuadrícula de excavación. El sitio cuenta con un total de 982 artefactos líticos (Tablas 7.2 y 7.3). En este total se consideran los 319 desechos de talla de tamaño igual o menor a $5 \mathrm{~mm}$ de lado (figuran como " $\leq 5 \mathrm{~mm}$ " en la Tabla 7.3 ; véase Capítulo 5). Al excluirlos, el $n$ total con el que se trabajó en el sitio CP-1 fue de 663 artefactos. De estos, la clase "desechos de talla" (desechos de tamaño mayor a $5 \mathrm{~mm}$ de lado) es la más representada en todo el conjunto y en cada una de las tres unidades cronoestratigráficas, constituyendo el 95,78\% $(\mathrm{n}=635)$ de los artefactos líticos de la cueva (Tabla 7.4).

Entre los instrumentos $(2,71 \%, \mathrm{n}=18)$ predominan los artefactos formatizados bifaciales $(n=7)$, seguidos por los AF unifaciales $(n=6)$, los AF compuestos $(n=3)$ (véase Capítulo 5), un artefacto manufacturado o modificado por abrasión, picado y/o pulido, y un percutor (Tabla 7.4). Los ocho artefactos sin formatización con rastros complementarios (en adelante, ASF RC), le siguen en frecuencia a los formatizados $(1,21 \%)$. Por último, se hallaron un ecofacto y un pigmento. En la Figura 7.9 se muestran las frecuencias relativas de las principales clases artefactuales, sin considerar a los numerosos desechos de talla (Salgán 2013). No se han registrado núcleos en ninguna de las distintas clases de roca presentes en la cueva.

\begin{tabular}{|c|c|c|c|c|c|c|c|c|c|c|c|}
\hline \multirow{2}{*}{ Nivel } & \multicolumn{2}{|c|}{ Desechos de talla } & \multirow{2}{*}{$\begin{array}{c}\text { AF } \\
\text { Bifac. }\end{array}$} & \multirow{2}{*}{$\begin{array}{c}\text { AF } \\
\text { Unifac. }\end{array}$} & \multirow{2}{*}{$\begin{array}{c}\text { AF } \\
\text { Comp. }\end{array}$} & \multirow{2}{*}{$\begin{array}{c}\text { Art. } \\
\text { manuf. } \\
\text { por } A, P, P\end{array}$} & \multirow{2}{*}{ ASF RC } & \multirow{2}{*}{$\mathbf{P}$} & \multirow{2}{*}{ Ecof. } & \multirow{2}{*}{ Pgm. } & \multirow{2}{*}{ Total } \\
\hline & $(>5 \mathrm{~mm})$ & $(\leq 5 \mathrm{~mm})$ & & & & & & & & & \\
\hline 1 & 22 & 5 & - & - & - & - & - & - & - & - & 27 \\
\hline 2 & 12 & 6 & - & - & - & - & - & - & - & - & 18 \\
\hline 3 & 26 & 26 & 1 & - & - & - & - & - & - & - & 53 \\
\hline 4 & 28 & 10 & - & - & - & - & - & - & - & - & 38 \\
\hline 5 & 30 & 21 & 1 & - & - & - & - & - & 1 & - & 53 \\
\hline 6 & 32 & 17 & 1 & 1 & - & - & 3 & 1 & - & - & 55 \\
\hline 7 & 30 & 17 & 1 & - & - & 1 & - & - & - & - & 49 \\
\hline 8 & 65 & 31 & 1 & 2 & - & - & 1 & - & - & - & 100 \\
\hline 9 & 25 & 13 & 1 & - & - & - & - & - & - & - & 39 \\
\hline 10 & 51 & 17 & - & - & 1 & - & 1 & - & - & - & 70 \\
\hline 11 & 28 & 14 & - & 1 & - & - & 1 & - & - & - & 44 \\
\hline 12 & 61 & 21 & - & 1 & - & - & 2 & - & - & - & 85 \\
\hline 13 & 42 & 18 & - & - & 1 & - & - & - & - & - & 61 \\
\hline
\end{tabular}




\begin{tabular}{|c|c|c|c|c|c|c|c|c|c|c|c|}
\hline 14 & 49 & 31 & - & 1 & - & - & - & - & - & - & 81 \\
\hline 15 & 35 & 19 & - & - & 1 & - & - & - & - & - & 55 \\
\hline 16 & 32 & 17 & - & - & - & - & - & - & - & - & 49 \\
\hline 17 & 33 & 24 & - & - & - & - & - & - & - & - & 57 \\
\hline 18 & 16 & 1 & - & - & - & - & - & - & - & - & 17 \\
\hline 19 & 17 & 11 & 1 & - & - & - & - & - & - & - & 29 \\
\hline 20 & 1 & - & - & - & - & - & - & - & - & 1 & 2 \\
\hline Total & 635 & 319 & 7 & 6 & 3 & 1 & 8 & 1 & 1 & 1 & 982 \\
\hline $\begin{array}{c}\text { Total } \\
\%\end{array}$ & 64,66 & 32,48 & 0,71 & 0,61 & $\mathbf{0 , 3 1}$ & 0,10 & $\mathbf{0 , 8 1}$ & 0,10 & 0,10 & 0,10 & $100 \%$ \\
\hline
\end{tabular}

Tabla 7.3. Clases artefactuales por nivel de excavación en CP-1. Referencias: AF: artefacto formatizado; Comp.: compuesto; Artefacto manuf. por A, P, P: artefacto manufacturado o modificado por abrasión, picado y/o pulido; ASF RC: artefacto sin formatización con rastros complementarios; P: percutor; Ecof.: Ecofacto; Pgm.: pigmento.

\begin{tabular}{|c|c|c|c|c|c|c|c|c|c|c|}
\hline Unidad & $\begin{array}{r}\text { Desechos } \\
\text { de talla }\end{array}$ & $\begin{array}{c}\text { AF } \\
\text { Bifacial }\end{array}$ & $\begin{array}{c}\text { AF } \\
\text { Unifac. }\end{array}$ & $\begin{array}{c}\text { AF } \\
\text { Comp. }\end{array}$ & $\begin{array}{c}\text { Art. } \\
\text { manuf. } \\
\text { por A, } \\
\mathbf{P}, \mathbf{P} \\
\end{array}$ & $\begin{array}{c}\text { ASF } \\
\text { RC }\end{array}$ & $\mathbf{P}$ & Ecof. & Pgm. & Total \\
\hline A & $\begin{array}{c}97,5 \% \\
(118)\end{array}$ & $\begin{array}{c}1,7 \% \\
(2)\end{array}$ & - & - & - & - & - & $\begin{array}{c}0,8 \% \\
(1)\end{array}$ & - & 121 \\
\hline B & $\begin{array}{c}93,6 \% \\
(292)\end{array}$ & $\begin{array}{c}1,3 \% \\
\text { (4) }\end{array}$ & $\begin{array}{c}1,6 \% \\
(5)\end{array}$ & $\begin{array}{c}0,3 \% \\
(1)\end{array}$ & $\begin{array}{c}0,3 \% \\
(1)\end{array}$ & $\begin{array}{c}2,6 \% \\
(8)\end{array}$ & $\begin{array}{c}0,3 \% \\
(1)\end{array}$ & - & - & 312 \\
\hline C & $\begin{array}{c}97,8 \% \\
(225) \\
\end{array}$ & $\begin{array}{c}0,4 \% \\
(1)\end{array}$ & $\begin{array}{c}0,4 \% \\
(1) \\
\end{array}$ & $\begin{array}{c}0,9 \% \\
(2) \\
\end{array}$ & - & - & - & - & $\begin{array}{c}0,4 \% \\
(1) \\
\end{array}$ & 230 \\
\hline Total & $\begin{array}{c}95,8 \% \\
(635) \\
\end{array}$ & $\begin{array}{c}1,1 \% \\
(7) \\
\end{array}$ & $\begin{array}{c}0,9 \% \\
(6) \\
\end{array}$ & $\begin{array}{c}0,5 \% \\
(3) \\
\end{array}$ & $\begin{array}{c}0,2 \% \\
(1) \\
\end{array}$ & $\begin{array}{c}1,2 \% \\
(8) \\
\end{array}$ & $\begin{array}{c}0,2 \% \\
(1) \\
\end{array}$ & $\begin{array}{c}0,2 \% \\
(1) \\
\end{array}$ & $\begin{array}{c}0,2 \% \\
\text { (1) }\end{array}$ & 663 \\
\hline
\end{tabular}

Tabla 7.4. Frecuencia de clases artefactuales por unidad cronoestratigráfica en CP-1.

Referencias: Idem Tabla 7.3.

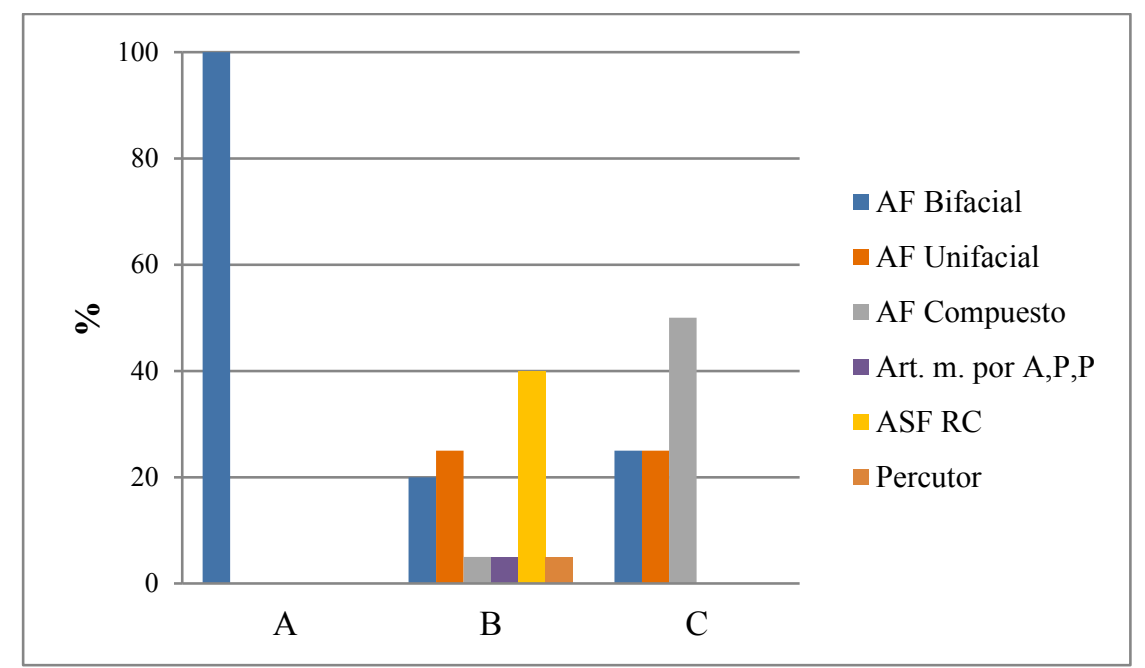

Figura 7.9. Frecuencias relativas de artefactos formatizados (AF), manufacturados por abrasión, picado y/o pulido (Art. m. por A, P, P), percutores y artefactos sin formatización con rastros complementarios (ASF RC), por unidad temporal en CP-1. 
A fin de evaluar el efecto del tamaño de muestra, se correlacionó el total de categorías de instrumentos representadas en cada unidad temporal con el tamaño de la muestra artefactual de cada una de dichas unidades (Figura 7.10). El resultado indica que la diversidad instrumental está fuertemente sesgada por el tamaño de la muestra $\left(\mathrm{r}^{2}=\right.$ 0,9938). Es decir, aquellas unidades de mayor tamaño tienen mayor diversidad de instrumentos, lo que limita la interpretación al respecto.

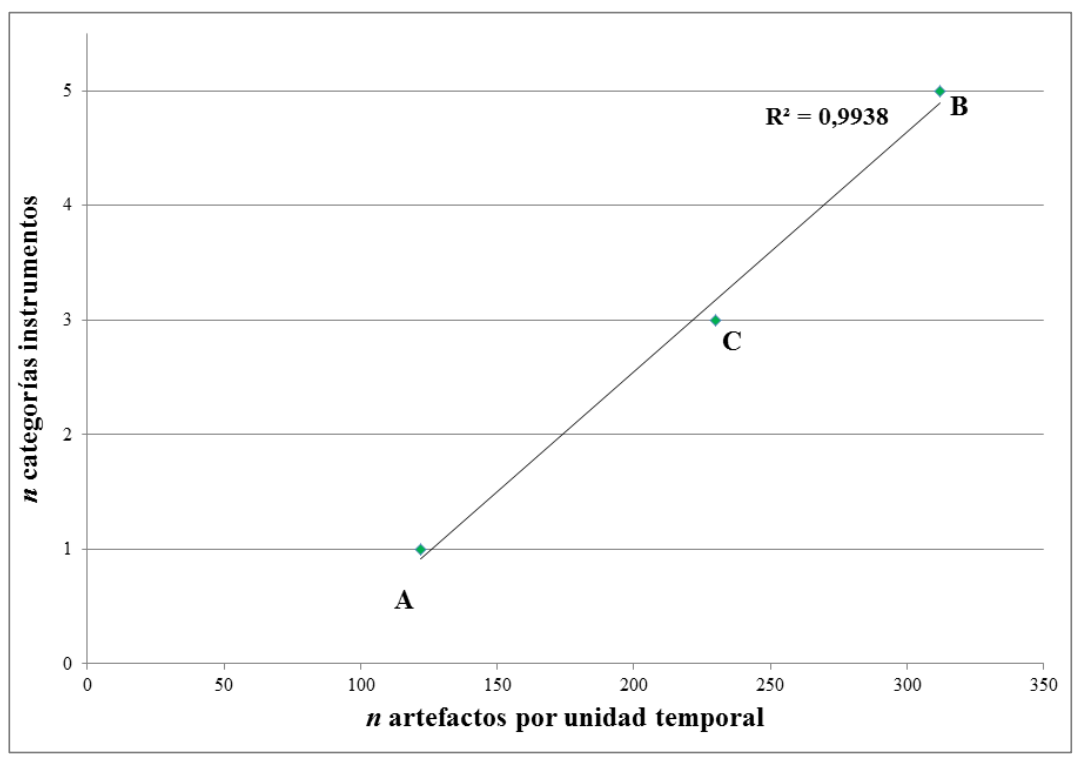

Figura 7.10. Tamaño de muestra vs. cantidad de categorías instrumentales en CP-1.

En relación a las materias primas, las rocas silíceas son las mayoritarias con el $46,91 \%(n=311)$, siendo relativamente menos frecuentes en la Unidad B $(44,23 \%, n=138$ de los 312 artefactos pertenecientes a dicha unidad temporal), que en las unidades A (47,93\%, n=58 de 121) y C (50\%, n=115 de 230 artefactos), pese a que el tamaño de muestra es mayor en la Unidad B (Tablas 7.5 y 7.6). La obsidiana $(38 \%, n=252)$ y el basalto $(11,61 \%, \mathrm{n}=77)$ también son menos frecuentes en la Unidad B $(42,95 \%$ de obsidianas, $n=134 ; 10,58 \%$ de basaltos, $n=33$ ). De estas tres rocas, las frecuencias relativas de la obsidiana aumentan de la Unidad C a la B y disminuyen de la B a la A; por el contrario, las rocas silíceas y el basalto, disminuyen y luego aumentan a través del tiempo (Tabla 7.7). Esto último también ocurre con la riolita, la cuarta roca en abundancia, que disminuye de la Unidad C $(3,04 \%, n=7)$ a la $B(0,96 \%, n=3)$ y aumenta de la Unidad B a la A $(5,79 \%, \mathrm{n}=7)$ (Tablas 7.5 y 7.6). Se han hallado sólo dos artefactos de vulcanita indeterminada, ambos correspondientes a la Unidad B. Por último, en cuatro artefactos líticos la materia prima es "indeterminada” (Tablas 7.5 y 7.6). 
A la hora de interpretar las diferencias en la diversidad de materias primas en las tres unidades temporales de CP-1, también se tuvo en cuenta el efecto del tamaño de muestra, correlacionando el total de las clases de roca con el tamaño de la muestra de cada unidad (Figura 7.11). En este caso, se observa que el valor de $\mathrm{r}^{2}=0,6765$, no indica necesariamente, que la diversidad de las materias primas responda al tamaño de la muestra.

\begin{tabular}{|c|c|c|c|c|c|c|c|}
\hline Nivel & BAS & OBS & RIO & SIL & VUL & Indet. & Total \\
\hline $\mathbf{1}$ & $5(22,7 \%)$ & $8(36,4 \%)$ & $1(4,5 \%)$ & $8(36,4 \%)$ & - & - & $\mathbf{2 2}$ \\
\hline $\mathbf{2}$ & $1(8,3 \%)$ & $2(16,7 \%)$ & $1(8,3 \%)$ & $8(66,7 \%)$ & - & - & $\mathbf{1 2}$ \\
\hline $\mathbf{3}$ & $4(14,8 \%)$ & $8(29,6 \%)$ & $2(7,4 \%)$ & $13(48,1 \%)$ & - & - & $\mathbf{2 7}$ \\
\hline $\mathbf{4}$ & $4(14,3 \%)$ & $11(39,3 \%)$ & $1(3,6 \%)$ & $12(42,9 \%)$ & - & - & $\mathbf{2 8}$ \\
\hline $\mathbf{5}$ & $3(9,4 \%)$ & $9(28,1 \%)$ & $2(6,3 \%)$ & $17(53,1 \%)$ & - & $1(3,1 \%)$ & $\mathbf{3 2}$ \\
\hline $\mathbf{6}$ & $5(13,2 \%)$ & $12(31,6 \%)$ & - & $20(52,6 \%)$ & $1(2,6 \%)$ & - & $\mathbf{3 8}$ \\
\hline $\mathbf{7}$ & $2(6,3 \%)$ & $12(37,5 \%)$ & $1(3,1 \%)$ & $16(50,0 \%)$ & - & $1(3,1 \%)$ & $\mathbf{3 2}$ \\
\hline $\mathbf{8}$ & $10(14,5 \%)$ & $33(47,8 \%)$ & - & $25(36,2 \%)$ & $1(1,4 \%)$ & - & $\mathbf{6 9}$ \\
\hline $\mathbf{9}$ & - & $14(53,8 \%)$ & - & $12(46,2 \%)$ & - & - & $\mathbf{2 6}$ \\
\hline $\mathbf{1 0}$ & $9(17,0 \%)$ & $26(49,1 \%)$ & - & $18(34,0 \%)$ & - & - & $\mathbf{5 3}$ \\
\hline $\mathbf{1 1}$ & $2(6,7 \%)$ & $12(40,0 \%)$ & $1(3,3 \%)$ & $15(50,0 \%)$ & - & - & $\mathbf{3 0}$ \\
\hline $\mathbf{1 2}$ & $5(7,8 \%)$ & $25(39,1 \%)$ & $1(1,6 \%)$ & $32(50,0 \%)$ & - & $1(1,6 \%)$ & $\mathbf{6 4}$ \\
\hline $\mathbf{1 3}$ & $3(7,0 \%)$ & $21(48,8 \%)$ & $1(2,3 \%)$ & $18(41,9 \%)$ & - & - & $\mathbf{4 3}$ \\
\hline $\mathbf{1 4}$ & $6(12,0 \%)$ & $14(28,0 \%)$ & $2(4,0 \%)$ & $28(56,0 \%)$ & - & - & $\mathbf{5 0}$ \\
\hline $\mathbf{1 5}$ & $8(22,2 \%)$ & $14(38,9 \%)$ & $1(2,8 \%)$ & $13(36,1 \%)$ & - & - & $\mathbf{3 6}$ \\
\hline $\mathbf{1 6}$ & $4(12,5 \%)$ & $11(34,4 \%)$ & - & $17(53,1 \%)$ & - & - & $\mathbf{3 2}$ \\
\hline $\mathbf{1 7}$ & $1(3,0 \%)$ & $11(33,3 \%)$ & - & $21(63,6 \%)$ & - & - & $\mathbf{3 3}$ \\
\hline $\mathbf{1 8}$ & $3(18,8 \%)$ & $3(18,8 \%)$ & - & $10(62,5 \%)$ & - & - & $\mathbf{1 6}$ \\
\hline $\mathbf{1 9}$ & $2(11,1 \%)$ & $6(33,3 \%)$ & $3(16,7 \%)$ & $7(38,9 \%)$ & - & - & $\mathbf{1 8}$ \\
\hline $\mathbf{2 0}$ & - & - & - & $1(50,0 \%)$ & - & $1(50,0 \%)$ & $\mathbf{2}$ \\
\hline Total & $\mathbf{7 7}$ & $\mathbf{2 5 2}$ & $\mathbf{1 7}$ & $\mathbf{3 1 1}$ & $\mathbf{2}$ & $\mathbf{4}$ & \multirow{6}{*}{$\mathbf{6 6 3}$} \\
& & $\mathbf{( 3 8 , 0 \% )}$ & $(\mathbf{2 , 6 \% )}$ & $\mathbf{( 4 6 , 9 \% )}$ & $\mathbf{( 0 , 3 \% )}$ & $\mathbf{( 0 , 6 \% )}$ & \\
\hline
\end{tabular}

Tabla 7.5. Distribución y frecuencia de materias primas por nivel de excavación en CP-1. Referencias: BAS: basalto; OBS: obsidiana; RIO: riolita; SIL: rocas siliceas; VUL: vulcanita indeterminada; Indet.: roca indeterminada. 


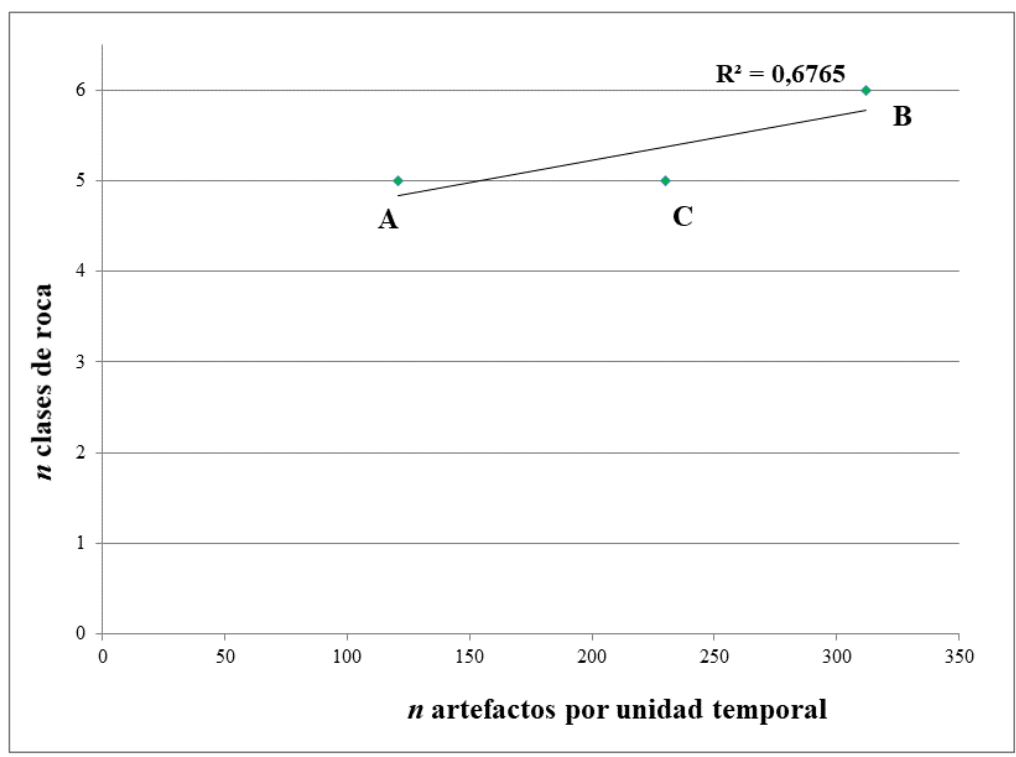

Figura 7.11. Tamaño de muestra vs. cantidad de clases de roca en CP-1.

Al observar la frecuencia relativa de la totalidad de los artefactos líticos, se advirtió una curva bastante oscilante. Esto puede tener relación con el método empleado durante la excavación (niveles artificiales de $5 \mathrm{~cm}$ cada uno) que, si bien provee mayor resolución, tiende a maximizar el error $(1 \mathrm{~cm}$ de error en un nivel de $5 \mathrm{~cm}$, equivale al $20 \%$ de inexactitud, mientras que en un nivel de $10 \mathrm{~cm}$ es sólo del 10\%). Por lo tanto, se decidió reunir de a dos a los niveles de $5 \mathrm{~cm}$, obteniendo así un total de diez niveles de $10 \mathrm{~cm}$ cada uno (Figura 7.12). De esta manera, se logra una curva más uniforme donde se aprecia que, si bien la Unidad B posee cierta oscilación, es el momento de la secuencia con mayor cantidad de artefactos (Tablas 7.6 y 7.7). Esta estrategia se ha aplicado al caso de las materias primas, en las que se observa una mayor homogeneidad en las tendencias de cada clase a lo largo de la secuencia (Tabla 7.6 y Figura 7.13).

La Unidad B presenta mayor variedad en cuanto a las clases de rocas (Tabla $7.7 \mathrm{y}$ Figura 7.13). En CP-1, al contrario de lo que ocurre en AP-1 y AP-2 como se verá luego, las rocas silíceas son más abundantes que la obsidiana (Tabla 7.7 y Figura 7.13). Sin embargo, en este momento se da la menor frecuencia relativa de artefactos sobre rocas silíceas, en comparación con las unidades A y C. 


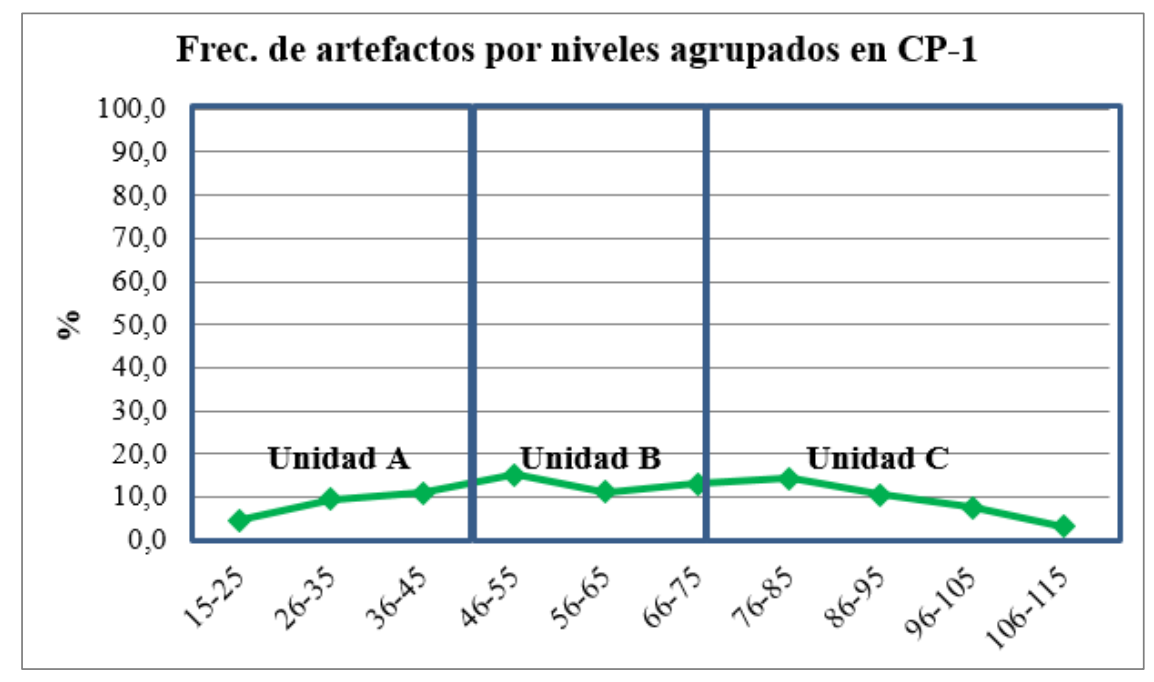

Figura 7.12. Frecuencia de artefactos por niveles agrupados y por unidad temporal en CP-1.

\begin{tabular}{|c|c|c|c|c|c|c|c|c|}
\hline \multicolumn{2}{|c|}{$\begin{array}{l}\text { Profundidad } \\
\text { (cm) }\end{array}$} & BAS & OBS & RIO & SIL & VUL & Indet. & Total \\
\hline \multirow[b]{2}{*}{$\mathbf{A}$} & $15-25$ & $6(17,6 \%)$ & $10(29,4 \%)$ & $2(5,9 \%)$ & $16(47,1 \%)$ & - & - & 34 \\
\hline & $26-35$ & $8(14,5 \%)$ & $19(34,5 \%)$ & $3(5,5 \%)$ & $25(45,5 \%)$ & - & - & 55 \\
\hline \multirow{4}{*}{ B } & $36-46$ & $8(11,4 \%)$ & $21(30,0 \%)$ & $2(2,9 \%)$ & $37(52,9 \%)$ & $1(1,4 \%)$ & $1(1,4 \%)$ & 71 \\
\hline & $46-55$ & $12(11,9 \%)$ & $45(44,6 \%)$ & $1(1,0 \%)$ & $41(40,6 \%)$ & $1(1,0 \%)$ & $1(1,0 \%)$ & 101 \\
\hline & $56-65$ & $9(11,4 \%)$ & $40(50,6 \%)$ & - & $30(38,0 \%)$ & - & - & 79 \\
\hline & 66-75 & $7(7,4 \%)$ & $37(39,4 \%)$ & $2(2,1 \%)$ & $47(50,0 \%)$ & - & $1(1,1 \%)$ & 94 \\
\hline \multirow{4}{*}{ C } & $76-85$ & $9(9,7 \%)$ & $35(37,6 \%)$ & $3(3,2 \%)$ & $46(49,5 \%)$ & - & - & 93 \\
\hline & $86-95$ & $12(17,6 \%)$ & $25(36,8 \%)$ & $1(1,5 \%)$ & $30(44,1 \%)$ & - & - & 68 \\
\hline & 96-105 & $4(8,2 \%)$ & $14(28,6 \%)$ & - & $31(63,3 \%)$ & - & - & 49 \\
\hline & $106-115$ & $2(10,0 \%)$ & $6(30,0 \%)$ & $3(15,0 \%)$ & $8(40,0 \%)$ & - & $1(5,0 \%)$ & 20 \\
\hline \multicolumn{2}{|c|}{ Total } & $77(11,6 \%)$ & $252(38,0 \%)$ & $17(2,6 \%)$ & $311(46,9 \%)$ & $2(0,3 \%)$ & $4(0,6 \%)$ & 663 \\
\hline
\end{tabular}

Tabla 7.6. Distribución y frecuencia de materias primas por niveles de excavación agrupados en

CP-1. Los distintos tonos de azul de las filas señalan las tres unidades cronoestratigráficas.

\begin{tabular}{|c|c|c|c|c|c|c|c|}
\hline Unidad & BAS & OBS & RIO & SIL & VUL & Indet. & Total \\
\hline A & $14,0 \%(17)$ & $31,4 \%(38)$ & $5,8 \%(7)$ & $47,9 \%(58)$ & - & $0,8 \%(1)$ & $\mathbf{1 2 1}$ \\
\hline B & $10,6 \%(33)$ & $42,9 \%(134)$ & $1,0 \%(3)$ & $44,2 \%(138)$ & $0,6 \%(2)$ & $0,6 \%(2)$ & $\mathbf{3 1 2}$ \\
\hline C & $11,7 \%(27)$ & $34,8 \%(80)$ & $3,0 \%(7)$ & $50,0 \%(115)$ & - & $0,4 \%(1)$ & $\mathbf{2 3 0}$ \\
\hline Total & $\mathbf{1 1 , 6 \% ( 7 7 )}$ & $\mathbf{3 8 , 0 \% ( 2 5 2 )}$ & $\mathbf{2 , 6 \% ( 1 7 )}$ & $\mathbf{4 6 , 9 \% ( 3 1 1 )}$ & $\mathbf{0 , 3 \% ( 2 )}$ & $\mathbf{0 , 6 \% ( 4 )}$ & $\mathbf{6 6 3}$ \\
\hline
\end{tabular}

Tabla 7.7. Frecuencia de materias primas por unidad cronoestratigráfica en CP-1. 


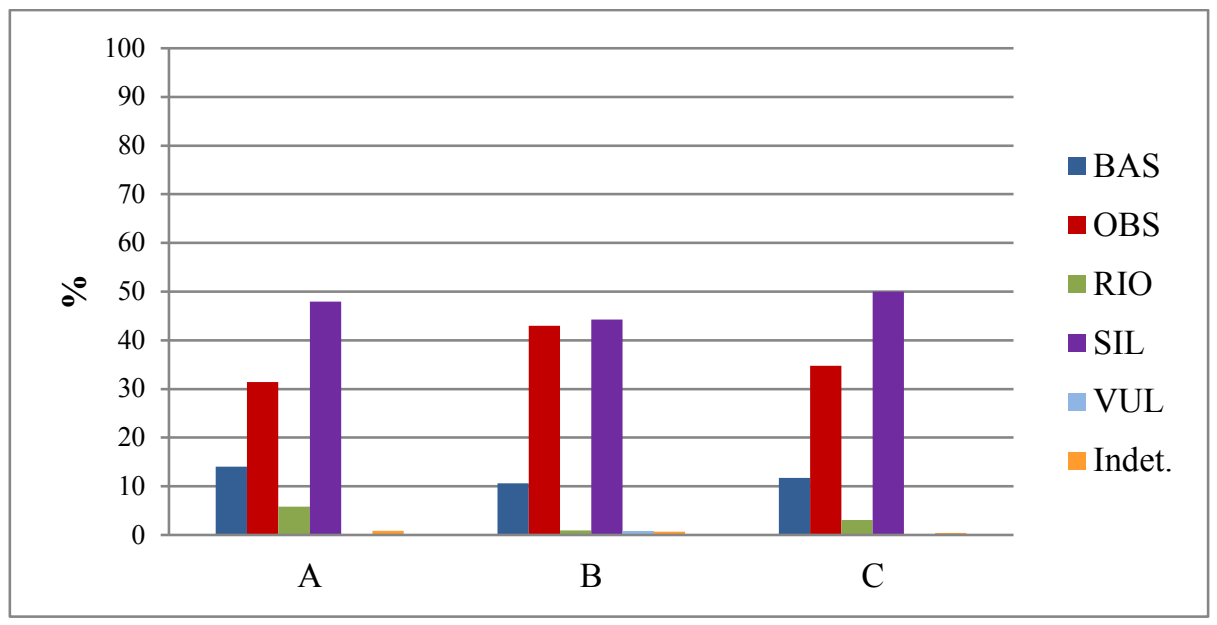

Figura 7.13. Frecuencias relativas de materias primas por unidad cronoestratigráfica en CP-1.

\subsection{Desechos de talla}

Los desechos de talla (DT) constituyen la categoría más abundante en todo el conjunto lítico de CP-1. En ella se presenta la mayor diversidad de rocas, aunque su distribución no es homogénea ya que la materia prima más representada es la roca silícea $(47,72 \%)$, seguida por la obsidiana $(37,8 \%)$, el basalto $(11,34 \%)$, la riolita $(2,68 \%)$ y las rocas indeterminadas $(0,15 \%)$.

Con respecto al estado de fragmentación, el 75,12\% $(n=477)$ se encuentra fracturado (Tabla 7.8). Los desechos enteros sin reserva de corteza representan el 93,04\% $(\mathrm{n}=147)$, seguidos por los desechos con el $25 \%$ de su cara dorsal cubierta por corteza $(4,43 \%, n=7)$, todos sobre rocas silíceas. Luego, aquellos con el $50 \%$ de corteza $(1,90 \%$, $\mathrm{n}=3$ ) y, por último, los desechos con el $75 \%$ de reserva de corteza en su cara dorsal; esta última categoría sólo se ve representada por desechos de basalto. En CP-1 no se registran lascas primarias (Tabla 7.8).

\begin{tabular}{|c|l|c|c|c|c|c|}
\hline Sitio & MP & $\mathbf{0 \%}$ & $\mathbf{2 5 \%}$ & $\mathbf{5 0 \%}$ & $\mathbf{7 5 \%}$ & Total \\
\hline \multirow{5}{*}{ CP-1 } & BAS & $87,50 \%(14)$ & - & $6,25 \%(1)$ & $6,25 \%(1)$ & $\mathbf{1 6}$ \\
\cline { 2 - 7 } & OBS & $98,31 \%(58)$ & - & $1,69 \%(1)$ & - & $\mathbf{5 9}$ \\
\cline { 2 - 7 } & RIO & $100 \%(2)$ & - & - & - & $\mathbf{2}$ \\
\cline { 2 - 7 } & SIL & $90 \%(72)$ & $8,75 \%(7)$ & $1,25 \%(1)$ & - & $\mathbf{8 0}$ \\
\cline { 2 - 7 } & Indet. & $100 \%(1)$ & - & - & - & $\mathbf{1}$ \\
\hline \multicolumn{2}{|c|}{ Total } & $\mathbf{9 3 , 0 4 \% ( 1 4 7 )}$ & $\mathbf{4 , 4 3 \% ( 7 )}$ & $\mathbf{1 , 9 0 \% ( 3 )}$ & $\mathbf{0 , 6 3 \% ( 1 )}$ & $\mathbf{1 5 8}$ \\
\hline
\end{tabular}

Tabla 7.8. Reserva de corteza en la cara dorsal en desechos de talla enteros en CP-1. 
Debido a la alta frecuencia de artefactos fracturados, y como se planteó en el Capítulo 5, se tuvieron en cuenta los conteos e índices propuestos por Hiscock (2002) para no sobreestimar la muestra y explorar procesos de formación de los conjuntos. Para esto se ha calculado el índice de MNF (número mínimo de lascas) para cada materia prima. Siguiendo la fórmula $\mathrm{MNF}=\mathrm{C}+\mathrm{T}+\mathrm{L}$ (detallada en el Capítulo 5), la muestra se reduce de 635 desechos de talla (de tamaño > a 5 x $5 \mathrm{~mm}$ ) a 337, esto es, un 53,07\% del total original (Tabla 7.9).

\begin{tabular}{|c|c|c|c|c|c|c|c|c|}
\hline Sitio & MP & NAS & DT ent. & DT fract. & DT ND & NFS & \multicolumn{2}{|c|}{ MNF (n y \%) } \\
\hline \multirow{4}{*}{ CP-1 } & BAS & 77 & 16 & 56 & - & 72 & 41 & 56,94 \\
\cline { 2 - 9 } & OBS & 252 & 59 & 178 & 3 & 240 & 126 & 52,50 \\
\cline { 2 - 9 } & RIO & 17 & 2 & 15 & - & 17 & 7 & 41,18 \\
\cline { 2 - 9 } & SIL & 311 & 80 & 218 & 5 & 303 & 161 & 53,14 \\
\cline { 2 - 9 } & VUL & 2 & - & 2 & - & 2 & 1 & 50,00 \\
\cline { 2 - 9 } & Indet. & 4 & 1 & - & - & 1 & 1 & 100,00 \\
\hline \multicolumn{2}{|c|}{ Total } & $\mathbf{6 6 3}$ & $\mathbf{1 5 8}$ & $\mathbf{4 6 9}$ & $\mathbf{8}$ & $\mathbf{6 3 5}$ & $\mathbf{3 3 7}$ & $\mathbf{5 3 , 0 7}$ \\
\hline
\end{tabular}

Tabla 7.9. Frecuencias de desechos de talla enteros, fracturados e índice de MNF, por materias primas en el sitio CP-1. Referencias: MP: materia prima; NAS: número de especímenes artefactuales; DT: desechos de talla; Ent.: enteros; Fract.: fracturados; ND: no diferenciados; NFS: número de especímenes identificados como lascas; MNF: número mínimo de lascas; BAS: basalto; OBS: obsidiana; RIO: riolita; SIL: rocas siliceas; VUL: vulcanita indeterminada; Indet.: rocas indeterminadas.

Para calcular los tipos de desechos de talla (Figura 7.14) y las frecuencias de etapas de manufactura (Figura 7.15), se tomaron únicamente los enteros. Entre las subclases o tipos de desechos, las lascas internas alcanzan el 86,71\% ( $\mathrm{n}=137)$ de los desechos enteros de CP-1 $(\mathrm{n}=158)$ (Tabla 7.10). Con un 10,12\% $(\mathrm{n}=16)$ le siguen las lascas de formatización de filo. Por último, las lascas externas representan el 3,16\% ( $\mathrm{n}=5)$ del total de desechos enteros del sitio. Como ya se mencionó, no se han registrado lascas primarias. Los desechos de talla de roca silícea tienen representantes de todos los tipos de lascas. En cambio, la riolita sólo está presente en forma de lascas angulares (Tabla 7.10). En la Figura 7.14 se aprecia el predominio de lascas internas, siendo las lascas angulares las mayoritarias en todas las rocas donde se presentan (basalto, obsidiana, riolita y rocas silíceas). Se observa también que las rocas silíceas son las que presentan mayor cantidad de tipos de lascas. Pese a que en el basalto el tamaño de muestra es menor que en las otras dos materias primas, la diversidad de tipos de lascas es alta. 
Las frecuencias por unidad temporal muestran que las lascas de formatización de filo son más frecuentes sobre silíceas y basaltos de las unidades C y B. Lo contrario ocurre con la obsidiana, cuyas lascas de formatización de filo están ausentes en la Unidad C y aumentan a través del tiempo (Figura 7.15).

\begin{tabular}{|c|c|c|c|c|c|c|c|c|c|}
\hline \multirow[b]{2}{*}{ Sitio } & \multirow[b]{2}{*}{ MP } & \multicolumn{7}{|c|}{ Tipo de lasca } & \multirow[b]{2}{*}{ Total } \\
\hline & & Sec. & $\begin{array}{c}\text { c/dorso } \\
\text { nat. }\end{array}$ & angular & de arista & $\begin{array}{c}\text { adelg. } \\
\text { bif. }\end{array}$ & plana & $\begin{array}{c}\text { de } \\
\text { react. }\end{array}$ & \\
\hline \multirow{5}{*}{ CP-1 } & BAS & $\begin{array}{c}6,25 \% \\
(1)\end{array}$ & - & $\begin{array}{c}56,25 \% \\
\text { (9) }\end{array}$ & $\begin{array}{c}18,75 \% \\
\text { (3) }\end{array}$ & $\begin{array}{c}6,25 \% \\
\text { (1) }\end{array}$ & $\begin{array}{c}12,50 \% \\
\text { (2) }\end{array}$ & - & 16 \\
\hline & OBS & - & $\begin{array}{c}1,69 \% \\
(1)\end{array}$ & $\begin{array}{c}57,63 \% \\
(34)\end{array}$ & $\begin{array}{c}27,12 \% \\
(16)\end{array}$ & $\begin{array}{c}11,87 \% \\
\text { (7) }\end{array}$ & $\begin{array}{c}1,69 \% \\
\text { (1) }\end{array}$ & - & 59 \\
\hline & RIO & - & - & $\begin{array}{c}100 \% \\
(2)\end{array}$ & - & - & - & - & 2 \\
\hline & SIL & $\begin{array}{l}2,50 \% \\
(2)\end{array}$ & $\begin{array}{c}1,25 \% \\
\text { (1) }\end{array}$ & $\begin{array}{c}60,00 \% \\
(48)\end{array}$ & $\begin{array}{c}28,75 \% \\
(23)\end{array}$ & $\begin{array}{c}3,75 \% \\
\text { (3) }\end{array}$ & $\begin{array}{c}2,50 \% \\
\text { (2) }\end{array}$ & $\begin{array}{c}1,25 \% \\
\text { (1) }\end{array}$ & 80 \\
\hline & Indet. & - & - & - & $\begin{array}{c}100 \% \\
(1)\end{array}$ & - & - & - & 1 \\
\hline \multicolumn{2}{|c|}{ Total } & $\begin{array}{c}1,90 \% \\
(3)\end{array}$ & $\begin{array}{c}1,27 \% \\
\text { (2) }\end{array}$ & $\begin{array}{c}59,49 \% \\
(94)\end{array}$ & $\begin{array}{c}27,22 \% \\
(43)\end{array}$ & $\begin{array}{c}6,33 \% \\
(10)\end{array}$ & $\begin{array}{c}3,16 \% \\
\text { (5) }\end{array}$ & $\begin{array}{c}0,63 \% \\
\text { (1) }\end{array}$ & 158 \\
\hline
\end{tabular}

Tabla 7.10. Tipos de desechos de talla procedentes de CP-1 discriminados por tipo de extracción y materia prima. Referencias: sec.: lasca secundaria; adelg. bif: lasca de adelgazamiento bifacial; de react.: lasca de reactivación; c/dorso nat.: lasca con dorso natural.

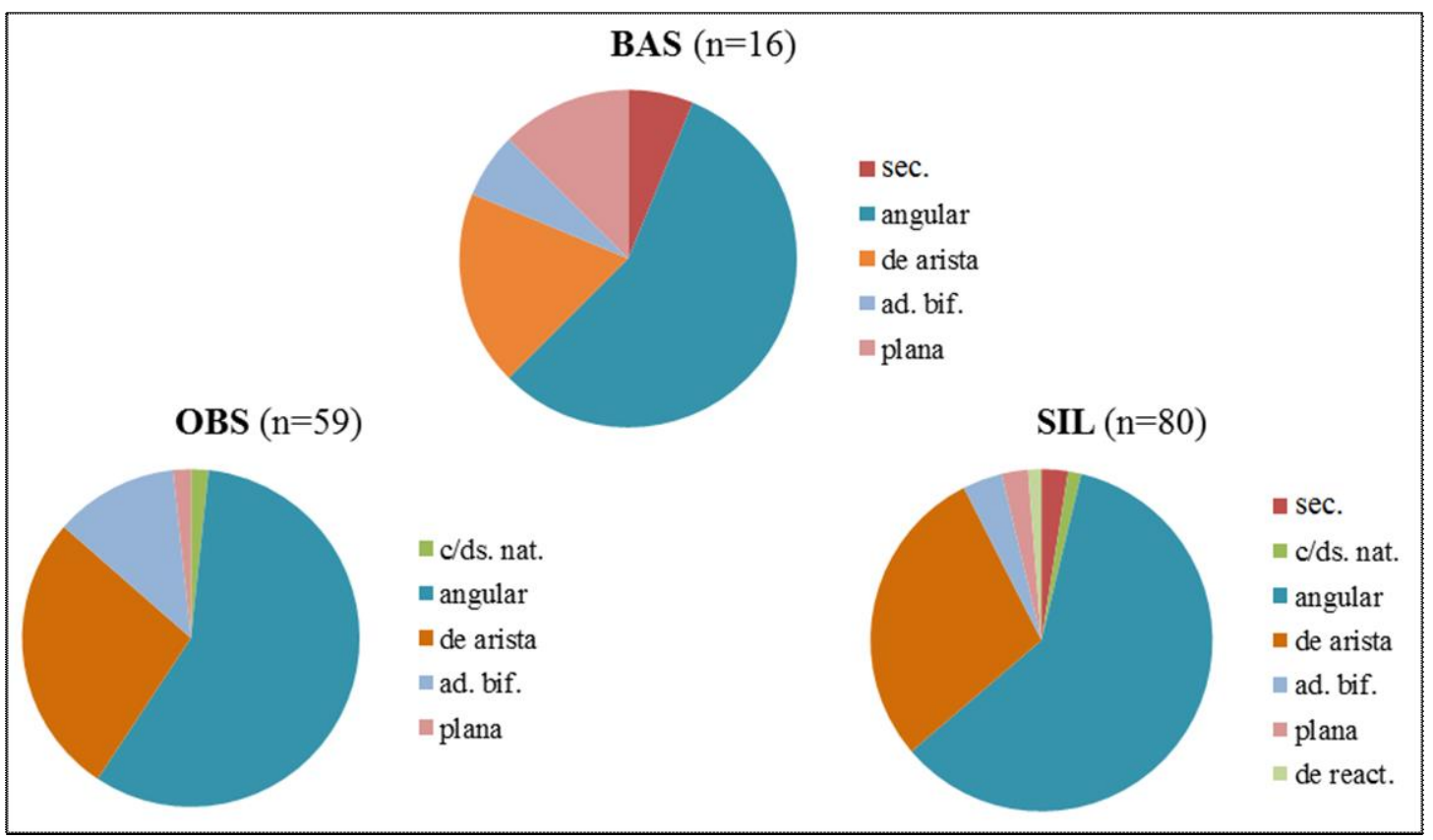

Figura 7.14. Frecuencias relativas de tipos de lasca por materia prima en CP-1. No se incluyeron las dos lascas angulares de riolita ni la lasca de arista sobre roca indeterminada. Entre paréntesis se indica el número total de lascas enteras por materia prima. Referencias: BAS: basalto; OBS; 
obsidiana; SIL: rocas siliceas; sec.: lasca secundaria; c/ds. nat.: lasca con dorso natural; ad. bif.: lasca de adelgazamiento bifacial; de react.: lasca de reactivación.

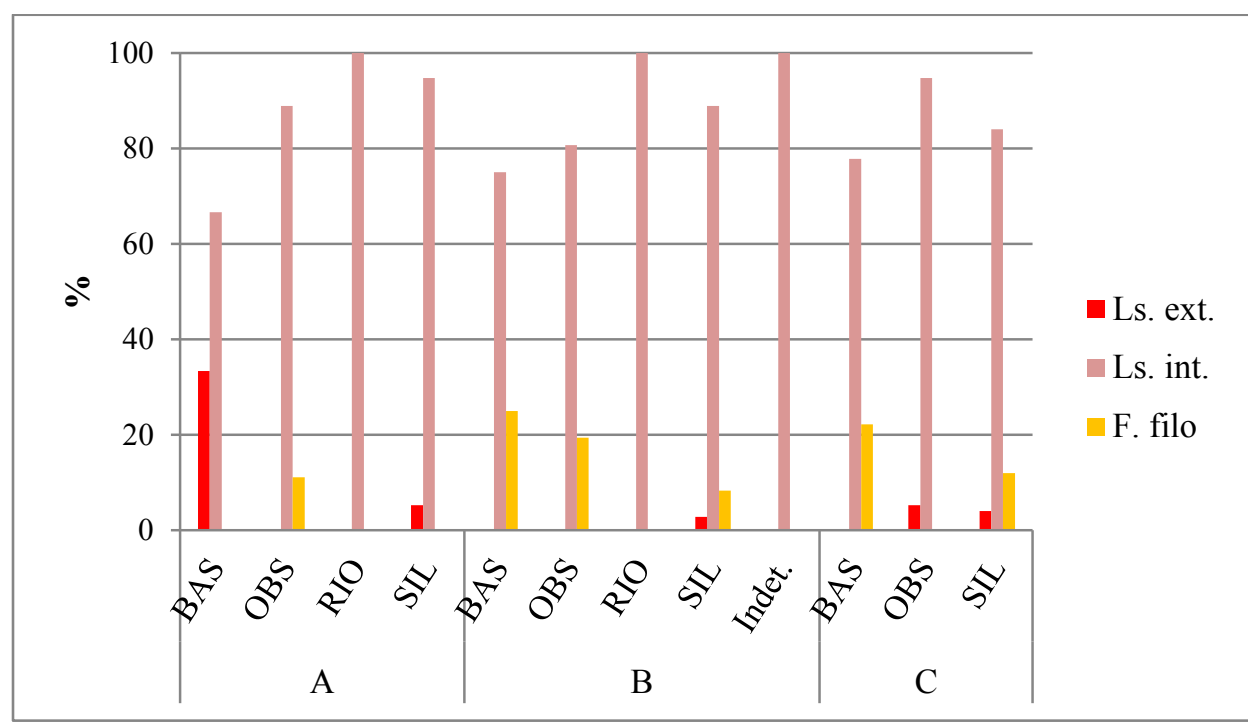

Figura 7.15. Frecuencia de etapas de manufactura por unidad temporal en CP-1. Referencias:

Ls. ext: Lascas externas; Ls. int: lascas internas; F. filo: lascas de formatización de filo.

\subsection{Instrumentos}

Los instrumentos alcanzan el 2,71\% $(\mathrm{n}=18)$ de los 663 artefactos de CP-1 y son la segunda clase artefactual más frecuente después de los DT $(95,78 \%, \mathrm{n}=635)$. La mayoría de los instrumentos están confeccionados sobre obsidiana $(44,44 \%, \mathrm{n}=8)$. Le siguen los instrumentos sobre basalto $(27,78 \%, n=5)$ y sobre roca silícea $(22,22 \%, n=4)$. Se identificó un artefacto manufacturado o modificado por picado, abrasión y/o pulido sobre una roca indeterminada (5,56\%) (Figura 7.16). Este último instrumento y los cinco instrumentos de basalto sólo se han registrado en la Unidad $B(66,67 \%, n=12)$, la más diversa de todo el conjunto (Tabla 7.11 y Figura 7.17).

El $50 \%$ de los instrumentos están enteros $(n=9)$; la otra mitad, fracturados. Estas tendencias se repiten en las tres unidades temporales (se registraron dos instrumentos fracturados de cuatro en la Unidad C, seis de 12 en la Unidad B y un instrumento fracturado de dos en la Unidad A) (Tabla 7.11). 


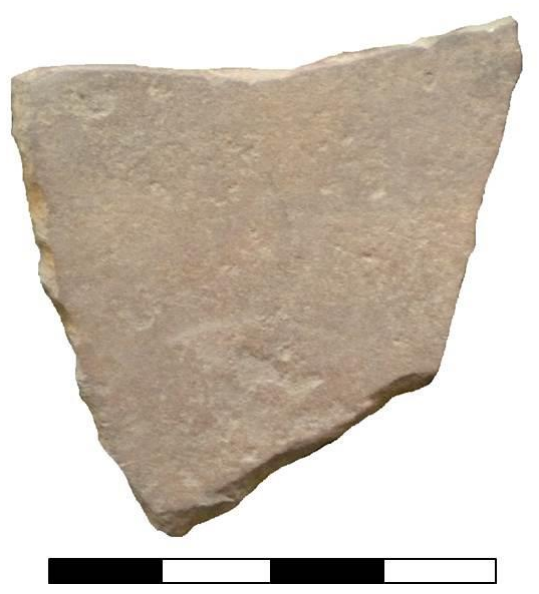

Figura 7.16. Artefacto manufacturado o modificado por picado, abrasión y/o pulido sobre roca indeterminada perteneciente a la Unidad B del sitio CP-1.

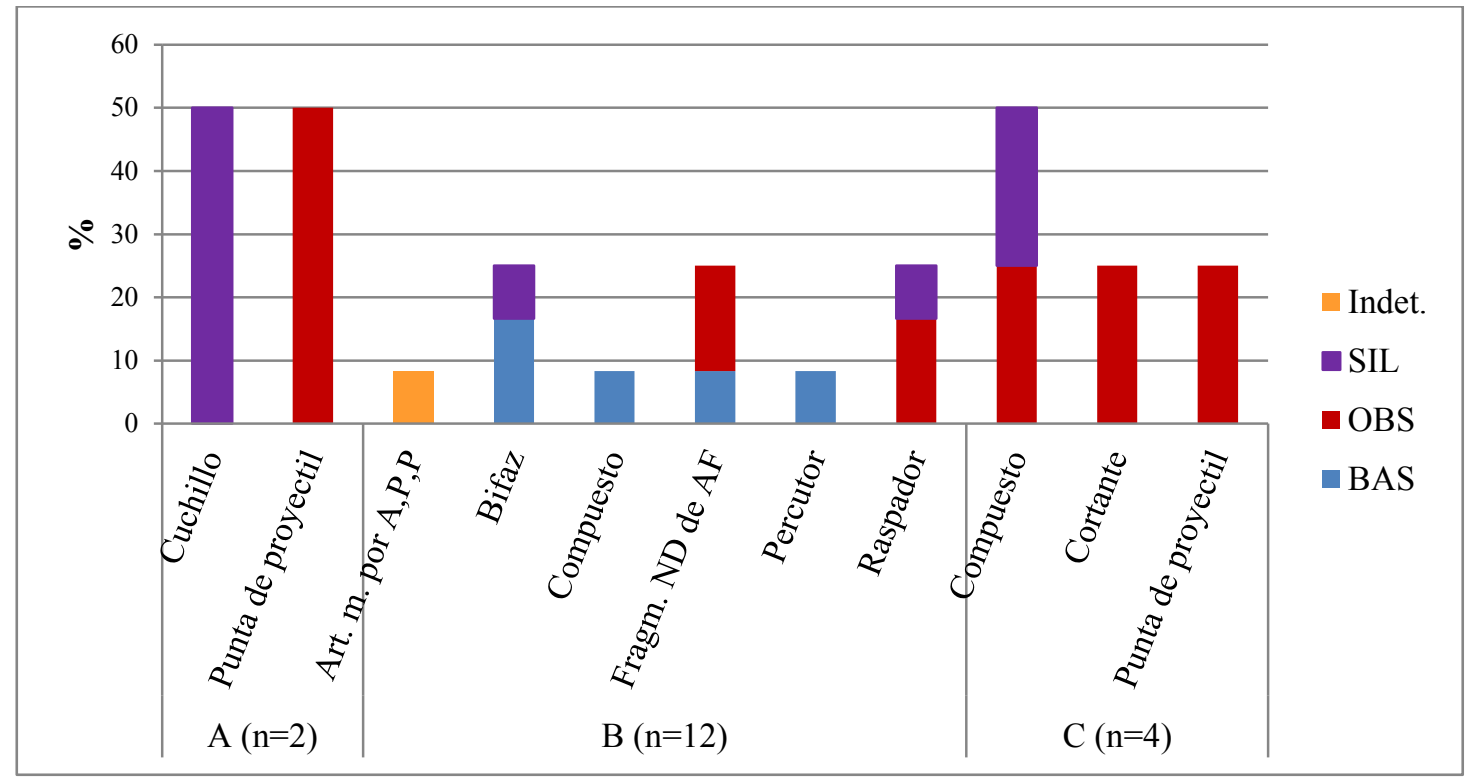

Figura 7.17. Frecuencias de grupos tipológicos por materia prima y unidad temporal en CP-1.

\begin{tabular}{|c|c|c|c|c|c|c|c|c|c|c|c|c|c|c|}
\hline \multirow[b]{2}{*}{ Unid } & \multirow[b]{2}{*}{$\begin{array}{c}\text { Grupo } \\
\text { tipológico }\end{array}$} & \multirow[b]{2}{*}{$\begin{array}{c}\text { Sub-grupo } \\
\text { tipológico }\end{array}$} & \multirow[b]{2}{*}{$n$} & \multirow{2}{*}{$\begin{array}{c}\text { Forma } \\
\text { base }\end{array}$} & \multirow{2}{*}{$\begin{array}{c}\text { Unifac. } \\
\quad 0 \\
\text { bifacial }\end{array}$} & \multirow{2}{*}{$\begin{array}{l}\text { Serie } \\
\text { técnica }\end{array}$} & \multirow{2}{*}{ 䎅 } & \multicolumn{4}{|c|}{ MP } & \multicolumn{2}{|c|}{ Estado } & \multirow[b]{2}{*}{$\begin{array}{l}\text { Obser- } \\
\text { vaciones }\end{array}$} \\
\hline & & & & & & & & $\frac{n}{n}$ & ڤै & E & $\stackrel{\Xi}{\Xi}$ & 馬 & $\stackrel{\mathscr{Z}}{\pi}$ & \\
\hline \multirow[b]{2}{*}{$\mathbf{A}$} & \begin{tabular}{|l|} 
Cuchillo \\
de filo \\
retocado
\end{tabular} & \begin{tabular}{|l|} 
Filo lateral \\
(sin ápice \\
activo)
\end{tabular} & 1 & $\begin{array}{c}\text { Ls. } \\
\text { angular }\end{array}$ & Bifacial & \multirow{2}{*}{$\begin{array}{l}\text { RTo- } \\
\text { MicRTo } \\
\text { ext. }\end{array}$} & Pequeño & - & - & 1 & - & 1 & - & \\
\hline & $\begin{array}{l}\text { Punta de } \\
\text { proyectil }\end{array}$ & \begin{tabular}{|l} 
Fragmento \\
no \\
diferenciado
\end{tabular} & 1 & ND & Bifacial & & NA & - & 1 & - & - & - & 1 & $\begin{array}{l}\text { Posible } \\
\text { fragmento } \\
\text { apical }\end{array}$ \\
\hline \multirow[b]{2}{*}{ B } & \multicolumn{2}{|c|}{$\begin{array}{l}\text { Artefacto } \\
\text { manufacturado por } \\
\text { picado, abrasión, pulido }\end{array}$} & 1 & ND & NA & NA & NA & - & - & - & 1 & - & 1 & \\
\hline & Bifaz & $\begin{array}{l}\text { Fragmento } \\
\text { no } \\
\text { diferenciado }\end{array}$ & 1 & ND & Bifacial & $\begin{array}{l}\text { RTa- } \\
\text { RTo } \\
\text { ext. }\end{array}$ & NA & - & - & 1 & - & - & 1 & $\begin{array}{l}\text { Fragmento } \\
\text { basal; } \\
\text { Posee } \\
\text { corteza }\end{array}$ \\
\hline
\end{tabular}




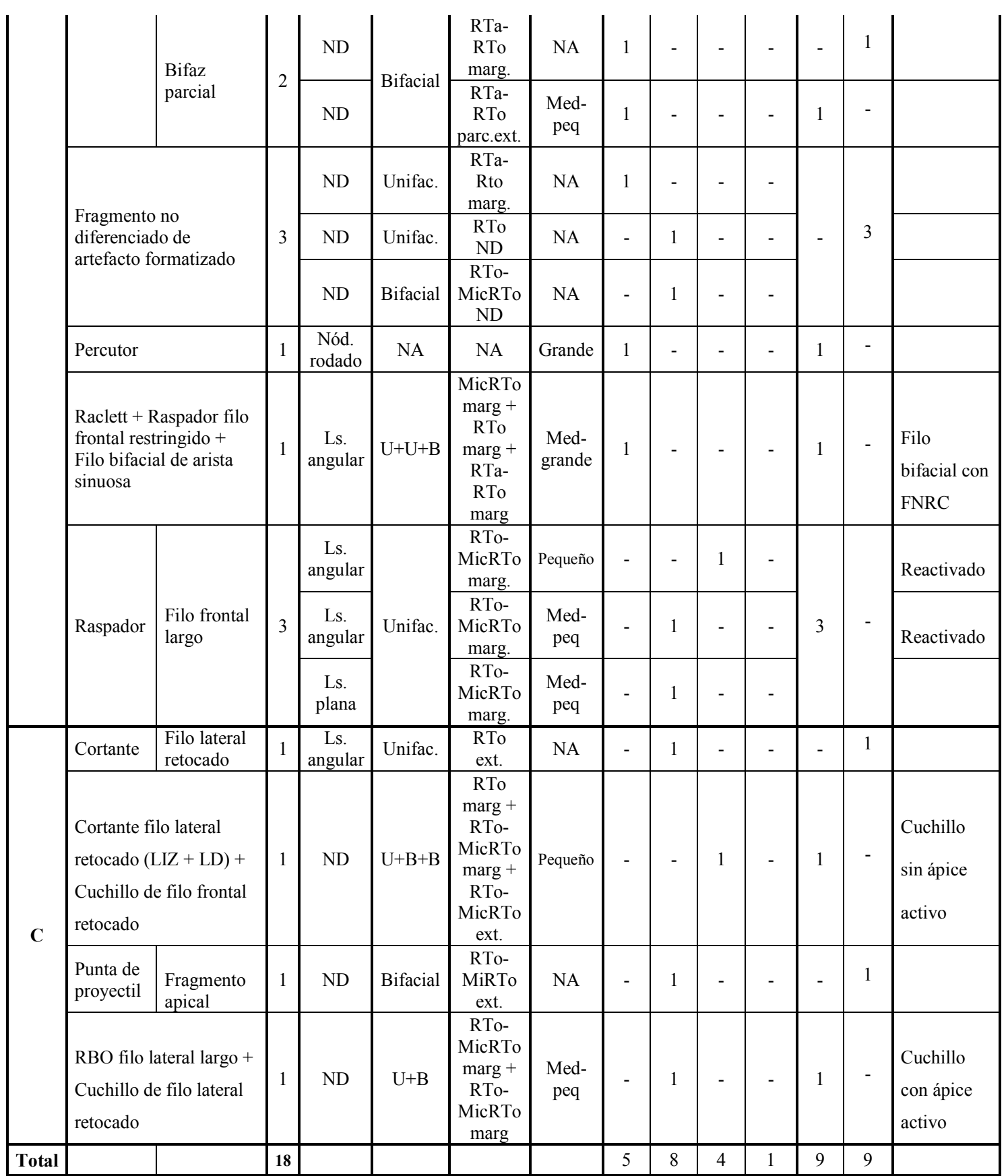

Tabla 7.11. Grupos y sub-grupos tipológicos de los instrumentos de CP-1 por unidad temporal. Referencias: Unid.: Unidad temporal; Unifac.: instrumento unifacial; U: unifacial; B: bifacial; MP: materia prima; BAS: basalto; OBS: obsidiana; SIL: roca silicea; Indet: roca indeterminada; Ent.: instrumento entero; Frac.: instrumento fracturado; Ls.: lasca; LIZ: lado izquierdo; LD: lado derecho; NA: no aplica; ND: no diferenciado/a; RTa: Retalla; RTo: Retoque; MicRTo: Microretoque; Ext.: extendido; Parc. ext.: parcialmente extendido; Marg.: marginal; Med-peq.: mediano-pequeño; Med-grande: mediano-grande.

La mayoría de los instrumentos bifaciales $(n=7)$ son de obsidiana $(42,86 \%, n=3)$, le siguen los de rocas silíceas $(28,57 \%, \mathrm{n}=2)$ y de basalto $(28,57 \%, \mathrm{n}=2)$, este último 
utilizado en ambos casos para la confección de los únicos "bifaces parciales" (sensu Aschero y Hocsman 2004) registrados en la cueva (Figura 7.18). La Unidad B es la que registra la mayor cantidad de instrumentos bifaciales $(57,14 \%, n=4)$. En la Unidad C sólo se registró uno (punta de proyectil de obsidiana) y en la A dos: una punta de proyectil (también sobre obsidiana) y un cuchillo de filo retocado bifacial sobre roca silícea (Tabla 7.11 y Figuras 7.17 y 7.19).

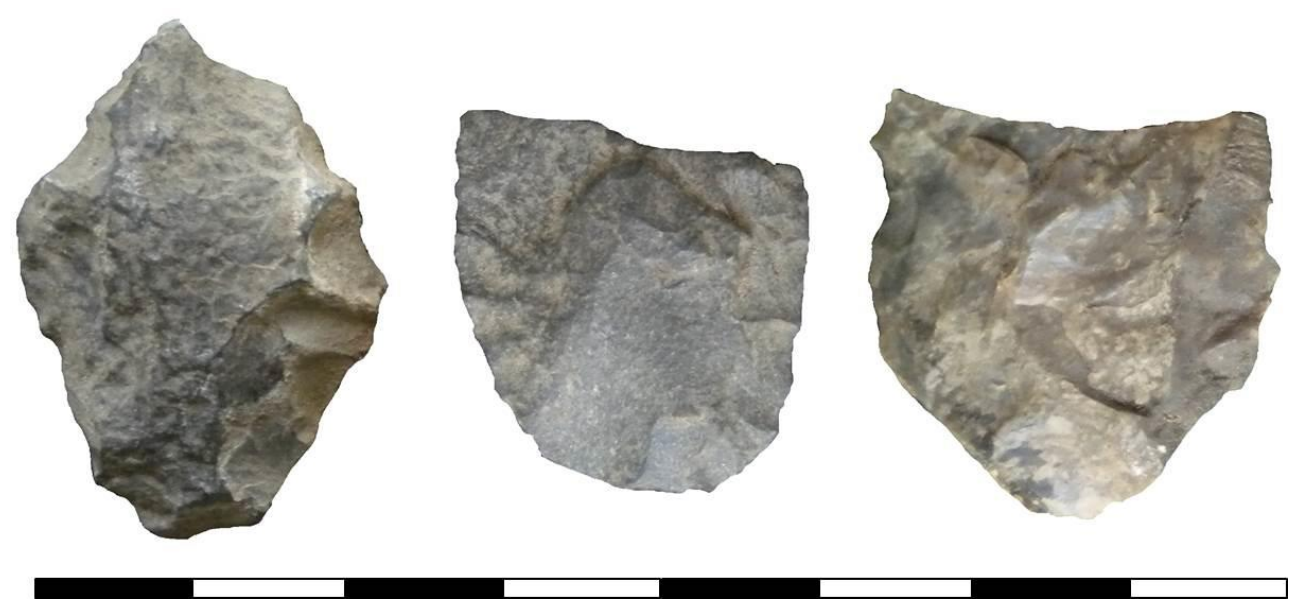

Figura 7.18. De izquierda a derecha: bifaces parciales sobre basalto, entero y fracturado, y fragmento no diferenciado de bifaz sobre roca silícea, registrados en la Unidad B de CP-1.

El $66,67 \%$ de los instrumentos unifaciales $(n=6)$ está confeccionado sobre obsidiana ( $\mathrm{n}=4)$; los otros dos sobre basalto y roca silícea. En la Unidad A no se han registrado instrumentos unifaciales, sino que provienen de la Unidad B $(83,33 \%, n=5)$ y de la Unidad C (n=1) (Tabla 7.11 y Figuras 7.17 y 7.19).

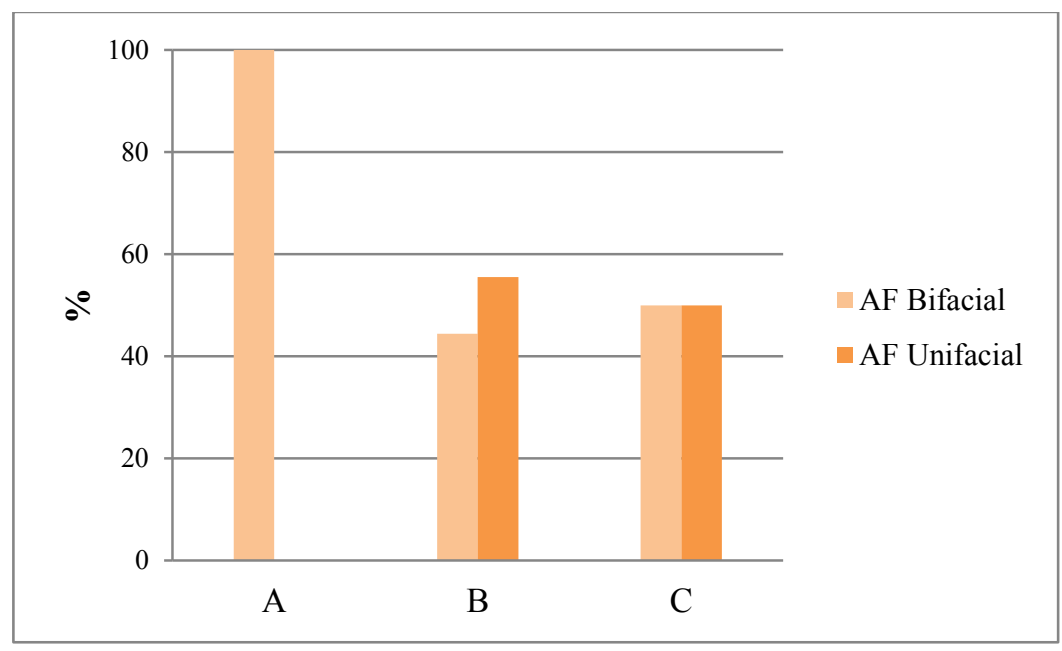

Figura 7.19. Frecuencias de instrumentos bifaciales y unifaciales por unidad temporal en CP-1. 
La serie técnica de los artefactos formatizados de CP-1, muestra que hay una mayor proporción de filos y/o puntas conformadas por retoque, microrretoque, extendido, parcialmente extendido y marginal, tanto en instrumentos unifaciales como bifaciales, de obsidiana, rocas silíceas y basalto, aunque sólo hay retalla en estas últimas dos materias primas (vinculados a bifaces).

Se registraron tres instrumentos compuestos, uno en la Unidad B, confeccionado sobre basalto; y los otros dos en la Unidad C $(66,67 \%)$, uno sobre roca silícea y el otro sobre obsidiana (Figura 7.20). Completa el conjunto de instrumentos un percutor sobre nódulo rodado, que es de basalto, pesa 127,7 gr, está entero y pertenece a la Unidad B.

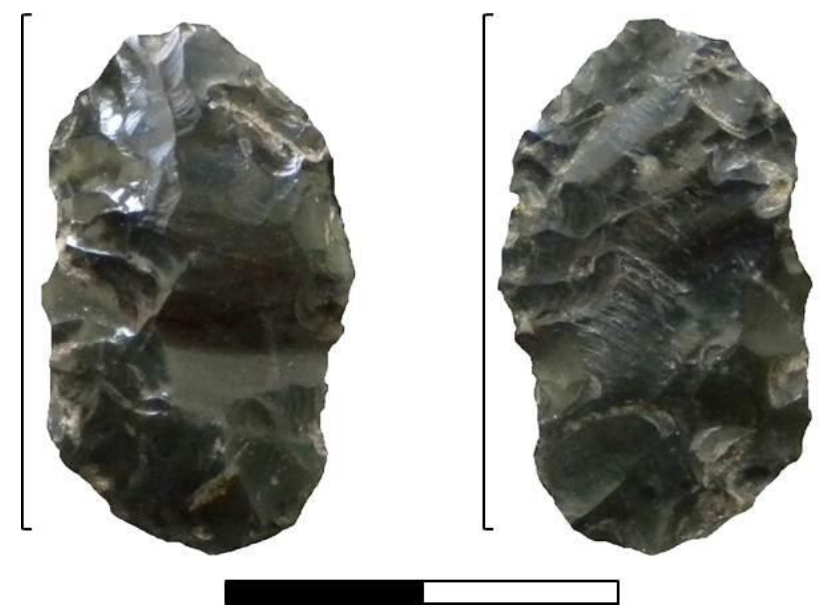

Figura 7.20. Instrumento de obsidiana compuesto por un RBO (filo lateral largo; a la izquierda) y un cuchillo (filo lateral retocado; a la derecha), procedente de la Unidad C del sitio CP-1.

La mitad de los instrumentos enteros $(50 \%, \mathrm{n}=4)$ son de tamaño medianopequeño, el 37,5\% $(n=3)$ pequeño y el 12,5\% $(n=1)$ mediano-grande. Nuevamente, la Unidad B es la que presenta mayor variedad de tamaños.

En la Tabla 7.11 se presenta la totalidad de grupos y sub-grupos tipológicos a través del tiempo. Allí se observa que los instrumentos son mayoritariamente compuestos en la Unidad C (50,0\% de esta unidad temporal) y ausentes en la Unidad A. Asimismo, se observan raspadores únicamente en la Unidad B (los tres de filo frontal largo), dos de ellos (uno de obsidiana y el otro de roca silícea) han sido reactivados, constituyendo la única evidencia de reactivación en CP-1. 


\subsubsection{Síntesis y discusión}

El sitio arqueológico Cueva Palulo 1 (CP-1) es uno de los pocos reparos rocosos localizados sobre la margen derecha del río Atuel. Posee fechados radiocarbónicos que lo remontan al Holoceno tardío inicial (HTI), con ocupaciones humanas desde $3.970 \pm 40$ años AP. Durante este tiempo (Unidad C), la tasa de depositación es de 0,14 artefactos líticos por año y aumenta a 1,56 en la Unidad B (2.230-2.030 años AP). Estos resultados muestran una intensa ocupación del sitio, algo que también puede deducirse de la alta tasa de fragmentación observada en los materiales óseos (Otaola y Llano 2015) y en el alto grado de fragmentación de los artefactos líticos (Tabla 7.9). Las distintas evidencias de procesos postdepositacionales que afectaron al sitio generaron la migración vertical de los distintos elementos (carbón, cerámica, lítico, vegetales). En la Unidad A, la tasa de depositación es de 0,93 artefactos líticos por año.

Según Otaola y Llano (2015) la cueva no presenta evidencias de intensificación para la región, ya que no han identificado aumento en la diversidad de taxones, incorporación de taxa de bajo rendimiento, ni disminución de taxa de alto rendimiento en las unidades B y A. Con respecto al registro lítico, se ha corroborado que la diversidad de instrumentos por unidad temporal, está determinada por el tamaño de la muestra $\left(\mathrm{r}^{2}=\right.$ 0,9938); concretamente, la mayor diversidad de la Unidad B se podría deber al mayor tamaño de muestra (Figura 7.9). Esto no ocurre con las materias primas en las que, el tamaño de la muestra, no determinaría la diversidad del conjunto. La Unidad B es la más variada en cuanto a clases de rocas representadas; en ella, al igual que en toda la secuencia, predominan las rocas silíceas, seguidas por la obsidiana, el basalto, entre otras de menor frecuencia.

En general, las tendencias tecnológicas indican que los desechos de talla y las rocas silíceas son, respectivamente, la clase artefactual y la materia prima más frecuentes. Sin embargo, la roca más utilizada para la confección de los instrumentos es la obsidiana: $50,0 \%(n=4)$ unifaciales, $37,5 \%(n=3)$ bifaciales y $12,5 \%(n=1)$ compuestos; este último proveniente de la Unidad C, la más antigua.

Respecto al estado de fragmentación de los artefactos, los desechos de talla se presentan mayormente fracturados $(73,86 \%, n=469)$, y la mayoría de los enteros $(24,88 \%$, $\mathrm{n}=158)$ no presentan reserva de corteza $(93,04 \%, \mathrm{n}=147)$. Esto es coherente con el predominio de lascas internas $(86,71 \%, \mathrm{n}=137)$ y lascas de formatización de filo $(10,13 \%$, $n=16)$; las lascas externas son escasas $(3,16 \%, n=5)$. Por su parte, la mitad de los 
instrumentos del conjunto ha sido descartado entero $(50 \%, \mathrm{n}=9)$ y la otra mitad fracturados.

En cuanto a las tendencias registradas en la tecnología lítica, se infirieron actividades relacionadas con las etapas avanzadas y finales del proceso de manufactura, incluyendo reactivación de instrumentos, evidenciada en dos raspadores de la Unidad B. La ausencia de núcleos y de lascas primarias, la baja presencia de reserva de corteza en los desechos y la preponderancia de lascas internas, es coherente con estas inferencias, e indican, un aprovechamiento intenso de las materias primas, ya sea por la distancia o por el acceso a las fuentes de aprovisionamiento. Los muestreos de materias primas en las cercanías de CP-1, indican que las rocas locales (basalto, riolita y vulcanita indeterminada, inmediatamente disponibles; y fuentes de rocas silíceas locales, aunque a mayor distancia), se presentan como nódulos con corteza. Por lo tanto, la escasez de esta en los desechos de talla no puede explicarse por la naturaleza intrínseca de estas rocas. Además, a partir de las funciones inferidas de los grupos tipológicos (sensu Aschero 1975, 1983), las cuales deben validarse mediante estudios funcionales, se considera que allí se realizaron actividades relacionadas con el procesamiento de recursos (e.g. madera, cuero, etc.). Entre otras: raspar (instrumentos compuestos en las Unidades B y C, y raspadores en la Unidad B), cortar (instrumento compuesto y cortante en la Unidad C, y cuchillo en la Unidad A), golpear y percutir (percutor en la Unidad B). Las puntas de proyectil registradas en las unidades $\mathrm{A}$ y $\mathrm{C}$, habrían formado parte del toolkit de caza de los grupos que ocuparon CP-1.

En suma, las tendencias obtenidas del análisis de la tecnología lítica, sumadas a las del estudio de los registros zooarqueológico y arqueobotánico, muestran que CP-1 es un sitio de actividades múltiples, con evidencias de procesamiento y consumo de recursos animales y vegetales.

\subsubsection{ARROYO PANCHINO 1 (AP-1)}

El sitio arqueológico Arroyo Panchino-1 (en adelante, AP-1) es un sitio a cielo abierto que se localiza a $2278 \mathrm{msnm}$, sobre la margen derecha del arroyo homónimo, a $500 \mathrm{~m}$ del sitio CP-1 y a $130 \mathrm{~m}$ de Arroyo Panchino-2 (AP-2) (Figuras 7.1, 7.2 y 7.21). Sus coordenadas geográficas lo ubican a $34^{\circ} 56^{\prime} 23^{\prime \prime}$ de LS y a 6950'30,4' de LO. El arroyo es de carácter permanente, con variaciones en su caudal vinculadas a los periodos de derretimiento (primavera-verano) y de acumulación nívea (otoño-invierno). La 
pequeña terraza donde se emplaza el sitio recibe lo sedimentos de las áreas elevadas que rodean el lugar (Figura 7.21). Además, gracias a la humedad que provee el arroyo, hay amplios sectores con vegas, cortaderas y adesmias que ayudan a retener los sedimentos. De esta forma, el lugar tiene un fuerte potencial para la acumulación, tanto de sedimentos como de materiales arqueológicos.

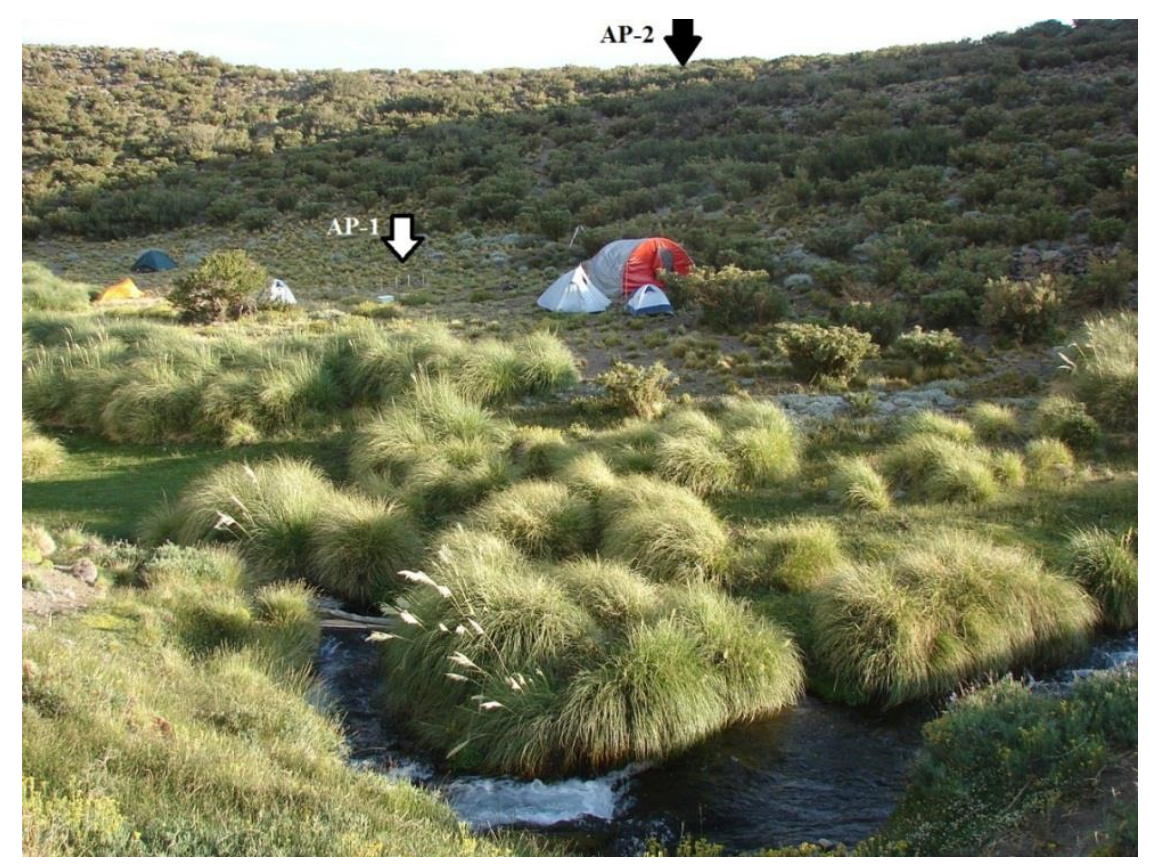

Figura 7.21. Vista panorámica del Arroyo Panchino. En la imagen puede verse la disposición de los sitios AP-1 y AP-2.

\subsubsection{Excavación y estratigrafía}

El sitio fue excavado durante el verano del año 2007 en una superficie de $1 \mathrm{~m}^{2}$, siguiendo niveles artificiales de $10 \mathrm{~cm}$, hasta alcanzar una profundidad de $115 \mathrm{~cm}$. La estratigrafía del sitio está caracterizada por un sedimento de tamaño arena, con algunos clastos angulosos (llegados al lugar desde las elevaciones circundantes por efecto de la gravedad) y redondeados (por las crecidas del arroyo Panchino) (Figura 7.22). 


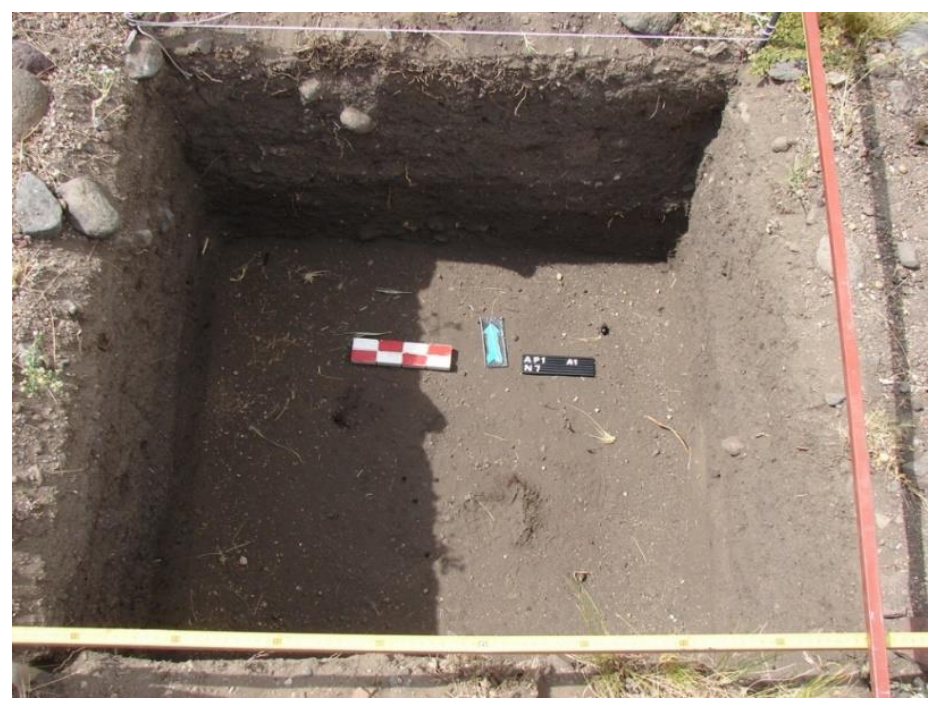

Figura 7.22. Planta de la excavación de AP-1 (nivel 7).

\subsubsection{Cronología y definición de las unidades de análisis}

Se enviaron dos muestras de carbón disperso en capa para ser fechadas por ${ }^{14} \mathrm{C}$. La primera, procedente del nivel 10 (el más profundo de la secuencia), dio una antigüedad de $2.793 \pm 39$ años ${ }^{14} \mathrm{C}$ AP, mientras que la segunda, proveniente del nivel 4, arrojó un resultado de $1.048 \pm 39$ años ${ }^{14} \mathrm{C}$ AP (Tabla 7.12 y Figura 7.23).

\begin{tabular}{|cccccc|} 
Cuadrícula & $\begin{array}{c}\text { Nivel } \\
\text { artific. }\end{array}$ & Fecha ${ }^{14} \mathrm{C}$ & $\begin{array}{c}\text { Edad } \\
\text { cal AP }\end{array}$ & Material & Código Lab \\
\hline A1 & 4 & $1.048 \pm 39$ & 910 & Carbón & AA85694 (AP-1/4) \\
\hline A1 & 10 & $2.793 \pm 39$ & 2.843 & Carbón & AA85695 (AP-1/10) \\
\hline
\end{tabular}

Tabla 7.12. Fechados radiocarbónicos y edades calibradas, obtenidos en AP-1.

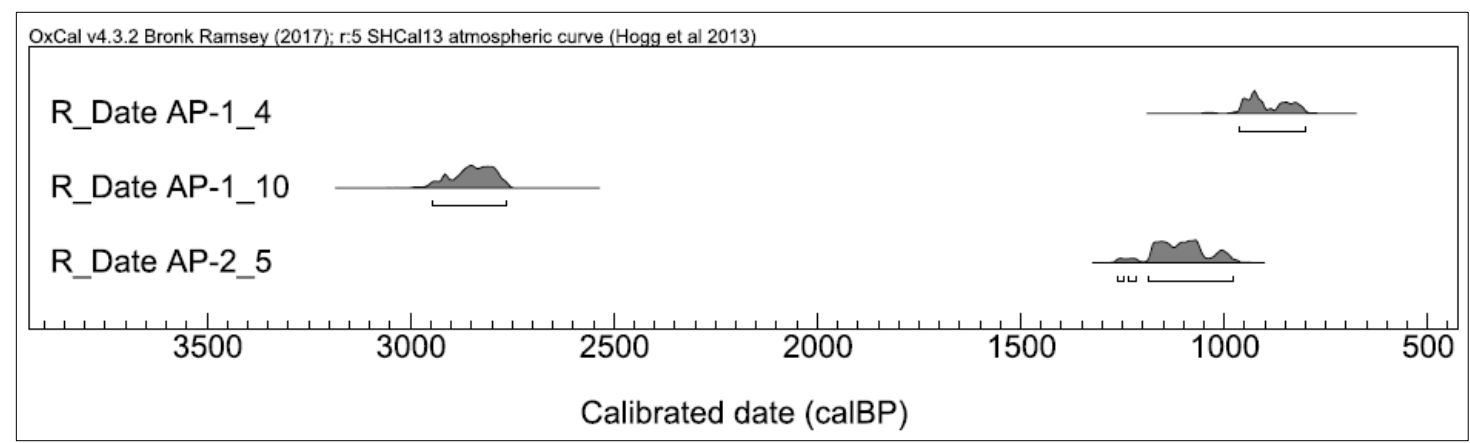

Figura 7.23. Edades calibradas para los sitios AP-1 y AP-2. Calibración realizada con el programa OxCal v4.3.2 (Ramsey 2009), usando la curva atmosférica SHCal 13 para el hemisferio sur (Hogg et al. 2013). 
Debido a la escasa diferenciación de los sedimentos a lo largo de la excavación, se decidió realizar una división de la secuencia en dos unidades cronoestratigráficas. La unidad más reciente, la Unidad A, comprende los primeros cuatro niveles y posee una antigüedad máxima de $1.048 \pm 39$ (Tabla 7.12). La tasa de depositación en este periodo es de 0,3 artefactos líticos por año. La Unidad, B, la más antigua, comprende los seis últimos niveles artificiales de excavación y tiene una antigüedad máxima de $2.793 \pm 39$. Su tasa de depositación es de 0,14 /año, es decir, menor que en la Unidad A, donde también se observa una mayor tasa de descarte de materiales arqueológicos. Por lo tanto, la ocupación aumenta su intensidad hacia momentos más recientes.

\subsubsection{Registro arqueológico}

Las frecuencias relativas de los artefactos líticos de AP-1 por unidad cronoestratigráfica (Figura 7.24), señalan un incremento a través del tiempo, con picos en el nivel $3(\mathrm{n}=131)$ de la Unidad A (últimos 2.000 años AP) y en el nivel $6(\mathrm{n}=130$ artefactos), correspondiente a la Unidad B ( $c a .4 .000-2.000$ años AP), donde la curva es más fluctuante.

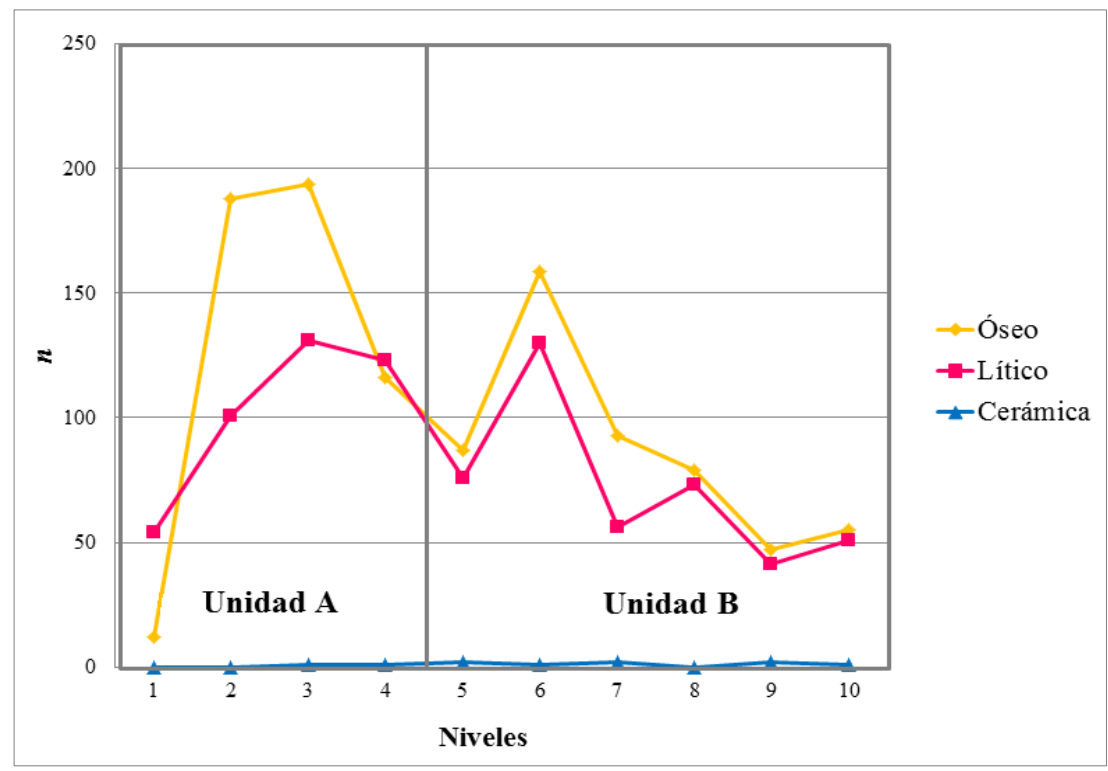

Figura 7.24. Frecuencias absolutas en la distribución de los materiales arqueológicos recuperados en AP-1.

A lo largo de la secuencia estratigráfica de AP-1 se observa que la distribución del material óseo y lítico es homogénea, con un pico máximo en el nivel 3, aunque el registro óseo es más abundante en todos los niveles excepto en el primero y en el 4 (Tabla 7.13 y 
Figura 7.24). Los materiales cerámicos se presentan en una baja cantidad en todos los niveles, aunque con una frecuencia mayor en la Unidad B, la cual posee una edad más antigua que el ingreso de esta tecnología en el sur mendocino; esto sugeriría la presencia de migración vertical desde niveles suprayacentes.

\begin{tabular}{|ccccc|} 
Fechados & $\begin{array}{c}\text { Nivel } \\
\text { artificial }\end{array}$ & Óseo & Lítico & Cerámica \\
\hline & $\mathbf{1}$ & 12 & 54 & 0 \\
& $\mathbf{2}$ & 188 & 101 & 0 \\
$1.048 \pm 39$ & $\mathbf{3}$ & 194 & 131 & 1 \\
& $\mathbf{4}$ & 116 & 123 & 1 \\
& $\mathbf{5}$ & 87 & 76 & 2 \\
& $\mathbf{6}$ & 159 & 130 & 1 \\
& $\mathbf{7}$ & 93 & 56 & 2 \\
& $\mathbf{8}$ & 79 & 73 & 0 \\
$2.793 \pm 39$ & $\mathbf{9}$ & 47 & 41 & 2 \\
\hline \hline & $\mathbf{1 0}$ & 55 & 51 & 1 \\
\hline
\end{tabular}

Tabla 7.13. Fechados y materiales arqueológicos registrados en AP-1 por nivel artificial de excavación.

\subsubsection{Registro lítico}

Se recuperó un total de 836 artefactos líticos (Tabla 7.14), incluyendo 356 desechos de talla no analizados de tamaño igual o menor a $5 \mathrm{~mm}$ de lado (“ $\leq 5 \mathrm{~mm}$ ” en la Tabla 7.14). Aún excluyendo estos artefactos, los desechos de talla son los más abundantes $(94,79 \%, \mathrm{n}=455)(">5 \mathrm{~mm}$ " en la Tabla 7.14). La misma tendencia es observada en ambas unidades cronoestratigráficas (Tabla 7.14).

\begin{tabular}{|c|c|c|c|c|c|c|c|c|c|c|c|}
\hline \multirow{2}{*}{ Nivel } & \multicolumn{2}{|c|}{ Desechos de talla } & \multirow{2}{*}{$\begin{array}{c}\text { AF } \\
\text { Bifacial }\end{array}$} & \multirow{2}{*}{$\begin{array}{c}\text { AF } \\
\text { Unifac. }\end{array}$} & \multirow{2}{*}{$\begin{array}{c}\text { AF } \\
\text { Comp. }\end{array}$} & \multirow{2}{*}{$\begin{array}{c}\text { Art. } \\
\text { manuf. } \\
\text { por } \\
\text { A, P, P }\end{array}$} & \multirow{2}{*}{ AF ND } & \multirow{2}{*}{$\mathbf{P}$} & \multirow{2}{*}{ PPF } & \multirow{2}{*}{ ND } & \multirow{2}{*}{ TOTAL } \\
\hline & $(>5 \mathrm{~mm})$ & $(\leq 5 \mathrm{~mm})$ & & & & & & & & & \\
\hline 1 & 28 & 24 & - & 1 & - & - & - & 1 & - & - & 54 \\
\hline 2 & 49 & 51 & - & - & - & - & - & - & - & 1 & 101 \\
\hline 3 & 80 & 48 & 1 & 1 & - & 1 & - & - & - & - & 131 \\
\hline 4 & 71 & 48 & 1 & 2 & - & - & - & - & - & 1 & 123 \\
\hline 5 & 35 & 35 & 1 & 2 & 1 & - & - & 1 & - & 1 & 76 \\
\hline 6 & 63 & 63 & - & - & - & - & 1 & - & 3 & - & 130 \\
\hline 7 & 27 & 26 & 1 & 1 & - & - & - & - & - & 1 & 56 \\
\hline 8 & 49 & 24 & - & - & - & - & - & - & - & - & 73 \\
\hline 9 & 30 & 10 & - & 1 & - & - & - & - & - & - & 41 \\
\hline 10 & 23 & 27 & - & 1 & - & - & - & - & - & - & 51 \\
\hline Total & 455 & 356 & 4 & 9 & 1 & 1 & 1 & 2 & 3 & 4 & 836 \\
\hline
\end{tabular}




\begin{tabular}{|c|c|c|c|c|c|c|c|c|c|c|c|}
$\begin{array}{c}\text { Total } \\
\%\end{array}$ & 54,43 & 42,58 & 0,48 & 1,08 & 0,12 & 0,12 & 0,12 & 0,24 & 0,36 & 0,48 & 100 \\
\hline
\end{tabular}

Tabla 7.14. Clases artefactuales por nivel de excavación en AP-1. Referencias: AF: Artefacto formatizado; Unifac.: unifacial; Comp.: compuesto; Art. manuf. por A, P, P: Artefacto manufacturado o modificado por abrasión, picado y/o pulido; AF ND: Artefacto formatizado no diferenciado; P: Percutor; PPF: Potencial percutor funcional; ND: Artefacto lítico no diferenciado.

Entre los instrumentos $(3,75 \%, \mathrm{n}=18)$, la segunda categoría preponderante luego de los desechos, predominan los artefactos formatizados unifaciales $(1,87 \%, n=9)$ sobre los bifaciales $(0,83 \%, n=4)$. Le siguen los percutores $(0,42 \%, n=2)$, un instrumento compuesto, un artefacto manufacturado o modificado por picado, abrasión y/o pulido, y un artefacto formatizado no diferenciado (0,21\% cada uno). Completan el total, cuatro artefactos no diferenciados ("ND"; $0,83 \%$ ) y tres "Potenciales Percutores Funcionales" (Frank et al. 2007) (“PPF”; 0,63\%). No se han registrado núcleos en toda la secuencia (Tabla 7.15).

\begin{tabular}{|c|c|c|c|c|c|c|c|c|c|c|}
\hline Unidad & $\begin{array}{c}\text { Desechos } \\
\text { de talla }\end{array}$ & $\begin{array}{c}\text { AF } \\
\text { Bifacial }\end{array}$ & $\begin{array}{c}\text { AF } \\
\text { Unifac. }\end{array}$ & $\begin{array}{c}\text { AF } \\
\text { Comp. }\end{array}$ & $\begin{array}{c}\text { Art. } \\
\text { manuf. } \\
\text { por A, } \\
\text { P, P }\end{array}$ & AF ND & $\mathbf{P}$ & PPF & ND & Total \\
\hline A & $\begin{array}{c}95,8 \% \\
(228) \\
\end{array}$ & $\begin{array}{c}0,8 \% \\
(2) \\
\end{array}$ & $\begin{array}{c}1,7 \% \\
(4)\end{array}$ & - & $\begin{array}{c}0,4 \% \\
(1)\end{array}$ & - & $\begin{array}{c}0,4 \% \\
(1) \\
\end{array}$ & - & $\begin{array}{c}0,8 \% \\
(2)\end{array}$ & 238 \\
\hline B & $\begin{array}{c}93,8 \% \\
(227)\end{array}$ & $\begin{array}{c}0,8 \% \\
(2)\end{array}$ & $\begin{array}{c}2,1 \% \\
(5)\end{array}$ & $\begin{array}{c}0,4 \% \\
\text { (1) }\end{array}$ & - & $\begin{array}{c}0,4 \% \\
(1)\end{array}$ & $\begin{array}{c}0,4 \% \\
\text { (1) }\end{array}$ & $\begin{array}{c}1,2 \% \\
\text { (3) }\end{array}$ & $\begin{array}{c}0,8 \% \\
\text { (2) }\end{array}$ & 242 \\
\hline Total & $\begin{array}{c}94,8 \% \\
(455)\end{array}$ & $\begin{array}{c}0,8 \% \\
\text { (4) }\end{array}$ & $\begin{array}{c}1,9 \% \\
(9)\end{array}$ & $\begin{array}{c}0,2 \% \\
\text { (1) }\end{array}$ & $\begin{array}{c}0,2 \% \\
(1)\end{array}$ & $\begin{array}{c}0,2 \% \\
(1) \\
\end{array}$ & $\begin{array}{c}0,4 \% \\
(2) \\
\end{array}$ & $\begin{array}{c}0,6 \% \\
(3) \\
\end{array}$ & $\begin{array}{c}\mathbf{0 , 8 \%} \\
\text { (4) }\end{array}$ & 480 \\
\hline
\end{tabular}

Tabla 7.15. Clases artefactuales por unidad cronoestratigráfica en AP-1. Entre paréntesis se señala el número de artefactos.

En general, se observan semejanzas entre ambas unidades temporales en relación a las clases artefactuales registradas y, salvo pocas excepciones (un PPF, un instrumento compuesto y uno no diferenciado en la Unidad B -más antigua- y un instrumento manufacturado o modificado por abrasión, picado y/o pulido en la Unidad A -más reciente), la composición artefactual es homogénea en ambos momentos de la secuencia temporal (Tabla 7.15 y Figuras 7.25 y 7.26 ). 


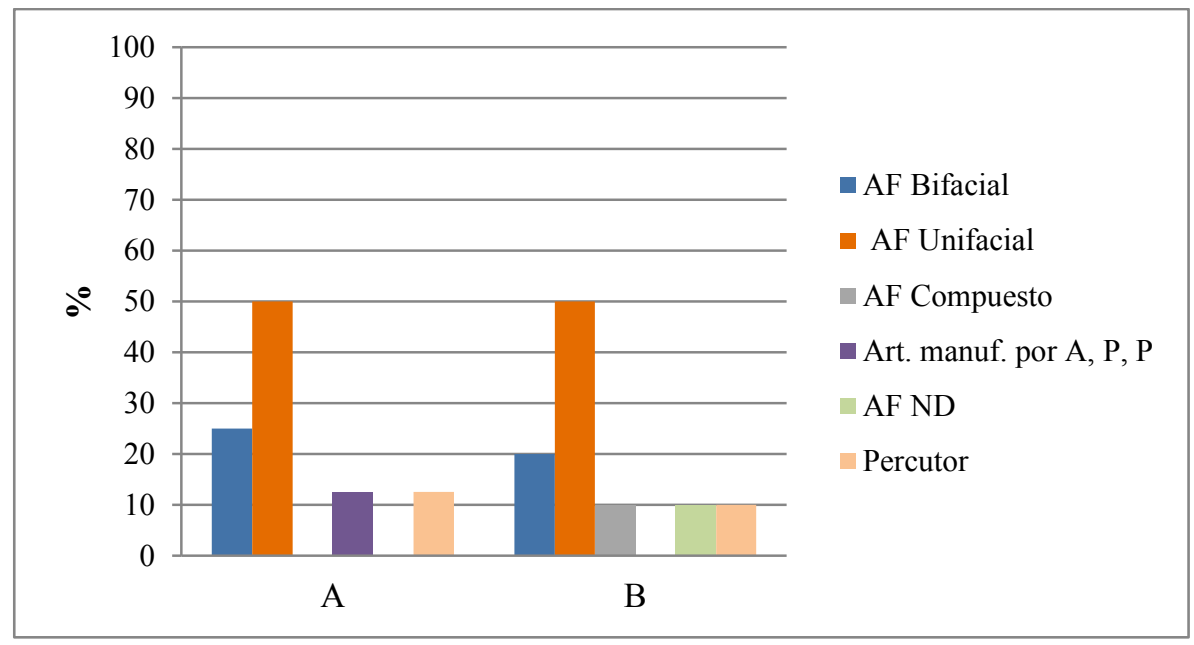

Figura 7.25. Frecuencias relativas de instrumentos por unidad cronoestratigráfica en AP-1.

En la Figura 7.26 se puede observar que, tanto el número de artefactos como la diversidad instrumental, se mantienen a lo largo del tiempo registrándose cuatro categorías por unidad temporal.

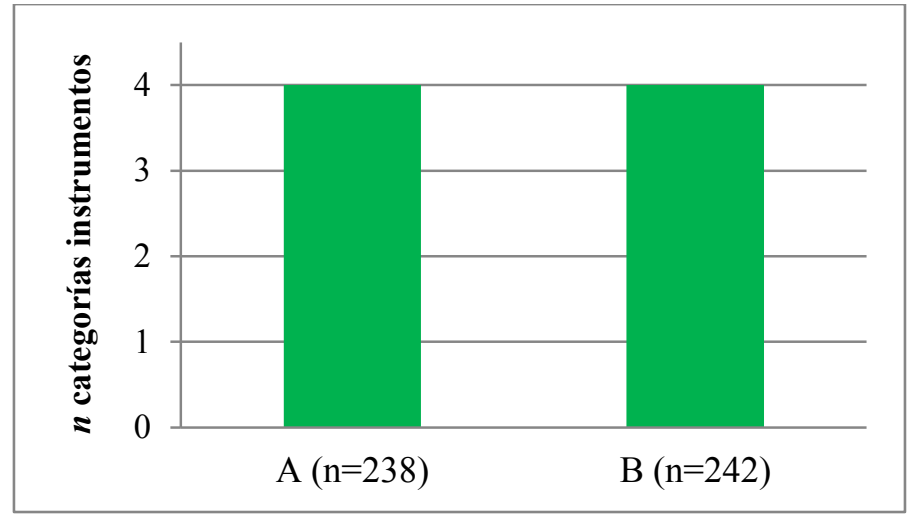

Figura 7.26. Categorías instrumentales por unidad temporal de AP-1. No se ha incluido el instrumento no diferenciado de la Unidad B, ya que podría corresponder a alguna de las otras categorías.

En cuanto a las materias primas predomina la obsidiana $(41,46 \%, n=199)$, aunque es más frecuente en la Unidad A $(54,77 \%, n=109)$ que en la $B(45,23 \%, n=90)$. La obsidiana es, además, la única materia prima que aumenta a través del tiempo. Las rocas silíceas, segunda materia prima más abundante $(37,29 \%, n=179)$, disminuyen desde el 50,84\% ( $\mathrm{n}=91)$ en la Unidad B, al 49,16\% $(\mathrm{n}=88)$ en la Unidad A. En tercer lugar, el basalto $(18,13 \%, \mathrm{n}=87)$ también disminuye desde $56,32 \%(\mathrm{n}=49)$ en la Unidad $\mathrm{B}$, a $43,68 \%(n=38)$ en la A. Las materias primas restantes son: riolita $(1,04 \%, n=5)$, vulcanita indeterminada $(0,83 \%, n=4)$ y seis rocas indeterminadas $(1,25 \%)$. Estas tres categorías de 
rocas se presentan en mayor proporción en la Unidad B (Tablas 7.16 y 7.17, y Figura 7.27). Entonces, la tendencia general del sitio muestra un incremento en el uso de la obsidiana, un decrecimiento en el uso del basalto, riolita y vulcanitas indeterminadas, y una estabilidad en el uso de las rocas silíceas.

\begin{tabular}{|c|c|c|c|c|c|c|c|}
\hline Nivel & BAS & OBS & RIO & SIL & VUL & Indet. & Total \\
\hline 1 & $3(10,0 \%)$ & $10(33,3 \%)$ & - & $17(56,7 \%)$ & - & - & 30 \\
\hline 2 & $3(6,0 \%)$ & $27(54,0 \%)$ & $1(2,0 \%)$ & $19(38,0 \%)$ & - & - & 50 \\
\hline 3 & $12(14,5 \%)$ & $43(51,8 \%)$ & - & $26(31,3 \%)$ & - & $2(2,4 \%)$ & 83 \\
\hline 4 & $20(26,7 \%)$ & $29(38,7 \%)$ & - & $26(34,7 \%)$ & - & - & 75 \\
\hline 5 & $7(17,1 \%)$ & $16(39,0 \%)$ & - & $17(41,5 \%)$ & $1(2,4 \%)$ & - & 41 \\
\hline 6 & $18(26,9 \%)$ & $25(37,3 \%)$ & - & $21(31,3 \%)$ & $3(4,5 \%)$ & - & 67 \\
\hline 7 & $6(20,0 \%)$ & $11(36,7 \%)$ & $3(10,0 \%)$ & $10(33,3 \%)$ & - & - & 30 \\
\hline 8 & $10(20,4 \%)$ & $18(36,7 \%)$ & $1(2,0 \%)$ & $20(40,8 \%)$ & - & - & 49 \\
\hline 9 & $4(12,9 \%)$ & $10(32,3 \%)$ & - & $13(41,9 \%)$ & - & $4(12,9 \%)$ & 31 \\
\hline 10 & $4(16,7 \%)$ & $10(41,7 \%)$ & - & $10(41,7 \%)$ & - & - & 24 \\
\hline Total & $87(18,1 \%)$ & $\begin{array}{c}199 \\
(41,5 \%)\end{array}$ & $5(1,0 \%)$ & $\begin{array}{c}179 \\
(37,3 \%)\end{array}$ & $4(0,8 \%)$ & $6(1,3 \%)$ & 480 \\
\hline
\end{tabular}

Tabla 7.16. Distribución y frecuencia de materias primas por nivel de excavación en AP-1. Referencias: BAS: basalto; OBS: obsidiana; RIO: riolita; SIL: rocas silíceas; VUL: vulcanita indeterminada; Indet.: roca indeterminada.

\begin{tabular}{|c|c|c|c|c|c|c|c|}
\hline Unidad & BAS & OBS & RIO & SIL & VUL & Indet. & TOTAL \\
\hline A & $16,0 \%(38)$ & $45,8 \%(109)$ & $0,4 \%(1)$ & $37,0 \%(88)$ & - & $0,8 \%(2)$ & $\mathbf{2 3 8}$ \\
\hline B & $20,2 \%(49)$ & $37,2 \%(90)$ & $1,7 \%(4)$ & $37,6 \%(91)$ & $1,7 \%(4)$ & $1,7 \%(4)$ & $\mathbf{2 4 2}$ \\
\hline Total & $\mathbf{1 8 , 1 \% ( 8 7 )}$ & $\mathbf{4 1 , 5 \% ( 1 9 9 )}$ & $\mathbf{1 , 0} \%(\mathbf{5})$ & $\mathbf{3 7 , 3 \%}(\mathbf{1 7 9})$ & $\mathbf{0 , 8} \%(\mathbf{4})$ & $\mathbf{1 , 3 \%}(\mathbf{6})$ & $\mathbf{4 8 0}$ \\
\hline
\end{tabular}

Tabla 7.17. Representación de las materias primas por unidad cronoestratigráfica en AP-1. Entre paréntesis se señala el número de artefactos.

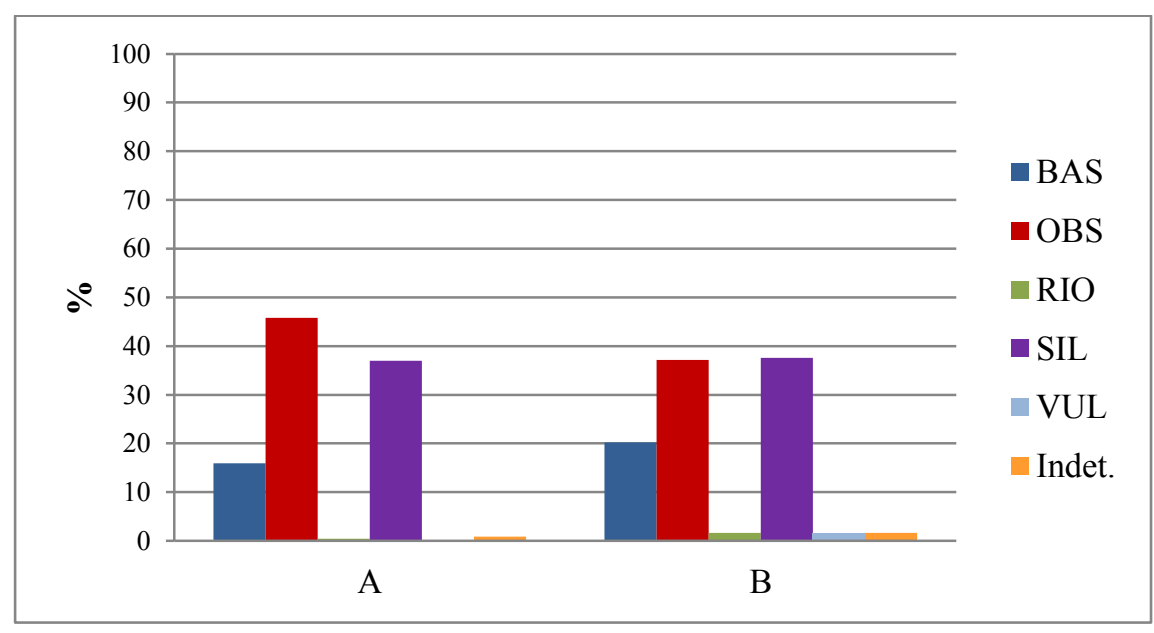

Figura 7.27. Frecuencias relativas de materias primas por unidad cronoestratigráfica en AP-1. 
En la Figura 7.28 se ve que el tamaño de muestra y la diversidad de clases de roca, disminuyen levemente hacia el segmento temporal más reciente (Unidad A). Así, de un total de 242 artefactos líticos en la Unidad B, se registraron seis clases de roca; luego, en la Unidad A $(\mathrm{n}=238)$ se registraron cinco.

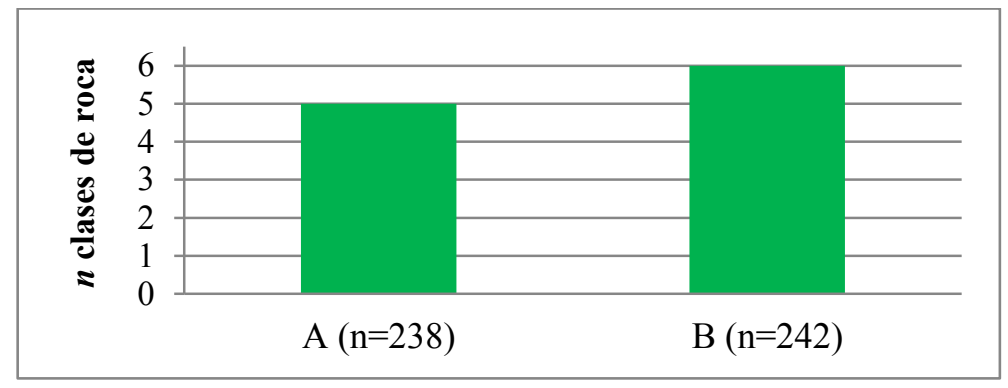

Figura 7.28. Clases de rocas por unidad temporal en AP-1.

\subsection{Desechos de talla}

Los desechos de talla son la clase artefactual predominante en AP-1 e incluyen todas las clases de roca registradas en el sitio. De ellas, la más representada es la obsidiana $(42,86 \%, n=195)$, seguida por las rocas silíceas $(36,92 \%, n=168)$, el basalto $(17,58 \%$, $\mathrm{n}=80)$, la riolita $(1,10 \%, \mathrm{n}=5)$, la vulcanita indeterminada $(0,22 \%, \mathrm{n}=1)$ y las rocas indeterminadas $(1,32 \%, \mathrm{n}=6)$.

En cuanto al estado de fragmentación, el 57,58\% $(n=262)$ se encuentra fragmentado y el 34,29\% $(n=156)$ entero; el $8,13 \%(n=37)$ restante son lascas indiferenciadas. La frecuencia de desechos enteros aumenta de la Unidad B (41,03\%) a la A $(58,97 \%)$. El 91,03\% $(\mathrm{n}=142)$ de los desechos enteros no posee reserva de corteza. Le siguen los desechos con el $25 \%$ de su cara dorsal cubierta por corteza $(5,13 \%, \mathrm{n}=8)$. Luego, aquellos con el $50 \%$ de corteza $(2,56 \%, n=4)$. Un desecho de obsidiana es el único en el que está representada la categoría de $75 \%$ de reserva de corteza en su cara dorsal, y un desecho de basalto con el 100\% de su cara dorsal cubierta por corteza (Tabla 7.18).

\begin{tabular}{|c|c|c|c|c|c|c|c|}
\hline Sitio & MP & $\mathbf{0 \%}$ & $\mathbf{2 5 \%}$ & $\mathbf{5 0 \%}$ & $\mathbf{7 5 \%}$ & $\mathbf{1 0 0 \%}$ & Total \\
\hline \multirow{5}{*}{ AP-1 } & BAS & $80,77 \%(21)$ & $11,53 \%(3)$ & $3,85 \%(1)$ & - & $3,85 \%(1)$ & $\mathbf{2 6}$ \\
\cline { 2 - 8 } & OBS & $95,59 \%(65)$ & $2,94 \%(2)$ & - & $1,47 \%(1)$ & - & $\mathbf{6 8}$ \\
\cline { 2 - 8 } & SIL & $91,67 \%(55)$ & $5,00 \%(3)$ & $3,33 \%(2)$ & - & - & $\mathbf{6 0}$ \\
\cline { 2 - 8 } & VUL & - & - & $100 \%(1)$ & - & - & 1 \\
\cline { 2 - 8 } & Indet. & $100 \%(1)$ & - & - & - & - & $\mathbf{1}$ \\
\hline \multicolumn{2}{|c|}{ Total } & $\mathbf{9 1 , 0 3 \% ( 1 4 2 )}$ & $\mathbf{5 , 1 3 \% ( 8 )}$ & $\mathbf{2 , 5 6 \% ( 4 )}$ & $\mathbf{0 , 6 4 \% ( 1 )}$ & $\mathbf{0 , 6 4 \% ( 1 )}$ & $\mathbf{1 5 6}$ \\
\hline
\end{tabular}

Tabla 7.18. Reserva de corteza en la cara dorsal en desechos de talla enteros en AP-1. 
Para el análisis de los artefactos líticos de AP-1 también se consideraron los conteos e índices propuestos por Hiscock (2002) con el fin de no sobreestimar la muestra. Al calcular el índice de MNF por materia prima, la muestra se redujo de 455 a 272, es decir, el 59,78\% del total original (Tabla 7.19).

\begin{tabular}{|l|l|c|c|c|c|c|c|c|}
\hline Sitio & MP & NAS & DT ent. & DT fract. & ND & NFS & \multicolumn{2}{|c|}{ MNF (n y \%) } \\
\hline \multirow{5}{*}{ AP-1 } & BAS & 87 & 26 & 47 & 7 & 80 & 41 & 51,25 \\
\cline { 2 - 9 } & OBS & 199 & 68 & 112 & 15 & 195 & 117 & 60,00 \\
\cline { 2 - 9 } & RIO & 5 & - & 4 & 1 & 5 & 2 & 40,00 \\
\cline { 2 - 9 } & SIL & 179 & 60 & 94 & 14 & 168 & 109 & 64,88 \\
\cline { 2 - 9 } & VUL & 4 & 1 & - & - & 1 & 1 & 100,00 \\
\cline { 2 - 9 } Indet. & 6 & 1 & 5 & - & 6 & 2 & 33,33 \\
\hline \multicolumn{2}{|l}{ Total } & $\mathbf{4 8 0}$ & $\mathbf{1 5 6}$ & $\mathbf{2 6 2}$ & $\mathbf{3 7}$ & $\mathbf{4 5 5}$ & $\mathbf{2 7 2}$ & $\mathbf{5 9 , 7 8}$ \\
\hline
\end{tabular}

Tabla 7.19. Frecuencias de desechos de talla enteros, fracturados e índice de MNF, por materias primas en el sitio AP-1. Referencias: MP: materia prima; NAS: número de especímenes artefactuales; DT: desechos de talla; Ent.: enteros; Fract.: fracturados; ND: no diferenciados; NFS: número de especímenes identificados como lascas; MNF: número mínimo de lascas; BAS: basalto; OBS: obsidiana; RIO: riolita; SIL: rocas siliceas; VUL: vulcanita indeterminada; Indet.: rocas indeterminadas.

Las lascas internas representan el $81,41 \%(n=127)$ del total de desechos enteros $(\mathrm{n}=156)$ (Tabla 7.19). Le siguen en frecuencia las lascas de formatización de filo $(16,03 \%$, $\mathrm{n}=25)$ y externas $(3,21 \%, \mathrm{n}=5)$. Las subclases de desechos de talla sobre rocas silíceas y sobre obsidiana corresponden a las etapas medias y finales de la talla, y no hay registro de las primeras etapas, excepto por la única lasca secundaria de obsidiana (de la Unidad A). Los desechos de basalto poseen tres representantes de estas primeras instancias de talla, sumándose una lasca secundaria sobre vulcanita indeterminada (Tabla 7.20). En la Figura 7.29 se observa que el uso de la obsidiana y de las rocas silíceas se asemeja más entre sí que con el basalto, que muestra la mayor cantidad de lascas externas (Figura 7.29).

\begin{tabular}{|c|c|c|c|c|c|c|c|c|c|c|}
\hline \multirow[b]{2}{*}{ Sitio } & \multirow[b]{2}{*}{ MP } & \multicolumn{8}{|c|}{ Tipo de lasca } & \multirow[b]{2}{*}{ Total } \\
\hline & & Pr. & Sec. & $\begin{array}{l}\text { c/ds. } \\
\text { nat. }\end{array}$ & $\begin{array}{c}\text { tableta } \\
\text { NU }\end{array}$ & angular & $\begin{array}{c}\text { de } \\
\text { arista }\end{array}$ & ad. bif. & plana & \\
\hline \multirow{3}{*}{ AP-1 } & BAS & $\begin{array}{c}3,85 \% \\
(1)\end{array}$ & - & $\begin{array}{c}3,85 \% \\
\text { (1) }\end{array}$ & $\begin{array}{c}3,85 \% \\
\text { (1) }\end{array}$ & $\begin{array}{c}57,69 \% \\
(15)\end{array}$ & $\begin{array}{c}26,92 \% \\
(7)\end{array}$ & $\begin{array}{c}3,85 \% \\
(1)\end{array}$ & - & 26 \\
\hline & OBS & - & $\begin{array}{c}1,47 \% \\
\text { (1) }\end{array}$ & - & - & $\begin{array}{c}64,71 \% \\
(44)\end{array}$ & $\begin{array}{c}17,65 \% \\
(12)\end{array}$ & $\begin{array}{c}14,71 \% \\
(10)\end{array}$ & $\begin{array}{c}1,47 \% \\
(1)\end{array}$ & 68 \\
\hline & SIL & - & - & - & - & $\begin{array}{c}68,33 \% \\
(41)\end{array}$ & $\begin{array}{c}11,67 \% \\
(7)\end{array}$ & $\begin{array}{c}10,00 \% \\
(6)\end{array}$ & $\begin{array}{c}10,00 \% \\
(6)\end{array}$ & 60 \\
\hline
\end{tabular}




\begin{tabular}{|c|c|c|c|c|c|c|c|c|c|}
\multirow{2}{*}{ VUL } & - & $\begin{array}{c}100 \% \\
(1)\end{array}$ & - & - & - & - & - & - & 1 \\
\cline { 2 - 9 } Indet. & - & - & - & - & $100 \%(1)$ & - & - & - & 1 \\
\hline \multirow{2}{*}{ Total } & $\begin{array}{c}\mathbf{0 , 6 4 \%} \\
(1)\end{array}$ & $\begin{array}{c}\mathbf{1 , 2 8 \%} \\
(2)\end{array}$ & $\begin{array}{c}\mathbf{0 , 6 4 \%} \\
(1)\end{array}$ & $\begin{array}{c}\mathbf{0 , 6 4 \%} \\
(1)\end{array}$ & $\begin{array}{c}\mathbf{6 4 , 7 4 \%} \\
(\mathbf{1 0 1})\end{array}$ & $\begin{array}{c}\mathbf{1 6 , 6 7 \%} \\
(26)\end{array}$ & $\begin{array}{c}\mathbf{1 0 , 9 0 \%} \\
(17)\end{array}$ & $\begin{array}{c}\mathbf{4 , 4 9 \%} \\
(7)\end{array}$ & 156 \\
\hline
\end{tabular}

Tabla 7.20. Tipos de desechos de talla procedentes de AP-1 discriminados por tipo de extracción y materia prima. Referencias: Pr.: lasca primaria; Sec.: lasca secundaria; c/ds. nat.:

lasca con dorso natural; tableta NU: tableta de núcleo; ad. bif: lasca de adelgazamiento bifacial.

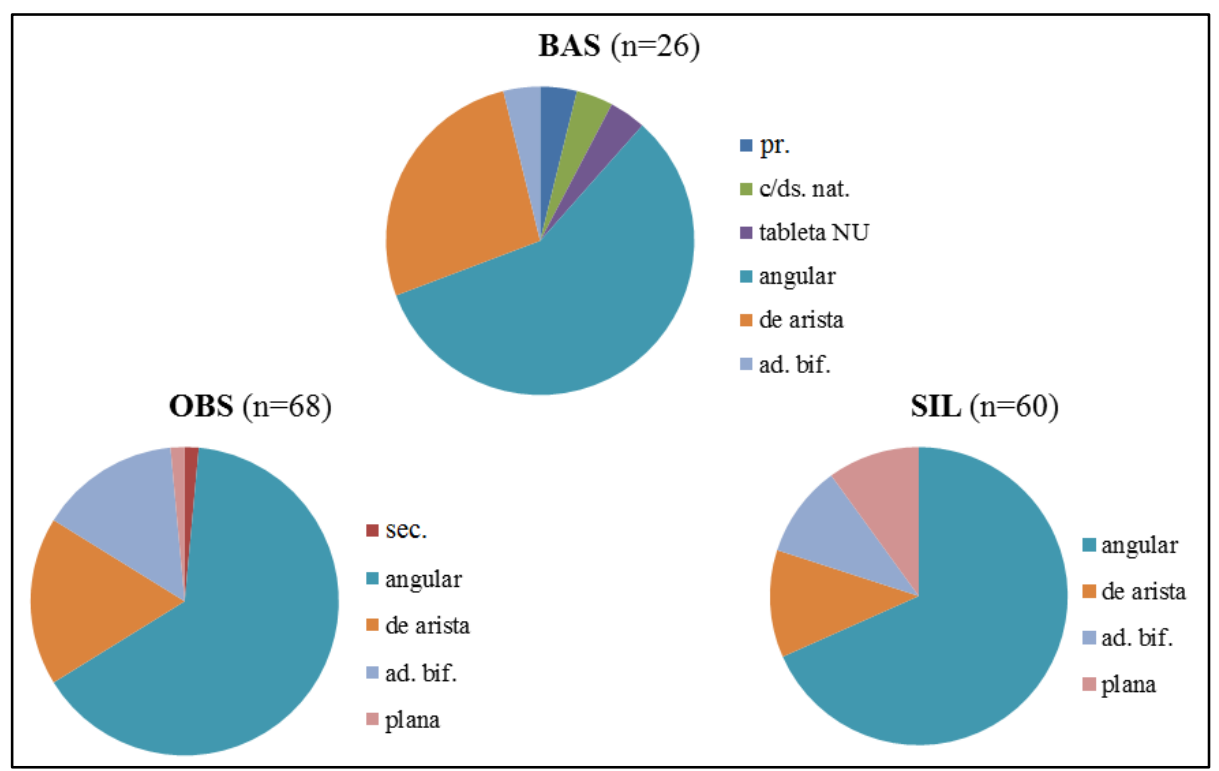

Figura 7.29. Frecuencias relativas de tipos de lasca por materia prima en AP-1. No se incluyó la lasca secundaria de vulcanita indeterminada ni la lasca angular sobre roca indeterminada. Entre paréntesis se indica el número total de lascas enteras por materia prima. Referencias: $B A S$ : basalto; OBS; obsidiana; SIL: rocas silíceas; pr.: lasca primaria; sec.: lasca secundaria; c/ds. nat.: lasca con dorso natural; tableta NU: tableta de núcleo; ad. bif.: lasca de adelgazamiento bifacial.

Las tendencias tecnológicas mencionadas se observan en las dos unidades temporales (Figura 7.30). Las lascas internas predominan en ambos momentos y en todas las clases de roca. Las lascas de formatización de filo de obsidiana y de rocas silíceas aumentan a través del tiempo y las de basalto están ausentes en la unidad más reciente. Las lascas externas de basalto aumentan en la unidad temporal más reciente (Figura 7.30). 


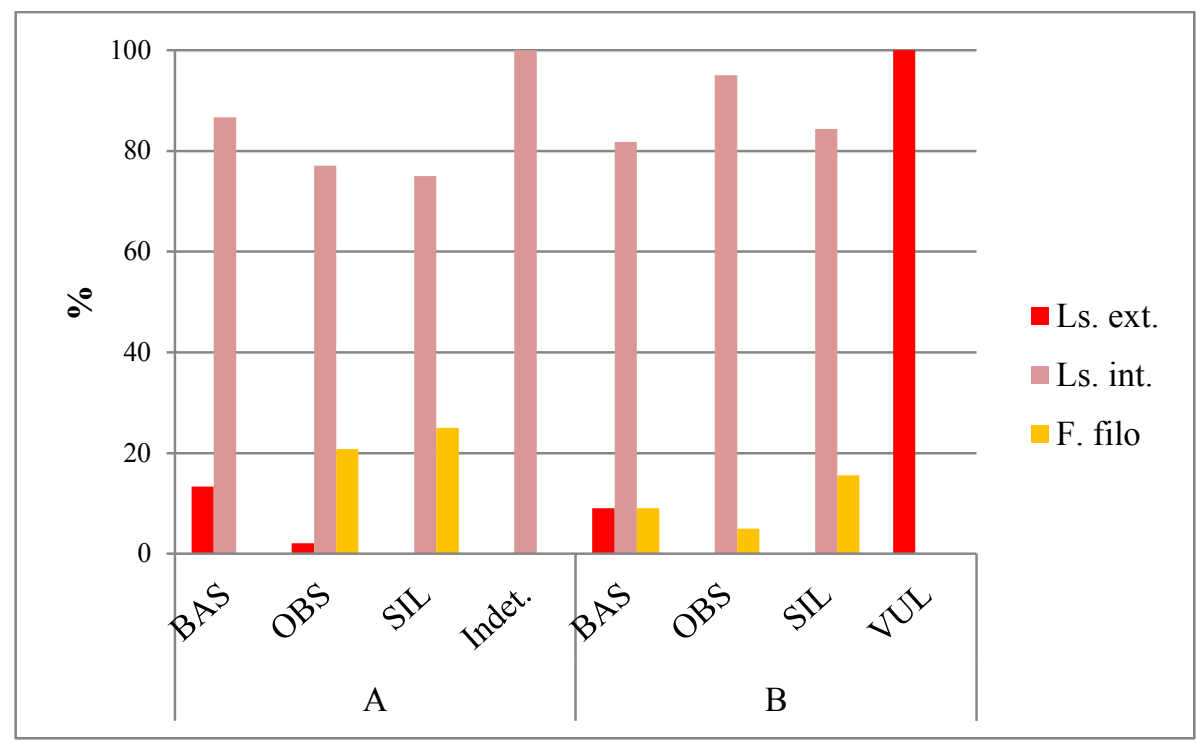

Figura 7.30. Frecuencia de etapas de manufactura por unidad temporal en AP-1. Referencias:

Ls.ext: Lascas externas; Ls.int: lascas internas; F. filo: lascas de formatización de filo.

\subsection{Instrumentos}

Los instrumentos constituyen el 3,75\% $(n=18)$ de los 480 artefactos de AP-1 y es la clase artefactual más frecuente después de los desechos de talla $(94,79 \%, \mathrm{n}=455)$. La mayoría se registraron en la Unidad B $(56,56 \%, n=10)$ y la mitad están confeccionados sobre rocas silíceas $(50 \%, \mathrm{n}=9)$. Le siguen en frecuencia los de basalto $(27,78 \%, \mathrm{n}=5)$ y los de obsidiana $(22,22 \%, n=4)$. Estas son las únicas tres rocas utilizadas en AP-1 para la confección de los instrumentos y están presentes en ambos momentos. Si bien la frecuencia de los instrumentos de basalto aumenta de un $40 \%(\mathrm{n}=2)$ en la Unidad $\mathrm{B}$, a un $60 \%(n=3)$ en la Unidad A, los de rocas silíceas y obsidiana disminuyen de la Unidad B (cinco instrumentos sobre roca silícea y tres sobre obsidiana $-55,55 \%$ y $75 \%$, respectivamente), a la Unidad A (cuatro sobre roca silícea y uno sobre obsidiana $-44,44 \%$ y el $25 \%$, respectivamente).

La mayoría de los instrumentos están enteros $(61,11 \%, n=11)$, aunque esto varía a lo largo del tiempo. En la unidad más antigua predominan los enteros $(70 \%, n=7)$; en la más reciente, los enteros y los fracturados alcanzan el 50\% ( $\mathrm{n}=4$ cada uno), aunque los enteros disminuyen con respecto a la Unidad B: desde 63,64\% $(n=7)$ a $36,36 \%(n=4)$. En la Unidad B hay un solo instrumento entero sobre basalto (un percutor; 14,28\%), tres enteros de obsidiana $(42,85 \%)$ y otros tres, también enteros, sobre rocas silíceas $(42,85 \%)$. Para este momento no se registraron instrumentos fracturados de obsidiana. En la Unidad A, el único instrumento sobre obsidiana está fracturado, de los tres instrumentos de 
basalto dos están enteros y el otro fracturado, y de los cuatro instrumentos sobre rocas silíceas la proporción es 50-50, es decir, dos están enteros y los otros dos fracturados (Tabla 7.21).

\begin{tabular}{|c|c|c|c|c|c|c|c|c|c|c|c|c|c|}
\hline \multirow{2}{*}{ Unid } & \multirow{2}{*}{$\begin{array}{c}\text { Grupo } \\
\text { tipológico }\end{array}$} & \multirow{2}{*}{$\begin{array}{c}\text { Sub-Grupo } \\
\text { tipológico }\end{array}$} & \multirow{2}{*}{$n$} & \multirow{2}{*}{$\begin{array}{c}\text { Forma } \\
\text { base }\end{array}$} & \multirow{2}{*}{$\begin{array}{c}\text { Unifac } \\
\text { o } \\
\text { bifacial }\end{array}$} & \multirow{2}{*}{$\begin{array}{c}\text { Serie } \\
\text { técnica }\end{array}$} & \multirow{2}{*}{ Tamaño } & \multicolumn{3}{|c|}{ MP } & \multicolumn{2}{|c|}{ Estado } & \multirow{2}{*}{ Observac. } \\
\hline & & & & & & & & BAS & OBS & SIL & Ent & Frac & \\
\hline \multirow{8}{*}{ A } & \multicolumn{2}{|c|}{$\begin{array}{l}\text { Artefacto manufacturado } \\
\text { por picado, abrasión, } \\
\text { pulido }\end{array}$} & 1 & $\begin{array}{l}\text { Nódulo } \\
\text { tabular }\end{array}$ & NA & NA & NA & 1 & - & - & - & 1 & $\begin{array}{l}\text { Con marcas } \\
\text { de impacto: } \\
\text { yunque? }\end{array}$ \\
\hline & \multirow{2}{*}{$\begin{array}{l}\text { Artefacto } \\
\text { burilante }\end{array}$} & \begin{tabular}{|l|} 
Muesca \\
burilante \\
lateral \\
\end{tabular} & \multirow[t]{2}{*}{1} & ND & Bifacial & $\begin{array}{l}\text { RTo } \\
\text { marg. }\end{array}$ & NA & - & 1 & - & - & 1 & \\
\hline & & \begin{tabular}{|l|} 
Punta \\
burilante \\
axial
\end{tabular} & & $\begin{array}{c}\text { Ls. } \\
\text { angular }\end{array}$ & Unifac. & \begin{tabular}{|c|} 
RTo- \\
MiRTo \\
marg. \\
\end{tabular} & $\begin{array}{l}\text { Med- } \\
\text { peq }\end{array}$ & 1 & - & - & 1 & - & \\
\hline & $\begin{array}{l}\text { Artefacto de } \\
\text { formatizac. } \\
\text { sumaria }\end{array}$ & $\begin{array}{l}\text { Con retoque } \\
\text { sumario }\end{array}$ & 1 & $\begin{array}{c}\text { Ls. } \\
\text { angular }\end{array}$ & Unifac. & $\begin{array}{l}\text { RTo } \\
\text { marg. }\end{array}$ & NA & - & - & 1 & - & 1 & $\begin{array}{l}\text { Retoque } \\
\text { unifacial } \\
\text { marginal }\end{array}$ \\
\hline & \multirow{2}{*}{$\begin{array}{l}\text { Muescas } \\
\text { retocadas y } \\
\text { de lascado } \\
\text { simple }\end{array}$} & \begin{tabular}{|l|} 
Muesca de \\
lasc. simple \\
filo frontal \\
\end{tabular} & 1 & $\begin{array}{c}\text { Ls. } \\
\text { angular }\end{array}$ & Unifac. & $\begin{array}{l}\text { RTo } \\
\text { marg. }\end{array}$ & $\begin{array}{l}\text { Med- } \\
\text { peq }\end{array}$ & - & - & 1 & 1 & - & \\
\hline & & \begin{tabular}{|l|} 
Muesca \\
retocada filo \\
lateral
\end{tabular} & 1 & $\begin{array}{c}\text { Ls. } \\
\text { angular }\end{array}$ & Unifac. & $\begin{array}{l}\text { RTa- } \\
\text { RTo } \\
\text { marg. }\end{array}$ & $\begin{array}{l}\text { Med- } \\
\text { peq }\end{array}$ & - & - & 1 & 1 & - & \\
\hline & \multicolumn{2}{|l|}{ Percutor } & 1 & $\begin{array}{l}\text { Nód. } \\
\text { rodado }\end{array}$ & NA & NA & \begin{tabular}{|c|} 
Muy \\
grande
\end{tabular} & 1 & - & - & 1 & - & \\
\hline & $\begin{array}{l}\text { Punta de } \\
\text { proyectil }\end{array}$ & \begin{tabular}{|l|} 
Preforma de \\
punta \\
apedunculada
\end{tabular} & 1 & ND & Bifacial & \begin{tabular}{|c|} 
RTo- \\
MiRTo \\
ext. \\
\end{tabular} & NA & - & - & 1 & - & 1 & $\begin{array}{l}\text { Conserva } \\
\text { una porción } \\
\text { de la base }\end{array}$ \\
\hline \multirow{10}{*}{ B } & Bifaz & $\begin{array}{l}\text { Bifaz } \\
\text { parcial }\end{array}$ & 1 & ND & Bifacial & $\begin{array}{l}\text { RTa- } \\
\text { Rto } \\
\text { ext. }\end{array}$ & $\begin{array}{l}\text { Med- } \\
\text { grande }\end{array}$ & - & - & 1 & 1 & - & \\
\hline & \multicolumn{2}{|c|}{$\begin{array}{l}\text { Cortante filo lateral } \\
\text { retocado + Perforador } \\
\text { punta de sec. simétrica }+ \\
\text { Filo pasivo }\end{array}$} & 1 & ND & $\mathrm{B}+\mathrm{B}+\mathrm{U}$ & \begin{tabular}{|c|} 
RTo- \\
MiRTo \\
ext. + \\
RTo- \\
MiRT \\
o marg \\
+ NA \\
\end{tabular} & Pequeño & - & 1 & - & 1 & - & $\begin{array}{l}\text { Perforador } \\
\text { sin base } \\
\text { formatizada }\end{array}$ \\
\hline & $\begin{array}{l}\text { Cuchillo de } \\
\text { filo retocado }\end{array}$ & $\begin{array}{l}\text { Filo fronto- } \\
\text { lateral }\end{array}$ & \multirow[t]{2}{*}{1} & \begin{tabular}{|c|} 
Ls. \\
angular
\end{tabular} & Unifac. & \begin{tabular}{|c|} 
MiRTo \\
marg.
\end{tabular} & $\begin{array}{c}\text { Med- } \\
\text { peq }\end{array}$ & - & - & 1 & 1 & - & $\begin{array}{l}\text { Con FNRC } \\
\text { y PNRC }\end{array}$ \\
\hline & \multicolumn{2}{|c|}{$\begin{array}{l}\text { Fragmento no diferenciado } \\
\text { de artefacto formatizado }\end{array}$} & & ND & ND & ND & NA & 1 & - & - & - & 1 & \\
\hline & \multicolumn{2}{|l|}{ Percutor } & 1 & $\begin{array}{l}\text { Nód. } \\
\text { rodado }\end{array}$ & NA & NA & Grande & 1 & - & - & 1 & - & \\
\hline & \multirow[b]{2}{*}{ Perforador } & $\begin{array}{l}\text { Punta tried. } \\
\text { sec. asim. }\end{array}$ & \multirow[b]{2}{*}{2} & $\begin{array}{c}\text { Ls. } \\
\text { angular }\end{array}$ & \multirow[b]{2}{*}{ Unifac. } & $\begin{array}{l}\text { RTo } \\
\text { marg. }\end{array}$ & Pequeño & - & 1 & - & 1 & - & $\begin{array}{l}\text { Cuerpo/base } \\
\text { formatizado }\end{array}$ \\
\hline & & $\begin{array}{l}\text { Punta tried. } \\
\text { o sec. asim. }\end{array}$ & & $\begin{array}{l}\text { Ls. de } \\
\text { adelg. } \\
\text { bifac. }\end{array}$ & & \begin{tabular}{|c|} 
RTo- \\
MiRT \\
o marg \\
\end{tabular} & $\begin{array}{l}\text { Med- } \\
\text { peq }\end{array}$ & - & 1 & - & 1 & - & $\begin{array}{l}\text { Base no } \\
\text { formatizada }\end{array}$ \\
\hline & $\begin{array}{l}\text { Punta de } \\
\text { proyectil }\end{array}$ & $\begin{array}{l}\text { Preforma de } \\
\text { punta } \\
\text { apedunculada }\end{array}$ & 1 & ND & Bifacial & \begin{tabular}{|c|} 
RTo- \\
MiRTo \\
ext. \\
\end{tabular} & NA & - & - & 1 & - & 1 & $\begin{array}{l}\text { Fragmento } \\
\text { meso-basal }\end{array}$ \\
\hline & \multirow[b]{2}{*}{ Raspador } & $\begin{array}{l}\text { Filo frontal } \\
\text { corto }\end{array}$ & \multirow[b]{2}{*}{2} & \begin{tabular}{|l|} 
Pdp \\
fracturada \\
reciclada \\
\end{tabular} & \multirow[b]{2}{*}{ Unifac. } & $\begin{array}{l}\text { MiRT } \\
\text { o marg }\end{array}$ & \multirow[b]{2}{*}{ Pequeño } & \multirow[b]{2}{*}{ - } & \multirow[b]{2}{*}{ - } & \multirow[b]{2}{*}{2} & 1 & - & Reactivado \\
\hline & & $\begin{array}{l}\text { Filo frontal } \\
\text { largo }\end{array}$ & & $\begin{array}{l}\text { Ls. } \\
\text { angular }\end{array}$ & & \begin{tabular}{|c|} 
RTo- \\
MiRTo \\
parc. \\
ext. \\
\end{tabular} & & & & & - & 1 & \\
\hline Total & & & 18 & & & & & 5 & 4 & 9 & 11 & 7 & \\
\hline
\end{tabular}

Tabla 7.21. Grupos y sub-grupos tipológicos de los instrumentos de AP-1 por unidad temporal. Referencias: Unid.: Unidad temporal; Unifac.: instrumento unifacial; U: unifacial; B: bifacial; 
MP: materia prima; BAS: basalto; OBS: obsidiana; SIL: roca silícea; Indet: roca indeterminada; Ent.: instrumento entero; Frac.: instrumento fracturado; Ls.: lasca; LIZ: lado izquierdo; LD: lado derecho; NA: no aplica; ND: no diferenciado/a; RTa: Retalla; RTo: Retoque; MicRTo: Microretoque; Ext.: extendido; Parc. ext.: parcialmente extendido; Marg.: marginal; Med-peq.: mediano-pequeño; Med-grande: mediano-grande; Pdp: punta de proyectil; FNRC: filo natural con rastros complementarios; PNRC: punta natural con rastros complementarios.

La mitad de los instrumentos son unifaciales $(50 \%, n=9)$ y el $22,22 \%(n=4)$ bifaciales. En la Unidad B, de los cinco instrumentos unifaciales $(50 \%)$, cuatro están enteros, el $60 \%$ está confeccionado sobre rocas silíceas $(n=3)$ y el $40 \%$ sobre obsidiana $(\mathrm{n}=2)$. En esta misma unidad los dos instrumentos bifaciales $(20 \%)$ están confeccionados sobre rocas silíceas; uno está entero y el otro fracturado. Luego, en la unidad temporal más reciente (Unidad A), de los cuatro instrumentos unifaciales (50\%) ninguno es de obsidiana; tres son de rocas silíceas (dos enteros y uno fracturado) y el otro de basalto (entero). Con respecto a los dos instrumentos bifaciales de la Unidad A (25\%), uno se confeccionó sobre roca silícea y el otro sobre obsidiana; ambos están fracturados. En la Figura 7.31 se observa la preponderancia de los artefactos formatizados de manera unifacial en ambas unidades, aunque con un leve aumento de los bifaciales en la unidad más reciente (Unidad A). En la Figura 7.32 se muestra un ejemplo de un instrumento unifacial.

La serie técnica de los artefactos formatizados de AP-1, señala mayor frecuencia de instrumentos unifaciales confeccionados por retoque marginal. Asimismo, se observa la presencia de microrretoque y un solo caso de retalla (en unifaciales y bifaciales). La extensión de los lascados sobre las caras también es extendida y parcialmente extendida. 


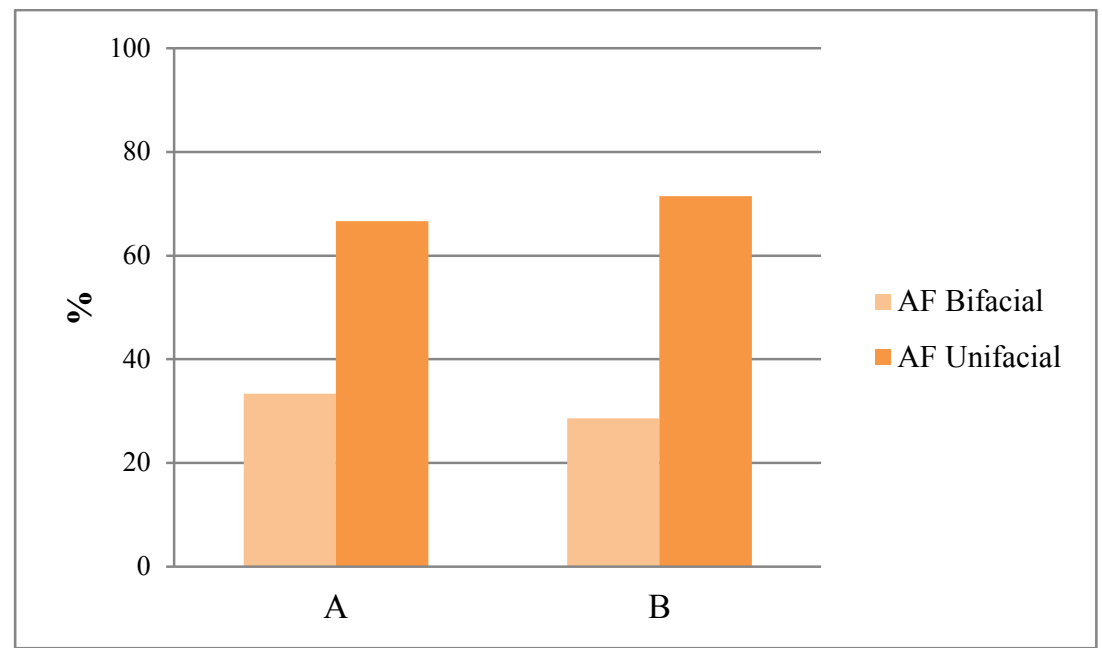

Figura 7.31. Frecuencias de instrumentos bifaciales y unifaciales por unidad temporal en AP-1.

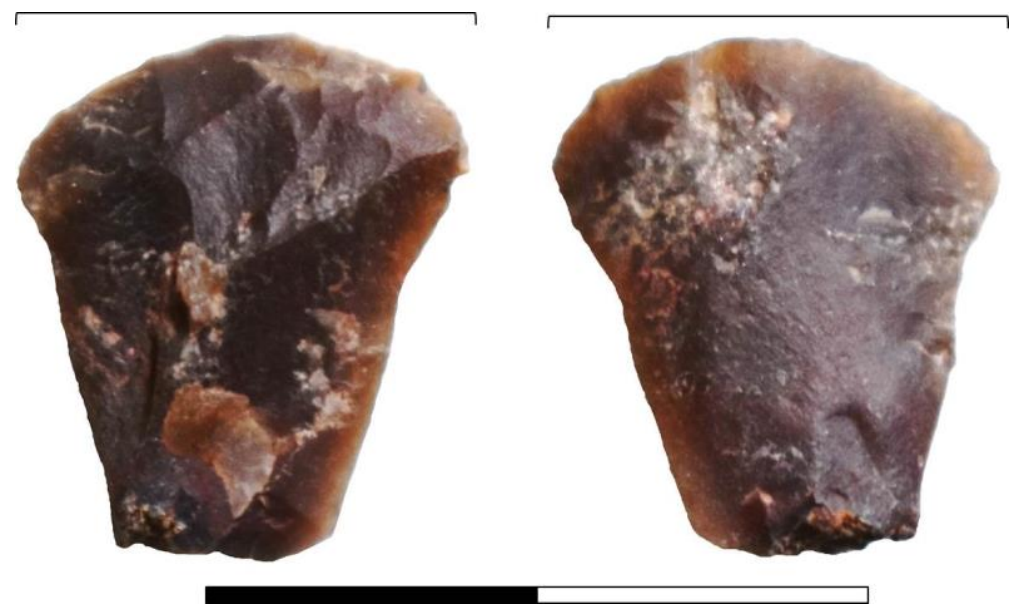

Figura 7.32. Raspador de filo frontal largo de roca silícea, procedente de la Unidad B de AP-1.

Completan el total de instrumentos $(\mathrm{n}=18)$ un fragmento no diferenciado de basalto hallado en la Unidad B, un instrumento compuesto de obsidiana fracturado, también registrado en esta unidad, dos percutores de basalto enteros, uno de la Unidad B y el otro de la A, y un fragmento de artefacto manufacturado o modificado por abrasión, picado y/o pulido sobre basalto, registrado en la Unidad A (Tabla 7.21). La tendencia de este tipo de instrumentos modificado por uso (el artefacto manufacturado o modificado por picado, abrasión y/o pulido) en la unidad más reciente, y la del instrumento compuesto en la unidad más antigua, concuerdan con las expectativas planteadas para cada uno de los dos segmentos del Holoceno tardío (véase Capítulo 1).

En cuanto a los tamaños, la mayoría de los instrumentos enteros tienden a ser pequeños o mediano-pequeños, excepto el único "bifaz parcial" (sensu Aschero y Hocsman 2004) confeccionado sobre roca silícea, de tamaño mediano-grande y registrado 
en la Unidad B de AP-1, y los dos percutores de basalto: el de la Unidad B es de tamaño grande y pesa 89,1 gr; y el de la A, es de tamaño muy grande y pesa 198,9 gr. No se han hallado instrumentos pequeños en la unidad más reciente, en cambio, en la más antigua son los más abundantes $(42,86 \%, \mathrm{n}=3)$. El resto corresponden a dos instrumentos de tamaño mediano-pequeño $(28,57 \%, \mathrm{n}=2)$, el bifaz parcial mediano-grande $(14,28 \%)$ y el percutor grande $(14,28 \%)$. El 75\% $(n=3)$ de los instrumentos enteros de la Unidad A son de tamaño mediano-pequeño y el $25 \%$ restante, muy grande (el percutor de basalto) (Tabla 7.21).

En la Tabla 7.21 están representados todos los grupos y sub-grupos tipológicos por unidad temporal. Se observa que las únicas dos puntas de proyectil registradas (una por unidad temporal) son preformas de puntas apedunculadas y están confeccionadas sobre rocas silíceas. Aunque la materia prima predominante en AP-1 es la obsidiana, la mayoría de los instrumentos y preformas están confeccionados sobre rocas silíceas. Por otro lado, en el sitio no se registraron raspadores en la unidad más reciente (tampoco instrumentos compuestos), sólo se identificaron dos ejemplares en la Unidad B, ambos confeccionados sobre rocas silíceas; uno de ellos reactivado y confeccionado sobre una punta de proyectil fracturada reciclada (Tabla 7.21). En la Figura 7.33 se presentan las frecuencias de los grupos tipológicos a través del tiempo, según la materia prima. Se observa que, salvo pocas excepciones (perforadores y raspadores en la Unidad B, y muescas y artefactos burilantes en la Unidad A), cada grupo tipológico está representado por un único instrumento: seis grupos tipológicos de un total de ocho instrumentos en la Unidad A; y ocho grupos tipológicos, de diez instrumentos en la Unidad B (Figura 7.33). 


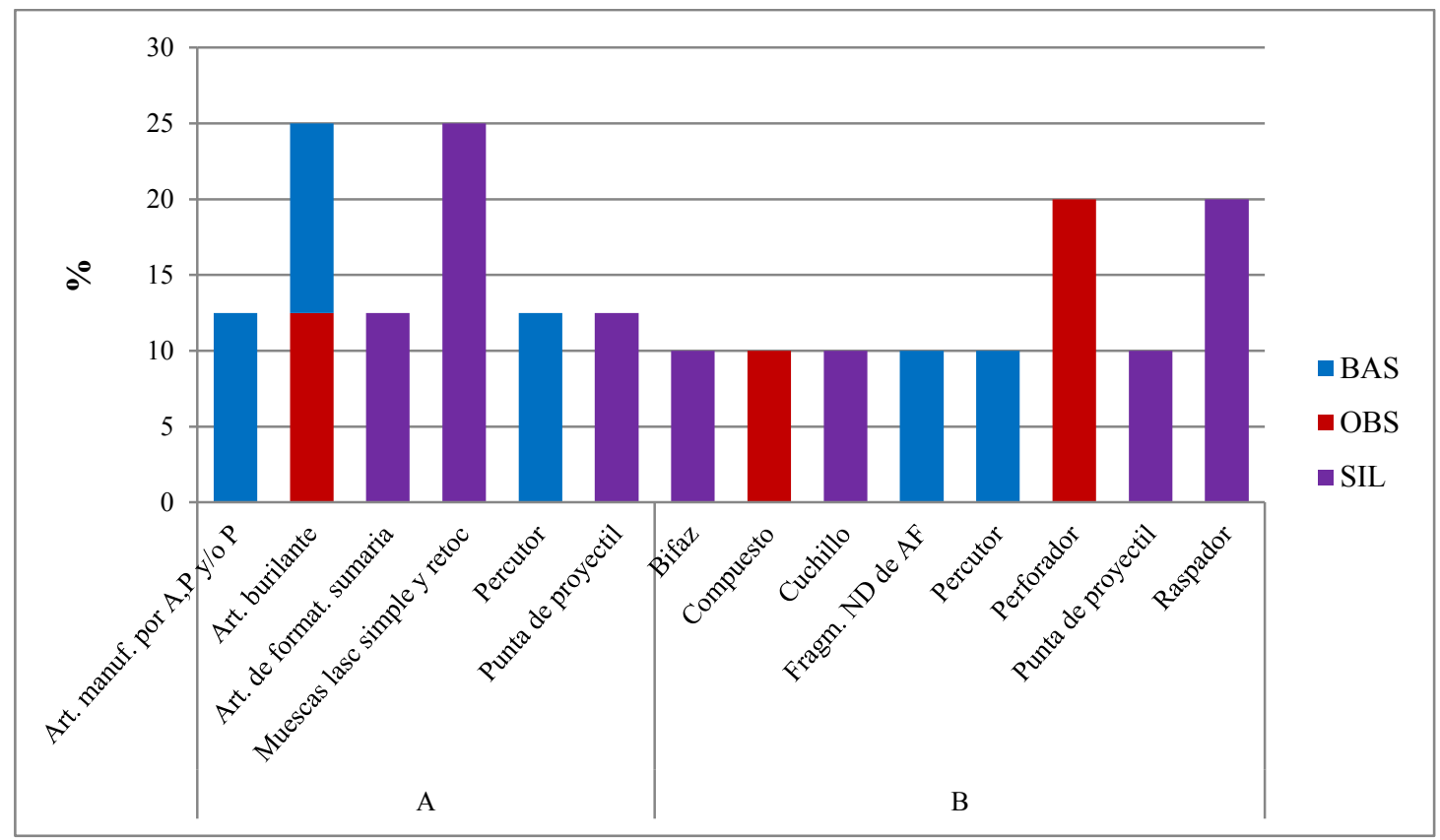

Figura 7.33. Frecuencias de grupos tipológicos por materia prima y unidad temporal en AP-1.

\subsubsection{Síntesis y discusión}

Arroyo Panchino 1 (AP-1) es un sitio arqueológico a cielo abierto con evidencias de presencia humana desde $2.793 \pm 39$ años ${ }^{14} \mathrm{C}$ a $1.048 \pm 39$ años ${ }^{14} \mathrm{C}$, por lo que el registro incluye tanto el HTI (desde $c a .4 .000$ hasta 2.000 años AP), como el HTF (últimos 2.000 años AP). La distribución estratigráfica de materiales óseos y líticos es homogénea, aunque los restos cerámicos se hallaron en niveles de una antigüedad mayor al ingreso de esta tecnología en la región. Esto podría indicar la ocurrencia de migración vertical, aunque haría falta contrastar esto con otras evidencias (e.g. análisis de remontajes de artefactos líticos).

El registro lítico es ligeramente mayor en la unidad más antigua (Unidad B: $50,42 \%)$ que en la Unidad A $(49,58 \%)$. Sin embargo, la Unidad B tiene una extensión temporal mayor a la de la Unidad A (1.700 y 1.000 años, respectivamente), por lo cual, la tasa de depositación es mayor en la Unidad A, más reciente $(0,3$ artefactos líticos descartados por año), que en la Unidad B $(0,14)$.

Las clases artefactuales registradas para uno y otro momento son semejantes, al igual que las materias primas, aunque en estas últimas hay un incremento en el uso de la obsidiana a lo largo del tiempo, y un decrecimiento en las demás. Las rocas silíceas predominan en la Unidad B y, en la Unidad A, la obsidiana. 
Las tendencias tecnológicas muestran el predominio de los desechos de talla entre las clases artefactuales y de la obsidiana entre las materias primas. La mayoría de los desechos está fracturado $(57,58 \%, \mathrm{n}=262) \mathrm{y}$, de los enteros $(34,29 \%, \mathrm{n}=156)$, el 91,03\% $(n=142)$ no posee reserva de corteza. Las lascas internas representan el 81,41\% $(n=127)$. Les siguen las lascas de formatización de filo con un $15,38 \%$ del total $(n=24)$ y las lascas externas con el 3,21\% $(n=5)$. Las lascas internas predominan a través del tiempo en todas las clases de roca. Las lascas de formatización de filo sobre obsidiana y sobre rocas silíceas aumentan hacia los momentos más tardíos; las lascas de formatización de filo de basalto están ausentes en la unidad más reciente (A) y aumentan las externas sobre la misma roca. En el mismo momento en que aumenta dicho tipo de lascas disminuye la cantidad de instrumentos, lo que sugiere un aumento en el mantenimiento de instrumentos, los cuales serían descartados en el lugar de uso.

Los instrumentos constituyen la segunda clase artefactual más frecuente y fueron confeccionados, principalmente, sobre rocas silíceas, luego en obsidiana y, en menor frecuencia, sobre basalto. No hay instrumentos sobre riolita ni vulcanita indeterminada; la riolita se presenta como desechos de talla fracturados y la vulcanita indeterminada está representada en una lasca secundaria y tres "potenciales percutores funcionales" (Frank et al. 2007). Predominan los instrumentos unifaciales en ambos momentos del Holoceno tardío. Hay más instrumentos enteros $(61,11 \%, n=11)$ que fracturados $(38,89 \%, n=7)$, aunque en la Unidad B la diferencia es mucho más notoria $(70 \%$ enteros y $30 \%$ fracturados) que en la Unidad A (50\% enteros y 50\% fracturados). Esto sugiere que en el lapso más antiguo el descarte de instrumentos enteros fue mayor $(63,64 \%, n=7)$ que en el segmento más reciente $(36,36 \%, n=4)$. Con respecto a los instrumentos fracturados, sus frecuencias son más similares entre ambos momentos $(42,86 \%, \mathrm{n}=3$ en la Unidad B y $57,14 \%, \mathrm{n}=4$ en la Unidad A) y sus fracturas pudieron ser la causa misma de su descarte (cf. Weitzel 2010 para considerar los tipos de fractura), sin ser reciclados (el único instrumento reactivado está entero). Es llamativo que, de las tres materias primas de los instrumentos, sólo la obsidiana es de procedencia no local y la que presenta mayor frecuencia de descarte de instrumentos enteros (75\%). Si a esto se incorpora la información brindada por el análisis de los desechos de talla, se puede apreciar que los enteros aumentan y los fracturados disminuyen a través del tiempo, es decir, ocurre lo contrario a instrumentos enteros y fracturados. Por lo tanto, disminuye la posibilidad de que procesos postdepositacionales como el pisoteo, sean la razón del estado de 
fragmentación, ya que si fuera así, tanto instrumentos como desechos deberían aumentar o disminuir sus frecuencias de un segmento temporal a otro.

Los únicos ASF RC son un filo y una punta naturales con rastros complementarios sobre el cuchillo de filo retocado de la Unidad B. No hay registro de núcleos en AP-1.

Las tendencias tecnológicas observadas sugieren que AP-1 habría sido un sitio de actividades múltiples a cielo abierto, donde se llevaron a cabo tareas relacionadas con las etapas avanzadas y finales de la confección, y mantenimiento de instrumentos líticos. La ausencia de núcleos y de evidencias de descortezamiento, la baja presencia de corteza en la cara dorsal de los desechos y el predominio de lascas internas, sostienen esta idea y sugieren también un aprovechamiento intensivo de las materias primas, ya sea por la distancia (e.g. obsidiana de procedencia no local, reducida en las canteras para su transporte) o el acceso a las fuentes de aprovisionamiento. Sin embargo, esto último no concuerda con lo mencionado acerca del descarte de instrumentos enteros confeccionados sobre obsidiana.

Además de las tareas de talla, la diversidad registrada de grupos tipológicos indica que en AP-1 se habrían realizado distintas actividades de procesamiento de recursos vegetales y animales, mediante tareas de raspado (raspadores durante el segmento temporal más antiguo y muescas en la Unidad A, más reciente), corte y perforación (cortantes y cuchillos, y perforadores, respectivamente, en la Unidad B, más antigua), golpe y percusión (percutores en ambos segmentos temporales), incisión (artefactos burilantes durante la Unidad A), entre otras, considerando las funciones inferidas para los grupos tipológicos de la muestra (sensu Aschero 1975, 1983). Esta idea, igualmente, requiere de su corroboración a partir de estudios funcionales específicos. Las puntas de proyectil, registradas para ambos momentos de la secuencia temporal, habrían conformado el toolkit utilizado para la caza.

\subsubsection{ARROYO PANCHINO 2 (AP-2)}

A unos 130 m de AP-1, se localiza el sitio Arroyo Panchino 2 (en adelante, AP2), también un sitio a cielo abierto, localizado en el borde de una extensa planicie de altura (Figura 7.1, 7.2, 7.21 y 7.34). Se emplaza a 2310 msnm (345 $56^{\prime} 28,3^{\prime \prime}$ ' de LS; 6950'31,6" de LO). Este sitio también ha arrojado una antigüedad correspondiente al Holoceno tardío. Al estar localizado por encima de la planicie de inundación del arroyo Panchino, 
la vegetación es más xerófila que la descripta en AP-1, y de tipo patagónica, con presencia de Adesmias, Schinus y pastizales.

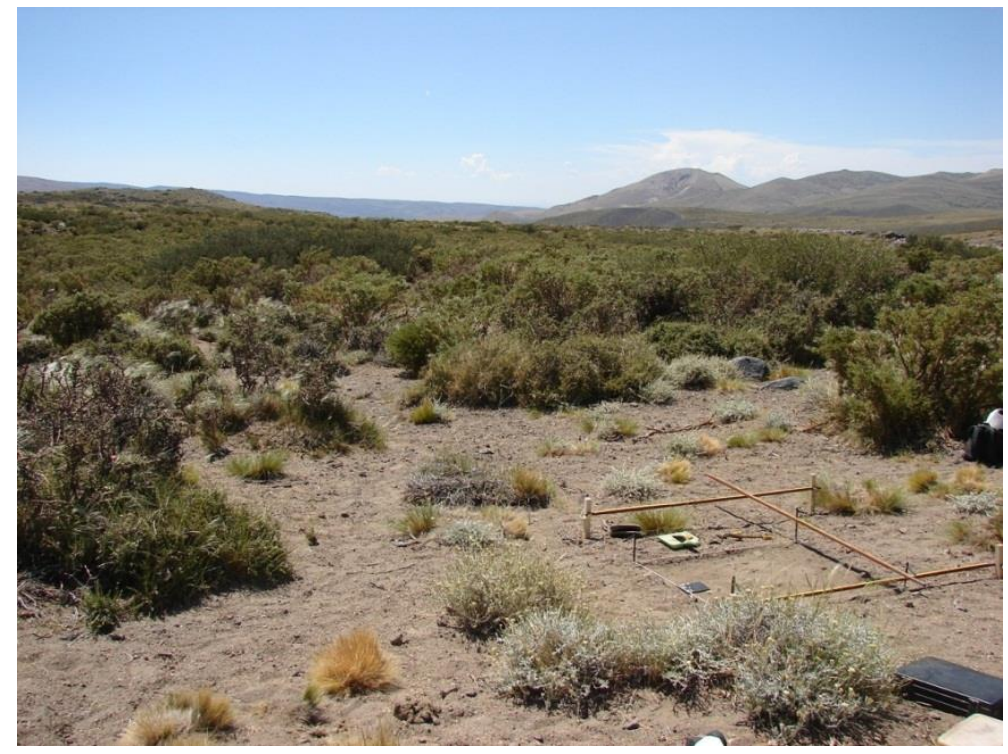

Figura 7.34. Vista panorámica del área y trazado de la cuadrícula B1 del sitio AP-2.

\subsubsection{Estratigrafía y cronología}

AP-2 fue excavado por niveles artificiales de $10 \mathrm{~cm}$, alcanzando una profundidad de $65 \mathrm{~cm}$. La composición del sedimento es arena suelta con abundantes clastos angulosos y poco seleccionados. En el nivel 4 comienza un nivel de tefra que se extiende por casi toda la cuadrícula, abarcando también parte del nivel 5, hasta los $55 \mathrm{~cm}$ de profundidad. En el nivel 6 vuelve a registrarse arena, un sector con tefra compactada y también clastos de roca pumícea. Hasta el nivel 7 se excavó con cucharín y en los niveles siguientes se procedió a excavar con pala hasta los $95 \mathrm{~cm}$ de profundidad, en donde se registró un nivel de tefra muy compacta (Figura 7.35). 


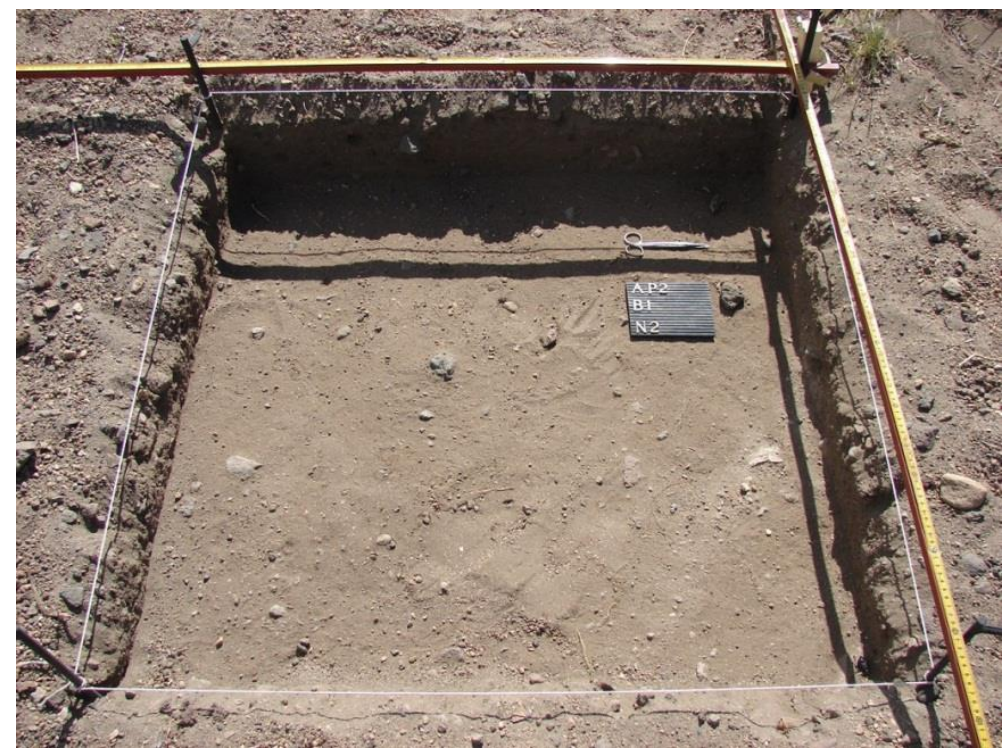

Figura 7.35. Planta de la excavación de AP-2 (nivel 2).

Se extrajo una muestra de carbón disperso en capa del nivel 5, el cual se envió para fechar, arrojando una antigüedad de $1.234 \pm 42$ años ${ }^{14} \mathrm{C}$ AP (Tabla 7.22) y una edad calibrada de 1.107 años cal AP (Figura 7.23).

\begin{tabular}{|cccccc|} 
Cuadrícula & $\begin{array}{c}\text { Nivel } \\
\text { artific. }\end{array}$ & Fecha ${ }^{14} \mathrm{C}$ & $\begin{array}{c}\text { Edad } \\
\text { cal AP }\end{array}$ & Material & Código Lab \\
\hline B1 & 5 & $1.234 \pm 42$ & 1.107 & Carbón & AA85693 (AP-2/5) \\
\hline
\end{tabular}

Tabla 7.22. Fechado radiocarbónico y edad calibrada del sitio AP-2.

\subsubsection{Registro arqueológico}

Como se dijo anteriormente, el trabajo de excavación no llegó a alcanzar el sedimento estéril. La distribución de los materiales disminuye a lo largo de la secuencia hacia los niveles inferiores y con picos de mayor frecuencia en los niveles 1 y 3 (Tabla 7.23 y Figura 7.36). Entre las alteraciones postdepositacionales se ha registrado, principalmente, la presencia de cuevas (producto de la actividad de roedores fosoriales), las cuales fueron rellenadas con sedimento suprayacente. Además, se detectó la alteración de sedimentos por acción de raíces e insectos (especialmente en el nivel 4). Estas alteraciones se pudieron ver con mayor claridad en sectores de los niveles 5 y 6 , en los que el nivel de tefra registrado se encuentra interrumpido. 


\begin{tabular}{|ccccc|}
\hline Fechados & $\begin{array}{c}\text { Nivel } \\
\text { artificial }\end{array}$ & Óseo & Lítico & Cerámica \\
\hline & $\mathbf{1}$ & 75 & 124 & 6 \\
& $\mathbf{2}$ & 80 & 65 & 2 \\
& $\mathbf{3}$ & 107 & 125 & 3 \\
& $\mathbf{4}$ & 31 & 69 & 1 \\
$1.234 \pm 42$ & $\mathbf{5}$ & 62 & 46 & 0 \\
& $\mathbf{6}$ & 11 & 18 & 0 \\
\cline { 2 - 5 } & & $\mathbf{3 6 6}$ & $\mathbf{4 4 7}$ & $\mathbf{1 2}$ \\
\hline
\end{tabular}

Tabla 7.23. Fechados y materiales arqueológicos registrados en AP-2 por unidad artificial de excavación.

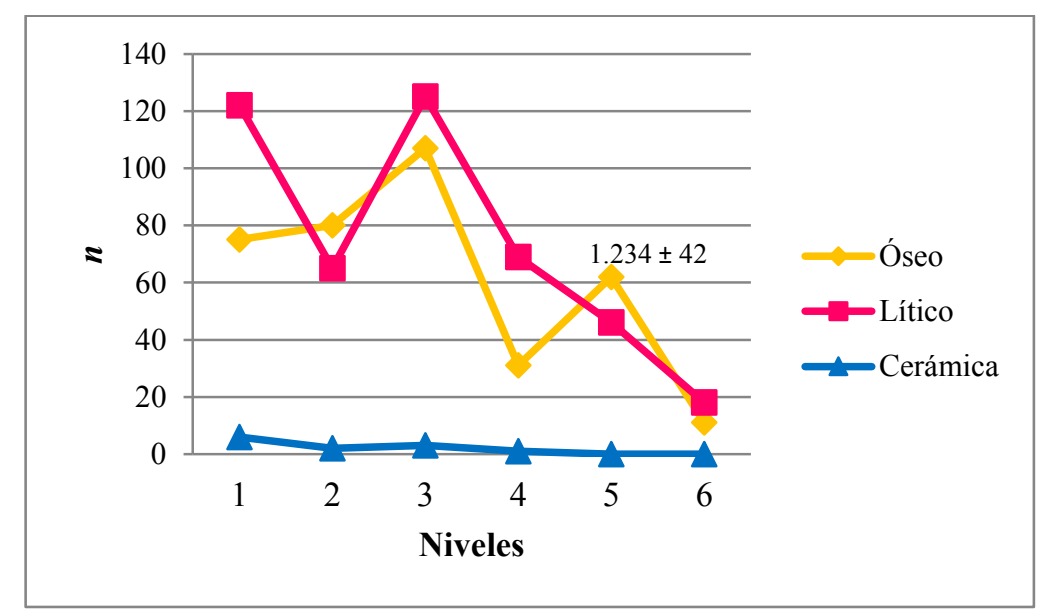

Figura 7.36. Frecuencias en la distribución de los materiales arqueológicos recuperados en AP-2.

\subsubsection{Registro lítico}

Durante la excavación se recuperaron 447 artefactos, de los cuales 152 son desechos de talla de tamaño igual o menor a $5 \mathrm{~mm}$ de lado (“ $\leq 5 \mathrm{~mm}$ ” en la Tabla 7.24), por lo tanto el total de artefactos analizados es de 295. En estos últimos predominan los desechos de talla ("> 5mm" en la Tabla 7.24), los cuales constituyen el 97,07\%. El resto de las clases artefactuales son artefactos formatizados bifaciales y unifaciales -dos especímenes de cada tipo-, y dos artefactos no diferenciados (Tablas 7.24 y 7.25).

\begin{tabular}{|c|c|c|c|c|c|c|}
\hline \multirow{2}{*}{ Nivel } & \multicolumn{2}{|c|}{ Desechos de talla } & \multirow{2}{*}{$\begin{array}{c}\text { AF } \\
\text { Bifacial }\end{array}$} & \multirow{2}{*}{$\begin{array}{c}\text { AF } \\
\text { Unifacial }\end{array}$} & \multirow{2}{*}{ ND } & \multirow{2}{*}{ TOTAL } \\
\hline & $(>5 \mathrm{~mm})$ & $(\leq 5 \mathrm{~mm})$ & & & & \\
\hline 1 & 90 & 29 & 1 & 2 & 2 & 124 \\
\hline 2 & 37 & 28 & - & - & - & 65 \\
\hline 3 & 69 & 56 & - & - & - & 125 \\
\hline 4 & 45 & 23 & 1 & - & - & 69 \\
\hline
\end{tabular}




\begin{tabular}{|c|c|c|c|c|c|c|}
$\mathbf{5}$ & 35 & 11 & - & - & - & $\mathbf{4 6}$ \\
\hline $\mathbf{6}$ & 13 & 5 & - & - & - & $\mathbf{1 8}$ \\
\hline Total & $\mathbf{2 8 9}$ & $\mathbf{1 5 2}$ & $\mathbf{2}$ & $\mathbf{2}$ & $\mathbf{2}$ & $\mathbf{4 4 7}$ \\
\hline Total \% & $\mathbf{6 4 , 6 5}$ & $\mathbf{3 4 , 0 0}$ & $\mathbf{0 , 4 5}$ & $\mathbf{0 , 4 5}$ & $\mathbf{0 , 4 5}$ & $\mathbf{1 0 0 \%}$ \\
\hline
\end{tabular}

Tabla 7.24. Clases artefactuales por nivel de excavación en AP-2. Referencias: AF: Artefacto formatizado; ND: clase artefactual no diferenciada.

\begin{tabular}{|c|c|c|c|c|c|}
\hline $\begin{array}{c}\text { Clases } \\
\text { artefactuales }\end{array}$ & $\begin{array}{c}\text { Desechos } \\
\text { de talla }\end{array}$ & $\begin{array}{c}\text { AF } \\
\text { Bifacial }\end{array}$ & $\begin{array}{c}\text { AF } \\
\text { Unifacial }\end{array}$ & ND & TOTAL \\
\hline Total & 289 & 2 & 2 & 2 & $\mathbf{2 9 5}$ \\
\hline Total \% & 97,96 & 0,68 & 0,68 & 0,68 & $\mathbf{1 0 0 \%}$ \\
\hline
\end{tabular}

Tabla 7.25. Frecuencias absoluta y relativa de clases artefactuales en AP-2. La categoría "desechos de talla" incluye sólo aquellos de tamaño mayor a 5 x $5 \mathrm{~mm}$.

Las materias primas más abundantes son la obsidiana $(51,5 \%)$, las rocas silíceas $(26,4 \%)$, el basalto $(17,6 \%)$, la riolita $(3,5 \%)$, el cuarzo $(0,7 \%)$ y las indeterminadas $(0,3 \%)$ (Tabla 7.26 y Figura 7.37$)$.

\begin{tabular}{|c|c|c|c|c|c|c|c|}
\hline Nivel & BAS & OBS & RIO & SIL & QZ & Indet. & Total \\
\hline 1 & $15(15,8 \%)$ & $51(53,7 \%)$ & $4(4,2 \%)$ & $22(23,2 \%)$ & $2(2,1 \%)$ & $1(1,0 \%)$ & 95 \\
\hline 2 & $4(10,8 \%)$ & $22(59,5 \%)$ & $1(2,7 \%)$ & $10(27,0 \%)$ & - & - & 37 \\
\hline 3 & $7(10,1 \%)$ & $40(58,0 \%)$ & $2(2,9 \%)$ & $20(29,0 \%)$ & - & - & 69 \\
\hline 4 & $11(23,9 \%)$ & $18(39,1 \%)$ & $1(2,2 \%)$ & $16(34,8 \%)$ & - & - & 46 \\
\hline 5 & $12(34,3 \%)$ & $15(42,9 \%)$ & $2(5,7 \%)$ & $6(17,1 \%)$ & - & - & 35 \\
\hline 6 & $3(23,1 \%)$ & $6(46,2 \%)$ & - & $4(30,8 \%)$ & - & - & 13 \\
\hline Total & $52(17,6 \%)$ & $\begin{array}{c}152 \\
(51,5 \%)\end{array}$ & $10(3,5 \%)$ & $78(26,4 \%)$ & $2(0,7 \%)$ & $1(0,3 \%)$ & 295 \\
\hline
\end{tabular}

Tabla 7.26. Distribución y frecuencia de materias primas por nivel de excavación en AP-2. Referencias: BAS: basalto; OBS: obsidiana; RIO: riolita; SIL: rocas siliceas; QZ: cuarzo; Indet.: roca indeterminada.

En la Tabla 7.27 y en la Figura 7.37 se presentan las frecuencias totales de las seis clases de rocas presentes en AP-2.

\begin{tabular}{|c|c|c|c|c|c|c|c|}
\hline MP & BAS & OBS & RIO & SIL & QZ & Indet. & Total \\
\hline $\boldsymbol{n}$ & 52 & 152 & 10 & 78 & 2 & 1 & $\mathbf{2 9 5}$ \\
\hline $\mathbf{\%}$ & 17,63 & 51,52 & 3,39 & 26,44 & 0,68 & 0,34 & $\mathbf{1 0 0}$ \\
\hline
\end{tabular}

Tabla 7.27. Frecuencias absoluta y relativa de materias primas en AP-2. 


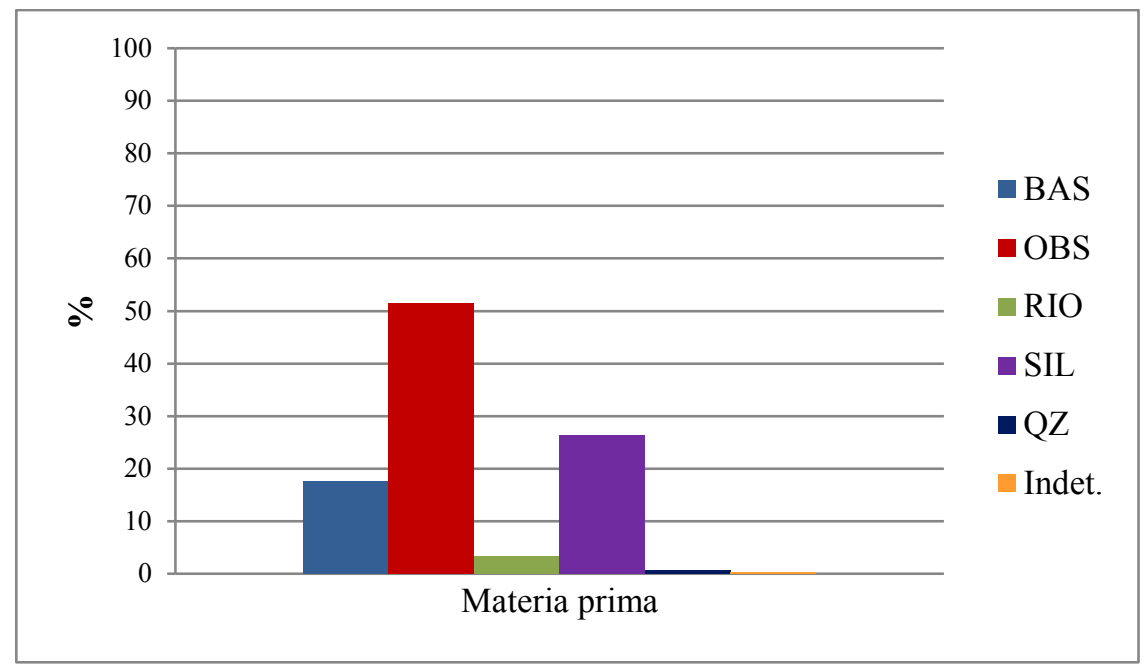

Figura 7.37. Frecuencia relativa de materias primas en AP-2.

\subsection{Desechos de talla}

Los desechos de talla constituyen la clase artefactual predominante y en ellos están representadas todas las materias primas, excepto los dos artefactos de cuarzo en los que no se pudo diferenciar su clase artefactual. Los desechos de talla de obsidiana son los más abundantes $(51,56 \%, n=149)$. Le siguen los de rocas silíceas $(26,64 \%, n=77)$, los de basalto $(17,99 \%, n=52)$ y los desechos de riolita $(3,46 \%, n=10)$. Del total de los desechos de talla $(n=289)$, el 76,12\% $(n=220)$ están fracturados.

De los desechos enteros, el 92,75\% $(n=64)$ no presenta reserva de corteza. Le siguen los desechos con el $25 \%$ de corteza $(5,80 \%, n=4)$ presente sólo en rocas silíceas y basalto. En esta última clase de roca se registró una lasca secundaria con el $75 \%$ de su cara dorsal con corteza $(8,33 \%)$ (Tabla 7.28$)$. No se registraron desechos con el $50 \mathrm{y}$ el $100 \%$ de reserva de corteza.

\begin{tabular}{|c|c|c|c|c|c|}
\hline Sitio & MP & $\mathbf{0 \%}$ & $\mathbf{2 5 \%}$ & $\mathbf{7 5 \%}$ & Total \\
\hline \multirow{4}{*}{ AP-2 } & BAS & $83,34 \%(10)$ & $8,33 \%(1)$ & $8,33 \%(1)$ & $\mathbf{1 2}$ \\
\cline { 2 - 6 } & OBS & $100 \%(37)$ & - & - & $\mathbf{3 7}$ \\
\cline { 2 - 6 } & RIO & $100 \%(1)$ & - & - & $\mathbf{1}$ \\
\cline { 2 - 6 } & SIL & $84,21 \%(16)$ & $15,79 \%(3)$ & - & $\mathbf{1 9}$ \\
\hline \multicolumn{2}{|c|}{ Total } & $\mathbf{9 2 , 7 5 \% ( 6 4 )}$ & $\mathbf{5 , 8 0 \% ( 4 )}$ & $\mathbf{1 , 4 5 \% ( 1 )}$ & $\mathbf{6 9}$ \\
\hline
\end{tabular}

Tabla 7.28. Reserva de corteza en la cara dorsal en desechos de talla enteros en AP-2.

El cálculo del índice de MNF (número mínimo de lascas) por materia prima, redujo los desechos de talla a 148 (51,21\% del número total de artefactos) (Tabla 7.29). 


\begin{tabular}{|l|l|c|c|c|c|c|c|c|}
\hline Sitio & MP & NAS & DT ent. & DT fract. & ND & NFS & \multicolumn{2}{c|}{ MNF (n y \%) } \\
\hline \multirow{4}{*}{ AP-2 } & BAS & 52 & 12 & 39 & 1 & 52 & 27 & 51,92 \\
\cline { 2 - 9 } & OBS & 152 & 37 & 107 & 5 & 149 & 75 & 50,34 \\
\cline { 2 - 9 } & RIO & 10 & 1 & 8 & 1 & 10 & 5 & 50,00 \\
\cline { 2 - 9 } & SIL & 78 & 19 & 58 & - & 77 & 40 & 51,95 \\
\cline { 2 - 9 } & Indet. & 1 & - & 1 & - & 1 & 1 & 100,00 \\
\hline \multicolumn{2}{|c|}{ Total } & $\mathbf{2 9 3}$ & $\mathbf{6 9}$ & $\mathbf{2 1 3}$ & $\mathbf{7}$ & $\mathbf{2 8 9}$ & $\mathbf{1 4 8}$ & $\mathbf{5 1 , 2 1}$ \\
\hline
\end{tabular}

Tabla 7.29. Frecuencias de desechos de talla enteros, fracturados e índice de MNF, por materias primas en el sitio AP-2. Referencias: MP: materia prima; NAS: número de especímenes artefactuales; DT: desechos de talla; Ent.: enteros; Fract.: fracturados; ND: no diferenciados; NFS: número de especímenes identificados como lascas; MNF: número mínimo de lascas; BAS: basalto; OBS: obsidiana; RIO: riolita; SIL: rocas siliceas; Indet.: rocas indeterminadas.

Las lascas internas constituyen el $88,41 \%(\mathrm{n}=61)$ de los desechos de talla enteros (Tabla 7.30); seguidos por las lascas de formatización de filo con el 10,14\% $(n=7)$ y las lascas externas $(1,45 \%, n=1)$. Los desechos de obsidiana son los que presentan más variedad de tipos, excepto los correspondientes a los primeros estadios de la talla: no hay lascas externas de obsidiana. El único desecho de riolita entero es una lasca interna (Tabla 7.30).

\begin{tabular}{|c|c|c|c|c|c|c|c|c|}
\hline \multirow{2}{*}{ Sitio } & \multirow{2}{*}{ MP } & \multicolumn{6}{|c|}{ Tipo de lasca } & \multirow{2}{*}{ Total } \\
\cline { 3 - 9 } & & sec. & angular & de arista & adelg. bif. & plana & de react. & \\
\hline \multirow{4}{*}{ AP-2 } & BAS & $8,33 \%(1)$ & $66,67 \%(8)$ & $25,00 \%(3)$ & - & - & - & $\mathbf{1 2}$ \\
\cline { 2 - 8 } & OBS & - & $64,87 \%(24)$ & $21,62 \%(8)$ & $2,70 \%(1)$ & $2,70 \%(1)$ & $8,11 \%(3)$ & $\mathbf{3 7}$ \\
\cline { 2 - 8 } & RIO & - & $100 \%(1)$ & - & - & - & - & $\mathbf{1}$ \\
\cline { 2 - 8 } & SIL & - & $57,90 \%(11)$ & $31,58 \%(6)$ & - & $5,26 \%(1)$ & $5,26 \%(1)$ & $\mathbf{1 9}$ \\
\hline \multicolumn{2}{|c|}{ Total } & $\mathbf{1 , 4 5 \% ( 1 )}$ & $\mathbf{6 3 , 7 7 \% ( 4 4 )}$ & $\mathbf{2 4 , 6 4 \% ( 1 7 )}$ & $\mathbf{1 , 4 5 \% ( 1 )}$ & $\mathbf{2 , 9 0 \% ( 2 )}$ & $\mathbf{5 , 7 9 \% ( 4 )}$ & $\mathbf{6 9}$ \\
\hline
\end{tabular}

Tabla 7.30. Tipos de desechos de talla procedentes de AP-2 discriminados por tipo de extracción y materia prima. Referencias: sec.: lasca secundaria; adelg. bif: lasca de adelgazamiento bifacial; de react.: de reactivación.

En la Figura 7.38 se presentan los tipos de lasca según la materia prima. Predominan las lascas internas en las tres clases de roca principales y de ellas son mayoritarias las angulares a las de arista. El basalto es la materia prima que presenta la menor variedad de tipos de lascas; la obsidiana y las silíceas presentan los mismos tipos 
de lascas, salvo por una lasca de adelgazamiento bifacial de obsidiana, cuya categoría no se registró entre las rocas silíceas (Tabla 7.30 y Figura 7.39).

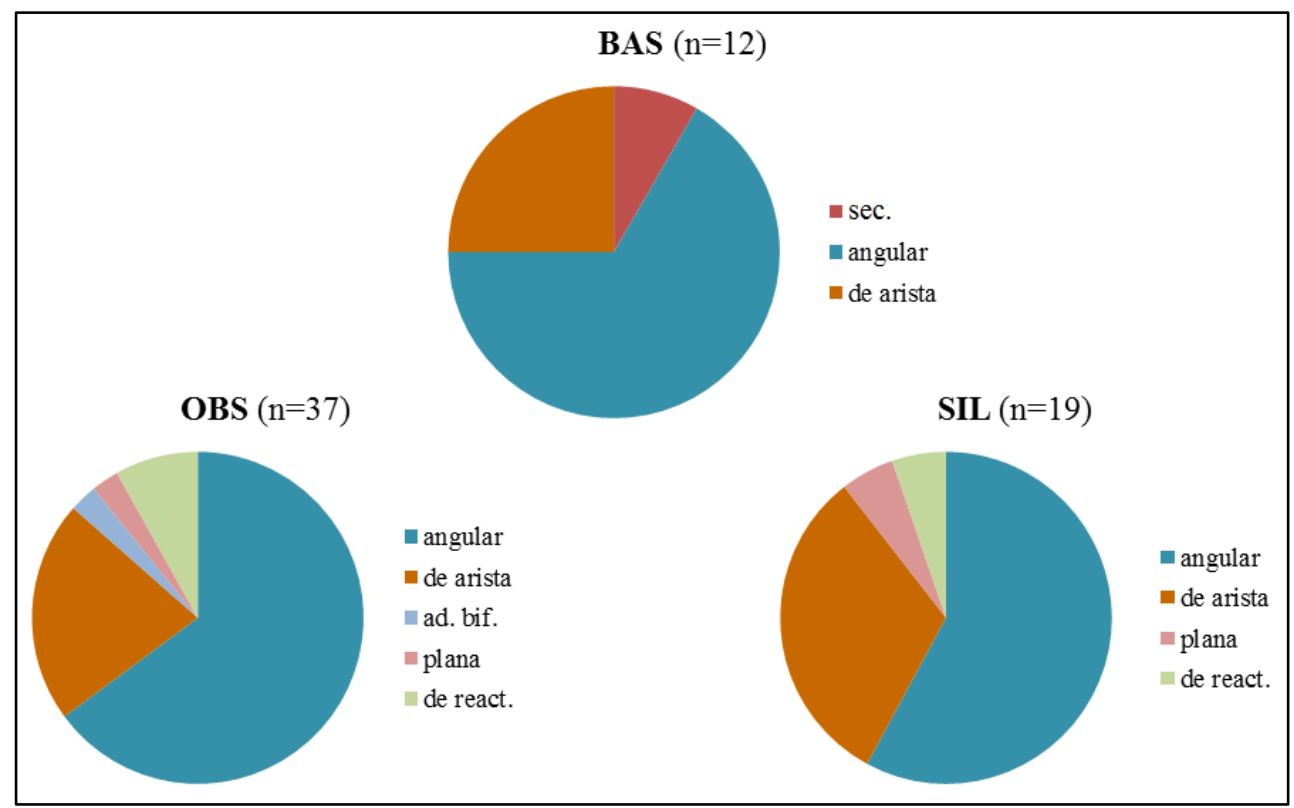

Figura 7.38. Frecuencias relativas de tipos de lasca por materia prima en AP-2. No se incluyó la lasca angular de riolita. Entre paréntesis se indica el número total de lascas enteras por materia prima. Referencias: BAS: basalto; OBS; obsidiana; SIL: rocas siliceas; sec.: lasca secundaria; ad. bif.: lasca de adelgazamiento bifacial; de react.: lasca de reactivación.

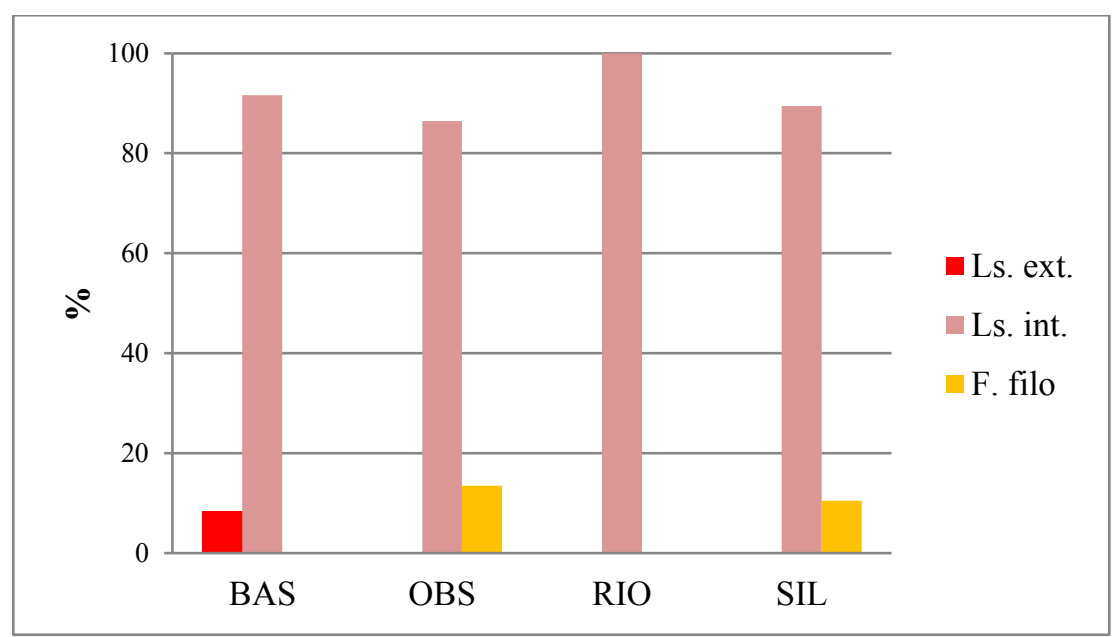

Figura 7.39. Frecuencia de etapas de manufactura en AP-2. Referencias: Ls. ext: Lascas externas; Ls. int: lascas internas; F. filo: lascas de formatización de filo.

\subsection{Instrumentos}

Los instrumentos alcanzan el 1,36\% $(n=4)$ del total, y son la segunda clase artefactual más frecuente después de los desechos de talla $(97,96 \%, \mathrm{n}=289)$. La mayoría 
de los instrumentos (75\%) fueron confeccionados sobre obsidiana $(n=3)$. El instrumento restante es un raspador entero sobre roca silícea (Figura 7.40.A). De los tres instrumentos de obsidiana, uno es unifacial y está entero; y los otros son bifaciales y están fracturados (uno de ellos es una punta de proyectil apedunculada con aletas fracturadas) (Figura 7.40.B). La mitad de los instrumentos está entero $(\mathrm{n}=2)$ y ambos son unifaciales, uno de tamaño pequeño (el de obsidiana) y el otro de tamaño mediano-pequeño (el de roca silícea). Los otros dos instrumentos son bifaciales y, debido a que están fracturados, no se ha considerado su tamaño (véase Tabla 7.31). La serie técnica de los artefactos formatizados de AP-2, incluye, principalmente, retoque marginal, aunque también se observó retoque y microrretoque marginal, ultramarginal y extendido, sobre ambas materias primas.

\begin{tabular}{|c|c|c|c|c|c|c|c|c|c|c|}
\hline \multirow{2}{*}{$\begin{array}{l}\text { Grupo } \\
\text { tipológico }\end{array}$} & \multirow{2}{*}{$\begin{array}{c}\text { Sub-grupo } \\
\text { tipológico }\end{array}$} & \multirow{2}{*}{$n$} & \multirow{2}{*}{$\begin{array}{c}\text { Forma } \\
\text { base }\end{array}$} & \multirow{2}{*}{$\begin{array}{l}\text { Unifacia } \\
10 \\
\text { bifacial }\end{array}$} & \multirow{2}{*}{$\begin{array}{l}\text { Serie } \\
\text { técnica }\end{array}$} & \multirow{2}{*}{$\begin{array}{c}\text { Tamañ } \\
\mathbf{0}\end{array}$} & \multicolumn{2}{|c|}{ MP } & \multicolumn{2}{|c|}{ Estado } \\
\hline & & & & & & & OBS & SIL & $\begin{array}{c}\text { Enter } \\
\text { o }\end{array}$ & Frac. \\
\hline $\begin{array}{l}\text { Artefacto de } \\
\text { formatización } \\
\text { sumaria }\end{array}$ & $\begin{array}{l}\text { Con } \\
\text { microretoque } \\
\text { sumario } \\
\end{array}$ & 1 & $\begin{array}{l}\text { Ls. } \\
\text { angular }\end{array}$ & Unifacial & $\begin{array}{l}\text { MicRTo } \\
\text { ultramarg }\end{array}$ & Pequeño & 1 & - & 1 & - \\
\hline Cortante & $\begin{array}{l}\text { Filo lateral } \\
\text { retocado }\end{array}$ & 1 & ND & Bifacial & $\begin{array}{c}\text { RTo- } \\
\text { MicRTo } \\
\text { marg. }\end{array}$ & NA & 1 & - & - & 1 \\
\hline $\begin{array}{l}\text { Punta de } \\
\text { proyectil }\end{array}$ & Apedunculada & 1 & ND & Bifacial & $\begin{array}{c}\text { RTo- } \\
\text { MicRTo } \\
\text { ext. }\end{array}$ & NA & 1 & - & - & 1 \\
\hline Raspador & $\begin{array}{l}\text { Filo frontal } \\
\text { largo }\end{array}$ & 1 & $\begin{array}{l}\text { Ls. } \\
\text { angular }\end{array}$ & Unifacial & $\begin{array}{c}\text { RTo- } \\
\text { MicRTo } \\
\text { marg. }\end{array}$ & $\begin{array}{l}\text { Med- } \\
\text { peq }\end{array}$ & - & 1 & 1 & - \\
\hline \multicolumn{2}{|c|}{ Total } & 4 & & & & & 3 & 1 & 2 & 2 \\
\hline
\end{tabular}

Tabla 7.31. Grupos y sub-grupos tipológicos de los artefactos formatizados de AP-2.

Referencias: MP: materia prima; OBS: obsidiana; SIL: roca silicea; Frac.: instrumento fracturado; Ls.: lasca; ND: no diferenciada; NA: no aplica; RTo: Retoque; MicRTo: Microretoque; Ext.: extendido; Marg.: marginal; Ultramarg.: ultramarginal; Med-peq.: mediano-pequeño. 

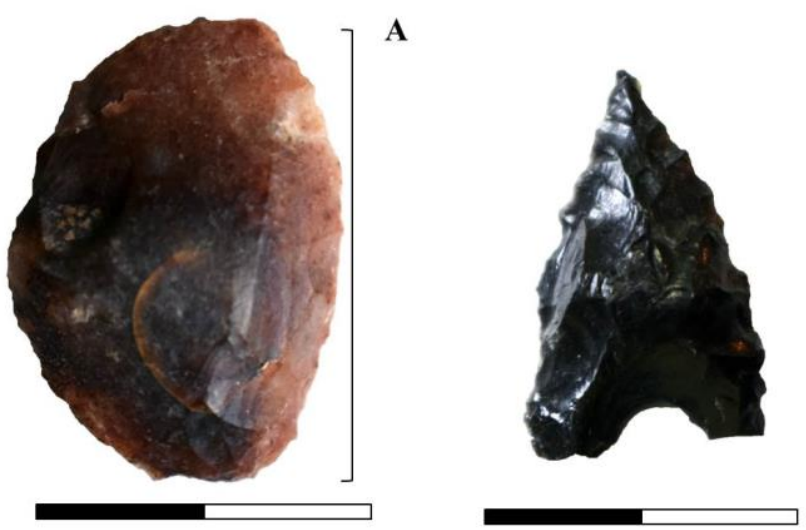

B

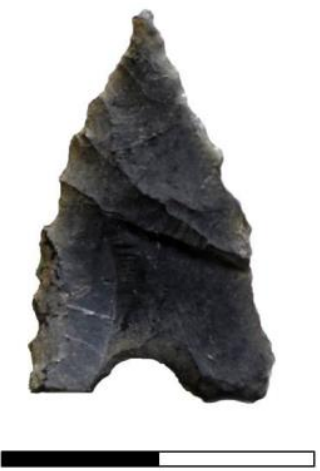

Figura 7.40. Instrumentos recuperados en AP-2. A-Raspador sobre roca silícea. B-Punta de proyectil apedunculada de obsidiana; se observa que el lado reverso (derecha) tiene pátina.

\subsubsection{Síntesis y discusión}

El sitio arqueológico a cielo abierto Arroyo Panchino 2 (AP-2) presenta evidencias de la presencia humana a partir de $1.234 \pm 342$ años ${ }^{14} \mathrm{C}$ (Holoceno tardío final: entre 2.000 y 200 años AP). La tasa de artefactos líticos fue de 0,3 depositados por año. Durante la excavación no se llegó al sedimento estéril por lo que el registro que ha quedado enterrado, puede contener información sobre el primer segmento de tiempo del Holoceno tardío. El análisis del registro lítico indica que predominan los desechos de talla que, junto a los instrumentos, constituyen las únicas dos clases artefactuales identificadas, además de dos artefactos cuya clase no ha sido distinguida. La materia prima más abundante es la obsidiana que predomina tanto en desechos como en instrumentos. Los dos artefactos no diferenciados son de cuarzo, materia prima ausente en los otros dos sitios.

El índice de fragmentación indica que los desechos de talla fracturados constituyen el 76,12\% del total de dicha clase artefactual. El 23,88\% restante corresponde a desechos enteros que en el $92,75 \%$ de los casos no poseen reserva de corteza, y en el $88,41 \%$ de ellos son lascas internas, seguidas por lascas de formatización de filo $(10,14 \%)$ y lascas externas $(1,45 \%)$. La mitad de los instrumentos están enteros; todos los enteros son unifaciales (uno sobre roca silícea y el otro sobre basalto) y los fracturados son bifaciales (ambos de obsidiana). Los grupos tipológicos identificados sugieren una baja inversión de energía o poco esfuerzo tecnológico y de baja estandarización. Se infiere que en AP-2 se realizaron tareas de formatización y/o de mantenimiento de instrumentos. La ausencia de núcleos y la única lasca secundaria de basalto presente en el sitio sostienen esta idea. 
En síntesis, AP-2 habría sido un sitio de actividades múltiples, donde se registraron cuatro instrumentos correspondientes a grupos tipológicos distintos. La punta de proyectil registrada habría desempeñado su función fuera del sitio, formando parte de un toolkit de caza y luego se habría descartado fracturada en AP-1. Las funciones que se pudieron inferir de los otros tres instrumentos (sensu Aschero 1975, 1983) señalan que en este sitio se habrían llevado a cabo tareas que implicaron cortar y raspar con el fin de procesar distintos tipos de recursos (e.g. madera, cuero, etc.). Se desconoce cuál pudo ser la función del artefacto de formatización sumaria (unifacial) y, el resto de las potenciales funciones, debe contrastarse con análisis funcionales.

\subsection{ANÁLISIS TECNO-TIPOLÓGICO DEL DESIERTO ALTOANDINO}

\subsubsection{MATERIAS PRIMAS LÍTICAS}

La materia prima más frecuente en los tres sitios (CP-1, AP-1 y AP-2) es la obsidiana $(41,93 \%, \mathrm{n}=603)$. Le siguen en importancia las rocas silíceas $(39,50 \%, \mathrm{n}=568)$, el basalto $(15,02 \%, n=216)$, la riolita $(2,22 \%, n=32)$, la vulcanita indeterminada $(0,42 \%$, $\mathrm{n}=6)$, el cuarzo $(0,14 \%, \mathrm{n}=2)$ y las indeterminadas $(0,76 \%)$. La distribución de las rocas entre los tres sitios es relativamente homogénea, ya que las primeras cuatro clases de roca se repiten en los tres sitios. AP-2 es el único sitio en que aparece cuarzo y en que no aparece vulcanita indeterminada.

En la Tabla 7.32 y en la Figura 7.41 se presentan las frecuencias en el tipo de calidad para la talla de las rocas registradas en CP-1, AP-1 y AP-2, a lo largo del Holoceno tardío. Un artefacto de obsidiana y otro de sílice procedentes de CP-1, cuya sustancia que tienen adherida impide ver ciertos atributos, han sido clasificados como de calidad "no diferenciada" (ND en la Tabla 7.32). Esta y otras variables analizadas más adelante son pertinentes a artefactos manufacturados por lascados y a sus productos de talla. Por lo tanto, se excluyeron del análisis 16 piezas (dos artefactos manufacturados o modificados por abrasión, picado y/o pulido, tres percutores, un ecofacto, tres potenciales percutores funcionales, un pigmento ni seis artefactos no diferenciados). Así, el $n$ sobre el cual se calcularon las tendencias, no es de 1438, sino de 1422 artefactos líticos.

En los tres sitios predomina la calidad para la talla "excelente" $(38,54 \%, \mathrm{n}=548)$ y "muy buena" $(35,94 \%, n=511)$, seguidas por la "buena" $(25,03 \%, n=356)$ y la "regular" 
$(0,35 \%, n=5$ desechos de basalto de CP-1) y, por último, la "ND" $(0,14 \%, n=2)$ (Tabla 7.32).

\begin{tabular}{|c|c|c|c|c|c|c|c|c|}
\hline$T$ & Sitio & MP & $\mathbf{E X}$ & MB & B & $\mathbf{R}$ & ND & Total \\
\hline \multirow{14}{*}{ 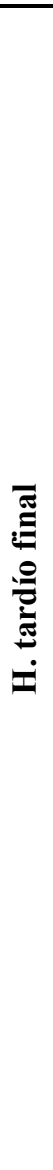 } & \multirow{4}{*}{ CP-1 } & BAS & - & $\begin{array}{c}17,65 \% \\
\text { (3) }\end{array}$ & $\begin{array}{c}70,59 \% \\
(12)\end{array}$ & $\begin{array}{c}11,76 \% \\
\text { (2) }\end{array}$ & - & 17 \\
\hline & & OBS & $\begin{array}{c}89,47 \% \\
(34)\end{array}$ & $\begin{array}{c}10,53 \% \\
(4)\end{array}$ & - & - & - & 38 \\
\hline & & RIO & - & $\begin{array}{c}42,86 \% \\
\text { (3) }\end{array}$ & $\begin{array}{c}57,14 \% \\
\text { (4) }\end{array}$ & - & - & 7 \\
\hline & & SIL & - & $\begin{array}{c}75,86 \% \\
(44)\end{array}$ & $\begin{array}{c}24,14 \% \\
(14)\end{array}$ & - & - & 58 \\
\hline & \multirow{5}{*}{ AP-1 } & BAS & - & - & $\begin{array}{c}100 \% \\
(35)\end{array}$ & - & - & 35 \\
\hline & & OBS & $\begin{array}{c}96,33 \% \\
(105) \\
\end{array}$ & $\begin{array}{c}3,67 \% \\
(4)\end{array}$ & - & - & - & 109 \\
\hline & & RIO & - & $\begin{array}{c}100 \% \\
\text { (1) }\end{array}$ & - & - & - & 1 \\
\hline & & SIL & - & $\begin{array}{c}45,98 \% \\
(40)\end{array}$ & $\begin{array}{c}54,02 \% \\
(47)\end{array}$ & - & - & 87 \\
\hline & & Indet. & - & $\begin{array}{c}50,00 \% \\
(1)\end{array}$ & $\begin{array}{c}50,00 \% \\
(1)\end{array}$ & - & - & 2 \\
\hline & \multirow{5}{*}{ AP-2 } & BAS & - & $\begin{array}{c}26,92 \% \\
(14)\end{array}$ & $\begin{array}{c}73,08 \% \\
(38)\end{array}$ & - & - & 52 \\
\hline & & OBS & $\begin{array}{c}78,95 \% \\
(120)\end{array}$ & $\begin{array}{c}21,05 \% \\
(32)\end{array}$ & - & - & - & 152 \\
\hline & & RIO & - & $\begin{array}{c}90,00 \% \\
(9)\end{array}$ & $\begin{array}{c}10,00 \% \\
\text { (1) }\end{array}$ & - & - & 10 \\
\hline & & SIL & - & $\begin{array}{c}73,08 \% \\
(57)\end{array}$ & $\begin{array}{c}26,92 \% \\
(21)\end{array}$ & - & - & 78 \\
\hline & & Indet. & - & - & $\begin{array}{c}100 \% \\
\text { (1) }\end{array}$ & - & - & 1 \\
\hline \multicolumn{3}{|c|}{ Total HTF } & $\begin{array}{c}40,03 \% \\
(259)\end{array}$ & $\begin{array}{c}32,77 \% \\
(212)\end{array}$ & $\begin{array}{c}26,89 \% \\
(174)\end{array}$ & $\begin{array}{c}0,31 \% \\
\text { (2) }\end{array}$ & - & 647 \\
\hline \multirow{11}{*}{ 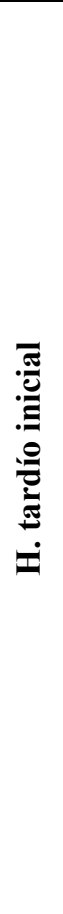 } & \multirow{6}{*}{ CP-1 } & BAS & - & $\begin{array}{c}54,24 \% \\
(32)\end{array}$ & $\begin{array}{c}40,68 \% \\
(24)\end{array}$ & $\begin{array}{c}5,08 \% \\
\text { (3) }\end{array}$ & - & 59 \\
\hline & & OBS & $\begin{array}{c}95,33 \% \\
(204)\end{array}$ & $\begin{array}{c}4,20 \% \\
(9)\end{array}$ & - & - & $\begin{array}{c}0,47 \% \\
\text { (1) }\end{array}$ & 214 \\
\hline & & RIO & - & $\begin{array}{c}30,00 \% \\
(3)\end{array}$ & $\begin{array}{c}70,00 \% \\
(7)\end{array}$ & - & - & 10 \\
\hline & & SIL & $\begin{array}{c}0,39 \% \\
\text { (1) }\end{array}$ & $\begin{array}{c}81,03 \% \\
(205)\end{array}$ & $\begin{array}{c}18,19 \% \\
(46)\end{array}$ & - & $\begin{array}{c}0,39 \% \\
\text { (1) }\end{array}$ & 253 \\
\hline & & VUL & - & - & $\begin{array}{c}100 \% \\
(2)\end{array}$ & - & - & 2 \\
\hline & & Indet. & - & - & $\begin{array}{c}100 \% \\
(1)\end{array}$ & - & - & 1 \\
\hline & \multirow{5}{*}{ AP-1 } & BAS & - & - & $\begin{array}{c}100 \% \\
(47)\end{array}$ & - & - & 47 \\
\hline & & OBS & $\begin{array}{c}93,33 \% \\
(84)\end{array}$ & $\begin{array}{c}6,67 \% \\
(6)\end{array}$ & - & - & - & 90 \\
\hline & & RIO & - & $\begin{array}{c}25,00 \% \\
\text { (1) }\end{array}$ & $\begin{array}{c}75,00 \% \\
\text { (3) }\end{array}$ & - & - & 4 \\
\hline & & SIL & - & $\begin{array}{c}47,78 \% \\
(43) \\
\end{array}$ & $\begin{array}{c}52,22 \% \\
(47) \\
\end{array}$ & - & - & 90 \\
\hline & & VUL & - & - & $\begin{array}{c}100 \% \\
\text { (1) }\end{array}$ & - & - & 1 \\
\hline
\end{tabular}




\begin{tabular}{|c|c|c|c|c|c|c|}
\hline Indet. & - & - & $\begin{array}{c}100 \% \\
(4)\end{array}$ & - & - & 4 \\
\hline Total HTI & $\begin{array}{c}37,29 \% \\
(289)\end{array}$ & $\begin{array}{c}38,58 \% \\
(299)\end{array}$ & $\begin{array}{c}23,48 \% \\
(182)\end{array}$ & $\begin{array}{c}0,39 \% \\
\text { (3) }\end{array}$ & $\begin{array}{c}0,26 \% \\
\text { (2) }\end{array}$ & 775 \\
\hline Total (n) & 548 & 511 & 356 & 5 & 2 & \multirow{2}{*}{1422} \\
\hline Total (\%) & $38,54 \%$ & $35,94 \%$ & $25,03 \%$ & $0,35 \%$ & $0,14 \%$ & \\
\hline
\end{tabular}

Tabla 7.32. Materias primas y calidad para la talla en el Desierto Altoandino por segmento temporal dentro del Holoceno tardío. Referencias: T: tiempo; EX: excelente; MB: muy buena;

B: buena; R: regular; ND: no diferenciada (por sustancia adherida). Sólo se incluyen los artefactos manufacturados por lascados y sus productos de talla.

Al ver la calidad para la talla a lo largo del tiempo (Tabla 7.32), se observa que la frecuencia relativa de las rocas "excelentes" aumenta progresivamente en la mayoría de los casos por la obsidiana. Este mismo aumento también se observa en la categoría “buena", representada por la mayoría de las rocas presentes en los tres sitios. La categoría "muy buena", en cambio, disminuye del HTI al HTF, y está presente en casi la totalidad de las clases de roca, a excepción de la vulcanita indeterminada, roca que sólo se registró en los subconjuntos que corresponden al HTI y que en el 100\% de los casos es de calidad "buena". Además de estas tendencias, se observa que los basaltos de calidad regular para la talla disminuyen de $60 \%$ a $40 \%$ en ambos bloques temporales. En la Figura 7.41 se presentan estas tendencias por materia prima a lo largo del tiempo. Se observa que la calidad "buena" está presente en la mayoría de las rocas, excepto en la obsidiana que es de calidad predominantemente excelente. La calidad muy buena es la categoría mayoritaria ya que se presenta en casi todas las materias primas, sobre todo en las más abundantes entre los artefactos.

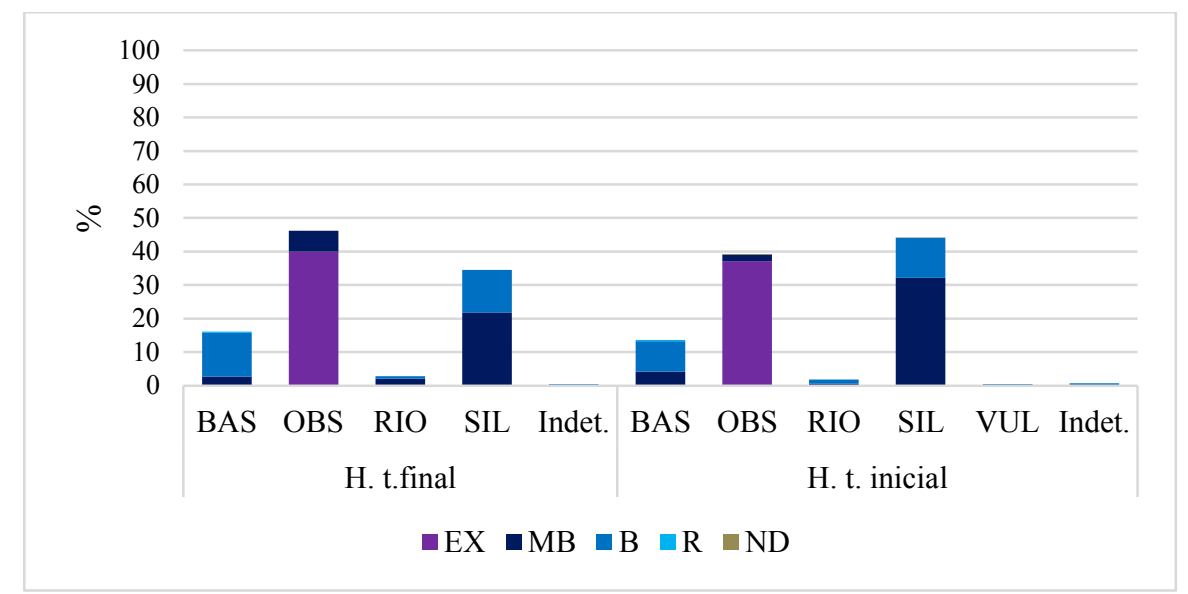

Figura 7.41. Frecuencias de las distintas categorías de calidad para la talla por materia prima y por segmento temporal del Holoceno tardío en el Desierto Altoandino (sitios agrupados). 
Referencias: BAS: basalto; OBS: obsidiana; RIO: riolita; SIL: rocas siliceas; VUL: vulcanita indeterminada; Indet.: roca indeterminada; EX: excelente; MB: muy buena; B: buena; $R$ : regular; ND: no diferenciada (por sustancia adherida). Sólo se incluyen los artefactos manufacturados por lascados y sus productos de talla.

Para evaluar el estado de fragmentación de los artefactos registrados en los tres sitios, se consideró la ecuación MNA/NAS (Número mínimo de artefactos / Número de piezas artefactuales). El índice muestra que la mayor frecuencia de fractura se da en los sitios CP-1 y AP-2, y que los artefactos fracturados han incrementado el tamaño de la muestra en un $47 \%$ en $\mathrm{CP}-1$ (MNA/NAS $=53 \%$ ), en un $40 \%$ en $\mathrm{AP}-1$ (MNA/NAS $=60 \%$ ) y en un 49\% en AP-2 (MNA/NAS=51\%). En los tres sitios la riolita se mantiene dentro de los índices de fragmentación más altos junto a la vulcanita indeterminada. Por el contrario, las rocas silíceas constituyen la clase de roca con menor índice de fragmentación (43\%, aproximadamente). Le siguen la obsidiana (alrededor del 46\%) y el basalto ( $47 \%$ promediando los tres sitios). Es de destacar que en el sitio AP-1, uno de los sitios con mayor cantidad de artefactos enteros, las rocas silíceas y la obsidiana presentan bajos índices de fragmentación (36\% y 40\%, respectivamente) (Tabla 7.33).

\begin{tabular}{|c|c|c|c|c|c|c|c|c|c|c|c|}
\hline \multirow[t]{2}{*}{ Sitio } & \multirow{2}{*}{$\frac{\text { MP }}{\text { BAS }}$} & \multirow{2}{*}{$\frac{\text { NAS }}{76}$} & \multirow{2}{*}{$\begin{array}{l}\begin{array}{c}\text { Instr. } \\
\text { ent. }\end{array} \\
3\end{array}$} & \multirow{2}{*}{$\begin{array}{l}\text { DT } \\
\text { ent. } \\
16 \\
\end{array}$} & \multirow{2}{*}{\begin{tabular}{|c|}
$\begin{array}{c}\text { DT } \\
\text { fract. }\end{array}$ \\
56 \\
\end{tabular}} & \multirow{2}{*}{$\frac{\text { ND }}{-}$} & \multirow{2}{*}{$\begin{array}{c}\text { NFS } \\
72 \\
\end{array}$} & \multicolumn{2}{|c|}{ MNF (n y \%) } & \multirow{2}{*}{$\begin{array}{c}\text { MNA } \\
44 \\
\end{array}$} & \multirow{2}{*}{$\begin{array}{c}\text { MNA/NAS } \\
58 \%\end{array}$} \\
\hline & & & & & & & & 41 & 56,94 & & \\
\hline \multirow{5}{*}{ CP-1 } & OBS & 252 & 3 & 59 & 178 & 3 & 240 & 126 & 52,50 & 129 & $51 \%$ \\
\hline & RIO & 17 & - & 2 & 15 & - & 17 & 7 & 41,18 & 7 & $41 \%$ \\
\hline & SIL & 311 & 3 & 80 & 218 & 5 & 303 & 161 & 53,14 & 164 & $53 \%$ \\
\hline & VUL & 2 & - & - & 2 & - & 2 & 1 & 50,00 & 1 & $50 \%$ \\
\hline & Indet. & 1 & - & 1 & - & - & 1 & 1 & 100,00 & 1 & $100 \%$ \\
\hline \multicolumn{2}{|c|}{ Total CP-1 } & 659 & 9 & 158 & 469 & 8 & 635 & 337 & 53,07 & 346 & $53 \%$ \\
\hline \multirow{6}{*}{ AP-1 } & BAS & 82 & 3 & 26 & 47 & 7 & 80 & 41 & 51,25 & 44 & $54 \%$ \\
\hline & OBS & 199 & 3 & 68 & 112 & 15 & 195 & 117 & 60,00 & 120 & $60 \%$ \\
\hline & RIO & 5 & - & - & 4 & 1 & 5 & 2 & 40,00 & 2 & $40 \%$ \\
\hline & SIL & 177 & 5 & 60 & 94 & 14 & 168 & 109 & 64,88 & 114 & $64 \%$ \\
\hline & VUL & 1 & - & 1 & - & - & 1 & 1 & 100,00 & 1 & $100 \%$ \\
\hline & Indet. & 6 & - & 1 & 5 & - & 6 & 2 & 33,33 & 2 & $33 \%$ \\
\hline \multicolumn{2}{|c|}{ Total AP-1 } & 470 & 11 & 156 & 262 & 37 & 455 & 272 & 59,78 & 283 & $60 \%$ \\
\hline \multirow{5}{*}{ AP-2 } & BAS & 52 & - & 12 & 39 & 1 & 52 & 27 & 51,92 & 27 & $52 \%$ \\
\hline & OBS & 152 & 1 & 37 & 107 & 5 & 149 & 75 & 50,34 & 76 & $50 \%$ \\
\hline & RIO & 10 & - & 1 & 8 & 1 & 10 & 5 & 50,00 & 5 & $50 \%$ \\
\hline & SIL & 78 & 1 & 19 & 58 & - & 77 & 40 & 51,95 & 41 & $53 \%$ \\
\hline & Indet. & 1 & - & - & 1 & - & 1 & 1 & 100,00 & 1 & $100 \%$ \\
\hline \multicolumn{2}{|c|}{ Total AP-2 } & 293 & 2 & 69 & 213 & 7 & 289 & 148 & 51,21 & 150 & $51 \%$ \\
\hline
\end{tabular}

Tabla 7.33. Número total de piezas artefactuales (NAS), de desechos de talla enteros, fracturados, número de especímenes identificados como lascas (NF), índice de MNF (número 
mínimo de lascas) e índice de fragmentación (MNA/NAS), por materias primas y sitios arqueológicos del Desierto Altoandino. Referencias: MP: materia prima; Instr: instrumentos; DT: desechos de talla; Ent.: enteros; Fract.: fracturados; ND: no diferenciados; BAS: basalto; OBS: obsidiana; RIO: riolita; SIL: rocas siliceas; VUL: vulcanita indeterminada; Indet.: rocas indeterminadas.

Se observa también que los artefactos enteros aumentan del HTI al HTF. Los fracturados, por su parte, disminuyen relativamente de un momento al otro dentro en todas las materias primas, excepto en el basalto (Tabla 7.34)

\begin{tabular}{|c|c|c|c|c|c|c|}
\hline $\mathbf{T}$ & Sitio & MP & Entero & Fracturado & ND & Total \\
\hline \multirow{14}{*}{ 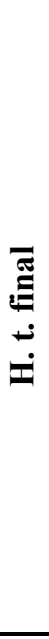 } & \multirow{4}{*}{ CP-1 } & BAS & $17,65 \%(3)$ & $82,35 \%(14)$ & - & 17 \\
\hline & & OBS & $23,68 \%(9)$ & $76,32 \%(29)$ & - & 38 \\
\hline & & RIO & $14,29 \%(1)$ & $85,71 \%(6)$ & - & 7 \\
\hline & & SIL & $34,48 \%(20)$ & $62,07 \%(36)$ & $3,45 \%(2)$ & 58 \\
\hline & \multirow{5}{*}{ AP-1 } & BAS & $45,71 \%(16)$ & $54,29 \%(19)$ & - & 35 \\
\hline & & OBS & $44,04 \%$ (48) & $50,46 \%(55)$ & $5,50 \%(6)$ & 109 \\
\hline & & RIO & - & $100 \%(1)$ & - & 1 \\
\hline & & SIL & $34,48 \%(30)$ & $55,17 \%(48)$ & $10,34 \%(9)$ & 87 \\
\hline & & Indet. & $50,00 \%(1)$ & $50,00 \%(1)$ & - & 2 \\
\hline & \multirow{5}{*}{ AP-2 } & BAS & $23,08 \%(12)$ & $75,00 \%(39)$ & $1,92 \%(1)$ & 52 \\
\hline & & OBS & $25,00 \%(38)$ & $71,71 \%(109)$ & $3,29 \%(5)$ & 152 \\
\hline & & RIO & $10,00 \%(1)$ & $80,00 \%(8)$ & $10,00 \%(1)$ & 10 \\
\hline & & SIL & $25,64 \%(20)$ & $74,36 \%(58)$ & - & 78 \\
\hline & & Indet. & - & $100 \%(1)$ & - & 1 \\
\hline \multicolumn{3}{|c|}{ Total HTF } & $30,76 \%(199)$ & $65,53 \%(424)$ & $3,71 \%(24)$ & 647 \\
\hline \multirow{12}{*}{ 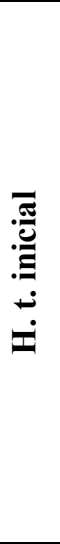 } & \multirow{6}{*}{ CP-1 } & BAS & $25,42 \%(15)$ & $74,58 \%(44)$ & - & 59 \\
\hline & & OBS & $26,17 \%(56)$ & $72,43 \%(155)$ & $1,40 \%(3)$ & 214 \\
\hline & & RIO & $10,00 \%(1)$ & $90,00 \%(9)$ & - & 10 \\
\hline & & SIL & $25,30 \%(64)$ & $73,52 \%(186)$ & $1,19 \%(3)$ & 253 \\
\hline & & VUL & - & $100 \%(2)$ & - & 2 \\
\hline & & Indet. & $100 \%(1)$ & - & - & 1 \\
\hline & \multirow{6}{*}{ AP-1 } & BAS & $23,40 \%(11)$ & $61,70 \%(29)$ & $14,89 \%(7)$ & 47 \\
\hline & & OBS & $25,56 \%(23)$ & $64,44 \%(58)$ & $10,00 \%(9)$ & 90 \\
\hline & & RIO & - & $75,00 \%(3)$ & $25,00 \%(1)$ & 4 \\
\hline & & SIL & $38,89 \%(35)$ & $55,56 \%(50)$ & $5,56 \%(5)$ & 90 \\
\hline & & VUL & $100 \%(1)$ & - & - & 1 \\
\hline & & Indet. & - & $100 \%(4)$ & - & 4 \\
\hline \multicolumn{3}{|c|}{ Total HTI } & $26,71 \%(207)$ & $69,68 \%(540)$ & $3,61 \%(28)$ & 775 \\
\hline \multicolumn{3}{|c|}{ Total (n) } & 406 & 964 & 52 & \multirow{2}{*}{1422} \\
\hline \multicolumn{3}{|c|}{ Total (\%) } & 28,55 & 67,79 & 3,66 & \\
\hline
\end{tabular}

Tabla 7.34. Materias primas y estado de fragmentación en el Desierto Altoandino por segmento temporal dentro del Holoceno tardío. Sólo se incluyen los artefactos manufacturados por lascados y sus productos de talla. 
En la Tabla 7.35 se observa que en los tres sitios predominan los artefactos de tamaños pequeños: muy pequeño, pequeño y mediano pequeño, en ese orden. Los artefactos enteros de los tres sitios son mayormente de tamaño muy pequeño ("MPE” en la Tabla 7.35) y esta tendencia aumenta hacia el HTF. En cambio, los pequeños y mediano pequeños (“P” y “MEP” en la Tabla 7.35), disminuyen del HTI hacia el HTF.

\begin{tabular}{|c|c|c|c|c|c|c|c|}
\hline $\mathbf{T}$ & Sitio & MP & MPE & $\mathbf{P}$ & МЕP & MEG & Total \\
\hline \multirow{12}{*}{ 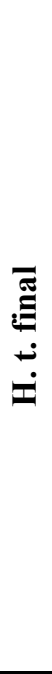 } & \multirow{4}{*}{ CP-1 } & BAS & $33,33 \%(1)$ & - & $33,33 \%(1)$ & $33,33 \%(1)$ & 3 \\
\hline & & OBS & $88,89 \%(8)$ & - & $11,11 \%(1)$ & - & 9 \\
\hline & & RIO & $100 \%(1)$ & - & - & - & 1 \\
\hline & & SIL & $60,00 \%(12)$ & $40,00 \%(8)$ & - & - & 20 \\
\hline & \multirow{4}{*}{ AP-1 } & BAS & $81,25 \%(13)$ & $12,50 \%(2)$ & $6,25 \%(1)$ & - & 16 \\
\hline & & OBS & $91,67 \%(44)$ & $8,33 \%(4)$ & - & - & 48 \\
\hline & & SIL & $83,33 \%(25)$ & $10,00 \%(3)$ & $6,67 \%(2)$ & - & 30 \\
\hline & & Indet. & $100 \%(1)$ & - & - & - & 1 \\
\hline & \multirow{4}{*}{ AP-2 } & BAS & $91,67 \%(11)$ & - & $8,33 \%(1)$ & - & 12 \\
\hline & & OBS & $71,05 \%(27)$ & $28,95 \%(11)$ & - & - & 38 \\
\hline & & RIO & $100 \%(1)$ & - & - & - & 1 \\
\hline & & SIL & $65,00 \%(13)$ & $30,00 \%(6)$ & $5,00 \%(1)$ & - & 20 \\
\hline \multicolumn{3}{|c|}{ Total HTF } & $78,89 \%(157)$ & $17,09 \%(34)$ & $3,52 \%(7)$ & $0,50 \%(1)$ & 199 \\
\hline \multirow{9}{*}{ نّ } & \multirow{5}{*}{ CP-1 } & BAS & $53,33 \%(8)$ & $26,67 \%(4)$ & $13,33 \%(2)$ & $6,67 \%(1)$ & 15 \\
\hline & & OBS & $71,43 \%(40)$ & $17,86 \%(10)$ & $10,71 \%(6)$ & - & 56 \\
\hline & & RIO & $100 \%(1)$ & - & - & - & 1 \\
\hline & & SIL & $70,31 \%(45)$ & $25,00 \%(16)$ & $4,69 \%(3)$ & - & 64 \\
\hline & & Indet. & - & $100 \%(1)$ & - & - & 1 \\
\hline & \multirow{4}{*}{ AP-1 } & BAS & $81,82 \%(9)$ & $9,09 \%(1)$ & $9,09 \%(1)$ & - & 11 \\
\hline & & OBS & $73,91 \%(17)$ & $17,39 \%(4)$ & $8,70 \%(2)$ & - & 23 \\
\hline & & SIL & $85,71 \%(30)$ & $8,57 \%(3)$ & $2,86 \%(1)$ & $2,86 \%(1)$ & 35 \\
\hline & & VUL & - & $100 \%(1)$ & - & - & 1 \\
\hline \multicolumn{3}{|c|}{ Total HTI } & $72,46 \%(150)$ & $19,32 \%(40)$ & $7,25 \%(15)$ & $0,97 \%(2)$ & 207 \\
\hline \multicolumn{3}{|c|}{ Total (n) } & 307 & 74 & 22 & 3 & \multirow{2}{*}{406} \\
\hline \multicolumn{3}{|c|}{ Total (\%) } & 75,62 & 18,23 & 5,42 & 0,74 & \\
\hline
\end{tabular}

Tabla 7.35. Tamaño de los artefactos enteros por materia prima en el Desierto Altoandino durante el Holoceno tardío. Referencias: T: tiempo; MPE: Muy pequeño (0-20 mm); P: Pequeño (21-40); MEP: Mediano pequeño (41-60); MEG: Mediano Grande (61-80); H.t. inicial: Holoceno tardio inicial; H.t. final: Holoceno tardio final. Sólo se incluyen los artefactos manufacturados por lascados y sus productos de talla.

De las categorías de mayor tamaño sólo está representada la mediano grande ("MEG" en la Tabla 7.35) en un artefacto de basalto y en otro sobre roca silícea 
correspondiente al HTI de los sitios CP-1 y AP-1, respectivamente; y en un artefacto de basalto registrado para el HTF en CP-1.

El 94,3 \% (n=383) de los 406 artefactos enteros corresponden a desechos de talla: el 49,6\% $(n=190)$ pertenecen al HTI y el 50,4\% $(n=193)$ al HTF. Las proporciones de tamaños de los desechos según las materias primas a través del tiempo, se presentan en la Figura 7.42. Se observa un predominio de desechos enteros de tamaño MPE y P en todas las materias primas representadas. Las únicas rocas con tamaños de desechos mayores son la obsidiana y el basalto, tanto en el HTI (tamaño MEP) como en el HTF (MEP y MEG), y las rocas silíceas en el HTI (tamaño MEP, aunque en muy baja frecuencia).

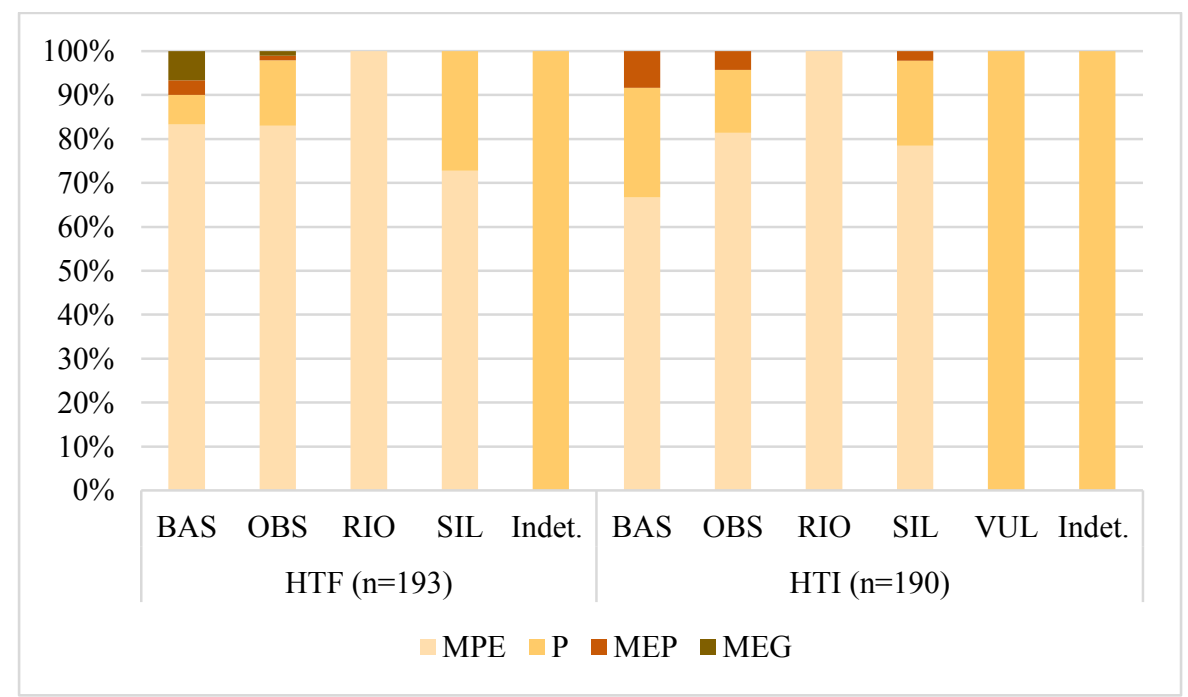

Figura 7.42. Frecuencias relativas de categorías de tamaño en los desechos de talla según la materia prima, a través del tiempo en el Desierto Altoandino. Referencias: MPE: Muy pequeño (0-20 mm); P: Pequeño (21-40); MEP: Mediano pequeño (41-60); MEG: Mediano Grande (61-80).

Al evaluar la reserva de corteza por materias primas en artefactos enteros (Tabla 7.36), se observa que la mayoría no presenta corteza $(91,87 \%, n=373)$. El basalto es sobre la que se observa mayor porcentaje de corteza en cualquiera de las cuatro categorías, desde $25 \%$ a $100 \%$. No se ha observado reserva de corteza en los artefactos de obsidiana del sitio AP-2; en CP-1 sólo en el 3\% ( $\mathrm{n}=2$, uno por segmento temporal) de artefactos de esta materia prima; y en AP-1 en el 4\% ( $n=3$; dos con el $25 \%$ y uno con el $75 \%$, y los tres del HTF). Algo semejante ocurre con los artefactos sobre rocas silíceas, de los cuales el $89,94 \%$ no presenta corteza y el resto $(10,06 \%)$ posee en porcentajes menores $(8,28 \%$ con $25 \%$ de corteza y $1,78 \%$ con $50 \%$ ). En AP-1 no se registraron artefactos enteros en riolita, 
y en CP-1 y AP-2 esta roca no presenta reserva de corteza en ninguno de los tres artefactos enteros.

A través del tiempo se observa que los artefactos enteros sin corteza disminuyen levemente hacia el HTF y que aumenta la frecuencia de los que poseen $25 \%$ de reserva de corteza. Los artefactos que tienen la mitad de su cara dorsal cubierta por corteza sólo fueron registrados en HTI. Lo contrario ocurre con los artefactos con 75 y $100 \%$ de corteza, que sólo aparecen, aunque en baja frecuencia, en el HTF (Tabla 7.36).

\begin{tabular}{|c|c|c|c|c|c|c|c|c|c|}
\hline $\mathbf{T}$ & Sitio & MP & $0 \%$ & $25 \%$ & $50 \%$ & $75 \%$ & $100 \%$ & ND & Total \\
\hline \multirow{12}{*}{ 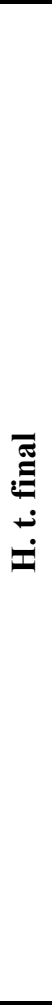 } & \multirow{4}{*}{ CP-1 } & BAS & $\begin{array}{c}66,67 \% \\
(2)\end{array}$ & - & - & $\begin{array}{c}33,33 \% \\
(1)\end{array}$ & - & - & 3 \\
\hline & & OBS & $\begin{array}{c}100 \% \\
(9)\end{array}$ & - & - & - & - & - & 9 \\
\hline & & RIO & $\begin{array}{c}100 \% \\
(1)\end{array}$ & - & - & - & - & - & 1 \\
\hline & & SIL & $\begin{array}{c}85,00 \% \\
(17)\end{array}$ & $\begin{array}{c}15,00 \% \\
(3) \\
\end{array}$ & - & - & - & - & 20 \\
\hline & \multirow{4}{*}{ AP-1 } & BAS & $\begin{array}{c}87,50 \% \\
(14)\end{array}$ & $\begin{array}{c}6,25 \% \\
(1) \\
\end{array}$ & - & - & $\begin{array}{c}6,25 \% \\
(1)\end{array}$ & - & 16 \\
\hline & & OBS & $\begin{array}{c}93,75 \% \\
(45)\end{array}$ & $\begin{array}{c}4,17 \% \\
(2) \\
\end{array}$ & - & $\begin{array}{c}2,08 \% \\
(1)\end{array}$ & - & - & 48 \\
\hline & & SIL & $\begin{array}{c}90,00 \% \\
(27)\end{array}$ & $\begin{array}{c}10,00 \% \\
\text { (3) }\end{array}$ & - & - & - & - & 30 \\
\hline & & Indet. & $\begin{array}{c}100 \% \\
(1)\end{array}$ & - & - & - & - & - & 1 \\
\hline & \multirow{4}{*}{ AP-2 } & BAS & $\begin{array}{c}83,33 \% \\
(10)\end{array}$ & $\begin{array}{c}8,33 \% \\
(1) \\
\end{array}$ & - & $\begin{array}{c}8,33 \% \\
(1)\end{array}$ & - & - & 12 \\
\hline & & OBS & $\begin{array}{c}100 \% \\
(38)\end{array}$ & - & - & - & - & - & 38 \\
\hline & & RIO & $\begin{array}{c}100 \% \\
(1)\end{array}$ & - & - & - & - & - & 1 \\
\hline & & SIL & $\begin{array}{c}85,00 \% \\
(17)\end{array}$ & $\begin{array}{c}15,00 \% \\
(3)\end{array}$ & - & - & - & - & 20 \\
\hline \multicolumn{3}{|c|}{ Total HTF } & $\begin{array}{c}91,46 \% \\
(182)\end{array}$ & $\begin{array}{c}6,53 \% \\
(13) \\
\end{array}$ & - & $\begin{array}{c}1,51 \% \\
(3)\end{array}$ & $\begin{array}{c}0,50 \% \\
(1) \\
\end{array}$ & - & 199 \\
\hline \multirow{8}{*}{ 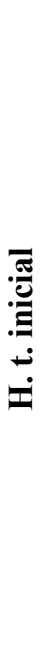 } & \multirow{5}{*}{ CP-1 } & BAS & $\begin{array}{c}86,67 \% \\
(13)\end{array}$ & - & $\begin{array}{c}6,67 \% \\
(1) \\
\end{array}$ & - & - & $\begin{array}{c}6,67 \% \\
(1)\end{array}$ & 15 \\
\hline & & OBS & $\begin{array}{c}96,43 \% \\
(54)\end{array}$ & - & $\begin{array}{c}3,57 \% \\
(2) \\
\end{array}$ & - & - & - & 56 \\
\hline & & RIO & $\begin{array}{c}100 \% \\
(1)\end{array}$ & - & - & - & - & - & 1 \\
\hline & & SIL & $\begin{array}{c}92,19 \% \\
(59) \\
\end{array}$ & $\begin{array}{c}6,25 \% \\
(4) \\
\end{array}$ & $\begin{array}{c}1,56 \% \\
(1)\end{array}$ & - & - & - & 64 \\
\hline & & Indet. & $\begin{array}{c}100 \% \\
(1)\end{array}$ & - & - & - & - & - & 1 \\
\hline & \multirow{3}{*}{ AP-1 } & BAS & $\begin{array}{c}72,73 \% \\
(8)\end{array}$ & $\begin{array}{c}18,18 \% \\
(2) \\
\end{array}$ & $\begin{array}{c}9,09 \% \\
(1) \\
\end{array}$ & - & - & - & 11 \\
\hline & & OBS & $\begin{array}{c}100 \% \\
(23)\end{array}$ & - & - & - & - & - & 23 \\
\hline & & SIL & $\begin{array}{c}91,43 \% \\
(32) \\
\end{array}$ & $\begin{array}{c}2,86 \% \\
(1)\end{array}$ & $\begin{array}{c}5,71 \% \\
(2) \\
\end{array}$ & - & - & - & 35 \\
\hline
\end{tabular}




\begin{tabular}{|c|c|c|c|c|c|c|c|}
\hline VUL & - & - & $\begin{array}{c}100 \% \\
(1)\end{array}$ & - & - & - & 1 \\
\hline Total HTI & $\begin{array}{c}\mathbf{9 2 , 2 7 \%} \\
(\mathbf{1 9 1})\end{array}$ & $\begin{array}{c}\mathbf{3 , 3 8 \%} \\
(\mathbf{7 )}\end{array}$ & $\begin{array}{c}\mathbf{3 , 8 6 \%} \\
(\mathbf{8})\end{array}$ & - & - & $\begin{array}{c}\mathbf{0 , 4 8 \%} \\
(\mathbf{1})\end{array}$ & $\mathbf{2 0 7}$ \\
\hline Total (n) & $\mathbf{3 7 3}$ & $\mathbf{2 0}$ & $\mathbf{8}$ & $\mathbf{3}$ & $\mathbf{1}$ & $\mathbf{1}$ & \multirow{4}{*}{$\mathbf{4 0 6}$} \\
\hline Total (\%) & $\mathbf{9 1 , 8 7}$ & $\mathbf{4 , 9 3}$ & $\mathbf{1 , 9 7}$ & $\mathbf{0 , 7 4}$ & $\mathbf{0 , 2 5}$ & $\mathbf{0 , 2 5}$ & \\
\hline
\end{tabular}

Tabla 7.36. Porcentaje de reserva de corteza en artefactos enteros por materia prima en el Desierto Altoandino durante el Holoceno tardío. Referencias: T: tiempo; MP: materia prima; ND: porcentaje de reserva de corteza no diferenciado; H.t. inicial: Holoceno tardio inicial; H.t. final: Holoceno tardio final. Sólo se incluyen los artefactos manufacturados por lascados y sus productos de talla.

En cuanto al porcentaje de corteza sobre la cara dorsal de los artefactos, algunos investigadores (Sullivan y Rozen 1985; Shott 1994; Charlin 2007), han sugerido que está influida por la forma en que aparecen las materias primas en la región. Como se vio en el Capítulo 6, las materias primas de disponibilidad inmediata desde los sitios (basalto, riolita y vulcanita indeterminada), se presentan como nódulos rodados y concreciones nodulares con corteza. Las rocas silíceas, aunque su disponibilidad deberá ser corroborada en futuras investigaciones, son de disponibilidad local (no inmediata) y están presentes a nivel regional como filones aislados de génesis aparentemente asociada a procesos de silicificación de rocas previas y precipitación química de sílice en forma de nódulos (Salgán 2010). Por último, la fuente de obsidiana identificada en los análisis de elementos traza de artefactos de los sitios CP-1 y AP-1 (Sección 7.2.3.), es la fuente cordillerana Las Cargas, localizada a un rango de distancia no local desde los tres sitios analizados. Esta fuente estaría asociada con toba volcánica con inclusiones nodulares de obsidiana y bloques que pueden alcanzar $0,5 \mathrm{~m}^{3}$, carentes de corteza (Salgán et al. 2015) (véase también, Capítulo 6).

$\mathrm{Al}$ analizar las clases de roca (Figura 7.43), se aprecia que las materias primas aptas para la talla, predominantes en ambos momentos del Holoceno tardío, son la obsidiana $(42,41 \%, \mathrm{n}=603)$ y las rocas silíceas $(39,80 \%, \mathrm{n}=566)$, con diferencias a lo largo del tiempo. Así, si se agrupan los artefactos de los sitios por lapso temporal se ve que la obsidiana aumenta del HTI (39,23\%, n=304 de 775) al HTF (46,21\%, n=299 de 647). En cambio, las rocas silíceas disminuyen de 44,26\% $(n=343)$ en el segmento de tiempo más temprano, a 34,47\% ( $\mathrm{n}=223)$ durante el HTF. Por su parte, el basalto, aumenta de $13,68 \%$ $(n=106)$ en el HTI a 16,07\% $(n=104)$ en el HTF. Asimismo, la riolita aumenta de $1,81 \%$ $(n=14)$ en el HTI a 2,78\% $(n=18)$ en el HTF. La vulcanita indeterminada sólo está presente 
durante el HTI $(0,39 \%, n=3)$. Por lo tanto, se observa que las rocas silíceas son las que más disminuyen y que la obsidiana es la que aumenta más de un momento al otro (Figura $7.43)$.

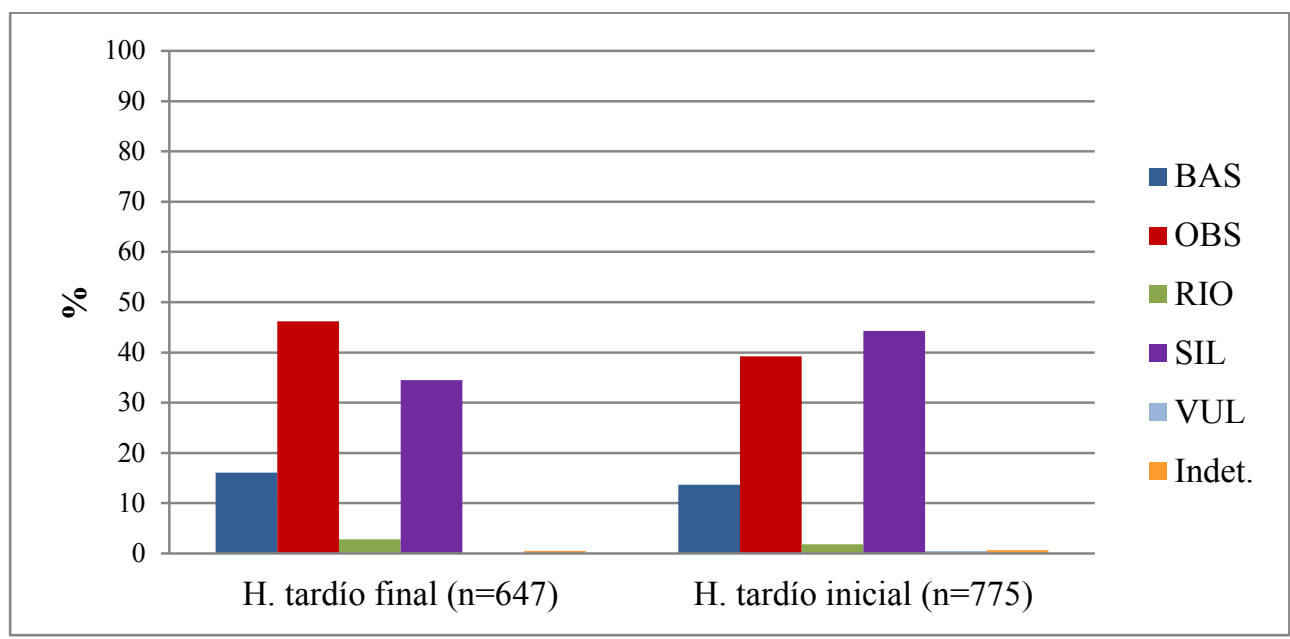

Figura 7.43. Frecuencias de las materias primas representadas en los artefactos líticos del Desierto Altoandino, por segmento temporal dentro del Holoceno tardío. Referencias: $B A S$ : basalto; OBS: obsidiana; SIL: rocas siliceas; VUL: vulcanita indeterminada; Indet.: roca indeterminada. Sólo se incluyen desechos de talla, instrumentos y artefactos sin formatización con rastros complementarios.

\subsubsection{ESTRUCTURA TECNOLÓGICA EN EL DESIERTO ALTOANDINO}

En los tres sitios del Desierto Altoandino (CP-1, AP-1 y AP-2), de las clases artefactuales principales predominan los desechos de talla con frecuencias cercanas al 95\% en el HTI y de alrededor del 97\% en el HTF. Los instrumentos siguen en importancia con el 2,78\% $(n=40)$, constituyendo el 3\% del HTI y el 2\% del HTF. En tercer lugar, se hallan los ASF RC $(0,56 \%, n=8)$, la mitad de obsidiana y la otra mitad sobre rocas silíceas, todos correspondientes al HTI. En la Tabla 7.37 se presenta el total de las clases artefactuales registradas en los tres sitios analizados.

\begin{tabular}{|c|c|c|c|c|c|c|c|c|c|c|c|c|c|c|c|}
\hline$T$ & Sit & MP & $\begin{array}{l}\text { AF } \\
\text { Bif. }\end{array}$ & $\begin{array}{c}\text { AF } \\
\text { Unif. }\end{array}$ & $\begin{array}{c}\mathrm{AF} \\
\text { comp. }\end{array}$ & $\begin{array}{l}\text { Art.m. } \\
\mathbf{A , P , P}\end{array}$ & $\begin{array}{l}\text { AF } \\
\text { ND } \\
\end{array}$ & $\begin{array}{l}\text { ASF } \\
\text { RC } \\
\end{array}$ & $\mathbf{P}$ & DT & Eco & PPF & Pgm & ND & Total \\
\hline \multirow{5}{*}{ 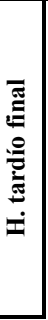 } & \multirow{5}{*}{ ปี } & BAS & - & - & - & - & - & - & - & $\begin{array}{c}100 \% \\
(17)\end{array}$ & - & - & - & - & 17 \\
\hline & & OBS & $\begin{array}{c}2,63 \% \\
(1) \\
\end{array}$ & - & - & - & - & - & - & $\begin{array}{c}97,37 \% \\
(37) \\
\end{array}$ & - & - & - & - & 38 \\
\hline & & RIO & - & - & - & - & - & - & - & $\begin{array}{c}100 \% \\
(7)\end{array}$ & - & - & - & - & 7 \\
\hline & & SIL & $\begin{array}{c}1,72 \% \\
(1)\end{array}$ & - & - & - & - & - & - & $\begin{array}{c}98,28 \% \\
(57)\end{array}$ & - & - & - & - & 58 \\
\hline & & $\begin{array}{l}\text { Indet } \\
\text {. }\end{array}$ & - & - & - & - & - & - & - & - & $\begin{array}{c}100 \% \\
(1)\end{array}$ & - & - & - & 1 \\
\hline
\end{tabular}




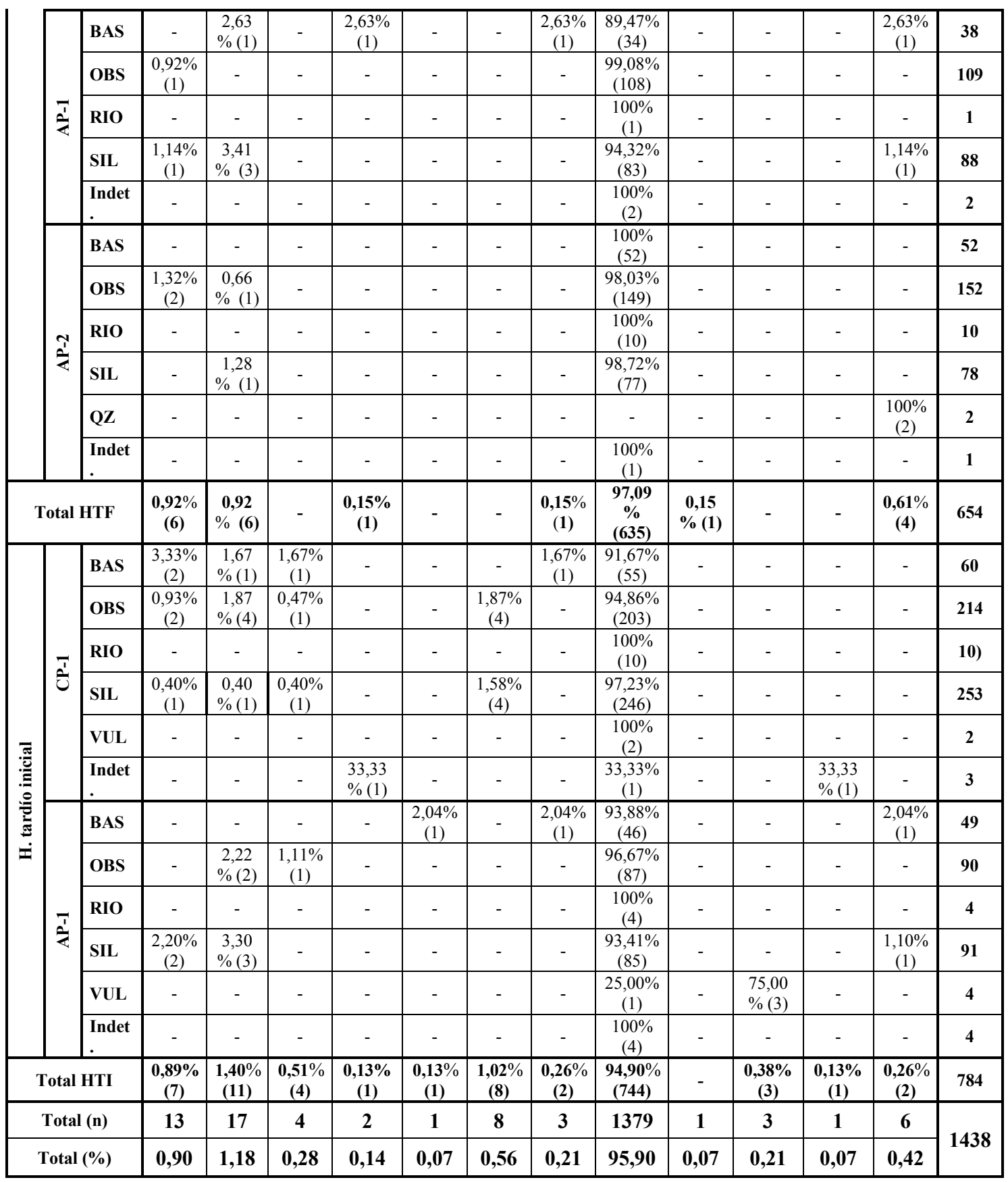

Tabla 7.37. Clases artefactuales por materia prima en el Desierto Altoandino durante el

Holoceno tardío. Referencias: T: tiempo; Sit.: sitio arqueológico; MP: materia prima; AF: artefacto formatizado; Bif.: bifacial; Unif.: unifacial; Comp.: instrumento compuesto; Art. m. A, P, P: artefacto manufacturado o modificado por abrasión, picado y/o pulido; AF ND: artefacto formatizado no diferenciado; ASF RC: artefacto sin formatización con rastros complementarios; P: percutor; DT: desecho de talla; Ecof.: ecofacto; PPF: Potencial percutor funcional; Pgm.: pigmento; ND: artefacto no diferenciado; $\mathrm{H}$ t. inicial: Holoceno tardio inicial; H. t. final: Holoceno tardio final. 


\subsubsection{Desechos de talla}

Las lascas internas son el tipo predominante $(84,86 \%, \mathrm{n}=325)$ de desechos de talla enteros de los tres sitios. Las lascas angulares representan el 73,54\% (n=239) y las de arista el 26,46\% ( $\mathrm{n}=86)$. Le siguen las lascas de formatización de filo $(12,27 \%, \mathrm{n}=47)$. De ellas, el 59,57\% ( $\mathrm{n}=28)$ son lascas de adelgazamiento bifacial, el 29,79\% $(\mathrm{n}=14)$ planas y el 10,64\% $(n=5)$ de reactivación. Las lascas externas representan el 2,87\% $(n=11)$ del total y entre ellas predominan las secundarias $(54,55 \%, \mathrm{n}=6)$, seguidas por las de dorso natural $(27,27 \%, n=3)$, las primarias $(9,09 \%, n=1)$ y una tableta de núcleo $(9,09 \%)$. En cuanto a las materias primas, en la Figura 7.44 se observa que las más frecuentes son la obsidiana, las rocas silíceas y el basalto, sobre las cuales, a su vez, se registró mayor variedad de tipos de lascas. Al agrupar las lascas enteras de los tres sitios (CP-1, AP-1 y AP-2), se observa una tendencia similar entre el tipo de lascas sobre obsidiana y rocas silíceas. Sobre ambas clases de roca se registraron todos los tipos de lascas internas y de formatización de filo; pero de las lascas externas, sólo están presentes las lascas con dorso natural, tanto en obsidiana como en rocas silíceas, y secundarias sólo sobre silíceas. Al contrario, sobre el basalto están representados todos los tipos de lascas externas e internas, aunque entre las de formatización de filo están ausentes las de reactivación. Las tres lascas de riolita son angulares (100\% lascas internas) (Figura 7.44).

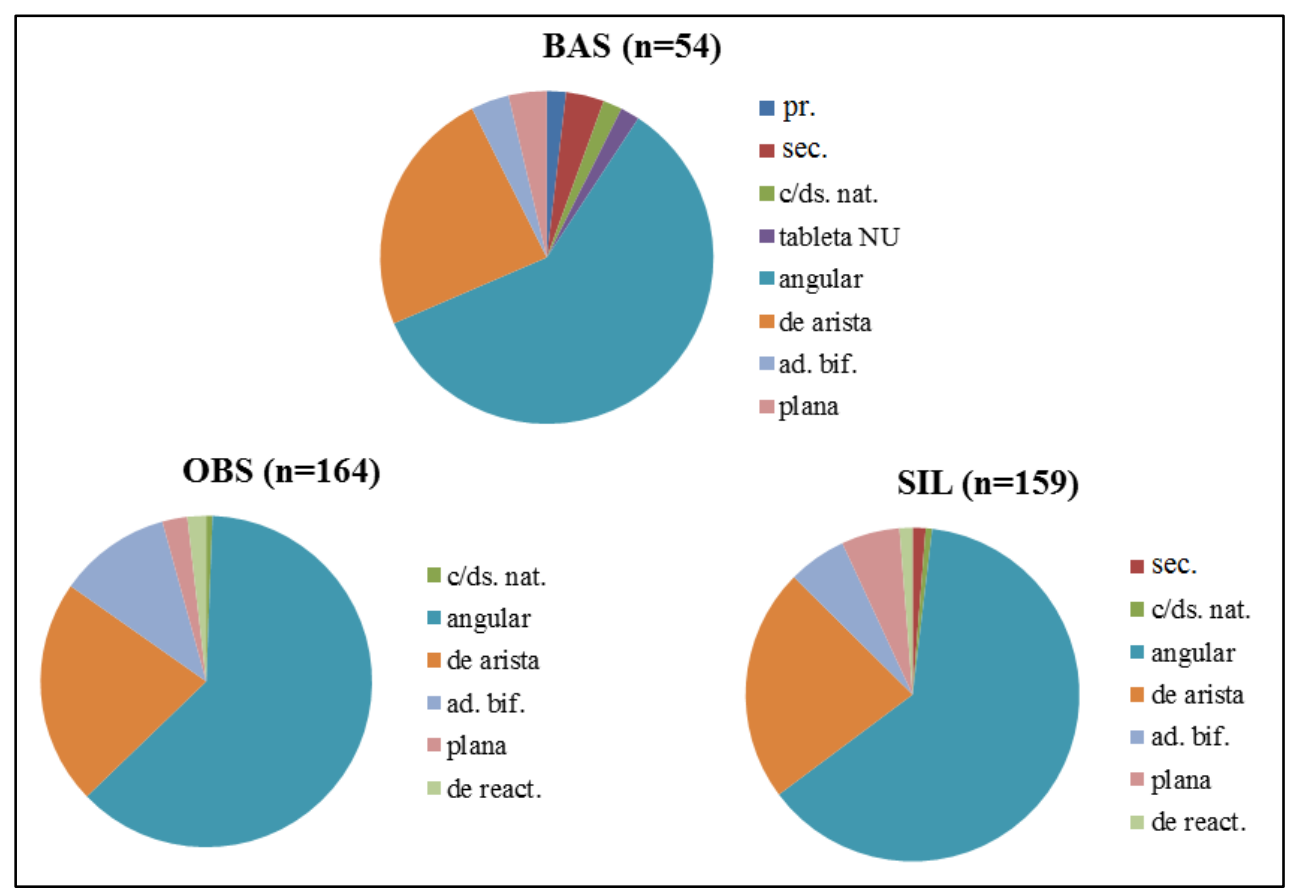

Figura 7.44. Frecuencias relativas de tipos de lasca por materia prima en el Desierto Altoandino.

No se incluyeron tres lascas angulares de riolita, una lasca secundaria de vulcanita indeterminada, ni dos lascas sobre roca indeterminada, una angular y otra de arista. Entre 
paréntesis se indica el número total de lascas enteras registradas en los tres sitios analizados correspondientes al Desierto Altoandino, por materia prima. Referencias: BAS: basalto; $O B S$; obsidiana; SIL: rocas silíceas; pr.: lasca primaria; sec.: lasca secundaria; c/ds. nat.: lasca con dorso natural; tableta NU: tableta de núcleo; ad. bif.: lasca de adelgazamiento bifacial; de react.: lasca de reactivación.

Para estimar el grado de reducción, se considera el índice de corteza (Ericson 1984; véase Capítulo 5) (Tabla 7.38) y la densidad de extracciones previas en la cara dorsal de las lascas enteras (Tabla 7.39). De los desechos enteros de los tres sitios sólo el $0,26 \%(n=1)$ corresponde a lascas primarias y el $1,57 \%(n=6)$ a lascas secundarias. Los valores más elevados del índice de corteza se hallan en la vulcanita indeterminada de AP1, seguida por los basaltos de los tres sitios y luego las rocas silíceas de CP-1, quedando en último lugar la obsidiana de AP-1 (Tabla 7.38). En el caso de la ausencia de lascas primarias y secundarias en riolitas y casi ausente sobre obsidianas y rocas silíceas, los valores menores del índice podrían indicar que estas rocas han ingresado al sitio como formas base o en estado avanzado de formatización. Sin embargo, se debe considerar que la riolita, junto con el basalto y la vulcanita indeterminada, se hallan en fuentes de abastecimiento que están inmediatamente disponibles a los sitios CP-1, AP-1 y AP-2. Las rocas silíceas posiblemente son locales, aunque no disponibles en lo inmediato, mientras que las obsidianas corresponden a rangos de distancia "no local".

\begin{tabular}{|l|l|c|c|c|c|}
\hline Sitio & MP & $n$ & $\begin{array}{c}\text { Ls. } \\
\text { pr. }\end{array}$ & $\begin{array}{c}\text { Ls. } \\
\text { sec. }\end{array}$ & $\begin{array}{c}\text { Índice } \\
\text { de corteza }\end{array}$ \\
\hline \multirow{4}{*}{ CP-1 } & BAS & 16 & - & 1 & 0,06 \\
\cline { 2 - 6 } & OBS & 59 & - & - & - \\
\cline { 2 - 6 } & RIO & 2 & - & - & - \\
\cline { 2 - 6 } & SIL & 80 & - & 2 & 0,03 \\
\cline { 2 - 6 } & Indet. & 1 & - & - & - \\
\hline \multirow{4}{*}{ AP-1 } & BAS & 26 & 1 & - & 0,04 \\
\cline { 2 - 6 } & OBS & 68 & - & 1 & 0,01 \\
\cline { 2 - 6 } & SIL & 60 & - & - & - \\
\cline { 2 - 6 } & VUL & 1 & - & 1 & 1,00 \\
\cline { 2 - 6 } & Indet. & 1 & - & - & - \\
\hline \multirow{4}{*}{ AP-2 } & BAS & 12 & - & 1 & 0,08 \\
\cline { 2 - 6 } & OBS & 37 & - & - & - \\
\cline { 2 - 6 } & RIO & 1 & - & - & - \\
\cline { 2 - 6 } & SIL & 19 & - & - & - \\
\hline
\end{tabular}

Tabla 7.38. Índice de corteza y frecuencia de lascas primarias y secundarias enteras por materia prima lítica en el Desierto Altoandino. Referencias: MP: materia prima; $N$ : abundancia de desechos de talla enteros; Ls. pr.: lasca primaria; Ls. sec.: lasca secundaria. 
La estadística descriptiva muestra que la densidad de extracciones previas en la cara dorsal de las lascas externas e internas enteras (Tabla 7.39) es mayor en la riolita y la obsidiana de CP-1, en la obsidiana y las rocas silíceas de AP-1 y en la riolita de AP-2. Al margen de estos cuatro casos, los valores menores de la densidad de negativos de lascado se hallan en el basalto de los tres sitios y, en general, la densidad mayor se da en obsidianas. Esto es coherente con los valores del índice de corteza (Tabl 7.38).

\begin{tabular}{|c|c|c|c|c|c|c|c|c|}
\hline Sitio & MP & $\boldsymbol{n}$ & Media & Mediana & $\begin{array}{c}\text { Desvío } \\
\text { estándar }\end{array}$ & Mínimo & Máximo & Rango \\
\hline \multirow{4}{*}{ CP-1 } & BAS & 13 & 0,04 & 0,04 & 0,03 & 0 & 0,07 & 0,07 \\
\cline { 2 - 9 } & OBS & 52 & 0,06 & 0,06 & 0,04 & 0,01 & 0,25 & 0,24 \\
\cline { 2 - 9 } & RIO & 2 & 0,09 & 0,09 & 0,01 & 0,08 & 0,10 & 0,02 \\
\cline { 2 - 9 } & SIL & 74 & 0,05 & 0,05 & 0,03 & 0 & 0,20 & 0,20 \\
\cline { 2 - 9 } & Indet. & 1 & 0,01 & - & - & - & - & - \\
\hline \multirow{4}{*}{ AP-1 } & BAS & 25 & 0,05 & 0,05 & 0,03 & 0 & 0,11 & 0,11 \\
\cline { 2 - 9 } & OBS & 57 & 0,07 & 0,07 & 0,05 & 0,01 & 0,30 & 0,29 \\
\cline { 2 - 9 } & SIL & 48 & 0,06 & 0,06 & 0,03 & 0,01 & 0,14 & 0,13 \\
\cline { 2 - 9 } & VUL & 1 & 0,01 & - & - & - & - & - \\
\cline { 2 - 9 } & Indet. & 1 & 0,01 & - & - & - & - & - \\
\hline \multirow{4}{*}{ AP-2 } & BAS & 12 & 0,04 & 0,04 & 0,02 & 0,01 & 0,08 & 0,07 \\
\cline { 2 - 9 } & OBS & 32 & 0,05 & 0,05 & 0,03 & 0,01 & 0,14 & 0,14 \\
\cline { 2 - 9 } & RIO & 1 & 0,10 & - & - & - & - & - \\
\cline { 2 - 9 } & SIL & 17 & 0,04 & 0,04 & 0,02 & 0,01 & 0,07 & 0,06 \\
\hline
\end{tabular}

Tabla 7.39. Estadística descriptiva de la densidad de extracciones previas en la cara dorsal de los desechos de talla enteros del Desierto Altoandino.

En las etapas finales de manufactura se encuentran las lascas de formatización de filo registradas únicamente sobre obsidiana, rocas silíceas y basalto (Figura 7.45). El porcentaje de lascas de adelgazamiento bifacial $(n=28)$ se mantiene constante del HTI al HTF $(50 \%, n=14)$, siendo mayoritarias sobre obsidiana $(n=17)$ en ambos segmentos temporales del Holoceno tardío; este tipo de lascas sobre obsidiana aumentan relativamente del HTI $(35,29 \%, n=6)$ al $\operatorname{HTF}(64,71 \%, n=11)$. Las lascas de adelgazamiento bifacial sobre rocas silíceas $(n=9)$, en cambio, disminuyen de un segmento temporal al otro, de $66,67 \%(n=6)$ a $33,33 \%(n=3)$. Este tipo de lascas sobre basalto sólo se ha registrado durante el HTI y representan el 14,29\% (n=2). Las lascas planas $(n=14)$ también mantienen su frecuencia de un momento a otro, representando el $50 \%(n=7)$ en cada segmento del Holoceno tardío. Las lascas planas sobre rocas silíceas 
$(n=9)$ son las mayoritarias en ambos segmentos temporales, estando un poco más representadas durante el segmento más reciente $(55,56 \%, n=5)$ que en el más antiguo $(44,44 \%, n=4)$. Las lascas planas de obsidiana $(n=3)$ aumentan hacia HTF, alcanzando el $66,67 \%(n=2)$. Las lascas planas sobre basalto $(n=2)$ se registraron sólo en el HTI, durante el cual superan a las lascas planas de obsidiana, y están ausentes durante el HTF. De las lascas de reactivación $(n=5)$, una $(20 \%)$ corresponde al HTI y es de roca silícea, y de las cuatro restantes tres son de obsidiana y una de roca silícea.

En la Figura 7.45 se observa que, durante el HTI, de las once lascas de formatización de filo sobre rocas silíceas el 54,55\% $(\mathrm{n}=6)$ son de adelgazamiento bifacial, el 36,36\% $(n=4)$ planas y el 9,09\% $(n=1)$ de reactivación. Hacia el HTF, esta tendencia se invierte: el 33,33\% $(\mathrm{n}=3)$ corresponde a lascas de adelgazamiento bifacial, el 55,55\% $(\mathrm{n}=5)$ a planas y el 11,11\% $(\mathrm{n}=1)$ a lascas de reactivación Por su parte, de las siete lascas de formatización de filo de obsidiana del HTI, el 85,71\% $(n=6)$ son de adelgazamiento bifacial y el 14,29\% ( $\mathrm{n}=1)$ planas; no hay lascas de reactivación de obsidiana registradas para este período. De las 16 lascas de formatización de filo de obsidiana del HTF, el $68,75 \%(n=11)$ son de adelgazamiento, el $18,75 \%(n=3)$ de reactivación y el 12,5\% $(n=2)$ planas. Como se mencionó antes, no hay lascas de formatización de filo de basalto del HTF (Figura 7.45).

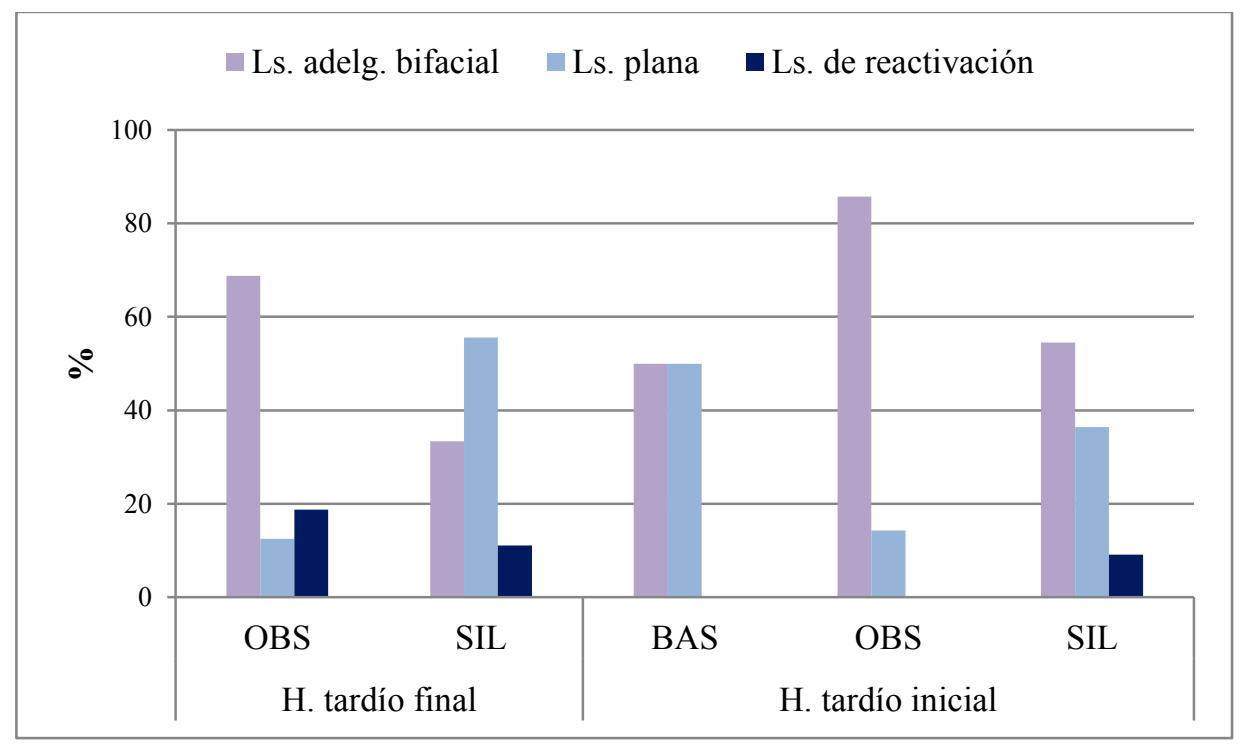

Figura 7.45. Frecuencia de tipos de lascas de formatización de filo a través del tiempo en el Desierto Altoandino. 


\subsubsection{Instrumentos}

Los instrumentos alcanzan el 2,78\% $(\mathrm{n}=40)$ del total de los artefactos líticos de los tres sitios del Desierto Altoandino. El 45\% (n=18) proviene de CP-1, el 45\% ( $\mathrm{n}=18)$ de AP-1 y el 10\% $(n=4)$ de AP-2. Las materias primas presentes son la obsidiana $(37,5 \%$, $\mathrm{n}=15)$, las rocas silíceas $(35 \%, \mathrm{n}=14)$ y el basalto $(25 \%, \mathrm{n}=10)$, principalmente, completando las frecuencias un instrumento confeccionado sobre materia prima indeterminada (2,5\%). Sólo en el sitio CP-1 se registraron artefactos sin formatización con rastros complementarios (ASF RC): son ocho en total, todos procedentes de la Unidad B de la cueva (HTI); de ellos, el 50\% es de obsidiana y la otra mitad $(n=4)$ corresponde a ASF RC sobre rocas silíceas.

En la Tabla 7.40 se observa que los instrumentos más frecuentes son los de formatización unifacial (42,5\%, n=17 de 40 instrumentos), que aumentan relativamente de 32,35\% ( $\mathrm{n}=11$ de 34 instrumentos y ASF RC del HTI) a 42,86\% (n=6 de 14 instrumentos del HTF); pero en cantidad, disminuyen de un momento más temprano al siguiente. Lo mismo ocurre con los artefactos formatizados bifaciales $(32,5 \%, n=13)$, frecuentes en un $26,92 \%(n=7)$ durante el HTI y, luego, pasan a representar el $42,86 \%$ $(n=6)$ del total de instrumentos correspondientes al HTF, es decir, la misma frecuencia que los artefactos de formatización unifacial, en este segundo segmento temporal. Siguen en frecuencia los ASF RC, cuya totalidad $(100 \%, n=8)$ se registró para el segmento de tiempo más antiguo. Lo mismo ocurre con los cuatro instrumentos compuestos y el único artefacto formatizado no diferenciado, ya que los cinco pertenecen al HTI. Uno de los dos artefactos manufacturados o modificados por abrasión, picado y/o pulido corresponde al HTI $(50 \%, n=1)$ y el otro al HTF. Algo semejante ocurre con los tres percutores: dos corresponden al HTI y uno al HTF. Así, en general, se observa que el 70,83\% (n=34) de los instrumentos y ASF RC corresponde al HTI y el 29,17\% restante $(n=14)$ al HTF. La mayoría de los artefactos de formatización unifacial está confeccionado sobre rocas silíceas $(47,06 \%, n=8)$, la mitad de ellos pertenecen al HTI y la otra mitad al HTF. En cantidades similares, pero en menor frecuencia, le siguen siete instrumentos unifaciales confeccionados sobre obsidiana (41,18\%), el 85,71\% $(n=6)$ del HTI y el $14,29 \%(n=1)$ del HTF. Por su parte, los instrumentos bifaciales están confeccionados mayoritariamente sobre obsidiana $(46,15 \%, n=6)$; el 33,33\% $(n=2)$ proviene del HTI y el 66,67\% $(n=4)$ del HTF, es decir, que los instrumentos bifaciales sobre obsidiana son los únicos de esta clase de instrumentos que aumentan con el tiempo. Los instrumentos bifaciales sobre rocas silíceas $(38,46 \%, n=5)$ disminuyen del 60 al 40\%, del HTI $(n=3)$ al HTF $(n=2)$, 
respectivamente. Por último, los dos únicos instrumentos bifaciales confeccionados sobre basalto $(15,39 \%)$ corresponden al HTI.

\begin{tabular}{|c|c|c|c|c|c|c|c|c|c|c|}
\hline$T$ & Sit & MP & $\underset{\text { Bifacial }}{\text { AF }}$ & $\begin{array}{c}\text { AF } \\
\text { Unifac }\end{array}$ & $\begin{array}{c}\mathbf{A F} \\
\text { Comp }\end{array}$ & $\begin{array}{c}\text { Art. m. } \\
\text { por } \\
\text { A,P,P }\end{array}$ & AF ND & $\begin{array}{c}\text { ASF } \\
\text { RC }\end{array}$ & $\mathbf{P}$ & Total \\
\hline \multirow{7}{*}{ 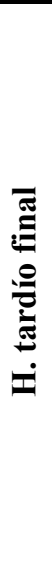 } & \multirow{2}{*}{ 竎 } & OBS & $\begin{array}{c}100 \% \\
(1)\end{array}$ & - & - & - & - & - & - & 1 \\
\hline & & SIL & $\begin{array}{c}100 \% \\
(1)\end{array}$ & - & - & - & - & - & - & 1 \\
\hline & \multirow{3}{*}{ 妾 } & BAS & - & $\begin{array}{c}33,33 \% \\
(1)\end{array}$ & - & $\begin{array}{c}33,33 \% \\
(1)\end{array}$ & - & - & $\begin{array}{c}33,33 \% \\
(1)\end{array}$ & 3 \\
\hline & & OBS & $\begin{array}{c}100 \% \\
(1)\end{array}$ & - & - & - & - & - & - & 1 \\
\hline & & SIL & $\begin{array}{c}25,00 \% \\
\text { (1) }\end{array}$ & $\begin{array}{c}75,00 \% \\
\text { (3) }\end{array}$ & - & - & - & - & - & 4 \\
\hline & \multirow{2}{*}{$\stackrel{i}{z}$} & OBS & $\begin{array}{c}66,67 \% \\
(2)\end{array}$ & $\begin{array}{c}33,33 \% \\
(1)\end{array}$ & - & - & - & - & - & 3 \\
\hline & & SIL & - & $\begin{array}{c}100 \% \\
\text { (1) }\end{array}$ & - & - & - & - & - & 1 \\
\hline \multicolumn{3}{|c|}{ Total HTF } & $\begin{array}{c}42,86 \% \\
(6) \\
\end{array}$ & $\begin{array}{c}2,86 \% \\
(6)\end{array}$ & - & $\begin{array}{c}7,14 \% \\
(1)\end{array}$ & - & - & $\begin{array}{c}7,14 \% \\
(1)\end{array}$ & 14 \\
\hline \multirow{7}{*}{ 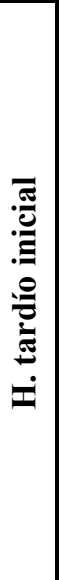 } & \multirow{4}{*}{$\tilde{u}^{\bar{\prime}}$} & BAS & $\begin{array}{c}40,00 \% \\
(2)\end{array}$ & $\begin{array}{c}20,00 \% \\
(1)\end{array}$ & $\begin{array}{c}20,00 \% \\
\text { (1) }\end{array}$ & - & - & - & $\begin{array}{c}20,00 \% \\
(1)\end{array}$ & 5 \\
\hline & & OBS & $\begin{array}{c}18,18 \% \\
\text { (2) }\end{array}$ & $\begin{array}{c}36,36 \% \\
(4)\end{array}$ & $\begin{array}{c}9,09 \% \\
\text { (1) }\end{array}$ & - & - & $\begin{array}{c}36,36 \% \\
\text { (4) }\end{array}$ & - & 11 \\
\hline & & SIL & $\begin{array}{c}14,29 \% \\
\text { (1) }\end{array}$ & $\begin{array}{c}14,29 \% \\
(1)\end{array}$ & $\begin{array}{c}14,29 \% \\
\text { (1) }\end{array}$ & - & - & $\begin{array}{c}57,14 \% \\
\text { (4) }\end{array}$ & - & 7 \\
\hline & & Indet. & - & - & - & $\begin{array}{c}100 \% \\
(1)\end{array}$ & - & - & - & 1 \\
\hline & \multirow{3}{*}{$\bar{z}$} & BAS & - & - & - & - & $\begin{array}{c}50,00 \% \\
\text { (1) }\end{array}$ & - & $\begin{array}{c}50,00 \% \\
\text { (1) }\end{array}$ & 2 \\
\hline & & OBS & - & $\begin{array}{c}66,67 \% \\
(2)\end{array}$ & $\begin{array}{c}33,33 \% \\
\text { (1) }\end{array}$ & - & - & - & - & 3 \\
\hline & & SIL & $\begin{array}{c}40,00 \% \\
\text { (2) }\end{array}$ & $\begin{array}{c}60,00 \% \\
(3)\end{array}$ & - & - & - & - & - & 5 \\
\hline \multicolumn{3}{|c|}{ Total HTI } & $\begin{array}{c}20,59 \% \\
(7)\end{array}$ & $\begin{array}{c}32,35 \% \\
(11)\end{array}$ & $\begin{array}{c}11,76 \% \\
\text { (4) }\end{array}$ & $\begin{array}{c}2,94 \% \\
\text { (1) }\end{array}$ & $\begin{array}{c}2,94 \% \\
(1)\end{array}$ & $\begin{array}{c}23,53 \% \\
\text { (8) }\end{array}$ & $\begin{array}{c}5,88 \% \\
\text { (2) }\end{array}$ & 34 \\
\hline \multicolumn{3}{|c|}{ Total (n) } & 13 & 17 & 4 & 2 & 1 & 8 & 3 & \multirow{2}{*}{48} \\
\hline \multicolumn{3}{|c|}{ Total (\%) } & 27,08 & 35,42 & 8,33 & 4,17 & 2,08 & 16,67 & 6,25 & \\
\hline
\end{tabular}

Tabla 7.40. Frecuencia de instrumentos y ASF RC en el Desierto Altoandino por segmento temporal dentro del Holoceno tardío. Referencias: T: tiempo; MP: materia prima; AF: Artefacto formatizado; Comp.: compuesto; Art. m. por A, P, P: Artefacto manufacturado o modificado por abrasión, picado y/o pulido; AF ND: Artefacto formatizado no diferenciado; ASF RC: artefacto sin formatización con rastros complementarios; P: percutor; BAS: basalto; OBS: obsidiana; SIL: rocas silíceas; Indet.: materia prima indeterminada.

En la Tabla 7.41 se observa que el índice de diversidad de materias primas no varía entre los artefactos compuestos, bifaciales y unifaciales, ya que presentan las 
mismas tres clases de roca representadas: obsidiana, rocas silíceas y basalto, en ese mismo orden de frecuencia. En artefactos manufacturados o modificados por abrasión, picado y/o pulido la diversidad es menor, y es equivalente el uso de basalto y el de roca indeterminada. Entre los percutores no hay diversidad de rocas ya que los tres son de basalto. En los ASF RC hay representación de rocas silíceas y obsidianas, y el único artefacto formatizado no diferenciado por fractura se confeccionó sobre basalto.

\begin{tabular}{|l|c|c|c|c|c|c|c|}
\hline & $\begin{array}{c}\text { AF } \\
\text { Bifacial }\end{array}$ & $\begin{array}{c}\text { AF } \\
\text { Unifacial }\end{array}$ & $\begin{array}{c}\text { AF } \\
\text { compuesto }\end{array}$ & $\begin{array}{c}\text { Art. manuf. } \\
\text { por A,P,P }\end{array}$ & AF ND & ASF RC & Percutor \\
\hline $\boldsymbol{n}$ MP & 3 & 3 & 3 & 2 & 1 & 2 & 1 \\
\hline $\boldsymbol{n}$ & 13 & 17 & 4 & 2 & 1 & 8 & 3 \\
\hline Dominancia & 0,3846 & 0,4048 & 0,375 & 0,5 & 1 & 0,5 & 1 \\
\hline Simpson & 0,6154 & 0,5952 & 0,625 & 0,5 & - & 0,5 & - \\
\hline Shannon-H & 1,012 & 0,9718 & 1,04 & 0,6931 & - & 0,6931 & - \\
\hline
\end{tabular}

Tabla 7.41. Diversidad de materias primas según clases artefactuales en el Desierto Altoandino.

En el $51,35 \%$ de los instrumentos $(\mathrm{n}=19)$ no se pudo distinguir la forma-base. Del $48,65 \%$ restante $(n=21)$, el $76,19 \%$ corresponde a lascas (internas: $87,5 \%, n=14 ;$ y de formatización de filo: $12,5 \%, \mathrm{n}=2)$ y el $23,81 \%$ restante a tres nódulos rodados $(14,29 \%)$, a un nódulo tabular de basalto $(4,76 \%)$ y a una punta de proyectil fracturada sobre roca silícea (forma-base de un raspador de filo frontal corto que a su vez está reactivado; 4,76\%). Para el HTI, predomina la calidad para la talla "muy buena", superior al 40\%, seguida por las rocas “excelentes" (32,35\%) y "buenas" (17,65\%). En cambio, durante el HTF, estas tres categorías se registran con la misma frecuencia: $28,57 \%, n=4$, cada una. En los dos casos de artefactos manufacturados o modificados por abrasión, picado y/o pulido, y los tres percutores $(10,42 \%, \mathrm{n}=5)$, no se definió la calidad para la talla; sus frecuencias a través del tiempo, obedecen a la presencia o no de estos tipos de instrumentos en cada segmento temporal (Tabla 7.42).

\begin{tabular}{|c|c|c|c|c|c|c|c|}
\hline $\mathbf{T}$ & Sitio & Calidad talla & EX & MB & B & NA & Total \\
\hline \multirow{6}{*}{ 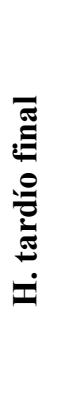 } & CP-1 & AF Bifacial & 1 & 1 & - & - & 2 \\
\hline & \multirow{4}{*}{ AP-1 } & AF Bifacial & 1 & 1 & - & - & 2 \\
\hline & & AF Unifacial & - & - & 4 & - & 4 \\
\hline & & Art. m. por A,P,P & - & - & - & 1 & 1 \\
\hline & & Percutor & - & - & - & 1 & 1 \\
\hline & AP-2 & AF Bifacial & 1 & 1 & - & - & 2 \\
\hline
\end{tabular}




\begin{tabular}{|c|c|c|c|c|c|c|c|}
\hline & & AF Unifacial & 1 & 1 & - & - & 2 \\
\hline \multicolumn{3}{|c|}{ Total HTF } & $\begin{array}{c}28,57 \% \\
(4) \\
\end{array}$ & $\begin{array}{c}28,57 \% \\
(4) \\
\end{array}$ & $\begin{array}{c}28,57 \% \\
(4) \\
\end{array}$ & $\begin{array}{c}14,29 \% \\
(2) \\
\end{array}$ & 14 \\
\hline \multirow{11}{*}{ 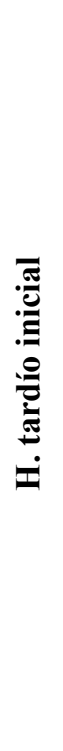 } & \multirow{6}{*}{ CP-1 } & AF Bifacial & 2 & 2 & 1 & - & 5 \\
\hline & & AF Unifacial & 4 & 2 & - & - & 6 \\
\hline & & AF Compuesto & 1 & 2 & - & - & 3 \\
\hline & & Art. m. por A,P,P & - & - & - & 1 & 1 \\
\hline & & ASF RC & 3 & 5 & - & - & 8 \\
\hline & & Percutor & - & - & - & 1 & 1 \\
\hline & \multirow{5}{*}{ AP-1 } & AF Bifacial & - & - & 2 & - & 2 \\
\hline & & AF Unifacial & - & 3 & 2 & - & 5 \\
\hline & & AF Compuesto & 1 & - & - & - & 1 \\
\hline & & AF ND & - & - & 1 & - & 1 \\
\hline & & Percutor & - & - & - & 1 & 1 \\
\hline \multicolumn{3}{|c|}{ Total HTI } & $\begin{array}{c}32,35 \% \\
(11)\end{array}$ & $\begin{array}{c}41,18 \% \\
(14)\end{array}$ & $\begin{array}{c}17,65 \% \\
(6)\end{array}$ & $\begin{array}{c}8,82 \% \\
(3)\end{array}$ & 34 \\
\hline \multicolumn{3}{|c|}{ Total (n) } & 15 & 18 & 10 & 5 & \multirow{2}{*}{48} \\
\hline \multicolumn{3}{|c|}{ Total (\%) } & 31,25 & $\mathbf{3 7 , 5 0}$ & 20,83 & 10,42 & \\
\hline
\end{tabular}

Tabla 7.42. Calidad para la talla de instrumentos y artefactos sin formatizar con rastros complementarios (ASF RC) en el Desierto Altoandino a lo largo del Holoceno tardío. Referencias: T: tiempo; EX: excelente; MB: muy buena; B: buena; NA: no aplica (para artefactos formatizados no por lascados).

Entre los artefactos unifaciales $(n=17)$, la mayoría son raspadores enteros $(n=5)$, más uno fracturado; están confeccionados sobre rocas silíceas $(\mathrm{n}=4)$ y sobre obsidiana $(n=2)$. Le siguen dos artefactos de formatización sumaria, también sobre rocas silíceas ( $\mathrm{n}=1$, fracturado) y sobre obsidiana $(\mathrm{n}=1$, entero), dos perforadores de obsidiana enteros, y otros dos instrumentos son fragmentos no diferenciados, sobre basalto y obsidiana. Completan el total de instrumentos unifaciales los grupos tipológicos correspondientes a un cortante de obsidiana fracturado, un cuchillo sobre roca silícea entero, una muesca de lascado simple y una muesca retocada, ambas sobre rocas silíceas y enteras, y una punta burilante de basalto entera.

En el caso de los artefactos bifaciales $(\mathrm{n}=13)$, predominan las puntas de proyectil $(38,46 \%, n=5)$, todas ellas fracturadas, tres sobre obsidiana y dos sobre rocas silíceas. Le sigue el grupo tipológico de los bifaces $(\mathrm{n}=4)$ ), la mitad sobre basalto (ambos son "bifaces parciales" sensu Aschero y Hocsman 2004, y uno está entero y el otro fracturado) y los 
otros dos sobre rocas silíceas (un "bifaz parcial” entero y un fragmento no diferenciado). Los cuatro instrumentos que completan el total corresponden a un cortante fracturado en obsidiana, un cuchillo de filo retocado entero sobre roca silícea, un fragmento no diferenciado de obsidiana y una muesca burilante fracturada sobre obsidiana (Tabla 7.43 y Figura 7.46).

Los grupos tipológicos más representados entre los instrumentos compuestos son: el de los cortantes y el de los cuchillos; también se registraron perforadores, raclettes (filos bisel asimétrico abrupto/oblicuo de microretoque ultramarginal), RBO (artefacto mediano pequeño/muy pequeño de retoque en bisel oblicuo y sección asimétrica) y raspadores (véase Tabla 7.1 del sitio CP-1 y Tabla 7.21 del sitio AP-1).

Los tres percutores registrados son de basalto, dos proceden de AP-1 y corresponden a segmentos temporales distintos dentro del Holoceno tardío. El otro percutor, fue registrado en el sitio CP-1 y corresponde al HTI. Los dos percutores de tamaño grande son del HTI y el de tamaño muy grande del HTF. Al margen de estas leves diferencias y teniendo en cuenta el pequeño tamaño de muestra, se podría considerar la posibilidad de que su presencia en los sitios residenciales tenga que ver con la reducción de núcleos (ya descortezados en otros sitios) y/o con las primeras instancias de la manufactura de instrumentos, por ejemplo, la formatización bifacial. El tamaño y peso de los tres percutores, sería coherente con estas etapas de la secuencia de formatización; su estado (enteros) podría vincularse con el "equipamiento" de los sitios.

Los artefactos sin formatización con rastros complementarios $(n=8)$, corresponden a filos naturales activos (los rastros complementarios pueden corresponder a rastros de utilización o factores postdepositacionales), la mitad de ellos registrados sobre rocas silíceas (tres fracturados y uno entero) y sobre obsidiana (tres enteros y uno fracturado). 


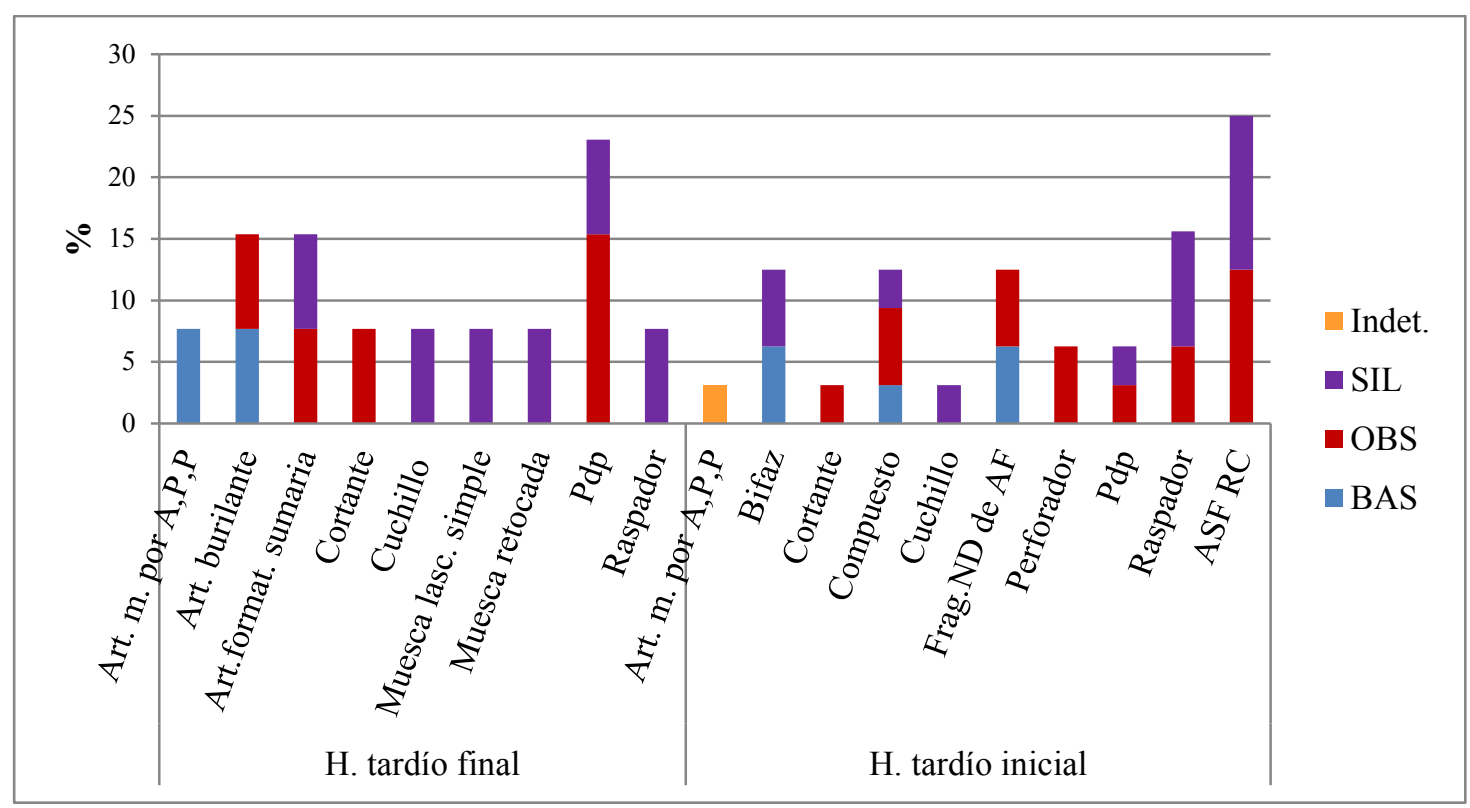

Figura 7.46. Frecuencia por segmento temporal de grupos tipológicos y de artefactos sin formatización con rastros complementarios (ASF RC) en el Desierto Altoandino según la materia prima.

En los 15 instrumentos confeccionados sobre obsidiana, se registraron ocho grupos tipológicos; el más frecuente es el de las puntas de proyectil (20\%, n=3). En los 14 de rocas silíceas se identificaron siete; el de los raspadores $(28,57 \%, \mathrm{n}=4)$ es el más frecuente. En los diez instrumentos de basalto se reconocieron cinco grupos tipológicos, más un "AF ND”, sin identificar; es decir, casi un grupo tipológico cada dos instrumentos: los más frecuentes son los percutores $(n=3)$. El instrumento restante, de los 40 registrados en los tres sitios, está confeccionado sobre roca indeterminada y corresponde al grupo tipológico de los artefactos manufacturados o modificados por abrasión, picado y/o pulido.

\begin{tabular}{|c|c|c|c|c|c|c|c|c|c|c|c|c|c|c|c|c|c|}
\hline \multirow{2}{*}{$\stackrel{\circ}{\stackrel{\circ}{\Xi}}$} & \multirow[t]{2}{*}{ 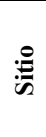 } & \multirow[t]{2}{*}{ MP } & \multicolumn{2}{|c|}{ AF Bifacial } & \multicolumn{2}{|c|}{ AF Unifacial } & \multicolumn{2}{|c|}{$\begin{array}{c}\text { AF } \\
\text { compuesto }\end{array}$} & \multicolumn{2}{|c|}{$\begin{array}{c}\text { Art. } \\
\text { manuf. } \\
\text { por } \mathbf{P}, \mathrm{A}, \mathrm{P}\end{array}$} & \multicolumn{2}{|c|}{ AF ND } & \multicolumn{2}{|c|}{ ASF RC } & \multicolumn{2}{|c|}{ Percutor } & \multirow[t]{2}{*}{ స్ } \\
\hline & & & Ent & Frac & Ent & Frac & Ent & Frac & Ent & Frac & Ent & Frac & Ent & Frac & Ent & Frac & \\
\hline \multirow{7}{*}{ 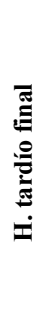 } & \multirow{2}{*}{ తI } & OBS & - & 1 & - & - & - & - & - & - & - & - & - & - & - & - & 1 \\
\hline & & SIL & 1 & - & - & - & - & - & - & - & - & - & - & - & - & - & 1 \\
\hline & \multirow{3}{*}{$\bar{z}$} & BAS & - & - & 1 & - & - & - & - & 1 & - & - & - & - & 1 & - & 3 \\
\hline & & OBS & - & 1 & - & - & - & - & - & - & - & - & - & - & - & - & 1 \\
\hline & & SIL & - & 1 & 2 & 1 & - & - & - & - & - & - & - & - & - & - & 4 \\
\hline & \multirow{2}{*}{$\hat{z}$} & OBS & - & 2 & 1 & - & - & - & - & - & - & - & - & - & - & - & 3 \\
\hline & & SIL & - & - & 1 & - & - & - & - & - & - & - & - & - & - & - & 1 \\
\hline \multicolumn{3}{|c|}{ Total HTF } & $\begin{array}{c}7,14 \% \\
\text { (1) }\end{array}$ & $\begin{array}{c}35,71 \% \\
(5)\end{array}$ & $\begin{array}{c}35,71 \% \\
(5)\end{array}$ & $\begin{array}{c}7,14 \% \\
(1)\end{array}$ & - & - & - & $\begin{array}{c}7,14 \% \\
\text { (1) }\end{array}$ & - & - & - & - & $\begin{array}{c}7,14 \% \\
\text { (1) }\end{array}$ & - & 14 \\
\hline & & BAS & 1 & 1 & - & 1 & 1 & - & - & - & - & - & - & - & 1 & - & 5 \\
\hline & & OBS & - & 2 & 2 & 2 & 1 & - & - & - & - & - & 3 & 1 & - & - & 11 \\
\hline
\end{tabular}




\begin{tabular}{|c|c|c|c|c|c|c|c|c|c|c|c|c|c|c|c|c|}
\hline & SIL & - & 1 & 1 & - & 1 & - & - & - & - & - & 1 & 3 & - & - & 7 \\
\hline & Indet. & - & - & - & - & - & - & - & 1 & - & - & - & - & - & - & 1 \\
\hline \multirow{3}{*}{$\bar{z}^{\prime}$} & BAS & - & - & - & - & - & - & - & - & - & 1 & - & - & 1 & - & 2 \\
\hline & OBS & - & - & 2 & - & 1 & - & - & - & - & - & - & - & - & - & 3 \\
\hline & SIL & 1 & 1 & 2 & 1 & - & - & - & - & - & - & - & - & - & - & 5 \\
\hline \multicolumn{2}{|c|}{ Total HTI } & $\begin{array}{l}5,88 \% \\
\text { (2) }\end{array}$ & $\begin{array}{c}14,71 \% \\
\text { (5) }\end{array}$ & $\begin{array}{c}20,59 \% \\
(7)\end{array}$ & $\begin{array}{c}11,76 \% \\
(4)\end{array}$ & $\begin{array}{c}11,76 \% \\
(4)\end{array}$ & - & - & $\begin{array}{l}2,94 \% \\
\text { (1) }\end{array}$ & - & $\begin{array}{l}2,94 \% \\
\text { (1) }\end{array}$ & $\begin{array}{c}11,76 \% \\
(4)\end{array}$ & $\begin{array}{c}11,76 \% \\
(4)\end{array}$ & $\begin{array}{l}5,88 \% \\
\text { (2) }\end{array}$ & - & 34 \\
\hline \multicolumn{2}{|c|}{ Total (n) } & 3 & 10 & 12 & 5 & 4 & - & - & 2 & - & 1 & 4 & 4 & 3 & - & \\
\hline \multicolumn{2}{|c|}{ Total (\%) } & 6,25 & 20,83 & 25,00 & 10,42 & 8,33 & - & - & 4,17 & - & 2,08 & 8,33 & 8,33 & 6,25 & - & 8 \\
\hline
\end{tabular}

Tabla 7.43. Frecuencia de fragmentación en instrumentos y ASF RC en el Desierto Altoandino a

través del Holoceno tardío. Referencias: T: tiempo; MP: materia prima; AF: Artefacto formatizado; Comp.: compuesto; Art. m. por P, A, P: Artefacto manufacturado o modificado por picado, abrasión y/o pulido; AF ND: Artefacto formatizado no diferenciado; ASF RC: artefacto sin formatización con rastros complementarios; Ent.: entero; Frac.: fracturado; BAS: basalto; OBS: obsidiana; SIL: rocas siliceas; Indet.: materia prima indeterminada.

La relación entre los desechos de talla enteros y los artefactos formatizados, provee un valor estimado del descarte y la producción y/o reparación de instrumentos (Tabla 7.44). Los valores más altos se registran en obsidiana del sitio AP-1, en el segmento temporal atribuido al HTF. Le siguen las rocas silíceas de CP-1 y AP-2 correspondientes al mismo lapso temporal. Estas tendencias (obsidiana en primer lugar, seguida por las rocas silíceas) se repiten en la relación entre desechos e instrumentos de ambos momentos, aunque particularmente durante el HTI, los valores mayores se dan en basalto de AP-1, el mismo sitio que el de la obsidiana del segmento de tiempo más reciente. En los valores intra-sitio de los otros dos sitios, CP-1 y AP-2, la relación desechos / instrumentos es mayor entre las rocas silíceas, en ambos momentos del Holoceno tardío.

\begin{tabular}{|c|l|c|c|c|c|c|c|c|}
\hline Tiempo & Sitio & BAS & OBS & RIO & SIL & VUL & QZ & Indet. \\
\hline \multirow{3}{*}{ HTF } & CP-1 & - & 9,00 & - & 19,00 & - & - & - \\
\cline { 2 - 9 } & AP-1 & 5,00 & 48,00 & - & 7,00 & - & - & - \\
\cline { 2 - 9 } & AP-2 & - & 12,33 & - & 19,00 & - & - & - \\
\hline \multirow{2}{*}{ HTI } & $\mathbf{C P - 1}$ & 2,6 & 4,55 & - & 8,71 & - & - & 1,00 \\
\cline { 2 - 9 } & AP-1 & 5,50 & 6,67 & - & 6,40 & - & - & - \\
\hline
\end{tabular}

Tabla 7.44. Relación entre el total de desechos de talla enteros e instrumentos por materia prima en el Desierto Altoandino a través del Holoceno tardío.

El grupo tipológico mayoritario dentro de los artefactos de formatización unifacial (Tabla 7.43 y Figura 7.46) es el de los raspadores $(15 \%, \mathrm{n}=6)$ confeccionados sobre rocas silíceas $(\mathrm{n}=4)$ y obsidiana $(\mathrm{n}=2)$. El único raspador fracturado está confeccionado sobre 
roca silícea y proviene del sitio AP-1. La mitad de los raspadores $(n=3)$ es de tamaño mediano pequeño (módulo de tamaño=3) y la otra mitad de tamaño pequeño (módulo: 2), aunque uno de estos últimos está fracturado. De los raspadores enteros, predomina el tamaño MEP (mediano pequeño) y el único pequeño $(P)$ es de roca silícea (Tabla 7.45). La reactivación está presente sobre uno de los raspadores de obsidiana y sobre uno de silícea (ambos procedentes de CP-1).

\begin{tabular}{|c|c|c|c|c|c|c|}
\hline \multirow[b]{2}{*}{ Sitio } & \multirow[b]{2}{*}{ MP } & \multirow[b]{2}{*}{ Tamaño } & \multicolumn{2}{|c|}{ Espesor máximo } & \multirow{2}{*}{$\begin{array}{l}\text { Índ. Geom. } \\
\text { de reducción }\end{array}$} & \multirow[b]{2}{*}{ Reactivación } \\
\hline & & & $\begin{array}{c}\text { del filo retoc. } \\
\text { (t) }\end{array}$ & $\begin{array}{c}\text { de la F-B } \\
(T)\end{array}$ & & \\
\hline \multirow{3}{*}{ CP-1 } & OBS & MEP & 5,0 & 6,5 & 0,8 & Presente \\
\hline & OBS & MEP & 4,5 & 4,5 & 1,0 & Ausente \\
\hline & SIL & $\mathrm{P}$ & 1,0 & 6,5 & 0,2 & Presente \\
\hline AP-2 & SIL & MEP & 3,0 & 7,0 & 0,4 & Ausente \\
\hline
\end{tabular}

Tabla 7.45. Tamaños e índices geométricos de reducción sobre raspadores enteros.

A pesar de que el tamaño de muestra es pequeño, al calcular el índice geométrico de reducción (sensu Kuhn 1990), se puede observar que ambos raspadores de obsidiana se acercan a una tasa $\mathrm{t} / \mathrm{T}$ de 1,0 (media de 0,9$)$ y que los confeccionados sobre rocas silíceas se acercan a 0 (media de 0,3 ). Por lo tanto, por más que uno de los raspadores de obsidiana no presenta evidencias de reactivación, el índice indica que ambos raspadores sobre esta roca presentan mayor frecuencia o intensidad de reactivación que los de rocas silíceas y que, contrariamente a lo esperado, el de roca silícea reactivado, posee mayor vida útil que los de obsidiana.

Como se dijo, del total de artefactos formatizados, las puntas de proyectil $(12,5 \%$, $\mathrm{n}=5)$ confeccionadas únicamente en obsidiana $(\mathrm{n}=3)$ y en rocas silíceas $(\mathrm{n}=2)$, constituyen el grupo tipológico preponderante dentro de los artefactos bifaciales. Los sub-grupos tipológicos incluyen dos fragmentos no diferenciados, dos preformas y una punta de proyectil apedunculada. En todos los casos, las piezas están fracturadas. Para estimar las dimensiones de las puntas fragmentadas, se calculan los valores medios de largo, ancho y espesor por materia prima en fragmentos distales, sumando la variable peso como un indicador de diferencia de tamaño. Sin embargo, la única pieza que podría incluirse en dicho cálculo es la punta apedunculada, fracturada en sus aletas, cuyas medidas son 23,0 $\mathrm{mm}$ de largo, 14,0 $\mathrm{mm}$ de ancho, 3,0 $\mathrm{mm}$ de espesor, y pesa 0,9 gr. 


\subsection{OBSIDIANAS EN EL DESIERTO PATAGÓNICO}

\subsubsection{ANÁLISIS DE ELEMENTOS TRAZA}

De los tres sitios arqueológicos del Desierto Altoandino, se realizaron análisis de elementos traza sobre artefactos de obsidiana de CP-1 y AP-1. Del primero se seleccionaron doce muestras, cinco de la Unidad A, correspondiente al HTF, y las siete restantes de las unidades asignadas al HTI: tres de la Unidad B y cuatro de la Unidad C. De estas doce muestras, once provienen de la fuente Las Cargas, localizada a unos 60 kilómetros. La muestra restante procede de una fuente desconocida, identificada como "Grupo A" y corresponde al HTF (Tabla 7.46).

\begin{tabular}{|c|c|c|c|c|c|}
\hline $\mathbf{T}$ & Sitio & $\begin{array}{l}\text { Unid } \\
\text { temp }\end{array}$ & Nivel & Cód. & Procedencia \\
\hline \multirow{9}{*}{ HTF } & \multirow{5}{*}{ CP-1 } & \multirow{5}{*}{ A } & 1 & $\# 26$ & Las Cargas \\
\hline & & & 1 & $\# 27$ & Las Cargas \\
\hline & & & 4 & $\# 17$ & "Grupo A" \\
\hline & & & 5 & \#18 & Las Cargas \\
\hline & & & 5 & $\# 34$ & Las Cargas \\
\hline & \multirow{4}{*}{ AP-1 } & \multirow{4}{*}{ A } & 1 & $\# 48$ & "Grupo A" \\
\hline & & & 2 & \#95 & "Grupo A" \\
\hline & & & 3 & $\# 124$ & Las Cargas \\
\hline & & & 4 & $\# 113$ & Las Cargas \\
\hline \multirow{13}{*}{ HTI } & \multirow{7}{*}{ CP-1 } & \multirow{3}{*}{ B } & 6 & \#39 & Las Cargas \\
\hline & & & 8 & \#66 & Las Cargas \\
\hline & & & 8 & \#67 & Las Cargas \\
\hline & & \multirow{4}{*}{ C } & 17 & $\# 55$ & Las Cargas \\
\hline & & & 18 & \#17 & Las Cargas \\
\hline & & & 19 & \#28 & Las Cargas \\
\hline & & & 19 & \#29 & Las Cargas \\
\hline & \multirow{6}{*}{ AP-1 } & \multirow{6}{*}{ B } & 5 & \#66 & Las Cargas \\
\hline & & & 6 & \#121 & Las Cargas \\
\hline & & & 7 & \#53 & Las Cargas \\
\hline & & & 7 & $\# 54$ & Las Cargas \\
\hline & & & 8 & $\# 74$ & Las Cargas \\
\hline & & & 10 & \#49 & Las Cargas \\
\hline
\end{tabular}

Tabla 7.46. Muestras de artefactos de obsidiana de los sitios CP-1 y AP-1, con su correspondiente fuente de procedencia y el momento asignado dentro del Holoceno tardío, según la secuencia temporal de cada sitio.

Del sitio AP-1 se analizaron diez artefactos, cuatro de la Unidad A, correspondiente al HTF y seis de la Unidad B, del HTI (Tabla 7.46). Ocho provienen de la fuente de obsidiana Las Cargas: seis del HTI y dos del HTF. Las dos restantes proceden de la fuente desconocida "Grupo A" y corresponden al HTF. 
Los análisis de elementos traza muestran el uso de la fuente de obsidiana cordillerana Las Cargas, de disponibilidad no local. Por el momento, y debido a la etapa en la que se encuentra la caracterización de las fuentes de obsidiana dentro de la región, no es posible asumir que la fuente desconocida "Grupo A" sea no local; aunque la baja frecuencia de artefactos de esta fuente $(13,64 \%, n=3)$, respecto del resto de los artefactos de obsidiana analizados geoquímicamente sugiere que pueden provenir de grandes distancias.

La fuente desconocida "Grupo A" habría sido utilizada únicamente durante el HTF (Tabla 7.46), mientras que la fuente Las Cargas, se registró durante todo el lapso temporal representado en los sitios aquí analizados.

\subsubsection{APROVISIONAMIENTO Y USO DE OBSIDIANAS}

Pese a que la obsidiana no proviene de fuentes locales, el $42 \%(n=603)$ de los 1438 artefactos líticos analizados de los tres sitios fueron confeccionados sobre esta materia prima. El 37,5\% $(n=15)$ de los instrumentos, el 42,35\% $(n=584)$ de los desechos de talla y la mitad de los ASF RC (50\%, $n=4)$, son de obsidiana. Estas consideraciones tecnológicas y el acceso directo a la fuente Las Cargas desde el valle del río Grande, sugieren un aprovisionamiento directo de dicha fuente.

En la Figura 7.47 se observa que la frecuencia de artefactos de obsidiana en los tres sitios analizados aumenta del HTI al HTF, con una disminución registrada hacia el último tramo del HTF. Se debe tener en cuenta que esta unidad fue fechada en 130 años AP y que, por ende, una gran parte de los materiales identificados son históricos (vidrios, huesos de chivo, metales, etc.). Esto puede haber influido sobre la representación de las materias primas. 


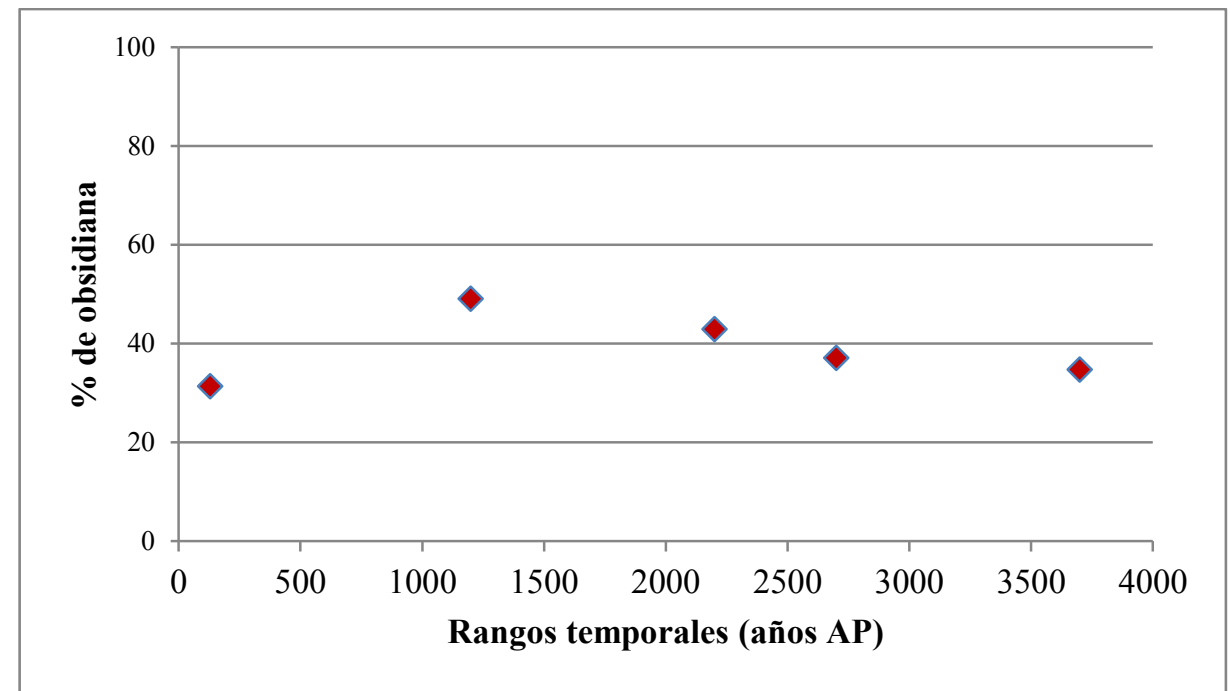

Figura 7.47. Distribución temporal de artefactos de obsidiana registrados en CP-1, AP-1 y AP-2.

\subsection{CONSIDERACIONES FINALES}

La tecnología lítica del Desierto Altoandino está caracterizada por el uso predominante de obsidianas y rocas silíceas. En ambas rocas es mayoritaria la calidad para la talla excelente y muy buena. La ausencia de reserva de corteza en los artefactos es predominante en la mayoría de las clases de roca. Asimismo, la categoría de tamaño más frecuente es la de "muy pequeños". En cuanto al estado de fragmentación, predominan los artefactos fracturados.

En relación a la estructura tecnológica se observa un marcado predominio de la clase artefactual de los desechos de talla. Predominan las lascas internas (sobre todo, angulares), seguidas por las de formatización de filo y las externas. Del índice de corteza, la vulcanita indeterminada y el basalto son las que poseen los valores más altos; y del lado opuesto se halla la obsidiana. Entre las lascas de formatización de filo, predominan las de obsidiana.

Los instrumentos mayoritarios son los de formatización unifacial, seguidos por los bifaciales; ambas clases se confeccionaron sobre obsidiana, rocas silíceas y basalto. La tendencia más destacada es la del uso de rocas silíceas para instrumentos unifaciales (sobre todo raspadores), y de obsidiana para bifaciales (principalmente, puntas de proyectil). Sin embargo, en CP-1 predominan los instrumentos unifaciales sobre obsidiana y, de los raspadores, la mayoría son de obsidiana en este sitio. Allí, también es notable el predominio de rocas silíceas, pero los instrumentos están mayormente confeccionados sobre obsidiana. En cambio, en AP-1 predominan, en general, los 
artefactos de obsidiana y, en particular, los confeccionados sobre rocas silíceas; los instrumentos de obsidiana son menos frecuentes. Además, entre los instrumentos bifaciales de estos dos sitios, las puntas de proyectil registradas en CP-1 son de obsidiana y las de AP-1 son de rocas silíceas. En AP-2 predomina el uso de obsidiana, evidenciado tanto en el conjunto total de artefactos líticos, como en el conjunto de instrumentos. Así, para la confección de instrumentos se usaron en los tres sitios, principalmente, tres materias primas distintas. Predomina la utilización de obsidiana, seguida por la de rocas silíceas y de basalto. Los ASF RC se registraron únicamente en el sitio CP-1 (aunque con evidencias en algunos instrumentos de AP-1) y sólo sobre obsidiana y rocas silíceas. En ninguno de los tres sitios se identificaron núcleos ni nódulos en ninguna de las seis materias primas registradas.

En cuanto a las tendencias temporales, no se registraron diferencias significativas en las frecuencias y tipos de materias primas entre el HTI (ca. 4.000-2.000 años AP) y el HTF (ca. últimos 2.000 años). El cambio más importante es el aumento en el uso de la obsidiana y la disminución de las rocas silíceas hacia el segmento de tiempo más reciente (Figuras 7.43 y 7.47). El basalto es, en ambos momentos, la tercera roca más frecuente (mayor en el lapso más reciente).

La categoría de calidad para la talla "excelente" aumenta hacia el HTF y disminuye la de calidad "muy buena". Esto tendría relación con el aumento en el uso de la obsidiana. Por otro lado, el porcentaje de artefactos enteros aumenta hacia el HTF, en detrimento de los artefactos fracturados. La categoría de tamaño más frecuente, "muy pequeño", aumenta en el HTF y disminuyen las demás categorías de tamaño. Por otro lado, la categoría " $0 \%$ " (ausencia de reserva de corteza), disminuye hacia el HTF y, las distintas categorías que indican su presencia, varían entre el aumento y la disminución, dependiendo sobre todo, de la materia prima.

Entre las clases artefactuales, se observa que la composición es similar entre un segmento temporal y otro, aunque los instrumentos compuestos y los ASF RC están presentes sólo durante el HTI. En ambos momentos predominan los desechos de talla, seguidos por los instrumentos que, para el HTI, están representados principalmente por los artefactos de formatización unifacial, seguidos por los ASF RC (ausentes durante el HTF), luego los artefactos formatizados bifaciales, los instrumentos compuestos (también ausentes en el segmento temporal más reciente). Por su parte, durante el HTF, también se hallan en primer lugar los desechos de talla, seguidos por los instrumentos unifaciales y bifaciales. 
En síntesis, en los tres sitios se identificaron actividades relacionadas con las etapas avanzadas y finales del proceso de manufactura de instrumentos líticos, incluyendo su mantenimiento y reactivación. La ausencia de núcleos y de evidencias de descortezamiento (baja frecuencia de lascas externas, baja presencia de reserva de corteza en desechos), y la preponderancia de lascas internas, apoyan esta idea. Además, los muestreos de materias primas realizados en las cercanías de CP-1, AP-1 y AP-2, señalan la presencia de rocas locales (basaltos, vulcanitas indeterminadas, andesitas y riolitas, inmediatamente disponibles; y fuentes de rocas silíceas locales) y no locales (obsidianas) en forma de nódulos y bloques masivos con y sin corteza. Estas evidencias tomadas en conjunto, también sugieren un aprovechamiento intenso de las materias primas líticas no locales; de hecho, la obsidiana es la roca más frecuente. Esto puede deberse a la distancia y/o al tipo de acceso a las fuentes de aprovisionamiento. La evidencia de instrumentos de obsidiana descartados enteros parece contradecir lo antedicho. Las funciones que se han inferido de los grupos tipológicos registrados sugieren que CP-1, AP-1 y AP-2 son sitios de actividades múltiples relacionadas con el procesamiento de recursos vegetales y animales (e.g. madera, cuero, etc.), como ser, raspar (raspadores, muescas, instrumentos compuestos), cortar (cortantes, cuchillos, instrumentos compuestos), perforar (perforadores, instrumentos compuestos), golpear y percutir (percutores), e incisión (artefactos burilantes), entre otros. 


\section{CAPÍTULO 8}

\section{RESULTADOS DEL ANÁLISIS DEL REGISTRO LÍTICO EN EL DESIERTO PATAGÓNICO}

\subsection{LOS SITIOS ARQUEOLÓGICOS BAJO ESTUDIO}

El Desierto Patagónico es un ambiente ecotonal o de transición, que puede ser habitado todo el año y posee amplia diversidad de especies y de materias primas. En este tramo de su recorrido, el río Atuel traslada recursos líticos de variada aptitud para la talla desde las altas cumbres de la Cordillera de los Andes, hasta la planicie oriental.

El objetivo de este capítulo es presentar los resultados del análisis de los conjuntos líticos de los cuatro sitios arqueológicos localizados en este desierto: Cueva Salamanca 1 (CSA-1), localizado en el piedemonte cordillerano (Figura 8.1 y 8.2); Arbolito 6 (AR-6), cuadrículas A1 y A2; Arbolito 7 (AR-7); y Barranca de Piedra 1 (BDP-1). Los cuatro se ubican en la localidad "Arbolito", que limita con el Desierto de Monte (Figuras 8.1 y 8.21). A continuación, se presentan los procedimientos de excavación y las características estratigráficas, cronológicas y arqueológicas de cada uno, haciendo hincapié en el registro lítico. 


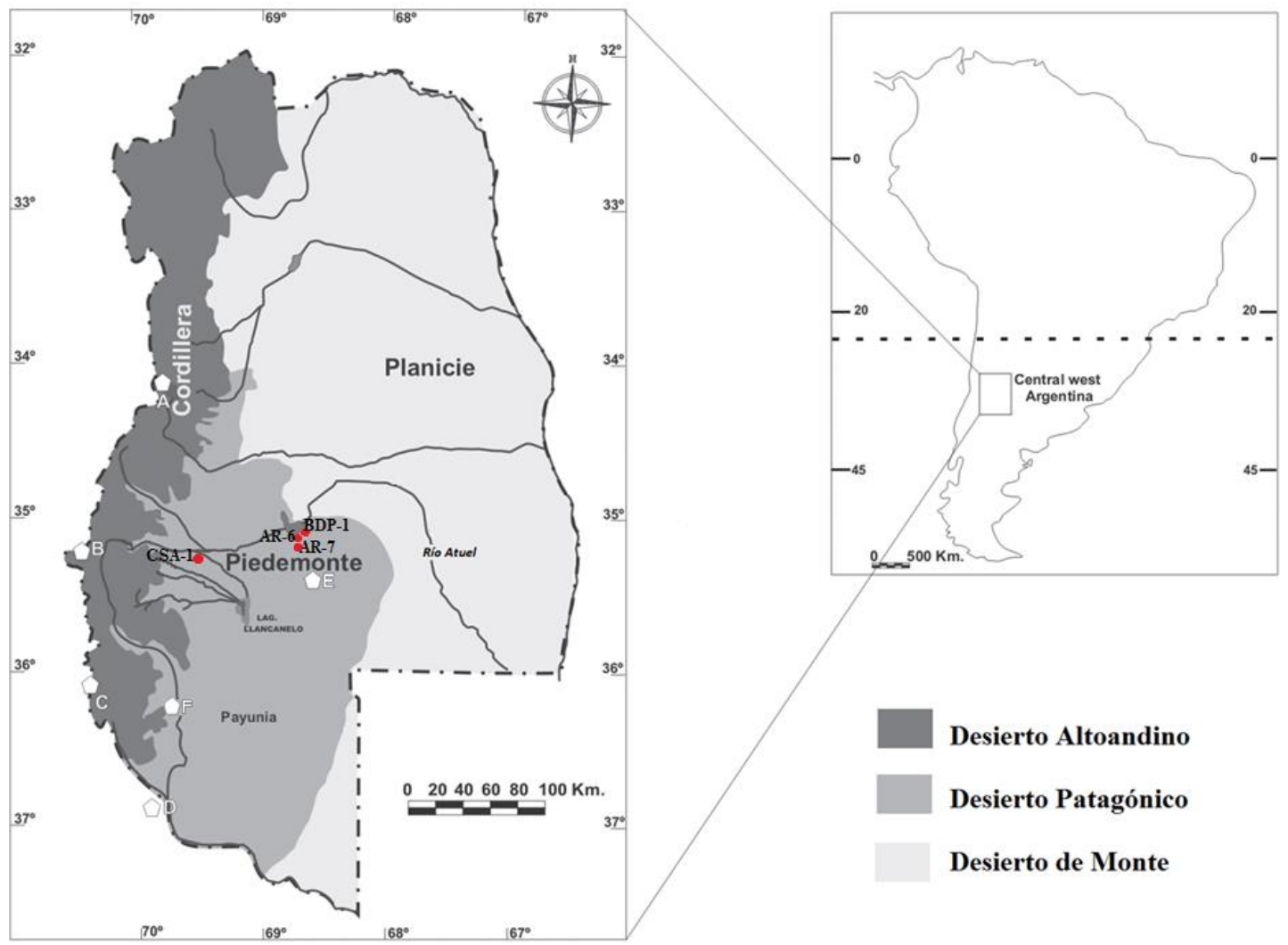

Figura 8.1. Localización de los sitios arqueológicos del Desierto Patagónico (cuenca media del río Atuel) y de las fuentes de obsidiana. Referencias: sitios arqueológicos: CSA-1: Cueva Salamanca 1; AR-6: Arbolito 6; AR-7: Arbolito 7; BDP-1: Barranca de Piedra 1. Fuentes de obsidiana: A- Laguna El Diamante; B- Las Cargas; C- Laguna del Maule; D- Cerro Huenul; EEl Peceño; F- Coche Quemado.

\subsubsection{CUEVA SALAMANCA 1 (CSA-1)}

Cueva Salamanca 1 (en adelante, CSA-1) es un reparo rocoso que se emplaza sobre una meseta a $1668 \mathrm{msnm}$ en el piedemonte de la Cordillera Principal (35 $17^{\circ} 4,11^{\prime \prime}$ de LS y a $69^{\circ} 41^{\prime} 33,34^{\prime \prime}$ de LO) (Figuras 8.1 , 8.2 y 8.3), en el yacimiento petrolífero "Puesto Rojas". Es una mesa formada por un flujo de lava basáltica de origen Pliocénico que sepultó un conglomerado de 1 a 2 metros de espesor, dispuesto de manera discordante sobre las areniscas rojizas continentales asignadas al Cretácico (Neme et al. 2018). Su excavación en el año 2010 permitió, entre otras cosas, asignar una cronología que se remonta hasta el Holoceno medio (8.000-4.000 años AP; en adelante HM), con claras evidencias de ocupación durante el Holoceno tardío inicial (4.000-2.000 años AP; en adelante HTI) y final (2.000 años AP-200; en adelante HTF). 


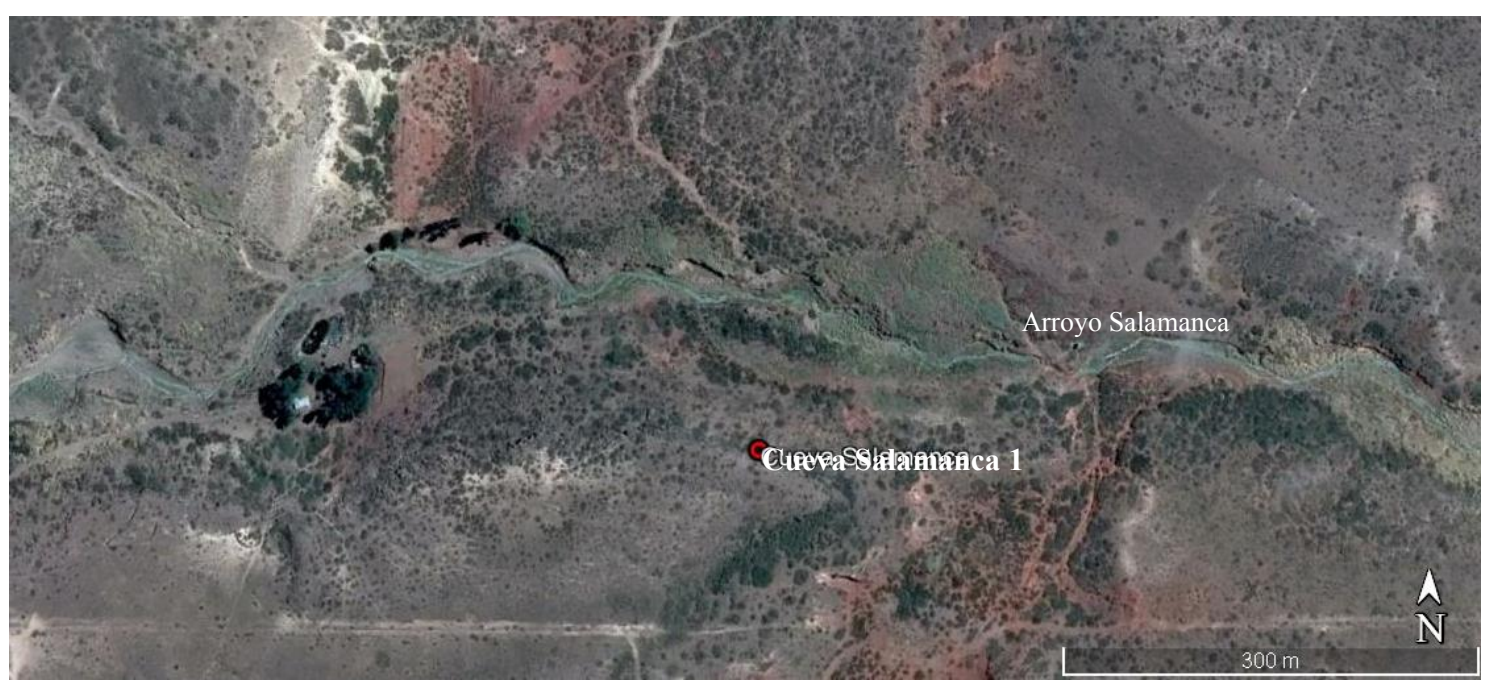

Figura 8.2. Localización del sitio Cueva Salamanca 1.

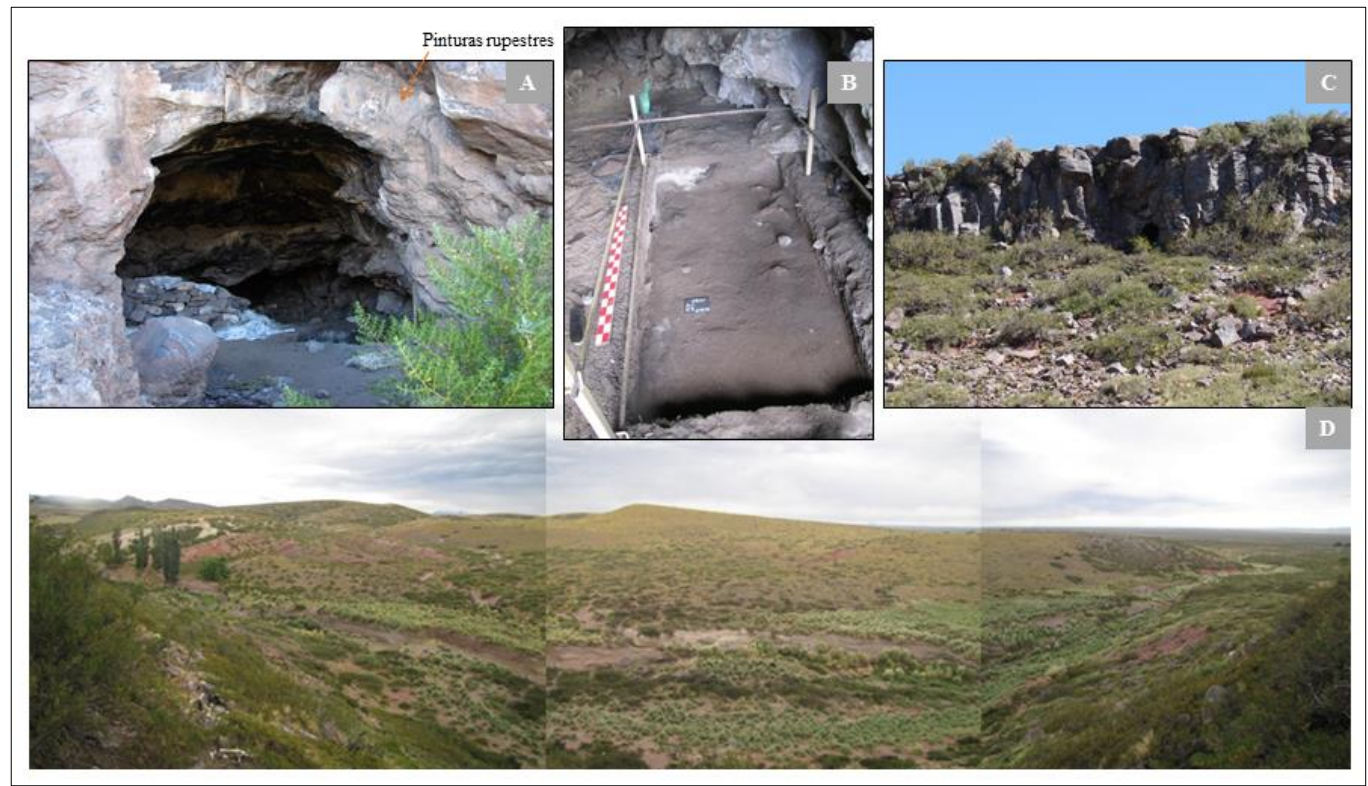

Figura 8.3. A. Entrada a la cueva; B. Cuadrícula de excavación; C. Vista del frente de la cueva (desde el norte); D. Vista desde la cueva (hacia el norte).

En la entrada de la cueva, sobre la pared izquierda, se reconocieron pinturas rupestres con motivos de tipo geométrico (Zig-zag) en color blanco (Figura 8.4), muy mal preservadas. 


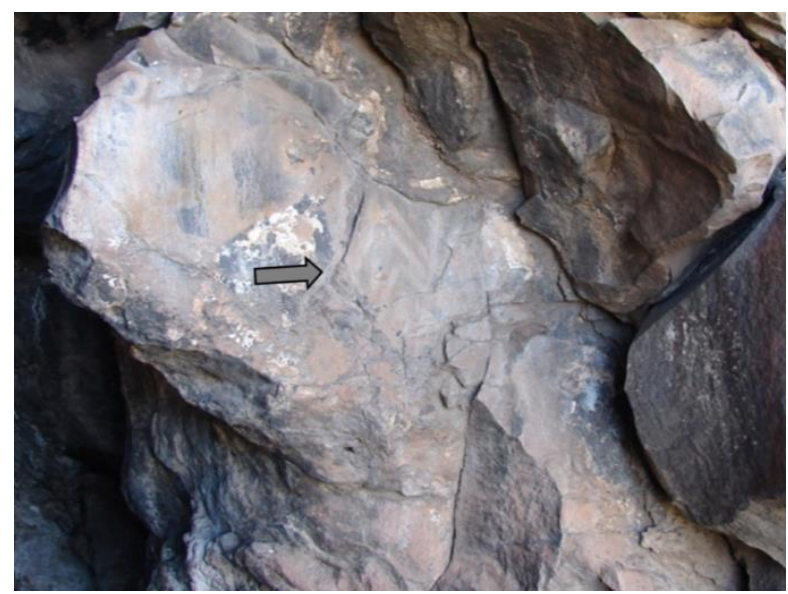

Figura 8.4. Detalle de los motivos rupestres de CSA-1.

\subsubsection{Excavación}

Las tareas de campo en CSA-1 consistieron en la excavación de una cuadrícula (A1) de $2 \times 1 \mathrm{~m}$, adyacente a la pared oeste de la cueva (Figura 8.5). La cuadrícula fue subdividida en dos sectores de $1 \mathrm{~m}^{2}$, sectores norte y sur, y se excavaron 20 niveles artificiales de $5 \mathrm{~cm}$ (Tabla 8.1), siguiendo la inclinación natural del piso de la superficie, hasta alcanzar un metro de profundidad. En la excavación se encontraron varios bloques rocosos medianos y pequeños que pueden corresponder a desprendimientos del techo de la cueva.

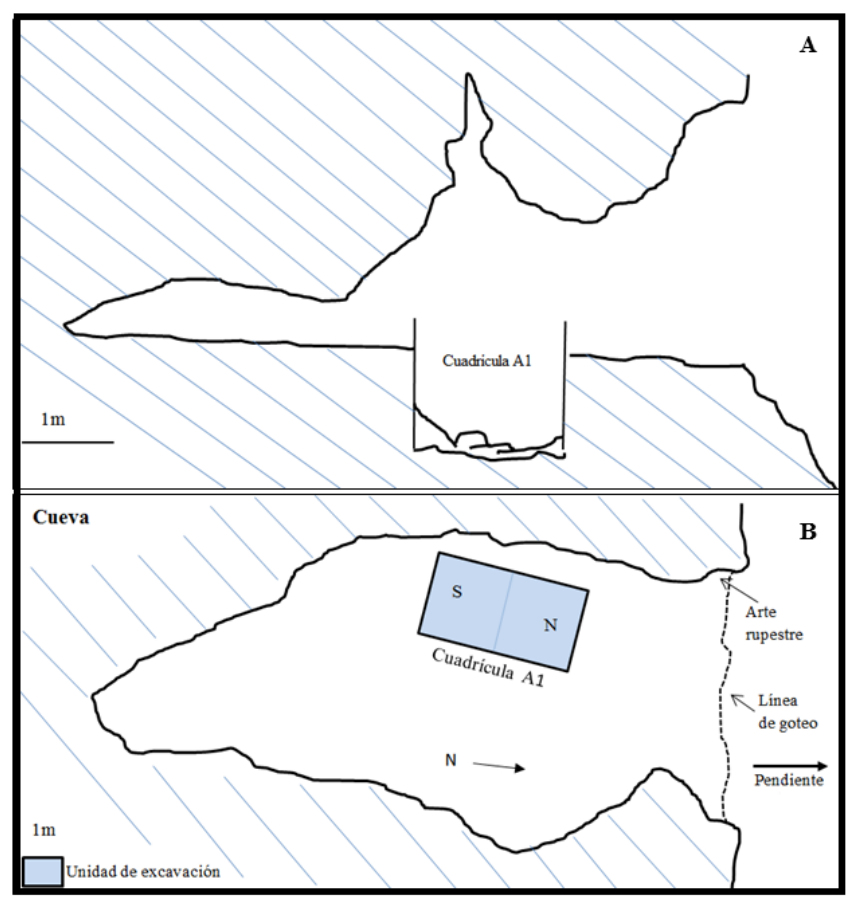

Figura 8.5. A. Perfil oeste del sitio CSA-1 y localización de la cuadrícula de excavación; B. Planta de CSA-1 y ubicación de la cuadrícula A1. 


\subsubsection{Estratigrafía}

El relleno de la cueva está constituido por 1,3 m de arenas finas con una fracción secundaria de clastos gruesos (10 cm de longitud), ubicados principalmente en la sección más baja que constituye la matriz sedimentaria del registro arqueológico. El relleno sedimentario se subdivide en cinco unidades estratigráficas ( 1 a 5, de arriba hacia abajo) sobre la base de la aparición de superficies discontinuas de sedimentación (Neme et al. 2018). Al noreste de la excavación se halla la sección menos perturbada y relativamente completa (Figura 8.6).

\begin{tabular}{|c|c|c|c|c|c|c|c|c|}
\hline $\begin{array}{c}\text { Nivel } \\
\text { artificial }\end{array}$ & Fecha ${ }^{14} \mathrm{C}$ & $\begin{array}{c}\text { Edad cal } \\
\qquad \text { AP }\end{array}$ & Material & Código & $\begin{array}{l}\text { Conjunto } \\
\text { temporal }\end{array}$ & Óseo & Lítico & Cerámica \\
\hline 1 & \multirow{6}{*}{$1.516 \pm 38$} & \multirow{6}{*}{1.355} & \multirow{6}{*}{ Carbón } & \multirow{6}{*}{ AA-94004 } & \multirow{10}{*}{$\mathbf{A}$} & 46 & 80 & 2 \\
\hline 2 & & & & & & 144 & 54 & 2 \\
\hline 3 & & & & & & 155 & 189 & 6 \\
\hline 4 & & & & & & 214 & 242 & 4 \\
\hline 5 & & & & & & 134 & 303 & 2 \\
\hline 6 & & & & & & 173 & 359 & - \\
\hline \multirow{2}{*}{7} & $1.352 \pm 35$ & 1.230 & Carbón & AA-94003 & & \multirow{2}{*}{240} & \multirow{2}{*}{325} & \multirow{2}{*}{7} \\
\hline & $1.055 \pm 36$ & 923 & Carbón & AA-94005 & & & & \\
\hline 8 & $1.366 \pm 35$ & 1.240 & Carbón & AA-94006 & & 115 & 311 & 3 \\
\hline 9 & & & & & & 103 & 468 & 3 \\
\hline 10 & $1.621 \pm 36$ & 1.469 & Carbón & AA-94007 & & 141 & 700 & - \\
\hline 11 & & & & & & 99 & 1176 & 1 \\
\hline 12 & $1.561 \pm 38$ & 1.401 & Carbón & AA-94002 & & 131 & 221 & - \\
\hline 13 & $1.920 \pm 20$ & 1.819 & Carbón & $\begin{array}{c}\text { UGAMS- } \\
7007\end{array}$ & B & 146 & 256 & - \\
\hline 14 & & & & & & 92 & 171 & - \\
\hline 15 & $2.200 \pm 20$ & 2.160 & Carbón & $\begin{array}{c}\text { UGAMS- } \\
7006\end{array}$ & & 99 & 71 & - \\
\hline 16 & & & & & & 111 & 16 & - \\
\hline 17 & & & & & & 247 & 26 & - \\
\hline 18 & & & & & & 19 & 15 & - \\
\hline 19 & $7.140 \pm 25$ & 7.934 & Carbón & $\begin{array}{c}\text { UGAMS- } \\
7004\end{array}$ & $\mathbf{C}$ & 13 & 7 & - \\
\hline 19 y 20 & $1.870 \pm 20$ & 1.773 & Carbón & $\begin{array}{c}\text { UGAMS- } \\
7005\end{array}$ & & & & \\
\hline 20 & $7.335 \pm 51$ & 8.101 & Carbón & AA-94001 & & 4 & - & - \\
\hline & & & & & Total & 2426 & 4990 & 30 \\
\hline
\end{tabular}

Tabla 8.1. Fechados y materiales arqueológicos registrados en el sector sur de CSA-1, por nivel artificial de excavación y conjunto temporal. 


\subsection{Caracterización sedimentológica de las unidades estratigráficas de CSA-1}

Unidad $1(0-15 \mathrm{~cm})$ : está moderadamente compactada por arenas finas sueltas masivas y lentes de ceniza volcánica bien conservadas (que pueden corresponder a la erupción del volcán Quizapú en 1932), laminadas finamente y localizadas en la pared oeste de la cuadrícula de excavación. El contacto inferior es irregular.

Unidad 2 (15-30 cm máximo, espesor promedio $15 \mathrm{~cm}$ ): se compone de arenas finas sueltas, guano de chivo masivo u homogéneo, y un fogón de $20 \mathrm{~cm}$ de largo por 12 $\mathrm{cm}$ de espesor en la pared este; el contacto inferior, agudo y ondulado, incluye una superficie similar a una depresión dentro de la parte superior de la unidad 3, subyacente.

Unidad $3(30-50 \mathrm{~cm})$ : está constituida por arenas finas marrones con clastos gruesos, abundantes restos arqueológicos tanto de fragmentos orgánicos como de artefactos líticos. El límite más bajo está representado por una superficie erosiva bien definida excavada en la subunidad 4, en el sector noroeste de la excavación. Consiste en una depresión de unos $40 \mathrm{~cm}$ de profundidad y $50 \mathrm{~cm}$ de ancho, que se extiende lateralmente a un límite depositacional.

Unidad 4 (25 a $50 \mathrm{~cm}-100 \mathrm{~cm}$ ): comprende unos $70 \mathrm{~cm}$ de espesor y arenas finas marrones con clastos basálticos; es friable, de capas sedimentarias que ingresan hacia la parte central de la cueva. Se han registrado algunas cuevas de roedores. El material arqueológico es abundante; incluye restos orgánicos (e.g., macro-restos vegetales, huesos de vertebrados), artefactos líticos, fragmentos de carbón y varios fogones; incluye una capa de arenas limosas de color café oscuro de $2 \mathrm{~cm}$ de espesor, que incluye numerosos fragmentos de carbón. El contacto inferior es suave. Un carbón recuperado en el fondo del depósito fue fechado en $7.335 \pm 51{ }^{14} \mathrm{C}$ años AP (AA-94001).

Unidad 5 (100-110 cm): está constituida por una capa relativamente delgada (aproximadamente de $10 \mathrm{~cm}$ de espesor), compuesta de arena muy fina de color marrón claro que incluye fragmentos angulares basálticos gruesos; esta unidad es arqueológicamente estéril. 


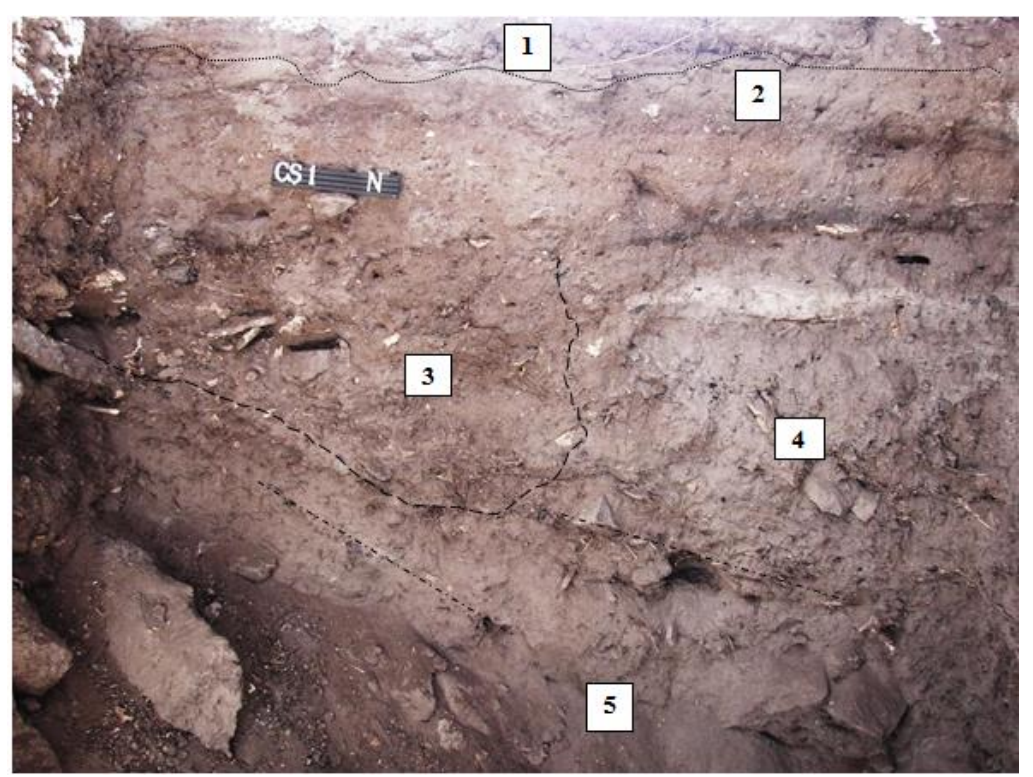

Figura 8.6. Perfil norte de la cuadrícula A1 del sitio CSA-1, mostrando las unidades estratigráficas.

\subsubsection{Cronología y definición de las unidades de análisis}

Se obtuvieron once fechados radiocarbónicos y sus respectivas edades calibradas a partir de muestras de carbón; siete provienen de los perfiles y el resto se recolectó en zaranda durante la excavación (Tabla 8.1 y Figura 8.7). En los trabajos de excavación y en los posteriores de levantamiento de perfiles realizados por el Dr. Marcelo Zárate, se detectaron factores postdepositacionales que afectaron a los sedimentos: cuevas de roedores, desprendimiento de bloques del techo de la cueva, excavación y posterior relleno de algunos sectores de la cueva, tanto en tiempos históricos como prehispánicos. La presencia de fechados invertidos corrobora la existencia de los procesos antes mencionados. Debido a esto, se dividió la secuencia en tres conjuntos temporales según las unidades descriptas por Zárate, los niveles de excavación y los fechados radiocarbónicos. El Conjunto $\mathrm{C}$ corresponde a los niveles 17 a 20, y a la Unidad estratigráfica 5 (Figura 8.6). La cronología asociada se encuentra entre 7.100 y 7.400 años AP. Entre estos niveles hay una tercera fecha de $1.870 \pm 20$ años AP (UGAMS 7005), cuyo material ha sido considerado como introducido por migración vertical (Neme et al. 2018). La tasa de depositación de los materiales del sitio fue calculada sobre la cantidad de artefactos líticos de cada conjunto temporal (sin desechos de talla de tamaño igual o menor a $5 \mathrm{~mm}$ de lado -véase Capítulo 5) ya que son los que presentan menos inconvenientes tafonómicos. La del Conjunto $\mathrm{C}$ es de 0,16 artefactos por año. El Conjunto $\mathrm{B}$ incluye los niveles de excavación 10 a 16 (unidad estratigráfica 4) y tiene una 
cronología de entre $c a$. 1.560 y 2.200 años AP. Su tasa de depositación es de 2,83 artefactos por año, mayor a la del componente anterior. El Conjunto A, comprende las unidades estratigráficas 1,2 y 3, de los niveles artificiales 1 a 9. La cronología varía entre ca. 1.350 a 1.530 años AP. La Unidad estratigráfica 3 fue interpretada como un pozo de basura, que ingresa por intrusión en el oeste de la Unidad 2 (Figura 8.6). La tasa de depositación es de 3,08 artefactos líticos por año, mayor que en el Conjunto B.

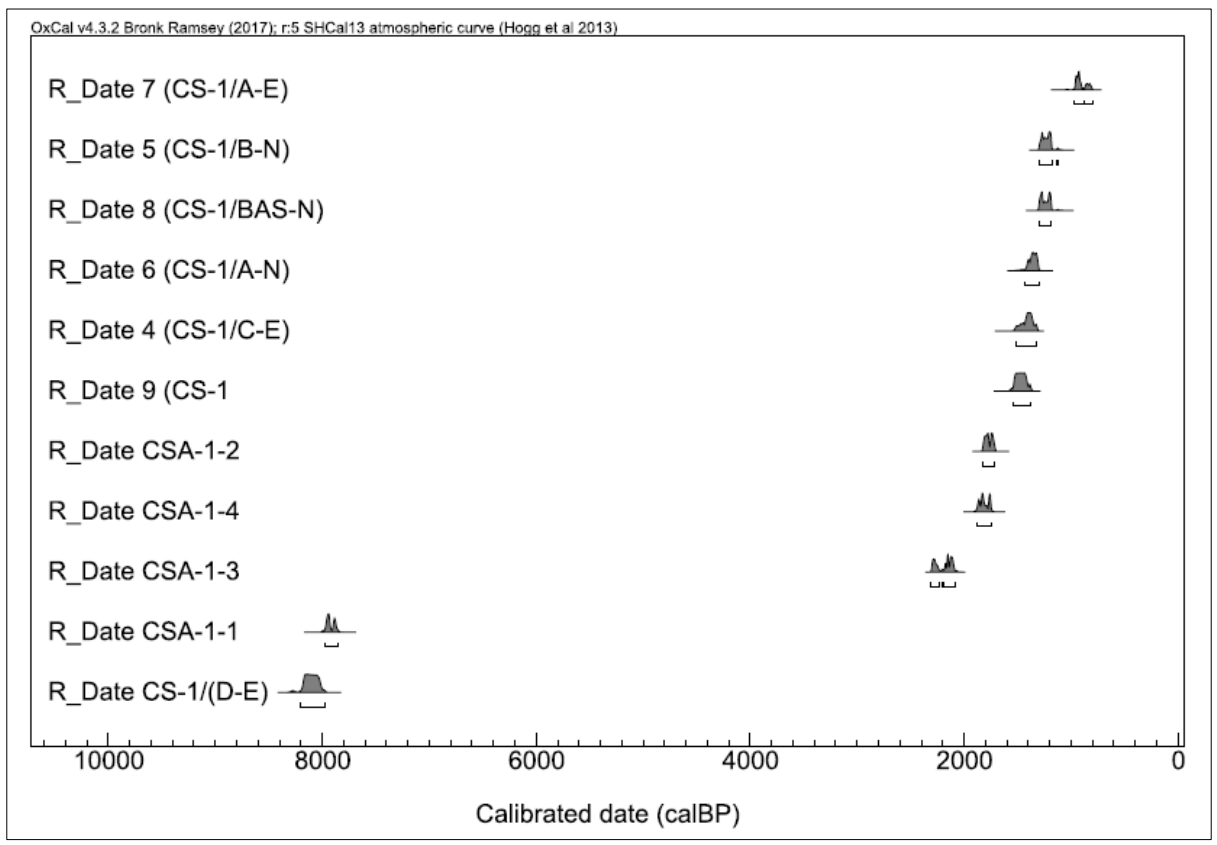

Figura 8.7. Edades calibradas para el sitio CSA-1. Calibración realizada con el programa OxCal v4.3.2 (Ramsey 2009), usando la curva atmosférica SHCal 13 para el hemisferio sur (Hogg et al. 2013).

\subsubsection{Registro arqueológico}

En CSA-1 se ha registrado una variedad de materiales arqueológicos orgánicos (e.g. restos vegetales y óseos) e inorgánicos (e.g. líticos y cerámicos). El registro zooarqueológico incluye un total de 26010 especímenes óseos, de los cuales 2393 pudieron ser asignados a alguna categoría taxonómica (Neme et al. 2018). Los resultados muestran la explotación de un amplio rango de especies, dominadas por las familias Camelidae, Chinchillidae y Dasipodidae. El cambio más importante tiene lugar entre el Conjunto C ( $c a .7 .000$ AP) y el Conjunto B (ca. 2.200-1.500 años AP). En el C se observa un aprovechamiento más intensivo de los Dasipódidos en detrimento de los Chinchillidos, predominantes en los conjuntos más tardíos (B y A). En estos últimos también predomina la familia Camelidae; tendencia que parece mantenerse desde el Conjunto C. 
Se registraron 66 fragmentos cerámicos: 62 procedentes del Conjunto A y 4 del Conjunto B. Predominan tiestos de tipología chilena PAT (Periodo Agroalfarero Temprano) y Marrón Pulido (Figura 8.8). Los valores de las variables asociadas a una alta inversión en atributos como espesor promedio (4,9 mm, i.e., delgado), tratamiento de superficie (79\% pulido), tamaño del antiplástico (63\% fino) y cocción (40\% reductora), sugieren que la cerámica fue reutilizada a lo largo de varios años según el modelo de movilidad y tecnología cerámica propuesto por Sturm et al. (2016) (Pompei et al. 2017).
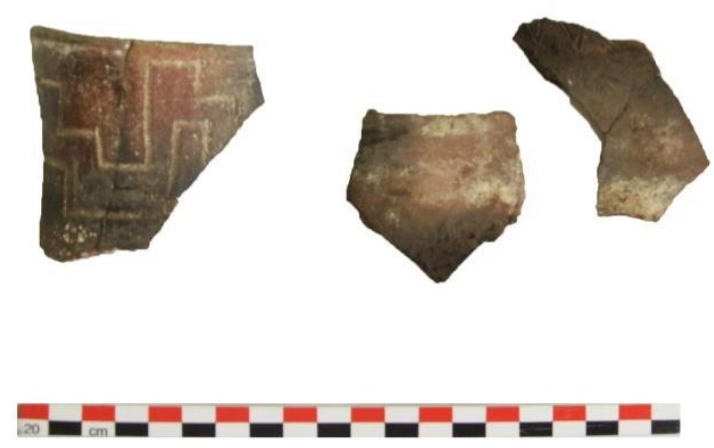

Figura 8.8. Registro cerámico en CSA-1: tiestos tipo PAT (el primero a la izquierda) y Marrón Pulido (los dos de la derecha). Tomado de Pompei (et al. 2017).

\subsubsection{Registro lítico}

Dada la gran cantidad de artefactos líticos recuperados durante la excavación, se analizaron sólo los provenientes del sector sur $(\mathrm{n}=4990)$ (Tablas 8.1 y 8.2). De ese total, 1728 corresponden a desechos de talla de tamaño igual o menor a $5 \mathrm{~mm}$ de lado (figuran como “ $\leq 5 \mathrm{~mm}$ ” en la Tabla 8.2; véase Capítulo 5), por lo que se analizaron 3262 artefactos. Los desechos de talla (" $>5 \mathrm{~mm}$ en la Tabla 8.2) constituyen la clase más representada $(96,57 \%, n=3150)$ en los tres conjuntos cronoestratigráficos (Tabla 8.3).

Entre los instrumentos $(2,54 \%, \mathrm{n}=83)$ predominan los bifaciales $(1,29 \%, \mathrm{n}=42)$. Le siguen los unifaciales $(0,71 \%, \mathrm{n}=23)$, los compuestos $(0,18 \%, \mathrm{n}=6)$ (véase clasificación en Capítulo 5), los manufacturados o modificados por picado, abrasión y/o pulido $(0,15 \%, \mathrm{n}=5)$, los percutores $(0,15 \%, \mathrm{n}=5)$ y los formatizados no diferenciados (AF ND; 0,06\%, $\mathrm{n}=2$ ). Además, se registraron 16 ASF $\mathrm{RC}$, nueve ecofactos, tres fragmentos de pigmento y un "Potencial Percutor Funcional" (Frank et al. 2007) (Tablas 8.2 y 8.3). No se han registrado núcleos (Figura 8.9). 


\begin{tabular}{|c|c|c|c|c|c|c|c|c|c|c|c|c|c|}
\hline \multirow{2}{*}{ Nivel } & \multicolumn{2}{|c|}{ Desechos de talla } & \multirow{2}{*}{$\begin{array}{c}\text { AF } \\
\text { Bifacial }\end{array}$} & \multirow{2}{*}{$\begin{array}{c}\text { AF } \\
\text { Unifacial }\end{array}$} & \multirow{2}{*}{$\begin{array}{c}\text { AF } \\
\text { Comp. }\end{array}$} & \multirow{2}{*}{$\begin{array}{c}\text { Art.m } \\
\text { por } \mathbf{A}, \\
\mathbf{P , P}\end{array}$} & \multirow{2}{*}{$\begin{array}{l}\text { AF } \\
\text { ND }\end{array}$} & \multirow{2}{*}{$\begin{array}{c}\text { ASF } \\
\text { RC }\end{array}$} & \multirow{2}{*}{$\mathbf{P}$} & \multirow{2}{*}{ PPF } & \multirow{2}{*}{ Ecof. } & \multirow{2}{*}{ Pgm } & \multirow{2}{*}{ Total } \\
\hline & $(>5 \mathrm{~mm})$ & $(\leq 5 \mathrm{~mm})$ & & & & & & & & & & & \\
\hline 1 & 58 & 17 & 1 & 1 & 1 & - & - & 2 & - & - & - & - & 80 \\
\hline 2 & 39 & 4 & 2 & - & 1 & - & - & 2 & 5 & 1 & - & - & 54 \\
\hline 3 & 128 & 56 & 1 & 2 & 2 & - & - & - & - & - & - & - & 189 \\
\hline 4 & 154 & 77 & 7 & 2 & - & - & 1 & - & - & - & 1 & - & 242 \\
\hline 5 & 183 & 110 & 6 & 2 & - & 1 & - & 1 & - & - & - & - & 303 \\
\hline 6 & 140 & 212 & 2 & - & - & - & - & 4 & - & - & 1 & - & 359 \\
\hline 7 & 160 & 155 & 5 & 2 & - & 1 & - & 2 & - & - & - & - & 325 \\
\hline 8 & 193 & 114 & 2 & 1 & - & - & - & 1 & - & - & - & - & 311 \\
\hline 9 & 295 & 167 & 1 & 5 & - & - & - & - & - & - & - & - & 468 \\
\hline 10 & 492 & 199 & 3 & 2 & - & - & - & - & - & - & 2 & 2 & 700 \\
\hline 11 & 756 & 409 & 6 & 3 & - & - & - & 1 & - & - & - & 1 & 1176 \\
\hline 12 & 161 & 54 & 1 & 2 & - & 1 & - & 2 & - & - & - & - & 221 \\
\hline 13 & 171 & 81 & 1 & - & - & - & 1 & 1 & - & - & 1 & - & 256 \\
\hline 14 & 127 & 38 & 2 & 1 & 1 & 1 & - & - & - & - & 1 & - & 171 \\
\hline 15 & 53 & 16 & 1 & - & - & - & - & - & - & - & 1 & - & 71 \\
\hline 16 & 10 & 2 & - & - & 1 & 1 & - & - & - & - & 2 & - & 16 \\
\hline 17 & 17 & 8 & 1 & - & - & - & - & - & - & - & - & - & 26 \\
\hline 18 & 8 & 7 & - & - & - & - & - & - & - & - & - & - & 15 \\
\hline 19 & 5 & 2 & - & - & - & - & - & - & - & - & - & - & 7 \\
\hline 20 & - & - & - & - & - & - & - & - & - & - & - & - & 0 \\
\hline Total & 3150 & 1728 & 42 & 23 & 6 & 5 & 2 & 16 & 5 & 1 & 9 & 3 & 4990 \\
\hline $\begin{array}{c}\text { Total } \\
\%\end{array}$ & 63,13 & 34,63 & 0,84 & 0,46 & 0,12 & 0,10 & 0,04 & $\mathbf{0 , 3 2}$ & 0,10 & $\mathbf{0 , 0 2}$ & 0,18 & 0,06 & 100 \\
\hline
\end{tabular}

Tabla 8.2. Clases artefactuales por nivel de excavación en CSA-1. Referencias: $A F$ : Artefacto formatizado; Comp.: compuesto; Art. manuf. por A, P, P: Artefacto manufacturado o modificado por abrasión, picado y/o pulido; AF ND: Artefacto formatizado no diferenciado; ASF RC: Artefacto sin formatización con rastros complementarios; P: Percutor; PPF: Potencial percutor funcional; Ecof.: Ecofacto; Pgm: Pigmento.

\begin{tabular}{|c|c|c|c|c|c|c|c|c|c|c|c|c|}
\hline Conj. & $\begin{array}{c}\text { Desechos } \\
\text { de talla }\end{array}$ & $\begin{array}{c}\text { AF } \\
\text { Bifacial }\end{array}$ & $\begin{array}{c}\text { AF } \\
\text { Unifacial }\end{array}$ & $\begin{array}{c}\text { AF } \\
\text { Comp. }\end{array}$ & $\begin{array}{c}\text { Art. } \\
\text { m. por } \\
\text { A, P, P }\end{array}$ & $\begin{array}{l}\text { AF } \\
\text { ND }\end{array}$ & $\begin{array}{c}\text { ASF } \\
\text { RC }\end{array}$ & $\mathbf{P}$ & PPF & Ecof. & Pgm & Total \\
\hline A & $\begin{array}{c}95,14 \% \\
(1350)\end{array}$ & $\begin{array}{c}1,90 \% \\
(27)\end{array}$ & $\begin{array}{c}1,06 \% \\
(15)\end{array}$ & $\begin{array}{c}0,28 \% \\
\text { (4) }\end{array}$ & $\begin{array}{c}0,14 \% \\
(2)\end{array}$ & $\begin{array}{c}0,07 \% \\
\text { (1) }\end{array}$ & $\begin{array}{c}0,85 \% \\
(12)\end{array}$ & $\begin{array}{c}0,35 \% \\
(5)\end{array}$ & $\begin{array}{c}0,07 \% \\
\text { (1) }\end{array}$ & $\begin{array}{c}0,14 \% \\
\text { (2) }\end{array}$ & - & 1419 \\
\hline B & $\begin{array}{c}97,68 \% \\
(1770)\end{array}$ & $\begin{array}{c}0,77 \% \\
(14)\end{array}$ & $0,44 \%(8)$ & $\begin{array}{c}0,11 \% \\
(2)\end{array}$ & $\begin{array}{c}0,17 \% \\
\text { (3) }\end{array}$ & $\begin{array}{c}0,06 \% \\
(1)\end{array}$ & $\begin{array}{c}0,22 \% \\
(4)\end{array}$ & - & - & $\begin{array}{c}0,39 \% \\
(7)\end{array}$ & $\begin{array}{c}0,17 \% \\
(3)\end{array}$ & 1812 \\
\hline C & $96,77 \%(30)$ & $\begin{array}{c}3,23 \% \\
\text { (1) }\end{array}$ & - & - & - & - & - & - & - & - & - & 31 \\
\hline Total & $\begin{array}{c}96,57 \% \\
(3150)\end{array}$ & $\begin{array}{c}1,29 \% \\
(42)\end{array}$ & $\begin{array}{c}0,71 \% \\
(23)\end{array}$ & $\begin{array}{c}0,18 \% \\
(6)\end{array}$ & $\begin{array}{c}0,15 \% \\
(5)\end{array}$ & $\begin{array}{c}0,06 \% \\
(2)\end{array}$ & $\begin{array}{c}0,49 \% \\
(16) \\
\end{array}$ & $\begin{array}{c}0,15 \% \\
(5)\end{array}$ & $\begin{array}{c}0,03 \% \\
\text { (1) }\end{array}$ & $\begin{array}{c}0,28 \% \\
(9)\end{array}$ & \begin{tabular}{|c|}
$0,09 \%$ \\
$(3)$ \\
\end{tabular} & 3262 \\
\hline
\end{tabular}

Tabla 8.3. Frecuencia de clases artefactuales por conjunto cronoestratigráfico en CSA-1.

Referencias: Idem Tabla 8.2. 


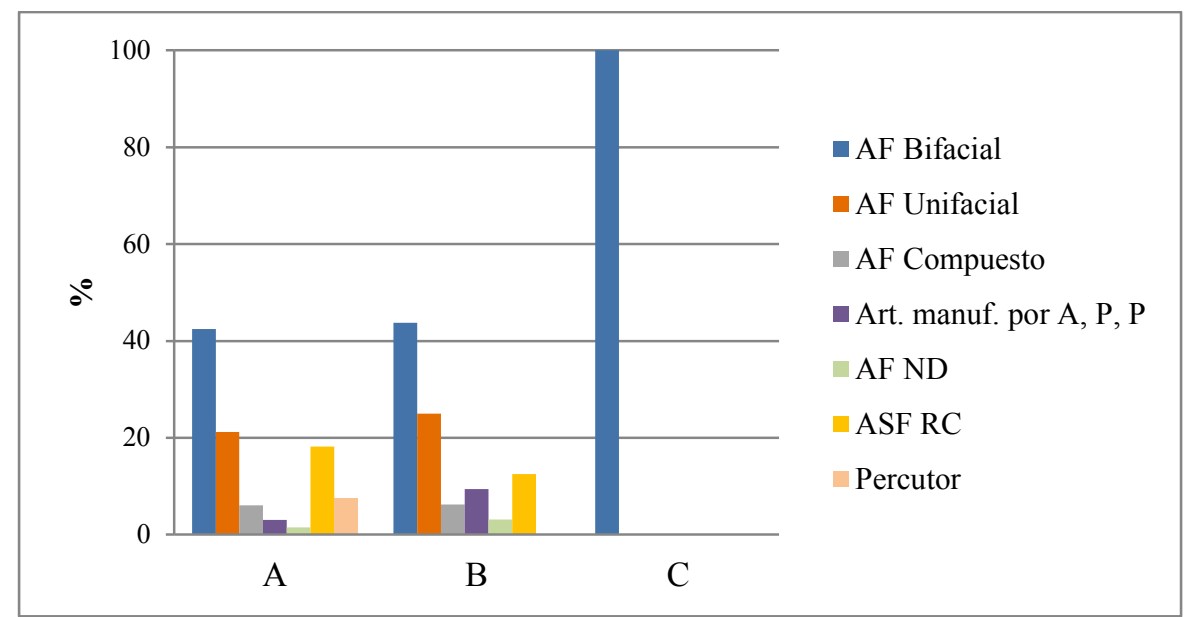

Figura 8.9. Frecuencias relativas de instrumentos y ASF RC por conjunto cronoestratigráfico en CSA-1.

El Conjunto $\mathrm{C}$ posee un único instrumento: una punta de proyectil. Para evaluar el efecto del tamaño de muestra se correlacionó el total de categorías de instrumentos representadas en cada conjunto temporal con el tamaño de la muestra artefactual (Figura 8.10). El resultado $\left(r^{2}=0,8075\right)$ señala que hay un sesgo generado por el tamaño de la muestra (los conjuntos de mayor tamaño poseen mayor diversidad de instrumentos), lo que limita la posibilidad de interpretación.

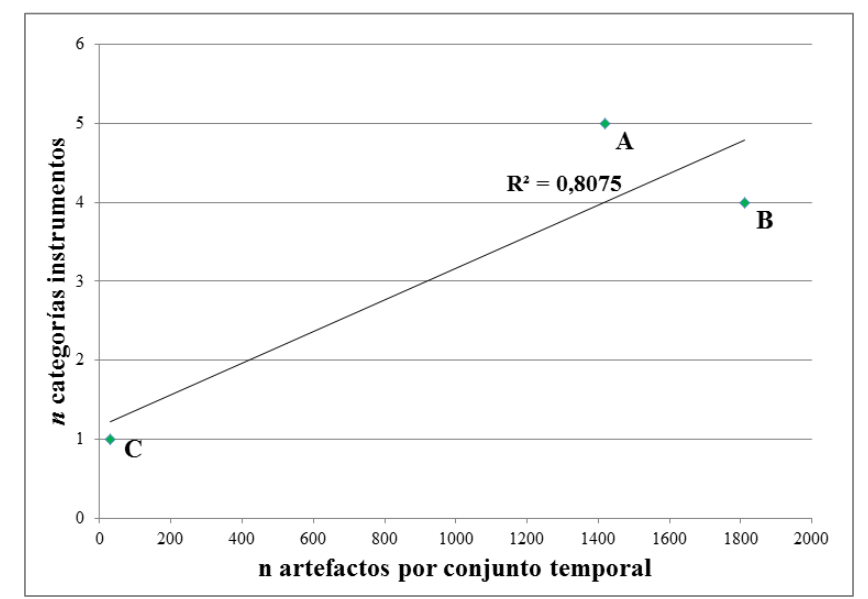

Figura 8.10. Tamaño de muestra vs. cantidad de categorías instrumentales en CSA-1.

La frecuencia relativa de artefactos de CSA-1 alcanza un pico marcado en el nivel 11 del Conjunto B (HTI). Con el fin de descartar que las fluctuaciones observadas por niveles de extracción se deban al método empleado durante la excavación (niveles artificiales de $5 \mathrm{~cm}$ cada uno, donde $1 \mathrm{~cm}$ de error corresponde al 20\% de inexactitud), se agruparon dichos niveles de a dos, obteniendo así un total de diez niveles de $10 \mathrm{~cm}$ (Figura 
8.11 y Tabla 8.4). Igualmente, se observa el incremento abrupto hacia el Conjunto B, por lo que se podría descartar la posibilidad de un sesgo de muestreo.

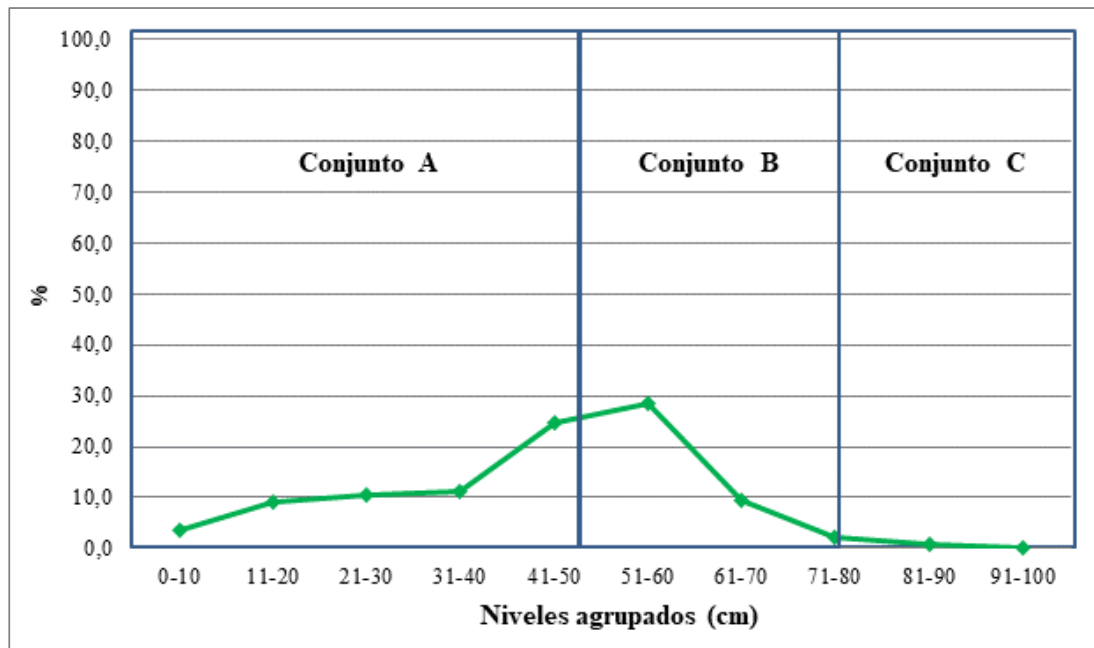

Figura 8.11. Frecuencia de artefactos por niveles agrupados y por conjunto temporal en CSA-1.

Las materias primas más frecuentes son las rocas silíceas $(57,17 \%, \mathrm{n}=1865)$, seguidas por la obsidiana $(38,81 \%, \mathrm{n}=1266)$, el basalto $(3,19 \%, \mathrm{n}=104)$, la riolita $(0,40 \%$, $\mathrm{n}=13)$ y la vulcanita indeterminada $(0,25 \%, \mathrm{n}=8)$, completando el conjunto "otras materias primas": una andesita $(0,03 \%)$, un cuarzo $(0,03 \%)$ y cuatro rocas que no han podido ser determinadas $(0,12 \%)$. Las dos materias primas más frecuentes, rocas silíceas y obsidiana, invierten sus frecuencias del Conjunto B (HTI) al A (HTF): las rocas silíceas predominan en los conjuntos $\mathrm{C}(61,29 \%, \mathrm{n}=19 ; \mathrm{HM})$ y $\mathrm{B}(65,84 \%, \mathrm{n}=1193)$; en cambio, la obsidiana es la mayoritaria durante el $\operatorname{HTF}(50,88 \%, \mathrm{n}=722)$ (Tablas 8.4 y 8.5 , y Figura 8.12). En el Conjunto B, se da la mayor cantidad de clases de rocas y la mayor frecuencia de cada una; pero debe tenerse en cuenta que en el Conjunto C ( $c a .7 .300$ a 2.200 años AP) el efecto del tamaño de la muestra es significativo (Figura 8.13) e indica que la diversidad de clases de roca está sesgada por el tamaño $\left(r^{2}=0,9617\right)$.

\begin{tabular}{|c|c|c|c|c|c|c|c|c|}
\hline $\begin{array}{c}\text { Profundidad } \\
(\mathbf{c m})\end{array}$ & BAS & OBS & RIO & SIL & VUL & Otras MP & Total \\
\hline \multirow{4}{*}{ A } & $\mathbf{0 - 1 0}$ & $3(2,7 \%)$ & $60(53,1 \%)$ & $1(0,9 \%)$ & $45(39,8 \%)$ & $4(3,5 \%)$ & - & $\mathbf{1 1 3}$ \\
\cline { 2 - 9 } & $\mathbf{1 1 - 2 0}$ & $10(3,4 \%)$ & $160(53,7 \%)$ & - & $128(42,9 \%)$ & - & - & $\mathbf{2 9 8}$ \\
\cline { 2 - 9 } & $\mathbf{2 1 - 3 0}$ & $8(2,4 \%)$ & $188(55,3 \%)$ & $1(0,3 \%)$ & $14241,8 \%)$ & - & $1(0,3 \%)$ & $\mathbf{3 4 0}$ \\
\cline { 2 - 9 } & $\mathbf{3 1 - 4 0}$ & $9(2,5 \%)$ & $157(42,8 \%)$ & - & $201(54,8 \%)$ & - & - & $\mathbf{3 6 7}$ \\
\hline & $\mathbf{4 1 - 5 0}$ & $37(4,6 \%)$ & $287(35,8 \%)$ & $6(0,7 \%)$ & $468(58,4 \%)$ & $2(0,2 \%)$ & $2(0,2 \%)$ & $\mathbf{8 0 2}$ \\
\hline \multirow{4}{*}{$\mathbf{B}$} & $\mathbf{5 1 - 6 0}$ & $15(1,6 \%)$ & $233(24,9 \%)$ & $\begin{array}{c}1 \\
(0,1 \%)\end{array}$ & $682(73,0 \%)$ & $2(0,2 \%)$ & $1(0,1 \%)$ & $\mathbf{9 3 4}$ \\
\hline
\end{tabular}




\begin{tabular}{|c|c|c|c|c|c|c|c|c|} 
& $\mathbf{6 1 - 7 0}$ & $15(4,9 \%)$ & $154(50,0 \%)$ & $2(0,6 \%)$ & $135(43,8 \%)$ & - & $2(0,6 \%)$ & $\mathbf{3 0 8}$ \\
\hline \multirow{5}{*}{$\mathbf{C 1 - 8 0}$} & $5(7,2 \%)$ & $17(24,6 \%)$ & $2(2,9 \%)$ & $45(65,2 \%)$ & - & - & $\mathbf{6 9}$ \\
\cline { 2 - 9 } & $\mathbf{8 1 - 9 0}$ & $2(7,7 \%)$ & $8(30,8 \%)$ & - & $16(61,5 \%)$ & - & - & $\mathbf{2 6}$ \\
\cline { 2 - 9 } & $\mathbf{9 1 - 1 0 0}$ & - & $2(40,0 \%)$ & - & $3(60,0 \%)$ & - & - & $\mathbf{5}$ \\
\hline \multicolumn{2}{|c|}{ Total } & $\mathbf{3 , 2 \%}$ & $\mathbf{3 8 , 8 \%}$ & $\mathbf{0 , 4 \%}$ & $\mathbf{5 7 , 2 \%}$ & $\mathbf{0 , 2 \%}$ & $\mathbf{0 , 2 \%}$ & $\mathbf{3 2 6 2}$ \\
\hline
\end{tabular}

Tabla 8.4. Distribución y frecuencia de materias primas por niveles de excavación agrupados en CSA-1. Los distintos tonos de azul de las filas señalan las tres unidades cronoestratigráficas.

Otras MP (otras materias primas) incluye: una andesita, un cuarzo y cuatro rocas indeterminadas.

\begin{tabular}{|c|c|c|c|c|c|c|c|}
\hline Conjunto & BAS & OBS & RIO & SIL & VUL & $\begin{array}{c}\text { Otras } \\
\text { MP }\end{array}$ & Total \\
\hline $\mathbf{A}$ & $\begin{array}{c}2,3 \% \\
(33)\end{array}$ & $\begin{array}{c}50,9 \% \\
(722)\end{array}$ & $\begin{array}{c}0,4 \% \\
(6)\end{array}$ & $\begin{array}{c}46,0 \% \\
(653)\end{array}$ & $\begin{array}{c}0,3 \% \\
(4)\end{array}$ & $\begin{array}{c}0,1 \% \\
(1)\end{array}$ & $\mathbf{1 4 1 9}$ \\
\hline $\mathbf{B}$ & $\begin{array}{c}3,8 \% \\
(69)\end{array}$ & $\begin{array}{c}29,5 \% \\
(534)\end{array}$ & $\begin{array}{c}0,4 \% \\
(7)\end{array}$ & $\begin{array}{c}65,8 \% \\
(1193)\end{array}$ & $\begin{array}{c}0,2 \% \\
(4)\end{array}$ & $\begin{array}{c}0,3 \% \\
(5)\end{array}$ & $\mathbf{1 8 1 2}$ \\
\hline \multirow{2}{*}{ Total } & $\begin{array}{c}6,5 \% \\
(2)\end{array}$ & $\begin{array}{c}32,3 \% \\
(10)\end{array}$ & - & $\begin{array}{c}61,3 \% \\
(19)\end{array}$ & - & - & $\mathbf{3 1}$ \\
\hline $\mathbf{1 0 4}$ & $\begin{array}{c}\mathbf{3 8 , 8} \% \\
(\mathbf{1 2 6 6})\end{array}$ & $\begin{array}{c}\mathbf{0 , 4} \% \\
(\mathbf{1 3})\end{array}$ & $\begin{array}{c}\mathbf{5 7 , 2 \%} \\
(\mathbf{1 8 6 5})\end{array}$ & $\begin{array}{c}\mathbf{0 , 2 \%} \\
\mathbf{( 8 )}\end{array}$ & $\begin{array}{c}\mathbf{0 , 2 \%} \\
(\mathbf{6})\end{array}$ & $\mathbf{3 2 6 2}$ \\
\hline
\end{tabular}

Tabla 8.5. Frecuencia de materias primas por conjunto cronoestratigráfico en CSA-1. Otras MP incluye: andesita, cuarzo e indeterminadas.

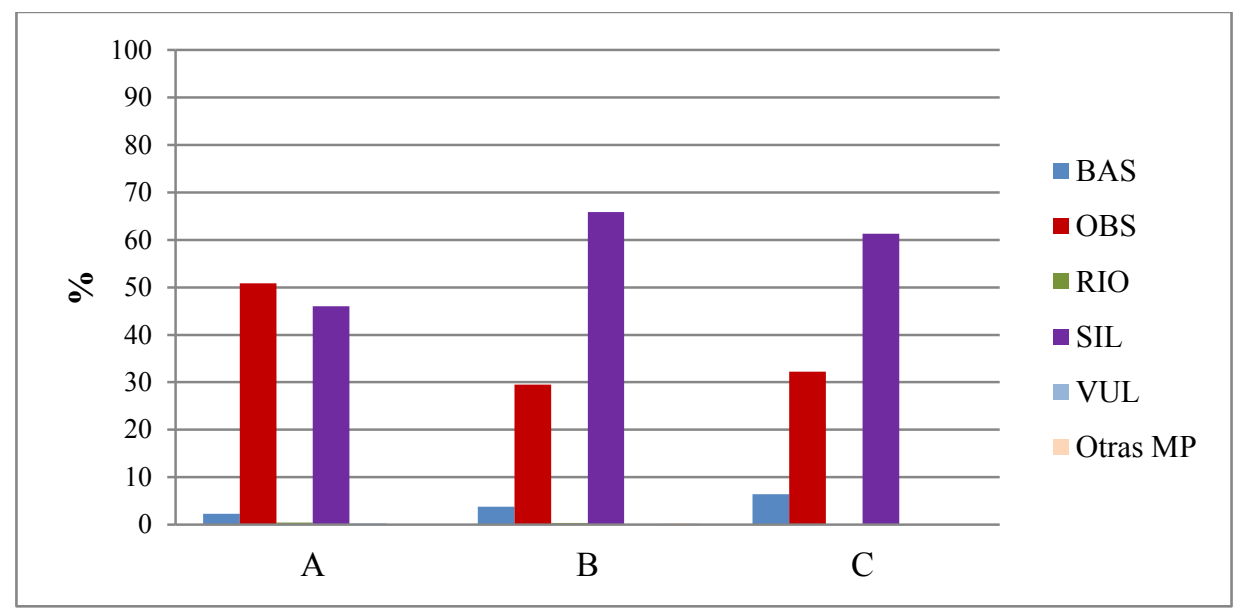

Figura 8.12. Frecuencias relativas de materias primas por conjunto cronoestratigráfico en CSA-1. Otras MP incluye: andesita, cuarzo e indeterminadas. 


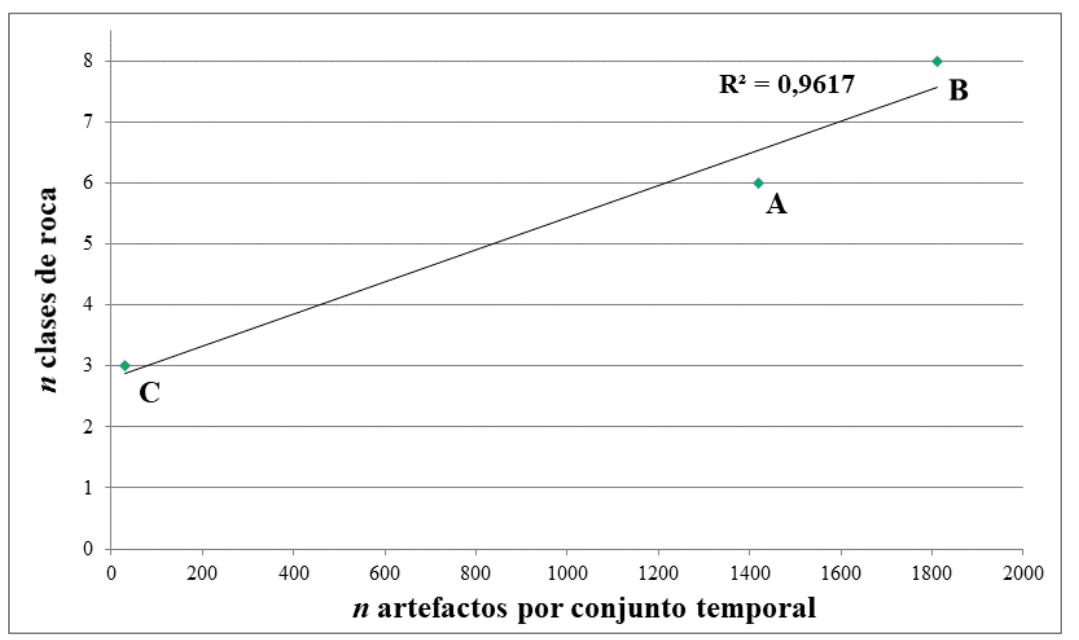

Figura 8.13. Tamaño de muestra vs. cantidad de clases de roca en CSA-1.

\subsection{Desechos de talla}

Entre los desechos de talla se registran todas las materias primas presentes en CSA-1, excepto el cuarzo. Las más representadas son las silíceas $(57,75 \%, \mathrm{n}=1819)$, seguidas por la obsidiana $(38,83 \%, n=1223)$, el basalto $(2,92 \%, n=92)$, la riolita $(0,41 \%$, $\mathrm{n}=13)$, la vulcanita indeterminada $(0,06 \%, \mathrm{n}=2)$ y la andesita $(0,03 \%, \mathrm{n}=1)$.

El grado de fragmentación es alto: sólo el 9,94\% $(\mathrm{n}=313)$ de los artefactos está entero. Entre ellos, predomina la ausencia de corteza $(92,65 \%, \mathrm{n}=290)$, seguida por desechos con el $25 \%$ de su cara dorsal cubierta por corteza $(3,83 \%, n=12)$, luego por aquellos con el $50 \%$ de corteza $(2,24 \%, \mathrm{n}=7)$; de estos últimos, uno es una lasca secundaria de basalto cuyo negativo de lascado abarca la mitad de la pieza. Por último, los desechos con el $75 \%$ de corteza representan el $0,96 \%(n=3)$ y corresponden a tres lascas secundarias: dos de rocas silíceas y una de andesita. El único registro de desechos de talla con su cara dorsal cubierta $100 \%$ por corteza, es una lasca primaria de basalto $(0,32 \%, \mathrm{n}=1)$ (Tabla 8.6).

\begin{tabular}{|c|c|c|c|c|c|c|c|}
\hline Sitio & MP & $\mathbf{0 \%}$ & $\mathbf{2 5 \%}$ & $\mathbf{5 0 \%}$ & $\mathbf{7 5 \%}$ & $\mathbf{1 0 0 \%}$ & Total \\
\hline \multirow{4}{*}{ CSA-1 } & AND & - & - & - & $100 \%(1)$ & - & $\mathbf{1}$ \\
\cline { 2 - 8 } & BAS & $49,99 \%(3)$ & $16,67 \%(1)$ & $16,67 \%(1)$ & - & $16,67 \%(1)$ & $\mathbf{6}$ \\
\cline { 2 - 8 } & OBS & $96,35 \%(132)$ & $(2,92 \%(4)$ & $0,73 \%(1)$ & - & - & $\mathbf{1 3 7}$ \\
\cline { 2 - 8 } & SIL & $91,72 \%(155)$ & $4,14 \%(7)$ & $2,96 \%(5)$ & $1,18 \%(2)$ & - & $\mathbf{1 6 9}$ \\
\hline \multicolumn{2}{|c|}{ Total } & $\mathbf{9 2 , 6 5 \% ( 2 9 0 )}$ & $\mathbf{3 , 8 3 \% ( 1 2 )}$ & $\mathbf{2 , 2 4 \% ( 7 )}$ & $\mathbf{0 , 9 6 \% ( 3 )}$ & $\mathbf{0 , 3 2 \% ( 1 )}$ & $\mathbf{3 1 3}$ \\
\hline
\end{tabular}

Tabla 8.6. Reserva de corteza en la cara dorsal en desechos de talla enteros en CSA-1. 
El índice de MNF (número mínimo de lascas), calculado para cada materia prima, (sensu Hiscock 2002; véase Capítulo 5), redujo la muestra de 3150 desechos de talla a 1144, un 36,32\% del total original (Tabla 8.7). Las dos rocas más frecuentes, obsidiana y rocas silíceas, son sin embargo, las de menor grado de confiabilidad.

\begin{tabular}{|c|l|c|c|c|c|c|c|c|}
\hline Sitio & MP & NAS & DT ent. & DT fract. & Indif. & NFS & \multicolumn{2}{c|}{ MNF (n y \%) } \\
\hline \multirow{4}{*}{} & AND & 1 & 1 & - & - & 1 & 1 & 100,00 \\
\cline { 2 - 9 } & BAS & 104 & 6 & 86 & - & 92 & 36 & 39,13 \\
\cline { 2 - 9 } & OBS & 1266 & 137 & 1085 & 1 & 1223 & 409 & 33,44 \\
\cline { 2 - 9 } \\
\begin{tabular}{c} 
CSA- \\
\cline { 2 - 9 }
\end{tabular} & QZ & 1 & - & - & - & - & - & - \\
\cline { 2 - 9 } & RIO & 13 & - & 13 & - & 13 & 5 & 38,46 \\
\cline { 2 - 9 } & SIL & 1865 & 169 & 1648 & 2 & 1819 & 692 & 38,04 \\
\cline { 2 - 9 } & VUL & 8 & - & 2 & - & 2 & 1 & 50,00 \\
\cline { 2 - 9 } & Indet. & 4 & - & - & - & - & - & - \\
\hline
\end{tabular}

Tabla 8.7. Frecuencias de desechos de talla enteros, fracturados e índice de MNF, por materias primas en el sitio CSA-1. Referencias: MP: materia prima; NAS: número de especímenes artefactuales; DT: desechos de talla; Ent.: enteros; Fract.: fracturados; Indif.: indiferenciados;

NFS: número de especímenes identificados como lascas; MNF: número mínimo de lascas; AND: andesita; BAS: basalto; OBS: obsidiana; QZ: cuarzo; RIO: riolita; SIL: rocas siliceas; VUL: vulcanita indeterminada; Indet.: rocas indeterminadas.

Los tipos de desechos de talla (Figura 8.14) y las frecuencias de etapas de manufactura (Figura 8.15), se han analizado sólo en desechos de talla enteros. Se observa que las lascas internas son el tipo de desechos de talla predominante, alcanzando el 87,86\% ( $\mathrm{n}=275)$ de los enteros de CSA-1 ( $\mathrm{n}=313)$ (Tabla 8.8). El 7,32\% ( $\mathrm{n}=23)$, corresponde a lascas de formatización de filo. Las lascas externas representan el 4,79\% $(n=15)$. Los desechos de talla de rocas silíceas tienen representantes de todos los tipos de lascas internas y de formatización de filo registrados; sobre obsidiana también, aunque no hay lascas de reactivación. No se han registrado lascas de formatización de filo de basalto. Las lascas externas están mayormente representadas por desechos de rocas silíceas $(n=9)$, de basalto $(n=3)$, de obsidiana $(n=2)$ y de andesita $(n=1)$ (Tabla 8.8). No se registraron desechos enteros de riolita ni de vulcanita indeterminada. La Figura 8.14 muestra que el uso de la obsidiana y de las rocas silíceas es semejante, a diferencia del basalto, con mayor registro de lascas externas. 


\begin{tabular}{|c|c|c|c|c|c|c|c|c|c|c|c|}
\hline \multirow[b]{2}{*}{ Sitio } & \multirow[b]{2}{*}{ MP } & \multicolumn{9}{|c|}{ Tipo de lasca } & \multirow[b]{2}{*}{ Total } \\
\hline & & Pr. & Sec. & $\begin{array}{l}\text { c/ds. } \\
\text { nat. }\end{array}$ & $\begin{array}{l}\text { tablet } \\
\text { a NU }\end{array}$ & angular & $\begin{array}{c}\text { de } \\
\text { arista }\end{array}$ & $\begin{array}{c}\text { de ad. } \\
\text { bif. }\end{array}$ & plana & $\begin{array}{c}\text { de } \\
\text { react. }\end{array}$ & \\
\hline \multirow{4}{*}{$\sum_{\circlearrowright}^{\pi}$} & AND & - & $\begin{array}{c}100 \% \\
(1)\end{array}$ & - & - & - & - & - & - & - & 1 \\
\hline & BAS & $\begin{array}{l}16,67 \\
\%(1)\end{array}$ & $\begin{array}{l}16,67 \\
\%(1)\end{array}$ & $\begin{array}{l}16,67 \\
\%(1)\end{array}$ & - & $\begin{array}{c}16,67 \% \\
\text { (1) }\end{array}$ & $\begin{array}{c}33,33 \% \\
(2)\end{array}$ & - & - & - & 6 \\
\hline & OBS & - & - & $\begin{array}{c}0,73 \% \\
(1)\end{array}$ & $\begin{array}{c}0,73 \% \\
(1)\end{array}$ & $\begin{array}{c}78,83 \% \\
(108) \\
\end{array}$ & $\begin{array}{c}15,33 \% \\
(21)\end{array}$ & $\begin{array}{c}3,65 \% \\
(5)\end{array}$ & $\begin{array}{c}0,73 \% \\
(1)\end{array}$ & - & 137 \\
\hline & SIL & - & $\begin{array}{c}1,18 \% \\
(2)\end{array}$ & $\begin{array}{c}4,14 \% \\
(7)\end{array}$ & - & $\begin{array}{c}62,72 \% \\
(106)\end{array}$ & $\begin{array}{c}21,89 \% \\
(37)\end{array}$ & $\begin{array}{c}3,55 \% \\
(6)\end{array}$ & $\begin{array}{c}5,33 \% \\
(9)\end{array}$ & $\begin{array}{c}1,18 \% \\
(2)\end{array}$ & 169 \\
\hline \multicolumn{2}{|c|}{ Total } & $\begin{array}{c}0,32 \% \\
\text { (1) }\end{array}$ & $\begin{array}{l}1,28 \% \\
(4)\end{array}$ & $\begin{array}{c}2,88 \% \\
(9)\end{array}$ & $\begin{array}{c}0,32 \% \\
\text { (1) }\end{array}$ & $\begin{array}{c}68,69 \% \\
(215)\end{array}$ & $\begin{array}{c}19,17 \\
\%(60)\end{array}$ & $\begin{array}{c}3,51 \% \\
(11)\end{array}$ & $\begin{array}{c}3,19 \% \\
(10)\end{array}$ & $\begin{array}{c}0,64 \% \\
\text { (2) }\end{array}$ & 313 \\
\hline
\end{tabular}

Tabla 8.8. Tipos de desechos de talla procedentes de CSA-1 discriminados por tipo de extracción y materia prima. Referencias: Pr.: lasca primaria; Sec.: lasca secundaria; c/dorso nat.: lasca con dorso natural; tabl. NU: tableta de núcleo; adelg. bif: lasca de adelgazamiento bifacial; de react.: lasca de reactivación.

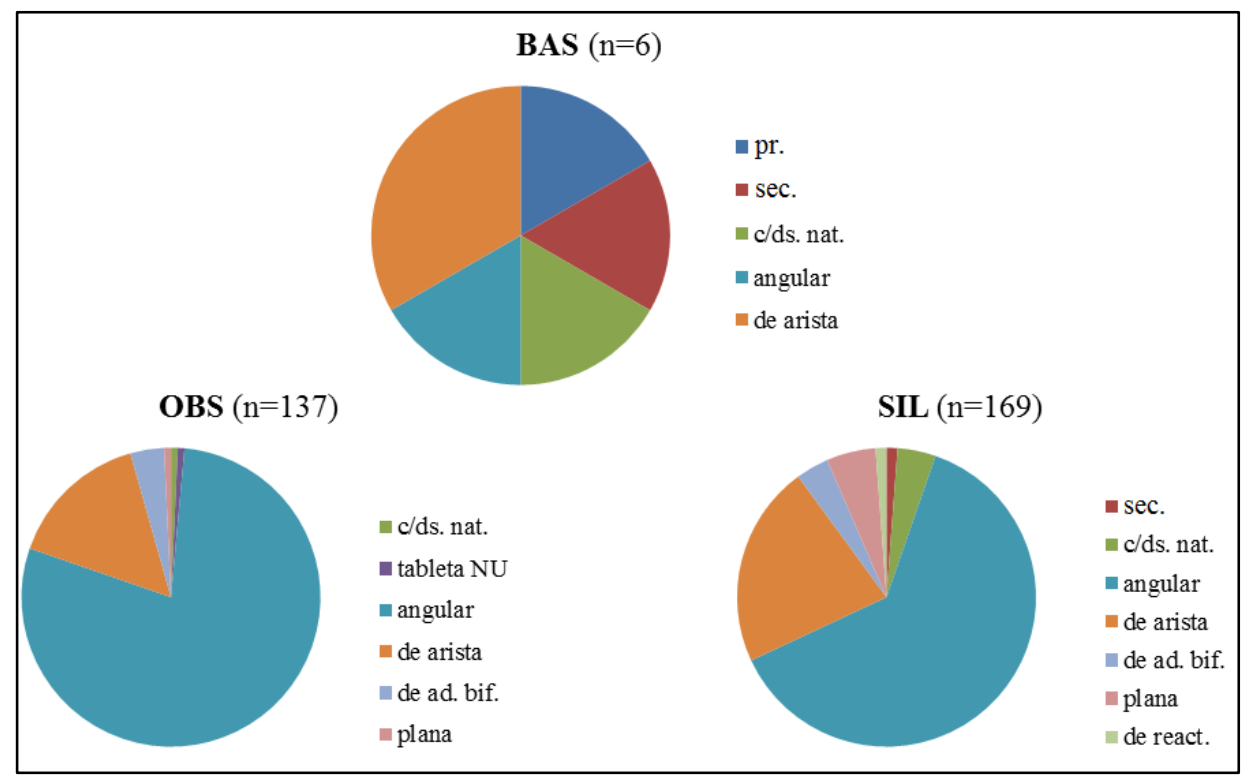

Figura 8.14. Porcentajes de tipos de lasca por materia prima en CSA-1. No se incluyó la lasca secundaria de andesita. Entre paréntesis se indica el número total de lascas enteras por materia prima. Referencias: BAS: basalto; OBS; obsidiana; SIL: rocas silíceas; pr.: lasca primaria; sec.: lasca secundaria; c/ds. nat.: lasca con dorso natural; tableta NU: tableta de núcleo; ad. bif.: lasca de adelgazamiento bifacial; de react.: lasca de reactivación.

A través del tiempo se observa que las lascas internas son las mayoritarias en los tres conjuntos (A, B y C). Las fluctuaciones observadas en la Figura 8.15 se relacionan con la clase de roca representada. Las frecuencias absolutas de las lascas de formatización de filo aumentan paulatinamente del Conjunto $\mathrm{C}$ al Conjunto $\mathrm{A}$; de hecho, son las 
mayoritarias en el C. Sin embargo, sus frecuencias relativas disminuyen del Conjunto $\mathrm{C}$ al B, y vuelven a aumentar del B al A. Las lascas externas están ausentes en el conjunto más antiguo y aumentan del Conjunto $\mathrm{B}$ al A. Asimismo, no hay desechos enteros de basalto ni de andesita en el Conjunto C. El Conjunto B es el más variado con respecto a las clases de rocas representadas; en cambio, el A es el más diverso en cuanto a tipos de desechos de talla, ya que están representados todos los tipos de lasca registrados en CSA1: lascas primarias, secundarias, con dorso natural, tableta de núcleo, angulares, de arista, de adelgazamiento bifacial, planas y de reactivación. En el Conjunto $\mathrm{B}$ están representados todos los tipos excepto lascas primarias y de tableta de núcleo. En el Conjunto $\mathrm{C}$ sólo se registraron una lasca angular, una lasca de arista y tres lascas planas, es decir, predominan las lascas de formatización de filo, y no hay lascas externas.

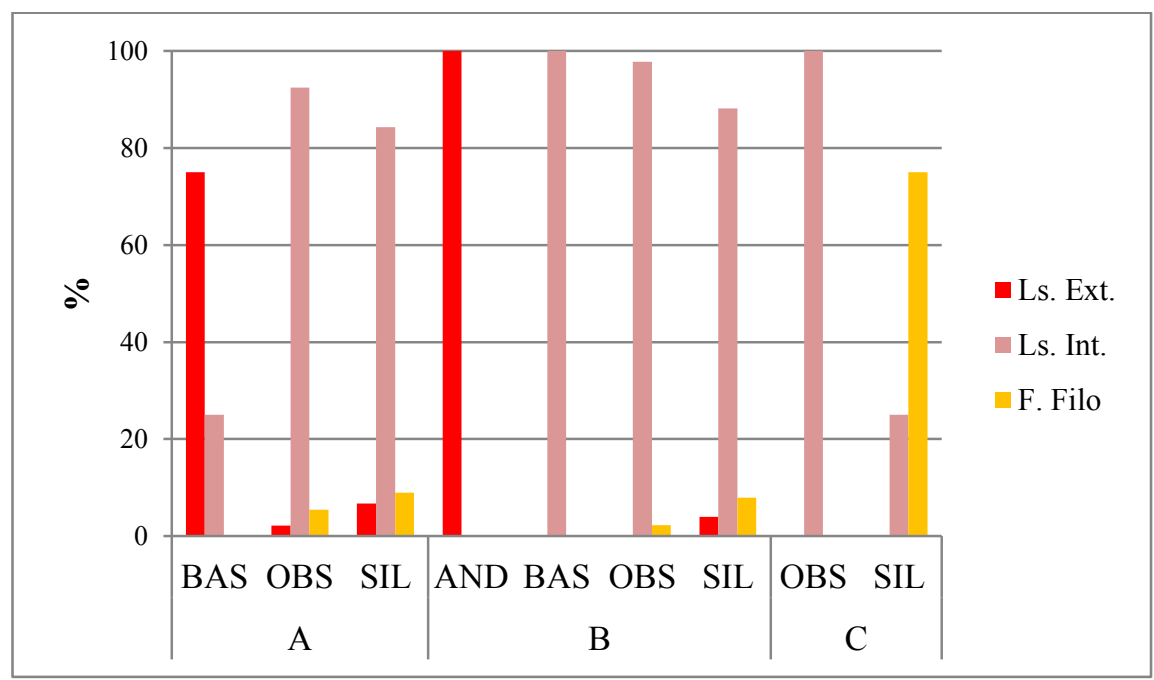

Figura 8.15. Frecuencia de etapas de manufactura por conjunto temporal en CSA-1.

Referencias: Ls. ext: lascas externas; Ls. int: lascas internas; F. filo: lascas de formatización de filo.

\subsection{Instrumentos}

En CSA-1 los instrumentos son la segunda clase artefactual más frecuente $(2,54 \%$; $\mathrm{n}=83)$. La mayoría están confeccionados sobre rocas silíceas $(48,19 \%, \mathrm{n}=40)$, seguidos por los de obsidiana $(38,55 \%, \mathrm{n}=32)$, basalto $(9,63 \%, \mathrm{n}=8)$ y vulcanita indeterminada $(3,61 \%, \mathrm{n}=3)($ Tabla 8.9$)$.

El 31,33\% (n=26) fueron descartados enteros. A través del tiempo, también suelen predominar los instrumentos fracturados, aunque el único instrumento perteneciente al Conjunto $\mathrm{C}(\mathrm{HM})$ es una punta de proyectil con pedúnculo entera (Figura 8.16). En el 
Conjunto B (HTI) los enteros disminuyen a 39,29\% $(\mathrm{n}=11)$ y vuelven a disminuir en el A (HTF) $(25,93 \%, n=14)$. Los instrumentos enteros suelen ser de rocas silíceas $(57,69 \%$, $\mathrm{n}=15)$. En el Conjunto B constituyen el $54,55 \%(\mathrm{n}=6$; fracturados $=10)$. Los de obsidiana de este periodo representan el $27,27 \%(n=3$; fracturados $=5)$ (Figura 8.17$)$ y el $18,18 \%$ son de basalto $(n=2$; fracturados $=2$ ). Para este periodo se registró un raspador de filo largo reciclado sobre el limbo de una punta de proyectil fracturada (Figura 8.18). En el Conjunto A, el $57,14 \%$ de los instrumentos enteros son de rocas silíceas $(n=8$; fracturados $=15)$, el $28,57 \%$ de obsidiana $(n=4$; fracturados $=20)$, el $7,14 \%$ de basalto $(n=1$; fracturados $=3)$ y el 7,14\% de vulcanita indeterminada $(n=1$; fracturados $=2)($ Tabla 8.9). En la Figura 8.19 se observan dos fragmentos de puntas de proyectil de obsidiana y un raspador entero sobre roca silícea, pertenecientes a este conjunto temporal.

\begin{tabular}{|c|c|c|c|c|c|c|c|c|c|c|c|c|c|c|}
\hline \multirow{2}{*}{ 莺 } & \multirow[b]{2}{*}{$\begin{array}{c}\text { Grupo } \\
\text { tipológico }\end{array}$} & \multirow[b]{2}{*}{$\begin{array}{l}\text { Sub-grupo } \\
\text { tipológico }\end{array}$} & \multirow[b]{2}{*}{$n$} & \multirow{2}{*}{$\begin{array}{c}\text { Forma } \\
\text { base }\end{array}$} & \multirow{2}{*}{$\begin{array}{l}\text { Unifac } \\
\text { o Bifac }\end{array}$} & \multirow{2}{*}{$\begin{array}{l}\text { Serie } \\
\text { técnica }\end{array}$} & \multirow[b]{2}{*}{ Tamaño } & \multicolumn{4}{|c|}{ MP } & \multicolumn{2}{|c|}{ Estado } & \multirow[b]{2}{*}{$\begin{array}{c}\text { Observa- } \\
\text { ciones }\end{array}$} \\
\hline & & & & & & & & $\sum_{\infty}^{\infty}$ & है & $\vec{\sigma}$ & 5 & $\underset{\mathbf{I}}{\stackrel{\vec{I}}{ }}$ & 苞 & \\
\hline \multirow[t]{6}{*}{ 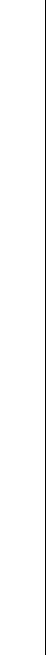 } & \multicolumn{2}{|c|}{$\begin{array}{l}\text { Artefacto manufacturado } \\
\text { por picado, abrasión, } \\
\text { pulido }\end{array}$} & 2 & ND & NA & NA & NA & 2 & - & - & - & - & 2 & \\
\hline & $\begin{array}{l}\text { Artefacto } \\
\text { de } \\
\text { format. } \\
\text { sumaria }\end{array}$ & $\begin{array}{l}\text { c/lascado } \\
\text { simple de } \\
\text { formatización }\end{array}$ & 1 & $\begin{array}{c}\text { Ls. } \\
\text { angular }\end{array}$ & Unifac & $\begin{array}{l}\text { Lasc. } \\
\text { simple } \\
\text { marg. }\end{array}$ & NA & - & - & 1 & - & - & 1 & $\begin{array}{l}\text { F-B } \\
\text { c/corteza }\end{array}$ \\
\hline & $\begin{array}{l}\text { Artefacto } \\
\text { burilante }\end{array}$ & Buril & 1 & $\begin{array}{l}\text { Fragm. } \\
\text { ND de } \\
\text { AF }\end{array}$ & Unifac & $\begin{array}{l}\text { RTo } \\
\text { marg. }\end{array}$ & Peq. & - & - & 1 & - & 1 & - & $\begin{array}{l}\text { Reciclado } \\
\text { sobre F-B } \\
\text { bifacial }\end{array}$ \\
\hline & Cortante & $\begin{array}{l}\text { Filo lateral } \\
\text { retocado }\end{array}$ & 1 & $\begin{array}{l}\text { Ls. } \\
\text { angular }\end{array}$ & Unifac & $\begin{array}{l}\text { RTo- } \\
\text { MiRTo } \\
\text { marg. }\end{array}$ & NA & - & 1 & - & - & - & 1 & $\mathrm{c} / \mathrm{FNRC}$ \\
\hline & $\begin{array}{l}\text { Cortante } \\
+\mathrm{RBO}\end{array}$ & $\begin{array}{l}\text { Filo lateral } \\
\text { retocado }+ \\
\text { filo lateral } \\
\end{array}$ & 1 & $\begin{array}{c}\text { Ls. } \\
\text { angular }\end{array}$ & $\mathrm{U}+\mathrm{U}$ & $\begin{array}{l}\text { RTo- } \\
\text { MiRTo } \\
\text { marg. }\end{array}$ & Peq. & - & 1 & - & - & 1 & - & \\
\hline & $\begin{array}{l}\text { Cuchillo } \\
\text { de filo } \\
\text { retocado }\end{array}$ & $\begin{array}{l}\text { Filo lateral } \\
\text { c/ápice activo }\end{array}$ & 1 & ND & Bifac & $\begin{array}{l}\text { MiRTo } \\
\text { ext. }\end{array}$ & NA & - & 1 & - & - & - & 1 & $\begin{array}{l}\text { Dentado } \\
\text { milimétrico }\end{array}$ \\
\hline \multirow[t]{11}{*}{$\mathbf{A}$} & \multirow{11}{*}{\multicolumn{2}{|c|}{ Fragmento ND de AF }} & \multirow{11}{*}{13} & $\begin{array}{c}\text { Ls. } \\
\text { angular }\end{array}$ & ND & ND & NA & - & 1 & - & - & - & 1 & \\
\hline & & & & \multirow{10}{*}{ ND } & \multirow[b]{2}{*}{ Unifac } & $\begin{array}{c}\text { RTo- } \\
\text { MiRTo } \\
\text { marg. } \\
\end{array}$ & NA & - & 1 & - & - & - & 1 & \\
\hline & & & & & & $\begin{array}{c}\text { RTa- } \\
\text { RTo } \\
\text { marg- } \\
\text { parc. ext. }\end{array}$ & NA & - & - & 1 & - & - & 1 & \\
\hline & & & & & \multirow{8}{*}{ Bifac } & RTo ND & NA & - & 1 & - & - & - & 1 & \\
\hline & & & & & & \multirow{2}{*}{ RTo ext. } & \multirow{2}{*}{ NA } & - & - & 1 & - & - & 1 & \\
\hline & & & & & & & & - & 1 & - & - & - & 1 & \\
\hline & & & & & & \multirow{2}{*}{$\begin{array}{l}\text { RTo- } \\
\text { MiRTo } \\
\text { ext. }\end{array}$} & NA & - & 2 & - & - & - & 2 & \\
\hline & & & & & & & NA & - & - & 2 & - & - & 2 & \\
\hline & & & & & & \multirow{3}{*}{$\begin{array}{l}\text { RTo- } \\
\text { MiRTo } \\
\text { ND }\end{array}$} & \multirow{3}{*}{ NA } & - & 1 & - & - & - & 1 & \\
\hline & & & & & & & & - & - & 1 & - & - & 1 & Reactivado \\
\hline & & & & & & & & - & - & 1 & - & - & 1 & \\
\hline
\end{tabular}




\begin{tabular}{|c|c|c|c|c|c|c|c|c|c|c|c|c|c|}
\hline \multirow{3}{*}{$\begin{array}{l}\text { Muescas } \\
\text { retocadas } \\
\text { y de lasc. } \\
\text { simple }\end{array}$} & $\begin{array}{l}\text { Muesca } \\
\text { retocada filo } \\
\text { lateral } \\
\end{array}$ & 1 & \multirow{3}{*}{$\begin{array}{l}\text { Ls. } \\
\text { angular }\end{array}$} & \multirow{3}{*}{ Unifac } & $\begin{array}{c}\text { RTo- } \\
\text { MiRTo } \\
\text { marg. }\end{array}$ & NA & - & 1 & - & - & - & 1 & \multirow{3}{*}{$\mathrm{c} / \mathrm{FNRC}$} \\
\hline & \multirow{2}{*}{$\begin{array}{l}\text { Muesca de } \\
\text { lasc. simple } \\
\text { filo lateral }\end{array}$} & \multirow{2}{*}{2} & & & $\begin{array}{c}\text { RTo } \\
\text { parc. ext. }\end{array}$ & Peq. & - & - & 1 & - & 1 & - & \\
\hline & & & & & RTa ext. & NA & - & 1 & - & - & - & 1 & \\
\hline \multirow{4}{*}{\multicolumn{2}{|c|}{ Percutor }} & \multirow{4}{*}{5} & \multirow{4}{*}{$\begin{array}{l}\text { Nód. } \\
\text { rodado }\end{array}$} & \multirow{4}{*}{ NA } & \multirow{4}{*}{ NA } & $\begin{array}{l}\text { Muy } \\
\text { grande }\end{array}$ & \multirow{2}{*}{2} & \multirow{2}{*}{-} & \multirow{2}{*}{ - } & \multirow{2}{*}{-} & 1 & - & \\
\hline & & & & & & NA & & & & & - & 1 & \\
\hline & & & & & & $\begin{array}{l}\text { Muy } \\
\text { grande }\end{array}$ & \multirow{2}{*}{ - } & \multirow{2}{*}{-} & \multirow{2}{*}{-} & \multirow{2}{*}{3} & 1 & - & \\
\hline & & & & & & NA & & & & & - & 2 & \\
\hline \multirow{12}{*}{$\begin{array}{l}\text { Punta de } \\
\text { proyectil }\end{array}$} & \multirow{3}{*}{$\begin{array}{l}\text { Fragm. apical } \\
\text { de pdp }\end{array}$} & \multirow{3}{*}{3} & \multirow{2}{*}{ ND } & \multirow{2}{*}{ Bifac } & $\begin{array}{c}\text { MiRTo } \\
\text { ext. }\end{array}$ & NA & - & 2 & - & - & - & 2 & \\
\hline & & & & & Rto ext. & NA & - & 1 & - & - & - & 1 & \\
\hline & & & ND & Bifac & $\begin{array}{c}\text { RTo- } \\
\text { MiRTo } \\
\text { ext. }\end{array}$ & NA & - & - & 3 & - & - & 3 & \\
\hline & $\begin{array}{l}\text { Preforma de } \\
\text { pdp } \\
\text { apedunculada }\end{array}$ & 1 & ND & Bifac & $\begin{array}{l}\text { RTa- } \\
\text { RTo- } \\
\text { MiRTo } \\
\text { ext. }\end{array}$ & $\begin{array}{l}\text { Med- } \\
\text { peq }\end{array}$ & - & - & 1 & - & 1 & - & \\
\hline & $\begin{array}{l}\text { Preforma de } \\
\text { pdp }\end{array}$ & 1 & ND & Bifac & $\begin{array}{l}\text { RTo- } \\
\text { MiRTo } \\
\text { ext. }\end{array}$ & Peq. & - & 1 & - & - & 1 & - & \\
\hline & $\begin{array}{l}\text { Fragm. ND } \\
\text { de pdp }\end{array}$ & 1 & ND & Bifac & $\begin{array}{l}\text { RTa- } \\
\text { RTo- } \\
\text { MiRto } \\
\text { ext. }\end{array}$ & NA & - & 1 & - & - & - & 1 & $\begin{array}{l}\text { Fragm. } \\
\text { limbo-basal } \\
\text { o basal }\end{array}$ \\
\hline & $\begin{array}{l}\text { Fragm. basal } \\
\text { de pdp }\end{array}$ & 1 & ND & Bifac & $\begin{array}{l}\text { RTo- } \\
\text { MiRTo } \\
\text { ext. }\end{array}$ & NA & - & 1 & - & - & - & 1 & \\
\hline & $\begin{array}{l}\text { Fragm. } \\
\text { limbo-apical } \\
\text { de pdp }\end{array}$ & 1 & ND & Bifac & $\begin{array}{c}\text { Rto- } \\
\text { MiRTo } \\
\text { parc.ext. } \\
\text {-ext. }\end{array}$ & NA & - & 1 & - & - & - & 1 & \\
\hline & $\begin{array}{l}\text { Fragm. } \\
\text { medial de } \\
\text { pdp }\end{array}$ & 2 & ND & Bifac & $\begin{array}{l}\text { RTo- } \\
\text { MiRTo } \\
\text { ext. }\end{array}$ & NA & - & 2 & - & - & - & 2 & \\
\hline & $\begin{array}{l}\text { Fragm. meso- } \\
\text { basal de pdp }\end{array}$ & 1 & ND & Bifac & RTo ext. & NA & - & 1 & - & - & - & 1 & \\
\hline & Apedunculada & 2 & ND & Bifac & $\begin{array}{l}\text { RTo- } \\
\text { MiRTo } \\
\text { ext. }\end{array}$ & Peq. & - & 2 & - & - & 2 & - & \\
\hline & & & & & $\begin{array}{l}\text { MiRTo } \\
\text { ext. }\end{array}$ & & & & & & & & \\
\hline \multirow{7}{*}{ Raspador } & \multirow{4}{*}{$\begin{array}{l}\text { Filo frontal } \\
\text { largo }\end{array}$} & \multirow{4}{*}{4} & Ls. & & $\begin{array}{c}\text { RTo- } \\
\text { MiRTo } \\
\text { parc. ext } \\
\end{array}$ & NA & - & - & 1 & - & - & 1 & Reactivado \\
\hline & & & angular & & $\begin{array}{l}\text { RTo- } \\
\text { MiRTo } \\
\text { marg. }\end{array}$ & Peq. & - & - & 1 & - & 1 & - & Reactivado \\
\hline & & & Ls. ND & Unifac & $\begin{array}{c}\text { RTa- } \\
\text { RTo- } \\
\text { MiRTo } \\
\text { parc.ext }\end{array}$ & $\begin{array}{l}\text { Med- } \\
\text { peq }\end{array}$ & - & - & 1 & - & 1 & - & \\
\hline & & & & & $\begin{array}{l}\text { RTo- } \\
\text { MiRTo } \\
\text { marg. }\end{array}$ & NA & - & - & 1 & - & - & 1 & \\
\hline & $\begin{array}{l}\text { Filo lateral } \\
\text { largo }\end{array}$ & 1 & $\begin{array}{l}\text { Fragm. } \\
\text { ND de } \\
\text { AF }\end{array}$ & Unifac & $\begin{array}{c}\text { RTo- } \\
\text { MiRTo } \\
\text { marg.- } \\
\text { parc.ext }\end{array}$ & Peq. & - & - & 1 & - & 1 & - & Reactivado \\
\hline & Fragmento & 0 & I N & If & RTo- & Na & - & - & 1 & - & - & 1 & Reactivado \\
\hline & ND & 2 & LS. ND & Unirac & marg. & NA & - & - & 1 & - & - & 1 & \\
\hline $\begin{array}{l}\text { Raspador } 1 \\
\text { corto }+ \text { RB } \\
\text { ND de AF }\end{array}$ & $\begin{array}{l}\text { llo frontal } \\
\text { O (LIZ) + Filo } \\
\text { (LD) }\end{array}$ & 1 & Ls. ND & $\begin{array}{c}\mathrm{U}+\mathrm{U}+ \\
\mathrm{U}\end{array}$ & $\begin{array}{c}\text { Rto- } \\
\text { MiRTo } \\
\text { parc.ext }\end{array}$ & Peq. & - & - & 1 & - & 1 & - & $\begin{array}{l}\text { Raspador } \\
\text { reactivado }\end{array}$ \\
\hline
\end{tabular}




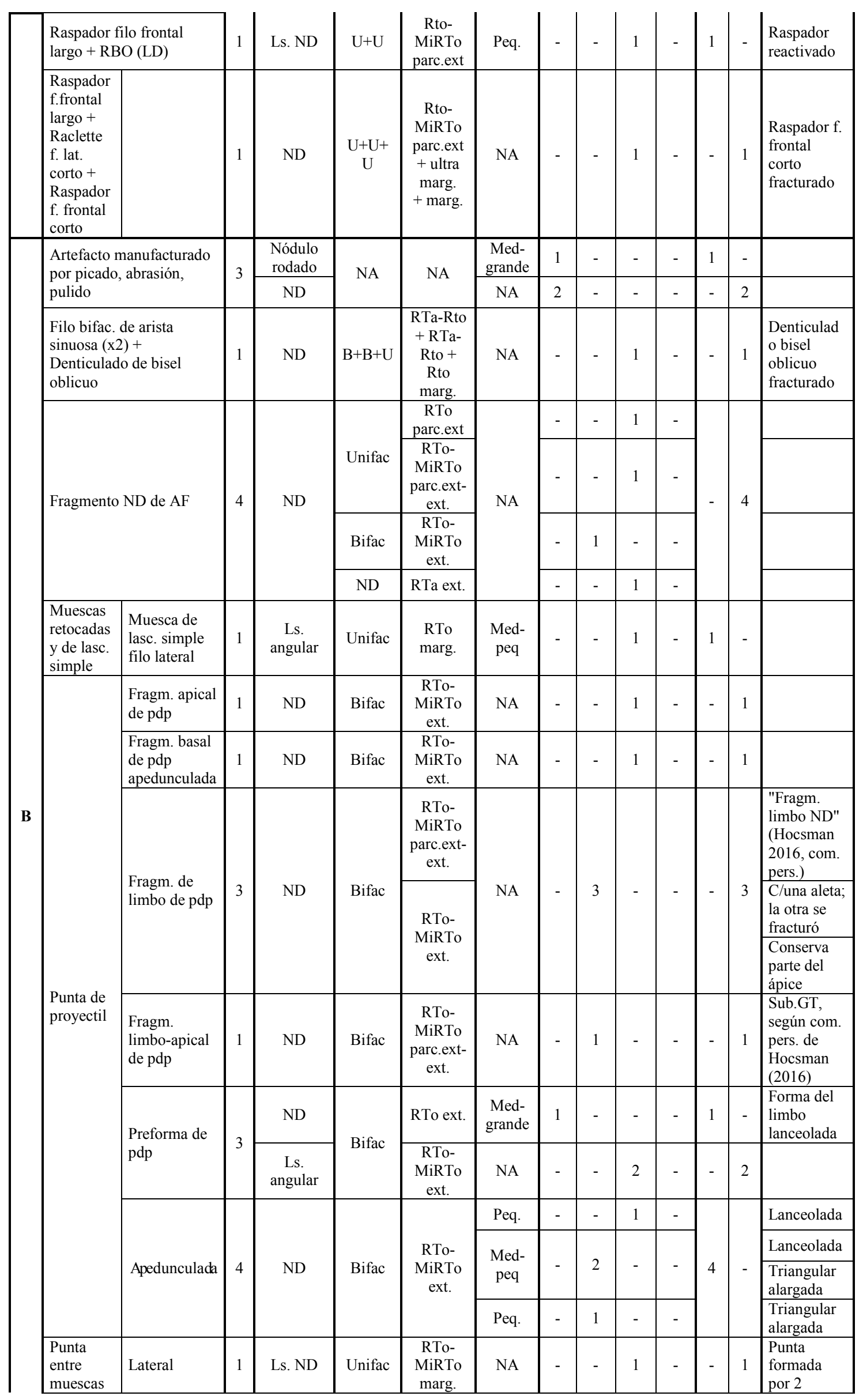




\begin{tabular}{|c|c|c|c|c|c|c|c|c|c|c|c|c|}
\hline & & & & & & & & & & & & $\begin{array}{l}\text { muescas } \\
\text { retocadas }\end{array}$ \\
\hline $\begin{array}{l}\text { Filo frontal } \\
\text { largo }\end{array}$ & 1 & $\begin{array}{l}\text { Ls. } \\
\text { angular }\end{array}$ & Unifac & $\begin{array}{c}\text { MiRTo } \\
\text { ultra } \\
\text { marg. }\end{array}$ & $\begin{array}{l}\text { Muy } \\
\text { peq. }\end{array}$ & - & - & 1 & - & 1 & - & \\
\hline $\begin{array}{l}\text { Filo frontal } \\
\text { corto }\end{array}$ & 1 & $\begin{array}{l}\text { Ls. } \\
\text { angular }\end{array}$ & Unifac & $\begin{array}{l}\text { RTa- } \\
\text { Rto } \\
\text { marg.- } \\
\text { parc.ext }\end{array}$ & Peq. & - & - & 1 & - & 1 & - & \\
\hline \multirow[b]{2}{*}{$\begin{array}{l}\text { Filo frontal } \\
\text { largo }\end{array}$} & \multirow[b]{2}{*}{2} & $\begin{array}{l}\text { Ls. } \\
\text { secundaria }\end{array}$ & \multirow[b]{2}{*}{ Unifac } & $\begin{array}{l}\text { MiRTo } \\
\text { ultra } \\
\text { marg. }\end{array}$ & \multirow[b]{2}{*}{ Peq. } & \multirow[b]{2}{*}{ - } & \multirow[b]{2}{*}{-} & \multirow[b]{2}{*}{2} & \multirow[b]{2}{*}{-} & \multirow[b]{2}{*}{2} & \multirow[b]{2}{*}{-} & \\
\hline & & $\begin{array}{l}\text { Frag. de } \\
\text { pdp }\end{array}$ & & $\begin{array}{c}\text { RTo- } \\
\text { MiRTo } \\
\text { marg. }\end{array}$ & & & & & & & & $\begin{array}{l}\text { Reciclado } \\
\text { sobre F-B } \\
\text { de bordes } \\
\text { dentados } \\
\end{array}$ \\
\hline $\begin{array}{l}\text { RBO + Filo ND de AF + } \\
\text { Filo ND de AF }\end{array}$ & 1 & ND & $\begin{array}{c}\mathrm{U}+\mathrm{U}+ \\
\mathrm{U}\end{array}$ & $\begin{array}{c}\text { RTo } \\
+ \text { RTo- } \\
\text { MiRTo } \\
\text { ultra } \\
\text { marg. } \\
\text { + parc.ext } \\
\text { + marg. }\end{array}$ & NA & - & - & 1 & - & - & 1 & $\begin{array}{l}\text { RBO entero } \\
\text { (tamaño } \\
\text { pequeño); } \\
\text { Reactivación }\end{array}$ \\
\hline $\begin{array}{l}\text { c/pedúnculo } \\
\text { diferenciado }\end{array}$ & 1 & Ls. ND & Bifac & $\begin{array}{c}\text { RTo- } \\
\text { MiRTo } \\
\text { parc.ext }\end{array}$ & $\begin{array}{c}\text { Med- } \\
\text { peq }\end{array}$ & - & - & 1 & - & 1 & - & $\begin{array}{l}\text { Limbo } \\
\text { c/bordes } \\
\text { dentados }\end{array}$ \\
\hline Total & 83 & & & & & 8 & 32 & 40 & 3 & 26 & 57 & \\
\hline
\end{tabular}

Tabla 8.9. Grupos y sub-grupos tipológicos de los artefactos formatizados de CSA-1 por conjunto temporal. Referencias: Conj.: conjunto temporal; Unifac.: instrumento unifacial; Bifac.: instrumento bifacial; U: unifacial; B: bifacial; Tam.: Tamaño; MP: materia prima; BAS: basalto; OBS: obsidiana; SIL: roca silicea; Ent.: instrumento entero; Frac.: instrumento fracturado; Observac.: Observaciones; ND: no diferenciado/a; NA: no aplica; Ls.: lasca; AF: artefacto formatizado; Lasc.: lascado; Fragm.: fragmento; Pdp.: punta de proyectil; LIZ: lateral izquierdo; LD: lateral derecho; RTa: Retalla; RTo: Retoque; MicRTo: Microretoque;

Ext.: extendido; Parc. ext.: parcialmente extendido; Marg.: marginal; Ultramarg.: ultramarginal; Med-peq.: mediano-pequeño; Med-grande: mediano-grande; F-B: forma-base;

FNRC: filo natural con rastros complementarios. En los casos en que se combinan, por ejemplo, "RTo ND", significa que la anchura de la boca de los lascados sobre el borde, sí se puede distinguir, pero la extensión de los lascados no.

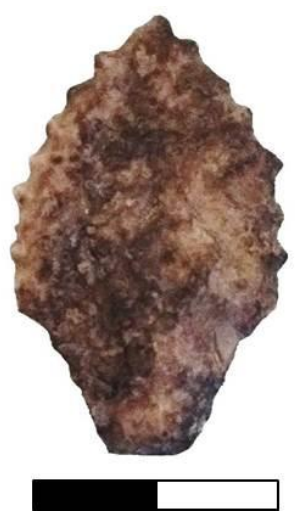

Figura 8.16. Punta de proyectil con pedúnculo diferenciado, de bordes convergentes rectos, base recta y aletas en hombro, abiertas; perteneciente al Conjunto C de CSA-1. 


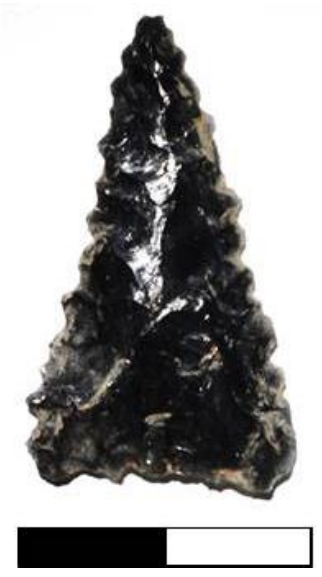

Figura 8.17. Punta de proyectil apedunculada de limbo triangular alargado y base cóncava atenuada, del Conjunto B de CSA-1.

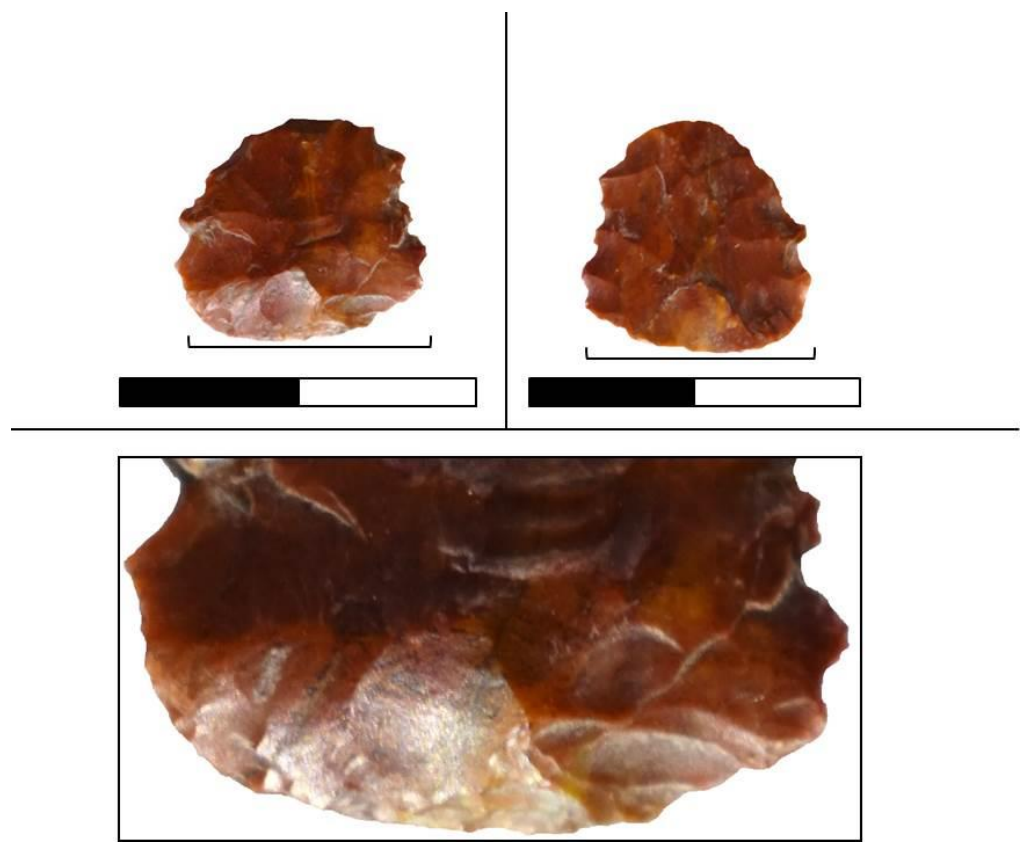

Figura 8.18. Raspador reciclado sobre fragmento de limbo de punta de proyectil de bordes dentados, del Conjunto B de CSA-1, con detalle del filo del raspador.
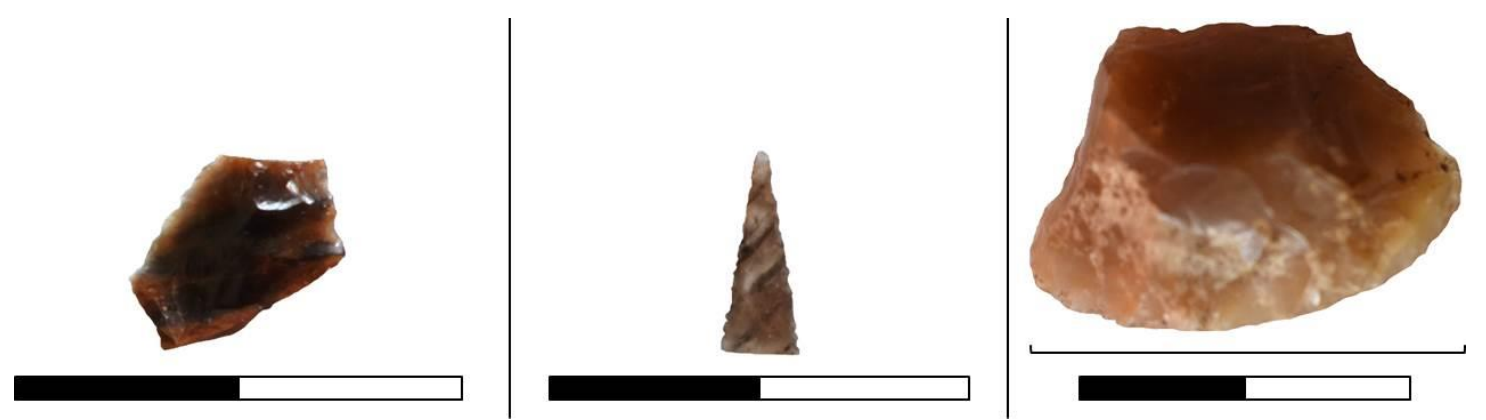

Figura 8.19. Fragmentos medial y apical de puntas de proyectil de obsidiana, y raspador entero de roca silícea con detalle del filo. 
Predominan los instrumentos (véase clasificación en Capítulo 5) de formatización bifacial $(50,60 \%, n=42)$ (Figura 8.20). La mayoría son de obsidiana $(61,91 \%, n=26)$, seguidos por los de rocas silíceas $(35,71 \%, n=15)$ y de basalto $(2,38 \%, n=1)$. La punta de proyectil con pedúnculo de roca silícea $(2,38 \%, n=1)$ corresponde al Conjunto $\mathrm{C}$. En el B la mitad de los instrumentos $(\mathrm{n}=14)$ son bifaciales; los ocho instrumentos de obsidiana son bifaciales $(57,14 \%)$, cinco están confeccionados sobre rocas silíceas $(35,72 \%)$ y uno sobre basalto (7,14\%). En el Conjunto A la mitad son bifaciales $(50 \%, n=27) ; 18$ de obsidiana $(66,67 \%)$ y nueve de rocas silíceas $(33,33 \%)$ (Tabla 8.9$)$.

De los 23 AF unifaciales registrados en CSA-1 (27,71\%), el 82,61\% fue confeccionado sobre rocas silíceas $(n=19)$. Los otros cuatro son de obsidiana. En el Conjunto B los ocho unifaciales $(28,57 \%)$ están confeccionados sobre rocas silíceas. En el A, de los 15 unifaciales (27,78\%), el 73,33\% se confeccionó sobre rocas silíceas ( $\mathrm{n}=11$; siete son raspadores) y los cuatro restantes sobre obsidiana $(26,67 \%, \mathrm{n}=4)$ (Tabla 8.9).

En general, la serie técnica de los artefactos formatizados de CSA-1, muestra que hay una mayor frecuencia de instrumentos con retoque y microrretoque extendido, además de parcialmente extendido y marginal, tanto en instrumentos unifaciales (especialmente, raspadores) como bifaciales (principalmente, puntas de proyectil), de obsidiana y rocas silíceas.

En la Figura 8.20 se observa que las proporciones entre instrumentos bifaciales y unifaciales son semejantes entre los conjuntos A y B: los bifaciales superan el 60\% (64,29\% en el A y 63,64\% en el B) y los unifaciales no alcanzan el 40\% (35,71\% y 36,36\% en A y B, respectivamente). En el Conjunto C, como se dijo, sólo se registró la punta de proyectil con pedúnculo; Figura 8.16) (Figura 8.20).

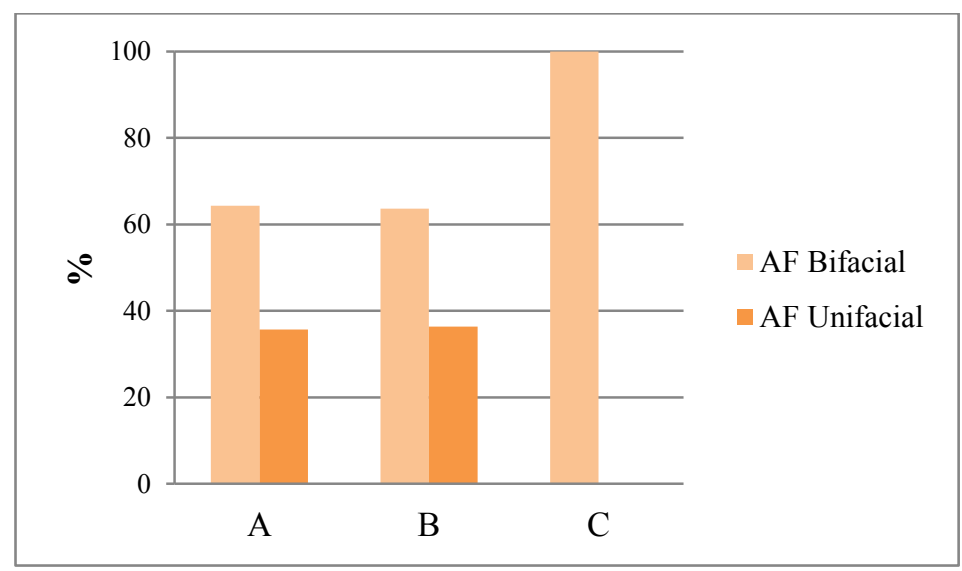

Figura 8.20. Frecuencias de instrumentos bifaciales y unifaciales por conjunto temporal enCSA-1. 
Los instrumentos compuestos $(n=6)$, constituyen el 7,23\%. El 33,33\% fueron confeccionados sobre rocas silíceas, provienen del Conjunto B (7,14\%); los otros cuatro $(66,67 \%)$, tres de rocas silíceas y uno de obsidiana, pertenecen al Conjunto A $(7,41 \%)$. Los artefactos manufacturados o modificados por abrasión, picado y/o pulido son de basalto y constituyen el 6,02\% $(n=5)$ : el $60 \%$ procede del Conjunto B y el $40 \%$ del A. Los cinco percutores registrados $(6,02 \%)$ provienen del Conjunto A: dos están enteros, son de tamaño muy grande, uno es de basalto y el otro de vulcanita indeterminada, y pesan 195,6 gr y 166,8 gr, respectivamente. Los otros tres están fracturados, uno es de basalto y pesa 134,9 gr; los otros dos son de vulcanita indeterminada y pesan 157, 4 gr y 94,9 gr. De los fragmentos no diferenciados de artefactos formatizados $(2,41 \%, n=2)$, uno es de roca silícea y pertenece al Conjunto B; el otro es de obsidiana del Conjunto A (Tabla 8.9). En CSA-1 se registraron 16 ASF RC: el 25\% ( $n=4$; todos fracturados) del Conjunto B (tres de rocas silíceas y uno de obsidiana), y el 75\% ( $n=12$; ocho fracturados y dos - de obsidiana- enteros) del Conjunto A (diez son de obsidiana y dos de rocas silíceas).

En los instrumentos fracturados, no se ha considerado la variable de tamaño. Del total de instrumentos enteros $(n=26)$, el $53,85 \%(n=14)$ es de tamaño pequeño, el $26,92 \%$ $(\mathrm{n}=7)$ mediano-pequeño, el 7,69\% $(\mathrm{n}=2)$ mediano-grande, el 7,69\% $(\mathrm{n}=2)$ muy grande (categoría que corresponde a los dos percutores enteros) y el 3,85\% $(\mathrm{n}=1)$ muy pequeño.

La Tabla 8.9 muestra la totalidad de Grupos y sub-grupos tipológicos por conjunto temporal. Se observa que los instrumentos bifaciales y los unifaciales aumentan a través del tiempo (Figura 8.20 y Tabla 8.3); la mayoría de los bifaciales se destinó a la confección de puntas de proyectil (la mayoría descartadas fracturadas); los grupos tipológicos de los unifaciales son variados, aunque son más frecuentes los raspadores, los cuales aumentan a través del tiempo. Los instrumentos compuestos están más representados en el Conjunto A que en el B, y ausentes en el C, lo cual no es congruente con las expectativas. Los artefactos manufacturados o modificados por abrasión, picado y/o pulido son más frecuentes en el Conjunto $B(n=3)$ que en el $A(n=2)$; esto también se opone a lo esperado. En CSA-1 hay evidencias de reciclado (instrumentos unifaciales sobre bifaciales) y de reactivación; esta última, más frecuente sobre raspadores.

\subsubsection{Síntesis y discusión}

Cueva Salamanca 1 se emplaza sobre el piedemonte andino, en la transición de diferentes ecosistemas y provincias geológicas, permitiendo el acceso a un set amplio de recursos. Posee evidencias de ocupación humana desde aproximadamente 7.300 años AP, 
con interrupción desde ca. 7.000 a 2.200 años AP. Mediante el análisis estratigráfico se identificaron varios procesos de bioturbación a través de la secuencia, incluyendo cuevas de roedores, alteración por raíces, actividad de insectos y perturbación antrópica, como los fogones y basureros; ambos con gran impacto sobre las capas naturales, lo cual dificultó la correlación entre los niveles artificiales, la cronología y los materiales arqueológicos (Neme et al. 2018). Sin embargo, al utilizar los fechados radiocarbónicos y los datos geoarqueológicos, se pudieron establecer tres conjuntos temporales principales: uno perteneciente al HM (Conjunto C: 7.300-7.000 años AP), otro al HTI (Conjunto B: 2.200-1.500 años AP) y el último al HTF (Conjunto A: 1.500- histórico). El análisis tecnológico y temporal muestra algunas diferencias que reflejan cambios en el uso humano de los recursos, la intensidad de la reocupación y, probablemente, la movilidad residencial a través del tiempo (Neme et al. 2018).

El conjunto más antiguo (C), se caracteriza por una baja tasa de depositación $(\mathrm{n}=31)$ y un conjunto reducido de actividades de subsistencia, incluyendo caza, cocción y confección y mantenimiento de instrumentos. Para este periodo, se explotan principalmente Dasipódidos y Camélidos; también se sugiere el consumo de Rheidos y Chinchillidos. Las rocas locales (silíceas, basalto, riolita, entre otras) obtenidas en un radio de menos de $40 \mathrm{~km}$, representan alrededor del 60\%. La obsidiana, obtenida de fuentes a $70-100 \mathrm{~km}$, no alcanza el $40 \%$.

El Conjunto B, muestra un aumento en la diversidad faunística y lítica, y en la tasa de descarte que aumenta a 2,83 artefactos líticos descartados por año. Esto sugiere una ocupación más intensa del sitio y, probablemente, con más eventos de reocupación. En este momento, habrían sido introducidas la tecnología cerámica y del arco y flecha, esta última sugerida por el tamaño pequeño de las puntas del proyectil (Martínez 2003; Ratto 2003; Banegas et al. 2014; Castro 2015, entre otros). Los recursos faunísticos explotados aumentan del Conjunto C al B, y se enfatiza sobre la chinchilla (Lagidium viscaccia), un taxón más pequeño, de menor rango y menos común en el registro zooarqueológico de la región. Las materias primas empleadas son más diversas, con aumento relativo de rocas silíceas y disminución del basalto.

El Conjunto A es más diverso que los anteriores en términos de explotación de la fauna e instrumental lítico, lo cual podría indicar una mayor cantidad de actividades realizadas en el sitio durante su última ocupación. Los fragmentos de cerámica aparecen del nivel 1 al 12; este último datado en $1.561 \pm 38$ años AP. Esta cronología es coherente con el registro arqueológico regional donde la cerámica ingresa alrededor de 2.000 años 
AP (Marsh 2017; Sugrañes 2017). La presencia de alfarería en estos últimos conjuntos podría reforzar la idea de un mayor número de actividades de subsistencia, que se refleja en la cantidad mencionada y en la diversidad, tanto del registro de la fauna como del lítico (Neme et al. 2018). Además, la cerámica recuperada en el sitio tiene una alta inversión de manufactura (reflejada en los valores mencionados para espesor promedio, tratamiento superficial, tamaño del antiplástico y tipo de cocción), lo cual sugiere una reutilización de grandes vasijas, probablemente durante varios años (cf. Sturm et al. 2016; Pompei et al. 2017; Neme et al. 2018). La alta proporción de cerámica no local (principalmente procedente de la vertiente occidental de la Cordillera de los Andes) refuerza la idea de las características patagónicas de las ocupaciones humanas, con una muy baja producción de este tipo de tecnología, su acceso a través de intercambio y altos niveles de conservación de la misma (Neme et al. 2018). Al igual que en momentos previos, se observa que en CSA-1 se realizaron las últimas etapas de formatización y/o reactivación de instrumentos, conforme a las clases artefactuales representadas. En cuanto al uso de materias primas líticas, se observa un uso creciente de la obsidiana (algo superior al 50\%) en consonancia con lo observado en sitios próximos de la región; las rocas silíceas disminuyen en este segmento temporal $\mathrm{y}$, junto al basalto, no alcanzan el $50 \%$ de las clases de rocas utilizadas. La tasa de depositación es de 3,08 artefactos líticos descartados por año.

Entre las tendencias tecnológicas obtenidas del análisis de los artefactos de CSA1, las rocas silíceas y la obsidiana son las materias primas mayoritarias sobre las cuales se registraron la mayoría de los desechos de talla y de los instrumentos, clases artefactuales más frecuentes. Predominan las lascas internas $(87,86 \%)$, seguidas por las de formatización de filo $(7,35 \%)$ y las externas $(4,79 \%)$. Los instrumentos más frecuentes son los bifaciales $(50,6 \%)$, principalmente confeccionados sobre obsidiana $(61,9 \%)$, seguidos por los unifaciales $(27,71 \%)$, la mayoría sobre rocas silíceas $(82,6 \%)$.

El estado de fragmentación de los artefactos es elevado. E1 89,97\% de los desechos de talla y el $68,67 \%$ de los instrumentos se encuentran fracturados. La mayoría de los desechos enteros no presentan reserva de corteza en su cara dorsal $(92,65 \%)$, lo cual es coherente con el predominio de lascas internas y lascas de formatización de filo, mencionado anteriormente; a esto se suma la ausencia de núcleos. De los instrumentos fracturados $(n=57)$, el 43,86\% son de obsidiana $(n=25)$, el 43,86\% $(n=25)$ de rocas silíceas, el 8,77\% $(n=5)$ de basalto y el 3,51\% $(n=2)$ de vulcanita indeterminada.

Las evidencias sugieren que en el sitio se realizaron actividades relacionadas con las etapas avanzadas y finales del proceso de manufactura de instrumentales líticos, y está 
presente la reactivación. La ausencia de núcleos, la escasa presencia de lascas externas y, en general, de lascas con reserva de corteza en su cara dorsal (sobre rocas que naturalmente presentan corteza), concuerda con este argumento. Además, señalan que habría un intensivo aprovechamiento de las materias primas líticas; la distancia, al menos en las rocas silíceas -locales-, no parece ser un factor para esta maximización. Esto

plantea al menos dos escenarios para las rocas disponibles en el espacio local (e.g. silíceas): uno en el que se aprovecha intensivamente las rocas por su calidad para la talla muy buena. Otro en el que el uso intensivo se relaciona, no con la distancia, sino con el tipo de acceso, el cual sería de tipo indirecto. En el caso de rocas no locales (e.g. obsidiana), la distancia a las fuentes sí jugaría un rol importante en la intensidad de uso, ya sea por los costos de búsqueda (aprovisionamiento directo) o por los involucrados en la interacción entre grupos (e.g. intercambio, mecanismos de visitas, de reciprocidad, etc.) dentro de un aprovisionamiento de tipo indirecto.

Sobre la base de las funciones inferidas de los grupos tipológicos (sensu Aschero 1975, 1983) registrados en la cueva, se estima que allí se procesaron recursos naturales (e.g. madera, cuero, etc.), a través de actividades relacionadas con el raspado (raspadores y muescas en los conjuntos temporales A y $\mathrm{B}$, además de los $\mathrm{RBO}$ de los instrumentos compuestos de ambos conjuntos; función que también pudieron haber tenido la raclette del Conjunto B y la raclette de un instrumento compuesto del Conjunto A), con cortar y/o desbastar (cuchillo del Conjunto A) y cortar (cortante también del conjunto temporal más reciente), con la incisión (artefacto burilante del mismo conjunto, A) y con golpear y percutir (percutores también del Conjunto A), etc. Asimismo, las puntas de proyectil (registradas en los tres conjuntos temporales), habrían conformado el toolkit de caza. Las funciones inferidas deben contrastarse con estudios funcionales apropiados. En suma, las evidencias arqueológicas y las tendencias de ellas obtenidas, sugieren que Cueva Salamanca 1 es un sitio de actividades múltiples.

\subsubsection{LOCALIDAD ARQUEOLÓGICA ARBOLITO}

La localidad arqueológica Arbolito se ubica sobre la margen sur del lago artificial El Nihuil (margen derecha del río Atuel) a $15 \mathrm{~km}$ del poblado homónimo (Figura 8.21). Se le ha dado el nombre "Arbolito" debido a que, en el lugar, se encontraba un pequeño árbol de algarrobo, que fue de referencia común entre los pescadores (Lagiglia 1977a). 
La localidad fue estudiada en la década de 1970 por Lagiglia (1977a) en el marco de su tesis doctoral y continua siendo visitada en la actualidad por distintos investigadores y aficionados. Gran parte de las colecciones recuperadas allí se hallan depositadas en el Museo de Historia Natural de San Rafael (MHNSR). En esta localidad, Lagiglia (1977a) definió varios sitios arqueológicos superficiales que abarcan un radio de $3 \mathrm{~km}$, a una distancia aproximada de $5 \mathrm{~km}$ del antiguo cauce del río (Figura 8.21).

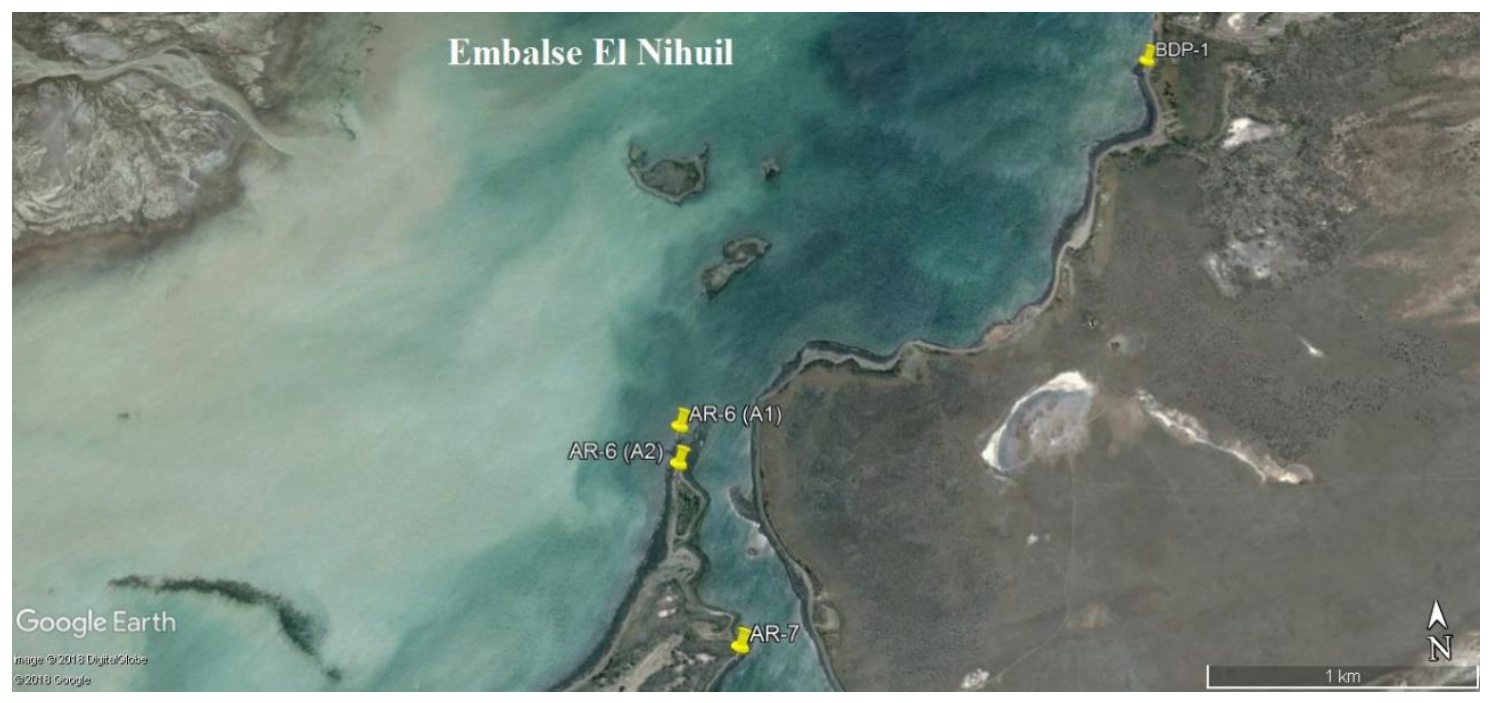

Figura 8.21. Localización de los sitios de la localidad arqueológica Arbolito sobre el Embalse El Nihuil. Referencias: AR-6 (A1): Arbolito 6 (cuadrícula A1); AR-6 (A2): Arbolito 6 (cuadrícula A2); AR-7: Arbolito 7; BDP-1: Barranca de Piedra 1.

En el área existen antiguos salitrales próximos al cauce original del río Atuel, sumergido en este tramo en las aguas del embalse El Nihuil. Cada año, las fluctuaciones del nivel del lago, provocan la inmersión y/o la erosión de la mayoría de los sitios definidos por Lagiglia (1977a); el efecto erosivo se potencia en aquellos sitios que quedan momentáneamente en la zona de playa, ya que el oleaje costero aumenta su acción. Otros sitios, localizados en los sectores más elevados de los médanos, quedan rodeados por el agua en forma de islas que afloran por encima del nivel del lago (Arbolito 1 a 4), especialmente durante los meses de enero a octubre, cuando no hay erogación de caudales por parte del dique. El resto del año, cuando bajan las aguas por el uso de las usinas hidroeléctricas, el resto de los sitios (Arbolito 5 a 10), quedan al descubierto; situación que puede variar según la cantidad de precipitaciones níveas en cordillera cada año.

Recientemente, se retomaron las tareas de campo en esta localidad con el fin de contextualizar la muestra superficial obtenida durante 50 años en la localidad, definir 
mejor la cronología disponible regionalmente y cuantificar la densidad de material por unidad de área. Así, en el verano de 2015 se realizaron por primera vez excavaciones sistemáticas en los sitios a cielo abierto Arbolito 6 (en adelante, AR-6), Arbolito 7 (en lo sucesivo, AR-7) y Barranca de Piedra 1 (en adelante, BDP-1), también emplazado en la localidad, en un sector de barrancas que da al embalse. En AR-6 se excavaron dos cuadrículas, A1 y A2. El material lítico recuperado de estas cuatro cuadrículas es el que se analiza en este capítulo.

\subsubsection{Excavaciones y estratigrafía de AR-6 y AR-7}

Ambos sitios se emplazan en un área de médanos con sedimento relativamente homogéneo. AR-6 y AR-7 (1298 msnm) se hallan a 0,85 km entre sí, y a 2,5 y $3 \mathrm{~km}$, respectivamente, del sitio BDP-1 (1305 msnm). En el trazado de la primer cuadrícula de AR-6 (cuadrícula A1; $1302 \mathrm{msnm}$ ) se consideró la densidad de material superficial expuesto en el área de inundaciones estacionales (Figura 8.22). En el caso de la cuadrícula A2 (1304 msnm), ubicada a $150 \mathrm{~m}$ al sur-sureste de la primer cuadrícula, se eligió un sector cercano al médano vegetado más próximo, para aumentar las posibilidades de hallar materiales enterrados (Figura 8.22).

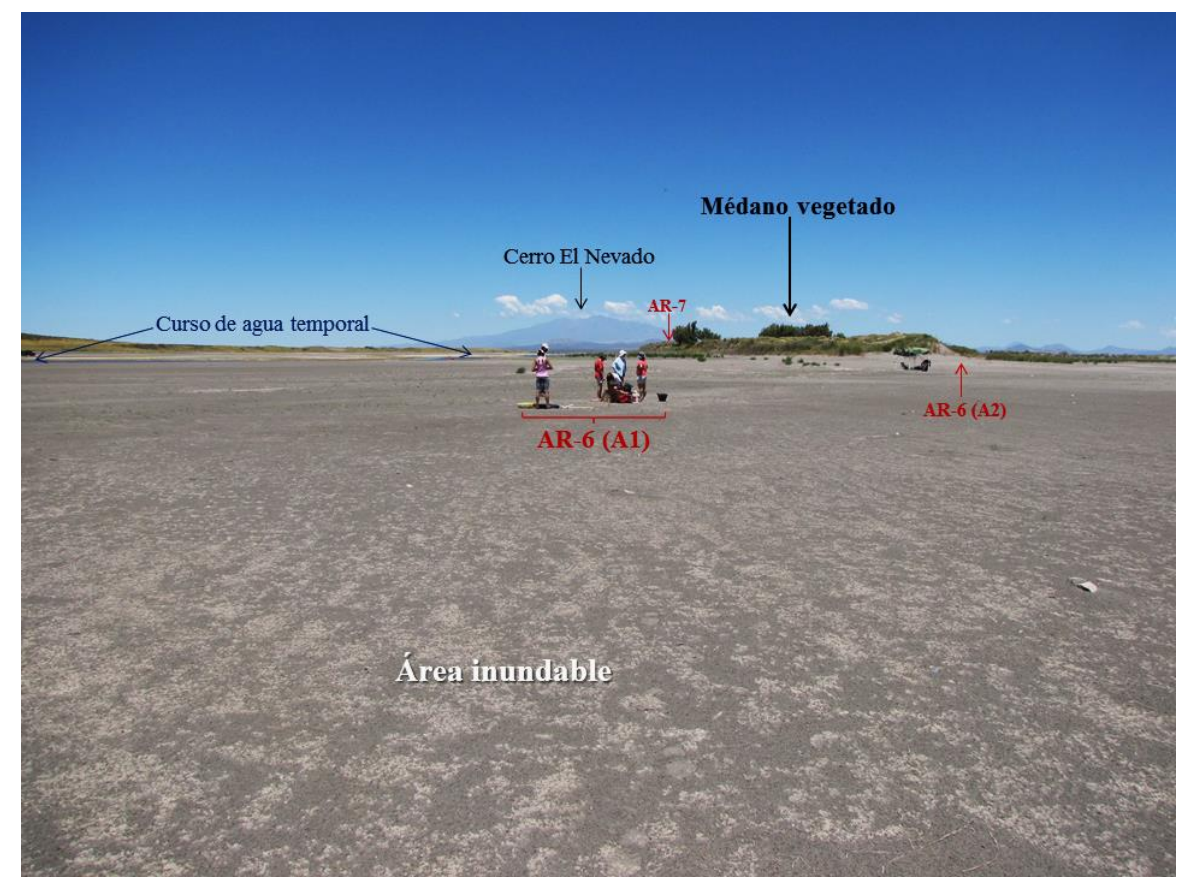

Figura 8.22. Vista panorámica hacia el sureste desde las orillas del embalse El Nihuil. Se observan los sectores de las dos cuadrículas de AR-6, y a AR-7 al otro lado del médano vegetado. En el área inundable queda expuesto el material arqueológico. 
La cuadrícula A1 de AR-6, de 2 x 1 m, está orientada en sentido norte-sur, se localiza a $35^{\circ} 5^{\prime} 47,9^{\prime \prime}$ de LS y a $68^{\circ} 44^{\prime} 14,7^{\prime \prime}$ de LO, y está dividida en dos sectores, norte y sur. Antes del inicio de la excavación se recolectó por sectores separados, el material procedente de la superficie (nivel superficial o "cero"). Posteriormente, se excavaron niveles artificiales de $10 \mathrm{~cm}$, debido a las características del sedimento (arena). La estratigrafía consiste en un sedimento arenoso y suelto que se va humedeciendo y compactando al alcanzar mayor profundidad. Tras alcanzar $20 \mathrm{~cm}$ de profundidad, se decidió realizar un sondeo en el sector sur de la cuadrícula, debido al escaso material arqueológico recuperado. La excavación finalizó en el nivel 4 del sondeo, a una profundidad de $59 \mathrm{~cm}$, debido a la ausencia de material (Figura 8.23).

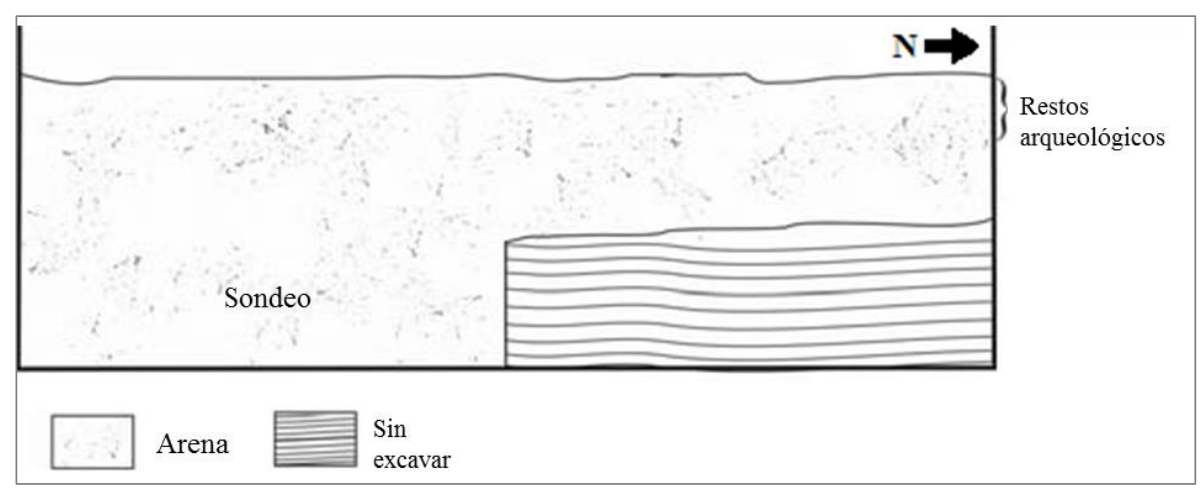

Figura 8.23. Perfil oeste de la cuadrícula A1 del sitio AR-6. Modificado de Sugrañes 2017: 246.

Para comparar las pautas estratigráficas de este sitio, se decidió excavar otra cuadrícula, debido a que se observó material arqueológico de superficie en la playa (cuadrícula A1), pero no en la zona vegetada (cuadrícula A2). Esto requirió analizar qué ocurría en estratigrafía.

La cuadrícula A2 se ubica a $35^{\circ} 5^{\prime} 52,8^{\prime \prime}$ de LS y a $68^{\circ} 44^{\prime} 15,1^{\prime \prime}$ de LO. Posee las mismas dimensiones, orientación y división por sectores que la cuadrícula A1 ( 2 x $1 \mathrm{~m}$ y sentido norte a sur) (Figura 8.24). Los niveles artificiales también fueron de $10 \mathrm{~cm}$. A partir del nivel tres se comenzó a excavar de manera asistemática dado que no había hallazgos. En el sector norte se alcanzó una profundidad de $69 \mathrm{~cm}$ y en el sector sur se decidió realizar un sondeo, finalizando a los $99 \mathrm{~cm}$ de profundidad por ausencia de restos arqueológicos. Se registró material lítico hasta el nivel 4 del sondeo. 


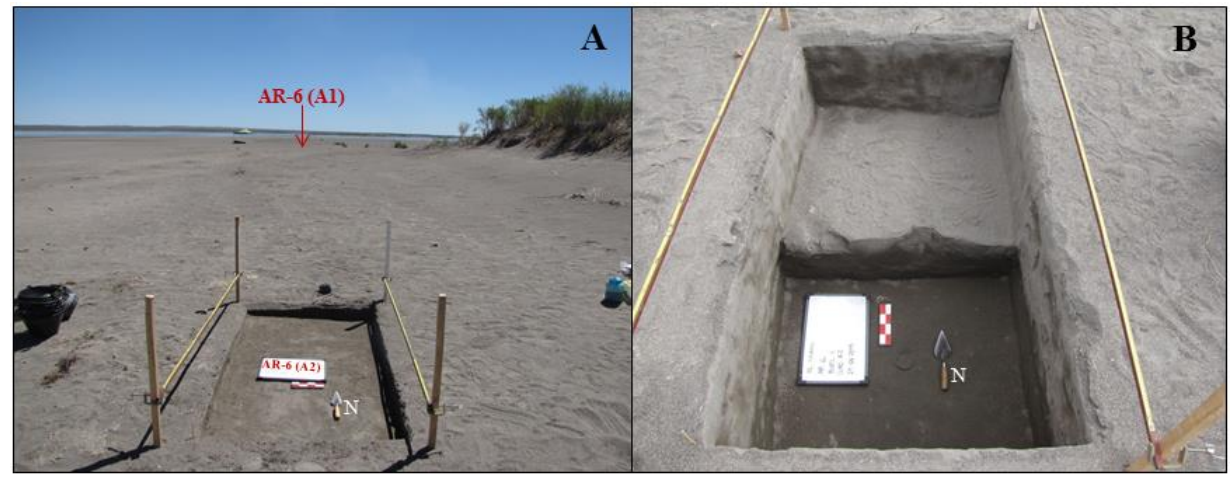

Figura 8.24. Cuadrícula A2 de AR-6. A. Vista panorámica desde AR-6 (A2), mostrando la ubicación de AR-6 (A1). B. Nivel 3 (sondeo) de AR-6 (A2), donde se observa homogeneidad en la estratigrafía y variación cromática del sedimento por aumento de la humedad a mayor profundidad.

El sedimento de la cuadrícula A2 es similar al de la A1 (i.e. arenoso y suelto); a medida que se excava, se vuelve más compacto y húmedo (Figura 8.24.B). Hacia los últimos 10-15 cm de excavación libre comenzaron a descubrirse pequeños lentes de arcilla.

El sitio AR-7 se localiza a $35^{\circ} 6^{\prime} 15,8^{\prime \prime}$ de LS y a $68^{\circ} 44^{\prime} 7,0^{\prime \prime}$ de LO. La cuadrícula de excavación se planteó en el lugar de una concentración de materiales líticos, mide $2 \mathrm{x}$ $1 \mathrm{~m}$ y está orientada de noreste-suroeste, mismo sentido en el que se dividieron los sectores de extracción. Al igual que en AR-6, se emplearon niveles artificiales de $10 \mathrm{~cm}$. Sin embargo, el material arqueológico no superó el primer nivel: se excavó el nivel 2 de forma sistemática y luego se continuó de manera libre hasta los $35 \mathrm{~cm}$ de profundidad (Figura 8.25). Esto mostró el mismo patrón de las cuadrículas A1 y A2 de AR-6, donde sólo aparece material arqueológico en los primeros 5-10 cm, desapareciendo a mayor profundidad. La única diferencia observada es que en los primeros cinco $\mathrm{cm}$ de AR-7 se registraron pequeños clastos y concreciones propias de un ambiente lacustre. 


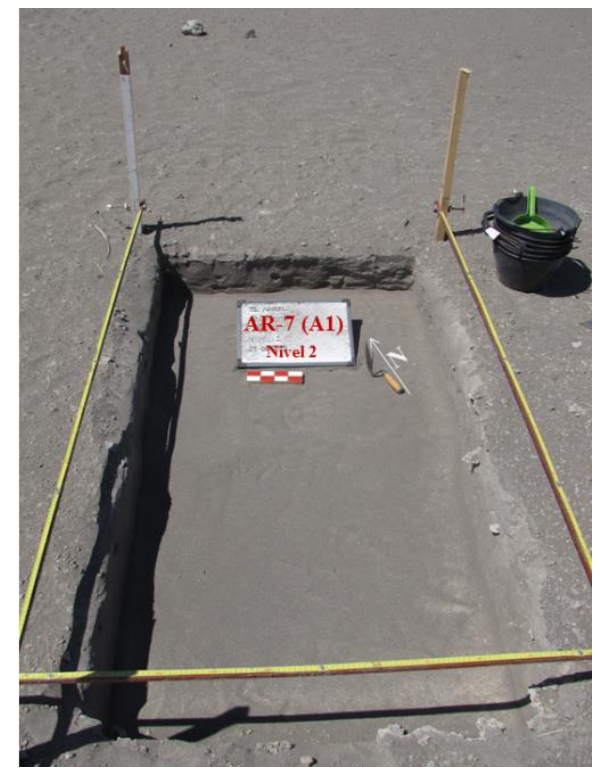

Figura 8.25. Vista en planta de la cuadrícula A1 de AR-7. En el nivel 2 se finalizó la excavación.

\subsubsection{Excavaciones y estratigrafía de BDP-1}

Al noreste de los sitios Arbolito, se localiza el sitio BDP-1 (35²'57,3' 'LS; $68^{\circ} 42^{\prime} 51,7^{\prime \prime}$ LO). El material arqueológico que yacía en su superficie en la temporada en que se realizaron los trabajos de excavación, era mayor que el observado en AR-6 y AR-7 (Figura 8.26), y algunas de sus características sugerían una ocupación más antigua y continua o persistente a lo largo del tiempo, respecto a dichos sitios Arbolito (e.g. ausencia de cerámica, punta de proyectil con pedúnculo). Por estos motivos, se decidió considerar de forma independiente a BDP-1. La localización de la cuadrícula excavada (A1) se definió por la densidad de materiales en superficie, por la localización y porque en la zona es frecuente la circulación de pobladores, pescadores y visitantes del embalse El Nihuil, provocando la afectación del conjunto. 


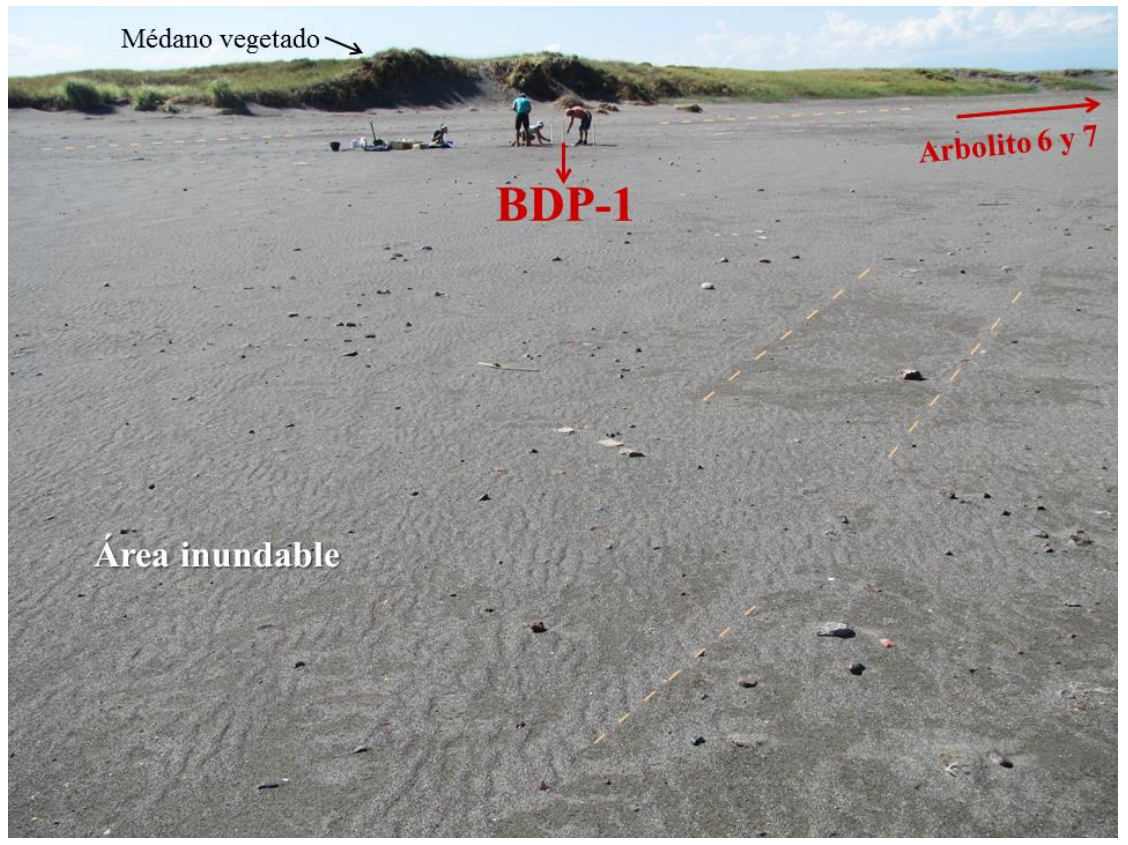

Figura 8.26. Vista panorámica del sitio BDP-1 desde el noroeste. Se observa un médano vegetado muy próximo a la cuadrícula A1 de BDP-1, separados por una de las vías de circulación actual (marcas en color beige). En el área inundable se observa gran cantidad de material arqueológico y huellas dejadas por el agua durante la inmersión.

La cuadrícula A1 de BDP-1 mide 2 x $1 \mathrm{~m}$, se excavó por niveles artificiales de 10 $\mathrm{cm}$ y se dividió en dos sectores de $1 \mathrm{~m}^{2} \mathrm{y}$ de orientación este-oeste (Figura 8.27). Debido a la naturaleza de la matriz sedimentaria, la arena disgregada aparecía más compacta a mayor profundidad. La excavación concluyó a los $45 \mathrm{~cm}$ de profundidad, en el nivel 3 (nivel de base: $0,15 \mathrm{~m}$ ), el cual fue excavado sólo en el sector este (Figura 8.27.B).

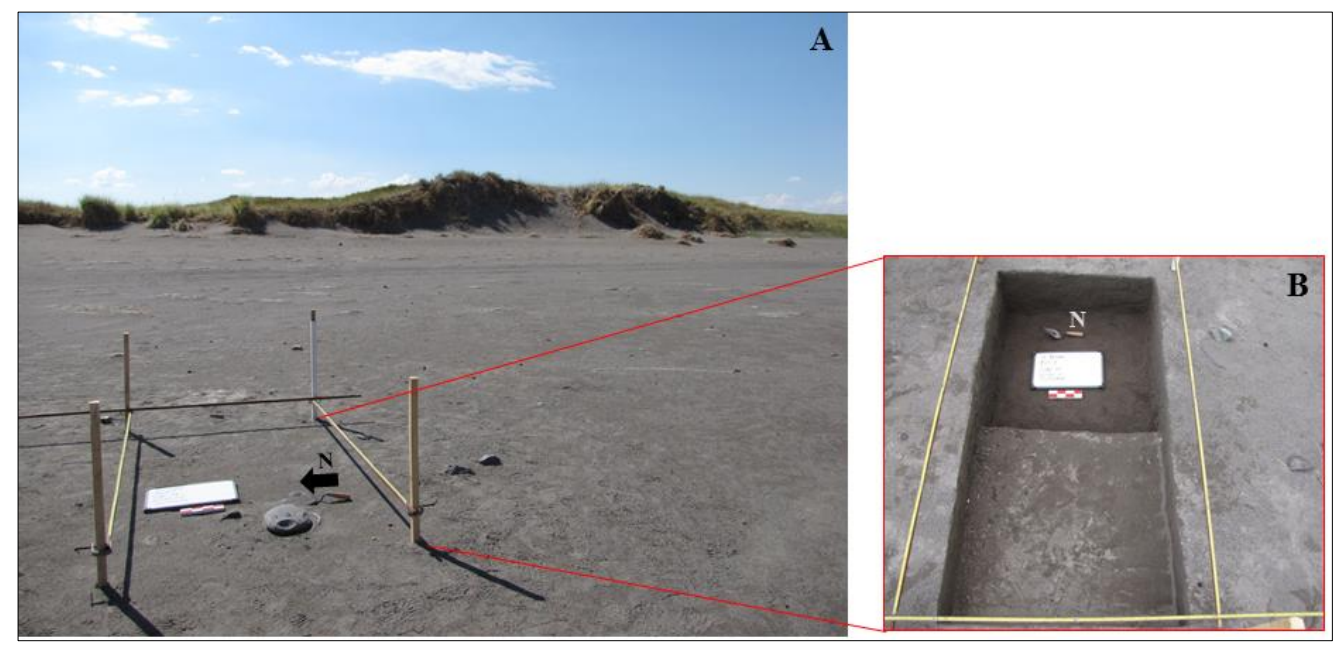

Figura 8.27. Cuadrícula A1 del sitio BDP-1. A. Contexto de emplazamiento; B. Último nivel de excavación (nivel 2, al oeste) y sondeo (nivel 3, al este). 


\subsubsection{Cronología de la localidad Arbolito}

Uno de los objetivos de las excavaciones realizadas en 2015 fue definir mejor la cronología, ya que los fechados previos se habían realizado sobre restos óseos humanos (Figura 8.28) de entierros localizados en diferentes sectores. Sin embargo, debido a que no se registraron materiales para fechar se debieron considerar las referencias previas (Gil et al. 2011a, 2014) que señalan correspondencia con el HTF (2.000-200 años AP) (Tabla 8.10).

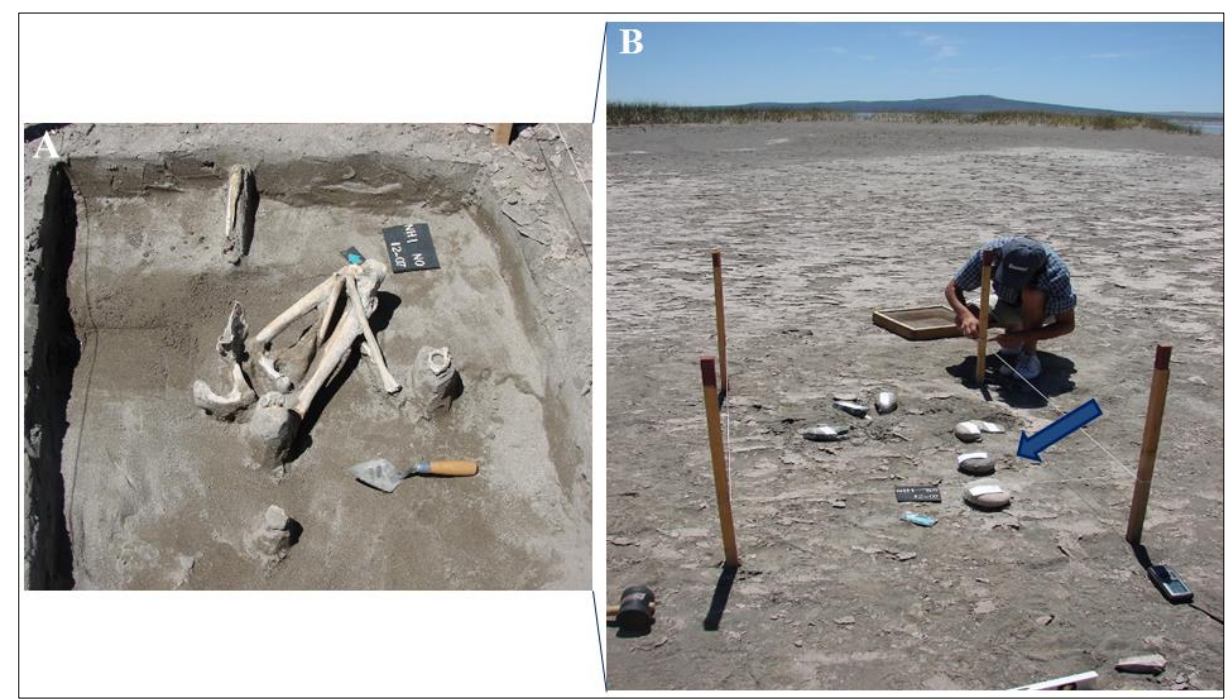

Figura 8.28. Uno de los entierros humanos (Arbolito 6: $16 \mathrm{NH}-1$ ) recuperado durante un rescate en conjunto con los médicos forenses del Hospital Schestacow y la policía de Mendoza. A) Detalle de los restos humanos; B) Contexto lítico recuperado por encima del entierro (señalado por la flecha).

Sobre esta base, se estimaron las tasas de depositación de las cuatro cuadrículas. En AR-6 (A1) sería de 0,04 artefactos líticos por año; en BDP-1 de 0,03 /año; en AR-6 (A2) de 0,008 /año; y en AR-7, la más baja, se estimó en 0,006 /año.

\begin{tabular}{|c|c|c|c|c|c|c|c|}
\hline Sitio & Unidad & Muestra & Código & ${ }^{14} \mathbf{C}$ & Min. & Media & Max. \\
\hline Arbolito 6 & AF-1083 & Hueso humano & AA-58284 & $97 \pm 36$ & 25 & 97 & 169 \\
\hline Arbolito 6 & $16(\mathrm{NH}-1)$ & Hueso humano & AA-85705 & $686 \pm 43$ & 600 & 686 & 772 \\
\hline $\begin{array}{c}\text { Arbolito, El } \\
\text { Nihuil }\end{array}$ & $\begin{array}{c}\text { ACRF } \\
2158\end{array}$ & Hueso humano & AA-93796 & $1621 \pm 45$ & 1531 & 1621 & 1711 \\
\hline El Nihuil & MRM-21 & Hueso humano & AA-62938 & $274 \pm 45$ & 184 & 274 & 364 \\
\hline El Nihuil & 2165 & Hueso humano & AA-90969 & $254 \pm 37$ & 180 & 254 & 328 \\
\hline
\end{tabular}

Tabla 8.10. Fechados radiocarbónicos realizados sobre huesos humanos procedentes de la localidad arqueológica Arbolito. Modificado de Gil et al. 2011 a y 2014. 


\subsubsection{Registro arqueológico de la localidad arqueológica Arbolito}

En los trabajos previos, Lagiglia (1977a) presentó información del material superficial recuperado en los sitios Arbolito (1 a 10), pero no había recolectado materiales arqueológicos del sitio BDP-1.

El registro arqueológico en AR-6 y AR-7 es escaso: los pocos restos vegetales no son de origen antrópico. Numerosas raíces en estado de descomposición sugieren alteraciones en la disposición de los sedimentos. Además de la información temporal brindada por los huesos humanos, los resultados del análisis de isotopos de $\mathrm{O}^{18}$ de los mismos sugieren que las poblaciones que habitaron estos espacios sostenían una gran movilidad (Gil et al. 2011a).

Los registros arqueológicos más claros corresponden a los materiales líticos y cerámicos, los más persistentes y resistentes a las condiciones lacustres de esta localidad arqueológica, aunque dichos restos tampoco son abundantes. Tampoco lo son los pigmentos, conchas marinas del pacífico y otros ítems no locales. Lagiglia (1977a), ha sostenido que la cerámica de este lugar está caracterizada por los tipos Arbolito y Nihuil, pero con una fuerte presencia de grupos tipológicos no locales. Sanhueza et al. (2004), al caracterizar las pastas de la cerámica de AR-6, sostienen la existencia de una variabilidad mucho mayor que la de los otros sitios analizados dentro de la región.

En su trabajo de tesis doctoral, Sugrañes (2017) analizó la tecnología cerámica procedente de los sitios AR-1 y AR-6; el primero a partir de material superficial y el segundo con materiales de excavación y superficial. La autora observó que el tamaño predominante de los fragmentos cerámicos es el mediano, mientras que la fractura es preferentemente irregular. Esto indicaría que, a pesar de ser un ambiente de médano, los fragmentos no se encuentran muy afectados por la acción de la intemperización y/o del agua. Por otro lado, señala que las huellas de uso identificadas en los fragmentos cerámicos (especialmente la presencia de hollín y residuos orgánicos) muestran diferencias importantes entre ambas caras. Una alta proporción de los fragmentos evidencia una fuerte exposición al fuego, seguramente para la cocción de alimentos (Sugrañes 2017). Observa también una baja inversión en la manufactura cerámica debido a que, en el tratamiento de superficie, predomina el alisado y, en muy bajas proporciones, el pulido y el cepillado, y en general, señala que las vasijas han sido manufacturadas de manera muy variada, pero que son homogéneas en cuanto a su exterior. Los fragmentos decorados son escasos y en la mayoría, implica la modificación de la superficie a través de algún instrumento o agregado (inciso, grabado, protúberos). Las formas presentes 
consisten en ollas restringidas y no restringidas, con cuerpos globulares y bases redondeadas, aunque se definieron bases diferenciadas. Así, las tipologías predominantes en AR-1 y AR-6 son los tipos Arbolito y Nihuil (Sugrañes 2017).

\subsubsection{Registro lítico de los sitios AR-6 y AR-7}

El registro lítico de las cuadrículas AR-6 A1, AR-6 A2 y AR-7 es bastante escaso. Debido a esto, se decidió presentar el análisis de las tres en conjunto.

En la cuadrícula A1 del sitio AR-6 se registró un total de 117 artefactos líticos, de los cuales 56 son desechos de talla de tamaño igual o menor a 5 x $5 \mathrm{~mm}$ (i.e. " $\leq 5 \mathrm{~mm}$ " en la Tabla 8.11). Así, el total es de 61 artefactos analizados. Igualmente, la clase de los desechos de talla ("> $>5 \mathrm{~mm}$ " en la Tabla 8.11 ), sigue siendo la predominante, constituyendo el $81,97 \%(\mathrm{n}=50)$. Completan el total de clases artefactuales, dos instrumentos unifaciales $(3,28 \%)$ y uno bifacial (1,64\%), tres ASF RC (4,92\%), tres ecofactos $(4,92 \%)$, un núcleo $(1,64 \%)$ y un nódulo (1,64\%) (Tablas 8.11 y 8.12).

\begin{tabular}{|c|c|c|c|c|c|c|c|c|c|}
\hline \multirow{2}{*}{ Niveles } & \multicolumn{2}{|c|}{ Desechos de talla } & \multicolumn{2}{|c|}{$\mathbf{A F}$} & \multirow{2}{*}{$\begin{array}{c}\text { ASF } \\
\text { RC }\end{array}$} & \multirow{2}{*}{$\mathbf{N U}$} & \multirow{2}{*}{ Ecofacto } & \multirow{2}{*}{ Nód. } & \multirow{2}{*}{ Total } \\
\hline & $(>5 \mathrm{~mm})$ & $(\leq 5 \mathrm{~mm})$ & Bifacial & Unifacial & & & & & \\
\hline ( (Superficial N) & 5 & 1 & 1 & 1 & 1 & 1 & - & - & 10 \\
\hline o (Superficial S) & 3 & 1 & - & 1 & - & - & - & - & 5 \\
\hline 1 Norte & 24 & 26 & - & - & 1 & - & 3 & - & 54 \\
\hline $1 \mathrm{Sur}$ & 13 & 20 & - & - & 1 & - & - & 1 & 35 \\
\hline 2 Norte & 3 & 4 & - & - & - & - & - & - & 7 \\
\hline 2 Sur & 1 & 2 & - & - & - & - & - & - & 3 \\
\hline 3 (sondeo) & - & 1 & - & - & - & - & - & - & 1 \\
\hline 4 (sondeo) & 1 & 1 & - & - & - & - & - & - & 2 \\
\hline Total & 50 & 56 & 1 & 2 & 3 & 1 & 3 & 1 & 117 \\
\hline Total \% & 42,74 & 47,86 & $\mathbf{0 , 8 5}$ & 1,71 & 2,57 & $\mathbf{0 , 8 5}$ & 2,57 & 0,85 & 100 \\
\hline
\end{tabular}

Tabla 8.11. Clases artefactuales por nivel y sector de excavación de la cuadrícula A1 del sitio AR-6. Referencias: AF: Artefacto formatizado; ASF RC: artefacto sin formatización con rastros complementarios; NU: núcleo; Nód: nódulo.

\begin{tabular}{|c|c|c|c|c|c|c|c|c|}
\hline $\begin{array}{c}\text { Clases } \\
\text { artefactuales }\end{array}$ & $\begin{array}{c}\text { Desechos } \\
\text { de talla }\end{array}$ & $\begin{array}{c}\text { AF } \\
\text { Bifacial }\end{array}$ & $\begin{array}{c}\text { AF } \\
\text { Unifacial }\end{array}$ & $\begin{array}{c}\text { ASF } \\
\text { RC }\end{array}$ & Ecofacto & NU & Nód. & Total \\
\hline Total & 50 & 1 & 2 & 3 & 3 & 1 & 1 & 61 \\
\hline Total \% & 81,97 & 1,64 & 3,28 & 4,92 & 4,92 & 1,64 & 1,64 & 100 \\
\hline
\end{tabular}

Tabla 8.12.Frecuencias absoluta y relativa de clases artefactuales en AR-6 (A1). La categoría "desechos de talla" incluye sólo aquellos de tamaño mayor a $5 \mathrm{~mm}$ de lado. 
De las materias primas líticas registradas en la cuadrícula A1 de AR-6, las más frecuentes son las rocas silíceas $(47,54 \%)$, seguidas por la obsidiana $(37,70 \%)$, la riolita en tercer lugar $(9,84 \%) \mathrm{y}$, por último, el basalto $(4,92 \%)$ (Tabla 8.13$)$.

\begin{tabular}{|l|c|c|c|c|c|}
\hline Niveles & BAS & OBS & RIO & SIL & Total \\
\hline $\mathbf{0}$ & - & $7(53,8 \%)$ & $1(7,7 \%)$ & $5(38,5 \%)$ & $\mathbf{1 3}$ \\
\hline $\mathbf{1}$ & $2(4,7 \%)$ & $15(34,9 \%)$ & $5(11,6 \%)$ & $21(48,8 \%)$ & $\mathbf{4 3}$ \\
\hline $\mathbf{2}$ & $1(25,0 \%)$ & $1(25,0 \%)$ & - & $2(50,0 \%)$ & $\mathbf{4}$ \\
\hline $\mathbf{4}$ & - & - & - & $1(100 \%)$ & $\mathbf{1}$ \\
\hline Total & $\mathbf{3 ( 4 , 9 2 \% )}$ & $\mathbf{2 3 ( 3 7 , 7 0 \% )}$ & $\mathbf{6 ( 9 , 8 4 \% )}$ & $\mathbf{2 9}(\mathbf{4 7 , 5 4 \% )}$ & $\mathbf{6 1}$ \\
\hline
\end{tabular}

Tabla 8.13. Distribución y frecuencia de materias primas por nivel y sector de excavación en AR-6 (A1). El nivel 3 no está representado debido a que los únicos artefactos presentes en este nivel son los desechos de talla de tamaño $\leq 5 \mathrm{~mm}$ de lado. Referencias: BAS: basalto; OBS:

obsidiana; RIO: riolita; SIL: rocas silíceas.

Por su parte, en la cuadrícula A2 se registró un total de 40 artefactos, 29 de los cuales son desechos de talla de 5 x $5 \mathrm{~mm}$ (i.e. “ $\leq 5 \mathrm{~mm}$ " en la Tabla 8.14), por lo que sólo se analizaron 11 artefactos: ocho $(72,73 \%)$ son desechos de talla ("> $>$ mm"); y tres $(27,27 \%)$ instrumentos bifaciales (Tabla 8.15), dos recuperados en la recolección superficial asistemática ("Recolecc. Sup." en la Tabla 8.14), realizada al margen de la cuadrícula A2 de AR-6, previamente a que esta fuera excavada.

\begin{tabular}{|l|c|c|c|c|}
\hline \multirow{2}{*}{ Niveles } & \multicolumn{2}{|c|}{ Desechos de talla } & \multirow{2}{*}{$\begin{array}{c}\text { AF } \\
\text { Bifacial }\end{array}$} & Total \\
\cline { 2 - 3 } & $(>\mathbf{5 m m})$ & $\mathbf{( \leq \mathbf { 5 m m } )}$ & 2 & $\mathbf{2}$ \\
\hline Recolecc. Sup. & - & - & - & $\mathbf{1}$ \\
\hline 0 (Superficial N) & 1 & - & - & $\mathbf{1}$ \\
\hline 0 (Superficial S) & 1 & - & 1 & $\mathbf{2 0}$ \\
\hline 1 Norte & 4 & 15 & - & $\mathbf{7}$ \\
\hline 1 Sur & 2 & 5 & - & $\mathbf{5}$ \\
\hline 2 Norte & - & 5 & - & $\mathbf{3}$ \\
\hline 2 Sur & - & 3 & - & 1 \\
\hline 3 Sur (sondeo) & - & 1 & $\mathbf{3}$ & $\mathbf{4 0}$ \\
\hline \multicolumn{1}{|c|}{ Total } & $\mathbf{8}$ & $\mathbf{2 9}$ & $\mathbf{7 , 5 0}$ & $\mathbf{1 0 0}$ \\
\hline \multicolumn{1}{|c|}{ Total \% } & $\mathbf{2 0 , 0 0}$ & $\mathbf{7 2 , 5 0}$ & & \\
\hline
\end{tabular}

Tabla 8.14. Clases artefactuales por nivel y sector de excavación de la cuadrícula A2 del sitio AR-6. Referencias: Recolecc. Sup.: Recolección superficial; AF: Artefacto formatizado. 


\begin{tabular}{|c|c|c|c|}
\hline $\begin{array}{c}\text { Clases } \\
\text { artefactuales }\end{array}$ & $\begin{array}{c}\text { Desechos } \\
\text { de talla }\end{array}$ & $\begin{array}{c}\text { AF } \\
\text { Bifacial }\end{array}$ & Total \\
\hline Total & 8 & 3 & 11 \\
\hline Total \% & 72,73 & 27,27 & 100 \\
\hline
\end{tabular}

Tabla 8. 15. Frecuencias absoluta y relativa de las dos clases artefactuales presentes en la cuadrícula A2 del sitio AR-6. La categoría "desechos de talla" incluye sólo aquellos de tamaño mayor a $5 \mathrm{~mm}$ de lado.

De las materias primas líticas presentes en la cuadrícula A2, la obsidiana $(n=5)$ y las rocas silíceas $(n=5)$ tienen la misma representación: 45,45\% en cada caso. La tercera materia prima está representada por un artefacto de riolita $(9,10 \%)$ (Tabla 8.16). A diferencia de la cuadrícula A1, no se ha registrado basalto (Tabla 8.16).

\begin{tabular}{|l|c|c|c|c|}
\hline Niveles & OBS & RIO & SIL & Total \\
\hline Recolecc. Sup. & $2(100 \%)$ & - & - & $\mathbf{2}$ \\
\hline $\mathbf{0}$ & $1(50,0 \%)$ & - & $1(50,0 \%)$ & $\mathbf{2}$ \\
\hline $\mathbf{1}$ & $2(28,6 \%)$ & $1(14,3 \%)$ & $4(57,1 \%)$ & 7 \\
\hline Total & $\mathbf{5 ( 4 5 , 4 5 \% )}$ & $\mathbf{1 ( 9 , 1 0 \% )}$ & $\mathbf{5 ( 4 5 , 4 5 \% )}$ & $\mathbf{1 1}$ \\
\hline
\end{tabular}

Tabla 8.16. Distribución y frecuencia de materias primas por nivel y sector de excavación en AR-6 (A2). Los niveles 2 y 3 no están representados ya que los únicos artefactos presentes en ambos niveles son los desechos de talla de tamaño $\leq 5 \mathrm{~mm}$ de lado. Referencias: Recolecc. Sup.:

Recolección superficial; OBS: obsidiana; RIO: riolita; SIL: rocas siliceas.

En el sitio AR-7 sólo se registraron 12 artefactos líticos; un tercio de estos corresponde a desechos de talla de tamaño igual o menor a 5 x $5 \mathrm{~mm}$ (“ $\leq 5 \mathrm{~mm}$ " en la Tabla 8.17), por lo tanto, el total analizado descendió a 8 artefactos. De estos, la mitad $(50 \%, \mathrm{n}=4)$ está conformada por desechos de talla (" $>5 \mathrm{~mm}$ " en la Tabla 8.17$)$, dos $(25 \%)$ corresponden a instrumentos unifaciales y los otros dos a nódulos de cuarzo (25\%) (Tablas 8.17 y 8.18 ).

\begin{tabular}{|l|c|c|c|c|c|}
\hline \multirow{2}{*}{ Niveles } & \multicolumn{2}{|c|}{ Desechos de talla } & AF & \multirow{2}{*}{ Nódulo } & \multirow{2}{*}{ Total } \\
\cline { 2 - 4 } & $\mathbf{( > \mathbf { 5 m m } )}$ & $\mathbf{( \leq \mathbf { 5 m m } )}$ & Unifacial & & \\
\hline 0 (Superficial NE) & 1 & - & - & 1 & $\mathbf{2}$ \\
\hline 0 (Superficial SW) & - & - & 2 & - & $\mathbf{2}$ \\
\hline 1 Noreste & 2 & 3 & - & - & $\mathbf{5}$ \\
\hline 1 Suroeste & 1 & 1 & - & 1 & $\mathbf{3}$
\end{tabular}




\begin{tabular}{|c|c|c|c|c|c|}
\hline Total & 4 & 4 & 2 & 2 & 12 \\
\hline Total \% & 33,33 & 33,33 & 16,67 & 16,67 & 100 \\
\hline
\end{tabular}

Tabla 8.17. Clases artefactuales por nivel y sector de excavación del sitio AR-7. Referencias: AF: Artefacto formatizado.

\begin{tabular}{|c|c|c|c|c|}
\hline $\begin{array}{c}\text { Clases } \\
\text { artefactuales }\end{array}$ & $\begin{array}{c}\text { Desechos } \\
\text { de talla }\end{array}$ & $\begin{array}{c}\text { AF } \\
\text { Unifacial }\end{array}$ & Nódulo & Total \\
\hline Total & 4 & 2 & 2 & 8 \\
\hline Total \% & 50,00 & 25,00 & 25,00 & 100 \\
\hline
\end{tabular}

Tabla 8.18. Frecuencias absoluta y relativa de clases artefactuales en AR-7. La categoría "desechos de talla" incluye sólo aquellos de tamaño mayor a 5 x $5 \mathrm{~mm}$.

Se registraron tres materias primas en AR-7: rocas silíceas $(62,5 \%)$, cuarzo $(25 \%)$ y riolita (12,5\%); como se mencionó arriba, los dos artefactos de cuarzo corresponden a nódulos naturales. Aquí tampoco se han registrado artefactos en basalto y, si bien la fuente de obsidiana El Peceño está dentro del rango local, no hay evidencias de su presencia en el sitio (Tabla 8.19).

\begin{tabular}{|l|c|c|c|c|}
\hline Niveles & RIO & QZ & SIL & Total \\
\hline $\mathbf{0}$ & - & $1(25,0 \%)$ & $3(75,0 \%)$ & $\mathbf{4}$ \\
\hline $\mathbf{1}$ & $1(25,0 \%)$ & $1(25,0 \%)$ & $2(50,0 \%)$ & $\mathbf{4}$ \\
\hline Total & $\mathbf{1}(\mathbf{1 2 , 5 \% )}$ & $\mathbf{2 ( 2 5 , 0 \% )}$ & $\mathbf{5 ( 6 2 , 5 \% )}$ & $\mathbf{8}$ \\
\hline
\end{tabular}

Tabla 8.19. Distribución y frecuencia de materias primas por nivel y sector de excavación en AR-7. Referencias: RIO: riolita; QZ: cuarzo; SIL: rocas siliceas.

\subsubsection{Registro lítico del sitio BDP-1}

En BDP-1, de los 69 artefactos líticos recuperados, 20 corresponden a desechos de talla de tamaño 5 x $5 \mathrm{~mm}$ o menor (i.e. “ $\leq 5 \mathrm{~mm}$ ” en la Tabla 8.20 ), por lo que se analizaron 49 artefactos. Los desechos de talla ("> $>5 \mathrm{~mm}$ " en la Tabla 8.20) son la clase predominante, constituyendo el 77,55\% $(\mathrm{n}=38)$ en BDP-1. Asimismo, se registraron cuatro artefactos manufacturados o modificados por abrasión, picado y/o pulido $(8,16 \%)$, un artefacto formatizado bifacialmente, otro unifacialmente y un instrumento compuesto $(2,04 \%$, cada uno); además de tres ASF RC (6,12\%) y un núcleo (2,04\%) (Tablas 8.20 y $8.21)$. 


\begin{tabular}{|c|c|c|c|c|c|c|c|c|c|}
\hline \multirow[b]{2}{*}{ Niveles } & \multicolumn{2}{|c|}{ Desechos de talla } & \multicolumn{3}{|c|}{$\mathbf{A F}$} & \multirow{2}{*}{$\begin{array}{c}\text { Art. m. } \\
\text { por } \\
\text { A,P,P }\end{array}$} & \multirow[b]{2}{*}{ ASF RC } & \multirow[b]{2}{*}{$\mathbf{N U}$} & \multirow[b]{2}{*}{ Total } \\
\hline & $(>5 \mathrm{~mm})$ & $\begin{array}{c}(\leq \\
5 \mathrm{~mm})\end{array}$ & Bifac. & Unifac. & Comp. & & & & \\
\hline Recolecc. Sup. & - & - & 1 & 1 & - & - & - & 1 & 3 \\
\hline Sup. Este & 3 & - & - & - & 1 & - & 1 & - & 5 \\
\hline Sup. Oeste & 7 & - & - & - & - & 3 & 1 & - & 11 \\
\hline 1 Este & 11 & 13 & - & - & - & 1 & 1 & - & 26 \\
\hline 1 Oeste & 7 & 2 & - & - & - & - & - & - & 9 \\
\hline 2 Este & 7 & - & - & - & - & - & - & - & 7 \\
\hline 2 Oeste & 3 & 3 & - & - & - & - & - & - & 6 \\
\hline $\begin{array}{l}\text { Este } \\
\text { (sondeo) }\end{array}$ & - & 2 & - & - & - & - & - & - & 2 \\
\hline Total & 38 & 20 & 1 & 1 & 1 & 4 & 3 & 1 & 69 \\
\hline Total \% & 55,07 & 28,99 & 1,45 & 1,45 & 1,45 & 5,80 & 4,35 & 1,45 & 100 \\
\hline
\end{tabular}

Tabla 8.20. Clases artefactuales por nivel y sector de excavación del sitio BDP-1. Referencias:

Recolecc. Sup.: Recolección superficial; AF: Artefacto formatizado; Art. m. por A, P, P: artefacto manufacturado o modificado por abrasión, picado y/o pulido; ASF RC: artefacto sin formatización con rastros complementarios; $N U$ : núcleo.

\begin{tabular}{|c|c|c|c|c|c|c|c|c|}
\hline $\begin{array}{c}\text { Clases } \\
\text { artefactuales }\end{array}$ & $\begin{array}{c}\text { Desechos } \\
\text { de talla }\end{array}$ & $\begin{array}{c}\text { AF } \\
\text { Bifacial }\end{array}$ & $\begin{array}{c}\text { AF } \\
\text { Unifacial }\end{array}$ & $\begin{array}{c}\text { AF } \\
\text { Compuesto }\end{array}$ & $\begin{array}{c}\text { Art. m. } \\
\text { por } \\
\text { A,P,P }\end{array}$ & $\begin{array}{c}\text { ASF } \\
\text { RC }\end{array}$ & NU & Total \\
\hline Total & $\mathbf{3 8}$ & $\mathbf{1}$ & 1 & 1 & 4 & 3 & 1 & 49 \\
\hline Total \% & $\mathbf{7 7 , 5 5}$ & $\mathbf{2 , 0 4}$ & $\mathbf{2 , 0 4}$ & $\mathbf{2 , 0 4}$ & $\mathbf{8 , 1 6}$ & $\mathbf{6 , 1 2}$ & $\mathbf{2 , 0 4}$ & $\mathbf{1 0 0}$ \\
\hline
\end{tabular}

Tabla 8.21. Frecuencias absoluta y relativa de clases artefactuales en BDP-1. La categoría "desechos de talla" incluye sólo aquellos de tamaño mayor a $5 \mathrm{~mm}$ de lado.

Entre las materias primas presentes en BDP-1, las rocas silíceas $(n=16)$ y las riolitas $(n=16)$ son las más frecuentes, representando el 32,65\% cada una. Le siguen la obsidiana $(20,41 \%, n=10)$, el basalto $(10,2 \%, n=5)$ y la vulcanita indeterminada $(4,08 \%$, $\mathrm{n}=2$ ). La frecuencia de esta última es muy baja pero no se ha registrado en las otras tres cuadrículas excavadas de la localidad Arbolito. Además, aquí también la riolita es más abundante no sólo que el basalto, sino también que la obsidiana, considerada la roca de mejor calidad para la talla y de disponibilidad local en esta localidad arqueológica (la fuente de obsidiana El Peceño se encuentra a 20km al sur de BDP-1) (Tabla 8.22). 


\begin{tabular}{|l|c|c|c|c|c|c|}
\hline Niveles & BAS & OBS & RIO & SIL & VUL & Total \\
\hline Recolecc. Sup. & - & $1(33,3 \%)$ & - & $2(66,7 \%)$ & - & $\mathbf{3}$ \\
\hline $\mathbf{0}$ & $3(18,7 \%)$ & $3(18,7 \%)$ & $4(25,0 \%)$ & $5(31,3 \%)$ & $1(6,3 \%)$ & $\mathbf{1 6}$ \\
\hline $\mathbf{1}$ & $2(10,0 \%)$ & $5(25,0 \%)$ & $7(35,0 \%)$ & $5(25,0 \%)$ & $1(5,0 \%)$ & $\mathbf{2 0}$ \\
\hline $\mathbf{2}$ & - & $1(10,0 \%)$ & $5(50,0 \%)$ & $4(40,0 \%)$ & - & $\mathbf{1 0}$ \\
\hline \multicolumn{1}{|c|}{ Total } & $\mathbf{5 ( 1 0 , 2 0 \% )}$ & $\mathbf{1 0}(\mathbf{2 0 , 4 1 \% )}$ & $\mathbf{1 6 ( 3 2 , 6 5 \% )}$ & $\mathbf{1 6 ( 3 2 , 6 5 \% )}$ & $\mathbf{2 ( 4 , 0 8 \% )}$ & $\mathbf{4 9}$ \\
\hline
\end{tabular}

Tabla 8.22. Distribución y frecuencia de materias primas por nivel y sector de excavación en BDP-1. El nivel 3 no está representado debido a que los únicos artefactos presentes en él son los desechos de talla de tamaño $\leq 5 \mathrm{~mm}$ de lado. Referencias: Recolecc. Sup.: Recolección superficial; BAS: basalto; OBS: obsidiana; RIO: riolita; SIL: rocas siliceas; VUL: vulcanita indeterminada.

\subsubsection{Registro lítico de la localidad Arbolito: sitios AR-6, AR-7 y BDP-1}

En la Figura 8.29 se presentan las frecuencias relativas de los conjuntos líticos recuperados de las cuatro cuadrículas excavadas en la localidad Arbolito. Se observa que, luego del registro del nivel superficial, la mayor frecuencia de artefactos se da en el Nivel 1 de cada cuadrícula y, luego, a pocos centímetros de excavación, tales frecuencias disminuyen abruptamente.

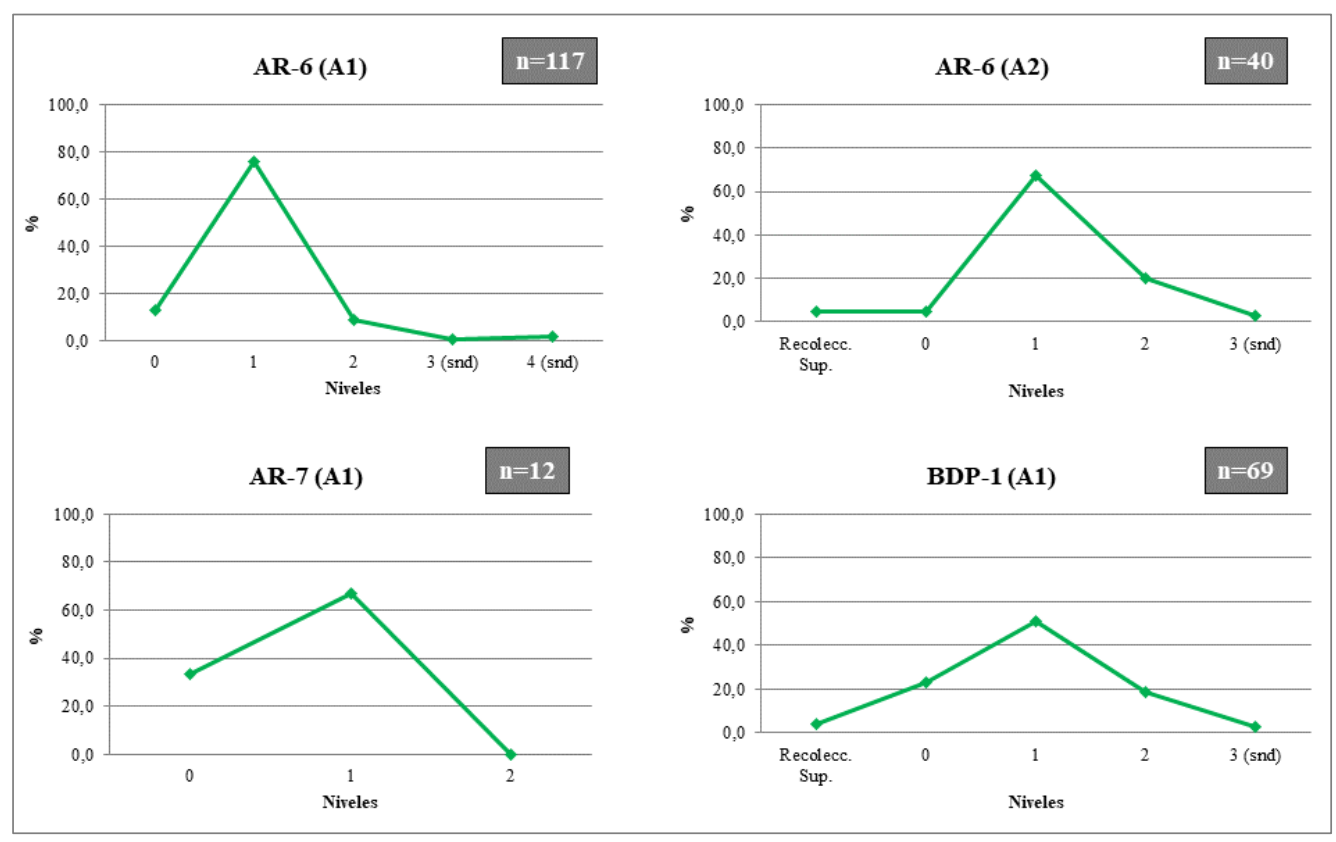

Figura 8.29. Frecuencias relativas de artefactos líticos por niveles de extracción en los sitios

AR-6 (cuadrículas A1 y A2), AR-7 y BDP-1. Referencias: Recolecc. Sup.: recolección superficial; 0: nivel de extracción superficial; Snd: sondeo; $N$ : total de artefactos por sitio. 
En la Figura 8.30 y en la 8.31 se presentan los instrumentos y ASF RC, y las materias primas, respectivamente, presentes en las dos cuadrículas de AR-6, en AR-7 y BDP-1.

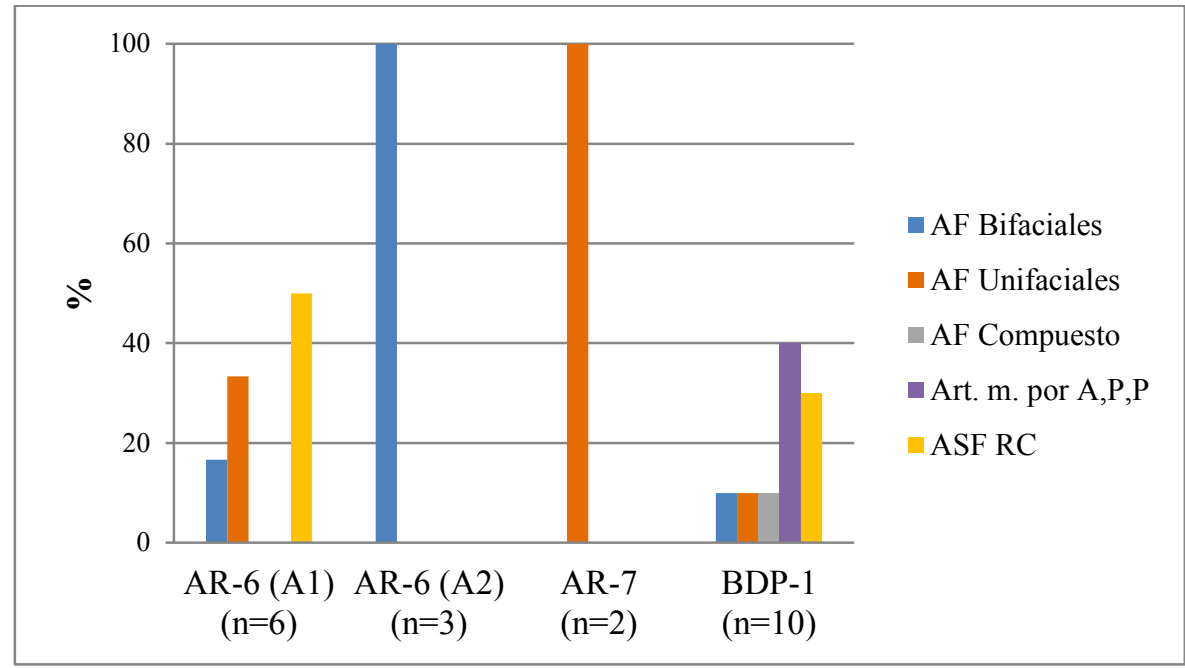

Figura 8.30. Frecuencias relativas de instrumentos y ASF RC en la localidad arqueológica Arbolito, registrados por sitio. El $n$ entre paréntesis señala el total de ambas categorías por sitio.

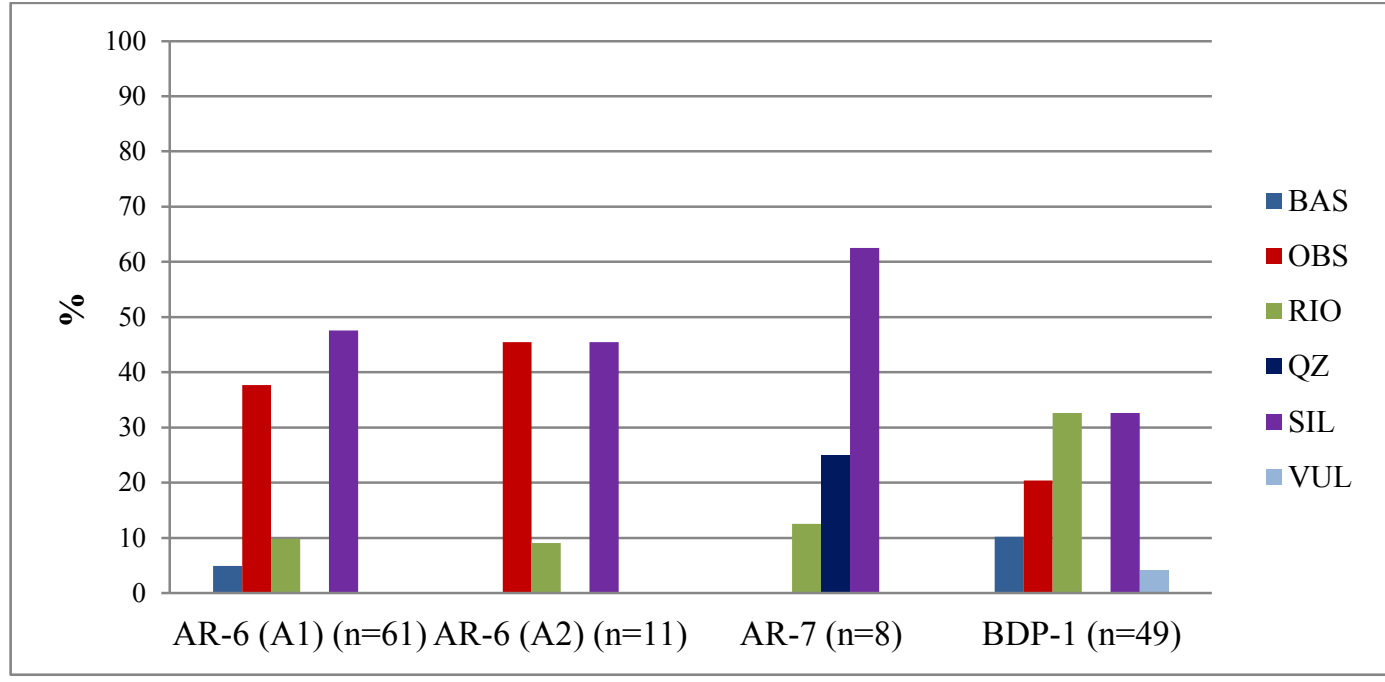

Figura 8.31. Frecuencias relativas de todas las materias primas presentes en la localidad arqueológica Arbolito registradas por sitio. El $n$ entre paréntesis señala el total de artefactos.

En ambos gráficos se observa que los sitios que poseen más materiales arqueológicos (AR-6 A1 y BDP-1), presentan mayor cantidad y variedad de clases artefactuales y de materias primas. La Figura 8.32, muestra que la diversidad de clases instrumentales no necesariamente está vinculada únicamente al tamaño de la muestra $\left(r^{2}=0,4845\right)$. Esto lo sugiere BDP-1 que, si bien tiene un tamaño de muestra menor que 
AR-6 (A1), posee mayor variedad de tipos de instrumentos. No se han considerado los ASF RC, registrados sólo en estos dos sitios (véase Figura 8.30).

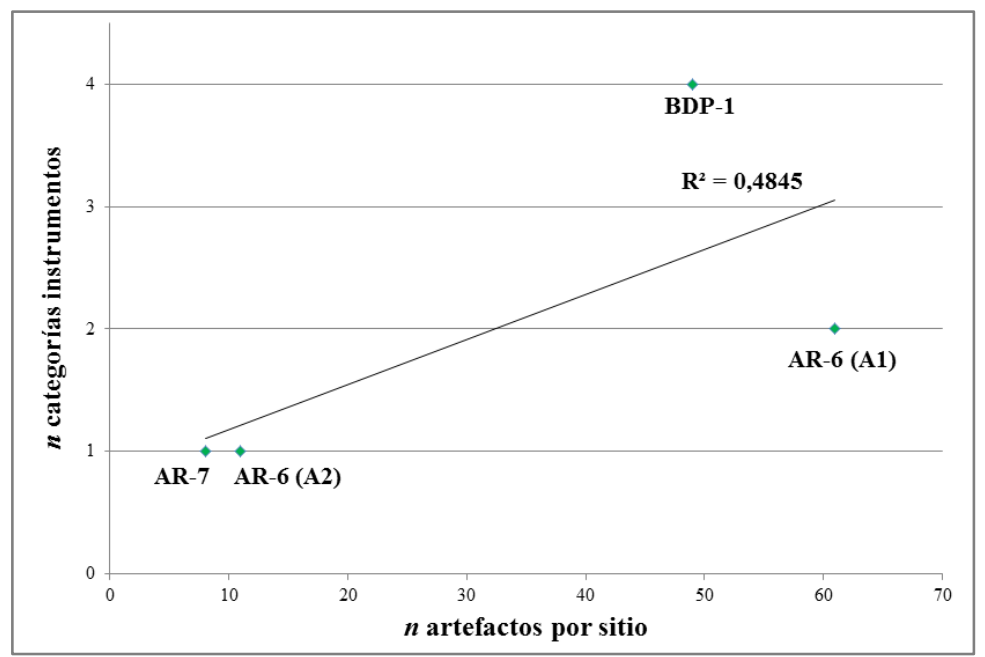

Figura 8.32. Tamaño de muestra vs. cantidad de categorías instrumentales en CSA-1.

En la Figura 8.33 se observa que el tamaño de muestra de cada sitio influye algo más -que en el caso anterior- sobre la diversidad de materias primas representadas, ya que el coeficiente de determinación es mayor $\left(\mathrm{r}^{2}=0,6564\right) \mathrm{y}$, por ende, está algo más sesgado por el tamaño de muestra.

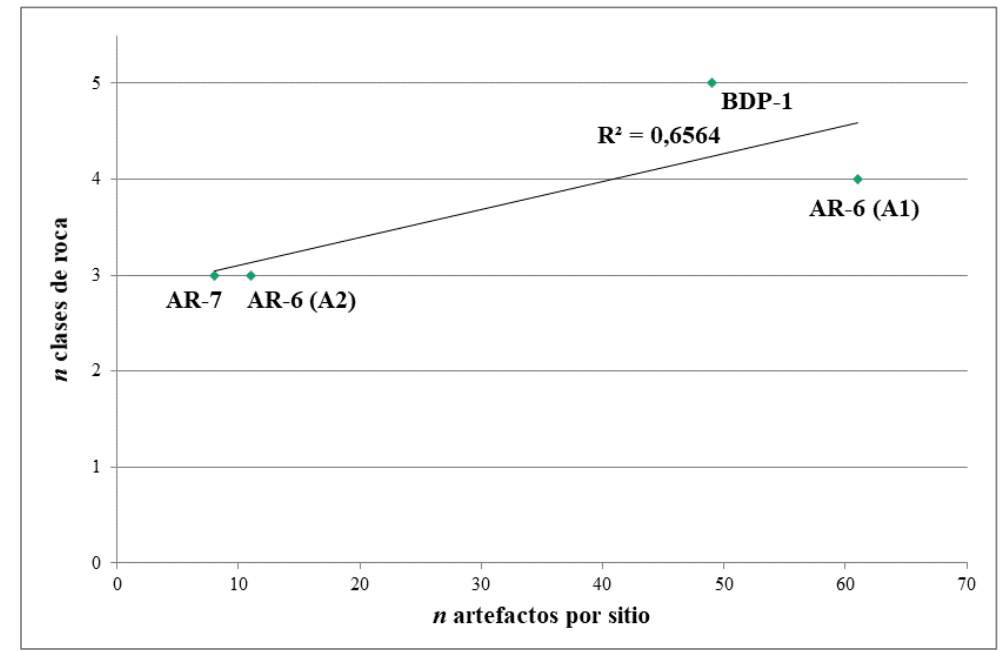

Figura 8.33. Tamaño de muestra $v s$. cantidad de clases de roca de cada sitio.

\subsection{Núcleos}

En Arbolito fueron recuperados dos núcleos de morfología poliédrica, ambos enteros, que representan el $1,55 \%$ del total de artefactos líticos de la localidad. Uno 
procede de la cuadrícula A1 del sitio AR-6 y es de roca silícea (Figura 8.34.A); el otro de BDP-1 y es de obsidiana (Figura 8.34.B). Ambos son amorfos, de forma-base nodular y de calidad muy buena; en ambos la mitad de su superficie está cubierta por corteza y ninguno está agotado. El núcleo de roca silícea es mediano-pequeño (módulo: 3), muy espeso (módulo AM/EM: 2,0), con un volumen de 6,27 $\mathrm{mm}^{3}(16 \times 28 \times 14)$ y pesa 9,2 gramos. Por su parte, el núcleo de obsidiana es mediano-grande (módulo: 4), muy espeso (módulo AM/EM: 1,4), con un volumen de $27600 \mathrm{~mm}^{3}(23,5 \times 40,5 \times 29)$ y un peso de 42,3 gramos. El primero presenta un total de cuatro negativos de extracción con boca de lascado; el de obsidiana, dos. El tamaño mínimo de dichas extracciones en el de roca silícea es de longitud muy pequeño (módulo: 1) a pequeño (modulo: 2); en el segundo, una de las extracciones es de tamaño muy pequeño y la otra de tamaño mediano-pequeño (módulo: 3). Además, en ambos casos se registraron negativos de lascado normales (módulo: E) y anchos (módulo: F).

Las evidencias sugieren que ambos núcleos fueron utilizados para la extracción de lascas de módulo corto y normal-ancho (i.e. más anchas que largas), lo cual es coherente con el empleo de formas-base pequeñas y mediano-pequeñas para la confección de los artefactos formatizados (véase, por ejemplo, Figura 8.38), presentes en los sitios sobre ambas materias primas. La distancia de BDP-1 a la fuente de obsidiana El Peceño es de $20 \mathrm{~km}$, por lo que se asume que el núcleo registrado en dicho sitio es de procedencia local.
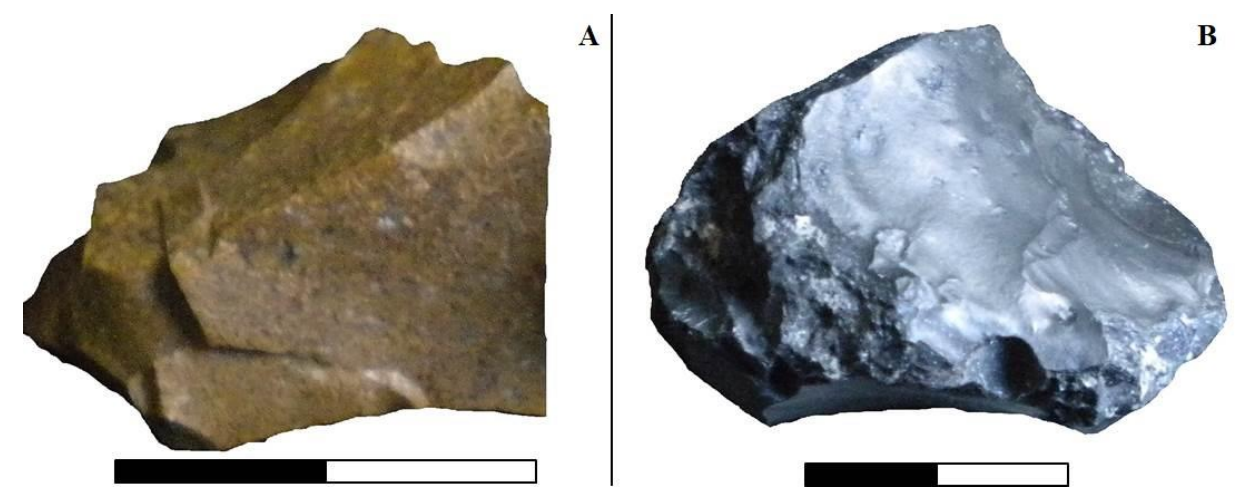

Figura 8.34. Núcleo sobre roca silícea del sitio AR-6 (A1) y núcleo de obsidiana del sitio BDP-1.

\subsection{Desechos de talla}

Los desechos de talla $(\mathrm{n}=100)$ constituyen la clase artefactual más representada en la localidad Arbolito (AR-6 -A1 y A2-, AR-7 y BDP-1) 1. En la Tabla 8.23 se presenta el NAS (número de especímenes artefactuales) de cada sitio, el cual representa la totalidad 
de artefactos líticos. Se observa que todas las materias primas registradas en estos sitios, excepto el cuarzo procedente de AR-7 (dos nódulos de esta roca), están representadas como desechos de talla. Las rocas silíceas son las más frecuentes $(45,0 \%, n=45)$, seguidas por la obsidiana $(28,0 \%)$, la riolita $(23,0 \%)$, el basalto $(2 \%)$ y la vulcanita indeterminada $(2,0 \%)$. El $80 \%$ corresponde a desechos de talla fracturados, siendo mayor la fragmentación en AR-7 donde los cuatro desechos están fracturados, seguido por la cuadrícula A2 de AR-6 con el 87,5\% ( $\mathrm{n}=7$ de 8 desechos de talla), BDP-1 (81,6\%, $\mathrm{n}=31$ de 38) y, por último, la cuadrícula A1 de AR-6 donde se da el menor porcentaje de fragmentación $(76 \%, \mathrm{n}=38$ de 50$)$ (Tabla 8.23). No se registraron lascas enteras de basalto, cuarzo ni vulcanita indeterminada. Debido a este alto grado de fragmentación se decidió calcular el número mínimo de lascas a través del índice de MNF (véase fórmula $\mathrm{C}+\mathrm{T}+\mathrm{L}$ en el Capítulo 5 -Metodología) para evitar la sobreestimación de la muestra. El porcentaje del MNF (Tabla 8.23) representa cuán confiable es la representación de las lascas por materia prima.

\begin{tabular}{|c|c|c|c|c|c|c|c|}
\hline Sitio & MP & NAS & DT enteros & DT fract. & NFS & \multicolumn{2}{|c|}{ MNF (n y \%) } \\
\hline \multirow{4}{*}{ AR-6 (A1) } & BAS & 3 & - & 1 & 1 & - & - \\
\hline & OBS & 23 & 2 & 16 & 18 & 12 & 66,67 \\
\hline & RIO & 6 & 3 & 2 & 5 & 3 & 60,00 \\
\hline & SIL & 29 & 7 & 19 & 26 & 16 & 61,54 \\
\hline \multicolumn{2}{|c|}{ Total } & 61 & $12(24 \%)$ & $38(76 \%)$ & 50 & 31 & 62,00 \\
\hline \multirow{3}{*}{ AR-6 (A2) } & OBS & 5 & - & 2 & 2 & 1 & 50,00 \\
\hline & RIO & 1 & 1 & - & 1 & 1 & 100 \\
\hline & SIL & 5 & - & 5 & 5 & 2 & 40,00 \\
\hline \multicolumn{2}{|c|}{ Total } & 11 & $1(12,5 \%)$ & $7(87,5 \%)$ & 8 & 4 & 50,00 \\
\hline \multirow{3}{*}{ AR-7 } & RIO & 1 & - & 1 & 1 & 1 & 100,00 \\
\hline & SIL & 5 & - & 3 & 3 & 3 & 100,00 \\
\hline & QZ & 2 & - & - & - & - & - \\
\hline \multicolumn{2}{|c|}{ Total } & 8 & - & $4(100 \%)$ & 4 & 4 & 100 \\
\hline \multirow{5}{*}{ BDP-1 } & BAS & 5 & - & 1 & 1 & 1 & 100 \\
\hline & OBS & 10 & 1 & 7 & 8 & 6 & 75,00 \\
\hline & RIO & 16 & 4 & 12 & 16 & 11 & 68,75 \\
\hline & SIL & 16 & 2 & 9 & 11 & 6 & 54,55 \\
\hline & VUL & 2 & - & 2 & 2 & 2 & 100 \\
\hline \multicolumn{2}{|c|}{ Total } & 49 & $7(18,4 \%)$ & $31(81,6 \%)$ & 38 & 26 & 68,42 \\
\hline \multicolumn{2}{|c|}{ Total sitios } & 129 & 20 & 80 & 100 & 65 & 65,00 \\
\hline
\end{tabular}

Tabla 8.23. Frecuencias de desechos de talla enteros, fracturados e índice de MNF, en la localidad arqueológica Arbolito por sitio y por materias primas. Referencias: MP: materia prima; NAS: número de especimenes artefactuales; DT fract.: desechos de talla fracturados; NFS: número de especímenes identificados como lascas; MNF: número mínimo de lascas; BAS: basalto; OBS: obsidiana; RIO: riolita; SIL: rocas siliceas; QZ: cuarzo; VUL: vulcanita indeterminada. 
El porcentaje de reserva de corteza en los desechos de talla se calculó sobre los enteros $(n=20)$. En la Tabla 8.24 se observa que el $85 \%(n=17)$ de los desechos enteros no poseen corteza, excepto en AR-6 (A2), cuyo único desecho entero posee la mitad de su cara dorsal cubierta por corteza. Las categorías $25 \%, 50 \%$ y $100 \%$, están representadas por tres desechos enteros de riolita, uno registrado en AR-6 (A2) y los otros dos en BDP1 (25 y 100\%) (Tabla 8.24). La categoría 75\% está ausente; la lasca secundaria de riolita de BDP-1 posee un único lascado previo y 25\% de corteza en su cara dorsal (Tabla 8.24).

\begin{tabular}{|c|c|c|c|c|c|c|}
\hline Sitio & MP & $\mathbf{0 \%}$ & $\mathbf{2 5 \%}$ & $\mathbf{5 0 \%}$ & $\mathbf{1 0 0 \%}$ & Total \\
\hline \multirow{3}{*}{ AR-6 (A1) } & OBS & $100 \%(2)$ & - & - & - & $\mathbf{2}$ \\
\cline { 2 - 7 } & RIO & $100 \%(3)$ & - & - & - & $\mathbf{3}$ \\
\cline { 2 - 7 } & SIL & $100 \%(7)$ & - & - & - & $\mathbf{7}$ \\
\hline \multicolumn{2}{|c|}{ Total } & $\mathbf{1 0 0 \% ( 1 2 )}$ & - & - & - & $\mathbf{1 2}$ \\
\hline AR-6 (A2) & RIO & - & - & $100 \%(1)$ & - & $\mathbf{1}$ \\
\hline \multicolumn{2}{|c|}{ Total } & - & - & $\mathbf{1 0 0 \%}(1)$ & - & $\mathbf{1}$ \\
\hline \multirow{3}{*}{ BDP-1 } & OBS & $100 \%(1)$ & - & - & - & $\mathbf{1}$ \\
\cline { 2 - 7 } & RIO & $50,0 \%(2)$ & $25,0 \%(1)$ & - & $25,0 \%(1)$ & $\mathbf{4}$ \\
\cline { 2 - 7 } & SIL & $100 \%(2)$ & - & - & - & $\mathbf{2}$ \\
\hline \multicolumn{2}{|c|}{ Total } & $\mathbf{7 1 , 4 \% ( 5 )}$ & $\mathbf{1 4 , 3 \%}(1)$ & - & $\mathbf{1 4 , 3 \%}(\mathbf{1})$ & $\mathbf{7}$ \\
\hline \multicolumn{2}{|c|}{ Total sitios (n) } & $\mathbf{1 7}$ & $\mathbf{1}$ & $\mathbf{1}$ & $\mathbf{1}$ & $\mathbf{2 0}$ \\
\hline \multicolumn{2}{|c|}{ Total sitios (\%) } & $\mathbf{8 5 , 0}$ & $\mathbf{5 , 0}$ & $\mathbf{5 , 0}$ & $\mathbf{5 , 0}$ & $\mathbf{1 0 0}$ \\
\hline
\end{tabular}

Tabla 8.24. Reserva de corteza en desechos de talla enteros de la localidad Arbolito.

Los tipos de desechos de talla (Tabla 8.25 y Figura 8.35) y las frecuencias de etapas de manufactura (Figura 8.36) fueron definidos y analizados sobre los enteros de las tres cuadrículas $(\mathrm{n}=20)$ ( frecuentes $(70 \%, \mathrm{n}=14)$ y están presentes en ambos sitios (Tabla 8.25 y Figuras 8.35 y 8.36); la mitad de estas lascas deriva de rocas silíceas $(n=7)$, el $28,57 \%$ de riolita $(n=4)$ y el 21,43\% de obsidiana ( $n=3)$. A las lascas internas le siguen las de formatización de filo (ausentes en la cuadrícula A2 de AR-6), las cuales constituyen el 20\% ( $\mathrm{n}=4)$; de estas, la mitad es de riolita $(\mathrm{n}=2)$ y la otra mitad de rocas silíceas. No se registraron obsidianas en este tipo de lascas, ni lascas de adelgazamiento bifacial en ninguna de las rocas. Se registraron dos lascas externas únicamente sobre riolita (100\%) de BDP-1. En general, los desechos de talla de riolita son los que presentan más variedad de tipos de lasca (Figura 8.35), ya que hay especímenes de cada una de las subclases de desechos presentes en esta localidad, excepto de reactivación, representadas sólo sobre rocas silíceas (Tabla 8.25 y Figuras 8.35 y 8.36 ). 


\begin{tabular}{|c|c|c|c|c|c|c|c|c|}
\hline \multirow[b]{2}{*}{ Sitio } & \multirow[b]{2}{*}{ MP } & \multicolumn{6}{|c|}{ Tipo de lasca } & \multirow[b]{2}{*}{ Total } \\
\hline & & pr. & sec. & angular & $\begin{array}{c}\text { de } \\
\text { arista }\end{array}$ & plana & $\begin{array}{c}\text { de } \\
\text { react. }\end{array}$ & \\
\hline \multirow{3}{*}{$\begin{array}{l}\text { AR-6 } \\
\text { (A1) }\end{array}$} & OBS & - & - & $\begin{array}{l}100 \% \\
(2)\end{array}$ & - & - & - & 2 \\
\hline & RIO & - & - & $\begin{array}{c}33,33 \% \\
(1)\end{array}$ & $\begin{array}{c}33,33 \% \\
\text { (1) }\end{array}$ & $\begin{array}{c}33,33 \% \\
\text { (1) }\end{array}$ & - & 3 \\
\hline & SIL & - & - & $\begin{array}{c}42,86 \% \\
\text { (3) }\end{array}$ & $\begin{array}{c}42,86 \% \\
\text { (3) }\end{array}$ & - & $\begin{array}{c}14,28 \% \\
(1)\end{array}$ & 7 \\
\hline \multicolumn{2}{|c|}{ Total } & - & - & $\begin{array}{c}50,00 \% \\
(6)\end{array}$ & $\begin{array}{c}33,33 \% \\
(4)\end{array}$ & $\begin{array}{c}8,33 \% \\
(1)\end{array}$ & $\begin{array}{c}8,33 \% \\
(1) \\
\end{array}$ & 12 \\
\hline $\begin{array}{l}\text { AR-6 } \\
\text { (A2) }\end{array}$ & RIO & - & - & $\begin{array}{c}100 \% \\
(1)\end{array}$ & - & - & - & 1 \\
\hline \multicolumn{2}{|c|}{ Total } & - & - & $\begin{array}{c}100 \% \\
(1)\end{array}$ & - & - & - & 1 \\
\hline \multirow{3}{*}{ BDP-1 } & OBS & - & - & $\begin{array}{c}100 \% \\
(1)\end{array}$ & - & - & - & 1 \\
\hline & RIO & $\begin{array}{c}25,00 \% \\
\text { (1) }\end{array}$ & $\begin{array}{l}25,00 \% \\
(1)\end{array}$ & $\begin{array}{c}25,00 \% \\
(1)\end{array}$ & - & $\begin{array}{l}25,00 \% \\
(1)\end{array}$ & - & 4 \\
\hline & SIL & - & - & $\begin{array}{c}50,00 \% \\
(1)\end{array}$ & - & - & $\begin{array}{c}50,00 \% \\
(1)\end{array}$ & 2 \\
\hline \multicolumn{2}{|c|}{ Total } & $\begin{array}{c}14,29 \% \\
(1)\end{array}$ & $\begin{array}{c}14,29 \% \\
(1)\end{array}$ & $\begin{array}{c}42,85 \% \\
(3)\end{array}$ & - & $\begin{array}{c}14,29 \% \\
(1)\end{array}$ & $\begin{array}{c}14,29 \% \\
(1)\end{array}$ & 7 \\
\hline \multicolumn{2}{|c|}{ Total sitios (n) } & 1 & 1 & 10 & 4 & 2 & 2 & 20 \\
\hline \multicolumn{2}{|c|}{$\begin{array}{c}\text { Total sitios } \\
(\%)\end{array}$} & 5,00 & 5,00 & 50,00 & 20,00 & 10,00 & 10,00 & 100 \\
\hline
\end{tabular}

Tabla 8.25. Tipos de desechos de talla procedentes de la localidad Arbolito, discriminados por tipo de extracción y materia prima. Referencias: pr.: lasca primaria; sec.: lasca secundaria; de react.: de reactivación.

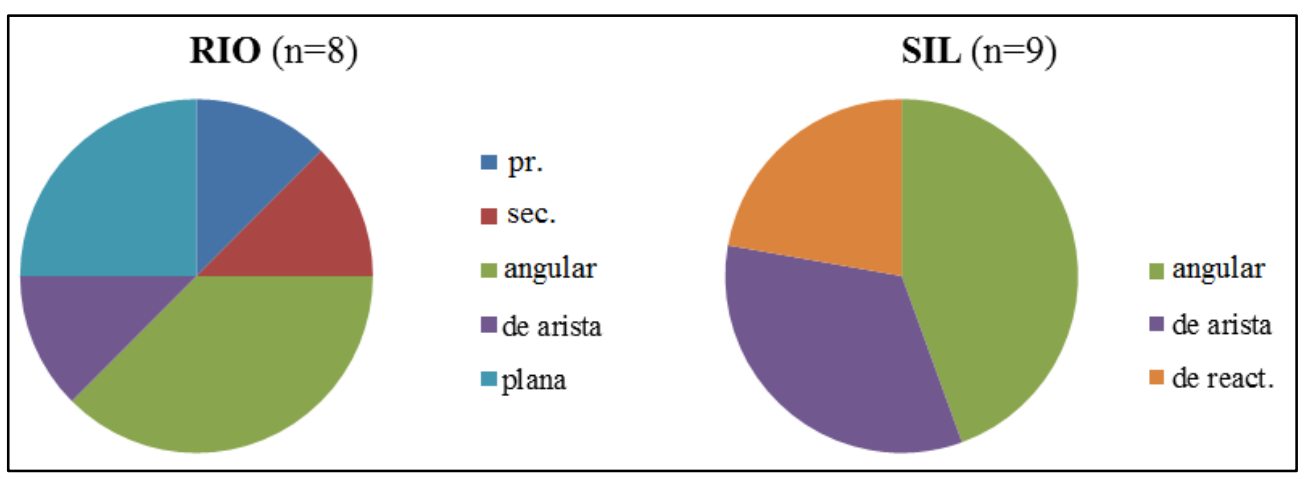

Figura 8.35. Frecuencias relativas de tipos de lasca por materia prima en los tres sitios de la localidad Arbolito. No se incluyeron las tres lascas angulares de obsidiana. Entre paréntesis se indica el número total de lascas enteras por materia prima. Referencias: RIO: riolita; SIL: rocas silíceas; pr.: lasca primaria; sec.: lasca secundaria; de react.: lasca de reactivación. 


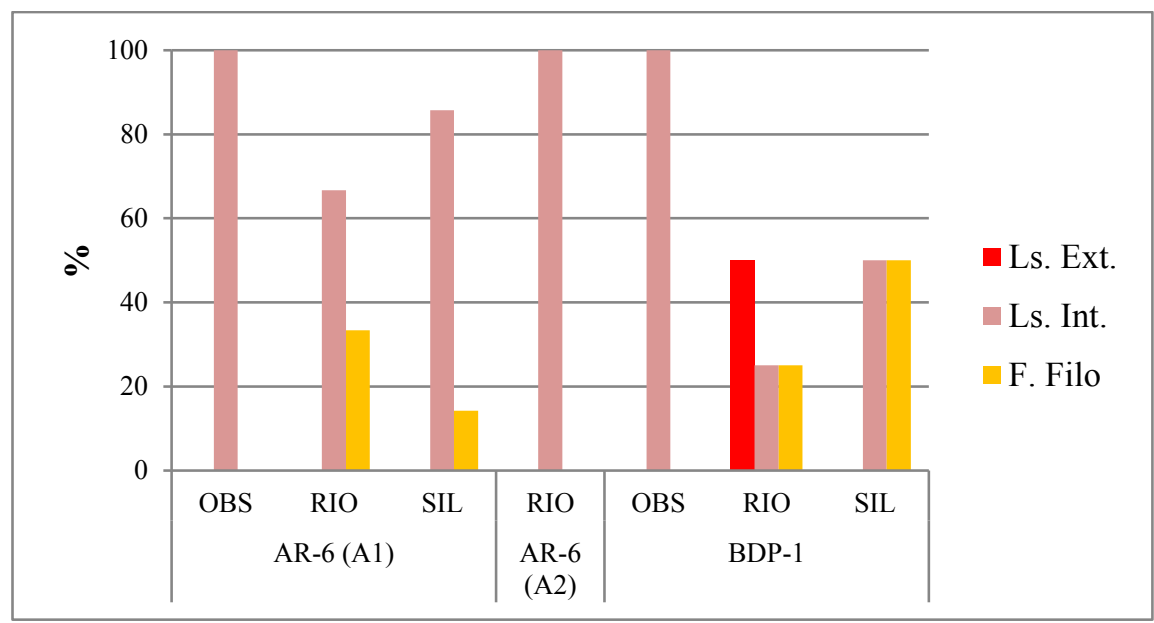

Figura 8.36. Frecuencia de etapas de manufactura en la localidad Arbolito. Referencias: Ls. ext: Lascas externas; Ls. int: lascas internas; F. filo: lascas de formatización de filo.

\subsection{Instrumentos}

Los instrumentos alcanzan el 11,63\% $(\mathrm{n}=15)$ de los 129 artefactos de la localidad Arbolito, constituyendo la segunda clase artefactual más frecuente después de los desechos de talla $(77,52 \%, n=100)$. La mayoría $(46,67 \%, n=7)$ se confeccionó sobre rocas silíceas, mayormente para la formatización unifacial $(57,14 \%, n=4)$, y en menor medida para instrumentos compuestos $(28,57 \%, n=2)$ y bifaciales $(14,29 \%, n=1)$. De los ocho instrumentos restantes, la mitad son bifaciales de obsidiana $(26,67 \%, \mathrm{n}=4)$ y la otra mitad, están manufacturados o modificados por abrasión, picado y/o pulido en basalto.

El $60 \%$ de los instrumentos se descartó en estado fracturado $(n=9)$. De los enteros $(n=6)$, el $66,67 \%(n=4)$ son de rocas silíceas (dos unifaciales, uno bifacial y el otro compuesto) y el 33,33\% ( $\mathrm{n}=2$ ) son de obsidiana (ambos bifaciales). En cuanto a los instrumentos fracturados, el 44,44\% lo constituyen los cuatro artefactos manufacturados o modificados por abrasión, picado y/o pulido de basalto, el 33,33\% corresponde a tres instrumentos confeccionados sobre rocas silíceas (dos instrumentos unifaciales y uno compuesto) y el $22,22 \%$ restante pertenece a dos instrumentos bifaciales de obsidiana. En la Tabla 8.26 se presentan estas tendencias tecnológicas. 


\begin{tabular}{|c|c|c|c|c|c|c|c|c|c|c|c|c|c|}
\hline \multirow{2}{*}{ Sitio } & \multirow{2}{*}{$\begin{array}{l}\text { Grupo } \\
\text { tipológico }\end{array}$} & \multirow{2}{*}{$\begin{array}{c}\text { Sub-grupo } \\
\text { tipológico }\end{array}$} & \multirow{2}{*}{$n$} & \multirow{2}{*}{$\begin{array}{c}\text { Form } \\
\text { a } \\
\text { base }\end{array}$} & \multirow{2}{*}{$\begin{array}{l}\text { Unifaci } \\
\text { al } \\
\text { o } \\
\text { bifacial }\end{array}$} & \multirow{2}{*}{$\begin{array}{l}\text { Serie } \\
\text { técnica }\end{array}$} & \multirow{2}{*}{$\begin{array}{l}\text { Tamañ } \\
\quad \text { o }\end{array}$} & \multicolumn{3}{|c|}{ MP } & \multicolumn{2}{|c|}{ Estado } & \multirow{2}{*}{ Observac. } \\
\hline & & & & & & & & $\begin{array}{c}\text { BA } \\
\text { S }\end{array}$ & $\begin{array}{c}\text { OB } \\
\text { S }\end{array}$ & $\begin{array}{l}\text { SI } \\
\text { L }\end{array}$ & $\begin{array}{c}\text { Ent } \\
.\end{array}$ & $\begin{array}{c}\text { Fract } \\
.\end{array}$ & \\
\hline \multirow{3}{*}{$\begin{array}{c}\text { AR- } \\
6 \\
\text { (A1) }\end{array}$} & \begin{tabular}{|l|} 
Artefacto de \\
formatización \\
sumaria \\
\end{tabular} & $\begin{array}{l}\text { Con retoque } \\
\text { sumario }\end{array}$ & 1 & \multirow{3}{*}{ ND } & \multirow{2}{*}{$\begin{array}{c}\text { Unifacia } \\
\quad 1\end{array}$} & $\begin{array}{l}\text { RTo } \\
\text { marg. }\end{array}$ & NA & \multirow{3}{*}{-} & \multirow{2}{*}{ - } & \multirow{2}{*}{2} & - & 1 & \\
\hline & Cortante & $\begin{array}{l}\text { filo frontal } \\
\text { retocado }\end{array}$ & 1 & & & $\begin{array}{c}\text { RTo- } \\
\text { MiRTo } \\
\text { marg. } \\
\end{array}$ & $\begin{array}{l}\text { Med- } \\
\text { peq }\end{array}$ & & & & 1 & - & \\
\hline & $\begin{array}{l}\text { Punta de } \\
\text { proyectil }\end{array}$ & $\begin{array}{l}\text { Fragm. } \\
\text { limbo-apical }\end{array}$ & 1 & & Bifacial & $\begin{array}{l}\text { RTo- } \\
\text { MiRTo } \\
\text { ext. }\end{array}$ & NA & & 1 & - & - & 1 & $\begin{array}{l}\text { Sub.GT, } \\
\text { sensu } \\
\text { Hocsman } \\
\text { 2016, coms. } \\
\text { pers. } \\
\end{array}$ \\
\hline \multirow{3}{*}{$\begin{array}{l}\text { AR- } \\
6 \\
(\mathrm{~A} 2)\end{array}$} & \multirow{3}{*}{$\begin{array}{l}\text { Punta de } \\
\text { proyectil }\end{array}$} & \multirow{2}{*}{$\begin{array}{l}\text { Apeduncula } \\
\text { da }\end{array}$} & \multirow{3}{*}{2} & \multirow{3}{*}{ ND } & \multirow{3}{*}{ Bifacial } & \multirow{3}{*}{$\begin{array}{l}\text { RTo- } \\
\text { MiRTo } \\
\text { ext. }\end{array}$} & \multirow{3}{*}{$\begin{array}{l}\text { Pequeñ } \\
\quad 0\end{array}$} & \multirow{3}{*}{-} & \multirow{3}{*}{3} & \multirow{3}{*}{-} & \multirow{2}{*}{2} & \multirow[b]{2}{*}{-} & $\begin{array}{c}\text { Triangular } \\
\text { corta }\end{array}$ \\
\hline & & & & & & & & & & & & & $\begin{array}{c}\text { Triangular } \\
\text { corta }\end{array}$ \\
\hline & & $\begin{array}{l}\text { Fragm. de } \\
\text { limbo }\end{array}$ & & & & & & & & & - & 1 & \\
\hline \multirow{2}{*}{$\begin{array}{c}\text { AR- } \\
7\end{array}$} & RBO & Filo lateral & 1 & \multirow[b]{2}{*}{ ND } & \multirow{2}{*}{$\begin{array}{c}\text { Unifacia } \\
\quad 1\end{array}$} & $\begin{array}{c}\text { RTo- } \\
\text { MiRTo } \\
\text { marg. }\end{array}$ & $\begin{array}{c}\text { Pequeñ } \\
0\end{array}$ & \multirow[b]{2}{*}{ - } & & & 1 & - & $\begin{array}{l}\text { Reactivació } \\
\mathrm{n} \text {; retoques } \\
\text { sobre dorso } \\
\text { p/prensión }\end{array}$ \\
\hline & Raspador & Fragm. ND & 1 & & & $\begin{array}{l}\text { RTo- } \\
\text { MiRTo } \\
\text { parc.ex } \\
\text { t. }\end{array}$ & NA & & - & 2 & - & 1 & $\begin{array}{l}\text { Reciclado } \\
\text { sobre AF } \\
\text { ND; } \\
\text { Reactivació } \\
\text { n }\end{array}$ \\
\hline & & & & & & & & & & & & & $\begin{array}{l}\text { Fragm. ND; } \\
\text { podría ser } \\
\text { un mortero }\end{array}$ \\
\hline & $\begin{array}{l}\text { Artefacto manu } \\
\text { picado, abrasión }\end{array}$ & $\begin{array}{l}\text { facturado por } \\
\text {, pulido }\end{array}$ & 4 & ND & NA & NA & NA & 4 & - & - & - & 4 & $\begin{array}{l}\text { Fragm. ND; } \\
\text { podría ser } \\
\text { una mano } \\
\text { de moler }\end{array}$ \\
\hline & & & & & & & & & & & & & $\begin{array}{l}\text { Fragmentos } \\
\text { ND }\end{array}$ \\
\hline $\begin{array}{c}\text { BDP } \\
-1\end{array}$ & \begin{tabular}{|l|} 
Denticulados \\
bisel \\
oblicuo/abrupt \\
o sec.asim. \\
(x2)
\end{tabular} & $\begin{array}{l}\text { Filo frontal } \\
\text { largo (x2) }\end{array}$ & 1 & $\begin{array}{c}\text { Bifaz } \\
\text { parcia } \\
1\end{array}$ & $\mathrm{U}+\mathrm{U}$ & $\begin{array}{c}\text { RTo- } \\
\text { MiRTo } \\
+ \text { RTa- } \\
\text { RTo- } \\
\text { MiRTo } \\
\text { parc. } \\
\text { ext }\end{array}$ & NA & - & - & 3 & - & 1 & $\begin{array}{l}\text { Origen de } \\
\text { las bocas de } \\
\text { lascado en } \\
\text { la fractura } \\
\text { del bifaz }\end{array}$ \\
\hline & Cortante & $\begin{array}{l}\text { filo lateral } \\
\text { retocado }\end{array}$ & 1 & & $\begin{array}{c}\text { Unifacia } \\
1\end{array}$ & $\begin{array}{c}\text { RTo } \\
\text { marg. }\end{array}$ & $\begin{array}{c}\text { Med- } \\
\text { grande }\end{array}$ & & & & & & \\
\hline & $\begin{array}{l}\text { Punta de } \\
\text { proyectil }\end{array}$ & $\begin{array}{l}\text { Con } \\
\text { pedúnculo } \\
\text { esbozado } \\
\text { (sin aletas) }\end{array}$ & 1 & ND & Bifacial & $\begin{array}{c}\text { RTa- } \\
\text { Rto ext. }\end{array}$ & $\begin{array}{l}\text { Med- } \\
\text { peq }\end{array}$ & & & & 2 & - & \\
\hline
\end{tabular}

Tabla 8.26. Grupos y sub-grupos tipológicos de los instrumentos de la localidad arqueológica Arbolito. Referencias: MP: materia prima; BAS: basalto; OBS: obsidiana; SIL: roca silícea; Ent.: entero; Frac.: instrumento fracturado; ND: no diferenciada; NA: no aplica; Fragm.: fragmento; RTa: Retalla; RTo: Retoque; MicRTo: Microretoque; Ext.: extendido; Parc. ext.: parcialmente extendido; Marg.: marginal; Med-peq.: mediano-pequeño; Med-grande: mediano-grande. 
Se observa que en AR-6 (A1), el 66,67\% (n=2) es unifacial y de roca silícea (uno entero y el otro fracturado); el otro instrumento es bifacial, de obsidiana y está fracturado (Figura 8.37.A). En AR-6 (A2) los tres instrumentos son puntas de proyectil de obsidiana: un fragmento de limbo y las otras dos, enteras, son apedunculadas y de tamaño pequeño. En AR-7 los dos instrumentos son unifaciales y de roca silícea; uno entero (RBO pequeño) y otro fracturado (Figura 8.38). Los instrumentos representan el 46,67\% $(n=7)$ de los artefactos de BDP-1 y allí es donde se da la mayor variabilidad de tipos de formatización y de grupos tipológicos: cuatro artefactos manufacturados o modificados por abrasión, picado y/o pulido sobre basalto, una punta de proyectil con pedúnculo esbozado (Figura 8.37.B), un instrumento unifacial y un instrumento compuesto; estos tres últimos confeccionados sobre rocas silíceas. No se registraron instrumentos en obsidiana y el único bifacial es de roca silícea, que además, es la única punta de proyectil de esta localidad arqueológica que posee pedúnculo. En el sitio CSA-1 (véase Sección 8.1.1; Figura 8.16), la única punta de proyectil con pedúnculo registrada corresponde al conjunto temporal perteneciente al Holoceno medio.

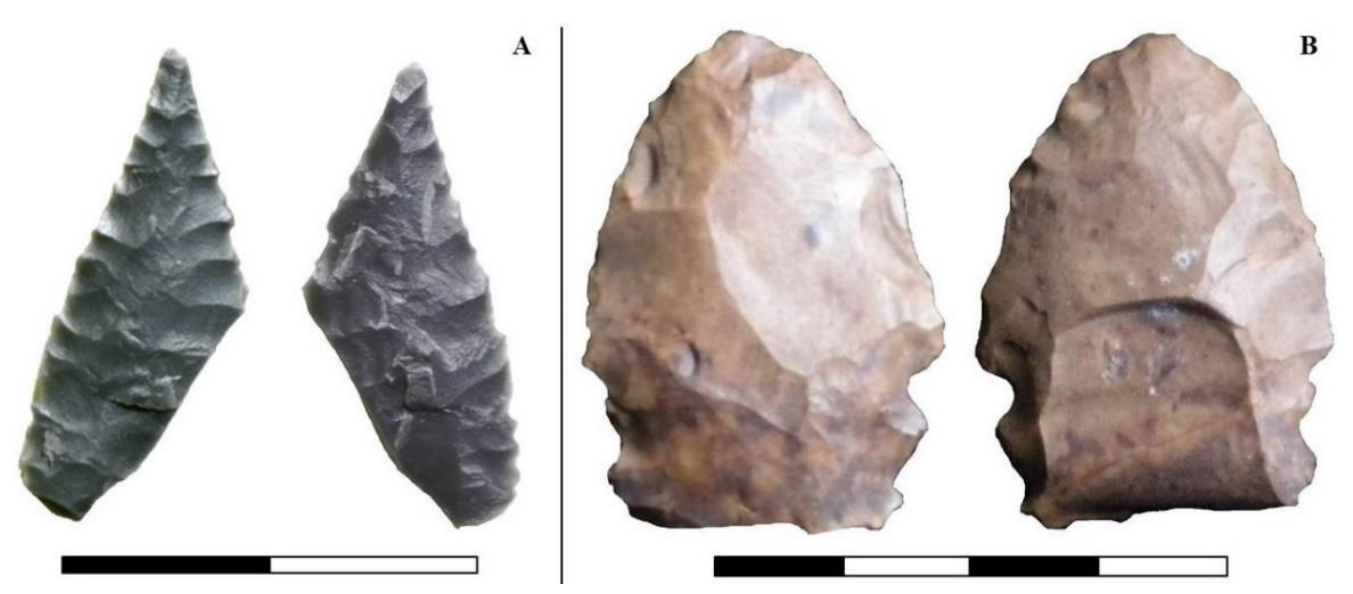

Figura. 8.37. A) Punta de proyectil fracturada en obsidiana, de AR-6 (A1); B) Punta de proyectil con pedúnculo esbozado sobre roca silícea, de BDP-1. 

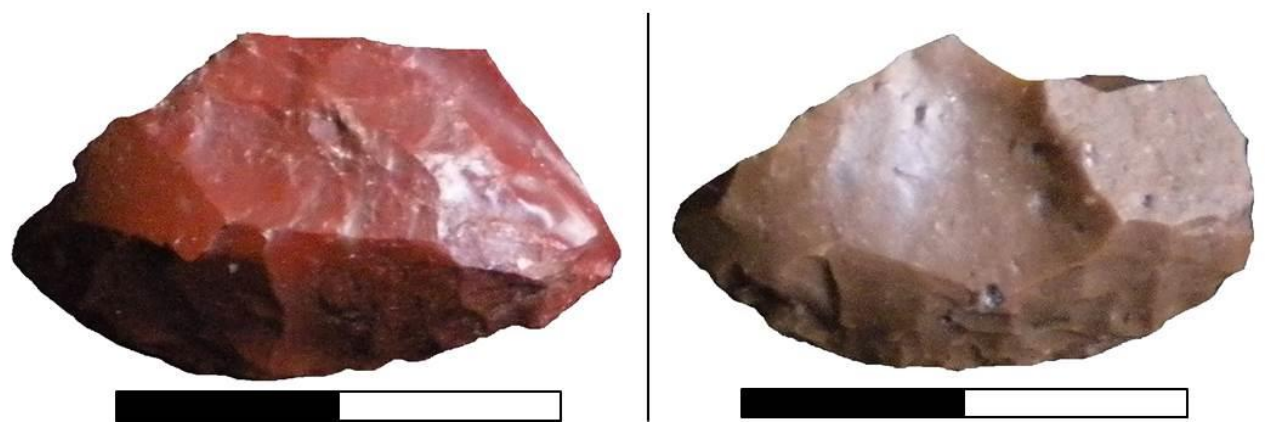

Figura. 8.38. Instrumentos unifaciales procedentes del sitio AR-7: raspador fracturado, reciclado sobre AF ND (izquierda) y RBO (derecha). Ambos están reactivados.

En las cuatro cuadrículas excavadas se han recuperado instrumentos de formatización bifacial ( $\mathrm{n}=5$ en total) y/o unifacial ( $\mathrm{n}=5$ en total): en AR-6 (A2) sólo se registraron instrumentos bifaciales (las tres puntas de proyectil sobre obsidiana), en AR7, sólo unifaciales (RBO y raspador sobre rocas silíceas) y en AR-6 (A1) y BDP-1, ambos tipos, aunque con variación en sus frecuencias (Figura 8.39).

Con respecto a la serie técnica de los artefactos formatizados de la localidad Arbolito, se observa mayor frecuencia de retoque y microrretoque extendido y parcialmente extendido, y también marginal, aunque en menor frecuencia. Asimismo, se observó retalla y retoque en la punta de proyectil con pedúnculo esbozado de BDP-1.

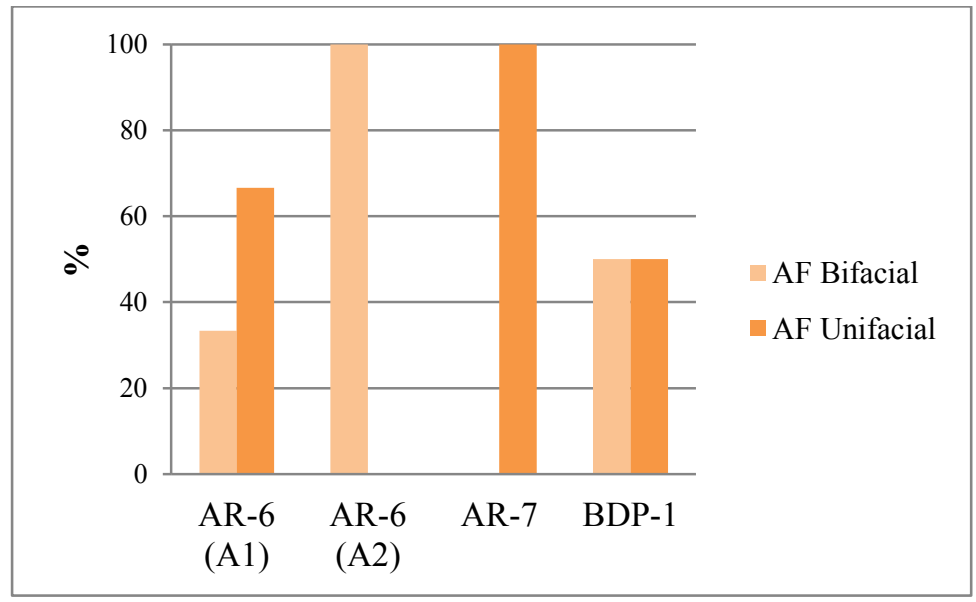

Figura 8.39. Frecuencias de instrumentos bifaciales y unifaciales por sitio en la localidad arqueológica Arbolito.

De los seis ASF RC, tres proceden de AR-6 (A1) y la otra mitad del sitio BDP-1. Los de AR-6 (A1) son de obsidiana, uno está entero (tamaño pequeño -módulo: 2) y los 
otros dos fracturados. De los de BDP-1, dos son de rocas silíceas, uno entero (pequeño) y el otro fracturado, y el tercero es de obsidiana y está fracturado.

\subsubsection{Síntesis y discusión acerca de la localidad arqueológica Arbolito}

La expectativa previa a las excavaciones realizadas en la localidad Arbolito era obtener una gran cantidad de materiales arqueológicos, acorde a los conjuntos recuperados previamente y depositados en el MHNSR. Sin embargo, los resultados mostraron un registro somero y escaso, que no pudo ser datado y que sugiere ocupaciones esporádicas, dispersas a lo largo del paisaje, y no confinadas a sectores concretos y recurrentes, como el caso del sitio del piedemonte, CSA-1. Las características de los sitios de la localidad tendrían relación con la homogeneidad del entorno de los emplazamientos: áreas medanosas extensas a lo largo de un gran curso de agua, que permiten el asentamiento de campamentos base en lugares aledaños, y no necesariamente concentrados o ligados entre sí. La presencia de esqueletos humanos, de artefactos líticos y cerámicos, elementos de molienda e ítems no locales (e.g. conchas marinas del pacífico, pigmentos, etc.), sugieren la realización de actividades múltiples.

Las tendencias obtenidas del análisis de la tecnología lítica de las cuatro cuadrículas, señalan que la clase artefactual más frecuente es la de los desechos de talla $(77,52 \%)$ y, entre las materias primas, predominan las rocas silíceas $(42,64 \%)$. Esta última tendencia es llamativa en el contexto de esta localidad, debido a que la fuente de obsidiana El Peceño se halla a $20 \mathrm{~km}$ del área donde se localizan estos sitios y, sin embargo, la obsidiana se utilizó en segundo lugar $(29,46 \%)$. La riolita (18,60\%), ocupa el tercer lugar, generalmente representado por el basalto en otros sitios del sur mendocino, que aquí ocupa el cuarto lugar (6,20\%). Todas las materias primas registradas en la localidad, son locales. De hecho, en los sitios AR-6 (cuadrícula A1) y BDP-1, se han hallado los únicos dos núcleos analizados de la totalidad de sitios involucrados en esta tesis. Esto también llama la atención debido, entre otras cosas, a la baja frecuencia de reserva de corteza de los artefactos. La mayoría de los desechos de talla no presenta reserva de corteza ( $85 \%)$ y están mayormente fracturados (80\%). De los desechos enteros, se pudieron definir distintos tipos de lasca: internas (70\%; sobre todo angulares: $71,43 \%, n=10)$, presentes en todas las materias primas sobre las que se registraron lascas enteras; de formatización de filo (20\%; dos planas y dos de reactivación), ausentes sobre obsidiana; y externas (10\%; una primaria y otra secundaria), ambas de riolita de BDP-1. 
Los instrumentos $(11,63 \%)$ están presentes en los tres sitios, aunque con mayor variedad de clases instrumentales en BDP-1, sitio donde se registraron una punta de proyectil con pedúnculo, un instrumento compuesto y, por otro lado, cuatro artefactos manufacturados o modificados por abrasión, picado y/o pulido; es decir, instrumentos que suelen atribuirse a segmentos temporales distintos. El 46,67\% de los instrumentos son de rocas silíceas. En AR-6 (A2) no hay instrumentos sobre esta materia prima, sino sobre obsidiana. En general, las puntas de proyectil están confeccionadas sobre obsidiana, salvo la punta de BDP-1, hecha sobre roca silícea. Todos los instrumentos unifaciales recuperados fueron confeccionados sobre rocas silíceas. Los fragmentos no diferenciados de artefactos manufacturados por picado, abrasión y/o pulido son de basalto. El $60 \%$ de los instrumentos se encuentra fracturado: el 44,44\% corresponde a los cuatro instrumentos de basalto, el 33,33\% $(\mathrm{n}=3)$ ha instrumentos de rocas silíceas y el 22,22\% $(\mathrm{n}=2)$ a instrumentos de obsidiana. El 66,67\% $(\mathrm{n}=4)$ de los instrumentos enteros son de rocas silíceas y el 33,33\% ( $\mathrm{n}=2)$ de obsidiana.

Las tendencias señaladas sugieren que en estos sitios se realizaron actividades relacionadas con las etapas avanzadas y finales del proceso de manufactura de instrumentos líticos, además de su reactivación. Si bien las materias primas son de disponibilidad local, el descortezamiento se habría realizado fuera de los sitios, posiblemente en las mismas canteras de extracción, y luego se las habría trasladado hasta los sitios. Los instrumentos recuperados sugieren que en los tres sitios se realizaron tareas vinculadas al procesamiento de recursos vegetales y animales, ya que las funciones que han sido inferidas de los grupos tipológicos (sensu Aschero 1975, 1983) identificados implican: cortar (cortantes de AR-6, cuadrícula A1 y BDP-1), raspar (raspador y RBO de AR-7) y, posiblemente, moler (fragmentos no diferenciados de artefactos manufacturados o modificados por abrasión, picado y/o pulido de BDP-1), entre otras posibles funciones, además de elementos como las puntas de proyectil (registradas en casi todos los sitios), que habrían formado parte de un toolkit de caza; tales funciones deben ser contrastadas con la aplicación de estudios funcionales. 


\subsection{ANÁLISIS TECNO-TIPOLÓGICO DEL DESIERTO PATAGÓNICO}

\subsubsection{MATERIAS PRIMAS LÍTICAS}

El sitio de piedemonte, CSA-1, más los tres sitios de la localidad arqueológica Arbolito (cuadrículas A1 y A2 de AR-6, AR-7 y BDP-1), reúnen un total de 3391 artefactos líticos. De ellos, el 56,52\% ( $\mathrm{n}=1920)$ son de rocas silíceas, seguidas por la obsidiana $(38,45 \%, \mathrm{n}=1304)$, el basalto $(3,30 \%, \mathrm{n}=112)$, la riolita $(1,09 \%, \mathrm{n}=37)$, la vulcanita indeterminada $(0,29 \%, \mathrm{n}=10)$, el cuarzo $(0,09 \%, \mathrm{n}=3)$ y un artefacto de andesita $(0,03 \%)$, completando el total de materias primas cuatro especímenes indeterminados $(0,12 \%)$. La distribución de las rocas entre los cuatro sitios es relativamente homogénea, siendo en casi todos los casos, las rocas silíceas y la obsidiana las dos rocas principales. Esta tendencia varía en la localidad Arbolito ya que en el sitio AR-7 no se registró ningún artefacto de obsidiana, y en el sitio BDP-1, las dos materias primas predominantes, que incluso poseen la misma frecuencia ( $\mathrm{n}=16$, en ambos casos), son las rocas silíceas y la riolita. Además, en dicha localidad, la riolita supera a la cantidad de artefactos de basalto (24 artefactos de riolita vs. ocho de basalto) que, asimismo está ausente en los sitos AR6 (A2) y AR-7; y no se han registrado andesita ni rocas indeterminadas.

En la Tabla 8.27 se presenta la variable "calidad para la talla" por materia prima y período (la información del HM y del HTI la provee sólo CSA-1 ya que, como se dijo, los sitios de la localidad Arbolito corresponden a los últimos 1.000 años, aproximadamente). Dicha tabla no incluye: artefactos manufacturados o modificados por abrasión, picado y/o pulido $(n=9)$, percutores $(n=5)$, ecofactos $(n=12)$, pigmentos $(n=3)$ ni un potencial percutor funcional. Debido a esto, el $n$ es de 3361 artefactos líticos. De este total, la mayoría $(51,9 \%, n=1744)$ corresponde a artefactos sobre materias primas de "muy buena" calidad.

$\mathrm{Al}$ analizar esta variable a través del tiempo, se observa que durante el HM y el HTI, predomina la calidad para la talla "muy buena", superando el 50\% en el HTI (Tabla 8.27). Esta categoría es seguida por la "buena" en el HM, y por la "excelente" durante el HTI. La calidad "regular" está ausente en el primer momento y es muy poco frecuente durante el HTI ( $0,2 \%$, representado por artefactos de basalto y riolita). Más tarde, en el HTF (incluye a los sitios de la localidad Arbolito), la calidad que predomina es la "excelente", seguida por la "muy buena", "buena" y "regular". Este último tipo sólo se observa en cinco artefactos de basalto de los sitios CSA-1 y AR-6 (cuadrícula A1) y en 
dos artefactos de riolita y vulcanita indeterminada del sitio BDP-1 (Tabla 8.27). En la Figura 8.40 se presentan estas tendencias temporales por materia prima.

\begin{tabular}{|c|c|c|c|c|c|c|c|}
\hline Tiempo & Sitio & MP & EX & MB & B & $\mathbf{R}$ & Total \\
\hline \multirow{19}{*}{ 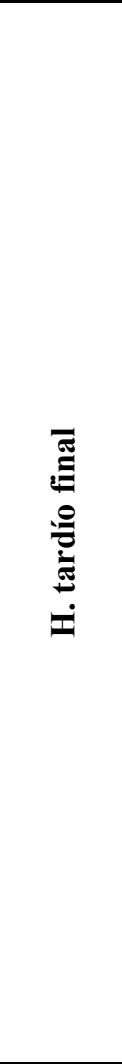 } & \multirow{4}{*}{ CSA-1 } & BAS & - & $2(7,1 \%)$ & $22(78,6 \%)$ & $4(14,3 \%)$ & 28 \\
\hline & & OBS & $709(98,2 \%)$ & $12(1,7 \%)$ & $1(0,1 \%)$ & - & 722 \\
\hline & & RIO & - & $3(50,0 \%)$ & $3(50,0 \%)$ & - & 6 \\
\hline & & SIL & $25(3,8 \%)$ & $539(82,5 \%)$ & $89(13,6 \%)$ & - & 653 \\
\hline & \multirow{4}{*}{$\begin{array}{c}\text { AR-6 } \\
\text { (A1) }\end{array}$} & BAS & - & - & - & $1(100 \%)$ & 1 \\
\hline & & OBS & $20(87,0 \%)$ & $3(13,0 \%)$ & - & - & 23 \\
\hline & & RIO & - & - & $5(100 \%)$ & - & 5 \\
\hline & & SIL & $2(6,9 \%)$ & $18(62,1 \%)$ & $9(31,0 \%)$ & - & 29 \\
\hline & \multirow{3}{*}{$\begin{array}{c}\text { AR-6 } \\
\text { (A2) }\end{array}$} & OBS & $5(100 \%)$ & - & - & - & 5 \\
\hline & & RIO & - & - & $1(100 \%)$ & - & 1 \\
\hline & & SIL & $5(100 \%)$ & - & - & - & 5 \\
\hline & \multirow{3}{*}{ AR-7 } & RIO & - & $1(100 \%)$ & - & - & 1 \\
\hline & & QZ & - & $1(50,0 \%)$ & $1(50,0 \%)$ & - & 2 \\
\hline & & SIL & - & $5(100 \%)$ & - & - & 5 \\
\hline & \multirow{5}{*}{ BDP-1 } & BAS & $1(100 \%)$ & - & - & - & 1 \\
\hline & & OBS & $6(60,0 \%)$ & $4(40,0 \%)$ & - & - & 10 \\
\hline & & RIO & - & $8(50,0 \%)$ & $7(43,8 \%)$ & $1(6,3 \%)$ & 16 \\
\hline & & SIL & $13(81,3 \%)$ & $3(18,8 \%)$ & - & - & 16 \\
\hline & & VUL & - & - & $1(50,0 \%)$ & $1(50,0 \%)$ & 2 \\
\hline \multicolumn{3}{|c|}{ Total HTF } & $786(51,3 \%)$ & $599(39,1 \%)$ & $139(9,1 \%)$ & $7(0,5 \%)$ & 1531 \\
\hline \multirow{6}{*}{ 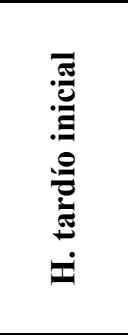 } & \multirow{6}{*}{ CSA-1 } & AND & - & - & $1(100 \%)$ & - & 1 \\
\hline & & BAS & $1(1,6 \%)$ & $38(60,3 \%)$ & $22(34,9 \%)$ & $2(3,2 \%)$ & 63 \\
\hline & & OBS & $532(99,6 \%)$ & $2(0,4 \%)$ & - & - & 534 \\
\hline & & RIO & - & $3(42,9 \%)$ & $3(42,9 \%)$ & $1(14,3 \%)$ & 7 \\
\hline & & SIL & $2(0,2 \%)$ & $1090(91,4 \%)$ & $100(8,4 \%)$ & - & 1192 \\
\hline & & VUL & - & - & $2(100 \%)$ & - & 2 \\
\hline \multicolumn{3}{|c|}{ Total HTI } & $535(29,7 \%)$ & $1133(63,0 \%)$ & $128(7,1 \%)$ & $3(0,2 \%)$ & 1799 \\
\hline \multirow{3}{*}{$\begin{array}{c}\stackrel{\ominus}{\mathscr{\Xi}} \\
\stackrel{\Xi}{\Xi} \\
\dot{x}\end{array}$} & \multirow{3}{*}{ CSA-1 } & BAS & - & - & $2(100 \%)$ & - & 2 \\
\hline & & OBS & $9(90,0 \%)$ & $1(10,0 \%)$ & - & - & 10 \\
\hline & & SIL & - & $11(57,9 \%)$ & $8(42,1 \%)$ & - & 19 \\
\hline \multicolumn{3}{|c|}{ Total HM } & $9(29,0 \%)$ & $12(38,7 \%)$ & $10(32,3 \%)$ & - & 31 \\
\hline \multicolumn{3}{|c|}{ Total (n) } & 1330 & 1744 & 277 & 10 & \multirow{2}{*}{3361} \\
\hline \multicolumn{3}{|c|}{ Total (\%) } & 39,6 & 51,9 & 8,2 & 0,3 & \\
\hline
\end{tabular}

Tabla 8.27. Materias primas y calidad para la talla a través del tiempo en el Desierto Patagónico. Referencias: MP: materia prima; AND: andesita; BAS: basalto; OBS: obsidiana; RIO: riolita; QZ: cuarzo; SIL: rocas siliceas; VUL: vulcanita indeterminada; EX: excelente; MB: muy 
buena; B: buena; R: regular. Sólo se incluyen los artefactos manufacturados por lascados, sus productos de talla, y núcleos y nódulos aptos para su explotación.

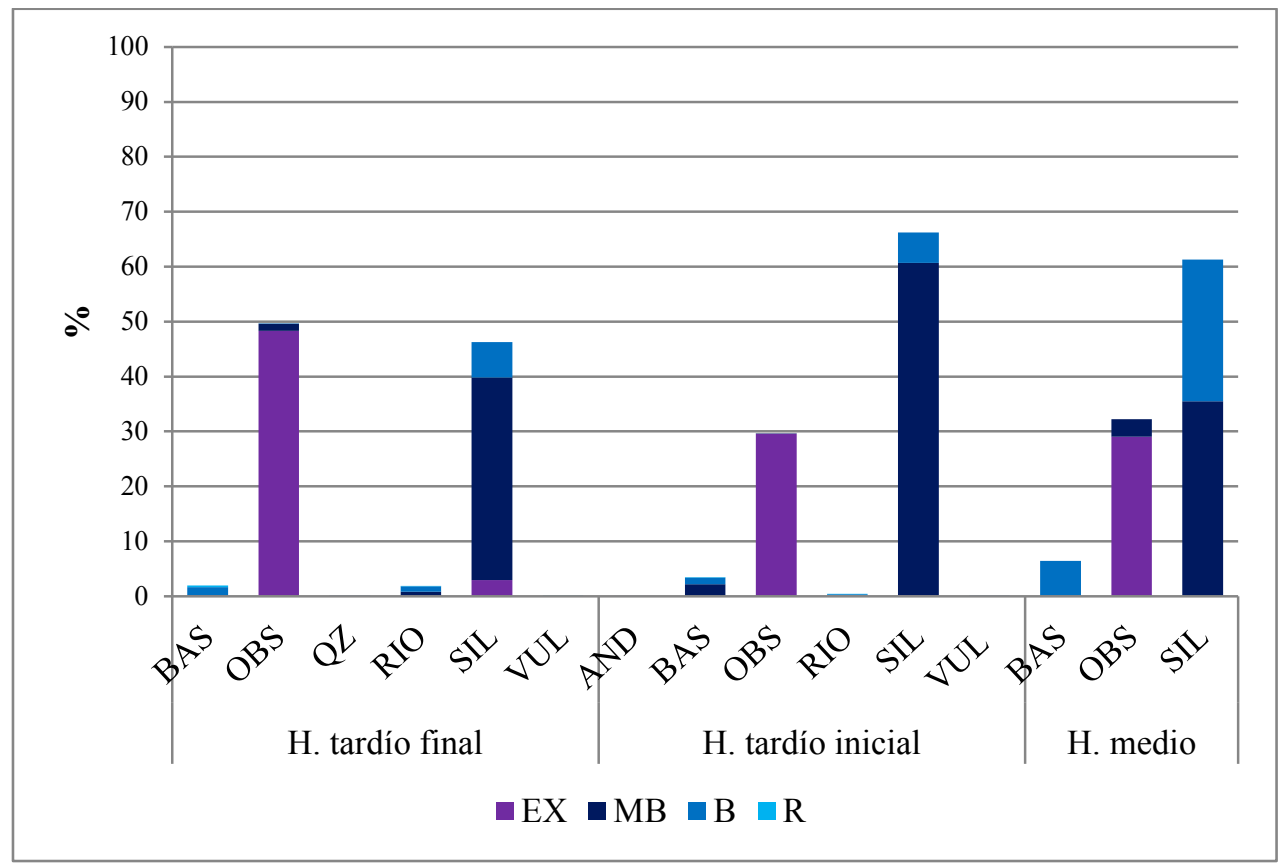

Figura 8.40. Frecuencias de las distintas categorías de calidad para la talla por materia prima y por segmento temporal en el Desierto Patagónico (sitios agrupados) durante el Holoceno. Referencias: AND: andesita; BAS: basalto; OBS: obsidiana; QZ: cuarzo; RIO: riolita; SIL: rocas siliceas; VUL: vulcanita indeterminada; EX: excelente; MB: muy buena; B: buena; $R$ : regular. Sólo se incluyen los artefactos manufacturados por lascados y sus productos de talla.

El análisis del estado de fragmentación de los artefactos registrados en CSA-1, AR-6 (A1 y A2), AR-7 y BDP-1, señala que la mayor frecuencia de fractura se da en el sitio CSA-1 en toda su secuencia $(89,18 \%, \mathrm{n}=2909)$ y en los tres conjuntos temporales: 80,65\% ( $\mathrm{n}=25)$ en el Conjunto C (HM), 92,22\% $(n=1671)$ en el Conjunto B (HTI) y 85,48\% ( $\mathrm{n}=1213)$ en el Conjunto A (HTF). De los sitios de la localidad Arbolito, BDP-1 es el que presenta mayor fragmentación $(77,55 \%, n=38)$, seguido por AR-7 $(75 \%, n=6)$ y AR-6 (72,73\%, n=8 en la cuadrícula A2; y 68,85\%, $\mathrm{n}=42$ en la A1). Siguiendo la ecuación MNA/NAS para evaluar el índice de fragmentación (véase Capítulos 5) se comprobaron estas tendencias y se observa que los fracturados han incrementado el tamaño de la muestra en un 64\% en CSA-1 (MNA/NAS=36\%), en un 48\% en AR-6, A1 $(\mathrm{MNA} / \mathrm{NAS}=52 \%$ ), en un $45 \%$ en $\mathrm{AR}-6, \mathrm{~A} 2$ (MNA/NAS=55\%), en un 37\% en AR-7 $(\mathrm{MNA} / \mathrm{NAS}=63 \%)$ y en un $41 \%$ en BDP-1 (MNA/NAS=59\%). Los sitios con menor fragmentación son BDP-1 y AR-7 que, sin embargo, es el sitio con menor tamaño de 
muestra y ausencia de desechos enteros. En ambos, la riolita y las rocas silíceas se presentan menos fracturadas que artefactos en otras materias primas, sumándose la obsidiana de BDP-1. Al contrario, en el sitio CSA-1 donde se da el mayor índice de fragmentación, la obsidiana aparece muy fracturada. Entre otras tendencias, el basalto, en los sitios donde se ha registrado, suele aparecer fracturado (Tabla 8.28).

\begin{tabular}{|c|c|c|c|c|c|c|c|c|c|c|c|c|}
\hline Sitio & MP & NAS & \begin{tabular}{|c}
$\begin{array}{c}\text { Instr. } \\
\text { ent. }\end{array}$ \\
\end{tabular} & $\begin{array}{l}\text { NU } \\
\text { ent. }\end{array}$ & $\begin{array}{l}\text { DT } \\
\text { ent. }\end{array}$ & $\begin{array}{c}\text { DT } \\
\text { fract. }\end{array}$ & Indif & NFS & \multicolumn{2}{|c|}{$\begin{array}{c}\text { MNF } \\
(\mathrm{n} y \%) \\
\end{array}$} & MNA & MNA/NAS \\
\hline \multirow{8}{*}{ CSA-1 } & AND & 1 & - & - & 1 & - & - & 1 & 1 & 100,00 & 1 & $100 \%$ \\
\hline & BAS & 104 & 4 & - & 6 & 86 & - & 92 & 36 & 39,13 & 40 & $38 \%$ \\
\hline & OBS & 1266 & 7 & - & 137 & 1085 & 1 & 1223 & 409 & 33,44 & 416 & $33 \%$ \\
\hline & QZ & 1 & - & - & - & - & - & - & - & - & - & - \\
\hline & RIO & 13 & - & - & - & 13 & - & 13 & 5 & 38,46 & 5 & $38 \%$ \\
\hline & SIL & 1865 & 14 & - & 169 & 1648 & 2 & 1819 & 692 & 38,04 & 706 & $38 \%$ \\
\hline & VUL & 8 & 1 & - & - & 2 & - & 2 & 1 & 50,00 & 2 & $25 \%$ \\
\hline & Indet. & 4 & - & - & - & - & - & - & - & - & - & - \\
\hline \multicolumn{2}{|c|}{ Total } & 3262 & 26 & - & 313 & 2834 & 3 & 3150 & 1144 & 36,32 & 1170 & $36 \%$ \\
\hline \multirow{4}{*}{$\begin{array}{c}\text { AR-6 } \\
\text { (A1) }\end{array}$} & BAS & 3 & - & - & - & 1 & - & 1 & - & - & - & - \\
\hline & \begin{tabular}{|l} 
OBS \\
\end{tabular} & 23 & - & - & 2 & 16 & - & 18 & 12 & 66,67 & 12 & $52 \%$ \\
\hline & RIO & 6 & - & - & 3 & 2 & - & 5 & 3 & 60,00 & 3 & $50 \%$ \\
\hline & SIL & 29 & 1 & 1 & 7 & 19 & - & 26 & 16 & 61,54 & 17 & $59 \%$ \\
\hline \multicolumn{2}{|c|}{ Total } & 61 & 1 & 1 & 12 & 38 & - & 50 & 31 & 62,00 & 32 & $52 \%$ \\
\hline \multirow{3}{*}{$\begin{array}{c}\text { AR-6 } \\
\text { (A2) }\end{array}$} & OBS & 5 & 2 & - & - & 2 & - & 2 & 1 & 50,00 & 3 & $60 \%$ \\
\hline & RIO & 1 & - & - & 1 & - & - & 1 & 1 & 100 & 1 & $100 \%$ \\
\hline & SIL & 5 & - & - & - & 5 & - & 5 & 2 & 40,00 & 2 & $40 \%$ \\
\hline \multicolumn{2}{|c|}{ Total } & 11 & 2 & - & 1 & 7 & - & 8 & 4 & $\mathbf{5 0 , 0 0}$ & 6 & $55 \%$ \\
\hline \multirow{3}{*}{ AR-7 } & \begin{tabular}{|l|} 
RIO \\
\end{tabular} & 1 & - & - & - & 1 & - & 1 & 1 & 100,00 & 1 & $100 \%$ \\
\hline & \begin{tabular}{|l} 
SIL \\
\end{tabular} & 5 & 1 & - & - & 3 & - & 3 & 3 & 100,00 & 4 & $80 \%$ \\
\hline & $\mathbf{Q Z}$ & 2 & - & - & - & - & - & - & - & - & - & - \\
\hline \multicolumn{2}{|c|}{ Total } & 8 & 1 & - & - & 4 & - & 4 & 4 & 100 & 5 & $63 \%$ \\
\hline \multirow{5}{*}{ BDP-1 } & BAS & 5 & - & - & - & 1 & - & 1 & 1 & 100 & 1 & $20 \%$ \\
\hline & OBS & 10 & - & 1 & 1 & 7 & - & 8 & 6 & 75,00 & 7 & $70 \%$ \\
\hline & \begin{tabular}{|l|} 
RIO \\
\end{tabular} & 16 & - & - & 4 & 12 & - & 16 & 11 & 68,75 & 11 & $69 \%$ \\
\hline & SIL & 16 & 2 & - & 2 & 9 & - & 11 & 6 & 54,55 & 8 & $50 \%$ \\
\hline & VUL & 2 & - & - & - & 2 & - & 2 & 2 & 100 & 2 & $100 \%$ \\
\hline \multicolumn{2}{|c|}{ Total } & 49 & 2 & 1 & 7 & 31 & - & 38 & 26 & 68,42 & 29 & $59 \%$ \\
\hline \multicolumn{2}{|c|}{ Total sitios } & 3391 & 32 & 2 & 333 & 2914 & 3 & 3250 & 1209 & 37,2 & 1242 & $37 \%$ \\
\hline
\end{tabular}

Tabla 8.28. Número total de piezas artefactuales (NAS), de desechos de talla enteros, fracturados, NFS (número de especímenes identificados como lascas: suma de desechos enteros, fracturados y no diferenciados), índice de MNF (número mínimo de lascas) e índice de fragmentación (MNA/NAS), por materias primas y sitios arqueológicos del Desierto 
Patagónico. Referencias: MP: materia prima; Instr: instrumentos; DT: desechos de talla; Ent.:

enteros; Fract.: fracturados; Indif.: indiferenciados; AND: andesita; BAS: basalto; OBS:

obsidiana; QZ: cuarzo; RIO: riolita; SIL: rocas siliceas; VUL: vulcanita indeterminada; Indet.:

rocas indeterminadas.

En la Tabla 8.29 se presentan las frecuencias de fragmentación por sitio y por materia prima a través del tiempo, aunque no se observa un patrón claro. Con respecto al tiempo, se observa que en el HTI hay mayor frecuencia de artefactos fracturados, disminuyendo hacia el HTF, aunque en este último momento, se observa mayor tendencia hacia la fragmentación que durante el HM (Tabla 8.29).

\begin{tabular}{|c|c|c|c|c|c|c|}
\hline Tiempo & Sitio & MP & Entero & Fracturado & ND & Total \\
\hline \multirow{21}{*}{ 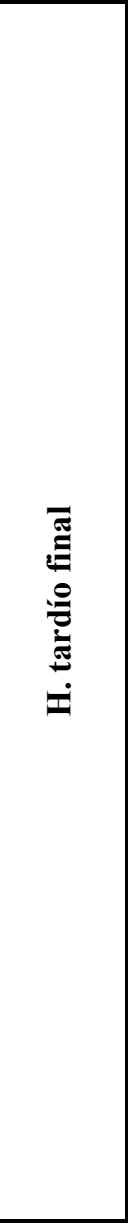 } & \multirow{6}{*}{ CSA-1 } & BAS & $18,2 \%(6)$ & $81,8 \%(27)$ & - & 33 \\
\hline & & OBS & $13,6 \%(98)$ & $86,4 \%(624)$ & - & 722 \\
\hline & & RIO & - & $100 \%(6)$ & - & 6 \\
\hline & & SIL & $14,7 \%(96)$ & $84,8 \%(554)$ & $0,5 \%(3)$ & 653 \\
\hline & & VUL & $50 \%(2)$ & $50 \%(2)$ & - & 4 \\
\hline & & Indet. & - & - & $100 \%(1)$ & 1 \\
\hline & \multirow{4}{*}{$\begin{array}{l}\text { AR-6 } \\
\text { (A1) }\end{array}$} & BAS & - & $33,3 \%(1)$ & $66,7 \%(2)$ & 3 \\
\hline & & OBS & $13,0 \%(3)$ & $82,6 \%(19)$ & $4,3 \%(1)$ & 23 \\
\hline & & RIO & $50,0 \%(3)$ & $33,3 \%(2)$ & $16,7 \%(1)$ & 6 \\
\hline & & SIL & $31,0 \%(9)$ & $69,0 \%(20)$ & - & 29 \\
\hline & \multirow{3}{*}{$\begin{array}{c}\text { AR-6 } \\
\text { (A2) }\end{array}$} & OBS & $40,0 \%(2)$ & $60,0 \%(3)$ & - & 5 \\
\hline & & RIO & $100 \%(1)$ & - & - & 1 \\
\hline & & SIL & - & $100 \%(5)$ & - & 5 \\
\hline & \multirow{3}{*}{ AR-7 } & RIO & - & $100 \%(1)$ & - & 1 \\
\hline & & QZ & - & $50,0 \%(1)$ & $50,0 \%(1)$ & 2 \\
\hline & & SIL & $20,0 \%(1)$ & $80,0 \%$ (4) & - & 5 \\
\hline & \multirow{5}{*}{ BDP-1 } & BAS & - & $100 \%(5)$ & - & 5 \\
\hline & & OBS & $20,0 \%(2)$ & $80,0 \%(8)$ & - & 10 \\
\hline & & RIO & $25,0 \%(4)$ & $75,0 \%(12)$ & - & 16 \\
\hline & & SIL & $31,3 \%(5)$ & $68,8 \%(11)$ & - & 16 \\
\hline & & VUL & - & $100 \%(2)$ & - & 2 \\
\hline \multicolumn{3}{|c|}{ Total HTF } & $15,0 \%(232)$ & $84,4 \%(1307)$ & $0,6 \%(9)$ & 1548 \\
\hline \multirow{5}{*}{ 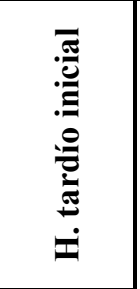 } & \multirow{5}{*}{ CSA-1 } & AND & $100 \%(1)$ & - & - & 1 \\
\hline & & BAS & $8,7 \%(6)$ & $91,3 \%(63)$ & - & 69 \\
\hline & & OBS & $8,8 \%(47)$ & $91,0 \%(486)$ & $0,2 \%(1)$ & 534 \\
\hline & & RIO & - & $100 \%(7)$ & - & 7 \\
\hline & & SIL & $6,9 \%(82)$ & $93,1 \%(1111)$ & - & 1193 \\
\hline
\end{tabular}




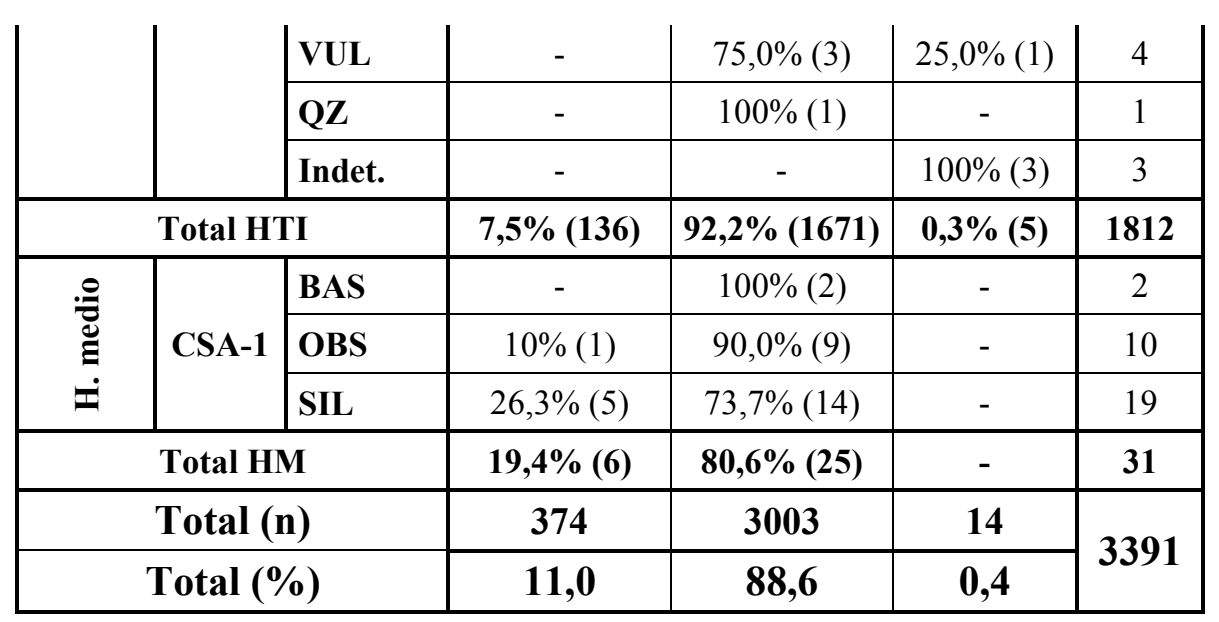

Tabla 8.29. Estado de fragmentación por materia prima y segmento temporal, en los cinco conjuntos líticos del Desierto Patagónico analizados aquí.

Para analizar el tamaño artefactual, sólo se consideraron los artefactos enteros por materia prima y por sitio. En la Tabla 8.30 se observa que el tamaño muy pequeño es el mayoritario en los tres momentos registrados del Holoceno. La única materia prima en la que están representados todos los tamaños es el basalto; aunque no se han registrado artefactos enteros de esta roca en el conjunto del HM (Tabla 8.30).

\begin{tabular}{|c|c|c|c|c|c|c|c|c|}
\hline Tiempo & Sitio & MP & MPE & $\mathbf{P}$ & МЕP & MEG & MG & Total \\
\hline \multirow{13}{*}{ 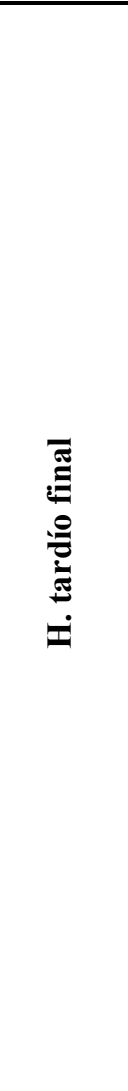 } & \multirow{4}{*}{ CSA-1 } & BAS & $\begin{array}{c}33,3 \% \\
(2)\end{array}$ & $\begin{array}{c}33,3 \% \\
(2)\end{array}$ & $\begin{array}{c}16,7 \% \\
\text { (1) }\end{array}$ & - & $\begin{array}{c}16,7 \% \\
\text { (1) }\end{array}$ & 6 \\
\hline & & OBS & $\begin{array}{c}85,7 \% \\
(84)\end{array}$ & $\begin{array}{c}14,3 \% \\
(14)\end{array}$ & - & - & - & 98 \\
\hline & & SIL & $\begin{array}{c}68,8 \% \\
(66)\end{array}$ & $\begin{array}{l}25,0 \\
(24) \\
\end{array}$ & $\begin{array}{c}6,3 \% \\
(6)\end{array}$ & - & - & 96 \\
\hline & & VUL & - & - & - & - & $\begin{array}{c}100 \% \\
(2)\end{array}$ & 2 \\
\hline & \multirow{3}{*}{ AR-6 (A1) } & OBS & $\begin{array}{c}66,7 \% \\
(2)\end{array}$ & $\begin{array}{c}33,3 \% \\
\text { (1) }\end{array}$ & - & - & - & 3 \\
\hline & & RIO & $\begin{array}{c}33,3 \% \\
(1)\end{array}$ & $\begin{array}{c}66,7 \% \\
(2)\end{array}$ & - & - & - & 3 \\
\hline & & SIL & $\begin{array}{c}77,8 \% \\
(7)\end{array}$ & - & $\begin{array}{c}22,2 \% \\
(2)\end{array}$ & - & - & 9 \\
\hline & \multirow{2}{*}{ AR-6 (A2) } & OBS & - & $\begin{array}{c}100 \% \\
(2)\end{array}$ & - & - & - & 2 \\
\hline & & RIO & - & - & - & $\begin{array}{c}100 \% \\
(1)\end{array}$ & - & 1 \\
\hline & AR-7 & SIL & - & $\begin{array}{c}100 \% \\
(1)\end{array}$ & - & - & - & 1 \\
\hline & \multirow{3}{*}{ BDP-1 } & OBS & - & $\begin{array}{c}50,0 \% \\
(1)\end{array}$ & - & $\begin{array}{c}50,0 \% \\
(1)\end{array}$ & - & 2 \\
\hline & & RIO & $\begin{array}{c}100 \% \\
(4)\end{array}$ & - & - & - & - & 4 \\
\hline & & SIL & $\begin{array}{c}40,0 \% \\
(2)\end{array}$ & $\begin{array}{c}20,0 \% \\
(1)\end{array}$ & $\begin{array}{c}20,0 \% \\
(1)\end{array}$ & $\begin{array}{c}20,0 \% \\
(1)\end{array}$ & - & 5 \\
\hline
\end{tabular}




\begin{tabular}{|c|c|c|c|c|c|c|c|c|}
\hline \multicolumn{3}{|c|}{ Total HTF } & $\begin{array}{c}72,4 \% \\
(168) \\
\end{array}$ & $\begin{array}{c}20,7 \% \\
(48) \\
\end{array}$ & $\begin{array}{c}4,3 \% \\
(10) \\
\end{array}$ & $\begin{array}{c}1,3 \% \\
(3)\end{array}$ & $\begin{array}{c}, 3 \% \\
(3) \\
\end{array}$ & 232 \\
\hline \multirow{4}{*}{ 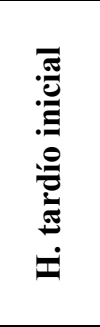 } & \multirow{4}{*}{ CSA-1 } & AND & - & $\begin{array}{c}100 \% \\
(1)\end{array}$ & - & - & - & 1 \\
\hline & & BAS & $\begin{array}{c}16,7 \% \\
(1)\end{array}$ & $\begin{array}{c}16,7 \% \\
(1)\end{array}$ & $\begin{array}{c}16,7 \% \\
(1) \\
\end{array}$ & $\begin{array}{c}16,7 \% \\
(1)\end{array}$ & $\begin{array}{c}33,3 \% \\
(2) \\
\end{array}$ & 6 \\
\hline & & OBS & $\begin{array}{c}74,5 \% \\
(35)\end{array}$ & $\begin{array}{c}17,0 \% \\
(8)\end{array}$ & $\begin{array}{c}8,5 \% \\
(4)\end{array}$ & - & - & 47 \\
\hline & & SIL & $\begin{array}{c}73,2 \% \\
(60) \\
\end{array}$ & $\begin{array}{c}20,7 \% \\
(17)\end{array}$ & $\begin{array}{c}6,1 \% \\
(5) \\
\end{array}$ & - & - & 82 \\
\hline \multicolumn{3}{|c|}{ Total HTI } & $\begin{array}{c}70,6 \% \\
(96)\end{array}$ & $\begin{array}{c}19,9 \% \\
(27)\end{array}$ & $\begin{array}{c}7,4 \% \\
(10)\end{array}$ & $\begin{array}{c}0,7 \% \\
\text { (1) }\end{array}$ & $\begin{array}{c}1,5 \% \\
(2)\end{array}$ & 136 \\
\hline \multirow{2}{*}{$\begin{array}{c}\text { H. } \\
\text { medio }\end{array}$} & \multirow{2}{*}{ CSA-1 } & OBS & $\begin{array}{c}100 \% \\
(1)\end{array}$ & - & - & - & - & 1 \\
\hline & & SIL & $\begin{array}{c}60,0 \% \\
\text { (3) }\end{array}$ & $\begin{array}{c}20,0 \% \\
(1)\end{array}$ & $\begin{array}{c}20,0 \% \\
\text { (1) }\end{array}$ & - & - & 5 \\
\hline \multicolumn{3}{|c|}{ Total HM } & $\begin{array}{c}66,7 \% \\
(4) \\
\end{array}$ & $\begin{array}{c}16,7 \% \\
(1) \\
\end{array}$ & $\begin{array}{c}16,7 \% \\
(1) \\
\end{array}$ & - & - & 6 \\
\hline \multicolumn{3}{|c|}{ Total (n) } & 268 & 76 & 21 & 4 & 5 & \multirow{2}{*}{374} \\
\hline \multicolumn{3}{|c|}{ Total (\%) } & 71,7 & 20,3 & 5,6 & 1,1 & 1,3 & \\
\hline
\end{tabular}

Tabla 8.30. Tamaño de los artefactos enteros por materia prima en el Desierto Patagónico. Referencias: MPE: Muy pequeño (0-20 mm); P: Pequeño (21-40); MEP: Mediano pequeño (4160); MEG: Mediano Grande (61-80); MG: Muy Grande (121-160). No se registraron las categorías Grande (G: 81-120 mm) ni Grandísimo (GD: >161 mm).

El 89,0\% (n=333) de los 374 artefactos enteros son desechos de talla, de los cuales, el 1,5\% $(n=5)$ corresponden al HM, el 36,9\% $(n=123)$ al HTI y el 61,6\% $(n=205)$ al HTF. En la Figura 8.41 se presentan los porcentajes de los tamaños de los desechos por materia prima y tiempo. Se puede observar que las categorías de tamaño MPE y P son las predominantes, seguidas por los tamaños MEP y MEG. Estas dos últimas categorías, se dan en baja frecuencia y están ausentes en el HM; y no hay desechos enteros "muy grandes" (MG) en ningún momento. La categoría MEP se registró sobre desechos de obsidiana del HTI y sobre rocas silíceas del HTI y HTF; y la categoría MEG sobre desechos de riolita del HTF, únicamente. 


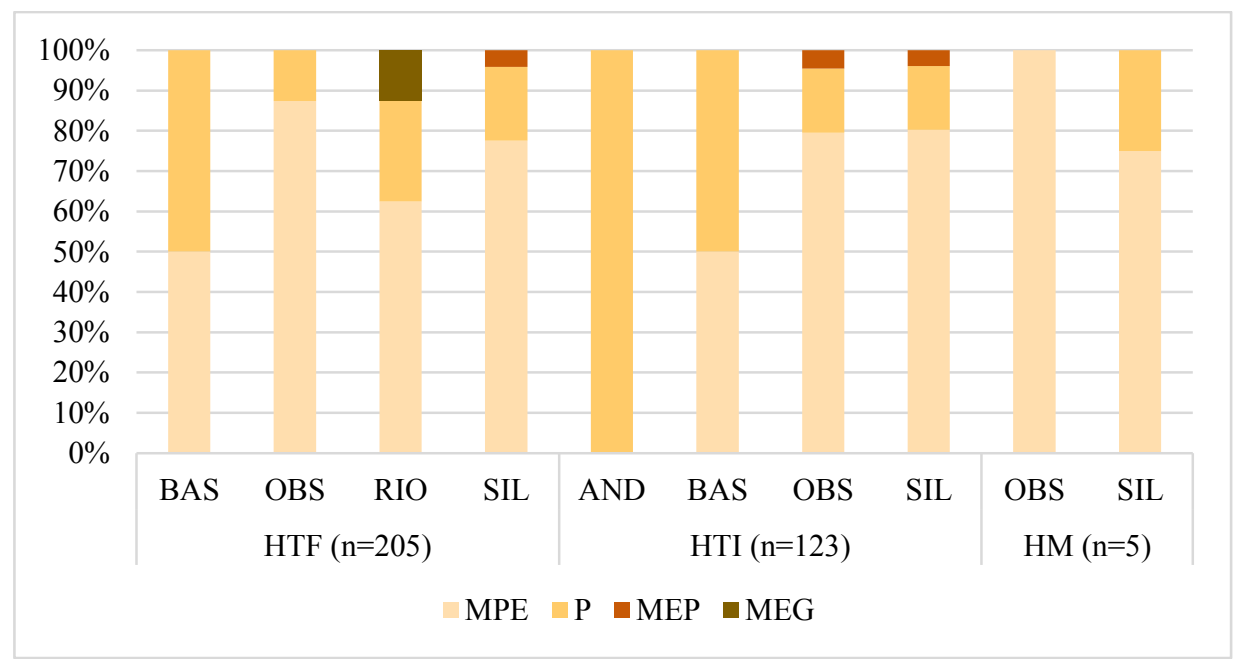

Figura 8.41. Frecuencias relativas de categorías de tamaño en los desechos de talla según la materia prima, a través del tiempo en el Desierto Patagónico.

En el 89,8\% (n=336) de los artefactos enteros no hay reserva de corteza. La misma tendencia se da a través del tiempo. El basalto, seguido por la riolita y la vulcanita indeterminada, son las materias primas donde se registra $100 \%$ de cobertura de la cara dorsal de los artefactos con corteza. En cambio, en las dos materias primas más frecuentes, rocas silíceas y obsidiana, raramente se alcanza el 50\% de reserva de corteza, y sólo en el segmento del HTF de CSA-1, las rocas silíceas tienen dos ejemplares con el $75 \%$ de su cara dorsal cubierto por corteza (Tabla 8.31). En AR-6 sólo un artefacto entero de roca silícea (cuadrícula A1) y otro de riolita (A2), presentan 25 y $50 \%$ de corteza, respectivamente, estando ausente en el resto de los artefactos de este sitio. Como se ha mencionado, deben conocerse lo mejor posible la procedencia y el modo en que se presentan las materias primas, ya que esto puede influir en la cantidad de corteza presente en los artefactos (Sullivan y Rozen 1985; Shott 1994; Charlin 2007). Tanto en el piedemonte andino, donde se localiza CSA-1, como en la localidad Arbolito, la andesita, el basalto, el cuarzo, la riolita y la vulcanita indeterminada se encuentran inmediatamente disponibles y todas ellas poseen corteza. La fuente de basalto de la Formación Colonia de los Coroneles (González Díaz 1964; Lagiglia 1968), en la cuenca del río Diamante, y la fuente de obsidiana El Peceño (Durán et al. 2004; Giesso et al. 2011a; Salgán y Pompei 2017), en el Área El Nevado, poseen corteza y se consideran locales en los sitios de la localidad Arbolito, pero no locales en CSA-1. Otras fuentes de obsidiana se hallan a distancias no locales de los cuatro sitios correspondientes al Desierto Patagónico. De ellas, la fuente Coche Quemado (registrada en CSA-1; véase Sección 8.3) localizada en el cauce medio del río Grande, se presenta en forma de nódulos que corresponden a la 
sección basal de la Formación Agua de la Piedra del Oligoceno y forman parte de los "Rodados Lustrosos" (Combina y Nullo 2011). Dichos nódulos presentan una corteza lustrosa a modo de pátina y poseen un diámetro aproximado de entre 4 y $5 \mathrm{~cm}$ (Salgán et al. 2017). Las rocas silíceas suelen presentar corteza y se encuentran a distancias locales de estos sitios; de hecho, una fuente se encuentra inmediatamente disponible de CSA-1, sitio donde esta materia prima supera a la obsidiana.

\begin{tabular}{|c|c|c|c|c|c|c|c|c|}
\hline Tiempo & Sitio & MP & $0 \%$ & $25 \%$ & $50 \%$ & $75 \%$ & $100 \%$ & Total \\
\hline \multirow{13}{*}{ 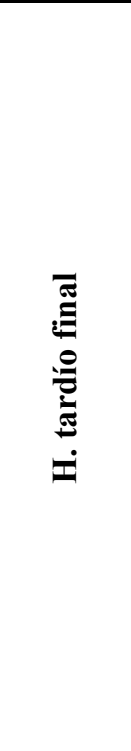 } & \multirow{4}{*}{ CSA-1 } & BAS & $16,7 \%(1)$ & $16,7 \%(1)$ & $16,7 \%(1)$ & - & $50,0 \%(3)$ & 6 \\
\hline & & OBS & $95,9 \%(94)$ & $3,1 \%(3)$ & $1,0 \%(1)$ & - & - & 98 \\
\hline & & SIL & $89,6 \%(86)$ & $4,2 \%(4)$ & $4,2 \%(4)$ & $2,1 \%(2)$ & - & 96 \\
\hline & & VUL & - & - & - & - & $100 \%(2)$ & 2 \\
\hline & \multirow{3}{*}{$\begin{array}{l}\text { AR-6 } \\
\text { (A1) }\end{array}$} & OBS & $100 \%(3)$ & - & - & - & - & 3 \\
\hline & & RIO & $100 \%(3)$ & - & - & - & - & 3 \\
\hline & & SIL & $88,9 \%(8)$ & $11,1 \%(1)$ & - & - & - & 9 \\
\hline & \multirow{2}{*}{$\begin{array}{l}\text { AR-6 } \\
\text { (A2) }\end{array}$} & OBS & $100 \%(2)$ & - & - & - & - & 2 \\
\hline & & RIO & - & - & $100 \%(1)$ & - & - & 1 \\
\hline & AR-7 & SIL & $100 \%(1)$ & - & - & - & - & 1 \\
\hline & \multirow{3}{*}{ BDP-1 } & OBS & $50,0 \%(1)$ & - & $50,0 \%(1)$ & - & - & 2 \\
\hline & & RIO & $50,0 \%(2)$ & $25,0 \%(1)$ & - & - & $25,0 \%(1)$ & 4 \\
\hline & & SIL & $100 \%(5)$ & - & - & - & - & 5 \\
\hline \multicolumn{3}{|c|}{ Total HTF } & $88,8 \%(206)$ & $4,3 \%(10)$ & $3,4 \%(8)$ & $0,9 \%(2)$ & $2,6 \%(6)$ & 232 \\
\hline \multirow{4}{*}{ } & \multirow{4}{*}{ CSA-1 } & AND & - & - & - & $100 \%(1)$ & - & 1 \\
\hline & & BAS & $50,0 \%(3)$ & - & - & - & $50,0 \%(3)$ & 6 \\
\hline & & OBS & $97,9 \%(6)$ & $2,1 \%(1)$ & - & - & - & 47 \\
\hline & & SIL & $92,7 \%(76)$ & $6,1 \%(5)$ & $1,2 \%(1)$ & - & - & 82 \\
\hline \multicolumn{3}{|c|}{ Total HTI } & $91,9 \%(125)$ & $4,4 \%(6)$ & $0,7 \%(1)$ & $0,7 \%(1)$ & $2,2 \%(3)$ & 136 \\
\hline \multirow{2}{*}{$\begin{array}{c}\mathrm{H} . \\
\text { medio }\end{array}$} & \multirow{2}{*}{ CSA-1 } & OBS & $100 \%(1)$ & - & - & - & - & 1 \\
\hline & & SIL & $80,0 \%$ (4) & $20,0 \%(1)$ & - & - & - & 5 \\
\hline \multicolumn{3}{|c|}{ Total HM } & $83,3 \%(5)$ & $16,7 \%(1)$ & - & - & - & 6 \\
\hline \multicolumn{3}{|c|}{ Total (n) } & 336 & 17 & 9 & 3 & 9 & \multirow{2}{*}{374} \\
\hline \multicolumn{3}{|c|}{ Total (\%) } & 89,8 & 4,5 & 2,4 & 0,8 & 2,4 & \\
\hline
\end{tabular}

Tabla 8.31. Porcentaje de reserva de corteza por materia prima en artefactos enteros del Desierto Patagónico a través del tiempo.

En la Figura 8.42, se observa que, dentro del Holoceno tardío, de las dos rocas más frecuentes, las silíceas disminuyen y la obsidiana aumenta del HTI al HTF. Por su parte, en el HM las silíceas casi duplican a la obsidiana, y no se registraron riolitas, 
vulcanitas indeterminadas, andesitas ni cuarzos durante este periodo; estas últimas, sí aparecen en el HTI, aportando mayor diversidad de materias primas a los conjuntos. En el HTF disminuye la frecuencia de estas clases de rocas secundarias, aunque la riolita es relativamente abundante entre los sitios de la localidad Arbolito.

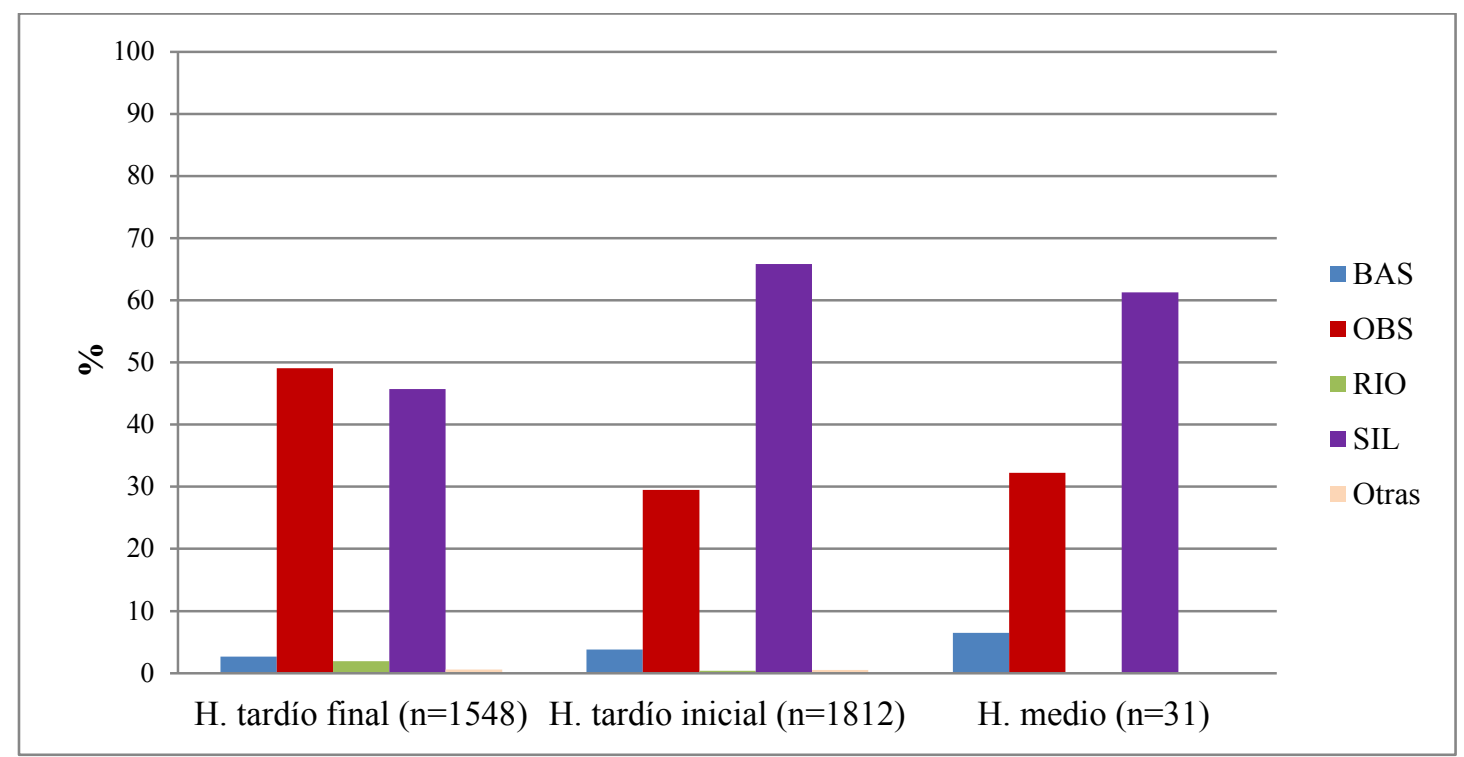

Figura 8.42. Frecuencias relativas de clases de rocas a través del tiempo en el Desierto Patagónico. La categoría de materias primas "Otras" incluye andesitas, cuarzos, vulcanitas indeterminadas y rocas indeterminadas.

\subsubsection{ESTRUCTURA TECNOLÓGICA EN EL DESIERTO PATAGÓNICO}

La clase artefactual predominante en los cuatro sitios analizados (CSA-1, AR-6 A1 y A2-, AR-7 y BDP-1) es la de los desechos de talla $(95,85 \%, n=3250)$, que aumentan del HM al HTI, pero luego vuelven a descender hacia el HTF, momento en el cual, sus porcentajes son incluso menores a los del HM (Tabla 8.32). Esto tiene que ver con el aumento -salvo pocas excepciones como los ecofactos y los pigmentos-, del resto de las clases artefactuales las cuales se hallan ausentes durante el HM (excepto los instrumentos bifaciales representados por una única punta de proyectil con pedúnculo; véase Figura 8.16). Los instrumentos constituyen la segunda clase artefactual más frecuente alcanzando el 2,89\% $(\mathrm{n}=98)$, seguida por los ASF RC $(0,65 \%, n=22$; ausentes en la cuadrícula A2 de AR-6 y en el sitio AR-7); ambas clases, aumentan del HTI al HTF. Siguen en frecuencia los ecofactos $(0,35 \%, \mathrm{n}=12$; ausentes en AR-6 -A2, AR-7 y BDP1); estos disminuyen hacia el HTF. Luego, los pigmentos (en el Conjunto B de CSA-1; presentes sólo durante el HTI) y los nódulos (en AR-6 -A1- y en AR-7; presentes 
únicamente en el HTF) se presentan en la misma frecuencia $(0,09 \%, n=3)$. Le siguen los núcleos $(0,006 \%, \mathrm{n}=2)$, presentes únicamente en la cuadrícula A1 de AR-6 y en BDP-1 (HTF), y un potencial percutor funcional $(0,03 \%)$ hallado en CSA-1, en el conjunto temporal correspondiente al HTF (Tabla 8.32).

\begin{tabular}{|c|c|c|c|c|c|c|c|c|c|c|c|c|c|c|c|c|}
\hline 高 & 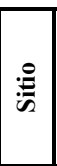 & MP & DT & $\begin{array}{c}\text { AF } \\
\text { Bifacia } \\
\quad \text { l }\end{array}$ & $\begin{array}{c}\text { AF } \\
\text { Unifa } \\
\mathbf{c}\end{array}$ & $\begin{array}{c}\text { AF } \\
\text { Comp } \\
.\end{array}$ & $\begin{array}{c}\text { Art. } \\
\text { m. } \\
\text { por } \\
\text { A, P, } \\
\text { P }\end{array}$ & $\begin{array}{l}\text { AF } \\
\text { ND }\end{array}$ & $\begin{array}{c}\text { ASF } \\
\text { RC }\end{array}$ & $\mathbf{P}$ & $\mathbf{N U}$ & Nód. & PPF & Ecof & Pgm & Total \\
\hline \multirow{21}{*}{ 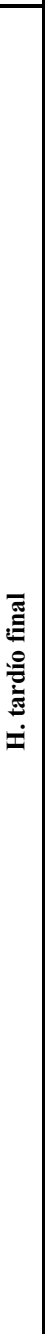 } & \multirow{6}{*}{ 交 } & BAS & $\begin{array}{c}84,8 \% \\
(28)\end{array}$ & - & - & - & $\begin{array}{l}6,1 \% \\
(2)\end{array}$ & - & - & $\begin{array}{l}6,1 \% \\
(2)\end{array}$ & - & - & - & $\begin{array}{c}3,0 \% \\
(1)\end{array}$ & - & 33 \\
\hline & & OBS & $\begin{array}{c}95,3 \% \\
(688)\end{array}$ & $\begin{array}{c}2,5 \% \\
(18) \\
\end{array}$ & $\begin{array}{c}0,6 \% \\
\text { (4) }\end{array}$ & \begin{tabular}{|c|}
$0,1 \%$ \\
$(1)$
\end{tabular} & - & $\begin{array}{c}0,1 \% \\
\text { (1) }\end{array}$ & $\begin{array}{c}1,4 \% \\
(10)\end{array}$ & - & - & - & - & - & - & 722 \\
\hline & & RIO & $\begin{array}{c}100 \% \\
(6)\end{array}$ & - & - & - & - & - & - & - & - & - & - & - & - & 6 \\
\hline & & SIL & $\begin{array}{c}96,2 \% \\
(628)\end{array}$ & $\begin{array}{c}1,4 \% \\
(9)\end{array}$ & $\begin{array}{c}1,7 \% \\
(11)\end{array}$ & $\begin{array}{c}0,5 \% \\
(3)\end{array}$ & - & - & $\begin{array}{c}0,3 \% \\
\text { (2) }\end{array}$ & - & - & - & - & - & - & 653 \\
\hline & & VUL & - & - & - & - & - & - & - & $\begin{array}{r}75,0 \\
\%(3) \\
\end{array}$ & - & - & $\begin{array}{c}25,0 \\
\%(1) \\
\end{array}$ & - & - & 4 \\
\hline & & \begin{tabular}{|l|} 
Indet \\
\end{tabular} & - & - & - & - & - & - & - & - & - & - & - & $\begin{array}{c}100 \% \\
(1) \\
\end{array}$ & - & 1 \\
\hline & \multirow{4}{*}{ 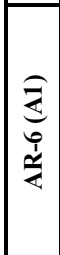 } & BAS & $\begin{array}{c}33,3 \% \\
\text { (1) }\end{array}$ & - & - & - & - & - & - & - & - & - & - & $\begin{array}{c}66,7 \\
\%(2)\end{array}$ & - & 3 \\
\hline & & OBS & $\begin{array}{c}78,3 \% \\
(18) \\
\end{array}$ & $\begin{array}{c}4,3 \% \\
(1)\end{array}$ & - & - & - & - & $\begin{array}{c}13,0 \\
\%(3)\end{array}$ & - & - & $\begin{array}{c}4,3 \% \\
(1) \\
\end{array}$ & - & - & - & 23 \\
\hline & & RIO & $\begin{array}{c}83,3 \% \\
(5) \\
\end{array}$ & - & - & - & - & - & - & - & - & - & - & $\begin{array}{c}16,7 \\
\%(1) \\
\end{array}$ & - & 6 \\
\hline & & SIL & $\begin{array}{c}89,7 \% \\
(26) \\
\end{array}$ & - & $\begin{array}{c}6,9 \% \\
(2)\end{array}$ & - & - & - & - & - & $\begin{array}{c}3,4 \% \\
\text { (1) }\end{array}$ & - & - & - & - & 29) \\
\hline & \multirow{3}{*}{ 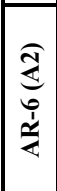 } & OBS & $\begin{array}{c}40,0 \% \\
(2)\end{array}$ & $\begin{array}{c}60,0 \% \\
\text { (3) }\end{array}$ & - & - & - & - & - & - & - & - & - & - & - & 5 \\
\hline & & RIO & $\begin{array}{c}100 \% \\
(1)\end{array}$ & - & - & - & - & - & - & - & - & - & - & - & - & 1 \\
\hline & & SIL & $\begin{array}{c}100 \% \\
(5)\end{array}$ & - & - & - & - & - & - & - & - & - & - & - & - & 5 \\
\hline & \multirow{3}{*}{ 宅 } & RIO & $\begin{array}{c}100 \% \\
(1)\end{array}$ & - & - & - & - & - & - & - & - & - & - & - & - & 1 \\
\hline & & QZ & - & - & - & - & - & - & - & - & - & $\begin{array}{c}100 \\
\%(2)\end{array}$ & - & - & - & 2 \\
\hline & & SIL & $\begin{array}{c}60,0 \% \\
\text { (3) }\end{array}$ & - & $\begin{array}{c}40,0 \% \\
\text { (2) }\end{array}$ & - & - & - & - & - & - & - & - & - & - & 5 \\
\hline & \multirow{5}{*}{ 高 } & BAS & $\begin{array}{c}20,0 \% \\
(1) \\
\end{array}$ & - & - & - & $\begin{array}{c}80,0 \\
\%(4)\end{array}$ & - & - & - & - & - & - & - & - & 5 \\
\hline & & OBS & $\begin{array}{c}80,0 \% \\
(8)\end{array}$ & - & - & - & - & - & $\begin{array}{c}10,0 \\
\%(1)\end{array}$ & - & $\begin{array}{c}10,0 \\
\%(1)\end{array}$ & - & - & - & - & 10 \\
\hline & & RIO & $\begin{array}{c}100 \% \\
(16)\end{array}$ & - & - & - & - & - & - & - & - & - & - & - & - & 16 \\
\hline & & SIL & \begin{tabular}{|c}
$68,8 \%$ \\
$(11)$ \\
\end{tabular} & $\begin{array}{c}6,3 \% \\
(1) \\
\end{array}$ & $\begin{array}{c}6,3 \% \\
(1) \\
\end{array}$ & \begin{tabular}{|c|}
$6,3 \%$ \\
$(1)$ \\
\end{tabular} & - & - & $\begin{array}{c}12,5 \\
\%(2) \\
\end{array}$ & - & - & - & - & - & - & 16 \\
\hline & & VUL & $\begin{array}{c}100 \% \\
(2)\end{array}$ & - & - & - & - & - & - & - & - & - & - & - & - & 2 \\
\hline \multicolumn{3}{|c|}{ Total HTF } & \begin{tabular}{|c|}
93,7 \\
$\%$ \\
$(1450)$ \\
\end{tabular} & $\begin{array}{c}2,1 \% \\
(32)\end{array}$ & $\begin{array}{c}1,3 \% \\
(20)\end{array}$ & $\begin{array}{c}\mathbf{0 , 3} \% \\
(5)\end{array}$ & $\begin{array}{c}0,4 \% \\
\text { (6) }\end{array}$ & $\begin{array}{c}0,1 \\
\% \\
(1) \\
\end{array}$ & $\begin{array}{c}1,2 \% \\
(18)\end{array}$ & $\begin{array}{c}0,3 \% \\
(5)\end{array}$ & $\begin{array}{c}0,1 \% \\
\text { (2) }\end{array}$ & $\begin{array}{c}0,2 \% \\
\text { (3) }\end{array}$ & $\begin{array}{c}0,1 \% \\
(1)\end{array}$ & $\begin{array}{c}\mathbf{0 , 3} \% \\
\text { (5) }\end{array}$ & - & 1548 \\
\hline \multirow{7}{*}{ 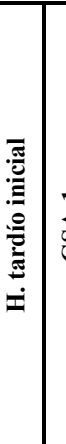 } & \multirow{7}{*}{ 离 } & AND & $\begin{array}{c}100 \% \\
(1)\end{array}$ & - & - & - & - & - & - & - & - & - & - & - & - & 1 \\
\hline & & BAS & $\begin{array}{c}89,9 \% \\
(62)\end{array}$ & $\begin{array}{c}1,4 \% \\
(1)\end{array}$ & - & - & $\begin{array}{l}4,3 \% \\
\text { (3) }\end{array}$ & - & - & - & - & - & - & $\begin{array}{l}4,3 \% \\
\text { (3) }\end{array}$ & - & 69 \\
\hline & & OBS & $\begin{array}{c}98,3 \% \\
(525)\end{array}$ & $\begin{array}{c}1,5 \% \\
(8)\end{array}$ & - & - & - & - & $\begin{array}{c}0,2 \% \\
\text { (1) }\end{array}$ & - & - & - & - & - & - & 534 \\
\hline & & RIO & $\begin{array}{c}100 \% \\
(7)\end{array}$ & - & - & . & - & - & - & - & - & - & - & - & - & 7 \\
\hline & & SIL & \begin{tabular}{|l|}
$98,3 \%$ \\
$(1173)$ \\
\end{tabular} & $\begin{array}{c}0,4 \% \\
(5) \\
\end{array}$ & $\begin{array}{c}0,7 \% \\
(8) \\
\end{array}$ & $\begin{array}{c}0,2 \% \\
(2) \\
\end{array}$ & - & $\begin{array}{c}0,1 \% \\
(1)\end{array}$ & $\begin{array}{c}0,3 \% \\
\text { (3) }\end{array}$ & - & - & - & - & $\begin{array}{c}0,1 \% \\
(1) \\
\end{array}$ & - & 1193 \\
\hline & & VUL & $\begin{array}{c}50,0 \% \\
(2)\end{array}$ & - & - & - & - & - & - & - & - & - & - & $\begin{array}{c}50,0 \\
\%(2)\end{array}$ & - & 4 \\
\hline & & QZ & - & - & - & - & - & - & - & - & - & - & - & $\begin{array}{c}100 \% \\
(1)\end{array}$ & - & 1 \\
\hline
\end{tabular}




\begin{tabular}{|c|c|c|c|c|c|c|c|c|c|c|c|c|c|c|c|c|}
\hline & & $\begin{array}{l}\text { Indet } \\
\text {. }\end{array}$ & - & - & - & - & - & - & - & - & - & - & - & - & $\begin{array}{c}100 \\
\%(3) \\
\end{array}$ & 3 \\
\hline \multicolumn{3}{|c|}{ Total HTI } & $\begin{array}{c}97,7 \\
\% \\
(1770)\end{array}$ & $\begin{array}{c}\mathbf{0 , 8 \%} \\
(14)\end{array}$ & $\begin{array}{c}0,4 \% \\
(8)\end{array}$ & $\begin{array}{c}0,1 \% \\
(2)\end{array}$ & $\begin{array}{c}0,2 \% \\
(3)\end{array}$ & $\begin{array}{l}\mathbf{0 , 1} \\
\% \\
(1)\end{array}$ & $\begin{array}{c}0,2 \% \\
(4)\end{array}$ & - & - & - & - & $\begin{array}{c}0,4 \% \\
(7)\end{array}$ & $\begin{array}{c}0,2 \% \\
\text { (3) }\end{array}$ & 1812 \\
\hline \multirow{3}{*}{ 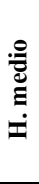 } & \multirow{3}{*}{ 交 } & BAS & $\begin{array}{c}100 \% \\
(2)\end{array}$ & - & - & - & - & - & - & - & - & - & - & - & - & 2) \\
\hline & & OBS & $\begin{array}{c}100 \% \\
(10)\end{array}$ & - & - & - & - & - & - & - & - & - & - & - & - & 10 \\
\hline & & SIL & $\begin{array}{c}94,7 \% \\
(18) \\
\end{array}$ & $\begin{array}{c}5,3 \% \\
(1)\end{array}$ & - & - & - & - & - & - & - & - & - & - & - & 19 \\
\hline \multicolumn{3}{|c|}{ Total HM } & $\begin{array}{c}96,8 \\
\% \\
(30) \\
\end{array}$ & $\begin{array}{c}3,2 \% \\
\text { (1) }\end{array}$ & - & - & - & - & - & - & - & - & - & - & - & 31 \\
\hline \multicolumn{3}{|c|}{ Total (n) } & 3250 & 47 & 28 & 7 & 9 & 2 & 22 & 5 & 2 & 3 & 1 & 12 & 3 & \multirow{2}{*}{$\begin{array}{c}339 \\
1\end{array}$} \\
\hline \multicolumn{3}{|c|}{ Total (\%) } & 95,84 & 1,39 & 0,83 & 0,21 & 0,27 & 0,06 & 0,65 & 0,15 & 0,06 & 0,09 & $\mathbf{0 , 0 3}$ & 0,35 & 0,09 & \\
\hline
\end{tabular}

Tabla 8.32. Clases artefactuales por materia prima a través del tiempo en el Desierto Patagónico. Referencias: T: tiempo; MP: materia prima; AF: artefacto formatizado; Unifac.: unifacial; Art. m. por A, P, P: artefacto manufacturado o modificado por abrasión, picado y/o pulido; AF ND: artefacto formatizado no diferenciado; $A S F R C$ : artefacto sin formatización con rastros complementarios; NU: núcleo; Nód: nódulo; P: percutor; Ecof.: ecofacto; Pgm.: pigmento.

\subsubsection{Desechos de talla}

Las lascas internas constituyen el $86,79 \%(n=289)$ del total de desechos de talla enteros analizados en los cuatro sitios del Desierto Patagónico. De estas, las angulares conforman el 77,85\% (n=225) y las de arista el 22,15\% $(n=64)$ restante. El 8,11\% $(n=27)$ corresponde a las lascas de formatización de filo. De ellas, el 44,44\% $(n=12)$ son lascas planas, el 40,74\% $(n=11)$ lascas de adelgazamiento bifacial y el $14,81 \%$ restante $(n=4)$ lascas de reactivación. Las lascas externas representan el 5,11\% $(\mathrm{n}=17)$ y dentro de ellas, las lascas con dorso natural son las mayoritarias $(52,94 \%, n=9)$, seguidas por las secundarias $(29,41 \%, n=5)$. Se registraron también, dos lascas primarias $(11,76 \%)$ y una tableta de núcleo $(5,88 \%)$. Las materias primas presentes en los distintos tipos de lascas enteras, son las rocas silíceas $(53,45 \%)$, la obsidiana $(42,04 \%)$, la riolita $(2,4 \%)$, el basalto $(1,8 \%)$ y la andesita $(0,3 \%)$; esta última roca se registró en una única lasca entera (secundaria), por lo cual, no se la consideró en la Figura 8.43. Cuando se incorporan los desechos fracturados y el resto de las clases artefactuales, las rocas silíceas y la obsidiana siguen ocupando el primer y segundo lugar, respectivamente, pero el tercero pasa a estar representado por el basalto (más frecuente en CSA-1, donde el índice de fractura es elevado) y no por la riolita (más frecuente en la localidad arqueológica Arbolito). En la Figura 8.43 se observa que las tendencias de las lascas de obsidiana y rocas silíceas son parecidas en cuanto a los tipos representados: en ambas se observa el predominio de 
internas, seguidas en frecuencia por las de formatización de filo. Las externas están más presentes sobre rocas silíceas que sobre obsidiana. Entre las lascas de basalto y las de riolita también se aprecian semejanzas: predominan las internas aunque, entre las de basalto son más frecuentes las de arista, y entre las de riolita abundan las angulares; se distinguen en la presencia de lascas de dorso natural sobre basalto y planas sobre riolita (Figura 8.43).

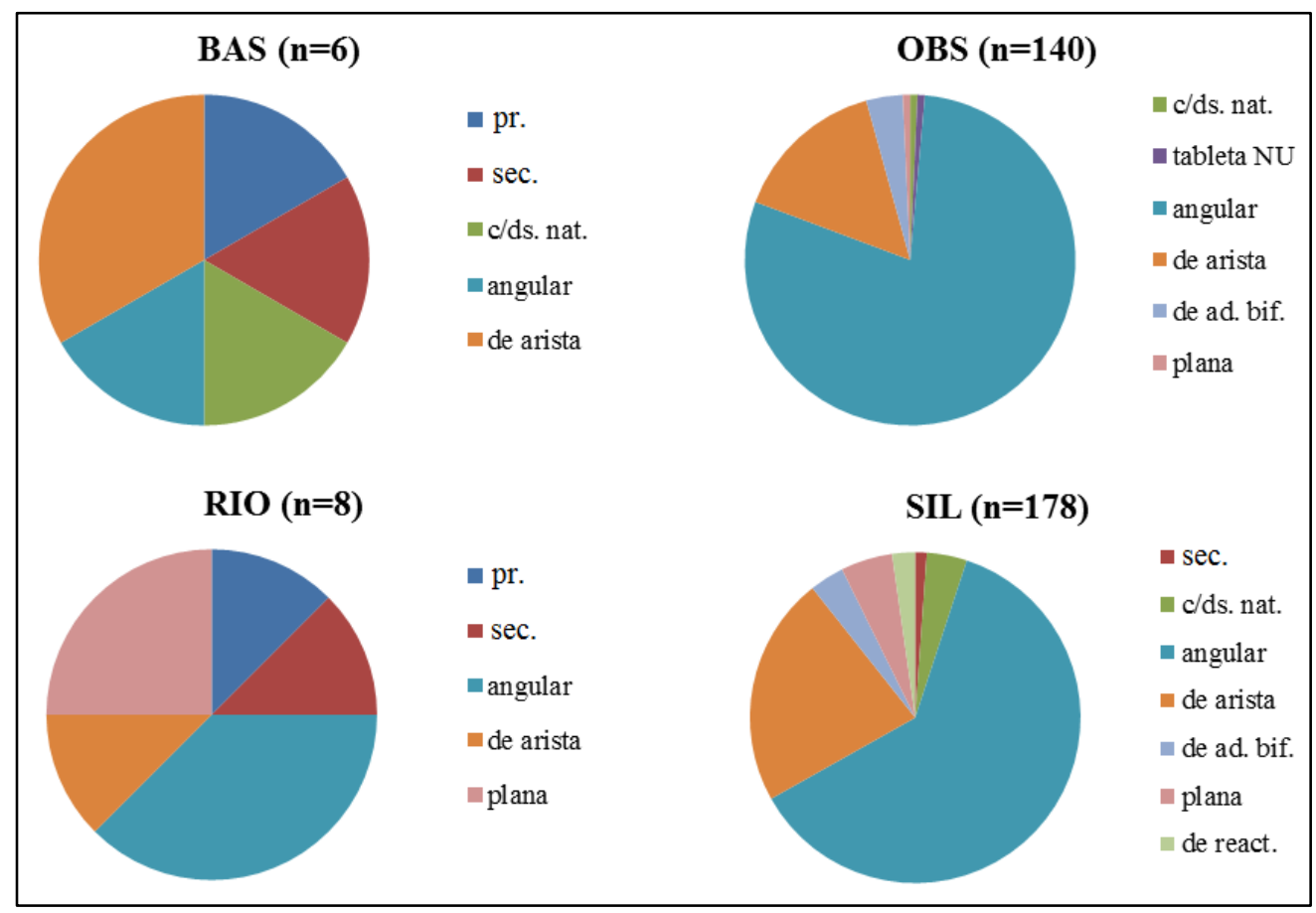

Figura 8.43. Frecuencias relativas de tipos de lasca por materia prima en el Desierto Patagónico.

No se incluyó una lasca secundaria de andesita. Entre paréntesis se indica el número total de

lascas enteras registradas en los cuatro sitios analizados correspondientes al Desierto Patagónico, por materia prima. Referencias: BAS: basalto; OBS; obsidiana; RIO: riolita; SIL: rocas siliceas; pr.: lasca primaria; sec.: lasca secundaria; c/ds. nat.: lasca con dorso natural; tableta NU: tableta de núcleo; de ad. bif.: lasca de adelgazamiento bifacial; de react.: lasca de reactivación.

Como se planteó anteriormente, es necesario considerar el grado de reducción de los desechos de talla, teniendo en cuenta cuál es su índice de corteza (Ericson 1984) (Tabla 8.33) y la relación con la densidad de negativos de lascado o de extracciones previas en la cara dorsal de las lascas enteras (Tabla 8.34). En el 97,90\% ( $n=326)$ de los desechos enteros de los cuatro sitios, no se registraron lascas primarias $(0,6 \%, n=2)$ ni secundarias $(1,5 \%, \mathrm{n}=5)$; en los sitios AR-6 (ambas cuadrículas) y AR-7 no hay lascas 
externas. Los valores más elevados del índice de corteza (Tabla 8.33) se hallan en la andesita de CSA-1, aunque esta corresponde a una única lasca secundaria. Le siguen la riolita, el basalto y las rocas silíceas de BDP-1, en ese mismo orden. No hay lascas primarias sobre rocas silíceas en CSA-1 y ninguna externa sobre esta roca en BDP-1. En ambos sitios no hay lascas externas sobre obsidiana, por lo que es posible que esta roca haya ingresado al piedemonte andino (CSA-1) y de la transición hacia el monte (BDP-1), como formas base o en un estadio avanzado de formatización. En BDP-1 se halló un núcleo de obsidiana entero, no agotado, que se infiere que proviene de la fuente de obsidiana El Peceño, próxima a unos $20 \mathrm{~km}$; es decir, que el núcleo es de procedencia local.

\begin{tabular}{|c|l|c|c|c|c|}
\hline Sitio & MP & $\mathbf{N}$ & $\begin{array}{c}\text { Ls. } \\
\text { pr. }\end{array}$ & $\begin{array}{c}\text { Ls. } \\
\text { sec. }\end{array}$ & $\begin{array}{c}\text { Índice } \\
\text { corteza }\end{array}$ \\
\hline \multirow{4}{*}{ CSA-1 } & AND & 1 & - & 1 & 1,00 \\
\cline { 2 - 6 } & BAS & 6 & 1 & 1 & 0,33 \\
\cline { 2 - 6 } & OBS & 137 & - & - & - \\
\cline { 2 - 6 } & SIL & 169 & - & 2 & 0,01 \\
\hline \multirow{3}{*}{ BDP-1 } & OBS & 1 & - & - & - \\
\cline { 2 - 6 } & RIO & 4 & 1 & 1 & 0,5 \\
\cline { 2 - 6 } & SIL & 2 & - & - & - \\
\hline
\end{tabular}

Tabla 8.33. Índice de corteza y frecuencia de lascas primarias y secundarias enteras por materia prima lítica en los sitios CSA-1 y BDP-1 (Desierto Patagónico). Referencias: MP: materia prima; N: abundancia de desechos de talla enteros; Ls. pr.: lasca primaria; Ls. sec.: lasca secundaria.

En la Tabla 8.34, se observa que la estadística descriptiva de la densidad de extracciones previas en la cara dorsal de las lascas externas e internas es mayor en la obsidiana y en las rocas silíceas de los tres sitios donde se recuperaron lascas enteras (en AR-7 están todas fracturadas), sobre todo en las de obsidiana de AR-6 (A1); pero es muy baja en las de obsidiana de BDP-1. El basalto (con lascas enteras sólo en CSA-1), se presenta con media a baja densidad de extracciones, al igual que la riolita, (ausente en CSA-1, pero presente en la localidad Arbolito, sobre todo en BDP-1, donde la densidad de extracciones previas es muy baja). Esto es coherente con los altos valores del índice de corteza (Tabla 8.33) sobre las rocas con baja densidad de extracciones (Tabla 8.34). 


\begin{tabular}{|c|c|c|c|c|c|c|c|c|}
\hline Sitio & MP & $n$ & Media & Mediana & $\begin{array}{c}\text { Desvío } \\
\text { estándar }\end{array}$ & Mínimo & Máximo & Rango \\
\hline \multirow{4}{*}{ CSA-1 } & AND & 1 & 0,01 & - & - & - & - & - \\
\hline & BAS & 6 & 0,04 & 0,04 & 0,02 & 0 & 0,05 & 0,05 \\
\hline & OBS & 131 & 0,07 & 0,06 & 0,03 & 0,02 & 0,23 & 0,21 \\
\hline & SIL & 152 & 0,07 & 0,06 & 0,04 & 0,01 & 0,30 & 0,30 \\
\hline \multirow{3}{*}{$\begin{array}{l}\text { AR-6 } \\
\text { (A1) }\end{array}$} & OBS & 2 & 0,14 & 0,14 & 0,08 & 0,09 & 0,20 & 0,11 \\
\hline & RIO & 2 & 0,05 & 0,05 & 0,04 & 0,02 & 0,08 & 0,06 \\
\hline & SIL & 6 & 0,09 & 0,08 & 0,04 & 0,03 & 0,14 & 0,11 \\
\hline $\begin{array}{c}\text { AR-6 } \\
\text { (A2) } \\
\end{array}$ & RIO & 1 & 0 & - & - & - & - & - \\
\hline \multirow{3}{*}{ BDP-1 } & OBS & 1 & 0,02 & - & - & - & - & - \\
\hline & RIO & 3 & 0,02 & 0,02 & 0,02 & 0 & 0,04 & 0,04 \\
\hline & SIL & 1 & 0,09 & - & - & - & - & - \\
\hline
\end{tabular}

Tabla 8.34. Estadística descriptiva de la densidad de extracciones previas en la cara dorsal de los desechos de talla enteros del Desierto Patagónico.

De las lascas de formatización de filo registradas sobre obsidiana, riolita y rocas silíceas (Figura 8.44), sólo sobre esta última $(70,37 \%, \mathrm{n}=19)$ se registraron los tres tipos: lascas planas (47,37\%), de adelgazamiento bifacial (31,58\%) y de reactivación $(21,05 \%)$. Las lascas de formatización de filo de obsidiana $(22,22 \%, n=6)$ son de adelgazamiento bifacial $(83,33 \%)$ y planas $(16,67 \%)$. Las dos de riolita $(7,41 \%)$, son planas. Las lascas planas $(n=12)$ son las únicas registradas para el HM (registrado en CSA-1), momento en el cual constituyen el 25\% ( $n=3)$, y sólo están representadas por lascas de rocas silíceas. Luego, en el HTI (CSA-1), se incorporan las lascas planas de obsidiana $(25 \%, \mathrm{n}=1)$ y la frecuencia absoluta de lascas planas de silíceas es la misma $(n=3)$. Entonces, durante el HTI, las lascas planas están representadas por el 33,33\%; algo más que durante el HM, pero menos que en el HTF (CSA-1 más AR-6 y BDP-1), donde conforman el 41,67\% $(\mathrm{n}=5)$. En este momento más reciente, se incorporan las dos lascas planas de riolita $(40 \%)$ y las de rocas silíceas siguen manteniendo su frecuencia absoluta $(n=3)$. Las lascas de adelgazamiento bifacial $(\mathrm{n}=11)$, presentes sólo en obsidiana y rocas silíceas de CSA-1, están ausentes en el HM, se presentan sólo sobre rocas silíceas en el HTI (18,18\%, n=2) y aumentan hacia el HTF $(81,81 \%, n=9)$, siendo mayoritarias en obsidiana $(55,55 \%, n=5)$ que en rocas silíceas $(44,44 \%, n=4)$. Por último, las lascas de reactivación $(n=4)$, todas sobre rocas silíceas, están ausentes durante el HM; se registró una sola durante el HTI $(25 \%, \mathrm{n}=1)$ y las otras tres corresponden al HTF (CSA-1, AR-6 -A1- y BDP-1, una por sitio) (Figura 8.44). 


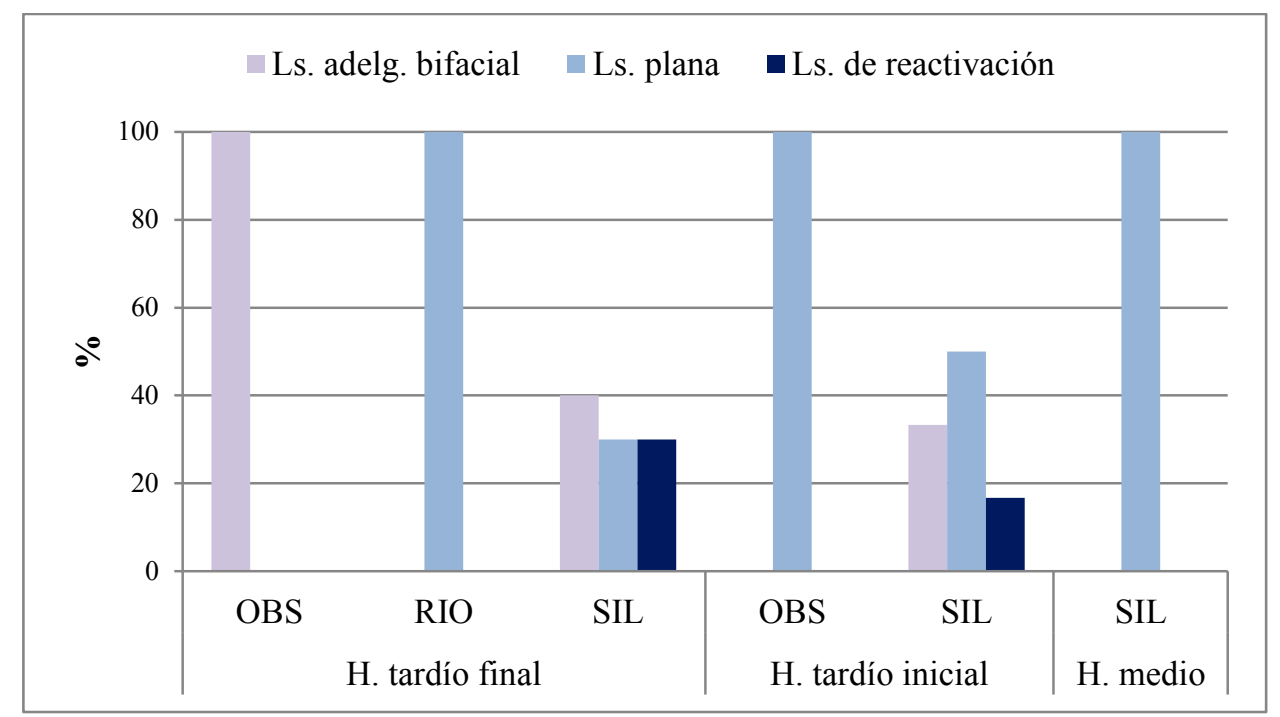

Figura 8.44. Frecuencia de tipos de lascas de formatización de filo a través del tiempo en el

Desierto Patagónico.

\subsubsection{Instrumentos}

Los instrumentos constituyen el 2,89\% $(n=98)$ del total de artefactos líticos del Desierto Patagónico. El 84,69\% (n=83) pertenece al sitio CSA-1, el 7,14\% (n=7) procede de BDP-1, el 6,12\% de las cuadrículas A1 ( $n=3)$ y A2 $(n=3)$ del sitio AR-6, y el 2,04\% $(\mathrm{n}=2)$ restante proviene de AR-7. Las materias primas utilizadas para la confección de instrumentos son las rocas silíceas $(47,96 \%, n=47)$, la obsidiana $(36,73 \%, n=36)$, el basalto $(12,24 \%, n=12)$ y la vulcanita indeterminada $(3,06 \%, n=3)$. Los instrumentos más representados son los de formatización bifacial $(47,96 \%, n=47)$, mayormente confeccionados sobre obsidiana $(63,83 \%, n=30)$, aunque también están presentes sobre rocas silíceas $(34,04 \%, \mathrm{n}=16)$ y basalto $(2,13 \%, \mathrm{n}=1)$. Esta clase de instrumentos es la única presente en el HM, HTI y HTF, siendo sus frecuencias absolutas, mayores durante el HTF. Siguen en frecuencia los instrumentos unifaciales $(28,57 \%, n=28)$; estos son predominantes sobre rocas silíceas $(85,71 \%, n=24)$; pero también se confeccionaron sobre obsidiana $(14,29 \%, \mathrm{n}=4)$. Asimismo, aumentan hacia el HTF, donde alcanzan el $71,43 \%(\mathrm{n}=20)$. Los artefactos manufacturados o modificados por abrasión, picado y/o pulido $(9,18 \%, \mathrm{n}=9)$ se registraron únicamente sobre basalto, en CSA-1 y sólo para el segmento de tiempo correspondiente al HTF. Le siguen los instrumentos compuestos $(7,14 \%, n=7)$, presentes sobre rocas silíceas $(85,71 \%, n=6)$ y uno sobre obsidiana; mayormente representados durante el $\operatorname{HTF}(71,43 \%, n=5)$. Los percutores $(5,10 \%, n=5)$ están presentes en basalto $(40 \%, \mathrm{n}=2)$, pero son más frecuentes sobre vulcanita 
indeterminada $(60 \%, n=3)$, roca registrada únicamente sobre esta clase de instrumentos; los cinco corresponden al HTF. Completan el total de instrumentos dos artefactos de formatización no diferenciada (AF ND) $(2,04 \%)$, la mitad sobre obsidiana $(50 \%, n=1)$ y la otra mitad sobre rocas silíceas.

En suma, cada clase instrumental aumenta hacia el HTF. Sin embargo, cuando se comparan en conjunto las proporciones de los distintos instrumentos y ASF RC por segmento temporal (Tabla 8.35), los porcentajes disminuyen a través del tiempo, salvo en el caso de los percutores (ausentes en el tardío inicial) y de los ASF RC (más frecuentes en el HTF). Esta última clase artefactual se suma al total de instrumentos, constituyendo el 18,33\% ( $\mathrm{n}=22$ de 120 instrumentos y ASF RC); son más frecuentes sobre obsidiana $(68,18 \%, \mathrm{n}=15)$, que sobre rocas silíceas $(31,82 \%, \mathrm{n}=7)$, y aumentan del HTI $(18,18 \%$, n=4), al HTF (81,81\%, n=18). En la Tabla 8.35 se presentan las frecuencias de las distintas clases instrumentales (véase Capítulo 5) y los ASF RC, por materia prima, sitio arqueológico y segmento temporal dentro del Holoceno.

\begin{tabular}{|c|c|c|c|c|c|c|c|c|c|c|}
\hline $\mathbf{T}$ & Sitio & MP & $\begin{array}{c}\mathbf{A F} \\
\text { Bifacial }\end{array}$ & $\underset{\text { Unifac }}{\text { AF }}$ & $\begin{array}{c}\mathbf{A F} \\
\text { comp }\end{array}$ & $\begin{array}{c}\text { Art. } \\
\text { manuf. } \\
\text { por } \\
\mathbf{A , P , P}\end{array}$ & $\begin{array}{l}\text { AF } \\
\text { ND }\end{array}$ & $\begin{array}{l}\text { ASF } \\
\text { RC }\end{array}$ & $\mathbf{P}$ & Total \\
\hline \multirow{11}{*}{ 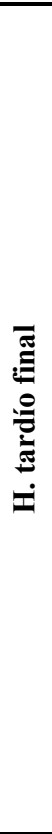 } & \multirow{4}{*}{ CSA-1 } & BAS & - & - & - & $\begin{array}{c}50,00 \% \\
\text { (2) }\end{array}$ & - & - & $\begin{array}{c}50,00 \% \\
\text { (2) }\end{array}$ & 4 \\
\hline & & OBS & $\begin{array}{c}52,9 \% \\
(18)\end{array}$ & $\begin{array}{c}11,8 \% \\
(4)\end{array}$ & $\begin{array}{c}2,9 \% \\
(1) \\
\end{array}$ & - & $\begin{array}{c}2,9 \% \\
(1)\end{array}$ & $\begin{array}{c}29,4 \% \\
(10) \\
\end{array}$ & - & 34 \\
\hline & & SIL & $\begin{array}{c}36,0 \% \\
(9)\end{array}$ & $\begin{array}{c}44,0 \% \\
(11)\end{array}$ & $\begin{array}{c}12,0 \% \\
(3)\end{array}$ & - & - & $\begin{array}{c}8,0 \% \\
(2)\end{array}$ & - & 25 \\
\hline & & VUL & - & - & - & - & - & - & $\begin{array}{c}100 \% \\
(3)\end{array}$ & 3 \\
\hline & \multirow{2}{*}{$\begin{array}{l}\text { AR-6 } \\
\text { (A1) }\end{array}$} & OBS & $\begin{array}{c}25,0 \% \\
(1) \\
\end{array}$ & - & - & - & - & $\begin{array}{c}75,0 \% \\
(3)\end{array}$ & - & 4 \\
\hline & & SIL & - & $\begin{array}{l}100 \% \\
(2)\end{array}$ & - & - & - & - & - & 2 \\
\hline & $\begin{array}{c}\text { AR-6 } \\
\text { (A2) }\end{array}$ & OBS & $\begin{array}{c}100 \% \\
(3)\end{array}$ & - & - & - & - & - & - & 3 \\
\hline & AR-7 & SIL & - & $\begin{array}{l}100 \% \\
(2)\end{array}$ & - & - & - & - & - & 2 \\
\hline & \multirow{3}{*}{ BDP-1 } & BAS & - & - & - & $\begin{array}{c}100 \% \\
(4)\end{array}$ & - & - & - & 4 \\
\hline & & OBS & - & - & - & - & - & $\begin{array}{c}100 \% \\
(1)\end{array}$ & - & 1 \\
\hline & & SIL & $\begin{array}{c}20,0 \% \\
(1)\end{array}$ & $\begin{array}{c}20,0 \% \\
(1)\end{array}$ & $\begin{array}{c}20,0 \% \\
(1)\end{array}$ & - & - & $\begin{array}{c}40,0 \% \\
(2)\end{array}$ & - & 5 \\
\hline \multicolumn{3}{|c|}{ Total HTF } & \begin{tabular}{|c|}
$36,78 \%$ \\
$(32)$ \\
\end{tabular} & $\begin{array}{c}22,99 \% \\
(20) \\
\end{array}$ & $\begin{array}{c}5,75 \% \\
(5) \\
\end{array}$ & $\begin{array}{c}6,90 \% \\
(6)\end{array}$ & $\begin{array}{l}1,15 \% \\
\text { (1) }\end{array}$ & $\begin{array}{c}20,69 \% \\
(18) \\
\end{array}$ & \begin{tabular}{|c|}
$5,75 \%$ \\
$(5)$ \\
\end{tabular} & 87 \\
\hline \multirow{3}{*}{ 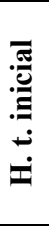 } & \multirow{3}{*}{ CSA-1 } & BAS & $\begin{array}{c}25,0 \% \\
(1) \\
\end{array}$ & - & - & $\begin{array}{c}75,0 \% \\
(3) \\
\end{array}$ & - & - & - & 4 \\
\hline & & OBS & $\begin{array}{c}88,9 \% \\
(8)\end{array}$ & - & - & - & - & $\begin{array}{c}11,1 \% \\
(1)\end{array}$ & - & 9 \\
\hline & & SIL & $\begin{array}{c}26,3 \% \\
(5)\end{array}$ & $\begin{array}{c}42,1 \% \\
(8)\end{array}$ & $\begin{array}{c}10,5 \% \\
(2)\end{array}$ & - & $\begin{array}{c}5,3 \% \\
(1)\end{array}$ & $\begin{array}{c}15,8 \% \\
(3)\end{array}$ & - & 19 \\
\hline
\end{tabular}




\begin{tabular}{|c|c|c|c|c|c|c|c|c|c|c|}
\hline \multicolumn{2}{|c|}{ Total HTI } & $\begin{array}{c}43,75 \% \\
(14)\end{array}$ & $\begin{array}{c}25,00 \% \\
(8)\end{array}$ & $\begin{array}{c}6,25 \% \\
(2)\end{array}$ & $\begin{array}{c}\mathbf{9 , 3 8 \%} \\
(3)\end{array}$ & $\begin{array}{c}3,13 \% \\
(1)\end{array}$ & $\begin{array}{c}12,50 \% \\
(4)\end{array}$ & - & 32 \\
\hline $\begin{array}{c}\text { H. } \\
\text { medio }\end{array}$ & CSA-1 & SIL & $\begin{array}{c}100 \% \\
(1)\end{array}$ & - & - & - & - & - & - & 1 \\
\hline \multicolumn{2}{|c|}{ Total HM } & $\begin{array}{c}100 \% \\
(1)\end{array}$ & - & - & - & - & - & - & 1 \\
\hline \multicolumn{2}{|c|}{ Total (n) } & 47 & 28 & 7 & 9 & 2 & 22 & 5 & \multirow{2}{*}{120} \\
\hline \multicolumn{2}{|c|}{ Total (\%) } & 39,17 & 23,33 & 5,83 & 7,50 & 1,67 & 18,33 & 4,17 & \\
\hline
\end{tabular}

Tabla 8.35. Frecuencia de instrumentos y ASF RC en el Desierto Patagónico a través del tiempo. Referencias: T: tiempo; MP: materia prima; AF: Artefacto formatizado; Unifac.: unifacial; Comp.: compuesto; Art. manuf. por A,P,P: Artefacto manufacturado o modificado por abrasión, picado y/o pulido; ND: no diferenciado; ASF RC: artefacto sin formatización con rastros complementarios; P: percutor; BAS: basalto; OBS: obsidiana; SIL: rocas silíceas;

\section{VUL: vulcanita indeterminada.}

En la Tabla 8.36 se presenta la diversidad de materias primas seleccionadas para la confección de instrumentos. El índice de diversidad más alto corresponde a los artefactos bifaciales, manufacturados preferentemente sobre obsidiana, luego sobre silíceas y -en un caso- sobre basalto. Los artefactos formatizados no diferenciados y los percutores son escasos, pero se presentan en más de una materia prima (obsidiana y silíceas; y basalto y vulcanita indeterminada, respectivamente). En cambio, los nueve artefactos manufacturados por abrasión, picado y/o pulido son de basalto. La obsidiana y las rocas silíceas también están representadas en ASF RC (sobre todo en obsidiana) y en instrumentos unifaciales y compuestos (mayoritariamente sobre silíceas).

\begin{tabular}{|l|c|c|c|c|c|c|c|}
\hline & $\begin{array}{c}\text { AF } \\
\text { Bifacial }\end{array}$ & $\begin{array}{c}\text { AF } \\
\text { Unifacial }\end{array}$ & $\begin{array}{c}\text { AF } \\
\text { compuesto }\end{array}$ & $\begin{array}{c}\text { Art. manuf. } \\
\text { por A,P,P }\end{array}$ & AF ND & ASF RC & Percutor \\
\hline $\boldsymbol{n}$ MP & 3 & 2 & 2 & 1 & 2 & 2 & 2 \\
\hline $\boldsymbol{n}$ & 47 & 28 & 7 & 9 & 2 & 22 & 5 \\
\hline Dominancia & 0,5238 & 0,7551 & 0,7551 & 1 & 0,5 & 0,5661 & 0,52 \\
\hline Simpson & 0,4762 & 0,2449 & 0,2449 & - & 0,5 & 0,4339 & 0,48 \\
\hline Shannon-H & 0,7353 & 0,4101 & 0,4101 & - & 0,6931 & 0,6255 & 0,673 \\
\hline
\end{tabular}

Tabla 8.36. Diversidad de materias primas según clases artefactuales en el Desierto Patagónico.

La forma-base de los instrumentos no se pudo definir en el 65,31\% $(n=64)$ de los casos. En los demás instrumentos $(n=34)$ se identificaron las siguientes: 14 lascas angulares $(41,18 \%)$, ocho lascas de tipo no diferenciado $(23,53 \%)$, seis nódulos rodados 
$(6,12 \%)$ dos fragmentos no diferenciados de artefactos formatizados $(5,88 \%)$, un bifaz, un bifaz parcial, un fragmento de punta de proyectil y una lasca secundaria.

La calidad para la talla varía a lo largo del tiempo: en el HM, el único instrumento recuperado está confeccionado sobre una roca silícea de calidad "buena". Luego, en el HTI, predomina la "muy buena", que supera el 55\% del segmento temporal; y en segundo lugar se halla la "excelente". En cambio, durante el HTF, este tipo ocupa el primer lugar (aunque no alcanza el 50\%), quedando la calidad muy buena en segundo lugar. Esto se vincula con el predominio de obsidiana en el segmento temporal más reciente. No se han registrado materias primas de calidad "regular" y en los nueve artefactos manufacturados o modificados por abrasión, picado y/o pulido, y los cinco percutores, "no aplica" (NA) esta variable (Tabla 8.37).

\begin{tabular}{|c|c|c|c|c|c|c|c|}
\hline $\mathbf{T}$ & Sitio & Calidad talla & EX & MB & B & NA & Total \\
\hline \multirow{17}{*}{ 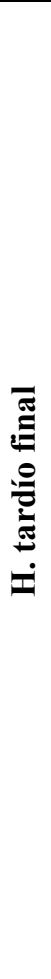 } & \multirow{7}{*}{ CSA-1 } & AF Bifacial & 18 & 9 & - & - & 27 \\
\hline & & AF Unifacial & 4 & 8 & 3 & - & 15 \\
\hline & & AF Compuesto & 1 & 2 & 1 & - & 4 \\
\hline & & Art. m. por A,P,P & - & - & - & 2 & 2 \\
\hline & & AF ND & 1 & - & - & - & 1 \\
\hline & & ASF RC & 9 & 3 & - & - & 12 \\
\hline & & Percutor & - & - & - & 5 & 5 \\
\hline & \multirow{3}{*}{$\begin{array}{c}\text { AR-6 } \\
\text { (A1) }\end{array}$} & AF Bifacial & 1 & - & - & - & 1 \\
\hline & & AF Unifacial & - & 2 & - & - & 2 \\
\hline & & ASF RC & 3 & - & - & - & 3 \\
\hline & $\begin{array}{c}\text { AR-6 } \\
\text { (A2) }\end{array}$ & AF Bifacial & 3 & - & - & - & 3 \\
\hline & AR-7 & AF Unifacial & - & 2 & - & - & 2 \\
\hline & \multirow{5}{*}{ BDP-1 } & AF Bifacial & - & 1 & - & - & 1 \\
\hline & & AF Unifacial & - & 1 & - & - & 1 \\
\hline & & AF Compuesto & - & 1 & - & - & 1 \\
\hline & & Art. m. por $\mathbf{A}, \mathbf{P}, \mathbf{P}$ & - & - & - & 4 & 4 \\
\hline & & ASF RC & - & 3 & - & - & 3 \\
\hline \multicolumn{3}{|c|}{ Total HTF } & $\begin{array}{c}45,98 \% \\
(40)\end{array}$ & $\begin{array}{c}36,78 \% \\
(32) \\
\end{array}$ & $\begin{array}{c}4,60 \% \\
(4) \\
\end{array}$ & $\begin{array}{c}12,64 \% \\
(11)\end{array}$ & 87 \\
\hline \multirow{6}{*}{ 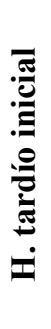 } & \multirow{6}{*}{ CSA-1 } & AF Bifacial & 9 & 4 & 1 & 0 & 14 \\
\hline & & AF Unifacial & 0 & 8 & 0 & 0 & 8 \\
\hline & & AF Compuesto & 0 & 2 & 0 & 0 & 2 \\
\hline & & Art. m. por A,P,P & 0 & 0 & 0 & 3 & 3 \\
\hline & & AF ND & 0 & 1 & 0 & 0 & 1 \\
\hline & & ASF RC & 1 & 3 & 0 & 0 & 4 \\
\hline \multicolumn{3}{|c|}{ Total HTI } & $\begin{array}{c}31,25 \% \\
(10) \\
\end{array}$ & $\begin{array}{c}56,25 \% \\
(18) \\
\end{array}$ & $\begin{array}{c}3,12 \% \\
(1)\end{array}$ & $\begin{array}{c}9,38 \% \\
(3) \\
\end{array}$ & 32 \\
\hline
\end{tabular}




\begin{tabular}{|c|c|c|c|c|c|c|}
$\begin{array}{c}\text { H. } \\
\text { medio }\end{array}$ & CSA-1 AF Bifacial & - & - & 1 & - & 1 \\
\hline Total HM & - & - & $\begin{array}{c}100 \% \\
(1)\end{array}$ & - & 1 \\
\hline Total (n) & 50 & 50 & 6 & 14 & \multirow{2}{*}{120} \\
\hline Total (\%) & 41,67 & 41,67 & 5,00 & 11,67 & \\
\hline
\end{tabular}

Tabla 8.37. Calidad para la talla de artefactos formatizados y sin formatizar con rastros complementarios en el Desierto Patagónico a través del tiempo. Referencias: EX: excelente; MB: muy buena; B: buena; NA: no aplica (para artefactos formatizados no por lascados).

Del total de instrumentos ( $\mathrm{n}=98)$, el 47,96\% $(\mathrm{n}=47)$ son bifaciales. Entre ellos se identificaron puntas de proyectil $(74,47 \%, n=35)$ y cuchillos de filo retocado $(2,13 \%$, $\mathrm{n}=1$ ); los 11 instrumentos restantes son fragmentos no diferenciados de artefactos formatizados $(23,4 \%)$. El cuchillo es de obsidiana; de las 35 puntas de proyectil, el $65,71 \%(n=23)$ es de obsidiana, el 31,43\% $(n=11)$ está confeccionado sobre rocas silíceas y se registró una punta de basalto; de los fragmentos no diferenciados, el 54,55\% $(n=6)$ es de obsidiana y el 45,45\% $(\mathrm{n}=5)$ de rocas silíceas (Figura 8.45).

Los artefactos unifaciales ( $\mathrm{n}=23$ ), constituyen el 23,47\% y presentan mayor variedad de grupos tipológicos que los bifaciales. El más frecuente es el de los raspadores $(47,83 \%, n=11)$, todos ellos confeccionados sobre rocas silíceas. Le siguen las muescas retocadas y de lascado simple $(17,39 \%, n=4)$, los cortantes $(13,04 \%, n=3)$, los artefactos de formatización sumaria $(8,7 \%, n=2)$, completando las frecuencias un artefacto burilante, un RBO (artefacto mediano pequeño/muy pequeño de retoque en bisel oblicuo y sección asimétrica), una punta entre muescas, una raclette y un instrumento del cual no se ha podido identificar su grupo tipológico. Este último, el cortante y dos de las muescas son los únicos instrumentos unifaciales de obsidiana; el resto fue confeccionado sobre rocas silíceas (Figura 8.45).

De los nueve artefactos manufacturados o modificados por abrasión, picado y/o pulido, el único que está entero es de basalto y pudo haber funcionado para abradir, ya que tiene una cara plana que habría sido la cara activa para la abrasión y, además, posee dos caras pasivas lisas que habrían servido para la prensión. Las fracturas en los ocho instrumentos restantes de este grupo tipológico impidieron definir su sub-grupo tipológico, aunque cabe mencionar que al menos la mitad de ellos están pulidos y el resto presenta evidencias de picado y/o abrasión.

Los grupos tipológicos más representados entre los instrumentos compuestos son: el de los raspadores y el de los RBO. Se registraron también: denticulados bisel 
oblicuo/abrupto sección asimétrica, cortantes y raclettes, además de filos bifaciales o no diferenciados de artefactos formatizados (véase Tabla 8.9 del sitio CSA-1 y Tabla 8.26 del sitio BDP-1, donde se describen los grupos tipológicos de ambos sitios y se detallan las características de estos instrumentos compuestos, registrados únicamente en estos dos sitios).

Los percutores son de vulcanita indeterminada $(n=3)$ y de basalto $(n=2)$, todos procedentes de CSA-1 y corresponden al HTF. Su presencia podría indicar que en dicho sitio se realizaron actividades relacionadas con la reducción de núcleos (previamente descortezados en otros locus) y/o con la confección de instrumentos. Los percutores enteros podrían estar equipando el sitio, mientras que los fracturados habrían sido descartados debido, justamente, a su estado. Los ASF RC ( $n=22)$, corresponden a filos naturales activos que pueden tener rastros de utilización (información que debe ser contrastada con análisis funcionales). El 68,18\% $(\mathrm{n}=15)$ es de obsidiana y, de ellos, el $80 \%$ está fracturado. El 31,82\% restante corresponde a rocas silíceas; fracturados en el $85,71 \%$. Por último, los grupos tipológicos de dos artefactos formatizados de obsidiana y roca silícea no pudieron ser distinguidos debido a que están fracturados sobre sectores no reconocidos.

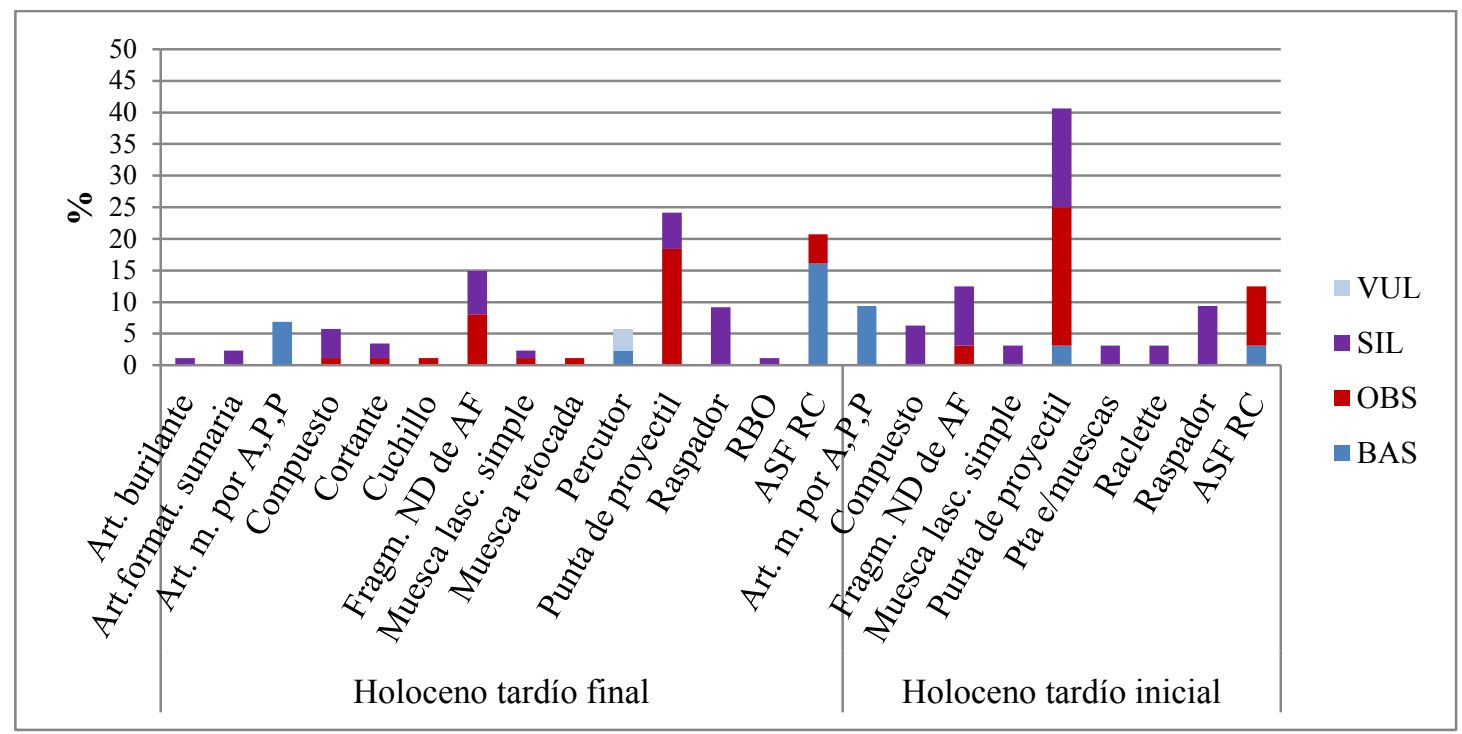

Figura 8.45. Frecuencia de grupos tipológicos y de artefactos sin formatización con rastros complementarios (ASF RC) por materia prima durante el Holoceno tardío en el Desierto Patagónico. El Holoceno medio no se incluye, ya que en este momento se registró un único instrumento: una punta de proyectil con pedúnculo confeccionada en sílice. 
En la Figura 8.45 , se observa que sobre rocas silíceas $(n=47)$ se registraron diez grupos tipológicos; los dos más frecuentes son: el de las puntas de proyectil $(23,40 \%$, $\mathrm{n}=11)$ y de los raspadores $(21,28 \%, \mathrm{n}=10)$. De los instrumentos confeccionados sobre obsidiana ( $\mathrm{n}=36)$ se identificaron cinco grupos tipológicos, predominando también el de las puntas de proyectil $(63,89 \%, \mathrm{n}=23)$. En basalto se confeccionaron 12 instrumentos: el $75 \%(n=9)$ corresponde a artefactos manufacturados o modificados por abrasión, picado y/o pulido, el $16,67 \%(\mathrm{n}=2)$ son raspadores y el restante es una preforma de punta de proyectil de morfología lanceolada y de tamaño mediano-grande (es el instrumento de mayor tamaño dentro del grupo de las puntas de proyectil). Los tres instrumentos de vulcanita indeterminada son percutores (Figura 8.45).

En la Tabla 8.38 se muestra la relación entre los desechos de talla enteros, por un lado, y los instrumentos y ASF RC, por el otro. Esto provee un valor estimado del descarte y la confección y/o reparación de instrumentos. Los valores más altos se registran en la obsidiana del HTI de CSA-1; al incorporar las otras materias primas, los mayores valores se dan durante este período, aunque el valor del basalto es muy bajo. Los valores de dicha relación en rocas silíceas son, en general, los más altos en todos los segmentos temporales $\mathrm{y}$ en todos los sitios, excepto en BDP-1. En andesita y riolita, se registraron desechos enteros, pero no se recuperó ningún instrumento ni ASF RC. En AR-6 (A2), sólo se registraron instrumentos sobre obsidiana, pero no hay lascas enteras sobre esta materia prima. En AR-7 se recuperaron dos instrumentos, ambos sobre rocas silíceas, pero no hay desechos enteros en ninguna materia prima. Por lo tanto, en estos últimos dos sitios no se pudo calcular la relación entre desechos enteros e instrumentos y ASR FC (Tabla 8.39).

\begin{tabular}{|c|c|c|c|c|c|c|c|c|c|c|c|c|c|c|c|c|c|}
\hline \multirow{2}{*}{$\mathbf{T}$} & \multirow{2}{*}{ Sitio } & \multirow{2}{*}{ MP } & \multicolumn{2}{|c|}{ AF Bifacial } & \multicolumn{2}{|c|}{ AF Unifacial } & \multicolumn{2}{|c|}{ AF compuesto } & \multicolumn{2}{|c|}{$\begin{array}{l}\text { Art. manuf. } \\
\text { por } P, A, P\end{array}$} & \multicolumn{2}{|c|}{ AF ND } & \multicolumn{2}{|c|}{ ASF RC } & \multicolumn{2}{|c|}{ Percutor } & \multirow{2}{*}{$\begin{array}{c}\text { Tota } \\
\text { I }\end{array}$} \\
\hline & & & Ent. & Frac. & Ent. & Frac. & Ent. & Frac. & Ent. & Frac. & Ent & Frac. & Ent. & Frac. & Ent. & Frac. & \\
\hline \multirow{11}{*}{ 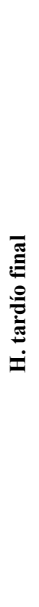 } & \multirow{4}{*}{$\begin{array}{c}\text { CSA } \\
-1\end{array}$} & BAS & - & - & - & - & - & - & - & 2 & - & - & - & - & 1 & 1 & 4 \\
\hline & & OBS & 3 & 15 & - & 4 & 1 & - & - & - & - & 1 & 2 & 8 & - & - & 34 \\
\hline & & SIL & 1 & 8 & 5 & 6 & 2 & 1 & - & - & - & - & - & 2 & - & - & 25 \\
\hline & & VUL & - & - & - & - & - & - & - & - & - & - & - & - & 1 & 2 & 3 \\
\hline & \multirow{2}{*}{$\begin{array}{c}\text { AR- } \\
6 \\
(\mathbf{A 1})\end{array}$} & OBS & - & 1 & - & - & - & - & - & - & - & - & 1 & 2 & - & - & 4 \\
\hline & & SIL & - & - & 1 & 1 & - & - & - & - & - & - & - & - & - & - & 2 \\
\hline & $\begin{array}{c}\text { AR- } \\
6 \\
\text { (A2) }\end{array}$ & OBS & 2 & 1 & - & - & - & - & - & - & - & - & - & - & - & - & 3 \\
\hline & $\begin{array}{c}\text { AR- } \\
7\end{array}$ & SIL & - & - & 1 & 1 & - & - & - & - & - & - & - & - & - & - & 2 \\
\hline & \multirow{3}{*}{$\begin{array}{c}\text { BDP } \\
-1\end{array}$} & BAS & - & - & - & - & - & - & - & 4 & - & - & - & - & - & - & 4 \\
\hline & & OBS & - & - & - & - & - & - & - & - & - & - & - & 1 & - & - & 1 \\
\hline & & SIL & 1 & - & 1 & - & - & 1 & - & - & - & - & 1 & 1 & - & - & 5 \\
\hline
\end{tabular}




\begin{tabular}{|c|c|c|c|c|c|c|c|c|c|c|c|c|c|c|c|c|c|}
\hline \multicolumn{3}{|c|}{ Total HTF } & $\begin{array}{c}8,05 \% \\
(7) \\
\end{array}$ & $\begin{array}{r}28,74 \\
\%(25) \\
\end{array}$ & $\begin{array}{c}9,20 \% \\
(8) \\
\end{array}$ & $\begin{array}{r}13,79 \\
\%(12) \\
\end{array}$ & $\begin{array}{c}3,45 \\
\%(3) \\
\end{array}$ & $\begin{array}{c}2,30 \\
\%(2) \\
\end{array}$ & - & $\begin{array}{c}6,90 \\
\%(6) \\
\end{array}$ & - & $\begin{array}{c}1,15 \\
\%(1) \\
\end{array}$ & $\begin{array}{c}4,60 \\
\%(4) \\
\end{array}$ & $\begin{array}{c}16,09 \\
\%(14)\end{array}$ & $\begin{array}{r}2,30 \\
\%(2)\end{array}$ & $\begin{array}{c}3,45 \\
\%(3)\end{array}$ & 87 \\
\hline \multirow{3}{*}{ 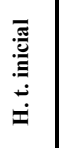 } & \multirow{3}{*}{$\begin{array}{c}\text { CSA } \\
-1\end{array}$} & BAS & 1 & - & - & - & - & - & 1 & 2 & - & - & - & - & - & - & 4 \\
\hline & & OBS & 3 & 5 & - & - & - & - & - & - & - & - & - & 1 & - & - & 9 \\
\hline & & SIL & 1 & 4 & 5 & 3 & - & 2 & - & - & - & 1 & - & 3 & - & - & 19 \\
\hline \multicolumn{3}{|c|}{ Total HTI } & $\begin{array}{l}15,63 \\
\%(5)\end{array}$ & $\begin{array}{l}28,12 \\
\%(9)\end{array}$ & $\begin{array}{l}15,63 \\
\%(5)\end{array}$ & $\begin{array}{c}9,38 \% \\
\text { (3) }\end{array}$ & - & $\begin{array}{c}6,25 \\
\%(2)\end{array}$ & $\begin{array}{c}3,12 \\
\%(1)\end{array}$ & $\begin{array}{c}6,25 \\
\%(2)\end{array}$ & - & $\begin{array}{c}3,12 \\
\%(1)\end{array}$ & - & $\begin{array}{c}12,5 \% \\
\text { (4) }\end{array}$ & - & - & 32 \\
\hline $\begin{array}{c}\text { H. } \\
\text { medi } \\
\text { o }\end{array}$ & \begin{tabular}{|c} 
CSA \\
-1
\end{tabular} & SIL & 1 & - & - & - & - & - & - & - & - & - & - & - & - & - & 1 \\
\hline \multicolumn{3}{|c|}{ Total HM } & $\begin{array}{l}100 \% \\
\text { (1) }\end{array}$ & - & - & - & - & - & - & - & - & - & - & - & - & - & 1 \\
\hline \multicolumn{3}{|c|}{ Total (n) } & 13 & 34 & 13 & 15 & 3 & 4 & 1 & 8 & - & 2 & 4 & 18 & 2 & 3 & \\
\hline \multicolumn{3}{|c|}{ Total (\%) } & 10,83 & 28,33 & 10,83 & 12,50 & 2,50 & 3,33 & $\mathbf{0 , 8 3}$ & 6,67 & - & 1,67 & 3,33 & 15,00 & 1,67 & 2,50 & 120 \\
\hline
\end{tabular}

Tabla 8.38. Frecuencia de fragmentación en instrumentos y ASF RC a través del tiempo en el Desierto Patagónico. Referencias: T: tiempo; MP: materia prima; AF: Artefacto formatizado; Coтp.: compuesto; Art. m. por A, P, P: Artefacto manufacturado o modificado por picado, abrasión y/o pulido; AF ND: Artefacto formatizado no diferenciado; ASF RC: artefacto sin formatización con rastros complementarios; P: percutor; Ent.: entero; Frac.: fracturado; BAS: basalto; OBS: obsidiana; SIL: rocas siliceas; VUL: vulcanita indeterminada.

\begin{tabular}{|c|c|c|c|c|c|c|}
\hline Tiempo & Sitio & AND & BAS & OBS & RIO & SIL \\
\hline \multirow{4}{*}{ HTF } & CSA-1 & - & 1,00 & 2,71 & - & 3,56 \\
\cline { 2 - 7 } & AR-6 (A1) & - & - & 0,50 & - & 3,50 \\
\cline { 2 - 7 } & AR-6 (A2) & - & - & - & - & - \\
\cline { 2 - 7 } & AR-7 & - & - & - & - & - \\
\cline { 2 - 8 } & BDP-1 & - & - & 1,00 & - & 0,40 \\
\hline HTI & CSA-1 & - & 0,50 & 4,89 & - & 4,00 \\
\hline HM & CSA-1 & - & - & - & - & 4,00 \\
\hline
\end{tabular}

Tabla 8.39. Relación entre el total de desechos de talla enteros e instrumentos y artefactos sin formatización con rastros complementarios, por materia prima a través del tiempo en el Desierto Patagónico.

Como se dijo, el grupo tipológico de las puntas de proyectil es el mayoritario. Sin embargo, muchos de los instrumentos que lo componen están fracturados y/o son preformas. De las puntas de proyectil fracturadas $(n=19), 14$ son de obsidiana y cinco de rocas silíceas. De las primeras, el $42,9 \%$ corresponde a fragmentos apicales y limboapicales $(n=6)$, el 42,9\% a fragmentos mediales y limbos $(n=6)$ y el 14,2\% $(n=2)$ a fragmentos basales y meso-basales. De las puntas de proyectil fracturadas de rocas silíceas, el $80 \%(\mathrm{n}=4)$ corresponde a fragmentos apicales y el $20 \%$ a un fragmento basal. De las preformas $(n=4)$, la mitad son de rocas silíceas y, de la otra mitad, una es de obsidiana y la otra de basalto. Para calcular la estadística descriptiva de las características 
métricas de las puntas de proyectil enteras de obsidiana (Tabla 8.40) y rocas silíceas (Tabla 8.41), se tomaron los valores medios de largo, ancho y espesor, y se sumó la variable peso como indicador de diferencia de tamaño. El cálculo se realizó sobre siete puntas de proyectil de obsidiana (tres pertenecen al HTI y cuatro al HTF) y sobre tres de rocas silíceas (una del HM, una del HTI y la otra del HTF). En la Tabla 8.40 se puede apreciar que la medida de tamaño con mayor variación entre las puntas de proyectil de obsidiana es el largo; el peso no presenta variaciones. En la Tabla 8.41, no se observan diferencias significativas entre la media y la mediana de las tres medidas de tamaño en rocas silíceas, diferencias que tampoco se observan en el peso. Al comparar las medias y medianas de ambas materias primas, se reconocen diferencias en el largo, ancho y espesor, como así también en el peso.

En la Figura 8.46 se presentan las tendencias en la distribución de las medidas de tamaño de las puntas de proyectil de obsidiana en comparación con las de rocas silíceas. Se observa que entre las de obsidiana, el largo es la medida más homogénea (contrariamente a lo observado en la estadística descriptiva) y que el espesor es la medida con mayor varianza dentro de estas puntas. Entre las puntas de proyectil de rocas silíceas, la mayor dispersión se da en el largo y en el espesor. Para observar si hay diferencias estadísticamente significativas en las tres medidas de tamaño entre las puntas de obsidiana y de rocas silíceas, se realizaron distintos test estadísticos. Para la medida del largo, se utilizó el test de Mann-Whitney y los resultados mostraron que no habrían diferencias estadísticamente significativas en el largo de las puntas de proyectil de rocas silíceas y obsidiana $(\mathrm{U}=2 ; p=0,06)$. El mismo test se realizó para el ancho: los resultados indicaron que tampoco habrían diferencias estadísticamente significativas en el ancho de estas piezas $(\mathrm{U}=2 ; p=0,06)$. Por último, debido a que la distribución de los datos de la medida del espesor no es normal, se realizó el test de Kolmogorov-Smirnov, cuyos resultados mostraron que no habrían diferencias estadísticamente significativas en el espesor $(\mathrm{D}=0,6 ; p=0,18)$. Es decir que, estadísticamente, no se observaron diferencias significativas en ninguna de las tres medidas entre puntas de proyectil de obsidiana y de rocas silíceas. 


\begin{tabular}{|l|c|c|c|c|}
\hline $\begin{array}{c}\text { Puntas de proyectil } \\
\text { de obsidiana }\end{array}$ & $\begin{array}{c}\text { Largo } \\
\mathbf{m m}\end{array}$ & $\begin{array}{c}\text { Ancho } \\
\mathbf{m m}\end{array}$ & $\begin{array}{c}\text { Espesor } \\
\mathbf{m m}\end{array}$ & Peso gr \\
\hline$n$ & 7 & 7 & 7 & 7 \\
\hline Media & 21,14 & 11,86 & 2,93 & 0,89 \\
\hline Desvío Estándar & 2,45 & 1,35 & 0,52 & 0,18 \\
\hline Mediana & 17,50 & 10,00 & 2,00 & 0,90 \\
\hline $\begin{array}{l}\text { Coeficiente de } \\
\text { variación }\end{array}$ & $30,67 \%$ & $30,18 \%$ & $46,68 \%$ & $53,92 \%$ \\
\hline Mínimo & 14,00 & 8,50 & 2,00 & 0,20 \\
\hline Máximo & 30,00 & 17,00 & 5,50 & 1,50 \\
\hline Rango & 16,00 & 8,50 & 3,50 & 1,30 \\
\hline
\end{tabular}

Tabla 8.40. Estadística descriptiva de las características métricas de puntas de proyectil de obsidiana pertenecientes al Desierto Patagónico.

\begin{tabular}{|l|c|c|c|c|}
\hline $\begin{array}{c}\text { Puntas de proyectil } \\
\text { de silíceas }\end{array}$ & $\begin{array}{c}\text { Largo } \\
\mathbf{m m}\end{array}$ & $\begin{array}{c}\text { Ancho } \\
\mathbf{m m}\end{array}$ & $\begin{array}{c}\text { Espesor } \\
\mathbf{m m}\end{array}$ & Peso gr \\
\hline$n$ & 3 & 3 & 3 & 3 \\
\hline Media & 30,33 & 21,00 & 5,67 & 4,50 \\
\hline Desvío Estándar & 6,66 & 5,57 & 2,31 & 2,95 \\
\hline Mediana & 32,00 & 22,00 & 7,00 & 5,4 \\
\hline $\begin{array}{l}\text { Coeficiente de } \\
\text { variación }\end{array}$ & 21,95 & 26,51 & 40,75 & 65,66 \\
\hline Mínimo & 23,00 & 15,00 & 3,00 & 1,20 \\
\hline Máximo & 36,00 & 26,00 & 7,00 & 6,90 \\
\hline Rango & 13,00 & 11,00 & 4,00 & 5,70 \\
\hline
\end{tabular}

Tabla 8.41. Estadística descriptiva de las características métricas de puntas de proyectil de rocas silíceas pertenecientes al Desierto Patagónico.

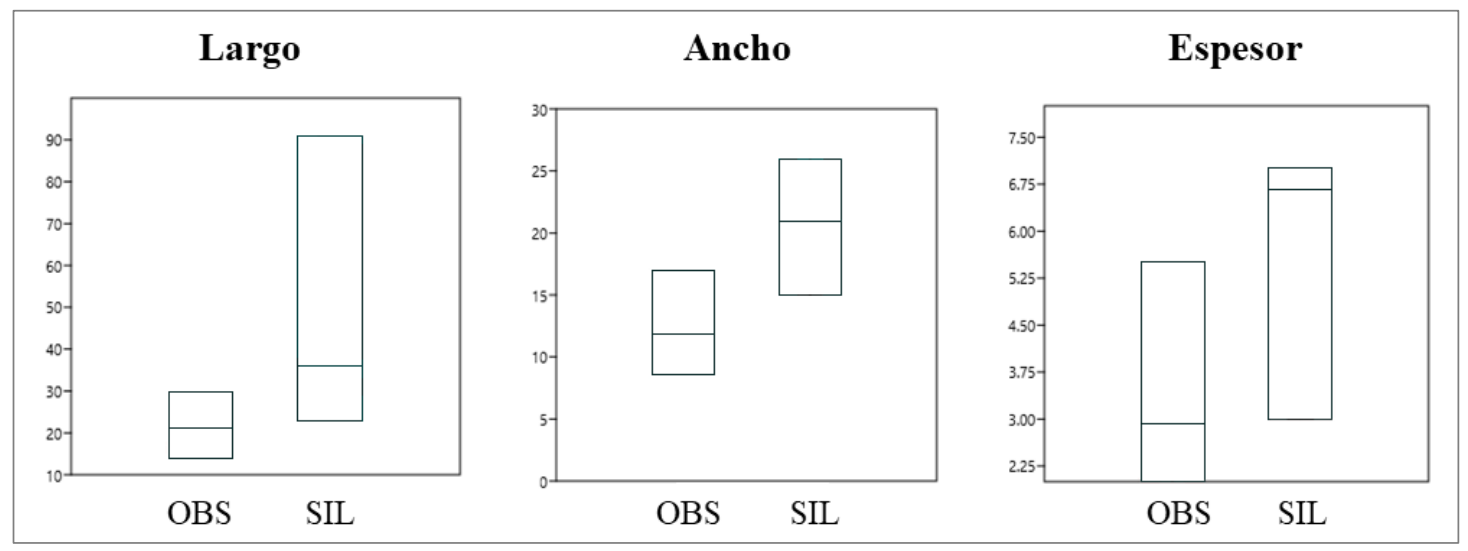

Figura 8.46. Box plot de las medidas de tamaño de puntas de proyectil en obsidiana (OBS) y rocas silíceas (SIL). 
El grupo tipológico más frecuente entre los instrumentos unifaciales es el de los raspadores. De los seis enteros $(n=6)$, todos confeccionados sobre rocas silíceas, el $83,33 \%(\mathrm{n}=5)$ es de tamaño pequeño (módulo tamaño=2) y el restante, perteneciente al $\mathrm{HTF}$, es mediano-grande (módulo=3) y el único de este segmento temporal que no está reactivado. Los que corresponden al HTI no están reactivados. Para evaluar las variaciones de tamaño en estos instrumentos y evaluar el grado o intensidad en que fueron reactivados (i.e. cuál es la vida útil del instrumento), se seleccionaron aquellos raspadores enteros que tuvieran algún tipo de lasca como forma-base (sensu Kuhn 1990), por lo cual, la muestra se redujo a cuatro raspadores (Tabla 8.42). La mitad de los raspadores analizados $(n=2)$ está reactivado. Sin embargo, al calcular el índice geométrico de reducción se observa que los cuatro raspadores se acercan a una tasa $\mathrm{t} / \mathrm{T}$ de cero (media de 0,25$)$, lo cual indica que pueden seguir reactivándose y que se han descartado cuando aún poseían vida útil.

\begin{tabular}{|c|c|c|c|c|c|c|}
\hline \multirow{2}{*}{ Sitio } & \multirow{2}{*}{ MP } & \multirow{2}{*}{ Tamaño } & \multicolumn{2}{|c|}{ Espesor máximo } & \multirow{2}{*}{$\begin{array}{l}\text { Índ. Geom } \\
\text { de reducc. }\end{array}$} & \multirow{2}{*}{ Reactivación } \\
\cline { 4 - 5 } & & & del filo retoc (t) & de la F-B (T) & \\
\hline \multirow{4}{*}{ CSA-1 } & SIL & $\mathrm{P}$ & 1,5 & 7,5 & 0,2 & Presente \\
\cline { 2 - 5 } & SIL & MEP & 2,5 & 11,0 & 0,2 & Presente \\
\cline { 2 - 5 } & SIL & $\mathrm{P}$ & 2,5 & 10,0 & 0,3 & Ausente \\
\cline { 2 - 5 } & SIL & $\mathrm{P}$ & 1,0 & 3,5 & 0,3 & Ausente \\
\hline
\end{tabular}

Tabla 8.42. Tamaños e índices geométricos de reducción sobre raspadores enteros.

\subsection{OBSIDIANAS EN EL DESIERTO PATAGÓNICO}

\subsubsection{ANÁLISIS DE ELEMENTOS TRAZA}

De los sitios CSA-1 y BDP-1 se seleccionaron artefactos de obsidiana para ser analizados por XRF. Para ello se utilizó un equipo ThermoScientific ARL Quantx del Laboratorio de Arqueometría del Research Reactor Center, de la Universidad de Missouri (MURR), Columbia (EE.UU.) en mayo-junio del año 2015. De CSA-1 se seleccionaron 10 muestras: dos provienen del segmento de la secuencia temporal correspondiente al HM; tres pertenecen al HTI; y las otras cinco al HTF. De BDP-1 se seleccionaron cinco muestras, todas asignadas al HTF. En la Tabla 8.43 se muestran los resultados del análisis de elementos traza. Se observa que el $46,67 \%(n=7)$ de las muestras proviene de la subfuente El Peceño-1 (Durán et al. 2004; Salgán y Pompei 2017), identificada únicamente para el HTF. El 40\% (n=6; todos de CSA-1) procede de la fuente Las Cargas, representada 
en todos los segmentos temporales (HM, HTI y HTF). Por último, el 13,33\% corresponde a dos artefactos cuyo análisis geoquímico concluyó que provienen de fuentes distintas y desconocidas, aquí denominadas "Grupo A" y "Desconocida". Ambas muestras provienen del segmento correspondiente al HTI de CSA-1 (Tabla 8.43)

\begin{tabular}{|c|c|c|c|c|}
\hline Tiempo & Sitio & Nivel & Cód & Procedencia \\
\hline \multirow{10}{*}{ HTF } & \multirow{5}{*}{ CSA-1 } & 4 & LSM 189 & Las Cargas \\
\hline & & 7 & LSM 190 & Las Cargas \\
\hline & & 7 & LSM 191 & El Peceño-1 \\
\hline & & 8 & LSM 192 & El Peceño-1 \\
\hline & & 9 & LSM 193 & Las Cargas \\
\hline & \multirow{5}{*}{ BDP-1 } & Sup. E & LSM 206 & El Peceño-1 \\
\hline & & Sup. E & LSM 208 & El Peceño-1 \\
\hline & & Sup. W & LSM 207 & El Peceño-1 \\
\hline & & $1 \mathrm{~W}$ & LSM 209 & El Peceño-1 \\
\hline & & $2 \mathrm{~W}$ & LSM 210 & El Peceño-1 \\
\hline \multirow{3}{*}{ HTI } & \multirow{3}{*}{ CSA-1 } & 13 & LSM 194 & $\begin{array}{r}\text { Desconocida } \\
\text { (s/identificar) }\end{array}$ \\
\hline & & 13 & LSM 196 & Grupo A \\
\hline & & 14 & LSM 198 & Las Cargas \\
\hline \multirow{2}{*}{ HM } & \multirow{2}{*}{ CSA-1 } & 18 & LSM 197 & Las Cargas \\
\hline & & 19 & LSM 199 & Las Cargas \\
\hline
\end{tabular}

Tabla 8.43. Muestras de artefactos de obsidiana de los sitios CSA-1 y BDP-1, por segmento temporal, sitio, y fuente de procedencia. Análisis realizados en 2015.

Con anterioridad a estos análisis, en marzo de 2014, se seleccionaron 80 muestras de artefactos de obsidiana de los dos sectores de la excavación de CSA-1 (norte y sur), para caracterizarlos en el mismo laboratorio del MURR, pero con el equipo Brukernewcal. Del análisis resultó que el $80,77 \%(n=63)$, procede de la fuente extra-cordillerana Coche Quemado, localizada a unos $100 \mathrm{~km}$ de CSA-1. E1 8,97\% $(\mathrm{n}=7)$ corresponde a una fuente desconocida que aún no ha sido asignada y que no se la puede agrupar con las otras fuentes desconocidas. Sólo el 5,13\% ( $n=4$; de CSA-1) ha sido identificado con la fuente Las Cargas. El 3,85\% $(\mathrm{n}=3)$ corresponde a la fuente Laguna del Maule-2 y un único artefacto $(1,28 \%)$ pertenece a la sub-fuente El Peceño-1. De los 27 artefactos recuperados del sector sur de la cuadrícula A1 de CSA-1 -sector seleccionado en esta investigación-, el 3,7\% (n=1) ha sido asignado al HM y procede de la fuente Coche Quemado. El 40,74\% $(\mathrm{n}=11)$ corresponde al HTI; la mayoría $(72,73 \%, \mathrm{n}=8)$ proviene de Coche Quemado, seguida por dos artefactos de la fuente desconocida y uno de Las Cargas. El 55,55\% $(n=15)$ restante fue atribuido al HTF; el 73,33\% $(n=11)$ procede de Coche Quemado, el 
$20 \%(\mathrm{n}=3)$ de la fuente desconocida y el último artefacto proviene de la sub-fuente Laguna del Maule-2.

En la Figura 8.47 se presentan las frecuencias relativas de los análisis de elementos traza realizados sobre los 37 artefactos de obsidiana (muestras caracterizadas en los años 2014 y 2015) procedentes del sector sur de la cuadrícula A1 de CSA-1, y las cinco muestras del sitio BDP-1, asignadas a la sub-fuente El Peceño-1. En relación a las fuentes identificadas en ambos sitios, es importante aclarar que, mientras Las Cargas, Laguna del Maule y Coche Quemado son fuentes no locales para ambos sitios arqueológicos (localizadas a 100, 200 y $120 \mathrm{~km}$, respectivamente de CSA-1; y 100, 200 y $200 \mathrm{~km}$, respectivamente de BDP-1), la fuente El Peceño es de procedencia no local para CSA-1 $(100 \mathrm{~km})$ y local para el sitio BDP-1 $(20 \mathrm{~km})$.

De las cuatro fuentes conocidas identificadas en los sitios, dos son cordilleranas (Laguna del Maule y Las Cargas) y dos extra-cordilleranas (Coche Quemado y El Peceño). Como se mencionó en el Capítulo 7, los artefactos asignados a la fuente desconocida Grupo A podrían provenir, dada su complejidad (Salgán et al. 2015), de la fuente Las Cargas; aunque debe tenerse en cuenta que la baja frecuencia de artefactos de la fuente Grupo A respecto al resto de los artefactos de obsidiana analizados geoquímicamente $(2,38 \%, n=1)$, sugiere que su origen puede encontrarse a una distancia mucho mayor, como Laguna del Maule, fuente representada en la misma proporción $(2,38 \%, n=1)$.

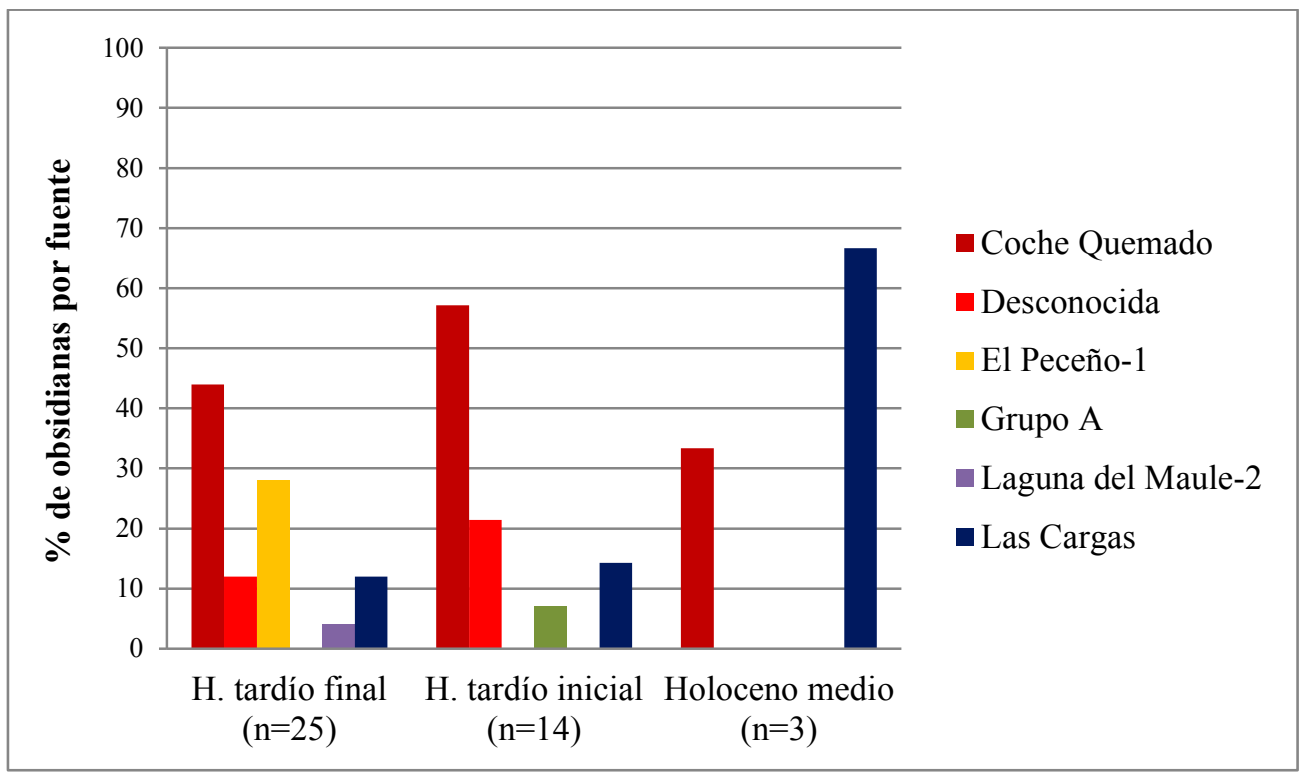

Figura 8.47. Distribución temporal de las fuentes de obsidiana identificadas en artefactos de los sitios CSA-1 y BDP-1. 
La Figura 8.47 muestra un aumento en la diversidad de fuentes utilizadas a lo largo del tiempo: dos fuentes durante el HM, cuatro durante el HTI y cinco en el HTF. Sin embargo, esta tendencia hacia el aumento en el uso de fuentes, puede estar mediada por el tamaño dispar de las muestras para cada lapso temporal. Al margen de esta consideración, se observa que las fuentes Las Cargas y Coche Quemado se registran en los tres segmentos temporales identificados (HM, HTI y HTF). Son las únicas presentes durante el HM, momento en que predominan las obsidianas de Las Cargas. En el HTI, en cambio, si bien ingresan otras fuentes (las dos desconocidas), es mayoritaria la fuente Coche Quemado, casi duplicando sus valores respecto al HM; y Las Cargas es superada por esta y la fuente Desconocida. Para el HTF, ambas fuentes aumentan cuantitativamente, pero las frecuencias relativas disminuyen con el ingreso de las subfuentes El Peceño-1 y Laguna del Maule-2, esta última en muy baja frecuencia; aunque no se registra la fuente Grupo A (Figura 8.47).

\subsubsection{APROVISIONAMIENTO Y USO DE OBSIDIANAS}

Si bien las rocas silíceas -de procedencia local- son las materias primas mayoritarias en este desierto $(56,65 \%, n=1921)$, el 38,45\% $(n=1304)$ de los artefactos líticos son de obsidiana. De estos, el 97,09\% proviene del sitio CSA-1, localizado a una distancia no local a las fuentes de obsidiana registradas en el mismo. En dicho sitio, la obsidiana representa el 37,33\% $(n=1266)$ del total de artefactos $(n=3262)$. En la localidad Arbolito, la obsidiana representa el 29,46\% $(n=38)$ del total de artefactos $(n=129)$, a pesar de que la fuente El Peceño está a una distancia "local" de los sitios involucrados.

El 36,73\% ( $n=36)$ de los instrumentos, el 38,49\% ( $\mathrm{n}=1251)$ de los desechos de talla, el 68,18\% $(\mathrm{n}=15)$ de los ASF RC, el 50\% $(\mathrm{n}=1)$ de los núcleos y el 33,33\% $(\mathrm{n}=1)$ de los nódulos, constituyen los 1304 artefactos y las cinco clases artefactuales sobre las que se registró esta materia prima. En suma, estas tendencias tecnológicas, cruzadas con la información geoquímica y la localización de sus fuentes, permiten proponer que en este desierto, el tipo de aprovisionamiento de obsidiana ha sido directo.

La Figura 8.48 esquematiza las tendencias en la distribución de los artefactos de obsidiana de los cuatro sitios analizados, a lo largo del tiempo. Se observa un leve aumento hacia el HTF. El último valor representado en la Figura 8.48 corresponde al promedio de los fechados realizados sobre huesos humanos de la localidad Arbolito ( $c a$. 580-600 años AP). 


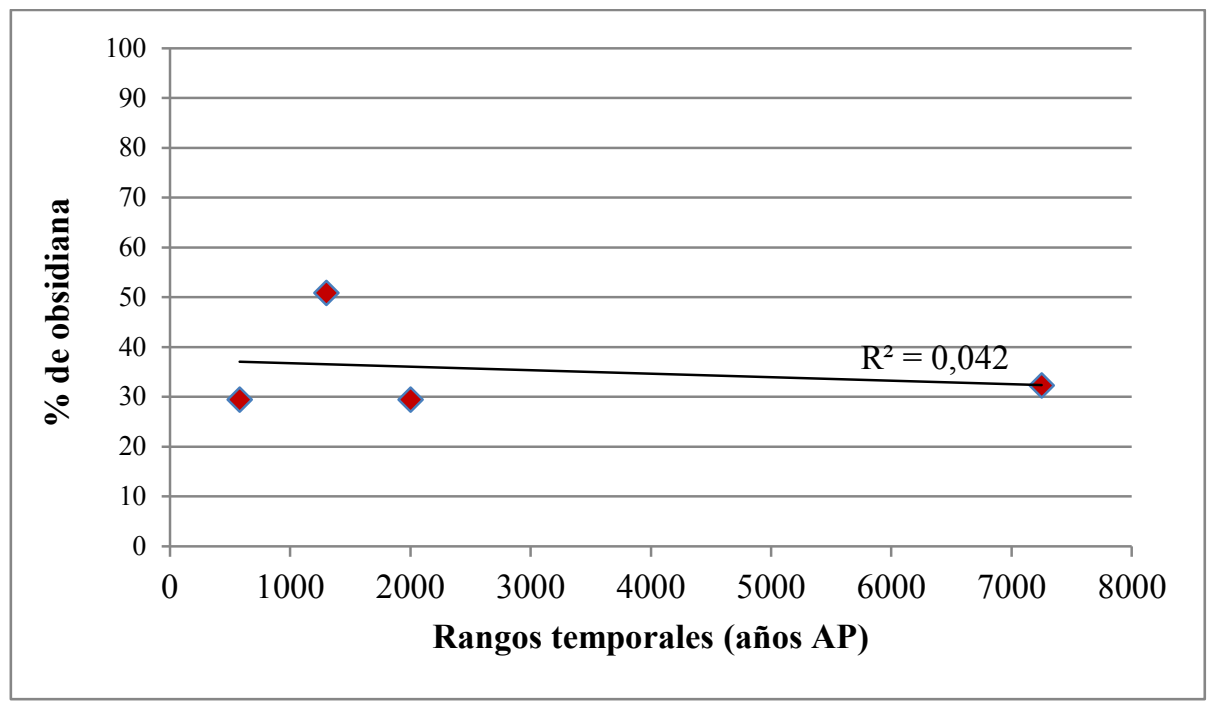

Figura 8.48. Distribución temporal y línea de tendencia de los artefactos de obsidiana registrados en CSA-1, AR-6 (cuadrículas A1 y A2), AR-7 y BDP-1.

En síntesis, el uso de la obsidiana muestra un incremento en la cantidad de fuentes explotadas del Holoceno medio al Holoceno tardío. Como se ha discutido en trabajos previos de la región (Giesso et al. 2011a, entre otros), la tendencia observada en estos análisis confirma el uso tardío de la fuente El Peceño; no se han recuperado artefactos de esta fuente con fechados previos a los 2.000 años AP en ninguno de los sitios arqueológicos en los que esta fuente ha sido identificada. Este aumento en la diversidad de fuentes a través del tiempo, se ve acompañado por el aumento en la cantidad de artefactos de obsidiana en los conjuntos arqueológicos, lo que estaría indicando una mayor disponibilidad de la misma, ya sea por el aumento en las redes de intercambio y/o por el descubrimiento de nuevas fuentes, como parece haber sido el caso de El Peceño.

\subsection{CONSIDERACIONES FINALES}

En el Desierto Patagónico la tecnología lítica se caracteriza por el uso predominante de rocas silíceas y de obsidiana. En las primeras es mayoritaria la calidad para la talla muy buena y, en la obsidiana, la excelente. En los artefactos enteros predomina la ausencia de corteza y el tamaño muy pequeño, en la mayoría de las materias primas. Es preponderante el estado fracturado de las piezas, sobre todo en el sitio CSA1. 
Los desechos de talla constituyen la clase artefactual predominante del Desierto Patagónico. De los enteros predominan las lascas internas, sobre todo las angulares, seguidas por las de formatización de filo (mayoritariamente sobre rocas silíceas) y las externas. La andesita y la riolita son las rocas con los valores más altos del índice de corteza, seguidas por el basalto y en último lugar, las rocas silíceas.

Entre los instrumentos predominan los bifaciales, seguidos por los unifaciales. Sobre los primeros, predomina la confección sobre obsidiana, y sobre los unifaciales, las rocas silíceas; sólo entre los instrumentos bifaciales se registró el uso de basalto. Predomina el grupo tipológico de las puntas de proyectil, la mayoría sobre obsidiana. Le sigue el grupo de los raspadores, todos sobre rocas silíceas. Esta última clase de roca fue las más utilizada en la manufactura de instrumentos, seguida por la obsidiana, el basalto y la vulcanita indeterminada (esta última, presente sólo en percutores de CSA-1). Los ASF RC fueron registrados sobre obsidiana y silíceas, en los sitios CSA-1, AR-6 (A1) y BDP-1. Sólo se registraron dos núcleos, ambos procedentes de la localidad Arbolito, uno sobre roca silícea de AR-6 (A1) y el otro de obsidiana de BDP-1, localizado a $20 \mathrm{~km}$ de la fuente El Peceño.

Entre las tendencias temporales, se observan diferencias entre el Holoceno medio y los dos periodos que abarca el Holoceno tardío: el HM tiene un tamaño de muestra considerablemente menor y la tasa de descarte fue mayor en el HTI que en el HTF. Sin embargo, no hay diferencias significativas en las clases de roca utilizadas: las rocas silíceas y las obsidianas son las más utilizadas en los tres momentos. Lo que sí varió fue el orden de preponderancia: durante el HM y HTI, las rocas silíceas son las mayoritarias, y hacia el HTF predomina la obsidiana. El basalto es, en los tres momentos, la tercera roca más importante, aunque en la localidad Arbolito (HTF) es superada por la riolita (Figura 8.42).

Con el aumento del uso de la obsidiana hacia el HTF, también aumenta la calidad para la talla "excelente". La calidad "muy buena" (representada sobre todo por las silíceas) aumenta del HM al HTI, pero disminuye hacia el HTF. El porcentaje de artefactos enteros disminuye del HM al HTI, pero aumenta hacia el HTF; los fracturados son mayoritarios en los tres segmentos temporales reconocidos. Los artefactos enteros de tamaños muy pequeños y pequeños aumentan a través del tiempo. Durante el HM no se evidenciaron artefactos con las categorías 50\%, 75\% y 100\% de reserva de corteza. Luego, estos aumentan en detrimento de los artefactos con $0 \%$ de corteza. 
Durante el HM (representado sólo por CSA-1) se registraron desechos de talla y una única punta de proyectil, la cual posee pedúnculo. En BDP-1 se registró una punta con pedúnculo esbozado, de lo cual se infiere que este sitio puede ser el más antiguo de la localidad Arbolito. Durante el HTI se suman otras clases artefactuales: ASF RC, ecofactos y pigmentos. Luego, en el HTF, se agregan los percutores, los potenciales percutores funcionales, los núcleos y los nódulos. Por lo tanto, es el segmento temporal con mayor diversidad de clases.

En suma, del análisis de los conjuntos líticos correspondientes al Desierto Patagónico (CSA-1, AR-6 -A1 y A2-, AR-7 y BDP-1), pueden reconocerse las etapas avanzadas y finales del proceso de manufactura y reactivación de instrumentos. A este desierto pertenecen los únicos dos núcleos registrados del total de sitios analizados en esta tesis. Ambos se recuperaron en la localidad Arbolito, donde la obsidiana y las rocas silíceas (materias primas de estos núcleos) son de procedencia local; las rocas silíceas son predominantes. La baja frecuencia de artefactos con corteza sugiere que las rocas fueron descortezadas en los sitios de aprovisionamiento y luego trasladadas a pocos kilómetros. El predominio de estas dos rocas es coherente con su calidad para la talla. Por su parte, la mayoría de los instrumentos fueron descartados en estado fracturado; del total de instrumentos enteros son mayoritarios, por un lado, los de formatización unifacial sobre rocas silíceas y, por otro, los bifaciales sobre obsidiana. De la caracterización de los distintos grupos tipológicos registrados dentro de los instrumentos, se infirieron distintas funciones relacionadas con el procesamiento de recursos vegetales y animales, principalmente aquellas que implican raspar (raspadores, RBO, muescas, raclettes), cortar (cortantes y cuchillos), golpear y percutir (percutores), pulir (artefactos manufacturados o modificados por abrasión, picado y/o pulido) e incidir (artefactos burilantes y puntas entre muescas); funciones que han de ser contrastadas con análisis funcionales. A las puntas de proyectil se las considera dentro de toolkits de caza, tarea desempeñada en otros locus cercanos a los sitios residenciales analizados. En estos últimos se habrían realizado actividades múltiples. 


\section{CAPítulo 9}

\section{RESULTADOS DEL ANÁLISIS DEL REGISTRO LÍTICO EN EL DESIERTO DE MONTE}

\subsection{LOS SITIOS ARQUEOLÓGICOS BAJO ESTUDIO}

En este capítulo se presentan los resultados del análisis de los conjuntos líticos del Desierto de Monte, localizado en el último tramo recorrido por el río Atuel. Aquí se incluyen tres de los sitios arqueológicos en estratigrafía, analizados en esta tesis: Los Gallegos 1 (LG-1), que incluye las cuadrículas A1 y B1; El Bosquecillo 3 (EB-3); y E1 Bosquecillo 5 (EB-5) (Figuras 9.1 y 9.2). Los tres se localizan sobre la margen derecha del río Atuel. A continuación, se detallan las características del registro arqueológico de las cuatro cuadrículas, incluyendo los procedimientos de excavación, estratigrafía y cronología. Luego se profundiza sobre el registro lítico.
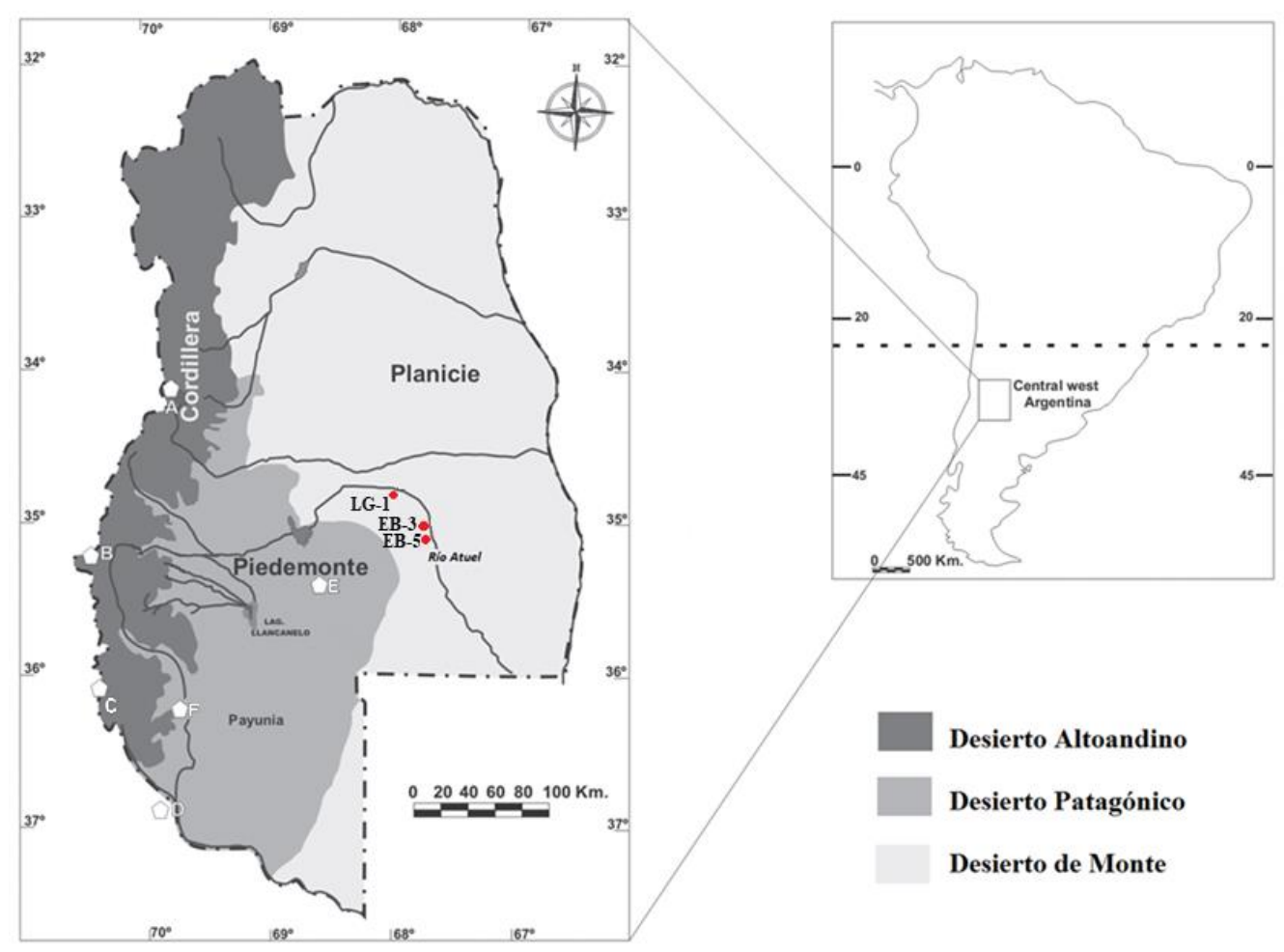

Figura 9.1. Localización de los sitios arqueológicos del Desierto de Monte (cuenca inferior del río Atuel) y de las fuentes de obsidiana. Referencias: sitios arqueológicos: LG-1: Los Gallegos 
1; EB-3: El Bosquecillo 3; EB-5: El Bosquecillo 5. Fuentes de obsidiana: A- Laguna El Diamante; B- Las Cargas; C- Laguna del Maule; D- Cerro Huenul; E- El Peceño; F- Coche Quemado.

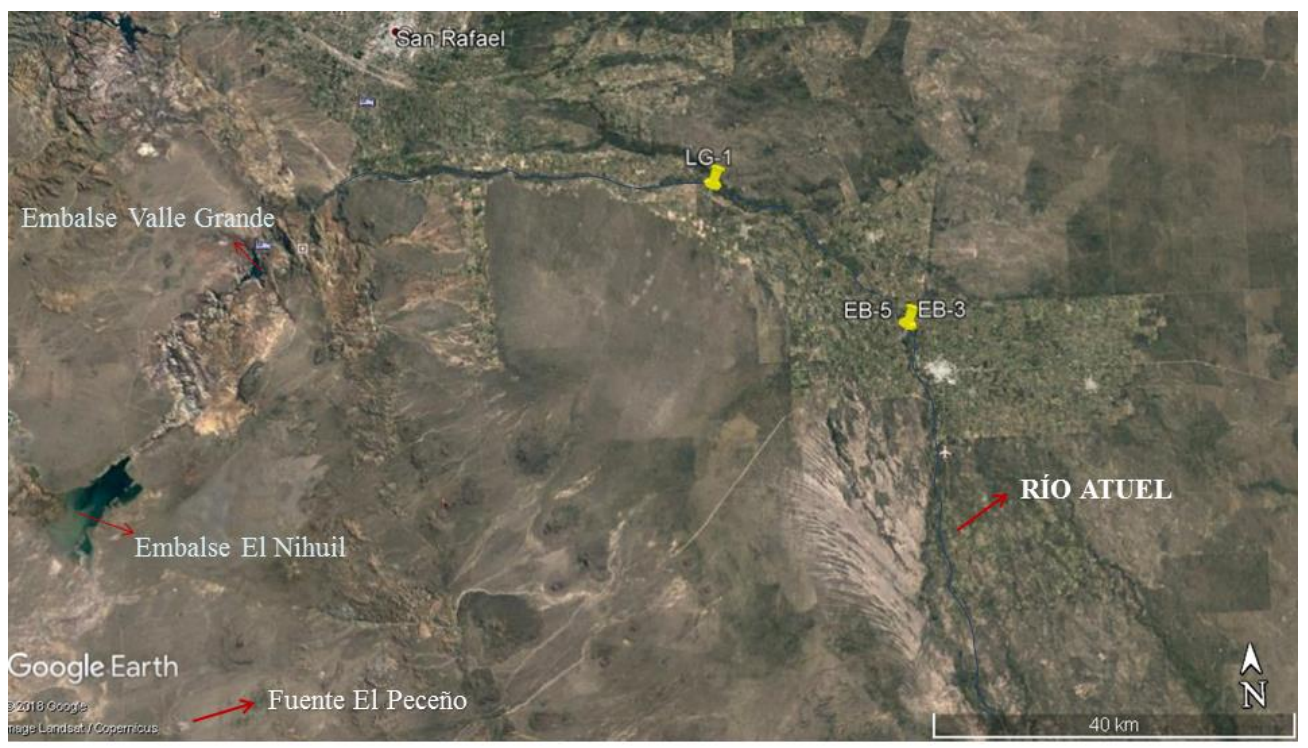

Figura 9.2. Localización de los sitios del Desierto de Monte en la cuenca inferior del Atuel.

Referencias: LG-1: Los Gallegos 1; EB-3: El Bosquecillo 3; EB-5: El Bosquecillo 5. En azul se resalta el curso actual del río. También se señala la localización de la ciudad de San Rafael, de los embalses El Nihuil (área de la Localidad Arbolito -Capítulo 8) y Valle Grande, y se muestra la localización de la fuente de obsidiana El Peceño.

\subsubsection{LOS GALLEGOS 1}

El sitio arqueológico a cielo abierto Los Gallegos 1 (3447'43,31' de LS y a $67^{\circ} 57^{\prime} 8,15^{\prime \prime}$ de LO, a $577 \mathrm{msnm}$ ) se emplaza sobre la margen derecha de río Atuel, a unos $600 \mathrm{~m}$ lineales de su barranca, sobre la planicie de inundación (Figuras 9.1, 9.2 y 9.3). 


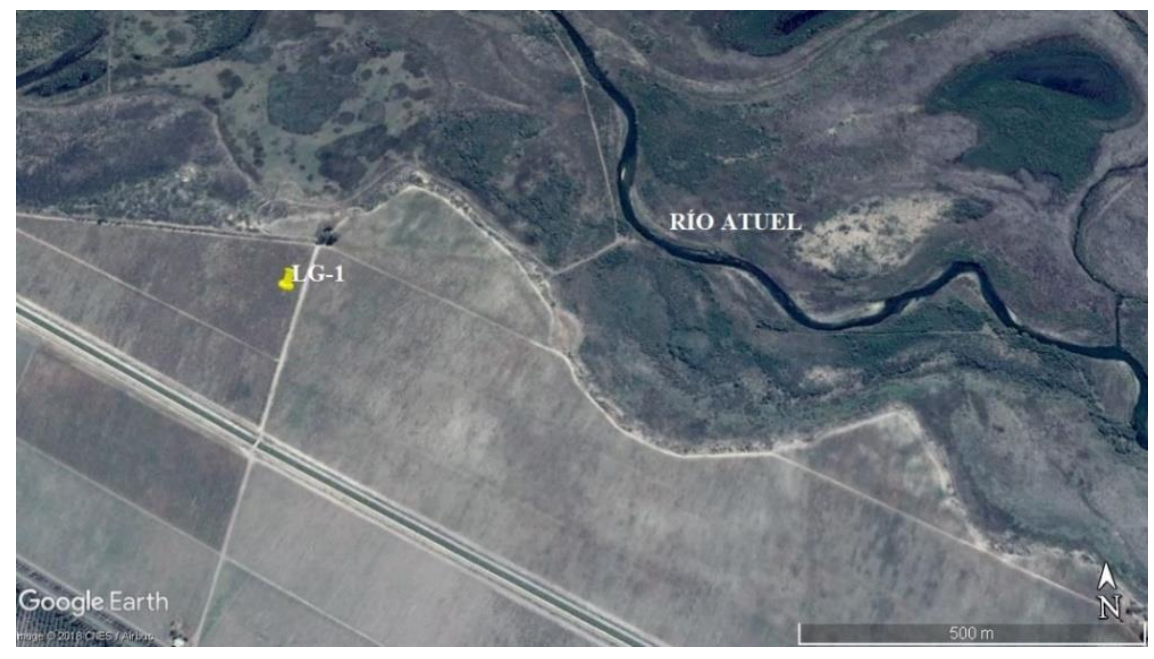

Figura 9.3. Localización del sitio LG-1 en relación a la cuenca del río Atuel.

\subsubsection{Excavación}

En el año 2004 se hizo un estudio de impacto previo a la construcción de la obra Canal Marginal del Atuel. En las transectas realizadas en el tramo II de dicho trabajo se detectó una concentración de materiales arqueológicos en superficie, dentro de una finca con plantaciones de olivos, a $32 \mathrm{~km}$ de la ciudad de General Alvear. Sobre la superficie del sitio, de $2160 \mathrm{~m}^{2}$, se plantearon dos cuadrículas de 2 × $2 \mathrm{~m}$ en sentido norte-sur. La cuadrícula A1 se posicionó a $628 \mathrm{~m}$ de distancia de las barrancas del río Atuel y la cuadrícula B1 cerca del límite actual de la plantación de olivos, en el sector con mayor densidad de hallazgos. Al comienzo de las excavaciones se realizó una nivelación hasta los $10 \mathrm{~cm}$. Ambas cuadrículas se dividieron en cuatro sectores de excavación según la orientación (NE, NW, SE y SW) y se trabajó por niveles artificiales de $5 \mathrm{~cm}$. Dado que a partir del nivel 3 el material arqueológico disminuyó sensiblemente en ambas cuadrículas, se decidió realizar un sondeo desde el nivel 4 en el sector noreste de ambas cuadrículas. El mismo se excavó siguiendo niveles de $10 \mathrm{~cm}$ (Figura 9.4). Luego, a la mitad del nivel 5 de la cuadrícula A1 y en el nivel 6 de la cuadrícula B1, reapareció gran cantidad de material cultural, por lo que se decidió continuar con los niveles de $5 \mathrm{~cm}$. Se prosiguió hasta el nivel 9 en la cuadrícula A1 y el nivel 10 en la B1. Así, en la cuadrícula A1 se llegó hasta el nivel 10 (de $10 \mathrm{~cm}$ ) y se alcanzó una potencia total de $72 \mathrm{~cm}$. Por su parte, la cuadrícula B1 se excavó hasta el nivel 11 (también de $10 \mathrm{~cm}$ ), alcanzando los $86 \mathrm{~cm}$ de profundidad. 


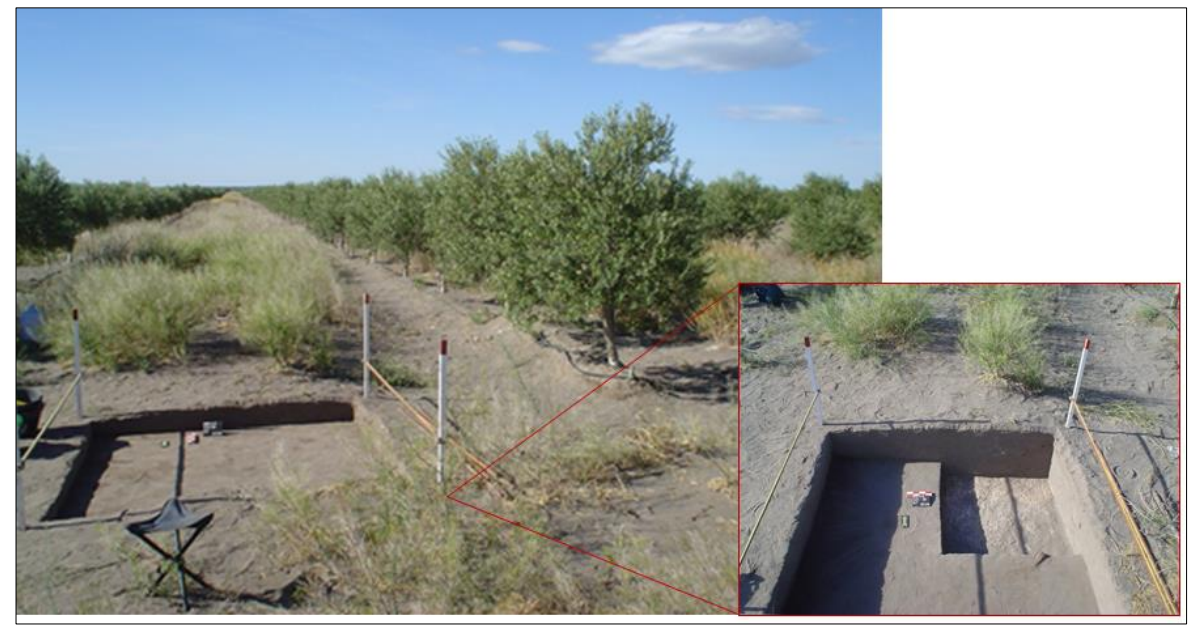

Figura 9.4. Vista panorámica del sitio LG-1 y localización de la cuadrícula B1 entre plantaciones de olivos, con detalle del sondeo realizado en el sector NE.

\subsubsection{Estratigrafía}

Si bien la cuadrícula A1 de LG-1 se estableció por fuera del área de cultivo (Figura 9.5) y la cuadrícula B1, sobre los callejones que separan las hileras de los olivares (Figura 9.6), toda el área muestra indicios de estar retrabajada por el uso del arado, por lo que se asumió que al menos los primeros $30 \mathrm{~cm}$ de ambas cuadrículas de LG-1 estarían modificados. Esto se confirmó con la aparición de camellones durante las excavaciones, dispuestos en la forma de los antiguos surcos del arado (Figura 9.6).

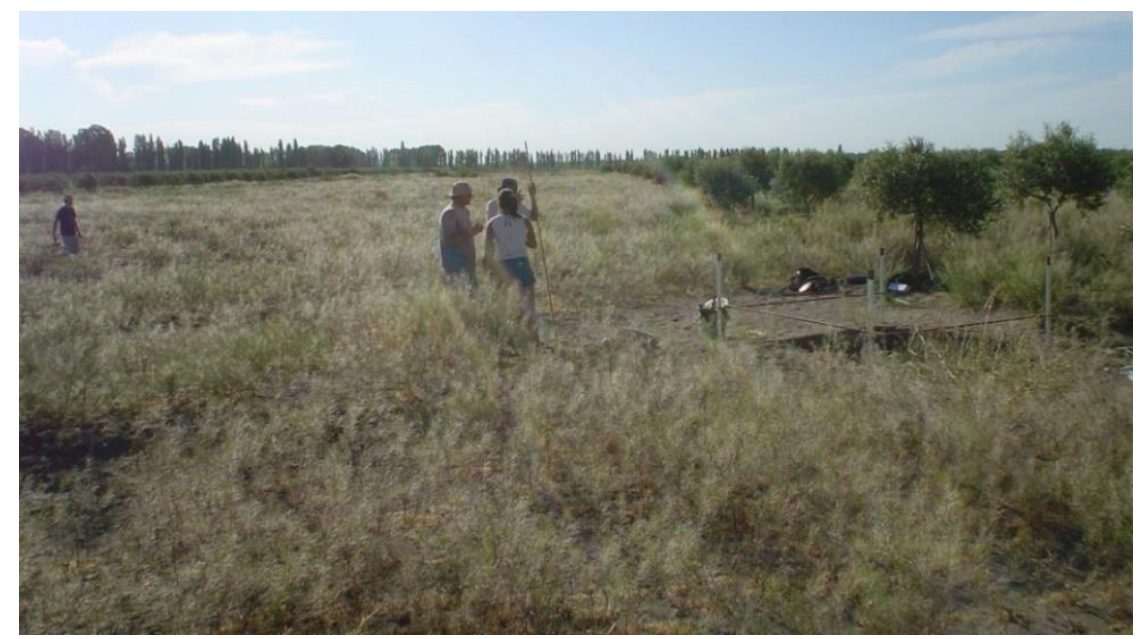

Figura 9.5. Vista panorámica del sitio LG-1 y localización de la cuadrícula A1. 


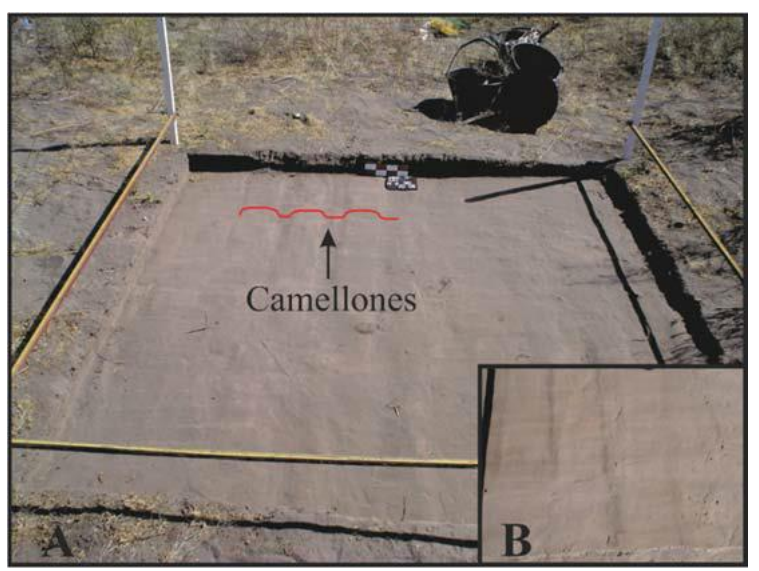

Figura 9.6. Sitio Los Gallegos 1. Referencias: A- Cuadrícula A1 de 2 x 2 m con detalle del perfil de los camellones (en rojo). B- Detalle de los camellones presentes en las cuadrículas.

Tomado de Sugrañes (2017: 312).

La estratigrafía de ambas cuadrículas es muy similar y simple. Consiste en una matriz arenosa, compacta y húmeda con motas de ceniza volcánica (Figura 9.7). En el sector suroeste de la cuadrícula B1 se observó un tipo de estructura que contiene mayor cantidad de ceniza y bordes de materia orgánica (Figura 9.8). En dicha cuadrícula, desde los $50 \mathrm{~cm}$ (nivel 6) de LG-1 (B1) se registró pumicita y también aparecen raíces entremezcladas en el sedimento arenoso. Luego, a unos $70 \mathrm{~cm}$ de profundidad (nivel 9) la arena se torna más compacta con manchones limo arcillosos. El sedimento del nivel 10 fue cernido en partes separadas: el sedimento arenoso superior (10a) por un lado y, el sedimento inferior limo arcilloso (10b), por otro. El sedimento limo arcilloso cubre toda la capa correspondiente al último nivel, el 11, salvo en el sector sureste.

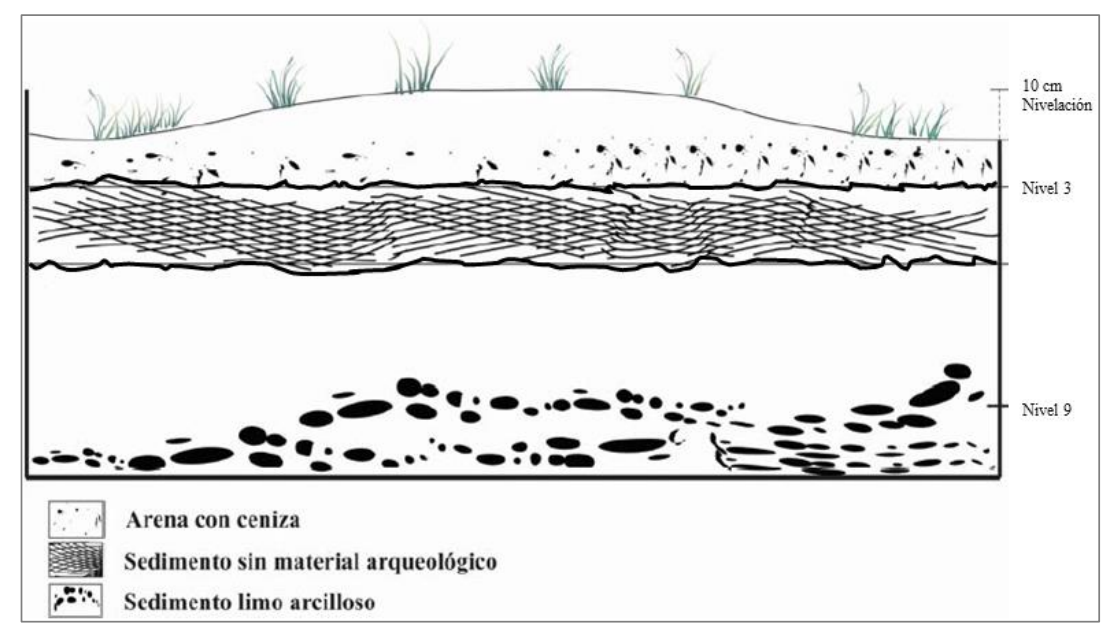

Figura 9.7. Estratigrafía de la cuadrícula B1 del sitio LG-1. Tomado y modificado de Sugrañes (2017: 313). 


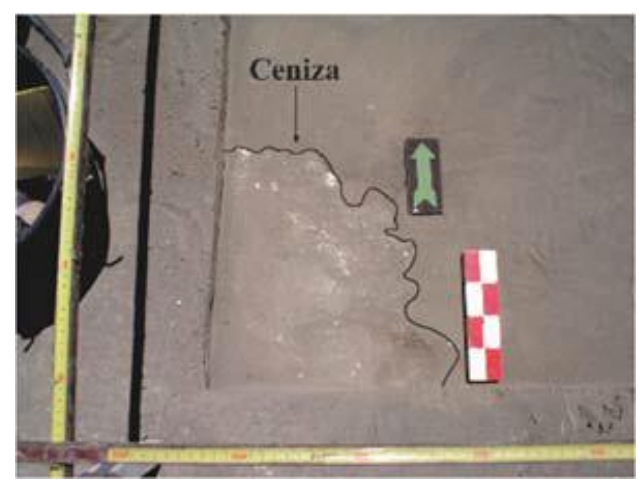

Figura 9.8. Estructura de ceniza en el sector SW de la cuadrícula B1 de LG-1. Tomado de Sugrañes (2017: 313).

\subsubsection{Cronología}

El sitio LG-1 cuenta con dos fechados radiocarbónicos, ambos sobre carbón disperso en capa recuperado de la cuadrícula B1 (Tabla 9.1). Los fechados se encuentran invertidos, lo cual es coherente y esperable en terrenos que fueron arados (Lewis et al. 1982). Igualmente, ambas corresponden al HTF (2.000-200 años AP) y las diferencias no son estadísticamente significativas por lo que se consideró una cronología aproximada para el sitio LG-1 de $c a$. 1.200 años AP, y de 1.050 años calibrados AP (Figura 9.9). Por lo tanto, la tasa de depositación, calculada sobre artefactos líticos (sin desechos de talla de tamaño igual o menor a $5 \mathrm{~mm}$ de lado; véase Capítulo 5), es de 0,05 artefactos depositados por año en la cuadrícula A1, y de 0,06 /año en LG-1 (B1); ambas tasas son las más bajas del Desierto de Monte.

\begin{tabular}{|c|ccccc|} 
Cuadrícula & $\begin{array}{c}\text { Nivel } \\
\text { artific. }\end{array}$ & $\begin{array}{c}\text { Fecha } \\
{ }^{14} \mathrm{C}\end{array}$ & $\begin{array}{c}\text { Edad cal } \\
\text { AP }\end{array}$ & Material & Código \\
\hline B1 & 6 & $1.217 \pm 37$ & 1.014 & Carbón & AA-66580 \\
\hline B1 & 10 & $1.159 \pm 38$ & 1.081 & Carbón & AA-66581 \\
\hline
\end{tabular}

Tabla 9.1. Fechados radiocarbónicos y edades calibradas, obtenidos en LG-1.

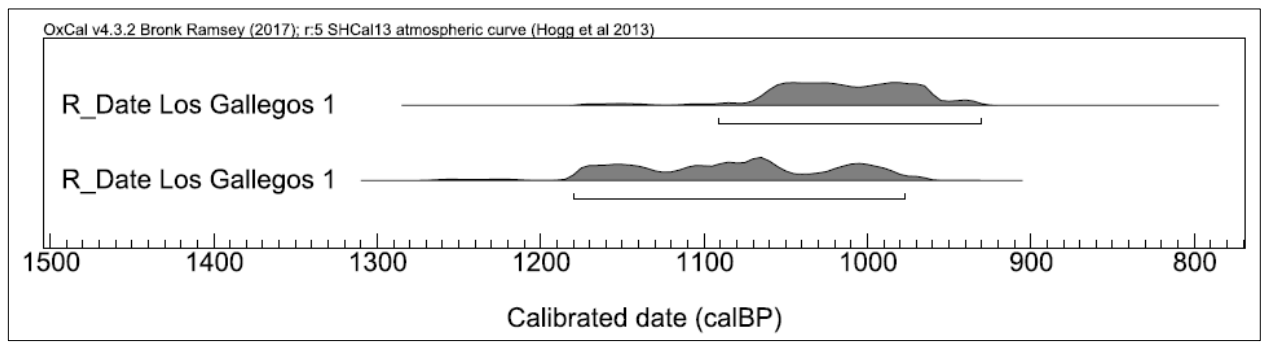

Figura 9.9. Edades calibradas para el sitio LG-1. Calibración realizada con el programa OxCal v4.3.2 (Ramsey 2009), usando la curva atmosférica SHCal 13 para el hemisferio sur (Hogg et al. 2013). 


\subsubsection{Registro arqueológico}

Las dos cuadrículas excavadas en el sitio LG-1 poseen una composición semejante en cuanto a restos arqueológicos, aunque en la cuadrícula A1 no se recuperaron fragmentos cerámicos (Sugrañes 2017). La cuadrícula B1 posee una mayor densidad de materiales y de análisis realizados hasta la fecha, por lo que el registro arqueológico se detalla con mayor profundidad que el de la A1. Los diferentes materiales recuperados de la cuadrícula B1, no se distribuyen de manera uniforme a lo largo de la estratigrafía y, aunque en todos los niveles se registró uno y/u otro tipo de materiales, la mayor densidad se da entre los niveles 6 y 9, especialmente de materiales zooarqueológicos (Tabla 9.2 y Figura 9.10). Según Neme (com. pers. 2018), los materiales arqueofaunísticos se hallan en un estado avanzado de meteorización, acompañados de una alta fragmentación, lo que resultó en la obtención de astillas, únicamente, e imposibilitó la identificación taxonómica del conjunto.

\begin{tabular}{|c|c|c|c|c|c|c|}
\hline \multirow{2}{*}{ Nivel } & \multicolumn{2}{|c|}{ Cuadrícula A1 } & \multirow{2}{*}{ Nivel } & \multicolumn{3}{|c|}{ Cuadrícula B1 } \\
\hline & Óseo & Lítico & & Óseo & Lítico & Cerámica \\
\hline 1 & 77 & 44 & 1 & 55 & 21 & - \\
\hline 2 & 36 & 36 & 2 & 51 & 16 & - \\
\hline 3 & 29 & 16 & 3 & 50 & 4 & - \\
\hline 4 & 2 & 5 & 4 & 21 & 18 & 2 \\
\hline 5 & - & 4 & 5 & 68 & 10 & 2 \\
\hline 6 & - & - & \multirow{2}{*}{6} & \multirow{2}{*}{216} & \multirow{2}{*}{17} & \multirow{2}{*}{3} \\
\hline 7 & - & 2 & & & & \\
\hline 8 & - & - & 7 & 149 & 21 & 4 \\
\hline 9 & - & - & 8 & 76 & 9 & 1 \\
\hline \multirow[t]{5}{*}{10} & - & 9 & 9 & 67 & 31 & 2 \\
\hline & 144 & 116 & $10 \mathrm{a}$ & 48 & 12 & 7 \\
\hline & & & $10 \mathrm{~b}$ & 1 & 1 & - \\
\hline & & & 11 & 1 & - & - \\
\hline & & & & 803 & 160 & 21 \\
\hline
\end{tabular}

Tabla 9.2. Materiales arqueológicos recuperados de las cuadrículas A1 y B1 del sitio LG-1 por nivel artificial de excavación de 5 o $10 \mathrm{~cm}$ (según el tamaño menor o mayor de la fila, respectivamente). 


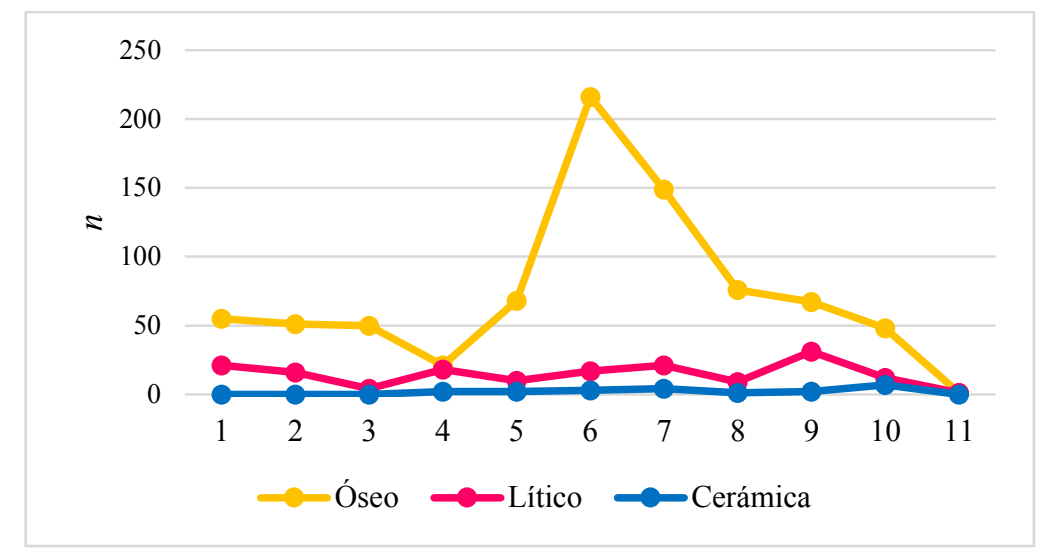

Figura 9.10. Distribución de los materiales arqueológicos por nivel de excavación de las cuadrículas A1 y B1 de LG-1.

En cuanto al conjunto cerámico, este consiste en 21 fragmentos recuperados de los niveles 4 a 10 de la cuadrícula B1 (Tabla 9.2), más seis tiestos obtenidos de una recolección superficial. Predominan el tamaño pequeño $(88,89 \%)$, la fractura regular $(62,96 \%)$ y la parte de la vasija correspondiente al cuerpo $(51,85 \%)$, con bajo porcentaje de huellas de uso; entre ellos, residuos orgánicos, hollín y atrición en la superficie interior, y sólo hollín en la exterior (Sugrañes 2017).

\subsubsection{Registro lítico}

En la cuadrícula A1 de LG-1, se recuperaron 116 artefactos líticos (Tabla 9.3); de ellos, 66 son desechos de talla de tamaño menor o igual a $5 \mathrm{~mm}$ de lado (" $\leq 5 \mathrm{~mm}$ " en la Tabla 9.3). Así, el $n$ total con el cual se trabajó es de 50 artefactos, los cuales incluyen sólo dos clases artefactuales: la de los desechos de talla ("> $>5 \mathrm{~mm}$ " en la Tabla 9.3), que representan el 98\% $(n=49)$; y la de los nódulos, con un único representante que es de cuarzo (Tabla 9.3).

Se registraron cuatro clases de roca, siendo las rocas silíceas las mayoritarias, seguidas por la riolita, el basalto, y el cuarzo; este último se registró en el único nódulo recuperado de la cuadrícula y en dos desechos de talla. Las otras tres clases de roca corresponden a desechos de talla (Tabla 9.4).

\begin{tabular}{|c|c|c|c|c|}
\hline \multirow{2}{*}{ Nivel } & \multicolumn{2}{|c|}{ Desechos de talla } & \multirow{2}{*}{ Nódulo } & \multirow{2}{*}{ Total } \\
\cline { 2 - 3 } & $(\mathbf{5} \mathbf{m m})$ & $\mathbf{( \leq \mathbf { 5 m m } )}$ & & \\
\hline $\mathbf{1}$ & 22 & 21 & 1 & $\mathbf{4 4}$ \\
\hline $\mathbf{2}$ & 6 & 30 & - & $\mathbf{3 6}$ \\
\hline $\mathbf{3}$ & 8 & 8 & - & $\mathbf{1 6}$ \\
\hline $\mathbf{4}$ & 4 & 1 & - & $\mathbf{5}$ \\
\hline $\mathbf{5}$ & 3 & 1 & - & $\mathbf{4}$ \\
\hline $\mathbf{6}$ & - & - & - & - \\
\hline
\end{tabular}




\begin{tabular}{|c|c|c|c|c|}
7 & 1 & 1 & - & 2 \\
\hline 8 & - & - & - & - \\
\hline 9 & - & - & - & - \\
\hline 10 & 5 & 4 & - & 9 \\
\hline Total & 49 & 66 & 1 & 116 \\
\hline Total \% & 42,24 & 56,90 & 0,86 & 100 \\
\hline
\end{tabular}

Tabla 9.3. Clases artefactuales por nivel de excavación en la cuadrícula A1 de LG-1.

\begin{tabular}{|c|c|c|c|c|c|}
\hline Nivel & BAS & QZ & RIO & SIL & Total \\
\hline $\mathbf{1}$ & $2(8,7 \%)$ & $2(8,7 \%)$ & $2(8,7 \%)$ & $17(73,9 \%)$ & $\mathbf{2 3}$ \\
\hline $\mathbf{2}$ & - & $1(16,7 \%)$ & $2(33,3 \%)$ & $3(50,0 \%)$ & $\mathbf{6}$ \\
\hline $\mathbf{3}$ & $1(12,5 \%)$ & - & $3(37,5 \%)$ & $4(50,0 \%)$ & $\mathbf{8}$ \\
\hline $\mathbf{4}$ & - & - & $2(50,0 \%)$ & $2(50,0 \%)$ & $\mathbf{4}$ \\
\hline $\mathbf{5}$ & - & - & $1(33,3 \%)$ & $2(66,7 \%)$ & $\mathbf{3}$ \\
\hline $\mathbf{6}$ & - & - & - & - & - \\
\hline $\mathbf{7}$ & - & - & - & $1(100 \%)$ & $\mathbf{1}$ \\
\hline $\mathbf{8}$ & - & - & - & - & - \\
\hline $\mathbf{9}$ & - & - & - & - & - \\
\hline $\mathbf{1 0}$ & $2(40,0 \%)$ & - & $2(40,0 \%)$ & $1(20,0 \%)$ & $\mathbf{5}$ \\
\hline Total & $\mathbf{5}$ & $\mathbf{3}$ & $\mathbf{1 2}$ & $\mathbf{3 0}$ & $\mathbf{5 0}$ \\
\hline Total \% & $\mathbf{1 0 , 0}$ & $\mathbf{6 , 0}$ & $\mathbf{2 4 , 0}$ & $\mathbf{6 0 , 0}$ & $\mathbf{1 0 0}$ \\
\hline
\end{tabular}

Tabla 9.4. Distribución y frecuencia de materias primas por nivel de excavación en la cuadrícula

A1 de LG-1. Referencias: BAS: basalto; QZ: cuarzo; RIO: riolita; SIL: rocas silíceas.

Los artefactos sobre rocas silíceas están presentes en todos los niveles en que se registraron artefactos líticos; en cambio, el basalto aparece en muy poca frecuencia, restringiéndose a los niveles 1,3 y 10 . El cuarzo sólo aparece en los niveles 1 y 2, y la riolita tiene una representación estratigráfica similar a la de las rocas silíceas, aunque no se registraron en el nivel 7 (Tabla 9.4 y Figura 9.11). La obsidiana sólo se registró en las categorías de tamaño inferior a 5 x $5 \mathrm{~mm}$, por lo que no es considerada en este análisis.

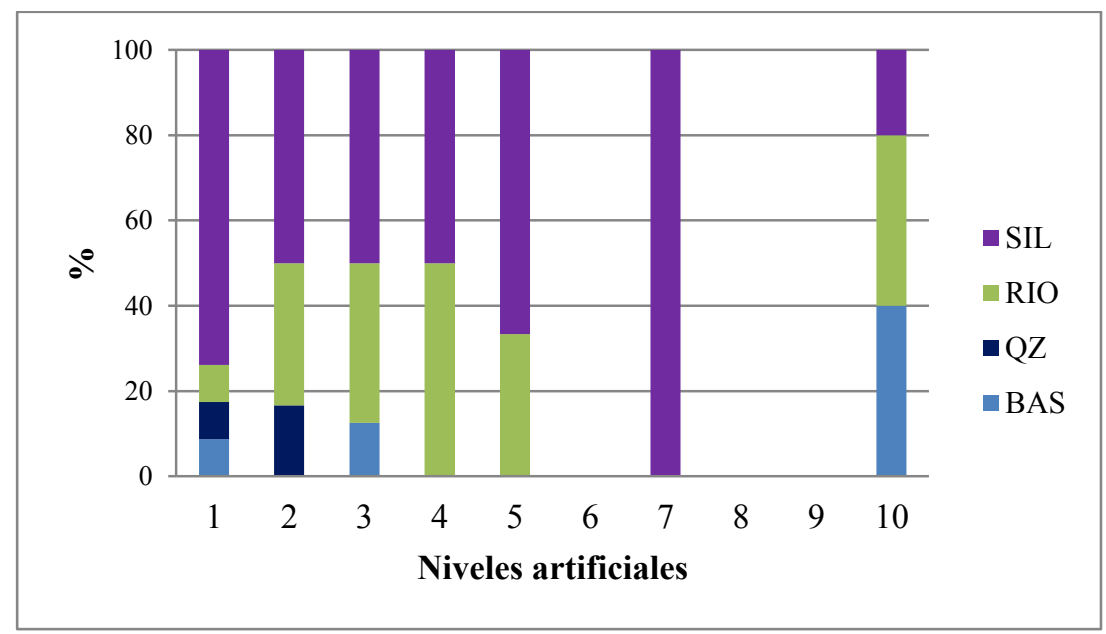

Figura 9.11. Frecuencia de materias primas por nivel artificial en LG-1 (A1). 
En el caso de la cuadrícula B1 del sitio LG-1, se registraron 160 artefactos líticos; 98 de ellos son desechos de talla de tamaño igual o menor a $5 \mathrm{~mm}$ de lado, por lo que el total de artefactos analizados es de 62. En esta cuadrícula se reconocieron dos clases artefactuales: desechos de talla $(93,75 \%, n=60)$ y nódulos $(6,25 \%, n=4)($ Tabla 9.5).

\begin{tabular}{|c|c|c|c|c|}
\hline \multirow{2}{*}{ Nivel } & \multicolumn{2}{|c|}{ Desechos de talla } & \multirow{2}{*}{ Nódulo } & \multirow{2}{*}{ Total } \\
\hline & $(>5 \mathrm{~mm})$ & $(\leq 5 \mathrm{~mm})$ & & \\
\hline 1 & 6 & 15 & - & 21 \\
\hline 2 & 1 & 14 & 1 & 16 \\
\hline 3 & - & 4 & - & 4 \\
\hline 4 & 5 & 12 & 1 & 18 \\
\hline 5 & 6 & 4 & - & 10 \\
\hline 6 & 8 & 8 & 1 & 17 \\
\hline 7 & 7 & 13 & 1 & 21 \\
\hline 8 & 5 & 4 & - & 9 \\
\hline 9 & 17 & 14 & - & 31 \\
\hline $10 \mathbf{a}$ & 4 & 8 & - & 12 \\
\hline $10 b$ & 1 & - & - & 1 \\
\hline 11 & - & - & - & - \\
\hline Total & 60 & 96 & 4 & 160 \\
\hline Total \% & $\mathbf{3 7 , 5 0}$ & 60,00 & 2,50 & 100 \\
\hline
\end{tabular}

Tabla 9.5. Clases artefactuales por nivel de excavación en la cuadrícula B1 de LG-1.

Por lo tanto, la composición artefactual es la misma que la registrada LG-1 (A1); pero la densidad de materiales líticos es mayor en LG-1 (B1). Lo mismo se observó con el resto de los materiales arqueológicos de ambas cuadrículas, aunque además de la mayor frecuencia de materiales, se observó la presencia de material cerámico (Sugrañes 2017).

En la Tabla 9.6 se agruparon los materiales del nivel 10, originalmente separados de acuerdo al tipo de sedimento (10a: arena; 10b: sedimento limo-arcilloso); y el nivel 11 no fue considerado, debido a la ausencia de materiales líticos. Se observa que las tres materias primas más representadas son las mismas que en la cuadrícula $\mathrm{A} 1$, y aparecen en el mismo orden de frecuencia: rocas silíceas, riolita y basalto (Tabla 9.6).

\begin{tabular}{|c|c|c|c|c|c|c|c|c|}
\hline Nivel & AND & BAS & OBS & QZ & RIO & SIL & Indet. & Total \\
\hline $\mathbf{1}$ & - & - & - & - & $\begin{array}{c}3 \\
(50,0 \%)\end{array}$ & $\begin{array}{c}3 \\
(50,0 \%)\end{array}$ & - & $\mathbf{6}$ \\
\hline $\mathbf{2}$ & - & $\begin{array}{c}1 \\
(50,0 \%)\end{array}$ & - & - & $\begin{array}{c}1 \\
(50,0 \%)\end{array}$ & - & - & $\mathbf{2}$ \\
\hline $\mathbf{3}$ & - & - & - & - & - & - & - & - \\
\hline $\mathbf{4}$ & - & - & 1 & 1 & 3 & 1 & - & $\mathbf{6}$ \\
\hline $\mathbf{5}$ & - & $\begin{array}{c}1 \\
(16,7 \%)\end{array}$ & $\begin{array}{c}1 \\
(16,7 \%)\end{array}$ & - & - & $\begin{array}{c}4 \\
(16,7 \%)\end{array}$ & - & $\mathbf{6}$ \\
\hline
\end{tabular}




\begin{tabular}{|c|c|c|c|c|c|c|c|c|}
\hline 6 & - & - & - & - & $\begin{array}{c}3 \\
(33,3 \%)\end{array}$ & $\begin{array}{c}6 \\
(66,7 \%)\end{array}$ & - & 9 \\
\hline 7 & - & - & - & $\begin{array}{c}1 \\
(12,5 \%)\end{array}$ & $\begin{array}{c}1 \\
(12,5 \%)\end{array}$ & $\begin{array}{c}6 \\
(75,0 \%)\end{array}$ & - & 8 \\
\hline 8 & - & - & - & - & $\begin{array}{c}2 \\
(40,0 \%)\end{array}$ & $\begin{array}{c}3 \\
(60,0 \%)\end{array}$ & - & 5 \\
\hline 9 & $\begin{array}{c}1 \\
(5,9 \%)\end{array}$ & $\begin{array}{c}2 \\
(11,8 \%)\end{array}$ & $\begin{array}{c}1 \\
(5,9 \%)\end{array}$ & - & $\begin{array}{c}6 \\
(35,3 \%)\end{array}$ & $\begin{array}{c}6 \\
(35,3 \%)\end{array}$ & $\begin{array}{c}1 \\
(5,9 \%)\end{array}$ & 17 \\
\hline 10 & - & $\begin{array}{c}1 \\
(20,0 \%)\end{array}$ & - & $\begin{array}{c}1 \\
(20,0 \%)\end{array}$ & $\begin{array}{c}2 \\
(40,0 \%)\end{array}$ & - & $\begin{array}{c}1 \\
(20,0 \%)\end{array}$ & 5 \\
\hline Total & 1 & 5 & 3 & 3 & 21 & 29 & 2 & 64 \\
\hline $\begin{array}{c}\text { Total } \\
\%\end{array}$ & 1,6 & 7,8 & 4,7 & 4,7 & 32,8 & 45,3 & 3,1 & 100 \\
\hline
\end{tabular}

Tabla 9.6. Distribución y frecuencia de materias primas por nivel de excavación en la cuadrícula

B1 de LG-1. Referencias: AND: andesita; BAS: basalto; OBS: obsidiana; QZ: cuarzo; RIO: riolita; SIL: rocas siliceas; Indet.: roca indeterminada.

La mayor densidad de materiales, asimismo, proporcionó un mayor registro en cuanto a variedad de materias primas líticas representadas en LG-1 (B1). Además del registro de nódulos de cuarzo $(3,13 \%, \mathrm{n}=2)$ como el registrado en LG-1 (A1), se registraron nódulos en basalto $(1,56 \%, \mathrm{n}=1)$ y en riolita $(1,56 \%, \mathrm{n}=1)$, dos de las rocas más frecuentes, pero no se registraron nódulos sobre rocas silíceas. Entre los desechos de talla, se registraron, además de estas tres rocas principales, obsidiana $(4,69 \%, n=3)$, dos rocas indeterminadas $(3,13 \%)$ y un desecho de andesita (1,56\%) (Tabla 9.6 y Figura 9.12).

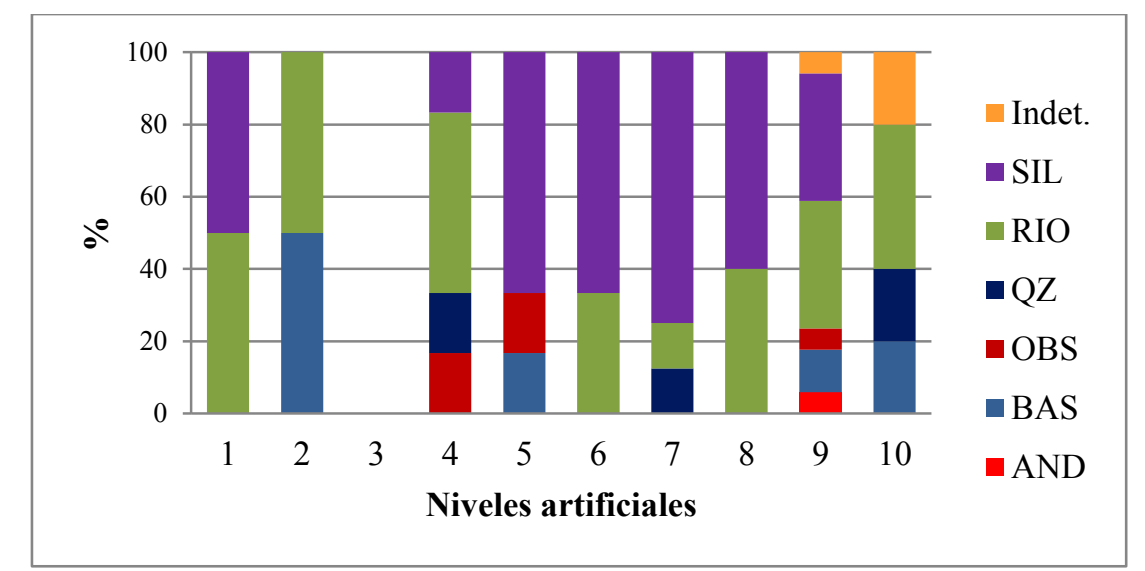

Figura 9.12. Frecuencia de materias primas por nivel artificial en LG-1 (B1).

En la Figura 9.12 se observa que los materiales líticos se distribuyen de manera heterogénea. Las rocas silíceas y las riolitas están presentes en la mayoría de los niveles (excepto las silíceas en los niveles 2 y 10, y la riolita en el nivel 5). La obsidiana se registró en los niveles 4 y 5 , y reaparece en el 9 . El basalto se registra primero en el nivel 2, luego en el 5 y se vuelve a registrar en los últimos dos. El cuarzo aparece en los niveles 4, 7 y 
10. El nivel 9 es el más variado; en él están presentes todas las materias primas, excepto el cuarzo. Algo semejante se observó entre el registro no lítico (Sección 9.1.1.4.).

En la Tabla 9.7 se integran las materias primas de ambas cuadrículas excavadas en LG-1. En la Figura 9.13 se presentan las tendencias obtenidas de dicha integración.

\begin{tabular}{|c|c|c|c|c|c|c|c|c|}
\hline Nivel & AND & BAS & OBS & QZ & RIO & SIL & Indet. & Total \\
\hline $\mathbf{1}$ & - & 2 & - & 2 & 5 & 20 & - & $\mathbf{2 9}$ \\
\hline $\mathbf{2}$ & - & 1 & - & 1 & 3 & 3 & - & $\mathbf{8}$ \\
\hline $\mathbf{3}$ & - & 1 & - & - & 3 & 4 & - & $\mathbf{8}$ \\
\hline $\mathbf{4}$ & - & - & 1 & 1 & 5 & 3 & - & $\mathbf{1 0}$ \\
\hline $\mathbf{5}$ & - & 1 & 1 & - & 1 & 6 & - & $\mathbf{9}$ \\
\hline $\mathbf{6}$ & - & - & - & - & 3 & 6 & - & 9 \\
\hline $\mathbf{7}$ & - & - & - & 1 & 1 & 7 & - & $\mathbf{9}$ \\
\hline $\mathbf{8}$ & - & - & - & - & 2 & 3 & - & $\mathbf{5}$ \\
\hline $\mathbf{9}$ & 1 & 2 & 1 & - & 6 & 6 & 1 & $\mathbf{1 7}$ \\
\hline $\mathbf{1 0}$ & - & 3 & - & 1 & 4 & 1 & 1 & $\mathbf{1 0}$ \\
\hline Total & $\mathbf{1}$ & $\mathbf{1 0}$ & $\mathbf{3}$ & $\mathbf{6}$ & $\mathbf{3 3}$ & $\mathbf{5 9}$ & $\mathbf{2}$ & $\mathbf{1 1 4}$ \\
\hline Total \% & $\mathbf{0 , 9}$ & $\mathbf{8 , 8}$ & $\mathbf{2 , 6}$ & $\mathbf{5 , 3}$ & $\mathbf{2 8 , 9}$ & $\mathbf{5 1 , 8}$ & $\mathbf{1 , 8}$ & $\mathbf{1 0 0}$ \\
\hline
\end{tabular}

Tabla 9.7. Distribución y frecuencia de materias primas por nivel de excavación en las cuadrículas A1 y B1 del sitio LG-1. Referencias: AND: andesita; BAS: basalto; OBS: obsidiana; QZ: cuarzo; RIO: riolita; SIL: rocas siliceas; Indet.: roca indeterminada.

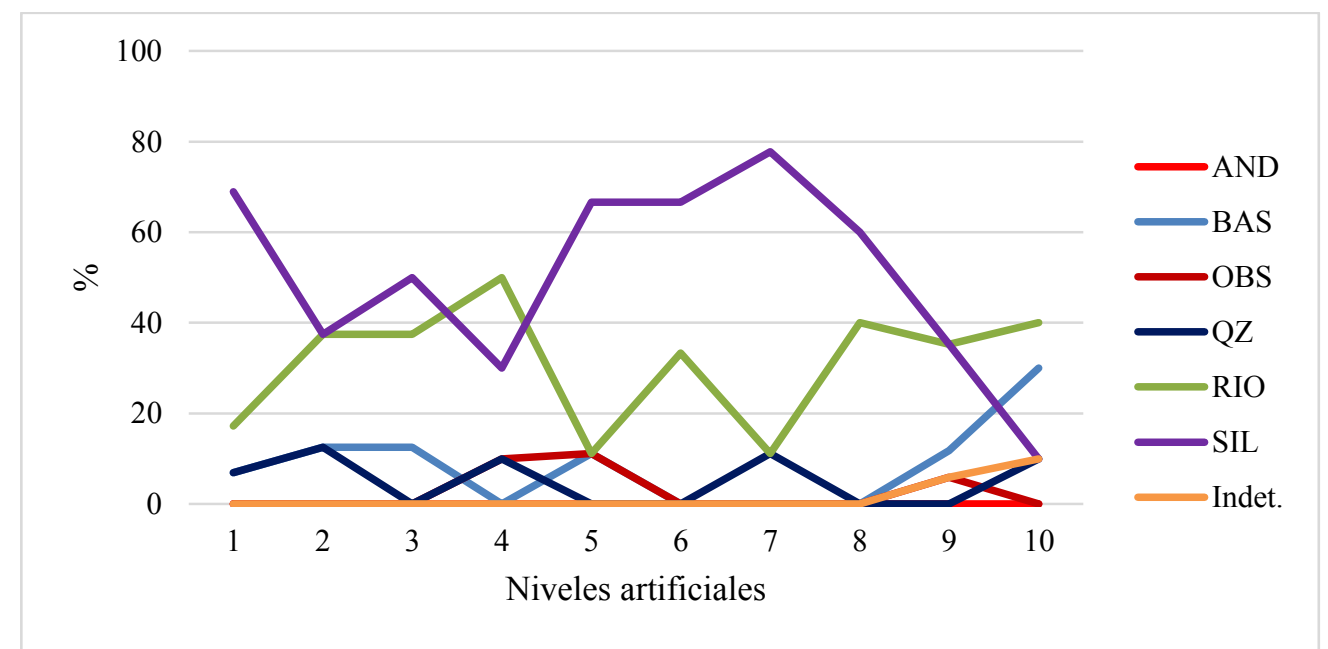

Figura 9.13. Frecuencia de materias primas en LG-1 (cuadrículas A1 y B1).

\subsection{Desechos de talla en LG-1 (cuadrículas Al y B1)}

Esta clase artefactual predomina en ambas cuadrículas. En este apartado, se decidió reunir los desechos de talla de ambas cuadrículas como un único conjunto. De esta manera, el $n$ analizado es de 109 desechos de talla. De estos, las silíceas son las rocas más representadas (Tabla 9.8 y Figura 9.14). En la Figura 9.14 se observa que, salvo en 
el caso de la riolita, las frecuencias de desechos de talla de la cuadrícula A1 superan a las de la B1, pero esta última presenta mayor variedad de materias primas.

\begin{tabular}{|c|c|c|c|c|c|c|c|c|}
\hline Cuadrícula & AND & BAS & OBS & QZ & RIO & SIL & Indet. & Total \\
\hline \multirow{2}{*}{$\mathbf{1} 1$} & - & $\begin{array}{c}10,2 \% \\
(5)\end{array}$ & - & $\begin{array}{c}4,1 \% \\
(2)\end{array}$ & $\begin{array}{c}24,5 \% \\
(12)\end{array}$ & $\begin{array}{c}61,2 \% \\
(30)\end{array}$ & - & \multirow{4}{4}{} \\
\hline \multirow{2}{*}{$\mathbf{1} 1$} & $\begin{array}{c}1,7 \% \\
(1)\end{array}$ & $\begin{array}{c}6,7 \% \\
(4)\end{array}$ & $\begin{array}{c}5,0 \% \\
(3)\end{array}$ & $\begin{array}{c}1,7 \% \\
(1)\end{array}$ & $\begin{array}{c}33,3 \% \\
(20)\end{array}$ & $\begin{array}{c}48,3 \% \\
(29)\end{array}$ & $\begin{array}{c}3,3 \% \\
(2)\end{array}$ & $\mathbf{6 0}$ \\
\hline Total & $\mathbf{1}$ & $\mathbf{9}$ & $\mathbf{3}$ & $\mathbf{3}$ & $\mathbf{3 2}$ & $\mathbf{5 9}$ & $\mathbf{2}$ & $\mathbf{1 0 9}$ \\
\hline Total \% & $\mathbf{0 , 9 2}$ & $\mathbf{8 , 2 6}$ & $\mathbf{2 , 7 5}$ & $\mathbf{2 , 7 5}$ & $\mathbf{2 9 , 3 6}$ & $\mathbf{5 4 , 1 3}$ & $\mathbf{1 , 8 3}$ & $\mathbf{1 0 0}$ \\
\hline
\end{tabular}

Tabla 9.8. Frecuencia de desechos de talla por materia prima y por cuadrícula de LG-1.

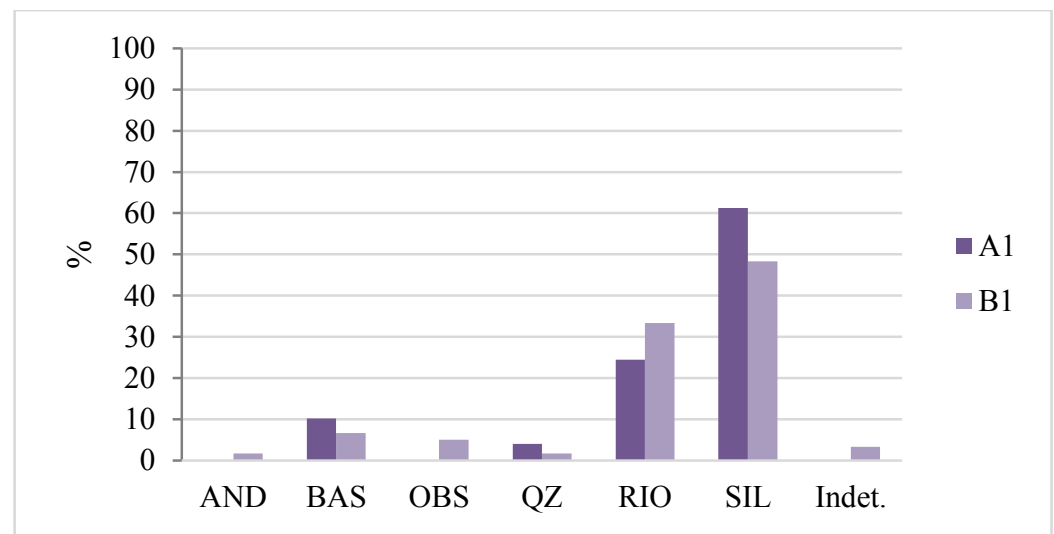

Figura 9.14. Frecuencia de desechos de talla por materia prima y por cuadrícula de LG-1.

El 90,83\% (n=99) de los desechos de talla de LG-1 (A1 y B1) está fracturado, el $6,42 \%(n=7)$ está entero y el 2,75\% restante corresponde a lascas indiferenciadas (sensu Bellelli 1991). De los desechos enteros, el 85,71\% $(n=6)$ no posee corteza y la lasca restante es angular, con la mitad de su cara dorsal cubierta por corteza.

El índice de MNF, calculado por materia prima (sensu Hiscock 2002), redujo la muestra a 55 desechos de talla, es decir, el 50,46\% del total original (Tabla 9.9).

\begin{tabular}{|c|l|c|c|c|c|c|c|c|}
\hline Sitio & MP & NAS & $\begin{array}{c}\text { DT } \\
\text { ent. }\end{array}$ & $\begin{array}{c}\text { DT } \\
\text { fract. }\end{array}$ & Indif. & \multicolumn{2}{|c|}{ NFS } & \multicolumn{2}{|c|}{ MNF (n y \%) } \\
\hline & AND & 1 & - & 1 & - & 1 & 1 & 100,00 \\
\cline { 2 - 9 } & BAS & 10 & - & 9 & - & 9 & 5 & 55,56 \\
\cline { 2 - 9 } LG-1 & OBS & 3 & - & 3 & - & 3 & 3 & 100,00 \\
\cline { 2 - 9 } (A1 y & QZ & 6 & - & 3 & - & 3 & 2 & 66,67 \\
\cline { 2 - 9 } & RIO & 33 & 1 & 29 & 2 & 32 & 14 & 43,75 \\
\cline { 2 - 9 } & SIL & 59 & 6 & 52 & 1 & 59 & 29 & 49,15 \\
\cline { 2 - 9 } & Indet. & 2 & - & 2 & - & 2 & 1 & 50,00 \\
\hline \multicolumn{2}{|c|}{ Total } & $\mathbf{1 1 4}$ & $\mathbf{7}$ & $\mathbf{9 9}$ & $\mathbf{3}$ & $\mathbf{1 0 9}$ & $\mathbf{5 5}$ & 50,46 \\
\hline
\end{tabular}

Tabla 9.9. Frecuencias de desechos de talla enteros, fracturados e índice de MNF, por materias primas en el sitio LG-1. Referencias: MP: materia prima; NAS: número de especímenes 
artefactuales; DT: desechos de talla; Ent.: enteros; Fract.: fracturados; ND: no diferenciados; NFS: número de especímenes identificados como lascas; MNF: número mínimo de lascas; BAS: basalto; OBS: obsidiana; RIO: riolita; SIL: rocas silíceas; VUL: vulcanita indeterminada; Indet.: rocas indeterminadas.

De las etapas de manufactura y las subclases de desechos de talla, sólo se pudo distinguir la presencia de lascas internas $(100 \%, \mathrm{n}=7)$ y lascas angulares, respectivamente. Como se observa en la Tabla 9.9, son mayoritarias las lascas enteras sobre rocas silíceas $(85,71 \%, \mathrm{n}=6)$ y hay una sola de riolita.

\subsubsection{Síntesis y discusión}

El sitio arqueológico a cielo abierto Los Gallegos 1 (LG-1) presenta evidencias de ocupación humana durante el HTF, a partir de $1.217 \pm 37$ años ${ }^{14} \mathrm{C}(1.081$ cal AP). La baja densidad de materiales y la dispersión espacial de este sitio y otros registrados en el área, donde los recursos son homogéneos, sugiere que LG-1 no fue ocupado recurrentemente a través del tiempo. Así, el registro es de buena resolución temporal, pero de escasa resolución espacial.

De las excavaciones realizadas en las cuadrículas A1 y B1, se recuperó un total de 114 artefactos líticos: el 95,61\% $(\mathrm{n}=109)$ son desechos de talla y el resto corresponde a cinco nódulos. La clase de roca más abundante es la de las silíceas $(54,13 \%, n=59)$, seguida por la riolita $(29,36 \%, n=32)$ y el basalto $(8,26 \%, n=9)$. El resto de las materias primas registradas son obsidiana y cuarzo en el mismo porcentaje $(2,75 \%, n=3$ por cada clase de roca), una andesita y dos desechos de talla de materia prima indeterminada. Los desechos de talla tienen ejemplares de todas las materias primas. Los cinco nódulos son de cuarzo $(n=3)$, basalto $(n=1)$ y riolita $(n=1)$. En la cuadrícula B1 de LG-1 se registraron todas estas materias primas; pero en la cuadrícula A1 no hay obsidiana ni andesita.

Los desechos de talla de ambas cuadrículas están, principalmente, fracturados $(90,83 \%, n=99)$. Todos los que están enteros son lascas angulares $(n=7)$ y la mayoría $(\mathrm{n}=6)$ no posee reserva de corteza. No se recuperó ningún instrumento y tampoco hay núcleos. Por lo que se puede suponer que las etapas iniciales y las finales de la manufactura se realizaron en otros lugares, y que en LG-1 se realizaron actividades vinculadas al mantenimiento de instrumentos, más que a su confección o al descortezamiento de núcleos, por ejemplo. 
Pese a la relativamente escasa cantidad de materiales recuperados en las cuadrículas, la diversidad de materias primas, la presencia de cerámica, fogones y restos faunísticos sugieren que LG-1 fue un sitio de actividades múltiples donde se priorizó la cercanía al curso de agua del río Atuel. Los fechados obtenidos y la baja cantidad de materiales depositados indicarían que se trató de un único evento de ocupación, o unos pocos eventos muy próximos en el tiempo.

\subsubsection{EL BOSQUECILLO 3 (EB-3)}

El sitio arqueológico El Bosquecillo 3 (en adelante, EB-3) es un sitio a cielo abierto que se emplaza sobre la planicie aluvial actual del río Atuel, a pocos metros de su barranca y a 469 msnm (Figura 9.15) en una zona desde la cual el río inicia la formación de sus bañados. Sus coordenadas lo ubican a $34^{\circ} 56^{\prime} 34,5^{\prime \prime}$ de LS y a $67^{\circ} 44^{\prime} 06,1^{\prime \prime}$ de LO (Figuras 9.1, 9.2 y 9.15). El nombre El Bosquecillo proviene de la vegetación típica del Monte (estepas arbustivas xerófilas, mesófilas e higrófilas), que se preservaron entre las fincas cultivadas del distrito de Real del Padre. Las imágenes satelitales muestran que el sitio arqueológico está emplazado en los bordes de antiguos meandros abandonados del río Atuel (Figura 9.15). Sin embargo, es difícil aseverar que dichos meandros se hubieran encontrado activos al momento de las ocupaciones humanas.

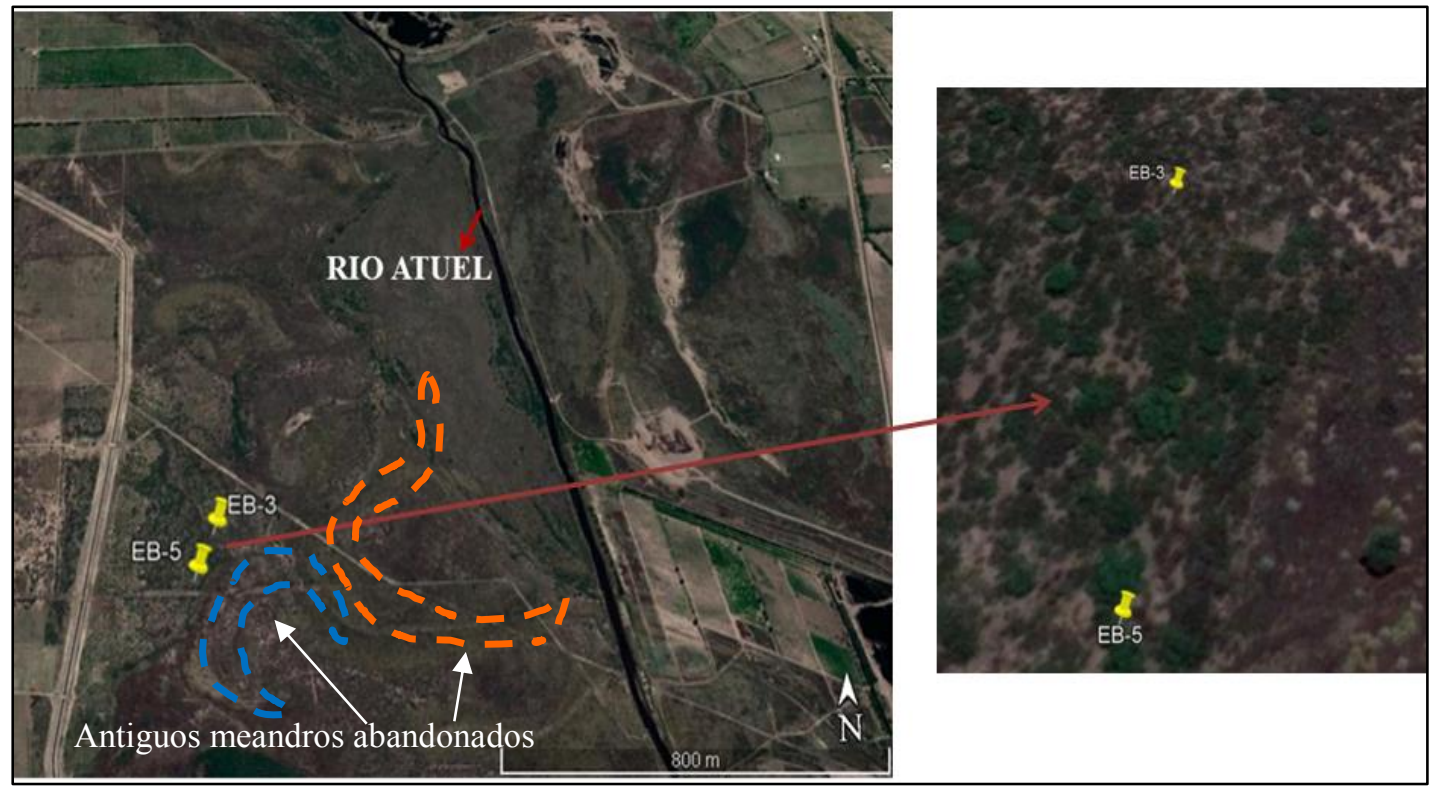

Figura 9.15. Localización de los sitios EB-3 y EB-5 en relación a la cuenca del río Atuel y detalle de la vegetación en vista aérea. Imágenes tomadas y modificadas de Google Earth. 


\subsubsection{Excavación, estratigrafía y cronología}

En el año 2006 se llevaron a cabo las excavaciones en este sitio y en EB-5, próximo a unos $100 \mathrm{~m}$ de distancia (Figura 9.15). En ellas se registraron materiales arqueológicos que incluyeron restos óseos, cerámicos y líticos. La cuadrícula A1 de EB3 (Figuras 9.16 y 9.17), se emplaza sobre un médano integrado por arenas eólicas de coloración gris pardo, próximo a los Médanos de Picardo (Krömer 1996; Tripaldi 2010), y no estaría alterado y/o modificado por la influencia humana, por lo que este "bosquecillo" está conformado por plantas silvestres relictuales (Llano 2011).

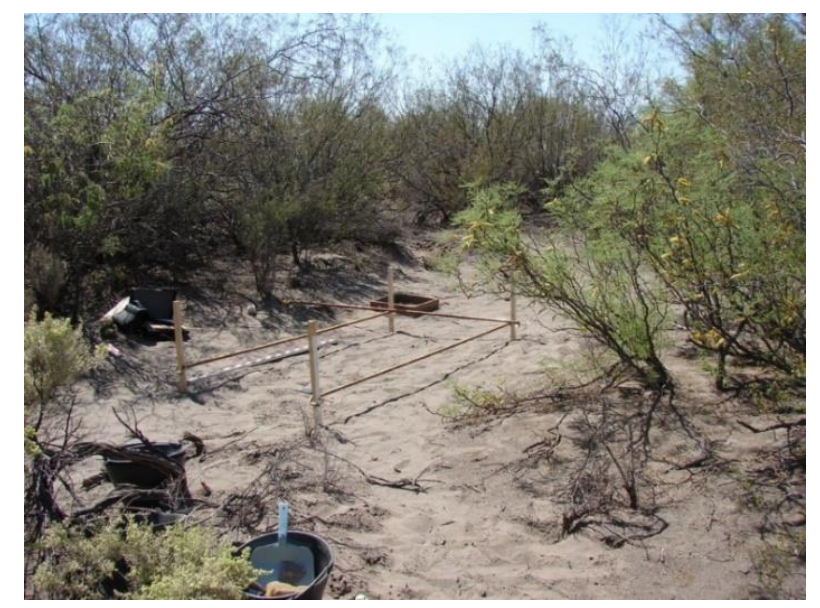

Figura 9.16. Contexto panorámico y cuadrícula A1 del sitio EB-3.

Las dimensiones de la cuadrícula fueron de $2 \times 1 \mathrm{~m}$, por lo que se cubrió una superficie de $2 \mathrm{~m}^{2}$, excavada por niveles artificiales de $5 \mathrm{~cm}$ de espesor, hasta alcanzar el nivel 14, totalizando un volumen excavado de $1,4 \mathrm{~m}^{3}$ (Figura 9.17).

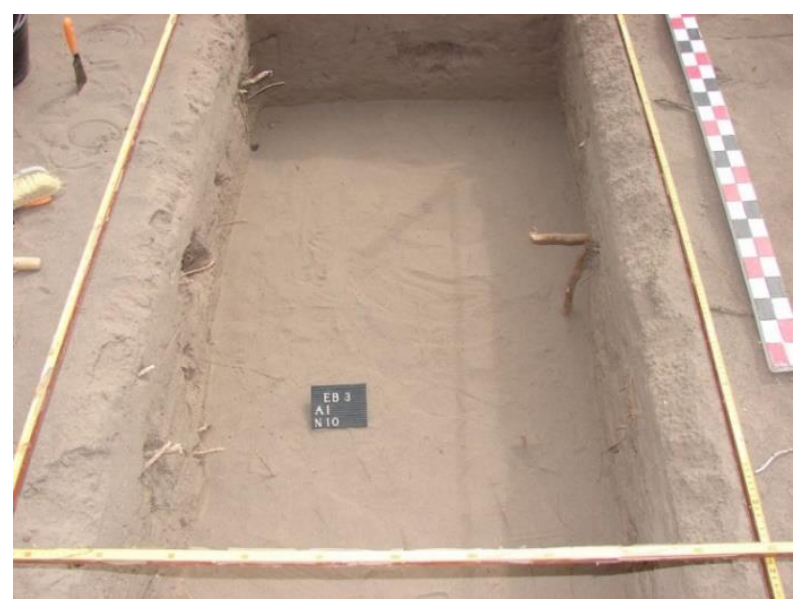

Figura 9.17. Planta de excavación de la cuadrícula A1 de EB-3 (Nivel 10). 
La estratigrafía es homogénea dado que el sedimento excavado está constituido, en toda la secuencia, por una matriz arenosa de textura media-gruesa y de consistencia friable, fácilmente transportable por la acción del viento (Tripaldi 2010), lo cual lo hace un ambiente muy dinámico. La alta frecuencia de raíces en este sitio (no así en EB-5), presentes a lo largo de toda la secuencia estratigráfica, es una de las pocas alteraciones postdepositacionales que se pudieron registrar.

En cuanto a la cronología, se realizaron dos fechados radiocarbónicos sobre muestras de carbón disperso de los niveles 5 y 13 (Tabla 9.10). Estos arrojan fechas disímiles, pero relativamente próximas, posteriores a los 1.000 años AP. Ambos fechados se corresponden con el HTF (2.000-200 años AP), diferenciado por un momento más antiguo, mayor a 500 años AP, y otro más reciente, menor a 500 años AP. Aun así, se analizó el depósito como una única unidad debido a lo tardío de las ocupaciones. Las edades calibradas se presentan en la Figura 9.18. Siguiendo el mismo criterio que en los sitios anteriores, se calculó la tasa de depositación sobre los artefactos líticos; esta es de 0,12 artefactos depositados por año.

\begin{tabular}{|cccccc|}
\hline Cuadrícula & $\begin{array}{c}\text { Nivel } \\
\text { artific. }\end{array}$ & Fecha ${ }^{14} \mathrm{C}$ & $\begin{array}{c}\text { Edad cal } \\
\text { AP }\end{array}$ & Material & Código \\
\hline A1 & 5 & $197 \pm 32$ & 183 & Carbón & AA-73242 \\
\hline A1 & 13 & $886 \pm 32$ & 748 & Carbón & AA-73240 \\
\hline
\end{tabular}

Tabla 9.10. Fechados radiocarbónicos y edades calibradas, obtenidos en EB-3.

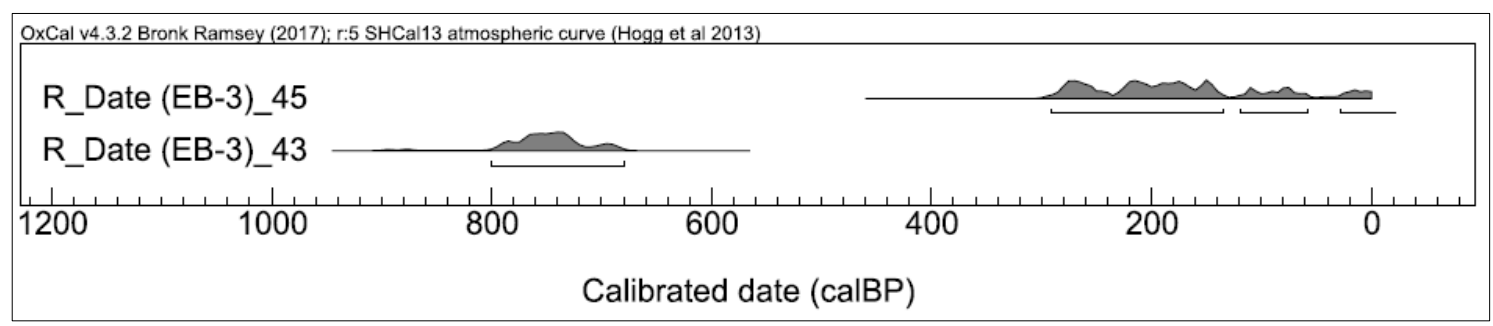

Figura 9.18. Edades calibradas para el sitio EB-3. Calibración realizada con el programa OxCal v4.3.2 (Ramsey 2009), usando la curva atmosférica SHCal 13 para el hemisferio sur (Hogg et al. 2013).

\subsubsection{Registro arqueológico}

La localidad arqueológica El Bosquecillo, que incluye a los sitios EB-3 y EB-5, está próxima al sitio La Olla (al sureste). Los primeros resultados de los trabajos en estos tres sitios se han focalizado en el estudio del registro arqueofaunístico, señalando una 
gran importancia -inusual para la región- en la proporción de peces (géneros Percichthys $s p$. - perca o trucha criolla- y Odontesthes sp. - pejerrey), incluso con casos en los que este taxón es el más abundante (Gil et al. 2008; Corbat et al. 2009; Gil y Neme 2010). Los escasos restos de peces en EB-3 se encuentran hacia los niveles más superficiales (nivel 1) y hacia los más profundos (nivel 13), ausentándose en los intermedios, lo que coincidiría con los hallazgos de cerámica -igualmente escasos (Corbat 2016). Los hallazgos de carbón también presentan un pico hacia los niveles inferiores, por lo cual, se podría plantear cierta simultaneidad en la distribución estratigráfica de materiales arqueológicos, aunque no hay ninguna correlación estadísticamente significativa (Corbat 2016).

En su tesis doctoral Llano (2011) estudió el registro de macrorrestos procedentes del sitio EB-3. Los especímenes identificados en el sitio coinciden con la distribución actual de especies y fueron determinadas como de origen antrópico. El taxa más denso y ubicuo es Chenopodium aff. papulosum. De la cuadrícula A1 de EB-3 se recuperaron frutos comestibles de cactáceas (Echinopsis y Cereus) (Llano 2011). Contrariamente a lo observado para los restos de carbón, peces y cerámicas, los restos vegetales, las cáscaras de huevos y los restos líticos (detallados en este capítulo), presentan una distribución estratigráfica que, aunque irregular, decrece hacia los niveles inferiores (Figura 9.19).

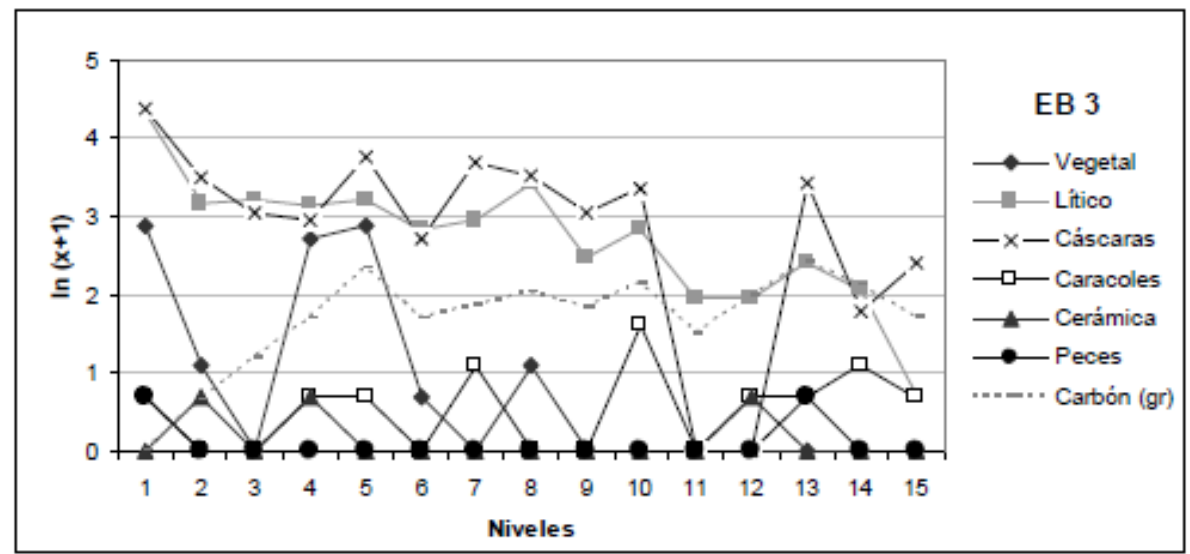

Figura 9.19. Distribución estratigráfica de los materiales recuperados en el sitio EB-3. Tomado de Corbat (2016: 306).

\subsubsection{Registro lítico}

De EB-3 se recuperaron 289 artefactos líticos, de los cuales 209 son desechos de talla de tamaño igual o menor a 5 x $5 \mathrm{~mm}$ (“ $\leq 5 \mathrm{~mm}$ ” en la Tabla 9.11). Al excluir esta categoría, el $n$ analizado fue de 80 artefactos. La clase artefactual predominante es la de 
los desechos de talla ("> 5mm" en la Tabla 9.11), que constituyen el 80\% ( $\mathrm{n}=64)$. De estos, la mayoría son de obsidiana $(75 \%, \mathrm{n}=48)$, seguidos por los de rocas silíceas $(20,31 \%, n=13)$. Completan las frecuencias un desecho de andesita, uno de basalto y otro de riolita (Tabla 9.11).

\begin{tabular}{|c|c|c|c|c|c|}
\hline \multirow{2}{*}{ Nivel } & \multicolumn{2}{|c|}{ Desechos de talla } & \multirow{2}{*}{$\begin{array}{c}\text { AF } \\
\text { Unifac }\end{array}$} & \multirow{2}{*}{ Ecofacto } & \multirow{2}{*}{ Tota } \\
\hline & $(>5 \mathrm{~mm})$ & $(\leq 5 \mathrm{~mm})$ & & & \\
\hline 1 & 21 & 62 & - & - & 83 \\
\hline 2 & 7 & 14 & - & - & 21 \\
\hline 3 & 7 & 13 & - & 4 & 24 \\
\hline 4 & 2 & 12 & - & 1 & 15 \\
\hline 5 & 5 & 20 & - & 1 & 26 \\
\hline 6 & 2 & 10 & - & 2 & 14 \\
\hline 7 & 5 & 14 & - & 3 & 22 \\
\hline 8 & 5 & 21 & - & 2 & 28 \\
\hline 9 & 2 & 7 & - & - & 9 \\
\hline 10 & 2 & 14 & - & - & 16 \\
\hline 11 & 3 & 5 & - & - & 8 \\
\hline 12 & 1 & 5 & - & - & 6 \\
\hline 13 & 2 & 7 & 1 & - & 10 \\
\hline 14 & - & 5 & - & 2 & 7 \\
\hline Total & 64 & 209 & 1 & 15 & 289 \\
\hline Total \% & 22,15 & 72,32 & 0,35 & 5,19 & 100 \\
\hline
\end{tabular}

Tabla 9.11. Clases artefactuales por nivel de excavación en EB-3. Referencias: AF: Artefacto formatizado; Unifac.: unifacial.

Las otras clases registradas son la de los instrumentos (véase Capítulo 5), representados por un único artefacto formatizado unifacial sobre roca silícea y fracturado; y la de los ecofactos $(n=15)$, la mayoría de los cuales $(86,67 \%, n=13)$ son de toba, roca que debió haber sido ingresada al sitio. Los otros dos son de cuarzo y de roca silícea.

En la Figura 9.20 se observan las frecuencias de las tres clases artefactuales representadas por nivel de extracción de la excavación. Se aprecia el predominio recurrente de los desechos de talla, la variación en la representación de los ecofactos y el un único instrumento, registrado en el anteúltimo nivel de excavación (Figura 9.20). 


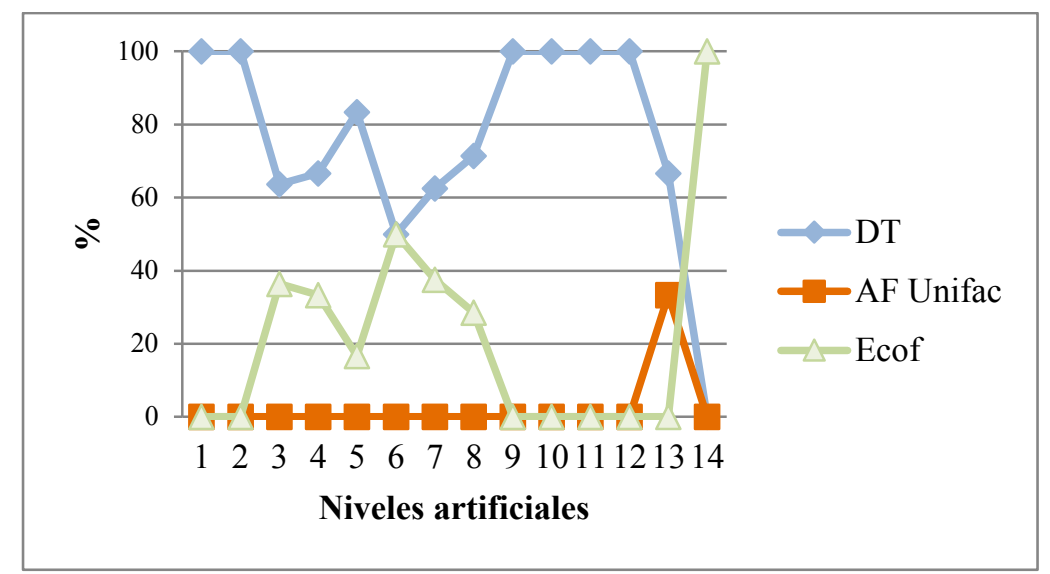

Figura 9.20. Frecuencia de clases artefactuales por nivel artificial en EB-3. Referencias: DT: desecho de talla; AF Unifac.: artefacto formatizado unifacial; Ecof.: ecofacto.

La obsidiana $(60 \%, n=48)$ es la materia prima predominante. Le siguen las rocas silíceas $(18,75 \%, \mathrm{n}=15)$, materia prima correspondiente al instrumento unifacial (Tabla 9.12 y Figura 9.21).

\begin{tabular}{|c|c|c|c|c|c|c|c|c|}
\hline Nivel & AND & BAS & OBS & QZ & RIO & SIL & TB & Total \\
\hline $\mathbf{1}$ & - & - & $\begin{array}{c}81,0 \% \\
(17)\end{array}$ & - & $\begin{array}{c}4,8 \% \\
(1)\end{array}$ & $14,3 \%(3)$ & - & $\mathbf{2 1}$ \\
\hline $\mathbf{2}$ & - & - & $71,4 \%(5)$ & - & - & $28,6 \%(2)$ & - & $\mathbf{7}$ \\
\hline $\mathbf{3}$ & $\begin{array}{c}9,1 \% \\
(1)\end{array}$ & - & $45,5 \%(5)$ & - & - & $9,1 \%(1)$ & $36,4 \%(4)$ & $\mathbf{1 1}$ \\
\hline $\mathbf{4}$ & - & - & $33,3 \%(1)$ & - & - & $33,3 \%(1)$ & $33,3 \%(1)$ & $\mathbf{3}$ \\
\hline $\mathbf{5}$ & - & - & $83,3 \%(5)$ & - & - & - & $16,7 \%(1)$ & $\mathbf{6}$ \\
\hline $\mathbf{6}$ & - & - & $50,0 \%(2)$ & - & - & - & $50,0 \%(2)$ & $\mathbf{4}$ \\
\hline $\mathbf{7}$ & - & - & $25,0 \%(2)$ & - & - & $37,5 \%(3)$ & $37,5 \%(3)$ & $\mathbf{8}$ \\
\hline $\mathbf{8}$ & - & $14,3 \%$ & $57,1 \%(4)$ & - & - & - & $28,6 \%(2)$ & $\mathbf{7}$ \\
\hline $\mathbf{9}$ & - & - & - & - & - & $100 \%(2)$ & - & $\mathbf{2}$ \\
\hline $\mathbf{1 0}$ & - & - & $50,0 \%(1)$ & - & - & $50,0 \%(1)$ & - & $\mathbf{2}$ \\
\hline $\mathbf{1 1}$ & - & - & $100 \%(3)$ & - & - & - & - & $\mathbf{3}$ \\
\hline $\mathbf{1 2}$ & - & - & $100 \%(1)$ & - & - & - & - & $\mathbf{1}$ \\
\hline $\mathbf{1 3}$ & - & - & $66,7 \%(2)$ & - & - & $33,3 \%(1)$ & - & $\mathbf{3}$ \\
\hline $\mathbf{1 4}$ & - & - & - & $50,0 \%$ & - & $50,0 \%(1)$ & - & $\mathbf{2}$ \\
\hline Total & $\mathbf{1}$ & $\mathbf{1}$ & $\mathbf{4 8}$ & $\mathbf{1}$ & $\mathbf{1}$ & $\mathbf{1 5}$ & $\mathbf{1 3}$ & $\mathbf{8 0}$ \\
\hline $\begin{array}{c}\text { Total } \\
\mathbf{1}\end{array}$ & $\mathbf{1 , 3}$ & $\mathbf{1 , 3}$ & $\mathbf{6 0 , 0}$ & $\mathbf{1 , 3}$ & $\mathbf{1 , 3}$ & $\mathbf{1 8 , 8}$ & $\mathbf{1 6 , 3}$ & $\mathbf{1 0 0}$ \\
\hline
\end{tabular}

Tabla 9.12. Distribución y frecuencia de materias primas por nivel de excavación en EB-3. Referencias: AND: andesita; BAS: basalto; OBS: obsidiana; QZ: cuarzo; RIO: riolita; SIL: rocas siliceas; $T B$ : toba. 


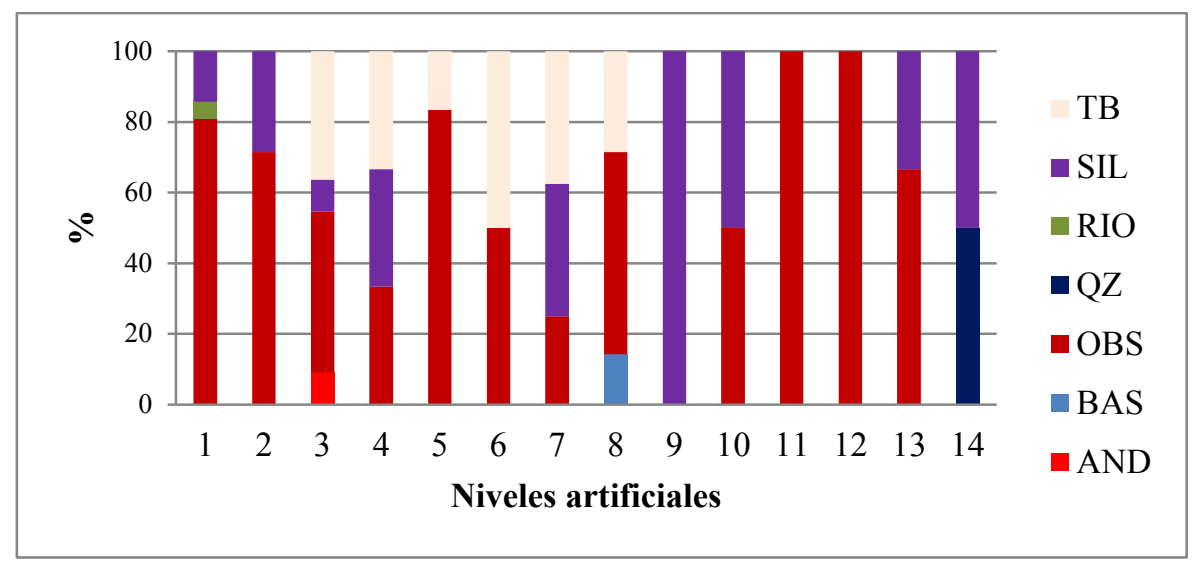

Figura 9.21. Frecuencia de materias primas por nivel artificial en EB-3.

\subsection{Desechos de talla}

Para el análisis de variables como el porcentaje de reserva de corteza en la cara dorsal de los desechos de talla y la definición del tipo de lasca y del estadio de manufactura, se tuvieron en cuenta sólo aquellos desechos enteros. En EB-3 el estado de fragmentación es elevado, ya que los desechos fracturados constituyen el 90,62\% $(n=58)$. Debido a esto, se calculó el índice de MNF (sensu Hiscock 2002). Así, el conjunto se redujo a 27 desechos de talla, es decir, el 42,19\% del total original (Tabla 9.13). Se observa que los desechos de rocas silíceas son los más fracturados y mayormente sobrerrepresentados. Los desechos de basalto y de riolita, poseen fracturas que no pudieron ser registradas con el índice de MNF (son fracturas mediales, en ambos casos).

\begin{tabular}{|c|l|c|c|c|c|c|c|}
\hline Sitio & MP & NAS & $\begin{array}{c}\text { DT } \\
\text { ent. }\end{array}$ & $\begin{array}{c}\text { DT } \\
\text { fract. }\end{array}$ & NFS & \multicolumn{2}{c|}{ MNF (n y \%) } \\
\hline \multirow{5}{*}{} & AND & 1 & - & 1 & 1 & 1 & 100,00 \\
\cline { 2 - 8 } & BAS & 1 & - & 1 & 1 & 0 & - \\
\cline { 2 - 8 } EB-3 & OBS & 48 & 6 & 42 & 48 & 23 & 47,92 \\
\cline { 2 - 8 } & QZ & 1 & - & - & - & - & - \\
\cline { 2 - 9 } & RIO & 1 & - & 1 & 1 & 0 & - \\
\cline { 2 - 9 } & SIL & 15 & - & 13 & 13 & 3 & 23,08 \\
\cline { 2 - 9 } & TB & 13 & - & - & - & - & $\mathbf{4 2 , 1 9}$ \\
\hline
\end{tabular}

Tabla 9.13. Frecuencias de desechos de talla enteros, fracturados e índice de MNF, por materias primas en el sitio EB-3. Referencias: MP: materia prima; NAS: número de especimenes artefactuales; DT: desechos de talla; Ent.: enteros; Fract.: fracturados; NFS: número de especimenes identificados como lascas; MNF: número mínimo de lascas; AND: andesita; BAS: basalto; OBS: obsidiana; QZ: cuarzo; RIO: riolita; SIL: rocas silíceas; TB: toba. 
De los seis desechos de talla enteros, además de que todos son de obsidiana y de tamaño "muy pequeño" (módulo: 1), ninguno posee reserva de corteza. Además, son lascas internas: el 50\% $(\mathrm{n}=3)$ son lascas angulares y la otra mitad, de arista.

\subsection{Instrumentos}

El único instrumento de EB-3 (1,25\% del total de artefactos) es de formatización unifacial sobre roca silícea. Fue descartado en estado fracturado, lo cual no permitió reconocer a qué grupo tipológico corresponde (lo más probable es que haya sido un raspador o un RBO) (Figura 9.22).

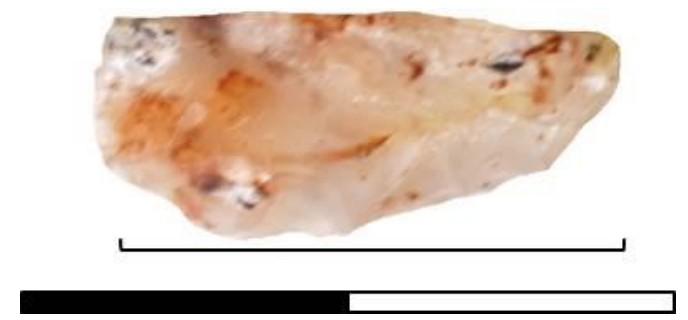

Figura 9.22. Fragmento no diferenciado de artefacto formatizado unifacial de EB-3.

\subsubsection{Síntesis y discusión}

El Bosquecillo 3 (EB-3), es un sitio a cielo abierto, con evidencias de ocupación desde $886 \pm 32{ }^{14} \mathrm{C}(\mathrm{HTF})$. La tasa de depositación de artefactos líticos es baja (0,12/año). El registro arqueológico recuperado incluye materiales líticos, óseos, vegetales, carbones y otros restos faunísticos como cáscaras de huevos. El registro lítico incluye 80 artefactos líticos, entre los cuales predominan los desechos de talla (80\%) y la obsidiana es la clase de roca más frecuente $(60 \%)$. La baja frecuencia de instrumentos $(1,25 \%, n=1)$, la ausencia de reserva de corteza sobre lascas, la ausencia de núcleos y el predominio de obsidiana, sugieren que en el sitio sólo se realizaron actividades relacionadas con el mantenimiento y reparación de instrumentos, aunque no se descarta la confección, sobre todo, en obsidiana debido a la cantidad de desechos sobre esta materia prima. Además, si bien, el único instrumento registrado en EB-3 está confeccionado sobre roca silícea, se puede proponer que los instrumentos de obsidiana ingresaron al sitio como parte del equipamiento personal y se descartaron en otros lugares por donde circularon los grupos. Asimismo, como todas las fuentes de obsidiana se hallan a distancias consideradas "no locales", se debe haber enfatizado en la conservación de los artefactos y en la maximización de esta materia prima. 
La totalidad de las evidencias arqueológicas registradas en EB-3 permiten plantear que este habría sido un sitio de actividades múltiples, donde se realizaron tareas vinculadas al procesamiento de vegetales, el procesamiento y consumo de recursos faunísticos y el mantenimiento y/o reparación de instrumentos líticos.

\subsubsection{EL BOSQUECILLO 5 (EB-5)}

El Bosquecillo 5 (en adelante, EB-5), es un sitio a cielo abierto localizado a unos $100 \mathrm{~m}$ de EB-3, sobre la planicie aluvial actual del río Atuel y cerca de la barranca del mismo (Figura 9.15). Sus coordenadas geográficas lo sitúan a $34^{\circ} 56^{\prime} 37,7^{\prime \prime}$ de LS y a $67^{\circ} 44^{\prime} 7,82^{\prime \prime}$ de LO, y a 470 msnm (Figuras 9.1, 9.2 y 9.15).

\subsubsection{Excavación, estratigrafía y cronología}

En la misma campaña en que se excavó el sitio EB-3 en el año 2006, se excavó también EB-5. Siguiendo la misma metodología, se trazó una cuadrícula de 2 x $1 \mathrm{~m}$, la cual fue excavada siguiendo niveles artificiales de $5 \mathrm{~cm}$ de espesor. En el caso de EB-5, la excavación concluyó en el nivel 10 , totalizando una superficie de $2 \mathrm{~m}^{2}$ y un volumen de $1 \mathrm{~m}^{3}$ (Figura 9.23).

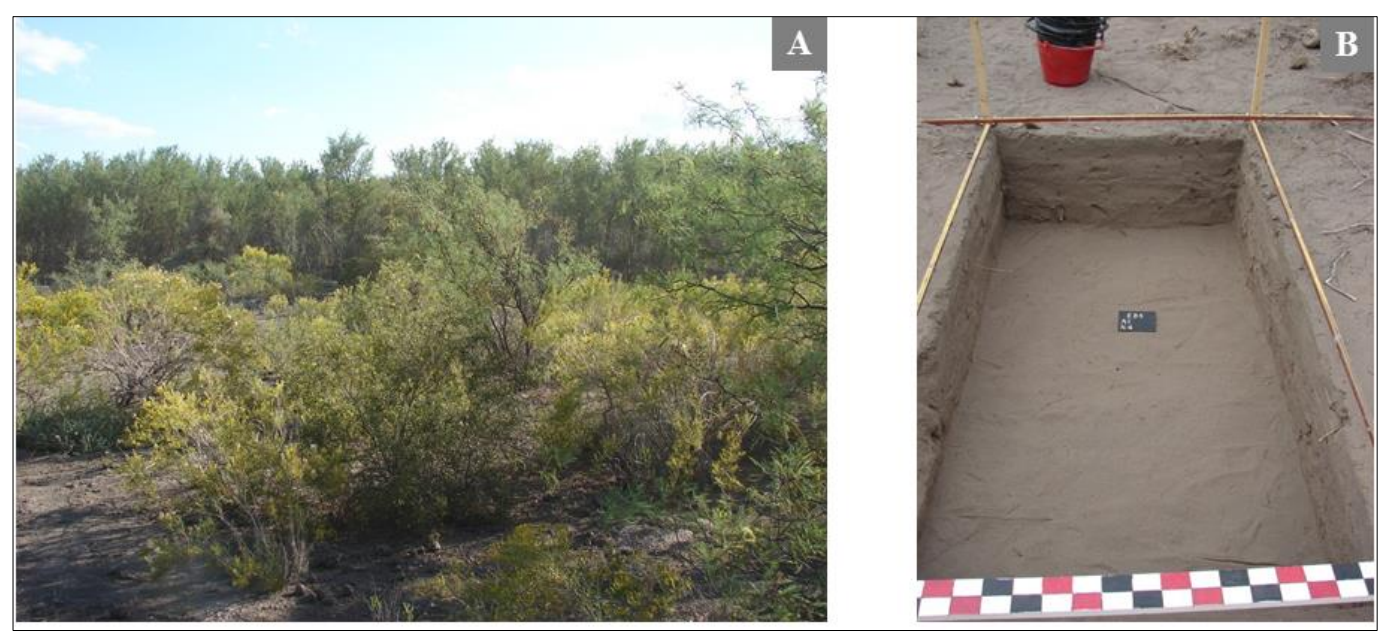

Figura 9.23. Sitio El Bosquecillo 5. A) Vegetación del Monte en el contexto del sitio; B) Planta de excavación de la cuadrícula A1 (Nivel 4).

De la cuadrícula A1 de EB-5 se recuperaron materiales arqueológicos que, al igual que EB-3, consisten en restos óseos (sobre todo, de peces), cerámicos y líticos. Dicha cuadrícula se dispone sobre un médano constituido por arenas eólicas de coloración gris 
pardo (Krömer 1996), cercano a los Médanos de Picardo localizados al suroeste de EB-3 y EB-5 (Tripaldi 2010). Dicho médano no presenta evidencias de alteraciones y/o modificaciones antrópicas, lo cual permite presentarse como un relicto dentro de una zona dedicada a la economía agrícola (Llano 2011).

El sedimento excavado está constituido por una matriz arenosa de textura mediagruesa y de consistencia friable a lo largo de toda la secuencia, lo cual le confiere homogeneidad a la estratigrafía. Presenta pocas alteraciones postdepositacionales y no se han registrado raíces como en el caso de EB-5.

La cronología del sitio está definida por un único fechado realizado sobre carbón disperso del nivel 8 (Tabla 9.14) que ubica temporalmente a EB-5 cerca de los 900 años AP, es decir, algo más antiguo que EB-3, aunque son estadísticamente indistinguibles y de edad asignada al HTF. La edad calibrada del fechado de EB-5 se presenta en la Figura 9.24. La tasa de depositación de artefactos líticos es de 0,17 /año, mayor que en LG-1 y EB-3, pero igualmente baja.

\begin{tabular}{|cccccc|}
\hline Cuadrícula & Nivel artific. & Fecha ${ }^{14} \mathrm{C}$ & Edad cal AP & Material & Código \\
\hline A1 & 8 & $903 \pm 32$ & 762 & Carbón & AA-73241 \\
\hline
\end{tabular}

Tabla 9.14. Fechado radiocarbónico y edad calibrada, obtenidos en EB-5.

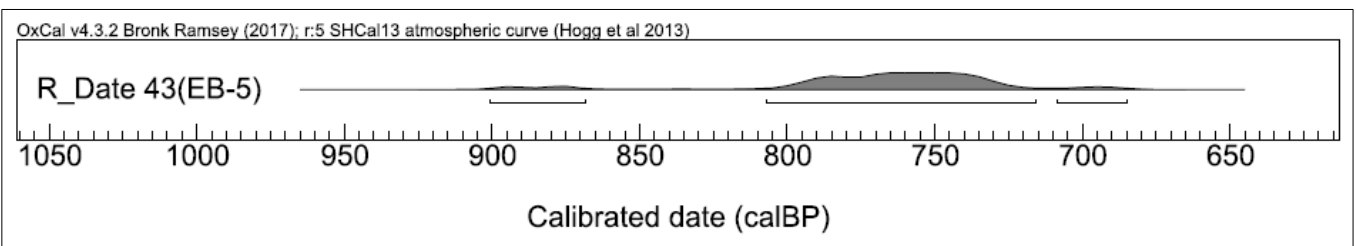

Figura 9.24. Edad calibrada para el sitio EB-5. Calibración realizada con el programa OxCal v4.3.2 (Ramsey 2009), usando la curva atmosférica SHCal 13 para el hemisferio sur (Hogg et al. 2013).

\subsubsection{Registro arqueológico}

En EB-5 se recuperaron restos faunísticos, botánicos, líticos y cerámicos. Los primeros consisten en fragmentos de cáscaras de huevos, caracoles y ocho especímenes óseos, de los cuales el 50\% (NISP=4) corresponde a restos de peces (otolito y vértebra precaudal de Percichthys trucha y vertebras caudales de una especie indeterminada) y el resto se mantiene taxonómicamente indeterminado (Corbat 2016).

En este sitio, los restos cerámicos y los botánicos no se han analizado, por lo que tampoco se han identificado tendencias comparables en la distribución estratigráfica de 
los distintos materiales arqueológicos. Lo que se pudo observar es una tendencia general hacia la disminución de materiales desde los niveles superiores hacia los inferiores, con diferencias entre los materiales de distinta naturaleza (Figura 9.25). El carbón y la cerámica se concentran en los niveles medios (los picos máximos de ambos se dan en el nivel 5), sector donde los materiales líticos y las cáscaras de huevo presentan mayor frecuencia relativa. Por su parte, los escasos peces registrados se distribuyen de manera relativamente estable a lo largo de la secuencia (Corbat 2016).

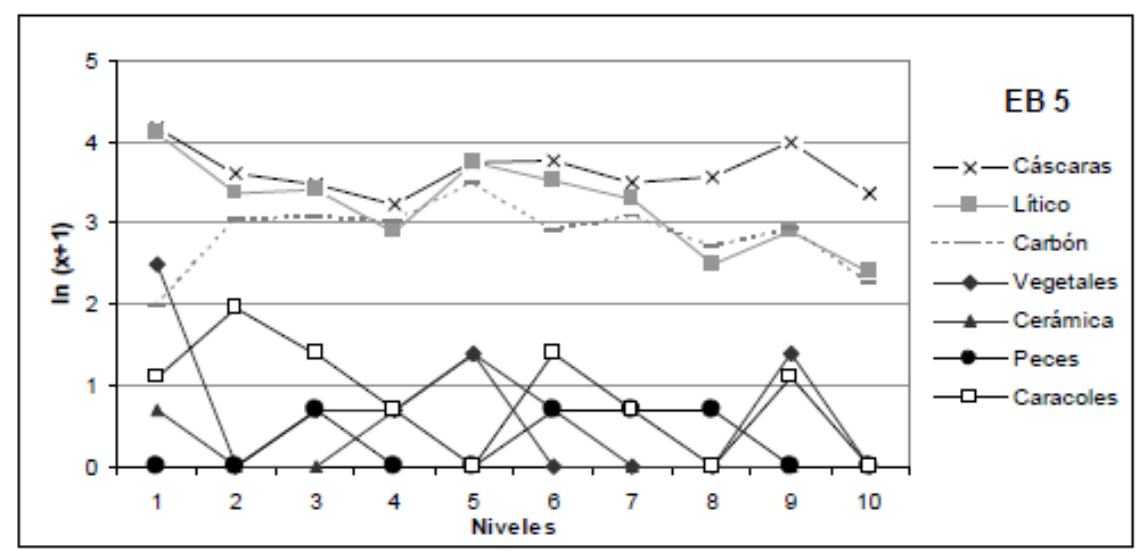

Figura 9.25. Distribución estratigráfica de los materiales recuperados en el sitio EB-5. Tomado de Corbat (2016: 307).

Cabe agregar que este sitio, a diferencia de EB-3, presenta una mayor densidad de hallazgos y evidencias de acción térmica, que coinciden con la mayor proporción de restos vegetales carbonizados.

\subsubsection{Registro lítico}

El sitio EB-5 cuenta con 303 artefactos líticos, 180 son desechos de talla de tamaño igual o menor a $5 \mathrm{~mm}$ de lado (“ $\leq 5 \mathrm{~mm}$ ” en la Tabla 9.15). Así, el total de artefactos analizados fue de 123. De ellos, los desechos de talla ("> $>5 \mathrm{~mm}$ " en la Tabla 9.15) constituyen el 95,93\% $(n=118)$. Le siguen los instrumentos $(2,44 \%, n=3)$, representados por dos artefactos formatizados bifaciales y un artefacto de formatización unifacial. También se registró un ASF RC y un pigmento (Tabla 9.15).

\begin{tabular}{|c|c|c|c|c|c|c|c|}
\hline \multirow{2}{*}{ Nivel } & \multicolumn{2}{|c|}{ Desechos de talla } & \multirow{2}{*}{ AF Bifac } & \multirow{2}{*}{ AF Unifac } & \multirow{2}{*}{ ASF RC } & \multirow{2}{*}{ Pgm } & \multirow{2}{*}{ Total } \\
\hline & $(>5 \mathrm{~mm})$ & $(\leq 5 \mathrm{~mm})$ & & & & & \\
\hline 1 & 26 & 47 & - & - & - & - & 73 \\
\hline 2 & 10 & 23 & - & - & - & - & 33 \\
\hline 3 & 13 & 22 & - & - & - & - & 35 \\
\hline 4 & 10 & 6 & - & - & 1 & - & 17 \\
\hline
\end{tabular}




\begin{tabular}{|c|c|c|c|c|c|c|c|}
$\mathbf{5}$ & 11 & 32 & - & - & - & - & $\mathbf{4 3}$ \\
\hline $\mathbf{6}$ & 15 & 20 & - & - & - & - & $\mathbf{3 5}$ \\
\hline $\mathbf{7}$ & 12 & 13 & - & 1 & - & - & $\mathbf{2 6}$ \\
\hline $\mathbf{8}$ & 6 & 6 & - & - & - & - & $\mathbf{1 2}$ \\
\hline $\mathbf{9}$ & 9 & 7 & 2 & - & - & - & $\mathbf{1 8}$ \\
\hline $\mathbf{1 0}$ & 6 & 4 & - & - & - & 1 & $\mathbf{1 1}$ \\
\hline Total & $\mathbf{1 1 8}$ & $\mathbf{1 8 0}$ & $\mathbf{2}$ & $\mathbf{1}$ & $\mathbf{1}$ & $\mathbf{1}$ & $\mathbf{3 0 3}$ \\
\hline Total \% & $\mathbf{3 8 , 9 4}$ & $\mathbf{5 9 , 4 1}$ & $\mathbf{0 , 6 6}$ & $\mathbf{0 , 3 3}$ & $\mathbf{0 , 3 3}$ & $\mathbf{0 , 3 3}$ & $\mathbf{1 0 0}$ \\
\hline
\end{tabular}

Tabla 9.15. Clases artefactuales por nivel de excavación en EB-5. Referencias: AF: Artefacto formatizado; Bifac.: bifacial; Unifac.: unifacial; ASF RC: artefacto sin formatización con rastros complementarios; Pgm: pigmento.

Entre los desechos de talla están representadas todas las clases de roca identificadas. El 44,92\% $(n=53)$ de los desechos es de obsidiana y el 31,36\% ( $n=37)$ es de rocas silíceas. Le siguen los desechos de talla de riolita $(13,56 \%, \mathrm{n}=16)$, los de basalto $(7,63 \%, n=9)$ y completan las frecuencias, un desecho de talla de andesita, uno de cuarzo y otro de vulcanita indeterminada. Ambos instrumentos bifaciales son de obsidiana y el unifacial se confeccionó sobre una roca silícea. El único ASF RC también es de roca silícea.

La Figura 9.26 muestra las frecuencias de las clases artefactuales representadas, incluyendo las dos clases de instrumentos (bifaciales y unifaciales) por nivel artificial de excavación. Se destaca la preponderancia de los desechos de talla y la baja frecuencia de instrumentos y de ASF RC (Figura 9.26).

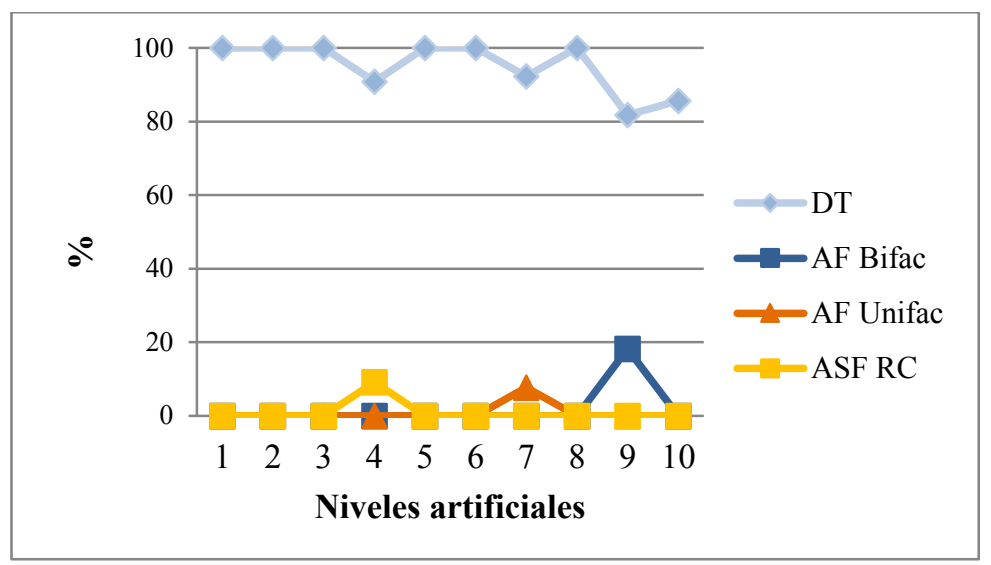

Figura 9.26. Frecuencia de clases artefactuales por nivel artificial en EB-5. Referencias: DT: desecho de talla; AF: artefacto formatizado; Bifac: bifacial; Unifac: unifacial; ASF RC: artefacto sin formatización con rastros complementarios. 
Sumando todos los artefactos, la obsidiana constituye la materia prima más abundante, seguida por las rocas silíceas y la riolita. Aquí, el basalto ocupa el cuarto lugar y el resto de las rocas están representadas por un artefacto cada una (Tabla 9.16).

\begin{tabular}{|c|c|c|c|c|c|c|c|c|c|}
\hline Nivel & AND & BAS & OBS & QZ & RIO & SIL & VUL & Indet & Total \\
\hline $\mathbf{1}$ & $\begin{array}{c}3,8 \% \\
(1)\end{array}$ & $\begin{array}{c}7,7 \% \\
(2)\end{array}$ & $\begin{array}{c}42,3 \% \\
(11)\end{array}$ & - & $\begin{array}{c}19,2 \% \\
(5)\end{array}$ & $\begin{array}{c}26,9 \% \\
(7)\end{array}$ & - & - & $\mathbf{2 6}$ \\
\hline $\mathbf{2}$ & - & $\begin{array}{c}10,0 \% \\
(1)\end{array}$ & $\begin{array}{c}50,0 \% \\
(5)\end{array}$ & - & $\begin{array}{c}10,0 \% \\
(1)\end{array}$ & $\begin{array}{c}30,0 \% \\
(3)\end{array}$ & - & - & $\mathbf{1 0}$ \\
\hline $\mathbf{3}$ & - & $\begin{array}{c}7,7 \% \\
(1)\end{array}$ & $\begin{array}{c}76,9 \% \\
(10)\end{array}$ & - & - & $\begin{array}{c}15,4 \% \\
(2)\end{array}$ & - & - & $\mathbf{1 3}$ \\
\hline $\mathbf{4}$ & - & $\begin{array}{c}18,2 \% \\
(2)\end{array}$ & $\begin{array}{c}45,5 \% \\
(5)\end{array}$ & - & $9,1 \%(1)$ & $\begin{array}{c}27,3 \% \\
(3)\end{array}$ & - & - & $\mathbf{1 1}$ \\
\hline $\mathbf{5}$ & - & - & $\begin{array}{c}54,5 \% \\
(6)\end{array}$ & - & $\begin{array}{c}27,3 \% \\
(3)\end{array}$ & $\begin{array}{c}18,2 \% \\
(2)\end{array}$ & - & - & $\mathbf{1 1}$ \\
\hline $\mathbf{6}$ & - & $\begin{array}{c}20,0 \% \\
(3)\end{array}$ & $\begin{array}{c}33,3 \% \\
(5)\end{array}$ & - & - & $\begin{array}{c}46,7 \% \\
(7)\end{array}$ & - & - & $\mathbf{1 5}$ \\
\hline $\mathbf{7}$ & - & - & $\begin{array}{c}38,5 \% \\
(5)\end{array}$ & - & $\begin{array}{c}23,1 \% \\
(3)\end{array}$ & $\begin{array}{c}38,5 \% \\
(5)\end{array}$ & - & - & $\mathbf{1 3}$ \\
\hline $\mathbf{8}$ & - & - & $\begin{array}{c}50,0 \% \\
(3)\end{array}$ & $\begin{array}{c}16,7 \% \\
(1)\end{array}$ & - & $\begin{array}{c}16,7 \% \\
(1)\end{array}$ & $\begin{array}{c}16,7 \% \\
(1)\end{array}$ & - & $\mathbf{6}$ \\
\hline $\mathbf{9}$ & - & - & $\begin{array}{c}36,4 \% \\
(4)\end{array}$ & - & $\begin{array}{c}18,2 \% \\
(2)\end{array}$ & $\begin{array}{c}45,5 \% \\
(5)\end{array}$ & - & - & $\mathbf{1 1}$ \\
\hline $\mathbf{1 0}$ & - & - & $\begin{array}{c}14,3 \% \\
(1)\end{array}$ & - & $\begin{array}{c}14,3 \% \\
(1)\end{array}$ & $\begin{array}{c}57,1 \% \\
(4)\end{array}$ & - & $\begin{array}{c}14,3 \% \\
(1)\end{array}$ & $\mathbf{7}$ \\
\hline Total & $\mathbf{1}$ & $\mathbf{9}$ & $\mathbf{5 5}$ & $\mathbf{1}$ & $\mathbf{1 6}$ & $\mathbf{3 9}$ & $\mathbf{1}$ & $\mathbf{1}$ & $\mathbf{1 2 3}$ \\
\hline $\begin{array}{c}\text { Total } \\
\mathbf{9}\end{array}$ & $\mathbf{0 , 8}$ & $\mathbf{7 , 3}$ & $\mathbf{4 4 , 7}$ & $\mathbf{0 , 8}$ & $\mathbf{1 3 , 0}$ & $\mathbf{3 1 , 7}$ & $\mathbf{0 , 8}$ & $\mathbf{0 , 8}$ & $\mathbf{1 0 0}$ \\
\hline
\end{tabular}

Tabla 9.16. Distribución y frecuencia de materias primas por nivel de excavación en EB-5. Referencias: AND: andesita; BAS: basalto; OBS: obsidiana; QZ: cuarzo; RIO: riolita; SIL: rocas siliceas; VUL: vulcanita indeterminada; Indet.: roca indeterminada.

En la Figura 9.27 se observa que las cuatro clases de rocas principales (obsidiana, silíceas, riolita y basalto) se presentan en todos los niveles, excepto el basalto que sólo se registró en los primeros niveles. La andesita se registró únicamente en el primer nivel y, en cambio, las indeterminadas, en el último. En el nivel 8 no hay artefactos en riolita, aunque sí se registraron, sólo en este nivel, cuarzo y vulcanita indeterminada. 


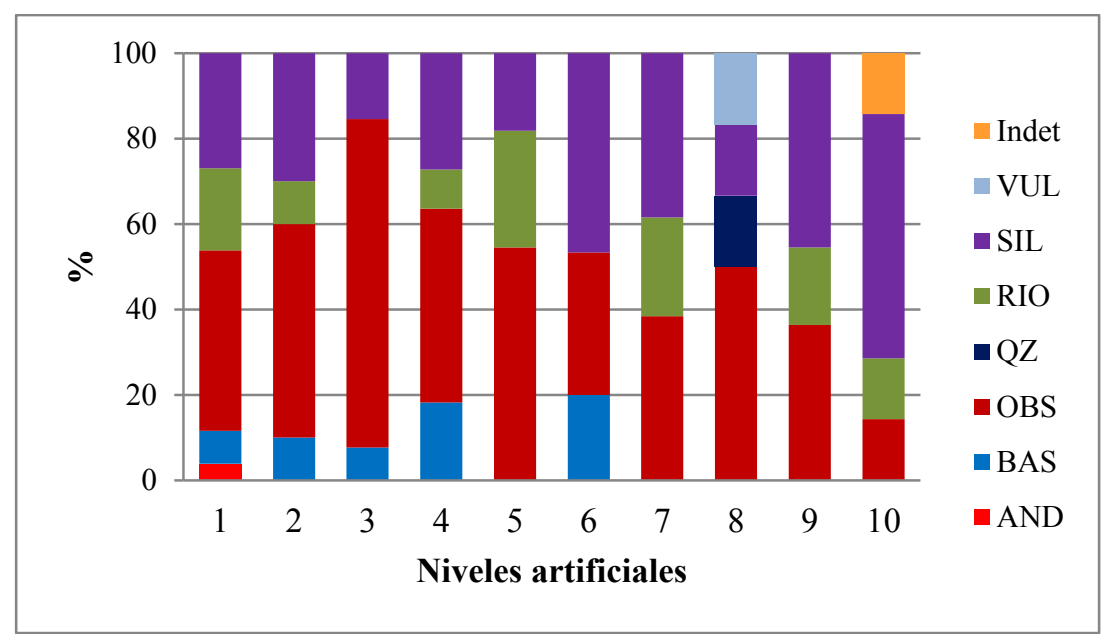

Figura 9.27. Frecuencia de materias primas por nivel artificial en EB-5.

\subsection{Desechos de talla}

Las variables como el tamaño y la reserva de corteza en la cara dorsal de los desechos de talla, así como la definición del tipo de lasca y del estadio de manufactura, fueron consideradas sólo sobre desechos enteros. Al igual que en el sitio EB-3, el estado de fragmentación es elevado y los desechos fracturados constituyen el 84,75\% ( $\mathrm{n}=100)$ del total de esta clase artefactual. Al calcular el índice de MNF (sensu Hiscock 2002) el conjunto de desechos de talla se redujo a 50 (42,37\% del total) (Tabla 9.17). Se observa que los desechos de talla de riolita son los más fracturados o sobrerrepresentados al $75 \%$, seguidos por los de basalto y los de rocas silíceas. Asimismo, las fracturas en los desechos de obsidiana $(\mathrm{MNF}=26)$ duplican su cantidad $(50,94 \%, \mathrm{n}=29)$. El desecho de cuarzo posee fractura longitudinal izquierda por lo que hay un mínimo de una lasca. Los dos desechos de andesita y de vulcanita indeterminada, están enteros, por lo tanto, no hay sobrerrepresentación (Tabla 9.17).

\begin{tabular}{|c|l|c|c|c|c|c|c|}
\hline Sitio & MP & NAS & $\begin{array}{c}\text { DT } \\
\text { ent. }\end{array}$ & $\begin{array}{c}\text { DT } \\
\text { fract. }\end{array}$ & NFS & \multicolumn{2}{c|}{ MNF (n y \%) } \\
\hline \multirow{5}{*}{ EB-5 } & AND & 1 & 1 & - & 1 & 1 & 100,00 \\
\cline { 2 - 8 } & BAS & 9 & - & 9 & 9 & 3 & 33,33 \\
\cline { 2 - 8 } & OBS & 55 & 9 & 44 & 53 & 26 & 49,06 \\
\cline { 2 - 8 } & QZ & 1 & - & 1 & 1 & 1 & 100,00 \\
\cline { 2 - 8 } & RIO & 16 & 2 & 14 & 16 & 4 & 25,00 \\
\cline { 2 - 8 } & SIL & 39 & 5 & 32 & 37 & 14 & 37,84 \\
\cline { 2 - 8 } & VUL & 1 & 1 & - & 1 & 1 & 100,00 \\
\cline { 2 - 8 } & Indet. & 1 & - & - & - & - & - \\
\hline \multicolumn{2}{|c}{ Total } & $\mathbf{1 2 3}$ & $\mathbf{1 8}$ & $\mathbf{1 0 0}$ & $\mathbf{1 1 8}$ & $\mathbf{5 0}$ & $\mathbf{4 2 , 3 7}$ \\
\hline
\end{tabular}


Tabla 9.17. Frecuencias de desechos de talla enteros, fracturados e índice de MNF, por materias primas en el sitio EB-5. Referencias: MP: materia prima; NAS: número de especímenes artefactuales; DT: desechos de talla; Ent.: enteros; Fract.: fracturados; ND: no diferenciados; NFS: número de especímenes identificados como lascas; MNF: número mínimo de lascas; AND: andesita; BAS: basalto; OBS: obsidiana; QZ: cuarzo; RIO: riolita; SIL: rocas siliceas; VUL: vulcanita indeterminada; Indet.: rocas indeterminadas.

De los 18 desechos de talla enteros, el 83,33\% $(n=15)$ no posee reserva de corteza, el $11,11 \%(n=2)$ posee el $25 \%$ de corteza y el 5,56\% $(n=1)$ tiene la mitad de su cara dorsal cubierta. Además, el 88,89\% $(\mathrm{n}=16)$ es de tamaño de módulo 1 (muy pequeño), y el $11,11 \%$ restante $(\mathrm{n}=2)$, de módulo 2 (pequeño).

La mayoría de los desechos enteros son lascas internas $(88,89 \%, \mathrm{n}=16)$, dentro de las cuales, las angulares son mayoritarias $(87,5 \%, n=14)$; la mitad de ellas son de obsidiana $(\mathrm{n}=7)$, el 28,57\% $(\mathrm{n}=4)$ de rocas silíceas y completan las frecuencias dos lascas angulares de riolita y una de andesita. Las dos lascas de arista restantes $(12,5 \%)$ son de roca silícea y de vulcanita indeterminada. Se registraron dos lascas de formatización de filo $(11,11 \%)$ : una de adelgazamiento bifacial y la otra de reactivación, ambas de obsidiana. No se registró ninguna lasca externa (Tabla 9.18).

En la Figura 9.28 se observa que las lascas angulares son las mayoritarias y constituyen el único tipo de lasca que se repite en ambas materias primas representadas allí. La obsidiana se presenta tanto en lascas internas como en lascas de formatización de filo.

\begin{tabular}{|c|c|c|c|c|c|c|}
\hline \multirow{2}{*}{ Sitio } & \multirow{2}{*}{ MP } & \multicolumn{4}{|c|}{ Tipo de lasca } & \multirow{2}{*}{ Total } \\
\hline & & angular & de arista & adelg. bif. & de react. & \\
\hline \multirow{5}{*}{ EB-5 } & AND & $100 \%(1)$ & - & - & - & 1 \\
\hline & OBS & $77,78 \%(7)$ & - & $11,11 \%(1)$ & $11,11 \%(1)$ & 9 \\
\hline & RIO & $100 \%(2)$ & - & - & - & 2 \\
\hline & SIL & $80,00 \%(4)$ & $20,00 \%(1)$ & - & - & 5 \\
\hline & VUL & - & $100 \%(1)$ & - & - & 1 \\
\hline \multicolumn{2}{|c|}{ Total } & $77,78 \%(14)$ & $11,11 \%(2)$ & $5,56 \%(1)$ & $5,56 \%(1)$ & 18 \\
\hline
\end{tabular}

Tabla 9.18. Tipos de desechos de talla procedentes de EB-5 discriminados por tipo de extracción y materia prima. Referencias: Adelg. bif: lasca de adelgazamiento bifacial; De react.: lasca de reactivación. 


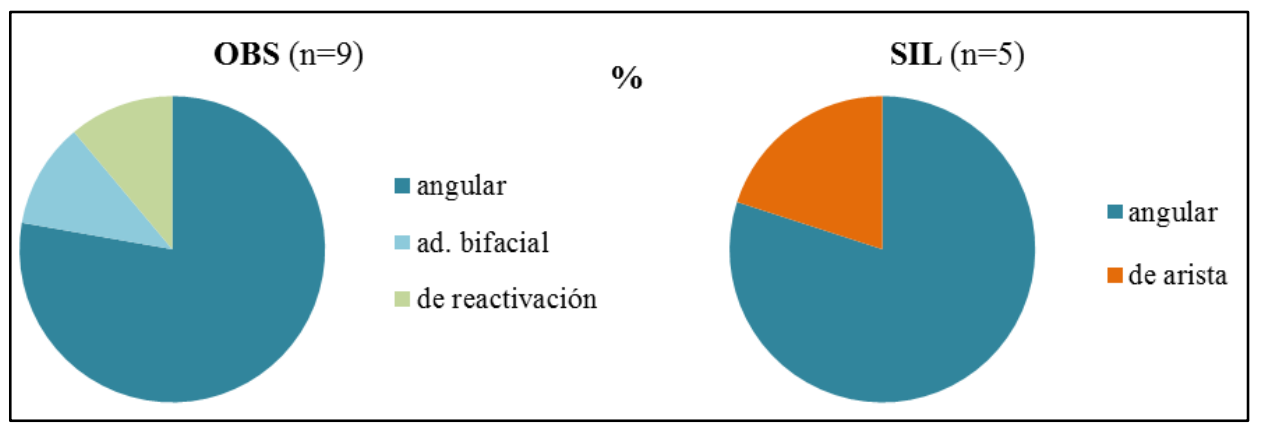

Figura 9.28. Frecuencias relativas de tipos de lasca por materia prima en EB-5. No se incluyeron las dos lascas angulares de riolita, la lasca angular de andesita ni la lasca de arista de vulcanita indeterminada. Entre paréntesis se indica el número total de lascas enteras por materia prima.

Referencias: OBS; obsidiana; SIL: rocas silíceas; ad. bifacial.: lasca de adelgazamiento bifacial.

\subsection{Instrumentos}

De los tres instrumentos (2,44\% del total analizado), el unifacial se confeccionó sobre roca silícea y también fue descartado fracturado, aunque se sabe que es de filo y/o arista irregular y posee un sector pasivo que pudo servir para sujetarlo (Figura 9.29.A). Los bifaciales $(n=2)$ están confeccionados sobre obsidiana y están fracturados, por lo que no se pudo conocer su tamaño. Uno corresponde a un fragmento meso-basal de punta de proyectil (Figura 9.29.B) y del otro no se pudo conocer a qué grupo tipológico corresponde, por lo que se lo considera como fragmento no diferenciado de artefacto formatizado de manera bifacial.

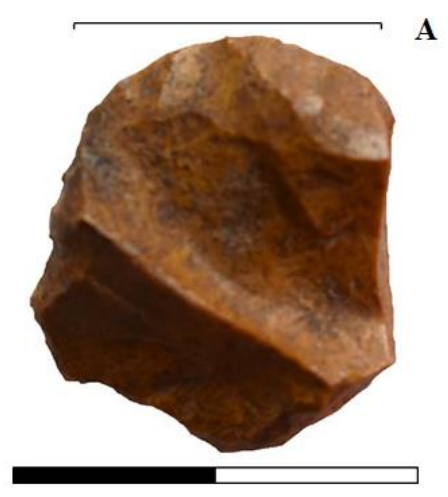

B

Figura 9.29. Dos de los artefactos formatizados del sitio EB-5. A) Fragmento de instrumento unifacial sobre roca silícea; B) Fragmento de punta de proyectil de obsidiana. 


\subsubsection{Síntesis y discusión}

Al igual que el sitio EB-3, El Bosquecillo 5 (EB-5), es un sitio a cielo abierto, con evidencias de ocupación a partir de $903 \pm 32{ }^{14} \mathrm{C}$ (HTF) y, de escasa evidencia arqueológica, lo cual es coherente con una ocupación de corta duración. Los materiales arqueológicos incluyen huesos, restos vegetales, artefactos líticos, carbones, cascaras de huevos y restos cerámicos. El registro lítico incluye 123 artefactos líticos, con predominio de desechos de talla $(95,93 \%)$ y la obsidiana es, al igual que en EB-3, la materia prima mayoritaria $(44,72 \%)$. Se registraron dos instrumentos bifaciales, ambos confeccionados sobre obsidiana, y un único instrumento unifacial, sobre roca silícea; el único ASF RC registrado también es de roca silícea. Los tres instrumentos $(2,44 \%$ del total $)$ fueron descartados fracturados. Predomina la ausencia de reserva de corteza sobre desechos y no hay núcleos. Estas evidencias permiten proponer que en EB-5, al igual que en EB-3, se llevaron a cabo actividades relacionadas con el mantenimiento y reparación de instrumentos, y quizás su confección, mayoritariamente sobre obsidiana dada la mayor frecuencia de desechos en esta roca. Cabe suponer, asimismo, que los instrumentos de obsidiana ingresaron al sitio como parte del equipamiento personal y que se descartaron en otros lugares cuando ya no se podían seguir utilizando.

En suma, las evidencias arqueológicas de EB-5 sugieren que ha sido un sitio de actividades múltiples, incluyendo el procesamiento y consumo de recursos faunísticos y vegetales, el mantenimiento y/o la reparación de instrumentos líticos.

\subsection{ANÁLISIS TECNO-TIPOLÓGICO DEL DESIERTO DE MONTE}

\subsubsection{MATERIAS PRIMAS LÍTICAS}

Al sumar los artefactos líticos de los tres sitios $(\mathrm{n}=317)$, se registró un total de ocho clases de rocas reconocidas y tres artefactos de rocas indeterminadas. Las rocas silíceas $(35,65 \%, \mathrm{n}=113)$ son las mayoritarias, seguidas por la obsidiana $(33,44 \%$, $\mathrm{n}=106)$, la riolita $(15,77 \%, \mathrm{n}=50)$, la toba $(4,1 \%, \mathrm{n}=13)$-aunque no corresponde a las cuatro clases artefactuales principales-, la andesita $(0,95 \%, n=3)$, las rocas indeterminadas $(0,95 \%, n=3)$ y la vulcanita indeterminada $(0,32 \%, n=1)$ (Figura 9.30). 


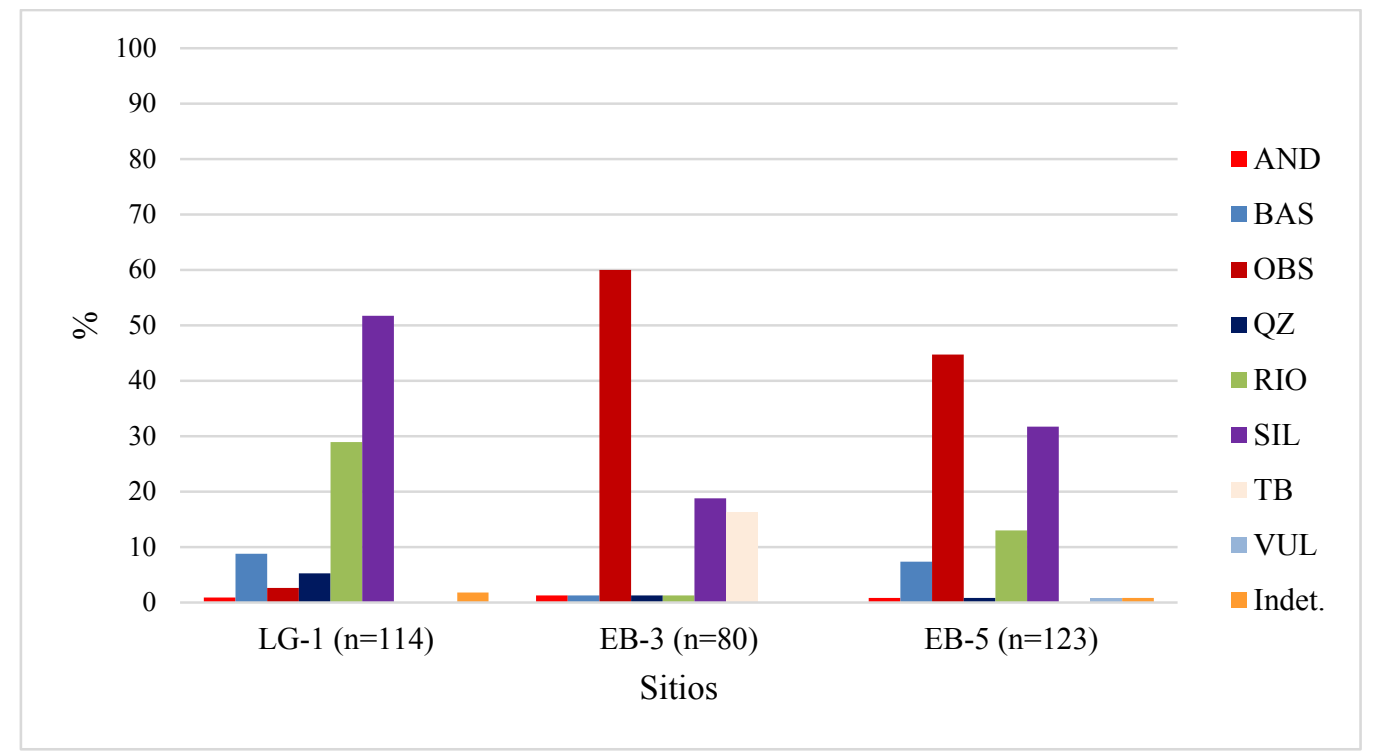

Figura 9.30. Frecuencias relativas de clases de rocas por sitio del Desierto de Monte.

Referencias: AND: andesita; BAS: basalto; OBS: obsidiana; QZ: cuarzo; RIO: riolita; SIL:

rocas silíceas; TB: toba; VUL: vulcanita indeterminada; Indet.: roca indeterminada.

En la Tabla 9.19 se presentan las frecuencias en el tipo de calidad para la talla en los tres sitios analizados del Desierto de Monte. Se observan variaciones: en los sitios de EB-3 y EB-5, es mayoritaria la calidad "excelente", aunque su predominio se acentúa en EB-3. En LG-1 (A1), no se registró esta calidad para la talla (en dicha cuadrícula no se registró obsidiana). Igualmente, predomina la calidad "muy buena" por sobre la "buena". En cambio, en la cuadrícula B1, de LG-1, si bien hay obsidiana, esta es muy escasa y la calidad "buena" está mayormente representada que la "muy buena". Al sumar los artefactos de los tres sitios, el promedio señala un predominio de la calidad muy buena, seguida por la excelente y la calidad buena. No se registraron artefactos de calidad "regular" o inferiores (Tabla 9.19).

\begin{tabular}{|c|l|c|c|c|c|}
\hline Sitio & MP & EX & MB & B & Total \\
\hline \multirow{4}{*}{$\begin{array}{c}\text { LG-1 } \\
\text { (A1) }\end{array}$} & BAS & - & $20,0 \%(1)$ & $80,0 \%(4)$ & $\mathbf{5}$ \\
\cline { 2 - 6 } & QZ & - & $66,7 \%(2)$ & $33,3 \%(1)$ & $\mathbf{3}$ \\
\cline { 2 - 6 } & RIO & - & $33,3 \%(4)$ & $66,7 \%(8)$ & $\mathbf{1 2}$ \\
\cline { 2 - 6 } & SIL & - & $80,0 \%(24)$ & $20,0 \%(6)$ & $\mathbf{3 0}$ \\
\hline \multicolumn{2}{|c|}{ Total } & - & $\mathbf{6 2 , 0 \% ( 3 1 )}$ & $\mathbf{3 8 , 0 \% ( 1 9 )}$ & $\mathbf{5 0}$ \\
\hline \multirow{4}{*}{$\begin{array}{c}\text { LG-1 } \\
\text { (B1) }\end{array}$} & AND & - & - & $100 \%(1)$ & $\mathbf{1}$ \\
\cline { 2 - 6 } & BAS & - & - & $100 \%(5)$ & $\mathbf{5}$ \\
\cline { 2 - 6 } & OBS & $100 \%(3)$ & - & - & $\mathbf{3}$ \\
\cline { 2 - 6 } & QZ & - & - & $100 \%(3)$ & $\mathbf{3}$ \\
\hline
\end{tabular}




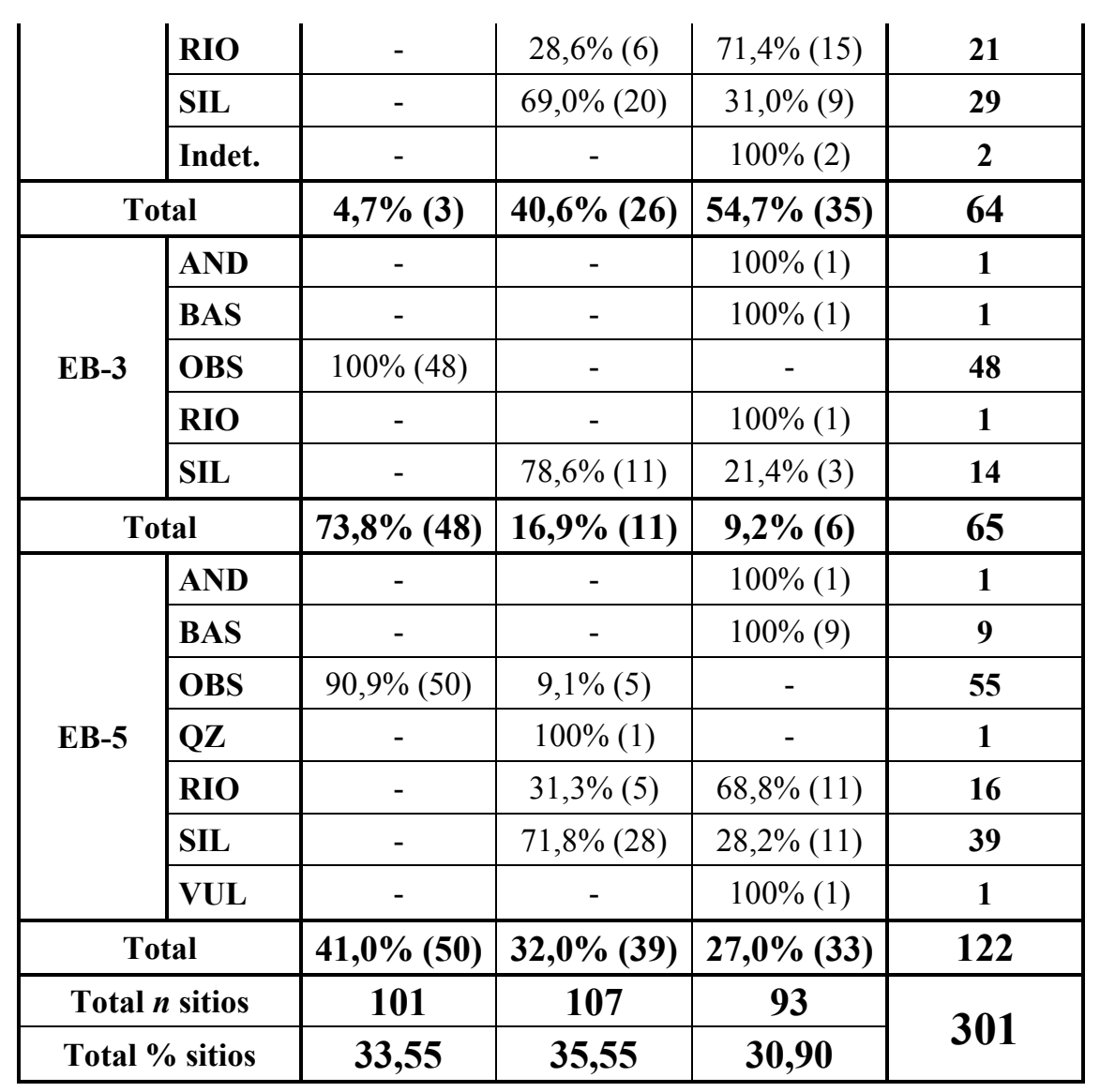

Tabla 9.19. Materias primas y calidad para la talla por sitio del Desierto de Monte. Referencias:

EX: excelente; MB: muy buena; B: buena. No se incluyen los ecofactos ni el pigmento.

En la Tabla 9.20 se presenta el estado de fragmentación de estos 301 artefactos (sin pigmento ni ecofactos). Se observa que la mayoría de los artefactos de los tres sitios está fragmentado y que el sitio que relativamente se encuentra menor preservado es EB3 (véase Tabla 9.13 en este capítulo). Los artefactos donde las impurezas, sustancias adheridas o alteraciones indiferenciadas no permitieron determinar el estado de la pieza, fueron clasificados en la categoría "no diferenciado" (ND en la Tabla 9.20).

\begin{tabular}{|c|l|c|c|c|c|}
\hline Sitio & \multicolumn{1}{|c|}{ MP } & Entero & Fracturado & ND & Total \\
\hline \multirow{4}{*}{ LG-1 (A1) } & BAS & - & $100 \%(5)$ & - & $\mathbf{5}$ \\
\cline { 2 - 6 } & QZ & $33,3 \%(1)$ & $66,7 \%(2)$ & - & $\mathbf{3}$ \\
\cline { 2 - 6 } & RIO & - & $91,7 \%(11)$ & $8,3 \%(1)$ & $\mathbf{1 2}$ \\
\cline { 2 - 6 } & SIL & $16,7 \%(5)$ & $83,3 \%(25)$ & - & $\mathbf{3 0}$ \\
\hline \multicolumn{2}{|c|}{ Total } & $\mathbf{1 2 , 0 \% ( 6 )}$ & $\mathbf{8 6 , 0 \% ( 4 3 )}$ & $\mathbf{2 , 0 \% ( 1 )}$ & $\mathbf{5 0}$ \\
\hline \multirow{3}{*}{ LG-1 (B1) } & AND & - & $100 \%(1)$ & - & $\mathbf{1}$ \\
\cline { 2 - 6 } & BAS & - & $80,0 \%(4)$ & $20,0 \%(1)$ & $\mathbf{5}$ \\
\cline { 2 - 6 } & OBS & - & $100 \%(3)$ & - & $\mathbf{3}$ \\
\hline
\end{tabular}




\begin{tabular}{|c|c|c|c|c|c|}
\hline & QZ & - & $33,3 \%(1)$ & $66,7 \%(2)$ & 3 \\
\hline & RIO & $9,5 \%(2)$ & $85,7 \%(18)$ & $4,8 \%(1)$ & 21 \\
\hline & SIL & $3,4 \%(1)$ & $93,1 \%(27)$ & $3,4 \%(1)$ & 29 \\
\hline & Indet. & - & $100 \%(2)$ & - & 2 \\
\hline \multicolumn{2}{|c|}{ Total } & $4,7 \%(3)$ & $87,5 \%(56)$ & $7,8 \%(5)$ & 64 \\
\hline \multirow{5}{*}{ EB-3 } & AND & - & $100 \%(1)$ & - & 1 \\
\hline & BAS & - & $100 \%(1)$ & - & 1 \\
\hline & OBS & $12,5 \%(6)$ & $87,5 \%(42)$ & - & 48 \\
\hline & RIO & - & $100 \%(1)$ & - & 1 \\
\hline & SIL & - & $100 \%(14)$ & - & 14 \\
\hline \multicolumn{2}{|c|}{ Total } & $9,2 \%(6)$ & $90,8 \%(59)$ & - & 65 \\
\hline \multirow{7}{*}{ EB-5 } & AND & $100 \%(1)$ & - & - & 1 \\
\hline & BAS & - & $100 \%(9)$ & - & 9 \\
\hline & OBS & $16,4 \%(9)$ & $83,6 \%(46)$ & - & 55 \\
\hline & QZ & - & $100 \%(1)$ & - & 1 \\
\hline & RIO & $12,5 \%(2)$ & $87,5 \%(14)$ & - & 1 \\
\hline & SIL & $12,8 \%(5)$ & $87,2 \%(34)$ & - & 39 \\
\hline & VUL & $100 \%(1)$ & - & - & 1 \\
\hline \multicolumn{2}{|c|}{ Total } & $14,8 \%(18)$ & $85,2 \%(104)$ & - & 122 \\
\hline \multicolumn{2}{|c|}{ Total $n$ sitios } & 33 & 262 & 6 & \multirow{2}{*}{301} \\
\hline \multicolumn{2}{|c|}{ Total \% sitios } & 10,96 & 87,04 & 1,99 & \\
\hline
\end{tabular}

Tabla 9.20. Materias primas y estado de fragmentación por sitio del Desierto de Monte. No se incluyen los ecofactos ni el pigmento.

Para el análisis del tamaño de los artefactos, se ha considerado el módulo de tamaño por materia prima únicamente en artefactos enteros $(n=33)$. En la Tabla 9.21 se aprecia el predominio del tamaño "muy pequeño" (Módulo: 1; "MPE" en la tabla mencionada), aunque esto varía según el sitio y la materia prima, como así también, de la clase artefactual. Así, por ejemplo, los únicos dos artefactos de tamaño "medianopequeño" (Módulo: 3; "MEP" en la tabla) corresponden a dos nódulos de cuarzo y riolita de las cuadrículas A1 y B1 de LG-1, respectivamente. Las rocas silíceas y la riolita son, en general, las dos materias primas con mayor variación de tamaño; pero sólo se representaron los módulos de tamaño 1, 2 y 3 (Tabla 9.21), sin registro de tamaños mayores. 


\begin{tabular}{|c|c|c|c|c|c|}
\hline Sitio & MP & MPE & $\mathbf{P}$ & MEP & Total \\
\hline \multirow{2}{*}{ LG-1 (A1) } & $\mathbf{Q Z}$ & - & - & $100 \%(1)$ & 1 \\
\hline & SIL & $40 \%(2)$ & $60 \%(3)$ & - & 5 \\
\hline \multirow{2}{*}{ LG-1 (B1) } & RIO & - & $50 \%(1)$ & $50 \%(1)$ & 2 \\
\hline & SIL & $100 \%(1)$ & - & - & 1 \\
\hline EB-3 & OBS & $100 \%(6)$ & - & - & 6 \\
\hline \multirow{5}{*}{ EB-5 } & AND & - & $100 \%(1)$ & - & 1 \\
\hline & OBS & $100 \%(9)$ & - & - & 9 \\
\hline & RIO & $100 \%(2)$ & - & - & 2 \\
\hline & SIL & $80 \%(4)$ & $20 \%(1)$ & - & 5 \\
\hline & VUL & $100 \%(1)$ & - & - & 1 \\
\hline \multicolumn{2}{|c|}{ Total $n$ sitios } & 25 & 6 & 2 & \multirow{2}{*}{33} \\
\hline \multicolumn{2}{|c|}{ Total \% sitios } & 75,76 & 18,18 & 6,06 & \\
\hline
\end{tabular}

Tabla 9.21. Tamaño de los artefactos enteros por materia prima y sitio del Desierto de Monte.

Referencias: MPE: Muy pequeño (0-20mm); P: Pequeño (21-40); MEP: Mediano pequeño (41-60).

Los desechos de talla enteros constituyen el 93,9\% $(n=31)$ de los 33 artefactos enteros presentados en la Tabla 9.21. De ellos, el 83,9\% $(n=26)$ son desechos de tamaño muy pequeño (MPE) y el 16,1\% $(\mathrm{n}=5)$ restante de tamaños pequeño $(\mathrm{P})$. Estas frecuencias se representan en la Figura 9.31 según la materia prima. Se observa que los desechos de obsidiana y vulcanita indeterminada poseen tamaños MPE; los de andesita, tamaños P; y los de riolita y rocas silíceas, tanto MPE como P, con predominio del tamaño menor.

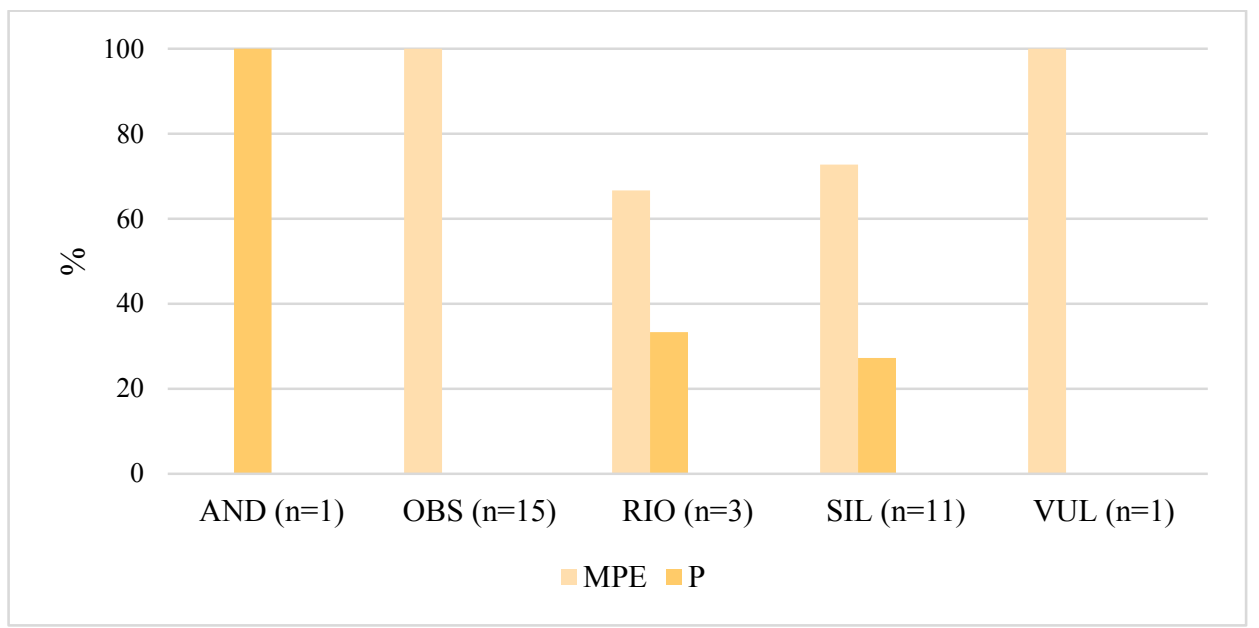

Figura 9.31. Frecuencias relativas de categorías de tamaño en los desechos de talla según la materia prima, a través del tiempo en el Desierto Altoandino.

Sobre artefactos enteros también se evaluó el porcentaje de reserva de corteza por materia prima y por sitio (Tabla 9.22). Predomina la ausencia de corteza en los artefactos 
de los tres sitios, en casi todas las materias primas. La excepción corresponde al cuarzo, la andesita y la vulcanita indeterminada. Estas rocas son de calidad buena (aunque inferior a las de otras rocas locales) y están a una distancia inmediatamente disponible; sin embargo, son poco frecuentes en los sitios. El nódulo de riolita de LG-1 (B1) es el único artefacto que posee el $100 \%$ de reserva de corteza. Los artefactos enteros de obsidiana no presentan corteza, lo cual es coherente con su disponibilidad no local (Tabla 9.22).

\begin{tabular}{|c|c|c|c|c|c|c|}
\hline Sitio & MP & $0 \%$ & $25 \%$ & $50 \%$ & $100 \%$ & Total \\
\hline \multirow{2}{*}{ LG-1 (A1) } & $\mathbf{Q Z}$ & - & - & $100 \%(1)$ & - & 1 \\
\hline & SIL & $80 \%(4)$ & - & $20 \%(1)$ & - & 5 \\
\hline \multirow{2}{*}{ LG-1 (B1) } & RIO & $50 \%(1)$ & - & - & $50 \%(1)$ & 2 \\
\hline & SIL & $100 \%(1)$ & - & - & - & 1 \\
\hline EB-3 & OBS & $100 \%(6)$ & - & - & - & 6 \\
\hline \multirow{5}{*}{ EB-5 } & AND & - & $100 \%(1)$ & - & - & 1 \\
\hline & \begin{tabular}{|l|} 
OBS \\
\end{tabular} & $100 \%(9)$ & - & - & - & 9 \\
\hline & RIO & $100 \%(2)$ & - & - & - & 2 \\
\hline & SIL & $80 \%(4)$ & $20 \%(1)$ & - & - & 5 \\
\hline & VUL & - & $100 \%(1)$ & - & - & 1 \\
\hline \multicolumn{2}{|c|}{ Total $n$ sitios } & 27 & 3 & 2 & 1 & \multirow{2}{*}{33} \\
\hline \multicolumn{2}{|c|}{ Total \% sitios } & 81,82 & 9,09 & 6,06 & 3,03 & \\
\hline
\end{tabular}

Tabla 9.22. Porcentaje de reserva de corteza en artefactos enteros por materia prima y sitio del

Desierto de Monte. No se registró la categoría $75 \%$ de corteza.

\subsubsection{ESTRUCTURA TECNOLÓGICA EN EL DESIERTO DE MONTE}

Entre las principales clases artefactuales de los tres sitios analizados del Desierto de Monte, los desechos de talla constituyen la clase artefactual predominante $(91,8 \%$, $\mathrm{n}=291)$. Continúan los nódulos $(1,58 \%, \mathrm{n}=5)$, los cuales se registraron en LG-1, pero están ausentes en los sitios de E1 Bosquecillo. Los instrumentos ( $n=4)$, recuperados en EB-3 $(n=1)$ y en EB-5 $(n=3)$, constituyen el 1,26\%; la mitad son unifaciales confeccionados sobre rocas silíceas y los otros dos son bifaciales sobre obsidiana. Por último, en EB-5 se registró un ASF RC de roca silícea (Tabla 9.23).

\begin{tabular}{|c|c|c|c|c|c|c|c|c|c|}
\hline Sitio & MP & DT & $\begin{array}{c}\text { AF } \\
\text { Bifac }\end{array}$ & $\begin{array}{c}\text { AF } \\
\text { Unifac }\end{array}$ & $\begin{array}{l}\text { ASF } \\
\text { RC }\end{array}$ & Ecofacto & Nódulo & Pgm & Total \\
\hline \multirow{4}{*}{$\begin{array}{l}\text { LG-1 } \\
\text { (A1) }\end{array}$} & BAS & $100 \%(5)$ & - & - & - & - & - & - & 5 \\
\hline & $\mathbf{Q Z}$ & $66,7 \%(2)$ & - & - & - & - & $\begin{array}{c}33,3 \% \\
\text { (1) }\end{array}$ & - & 3 \\
\hline & RIO & $\begin{array}{c}100 \% \\
(12)\end{array}$ & - & - & - & - & - & - & 12 \\
\hline & SIL & $\begin{array}{c}100 \% \\
(30)\end{array}$ & - & - & - & - & - & - & 30 \\
\hline \multicolumn{2}{|c|}{ Total } & $\begin{array}{c}98,0 \% \\
(49)\end{array}$ & - & - & - & - & $\begin{array}{c}2,0 \% \\
(1)\end{array}$ & - & 50 \\
\hline
\end{tabular}




\begin{tabular}{|c|c|c|c|c|c|c|c|c|c|}
\hline \multirow{7}{*}{$\begin{array}{c}\text { LG-1 } \\
\text { (B1) }\end{array}$} & AND & $100 \%(1)$ & - & - & - & - & - & - & 1 \\
\hline & BAS & $80,0 \%(4)$ & - & - & - & - & $\begin{array}{c}20,0 \% \\
(1)\end{array}$ & - & 5 \\
\hline & OBS & $100 \%$ & - & - & - & - & - & - & 3 \\
\hline & QZ & $33,3 \%(1)$ & - & - & - & - & $\begin{array}{c}66,7 \% \\
(2)\end{array}$ & - & 3 \\
\hline & RIO & $\begin{array}{c}95,2 \% \\
(20)\end{array}$ & - & - & - & - & $\begin{array}{c}4,8 \% \\
(1)\end{array}$ & - & 21 \\
\hline & SIL & $\begin{array}{l}100 \% \\
(29)\end{array}$ & - & - & - & - & - & - & 29 \\
\hline & Indet. & $100 \%(2)$ & - & - & - & - & - & - & 2 \\
\hline \multicolumn{2}{|c|}{ Total } & $\begin{array}{c}93,8 \% \\
(60)\end{array}$ & - & - & - & - & $\begin{array}{c}6,3 \% \\
(4)\end{array}$ & - & 64 \\
\hline \multirow{7}{*}{ EB-3 } & AND & $100 \%(1)$ & - & - & - & - & - & - & 1 \\
\hline & BAS & $100 \%(1)$ & - & - & - & - & - & - & 1 \\
\hline & OBS & $\begin{array}{c}100 \% \\
(48)\end{array}$ & - & - & - & - & - & - & 48 \\
\hline & QZ & - & - & - & - & $\begin{array}{c}100 \% \\
(1)\end{array}$ & - & - & 1 \\
\hline & RIO & $100 \%(1)$ & - & - & - & - & - & - & 1 \\
\hline & SIL & $\begin{array}{c}86,7 \% \\
(13)\end{array}$ & - & $\begin{array}{c}6,7 \% \\
(1)\end{array}$ & - & $6,7 \%(1)$ & - & - & 15 \\
\hline & TB & - & - & - & - & $\begin{array}{c}100 \% \\
(13)\end{array}$ & - & - & 13 \\
\hline \multicolumn{2}{|c|}{ Total } & $\begin{array}{c}80,0 \% \\
(64)\end{array}$ & - & $\begin{array}{c}1,3 \% \\
(1)\end{array}$ & - & $\begin{array}{c}18,8 \% \\
(15)\end{array}$ & - & - & 80 \\
\hline \multirow{8}{*}{ EB-5 } & AND & $100 \%(1)$ & - & - & - & - & - & - & 1 \\
\hline & BAS & $100 \%(9)$ & - & - & - & - & - & - & 9 \\
\hline & OBS & $\begin{array}{c}96,4 \% \\
(53)\end{array}$ & $\begin{array}{c}3,6 \% \\
(2)\end{array}$ & - & - & - & - & - & 55 \\
\hline & QZ & $100 \%(1)$ & - & - & - & - & - & - & 1 \\
\hline & RIO & $\begin{array}{c}100 \% \\
(16)\end{array}$ & - & - & - & - & - & - & 16 \\
\hline & SIL & $\begin{array}{c}94,9 \% \\
(37)\end{array}$ & - & $\begin{array}{c}2,6 \% \\
(1)\end{array}$ & $\begin{array}{c}2,6 \% \\
(1)\end{array}$ & - & - & - & 39 \\
\hline & VUL & $100 \%(1)$ & - & - & - & - & - & - & 1 \\
\hline & Indet. & - & - & - & - & - & - & $\begin{array}{c}100 \% \\
(1)\end{array}$ & 1 \\
\hline \multicolumn{2}{|c|}{ Total } & $\begin{array}{c}95,9 \% \\
(118) \\
\end{array}$ & $\begin{array}{c}1,6 \% \\
(2) \\
\end{array}$ & $\begin{array}{c}0,8 \% \\
(1) \\
\end{array}$ & $\begin{array}{c}0,8 \% \\
(1)\end{array}$ & - & - & $\begin{array}{c}0,8 \% \\
(1) \\
\end{array}$ & 123 \\
\hline \multicolumn{2}{|c|}{ Total $n$ sitios } & 291 & 2 & 2 & 1 & 15 & 5 & 1 & \multirow{2}{*}{317} \\
\hline \multicolumn{2}{|c|}{ Total \% sitios } & 91,80 & 0,63 & 0,63 & $\mathbf{0 , 3 2}$ & 4,73 & $\mathbf{1 , 5 8}$ & 0,32 & \\
\hline
\end{tabular}

Tabla 9.23. Clases artefactuales por materia prima y sitio del Desierto de Monte. Referencias: DT: desecho de talla; AF: artefacto formatizado; Bifac.: bifacial; Unifac.: unifacial; ASF RC: artefacto sin formatización con rastros complementarios; Pgm: pigmento.

En la Sección 9.2.2.1. se presenta la integración de los desechos de talla de los tres sitios; pero no se presenta la integración de los instrumentos debido a que, como se dijo, son sólo cuatro y están fracturados, por lo que no se pueden evaluar otras variables ni 
definir con precisión a qué grupo tipológico corresponden, salvo en el caso del fragmento de punta de proyectil sobre obsidiana, procedente de EB-5.

\subsubsection{Desechos de talla}

En el Desierto de Monte, entre los desechos de talla enteros $(n=31)$, predominan las lascas internas $(93,55 \%, \mathrm{n}=29) \mathrm{y}$, dentro de esta categoría, abundan las angulares $(82,76 \%, \mathrm{n}=24)$ por sobre las de arista $(17,24 \%, \mathrm{n}=5)$. Las lascas de formatización de filo $(6,45 \%, n=2)$ ocupan el segundo y último lugar (no se registraron lascas externas en ninguno de los tres sitios); ambas lascas son de obsidiana de EB-5: una es de adelgazamiento bifacial y la otra de reactivación. En la Figura 9.32 se presentan las principales materias primas registradas entre los distintos tipos de lascas. Se observa que las lascas internas están representadas en ambos tipos (angulares y de arista), tanto en obsidiana como en rocas silíceas; pero que en estas últimas no se registraron lascas de formatización de filo (una lasca de adelgazamiento bifacial y otra de reactivación; las planas están ausentes) como sí ocurre con la obsidiana, que es, en los tres sitios, de procedencia no local.

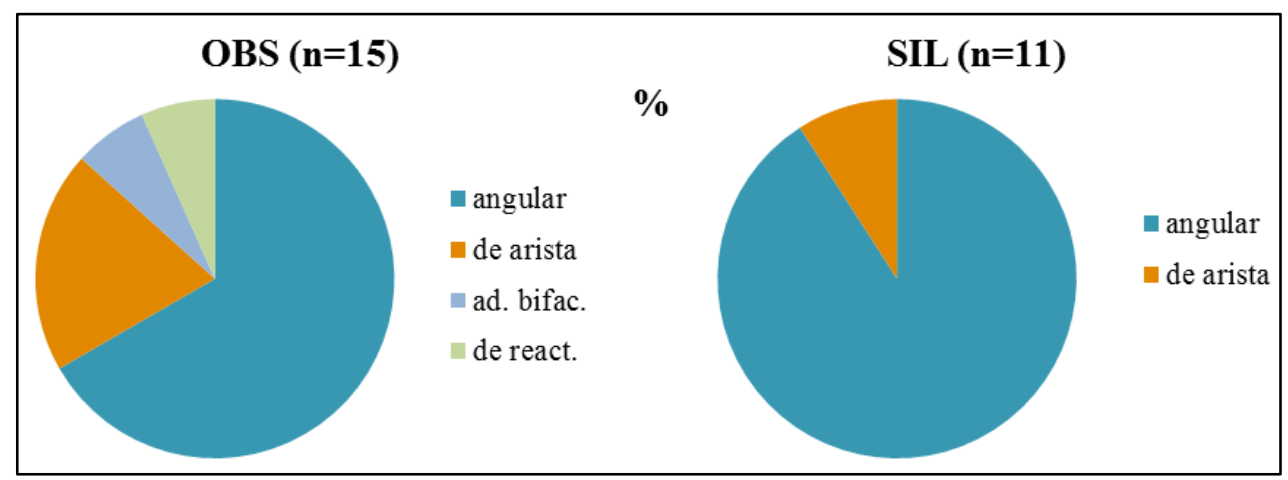

Figura 9.32. Frecuencias relativas de tipos de lasca por materia prima en el Desierto de Monte.

No se incluyeron las tres lascas angulares de riolita, la lasca angular de andesita ni la lasca de arista de vulcanita indeterminada. Entre paréntesis se indica el número total de lascas enteras

por materia prima. Referencias: OBS; obsidiana; SIL: rocas silíceas; ad. bifac.: lasca de adelgazamiento bifacial; de react.: lasca de reactivación.

Debido a la ausencia de lascas externas y la escasa representación de lascas de formatización de filo $(n=2)$, no se han considerado las representaciones gráficas de las frecuencias de etapas de manufactura y, específicamente, no se ha calculado el índice de corteza para lascas primarias y secundarias por materia prima, ni se ha graficado las tendencias de lascas de formatización de filo; como se ha hecho en los Capítulos 7 y 8. 
En la Tabla 9.24 se presenta la estadística descriptiva de la densidad de extracciones previas en la cara dorsal de las lascas internas enteras, por materia prima y por sitio. Allí se observa que la obsidiana (EB-3 y EB-5), de procedencia no local, es la clase de roca con mayor reducción. Le siguen la riolita y las rocas silíceas (LG-1 y EB5), locales. Esto puede sugerir un énfasis en el aprovechamiento intenso sobre rocas foráneas de excelente calidad para la talla, seguidas por las rocas locales de calidad muy buena (silíceas) y buena (riolita).

\begin{tabular}{|c|c|c|c|c|c|c|c|c|}
\hline Sitio & MP & $\boldsymbol{n}$ & Media & Mediana & $\begin{array}{c}\text { Desvío } \\
\text { estándar }\end{array}$ & Mínimo & Máximo & Rango \\
\hline LG-1 (A1 & RIO & 1 & 0,04 & - & - & - & - & - \\
\cline { 2 - 9 } y B1) & SIL & 6 & 0,04 & 0,03 & 0,02 & 0,01 & 0,06 & 0,05 \\
\hline EB-3 & OBS & 6 & 0,06 & 0,06 & 0,02 & 0,02 & 0,08 & 0,06 \\
\hline & AND & 1 & 0,02 & - & - & - & - & - \\
\cline { 2 - 9 } & OBS & 7 & 0,07 & 0,06 & 0,03 & 0,02 & 0,13 & 0,10 \\
\cline { 2 - 9 } EB-5 & RIO & 2 & 0,06 & 0,06 & 0,02 & 0,04 & 0,07 & 0,03 \\
\cline { 2 - 9 } & SIL & 5 & 0,05 & 0,04 & 0,02 & 0,02 & 0,08 & 0,06 \\
\cline { 2 - 9 } & VUL & 1 & 0,03 & - & - & - & - & - \\
\hline
\end{tabular}

Tabla 9.24. Estadística descriptiva de la densidad de extracciones previas en la cara dorsal de los desechos de talla enteros del Desierto de Monte.

\subsection{OBSIDIANAS EN EL DESIERTO DE MONTE}

\subsubsection{ANÁLISIS DE ELEMENTOS TRAZA}

De los tres sitios arqueológicos del Desierto de Monte, sólo se realizaron análisis de elementos traza sobre artefactos de obsidiana procedentes de EB-3 y EB-5, ya que de la cuadrícula A1 de LG-1 no se obtuvieron artefactos sobre dicha materia prima, y los desechos de talla de obsidiana de la cuadrícula B1 de este sitio son muy pequeños y no cumplen con los requerimientos para realizar este estudio geoquímico por la técnica no destructiva de Fluorescencia de Rayos X (XRF). Debido a las mismas limitaciones de tamaño, se seleccionaron dos muestras de cada sitio. Además, se incorporó al análisis un artefacto recuperado de la recolección superficial realizada en las inmediaciones de ambos sitios. Todos los análisis dieron como resultado que estos cinco artefactos analizados geoquímicamente, proceden de la sub-fuente El Peceño 1 (Tabla 9.25). 


\begin{tabular}{|c|c|c|c|}
\hline Sitio & Nivel & Cód & Procedencia \\
\hline El Bosquecillo & Rec. Sup & LSM 205 & El Peceño-1 \\
\hline \multirow{2}{*}{ EB-3 } & 1 & LSM 201 & El Peceño-1 \\
\cline { 2 - 4 } & 7 & LSM 200 & El Peceño-1 \\
\hline \multirow{2}{*}{ EB-5 } & 3 & LSM 203 & El Peceño-1 \\
\cline { 2 - 4 } & 9 & LSM 202 & El Peceño-1 \\
\hline
\end{tabular}

Tabla 9.25. Muestras de artefactos de obsidiana por nivel y procedencia, seleccionados para análisis geoquímico de los sitios EB-3, EB-5 y recolección superficial en la localidad El

Bosquecillo.

La fuente de obsidiana El Peceño se localiza a $90 \mathrm{~km}$ de EB3 y EB-5, y a $82 \mathrm{~km}$ del sitio LG-1 (Figuras 9.1, 9.2). Si bien la fuente extra-cordillerana El Peceño es la más próxima de todas las fuentes identificadas en el sur de Mendoza, la distancia a la que se encuentra es considerada no local a los sitios analizados en este capítulo. Se destaca que, si bien LG-1 se encuentra más próximo a la fuente, el porcentaje de obsidiana es mucho menor que el identificado en EB-3 y en EB-5, más distantes. Esto se puede deber, por ejemplo, a que LG-1 se halla más próximo al cauce del Atuel, lo cual provee mayor acceso a rodados de otras materias primas.

\subsubsection{APROVISIONAMIENTO Y USO DE OBSIDIANAS}

En los tres sitios arqueológicos, la obsidiana habría sido conservada y maximizada, además de transportada, dejando como evidencias desechos de talla originados durante el mantenimiento o reparación de instrumentos; estos últimos descartados sólo en estado fracturado.

La obsidiana constituye el 33,44\% (n=106) del total de artefactos líticos de los tres sitios; es decir, es la segunda clase de roca más utilizada después de las rocas silíceas (35,65\%, n=113). En la Figura 9.33.A se observa que la obsidiana está mayormente representada en los sitios EB-5 (51,87\%) y EB-3 (45,28\%), siendo muy escasa en la cuadrícula B1 del sitio LG-1 y ausente en LG-1 (A1). En la Figura 9.33.B se puede apreciar que, si bien la obsidiana es más numerosa en EB-5 $(n=55)$, en EB-3 es la roca más frecuente y alcanza el $60 \%(\mathrm{n}=48)$ de un total de 80 artefactos líticos; en EB-5 representa el 44,72\% $(\mathrm{n}=55)$ de 123 artefactos; y en LG-1 el 2,83\% (n=3) de 114 (Figura 9.33). 


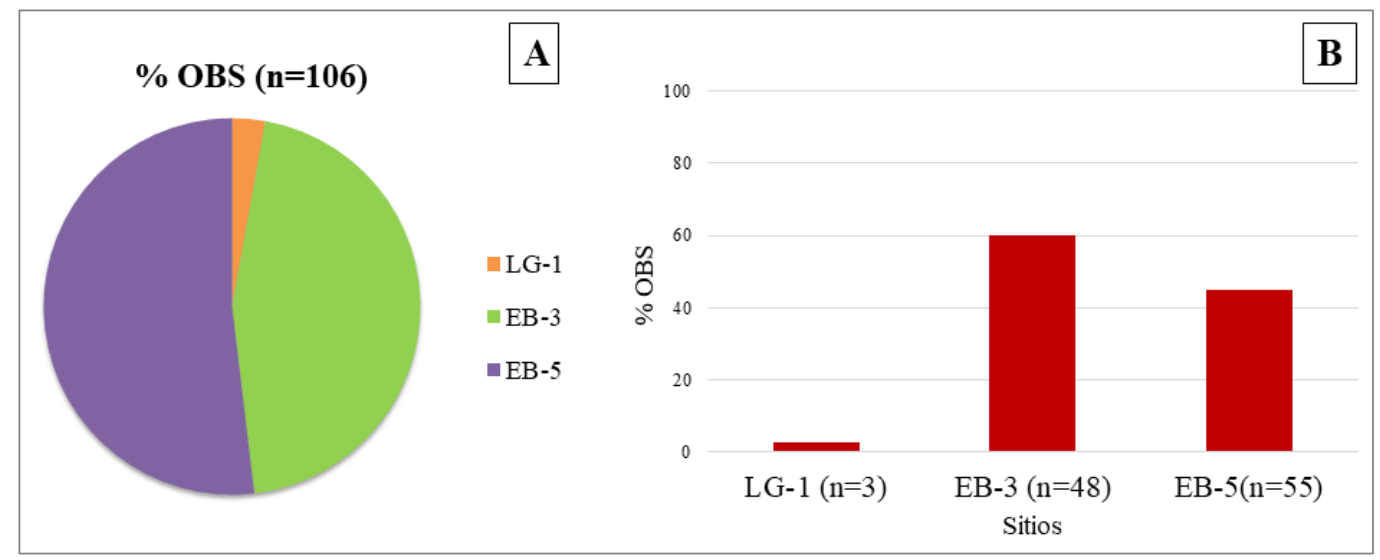

Figura 9.33. Frecuencias de artefactos de obsidiana en el Desierto de Monte. A-Porcentajes de obsidiana entre sitios; B- Representación de la obsidiana en cada sitio.

\subsection{CONSIDERACIONES FINALES}

En el Desierto de Monte, la tecnología lítica se manifiesta en el uso predominante de rocas silíceas y de obsidiana, únicas materias primas en las que se registraron instrumentos (la mitad unifaciales de rocas silíceas y la otra mitad bifaciales de obsidiana, incluyendo al fragmento de punta de proyectil). Todos los instrumentos fueron descartados fracturados; esto sugiere que fueron conservados y sólo se descartaron cuando perdieron su funcionalidad. El producto de su mantenimiento y/o reparación se refleja en los numerosos desechos de talla sobre ambas materias primas y también sobre otras rocas, como la riolita, el basalto y el cuarzo. Sobre estas tres clases de roca no se registraron instrumentos ni núcleos, aunque sí se recuperaron nódulos. La obsidiana es mayoritariamente de calidad excelente y las rocas silíceas de calidad muy buena. La calidad buena se registró sobre todas las rocas representadas, a excepción de la obsidiana, la cual no posee ningún ejemplar con reserva de corteza. Salvo pocas excepciones, los artefactos con mayores porcentajes de corteza corresponden a nódulos. El tamaño predominante es el muy pequeño y las otras dos categorías registradas son pequeño y mediano pequeño. Esta variable y la del porcentaje de corteza se analizaron sobre artefactos enteros, los cuales constituyen un porcentaje considerablemente menor que el de los fracturados.

Los desechos de talla, como en los Desiertos Altoandino y Patagónico, constituyen la clase artefactual preponderante. Entre ellos, predominan las lascas internas, sobre todo, las angulares, seguidas por las de formatización de filo (predominantemente de adelgazamiento bifacial y con ausencia de lascas planas). No se han registrado lascas 
externas en ninguno de los tres sitios, por lo cual no se pudo calcular el índice de corteza. La ausencia de núcleos, de reserva de corteza y de lascas externas, sugiere que las materias primas -sobre todo las de procedencia no local- fueron descortezadas en su lugar de origen. Se desconoce el tamaño de las formas-base que se trasladaron a estos sitios debido a la ausencia de instrumentos enteros y de núcleos que permitan estimar el tamaño de las bocas de lascado en relación a los desechos de talla hallados en los sitios.

No se pudieron hacer comparaciones temporales dado que los tres sitios poseen ocupaciones iniciales fechadas en el HTF. En los tres casos, la baja densidad de materiales y la dispersión espacial entre ellos y otros sitios localizados en el Desierto de Monte, permiten plantear que son sitios de ocupaciones esporádicas, con escasa reocupación a través del tiempo, lo que confiere al registro una buena resolución temporal, pero una escasa resolución espacial.

Los tres sitios, LG-1 (A1 y B1), EB-3 y EB-5 se emplazan a cielo abierto y están localizados en un ambiente donde los recursos se distribuyen de manera homogénea. Los materiales arqueológicos incluyen restos faunísticos, botánicos, líticos y cerámicos. En conjunto, estas evidencias permiten sostener que los sitios del Monte, son sitios de actividades múltiples, donde se realizaron tareas vinculadas al procesamiento de vegetales y animales, a su consumo, y al mantenimiento, reparación de instrumentos y, quizás, su confección. La escasa evidencia de instrumentos, sin embargo, admite la idea de que los unifaciales, de rocas silíceas, se utilizaron en EB-3 y EB5 en dicho procesamiento de recursos alimenticios; y que los instrumentos bifaciales de obsidiana, en EB-5 fueron mantenidos y/o reparados para su función en sitios de caza, por ejemplo, siendo descartados únicamente cuando estuvieran fracturados o cuando llegaran al final de su vida útil, debido al interés por conservar y maximizar esta materia prima. 


\section{CAPÍTULO 10}

\section{TENDENCIAS ESPACIALES Y TEMPORALES DEL REGISTRO LÍTICO EN LA CUENCA DEL RÍO ATUEL}

En este capítulo se integran los resultados de los análisis realizados en los tres desiertos del sur mendocino (Altoandino, Patagónico y de Monte) y se presentan las principales tendencias tecnológicas espaciales y temporales. Sobre esta base, se contrastarán y discutirán las hipótesis que guiaron esta investigación (Capítulo 11).

En capítulos anteriores (2, 3 y 4$)$ se ha visto que en regiones de ambientes áridossemiáridos, las poblaciones deben utilizar amplios territorios, que suelen superponerse. De esta forma, toman contacto e interactúan, accediendo a recursos alóctonos y/o complementarios (Gamble 1990; Yellen 1977, entre otros). En el sur de Mendoza, la heterogeneidad ambiental genera variabilidad en el registro arqueológico (Neme y Gil 2008a).

A partir de los resultados obtenidos de los muestreos de materias primas (Capítulo 6) y del análisis tecnológico de los conjuntos líticos de los tres desiertos (capítulos 7, 8 y 9), se analizan las trayectorias o historias de vida de los artefactos, según la materia prima, con el fin de lograr una aproximación a la estructura regional de estos recursos en la cuenca del río Atuel. La relación entre la distancia de transporte y las trayectorias artefactuales es un indicador confiable de las transformaciones e intensidad de uso de los artefactos, entre la fuente de materia prima y el punto de descarte (Kuhn 2004) (véase Capítulo 4). En conjunto, estos modos de obtención, explotación y circulación, posibilitan el acercamiento al conocimiento sobre las formas de uso del espacio y de la interacción entre grupos humanos.

El abordaje de las trayectorias artefactuales implicó la integración de los conjuntos líticos analizados en cada desierto. El Desierto Altoandino incluye a los sitios Arroyo Panchino 1 (AP-1), Arroyo Panchino 2 (AP-2) y Cueva Palulo 1 (CP-1). El Desierto Patagónico a los sitios Cueva Salamanca 1 (CSA-1), Arbolito 6 (AR-6), Arbolito 7 (AR7) y Barranca de Piedra 1 (BDP-1). El Desierto de Monte incluye a Los Gallegos 1 (LG- 
1), El Bosquecillo 3 (EB-3) y El Bosquecillo 5 (EB-5). De los conjuntos líticos de estos sitios, sólo se consideraron, para su integración, las principales clases artefactuales (desechos de talla, artefactos de formatización bifacial y unifacial, instrumentos compuestos, ASF RC y núcleos) y, si bien se muestra la variedad de todas las materias primas utilizadas en cada desierto, se hace hincapié en las rocas más frecuentes: silíceas, obsidiana, basalto y riolita.

\subsection{TENDENCIAS TECNOLÓGICAS EN PERSPECTIVA ESPACIAL 10.1.1. APROVISIONAMIENTO Y USO DE RECURSOS LÍTICOS EN EL ESPACIO}

Los recursos líticos más utilizados en la cuenca del río Atuel fueron las rocas silíceas $(51,4 \%, n=2597)$, la obsidiana $(39,9 \%, n=2014)$, el basalto $(6,4 \%, n=323)$ y la riolita $(2,3 \%, \mathrm{n}=117)$ (Figura 10.1). El resto de las materias primas registradas (andesita, cuarzo, vulcanitas indeterminadas y rocas indeterminadas) tomadas en conjunto representan un porcentaje mínimo $(0,51 \%, \mathrm{n}=26)$. A excepción de la obsidiana, las demás materias primas están disponibles localmente en fuentes primarias y secundarias. Según datos geoquímicos regionales, la obsidiana proviene de distintas fuentes no locales (Las Cargas, Coche Quemado, El Peceño, entre otras); excepto en la localidad Arbolito (Capítulo 8), donde la fuente El Peceño se halla a $20 \mathrm{~km}$ de los sitios estudiados (es un recurso "local cercano" sensu Civalero y Franco 2003).

En la Figura 10.1 se observa que la obsidiana es la materia prima más frecuente en el Desierto Altoandino, seguida por las rocas silíceas. En cambio, en los desiertos Patagónico y de Monte, es superada por las silíceas. El basalto ocupa el tercer lugar en el Desierto Altoandino y en el Patagónico, pero en el Desierto de Monte lo ocupa la riolita. Estas últimas dos clases de roca son menos frecuentes en el Desierto Patagónico, donde las silíceas son predominantes (Figura 10.1). 


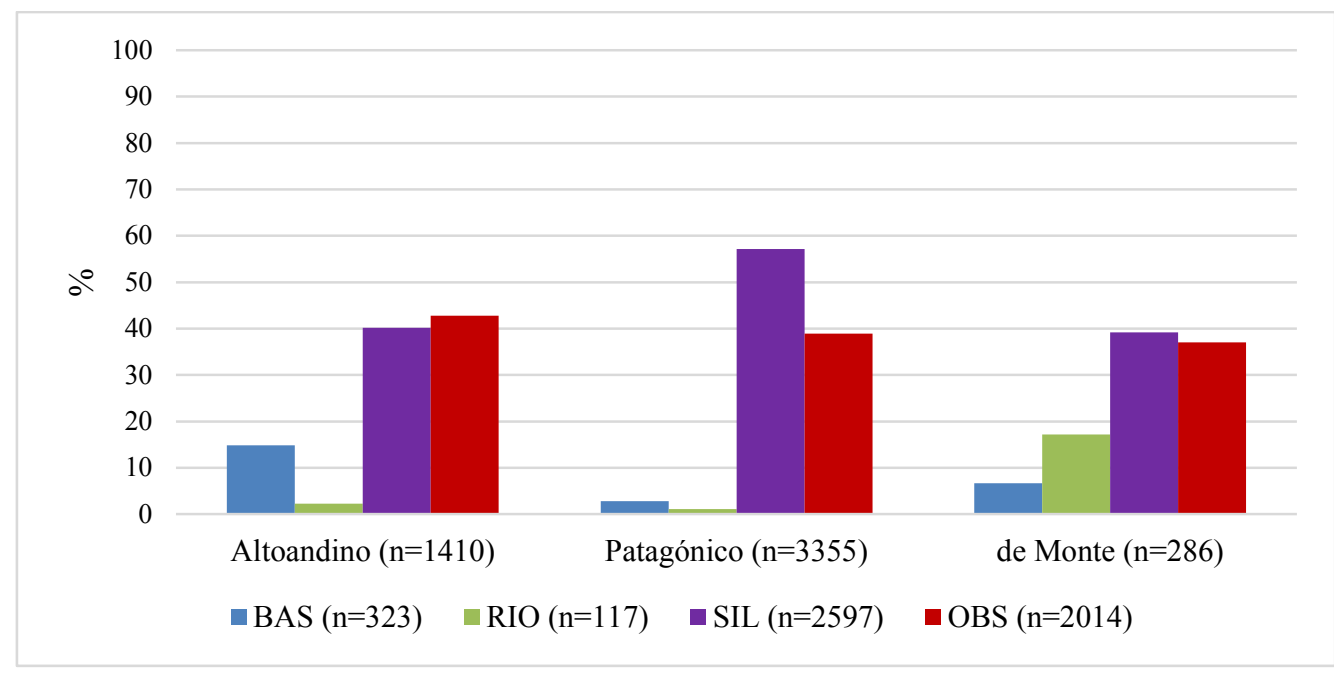

Figura 10.1. Frecuencias relativas de las principales materias primas por desierto.

El uso de estas cuatro materias primas sigue las mismas tendencias de cada desierto, aunque con algunas variaciones. En los desiertos Patagónico y Altoandino el basalto supera a la riolita, y en el de Monte, las frecuencias se invierten. Otro punto importante es cómo se representa la obsidiana, que en los desiertos de Monte y Patagónico es la segunda roca más frecuente y en el Altoandino es la más representada, superando el 40\%. A la inversa, las rocas silíceas son las más abundantes en el Monte y Patagonia, y la segunda en cordillera (Altoandino) (Figura 10.2).

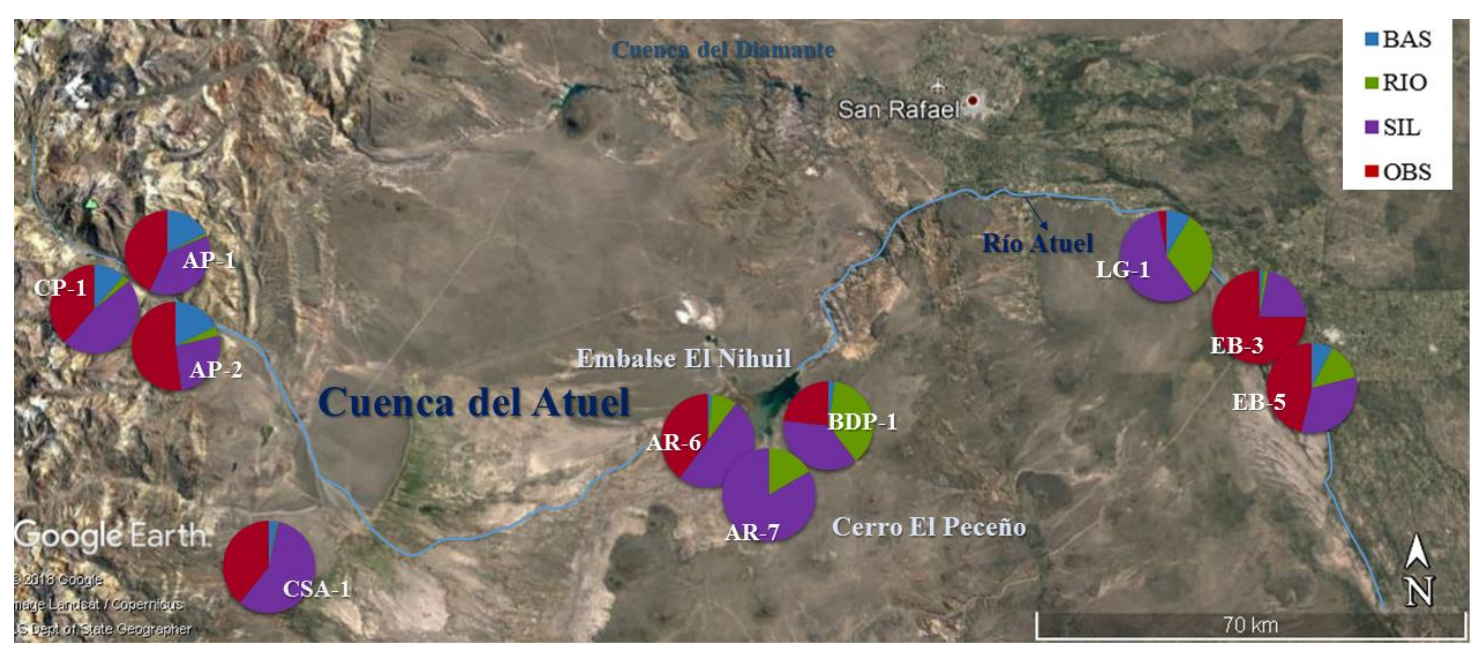

Figura 10.2. Distribución espacial de las materias primas principales por sitio a lo largo de la cuenca del río Atuel. En celeste, se resalta el recorrido del río.

Dentro de estas tendencias generales, es importante remarcar que el sitio CSA-1 (Patagónico), tiene similitudes con sitios del desierto Altoandino, mientras que los sitios 
ecotonales de la localidad Arbolito (AR-6, AR-7 y BDP-1) se asemejan a los del Monte (Figuras 10.2 y 10.3).

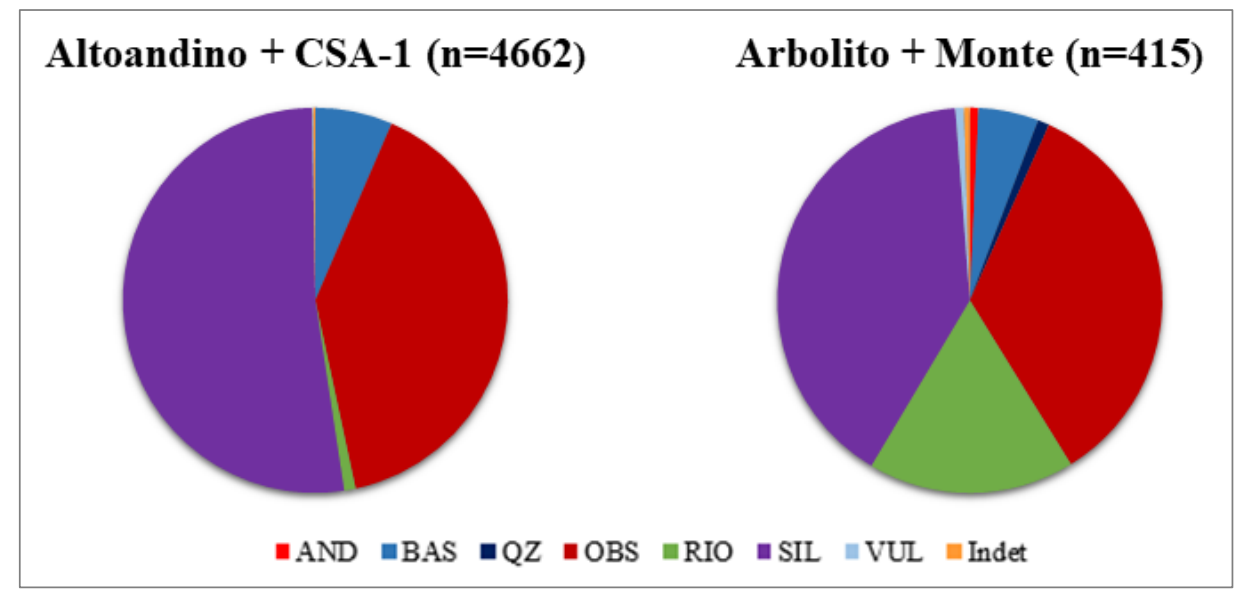

Figura 10.3. Materias primas en el Desierto Altoandino y CSA-1 vs. Localidad Arbolito y el

Desierto de Monte.

En la Figura 10.4 se observa que en el Desierto de Monte hay un mayor $n$ de materias primas que en el resto de los desiertos, especialmente de aquellas menos frecuentes y de menor calidad para la talla (i.e. andesita, cuarzo, vulcanita indeterminada, etc.). Además, el Desierto de Monte es el que posee menor tamaño de muestra, lo cual realza esta diferencia. Esto es coherente con lo observado en la Tabla 10.1, que muestra que la diversidad de materias primas en cada desierto presenta diferencias significativas. El índice mayor corresponde al Desierto de Monte (Shannon-H: 1,367), y el Desierto Patagónico es el que presenta menores valores de diversidad. En todos los casos hay dominancia de una materia prima sobre el total de rocas utilizadas, pero es en el Desierto Patagónico donde se destaca la frecuencia de rocas silíceas por sobre el resto de las materias primas.

\begin{tabular}{|l|c|c|c|}
\hline & Altoandino & Patagónico & de Monte \\
\hline $\boldsymbol{n}$ MP & 6 & 6 & 8 \\
\hline $\boldsymbol{n}$ & 1421 & 3360 & 296 \\
\hline Dominancia & 0,3609 & 0,478 & 0,3033 \\
\hline Simpson & 0,6391 & 0,522 & 0,6967 \\
\hline Shannon-H & 1,14 & 0,8471 & 1,367 \\
\hline
\end{tabular}

Tabla 10.1. Diversidad de materias primas por desierto. 


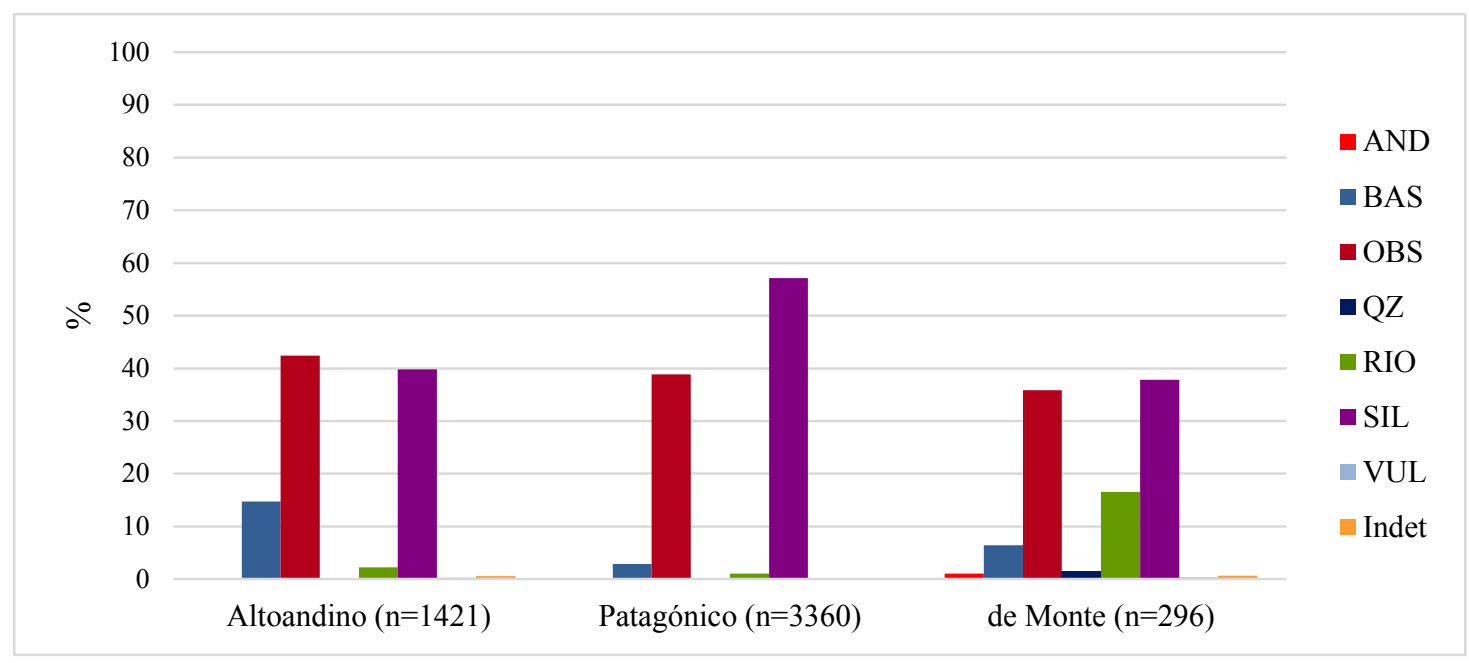

Figura 10.4. Materias primas registradas en los tres desiertos de la cuenca del río Atuel.

La prioridad e intensidad de uso de rocas silíceas y obsidiana en los tres desiertos es congruente con su calidad (entre muy buena y excelente), respecto a la menor calidad del resto de las materias primas ${ }^{14}$ (Figura 10.5). La mayor representación de rocas de menor calidad en el Desierto de Monte -que además presenta un bajo número de artefactos- puede responder a un uso de las rocas inmediatamente disponibles y constantes (sensu Crolwell 1974, citado en Cashdan 1992) (véase Capítulo 4), priorizando las locales de mejor calidad, pero sin hacer un uso intensivo de ellas.

La proporción de rocas de buena o menor calidad en el Desierto Altoandino (Figura 10.5), sugiere un mayor aprovechamiento de las rocas disponibles de forma secundaria en el río Atuel y arroyos circundantes a los sitios. Además, en este desierto, ante el estrés temporal los grupos se habrían abastecido de modo intensivo con recursos líticos contingentes (Crolwell 1974 citado en Cashdan 1992), como la obsidiana. La mayor representación de los instrumentos de basalto de mejor calidad se encuentra en este desierto $(83 \%)$, lo que refuerza un uso intensivo de las rocas de muy buena y excelente calidad para la talla, disponibles en cada ambiente.

\footnotetext{
${ }^{14} \mathrm{Si}$ bien también se registró basalto de muy buena calidad en algunos sitios (e.g. CP-1 y CSA-1; véase capítulos 7 y 8), la variable de calidad para la talla se ha estimado incluyendo a todos los artefactos de basalto en la categoría buena/regular para poder facilitar la comparación.
} 


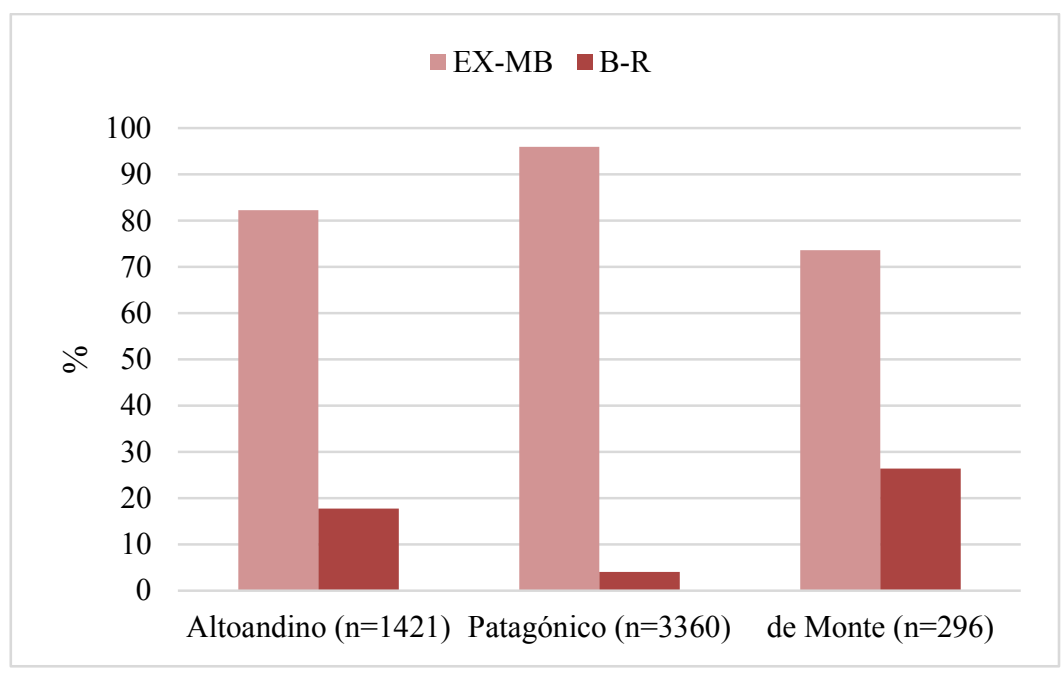

Figura 10.5. Materias primas de calidad excelente-muy buena $v s$. buena- regular.

El uso mayoritario de la obsidiana en el Desierto Altoandino y el aumento en el uso de la riolita y otras materias primas de menor calidad en el Desierto de Monte son tendencias acordes con la procedencia de estas rocas. Las fuentes de obsidiana más utilizadas a nivel regional se localizan en la cordillera y la riolita se encuentra disponible en el río Atuel que la transporta desde sus afloramientos en la cordillera y en el Bloque de San Rafael.

Con respecto a la obsidiana, si se considera la distancia y el acceso a las fuentes, se observa una correlación positiva entre la frecuencia y la altitud (Neme y Gil 2012; Salgán et al. 2012b). En la Figura 10.1 puede observarse que la obsidiana es menos frecuente en el Desierto de Monte (planicie) y aumenta con la altitud hacia los desiertos Patagónico y Altoandino (cordillera), en los cuales hay disponibilidad de fuentes de obsidiana. Igualmente, aunque las frecuencias aumentan con la altitud, la representación de la obsidiana tampoco muestra cambios importantes en los tres desiertos $(42 \%$ en el Altoandino, 39\% en el Patagónico y 36\% en el de Monte). Debe destacarse que la diversificación en el uso de fuentes de obsidiana es mayor en el Desierto Patagónico (donde se utilizaron seis fuentes distintas), mientras que en el Desierto de Monte se utilizó únicamente la fuente extra-cordillerana El Peceño.

La abundancia y ubicuidad de las rocas silíceas en la cuenca del Atuel puede informar acerca del rango mínimo de acción de los grupos humanos. Su uso predominante e intensivo es coherente con lo esperado para materias primas locales de alta calidad para la talla, ya que mejoran las tasas de retorno frente a las locales de menor calidad ( $c f$. Garvey 2015; véase Capítulo 4) (Figura 10.5). La trayectoria tecnológica de las silíceas 
comenzaría en fuentes primarias y secundarias inmediatamente disponibles (Figura 10.6). En los muestreos realizados a lo largo de la cuenca del río Atuel, se observó que el basalto es una de las rocas más ubicuas, de amplia distribución, abundancia y accesibilidad en todos los sectores analizados.

En resumen, las materias primas consideradas por desierto muestran cuatro tendencias principales. En primer lugar, la obsidiana muestra un incremento con la altura, alcanzando la máxima frecuencia en la cordillera. En segundo lugar, los sitios del Monte presentan mayor variedad de materias primas. Tercero, las rocas silíceas mantienen a lo largo de la cuenca valores de frecuencia altos, especialmente en los desiertos Patagónico y de Monte, donde es la principal materia prima representada. Cuarto, las materias primas de menor calidad, tienen una importante representación en el Desierto de Monte.

Todas estas tendencias pueden ser explicadas en gran parte por la disponibilidad diferencial de las materias primas de alta calidad (Figura 10.5). Mientras en los desiertos Altoandino y Patagónico la obsidiana se encuentra a menos de $60 \mathrm{~km}$ (Las Cargas), en los sitios del Monte está a más de $80 \mathrm{~km}$ (El Peceño). Además, los sitios localizados en el Desierto Altoandino y Patagónico disponen de fuentes primarias de rocas silíceas a distancias de entre 13 y $30 \mathrm{~km}$, mientras que en los sitios del Monte esas materias primas están a 45-65 km o a fuentes secundarias inmediatamente disponibles, pero de una distribución acotada y de poca abundancia. Estas mayores distancias a las materias primas de muy buena o excelente calidad desde los sitios localizados en el Desierto de Monte, habrían jugado un rol importante en la selección de materias primas de menor calidad para la talla como la riolita, el basalto y la andesita, localmente disponibles y relativamente abundantes. En este ambiente se observa, además, un aumento en la variedad de materias primas disponibles en el espacio local y en las rocas no locales de alta calidad para la talla, sólo se recuperaron instrumentos bifaciales fracturados. La presencia de instrumentos formales de obsidiana correspondería, en términos de Andrefsky (1994), a su predilección por su calidad excelente para la talla y su menor abundancia en el Monte. 


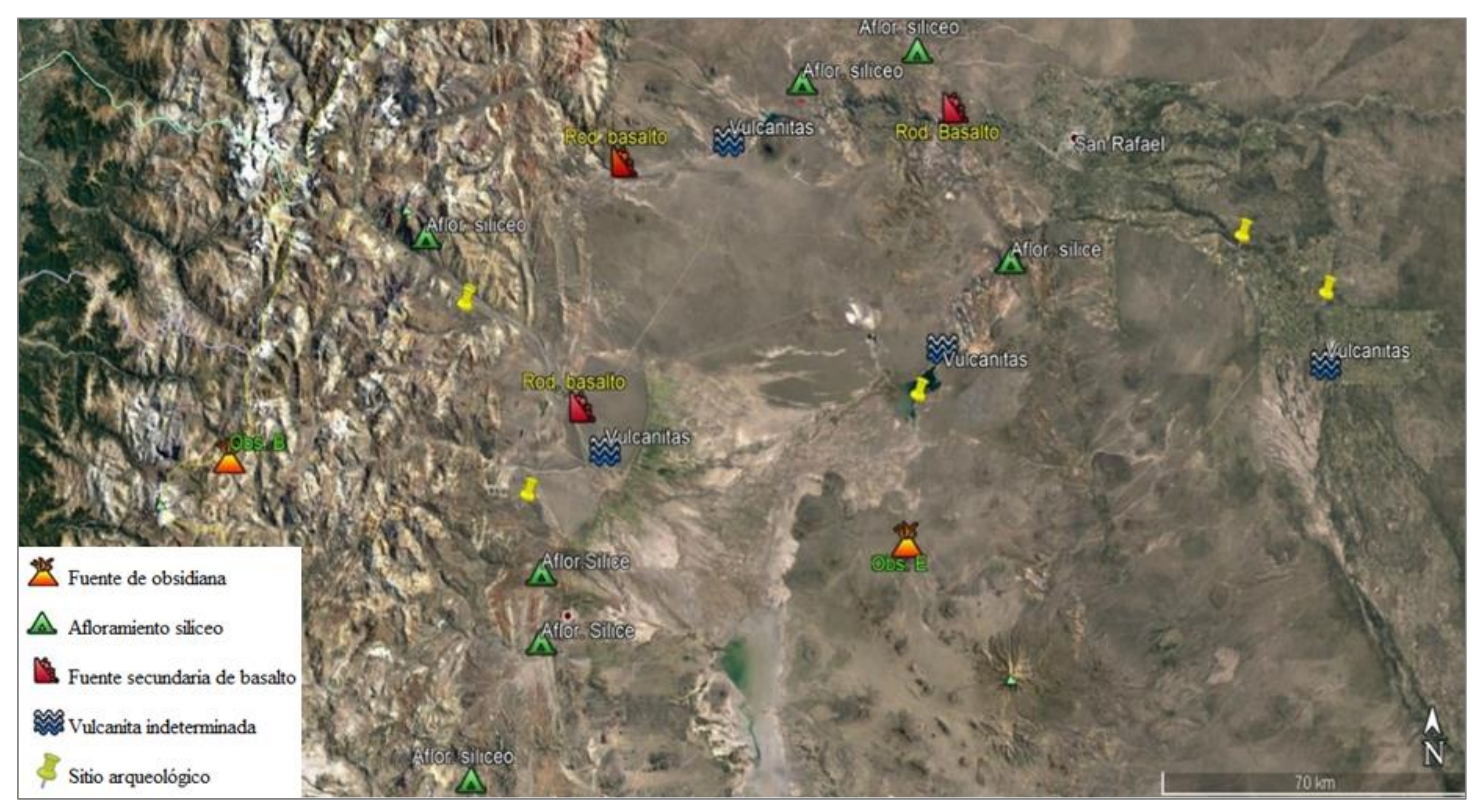

Figura 10.6. Mapa mostrando la disposición de los sitios y de las principales fuentes de materias primas identificadas en la región de estudio.

\subsubsection{CLASES ARTEFACTUALES EN EL ESPACIO}

Del análisis de las principales clases artefactuales, se observó un claro predominio de los desechos de talla: 97\% en los Desiertos Altoandino y Patagónico, y 98\% en el de Monte. Los instrumentos bifaciales y unifaciales, y los ASF RC, están presentes en los tres desiertos. Los compuestos no se registraron en el Desierto de Monte. Los núcleos están presentes únicamente en el Desierto Patagónico, en muy baja frecuencia $(0,1 \%$, $\mathrm{n}=2$ ) (Figura 10.7). En general, la proporción de instrumentos es mayor en el Desierto Patagónico. Aquí, los bifaciales son mayoritarios, en el Altoandino los unifaciales y, en el de Monte, se presentan en la misma proporción bifaciales y unifaciales. Es llamativo el predominio de unifaciales en la región cordillerana donde se destaca el uso de obsidiana. Esta tendencia es acorde con el aprovisionamiento directo, pero restringido estacionalmente, a las fuentes de esta materia prima en el Desierto Altoandino.

Por otra parte, se registra un aumento con la altura de los instrumentos compuestos: en el Monte están ausentes, en Patagonia alcanzan el 6\% y en el Altoandino el 10\%. Este tipo de instrumentos ha sido asociado tradicionalmente a diseños versátiles y flexibles (mantenibles), dentro de una estrategia conservada. 


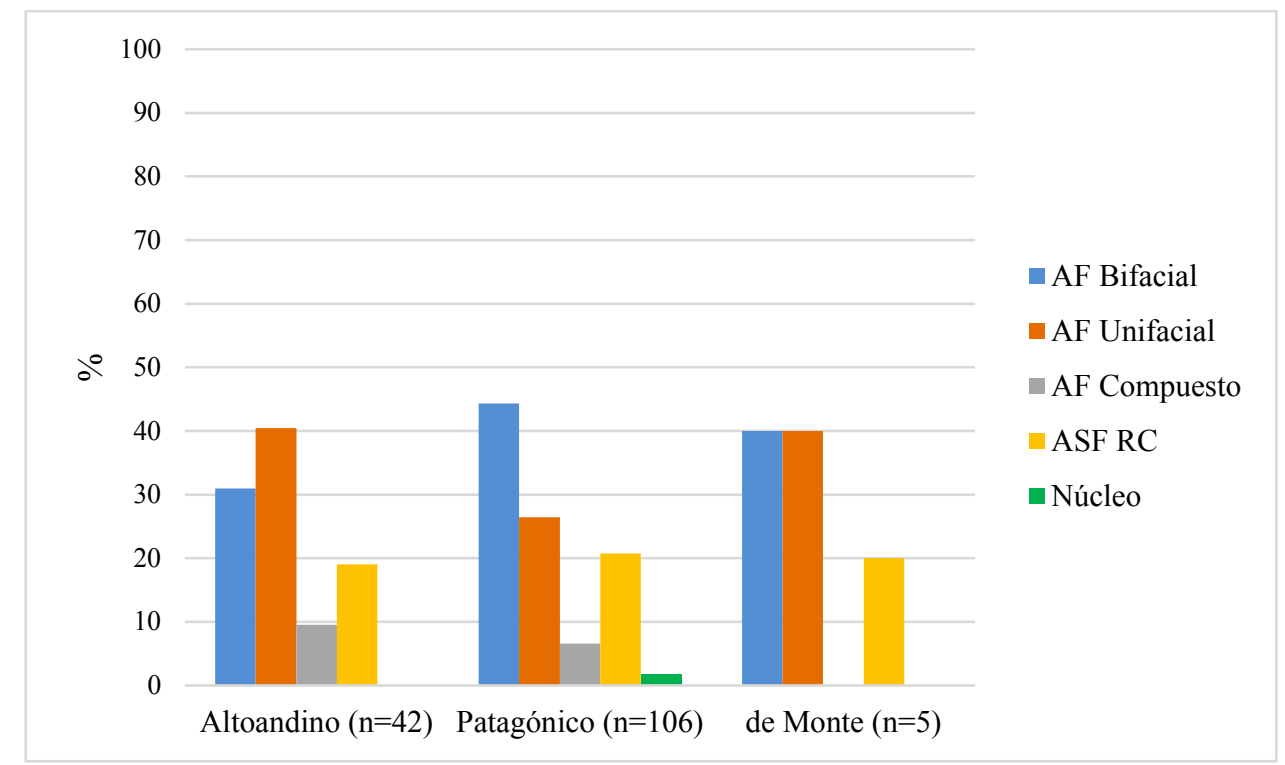

Figura 10.7. Frecuencias relativas de artefactos formatizados (AF), ASF RC y núcleos, por desierto.

Entre los desechos de talla enteros predominan las lascas internas en los tres desiertos, seguidas por las de formatización de filo y las externas. Las internas están representadas en las cuatro materias primas principales de los tres desiertos, pero se observan variaciones en las lascas de formatización de filo y las externas, respecto a la clase de roca: de las de formatización de filo, la mitad son de rocas silíceas, aunque no se registraron en el Desierto de Monte. Le siguen las de obsidiana en los tres desiertos; las de basalto sólo en el Desierto Altoandino; y las de riolita sólo en el Patagónico. Aunque entre los desechos de talla de rocas silíceas, la primer etapa de manufactura es la menos representada, las lascas externas son mayoritarias sobre esta materia prima (48\%), seguidas por las de basalto (32\%) y las de obsidiana (12\%), en los desiertos Altoandino y Patagónico; las externas de riolita (8\%) sólo se registraron en el Patagónico (Figura $10.8)$. 


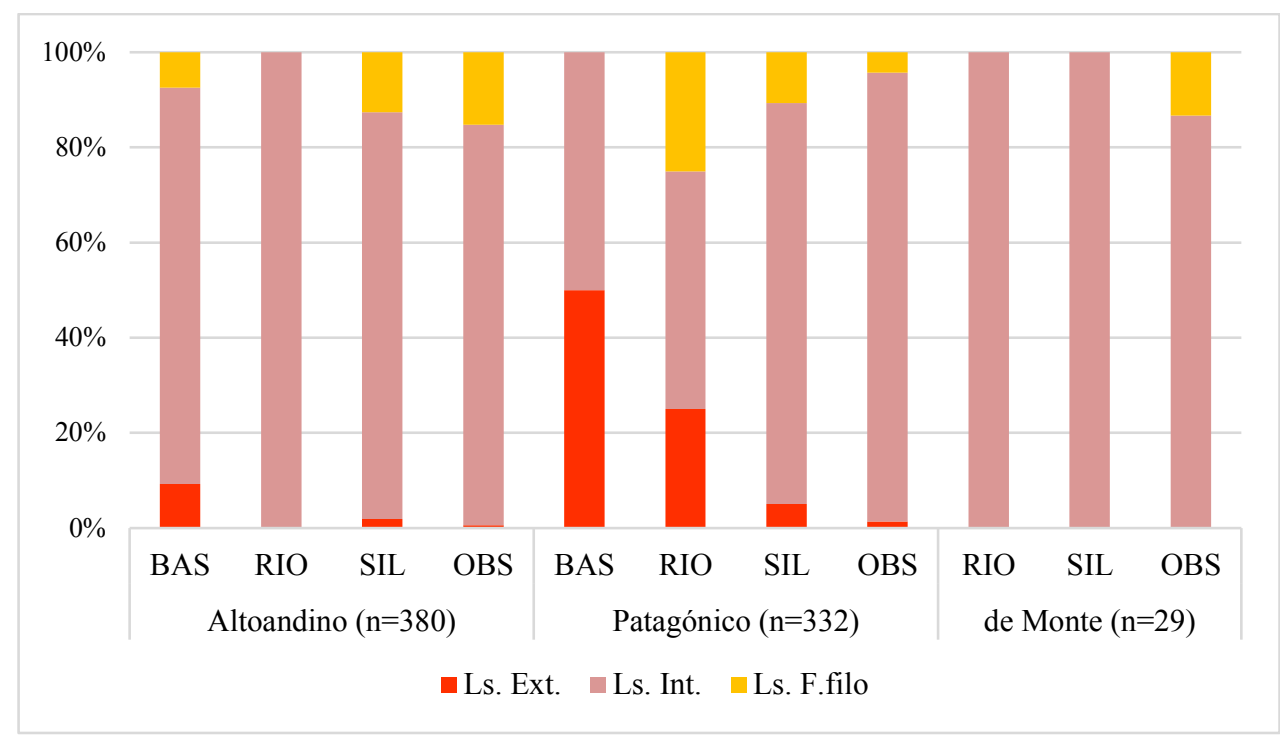

Figura 10.8. Frecuencia de etapas de manufactura por materia prima y desierto.

Se observa que las etapas iniciales de manufactura están mejor representadas sobre las materias primas de disponibilidad local; en cambio, la obsidiana es la roca minoritaria entre las lascas externas. Lo llamativo es que no hay lascas externas de esta roca en los sitios de la localidad Arbolito, donde la fuente El Peceño está dentro del rango local. Pero en CSA-1 (el sitio pedemontano del Desierto Patagónico), sí se registraron lascas externas, y podría considerarse que allí habrían llegado formas-base como nódulos, lascas nodulares y/o núcleos, en concordancia con lo planteado en Salgán y Pompei (2017), en relación a la sub-fuente El Peceño-1. Igualmente, la cantidad de externas en CSA-1 no es suficiente para validar esta idea. En cuanto a esto, se incluyeron las lascas fracturadas de obsidiana con corteza y se observó que en ningún caso los desechos fracturados de obsidiana con corteza superaron el $2 \%$ del total de desechos de obsidiana. Es decir, que el descortezamiento se realizó en otros locus.

En la Figura 10.9 se observa que los instrumentos bifaciales $(41,1 \%)$ y unifaciales $(31,1 \%)$ son los más frecuentes en los tres desiertos, seguidos por los ASF RC $(20,5 \%)$, y por los instrumentos compuestos (7,3\%). La mayoría se encuentran trabajados en rocas silíceas, seguidos por los de obsidiana y, en tercer lugar -en el Altoandino y el Patagónico-, por los de basalto. No se observan diferencias entre los tres desiertos en la selección de una determinada materia prima para la confección de instrumentos $\left[X^{2}\right.$ (two samples $)=56,44 ; p=6,5908 \mathrm{E}-11]$. Dado el pequeño número de la muestra se realizó el cálculo del test de permutación Monte Carlo, con valor de $p$ bajo $(0,0001)$, que en este caso coincide con los valores obtenidos con la prueba de $X^{2}$ de no asociación. 


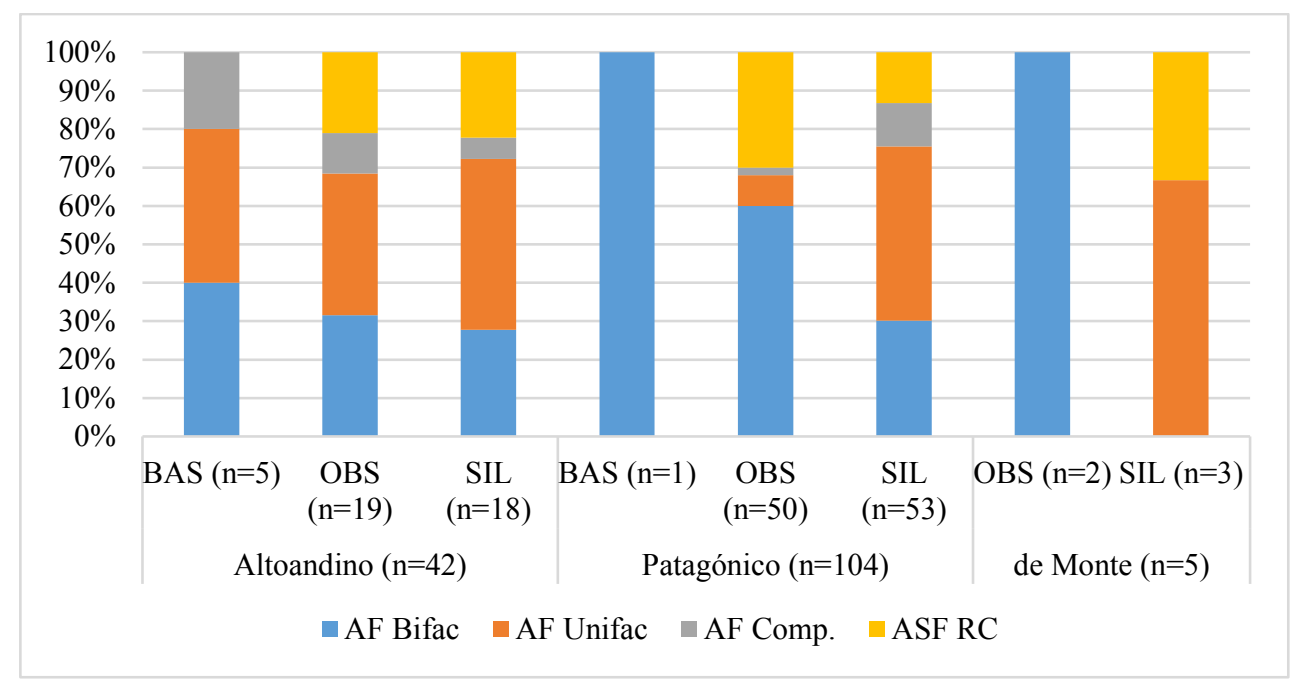

Figura 10.9. Frecuencia de instrumentos y ASF RC según materia prima por desierto.

En las Figuras 10.9 y 10.10 se observa que los instrumentos bifaciales son mayoritarios en obsidiana y los unifaciales en rocas silíceas. En los tres desiertos los instrumentos bifaciales están confeccionados mayormente en obsidiana y los unifaciales en rocas silíceas, mientras que los ASF RC presentan mayor variación. En el Desierto de Monte se registraron instrumentos bifaciales en obsidiana y unifaciales sobre rocas silíceas. En el Altoandino, el uso de las materias primas es equilibrado, sobre todo en relación a las proporciones de instrumentos bifaciales y unifaciales. En cambio, en el Patagónico hay diferencias sensibles en la frecuencia de instrumentos y ASF RC sobre cada materia prima (Figura 10.10); y, en el tipo de formatización (bifacial vs. unifacial), se observa una marcada diferencia entre el uso predominante de obsidiana sobre instrumentos bifaciales respecto a los unifaciales en el Desierto Patagónico. También se observa que el basalto es utilizado indistintamente en el Altoandino, pero únicamente sobre bifaciales en el Patagónico. El uso de rocas silíceas es similar entre desiertos. En la Tabla 10.2 el índice de bifacialidad por tiempo, desierto y materia prima muestra que la obsidiana posee un índice mayor que las rocas silíceas, excepto en el HTI dentro del Desierto Altoandino, donde es mayor sobre rocas silíceas, y donde la obsidiana y el basalto poseen el mismo valor. 


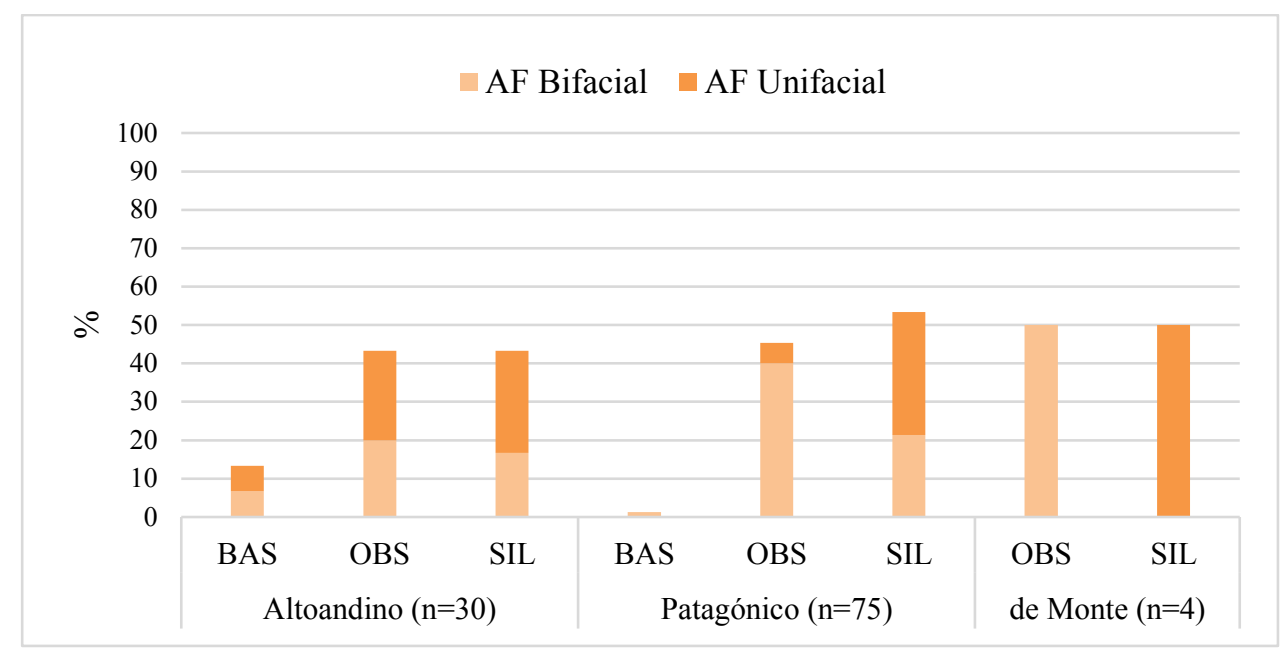

Figura 10.10. Frecuencia de instrumentos bifaciales $v s$. unifaciales por materia prima y por desierto.

\begin{tabular}{|c|c|c|c|c|c|c|}
\hline Tiempo & Desierto & MP & Aprovisionamiento & $\begin{array}{c}\text { Índice de } \\
\text { corteza }\end{array}$ & $\begin{array}{l}\text { Índice de } \\
\text { producción }\end{array}$ & $\begin{array}{c}\text { Índice de } \\
\text { bifacialidad }\end{array}$ \\
\hline \multirow{16}{*}{ HTF } & \multirow{4}{*}{ Altoandino } & BAS & Local & 0,015 & 103,00 & - \\
\hline & & OBS & No local & 0,005 & 58,80 & 0,33 \\
\hline & & RIO & Local & - & - & - \\
\hline & & SIL & Local & 0,005 & 36,16 & 0,16 \\
\hline & \multirow{4}{*}{$\begin{array}{l}\text { Patagónico } \\
\text { (CSA-1) }\end{array}$} & BAS & Local & 0,006 & - & - \\
\hline & & OBS & No local & - & 29,91 & 0,39 \\
\hline & & RIO & Local & - & - & - \\
\hline & & SIL & Local & 0,006 & 27,30 & 0,20 \\
\hline & \multirow{4}{*}{$\begin{array}{l}\text { Patagónico } \\
\text { (Loc. } \\
\text { Arbolito) }\end{array}$} & BAS & Local & - & - & - \\
\hline & & OBS & Local & - & 7,00 & 0,36 \\
\hline & & RIO & Local & 0,10 & - & - \\
\hline & & SIL & Local & - & 6,43 & 0,09 \\
\hline & \multirow{4}{*}{ de Monte } & BAS & Local & - & - & - \\
\hline & & OBS & No local & - & 52,00 & 0,5 \\
\hline & & RIO & Local & - & - & - \\
\hline & & SIL & Local & - & 54,50 & - \\
\hline \multirow{8}{*}{ HTI } & \multirow{4}{*}{ Altoandino } & BAS & Local & - & 25,25 & 0,09 \\
\hline & & OBS & No local & - & 29,00 & 0,09 \\
\hline & & RIO & Local & - & - & - \\
\hline & & SIL & Local & 0,005 & 41,38 & 0,14 \\
\hline & \multirow{4}{*}{$\begin{array}{l}\text { Patagónico } \\
\text { (CSA-1) }\end{array}$} & BAS & Local & - & 62,00 & 0,04 \\
\hline & & OBS & No local & - & 65,62 & 0,33 \\
\hline & & RIO & Local & - & - & - \\
\hline & & SIL & Local & - & 78,20 & 0,21 \\
\hline \multirow{3}{*}{ HM } & \multirow{3}{*}{$\begin{array}{l}\text { Patagónico } \\
\text { (CSA-1) }\end{array}$} & BAS & Local & - & - & - \\
\hline & & OBS & No local & - & - & - \\
\hline & & SIL & Local & - & 18,00 & 1,00 \\
\hline
\end{tabular}

Tabla 10.2. Índices vinculados a intensidad y modos de uso de las materias primas por desierto y a través del tiempo. 
En la Figura 10.11 se muestran las frecuencias relativas de artefactos formatizados y ASF RC a través de la cuenca del río Atuel. Las tendencias generales de predominio de instrumentos unifaciales en el Desierto Altoandino y de bifaciales en el Patagónico, varían según el sitio. Por ejemplo, en CP-1 predominan los ASF RC, seguidos por los instrumentos bifaciales. En el Desierto Patagónico, la tendencia general de predominio de bifaciales se ve bien reflejada en CSA-1; en cambio, de los sitios de la localidad Arbolito, sólo en AR-6 se observa dicha tendencia. En AR-7 sólo hay instrumentos unifaciales, aunque debe considerarse que se trata sólo de dos instrumentos. La frecuencia de instrumentos bifaciales, unifaciales y compuestos en BDP-1 es la misma ( $\mathrm{n}=3$; i.e., un instrumento por clase) y predominan los ASF RC. De los cuatro instrumentos del Desierto de Monte, uno solo pertenece a EB-3 (unifacial) y los otros tres a EB-5 (dos bifaciales y uno unifacial), donde también hay un ASF RC.

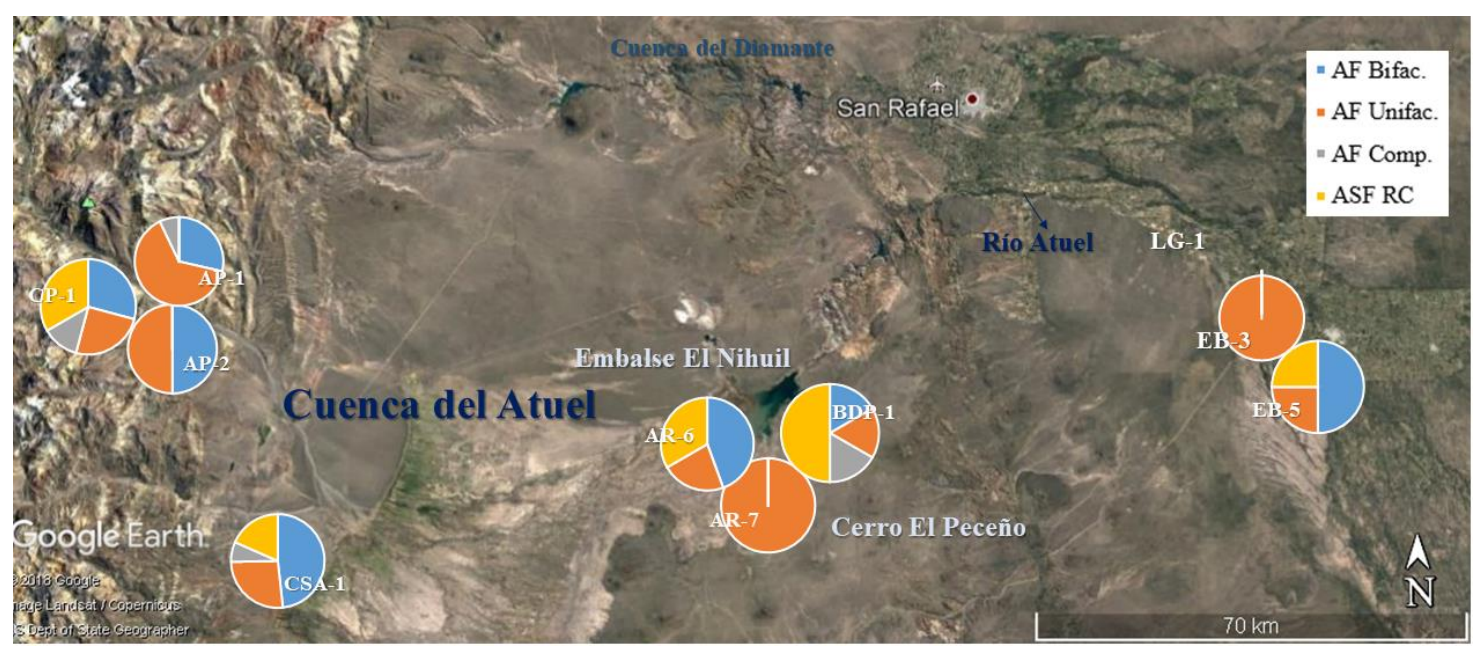

Figura 10.11. Distribución espacial de instrumentos y ASF RC por sitio a lo largo de la cuenca del río Atuel.

En el Desierto de Monte, sólo se pudo reconocer el grupo tipológico de una punta de proyectil fracturada. En los desiertos Altoandino y Patagónico se observa que, en general, hay diversidad de grupos tipológicos entre desiertos y dentro de cada uno (Figura 10.12). Mientras en el Altoandino hay artefactos burilantes (para incidir), bifaces (para múltiples usos, sensu Kelly 1988) y perforadores (para perforar), en el Patagónico se registró un buril, una punta entre muescas (también para incidir), una raclette y un RBO (ambos para raspar; función presente también en el Altoandino por los raspadores), aunque estas y otras tareas deben ser contrastadas con análisis funcionales. En general, las funciones de los instrumentos son semejantes en el Altoandino y el Patagónico, pero 
al cambiar la forma del filo, también puede ser distinto el material a trabajar (e.g. raspado o incisión sobre superficies duras o blandas, como madera, hueso, cuero, fibras vegetales).

El índice de Diversidad para grupos tipológicos en los tres desiertos es mayor en el Altoandino (Tabla 10.3). La Figura 10.13 muestra que el índice de diversidad de Shannon es mayor en el Desierto Altoandino, intermedio en el Patagónico y bajo en el de Monte, y que hay una variación más acotada en la representación de cada grupo tipológico en el Desierto Altoandino, con una dispersión intermedia en el Patagónico y una muy amplia en el Monte. El índice de Dominancia en el Patagónico es mayor que en el Altoandino debido a que las puntas de proyectil se encuentran más representadas que los otros grupos tipológicos (Tabla 10.3).

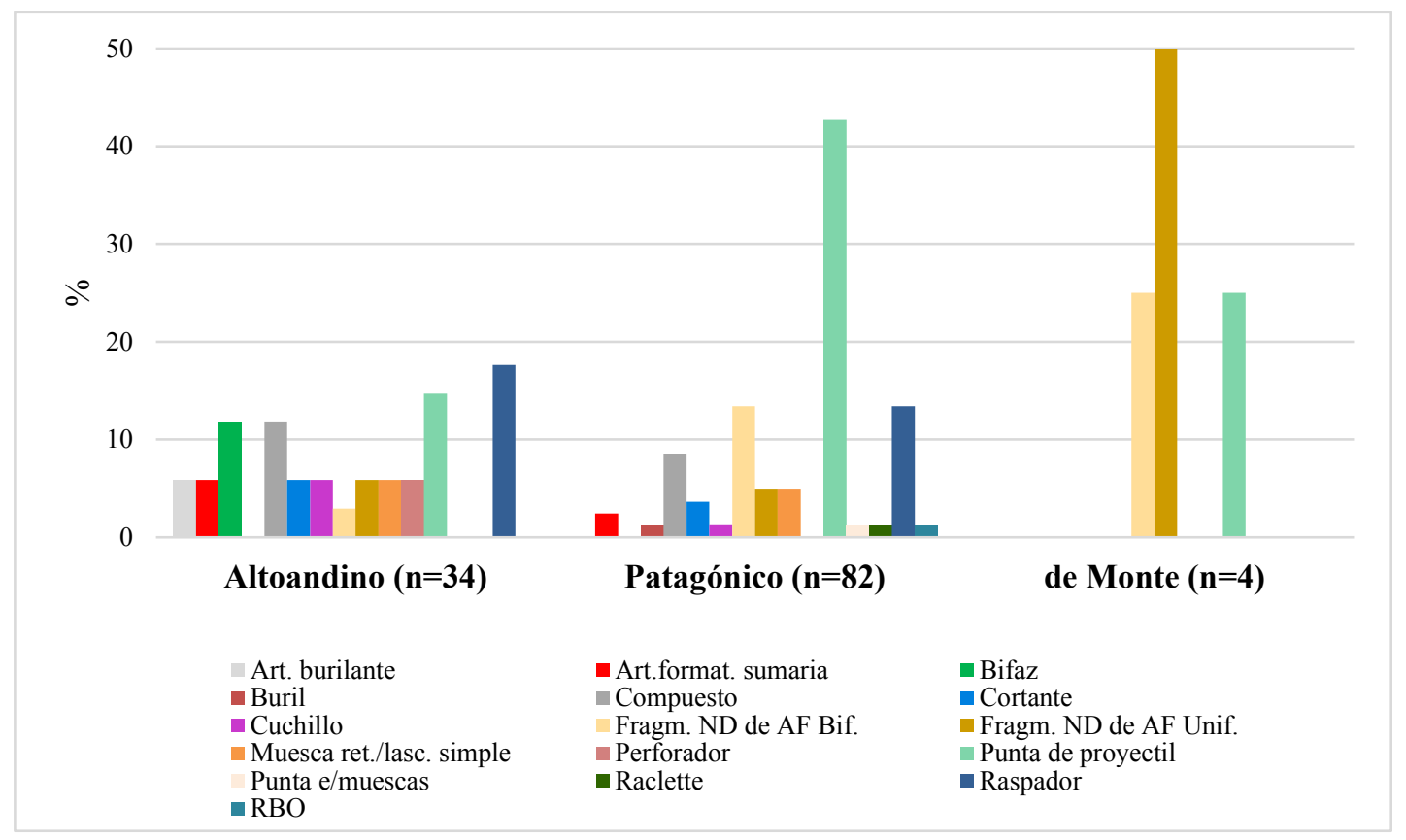

Figura 10.12. Grupos tipológicos de la cuenca del Atuel, por desierto (eje de ordenadas hasta 50\%).

\begin{tabular}{|l|c|c|c|}
\hline & Altoandino & Patagónico & de Monte \\
\hline $\boldsymbol{n}$ GT & 12 & 13 & 3 \\
\hline $\boldsymbol{n}$ & 34 & 82 & 4 \\
\hline Dominancia & 0,1055 & 0,2329 & 0,375 \\
\hline Simpson & 0,8945 & 0,7671 & 0,625 \\
\hline Shannon-H & 2,362 & 1,887 & 1,04 \\
\hline
\end{tabular}

Tabla 10.3. Diversidad de grupos tipológicos por desierto. 


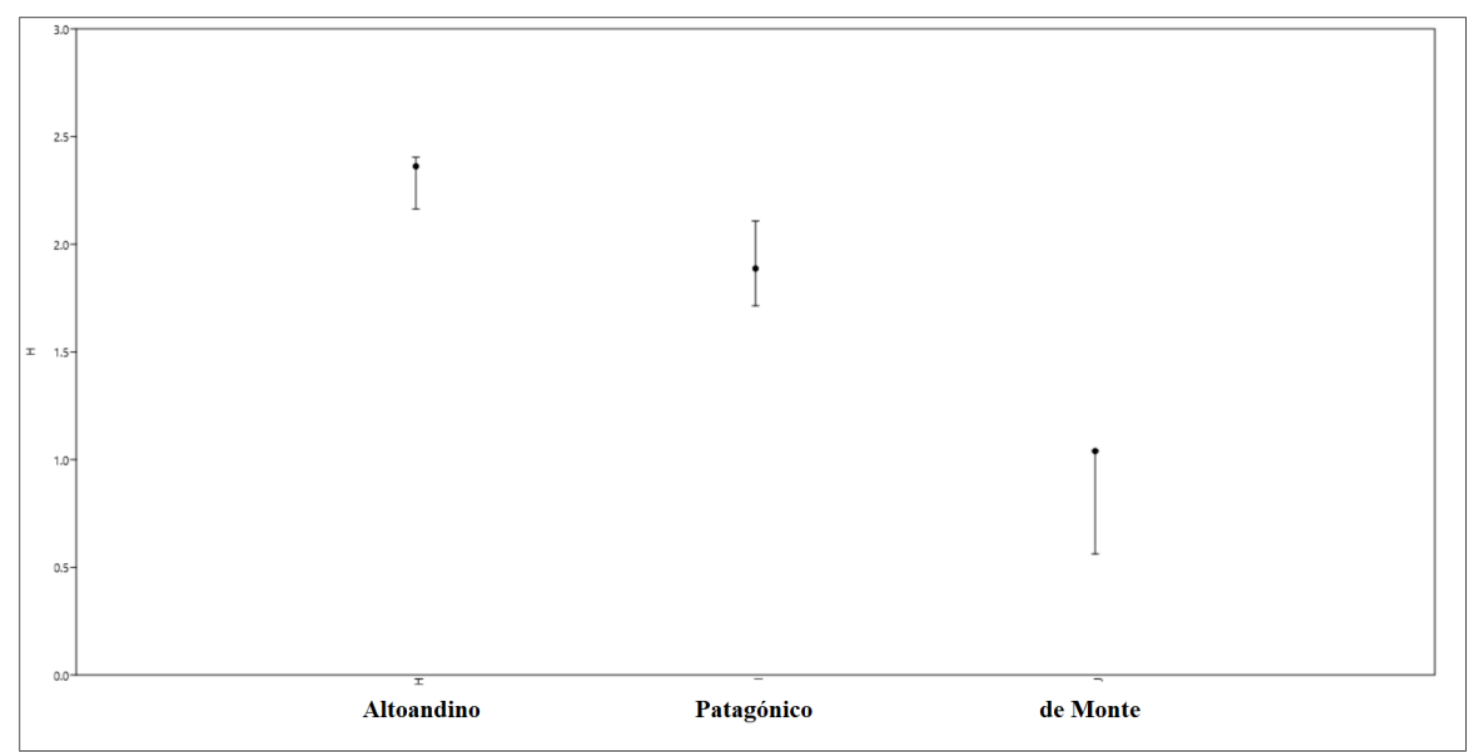

Figura 10.13. Índice de diversidad de Shannon de grupos tipológicos por desierto.

Las diferencias observadas en la representación de los grupos tipológicos por desierto sugieren una baja representación de tareas desarrolladas en el Monte, lo cual puede estar influenciado por el tamaño de muestra. Los sitios a cielo abierto incluidos en la muestra de este desierto mostraron una baja densidad de materiales y una amplia dispersión espacial.

\subsubsection{CONSIDERACIONES GENERALES DE LAS TENDENCIAS} TECNOLÓGICAS ESPACIALES EN EL ATUEL

En la cuenca del río Atuel, las materias primas más utilizadas fueron las rocas silíceas, seguidas por la obsidiana, el basalto y la riolita (Figuras 10.1, 10. 2 y 10.3). Los desechos de talla son mayoritarios, seguidos por los instrumentos bifaciales, los unifaciales, los ASF RC y, por último, los instrumentos compuestos. El índice de corteza es mayor en desechos de basalto del Desierto Altoandino y de riolita en el Patagónico. El mayor índice de bifacialidad se da, en general, en obsidiana. En el Desierto de Monte, la variedad de rocas es mayor y la cantidad de instrumentos es baja, aunque allí el tamaño de muestra también es menor. Hacia la cordillera (Desierto Altoandino) aumenta la frecuencia de obsidiana y se presenta mayor diversidad de grupos tipológicos. En el Patagónico predominan las rocas de muy buena y excelente calidad para la talla, y hay menor variedad de rocas representadas. Los modos de aprovisionamiento y uso de los recursos líticos, habrían sido distintos en cada desierto. 
Las rocas silíceas son, en general, la materia prima más utilizada a lo largo de la cuenca del río Atuel. Las trayectorias artefactuales se inician en las fuentes inmediatamente disponibles y locales cercanas (sensu Civalero y Franco 2003). Las etapas de obtención y selección de esta materia prima están representadas por un núcleo en el Desierto Patagónico y por las lascas externas en este desierto y en el Altoandino. La baja reserva de corteza en artefactos de los tres desiertos sugiere que esta roca fue mayormente descortezada en los sitios de aprovisionamiento y luego ingresó a los sitios residenciales como formas-base de tamaños pequeños y sin corteza o muy poca. La alta frecuencia de lascas internas (sobre todo angulares) sugiere que esta roca fue manufacturada en los sitios residenciales, destinando su uso para una gran variedad de clases de instrumentos y grupos tipológicos, sobre todo, de formatización unifacial. Los filos y puntas naturales también fueron aprovechados (ASF RC). Las evidencias de las últimas etapas de manufactura también están representadas por lascas de formatización de filo en los desiertos Altoandino y Patagónico (lascas de adelgazamiento bifacial, planas y de reactivación, en ambos desiertos), estando ausentes en el de Monte. Esto sugiere que los instrumentos que ingresaron a los sitios no fueron mantenidos ni reparados, ya que fueron descartados allí fracturados, cuando ya no poseían vida útil (tampoco fueron reciclados). En el Altoandino y en el Patagónico, las rocas silíceas están mejor representadas en instrumentos unifaciales que bifaciales. Todas estas evidencias permiten proponer que las rocas silíceas representan sistemas de producción lítica terminal (sensu Ericson 1984). Es decir, que el proceso de producción se encuentra completo dentro de una misma área, la cual no supera los $c a .10 \mathrm{~km}$ de radio.

Algo semejante ocurre con el basalto, de disponibilidad inmediata y local cercana (Civalero y Franco 2003) y de gran ubicuidad; pero no fue tan intensamente utilizado como las silíceas. Se presume que esto se debe a su menor calidad para la talla. En los sitios del Desierto Altoandino y en CSA-1 son más frecuentes los artefactos de basalto de muy buena calidad. Esto puede deberse a la presencia de fuentes locales como la detectada en el Área de la Laguna de la Niña Encantada (véase Capítulo 6), que provee bloques y nódulos de basalto de muy buena calidad. En los sitios de la localidad Arbolito y del Desierto de Monte, su calidad es generalmente buena y, en algunos casos regular, por lo cual, es más difícil contrastar el uso de la fuente Formación Colonia Los Coroneles de muy buena calidad para la talla, localizada en la cuenca media del río Diamante. No se han registrado núcleos en esta materia prima en ninguno de los tres sitios. La etapa inicial está representada por lascas externas en los desiertos Altoandino y Patagónico. De hecho, 
en este último se presentan en la misma frecuencia que las lascas internas (no hay lascas de formatización de núcleo), las más abundantes en ambos desiertos. En el Altoandino también hay evidencias de reactivación de núcleos (se registró una tableta de núcleo de calidad buena) y de lascas de formatización de filo. En consonancia con estos datos, los instrumentos sobre basalto son más frecuentes y más diversos (bifaciales, unifaciales y compuestos) en el Desierto Altoandino que en el Patagónico, donde sólo se registraron instrumentos bifaciales. En el Desierto de Monte no se registraron lascas enteras ni instrumentos de basalto, y en ninguno de los tres hay ASF RC sobre esta roca. El sistema de producción lítica del basalto sería terminal en los Desiertos Altoandino y Patagónico, y de tipo irregular en el de Monte. Este último tipo de sistema implica que no hay un patrón claro.

Las trayectorias artefactuales de la riolita en los tres desiertos se diferencian sensiblemente. En CSA-1 su baja representación se asemeja más a la de los sitios del Desierto Altoandino que a la de los otros sitios del Patagónico, donde es más frecuente. En el Desierto de Monte es la tercera roca en LG-1 y EB-5, y comparte este lugar con el basalto en EB-3 Esta materia prima se encuentra dentro del rango de disponibilidad inmediata y local cercana a todos los sitios. Sin embargo, no se registraron núcleos, ASF $\mathrm{RC}$, ni instrumentos; y las lascas externas y de formatización de filo se registraron únicamente en el Desierto Patagónico. Su representación se da con mayor frecuencia como lascas internas. Esta escasa representación de las distintas etapas de manufactura, pese a ser una roca de disponibilidad local a los sitios, no permite tener un esquema claro de su trayectoria artefactual en cada desierto y tampoco es suficiente para inferir un sistema de producción terminal, pese a su proximidad a los sitios residenciales; quizás las primeras etapas de manufactura se encuentran junto al río, que funciona como fuente secundaria. Estas tendencias se corresponden con un sistema de producción de tipo irregular.

Las fuentes de obsidiana detectadas por análisis geoquímicos, permiten rastrear las trayectorias artefactuales en los tres desiertos. Sólo se halló un núcleo de esta roca en la localidad Arbolito, de procedencia local (todas las muestras revelaron que provienen de la fuente El Peceño, distante $20 \mathrm{~km}$ ), que no está agotado, no es estandarizado y es de tamaño mediano-grande. Las lascas externas están poco representadas en los desiertos Altoandino y Patagónico y ausentes en el de Monte. La baja o ausente reserva de corteza sugiere que el descortezamiento se llevó a cabo, en los sitios de aprovisionamiento, y que ingresó a los sitios estudiados como formas-base de tamaños pequeños mayormente 
desprovistos de corteza. Allí se habrían manufacturado instrumentos, principalmente de formatización bifacial, congruente con la alta frecuencia de lascas internas y también las de formatización de filo en los tres desiertos. Igualmente, también se identificó el aprovechamiento de filos con rastros complementarios (ASF RC) e instrumentos unifaciales de confección simple. La ausencia o escasez de la etapa inicial de manufactura, sumado a los costos de transporte desde las fuentes de aprovisionamiento, permiten estimar un uso conservado e intensivo de esta materia prima, cuya preferencia respondería a su excelente y muy buena calidad para la talla. Si bien el costo de aprovisionamiento sería menor en el Desierto Altoandino, el predominio de instrumentos unifaciales sobre bifaciales de obsidiana en este ambiente -al cual se ingresa sólo de manera estacional (estrés temporal)-, permite suponer una optimización en el uso de este recurso. La variedad de diseños (confiables, mantenibles -versátiles y flexibles-, etc.) en este desierto, evidenciada en el uso de instrumentos compuestos (sobre todo, en obsidiana), bifaces y raspadores reactivados, entre otros, apoyan esta idea. Dado que en general la obsidiana es de procedencia no local su aprovisionamiento pudo ser directo, a través de la ampliación de los rangos de obtención, o indirecto, a través de la interacción (e.g. intercambio, visitas) con otros grupos. Ambos escenarios y las evidencias señaladas en cuanto a las trayectorias artefactuales de esta roca en los tres desiertos, permiten proponer un sistema de producción secuencial con etapas de abastecimiento, manufactura y descarte en espacios diferentes (Ericson 1984).

En síntesis, los modos de aprovisionamiento, explotación y circulación de las materias primas presentan diferencias entre las trayectorias de cada materia prima y entre los tres desiertos. Entre las rocas locales de mayor frecuencia (rocas silíceas y basalto), se observaron trayectorias completas o terminales. En las rocas no locales (obsidiana), las trayectorias responden a un sistema de producción secuencial, donde están representadas, principalmente, las últimas etapas de manufactura. 


\subsection{TENDENCIAS TECNOLÓGICAS EN PERSPECTIVA}

\section{TEMPORAL}

\subsubsection{APROVISIONAMIENTO Y USO DE RECURSOS LÍTICOS A TRAVÉS}

\section{DEL TIEMPO}

Para abordar las tendencias en el uso de los recursos líticos a lo largo del tiempo, se agruparon los conjuntos en tres lapsos temporales: Holoceno medio (HM) (ca. 8.0004.000 años AP), Holoceno tardío inicial (HTI) (ca. 4.000-2.000 años AP) y Holoceno tardío final (HTF) (ca. 2.000-200 años AP) (para mayor detalle, véase la Tabla 10.4).

\begin{tabular}{|c|c|c|c|c|}
\hline Tiempo & Cronología & Desierto & Sitio & $\begin{array}{c}\text { Segmento } \\
\text { temporal }\end{array}$ \\
\hline \multirow{10}{*}{ HTF } & \multirow{10}{*}{$2.000-200 \mathrm{AP}$} & \multirow{3}{*}{ Altoandino } & CP-1 & Unid. A \\
\hline & & & AP-1 & Unid. A \\
\hline & & & $\mathrm{AP}-2$ & - \\
\hline & & \multirow{4}{*}{ Patagónico } & CSA-1 & Conj. A \\
\hline & & & AR-6 & - \\
\hline & & & AR-7 & - \\
\hline & & & BDP-1 & - \\
\hline & & \multirow{3}{*}{ de Monte } & LG-1 & - \\
\hline & & & EB-3 & - \\
\hline & & & EB-5 & - \\
\hline \multirow{3}{*}{ HTI } & \multirow{3}{*}{ 4.000-2.000 AP } & \multirow{2}{*}{ Altoandino } & $\mathrm{CP}-1$ & Unid. B y C \\
\hline & & & AP-1 & Unid. B \\
\hline & & Patagónico & CSA-1 & Conj. B \\
\hline HM & 8.000-4.000 AP & Patagónico & CSA-1 & Conj. C \\
\hline
\end{tabular}

Tabla 10.4. Disposición de los conjuntos artefactuales según la estructura cronológica y ambiental.

Las únicas materias primas registradas para el HM son las silíceas $(61,3 \%)$, la obsidiana $(32,3 \%)$ y el basalto (6,5\%). En el HTI se incorporan la riolita y las vulcanitas indeterminadas en los desiertos Altoandino y Patagónico, respectivamente. Por último, en el HTF se registra cuarzo únicamente en el Desierto de Monte. En general, se observa que las frecuencias relativas de las rocas silíceas disminuyen paulatinamente del HM (61\%) al HTF (42\%), mientras que la obsidiana aumenta de manera gradual del HM (32\%) al HTF (47\%), hasta superar la representación de las silíceas. El basalto se 
mantiene estable con valores que no superan el 7\%. La riolita, ausente en el HM, alcanza valores de hasta $4 \%$ durante el HTF.

Las tendencias mencionadas se repiten de manera semejante por desierto (Tabla 10.5). Un cambio importante es el aumento en la diversidad de rocas, sobre todo en el HTF (Tabla 10.6 y Figura 10.14). Este aumento en la diversidad hacia los últimos 2.000 años se vincula con la incorporación de los sitios del Desierto de Monte que, como se observó en el análisis de las tendencias espaciales, es el más diverso en cuanto a materias primas.

\begin{tabular}{|c|c|c|c|c|c|c|c|c|c|c|}
\hline Tiempo & Desierto & AND & BAS & $\mathbf{C Z}$ & OBS & RIO & SIL & VUL & Indet & Total \\
\hline \multirow{3}{*}{ HTF } & Altoandino & - & $\begin{array}{c}16,07 \% \\
(104)\end{array}$ & - & $\begin{array}{c}46,21 \% \\
(299)\end{array}$ & $\begin{array}{c}2,78 \% \\
(18)\end{array}$ & $\begin{array}{c}34,47 \% \\
(223)\end{array}$ & - & $\begin{array}{c}0,46 \% \\
\text { (3) }\end{array}$ & 647 \\
\hline & Patagónico & - & $\begin{array}{c}1,96 \% \\
(30)\end{array}$ & - & $\begin{array}{c}49,71 \% \\
(761)\end{array}$ & $\begin{array}{c}1,89 \% \\
(29)\end{array}$ & $\begin{array}{c}46,31 \% \\
(709)\end{array}$ & $\begin{array}{c}0,13 \% \\
(2)\end{array}$ & 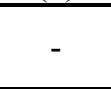 & 1531 \\
\hline & de Monte & $\begin{array}{c}1,01 \% \\
\text { (3) }\end{array}$ & $\begin{array}{c}6,42 \% \\
(19) \\
\end{array}$ & $\begin{array}{c}1,35 \% \\
(4)\end{array}$ & $\begin{array}{c}35,81 \% \\
(106)\end{array}$ & $\begin{array}{c}16,55 \% \\
(49)\end{array}$ & $\begin{array}{c}37,84 \% \\
(112)\end{array}$ & $\begin{array}{c}0,34 \% \\
(1) \\
\end{array}$ & $\begin{array}{c}0,68 \% \\
(2)\end{array}$ & 296 \\
\hline \multirow{2}{*}{ HTI } & Altoandino & - & $\begin{array}{c}13,57 \% \\
(105)\end{array}$ & - & $\begin{array}{c}39,28 \% \\
(304)\end{array}$ & $\begin{array}{c}, 81 \% \\
(14)\end{array}$ & $\begin{array}{c}44,32 \% \\
(343)\end{array}$ & $\begin{array}{c}0,39 \% \\
\text { (3) }\end{array}$ & $\begin{array}{c}0,65 \% \\
(5)\end{array}$ & 774 \\
\hline & Patagónico & $\begin{array}{c}0,06 \% \\
\text { (1) }\end{array}$ & $\begin{array}{c}3,50 \% \\
(63)\end{array}$ & - & $\begin{array}{c}29,70 \% \\
(534)\end{array}$ & $\begin{array}{c}0,39 \% \\
(7) \\
\end{array}$ & $\begin{array}{c}66,24 \% \\
(1191) \\
\end{array}$ & $\begin{array}{c}0,11 \% \\
(2)\end{array}$ & - & 1798 \\
\hline HМ & Patagónico & - & $\begin{array}{c}6,45 \% \\
(2)\end{array}$ & - & $\begin{array}{c}32,26 \% \\
(10)\end{array}$ & & $\begin{array}{c}61,29 \% \\
(19) \\
\end{array}$ & & - & 31 \\
\hline \multicolumn{2}{|c|}{ Total } & $\begin{array}{c}0,08 \% \\
\text { (4) }\end{array}$ & $\begin{array}{c}6,36 \% \\
(323)\end{array}$ & $\begin{array}{c}\mathbf{0 , 0 8 \%} \\
\text { (4) }\end{array}$ & $\begin{array}{r}39,67 \% \\
(2014)\end{array}$ & $\begin{array}{c}2,30 \% \\
(117)\end{array}$ & $\begin{array}{c}51,15 \% \\
(2597)\end{array}$ & $\begin{array}{c}0,16 \% \\
(8)\end{array}$ & $\begin{array}{c}\mathbf{0 , 2 0 \%} \\
(10)\end{array}$ & $\mathbf{5 0 7 7}$ \\
\hline
\end{tabular}

Tabla 10.5. Frecuencia de materias primas por desierto a través del tiempo.

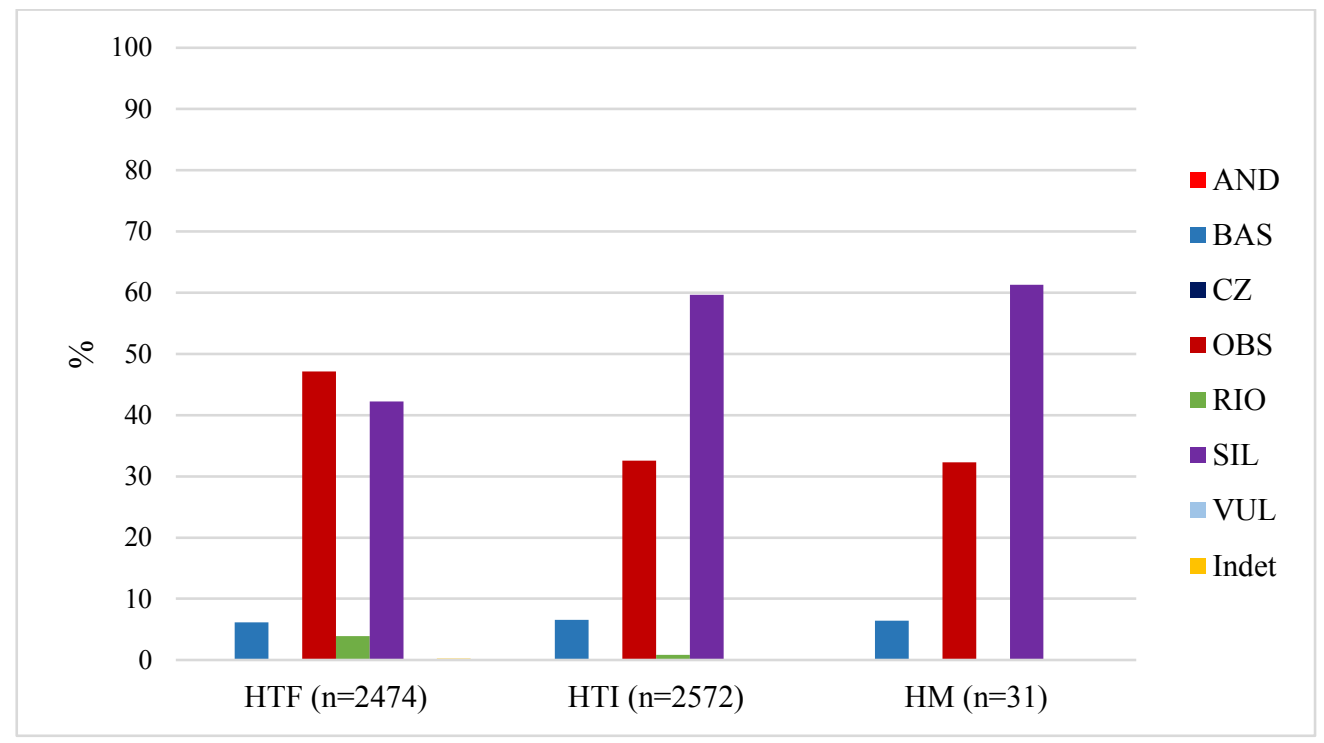

Figura 10.14. Frecuencia de materias primas a través del tiempo. 


\begin{tabular}{|l|c|c|c|}
\hline & HTF & HTI & HM \\
\hline $\boldsymbol{n}$ MP & 8 & 7 & 3 \\
\hline $\boldsymbol{n}$ & 2474 & 2572 & 31 \\
\hline Dominancia & 0,4055 & 0,4662 & 0,4839 \\
\hline Simpson & 0,5945 & 0,5338 & 0,5161 \\
\hline Shannon-H & 1,056 & 0,9184 & 0,8418 \\
\hline
\end{tabular}

Tabla 10.6. Diversidad de materias primas por tiempo.

Las materias primas de excelente y muy buena calidad para la talla (obsidiana y rocas silíceas) son las predominantes en los tres momentos (HM, HTI y HTF). El uso de rocas de menor calidad (basalto, riolita, andesita, cuarzo, vulcanita indeterminada y rocas indeterminadas), en general, aumenta a través del tiempo (Figura 10.15), especialmente en el Monte donde estas rocas de menor calidad tienen porcentajes de representación más altos, con valores que superan el $25 \%$ de la muestra (Figura 10.16).

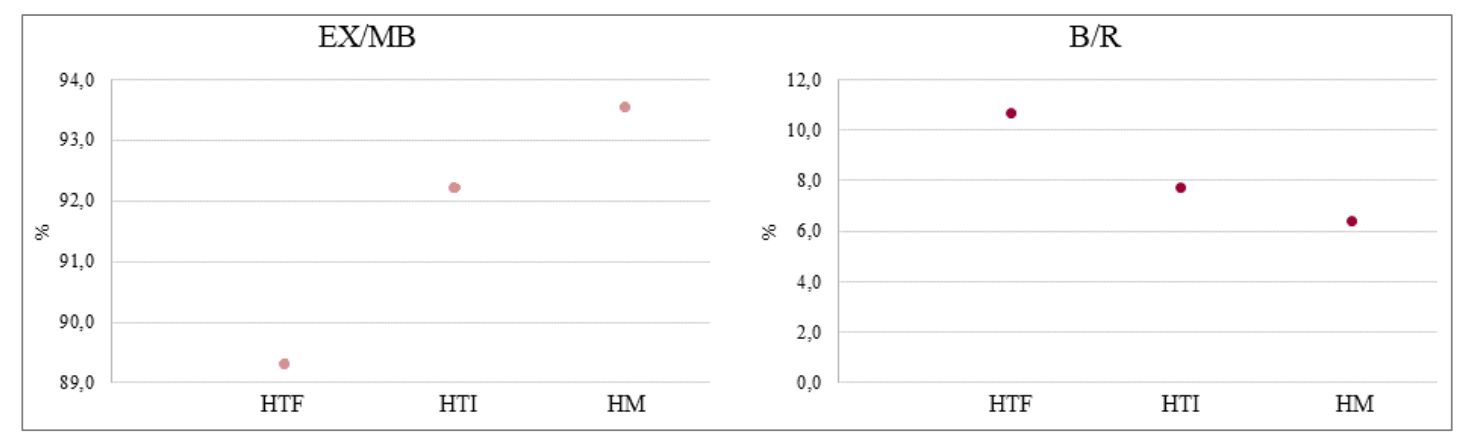

Figura 10.15. Detalle de calidad de materias primas según períodos temporales.

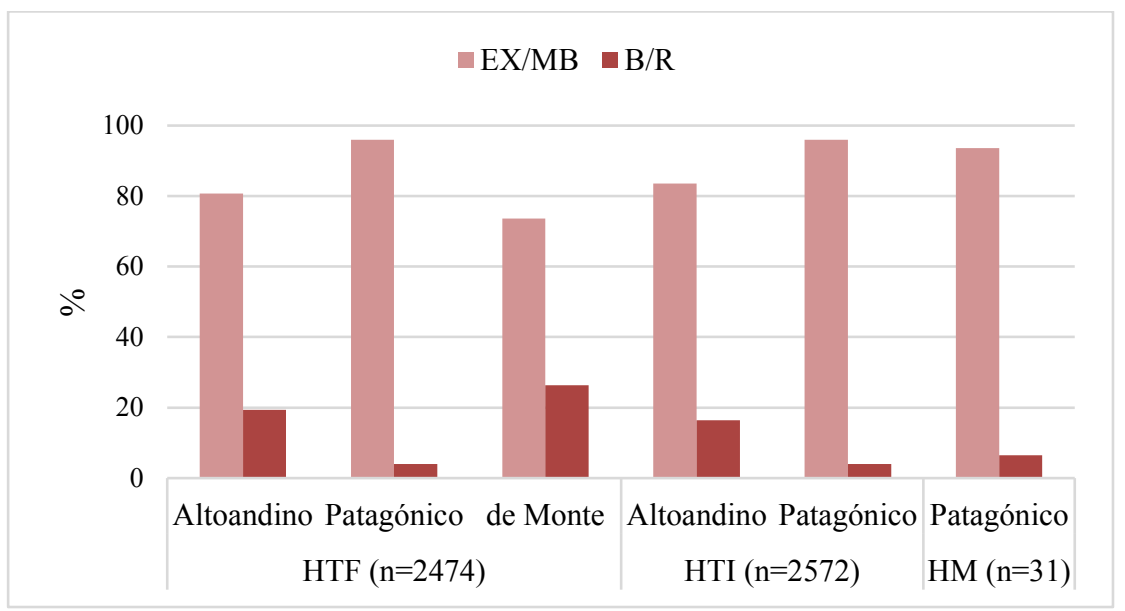

Figura 10.16. Materias primas de calidad excelente-muy buena $v s$. buena-regular, por tiempo y por desierto. 
En general, las tendencias en el uso de materias primas muestran una cierta estabilidad a lo largo del tiempo (Figura 10.14), con el predomino de las rocas de muy buena y excelente calidad para la talla (rocas silíceas y obsidiana). Las diferencias más importantes se dan hacia el HTF donde la diversidad de materias primas es mayor, aumentando el porcentaje de rocas de baja calidad para la talla, que alcanzan alrededor del 10\%. Ambas tendencias están traccionadas por la inclusión de los sitios pertenecientes al Desierto del Monte. La merma en los porcentajes de rocas de alta calidad para la talla puede estar vinculada a la disminución en la proporción de las rocas silíceas hacia el HTF. La representación de la obsidiana, por el contrario, aumenta a lo largo del tiempo, de $32 \%$ en el HM a 47\% en el HTF (Figura 10.14 y Tabla 10.6). Esta incongruencia, en la que las rocas de menor calidad aumentan a lo largo del tiempo del mismo modo que la obsidiana, podría estar indicando una selección de las rocas de excelente calidad para la manufactura de instrumentos y el uso expeditivo de las rocas disponibles en el espacio local. Los resultados obtenidos de los análisis geoquímicos sobre artefactos de obsidiana (véase Anexo 2), muestran un incremento en la variedad de fuentes utilizadas hacia el HTF (Figuras 10.17 y 10.18).

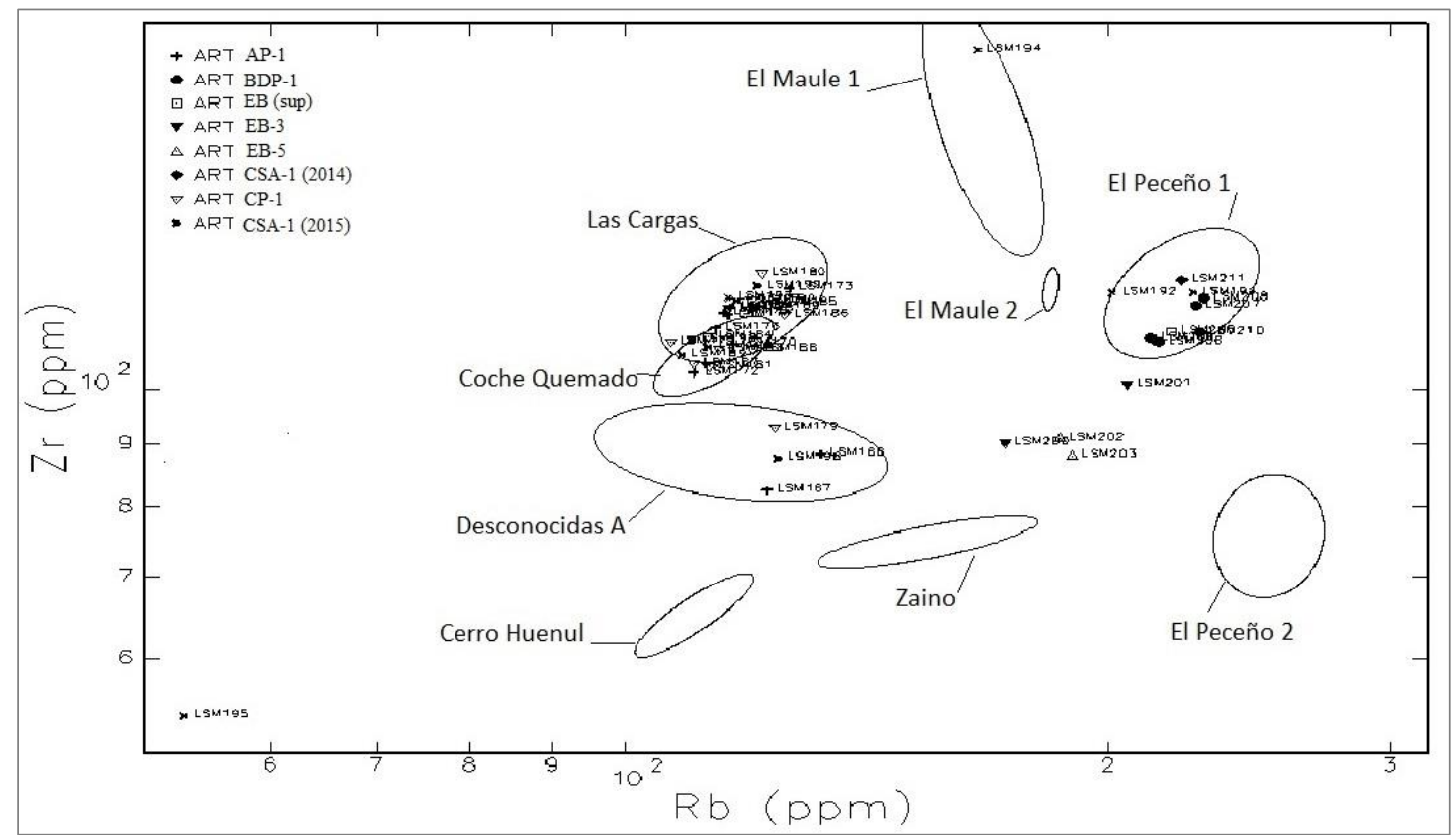

Figure 10.17. Gráfico bivalente de las concentraciones de $\mathrm{Zr}$ y Rb (ppm). La elipse representa el $90 \%$ de nivel de confianza.

Las fuentes identificadas para el período del HM son Las Cargas y Coche Quemado. Luego, en el HTI se observó que la única fuente de obsidiana registrada en el 
Desierto Altoandino fue Las Cargas, y en el Patagónico, además de esta fuente, se detectaron Coche Quemado y dos fuentes desconocidas, una de ellas identificada como Grupo A, la cual no se registra hacia el HTF en este desierto, pero sí en el Altoandino. También en el HTF se registra Las Cargas en ambos desiertos, y en el Patagónico se incorporan Laguna del Maule-2 y El Peceño, además de la fuente desconocida sin identificar. Todas las muestras analizadas del sitio BDP-1 y de los sitios del Desierto de Monte provienen de El Peceño, localizada a $20 \mathrm{~km}$ del primer sitio y a unos $90-100 \mathrm{~km}$ de los del Monte. La fuente Coche Quemado (también extra-cordillerana) está a $150 \mathrm{~km}$, aproximadamente, de los sitios de la localidad Arbolito y a unos $220 \mathrm{~km}$ del Desierto de Monte. Las fuentes cordilleranas se localizan a más de $225 \mathrm{~km}$ de estos sitios (Figura 10.18).

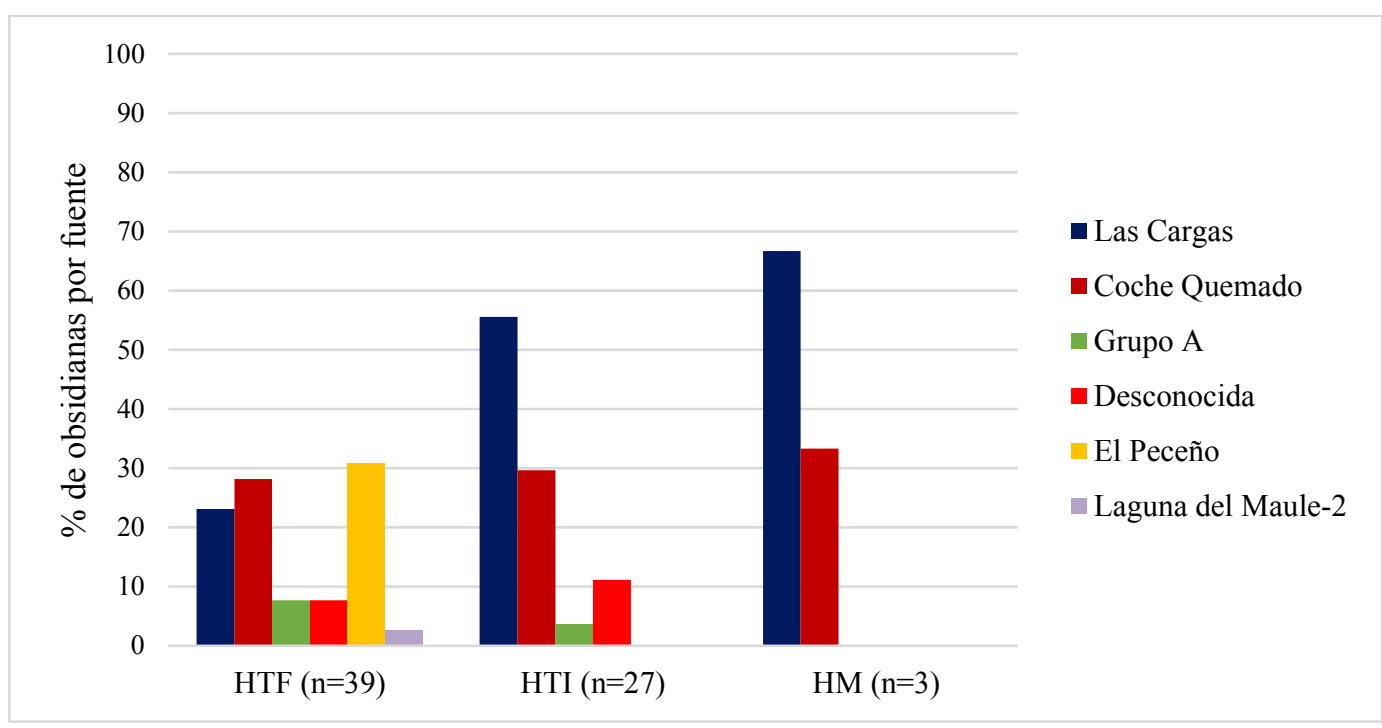

Figura 10.18. Distribución temporal de las fuentes de obsidiana identificadas en los tres desiertos.

En el Desierto Patagónico se observa una mayor estabilidad en el modo de empleo de las materias primas desde el HM hasta el HTF. La falta de muestras previas a los 2.000 años en los sitios del Desierto de Monte no permiten plantear un panorama tiempo transgresivo de los sitios localizados en este ambiente. Esta mayor estabilidad en el uso de materias primas en Patagonia puede estar indicando menos cambios en su movilidad y probablemente en la subsistencia, algo que ya ha sido sugerido en trabajos previos (Neme y Gil 2012; Gil et al. 2017). 


\subsubsection{CLASES ARTEFACTUALES A TRAVÉS DEL TIEMPO}

Los desechos de talla constituyen la clase artefactual predominante en los tres momentos, pero se observan diferencias en cuanto a la representación de las demás clases a través del tiempo. Durante el HM, la otra clase presente es la de los instrumentos bifaciales (una punta de proyectil de roca silícea). En el HTI se registran también instrumentos unifaciales y compuestos, y ASF RC, aunque los bifaciales son el tipo más frecuente. En el HTF se incorporan los núcleos a las clases anteriores, por lo que este es el periodo con mayor variedad de clases. Los bifaciales siguen siendo los instrumentos mayoritarios, las frecuencias de los unifaciales y ASF RC, aumentan, y las de los compuestos se mantienen del HTI al HTF (Figura 10.19).

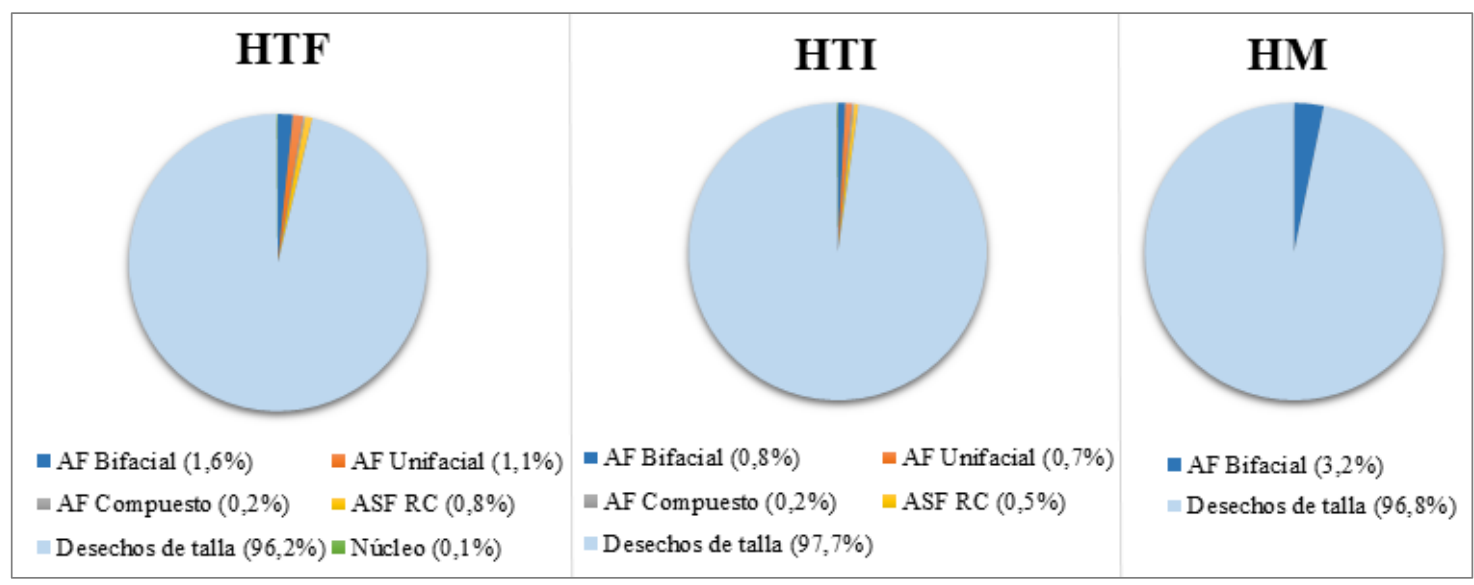

Figura 10.19. Frecuencias relativas de las principales clases artefactuales por tiempo.

En el HM los desechos de talla enteros más frecuentes son las lascas de formatización de filo (60\%) sobre rocas silíceas, seguidas por las internas $(40 \%)$ de obsidiana y silíceas; las externas están ausentes. En el HTI predominan las lacas internas (89\%) en las cuatro clases de roca principales (silíceas, obsidiana, basalto y riolita). Le siguen las de formatización de filo ( $9 \%$ ), ausentes en riolita; y aparecen las externas ( $2 \%)$, mayoritariamente en rocas silíceas (sobre todo en el Desierto Patagónico), aunque también presentes en basalto y obsidiana (sólo en el Altoandino). En el HTF disminuyen las lascas internas (83\%) en las cuatro materias primas, aumentan paulatinamente las de formatización de filo (10\%); y de manera más marcada las externas (7\%), predominantemente en basalto (Figura 10.20). En el Desierto de Monte (correspondiente al HTF) no se registraron lascas externas. En el Patagónico, las internas aumentan del HM (40\%) al HTI (92\%) y disminuyen hacia el HTF (85\%); las externas también se 
incrementan del HTI (2\%) al HTF (6\%) y las de formatización de filo disminuyen del HM (60\%) al HTI (6\%), y aumentan hacia el HTF (8\%). En el Desierto Altoandino se da un marcado aumento de las externas del HTI (2\%) al HTF (6\%); las de formatización de filo son más frecuentes que las externas y también aumentan a través del tiempo, pero de manera atenuada del HTI (12\%) al HTF (13\%). Las internas, aunque son mayoritarias en los tres momentos, disminuyen. En la Figura 10.21 se observa dicha disminución y el aumento de las de formatización de filo y de las externas, del HTI al HTF (no está representado el HM debido a su pequeño tamaño de muestra). En la Tabla 10.2 se presenta el índice de corteza calculado sobre desechos enteros. En varias rocas no se pudo calcular, aunque es más común entre rocas silíceas (ambos periodos de tiempo del Desierto Altoandino y HTF del Patagónico), pero con un índice bajo. El valor más alto se da en la riolita de la localidad Arbolito (Desierto Patagónico), donde esta roca está disponible en el espacio local, es accesible y abundante.

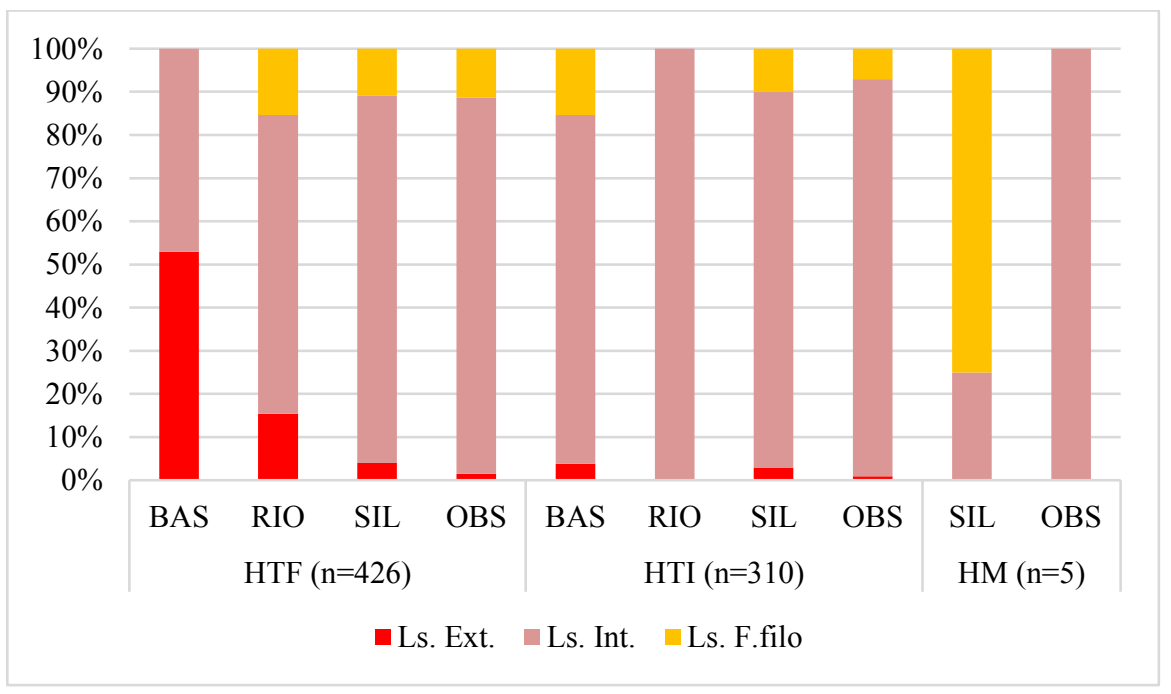

Figura 10.20. Frecuencia de etapas de manufactura por materia prima y por tiempo. 


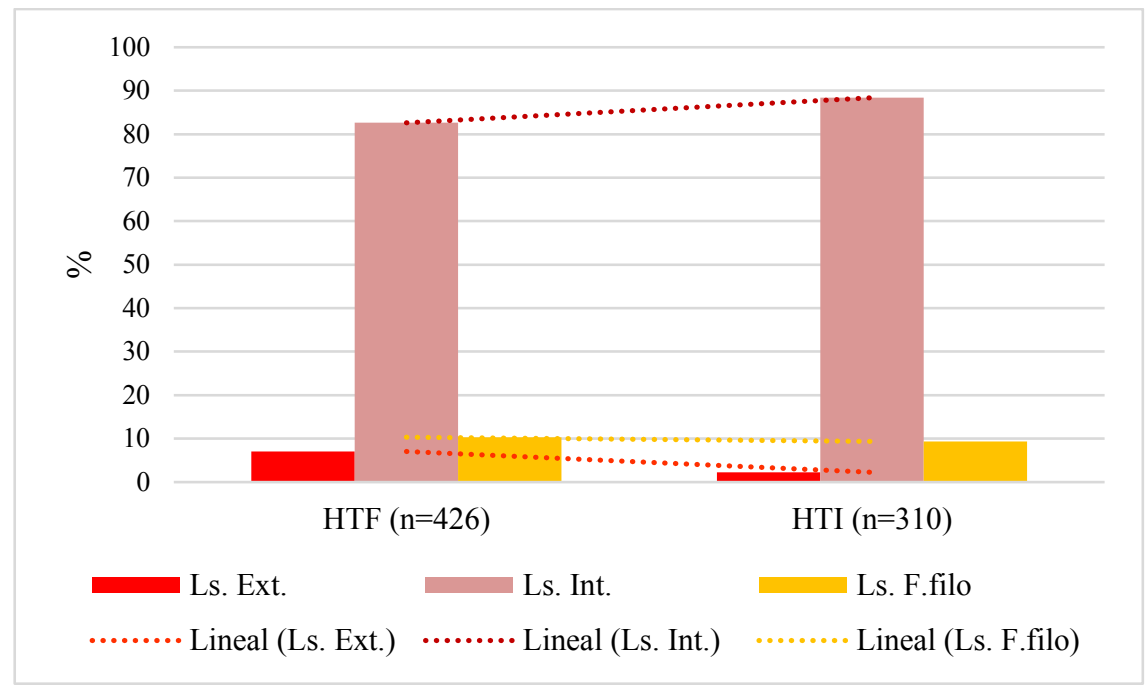

Figura 10.21. Frecuencia de etapas de manufactura en el HTI y HTF.

Los tamaños de los desechos de talla enteros no varían de manera significativa a través del tiempo y se observa un predominio de lascas de tamaño muy pequeño, seguidas por las de tamaño pequeño en los tres momentos (Figura 10.22). En el HM sólo se registraron estas dos categorías de tamaño. En el HTI se incorpora la categoría mediano pequeño y en el HTF también se registraron lascas de tamaño mediano grande, aunque ambas categorías aparecen en baja proporción. La ausencia de tamaños MEP y MEG en el HM, se debería a un efecto del tamaño de muestra $(n=5)$. Como se vio en los Capítulos 7, 8 y 9, los tamaños de los desechos enteros pueden variar según la materia prima, pero igualmente predominan los tamaños MPE y P.

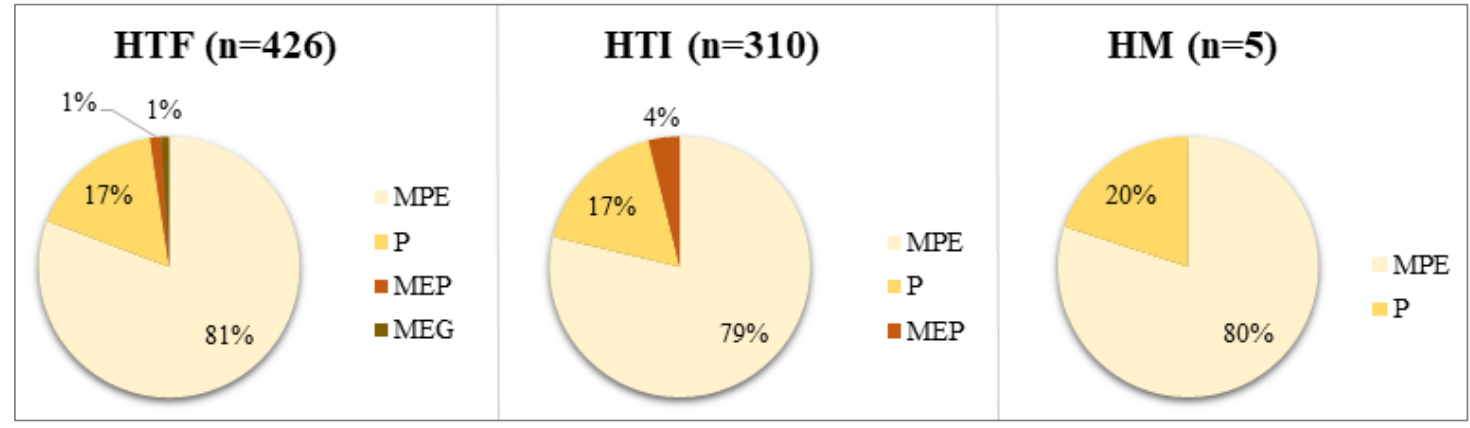

Figura 10.22. Frecuencias relativas de los tamaños de desechos de talla enteros a través del tiempo. Referencias: MPE: Muy pequeño (0-20 mm) (módulo 1); P: Pequeño (21-40) (módulo 2); MEP: Mediano pequeño (41-60) (módulo 3); MEG: Mediano Grande (61-80) (módulo 4).

En la cuenca del río Atuel, entre los desechos de talla enteros y fracturados con talón, el tipo de talón más frecuente es el diedro (26\%), seguido por los de tipo liso (23\%), 
facetado (19\%), filiforme (17\%), puntiforme (8\%), estallado $(5 \%) \mathrm{y}$, por último, el de tipo natural (cortical) (2\%). Estas frecuencias varían a lo largo del tiempo y según las materias primas (locales vs. no locales). En la Figura 10.23 se observa que la proporción de talones en el HTI y el HTF es bastante similar dentro de las rocas locales y no locales. Incluso, si se aparta al conjunto del HM (representado por 11 desechos), los tipos de talones representados también se asemejan entre las rocas locales y no locales del mismo periodo. Los facetados mantienen las mismas frecuencias, aunque aumentan del HTI al HTF entre los desechos de rocas locales. Los estallados son más frecuentes entre no locales; esto puede deberse a la materia prima (en este caso, obsidiana) y/o a la etapa de manufactura (e.g. percusión dura). Los talones de rocas locales y no locales se distinguen, principalmente, en la mayor representación de talones naturales y lisos en las primeras, y de diedros, filiformes y puntiformes en las no locales. Estas diferencias podrían deberse a distintas etapas y actividades (véase Capítulo 5). Por ejemplo, la manufactura en una etapa inicial a través de la percusión dura, podría generar talones corticales y lisos (aunque no siempre es el caso), como lo observado en rocas locales; la manufactura en una etapa más avanzada, podría quedar evidenciada por talones diedros (con aristas de extracciones previas) y filiformes (vinculados con técnicas de adelgazamiento bifacial de formasbase); y el mantenimiento, representado por talones puntiformes (asociados a técnicas de confección de artefactos formatizados por presión) (Magne 1989; Tomka 1989; Nami 1991; Espinosa 1995), predominantes entre las no locales (obsidiana). Además, la materia prima local pudo ser explotada de manera menos intensiva que la no local. Sobre esta base podría plantearse que el aumento de los talones de instancias iniciales de manufactura (corticales y lisos) e intermedias (diedros), y la disminución de los talones representativos de etapas avanzadas y de mantenimiento (filiformes, puntiformes), tanto en rocas locales como no locales a través del tiempo, responde a cambios en la estrategia tecnológica y/o en el patrón de movilidad (véase Capítulo 11). No obstante, además de la consideración de la procedencia de las rocas, se deben tener en cuenta sus propiedades físicas (tipo de fractura, dureza, tenacidad, calidad para la talla, etc.) (Nami 1992; Aragón y Franco 1997) y otras características, como el tamaño de los artefactos y atributos de la cara ventral (e.g., bulbo pronunciado o difuso) (Aschero 1975, 1983; Espinosa 1995). Así, sería oportuno realizar estudios experimentales de técnicas de talla sobre distintas rocas del sur de Mendoza, con el fin de corroborar o refutar la correspondencia de los distintos tipos de talones con las etapas de la secuencia de reducción mencionadas. 


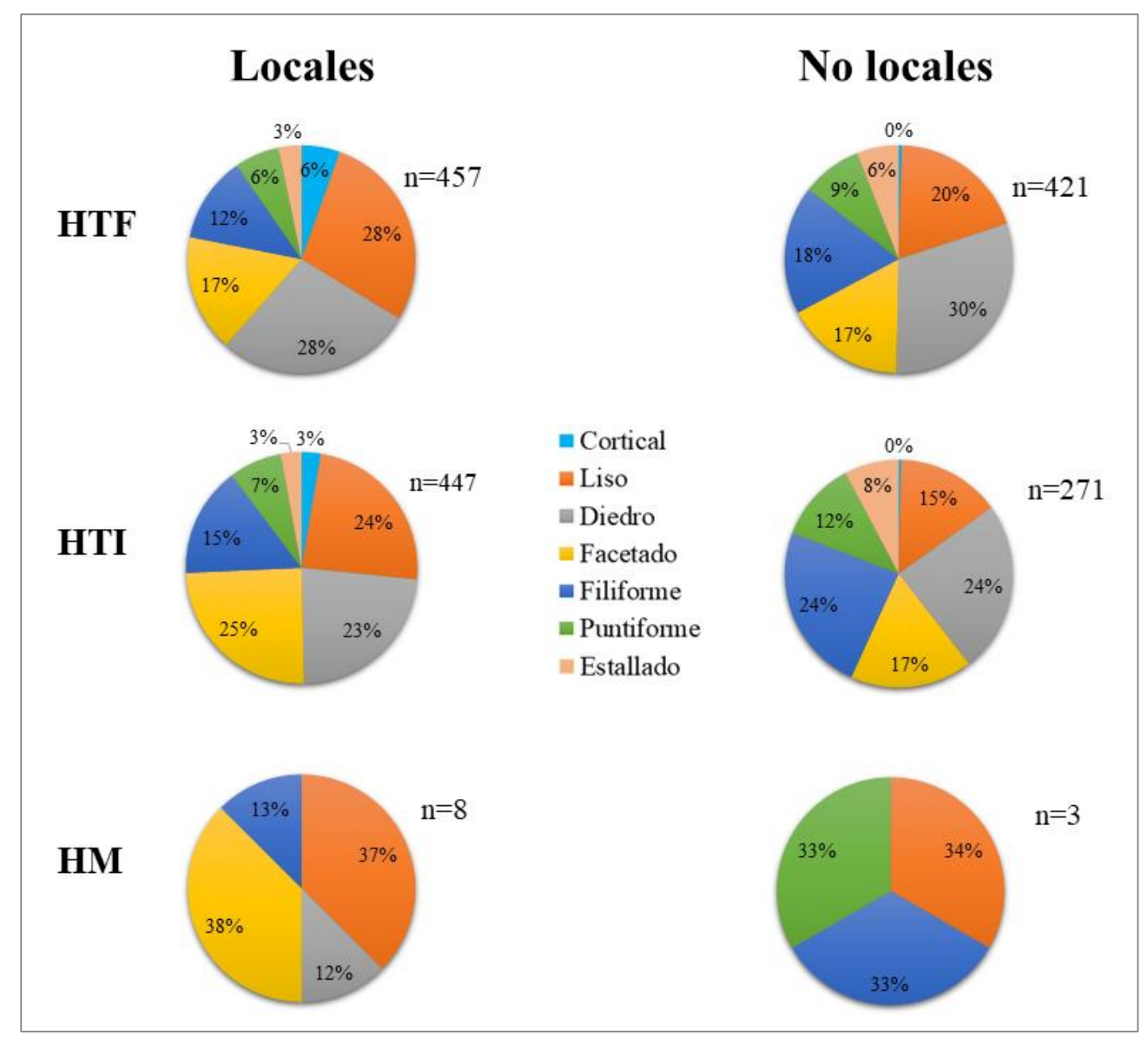

Figura 10.23. Frecuencia de tipos de talón en materias primas locales y no locales a través del tiempo.

En el Desierto Altoandino, durante el HTI la mitad de los instrumentos enteros es de tamaño pequeño (véase Capítulo 7). Luego, en el HTF, predominan los instrumentos mediano-pequeños sobre rocas silíceas y unifaciales. En el Desierto Patagónico (véase Capítulo 8), la punta de proyectil pedunculada sobre roca silícea del HM tiene un tamaño mediano-pequeño. Para el HTI se registraron instrumentos pequeños y mediano-pequeños en la misma proporción. Hacia el HTF los instrumentos son predominantemente de tamaño pequeño; el más grande registrado es un cortante de roca silícea de tamaño mediano-grande. Los tamaños de los instrumentos del Desierto de Monte no se conocen debido a que están fracturados. En general, se observa que tanto en el Desierto Altoandino como en el Patagónico predominan los instrumentos pequeños y mediano-pequeños; pero, mientras en el Desierto Altoandino, las tendencias cambian desde el uso de instrumentos pequeños en el HTI, hacia mediano-pequeños en el HTF (i.e. aumentan de tamaño); en el Patagónico se observa la disminución del tamaño desde mediano-pequeño en el HM a pequeños en el HTF; en el HTI predominan ambos tamaños. 
El índice de producción (desechos de talla/ instrumentos por materia prima) (Tabla 10.2), muestra diferencias entre los tres períodos de tiempo analizados. Durante el HM, el índice para rocas silíceas indica que en el sitio CSA-1 se habrían realizado las etapas avanzadas y finales de manufactura y/o mantenimiento, dado que el valor $(18,0)$ no es alto y coincide con el índice de corteza nulo. Durante el HTI, el índice de producción es mayor en el Desierto Patagónico que en el Altoandino, y las rocas silíceas presentan los valores más altos. De esto se puede inferir que las formas-base que ingresaron a los sitios del Desierto Patagónico pudieron ser núcleos descortezados de tamaños considerables como para generar mayor cantidad de desechos por instrumento, por lo cual, la secuencia de reducción es más completa, aunque no se registraron lascas primarias ni secundarias (no se pudo calcular el índice de corteza). En el Altoandino, las formasbase pudieron ser de tamaños menores y/o allí se llevaron a cabo las etapas intermedias a finales de confección y/o mantenimiento de instrumentos. Hacia el HTF, el índice de producción en el Desierto de Monte, muestra valores intermedios y semejantes entre obsidiana y rocas silíceas (52,0 y 54,5, respectivamente). También se incorporan los sitios de la localidad Arbolito, donde el índice es mayor en artefactos de obsidiana, aunque con valores bajos (7,0); y la riolita es la única que presenta índice de corteza. Esto sugiere que las rocas de mejor calidad ingresaron a los sitios como formas-base ya trabajadas en otros sitios; la riolita se incorporó en forma de núcleos y/o nódulos con corteza. En el Desierto Altoandino, el índice de producción aumenta, en general, con respecto al HTI, sobre todo en basalto $(103,0)$ y obsidiana $(58,8)$, aunque se observa una disminución en el valor del índice para las rocas silíceas (de 41,4 a 36,2). Asimismo, el basalto es el que presenta mayor índice de corteza, lo cual permite proponer que las etapas de reducción están completas sobre esta roca en los sitios del Altoandino. La obsidiana (no local) ingresó como formas-base con corteza (índice de corteza bajo, pero presente) y la secuencia de reducción estaría completa, aunque con mayor representación de las etapas intermedias a finales. El índice de producción de rocas silíceas indica que no se generaron tantos desechos por instrumento, por lo que se infiere que se habría enfatizado en las etapas avanzadas y finales de manufactura.

Los instrumentos bifaciales son los mayoritarios en los tres segmentos temporales $(\mathrm{HM}=100 \%$; HTI $=36 \% ; \mathrm{HTF}=43 \%)$. En el HTI los instrumentos y ASF RC sobre rocas silíceas superan el 50\%, seguidos por los de obsidiana y los de basalto. Esta tendencia se da en el Desierto Patagónico donde, además, el basalto y la obsidiana se registraron únicamente en instrumentos bifaciales. En el Altoandino predominan los instrumentos y 
ASF RC sobre obsidiana; sobre todo los unifaciales (Tabla 10.7 y Figura 10.24). Hacia el HTF, la obsidiana supera el 50\% y pasa a ocupar el primer lugar en el ranking de rocas utilizadas para la confección de instrumentos y ASF RC. Este aumento en la representación de la obsidiana, no se aprecia en los desiertos Altoandino y de Monte, en los cuales las rocas silíceas alcanzan el 50\% y el 60\%, respectivamente. Para este momento, en el Desierto Patagónico, la obsidiana (55\%) se registró en las cuatro clases artefactuales analizadas (instrumentos bifaciales, unifaciales, compuestos y ASF RC), con predominio de bifaciales; para este momento, el índice de bifacialidad es mayor sobre esta materia prima (Tabla 10.2). En el Desierto Altoandino, la obsidiana está presente sobre bifaciales y unifaciales (estos últimos son minoritarios, es decir, ocurre lo contrario a lo observado para el HTI); y en el Desierto de Monte sólo sobre bifaciales. En el Desierto Patagónico, se registraron las cuatro clases artefactuales analizadas tanto en obsidiana (55\%) como en rocas silíceas (45\%), pero ninguna sobre basalto, materia prima que tampoco se registró en el Desierto de Monte y que sólo está presente en un instrumento unifacial del Altoandino (una punta burilante axial de AP-1; véase Capítulo 7). De los tres desiertos, el que presenta mayor registro de instrumentos y ASF RC es el Patagónico (69\%), seguido por el Altoandino (28\%) y, por último, el de Monte (3\%). Estas clases artefactuales se registraron mayoritariamente en el HTF (61\%), seguido por el HTI (38\%) y por un único instrumento en el HM (1\%) (Tabla 10.7); por lo que se puede apreciar un aumento de instrumentos y ASF RC a través del tiempo, además de una continuidad en el uso del Desierto Patagónico, único ambiente donde se pudo ver, a través de los instrumentos, la sustitución de las rocas silíceas por la obsidiana. En el Desierto Altoandino, el registro del HTF muestra un uso mayoritario de la obsidiana sobre instrumentos bifaciales y de las rocas silíceas sobre unifaciales (Tabla 10.2 y 10.7). Lo más llamativo es la gran disminución en la representación de instrumentos y ASF RC en este momento $(\mathrm{HTF}=29 \%$ vs. $\mathrm{HTI}=71 \%)$. Lo contrario ocurre para estos dos momentos en el Desierto Patagónico, ya que la representación de estas clases artefactuales aumenta del HTI (27\%) al HTF (72\%). 


\begin{tabular}{|c|c|c|c|c|c|c|c|c|c|}
\hline \multirow{2}{*}{ Desierto } & \multirow{2}{*}{ Clase } & \multicolumn{3}{|c|}{ HTF } & \multicolumn{3}{|c|}{ HTI } & \multirow{2}{*}{$\begin{array}{l}\text { HM } \\
\text { SIL }\end{array}$} & \multirow{2}{*}{ Total } \\
\hline & & BAS & OBS & SIL & BAS & OBS & SIL & & \\
\hline \multirow{4}{*}{ Altoandino } & AF Bifac. & - & $33,3 \%(4)$ & $16,7 \%(2)$ & $6,7 \%(2)$ & $6,7 \%(2)$ & $10,0 \%(3)$ & - & 13 \\
\hline & AF Unifac. & $\begin{array}{c}8,3 \% \\
(1)\end{array}$ & $8,3 \%(1)$ & $33,3 \%(4)$ & $3,3 \%(1)$ & $20,0 \%(6)$ & $13,3 \%(4)$ & - & 17 \\
\hline & AF Comp. & - & - & - & $3,3 \%(1)$ & $6,7 \%(2)$ & $3,3 \%(1)$ & - & 4 \\
\hline & ASF RC & - & - & - & - & $13,3 \%(4)$ & $13,3 \%(4)$ & - & 8 \\
\hline \multicolumn{2}{|c|}{ Total por MP } & $\begin{array}{c}8,3 \% \\
\text { (1) }\end{array}$ & $\begin{array}{c}41,7 \% \\
(5)\end{array}$ & $\begin{array}{c}50,0 \% \\
(6)\end{array}$ & $\begin{array}{c}13,3 \% \\
(4)\end{array}$ & $\begin{array}{c}46,7 \% \\
(14)\end{array}$ & $\begin{array}{c}40,0 \% \\
(12)\end{array}$ & - & \multirow{2}{*}{$\begin{array}{c}27,8 \% \\
(42)\end{array}$} \\
\hline \multicolumn{2}{|c|}{ Total D. Altoandino } & \multicolumn{3}{|c|}{$28,6 \%(12)$} & \multicolumn{3}{|c|}{$71,4 \%(30)$} & - & \\
\hline \multirow{4}{*}{ Patagónico } & AF Bifac. & - & $29,3 \%(22)$ & $\begin{array}{c}13,3 \% \\
(10)\end{array}$ & $3,6 \%(1)$ & $28,6 \%(8)$ & $17,9 \%(5)$ & $100 \%(1)$ & 47 \\
\hline & AF Unifac. & - & $5,3 \%(4)$ & $\begin{array}{c}21,3 \% \\
(16)\end{array}$ & - & - & $28,6 \%(8)$ & - & 28 \\
\hline & AF Comp. & - & $1,3 \%(1)$ & $5,3 \%(4)$ & - & - & $7,1 \%(2)$ & - & 7 \\
\hline & ASF RC & - & $18,7 \%(14)$ & $5,3 \%(4)$ & - & $3,6 \%(1)$ & $10,7 \%(3)$ & - & 22 \\
\hline \multicolumn{2}{|c|}{ Total por MP } & - & $\begin{array}{c}54,7 \% \\
(41)\end{array}$ & $\begin{array}{c}45,3 \% \\
(34)\end{array}$ & $\begin{array}{c}3,6 \% \\
\text { (1) }\end{array}$ & $\begin{array}{r}32,1 \\
(9)\end{array}$ & $\begin{array}{c}64,3 \% \\
(18)\end{array}$ & $100 \%(1)$ & \multirow{2}{*}{$\begin{array}{c}68,9 \% \\
(104)\end{array}$} \\
\hline \multicolumn{2}{|c|}{ Total D. Patagónico } & \multicolumn{3}{|c|}{$72,1 \%(75)$} & \multicolumn{3}{|c|}{$26,9 \%(28)$} & $1,0 \%(1)$ & \\
\hline \multirow{3}{*}{ de Monte } & AF Bifac. & - & $40,0 \%(2)$ & - & - & - & - & - & 2 \\
\hline & AF Unifac. & - & - & $40,0 \%(2)$ & - & - & - & - & 2 \\
\hline & ASF RC & - & - & $20,0 \%(1)$ & - & - & - & - & 1 \\
\hline \multicolumn{2}{|c|}{ Total por MP } & - & $40,0 \%(2)$ & $60,0 \%(3)$ & - & - & - & - & \multirow{2}{*}{$\begin{array}{c}3,3 \% \\
(5)\end{array}$} \\
\hline \multicolumn{2}{|c|}{ Total D. de Monte } & \multicolumn{3}{|c|}{$100 \%(5)$} & \multicolumn{3}{|c|}{-} & - & \\
\hline \multicolumn{2}{|c|}{ Total MP por tiempo } & $\begin{array}{c}1,1 \% \\
(1)\end{array}$ & $\begin{array}{c}52,2 \% \\
(48)\end{array}$ & $\begin{array}{c}46,7 \% \\
(43)\end{array}$ & $\begin{array}{c}8,6 \% \\
(5) \\
\end{array}$ & $\begin{array}{c}39,7 \% \\
(23) \\
\end{array}$ & $\begin{array}{c}51,7 \% \\
(30) \\
\end{array}$ & $\begin{array}{c}100 \% \\
(1)\end{array}$ & \multirow{2}{*}{151} \\
\hline \multicolumn{2}{|c|}{ Total Tiempo } & \multicolumn{3}{|c|}{$60,9 \%(92)$} & \multicolumn{3}{|c|}{$38,4 \%(58)$} & $0,7 \%(1)$ & \\
\hline
\end{tabular}

Tabla 10.7. Frecuencia de instrumentos y ASF RC por materia prima y desierto, a través del tiempo.

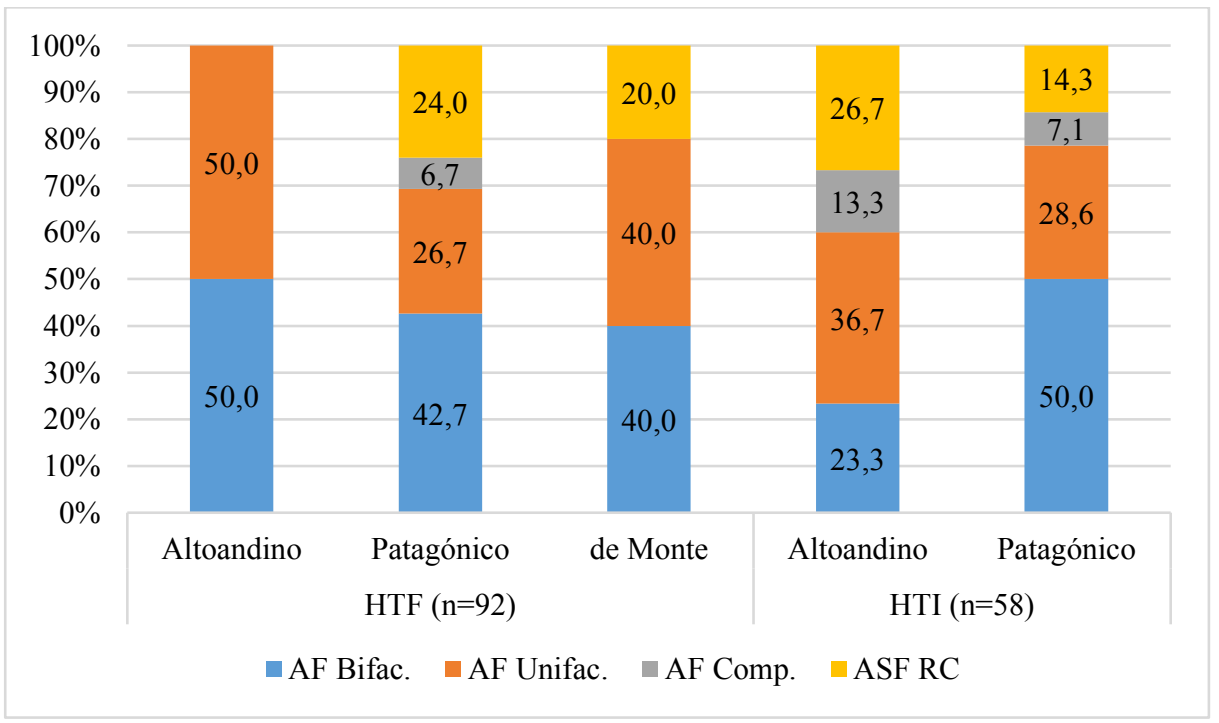

Figura 10.24. Frecuencias relativas de instrumentos y ASF RC por desierto y por tiempo.

En el Desierto Altoandino se observó que la clase de instrumentos que presenta mayor proporción de fracturas es la de los bifaciales, sobre todo en obsidiana, tanto para 
el HTI como para el HTF. También para ambos momentos, los instrumentos unifaciales están mayoritariamente enteros, siendo parecidas las frecuencias entre unifaciales de obsidiana y de rocas silíceas. Los compuestos están todos enteros y la mitad de los ASF RC están enteros; ambas clases se registraron sólo para el HTI. Estas tendencias señalan que las fracturas en los instrumentos y ASF RC, al margen de la posibilidad de producirse por procesos postdepositacionales, pueden deberse al uso mismo y/o al mantenimiento, provocando el descarte en los sitios. Se esperaría que los instrumentos compuestos formaran parte de un toolkit que los individuos llevarían como equipamiento personal en situaciones de alta movilidad. Su presencia en el HTI es coherente con las expectativas para ese momento (mayor movilidad residencial). Sin embargo, que se hayan "descartado" enteros, plantea la posibilidad de equipamiento de sitios para futuras estadías en el lugar.

En el Desierto Patagónico, la punta de proyectil pedunculada del HM está entera. Para el HTI, los bifaciales están mayoritariamente fracturados y los unifaciales, principalmente enteros. Los instrumentos compuestos y los ASF RC están fracturados, sobre todo, en rocas silíceas. En el HTF, predominan los instrumentos y ASF RC fracturados. Dichas fracturas se observan mayoritariamente en bifaciales y ASF RC de obsidiana, y en unifaciales y compuestos de rocas silíceas. En general, el estado de las piezas no estaría vinculado sólo a su tenacidad, ya que la proporción de fracturas no se correlaciona con la materia prima. Accidentes durante la confección, el uso mismo y/o el mantenimiento (e.g. reactivación de raspadores de rocas silíceas) habrían generado las rupturas en las piezas y, de no ser reparables o reciclables, se habrían descartado.

Entre los instrumentos, se reconoció la misma cantidad de grupos tipológicos para el HTI ( $n=12)$ y el HTF (n=12) (se excluye el HM dado que sólo hay una punta) (Figura 10.25). Sin embargo, de los 14 grupos tipológicos identificados, menos de la mitad están presentes en ambos momentos: las puntas de proyectil, los raspadores, los instrumentos compuestos, las muescas retocadas y de lascado simple, los cortantes y los cuchillos. De estos, predomina el grupo de las puntas de proyectil, seguido por el de los raspadores, en ambos momentos, aunque la frecuencia del primero se mantiene del HTI (33\%) al HTF (34\%) y el grupo de los raspadores disminuye del HTI (17\%) al HTF (12\%). Como se vio antes, los instrumentos compuestos, son más frecuentes durante el HTI; en cambio las muescas, los cortantes y los cuchillos, son mayoritarios en el HTF. De los ocho grupos tipológicos restantes, cuatro corresponden al HTI (cuatro bifaces, dos perforadores, una punta entre muescas y una raclette) y la otra mitad al HTF (cuatro artefactos de 
formatización sumaria, dos artefactos burilantes, un buril y un RBO). Por lo tanto, la función de incidir se habría realizado en ambos momentos, según se infiere de la punta entre muescas del HTI y del buril y los dos artefactos burilantes del HTF. Lo mismo se puede decir de la función de raspado de la raclette del HTI y del RBO del HTF. Igualmente, como se dijo antes, al cambiar la forma del filo, puede cambiar el material sobre el cual se ejerce la función de cada instrumento (e.g. raspado o incisión sobre superficies duras o blandas, como madera, hueso, cuero, fibras vegetales, etc.). El grupo de los bifaces sólo se registró en el HTI y los cuatro corresponden al Desierto Altoandino. A esto se suman los seis grupos tipológicos comunes a ambos momentos, de los cuales se pueden inferir funciones múltiples (instrumentos compuestos), cortar (cortantes y cuchillos), raspar (raspadores y muescas). Las puntas de proyectil serían parte de toolkits de caza y serían utilizadas presumiblemente cerca de los sitios residenciales.

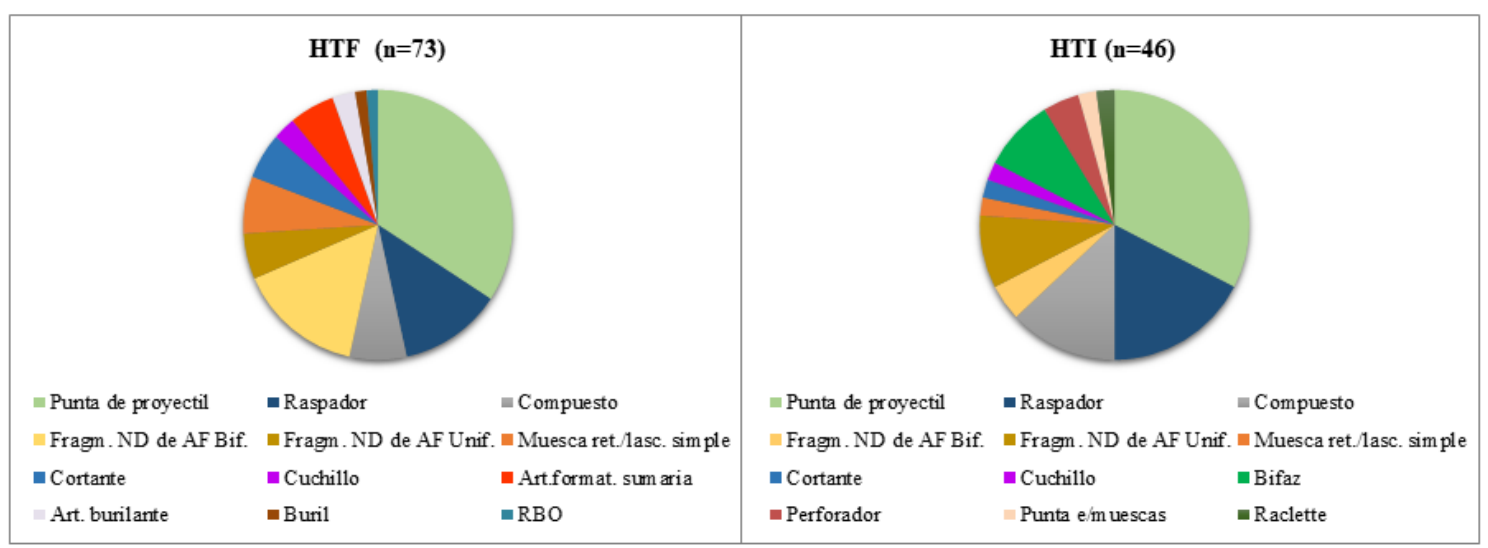

Figura 10.25. Grupos tipológicos de la cuenca del río Atuel, presentados por tiempo.

En las puntas de proyectil enteras o que posean la base ( $\mathrm{n}=20)$ (una del HM, ocho del HTI y once del HTF), se observa una disminución en las medidas tanto de ancho como de espesor, del HTI al HTF (en el HTF se presentan los espesores más pequeños registrados) (Figura 10.26). Las puntas de proyectil sobre rocas silíceas también muestran una disminución en ambas medidas del HM al HTI y luego, en el HTF, la dispersión es mayor en las medidas del espesor. El ancho también presenta mayor varianza en las medidas durante el HTF, pero la mediana muestra una disminución también durante dicho período. Así, se observa una disminución en ambas medidas de tamaño de las dos materias primas a través del tiempo. No se observan diferencias estadísticamente significativas en el ancho de las puntas considerando la totalidad de los conjuntos (One Way ANOVA; $\mathrm{F}=2,56 ; p=0,09)$. Sí se observan diferencias significativas entre los 
espesores (Kruskall-Wallis; $\mathrm{H}=10,68 ; p=0,01$ ). Se observó también una diferencia significativa en los espesores de las puntas de obsidiana del HTI y del HTF (Withney; $\mathrm{U}=3 ; p=0.006$ ). La punta de proyectil pedunculada del HM posee medidas, tanto de ancho como de espesor, semejantes a las de las puntas de mayor tamaño registradas en el HTI y HTF.

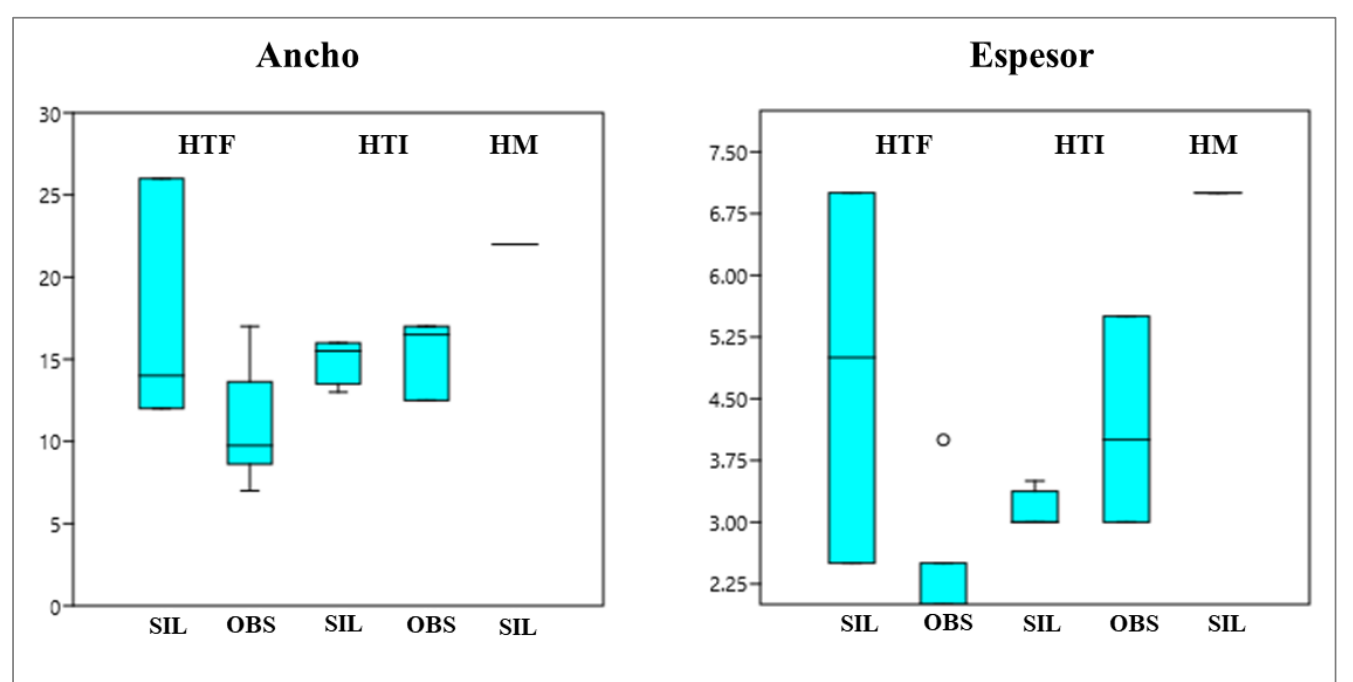

Figura 10.26. Box plot de las medidas de ancho y espesor de puntas de proyectil enteras y fragmentos basales, en obsidiana (OBS) y rocas silíceas (SIL), a través del tiempo.

En la Figura 10.27 se observa que el ancho y el espesor disminuyen con el tiempo y que el espesor presenta mayor dispersión que el ancho. Mediante el test no paramétrico de Kolmogorov-Smirnov no se observaron diferencias significativas en el ancho de las puntas provenientes del conjunto del HTI y del HTF $(\mathrm{D}=0,56 ; p=0,06)$, pero sí en el espesor $(\mathrm{D}=0,72 \mathrm{M} ; p=0,06)$, es decir, se mantienen las tendencias observadas por materia prima. Esta mayor disminución en el espesor a través del tiempo puede deberse a cambios en los sistemas de armas, en la selección de formas-base y/o en las modalidades de la talla por percusión o por presión implementadas para rebajar el espesor de la forma-base elegida (Martínez 2003; Aschero y Hocsman 2004). 


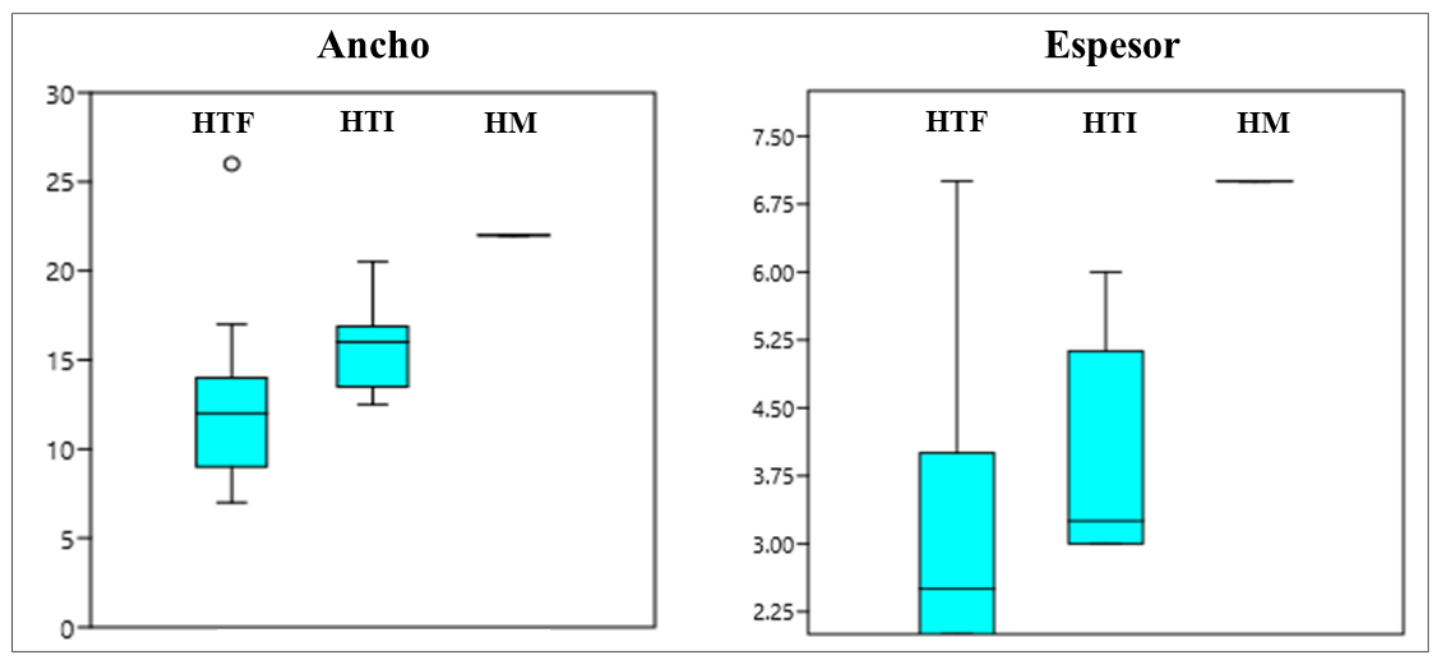

Figura 10.27. Box plot de las medidas de ancho y espesor de puntas de proyectil enteras y fragmentos basales de la cuenca del río Atuel a través del tiempo.

Los resultados de los índices de Diversidad señalan que no hay diferencias significativas entre la diversidad de grupos tipológicos del HTI y del HTF. La única diferencia importante tiene lugar entre estos conjuntos con el del HM, aunque allí sólo se registró un instrumento (Tabla 10.8). El índice de diversidad de Shannon muestra que los valores del índice entre el HTI y el HTF son semejantes, aunque la variación en la representación es un poco más acotada en el HTI que en el HTF (Figura 10.28).

\begin{tabular}{|l|c|c|c|}
\hline & HTF & HTI & HM \\
\hline $\boldsymbol{n}$ GT & 12 & 12 & 1 \\
\hline $\boldsymbol{n}$ & 73 & 46 & 1 \\
\hline Dominancia & 0,1755 & 0,1749 & 1 \\
\hline Simpson & 0,8245 & 0,8251 & - \\
\hline Shannon-H & 2,070 & 2,049 & - \\
\hline
\end{tabular}

Tabla 10.8. Diversidad de grupos tipológicos por tiempo. 


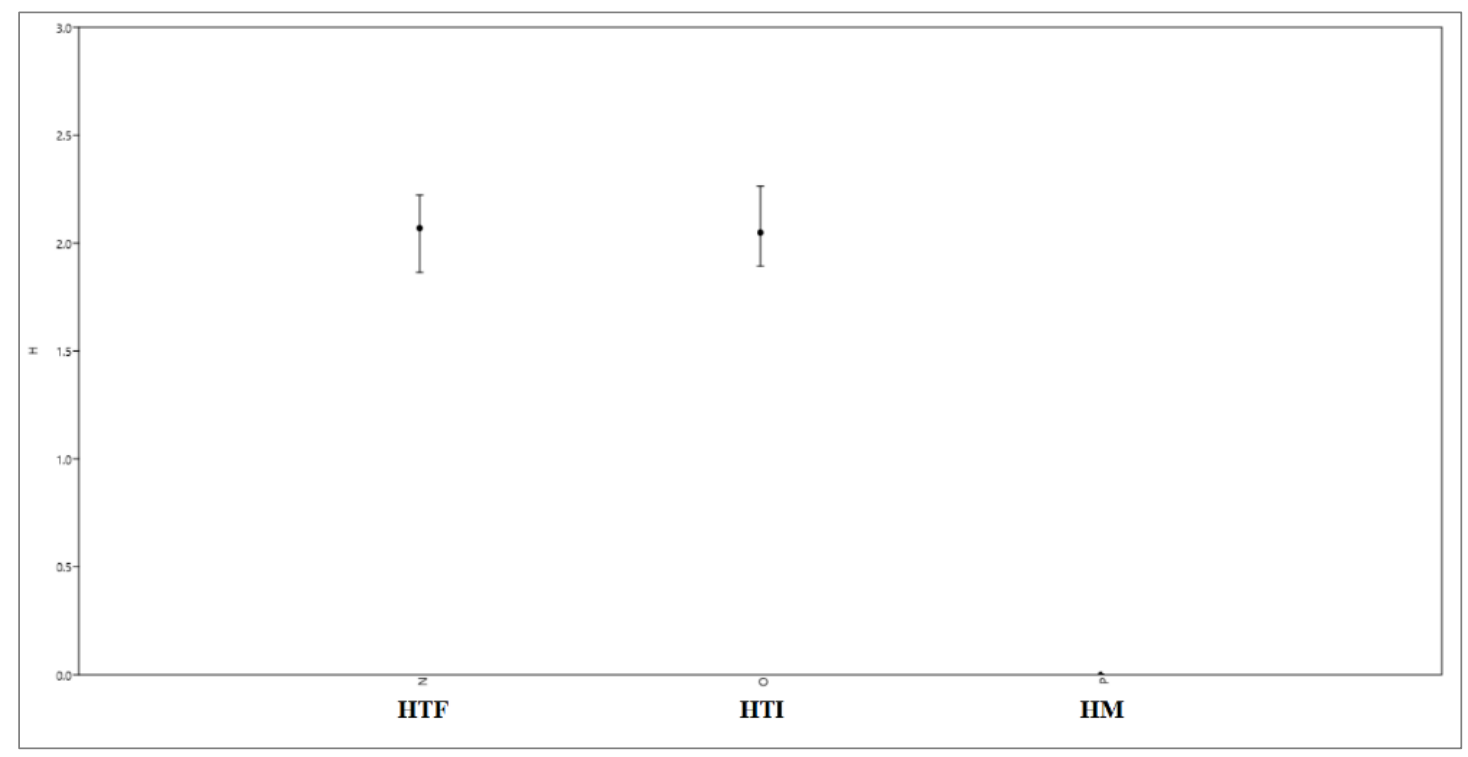

Figura 10.28. Índice de Shannon de grupos tipológicos por tiempo.

\subsubsection{CONSIDERACIONES GENERALES DE LAS TENDENCIAS} TECNOLÓGICAS TEMPORALES EN EL ATUEL

La información cronológica de los sitios analizados permite observar diferencias en cuanto a la ocupación de los tres ambientes bajo estudio. Los fechados radiocarbónicos más antiguos de CSA-1 (ca. 7.400-7.100 años AP), en el Desierto Patagónico, dan cuenta de ocupaciones previas al hiatus del Holoceno medio (HM). Este sitio también sugiere cambios en la intensidad de sus ocupaciones a través del tiempo (véase Capítulo 8), ya que es el único sitio con evidencias previas al HTI. El análisis evidenció diversos cambios en el uso de las materias primas y en sus trayectorias artefactuales desde el HM al HTI, y desde el HTI al HTF.

En los tres segmentos temporales las materias primas más utilizadas fueron las rocas silíceas, la obsidiana y el basalto. La riolita no se registró en el HM, y es la cuarta roca más frecuente tanto en el HTI como en el HTF. Las frecuencias relativas de las rocas silíceas y de la obsidiana se invierten entre el HTI y el HTF: en el primero, predominan las silíceas y durante el HTF, la obsidiana (excepto en el Desierto de Monte; Tabla 10.5). Asimismo, hacia el HTF se incorporan otras materias primas de buena y regular calidad en el Desierto de Monte. Sin embargo, en los desiertos Altoandino y Patagónico la diversidad de rocas representadas disminuye. Las rocas de muy buena y excelente calidad para la talla son predominantes en los tres desiertos y en los tres momentos. 
En relación a la obsidiana, las tendencias mostraron que la variedad de fuentes utilizadas aumenta a través del tiempo, tanto a nivel macro-regional como dentro de cada uno de los desiertos. El Patagónico es el que muestra el mayor aumento, desde dos fuentes utilizadas durante el HM, a cuatro en el HTI y cinco en el HTF. Esta situación podría implicar modificaciones en los sistemas de interacción y/o ampliación en las redes de intercambio. Esto puede vincularse con un cambio en el modo de aprovisionamiento: desde uno local (que implica trasladarse hasta la fuente con ese único fin), hacia otro indirecto. Ambas estrategias, en términos de Custer y colaboradores (1983), se corresponderían con un aprovisionamiento cíclico.

Entre los desechos de talla, las evidencias registradas en los tres lapsos temporales mostraron el predominio de etapas intermedias y finales de manufactura, un elevado porcentaje de tamaños muy pequeños, una baja o nula presencia de corteza y baja representación de talones naturales (corticales). Sin embargo, las lascas externas, los tamaños mediano pequeños y mediano grandes, y los talones corticales y lisos (especialmente, sobre rocas locales), aumentan hacia el HTF, momento al que, además, pertenecen los únicos dos núcleos registrados del total de sitios analizados. Si bien debe tenerse en cuenta que estos aumentos están representados por pocos sitios, marca un cambio respecto al HTI y más aún en relación al HM.

Tanto en el HTI como en el HTF predominan los instrumentos bifaciales, pero durante el HTI, en el Desierto Altoandino son más frecuentes los unifaciales, sobre todo, en obsidiana. Luego, en el HTF, la obsidiana es mayormente utilizada para la formatización de instrumentos bifaciales, y las rocas silíceas para los unifaciales. Esta misma tendencia se da en el Desierto Patagónico (HTI y HTF), y en el Desierto de Monte (HTF). El aprovechamiento de filos y/o puntas naturales se incrementa hacia el HTF; aunque, al segregar por desierto, se observó que los ASF RC están ausentes en el Altoandino. En instrumentos bifaciales, las únicas puntas de proyectil pedunculadas registradas son la del Conjunto C de CSA-1 (HM), con pedúnculo diferenciado, y la de BDP-1 (presumiblemente del HTF), con pedúnculo esbozado. Ambas están confeccionadas sobre rocas silíceas. Sin embargo, en el HTI predomina esta materia prima sobre instrumentos unifaciales, tendencia que se mantiene hacia el HTF en dicho desierto. En el Desierto Altoandino, durante el HTI la obsidiana fue utilizada mayoritariamente para la confección de instrumentos unifaciales. En cambio, en el HTF, esta roca es más frecuente sobre bifaciales. 
En los tres desiertos predominan los instrumentos fracturados, que aumentan del HTI al HTF en los desiertos Altoandino (43\% a 50\%) y Patagónico (64\% a 71\%). Esta tendencia podría indicar un mayor aprovechamiento de la vida útil de los instrumentos y un aumento en la intensidad de uso de las materias primas de muy buena y excelente calidad, como las rocas silíceas y la obsidiana, sobre todo en el Desierto Patagónico, donde el índice de producción disminuye hacia este período más tardío y sugiere un énfasis en las etapas avanzadas y finales de reducción, y/o mantenimiento de instrumentos en los sitios residenciales.

En síntesis, a través del tiempo se observan modificaciones en los modos de obtención, uso y circulación de los recursos líticos, con una tendencia hacia su aprovechamiento intensivo durante momentos tardíos, evidenciado en: el aumento de la representación de lascas externas en materias primas inmediatamente disponibles o local cercanas; el aumento en la frecuencia de lascas de formatización de filo, vinculadas al mantenimiento de instrumentos; mayor intensidad de uso de la obsidiana de procedencia no local; un aumento en la diversidad de fuentes de obsidiana representadas en los sitios; y un incremento en el rango de materias primas explotadas hacia el HTF, donde las materias primas de buena y regular calidad para la talla alcanzan valores del $20 \%$. Esta última tendencia no se da en el Desierto Patagónico, en el que se observa una mayor estabilidad en el modo de empleo de las materias primas desde el HM hasta el HTF, lo cual puede estar vinculado a menores cambios en la movilidad y posiblemente en la subsistencia (Neme y Gil 2012; Gil et al. 2017). La disminución en las medidas del espesor de las puntas de proyectil a través del tiempo, es una evidencia tecnológica que puede avalar esta idea. 


\section{CAPÍ́TULO 11}

\section{INTEGRACIÓN Y DISCUSIÓN}

En capítulos previos se han presentado los resultados y las tendencias espaciales en el uso de los recursos líticos de acuerdo a la localización de las materias primas y a las condiciones ambientales en cada uno de los tres desiertos involucrados. La comparación de los conjuntos en escala temporal mostró diferencias importantes a lo largo del tiempo. Esta información será discutida a continuación en relación a las hipótesis planteadas en el Capítulo 1 e integrada con la información arqueológica regional.

\subsection{CONTRASTACIÓN DE LAS HIPÓTESIS}

La primera de las hipótesis planteadas es de tipo espacial, se fundamenta en la heterogeneidad ambiental del sur mendocino y sostiene que los modos de uso de la región fueron distintos según las características ambientales. Las Hipótesis 2 y 3 son temporales y sostienen la existencia de cambios en las formas en que fueron ocupados estos ambientes a través del tiempo.

\section{Hipótesis 1:}

1) a- Acerca de la disposición y densidad de los sitios a mayor altitud (más concentrados y más densos) vs. menor altitud (más dispersos y con menor frecuencia de materiales), los resultados obtenidos confirman que las mayores densidades artefactuales se dan en los sitios localizados en los Desiertos Altoandino y Patagónico (especialmente en este último), que aquellos localizados en el Desierto de Monte (Figura 11.1.A). Al separar los sitios del Patagónico (CSA-1 vs. localidad Arbolito), e incluir a CSA-1 (piedemonte) con los sitios de cordillera y, por otro lado, a AR-6, AR-7 y BDP-1 con los sitios del Monte (planicie), se pueden distinguir dos agrupamientos: por un lado, los sitios de cordillera y piedemonte presentan altas tasas de depositación de materiales y, por el otro, los de planicie presentan tasas bajas (Figura 11.1.B).

Los sitios localizados en el Desierto de Monte muestran una tasa media de descarte por año por metro cuadrado de 0,006 , los del Patagónico de 1,02 artefactos/ año por $\mathrm{m}^{2} \mathrm{y}$ 
los del Altoandino de $0,17 /$ año por $\mathrm{m}^{2}$. Esto puede tener relación con el patrón de ocupación del espacio tal como ha sido sugerido en trabajos previos: un patrón de asentamiento más focalizado en lugares óptimos, con alta reocupación (cordillerapiedemonte) y un patrón de asentamiento disperso, con ocupaciones cortas y de baja recurrencia. En trabajos previos (Neme y Gil 2008a; Gil et al 2008, 2017; Giardina et al. 2015) se ha sugerido que esto tiene que ver con la estructura ambiental regional, que muestra ambientes más homogéneos en la planicie, a lo largo de los cursos principales de agua como los ríos Atuel y Diamante, donde la distribución de materiales es dispersa y de baja intensidad. Por su parte, en cordillera y piedemonte, la heterogeneidad ambiental y la distribución desigual de recursos y espacios habitables, hace que los sitios tiendan a localizarse en lugares óptimos, con alta recurrencia y alta tasa de depositación de materiales.

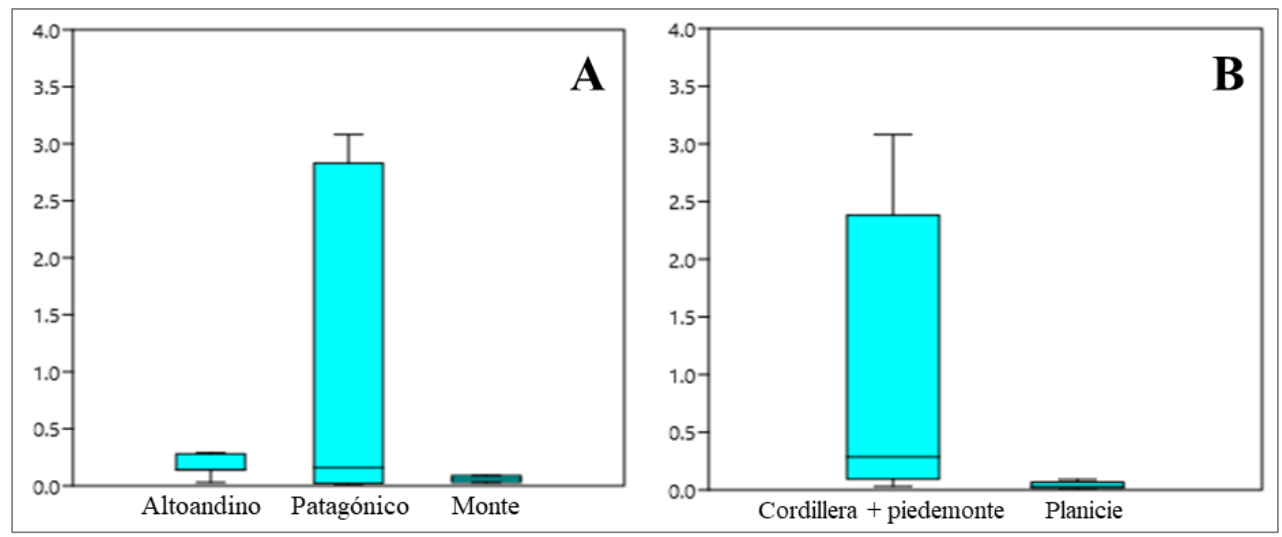

Figura 11.1. Densidad de materiales en los distintos ambientes según las tasas de depositación. A) agrupamiento de sitios por desierto; B) Sitios del Desierto Altoandino y CSA-1 vs. sitios de la localidad Arbolito y del Desierto de Monte.

1) b- Con respecto al modo de uso de las rocas vinculado a la disponibilidad diferencial de las fuentes de materias primas en cada desierto, de los análisis realizados se desprende que las materias primas utilizadas en los distintos ambientes son las mismas y que fueron utilizadas para clases artefactuales semejantes. Las discrepancias se observan en las frecuencias en que se registran los distintos tipos de artefactos, es decir, hay diferencias en densidad pero no en composición artefactual. En los sitios del Desierto Altoandino predomina la obsidiana, utilizada en artefactos formatizados, incluyendo los unifaciales, menos comunes sobre esta roca en los otros ambientes. Esta implicancia no se puede corroborar. 
1) c- En relación a la expectativa de un predominio en el uso de fuentes inmediatamente disponibles o locales cercanas en espacios altos vs. mayor variabilidad en el uso de rocas locales y no locales en tierras bajas, la alta representación de la obsidiana en el Desierto Altoandino, de procedencia no local, no es acorde. En este desierto se esperaba mayor uso de rocas inmediatamente disponibles, dados los mayores costos de traslado. Igualmente, la frecuencia de rocas silíceas y basalto indica que, aunque no sean las mayoritarias, son importantes. Por otro lado, en el Desierto de Monte, en la Planicie Oriental, hay mayor variabilidad de materias primas locales, aunque se identificó una única fuente no local (fuente de obsidiana El Peceño). Los sitios de actividades múltiples localizados a mayor altitud (AP-1, AP-2 y CP-1), en los cuales se realizan tareas de procesamiento, utilización y descarte, se encuentran próximas a las áreas de explotación, aunque en algunos casos (e.g. fuentes de rocas silíceas, de basalto de mejor calidad), el abastecimiento de recursos líticos implica realizar excursiones especiales a las canteras (aprovisionamiento directo). Las primeras etapas de reducción son muy escasas (e.g. baja frecuencia de lascas externas y de presencia de corteza) o están ausentes (e.g. núcleos). La baja frecuencia de corteza se da tanto en rocas locales como no locales; esto se esperaba sólo para las de procedencia no local.

De acuerdo con las expectativas, en las tierras bajas los lugares de abastecimiento de rocas óptimas para la talla se localizan a mayor distancia y es mayor la proporción de materias primas de menor calidad, disponibles en la inmediata vecindad. Las frecuencias de materias primas locales y no locales son similares. Además, prevalecen las etapas avanzadas en rocas locales y las finales en no locales; las lascas externas están ausentes en el Desierto de Monte. En los desiertos Patagónico y Altoandino, el porcentaje de materias primas de menor calidad es menor y las lascas externas son más frecuentes sobre rocas locales.

Contrariamente a lo esperado, la mayor proporción de fracturas, en general, se da en los sitios del Desierto de Monte, lo cual no puede atribuirse al pisoteo por la mayor cantidad de gente ocupando estos sitios. El sitio CSA-1 sí presenta alta proporción de fracturas, por lo que se puede sugerir una mayor reocupación.

1) d- En cuanto a la implicancia en la que se esperaba un énfasis en una estrategia conservada en ambientes de mayor altura y el empleo de una estrategia expeditiva en espacios bajos, en los sitios localizados en el Desierto Altoandino se infiere el empleo de una estrategia conservada, vinculada al uso estacional de este ambiente por estrés temporal. En dichos sitios se evidenció el uso de bifaces (sensu Kelly 1988), instrumentos 
compuestos y raspadores reactivados, vinculados a diseños confiables, mantenibles (versátiles y flexibles) y, presumiblemente, transportables. En el Desierto Patagónico, el sitio pedemontano CSA-1 provee evidencias vinculadas a una estrategia expeditiva: utilización de rocas de muy buena calidad como las silíceas, disponibles en el espacio local, aprovechadas y seleccionadas recurrentemente a través del tiempo. En los sitios de la localidad Arbolito y los del Desierto de Monte (Planicie Oriental), la estrategia implementada habría sido expeditiva, dado el uso de materias primas disponibles en la inmediata vecindad; pero no están representadas las primeras etapas de manufactura que, sumado a la poca cantidad de instrumentos, no es suficiente para hablar de una mayor o menor inversión de trabajo.

La expectativa que no se pudo constatar es la que hacía referencia a la representación de todas las etapas de reducción lítica sobre rocas disponibles en el espacio local. Esto puede suponerse en la localidad Arbolito (e.g. índice de corteza de la riolita, el mayor de la región), pero no en los sitios del Desierto de Monte, donde no hay evidencias de las primeras etapas de formatización, aunque sí de un mayor aprovechamiento de las rocas de menor calidad, inmediatamente disponibles.

1) e- En relación a cambios en los patrones de movilidad a lo largo del tiempo -tanto en tierras altas como bajas-, en la Planicie Oriental (tierras bajas) los sitios de la localidad Arbolito y los del Desierto de Monte, no proveen evidencias de ocupaciones previas a 2.000 años AP, por lo que, por el momento, no se puede determinar si los patrones de movilidad cambiaron en estos ambientes. En los sitios del Desierto Altoandino y en CSA1, en cambio, los fechados radiocarbónicos permitieron observar a lo largo del Holoceno, modificaciones vinculadas a los patrones de movilidad. Dada la limitación en la comparación de contextos de ambientes diferentes, dichos cambios serán discutidos en la contrastación de la última hipótesis. Esta implicancia, entonces, no pudo ser contrastada por las limitaciones del registro regional.

En síntesis, los resultados descriptos en los capítulos 7, 8 y 9, la información provista por la base regional de recursos líticos (Capítulo 6) y la descripción de las tendencias espaciales presentadas en el Capítulo 10, permiten apoyar sólo parcialmente la Hipótesis 1, dado que no todas las expectativas fueron confirmadas. 


\section{Hipótesis 2:}

2) a- La primer implicancia contrastadora para esta hipótesis sugería un aumento en la tasa de descarte del HM al HTI. Como se vio, el único de los sitios analizados que presenta evidencias correspondientes al HM es CSA-1. Al comparar las tasas de descarte del Conjunto C (HM) y del B (HTI), ambas calculadas sobre el total de artefactos líticos (véase Capítulo 8), se observó un aumento desde 0,16 artefactos depositados por año a 2,83 artefactos/ año. El valor de $p$ entre el HM y el HTI es de 0,0016. Esto implica que la diferencia es estadísticamente significativa para un nivel de significancia de $p=0,05$. Esto confirma la expectativa plateada, teniendo en cuenta que el tamaño de muestra del HM es pequeño.

2) b- En cuanto a la expectativa de que los conjuntos líticos tengan mayor variabilidad hacia el HTI, se observó que, entre ambos conjuntos temporales de CSA-1, se observa una mayor variabilidad representada en: mayor variedad de clases de roca disponibles en el espacio local y mayor diversidad de clases artefactuales. Para el HTI, se registran desechos de talla de riolita, vulcanita indeterminada, andesita y rocas indeterminadas, materias primas locales de calidad buena a regular, ausentes en el HM. Sin embargo, las primeras etapas de manufactura están poco representadas: predominan las lascas internas, seguidas por las de formatización de filo; es decir, no es congruente con lo que proponían las expectativas; aunque se registraron lascas externas que están ausentes en el HM. Los tamaños de las lascas son, en general, muy pequeños y pequeños en los tres momentos estudiados. Pero, al contrario de lo esperado, los tamaños no se reducen con el transcurso del tiempo, sino que se registraron lascas de tamaño mediano-pequeño en el HTI (ausentes en el HM) y mediano-grande en el HTF (ausentes en el HM y HTI); la ausencia de categorías de tamaño mayor durante el HM puede deberse a un problema del tamaño de la muestra. La ausencia de núcleos (sólo presentes en el HTF, en los sitios de la localidad Arbolito) no permite estimar el grado de explotación de los núcleos y/o diferencias en el modo de transporte de la materia prima. Los ASF RC, ausentes en el HM, son más frecuentes sobre rocas locales (silíceas), pero también se registraron sobre obsidiana, en el HTI. Asimismo, para este momento predominan las lascas de formatización de filo sobre rocas silíceas (únicas registradas durante el HM), seguidas por las de obsidiana. Entre el HM y el HTI se da una diferencia en la variable "tipo de talón": entre otras tendencias, se observa que los talones lisos eran los más frecuentes en el HM entre las rocas no locales y el segundo tipo más común entre las locales (después de los facetados). Luego, durante el HTI, los talones lisos pasan ocupar el cuarto lugar 
entre las rocas no locales y mantienen el segundo lugar entre las locales. Esto, al margen de la baja frecuencia de talones naturales que, igualmente aumenta con el tiempo, permitiría hacer cierta distinción en el uso de rocas locales y no locales, si se considera que los talones diedros, filiformes y facetados, predominantes en rocas no locales, se vinculan a las etapas avanzadas y finales de la secuencia de reducción (véase Capítulo 5). Pero, casi la mitad de los artefactos sobre rocas locales presentan talones facetados, filiformes y puntiformes (en el HTI); los dos últimos, representativos de la talla por presión, atribuida a las últimas etapas de manufactura y al mantenimiento de instrumentos (Magne 1989; Tomka 1989; Nami 1991; Espinosa 1995, entre otros).

El único instrumento registrado para el HM es una punta de proyectil pedunculada entera. En este mismo sitio, los instrumentos correspondientes al segmento temporal del HTI están mayormente fracturados; y de los enteros, la mitad son bifaciales de obsidiana y la otra mitad, unifaciales sobre rocas silíceas; los ASF RC están fracturados (véase Capítulo 8). Para este mismo momento (HTI), en los sitios del Desierto Altoandino se registran instrumentos mayoritariamente enteros sobre rocas locales, aunque la obsidiana se presenta en instrumentos enteros unifaciales y compuestos, y en bifaciales fracturados. El aprovechamiento de filos -con rastros complementarios- se da sobre roca local (silíceas) como no local (obsidiana). De estos, los ASF RC sobre rocas silíceas están casi todos fracturados; en cambio, los ASF RC de obsidiana, son más frecuentes enteros. Esto implica que no hay diferencias importantes en el uso de rocas locales y no locales para la confección de instrumentos, y que estos últimos presentan diseños confiables o mantenibles, vinculados a una estrategia conservada (Torrence 1989b; Bousman 1993; Carr 1994), no necesariamente relacionados a una estrategia expeditiva (Escola 2000).

Los núcleos, tanto sobre materia prima local como no local, están ausentes en ambos momentos. Tampoco se registraron raederas. Además, los percutores recuperados de CSA-1 $(n=5)$ pertenecen al segmento temporal más reciente (Conjunto A; HTF); aunque entre los artefactos de las unidades B (HTI) de los sitios CP-1 y AP-1, se registraron dos percutores enteros, que sugieren la manufactura local de instrumentos (Franco 2004). Si bien hay un aumento en la representación de la obsidiana, no es significativo si se consideran las frecuencias relativas. Las frecuencias absolutas muestran un aumento general en las tasas de depositación de un periodo al otro, pero dicho incremento no tiene relevancia al considerar los tamaños de muestra totales.

2) c- Acerca del resultado esperado de que el registro arqueológico presente una alta visibilidad y buena resolución, y que los sitios se localicen en lugares más óptimos, el 
registro con evidencias del HM es muy escaso y está representado únicamente por CSA1. En cambio, hacia el HTI se incorporan dos de los tres sitios del Desierto Altoandino: AP-1 y CP-1. Sin embargo, este periodo no fue identificado entre los sitios de la Planicie Oriental (localidad Arbolito y Desierto de Monte), por lo que no se puede hablar de una alta visibilidad. Si se considera el total del registro lítico estudiado a lo largo del río Atuel, se observa que su visibilidad y representación aumenta sensiblemente, con concentraciones -superficiales y en estratigrafía- que se distribuyen en todos los ambientes y situaciones. El registro lítico correspondiente a otros sitios del sur de Mendoza estudiados por otros autores (Dieguez et al. 2004; Gil 2000, 2006; Neme 2001, 2007; Pérez Winter 2008, 2010; Bonnat 2009; Paulides 2011; Garvey 2012; Salgán 2013; Giardina et al. 2015) repite este patrón, según se desprende de los escasos sitios arqueológicos con ocupaciones del HM y de la abundante información tanto de momentos previos (especialmente entre 7.000-9.000 años AP), como posteriores a ese lapso temporal (entre 4.000 y 200 años AP) (Gil et al. 2005; Neme y Gil 2008, 2009, 2012).

En resumen, los resultados presentados en los capítulos 7, 8 y 9, y la descripción de las tendencias espaciales y temporales presentadas en el Capítulo 10, permiten corroborar parcialmente la Hipótesis 2, ya que no se pudieron validar todas las expectativas. Por lo tanto, no se puede afirmar fehacientemente la ocurrencia de un momento de recolonización para el HTI.

\section{Hipótesis 3:}

3) a- En relación a la expectativa acerca de que se incremente la tasa de descarte de artefactos hacia el HTF debido al aumento demográfico, la tasa correspondiente al HTI es de 1,04 y en el HTF de 0,4. Dado que ninguna de las muestras posee una distribución normal, se realizó el test de Kolmogorov-Smirnov, cuyo resultado indica que no hay diferencias estadísticamente significativas $(\mathrm{D}=0,7 ; p=0,11)$. Por lo tanto, no se puede confirmar que hubo un aumento significativo en la tasa de descarte de un segmento temporal al otro en relación a un aumento demográfico. Los datos muestran que CSA-1 tiene las mayores tasas de depositación en comparación con los demás sitios, por lo que sus valores pueden ser considerados outliers (Figura 11.2.A). Por este motivo, se excluyó a los conjuntos del HTI y HTF de CSA-1 (Figura 11.2.B), lo que mostró tasas de depositación mayores durante el HTF. Sin embargo, dichas tendencias no son estadísticamente significativas y tampoco se aprecian al incluir los conjuntos del sitio 
CSA-1. La idea de un incremento en la ocupación hacia el HTF en relación al HTI no se puede confirmar.

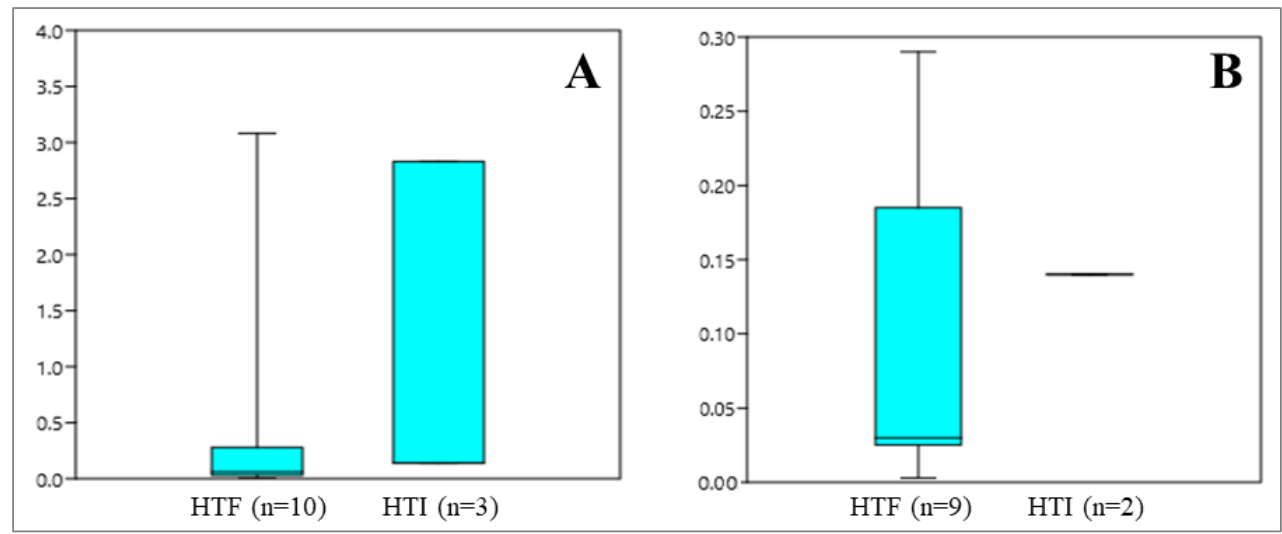

Figura 11.2. Tasas de depositación durante el Holoceno tardío; entre paréntesis la cantidad de sitios por segmento temporal. A) Agrupamiento de sitios por periodo; B) Agrupamiento de sitios por periodo, sin CSA-1.

3) b- Otra de las expectativas hacía referencia al aumento en la variabilidad de las materias primas en el HTF; en general, sí se observó un aumento (Figura 10.14 en el Capítulo 10). Sin embargo, se observa que únicamente en el Desierto de Monte se presenta mayor variedad de rocas, y que en los desiertos Altoandino y Patagónico disminuye con respecto al periodo anterior. Las rocas no locales pasan a ocupar el primer lugar en el ranking de rocas explotadas, aunque, nuevamente al discriminar por desierto, esta tendencia no se da en el Desierto de Monte, donde las rocas silíceas son las predominantes. Aquí sólo se registró obsidiana de la fuente El Peceño (extracordillerana), utilizada en la región desde el HTF. Esta fuente también es la única registrada en los sitios de la localidad Arbolito donde se considera local. En el HTF se da la mayor variedad de fuentes registradas de esta roca. Las distancias desde las fuentes hacia los sitios sugieren modificaciones en los sistemas de intercambio y/o la ampliación de sus redes. A esto se debería la presencia de instrumentos de obsidiana conservados, transportados, reparados y reactivados (prolongación de su vida útil).

3) c- Sobre lo esperado para las estrategias de aprovisionamiento de materias primas de procedencia local y no local (que fueran distintas), esto se pudo demostrar: en rocas inmediatamente disponibles, ya sea en fuentes primarias o secundarias, el abastecimiento habría sido incluido dentro de otras actividades sin generar importantes costos (estrategia “embedded", sensu Binford 1979) (e.g. basalto, riolita, vulcanita indeterminada). En el 
caso de rocas disponibles a una distancia local cercana (e.g. obsidiana de la fuente El Peceño en la localidad Arbolito; silíceas en la localidad Arbolito y en el Desierto Altoandino) o local lejana (quizás, riolita en el Desierto Altoandino), el aprovisionamiento habría sido directo (traslados a las canteras con el fin único de obtener recursos líticos). Para rocas de procedencia no local, se plantean dos alternativas: aprovisionamiento directo, pero con rangos de obtención más amplios (e.g. obsidiana de El Peceño en los sitios del Desierto de Monte), y aprovisionamiento indirecto a través de mecanismos de interacción con otros grupos, por ejemplo, a través de redes de intercambio (e.g. fuentes cordilleranas en la localidad Arbolito y en el Desierto de Monte). En el caso del Desierto Altoandino, si bien la distancia desde los sitios hasta la fuente Las Cargas supera el rango de obtención dentro del espacio local (60 km), se plantea aquí la posibilidad de que se trate de un aprovisionamiento serial (sensu Custer et al. 1983) de tipo directo, ya que esta roca está presente en una alta proporción en ambos periodos del Holoceno tardío. Lo mismo se puede plantear para el caso de la obsidiana en el sitio CSA-1 para el HTF, donde el porcentaje de esta roca supera al de las silíceas. Sin embargo, aquí es más difícil visibilizar de qué fuente se trataría ya que, como se dijo, las fuentes de obsidiana representadas son variadas.

La disminución en la frecuencia de instrumentos descartados en los sitios del Desierto Altoandino puede sugerir un aumento en la transportabilidad de los mismos como parte de toolkits personales, como así también de formas-base, nódulos y/o núcleos (equipamiento personal). La ausencia de registro de núcleos en dicho desierto puede deberse a su reducción en otros locus de actividad. La presencia de núcleos en la localidad Arbolito, podría validar la expectativa de un equipamiento de sitios con las materias primas de mejor calidad (obsidiana, presumiblemente de El Peceño, y roca silícea) disponibles en el espacio local.

3) d- Acerca de la implicancia contrastadora referida a un cambio en el tipo de estrategias tecnológicas (hacia la expeditividad en el HTF), en los sitios del Desierto Altoandino, se observó que la estrategia implementada en ambos períodos del Holoceno tardío habría sido conservada, evidenciada sobre todo, por el cuidado de los instrumentos y la presencia de diseños no sólo confiables, sino también mantenibles (versátiles y flexibles), que aumentan la eficacia ante el riesgo o el estrés temporal de estos ambientes de altura. La estrategia tecnológica de tipo expeditiva se habría implementado en los desiertos Patagónico y de Monte, al menos durante el HTF. En el sitio CSA-1, tanto en el HTI como en el HTF, estaría evidenciada por la explotación de rocas de muy buena 
calidad para la talla en las inmediaciones al sitio (incluyendo el aprovechamiento de filos naturales -ASF RC). A esto estaría vinculada la alta tasa de depositación de este sitio, el cual habría sido reocupado recurrentemente, dedicando tiempo para explotar los recursos óptimos (hídricos, líticos y de vegetales y animales), disponibles y abundantes en las cercanías al sitio. Sin embargo, CSA-1 también presenta evidencias de una estrategia conservada, como por ejemplo, la reactivación y reciclado de raspadores de rocas silíceas, el uso intensivo de instrumentos bifaciales sobre obsidiana, la presencia de instrumentos compuestos sobre obsidiana y rocas silíceas, entre otras evidencias registradas tanto para el HTI como para el HTF. Igualmente, como se ha mencionado en el Capítulo 4, ambas estrategias tecnológicas (conservada y expeditiva), no constituyen tipos fijos de comportamiento que respondan siempre a circunstancias específicas (Escola 2000: 11). En el Desierto de Monte, la estrategia tecnológica implementada habría sido expeditiva.

3) e- En cuanto a que el registro arqueológico presente una alta visibilidad, pero una baja resolución, se validan ambas expectativas: hay mayor variabilidad de materias primas y de clases artefactuales representadas, y la baja resolución dificultó la separación de los conjuntos a lo largo de la secuencia. Por ejemplo, en los sitios en cueva, CP-1 y CSA-1, las características estratigráficas, la presencia de fechados cruzados a lo largo de las secuencias y de basureros sobre los perfiles, además de la alta frecuencia de materiales encontrados (sobre todo en CSA-1), dificultó la definición de eventos de ocupación claros.

En síntesis, a partir de la caracterización de la base regional de recursos líticos, de los resultados obtenidos y del análisis de las tendencias espaciales y temporales (capítulos 6 al 10), la Hipótesis 3 sólo se valida parcialmente, ya que no todas las expectativas se cumplieron. Por un lado, la información obtenida no es suficiente para apoyar la idea de un aumento demográfico, dado que las tasas de depositación no muestran un aumento a través del tiempo. Por otro lado, las evidencias observadas en el Desierto Patagónico, sugieren que hubo una disminución en la movilidad residencial y un aumento en la movilidad logística; pero esto no se infiere de lo registrado en los desiertos Altoandino y de Monte. Esto permite plantear dos escenarios para el HTF: uno en el que la cuenca del río Atuel fue ocupada por distintos grupos con pautas de movilidad distinta, residencial en unos y logística en los otros grupos. En el otro, los mismos grupos habrían ido ocupando el espacio jerárquicamente, priorizando los valles intermedios y el piedemonte (Desierto Patagónico), donde habrían permanecido por más tiempo y habrían 
aprovechado el acceso tanto a la cordillera (Desierto Altoandino), como a la planicie (este del Desierto Patagónico y Desierto de Monte), según la estación en la que fueran más óptimos para la explotación de distintos recursos.

\subsection{INTEGRACIÓN REGIONAL}

Los resultados obtenidos a partir del análisis de los sitios de la cuenca del río Atuel, permiten discutir distintas tendencias tecnológicas en los modos de uso de las materias primas y en las trayectorias artefactuales de cada una, a saber:

$a$ - notable diferenciación en las tasas de depositación de artefactos líticos entre los distintos ambientes (desiertos Altoandino, Patagónico y de Monte): tasas altas en los ambientes de mayor altitud (cordillera y piedemonte) $v s$. bajas en la planicie.

$b$ - mayor variedad de materias primas utilizadas en los sitios localizados en las tierras bajas (Planicie Oriental).

$c$ - mayor uso de materias primas de muy buena y excelente calidad para la talla en los sitios a mayor altitud $v s$. rocas de buena y regular calidad en los sitios localizados a menor altitud.

$d$ - predominio de desechos de talla de tamaños muy pequeños y pequeños, y de etapas avanzadas y finales de manufactura, en los tres desiertos.

e- predominio de rocas silíceas, destinadas principalmente a la formatización unifacial, en los desiertos Patagónico y de Monte vs. predominio de obsidiana en instrumentos bifaciales y unifaciales, en el Desierto Altoandino.

Asimismo, las tendencias temporales sugieren cambios en el uso de los recursos líticos a través del tiempo:

$a$ - incremento en el uso de la obsidiana y de las materias primas de excelente calidad.

$b$ - aumento en la diversidad de materias primas aprovechadas.

$c$ - aumento en la tasa de descarte de materiales hacia el Holoceno tardío.

$d$ - disminución en el tamaño de los instrumentos (puntas de proyectil).

$e$ - incremento en la diversidad de fuentes de obsidiana utilizadas.

$f$ - aumento en la representación de lascas externas y de formatización de filo.

$g$ - incremento de la bifacialidad.

En los sitios localizados en la Planicie Oriental (localidad Arbolito y Desierto de Monte) las ocupaciones fueron de corta duración y esporádicas, y se aprovecharon los 
recursos de disponibilidad local, ya sean de calidad buena o regular. Dado el breve tiempo de ocupación y la baja inversión de trabajo sobre rocas de menor calidad para la talla, se podría interpretar que la estrategia tecnológica fue oportunística. Los tamaños de muestra pequeños también podrían ir en la misma línea, aunque no es suficiente para afirmar esta posibilidad. Además, la ausencia de núcleos, lascas externas y de otras evidencias de las primeras etapas de manufactura, no son acordes con este tipo de estrategia, en la cual se espera que las evidencias de confección, uso y descarte, se encuentren en el mismo lugar. A pesar del uso esporádico de estos sitios, la estrategia pudo ser la expeditiva, ya que existiría una planificación en la utilización de estos sitios. Por ejemplo, la manufactura y/o mantenimiento de instrumentos de obsidiana, evidenciada por desechos de talla de esta materia prima, y el traslado de esta roca desde la fuente El Peceño a más de $90 \mathrm{~km}$ de distancia; o el uso de obsidiana de fuentes más distantes, obtenida por mecanismos de interacción como el intercambio.

Para los sitios del piedemonte (CSA-1) y del Desierto Altoandino, la evidencia permite proponer la implementación de una estrategia expeditiva en el primero y conservada en los sitios cordilleranos. Igualmente, se debe considerar que una estrategia no excluye a la otra.

En cuanto a lo temporal, la tendencia se inclinaría hacia grupos con menor movilidad hacia el HTF, con sistemas de aprovisionamiento indirecto de recursos líticos de excelente calidad (e.g. obsidiana). La disminución en el tamaño de las puntas de proyectil (i.e. disminución de los valores medios del espesor) hacia el HTF podría responder al ingreso del arco y flecha como innovación tecnológica, que implicó un cambio en el sistema de armas. Las puntas de proyectil con pedúnculo, podrían pertenecer a momentos tempranos, como la punta con pedúnculo diferenciado de CSA-1 correspondiente al HM. La punta con pedúnculo esbozado del sitio BDP-1 puede señalar que este sitio es más antiguo que la edad que se le asignó indirectamente. El aumento en la diversidad de materias primas hacia el tardío puede estar reflejando dos situaciones distintas: por un lado, la incorporación a la muestra de los sitios del Monte (más alejados de las fuentes de materias primas de excelente calidad); por otro lado, la movilidad decreciente, que traería aparejada la explotación de los recursos líticos inmediatamente disponibles de menor calidad para la talla. El aumento en la diversidad de fuentes de obsidiana, posiblemente debido a una mayor estructuración de las redes de circulación de materiales por interacción entre grupos humanos, es otro argumento a favor de dicha idea. Al margen de que la baja frecuencia en el uso de la fuente El Peceño en los sitios de la 
localidad Arbolito donde está disponible localmente, pueda deberse - entre otras causasa procesos postdepositacionales, su uso diferencial al este (sitios del Monte) y al oeste (en el piedemonte; ausente en cordillera), no permiten identificar claramente sus modos de explotación. Dado que es una fuente de disponibilidad anual, de fácil acceso, de excelente calidad para la talla y que no posee evidencias de uso previas al HTF, se plantean ciertos interrogantes: ¿su baja representación en los sitios tiene que ver con tipos de acceso (directo vs. indirecto) por situaciones de control territorial? ¿Pudo no ser conocida antes del HTF? ¿Su descubrimiento tardío se debe a su localización dentro de un área "marginal” (sensu Gil 2000, 2006)? Las respuestas a estos interrogantes podrán ser abordadas a la luz de nueva información, por ejemplo, la cronología de los conjuntos superficiales con métodos alternativos (e.g. hidratación de obsidiana); la tecnología y geoquímica de esta fuente; y los conjuntos arqueológicos locales y no locales (Salgán y Pompei 2017).

El presente trabajo de tesis doctoral enfrentó dos problemas principales: el número de sitios arqueológicos analizados $(\mathrm{n}=10)$, en relación al tamaño de la región, y que no se contó con una muestra adecuada para discutir las tendencias temporales, especialmente, para los momentos previos al Holoceno tardío, lo que limitó el alcance de las discusiones planteadas a partir de la Hipótesis 2. Sin embargo, estudios regionales han abordado el estudio de la tecnología lítica en distintos sitios a lo largo de la cuenca del río Atuel desde la óptica organizativa (Pérez Winter 2008, 2010; Garvey 2012; Giardina et al. 2015, entre otros). En el sector cordillerano de las cuencas de los ríos Atuel y Salado (tributario del primero), se localizan los sitios arqueológicos Arroyo Malo 3 (AMA-3) y Arroyo El Desecho (AD-4), estudiados por Pérez Winter (2008, 2010) y por Garvey (2012), respectivamente, cuyas evidencias datan de periodos previos al Holoceno tardío (Figura 11.3). Por lo tanto, los resultados de dichas investigaciones permiten contrarrestar el pequeño tamaño de muestra representativo del HM $(n=31)$ e incorporar la información brindada allí a la discusión acerca de la "recolonización" en el HTI (Hipótesis 2). En la cuenca media del Atuel, otro de los sitios con evidencias previas al Holoceno tardío es Gruta del Indio; sin embargo, el registro lítico está constituido por tres instrumentos y un desecho, pertenecientes al Holoceno temprano (Gil 2006; Lagiglia 2001) (véase Capítulo 3). También se incorporaron a la discusión, los resultados de los conjuntos líticos de los sitios Rincón del Atuel 1 (RA-1) (Dieguez et al. 2004) y La Olla 1 (LO-1) (Giardina et al. 2015). Ambos sitios se localizan en la cuenca baja del río Atuel y no poseen fechados previos al HTF. 
La secuencia temporal de AMA-3 fue dividida en cuatro conjuntos (Neme 2001, 2007; Pérez Winter 2008, 2010). De ellos, el Conjunto 4 fue datado entre 8.900 y 7.600 años AP (transición Holoceno temprano-Holoceno medio) y posee un total de 866 artefactos líticos, entre los que predomina el basalto (75\%), seguido por las rocas silíceas (11\%) y la obsidiana (4\%), entre otras rocas. En el Conjunto 3, correspondiente al HM (7.600 y 5.000 años AP), se da una reducción en el tamaño de la muestra a un total de 564 artefactos líticos (la tasa de depositación disminuye de 0,63 en el Conjunto 4, a 0,23 en el Conjunto 3). Pese a ello, las materias primas se registraron en el mismo orden de importancia que en el conjunto más temprano. En el Conjunto 2 del HTI (ca. 5.000-2.000 años AP), la muestra alcanza un total de 933 artefactos (0,3/ año). La roca más frecuente también es el basalto y la obsidiana pasa a ocupar el segundo lugar, en detrimento de las rocas silíceas. Este orden se mantiene en el Conjunto 1. Por lo tanto, a lo largo de la secuencia de AMA-3, los resultados de los análisis publicados (Neme 2007; Pérez Winter 2010), muestran una disminución en las frecuencias de basalto y un aumento en la proporción de obsidiana, a través del tiempo (Figura 11.3). Así, salvo por la alta frecuencia de basalto, las tendencias tecnológicas temporales de AMA-3 son semejantes a los resultados del análisis de los sitios del Desierto Altoandino para el HTI y el HTF, analizados en esta tesis.

Los diez fechados radiocarbónicos que provee el sitio AD-4, rondan entre 6.283 \pm 42 y $5.204 \pm 40$ años AP; es decir, su cronología pertenece al Holoceno medio. Dentro de este periodo, Garvey (2012) observó una alta proporción de obsidiana (72\%), seguida por las rocas silíceas $(14 \%)$, el basalto (8\%), entre otras. El alto porcentaje de obsidiana es coherente con su procedencia local en este sitio (Figura 11.3). Así, las frecuencias registradas en $\mathrm{AD}-4$, son coherentes con lo mencionado para la cuenca del río Atuel, acerca de la selección y uso prioritario de rocas de excelente y muy buena calidad para la talla, disponibles en el espacio local. 


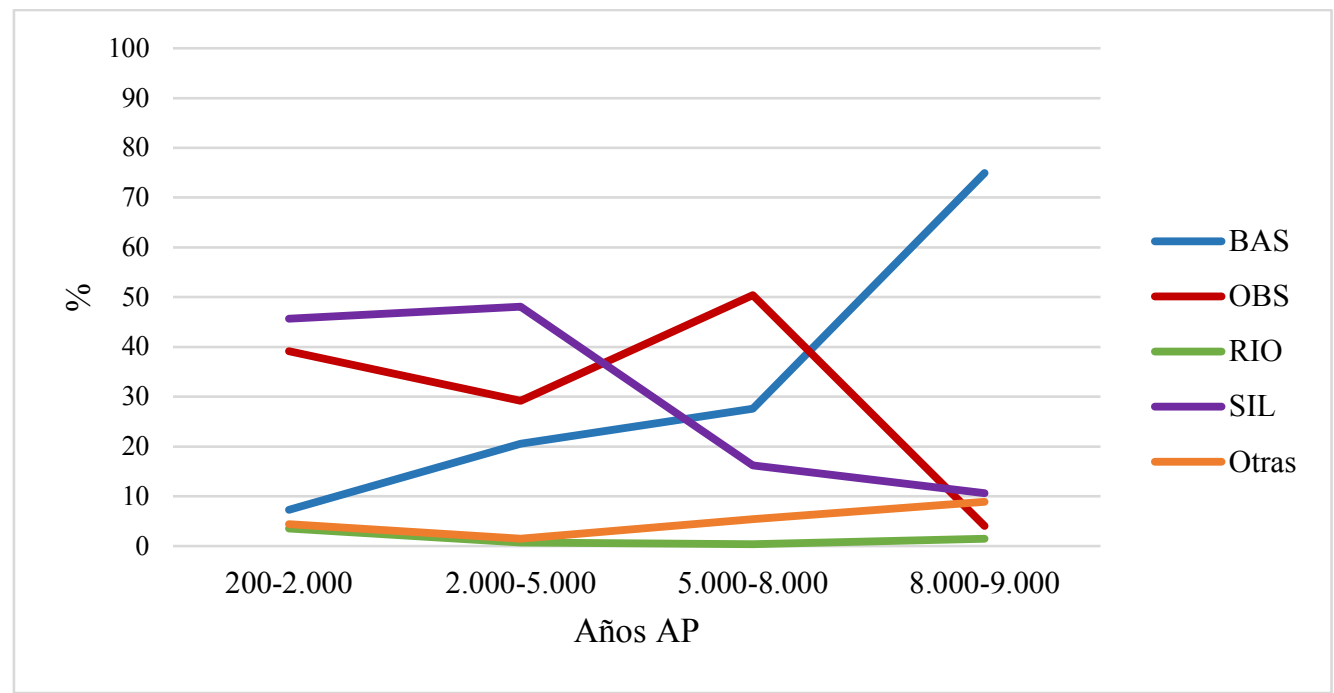

Figura 11.3. Frecuencia de materias primas de la cuenca del río Atuel, a través del tiempo. Se incluyen los sitios estudiados en esta tesis y los abordados en otros trabajos (AMA-3, AD-4, RA-1 y LO-1). La categoría "Otras" materias primas incluye: andesitas, cuarzos, vulcanitas indeterminadas y rocas indeterminadas.

De los sitios localizados en la planicie, RA-1 y LO-1, el primero tiene una antigüedad de al menos 1.520 años y está compuesto por 3205 artefactos (Dieguez et al. 2004). Predominan las rocas silíceas (49\%), seguidas por la obsidiana (33\%), el basalto (7\%) y la riolita (5\%), entre otras materias primas. Es decir, la misma tendencia observada en los conjuntos analizados en esta tesis, aunque en RA-1, el basalto supera a la riolita; distinto a la tendencia observada en los sitios del Desierto de Monte, donde la riolita es más frecuente que el basalto. Igualmente, la diferencia porcentual es mínima. Algo semejante a RA-1 sucede en el sitio LO-1, el cual data de ca. 1.900 años AP (Giardina et al. 2015) y presenta un conjunto lítico compuesto por 522 artefactos: la materia prima más representada es la roca silícea (56\%), seguida por la obsidiana (41\%), el basalto $(2 \%)$ y otras rocas minoritarias. Además, los datos suministrados por el trabajo de Giardina et al. (2015), sugieren que los desechos de talla de obsidiana y rocas silíceas presentan mayor intensidad de uso, así como diferentes etapas de la secuencia de reducción. La presencia de corteza en el conjunto de desechos es baja (4\%) y es más frecuente en desechos de basalto. El empleo de núcleos o lascas como formas-base trasladadas al sitio, implican diferencias que pueden estar vinculadas a una disminución -en términos de movilidad- en los rangos de acción de las poblaciones y/o a un acceso restringido a los recursos durante los últimos 700 años AP, tendencia planteada en esta tesis y postulada para otras regiones del sur de Mendoza (Gil 2006; Neme 2007). 
La Figura 11.3 muestra la representación de las materias primas utilizadas en los distintos segmentos temporales de los diez sitios analizados en esta tesis, junto con los disponibles en la bibliografía: AMA-3 (Pérez Winter 2008, 2010), AD-4 (Garvey 2012), RA-1 (Dieguez et al. 2004) y LO-1 (Giardina et al. 2015). Más allá de las diferencias en las representaciones vinculadas a la proximidad de algunos sitios arqueológicos a distintas fuentes de materias primas, cuando se toman todos los conjuntos analizados y se los separa en los grandes lapsos temporales desde el Holoceno temprano hasta el tardío (Figura 11.3), se puede apreciar un aumento en la representación de las materias primas de muy buena y excelente calidad para la talla (rocas silíceas y obsidiana) y una disminución en la representación de aquellas de calidad buena o regular (especialmente del basalto). Esto estaría sugiriendo un aprovechamiento más intensivo de las materias primas de mejor calidad para la talla, cuyo aprovisionamiento pudo darse por vías directas o indirectas (e.g. intercambio). En el caso de la obsidiana, los costos de aprovisionamiento (directo o indirecto) habrían implicado un uso conservado de esta roca.

Al comparar por segmento temporal los tipos de instrumentos registrados en los sitios AMA-3, AD-4, RA-1 y LO-1 con los que fueron abordados en esta tesis, se observa una constante disminución de la formatización unifacial (del 75\% al 35\%) y un aumento en la bifacialidad (del 25\% al 60\%) hacia el HTF (Figura11.4). Hay una alta frecuencia de instrumentos bifaciales sobre obsidiana que se incrementa desde el HM (mayormente representada en dicho periodo por el sitio AD-4 donde la obsidiana está a una distancia local). Sin embargo, el incremento en la bifacialidad también se registró sobre rocas silíceas, por lo que se pueden explorar otros motivos. En general, la formatización bifacial requiere mayor inversión de trabajo (Hayden et al. 1996; Andrefsky 1998, entre otros). Sin embargo, esto no necesariamente fue así para todos los instrumentos analizados. Por ejemplo, en el caso de las puntas de proyectil, pudieron ser confeccionadas mediante adelgazamiento bifacial (mayor inversión) o reducción bifacial (menor inversión) (Escola 2004; Hocsman y Escola 2006-2007). Para corroborar o no el supuesto de un aumento en la inversión de trabajo a través del tiempo -vinculado al incremento en la bifacialidad-, a futuro será necesario aumentar la muestra de instrumentos bifaciales y unifaciales e incorporar otras variables al análisis, que sean sensibles a la inversión de trabajo (e.g. requerimiento de extracción de formas-base, requerimiento de formatización de la formabase y requerimiento de imposición de forma) (Hocsman y Escola 2006-2007). La mayor representación de los instrumentos compuestos se da en el HTI, momento en el que se los registró con mayor frecuencia en los sitios del Desierto Altoandino. 


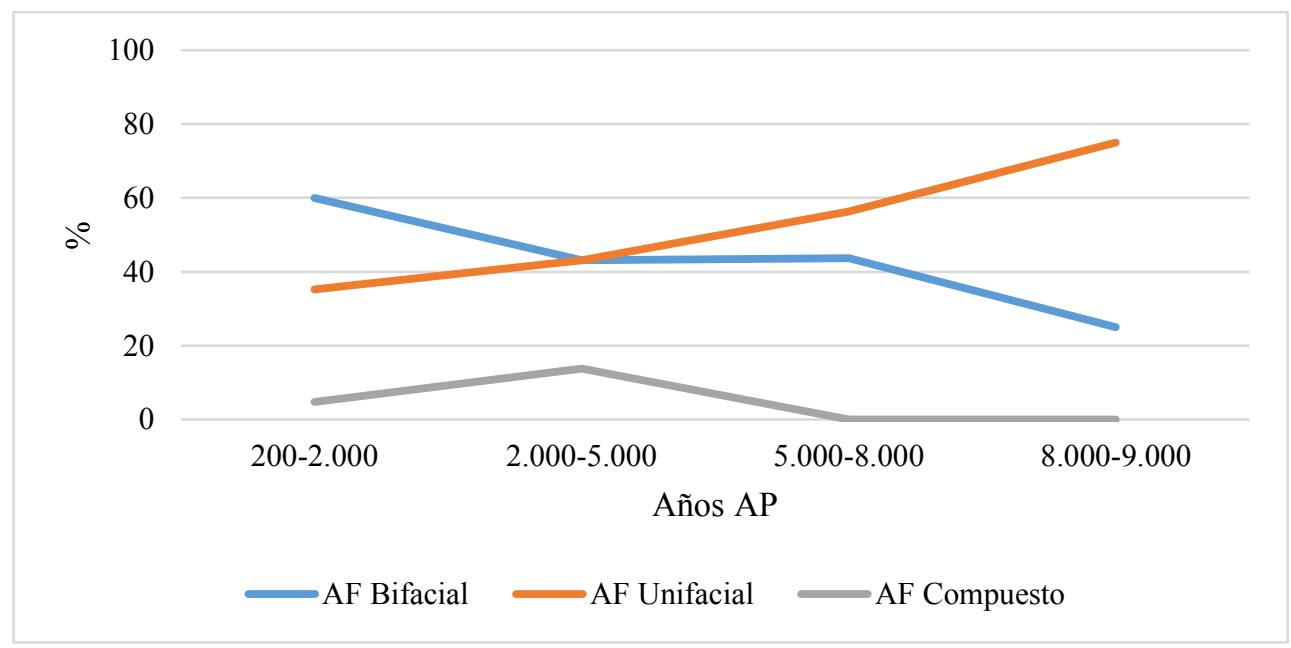

Figura 11.4. Frecuencia de artefactos formatizados de la cuenca del río Atuel, a través del tiempo. Se incluyen los sitios estudiados en esta tesis y los abordados en otros trabajos (AMA-3,

$$
\text { AD-4, RA-1 y LO-1). }
$$

Tanto el aumento en el uso de instrumentos bifaciales como el incremento en el uso de obsidiana, se acentúan hacia la segunda mitad del Holoceno tardío, momento para el que también se propuso aquí una disminución del tamaño de las puntas de proyectil y una disminución en la movilidad residencial. Estas tendencias serían acordes con las expectativas del modelo de intensificación propuesto para el sur de Mendoza (Neme 2007). Sin embargo, el esperado aumento en las tasas de depositación a lo largo del tiempo no pudo demostrarse a nivel regional. Por el contrario, sólo se registra en los sitios con secuencias de ocupación largas (e.g. CSA-1, CP-1, AMA-3) y queda desdibujado al incorporar los sitios arqueológicos de la planicie. Es probable que este desbalance entre los resultados a diferentes escalas tenga que ver con los modos de uso y ocupación de cada uno de los sitios, el probable aumento de la movilidad logística, y la estructura ambiental de los recursos (homogénea en el Desierto de Monte y heterogénea -y circunscripta- en los desiertos Patagónico y Altoandino). En asociación a un proceso de intensificación, sería esperable que aumentara la variedad de grupos tipológicos hacia el HTF, dada la incorporación de nuevos recursos y la necesidad de nuevas tecnologías asociadas a su obtención y procesamiento. Sin embargo, esta tendencia no se ha observado con claridad. 


\subsection{UN MODELO DE APROVISIONAMIENTO PARA EL SUR DE MENDOZA}

En su trabajo sobre la organización de la tecnología lítica en el campo volcánico La Payunia (sur de la provincia de Mendoza), Salgán (2013) propuso un modelo de aprovisionamiento de los recursos líticos, considerando los conceptos planteados por Custer et al. (1983) para diagramar posibles vínculos entre las áreas de abastecimiento y los locus de descarte. Planteó dos estrategias de aprovisionamiento directo para el Holoceno tardío en dicha región. Una de las estrategias se vincula al aprovisionamiento de los recursos locales de abundante disponibilidad (rocas silíceas), que responderían a una estrategia de aprovisionamiento serial (sensu Custer et al. 1983), donde los grupos móviles hacen uso de fuentes líticas próximas, situadas en puntos diferentes del espacio a lo largo de su ciclo anual. La otra estrategia hace referencia a las rocas no locales, cuyo aprovisionamiento respondería a una estrategia de tipo cíclica (Custer et al. 1983), que implica el abastecimiento repetido de una fuente por parte de una población, que retorna periódicamente a abastecerse en su ciclo anual o estacional de desplazamiento. En esta estrategia se espera que no sea frecuente el abastecimiento de otras rocas de características similares (en distancia y calidad para la talla) y que en los sitios la fuente posea altas frecuencias, debido a su transporte y uso sostenido en el tiempo (Salgán 2013).

Al aplicar este modelo a la cuenca del río Atuel se pueden observar distintos tipos de aprovisionamiento (sensu Custer et al. 1983), independientemente del rango de distancia del sitio residencial a la fuente de abastecimiento lítico (Tabla 11.1). Se observa, por ejemplo, que las fuentes de materias primas de menor calidad son, asimismo, las que están inmediatamente disponibles en la mayoría de los sitios analizados; y en ellas el aprovisionamiento sería de tipo "serial" y su abastecimiento estaría incluido dentro de otras actividades. En cambio, en casos como los de las rocas silíceas, su disponibilidad es inmediata, local cercana o local lejana (sensu Civalero y Franco) a los sitios, pero su mejor calidad para la talla hace que el aprovisionamiento se realice con ese fin específico (serial directo). Esto también ocurre con la obsidiana en los sitios de la localidad Arbolito, donde está disponible en el espacio local cercano. Sin embargo, como la frecuencia con que se registra obsidiana en estos sitios es baja (AR-6 y BDP-1) o nula (AR-7), se infiere que el tipo de aprovisionamiento habría sido incluido ("embedded" sensu Binford 1979).

En el caso de fuentes no locales de obsidiana, el aprovisionamiento sería "cíclico" $\mathrm{y}$, dentro de este, directo o indirecto. En el primer caso, el traslado hacia las fuentes 
implica un alto costo que sería compensado por la calidad de la materia prima obtenida. Este sería el caso, por ejemplo, de la fuente El Peceño en los sitios del Desierto de Monte o en CSA-1; o de la obsidiana de Las Cargas, Coche Quemado, El Peceño y, presumiblemente, de la fuente Laguna del Maule-2, en el sitio CSA-1. En el caso del aprovisionamiento indirecto, el acceso a la obsidiana se daría a través de mecanismos de interacción, por ejemplo, a través de redes de intercambio, comercio y/o regalos, entre otros. Esta sería la situación de las fuentes cordilleranas en la localidad Arbolito y en el Desierto de Monte; de la fuente Laguna del Diamante en CSA-1; El Peceño y Laguna del Maule-2 en el Desierto Altoandino; y otros escenarios posibles que son planteados aunque no se ha comprobado la presencia de estas fuentes en dichos sitios con análisis geoquímicos (Figura 11.5).

En el caso de la fuente de obsidiana Las Cargas, la distancia a los sitios del Desierto Altoandino es no local. Sin embargo, la importante representación de la obsidiana en estos sitios (donde sólo se identificó esta fuente y la desconocida Grupo A), implica que el aprovisionamiento tuvo que ser directo dentro del tipo serial, no cíclico, ya que la distancia no jugó el rol más importante en el modo de aprovisionamiento.

En la Figura 11.5 se presenta el esquema propuesto para la cuenca del río Atuel, junto a lo diagramado por Salgán (2013) para La Payunia. En general, se observa un predominio de la estrategia de aprovisionamiento serial, generalmente incluido, que involucra, en ambos casos, a las rocas silíceas; y un aprovisionamiento cíclico directo, principalmente vinculado al abastecimiento de obsidiana en ambas áreas. En el Atuel, el aprovisionamiento serial incluido incluye a todas las rocas de menor calidad para la talla (basalto, riolita, cuarzo, andesita, vulcanita indeterminada) y a las rocas silíceas, aunque estas últimas también implicaron la estrategia de aprovisionamiento serial directo, dado que su mejor calidad conllevó a que se realicen incursiones a las fuentes con ese único fin. En cambio, en La Payunia, la alta ubicuidad de las rocas silíceas en las inmediaciones a los sitios arqueológicos, conllevó a una selección primordial de estas rocas, las cuales constituyen el 90\% de los conjuntos analizados por Salgán (2013).

Con respecto al aprovisionamiento de obsidiana, mientras que las fuentes Las Cargas y El Peceño implican un aprovisionamiento cíclico directo en la cuenca del Atuel, estas llegarían a La Payunia por medio de intercambio u otros medios de interacción entre poblaciones. Algo semejante a lo que ocurre con la fuente Cerro Huenul, cuyo aprovisionamiento es cíclico en ambas áreas (sensu Custer et al. 1983), pero de tipo directo en La Payunia, y sería indirecto en el Atuel. La distancia paralela entre la fuente 
Laguna del Maule y ambas áreas de estudio, queda reflejada en el mismo tipo de estrategia de aprovisionamiento: cíclico directo.

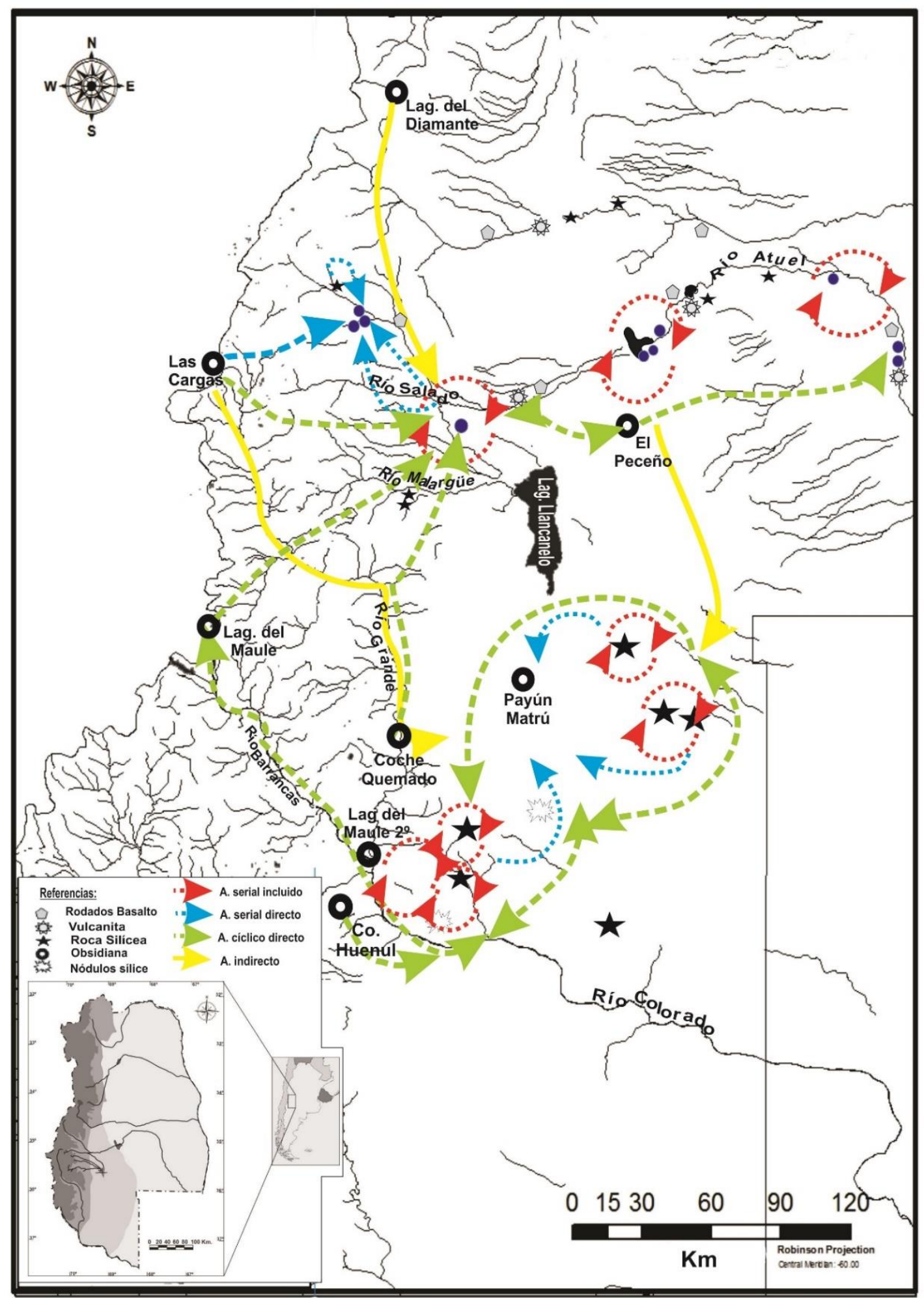

Figura 11.5. Modelo espacial de aprovisionamiento de recursos líticos en la cuenca del río Atuel y en La Payunia. Modificado de Salgán 2013: 387. 


\begin{tabular}{|c|c|c|c|c|c|c|c|c|c|c|c|c|c|c|}
\hline MP & \multicolumn{2}{|c|}{ AND } & \multicolumn{2}{|c|}{ BAS } & \multicolumn{2}{|c|}{$\mathbf{C Z}$} & \multicolumn{2}{|c|}{ OBS } & \multicolumn{2}{|c|}{ RIO } & \multicolumn{2}{|c|}{ SIL } & \multicolumn{2}{|c|}{ VUL } \\
\hline & $\begin{array}{c}\text { Rango } \\
\text { distancia }\end{array}$ & Aprovis. & $\begin{array}{c}\text { Rango } \\
\text { distancia }\end{array}$ & Aprovis. & $\begin{array}{c}\text { Rango } \\
\text { distancia }\end{array}$ & Aprovis & $\begin{array}{c}\text { Rango } \\
\text { distancia }\end{array}$ & Aprovis & $\begin{array}{c}\text { Rango } \\
\text { distancia }\end{array}$ & Aprovis. & $\begin{array}{c}\text { Rango } \\
\text { distancia }\end{array}$ & Aprovis. & $\begin{array}{c}\text { Rango } \\
\text { distancia }\end{array}$ & Aprovis \\
\hline CP-1 & $\begin{array}{c}\text { Inmediat. } \\
\text { disponibl } \\
\mathrm{e}\end{array}$ & $\begin{array}{c}\text { Serial } \\
\text { incluido }\end{array}$ & $\begin{array}{c}\text { Inmed. } \\
\text { disp.y } \\
\text { local } \\
\text { cercano }\end{array}$ & $\begin{array}{l}\text { Serial } \\
\text { incl. y } \\
\text { directo }\end{array}$ & $\begin{array}{l}\text { Local } \\
\text { cercano } \\
\text { lejano }\end{array}$ & $\begin{array}{c}\text { Serial } \\
\text { incluido }\end{array}$ & No local & $\begin{array}{l}\text { Cíclico } \\
\text { directo }\end{array}$ & $\begin{array}{c}\text { Local } \\
\text { cercano } \\
\text { lejano }\end{array}$ & $\begin{array}{c}\text { Serial } \\
\text { incluido }\end{array}$ & $\begin{array}{c}\text { Local } \\
\text { cercano } \\
\text { lejano }\end{array}$ & $\begin{array}{c}\text { Serial } \\
\text { directo }\end{array}$ & $\begin{array}{l}\text { Inmediat. } \\
\text { disponible }\end{array}$ & $\begin{array}{c}\text { Serial } \\
\text { incluido }\end{array}$ \\
\hline $\begin{array}{c}\text { AP-1 } \\
\mathbf{y} \\
\text { AP-2 }\end{array}$ & $\begin{array}{c}\text { Inmediat. } \\
\text { disponibl } \\
\mathrm{e}\end{array}$ & $\begin{array}{c}\text { Serial } \\
\text { incluido }\end{array}$ & $\begin{array}{c}\text { Inmed. } \\
\text { disp.y } \\
\text { local } \\
\text { cercano } \\
\end{array}$ & $\begin{array}{l}\text { Serial } \\
\text { incl. y } \\
\text { directo }\end{array}$ & $\begin{array}{c}\text { Local } \\
\text { cercano } \\
\text { lejano }\end{array}$ & $\begin{array}{c}\text { Serial } \\
\text { incluido }\end{array}$ & No local & $\begin{array}{l}\text { Cíclico } \\
\text { directo }\end{array}$ & $\begin{array}{c}\text { Local } \\
\text { cercano } \\
\text { lejano }\end{array}$ & $\begin{array}{c}\text { Serial } \\
\text { incluido }\end{array}$ & $\begin{array}{c}\text { Local } \\
\text { cercano } \\
\text { lejano }\end{array}$ & $\begin{array}{c}\text { Serial } \\
\text { directo }\end{array}$ & $\begin{array}{l}\text { Inmediat. } \\
\text { disponible }\end{array}$ & $\begin{array}{c}\text { Serial } \\
\text { incluido }\end{array}$ \\
\hline $\begin{array}{c}\text { CSA } \\
-1\end{array}$ & $\begin{array}{c}\text { Inmediat. } \\
\text { disponibl } \\
\mathrm{e}\end{array}$ & $\begin{array}{c}\text { Serial } \\
\text { incluido }\end{array}$ & $\begin{array}{c}\text { Inmed. } \\
\text { disp.y } \\
\text { local } \\
\text { cercano } \\
\end{array}$ & $\begin{array}{l}\text { Serial } \\
\text { incl. y } \\
\text { directo }\end{array}$ & $\begin{array}{c}\text { Local } \\
\text { cercano }\end{array}$ & $\begin{array}{c}\text { Serial } \\
\text { incluido }\end{array}$ & No local & $\begin{array}{l}\text { Cíclico } \\
\text { directo }\end{array}$ & $\begin{array}{c}\text { Local } \\
\text { cercano } \\
\text { lejano }\end{array}$ & $\begin{array}{c}\text { Serial } \\
\text { incluido }\end{array}$ & $\begin{array}{c}\text { Inmed. } \\
\text { disp.y } \\
\text { local } \\
\text { cercano }\end{array}$ & $\begin{array}{l}\text { Serial } \\
\text { incl. y } \\
\text { directo }\end{array}$ & $\begin{array}{l}\text { Inmediat. } \\
\text { disponible }\end{array}$ & $\begin{array}{c}\text { Serial } \\
\text { incluido }\end{array}$ \\
\hline $\begin{array}{c}\text { AR-6 } \\
\text { y } \\
\text { AR-7 }\end{array}$ & $\begin{array}{c}\text { Inmediat. } \\
\text { disponibl } \\
\mathrm{e}\end{array}$ & $\begin{array}{c}\text { Serial } \\
\text { incluido }\end{array}$ & $\begin{array}{c}\text { Inmediat. } \\
\text { disponibl } \\
\mathrm{e}\end{array}$ & $\begin{array}{c}\text { Serial } \\
\text { incluido }\end{array}$ & $\begin{array}{l}\text { Local } \\
\text { cercano }\end{array}$ & $\begin{array}{c}\text { Serial } \\
\text { incluido }\end{array}$ & $\begin{array}{c}\text { Local } \\
\text { cercano }\end{array}$ & $\begin{array}{c}\text { Serial } \\
\text { incluido }\end{array}$ & $\begin{array}{c}\text { Inmediat. } \\
\text { disponibl } \\
\mathrm{e}\end{array}$ & $\begin{array}{c}\text { Serial } \\
\text { incluido }\end{array}$ & $\begin{array}{l}\text { Inmed. } \\
\text { disp.y } \\
\text { local } \\
\text { cercano }\end{array}$ & $\begin{array}{l}\text { Serial } \\
\text { incl. y } \\
\text { directo }\end{array}$ & $\begin{array}{l}\text { Inmediat. } \\
\text { disponible }\end{array}$ & $\begin{array}{c}\text { Serial } \\
\text { incluido }\end{array}$ \\
\hline $\begin{array}{c}\text { BDP } \\
-1\end{array}$ & $\begin{array}{c}\text { Inmediat. } \\
\text { disponibl } \\
\mathrm{e}\end{array}$ & $\begin{array}{c}\text { Serial } \\
\text { incluido }\end{array}$ & $\begin{array}{c}\text { Inmediat. } \\
\text { disponibl } \\
\mathrm{e}\end{array}$ & $\begin{array}{c}\text { Serial } \\
\text { incluido }\end{array}$ & $\begin{array}{l}\text { Local } \\
\text { cercano }\end{array}$ & $\begin{array}{c}\text { Serial } \\
\text { incluido }\end{array}$ & $\begin{array}{c}\text { Local } \\
\text { cercano }\end{array}$ & $\begin{array}{c}\text { Serial } \\
\text { incluido }\end{array}$ & $\begin{array}{c}\text { Inmediat. } \\
\text { disponibl } \\
\text { e }\end{array}$ & $\begin{array}{c}\text { Serial } \\
\text { incluido }\end{array}$ & $\begin{array}{c}\text { Inmed. } \\
\text { disp.y } \\
\text { local } \\
\text { cercano }\end{array}$ & $\begin{array}{l}\text { Serial } \\
\text { incl. y } \\
\text { directo }\end{array}$ & $\begin{array}{l}\text { Inmediat. } \\
\text { disponible }\end{array}$ & $\begin{array}{c}\text { Serial } \\
\text { incluido }\end{array}$ \\
\hline LG-1 & $\begin{array}{c}\text { Inmediat. } \\
\text { disponibl } \\
\mathrm{e}\end{array}$ & $\begin{array}{c}\text { Serial } \\
\text { incluido }\end{array}$ & $\begin{array}{c}\text { Inmediat. } \\
\text { disponibl } \\
\mathrm{e}\end{array}$ & $\begin{array}{c}\text { Serial } \\
\text { incluido }\end{array}$ & $\begin{array}{c}\text { Inmediat. } \\
\text { disponibl } \\
\mathrm{e}\end{array}$ & $\begin{array}{c}\text { Serial } \\
\text { incluido }\end{array}$ & No local & $\begin{array}{l}\text { Cíclico } \\
\text { directo }\end{array}$ & $\begin{array}{c}\text { Inmediat. } \\
\text { disponibl } \\
\text { e }\end{array}$ & $\begin{array}{c}\text { Serial } \\
\text { incluido }\end{array}$ & $\begin{array}{c}\text { Inmed. } \\
\text { disp.y } \\
\text { local } \\
\text { cercano }\end{array}$ & $\begin{array}{l}\text { Serial } \\
\text { incl. y } \\
\text { directo }\end{array}$ & $\begin{array}{l}\text { Inmediat. } \\
\text { disponible }\end{array}$ & $\begin{array}{c}\text { Serial } \\
\text { incluido }\end{array}$ \\
\hline $\begin{array}{c}\text { EB-3 } \\
\text { y } \\
\text { EB-5 }\end{array}$ & $\begin{array}{c}\text { Inmediat. } \\
\text { disponibl } \\
\mathrm{e}\end{array}$ & $\begin{array}{c}\text { Serial } \\
\text { incluido }\end{array}$ & $\begin{array}{c}\text { Inmediat. } \\
\text { disponibl } \\
\mathrm{e}\end{array}$ & $\begin{array}{c}\text { Serial } \\
\text { incluido }\end{array}$ & $\begin{array}{c}\text { Inmediat. } \\
\text { disponibl } \\
\mathrm{e}\end{array}$ & $\begin{array}{c}\text { Serial } \\
\text { incluido }\end{array}$ & No local & $\begin{array}{l}\text { Cíclico } \\
\text { directo }\end{array}$ & $\begin{array}{c}\text { Inmediat. } \\
\text { disponibl } \\
\text { e }\end{array}$ & $\begin{array}{c}\text { Serial } \\
\text { incluido }\end{array}$ & $\begin{array}{c}\text { Inmed. } \\
\text { disp.y } \\
\text { local } \\
\text { cercano }\end{array}$ & $\begin{array}{l}\text { Serial } \\
\text { incl. y } \\
\text { directo }\end{array}$ & $\begin{array}{l}\text { Inmediat. } \\
\text { disponible }\end{array}$ & $\begin{array}{c}\text { Serial } \\
\text { incluido }\end{array}$ \\
\hline
\end{tabular}

Tabla 11.1. Rangos de distancia de materias primas a los sitios estudiados, y modo de aprovisionamiento sensu Custer (1983). 


\subsection{CONSIDERACIONES FINALES}

La información brindada por el estudio de los conjuntos líticos de la cuenca del río Atuel, permitió delinear tendencias tecnológicas espaciales y temporales. Se ha planteado el predominio de las rocas silíceas; el aumento de la obsidiana y de la diversidad de fuentes de esta roca a través del tiempo; el incremento de la bifacialidad hacia el HTF; el uso de rocas de menor calidad para la talla y la ocupación de los sitios del Monte hacia fines del Holoceno tardío; la formatización bifacial mayoritariamente sobre obsidiana y la unifacial principalmente sobre rocas silíceas; la ausencia o baja presencia de núcleos como modo de transporte de rocas; la baja o nula reserva de corteza en los sitios; la inversión de trabajo que se incrementa a mayor altitud; el aumento de la obsidiana con la altitud; la disminución en el tamaño de las puntas de proyectil y la estabilidad en los tamaños de los desechos de talla (generalmente, muy pequeños) a través del tiempo; la similitud en las funciones inferidas de los grupos tipológicos de los instrumentos entre el HTI y el HTF; diseños confiables y mantenibles (versátiles y flexibles), sobre todo en ambientes estacionales como el Desierto Altoandino; un predominio en el aprovisionamiento serial incluido en rocas locales y cíclico directo en rocas no locales; la baja representación de las etapas iniciales de manufactura; las trayectorias artefactuales más completas sobre rocas silíceas; y las trayectorias artefactuales de tipo secuenciales sobre rocas no locales (obsidiana). La integración de estas tendencias con los datos obtenidos en estudios previos, permitió generar modelos más sólidos vinculados a la organización de la tecnología lítica en el sur de Mendoza y, específicamente, en la cuenca del río Atuel. 


\section{CAPÍ́TULO 12}

\section{CONCLUSIONES Y PERSPECTIVAS}

En esta tesis se estudió la organización de la tecnología lítica de las poblaciones humanas prehispánicas que ocuparon los desiertos que atraviesa el río Atuel. Los objetivos estuvieron orientados a reconocer los modos de aprovisionamiento lítico y reconstruir las trayectorias artefactuales; y para alcanzarlos se plantearon tres hipótesis principales, que fueron validadas parcialmente.

Con respecto a la Hipótesis 1 (espacial), se concluye que la variabilidad topográfica, ecológica, climática y estacional de los ambientes del sur mendocino, habría influido en los modos de uso de la región y en las estrategias tecnológicas en los distintos ambientes. En la cuenca del Atuel, el estudio de los conjuntos líticos y la tasa de densidad de ocupaciones registrados en piedemonte y cordillera, muestran la selección de espacios con alta heterogeneidad de recursos, con locus de alta reocupación y circunscriptos a espacios estratégicos para la explotación de una alta variedad de recursos, distribuidos de manera desigual. El contexto de ocupación de la planicie, por su parte, presenta recursos distribuidos de manera más homogénea y con un patrón de asentamiento disperso, de ocupaciones cortas y de baja recurrencia. En conjunto, la caracterización de la base regional de recursos líticos y el análisis tecnológico, muestran una utilización recurrente -aunque de uso principalmente expeditivo- de las rocas de muy buena calidad para la talla disponibles en el espacio local. La explotación de rocas no locales (obsidiana) mostró un uso conservado en tierras altas y bajas, cuya representación se incrementa con la altitud. Las trayectorias artefactuales de los recursos líticos son semejantes en los tres ambientes, con predominio de las etapas intermedias y finales de manufactura sobre rocas silíceas, principalmente, para la confección de instrumentos bifaciales y unifaciales. Esto implica cierta disparidad en cuanto a la densidad de artefactos en cada ambiente, pero con una composición artefactual similar.

En relación a la Hipótesis 2, en el estudio de los conjuntos líticos no se observan indicadores de "recolonización" de los valles extra-cordilleranos (planicie), que habían sido ocupados durante el Holoceno temprano y principios del Holoceno medio (e.g. Gruta del Indio). Además, la información arqueológica es escasa -en su mayoría procedente de sitios de la cordillera y el piedemonte- e insuficiente para validar la hipótesis. Aun así, la mayor variedad de clases de roca y el aumento en la diversidad de clases artefactuales hacia 
principios del Holoceno tardío es congruente con una mayor explotación del ambiente y los recursos, y con una diversificación de las actividades llevadas a cabo en las áreas de ocupación.

Por último, en cuanto a la Hipótesis 3, no es posible validar ni rechazar el comienzo de la ocupación efectiva del espacio en el Holoceno tardío final, como lo sugieren el resto de los registros analizados en la región. Por un lado, no se identificó un incremento en la ocupación (vinculado a un aumento demográfico), del HTI al HTF. Por otro lado, las estrategias tecnológicas implementadas en cada ambiente fueron similares con el paso del tiempo, sin registrar cambios de un uso conservado en el HTI a un uso expeditivo en el HTF. Ambas estrategias se aplicaron complementariamente de acuerdo a las características de cada ambiente y en ambos periodos del Holoceno tardío. Otras expectativas sí fueron validadas: hacia el HTF se observó mayor variabilidad de materias primas y de fuentes de obsidiana, lo que habría implicado modificaciones en los modos de aprovisionamiento y de interacción.

La información obtenida en esta tesis y su integración con el registro arqueológico regional, permitieron definir las distintas estrategias humanas empleadas en los ambientes árido-semiáridos del sur de Mendoza. Considerando a las materias primas líticas como un recurso más (al igual que las plantas y animales), se utilizaron modelos procedentes de la biogeografía humana, la Teoría de Forrajeamiento Óptimo y la Organización de la Tecnología, para discutir la implementación de las estrategias tecnológicas a través del tiempo en relación a la base regional de recursos líticos, los modos de aprovisionamiento y las trayectorias artefactuales de cada materia prima en los tres desiertos donde se emplazan los sitios arqueológicos estudiados, así como sus modos de ocupación. Por ejemplo, la distancia a las fuentes de aprovisionamiento de las rocas de mejor calidad para la talla y su grado de accesibilidad, fueron variables discutidas siguiendo el principio de optimización.

A futuro, resta complementar la información generada con otras líneas de evidencia arqueológica disponibles, evaluar modelos específicos de optimización (e.g. amplitud de dieta y elección de parches), abordar otros aspectos de la tecnología lítica (e.g. estudios petrográficos, funcionales, experimentales de sistemas de armas, etc.) e incrementar el número de muestras analizadas, para determinar si las tendencias observadas en la cuenca del Atuel van más allá de los límites geográficos definidos por este río. No obstante, aquí se pudieron reconocer patrones similares entre los tres desiertos en relación al uso de materias primas, a sus trayectorias artefactuales y al tipo de estrategia tecnológica utilizada a lo largo del tiempo. Más allá de sus similitudes, cada desierto implicó estrategias adaptativas (tecnológicas y de aprovisionamiento) y rangos de movilidad particulares, que permiten discutir y ampliar modelos acerca de las poblaciones que habitaron la región. 


\section{REFERENCIAS BIBLIOGRÁFICAS}

ABRAHAM, E.M. 1996. Mapa Geomorfológico de la Provincia de Mendoza en escala 1:500.000.

En: Atlas básico de Recursos de la región Andina Argentina. Informe Final. Enviado a Universidad de Granada, Junta de Gobierno Andalucía, España.

-2000. Geomorfología de la Provincia de Mendoza. En: ARGENTINA. Recursos y problemas ambientales de la zona árida. Primera parte: provincias de Mendoza, San Juan y La Rioja. Tomo I, Caracterización ambiental, E.M. Abraham y F. Rodriguez Martinez (eds.), pp: 2948. IADIZA. Mendoza.

ALDENDERFER, M. 1998. Mountain Forager. Asana and the South Central Archaic. University of Iowa Press, Iowa city.

AMBROSETTI, J. 1905. Arqueología Argentina. Insignia lítica de mando de tipo chileno. Anales del Museo Nacional de Buenos Aires Serie III (IV): 25-32.

AMBRÚSTOLO, P. 2011 Estudio de las Estrategias de Aprovisionamiento y Utilización de los Recursos Líricos por Grupos Cazadores Recolectores en la Costa Norte de Santa Cruz (Patagonia Argentina). Tesis doctoral inédita, 441 páginas. Facultad de Ciencias Naturales y Museo, Universidad Nacional de La Plata.

AMBRÚSTOLO, P., M.A. ZUBIMENDI, A. CASTRO, L. CIAMPAGNA, H. HAMMOND, L. ZILIO Y L. MAZZITELLI. 2015. Fuentes de materias primas líticas en la costa norte de Santa Cruz (Patagonia Argentina): el caso del sur de la ría Deseado. Intersecciones en Antropología, Volumen especial 2: 51-60.

AMICK, D. S. 1994. Technological organization and the structure of inference in lithic analysis: an examination of Folsom hunting behavior in the American Southwest. En: The organization of North American prehistoric chipped stone tools technologies, P. Carr (ed.), pp. 9-34. International Monographs in Prehistory, Archaeological Series 7. Ann Arbor, Michigan.

AMICK, D. Y R. MAULDIN. 1989. Experiments in Lithic Technology, D. Amick y R. Mauldin (eds.). BAR International Series 528.

ANDREFSKY JR., W. 1994. Raw-material availability and the organization of technology. American Antiquity 59 (1): 21-34.

-1998. Lithics. Macroscopic Appraches to Analysis. Manuals in Archaeology, Cambridge University Press.

-2009. The analysis of stone tool procurement, production, and maintenance. Journal of Archaeological Research 17: 65-103. 
ARAGÓN, E. Y N. V. FRANCO. 1997. Características de rocas para la talla por percusión y propiedades petrográficas. Anales del Instituto de la Patagonia (Serie Ciencias Humanas) 25: 87-199.

ARNOLD, E.R. Y H.J. GREENFIELD. 2004. A zooarchaeological perspective on the origins of vertical transhumant pastoralism and the colonization of marginal habitats in temperate southeastern Europe. En: Colonisation, Migration, and Marginal Areas. A Zooarchaeological Approach, M. Mondini, S. Muñoz y S. Wickler (eds.), pp. 96-117. Oxbow Books. UK.

ASCHERO, C. 1975. Ensayo para una clasificación morfológica de artefactos líticos aplicados a estudios tipológicos comparativos. Informe a CONICET. Ms.

-1983. Ensayo para una clasificación morfológica de artefactos líticos aplicada a estudios tecnológicos comparativos. Apéndice A-C. Revisión 1983. Cátedra de Ergología y Tecnología. Facultad de Filosofía y Letras. Universidad de Buenos Aires. Ms.

ASCHERO, C., L. MOYA, C. SOTELOS Y J. MARTÍNEZ. 1995. Producción lítica en los límites del bosque cordillerano: el sitio Campo Río Roble 1 (Santa Cruz, Argentina). Relaciones XX: 205-237, Sociedad Argentina de Antropología. Buenos Aires.

ASCHERO, C. Y S. HOCSMAN. 2004. Revisando cuestiones tipológicas en torno a la clasificación de artefactos bifaciales. En: Temas de Arqueología. Análisis Lítico, M. Ramos, A. Acosta y D. Loponte (eds.), pp. 7-25. Luján, Universidad Nacional de Luján.

BAMFORTH, D.B. 1986. Technological Efficiency and Tool Curation. American Antiquity 51 (1): $38-50$

-1991 Technological organization and hunter-gatherer land use: A California example. American Antiquity 56: 216-234.

-2006. The Windy Ridge quartzite quarry: hunter-gatherer mining land use in the North American Continental Divide. World Archaeology 38 (3): 511-527.

BAMFORTH, D. Y P. BLEED. 1997. Technology, flaked stone technology and risk. En: Rediscovering Darwin: evolutionary theory and archaeological explanation, C.M. Barton, y G.A. Clark (eds.), pp. 109-140. Archaeological Papers of the American Anthropological Association $\mathrm{N}^{\circ} 7$.

BANEGAS, A., J. GÓMEZ OTERO, S. GOYE y N. RATTO. 2014. Cabezales líticos del Holoceno tardío en Patagonia Meridional: diseños y asignación funcional. Magallania 42 (2):155-174.

BARBERENA, R. 2008. Arqueología y Biogeografía Humana en Patagonia Meridional. Colección Tesis Doctorales dirigida por V. Horwitz. Sociedad Argentina de Antropología. Buenos Aires.

-2013. Biogeografía, competencia y demarcación simbólica del espacio: Modelo arqueológico para el norte de Neuquén. Intersecciones en Antropología 14: 367-381. 
BARberenA R., M. P. POMPEI, C. OTAOLA, G. NEME, A. GIL, K. BORRAZZO, V. DURÁN Y R. HOGUIN. 2010. Pleistocene-Holocene transition in northern Patagonia: evidence from Huenul Cave (Neuquén, Argentina). Current Research in the Pleistocene 27: 4-7.

BARBERENA R., A. HAJDUK, A. F. GIL, G. A. NEME, V. DURÁN, M. D. GLASCOCK, M. GIESSO, K. BORRAZZO, M. P. POMPEI, M. L. SAlgÁn, V. CORTEGoso, G. VILLAROSA, A. Y A. RUGHINI. 2011. Obsidian in the south-central Andes: Geological, geochemical, and archaeological assessment of north Patagonian sources (Argentina), Quaternary International 245 (1): 25-36.

BARRIENTOS, G. 2016. On the problem of identifying homologies in lithic artifacts. En: Darwin's Legacy: The Status of Evolutionary Archaeology in Argentina, M. Cardillo y H. Muscio (eds.), pp. 49-66. Archaeopress. Oxford.

BARRIENTOS, G., L. CATELLA Y F. OLIVA. 2014. The spatial structure of lithic landscapes: The Late Holocene record of east-central Argentina as a case study. Journal of Archaeological Method and Theory. Online First. DOI 10.1007/s10816-014-9220-0.

BAYÓN, C. Y N. FLEGENHEIMER. 2004. Cambio de planes a través del tiempo para el traslado de roca en la pampa bonaerense. Estudios Atacameños 28: 59-70.

BAYÓN, C., N. FLEGENHEIMER, M. VALENTE Y A. PUPIO. 1999. Dime cómo eres y te diré de dónde vienes: procedencia de rocas cuarcíticas en la Región Pampeana. Relaciones de la Sociedad Argentina de Antropología XXIV: 187-217.

BEATON, J. M. 1973. The Nature of Aboriginal Exploitation of Mollusk Populations in Southern California. Tesis de maestría. University of California, Los Angeles.

BECK, C., A.K. TAYLOR, G. T. JONES, C.M. FADEM, C. R. COOK y S. A. MILLWARD. 2002. Rocks are heavy: transport costs and Paleoarchaic quarry behavior in the Great Basin. Journal of Anthropological Archaeology 21: 481-507.

BECK, C. Y G.T. JONES. 2011. The Role of Mobility and Exchange in the Conveyance of Toolstone During the Great Basin Paleorchaic. En: Perspectives on Prehistoric Trade and Exchange in California and the Great Basin, Hughes, R. E. (ed.), pp. 55-82. The University of Utah Press, Salt Lake City. Utah.

BELARDI, J. B. 2005. Paisajes arqueológicos: un estudio comparativo de diferentes ambientes patagónicos. Oxford, British Archaeological Reports 1390.

BELARDI, J.B., L.A. BORRERO, P.A. CAMPAN, F. CARBALLO MARINA, N.V. FRANCO, M.F. GARCÍA, V.D. HORWITZ, J.L. LANATA, F.M. MARTIN, F.E. MUÑOZ, A.S. MUÑOZ Y F. SAVANTI. 1992. Intensive archaeological survey in the Upper Santa Cruz basin, Southern Patagonia. Current Anthropology 33: 451-454.

BELLELLI, C. 1991. Los desechos de talla en la interpretación arqueológica. Un sitio de superficie en el Valle de Piedra Parada (Chubut). Shincal 3 (2): 79-93. 
-2004. Tecnología y materias primas a la sombra de Don Segundo. Una cantera-taller en el valle de Piedra Parada. Intersecciones en Antropología 6: 75-92.

BELLELLI, C., A. GURAIEB y J. GARCÍA. 1987. Propuesta para el análisis y procesamiento por

computadora de desechos de talla lítica (DELCO). Arqueología Contemporánea 2: 36-53.

BELlelli, C., F. X. PEREYRA Y M. CARBALLIDO. 2006. Obsidian localization and circulation in northwestern Patagonia (Argentina): sources and archaeological record. En: Geomaterials in Cultural Heritage, M. Maggetti y B. Messiga (eds.), pp. 241-255. Geological Society, Special Publications, Londres.

BERBEL, M. 1972 (2017). Flecha. En: Cuentos al viento: relatos de la Patagonia, C. Abadie (ed.), pp. 75-76. Trelew, Chubut.

BERMÚdEZ, A., D. DELPINO, F. FREY y A. SAAL. 1993. Los Basaltos de Retroarco Extraandinos. En: Geología y Recursos Naturales de Mendoza. XII ${ }^{\circ}$ Congreso Geológico Argentino y II $^{\circ}$ Congreso de Exploración de Hidrocarburos (Mendoza, 1993), V.A. Ramos (ed.), Relatorio, I (13), pp.: 161-172. Buenos Aires.

BERÓN, M. A. 2004. Dinámica Poblacional y Estrategias de Subsistencia de Poblaciones Prehispánicas de la Cuenca Atuel-Salado-Chadileuvú-Curacó, Provincia de La Pampa. Tesis Doctoral inédita. Facultad de Filosofía y Letras, UBA, Buenos Aires.

-2007. Circulación de bienes como indicador de interacción entre las poblaciones de la pampa occidental y sus vecinos. En: Arqueología en la Pampas, C. Bayón, A. Pupio, M. I. González, N. Flegenheimer y M. Frere (eds.), pp. 345-364. Sociedad Argentina de Antropología. Buenos Aires.

BETTINGER, R. 1983. Return rates and intensity of resource use in Numic and Prenumic adaptative strategies. American Antiquity 48 (4): 830-834.

-1991. Hunter-Gatherers: Archaeological and Evolutionary Theory. Plenum Press, Nueva York. -2001. Holocene hunter-gatherers. En: Archaeology at the millenium: A sourcebook, G. M. Feinman y T. Douglas Price (comps.), pp.137-195. Kluwer Academia/ Plenum Publishers, Nueva York.

-2009. Hunter-gatherer foraging: five simple models. Clinton Corners, New York: Eliot Werner.

BETTINGER, R. L. Y M. A. BAUMHOFF. 1982. The Numic spread: Great Basin cultures in competition. American Antiquity 47: 485-503.

BETTINGER R. L., B. WINTERHALDER Y R. MC ELREATH. 2006. A simple model of technological intensification. Journal of Archaeological Science 33: 538-545.

BETTS, M. W. Y FRIESEN, T. M. 2004. Quantifying hunter-gatherer intensification: a zooarchaeological case study from Arctic Canada. Journal of Anthropological Archaeology 23: 357-384. 
BINFORD, L.R. 1973. Interassemblage variability - the Mousterian and the "functional" argument. En: The Explanation of Culture Change, C. Renfrew (comp.), pp. 227-254Londres, Duckworth Press.

-1977. Forty-seven trips: a case study in the character of archaeological formation processes. En:

Stone tools as cultural markers, R. Wright (ed.), pp. 24-36. Australian Institute of Aboriginal Studies, Canberra.

-1979. Organization and Formation Processes: Looking at Curated Technologies. Journal of Anthropological Research 35 (3): 255-273.

-1980. Willow smoke and dog's tails: hunter-gatherer settlement system and archaeological site formation. American Antiquity 45 (1): 4-20.

-1982. The Archaeology of Place. Journal of Anthropological Archaeology 1:5-31.

-1983. Long-term land use patterns: Some implications for archaeology. En: Lulu linear punctuated: Essays in honor of George Irving Quimby, R. C. Dunnell y D. K. Grayson (eds.), pp. 27-53. Anthropological Papers 72, University of Michigan Museum of Anthropology.

-2001. Constructing Frames of Reference: An Analytical Method for Archaeological Theory Building Using Ethnographic and Environmental Data Sets. University of California, Berkeley.

BIRD, D. Y J. O'CONNELL. 2006. Behavioral Ecology and Archaeology. Journal of Archaeological Research 14: 143-188.

BLEED, P. 1986. The Optimal design of hunting weapons: Maintainability or Reliability. American Antiquity 51 (4): 737-747.

BLEED, P. Y A. BLEED. 1987. Energetic efficiency and hand tool design: a performance comparison of push and pull stroke saws. Journal of Anthropological Archaeology 6: 189-197.

BOBILLO, F. M. Y S. HOCSMAN. 2015. Mucho más que solo aprovisionamiento lítico: actividades en canteras y prácticas sociales en las fuentes de Pampa Oeste, Quebrada Seca y Punta de la Peña (Antofagasta de la Sierra, Catamarca). Revista del Museo de Antropología 8: 23-44.

BÖCHER, T. W., J. P. HJERTING Y K. RAHN. 1972. Botanical Studies in the Atuel Valley Area, Mendoza Province, Argentina. Part III. Dansk Botanisk Arkiv 22. Ejnar Munksgaard, Copenhagüe.

BÖEDA, E. 1995. Levallois: A volumetric construction, methods, a technique. En: The Definition and Interpretation of Levallois Technology, H. L. Dibble y O. Bar-Yosef (eds.), pp. 41-68. University of Pennsylvania Press, Filadelfia.

BOMAN, E. 1920. Cementerio Indígena de Viluco, posterior a la conquista. Anales del Museo Nacional de Buenos Aires. Tomo XXX, 562 páginas. Buenos Aires.

BONNAT, G. F. 2009. Estrategias de Abastecimiento y Producción Lítica Durante el Holoceno Tardío en el Sitio Valle Hermoso 1 (Malargüe, Mendoza). Tesis de licenciatura, 137 páginas. 
Facultad de Ciencias Sociales, Universidad del Centro de la Provincia de Buenos Aires. Olavarría, Buenos Aires.

-2011. Abastecimiento y producción lítica en el sitio Valle Hermoso I (Malargüe, Mendoza). Intersecciones en Antropología 12: 121-134.

BOONE, J.L. Y E.A. SMITH. 1998. Is it Evolution yet? A critique of Evolutionary Archaeology. Current Anthropology 39 (S1): 141-173.

BORDES, F. 1961. Typologie du Paléolithique ancien et moyen. Bordeaux, Ed. Delmas.

BORRAZZO, K. 2010. Arqueología de los esteparios Fueguinos: Tecnología y Tafonomía Lítica en el Norte de Tierra del Fuego. Tesis Doctoral inédita, 917 páginas. Facultad de Filosofía y Letras, Universidad de Buenos Aires. Buenos Aires.

BORRERO, L.A. 1989-90. Evolución cultural divergente en la Patagonia austral. En: Anales del Instituto de la Patagonia, Serie Ciencias Sociales 19: 133-140.

-1994-95 Arqueología de la Patagonia. Palimpsesto 4:9-69.

-2001. Cambios, Continuidades y Discontinuidades: Discusiones sobre Arqueología FuegoPatagónica. En: Historia Prehispánica Argentina (Tomo II), E. Berberián y A.E. Nielsen (eds.), pp. 815-838. Ed. Brujas, Córdoba.

-2002. Arqueología y biogeografía humana en el sur de Mendoza (Comentario crítico). En: Entre Montañas y Desiertos: Arqueología del sur de Mendoza, A. F. Gil y G. A. Neme (eds.), pp. 195-202. Sociedad Argentina de Antropología. Buenos Aires.

-2004. The Archaeozoology of the Andean 'Dead End' in Patagonia: Living near the Continental Ice Cap. En: Colonization, Migration and Marginal Areas. A Zooarchaeological approach, M. S. Mondini, A.S. Muñoz y S. Wickler (eds.), pp. 55-61. Oakville, Oxbow Books. UK.

-2005. The Archaeology of the Patagonian Deserts: Hunter-Gatherers in a Cold Desert. En: Desert Peoples. Archaeological Perspectives, P. Veth, M. Smith y P. Hiscock (eds.), pp. 142-158. Oxford, Blackwell.

-2011. La arqueología de cazadores-recolectores: ambiente y conocimiento. CazadoresRecolectores del Cono Sur 4:43-58.

-2012. La Patagonia cuyana. Logros y desafíos. En: Paleoecología humana en el sur de Mendoza: perspectivas arqueológicas, G. Neme y A. Gil (comps.), pp. 281-295. Sociedad Argentina de Antropología. Buenos Aires.

BORRERO, L.A. Y N. FRANCO. 1997. Early patagonian hunter-gatherers: subsistence and technology. Journal of Anthropological Research 53: 219-239.

BOSCHÍN, M.T. Y A.M. LLAMAZARES. 1984. La Escuela Histórico-Cultural como factor retardatario del desarrollo científico de la Arqueología Argentina. Etnia 32: 101-156.

BOUSMAN, C. B. 1993. Hunter-Gatherer Adaptations, Economic Risk and Tool Design. Lithic Technology 18 (1/2): 59-86. 
-2005. Coping with risk: Later Stone Age technological strategies at Blydefontein Rock Shelter, South Africa. Journal of Anthropological Archaeology 24: 193-226.

BRADBURY, C. Y R. CARR. 1995. Flake typologies and alternative approaches: an experimental assessment. Lithic Technology 20: 100-116.

BRANTINGHAM, P. J. 2003. A neutral model of stone raw material procurement. American Antiquity 68 (3): 487-509.

BROUGHTON J.M. 1994a. Declines in Mammalian foraging Efficiency during the Late Holocene, San Francisco Bay, California. Journal of Antrhopological Archaeology 13: 371401.

BROUGHTON, J.M. 1994b. Late Holocene Resource Intensification in the Sacramento Valley, California: The Vertebrate Evidence. Journal of Archeological Science 21: 501-514.

BRUNIARD, E. D. 1982. La Diagonal Árida argentina. Un límite climático real. Revista Geográfica IPGH 95: 5-20.

BRYSON, R. 1994. On integratin Climatic change and Culture change study. Human Ecology, vol $22 \mathrm{~N}^{\mathrm{o}} 1: 115-128$.

BURCKHARDT, C. Y H. WHERLI. 1900. Profils geologiques transversaux de la cordillere argentino-chilienne. Anales del Museo de La Plata 2 (1): 136.

BUTLER, V. L. Y S. K. CAMPBELL. 2004. Resource Intensification and Resource Depression in the Pacific Northwest of North America: A Zooarchaeological Review. Journal of World Prehistory 18 (4): 327-405.

CABRERA, A.L. 1971. Fitogeografía de la República Argentina. Boletín de la Sociedad Argentina de Botánica 14: 1-42.

-1976. Regiones Fitogeográficas Argentinas. Enciclopedia Argentina de Agricultura y Jardinería, II (1) Ed. Acme. Buenos Aires.

CABRERA, A. L. Y A. WILLINK. 1973. Biogeografia de América Latina. Organización de los Estados Americanos, Washington, DC.

CAMPOS, G., V. CORTEGOSO Y C. MAZZANTI. 2006. Estrategias tecnológicas y cambios en el uso de los recursos líticos. Caverna de las Brujas, Malargüe, Mendoza. En: Arqueología y Ambiente de Áreas Naturales Protegidas de la Provincia de Mendoza, V. Durán y V. Cortegoso (eds.). Anales de Arqueología y Etnología. Vol. Especial No 61. Mendoza.

CANALS FRAU, S. 1937. Etnología Histórica de la provincia de Mendoza. Relaciones de la Sociedad Argentina de Antropología I, pp-91-106.

-1953. Las Poblaciones Indígenas de la Argentina. Ed. Sudamericana, 575 páginas. Buenos Aires. -1955. Las civilizaciones prehispánicas de América. Ed. Sudamericana, 648 páginas. Buenos Aires.

-1956. Algunos aspectos de la cultura de Agrelo (Prov. de Mendoza). Anales de Arqueología y Etnología. Tomo XII: 7-18. Universidad Nacional de Cuyo. 
CANALS FRAU, S. y J. SEMPER. 1956. La cultura de Agrelo (Mendoza). Runa Vol. VII, segunda parte, pp.160-187. Buenos Aires.

CANNON, M.D. Y J.M. BROUGHTON. 2010. Evolutionary Ecology and Archaeology. An introduction. En: Evolutionary Ecology and Archaeology. Applications to problems in Human Evolution and Prehistory, J.M. Broughton y M.D. Cannon (eds.). The University of Utah Press, Salt Lake City.

CAPITANELLI, R. 1972. Geomorgología y Clima de la provincia de Mendoza. En: Boletín de la Sociedad Argentina de Botánica, Suplemento del volumen XIII, A. L. Cabrera (director), pp15-48. X Jornadas Argentinas de Botánica. Las ciencias Naturales en la Provincia de Mendoza. Mendoza.

-2005. Climatología de Mendoza. Colección Cumbre Andina, Editorial de la Facultad de Filosofía y Letras. Mendoza.

CARDILLO, M. Y J. ALBERTI. 2015. The evolution of projectile points and technical systems: A case from Northern Patagonian coast (Argentina). Journal of Archaeological Science: Reports 2: 612-623.

CARDILlO, M. Y J. CHARLIN. 2007. Tendencias observadas en la variabilidad de los raspadores de Norte y Sur de Patagonia. Explorando las interrelaciones entre forma, tamaño e historia de vida. Trabajo presentado en $2^{\circ}$ Congreso Argentino y $1^{\circ}$ Latinoamericano de Arqueometría, Buenos Aires.

CARR, P. 1994. The organization of technology: impact and potential. En: The Organization of North American Prehistoric Chipped Stone Toll Technologies, P. Carr (ed.), pp. 1-8. International Monographs in Prehistory, Archaeological Series 7.

CASHDAN, E. 1990. Introduction. En: Risk and Uncertainty in Tribal and Peasant Economies, E. Cashdan (ed.), pp. 1-16. Westview Press, USA.

-1992. Spatial organization and habitat use. En: Evolutionary Ecology and Human Behavior, E. Smith y B. Winterhalder (eds.), pp. 237-266. Aldine de Gruyter. New York.

CASTRO, S.C. 2015. Explotación de recursos líticos durante el Holoceno en el límite de vertientes cordilleranas. Valle del rio de Las Taguas, San Juan, Argentina. Tesis Doctoral inédita, 432 páginas. Facultad de Filosofía y Humanidades, Universidad Nacional de Córdoba. Córdoba.

CASTRO, S., A. GASCO, G.F. LUCERO, V. CORTEGOSO Y V. DURÁN. 2013. Mid-Holocene hunters and herders of southern cordillera, Northwestern Argentina. Quaternary International 307: 96-104.

CATTANEO, R. 2004. Desarrollo metodológico para el estudio de fuentes de aprovisionamiento lítico en la meseta central santacruceña, Patagonia argentina. Estudios Atacameños 28: 105119. 
CHARLIN, J. 2007. Una perspectiva espacial de la intensidad de uso de las materias primas líticas en el campo volcánico Pali Aike (Prov. Santa Cruz, Argentina). En: Arqueología de FuegoPatagonia. Levantando piedras, desenterrando huesos... y develando arcanos. F., M. Carballo, A. Martinic, Prieto, y G. Bahamonde (eds.), pp. 129-150. CEQUA. Punta Arenas, Chile.

-2009a. Aprovisionamiento, explotación y circulación de obsidianas durante el Holoceno tardío en Pali Aike (Provincia de Santa Cruz). Relaciones de la Sociedad Argentina de Antropología XXXIV: 53-73.

-2009b. Estrategias de aprovisionamiento y utilización de las materias primas líticas en el Campo Volcánico Pali Aike (Prov. Santa Cruz, Argentina). British Archaeological Reports International, Oxford, Archaeopress.

CHARLIN, J. Y R. GONZÁLEZ-JOSÉ. 2012. Size and Shape Variation in Late Holocene Projectile Points of Southern Patagonia: a Geometric Morphometric Study. American Antiquity 77 (2): 221-242.

CHARNOV, E. L. 1976. Optimal foraging and the Marginal Value Theorem. Theoretical Population Biology 9: 129-136.

CHURCH, T. 1994. Terms in lithic resource studies. Lithic resource studies: a source for archaeologist. Lithic Technology 3: 9-25.

CINGOLANI, C.A. 2017. Pre-Carboniferous Evolution of the San Rafael Block, Argentina. Springer International Publishing.

CIVALERO, M.T. 2000. Circulación, aprovechamiento de recursos líticos y estrategias de diseño en el sur patagónico. Arqueología 10: 135-152.

-2006. De roca están hechos: introducción a los análisis líticos. En: El modo de hacer las cosas. Artefactos y ecofactos en Arqueología, C. Pérez de Micou (ed.), pp. 35-75. Dpto. de Ciencias Antropológicas, Facultad de Filosofía y Letras. Universidad de Buenos Aires. Buenos Aires.

CIVALERO, M.T. Y N. FRANCO. 2003. Early human occupations in Western Santa Cruz Province, Southermost South America. Quaternary Internacional: 77-86.

CODDING, B.F. Y D. W. BIRD. 2015. Behavioral Ecology and the Future of Archaeological Science. Journal of Archaeological Science 56: 2-20.

COLES, G. Y C.M. MILLS. 1998. Clinging on for grim life: an introduction to marginality as an archaeological issue. En: Life on the Edge: Human Settlement and Marginality (Symposia of the Association for Environmental Archaeology 13), C. M. Mills y G. Coles (eds.), pp. vii-xii. Oxford, Oxbow Books.

COLOMBO, M. 2013. Los cazadores recolectores pampeanos y sus rocas. La obtención de materias primas líticas vista desde las canteras arqueológicas del centro de Tandilia. Tesis Doctoral inédita, 476 páginas. Facultad de Ciencias Naturales y Museo, Universidad Nacional de La Plata. La Plata. 
COLOMBO M. Y N. FLEGENHEIMER. 2013. La elección de rocas de colores por los pobladores tempranos de las sierras de Lobería (Buenos Aires, Argentina). Nuevas consideraciones desde las canteras. En: Boletín del Museo Chileno de Arte Precolombino 18:125-137.

COMBINA, A.M. Y NULLO, F. 2011. Ciclos tectónicos, volcánicos y sedimentarios del Cenozoico del sur de Mendoza- Argentina ( $35^{\circ}-37^{\circ} \mathrm{S}$ y $\left.69^{\circ} 30^{\prime} \mathrm{W}\right)$. Andean Geology 38: 198-218.

CORBAT, M. 2016. Variabilidad ambiental y sociocultural en la explotación de peces en el centro-occidente argentino: Una evaluación zooarqueológica. Tesis Doctoral inédita, 587 páginas. Facultad de Filosofía y Letras, Universidad de Buenos Aires. Buenos Aires

CORBAT, M., A.F.J. ZANGRANDO Y A. GIL. 2009. El estudio de restos de peces en conjuntos arqueológicos del sur de Mendoza. En: Arqueología de Patagonia: una mirada desde el último confin, M. Salemme, F. Santiago, M. Álvarez, E. Piana, M. Vázquez y E. Mansur (eds.), 717727, Editorial Utopías. Ushuaia.

CORTEGOSO, V. 2004. Organización Tecnológica: Explotación de recursos líticos y el cambio en la subsistencia de cazadores a agricultores en el N.O. de Mendoza. Tesis doctoral inédita, 454 páginas. Facultad de Ciencias Naturales y Museo, Universidad Nacional de La Plata. La Plata.

-2005a. Mid-Holocene hunters in the Andes Mountains: environment, resources and technological strategies. Quaternary International 132: 71-80.

-2005b. Aproximaciones teóricas y metodológicas para el estudio tecnológico: variables sincrónicas y diacrónicas en el análisis lítico. En: Anales de Arqueología y Etnología $\mathrm{N}^{\mathrm{o}} 59 \mathrm{y}$ 60: 107-148. Universidad Nacional de Cuyo, Facultad de Filosofía y Letras, Instituto de Arqueología y Etnología. Mendoza.

-2009. Disponibilidad de recursos líticos en el noroeste de Mendoza: cambios en la organización tecnológica en la cuenca del río Blanco. Cazadores y Recolectores del Cono Sur 3: 95-113.

CORTEGOSO, V., G. NEME, M. GIESSO, V. DURÁN Y A. GIL. 2012. El uso de la obsidiana en el sur de Mendoza. En: Paleoecología humana en el sur de Mendoza: perspectivas arqueológicas, G. Neme y A. Gil (comps.), pp. 181-212. Sociedad Argentina de Antropología. Buenos Aires.

CUSTER, J., J. CAVAllO y M. STEWART. 1983. Lithic Procurement an Paleo-Indian Settlement Patterns on the Middle Atlantic Coastal Plain. North American Archaeologist 4: 263-275.

D’ANTONI, H. L. 1983. Pollen analysis of Gruta del Indio. En: Quaternary of South America and Antartic Peninsula, №1, Rabassa, J. (ed.), pp. 81-109. Holanda.

DEARING, J. 2006. Climate-human-environment interactions: resolving our past. Climate of the Past 2: 187-203. 
DEBENEDETTI, S. 1917. Investigaciones arqueológicas en los Valles Preandinos de San Juan.

En: Publicaciones de la Sección Antropología de la Facultad de Filosofia y Letras, №15, pp. 1-185. Buenos Aires.

DE FRANCESCO, C. G. 2010. Moluscos y paleoambientes del centro-oeste de Argentina durante el Cuaternario. En: Condiciones Paleoambientales y ocupaciones humanas durante la transición Pleistoceno-Holoceno de Mendoza, M. Zárate, A. Gil y G. Neme (eds.), pp. 151174. Sociedad Argentina de Antropología. Buenos Aires.

DE FRANCESCO, C. G. y S. DIÉGUEZ. 2006. Anales de Arqueología y Etnología. Vol. Especial: $\mathrm{N}^{\mathrm{o}} 61$.

DE FRANCESCO, A., V. DURÁN, A. BLOISE Y G. NEME. 2006. Caracterización y Procedencia de Obsidiana de Sitios Arqueológicos de Área Natural Protegida Laguna del Diamante (Mendoza, Argentina) con Metodología No Destructiva por Fluorescencia de Rayos (XRF). En: Arqueología y Ambiente de Áreas Naturales Protegidas de la Provincia de Mendoza, V. Durán y V. Cortegoso (eds.), pp. 53-67. Anales de Arqueología y Etnología. Vol. Especial No 61 . Mendoza.

DIBBLE, H. L. 1984. Interpreting typological variation of Middle Paleolithic scraperss: function, style, or sequence of reduction? Journal of Field Archaeology 11: 431-436.

-1987. The interpretation of Middle Paleolithic Scraper Morfology. American Antiquity 52 (1): 109-117.

DIEGUEZ S. Y G. NEME. 2003. Geochronology of the archaeological site Arroyo Malo 3 and the first human occupations in the Northpatagonia early Holocene. En: Ancient Evidence for Paleo South Americans: From Where the South Winds Blows, Miotti, L.; Salemme M., and Flegenheimer, N. (eds), pp. 87-92. Center for the Study of the First Americans. Texas A\&M University Press.

DIEGUEZ, S., A. GIL, G. NEME, M. ZÁRATE, C. DE FRANCESCO y E. STRASSER. 2004. Cronoestratigrafía del sitio Rincón del Atuel-1 (San Rafael, Mendoza): formación del sitio y ocupación humana. Intersecciones 5: 71-80.

DINCAUZE, D.F. 2000. Environmental Archeology: Principles and practice. Cambridge University Press.

DUNNELL, R.C. 1980. Evolutionary theory and archaeology. Advances in Archaeological Method and Theory 3: 35-99.

DURÁN, V. 1992. Estudios Arqueológicos en el Curso Medio del Valle del Río Grande (Malargüe-Mza). Ms. Informe final beca de formación superior. CONICET. Buenos Aires. -1997. Arqueología del valle río Grande, Malargüe, Mendoza. Tesis Doctoral Inédita. Tomo 2. Facultad de Ciencias Naturales y Museo. Universidad Nacional de La Plata. La Plata. 
-2002. Nuevas consideraciones sobre la problemática arqueológica del valle del río Grande (Malargüe, Mendoza). En: Entre Montañas y Desiertos: arqueología del sur de Mendoza. A. Gil y G. Neme (eds.), Sociedad Argentina de Antropología. Buenos Aires.

-2000. Poblaciones indígenas de Malargüe. Su Arqueología e Historia. Universidad Nacional de Cuyo/ Facultad de Filosofía y Letras. CEIDER, Serie libros No 1 . Mendoza.

DURÁN, V. Y J. FERRARI. 1991. El proceso de araucanización en el sur mendocino desde una perspectiva arqueológica. En: Actas del XI Congreso Nacional de Arqueoloía Chilena III, pp. 165-188. Chile.

DURÁN, V., G. NEME Y A. GIL. 1999. Algunos problemas relacionados con el registro arqueológico de alero Puesto Carrasco (curso medio del valle del río Grande, Malargüe, Mendoza). En: Soplando el Viento... Actas de las Terceras Jornadas de Arqueología de la Patagonia, pp. 333-356. Puerto Madryn. Chubut.

DURÁN, V., M. GIESSO, M. GLASCOCK, G. NEME, A. GIL y L. SANHUEZA. 2004. Estudio de fuentes de aprovisionamiento y redes de distribución de obsidiana durante el Holoceno tardío en el sur de Mendoza (Argentina). Estudios Atacameños 28: 25-43. San Pedro de Atacama, Chile.

DURÁN V., Y R. MIKKAN. 2009. Impacto del volcanismo holocénico sobre el poblamiento humano del sur de Mendoza (Argentina). Intersecciones en Antropología 10: 295-310.

EERKENS, J. 2011. Pot Conveyance, Design Characteristics, and Precontact Adaptations to Arid Environments. En: Perspectives on Prehistoric Trade and Exchange in California and the Great Basin, Hughes, R. E. (ed.), pp. 135-147. The University of Utah Press, Salt Lake City. Utah.

-2012. A model for predicting economic interaction in arid lands and an evaluation in Eastern California based on brownware ceramics. En: Meet at the Margins. Prehistoric Cultural Interaction in the Intermountain West, D. Rhode (ed.), pp. 229-245. Utah Press.

ERICSON, J.E. 1984. Toward the analysis of lithic production systems. En: Prehistoric quarries and lithic production, J.E. Ericson, y B.A. Purdy (eds.), pp. 1-9. Cambridge University Press. Cambridge.

ERICSON, E. Y B. PURDY. 1984. Prehistoric quarries and lithic production. Cambridge University Press. Cambridge.

ESCOLA, P.S. 2000. Tecnología Lítica y Sociedades Agro-pastoriles Tempranas. Tesis Doctoral Inédita, 335 páginas. Facultad de Filosofía y Letras, Universidad de Buenos Aires. Buenos Aires.

-2002. Disponibilidad de recursos líticos y fuentes de aprovisionamiento en un sector de la puna meridional. Mundo de Antes 3: 65-84.

-2004a. La expeditividad y el registro arqueológico. Chungara; vol. Especial, pp. 49-60. 
-2004b. Variabilidad en la explotación y distribución de obsidianas en la Puna Meridional argentina. Estudios Atacameños 28: 9-24.

ESPINOSA, S. 1995. Dr. School y Monsier Fleur: de Talones y Bulbos. Cuadernos del Instituto Nacional de Antropología y Pensamiento Latinoamericano 16: 315- 328.

ESPIZÚA, L. E. 1993. Quaternary glaciations in the Río Mendoza valley, Argentine Andes. Quaternay Research 40: 150-162.

-1998. Secuencia glacial del Pleistoceno tardío en el valle del Río Grande, Mendoza, Argentina. Bamberger Geographische Schriften 15(S): 85-99. Bamberger.

-2003. Holocene glacier fluctuations in South of Mendoza Andes. Actas II Congreso de Cuaternario y Geomorfología, pp. 87-92. Universidad Nacional de Tucumán. Tucumán.

FERNÁNDEZ, F.J. 2010. Paleozoogeography of the Wine Mouse (Akodon oenos) \& Late Holocene Paleoenvironments in South-Central Mendoza, Argentina. Ethnobiology Letters 1: $52-57$.

-2012. Microvertebrados del Holoceno de sitios arqueológicos en el sur de Mendoza (República Argentina): aspectos tafonómicos y sus implicancias en la subsistencia humana. Tesis Doctoral inédita, 520 páginas. Facultad de Ciencias Naturales y Museo, Universidad Nacional de La Plata. La Plata.

FERNÁNDEZ, F.J., S.M. RUDZIK, G. NEME y L.J.M. DE SANTIS. 2015. Micromamíferos, tafonomía y ambientes durante los últimos 3.800 años A.P. en el valle medio del río Grande, Mendoza, Argentina. Chungara 47: 267-267.

FERNÁNDEZ, M.V., R. BARBERENA, A.A. RUGHINI, M. GIESSO, V. CORTEGOSO, V. DURÁN, G. ROMERO VILLANUEVA, K. BORRAZZO, G. LUCERO, R. GARVEY, B. L. MACDONALD Y M. D. GLASCOCK. 2017. Obsidian geochemistry, geoarchaeology, and lithic technology in northwestern Patagonia (Argentina). Journal of Archaeological Science: Reports 13: 372-381.

FLEGENHEIMER, N. Y C. BAYÓN. 1999. Abastecimiento de rocas en sitios pampeanos tempranos: recolectando colores. En: Los Tres reinos: prácticas de recolección en el cono sur de América, C. Aschero, M. Korstanje y P. Vuoto (eds.), pp. 95-107. Tucumán, Magna Publicaciones-Universidad Nacional de Tucumán. San Miguel de Tucumán.

FLEGENHEIMER, N. Y C. BELLELLI. 2007. La arqueología y las piedras, un recorrido por los estudios líticos en argentina. Relaciones de la Sociedad Argentina de Antropología XXXII: $141-168$.

FOLEY, R. 1981a. Off-Site Archaeology and Human Adaptation in Eastern Africa. An Analysis of Regional Artefact Density in the Amboseli, Southern Kenia. En: Cambridge Monographs in African Archaeology 3. BAR International Series 97. Oxford. 
-1981b. Off Site Archaeology: an Alternative Approach for the Short Sited. En: Pattern in the

Past: Essays in Honour of David Clarke, I. Hodder; N. Hammond y G. Isaac (eds.), pp. 157-

183. Cambridge University Press. Cambridge.

-1981c. A model of regional archaeological structure. Proceedings of the Prehistoric Society 47: $1-17$.

FORASIEPI, A.M., A.G. MARTINELLI, A. GIL, G. NEME y E. CERDEÑO. 2010. Fauna extinta y ocupaciones humanas en el Pleistoceno final - Holoceno Temprano del Centro Occidente Argentino. En: Zooarqueología a principios del Siglo XXI: Aportes Teóricos, Metodológicos y Casos de Estudio, M. De Nigris, P.M. Fernández, M. Giardina, A. Gil, M.A. Gutiérrez, A. Izeta, G. Neme y H. Yacobaccio (eds), pp. 219-229. Ediciones El Espinillo, Buenos Aires.

FORD, R.I. 1983. Inter-Indian exchange in the Southwest. En: Ortiz, Handbook of North American Indians 10, A. (ed.), Southwest, Sturtevant, W.C. (ed. gral.), pp. 711-722. Smithsonian Institution, Washington D.C.

FRANCO, N.V. 1994. Maximización en el aprovechamiento de los recursos líticos. Un caso analizado en el Área Interserrana Bonaerense. En: Arqueología de cazadores recolectores. Límites, casos y aperturas. J.L. Lanata y L.A. Borrero (comps.), pp. 75-88. Arqueología contemporánea 5. Edición Especial.

-2002a. ¿Es posible diferenciar los conjuntos líticos atribuidos a la exploración de un espacio de los correspondientes a otras etapas del poblamiento? Werken 3: 119-132.

-2002b. Estrategias de utilización de recursos líticos en la cuenca superior del río Santa Cruz (Argentina).Tesis doctoral inédita, 581 páginas. Facultad de Filosofia y Letras, Universidad de Buenos Aires. Buenos Aires.

-2004. La Organización Tecnológica y el uso de escalas espaciales amplias. El caso del sur y oeste de Lago Argentino. Temas de Arqueología, Análisis lítico, A. Acosta, D. Loponte y M. Ramos (eds.), pp. 101-144. Buenos Aires.

-2007. Lithic Artifacts and the Information about Human Utilization of Large Areas. En: Artefactos Liticos, Movilidad y Funcionalidad de Sitios: Problemas y Perspectivas, P. Escola y S. Hocsman (eds.), pp. 117-127. BAR, International Series, John and Erica Hedge Ltd., Oxford.

FRANCO, N.V. Y L.A. BORRERO. 1996. El stress temporal y los artefactos líticos. La cuenca superior del Río Santa Cruz. En: Arqueología. Solo Patagonia. Ponencias de las segundas Jornadas de Arqueología de la Patagonia, J. Gómez Otero (ed.), pp. 341-348. CENPAT. Puerto Madryn.

-1999. Metodología de análisis de la estructura regional de recursos líticos. En: En los tres reinos de recolección. Cono Sur de América, C. Aschero, M. Korstanje y P. Vuoto (eds.), pp. 27-37. Ediciones Magna Publicaciones, Universidad Nacional de Tucumán. San Miguel de Tucumán. 
FRANCO, N.V. Y E. ARAGÓN. 2004. Variabilidad en fuentes secundarias de aprovisionamiento lítico: El caso del sur del lago Argentino (Santa Cruz, Argentina). Estudios Atacameños 28: $71-85$.

FRANK, A.D., F. SKARBUN Y M.F. PAUNERO. 2007. Hacia una aproximación de las primeras etapas de reducción lítica en el Cañadón de la Mina, localidad arqueológica La María, Meseta Central de Santa Cruz, Argentina. Magallania 35 (2):133-144.

FRISANCHO, A. 1979. Human adaptation: a functional interpretation. St. Louis: Mosby.

GAMBIER, M. 1980. Excavaciones arqueológicas en la gruta de El Manzano, Río Grande, Mendoza. Boletín del Museo de Ciencias Naturales y Antropológicas Juan Cornelio Moyano 1: $45-55$.

-1985. La cultura de los Morrillos. Instituto de Investigaciones Arqueológicas y Museo. Facultad de Filosofía, Humanidades y Artes, Universidad Nacional de San Juan. San Juan.

-1987. Excavaciones arqueológicas en la Gruta El Manzano. En: Iras Jornadas de Arqueología de la Patagonia-Comunicaciones. Gobierno de la Provincia de Chubut. Serie Humanidades 2: 123. Trelew. Chubut.

GAMBLE, C. 1990. El poblamiento paleolítico de Europa. Crítica. España.

-1993. Exchange, foraging and local hominid networks. En: Trade and exchange in prehistoric Europe, C. Scarre y F. Healy (eds.), pp. 35-44. Oxford, Oxbow Books, Prehistoric Society y Société Préhistorique Francaise.

GARCÍA, A. 1995. Agua de la Cueva Rockshelter and its Relationship to the Early Peopling of Central West Argentina. Current Research in the Pleistocene 12:13-14.

-2003. La ocupación temprana de los Andes Centrales argentinos (ca. 11.000-8.000 años $C^{14}$ AP). Relaciones de la Sociedad Argentina de Antropología XXVIII. Buenos Aires.

-2005. Human Occupation of the Central Andes of Argentina $\left(32^{\circ}-34^{\circ} \mathrm{S}\right)$ during the midHolocene. Quaternary International 132: 61-70.

-2010. Human occupation during the mid-Holocene in western Argentina: a comment on Neme and Gil. Current Anthropology 51 (3): 415-416.

GARCÍA, A., M. ZÁRATE Y M. PÁEZ. 1999. The Pleistocene - Holocene transition and human occupation in the Central Andes of Argentina: Agua de la Cueva locality. Quaternary International. 53/54: 43-52.

GARCÍA MORENO, A. 2010. Haciendo humanos a los humanos. Una reflexión crítica sobre la aplicación de las teorías del forrajeo óptimo a las sociedades de cazadores-recolectores. Revista Atlántica-Mediterránea de Prehistoria y Arqueología Social 12: 25-34.

GARCÍA, A. Y H. LAGIGLIA. 1999. A 30,000-year-old megafauna dung layer from Gruta del Indio (Mendoza, Argentina). Current Research in the Pleistocene 16: 116-118.

GARREAUD, M. 2009. The Andes climate and weather. Advances in Geosciences 7: 1-9. 
GARVEY, R. 2012. Human behavioral responses to Middle Holocene climate changes in Northern Argentine Patagonia. Doctoral dissertation, on file with the Department of Anthropology. University of California, Davis.

-2015. A model of lithic raw material procurement. En: Lithic Technological Systems and Evolutionary Theory, N. Goodale y W. Andrefsky, Jr. (eds.), pp. 156-171. Cambridge University Press. Cambridge.

GIARDINA, M. 2010. El aprovechamiento de la avifauna entre las sociedades cazadorasrecolectoras del sur de Mendoza, un enfoque arqueozoológico. Tesis Doctoral inédita. Facultad de Ciencias Naturales y Museo, Universidad Nacional de La Plata. La Plata.

-2012. Intensificación en el sur de Mendoza: un enfoque avifaunístico. Archaeofauna 21: 219234.

GiARdinA, M., M. CORBAt, E. PERAltA, G. COCHERO, F. FRANCHETTI, M.L. SALGÁN Y A. GIL. 2015. El registro arqueológico en el sitio La Olla (San Rafael, Mendoza): Implicaciones para las ocupaciones humanas en el valle medio del río Atuel. Revista del Museo de Antropología 8 (1): 51-66.

GIESSO M., M. D. GLASCOCK, V. DURÁN, V. CORTEGOSO, A. GIL, G. NEME y L. SANHUEZA. 2008. Tendencias temporales y espaciales en el uso de la obsidiana en los Andes Meridionales. $M s$.

GIESSO, M., DURÁN, V., NEME, G.A., GLASCOCK, M.D., CORTEGOSO, V., GIL, A.F. Y L. SANHUEZA. 2011a. A study of obsidian source usage in the central Andes of Argentina and Chile. Archaeometry 53 (1): 1-21.

GIESSO, M., V. DURÁN, V. CORTEGOSO y M. D. GLASCOCK. 2011b. Circulación de obsidiana y redes de interacción inter-regionales en el extremo norte de la Patagonia argentina. Trabajo presentado en VII Jornadas de Arqueología de la Patagonia, Libro de Resúmenes, pp. 38. Malargüe, Mendoza.

GIL, A. 1997-1998. Cultígenos prehispánicos en el sur de Mendoza. Discusiones en torno al límite meridional de la agricultura andina. Relaciones de la Sociedad Argentina de Antropología XXII-XIII: 295-313.

-2000. Arqueología de La Payunia: sur de Mendoza. Tesis doctoral. 2 tomos. Facultad de Ciencias Naturales y Museo. Universidad Nacional de La Plata. La Plata.

-2002. El registro arqueológico de la ocupación humana de La Payunia. En: Entre Montañas y Desiertos. Arqueología del sur de Mendoza, A. Gil y G. Neme (eds.), pp. 103-118. Publicaciones de la Sociedad Argentina de Antropología. Buenos Aires.

-2003. Zea mays on the South American periphery: chronology and dietary importance. Current Anthropology 44 (2): 295-300.

-2006. Arqueología de La Payunia. BAR International Series 1477. Inglaterra. 
GIL, A. Y G. NEME. 2002. Entre montañas y el desierto: aportes a la arqueología del sur de Mendoza. Sociedad Argentina de Antropología. Buenos Aires.

-2010. Registro arqueológico en la cuenca media del Atuel: viejos y nuevos problemas; viejos y nuevos datos. En: Condiciones Paleoambientales y ocupaciones humanas durante la transición Pleistoceno-Holoceno de Mendoza, M. Zárate, A. Gil y G. Neme (eds.), pp. 239276. Sociedad Argentina de Antropología. Buenos Aires.

-2013. Informe de parte Arqueología: Área Ranquil Norte. Informe de impacto arqueológico presentado a la empresa BIOS Consultores S.A.

GIL, A., M. ZÁRATE, Y G. NEME. 2005. Mid-Holocene Paleoenvironments and the Archaeological Record of Southern Mendoza, Argentina. Quaternary International 132: 8194.

GIL, A., G. NEME, A. HERNÁNDEZ, P. NOVELLINO, M. GIARDINA, M.L. SALGÁN, H. TUKER y E. ALBARRÁN. 2008. Rincón del Atuel-1 (San Rafael, Mendoza): Evidencias arqueológicas e implicancias regionales. Intersecciones en Antropología 9: 113-132.

GIL A., G. NEME Y R. TYKOT. 2010. Stable isotopes and human diet in central western Argentina. Journal of Archaeological Science 38: 1395-1404.

GIL, A., G. NEME, A. UGAN Y R. TYKOT. 2011a. Oxygen isotopes and human mobility in central-western Argentina. International Journal of Osteoarchaeology doi: 10.1002/oa.1304.

GIL, A., G. NEME, C. OTAOLA, Y A. GARCÍA. 2011b. Registro Arqueofaunístico en los Andes Meridionales entre 11.000 y 5.000 años AP. Evidencias en Agua de la Cueva-Sector Sur (Mendoza, Argentina). Latin American Antiquity 22: 595-617.

GIL, A., L. SALGÁN y G. NEME. 2011c. Obsidian Sources Explotation in the La Payunia Volcanic Field (Mendoza Province, Argentina). Trabajo presentado en $78^{\circ}$ Annual Meeting of $S A A$. Sacramento, USA.

GIL, A., G. NEME, A. UGAN y R. TYKOT. 2012. Isótopos estables (14C, 15N y18O) en la arqueología del sur de Mendoza. En: Paleoecología humana en el sur de Mendoza: perspectivas arqueológicas, G. Neme y A. Gil (comps.), pp. 135-156. Sociedad Argentina de Antropología. Buenos Aires.

GIL, A., M. GIARDINA, G. NEME y A. UGAN. 2014. Demografía humana e incorporación de cultígenos en el Centro Oeste Argentino: explorando tendencias en las fechas radiocarbónicas. Revista Española de Antropología Americana 44 (2): 523-553.

GIL, A., L.P. MENÉNDEZ, J.P. ATENCIO, E.A. PERALTA, G. NEME Y A. UGAN. 2017. Estrategias humanas, estabilidad y cambio en la frontera agrícola sur americana. Latin American Antiquity 29 (1): 6-26.

GLASCOCK, M. D. 1998. A systematic approach to obsidian source characterization. En: Archaeological obsidian studies: Method and theory, MS. Shackley (ed.), pp. 15-65. Plenum Press, Nueva York y Londres. 
-2008. Archaeometry. D. M. Pearsall (Ed.), Encyclopedia of Archaeology, pp. 489-494. Oxford: Academic.

-2010. X-ray Fluorescence Analysis of Obsidian from Argentina. Archaeometry Laboratory Report. $M s$.

-2011. Comparison and Contrast between XRF and NAA: Used for Characterization of Obsidian Sources in Central Mexico. M. S. Shackley (Ed.), X-Ray Fluorescence Spectrometry (XRF) in Geoarchaeology, pp. 161-192, Springer, New York.

GLASCOCK, M.D. Y J.R. FERGUSON. 2012. Report on the Analysis of Obsidian Source Samples by Multiple Analytical Methods. Archaeometry Laboratory at MURR, University of Missouri- Columbia.

GONZÁLEZ DÍAZ, E. F. 1964. Rasgos geológicos y evolución geomorfológica de la hoja 27-d (San Rafael) y zona occidental vecina (Prov. de Mendoza ), Asociación Geológica Argentina, Revista, XIX (3): 151-188. Buenos Aires.

-1972. Descripción geológica de la hoja 27d, San Rafael, Mendoza, Servicio Nacional Minero geológico- Boletín 132. Ministerio de Industria y Minería. Buenos Aires.

GONZÁLEZ DÍAZ, E. Y L. FAUQUÉ. 1993. Geomorfología. En: Geología y Recursos Naturales de Mendoza, V. Ramos (ed.), pp. 161-172. Relatorio del XII Congreso Geológico Argentino I. Mendoza.

GOULD, R.A. 1980. Living Archaeology. Cambridge University Press. Cambridge.

-1991. Arid-land foraging as seen from Australia: adaptative models and behavioral realities.

Oceania 62: 12-33.

GOULD, R.A., D.A. KOSTER Y A.H. SONTZ. 1971. The lithic assemblage of the western desert aborigines of Australia. American Antiquity 36 (2): 149-169.

GOULD, R. A. Y S. SAGGERS. 1985. Lithic procurement in central Australia: A closer look at Binford's idea of embeddedness in archaeology. American Antiquity 50 (1):117-136.

GOTELLI, N. Y G. GRAVES. 1996. Null models in ecology. Smithsonian Institution Press, Washington y London.

GRAYSON, D. K. 1989 Bone transport, bone destruction, and reverse utility Curves. Journal of archaeological Science 16: 643-652.

GREMILLION, K.J. 2004. Seed processing and the origins of food production in eastern North America. American Antiquity 69: 215-234.

GROEBER, P. 1939. Informe Geológico sobre la zona del Embalse del Proyectado Dique en Nihuil, Mendoza. Dirección Nacional de Geología y Minas. Buenos Aires. Inédito.

-1946-1947. Observaciones geológicas a lo largo del meridiano 70 (con hojas geológicas 1:500.000). Hojas Bardas Blancas, Los Molles, Sosneado, Maipo. Rev. Soc. Geol. Arg., I-II. Buenos Aires. 
GROSJEAN, M. I. CARTAJENA, M.A. GEYH y L. NUÑEZ. 2003. From Proxy Data to Paleoclimate interpretation: the mid-Holocene paradox of Atacama Desert northern Chile. Paleogeography, Paleoclimatology, Paleoecology 194: 247-258.

HALSTEAD, P. Y J. O'SHEA. 1989. Introduction: Cultural Responses to risk and uncertainty. En: Bad Year Economics, P. Halstead y J. O'Shea (eds.), pp. 1-7. Cambridge University Press. Cambridge.

HAMMER, Ø., HARPER, D.A.T. Y P.D. RYAN. 2001. PAST: Paleontological Statistics Software Package for Education and Data Analysis. Palaeontologia Electronica 4(1): 9 pp. http://palaeo-electronica.org/2001_1/past/issue1_01.htm

HAMMER, Ø., HARPER, D. Y P. RYAN. 2004. PAST - PAlaeontological STatistics, versión 1.21. http://folk.uio.no/ohammer/past

HAURY, C. E. 1995. Defining Lithic Procurement Technology. En: Lithic Resource Studies: A Sourcebook for Archaelogists, T. Church (ed.), pp. 26-31. Lithic Technology, Special Publication 3. Department of Anthropology, University of Tulsa. Tulsa, Oklahoma.

HAYDEN, B. 1979. Palaeolithic reflections. Lithic technology and ethnographic excavations among Australian Aborigines. Australian Institute of Aboriginal Studies, Canberra, Australia. Humanities Press Inc., New Jersey, U.S.A.

-1989. From chopper to celt: the evolution of resharpening techniques. En: Time, energy and stone tools, R. Torrence (ed.), pp. 7-16. Cambridge University Press. Cambridge.

-1998 [1977]. Stone tool functions in the Western Desert. En: Archaeology of Aboriginal Australia: A reader, T. Murray (ed.), pp.: 266-284. Sydney. Unwin and Allen.

HAYDEN B. Y W.K. HUTCHINGS. 1989: Whither the Billet Flake. En: Experiments in Lithic Tecnology, D.S. Amick y R.P. Mauldin (eds.), pp 235-258. BAR International Series 528. Oxford.

HAYDEN, B.; N. FRANCO Y J. SPAFFORD. 1996. Evaluating Lithic Strategies and Design Criteria. En: Stone Tools. Theoretical Insights into Human Prehistory, G. Odell (ed), pp. 9-45. Plenum Press, New York.

HELDAL, T. 2009. Constructing a quarry landscape from empirical data. General perspectives and a case study at the Aswan West Bank, Egypt. En: Quarry Scapes: Conservation of ancient stone quarry landscapes in the Eastern Mediterranean, N. Abu-Jaber, E.G. Bloxam, P. Degryse y T. Heldal (eds.), pp. 125-154. Geological Survey of Norway, Special publication 12. Noruega.

HERMO, D.O. 2008. Los cambios en la circulación de las materias primas líticas en ambientes mesetarios de Patagonia. Tesis Doctoral inédita. Facultad de Ciencias Naturales, Universidad Nacional de La Plata. 2 tomos. La Plata.

-2009. Estructura de los recursos líticos y paisajes arqueológicos en el Nesocratón del Deseado (Santa Cruz, Argentina). Arqueología Sudamericana 5 (2): 178-203. 
HERNÁNDEZ, A., A. GIL, Y H. LAGIGLIA. 2001. El registro arqueobotánico en el sitio "Agua de los Caballos-1" (San Rafael, Mendoza). Anales de Arqueología y Etnología. Facultad de Filosofía y Letras, Universidad Nacional de Cuyo. Mendoza.

HERNÁNDEZ, J. Y N. MARTINIS. 2002. Particularidades de las cuencas hidrogeológicas explotadas con fines de riego en la provincia de Mendoza. Instituto Nacional del Agua (INA) -Centro Regional Andino. Mendoza.

HEUSSER, C. J. 1990. Ice age vegetation and climate of subtropical Chile. Paleogeography, Paleoclimatology, Paleoecology 80: 107- 127.

HISCOCK, P. 1994. Technological Response to Risk in Holocene Australia. Journal of World Prehistory 8 (3): 267-292.

-2001. Looking the other way: a materialist/technological approach to classifying tools and implements, cores and retouched flakes, with examples from Australia. En: Tools or cores? The identification and study of alternative core technology in lithic assemblages, S. McPherron y J. Lindley (eds.). University of Pennsylvania Museum. University of Pennsylvania Museum. Pennsylvania.

-2002. Quantifying the size of artifact assemblages. Journal of Archaeological Science 29: 251258.

HISCOCK, P. Y V. ATTENBROW. 2002. Morphological and reduction continuums in Eastern Australia: Measurement and implications at Capertee 3. Tempus 7: 167-174.

- 2003. Early Australian implement variation: a reduction model. Journal of Achaeological Science 30: 239-249.

-2005. Australia's Eastern Regional Sequence revisited: Technology and change at Capertee 3. British Archaeological Reports. International Monograph Series 1397. Oxford: Archaeo press. HISCOCK, P. Y C. CLARKSON. 2005a. Measuring artefact reduction. An examination of Kuhn's geometric index of reduction. En: Lithics "Down Under". Recent Australian Approches to lithic reduction, use and classification. C. Clarkson y L. Lamb (eds). British Archaeological Reports International Monograph series. Oxford: Archaeopress.

-2005b. Experimental evaluation of Kuhn's geometric index of reduction and the flat-flake problem. Journal of Achaeological Science 32: 1015-1022.

HISCOCK, P. Y S. O'CONNOR. 2005. Arid Paradises or Dangerous Landscapes: A Review of Explanations for Paleolithic Assemblage Change in Arid Australia and Africa. En: Desert Peoples: Archaeological Perspectives, P. Veth, M. Smith y P. Hiscock (eds.), pp. 58-77. Blackwell Publishing Ltd, Malden, EE.UU.

HOCSMAN S. 2009. Una propuesta de aproximación teórico-metodológica a conjuntos de artefactos líticos tallados. En: Perspectivas actuales en arqueología argentina, R. Barberena, K. Borrazzo y L. Borrero (eds.), pp. 271-302. IMHICIHU, Buenos Aires. 
-2016. Comunicación personal realizada en el marco de la Pasantía titulada "Análisis tecnotipológico de puntas de proyectil: historias de vida, transformaciones morfológicas y estilo", dictada por el Dr. Salomon Hocsman y organizada por la Facultad de Ciencias Naturales e Instituto Miguel Lillo, Universidad Nacional de Tucumán. Tucumán.

HOGG, A. G., Q., HUA, P.G. BLACKWELL, M. NIU, C.E. BUCK, T.P. GUILDERSON Y C.S. TURNEY. 2013. SHCal13 Southern Hemisphere calibration, 0-50,000 years cal BP. Radiocarbon 55 (4): 1889-1903.

HUGHES, R. E. 2011a. Sources of Inspiration for Studies of Prehistoric Resource Acquisition and Materials Conveyance in California and the Great Basin. En: Perspectives on Prehistoric Trade and Exchange in California and the Great Basin, Hughes, R. E. (ed.), pp. 1-21. The University of Utah Press, Salt Lake City. Utah.

-2011b. Perspectives on Prehistoric Trade and Exchange in California and the Great Basin. The University of Utah Press, Salt Lake City. Utah.

INGBAR, E. 1994. Lithic Material Selection and Technological Organization. En: The organization of North American prehistoric chipped stone Technologies, P. Carr (ed.), pp. 4556. International Monographs in Prehistory. Archaeological Series 7. Michigan.

INGBAR, E., M. LARSON y B. BRADLEY.1989. A Nontypological Approach to Debitage Análisis, En: Experiments in Lithic Technology, DS. Amick y R.P Mauldin (eds.), pp. 67-99. BAR International Series 528, Oxford.

IRIARTE, J. 1995. Afinando la puntería: tamaño, forma y rejuvenecimiento en las puntas de proyectil pedunculadas del Uruguay. En: Arqueología en el Uruguay: 120 años después. VII Congreso Nacional de Arqueología Uruguaya, M. Consens, J. M. López Mass y M. C. Curbelo (eds.), pp. 142-151. Editorial SURCOS, Montevideo.

JANETSKI, J. 2002. Trade in Fremont Society: Contexts and Contrasts. Journal of Anthropological Archaeology 21 (3): 344-370.

JENNY, B., B. L. VALERO-GARCÉS, R. VILLA-MARTÍNEZ, R. URRUTIA, M. A. GEIH Y H. VEIT. 2002. Early to Mid-Holocene Aridity in Central Chileand the Southern Westerlies: the Laguna Aculeo Record (34 S). Quaternary Research 58: 160-170.

JESKE, R.J. 1989. Economics in raw material use by prehistoric hunter-gatherer. En: Time, energy and stone tools, R. Torrence (ed.), pp. 34-56. Cambridge University Press. Cambridge.

-1992. Energetic efficiency and lithic technology: An Upper Mississippian example. American Antiquity 57 (3): 467-481.

JOCHIM, M. A. 1981. Strategies for survival, cultural behavior in an ecological context. Academic Press. Nueva York.

-1989. Optimization and stone tool studies: problem and potentials. En: Time, energy and stone tools: 106-120. R. Torrance (ed.). Cambridge University Press. Cambridge. 
-1998. A Hunter-Gatherer Landscape. Southwest Germany in the Late Paleolithic and Mesolithic.

Plenum Press. Nueva York.

JOHNSON A., A. GIL, G. NEME Y J. FREEMAN. 2009. Maíces e intensificación: explorando el uso de los marcos de referencia. En: Teoría, Métodos y Casos de Estudio en Arqueología Evolutiva, G. López y M. Cardillo (eds.), pp. 23-44. Colección de Complejidad Humana, Editorial SB: Buenos Aires.

JONES, G.T. Y R. LEONARD. 1989. The concept of diversity: an introduction. En: Quantifying

Diversity in Archaeology, R. Leonard y G.T. Jones (eds), pp. 1-3. Cambridge University Press, Cambridge.

JONES, G.T., C. BECK, E.E. JONES Y R.E. HUGHES. 2003. Lithic Source Use and Paleoarchaic Foraging Territories in the Great Basin. American Antiquity 68 (1): 5-38.

JONES, G.T, L. M. FONTES, R. A. HOROWITZ, C. BECK, Y D. G. BAILEY. 2012. Reconsidering Paleoarchaic Mobility in the Central Great Basin. American Antiquity 77 (2): 351-368.

KELLY, R. 1983. Hunter-Gatherer mobility strategies. Journal of Anthropological Research 39: 277-306.

-1988. The three sides of a Biface. American Antiquity 53 (4): 717-734.

-1992. Mobility/Sedentism: Concepts, Archaeological Measures, and Effects. Annual Review of Anthropology 21: 43-66.

-1995. The Foraging Spectrum. Diversity in Hunter-Gatherer Lifeways. Smithsonian Institution Press.

-2001. Prehistory of the Carson Desert and Stillwater Mountains: Environment, Mobility, and Subsistence in a Great Basin Wetland. University of Utah Anthropological Papers No123. Salt Lake City. Utah.

-2011. Obsidian in the Carson Desert: Mobility or Trade? En: Perspectives on Prehistoric Trade and Exchange in California and the Great Basin, Hughes, R. E. (ed.), pp. 189-200. The University of Utah Press, Salt Lake City. Utah.

KINTIGH, K. 1989. Sample size, significance, and measures of diversity. En: Quantifying Diversity in Archaeology, R. Leonard y G. Jones (eds.), pp. 25-36. Cambridge University Press, Cambridge.

KOLDEHOFF, B. 1987 The Cahokia flake tool industry: socioeconomic implications for Late Prehistory in the Central Mississippi Valley. En: The Organization of Core Technology, J.K. Johnson y C.A. Morrow (eds.), pp. 151-185. Westview Press. Boulder, Colorado.

KORNFELD, M. 2003. Pull of the hills. Technological structures around biogeographical islands.

En: Islands on the plains. Ecological, social and ritual use of landscapes, M. Kornfeld, y A. Osborn (eds.), pp. 111-141. Salt Lake City, University of Utah Press.

KREBS, C.J. 1989. Ecological Methodology. Harper and Row Publishers, New York. 654 pp. 
KRÖMER, R. A. 1996 Los sedimentos cuaternarios del sureste de la llanura mendocina. Implicancias paleoclimáticas. Multequina 5: 49-55.

KUHN, S.L. 1989. Hunter-gatherer foraging organization and strategies of artifact replacement and discard. En: Experiments in lithic technology, D. S. Amick y R. P. Mauldin (eds.), pp. 3347. BAR International Series 528. Oxford: British Archaeological Reports.

-1990. A geometric index of reduction for unifacial stone tools. Jounal of Achaeological Science 17: 583-593.

-1991. Unpacking reduction: lithic raw material economy in the Mousterian of west-central Italy. Journal of Anthropological Archaeology 10: 76-106.

-1992. On planning and curated technologies in the Middle Paleolithic. Journal of Anthropological Research 48 (3): 185-214.

-1994. A formal approach to the design and assembly of mobile toolkits. American Antiquity 59 (3): 426-442.

-1995. Mousterian Lithic Technology: An Ecological Perspective. Princeton University Press. Princeton, Nueva Jersey.

-2004. Upper Paleolithic raw material economies at Üçagızlı cave, Turkey. Journal of Anthropological Archaeology 23: 431-448.

KUHN, S.L. Y D. S. MILLER. 2015. Artifacts as patches: the Marginal Value Theorem and stone tool life histories. En: Lithic Technological Systems and Evolutionary Theory, N. Goodale y W. Andrefsky, Jr (eds.), pp. 172-197. Cambridge University Press, Nueva York.

LAGIGLIA, H. 1956a. La gruta del Indio del Rincón del Atuel. Un reparo con pinturas rupestres de San Rafael (Mendoza). Revista Cientifica de Investigaciones del Museo de Historia Natural de San Rafael, 1 (1): 5-18. San Rafael.

-1956b. Estudios arqueológicos en el Rincón del Atuel. Anales de Arqueología y Etnología XII: 229-288. Universidad Nacional de Cuyo. Mendoza.

-1968. Secuencias culturales del Centro-Oeste argentino: Valles del Atuel y del Diamante. Revista Cientifica de Investigaciones del Museo de Historia Natural de San Rafael I (4): 159-176. -1970. Primer diagrama polínico de la estratigrafía arqueológica argentina. Actas y Trabajos del Primer Congreso de Arqueología Argentina, pp. 163-167. Rosario.

-1972. Secuencias culturales del centro oeste argentino con especial referencia a los valles del Atuel y Diamante. Revista del Museo de Historia Natural de San Rafael, II (3): 83-122.

-1974. Síntesis cronológico cultural del Centro Oeste Argentino con especial referencia a los valles del Atuel y Diamante. Revista del Museo de Historia Natural de San Rafael 2 (3): 83101.

-1977a. Arqueología y ambiente natural de los valles del Atuel y del Diamante. Tesis Doctoral No 353; 2 tomos. Facultad de Ciencias Naturales y Museo, Universidad Nacional de La Plata. La Plata. 
-1977b. Dinámica cultural en el Centro Oeste y sus relaciones con áreas aledañas argentinas y chilenas. Actas del VII Congreso de Arqueología Chilena II, pp. 531-560. Chile.

-1980. El proceso de agriculturización en el sur de Cuyo: La cultura del Atuel II. Actas del V

Congreso Nacional de Arqueología Argentina, pp. 231-254. San Juan.

-1981. Problemática del precerámico y del proceso de agriculturización en el Centro Oeste

Argentino. Notas del Museo Municipal de Historia Natural de San Rafael 24: 73-93.

-1989. Libreta de campo del Dr. Lagiglia de los trabajos realizados en el valle del Salado.

-1997a. Arqueología de Cazadores- Recolectores Cordilleranos de Altura. Ediciones Ciencia y

Arte. Instituto de Ciencias Naturales de San Rafael, Museo Municipal de Historia Natural, San Rafael.

-1997b. Arqueología prehistórica del Atuel y Diamante. Revista del Centro de Integración Territorial (CINTER) N², pp. 29-46. Mendoza.

-1999. Nuevos fechados radiocarbónicos para los agricultores incipientes del Atuel. Actas del XII

Congreso Nacional de Arqueología Argentina, pp 239-250. La Plata.

-2001. El Paleoindio del Atuel en Sudamérica (Análisis de la Cronología absoluta del Paleoindio del Atuel). Notas del Museo de Historia Natural de San Rafael N48: 3-12.

-2002. Arqueología prehistórica del sur mendocino y sus relaciones con el Centro Oeste Argentino. En: Entre Montañas y Desiertos: Arqueología del Sur de Mendoza, A. Gil y G. Neme (eds.), pp.43-64. Sociedad Argentina de Antropología. Buenos Aires.

LAGIGLIA, H., G. NEME y A. GIL. 1994. Informe de los trabajos de campo en el sitio "E1 Indígeno" (3ra campaña arqueológica, febrero de 1994). Actas del XI Congreso Nacional de Arqueología Argentina, pp. 116-118. San Rafael, Mendoza.

LAGIGLIA, H. Y A. GARCÍA. 1999. Las ocupaciones tempranas del Atuel (nuevos estudios en la Gruta del Indio). En: Actas del XII Congreso Nacional de Arqueología Argentina III, Cristina Diez Marín (ed.), pp. 251-255. La Plata.

LAMY, F., D. HEBBELN Y G. WEFER.1999. High resolution marine record of climatic change in mid-latitude Chile during the last 28,000 years based on terrigenous sediment parameters. Quaternary Research 51, 83-93.

LAMY, F., C. RÜHLEMANN, D. HEBBELN y G. WEFER. 2002. High- and low-latitude climate control on the position of the southern Peru-Chile Current during the Holocene. Paleoceanography 17 (2): 16-1-16-10.

LEMONNIER, P. 1992. Elements for an Anthropology of Technology. Anthropological Papers, Museum of Anthropology, No. 88, Cap. 1: 1-24. University of Michigan. Anne Arbor, Michigan.

LEROI-GOURHAN, A. 1964. Le geste et la parole. En: vol.1: Technique et langage; vol.2: La Mémoire et les Rythmes. París, Albin Michel (Traducido en 1971 como El gesto y la palabra por F.D. Carrera. Ediciones de la Biblioteca, Universidad Central de Venezuela. Caracas. 
LEWIS, R., O'BRIEN Y D. LEWARCH. 1982. Plowzone archaeology: Contributions to theory and technique. American Antiquity 4: 916.

LLANO, C. 2011. Aprovechamiento de los Recursos vegetales entre las sociedades cazadorasrecolectores del Sur de Mendoza. Tesis Doctoral inédita, 465 páginas. Universidad Nacional del Comahue. Neuquén.

LLANO, C. Y D. ANDREONI. 2012. Caracterización espacial y temporal en el uso de los recursos vegetales entre los grupos cazadores-recolectores del sur mendocino durante el Holoceno. En: Paleoecología humana en el sur de Mendoza: perspectivas arqueológicas, G. Neme y A. Gil (comps.), pp. 57-84. Sociedad Argentina de Antropología. Buenos Aires.

LLANO C., A. UGAN, A. GUERCI y C. OTAOLA. 2012. Arqueología experimental y valoración nutricional del fruto de algarrobo (Prosopis flexuosa): inferencias sobre la presencia de macrorrestos en sitios arqueológicos. Intersecciones en Antropología 13: 513524.

LONG, A., P. MARTIN Y H. LAGIGLIA. 1998. Ground Sloth Extintion and Human Occupation at Gruta del Indio, Argentina. Radiocarbon 40: 693-700.

LÓPEZ L., A. PÉREZ y C. R. STERN. 2009. Fuentes de aprovisionamiento y distribución de obsidianas en la provincia del Neuquén, noroeste de la Patagonia, Argentina. Intersecciones en Antropología 10: 75-80.

LOWELL, T., C. HEUSSER, B. ANDERSEN, P. MORENO, L. HEUSSER, C. SCLUCHTER, D. MARCHANT Y G. DENTON. 1995. Interhemispheric correlation of late Pleistocene glacial events. Science 269, 1541-1549.

LUCERO, G.F. 2015. Biogeografía y Paleoecología humana de tierras altas: subsistencia y tecnología en el Valle del Río de las Taguas (Departamento de Iglesia, Provincia de San Juan). Tesis doctoral inédita, pp. 444. Facultad de Filosofía y Letras, Universidad Nacional de Cuyo. Mendoza.

LUCERO G.F., V. CORTEGOSO y S. CASTRO. 2006. Cazadores-recolectores del holoceno Temprano: Explotación de Recursos líticos en el Sitio Agua de la cueva Sector Norte. En: Arqueología y Ambiente de Áreas Naturales Protegidas de la Provincia de Mendoza, V. Durán y V. Cortegoso (eds.), pp. 185-215. Mendoza.

LUCERO, G.F., S. C. CASTRO y V. CORTEGOSO. 2017. Tecnología lítica de cazadores y pastores andinos: cambios y continuidades en la explotación de recursos líticos durante el Holoceno en el NO de San Juan. Revista del Museo de Antropología, Suplemento Especial 1: $65-74$.

LURIE, R. 1989. Lithic Technology and Mobility Strategies. The Kosher Site Middle Archaic'. En Time, Energy and Stone Tools, R. Torrence (ed). Cambridge University Press. pp. 46-56.

LYMAN, R.L. Y M.J. O'BRIEN. 1998. The goals of Evolutionary Archaeology: History and explication. Current Anthropology 39: 615-652. 
MACARTHUR, R.H. Y E.R. PIANKA. 1966. On optimal use of a patchy environment. Amer. Natur. 100: 603-609.

MACDONALD, D.H. 1995. Mobility and raw material use at the hunting camp spring site (3SWA96), Blue Mountains, Oregon. North American Archaeologist 16(4): 343-361.

MACDONALD, D.H. Y B.S. HEWLETT. 1999. Reproductive Interests and Forager Mobility. Current Anthropology 40: 501-523.

MAGNE, M. 1989. Lithic Reduction Stage and Assemblage Formation Processes. En: Experiments in Lithic Technology, DS. Amick y R.P. Mauldin (eds.), pp. 15-31. BAR, International Series 528, Oxford.

MANDRYK, C. 1993. Hunter-gatherer social costs and the nonviability of submarginal environments. Journal of Anthropological Research 49: 39-70.

MARES, M., J. MORELLO y G. GOLDSTEIN. 1985. The Monte desert and other subtropical semi-arid biomes of Argentina, with comments on their relation to North American arid areas. En: Hot Deserts and Arid Shrublands, M. Evenari, I. Noy-Meir, y D.W. Goodall (eds.), pp. 203-237. Elsevier Science. Amsterdam.

MARKGRAF, V. 1983. Late postglacial vegetational and paleoclimatic changes in subantartic and temperate, and arid environments in Argentina. Palinology 7. Colorado.

-1989. Paleoclimates in Central and South America since 18,000 BP based on pollen and lake level recordos. Quaternary Science Review 8:1-24.

MARSH, E. 2017. La fecha de la cerámica más temprana en los Andes sur. Una perspectiva macrorregional mediante modelos bayesianos. Revista del Museo de Antropología, Suplemento Especial 1: 83-94.

MARTÍNEZ J. 2003. Ocupaciones humanas tempranas y tecnología de caza en la microrregión de Antofagasta de la Sierra (10000-7000 AP). Tesis Doctoral inédita, 206 páginas. Facultad de Ciencias Naturales e Instituto Miguel Lillo, Universidad Nacional de Tucumán. Tucumán.

MARTÍNEZ, G. A. Y Q. MACKIE 2003-2004. Late Holocene human occupation of the Quequén River valley bottom: settlement systems and an example of a built environment in the Argentine Pampas. Before Farming: The Archaeology and Anthropology of Hunter-Gatherers 1: $178-202$.

MCANANY, P. 1988. The effects of lithic procurement strategies on tool curation and recycling. Lithic Technology 17 (1): 3-11.

MELTZER, D. 1989. Was Stone Exchange Among Eastern North American Paleoindians? En: Eastern Paleoindian lithic resource use, C. Ellis y J. Lothrop (ed.), pp.11-39. Westview Press. Boulder, Colorado.

MONDINI, M Y S. MUÑOZ. 2004. Behavioural Variability in the So-Called Marginal Areas from a Zooarchaeological Perspective: An Introduction. En: Colonisation, Migration, and 
Marginal Areas. A Zooarchaeological Approach, M. Mondini, S. Muñoz y S. Wickler (eds.), pp. 42-45 Oxbow Books. UK.

MORGAN, C. 2015. Is it Intensification Yet? Current Archaeological Perspectives on the Evolution of Hunter-Gatherer Economies. Journal of Archaeological Research 23: 163-213.

MORRONE, J. J. 2000. What is the Chacoan subregion? Neotropica 46: 51-68.

-2001. Biogeografia de América Latina y el Caribe. M\&T-Manuales \& Tesis SEA, vol. 3. Zaragoza, $148 \mathrm{pp}$.

-2004. Panbiogeografía, componentes bióticos y zonas de transición. Revista Brasileira de Entomología 48: 149-162.

-2006. Biogeographic areas and transition zones of Latin America and the Caribbean Islands based on panbiogeographic and cladistic analyses of the entomofauna. Annual Review of Entomology 51: 467-494.

NAMI, H.G. 1986. Experimentos para el estudio de la tecnología bifacial de las ocupaciones tardías en el extremo sur de Patagonia Continental. PREP: Informes de Investigación 5: 1-120. -1991. Desechos de talla y teoría de alcance medio: un caso de Península Mitre. Tierra del Fuego.

Shincal 3: 94-112.

-1992. El subsistema tecnológico de confección de instrumentos líticos y explotación de los recursos del ambiente: Una nueva vía de aproximación. Shincal 2: 33-53.

- 2001. Current Trends in Lithic Technology in Argentina. Lithic Technology 26 (2): 94-104.

NAVARRO, D. Y WHITLOCK, C. 2010. Changes in vegetation, climate and fire regimes in SW Mendoza (Argentina) over the last $6400 \mathrm{cal}$ yrs BP: Laguna El Sosneado record. En: 2nd International Symposium "Reconstructing Climate Variations in South America and the Antarctic Peninsula over the las 2000 years" (Valdivia), Abstracts, pp. 95.

NAVARRO D., L.D. ROJO, C. DE FRANCESCO Y G.S. HASSAN. 2012. Paleoecologia y reconstrucciones paleoambientales en Mendoza durante el Holoceno. En: Paleoecología humana en el sur de Mendoza: perspectivas arqueológicas, G. Neme y A. Gil (comps.), pp. 17-56. Sociedad Argentina de Antropología. Buenos Aires.

NELSON, M.C. 1991. The Study of Technological Organization. En: Archaeological Method and Theory 3, M. Schiffer (ed.), pp. 57-100. University of Arizona Press. Tucson.

NEME, G. 2001. Arqueología del Alto valle del Atuel: Provincia de Mendoza. Tesis Doctoral inédita, 2 tomos. Facultad de Ciencias Naturales y Museo, Universidad de La Plata. La Plata. -2002. Arqueología del Alto valle del río Atuel: modelos, problemas y perspectivas en el estudio arqueológico de las regiones de altura del sur de Mendoza. En: Entre Montañas y Desiertos. Arqueología del sur de Mendoza, A. Gil y G. Neme (eds.), pp. 65-83. Publicaciones de la Sociedad Argentina de Antropología. Buenos Aires.

-2007. Cazadores Recolectores de Altura en Los Andes Meridionales: El Alto Valle del Atuel (Mendoza, Argentina). BAR Internacional Series 1591. Inglaterra. 
-2009. Un enfoque regional en cazadores-recolectores del oeste argentino: el potencial de la ecología humana. En: Perspectivas actuales en arqueología argentina, R. Barberena, K. Borrazo, L.A. Borrero (eds.), pp. 303-326. CONICET-IMHICIHU. Buenos Aires.

NEME, G. Y A. GIL. 2002. La explotación faunística y la frecuencia de partes esqueletarias en el registro arqueológico del sur de mendocino. En: Entre Montañas y Desiertos. Arqueología del sur de Mendoza, A. Gil y G. Neme (eds.), pp. 141-156. Publicaciones de la Sociedad Argentina de Antropología. Buenos Aires.

-2005. Aportes para la discusión del intercambio en el sur de Mendoza. Actas XVI Congreso Nacional de Arqueología Chilena, pp. 317-326. Tomé, Chile.

-2006. Discusiones teórico-metodológicas y el desarrollo de la investigación en la macroregión Cuyo-Chile Central. Actas del XVII Congreso Nacional de Arqueología Chilena 1: 373-382. Valdivia, Universidad Austral de Chile.

-2008a. Biogeografía humana en los Andes meridionales: tendencias arqueológicas en el sur de Mendoza. Chungara 40 (1): 5-18.

-2008b. Faunal exploitation and agricultural transitions in the South American agricultural limit. International Journal of Osteoarchaeology 18: 293-306.

-2009. Human occupation and increasing Mid-Holocene Aridity. Current Anthropology 50: 149163.

-2010. What happened during the Mid-Holocene in arid western Argentina? Current Anthropology 51: 417-419.

-2012. El registro arqueológico del sur de Mendoza en perspectiva biogeográfica. En: Paleoecología humana en el sur de Mendoza: perspectivas arqueológicas, G. Neme y A. Gil (comps.), pp. 255-280. Sociedad Argentina de Antropología. Buenos Aires.

NEME, G., A. GIL Y V. DURÁN. 2005. Late Holocene in southern Mendoza (northewestern Patagonia): Radiocarbon pattern and human occupation. Before Farming 2 (5): 1-18.

NEME, G., M. ZÁRATE, M. P. POMPEI, F. FRANCHETTI, A. GIL, M. GIARDINA, V. SEITZ Y M.L. SALGÁN. 2018. Cueva Salamanca 1: a Holocene archaeological record of human occupations at the arid andean piedmont of southern Mendoza, Argentina. Ms. en preparación.

NORTE, F. 2000. Mapa climático de Mendoza. En: ARGENTINA. Recursos y problemas ambientales de la zona árida. Primera parte: provincias de Mendoza, San Juan y La Rioja. Tomo I, Caracterización ambiental, E.M. Abraham y F. Rodriguez Martinez (eds.), pp. 25-27. IADIZA. Mendoza.

NOVELLINO, P. 2002. Bioarqueología del Sur de Mendoza. En: Entre Montañas y Desiertos. Arqueología del sur de Mendoza, A. Gil y G. Neme (eds.), pp. 119-139. Publicaciones de la Sociedad Argentina de Antropología. Buenos Aires. 
NOVELLINO, P. Y R. GUICHÓN. 1997-1998. Comparación de indicadores de dieta y salud entre el sur de Mendoza y el sur de San Juan-Norte de Mendoza. Relaciones de la Sociedad Argentina de Antropología XXII-XXIII: 125-138.

NOVELLINO, P. Y G. NEME. 1999. Hallazgo de restos esqueletales humanos en Laguna Blanca y El Sosneado (sur de Mendoza). Actas del XII Congreso Nacional de Arqueología Argentina; Tomo III: 256-260. La Plata.

NULLO, F.E., G, STEPHENS, A. COMBINA, L. DIMIERI, P. BALDAUF, P. BOUZA Y J.C.M. ZANETTINI. 2005. Hoja Geológica 3569-III, Malargüe, provincia de Mendoza. Instituto de Geología y Recursos Minerales, Servicio Geológico Minero Argentino, Boletín 346. Buenos Aires.

ODELL, G. H. 1996 Economizing Behavior and the Concept of "Curation". In Stone Tools: Theoretical Insights into Human Prehistory, G.H. Odell (ed), pp. 51-100. Plenum Press, New York.-2003. Lithic Analysis -Manuals in Archaeological Method, Theory and Technique. Springer. Nueva York.

OTAOLA, C. 2012. Procesos de intensificación y aprovechamiento de médula y grasa ósea en el sur de Mendoza, Argentina. Archaeofauna 21: 235-247.

-2013. Zooarqueología en la Cordillera del Sur de Mendoza: un Enfoque Tafonómico. Tesis doctoral inédita, 432 páginas. Facultad de Filosofía y Letras, Universidad de Buenos Aires.

OTAOLA, C., M. GIARDINA, M. CORBAT Y F.J. FERNÁNDEZ. 2012. Zooarqueología en el Sur de Mendoza: Integrando perspectivas zooarqueológicas en un marco biogeográfico. En: Paleoecología humana en el sur de Mendoza: perspectivas arqueológicas, G. Neme y A. Gil (comps.), pp. 85-116. Sociedad Argentina de Antropología. Buenos Aires.

OTAOLA, C. Y C. LLANO. 2015. Consumo de vegetales y animales en el sur de Mendoza: el caso del Sitio Cueva Palulo. Intersecciones en Antropología 16: 221-235.

OUTES, F. 1906. Instrumentos y armas neolíticas de Cochicó (Provincia de Mendoza). Anales del Museo Nacional de Buenos Aires, Tomo XIII (Serie 3, t. VI), pp. 277-286. Buenos Aires.

OUTRAM, A. 2004. Identifying dietary stress in marginal environments: bone fats, optimal foraging theory and the seasonal round. En: Colonisation, Migration, and Marginal Areas. A Zooarchaeological Approach, M. Mondini, S. Munoz y S. Wickler (eds.), pp. 74-85. Oxford: Oxbow.

PÁEZ, M. Y M. ZÁRATE. 2000. Condiciones ambientales durante la transición PleistocenoHoloceno en el noroeste de Mendoza, Argentina. XI Simposio Argentino de Paleobotánica y Palinología. 81. Tucumán.

PAEZ, M., D. NAVARRO, L. ROJO Y A. GUERCI. 2010. Vegetación y Paleoambientes Durante el Holoceno. En: Condiciones paleoambientales y ocupaciones humanas durante la transición Pleistoceno-Holoceno y Holoceno de Mendoza, M. Zárate, A. Gil y G. Neme (eds.), pp. 175211. Sociedad Argentina de Antropología. Buenos Aires. 
PALLO, M.C. Y L.A. BORRERO. 2015. ¿Intercambio o Movilidad?: Una Evaluación Sobre el Uso de Escalas de Análisis Espaciales y Curvas de Declinación en Patagonia CentroMeridional (Argentina). Latin American Antiquity 26 (3): 287-303.

PARRY, W.J. Y R. L. KELLY. 1987. Expedient Core Technology and Sedentism. En: The Organization of Core Technology, J. K. Johnson y C. A. Morrow (eds.), pp. 285-304. Westview Press. Boulder, Colorado.

PAULIDES, L. S. 2011. Organización de la tecnología lítica en el curso superior del Río Salado (Mendoza): el Sitio Puesto Jaque 2. Trabajo presentado en XVII Congreso Nacional de Arqueología Argentina. Mendoza.

PÉREZ WINTER, C. 2008. Organización de la Tecnología Lítica en el sur de Mendoza, alto valle del río Atuel. Caso: Arroyo Malo 3. Tesis de Licenciatura inédita, 148 páginas. Facultad de Filosofía y Letras, Universidad Nacional de Buenos Aires. Buenos Aires.

-2010. Tendencias del registro lítico durante el Holoceno medio: sitio Arroyo Malo 3, alto valle del río Atuel, sur de Mendoza. Intersecciones en Antropología 11: 159-172.

PIANKA, E. 1982. Evolutionary Ecology. Harper and Row. New York.

POLANSKI, J. 1954. Rasgos geomorfológicos del territorio de la provincia de Mendoza. Ministerio de Economía, Instituto de investigaciones Económicas y tecnológicas. Cuaderno de investigaciones y Estudios 4.

POLITIS, G., L. PRATES, M. MERINO Y M. TOGNELLI. 2011. Distribution parameters of guanaco (Lama guanicoe), pampas deer (Ozotoceros bezoarticus) and marsh deer (Blastocerus dichotomus) in Central Argentina. Archaeological and paleoenvironmental implications. Journal of Archaeological Science 38: 1405-1416.

POMPEI, M.P., G. NEME, M. ZÁRATE, F. FRANCHETTI Y A. GIL. 2017. En el límite norte de la Patagonia: excavaciones en Cueva Salamanca (Malargüe, Mendoza). Trabajo presentado en X Jornadas de Arqueología de la Patagonia. Libro de resúmenes, pp. 119. Puerto Madryn, Chubut.

PRADERIO, A. A. GIL, Y A. FORASIEPI. 2012. El registro de Megatherium (Xenarthra, tardígrada) en Mendoza (Argentina): aspectos taxonómicos, cronológicos y paleoecológicos. Mastozoología Neotropical. 19 (2): 279-291.

PRATES, L. 2004. Arqueología de la cuenca media del río Negro (provincia de Río Negro). Una primera aproximación. Intersecciones en Antropología (5): 55-69.

-2008. Los indígenas del Río Negro. Un enfoque arqueológico. Colección Tesis Doctorales dirigida por V. Horwitz. Sociedad Argentina de Antropología. Buenos Aires.

RAMONELL, C., M. IRIONDO Y R. KRÖMER. 1992. Guía de Campo CADINQUA (Comité Argentino de Investigación del Cuaternario), Universidad Nacional de San Luis: Departamento de Geología y Minería, pp: 1-37. San Luis.

RAMSEY, C. B. 2009. Bayesian analysis of radiocarbon dates. Radiocarbon 51 (1): 337-360. 
RATTO, N. 2003. Estrategias de caza y propiedades del registro arqueológico en la Puna de Chaschuil (Departamento Tinogasta, Catamarca). Tesis Doctoral, Universidad de Buenos Aires. Disponible en: http://cambiocultural.homestead.com/ratto.html

REED, C. 1918. Cementerio Indígena postcolombiano de Viluco, provincia de Mendoza (Comunicación preliminar presentada por Eric Boman). Physis, t. IV, $\mathrm{N}^{\circ} 16$, pp. 94-96. Buenos Aires.

RENFREW, C. 1977. Alternative models for exchange and spatial distribution. En: Exchange Systems in Prehistory, T. Earle y J. Ericson (ed.), pp. 71-90. Academic Press. New York.

RENFREW, C. Y P. BAHN. 1993. Arqueología. Teorías, métodos y práctica. Akal, España.

RINDOS, D. 1985. Darwinian selection, symbolic variation, and the evolution of culture. Current Anthropology 26: 65-88.

RINGUELET, R. A. 1961. Rasgos fundamentales de la Zoogeografía de la Argentina. Physis 22 (63): 151-170.

RODRÍGUEZ E. Y A. REGAIRAZ. 1972. Resumen geológico de la provincia de Mendoza. En: Boletín de la Sociedad Argentina de Botánica, Suplemento del volumen XIII, A. L. Cabrera (director), pp. 5-14. X Jornadas Argentinas de Botánica. Las ciencias Naturales en la Provincia de Mendoza. Mendoza.

ROIG, F. A. 1972. Bosquejo fisionómico de la vegetación de la provincia de Mendoza. En: Boletín de la Sociedad Argentina de Botánica, Suplemento del volumen XIII, A. L. Cabrera (director), pp. 49-80. X Jornadas Argentinas de Botánica, Las ciencias Naturales en la Provincia de Mendoza.

ROIG, V.G. 1972. Esbozo general del poblamiento animal en la provincia de Mendoza. En: Boletín de la Sociedad Argentina de Botánica, Suplemento del volumen XIII, A. L. Cabrera (director), pp 81-88. X Jornadas Argentinas de Botánica, Las ciencias Naturales en la Provincia de Mendoza.

ROIG, F. A.; E. MARTÍNEZ CARRETERO y E. MÉNDEZ. 2000. Mapa de vegetación de la Provincia de Mendoza. En: Recursos y problemas ambientales de zona árida, M. E. Abraham y F. Rodríguez Martínez (eds.) pp. 10. Mendoza: CRICYT.

RUGHINI, A.A. 2016. Tecnología lítica del noreste de Neuquén. Análisis del sitio Cueva Huenul 1 (Departamento Pehuenches, localidad Barrancas, Provincia de Neuquén, Argentina. Tesina de Licenciatura inédita, 159 páginas. Facultad de Filosofía y Letras, Universidad de Buenos Aires. Buenos Aires.

RUSCONI, C. 1940. Noticia preliminar sobre la Antropología y Arqueología Prehispánica de Mendoza. Anales de la Academia de Ciencias de Buenos Aires, t. I. 61-71. Buenos Aires.

RUSCONI, C. 1961-1962. Poblaciones Pre y Posthispánicas de Mendoza. I: Etnografia, 750 págs.; II: Antropología, 607 págs.; III: Arqueología, 623 págs.; IV: Genealogías aborígenes, 638 págs. Edición Oficial Provincia de Mendoza. 
SALGÁN, M.L. 2010. Análisis petrográfico y fuentes primarias de rocas silíceas. Avances y perspectivas en el estudio de la organización tecnológica de poblaciones cazadoras y recolectoras de La Payunia (Mendoza, Argentina). Trabajo presentado en XVII Congreso Nacional de Arqueología Argentina. Mendoza.

-2011. Obsidianas en el campo volcánico de La Payunia: aprovisionamiento, patrones de distribución e implicancias para la ocupación regional. Trabajo presentado en VIII Jornadas de Arqueología de la Patagonia. Libro de Resúmenes, pp. 71. Malargüe, Mendoza.

-2013. Organización tecnológica y biogeografía humana en La Payunia, sur de la Provincia de Mendoza. Tesis Doctoral Inédita, 448 páginas. Facultad de Ciencias Naturales y Museo, Universidad Nacional de La Plata. La Plata.

-2015. Disponibilidad, estrategias de aprovisionamiento y uso de recursos líticos en La Payunia, sur de Mendoza. Revista del Museo de Antropología 8 (2): 119-132.

SALGÁN, M.L. Y M.P. POMPEI. 2017. Fuente de obsidiana El Peceño: primeros resultados de su abordaje tecnológico, geoquímico y espacial. Revista del Museo de Antropología, Suplemento Especial 1: 51-58.

SALGÁN, M.L., A. F. GIL y G. A. NEME. 2012a. Obsidianas en La Payunia (sur de Mendoza, Argentina): patrones de distribución e implicancias en la ocupación regional. Magallania 40 (1): 263-277.

SALGÁN, M. L., S. PAULIDES Y V. CORTEGOSO. 2012b. Rocas, rangos de acción y biogeografía humana en el sur de Mendoza. En: Paleoecología humana en el sur de Mendoza: perspectivas arqueológicas, G. Neme y A. Gil (comps.), pp. 157-180. Sociedad Argentina de Antropología. Buenos Aires.

SALGÁN, M. L., R. GARVEY, G. NEME, A. GIL, M. GIESSO, M. GLASCOCK Y V. DURÁN. 2015. Las Cargas: Characterization of a Southern Andean Obsidian Source and Its Prehistoric Use. Geoarchaeology. An International Journal 30 (2): 139-150.

SALGÁN, M.L., G. NEME, S. DIEGUEZ, M.P. POMPEI, A. GIL Y M.D. GLASCOCK. 2017. Geoarchaeology, geochemical and spatial distributions of the Coche Quemado obsidian sources: southern Mendoza (Argentina). Trabajo presentado en 11th International Symposium on Knappable Materials "From toolstone to stone tools". Book of Abstracts, pp. 100. Buenos Aires, Argentina.

SALVARREDI, J. A., 1996. Caldera del Potrerito. Sección superior del Grupo Choiyoi. Bloque de San Rafael (Mendoza). En: XII Congreso Geológico Argentino y III Congreso de Exploración de Hidrocarburos, Actas I, pp: 347. Buenos aires.

SANHUEZA, L., F. FALABELLA, E. FONSECA y O. ANDONIE. 2004. Aplicación de análisis de pastas macroscópicos, petrográficos y de composición de elementos químicos al problema de la procedencia de cerámica en el Período Alfarero Temprano de Chile central y Cuyo, Argentina. Estudios Atacameños 28: 121-132. 
SARIO, G. 2011. Poblamiento humano en la provincia de San Luis: una perspectiva arqueológica a través del caso de la organización de la tecnología en la Ea. La Suiza. Tesis doctoral inédita, 289 páginas. Facultad de Filosofía y Humanidades, Universidad Nacional de Córdoba.

SCHIFFER, M.B. 1972. Archaeological Context and Systemic Context. American Antiquity 37: 156-165.

-1975. Behavioral Chain analysis: Activities, organization and the use of space. Fieldiana Anthropology 65: 103-119.

-1976. Behavioral Archaeology. Nueva York, Academic Press.

SCHIFFER, M. B. Y J.M. SKIBO. 1987. Theory and experiment in the study of technological change. Current Anthropology 28: 595-622.

SCHOBINGER J. 1975. Prehistoria y protohistoria de la Región Cuyana. Museo de Ciencias Naturales y Antropológicas “Juan Cornelio Moyano”. Mendoza.

SEELENFREUD, A., C. ROES, R. BIRD, G. BAILEY, R. BÁRCENA Y V. DURÁN. 1996. Trace-Element Analysis of Obsidian Sources and Artifacts of Central Chile (Maule River Basin) and Western Argentina (Colorado River). Latin American Antiquity 7 (1): 7-20.

SEMPER, J. Y H. LAGIGLIA. 1962-68. Excavaciones arqueológicas en el Rincón del Atuel (Gruta del Indio), Dto. de San Rafael, (Mendoza, Argentina), (notas preliminares). Revista Cientifica de Investigaciones I (4): 89-158.

SEPÚlVEDA, E., A. BERMÚDEZ, O. BORDONARO y D. DELPINO. 1999. Hoja Geológica 3569-IV, Embalse El Nihuil, provincia de Mendoza. Instituto de Geología y recursos minerales, Servicio Geológico Minero Argentino, Boletín 268. Buenos Aires.

SEPÚLVEDA, E., F. CARPIO, M.C. REGAIRAZ, M. ZÁRATE y J.C.M. ZANETTINI. 2000. Hoja Geológica 3569-II, San Rafael, provincia de Mendoza. Instituto de Geología y recursos minerales, Servicio Geológico Minero Argentino, Boletín 321. Buenos Aires.

SHACKLEY, M.S. 2005. Obsidian: Geology and Archaeology in the North American Southwest. Tucson, The University of Arizona Press.

SHENNAN, S. 2002. Archaeology and Evoutionary Ecology. World Archaeology 34 (1): 1-5.

SHOTT, M. 1986. Technological organization and settlement mobility: an ethnographic examination. Journal of Anthropological Research 4 (2): 15-51.

-1989. Diversity, organization, and behavior in the material record. Ethnographic and archaeological examples. Current Anthropology 30: 283-315.

-1994. Size and form in the analysis of flake debris: review and recent approaches. Journal of Archaeological Method and Theory 1: 69-110.

-1996. An Exegisis in the Curation concept. Journal of Anthropological Research 52 (3): 259280. 
S.I.C.A.R. 2018. Sistema de Información Catastral y Registral. Dirección de Información Departamento General de Irrigación. http://www.irrigacion.gov.ar/mapserver/sicar_web_produccion/intro/paginas/mapas.htm

SMITH, E.A. 1983. Anthropological Applications of Optimal Foraging Theory: A Critical Review. Current Anthropology 24: 625-651.

SMITH, M.A 1988. The pattern and timing of prehistoric settlement in central Australia. Unpublished PhD thesis, Armidale: University of New England.

SMITH, E.A. Y B. WINTERHALDER. 1992. Natural Selection and Decision Making: Some Fundamental Principles. En: Evolutionary Ecology and Human Behavior, E. Smith y B. Winterhalder (eds.), pp. 25-60. Aldine de Gruyter. Nueva York.

SMITH, M., P. VETH, P. HISCOCK Y L.A. WALLIS. 2005. Global Deserts in Perspective. En: Desert Peoples. Archaeological Perspectives, P. Veth, M. Smith y P. Hiscock (eds.), pp. 1-13. Oxford, Blackwell.

SRUOGA, P., P. GUERSTEIN Y A. BERMUDEZ. 1993. Riesgo Volcánico. Relatorio del XII Congreso de Geología Argentina 1: 695-667. Mendoza.

SRUOGA, P., M. P. ETCHEVERRÍA, A. FOLGUERA, D. REPOL, J. M. CORTES Y J. C. ZANETTINI. 2005. Hoja Geológica 3569-I, Volcán Maipo, provincia de Mendoza. Instituto de Geología y Recursos Minerales, Servicio Geológico Minero Argentino, Boletín 290. Buenos Aires.

STINGL, H. Y K. GARLEFF. 1985. Glacier Variations and Climate of the Late Quaternary in the Subtropical and Mid-latitude Andes of Argentina. Aeitschrift Fur Gletscherkunde. Band 21: 225-228. Bamberg.

STOUT D. 2002. Skill and Cognition in Stone Tool Production. An Ethnographic Case Study from Irian Jaya. Current Anthropology Volume 43 (5): 693-722.

STURM, C., J.K. CLARK Y L. BARTON. 2016. The logic of ceramic technology in marginal environments: implications for mobile life. [HYPERLINK https://www.researchgate.net/journal/0002-7316_American_Antiquity] 81 (4): 645-663.

SUGRAÑES, N. 2017. La tecnología cerámica y su relación con las estrategias de subsistencia y movilidad de poblaciones humanas en la cuenca del Atuel (sur de Mendoza), durante el Holoceno tardío. Tesis doctoral inédita, 472 páginas. Facultad de Ciencias Sociales, Universidad del Centro de la Provincia de Buenos Aires. Olavarría.

SUGRAÑES, N. Y F. FRANCHETTI. 2012. Antecedentes, problemas y perspectivas del análisis cerámico en el sur de Mendoza. En: Paleoecología humana en el sur de Mendoza: perspectivas arqueológicas, G. Neme y A. Gil (comps.), pp. 229-254. Sociedad Argentina de Antropología. Buenos Aires.

SULLIVAN, A. P. Y K. ROZEN.1985. Debitage Analysis and Archaeological Interpretation. American Antiquity 50 (4): 755-779. 
TANAKA J. 1982. Adaptation to arid environment: a comparative study of hunter-gatherers and pastoralists in Africa. African Study Monographs, Supplementary Issue 1: 1-12.

TAYLOR, W. 1964. Thethered nomadism and water territoriality hypothesis. En: Acts of the 5 th Congress of Americanist, pp. 197-203.

TORRENCE, R. 1983. Time budgeting and hunter-gatherer technology. En: Pleistocene huntergatherers in Europe, G. Bailey (ed.), pp. 11-22. Cambridge University Press. New York.

-1984. Monopoly or direct access? Industrial organization at the Melos obsidian quarries. En: Prehistoric quarries and lithic production, J.E. Ericson y B. Purdy (eds.), pp. 49-64. Cambridge University Press. Cambridge.

-1989a. Retooling: toward a behavioral theory of stone tools. En: Time, Energy, and Stone Tools, R. Torrence (ed.), pp. 57-66. Cambridge University Press. Cambridge.

-1989b. Tools as optimal solutions. En: Time, energy and stone tools, R. Torrence (ed.), 1-6. Cambridge University Press. Cambridge.

-2001. Hunter-gatherer technology: macro and microscale approaches. En: Hunter-Gatherers: An Interdisciplinary Perspective, C. Panter-Brick, R. Layton y P. Rowley-Conwy (eds.), pp. 7398. Cambridge University Press. Cambridge.

TORRES, E Y J. ZAMBRANO. 2000. Hidrogeología de la Provincia de Mendoza. En: ARGENTINA. Recursos y problemas ambientales de la zona árida. Primera parte: provincias de Mendoza, San Juan y La Rioja. Tomo I, Caracterización ambiental, E.M. Abraham y F. Rodriguez Martinez (eds.), pp: 49-58. IADIZA. Mendoza.

TRIPALDI, A. 2010 Campos de dunas en la planicie sanrafaelina: patrones de dunas e inferencias paleoclimáticas durante el Pleistoceno tardío-Holoceno. En: Condiciones paleoambientales y ocupaciones humanas durante la transición Pleistoceno.Holoceno y Holoceno de Mendoza, pp.65-94. M. Zárate, A. Gil y G. Neme (comps). Sociedad Argentina de Antropología, Buenos Aires.

TRIPALDI A, M ZÁRATE y G BROOK. 2010. Sucesiones eólicas y fluviales del Pleistoceno tardío-Holoceno de la planicie sanrafaelina: paleoambientes y paleoclima. En: Condiciones paleoambientales y ocupaciones humanas durante la transición Pleistoceno-Holoceno y Holoceno de Mendoza, M Zárate, A Gil y G Neme, (comps.). Sociedad Argentina de Antropología, Buenos Aires

UGAN A., J. BRIGHT Y A. ROGERS. 2003. When technology worth the trouble? Journal of Archaeological Science 30: 1315-1329.

UGAN A., G. NEME, A. GIL, J. COLTRAIN, R. TYKOT Y P. NOVELLINO. 2012. Geographic variation in bone carbonate and water $\delta 180$ values in Mendoza, Argentina and their relationship to prehistoric economy and settlement. Journal of Archaeological Science 39 (8): $2752-2763$. 
VEIT, H. 1998. Holocene Climatic Changes and atmospheric paleocirculation in the northwestern part of the Arid Diagonal of South America. Bamberger Geographische Schriften 15 (S): 359369. Bamberger.

VETH, P. M. 1989. Islands in the interior: a model for the colonization of Australia's arid zone. Archaeology in Oceania 24: 81-92.

-1993. Islands in the Interior. The Dynamics of Prehistoric Adaptations within the Arid Zone of Australia. Ann Arbor, International Monographs in Prehistory, Archaeological Series 3.

VIGNATI, M. A. 1931. Contribución al conocimiento de la etnografía moderna de las Lagunas Guanacache. Habitación y graneros. Notas preliminares del Museo de La Plata, t. I. E. 2a. pp. 225-240. Buenos Aires.

-1934. El ajuar de una momia de Angualasto. Notas preliminares del Museo de La Plata, Vol. 2 , pp. 187-232. Buenos Aires.

-1937. El hallazgo de esqueletos embarrados en la región Cuyana. Relaciones de la Sociedad Argentina de Antropología, t. I. pp. 85-89. Buenos Aires.

-1940. Los aborígenes de Cuyo. Enumeración y distribución desde la conquista hasta fines del siglo XVIII. Notas del Museo de La Plata. Sección Antropología V (19): 69-93.

-1953. Aportes al conocimiento antropológico de la provincia de Mendoza. I: Arqueología y etnografía de las Lagunas Guanacache (Antropología N58, pp. 27-46); II: La roca con litoglifos de Viluco (Antropología $\mathrm{N}^{\circ} 59$, pp. 47-50); III: Diario de viaje por las Lagunas Guanacache en el año 1789 (Antropología N60, pp. 51-109). Notas del Museo de La Plata, t. XVI, pp. 27-109. La Plata.

VILLALBA, R. 1990. Latitude of the surface High-Pressure Belt over Western South American during the Last 500 years as inferred from Tree-Ring Analysis. Quaternary of South America and Antartic Peninsula 7: 272-303.

VOLKHEIMER, W. 1978. Descripción geológica de la Hoja 27b, Cerro Sosneado, Provincia de Mendoza. Ministerio de Economía, Secretaría de Estado de Minería. Servicio Geológico Nacional, Buenos Aires.

WEBB, K. 1993. The lithification of a sandy environment. Archaeology in Oceania 28: 105-111. WEITZEL, C. 2010. El estudio de los artefactos formatizados fracturados. Contribución a la comprensión del registro arqueológico y las actividades humanas. Tesis Doctoral inédita, 409 páginas. Facultad de Filosofía y Letras, Universidad de Buenos Aires. Buenos Aires.

WHALLON, R. 2006. Social networks and information: Non-“utilitarian" mobility among huntergatherers. Journal of Anthropological Archaeology 25: 259-270.

WHITFORD, W.G. 2002. Ecology of Desert Systems. Academic Press, London.

WHITTAKER, J.C.1997. Flintknapping: making and understanding stone tools. University of Texas Press. USA. 
WILMSEN, E. N. 1973. Interaction, spacing behavior and the organization of hunting bands. Journal of Anthropological Research 29: 1-31.

WILSON, L. 2007a. The Vaucluse raw material project: artifact provenance and landscape context in the Middle Palaeolithic of southern France. In L. Wilson, P. Dickinson, \& J. Jeandron (Eds.), Reconstructing Human-Landscape Interactions: Papers of the Developing International Geoarchaeology 2005 conference (pp. 234-251). Newcastle-upon-Tyne: Cambridge Scholars Publishing.

WINTERHALDER, B. 2000. Models. En: Darwin and archaeology: A Handbook of Key Concepts, J. P. Hart y J. E. Terrell (eds.), pp. 201-223. Bergin \& Garvey, Westport. Connecticut.

WINTERHALDER, B. Y E. SMITH. 1992. Evolutionary Ecology and the Social Sciences. En: Evolutionary Ecology and Human Behavior, E. Smith y B. Winterhalder (eds.), pp. 3-23. Aldine de Gruyter. Nueva York.

YELLEN, J. 1977. Long Term Hunter-Gatherer Adaptation to Desert Environments: A Biogeographical Perspective. World Archaeology 8 (3): 262-274.

YRIGOYEN, M.R. 1979. Cordillera Principal. En: Segundo Simposio Geología Regional Argentina, J.C.M. Turner (ed.), pp. 651-694. Academia Nacional de Ciencias I. Córdoba.

ZANGRANDO, A. F. J. 2009. Historia evolutiva y subsistencia de cazadores-recolectores marítimos de Tierra del Fuego. Sociedad Argentina de Antropología, Buenos Aires.

ZÁRATE, M. 2002. Los ambientes del tardiglacial y Holoceno en Mendoza. En: Entre Montañas y Desiertos. Arqueología del sur de Mendoza. A. Gil y G. Neme (eds.), pp. 19-42. Publicaciones de la Sociedad Argentina de Antropología. Buenos Aires.

ZÁRATE, M., G. NEME Y A. GIL 2005. Mid Holocen Paleoenvironments and Human Occupation in southern South América. Quaternary International 132: 1-3.

ZÁRATE, M., J. URRUTIA, R. LANZILLOTTA Y A. MEHL. 2006. Características geomorfológicas y sedimento-pedológicas. Capítulo 6. En: Estudio para la determinación del caudal mínimo necesario para el restablecimiento del sistema ecológico fluvial en el curso inferior del rio Atuel. Informe inédito. UNLPAM-Secretaría de recursos Hídricos, Gobierno de la provincia de la Pampa.

ZÁRATE, M., A. GIL Y G. NEME. 2010. Integrando los registros: generalizaciones, alcances y limitaciones. En: Condiciones paleoambientales y ocupaciones humanas durante la transición Pleistoceno-Holoceno y Holoceno de Mendoza, M. Zárate, A. Gil y G. Neme (comps), pp. 309-330. Sociedad Argentina de Antropología, Buenos Aires. 


\section{ANEXOS}




\section{ANEXO 1: HOJAS GEOLÓGICAS INTEGRADAS}

REFERENCIAS DE LA FIGURA 6.1 (página 171).

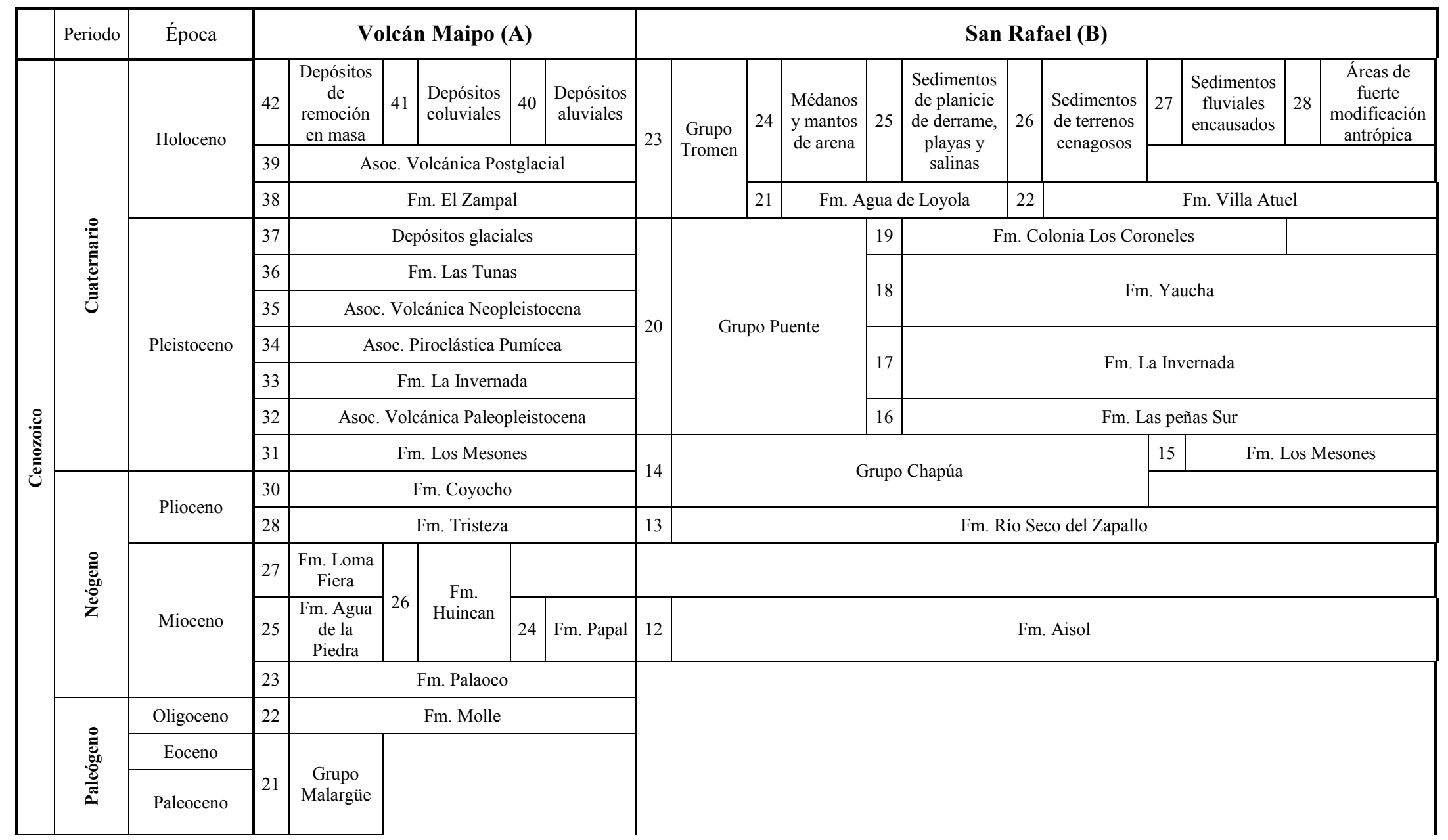




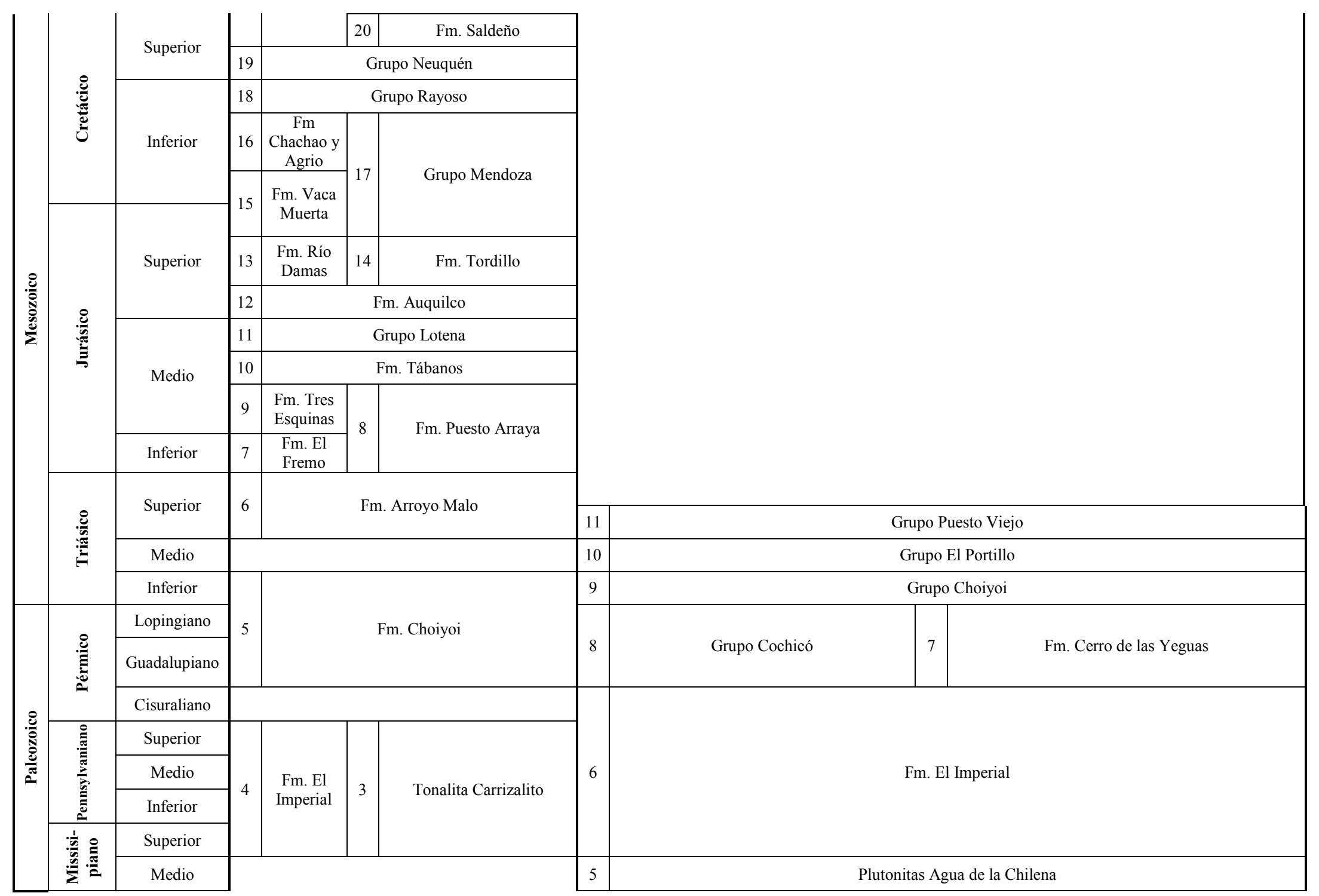




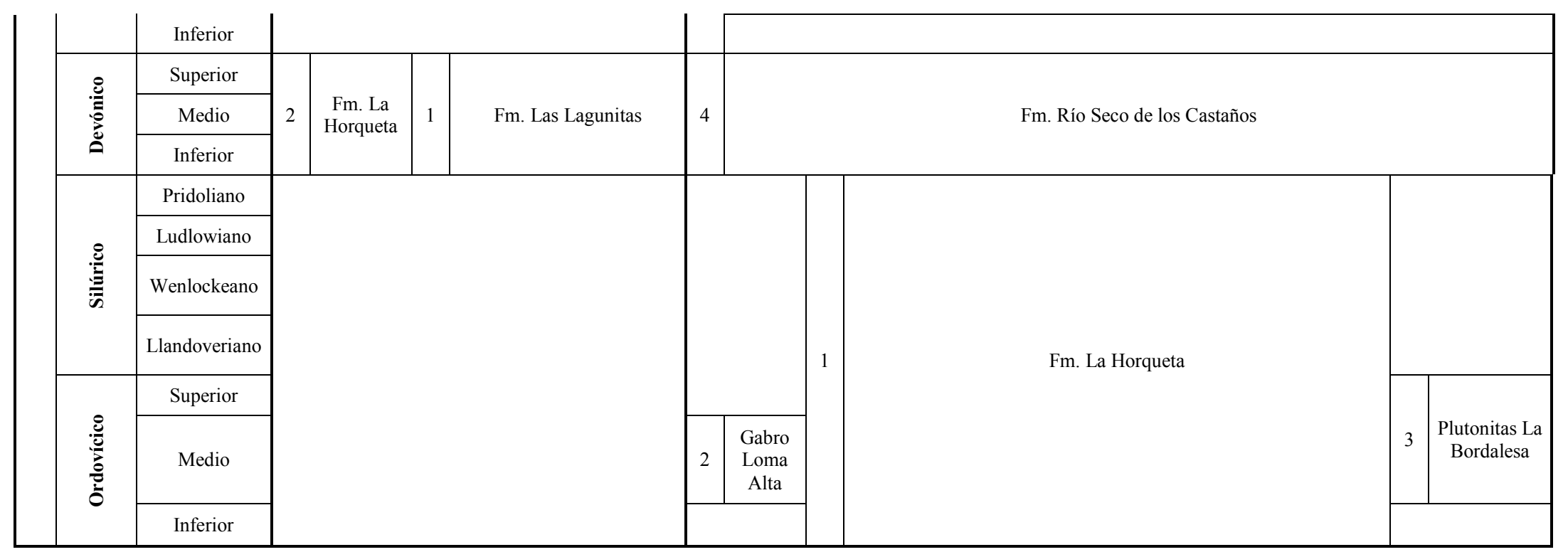

\begin{tabular}{|c|c|c|c|c|c|c|c|c|c|c|c|c|c|c|c|c|c|c|c|c|c|c|}
\hline \multirow{5}{*}{$\begin{array}{l}0 \\
.0 \\
0 \\
0 \\
0 \\
0\end{array}$} & Periodo & Época & & & Ма & largüe (C & & & & & & & & El & Nil & uil (D) & & & & & & \\
\hline & \multirow{4}{*}{ 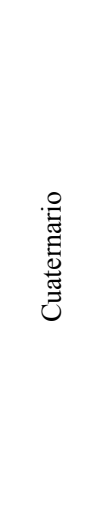 } & & 33 & $\begin{array}{l}\text { Fm. } \\
\text { Tromen }\end{array}$ & 34 & $\begin{array}{l}\text { Depósito } \\
\text { s eólicos }\end{array}$ & 35 & $\begin{array}{c}\text { Depósitos } \\
\text { aluviales }\end{array}$ & & \multirow{4}{*}{$\begin{array}{l}\text { Dep. aluviales } \\
\text { pedemontanos }\end{array}$} & \multirow{4}{*}{19} & \multirow{4}{*}{$\begin{array}{c}\text { Depósito } \\
\text { s de la } \\
\text { llanura } \\
\text { aluvial } \\
\text { del río } \\
\text { Atuel }\end{array}$} & \multirow{4}{*}{20} & \multirow{4}{*}{$\begin{array}{l}\text { Depósitos } \\
\text { Eólicos } \\
\text { de } \\
\text { médanos } \\
\text { vegetados }\end{array}$} & \multirow{4}{*}{2} & \multirow{4}{*}{$\begin{array}{l}\text { Depósitos } \\
\text { Eólicos } \\
\text { de } \\
\text { médanos } \\
\text { activos }\end{array}$} & \multirow{4}{*}{22} & \multirow{4}{*}{$\begin{array}{l}\text { Depósitos } \\
\text { asalitrosos } \\
\text { de playas }\end{array}$} & & \multirow{4}{*}{\begin{tabular}{|c} 
Depósitos \\
aluviales \\
encausados
\end{tabular}} & \multirow{4}{*}{24} & \multirow{4}{*}{$\begin{array}{l}\text { Fm. } \\
\text { Del } \\
\text { Pozo } \\
\text { Azul }\end{array}$} \\
\hline & & Holoceno & 32 & $\begin{array}{l}\text { Depósitos } \\
\text { morrénicos }\end{array}$ & 31 & $\begin{array}{l}\text { Basalto } \\
\text { Peteroa }\end{array}$ & 30 & $\begin{array}{c}\text { Basalto } \\
\text { cerro } \\
\text { campanari } \\
\text { o }\end{array}$ & 18 & & & & & & & & & & 23 & & & \\
\hline & & \multirow[t]{2}{*}{ Pleistoceno } & 28 & \multicolumn{3}{|c|}{ Fm. Loma Seca } & 29 & $\begin{array}{c}\text { llanura } \\
\text { pedemonta } \\
\text { na }\end{array}$ & & & & & & & & & & & & & & \\
\hline & & & 26 & $\begin{array}{c}\text { Depósitos } \\
\text { del }\end{array}$ & 27 & \multicolumn{3}{|c|}{ Fm. El Puente } & & & & & & & & & & & & & & \\
\hline
\end{tabular}




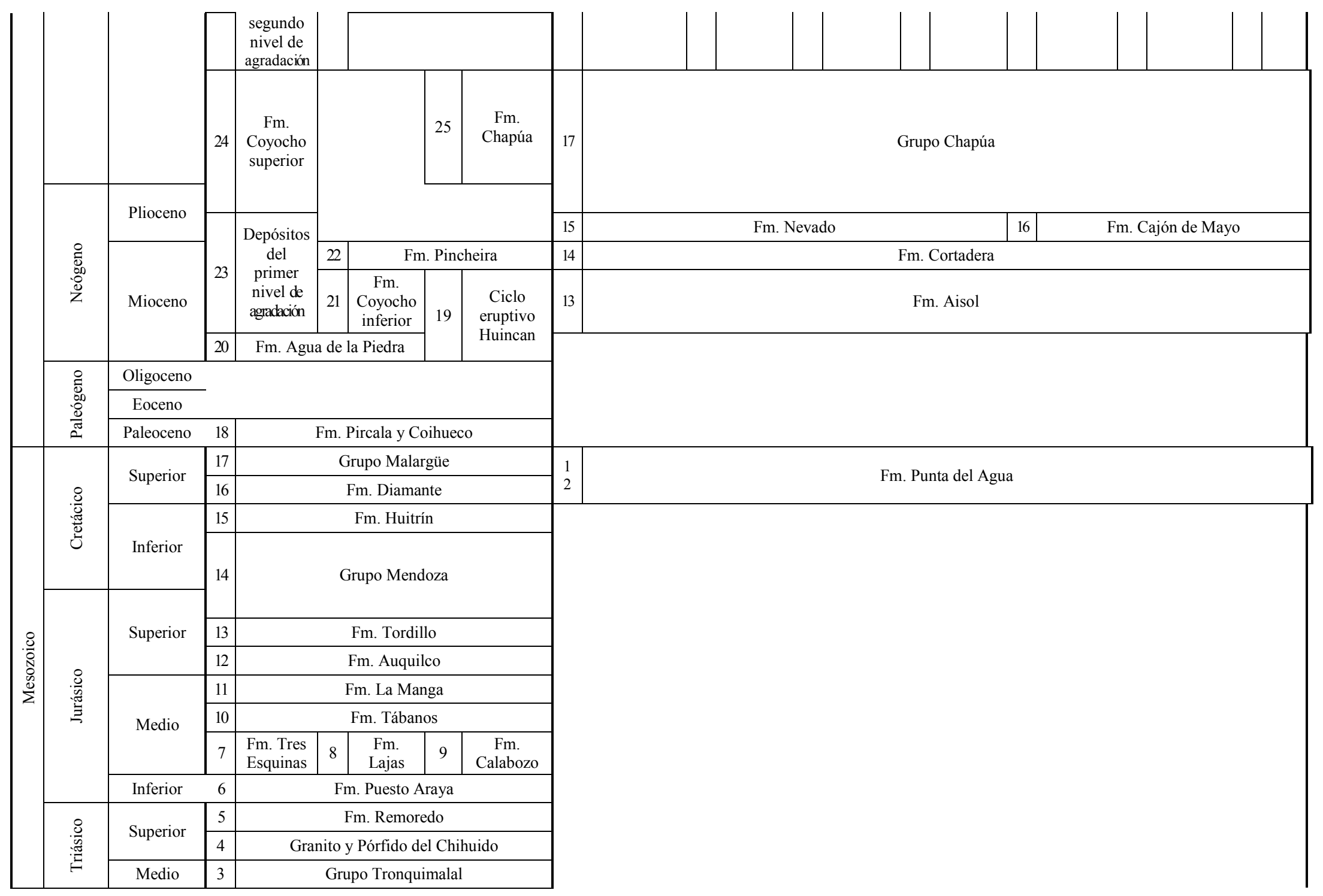




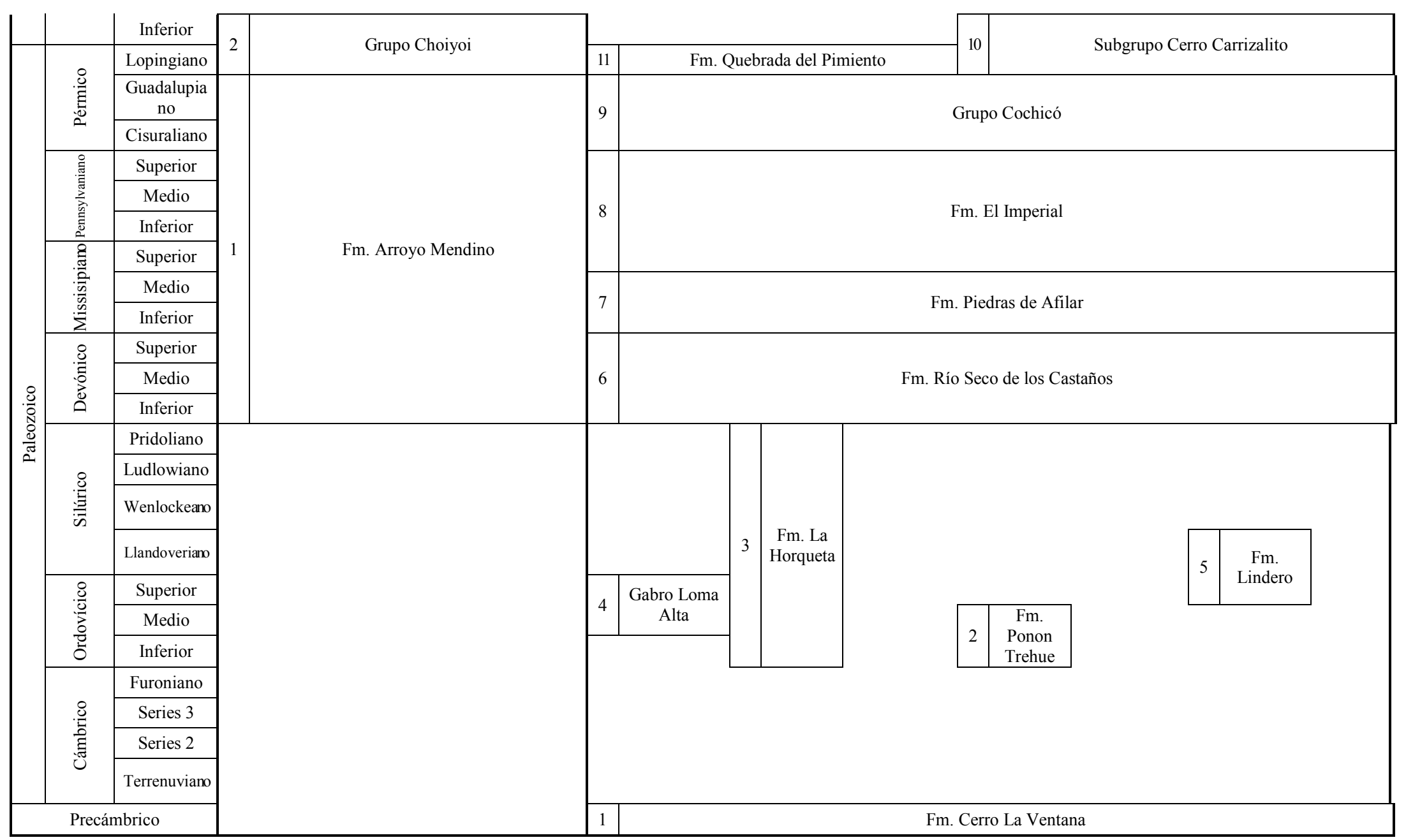




\section{ANEXO 2: ANÁLISIS GEOQUÍMICOS}

RESULTADOS DE LOS ANÁLISIS GEOQUÍMICOS DE ARTEFACTOS DE OBSIDIANA EN LA CUENCA DEL RÍO ATUEL

\begin{tabular}{|c|c|c|c|c|c|c|c|c|c|c|c|c|c|}
\hline Sitio & Código & $\begin{array}{c}\text { Clase } \\
\text { artefac. }\end{array}$ & Procedencia & Mn & $\mathbf{F e}$ & Zn & $\mathbf{R b}$ & $\mathrm{Sr}$ & $\mathbf{Y}$ & $\mathbf{Z r}$ & $\mathbf{N b}$ & Ba & Th \\
\hline $\mathrm{AP}-1$ & LSM167 & DT & Grupo A & 569,3 & 8445,9 & 25,7 & 122,6 & 137,4 & 14,2 & 82,5 & 8 & 491,8 & 16,3 \\
\hline AP-1 & LSM168 & DT & Grupo A & 616,8 & 10008,8 & 30,4 & 132,4 & 149,4 & 14,2 & 88,3 & 7,8 & 428,9 & 16,2 \\
\hline AP-1 & LSM169 & DT & Las Cargas & 609,7 & 10822,7 & 34,6 & 120,5 & 174,8 & 14,3 & 116,8 & 9,6 & 500,7 & 15,7 \\
\hline AP-1 & LSM170 & DT & Las Cargas & 639,5 & 11180,6 & 35,9 & 116,6 & 163,6 & 12,8 & 108,9 & 7,5 & 328 & 13,4 \\
\hline AP-1 & LSM171 & $\begin{array}{c}\mathrm{AF} \\
\text { Compuesto } \\
\end{array}$ & Las Cargas & 601,3 & 9716,4 & 30,3 & 115,9 & 169,4 & 14 & 115 & 8,7 & 466 & 15,9 \\
\hline AP-1 & LSM172 & DT & Las Cargas & 620,1 & 9594,3 & 30,4 & 110,5 & 157,8 & 13,4 & 103,1 & 6,8 & 358,9 & 13,2 \\
\hline AP-1 & LSM173 & DT & Las Cargas & 652,6 & 10325,7 & 28,7 & 126,6 & 181,1 & 14,2 & 120,9 & 9 & 593,1 & 14,9 \\
\hline AP-1 & LSM174 & $\begin{array}{c}\mathrm{AF} \\
\text { Unifacial }\end{array}$ & Las Cargas & 580,8 & 9609,8 & 25,7 & 116,3 & 169,8 & 14,6 & 116,7 & 7,8 & 491,6 & 14 \\
\hline AP-1 & LSM175 & ASF RC & Las Cargas & 574,6 & 9315,5 & 29,3 & 115,2 & 168,3 & 14,7 & 115,5 & 8,9 & 479,1 & 15 \\
\hline AP-1 & LSM176 & $\begin{array}{c}\text { AF } \\
\text { Unifacial } \\
\end{array}$ & Las Cargas & 576 & 9266,4 & 31 & 113,8 & 165,7 & 13,7 & 112,1 & 6,4 & 508,5 & 13,4 \\
\hline CP-1 & LSM177 & DT & Las Cargas & 561,6 & 8886,6 & 28,6 & 106,7 & 156,4 & 13,2 & 109,2 & 7,2 & 472,3 & 13,4 \\
\hline $\mathrm{CP}-1$ & LSM178 & DT & Las Cargas & 588,7 & 9159,7 & 27,5 & 116 & 168,8 & 14,9 & 116,2 & 8,7 & 533,7 & 14,6 \\
\hline $\mathrm{CP}-1$ & LSM179 & DT & Grupo A & 602,9 & 9435,4 & 33,7 & 123,9 & 149,4 & 14,2 & 92,8 & 8,3 & 415,7 & 15,9 \\
\hline $\mathrm{CP}-1$ & LSM180 & DT & Las Cargas & 590,5 & 12996,6 & 40,4 & 121,6 & 180,4 & 15,4 & 124,3 & 10,3 & 573,7 & 15,5 \\
\hline CP-1 & LSM181 & DT & Las Cargas & 597,2 & 9358,3 & 32,6 & 112,7 & 161 & 12,5 & 104,2 & 8 & 391,1 & 14 \\
\hline CP-1 & LSM182 & $\begin{array}{c}\mathrm{AF} \\
\text { Unifacial } \\
\end{array}$ & Las Cargas & 593,8 & 9187,8 & 26,8 & 119,8 & 173,8 & 14,7 & 118 & 9,1 & 583,7 & 14,1 \\
\hline CP-1 & LSM183 & $\begin{array}{c}\text { Fragm. ND } \\
\text { de AF }\end{array}$ & Las Cargas & 640,4 & 9883,8 & 30,6 & 114,4 & 164 & 11,7 & 107,7 & 7,6 & 455,6 & 14,4 \\
\hline CP-1 & LSM184 & $\begin{array}{c}\text { Fragm. ND } \\
\text { de AF }\end{array}$ & Las Cargas & 608,8 & 10477 & 33,1 & 112,6 & 162,8 & 12,9 & 110,4 & 8,2 & 430,9 & 14,5 \\
\hline $\mathrm{CP}-1$ & LSM185 & DT & Las Cargas & 664,9 & 10267,7 & 33,7 & 123,6 & 174,5 & 14,1 & 117,5 & 8,7 & 396,7 & 15,5 \\
\hline
\end{tabular}




\begin{tabular}{|c|c|c|c|c|c|c|c|c|c|c|c|c|c|}
\hline $\mathrm{CP}-1$ & LSM186 & DT & Las Cargas & 691,4 & 10857,9 & 38,2 & 125,7 & 178,9 & 13,8 & 115 & 7,4 & 367,1 & 16,6 \\
\hline $\mathrm{CP}-1$ & LSM187 & DT & Las Cargas & 574,8 & 9038 & 32,8 & 110,4 & 154,9 & 12,3 & 104,8 & 6,4 & 391,4 & 13,2 \\
\hline $\mathrm{CP}-1$ & LSM188 & DT & Las Cargas & 678,6 & 11061,6 & 41,3 & 120 & 171,2 & 13 & 107,8 & 8,2 & 410,4 & 15 \\
\hline CSA-1 & LSM189 & DT & Las Cargas & 583,5 & 9101,5 & 29,2 & 108,5 & 156,4 & 12,7 & 106,6 & 7,5 & 476,5 & 13 \\
\hline CSA-1 & LSM190 & DT & Las Cargas & 583,2 & 9236,8 & 31,6 & 112,6 & 163,7 & 13 & 108,3 & 8,2 & 427,8 & 12,9 \\
\hline CSA-1 & LSM191 & AF Bifacial & El Peceño 1 & 1010,7 & 6901,3 & 55,7 & 226 & 251,5 & 12,1 & 119,8 & 23,5 & 982,9 & 11,6 \\
\hline CSA-1 & LSM192 & DT & El Peceño 1 & 849,4 & 6398,8 & 44,9 & 201,2 & 218,8 & 9,6 & 119,8 & 21,5 & 891,2 & 9,4 \\
\hline CSA-1 & LSM193 & DT & Las Cargas & 589,2 & 9228 & 29,8 & 115,9 & 169,9 & 15,3 & 118,8 & 10 & 486,2 & 13,9 \\
\hline CSA-1 & LSM194 & DT & Indeterminada & 555,2 & 11112,3 & 35 & 165,8 & 157,8 & 12,6 & 190,1 & 8,5 & 570,5 & 20,3 \\
\hline CSA-1 & LSM195 & DT & Silícea & 374,8 & 4854,3 & 11,8 & 53,1 & 79,6 & 5,1 & 53,8 & 3 & 287,6 & 7 \\
\hline CSA-1 & LSM196 & DT & Grupo A & 561,5 & 9243,8 & 26,2 & 124,4 & 147,7 & 15,6 & 87,6 & 7,7 & 508,2 & 14,3 \\
\hline CSA-1 & LSM197 & DT & Las Cargas & 586,3 & 9095,6 & 24,6 & 117,2 & 171,7 & 14,4 & 118 & 8 & 564,7 & 13,8 \\
\hline CSA-1 & LSM198 & $\begin{array}{c}\text { Fragm. ND } \\
\text { de AF }\end{array}$ & Las Cargas & 584,1 & 8938,9 & 30,8 & 110 & 160,5 & 13,1 & 109,7 & 7,7 & 463,2 & 13,9 \\
\hline CSA-1 & LSM199 & AF Bifacial & Las Cargas & 629,3 & 9317,4 & 27,2 & 120,8 & 177,5 & 14,1 & 121,4 & 8,3 & 554,6 & 15 \\
\hline EB-3 & LSM200 & DT & El Peceño 1 & 797,4 & 5393,7 & 45,6 & 172,6 & 189,4 & 8,6 & 90,1 & 18,1 & 706,6 & 8,2 \\
\hline EB-3 & LSM201 & DT & El Peceño 1 & 936,8 & 6261,9 & 53,4 & 205,6 & 221,4 & 10,5 & 100,9 & 21 & 741,9 & 10,6 \\
\hline EB-5 & LSM202 & $\begin{array}{c}\text { Fragm. ND } \\
\text { de AF }\end{array}$ & El Peceño 1 & 864,2 & 5785,1 & 43,7 & 186,6 & 205,1 & 8,7 & 90,9 & 20,3 & 622,5 & 9,8 \\
\hline EB-5 & LSM203 & DT & El Peceño 1 & 836,9 & 5812,1 & 48,3 & 190 & 206,7 & 7,9 & 88 & 19,4 & 676,2 & 9,6 \\
\hline EB-5 & LSM204 & DT & Silícea & 757,5 & 1354,9 & 4,3 & 0 & 6,8 & 0 & 1,5 & 2,8 & 150 & 0,4 \\
\hline $\begin{array}{c}\text { EB } \\
\text { Localidad } \\
\end{array}$ & LSM205 & DT & El Peceño 1 & 923 & 6379,9 & 53,5 & 219 & 244,6 & 11,2 & 111,3 & 23,6 & 984,5 & 10,9 \\
\hline BDP-1 & LSM206 & DT & El Peceño 1 & 912,5 & 6154 & 52,6 & 215 & 243,6 & 10,9 & 109,2 & 23,1 & 894,1 & 11,4 \\
\hline BDP-1 & LSM207 & DT & El Peceño 1 & 961,7 & 6637,9 & 55,1 & 226,9 & 275,8 & 11,2 & 117,1 & 23 & 818,3 & 12,8 \\
\hline BDP-1 & LSM208 & DT & El Peceño 1 & 913,5 & 6616,2 & 47,6 & 229,6 & 269,9 & 11,3 & 118,7 & 25,2 & 1180,2 & 11,4 \\
\hline BDP-1 & LSM209 & DT & El Peceño 1 & 947,2 & 6488,1 & 50,8 & 212,6 & 262,3 & 11,1 & 110,1 & 22,4 & 1012,3 & 9,8 \\
\hline BDP-1 & LSM210 & DT & El Peceño 1 & 1086,4 & 6881,1 & 59,9 & 228,3 & 246,6 & 10,3 & 111,3 & 23,4 & 810,3 & 12 \\
\hline
\end{tabular}

